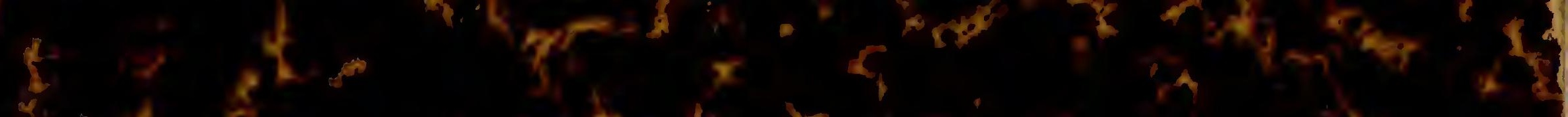

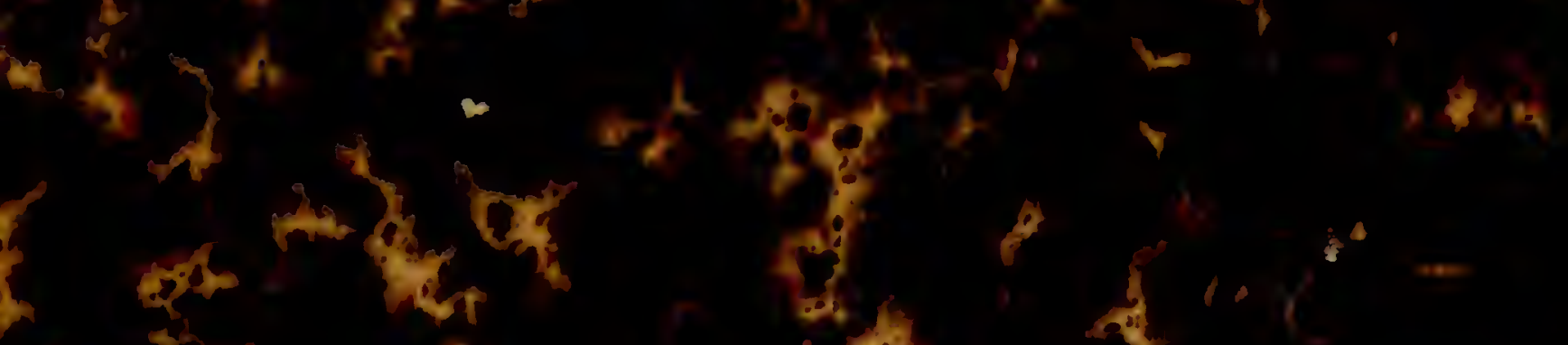

the

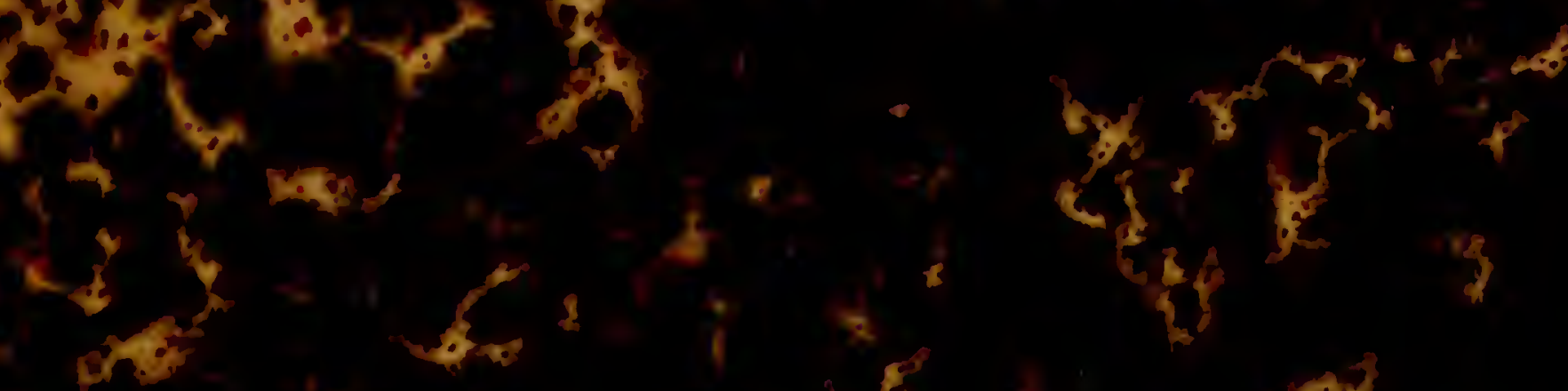

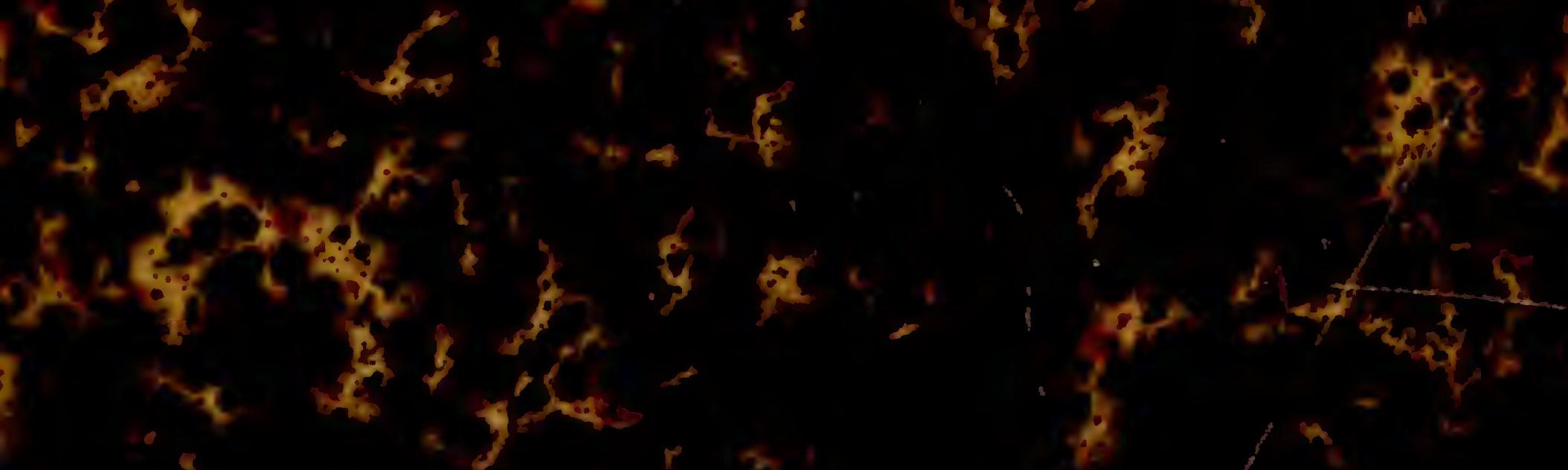
$2+3$

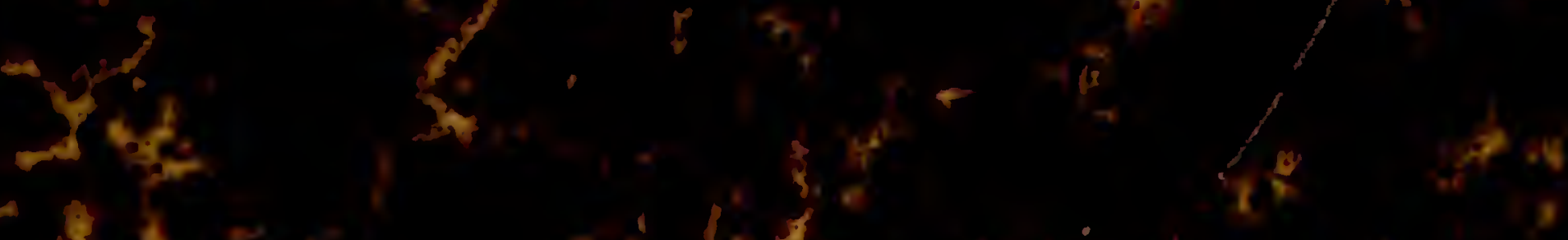

$8,2=2+1+8$

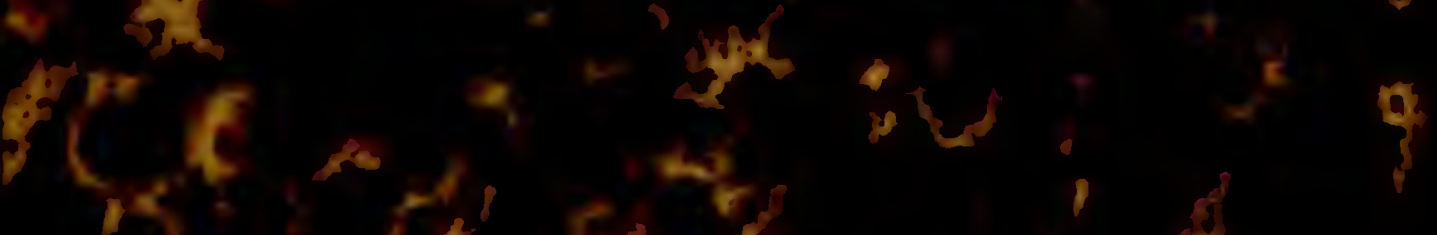

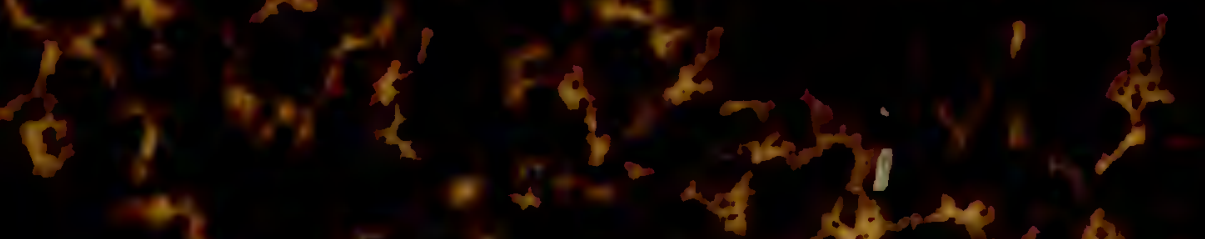

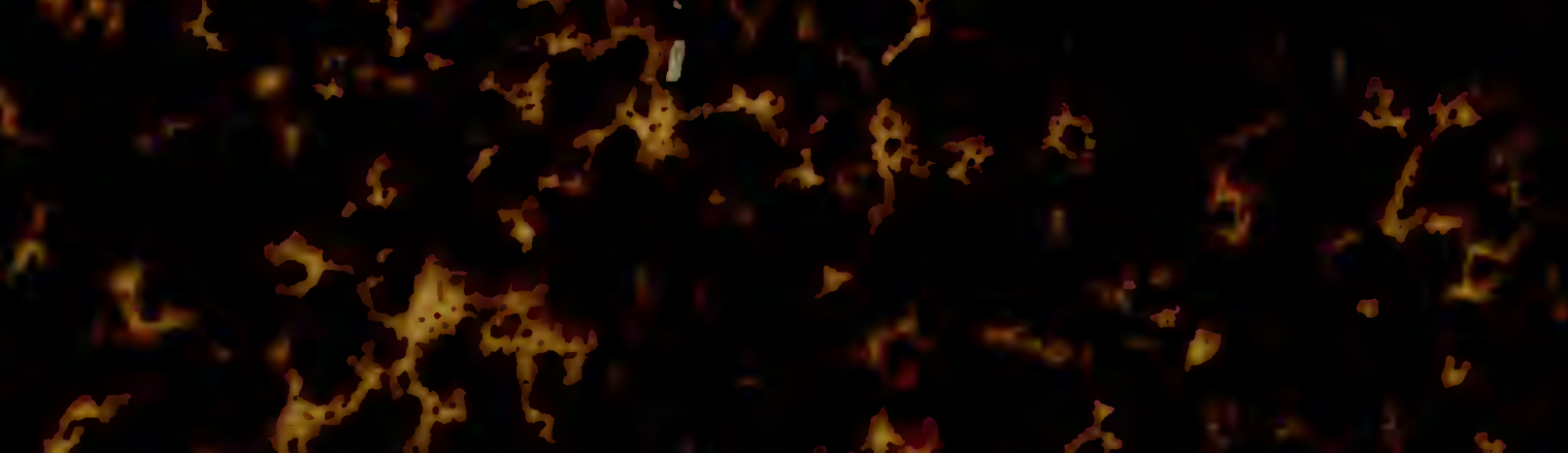

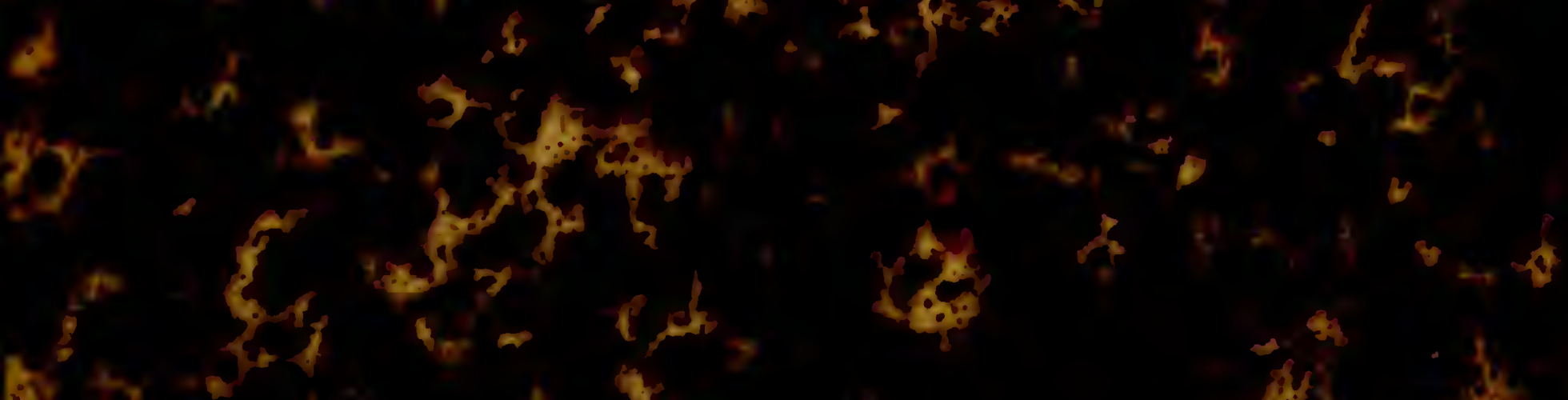

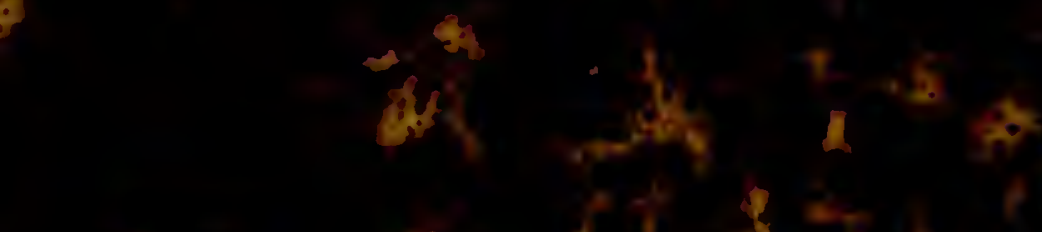
$a^{+}+2+5$

$A x^{2}+2$

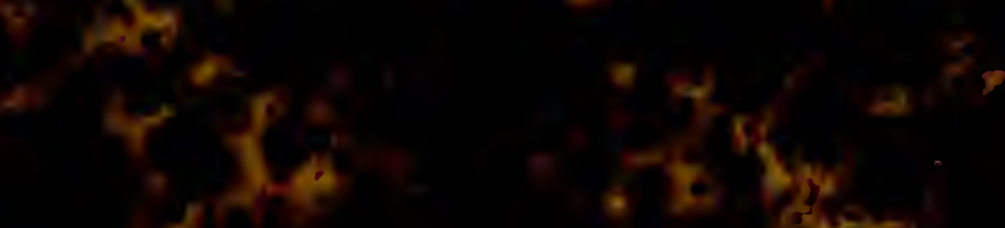

$x \rightarrow-1$

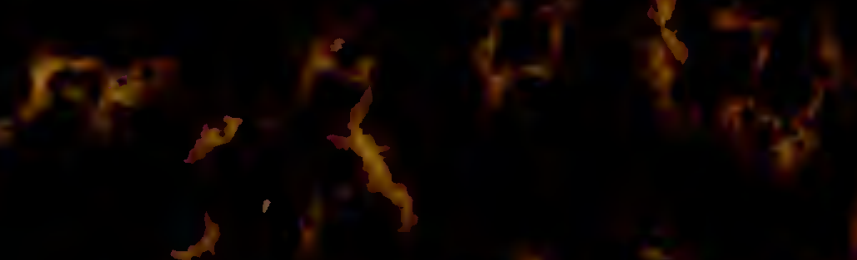







\section{LES MERVEILLES}





\section{LES MERVEILLES}

DE

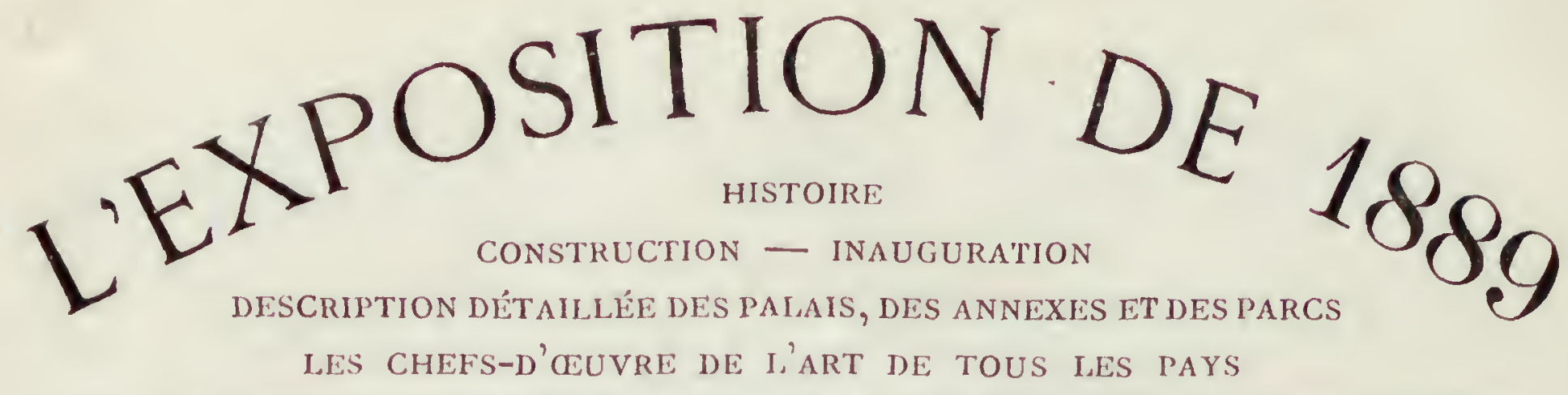

LES MACHINES - LES ARTS INDUSTRIELS - LES PRODUITS MANUFACTURÉS

LES EXPOSITIONS SPÉCIALES - LA TOUR EIFFEL

\section{OUVRAGE RÉdGÉ PAR DES ÉCRIVAINS SPÉCIAUX ET DES INGÉNIEURS ILLUSTRÉ}

Par MM. Clemget, Ci.érice, Deroy, Férat, Fichot, Gilbert, G. Fraipont, lanos

lix, A. Marie, C. Morel, H. Meyer, Normand, Parys, Scott, Thiriat, Tinayre, Toffani, Vierge, etc. de Vues d'ensemble et de détail, de Scènes, de Reproductions d'objets exposès, etc.

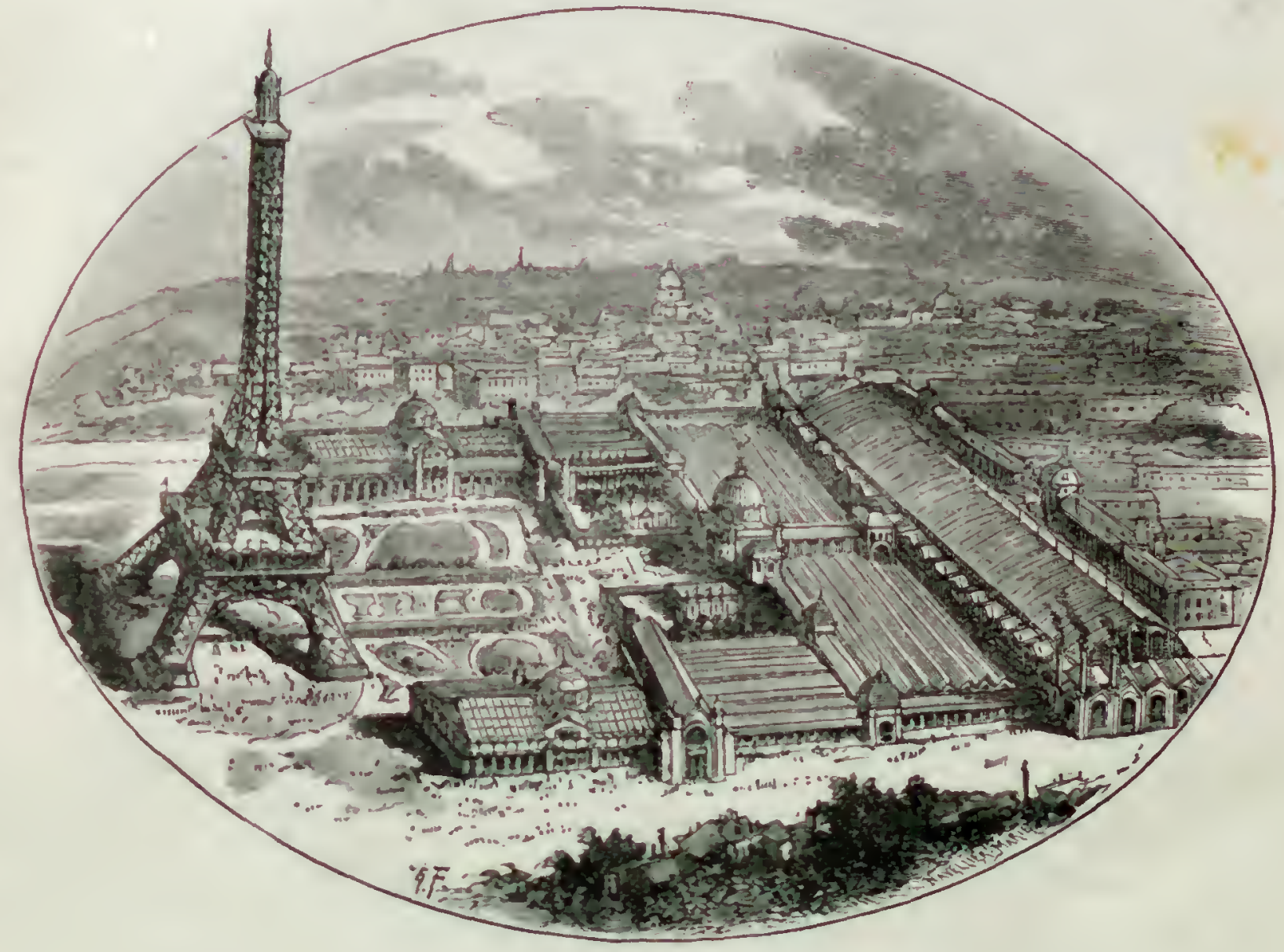

PARIS

E. GIRARD ET A. BOI T TE

42 , RUE DE L'ÉCHIQUIER, 42 
- 802

E.1M57

1899

CHEXPF 


\section{LES NERVEILLES}

DIE

\section{L'EXPOSITION DE 1889}

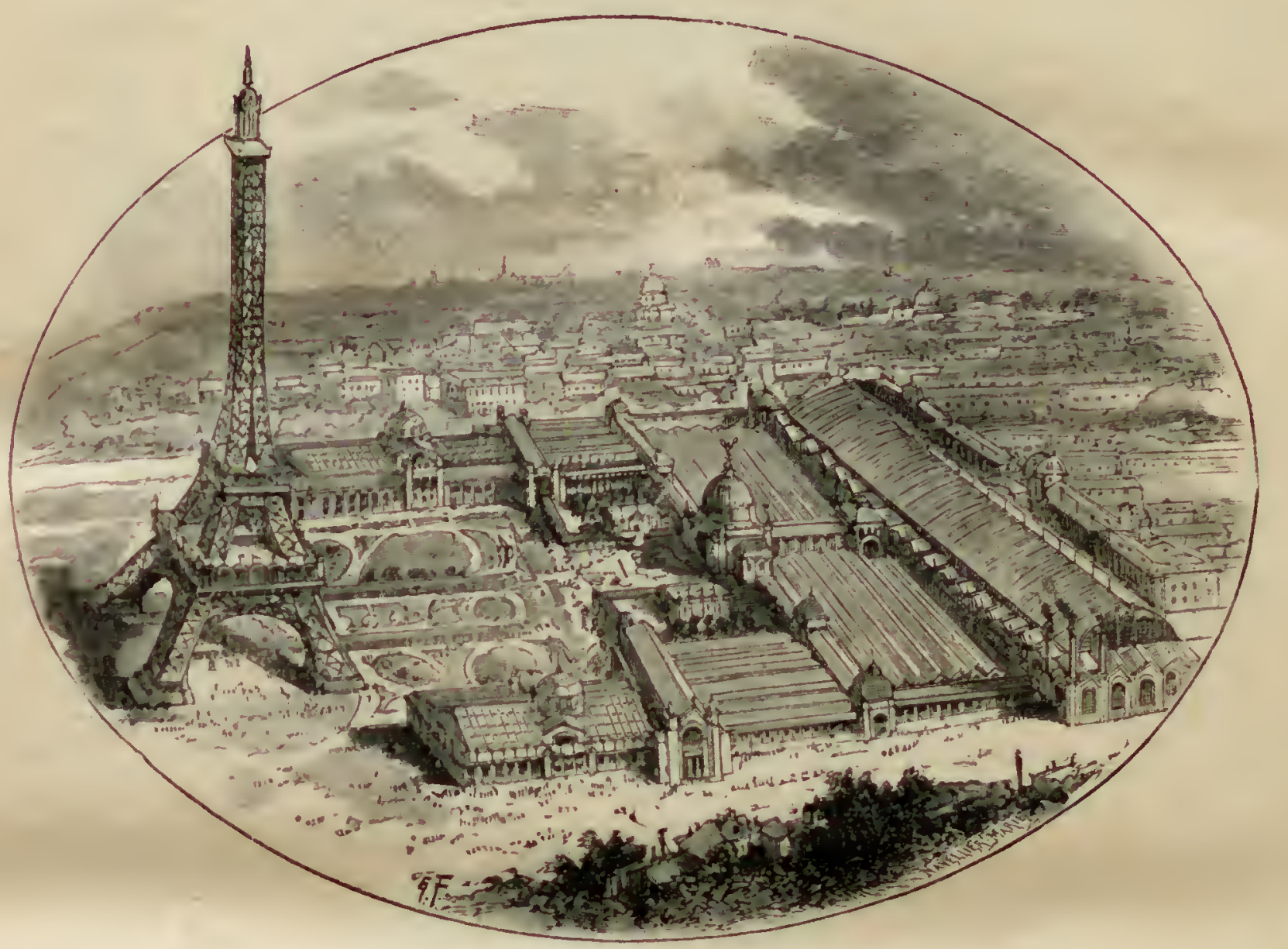

PREFAGE

C'est un beau spectacle que la France va donner au monde.

Alors que l'Europe plie sous le faix des armes, que les nations civilisées se ruinent en incessants achats de fusils et de mélinite, que l'on sonde vainement, sans en trouver le fond, le gouffre où s'engloutit le plus clair de nos ressources, la France choisit ce moment pour dire aux peuples: Non, le dernier mot de la science n'est pas un mot de destruction; non, la guerre n’est pas le but le plus élevé des sociétés humaines, et ce n'est pas à couvrir le monde de canons et de forteresses que l'homme, éclairé par les lumières de la science, doit consumer son activité.

Liv. 1.

MerveILles Expositiox. 
L'Exposition de 1889 ast nér, on oflet, d'une pensée sincèrement pacifique. Il élait bon, il élail utile de protester contre les tendances exclusirrment belliqueuses de certains Etats par une imposante manifestation de notre génie national, et de montrer à ceux qui nous accusent de vouluir déchainer sur l'Europe un conflit encore sans pareil dans l'histoire, yur nous plaçons avant toute chose les féconts triomphes de la paix. Décréter une Exposition universelle ef faire coincider son onverture avec la date inaugurale de la Révolution française, c'était nettement dire, à la face de l'unirers, que si la France s'entoure elle aussi de torpilleurs et de fortiresses, que si notre pays, dans l'intérèt supéricur de son indépendance, prend de plus en plus l'aspect d'un camp retranché, ce camp du moins mo protège pas d’insatiables bandes de Vandales, mais une armée de travailleurs ne demandant qu'une chose : la certitude de la paix et la fin de crs inquiétudes paralysantes qui contribuent ì entretenir la crise économique dont lEurope souffre depuis 1870.

Lorsque plus tard on étudiera la fin du xix siecle et que l’on jngera sans passion les événements qui la remplissent, on réservera à l'Lxposition universelle de 1889 une page des plus honorables. Oı fera certainement ressortir que, pour répondre à la triple alliance formée contre elle, lia France, forte de son droit et de ses intentions, convia simplement ses adrersaires à tenir chez elle les grandes assises de la Paix.

\section{La Rédaction des Merveilles ue l'Lxpositiox.}

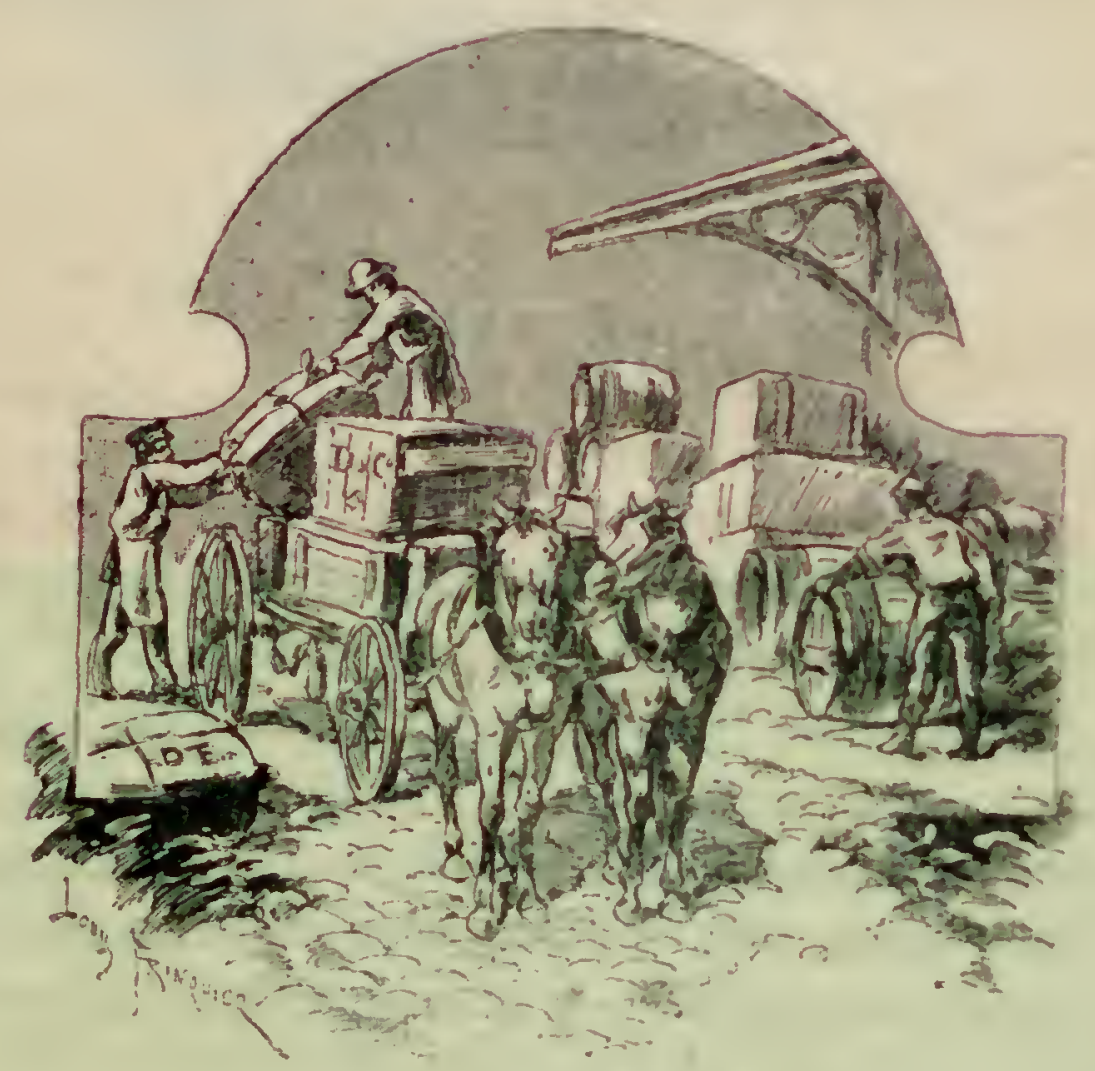




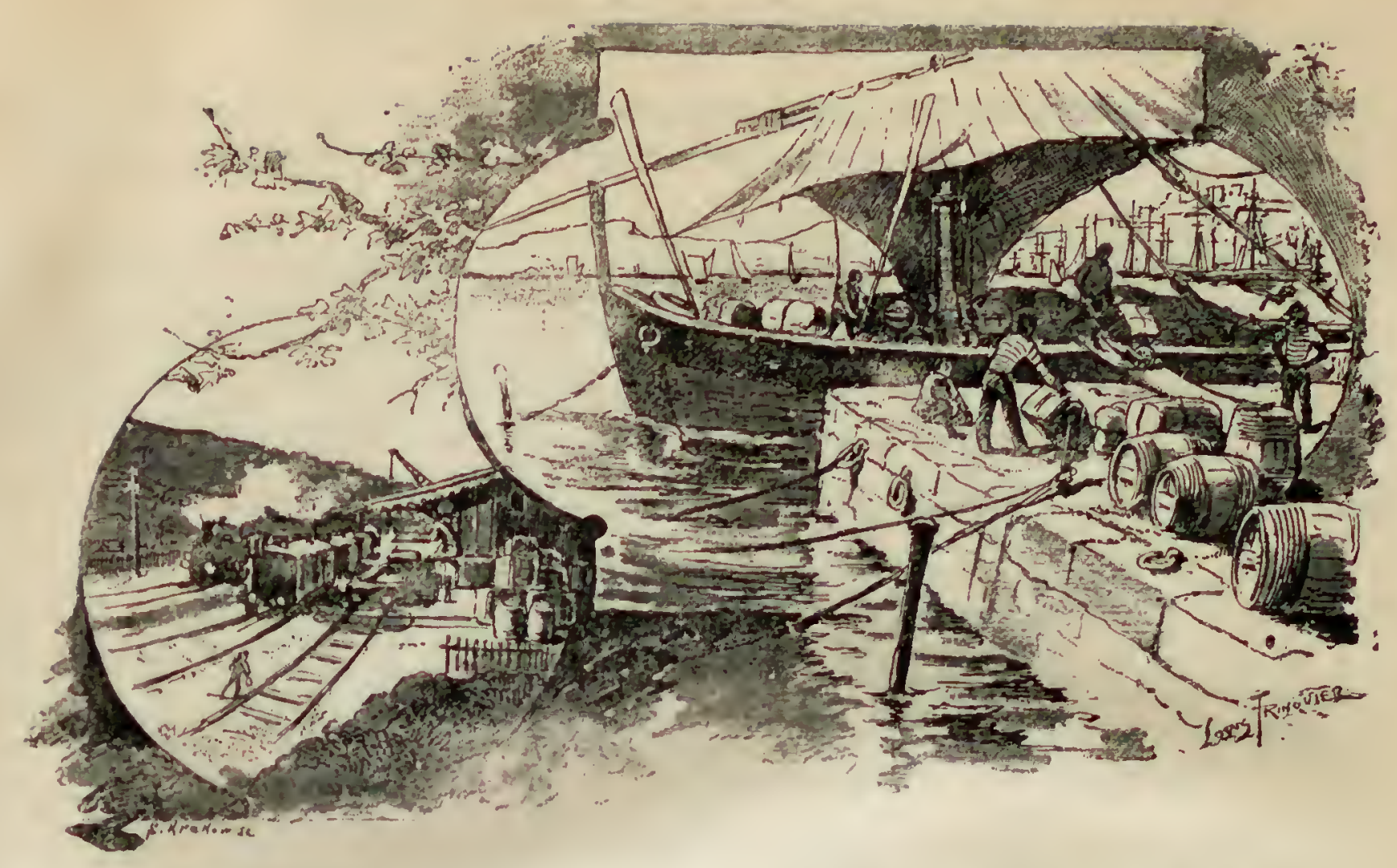

\section{LES IIERVEILLES DE L'EXPOSITION}

\section{LES ORIGINES ET LE PLAN DE L'BXPOSITION}

C'est en 1883, au commencement du mois de juin, qu'un petit groupe de membres du Parlement, parmi lesquels MM. Hervé-Mangon, Liouville, Million, etc., allèrent trouver le ministre du commerce, M. Hérisson, pour l'entretenir d'un projet d'Exposition nationale qui serait ouverte à Paris en $188 \%$.

Cette nouvelle s'étant promptement répandue, on discuta dans la presse et dans le public sur l'opportunité d'une semblable entreprise. Beaucoup pensèrent, non sans raison, qu'on approchait du Centenaire de 1789 , et qu'il était évidemment préférable de faire coïncider avec la célébration de cette date mémorable l'ouverture d'une exposition, non pas nationale, mais universelle. L'idée était bonne: elle fit son chemin par l'intermédiaire des journanx et gräce aussi à d'éloquents discours de ceux qui semblaient dès le début appelés ì jouer un rôle dans l'organisation future.

II. Jules Ferry, alors Président du Conseil, cut à examiner, en 1884, la question de savoir s'il était prudent de convier les nations étrangères, vivant presque toutes sous le rẻgiment monarchique, à célébrer la commémoration d'une Révolution qui, dès le début, portait en germe la forme républicaine. M. Ferry ne vit à cela aucun inconvénient. II $y^{*}$ a, pensa-t-il, une distinction a faire entre les principes de 1789 et ceux de $\mathbf{1 7 9 3 .}$ Or, ceux-la, les gouvernements du monde entier les ont subis ou les ont adoptés dans le cours du siècle; ils ont servi de base à la généralisation du régime constitutionnel en Europe, el il n'y a vraiment, pour les États monarchiques, aucune raison sérieuse de s'abstenir. En outre, le président du conseil estima que, si l'on donnait à l'Exposition le caractère dune manifestation internationale, on contribuerait pour une large 

part à assurer la paix de l'Europe, puisque nous, que le chancelier de paix représente toujours comme prêts à déchaîner la guerre, nous prendrions l'engagement moral de

Le 8 novembre 1884, le Président de la République, M. Jules Grévy, signa done, sur le rapport de M. Rouvier, ministre du Commerce, un décret portant qu'une Lxpo-

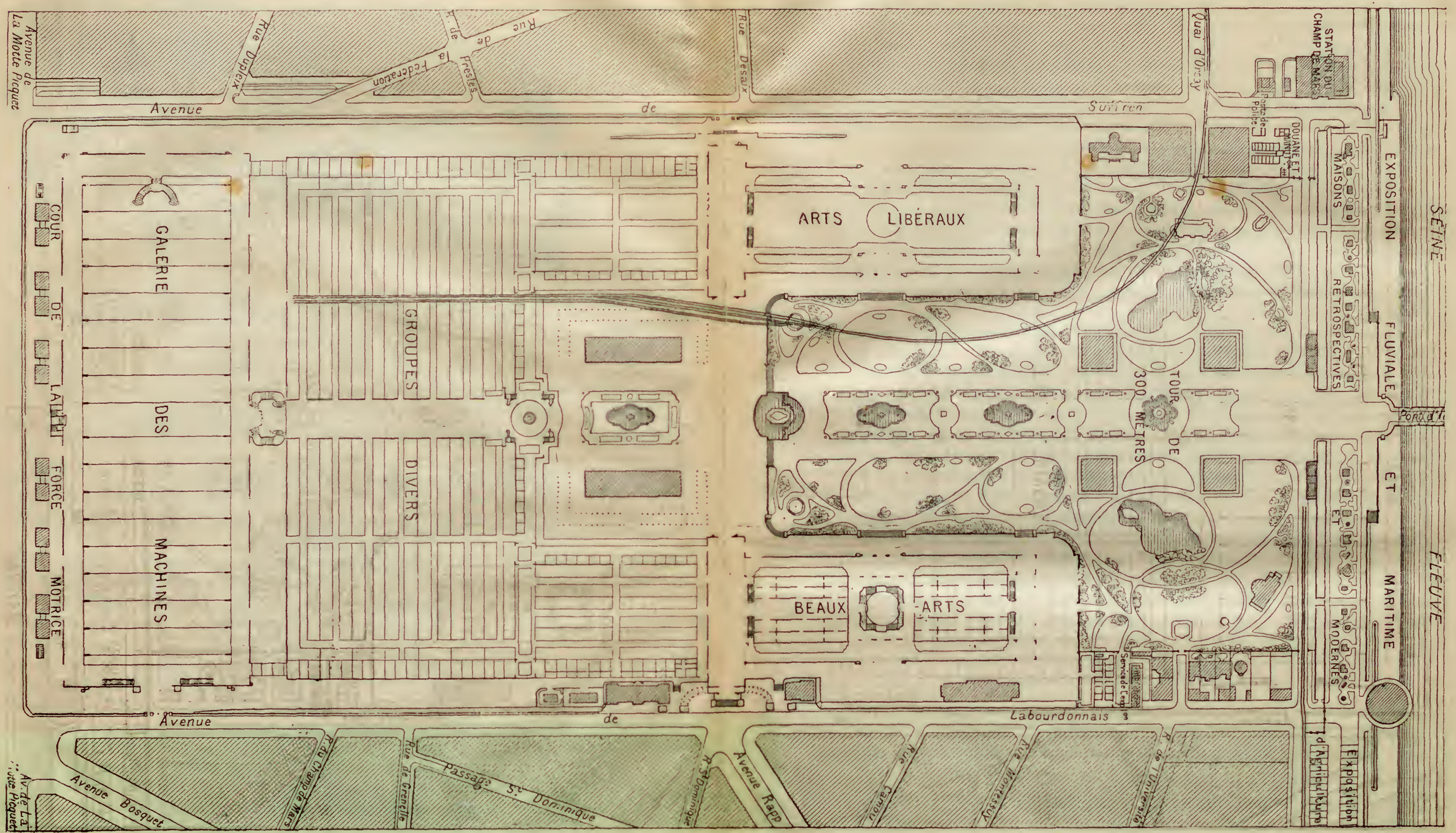

PLAN DU CHAMP DF MARS ET DES CONSTRUCTIONS DOST IL SERA COUVERT

:onsacrer aux luttes pacifiques de l'industrie et du commerce notre activité, nos Ifforts et notre argent.
SITIOY uvivenselue s'ouvrirait à Paris le 5 mai 1889 et serait close:le 31 octobre suivant. En mêne temps une commission consultative était constituée avec la mission e d'étu- 
dier et de rechercher les moyens propres à réaliser le projet du gouvernement *. Définissant l'œuvre à accomplir, le président de cette commission s'exprimait en ces termes: 'L'Exposition de $\mathbf{1 8 8 9}$ aura le caractère d'une Exposition centenale, rísumant ce que la liberté du travail, inaugurée en 1789, date économique en mème temps que date politique, a produft de progrès au cours du siècle qui vient de s'écouler. C'est à cet examen de la situation économique universelle que sont conviées toutes les nations. , Sur ces entrefaites, la chute du cabinet Ferry eut lieu au mois de mars 188;. Sous le cabinet Brisson, on s'occupa surtout, en haut lieu, des élections législatives, et ce n'est qu'un peu plus tard, sous le ministère Freycinet, que II. Luckroy, ministre du Commerce et de l'Industrie, demanda aux Chambres des crédits. Celte fois, il n'y avait plus à en douter, l'Exposition entrait réellement dans la période d'exécution.

Le gouvernement écarta, dès le début, la combinaison contiant lorganisation de l'Exposition à l'initiative privée, afin d’éviter la spéculation. Il n'accepta pas davantage la combinaison qui, comme en 1878 , laissait à l'ítat les charges de l'entreprise, ne voulant pas imposer à l'État des sacrifices excessifs. Il se prononça pour le systèmo de l'organisation par l'Ĺtat avec le concours d'une société de garantie, comme en 1867 , système qui conciliait assez heureusement les avantages des deux premières combinaisons.

"Cetle association, lisait-on dans le Bulletin offeciel de l'Exposition, garantirait it l'État dix-huit millons de recetles, chiffre ferme; elle renoncerait à ses bénéfices, une fois ses capitaux renboursés, dans le cas où les dépenses de l'Étąt auraient dépassé les prévisions. L'action de la Société de garantie s'exercerail par une commission de contrôle et des finances composée de huit conseillers municipaux, de dix-sept sénateurs, députés et aģents de l'État, et de dix-huit souscripteurs de la garantie, clatque commissaire représentant un nillion. Cette commission partagerait avec l'État et le Conseil municipal le druit d'ètre consultée par le ministre du Commerce sur tontes les questions intéressant la gestion tinancière de l'Exposition et il ne pourrait atre passé outre à son avis toutes les fois qu'il s'agirait de questions concernant les receltes de toute nature à percevoir à l'occasion de l'Lxposition. En résumé, l'État garderait la haute main sur l'Exposition, la Ville aurait sa part de surveillance, l'association de garantie ne perdrait pas de vue ses capitaux, l'État rentrerait dans une large partie de ses dépenses par la circulation immense qui s'établirait et par la surproduction de ses impôts indirects, la Ville rentrerait en graude partie dans ses déboursés par les droits d'octroi, l'association de gurantic retrouverait au delà de son apport dans les recettes qui lui seraient abandonnées. Une loi, sn date du 6 juillet 1886 , sanclionna cette combinason, et quelques jours après, le 28 juillet, un décret réğla l'organisalion des servicts :

Le ministre du Commerce et de l'Industrie prit le titre de Commisative gémiral de lExposition et eut sous ses ordres immédials trois directeurs généraux:

M. Alphand, Directeur général des Travaux.

M. Georges Berger, Directeur général de l'Exploitation.

M. Grison, Directeur général des Finances.

Sur la proposition de M. Alphand, le ininistre nomma M. Bartet, ingénieul en chefadjoint au Directeur des Travaux. Pour le contrôle des constructions métalliques, il 
choisit MII. Contamin, J. Charton et Pierron. MN. Bouvard, Dutert, Formigé, furent nommés arehitectes de l'Exposition. Enfin, MM. Lafor'cade et Lion se trouvèrent spécialement chargés des jardins et des plantations.

II r'estait à déterminer le règlement général de l'Exposition. Ce fut l'objet d'un arrêté ministériel en date du 26 aout 1886.

Aux termes de cet arrêté, il fut institué auprès du Commissaire général de l'Exposition, e'est-it-dire aupu'ès du ministre du Commerce, une commission consultative de 300 membres, dite Grand Conseil de l'Exposition universelle de 1889, et subdivisée en 22 commissions consultatives, savoir : Commission de contrỏle et de finances, du Contentieux, des Constructions, des Fìtes et cérémonies, des Transports, des Beaux$\Lambda \mathrm{rts}$, de l'A griculture, des Colonies et pays de protectorat, des Expositions militaires et maritimes, de l'Enseignement des arts libéraux, d'llygiène, du Mobilier et accessoires, des Tissus, vêtements et accessoires, des Industries extractives, des Industries mécaniques, des P'roduits alimentaires, de l'Électricité, de la Presse, des Auditions musicales et thêatrales, des Congrìs et Conférences, de l'Exposition rétrospective du travail.

Dans chaque département, l'arrèté du 26 aoùt créa un comité départemental, ayant pour mission de faire connaitre dans toute l'étendue du département les règlements concernant l'organisation de l'Exposition, de distribuer les formules de demandes d'admission, ainsi que tous autres documents relatif's à l'Exposition, de signaler les principaux artistes, agriculteurs et manufacturiers dont le concours serait particulièrement utile à l'éclat de l'Exposition, de provoquer et d'organiser le groupe collectif des produits similaires du département, d'accréditer un délégué chargé de représenter - chique exposition collective, de préparer par voie de souscription ou par toutes autres mesures la création d'un fonds spécial destiné à faciliter la visite et l'étude de l'Exposition universelle a un certain nombre de contremaitres, ouvriers et cultivateurs de province. Quant aux Commissions étrangères constituées à la demande du gouvernement français, elles furent invitées à se faire représenter auprès de lui par un délégué, chargé de traiter des questions intéressant ses nationaux. Le ministre, commissaire général, ne devait done pas correspondre directement avec les exposants étrangers, et tous les produits présentès par eux ne furent admis que par l'entremise de leurs commissaires respectifs.

Dans chaque section consacréc aux exposants d'une même nation, on décida que les oljets exposés seraient répartis entre neuf groupes :

1 er groupe. - OEuvres d'art (classes 1 ì 5 );

2 groupe. - Éducation, Enseignement, Matériel et procédés des arts libéraux (classes 6 a 16);

$3^{n}$ groupe. - Mobilier et accessoires (classes 17 à 29);

4. groupe. - Tissus, rêtements et accessoires (classes 30 à 40);

3e groupe. - Industries extractives. Produits bruts et ouvrés (classes 41 à 4T));

$6^{e}$ groupe. - Outillage et procédés des industries mécaniques. Electricilé (classes 48 d. 66$)$;

7e yroupe. - Produits alimentaires (classes 67 a 73 );

$8^{\circ}$ groupe. - Agriculture, viticulture et pisciculture (classes 74 à 77 );

$9^{\text {r groupe. }}$ - Horticulture (classe 78 à 83 ). 
La répartition de chaque groupe, dans le plan total de l'Exposition, fut. faite au mieux des intérêts pratiques et des intérêts de l'art. Mais on songea que cet ensemble sans pareil, ce tableau complet de la vie contemporaine dont l'Exposition donnerait l'idée palpable et saisissable, devait avoir une préface, un préambule obligé, et l'on résolut d'instituer, sous le titre d'Exposition rétrospective du tratail et des sciences anthropologiques; une section destinée à montrer aux visiteurs " par quelles transformations successires l'homme a passé depuis les temps les plus reculés dont nous ayons la conscience et la preuve pàr des témoignages qu'on lui mettra sous les yeux.

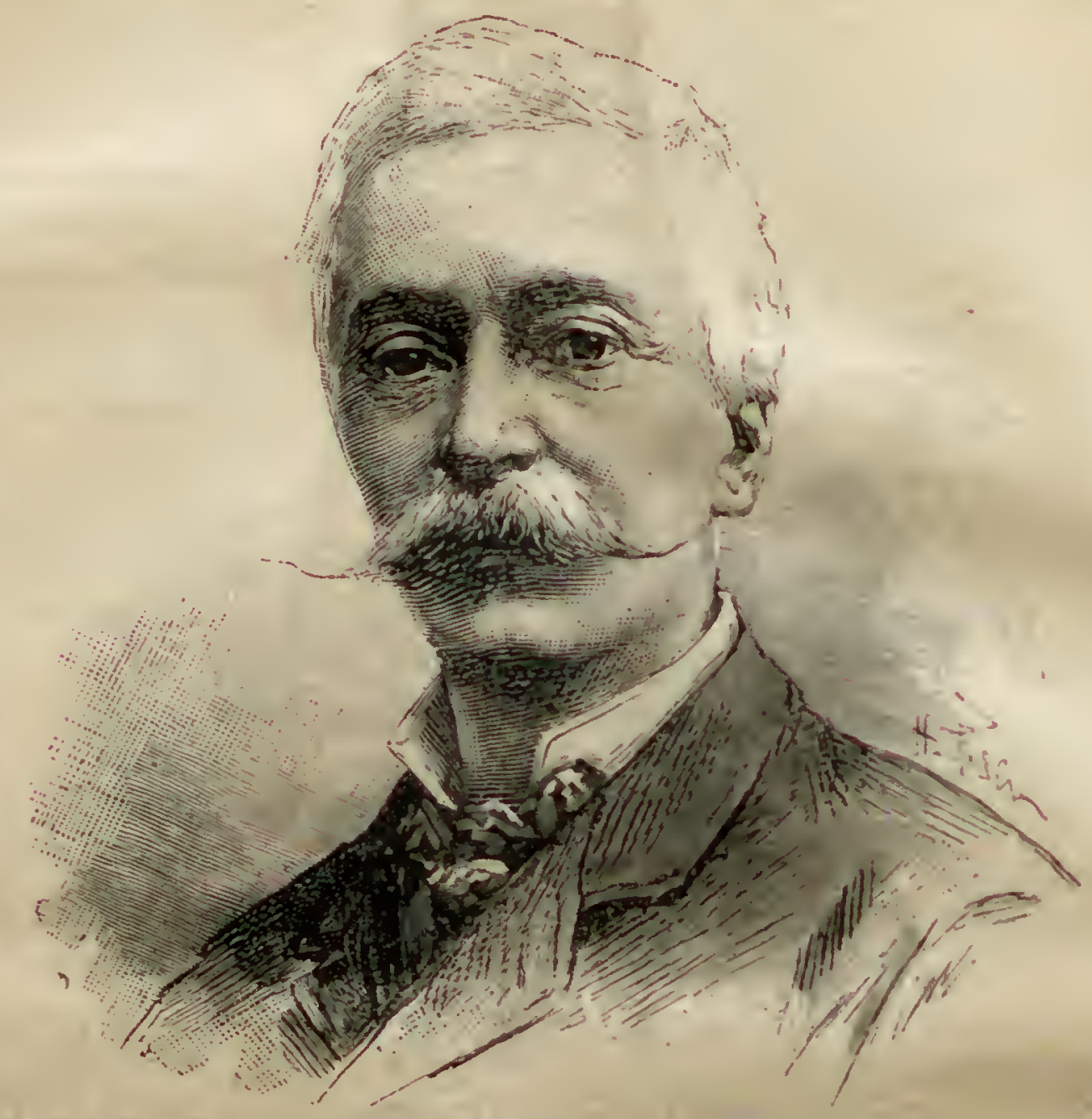

M. EDOUARD LOCKnOY

Premier Commissaire général de l'Exposition univers lle.

L'astronomie, par exemple, nous montrera le télęscope de Galilée qu'on pourra opposer au plus prodigieux des télescupes modernes, et la mécanique opposera a l'original de la première machine à vapeur de Stephenson la dernière locomolive des Cail et des Schneider .

L'Exposition de 1889 occupera un espace beaucoup plus considérable que les précédentes, sans en excepter celle de 1878 : ses bâtiments et ses jardins ne couvriront pas moins de 291,000 mètres. La somme totale des dépenses à effectuer fut arrêtée à 43 millions, dont 18 fournis par la Société de garantie, le reste par l'État et la Ville do Paris.

Six mois nous séparent de la date fixée pour l'ouverture de l'Exposition. Malgré les doutes que l'on a cru, de certains cỏtés, devoir émettre sur sa réussite, il est dès aujourd'hui constant que cette grande œuvre sera digne de la réputation de ceux qui n'ont.pas craint de l'entreprendre, malgré l'état troublé de l'Europe. ، L'Exposition de 


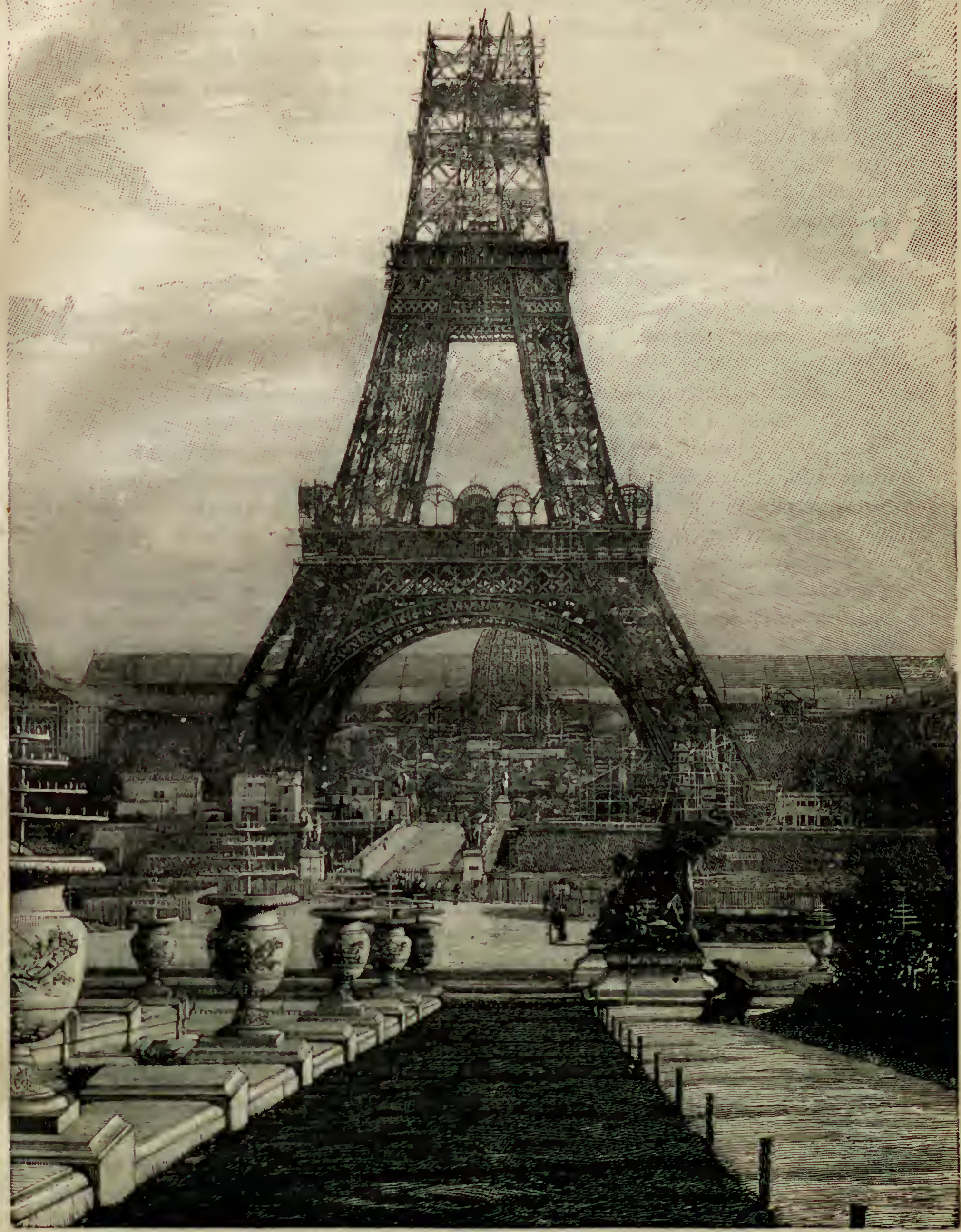

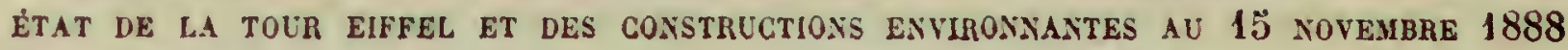

LIv. 2.

Merveilles Exposition. 
1889, disait dernièrement l'un des Directeurs généraux chargés de l'organiser, doit ètre considérée comme une sorte d'oasis au milieu du débordement actuel de la politique, de son effervescence et de ses événements. Le monde des arts, de l'industrie, des affaires, doit oublier, à la vue et à l'ombre de la bannière de l'Exposition, que les Ł.ommes peuvent ètre divisés, mais non sur les questions qui intéressent lé développeminnt effectif du bien-ètre matériel et moral des classes, le progrès technique et économique - industriellement lié aux progrès social, - l'avènement rationnel du beau et de l'utile. '

On s'est demandé si l'Exposition de 1889 est d'une opportunité bien démónl'ée, au milieu de la crise économique dont souffre l'Europe industrielle. Plutút que de réfuter par des arguments quelconques les objections soulevées à ce sujet, nous laisserons la parole à M. Georges Berger, qui, dans une confërence faite ì la Société centrale des architectes, s'exprimait en ces termes:

"Je demanderai, par contre, si le moyen d'atténuer et de vaincre une crise consist. bien à s'abstenir, ì cause d'elle, de toutes les entreprises des teinps prospères, et si l'on ose vraiment soutenir qu'il n'est pas toujours opportun d'instruire, d'intéressere el d'enthousiasmer le public par quelque révélation grandiose et attrayante de l'état inventif du monde.

" Dans un autre ordre d'idées, on a objecté que les Expositions universelles ont le grand inconvénient de révéler trop largement et de livrer les secrets de la fabrication nationale. Ce reproche est puéril. Les négociants et les industriels sérieux du monde entier n'ont-ils pas des correspondants, des royageurs, des agents qui les liennent journellement, heure par heure, au courant des modèles el des nouveautés qui se produisent en tous lieux?

- On a dit encore que les périodes d'Expositions font hausser, sans espoir d'alaissement ultérieur, les prix de toutes choses dans les villes où ont licu les Expositions. Cela est loin d'ètre absolument vrai. Line hausse de prix exagérée se produil certainement dans les magasins d'articles de fantaisie, dans les hotels dits aristocratiques, dans les restaurants de luxe, et ces prix se maintiennent quelquefois, mais cela par la faute. de gens qui veulent bien continuer de les payer au lieu d'aller achalander d'autres établissements où le confortable est aussi grand, tout en étant moins brillant, et des unaga sins où des marchandises de qualités égrales se débitent sur des comptoirs inoins dorés. Vous allez peut-être me trouver paradoxal; inais je prétends que l'enchérissement des denrées, des objets qui constituent le luxe et le superflu de l'existence, n'est pas une chose aussi mauraise qu'on le suppose. Du moment que des consommuteurs prodigues ou riches à l'excès tolèrent que certains de leurs fournisseurs réalisent des bénéfices de 150 , de 200 , de 300 pour 100 , ces fournisseurs ne deviennent riches que plus rapidement, et font place à d'autres qui arrivent non moins vite à l'aisance et à la fortune: tous deviennent des consommateurs sérieux, et, comme ils n'ont généralement pas la naïveté de s'adresser à des maisons du genre de celles qu'ils ont tenues, leurs dépenses profitent à la classe vraiment intéressante des industriels et des commergants. C'est ainsi que la richesse publique s'augmente et multiplie le nombre de ses détenteurs.

« Cela est parfait dans ce sens, grace aux Expositions universelles, d'autant plus que, dansle sens contraire, celles-ci aident à l'ouverture d'établissements, à la création de Sociétés qui facilitent la vie à bon marché pour les classes noyennes et ouvrières : les établissements de consommation dits a bouillons Dural, sont nés de l'Exposition 
de 1867, ainsi que les bateaux de la Seine, qui ont inauguré une nouvelle voie de transport des voyageurs rapide et a prix modiques. Et je ne sache pas qu'aucune Exposition ait arrêté l'abaissement de prix dans la confection des vêtements usuels et des articles courants de mohilier, en un mot des objets de première nécessité. Ce sont les Expositions aussi qui ont donné l'essor aux voyages à prix réduits, avec billets aller et retour, ou billets circulaires.

"Il faut reconnaitre enfin que les Expositions sont des aubaines excellentes pour Jes classes laborieuses auxquelles elles fournissent pendant quelques années un travail extraordinaire dans tous les genres. $\Lambda$ u cours de la discussion qui a eu lieu au Parlement sur le projet de loi de l'Exposition de 1889, un honorable député s'est alarmé en présence du nombre des ouvricrs que les travaux de l'Exposition attireraient à Paris et y laisseraient sur le pavé après sa clôture. J'aurais voulu qu'on demandât au député en question de penser au présent avant de redouter tant l'avenir et de dire ce qu'on pourrait bien faire, à défaut des travaux de l'Exposition, des ouvriers qui sont actuellement sans ouvrage dans nos murs, aussi nombreux peut-être qu'ils le seront en 1890.

"Si vous me demandiez de vons indiquer quels seront le rôle ct le sort des Expositions universelles dans l'avenir, je serais embarrassé pour vous répondre. Je vous demanderais tout d'abord de vouloir bien réfléchir a ce que pourra être la situation industrielle de l'ancien monde et de la France en particulier à la fin du xix ${ }^{\mathbf{e}}$ siècle. L'an 1789 a daté le commencement d'une transformation sociale qui semble n'avoir pas encore achevé son cycle; il pourrait se faire que 1889 datat le commencement d'une transformation économique dont tout signale l'approche, dont les bruits précurseurs sont trop volontiers pris pour les indices d'un bouleversement révolutionnaire.

"Je laisso aux économistes purs le souci de considérer la question générale de l'avilissement du prix de l'argent, de dire comment l'équilibre nécessaire à la bonne marche du monde économique et social pourra se rétablir entre le capital, de moins en moins rémunéré, et le salairc qui demande de plus en plus à s'augmenter. Je vouurais seulement considérer l'avenir en face de deux faits brutaux qui doivent ou qui peuvent se produire.

"Quelles sont aujourd'luui les deux assises fondamentales de la fortune publique en dehors de l'ngriculture qui sera toujours la ressource première et la ressource extrême parce qu'elle procure directement l'aliment, en dehors du commerce proprement dit qui est un moyen relatif et intermédiaire? Ce sont l'industrie manufacturière et l'industrie des transports. La seconde apporte à la première les substances que celle-ci dénature; elle la fournit de matériaux de fabrication qui viennent souvent de loin parce que notre sol et notre climat ne les produisent pas. Ces deux industries sont naturellement d'intérèts opposés sous certains rapports : l'industrie manufacturière se plaint du prix élevé des transports; l'industrie du transport ferme l'oreille à ces plàintes et défend ses tarifs. Laccord ne s'établira jamais à l'état parfait. Mais que va-t-il arriver? Il est évident qu'on se dira un jour qu'il est bien inutile de transporter à prix collteux les gangues et les parties stériles qui grèvent le poids de la matière première utilisable. On s'ingéniera pour traiter ou du moins élaborer la matière première sur le licu de sa production : celia sera d'autant plus facile que le charbon est partout à portée ou apportable sans dépenses excessives et que la mécanique industrielle est perfectionnée suffisamment pour que le premier manceuvre venu accomplisse, en tournant une inanivelle ou en déclinchant un métier, la besogne pour laquelle il fallait autrefois le 
concours de plusieurs ouvriers experts et intelligents. Avec cette simplicité du travil on trouvera en tous pays une main-d'ousre plus abondante et moins avide de gros salaires que dans notre vieille Europe. L'ancien monde serait done menací de no plus fabriquer que de seconde main, éest-i-dire de receroir une matière première légère moins encombrante et déjà élaborée ì différents degrés; il ne lni resterait qụe la res. source de façonner industriellement et artistement cette matière suivant les gouls des différents peuples, suivint les instincts naturels, les capacités professionnelles et les besoins nationanx de ceux-ci. La France est un pays éminemmont consommateur; il lui faut travailler beaucoup pour suffire à ses besoins réels on factices et pour réaliser, en outre, la richesse et l'épargne dont elle a l'ambition et le désir. Qu'adviendra-t-il de nous le jour où notre pays verra, d'un côté, se fermer beaucoup de ces usines d'élaburation et de dénaturation qui répandaient des salaires et des bénéfices; de l'autre, diminuer les revenus de titres émis financièrement par les compagnies de transportauxquelles l'usage répandu du télégraphe et du téléphone enlèvera des voyageur's en même temps que le tonnage de leur trafic sera diminué? Végéterons-nous? l'érironsnous ensuite? Non, certainement. Des combats comme ceux qu'il nous faudra entreprendre pour notre existence sortent les renaissances, les brillantes époques de rércil pendant lesquelles le génie national, retrempé par l'épreuve, se repreud aux nobles entreprises et rallume au foyer de son travail le flanbeau de la prospirité.

"En 1889, nous montrerons à nos fils ce que leurs pères ont fait en un siecle par to progrès de l'instruction, l'amour du travial et le respect de la liberté; nous leur ferons voir de haut la pente abrupte qui a été cscaladéc depuis les ténèbres du passé, et, s'il leur faut un jour redescendre vers quelque vallée d'erreur et de misère, ils se souviendront, feront se souvenir leurs enfants, et les gienerations futures ne seront que plis acharnées à gravir plus haut encore que nous n’avions gravi, car la loi du progrès est immortelle comme le progrìs lui-mème est l'infini.

* Je termine en disant : A 1883 ! Jarchons fièrement et patriotiquement ver's cette date.

\section{1}

\section{LA TOLR RIFFEL}

Les études que M. Eiffel eut, comme ingénicur, l'occasion de faire sur de hautes piles métalliques supportant les viaducs de chemins de fer, comme celui de fiarabit, le conduisirent a periser que l'on prouvitit donner a ces piles des hauteurs notablement supérieures à celles que l'on avail atteintes jusque-li. De l'ensemble de ses recherches, M. Eiffel tira cette conclusion qu'il serait possible : d'élever une tour ou pylóne de 300 mètres qui serait inaugurée en mème tempis que l'Exposition de 1889, comme un symbole gigantesque de notre siècle de science et d'industrie. Il somnit son idée au gouvernement, qui l'agréa. et dans le courant de l'année 1887, les Parisiens virent s'élever peu à peu la Tour Eiffel entre l'enceinte du Champ de Mars et le pont d'léna. 


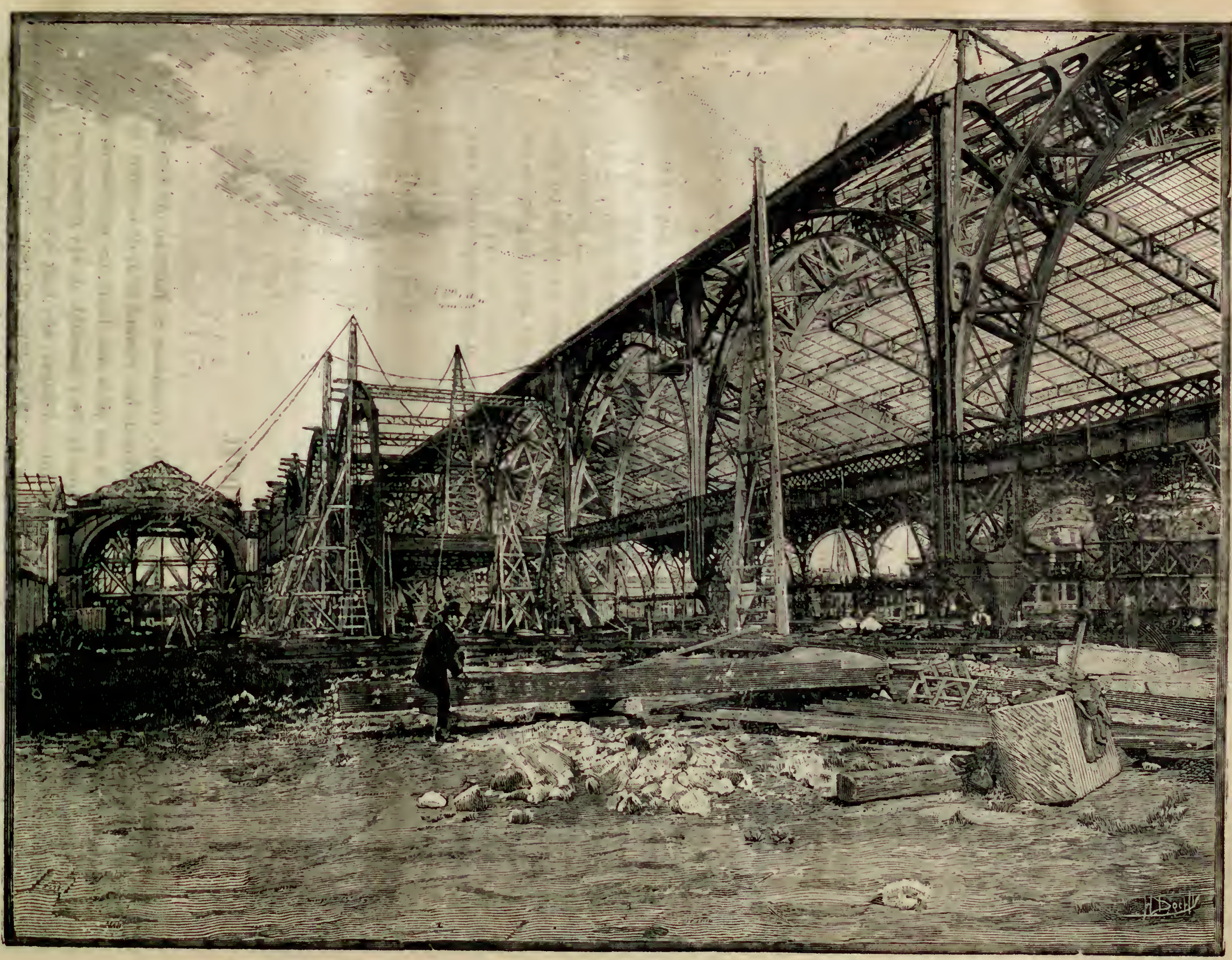


Nous disons « symbole gigantesque , et non sans raison, car la Tour Eiffel dépas. sera dans des proportions considérables les plus grands monuments connus. Qu'on en juge par les chiffres suivants:

Tour Eiffel, 300 mètres.

Notre-Dane de Paris, 66 mètres.

Panthéon, 83 mètres.

Dòme des Invalides, $10 \Xi ّ$ mètres.

Saint-Pierre de Rome, 132 mètres.

Cathédrale de Strasbourg, 142 mètres.

Grande Pyramide, 146 mètres.

Cathédrale de Cologne, $1: 9$ mètres.

Monument de Washington, a Philadelphie, $169^{\mathrm{m}}, 2 \%$.

Arc de Triomphe de l'Étoile, 49 mètres.

Cathédrale de Rouen, 150 mètres.

Jamais les cliffres n'ont été plus éloquents et l'on comprend qu'une nuvre de cette importance soit la grande attraction de 1889, dont elle dominera les pares et les édifices. Il est donc naturel de commencer par la Tour Eiffel notre descriplion de rExposition universelle.

Les précédents de la Tour Liffel. - En 1874, une tour de 1,000 pieds fut projelée a l'occasion de l'Exposition de Philadelphie, mais les plans de ce monument ne virent jamais le jour. L'idée émise par M. Sébillot, en 1881, d'éclairer Paris au moyen l'un foyer électrique, placé à 300 mètres de hauteur, cette idée, disons-nous, n'a reçu encore aucun commencement de réalisation.

L'énumération que nous avons donnée des monuments les plus élevés du glolie montre que le grand obélisque en pierre, connu sous le nom de moumment de Washingtnn et élevé en 1873, se rapproche le plus par sa hauleur du pylône de M. Viffel. Cet ohrilisque en granit, avec revêtement de marbre, a exactement $169^{\mathrm{m}}, 2 \mathrm{2i} ;$; il est carré dı haut en bas; il a $16^{\mathrm{m}}, 7 \mathrm{~s}$ de cỏté a la base et $10^{\mathrm{m}}, 30$ au-dessus du pyranidion. lequel a lui-mème $16^{\mathrm{m}}, 86$ de hanteur. Il est évidé à l"intérieur, et le vide rẹoit un ascenseur 丸̀ vapeur. Il pèse 4,500 tonnes qui, réparties sur une base de 223 mètres carrés, donnent un coefficient à la compression de 20 kilogrammes par centimètre carré.

En France, les ouvrages d'art les plus hardis ont été presque tous construits par 1I. Eiffel ou avec sa collaboration. En 1838, il dirigea la construction du pont métallique de Bordeaux, fondé sur des piles établies à l'air comprimé, à une profonden' de 25 mètres dans l'eau. Dix ans plus tard, il éleva pour le compte de la Compagric d'Orléans les viaducs sur piles métalliques de la Sioule et de Neuvial, sur la ligne de Commentry à Gannat. Plus récemment, il exécuta le viaduc de Garabit qui franchil à une hauteur de 122 mètres la vallée de Truyère, sur la ligne de Marvejols à Neussargues. Le viaduc de Garabit repose sur 5 piles dont la plus hante a $89^{\mathrm{m}}$, 64 et est formée par un socle en maçonnerie de $28^{m}, 70$ de hauteur sur 23 mètres de largeur; il píse 3,254 tonnes. Mentionnons enfin le pont droit construit par $\mathbf{M}$. Liffel sur le Tage. Ie pont de Vianna (Portugal), le pont de Cobas (ligne des Asturies), le grand port-route de Szégedin en Hongrie, le pont du Douro, à Porto. I'ersonne, mieux que M. Eiffel, n'était donc désigné pour construire la Tour de 300 mètres.

Lorsque l'honorable ingénieur soumit au gouvernement son projet gigantesque, 
l'idée fut accueillie avec faveur. Une seule protestation se produisit, mais elle était signée de noms célèbres : Meissonier, Gounod, Charles Garnier, Géròme, Bonnat, Bouguereau, Dumas fils, Vaudremer, Sully-P'rudhomme, Delaunay, etc. Ces littérateurs et ces artistes protestaient « de toule leur indignation» au nom du goùt français, au nom de l'histoire de notre art national, ne voulant pas que a le Paris des gothiques sublimes, le Paris de Jean Goujon, de Germain Pilon, de Puget, de Rude, de Barye, devint le Paris de M. Eiffel ». Et ils ajoutaient: "II suffit d'ailleurs, pour se rendre comple de ce que nous avançons, de se figurer un instant une tour vertigineusement ridicule, dominant Paris, ainsi qu'une gigantesque et noire cheminée d'usine, écrasant de sa masse barbare Notre-Dame, la Sainte-Chapelle, la tour Saint-Jacques, le dôme des Invalides, l'Arc de Triomphe, tous.nos monuments humiliés, toutes nos architectures rapetissées, qui disparaîtront dans ce rêve stupéfiant. Et nous verrons s'allonger sur la ville entière frémissante encore du génic de tant de siècles, nous verrons s'allonger, comme une tache d'encre, l'ombre odieuse de l'odieuse colonne de tôle boulonnée.

Cette virulente diatribe, qui fut publiće par les journaux en février 1887 sous forme de Ieltre à M. Alphand, se produisait trop tard. Depuis plusieurs mois dẻjà, il était entendu que M. Eiffel construirait pour l'ĺtat la Tour de 300 metres, qu'il recerrait de lui une première subvention de $1,300,000$ francs, plus le droit d'exploiter le monument pendant l'Exposition. Après l'Lxposition, l'Ĺtat la céderait al la Ville de Paris qui, comme seconde subvention, accorderait, elle aussi, a l'ingénieur le droit de l'exploiter pendant 20 ans. Ce délai écoulé, il était entendu que la Tour appartiendrait définitivement a la Ville, qui - en aurait la pleine el entière disposition. Enfin, les travaux étaient commencés, les fondations posées. Quel intérêt pratique pouvait donc avoir la protestatiou?

Aucun, ou plutôt un seul: celui de jeter le discrédit sur une des grandes attractions de l'lixposition, sur un monument que l'on ne connaissait alors que d'après un dessin géométral. "Je crois, moi, répondit bravement M. Eiffel, que ma tour sera belle. Parce que nous sommes des ingénicurs, croit-on donc que la beauté ne nous préoccupe pas dans nos constructions et qu'en mene temps que nous faisons solide et durable, nous ne nous efforçous pas de faire élégant?... Il y a dans le colossal une attraction, ull charme propre auxquels les theorics d'art ordinaires ne sont guère applicables. Soutiendra-t-on que c'est par leur valeur artistique que les Pyramides ont si fortement frappé l'imagrination des hommes? Qu'est-ce autre chosse, après tout, que des monticules artificiels? Et pourtant quel est le visiteur qui reste froid en leur présence? Qui n'en est pas revenu rempli d'une irrésistible admiration! Et où est la source de cette admiration, sinou dans l'immensité de l'effort, et dans la grandeur du r'ésultat? Ma Tour sera le plus hantédifice qu'aient jamais élevé les lıommes. Ne sera-t-elle donc pas grandiose aussi à sa faron? Et pourquoi ce qui est admirable en Égypte deviendrait-il hideux et ridicule à Paris? Je cherche et j'avoue que je ne trouve pas.

- La protestation dit que ma Tour va écraser de sa grosse masse barbare Notre-Dame, la Sainte-Chapelle, la tour Saint-Jacques, le Louvre, le dôme des Invalides, l'Are de Triomphe, tous nos monuments. Que d'affaires dans une tour! Cela fait sourire, vraiment. Quand on veut admirer Notre-Dane, on va la voir du parvis. En quoi, du Cliamp de Mars, la Tour gênera-t-elle le curieux placé sur le parvis Notre-Dame, qui we la verra pas? C'est d'ailleurs une des idées les plus fausses que celle qui consiste à croire qu'un édifice élevé écrase les constructions environnantes. Regardez si l’Opéra 
ne parait pas plus écrasé par les maisons dn voisinagre qu'il ne les écrase lui-mème. Allez au rond-point de l'Éloile, et parce que l'Are de Triomphe est grand, les maisons de la place ne vous en paraitront pas plus petites. Au contraire, les maisons ont bien l'air d'avoir quinze mètres de haut, et il faut un effort de l'esprit pour croire que l's re de Triomphe en mesure quarante-cinq.

"La protestation gratifie ma Tour d' * odicuse colonne de tùle boulonnée. Je 11 'a point ru ce ton de dédain sans ìtre irrité. Il y a parmi les signataires des hommes que jadmire et que j'estime. Il y en a d'autres qui sont connus ponr peindre de jolies petites femmes se meltant une fleur au corsage ou pour avoir tourné spiriluellenent quelrues couplets de vaudeville. Eh bien! frarchement, je crois que toute la france

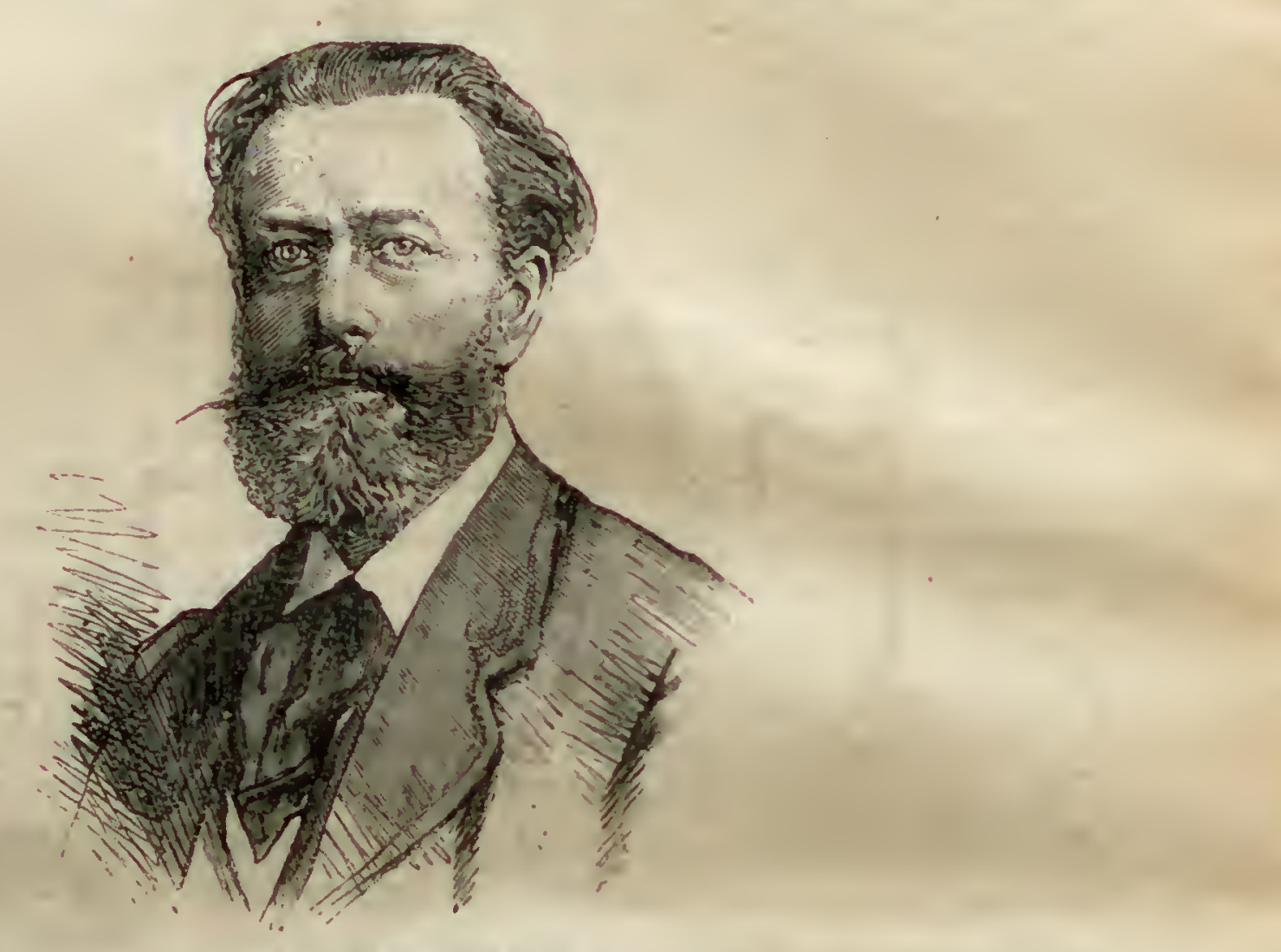

11. AxTOXIX pRULST

n'est pas lì dedans. II. de Vogüé, dans un récent anticle de la Reche tes Den-Momtes. après avoir constaté que dans n'importe quelle ville d'Europe où il passait, il entendait chanter Lgène, tu mu fais de la peine, et le Bi du bout du lumr, se demandait si nous étions en train de devenir les yruculi du inonde contenupurain. 11 me semble que. nent. elle pas d'autre raison d'être que de montrer que nous ne sommes pas seulement le pays des amusements, mais aussi celui des ingénieurs et des constructeurs qu'on appelle de toutes les régions du monde pour édifier les ponts, les viaducs, les gares et les grands monuments de l'industrie moderne, la Tour Fiffel mériterait d'ètre traitíe avec plus de considération.

De son cóté, M. Lockroy, alors ministre du Commerce, adressa a M. Mlphand, en réponse à la protestation que ce dernier avait reçue, une lettre où il apprécinit avec une ironie peu déguisée le fond du document au bas duquel lo tout-1'aris des lettres et des arts avait apposé sa signature. Après avoir rendu hommage à l'ampleur des périodes, à la beauté des métaphores, a l'alticisme d'un style délicat et précis, le ministre exprimait le regret que la prolestation manquât d'a-propos. a J'en suis profondément peiné, continuait M. Lockroy. Ce n'est pas que je craigne pour Paris: Notre-Dame restera 


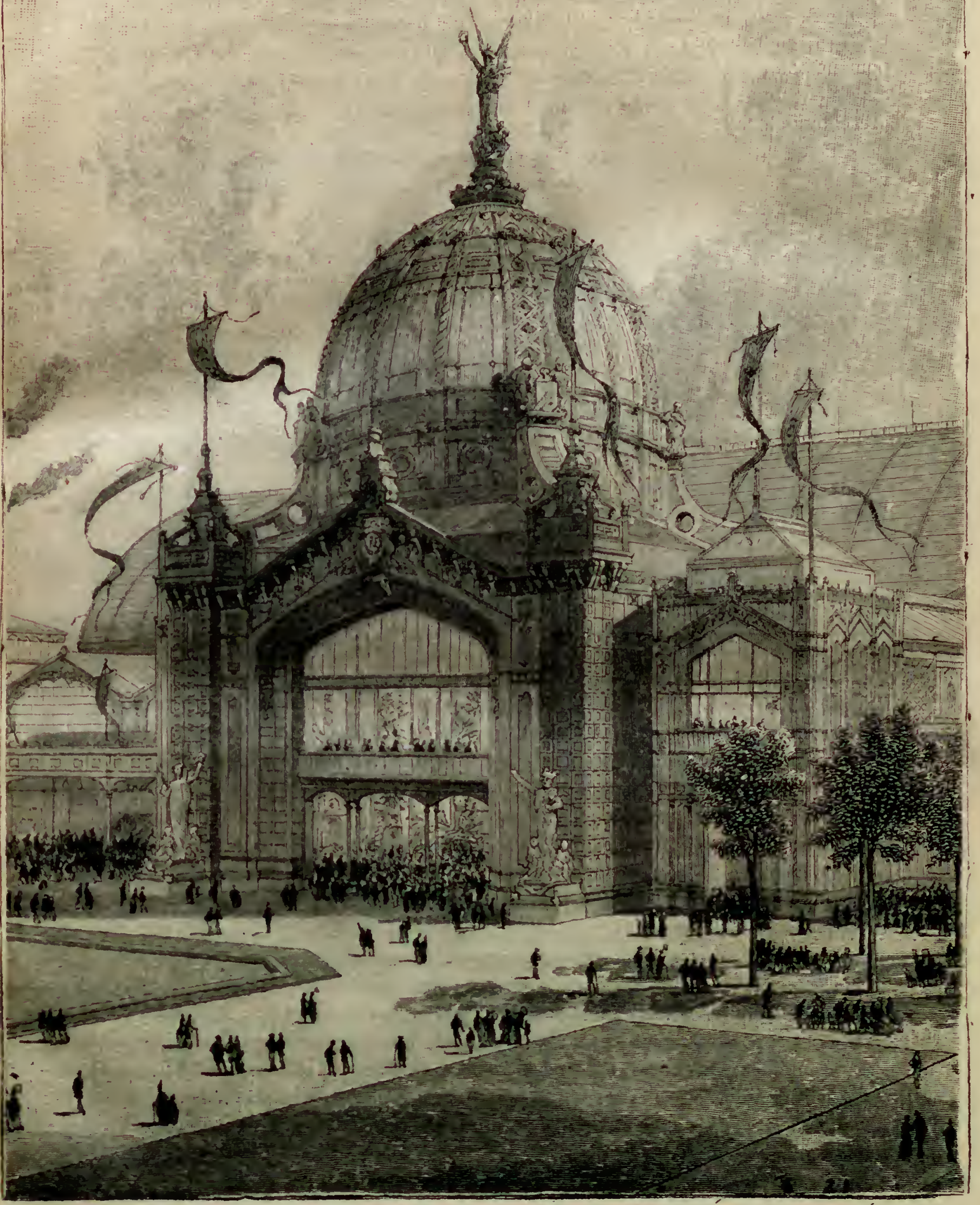

LE DOME CENTRAI DU PALAIS DES INDUSTRIES DIVERSES

M. Bouvard, arthitccte. - Dessin de M. IIolfbauer, d'après les documents officiels.

Menieilles Exposition. 
Notre-Dame et l'Arc de Triomphe restera l'Arc de Triomphe, mais j'aurais pusauver la seule partie de la grande ville qui fut sérieusement menacée : cet incomparable carró de sable qu'on appelle le Champ de Mars, si digne d'inspirer les poèles et de sédure les paysagistes.

"Vous pouvez exprimer ce regret à ces messieurs; ne leur diles pas qu'il cst pénible de ne voir a l'avance altaquer l'lixposition universelle que par ceux qui devraient la défendre; qu'une protestalion signée de noms si illustres aura du retentissement dans toute l'Europe et risquera de fournir un prétexte à certains ćlranger's pour ne point participer a nos fètes; qu'il est mauvais de chercher à ridiculiser une œuvre pacifique à laquelle la France s'attache avec d'autant plus d'ardeur, it l'henre présente, qu'elle se voit plus injustement suspectée au dehors.

a De si mesquines considérations touchent un ministre; elles n'auraient point de valeur pour des esprits élevés que préoccupent, avant tout, les intérêts de l'art el l'amour du beau.

* Ce que je vous prie de faire, c'est de recevoir la protestation el de la garder. Elle devra figurer dans les vitrines de l'lixposition.

* Une si belle et si noble prose, signée de noms connus dans le monde entier, ne pourra manquer d'attirer la foule et peut-etre de l'atonner. "

Priscipe sciextifinue de la Tour. - A diverses reprises, notamment dans une conférence faite en présence des anciens élèves de l'École centrale, M. Eiffel a eu l'occasion de fournir sur son projet des renseignements d'une grande précision que nous avons exclusivement utilisés pour tout ce qui, dans la description de la Tour, présente un caractère technique.

Lorsque l'on veut établir de hautes piles métalliques, la principale diffienlté que l'on rencontre est celle-ci : Dans le mode habituel de construction des viadues, on dispose dans le plan des grandes faces normales a l'axe du viarduc un systeme de treillis très énergique destiné à résister à l'action du vent; la base des piles venant naturellement à s'élargir en raison de l'augrmentation de la hautenr, ces barres de treillis, par suite de leur grande longueur, deviennent d'une eflicacité a peu pris illusoire.

On peut bien leur donner la forme de caissons (ainsi que M. Eilfel en fit le premier l'application), de manière à ce que chacune d'elles puisse servir à la traction anssi bicn qu'à la compression; mais elles n'en restent pas moins un grand sujet de difficulté, si l'écartement des pieds de la pile atteint $2: 3$ ou 30 mètres. Il y a donc intérèt à se déharrasser complètement de ces pièces accessoires, dont le poids est relativement très élevi, et à donner à la pile une forme telle que tous les efforts tranchants vienuent se concentrerdans ses aretes. Pour cela, il faut réduire la pile à quatre grands montants dégagés de tout treillis de contreventement, et réunis simplement par quelques ceintures horizontales très espacées.

S'il s'agit d'une pile supportant un tablier mélallique et si l'on ne tient comple qune de l'effort du vent sur le tablier lui-mème, lequel est toujours très considerable par rapport à l'effort exercé sur la pile, il suffira, pour pouvoir supprimer les barres de contreventement des faces verticales, de fairc passer les deux axes des arbalitriers par un point unique placé sur le sommet de cette pile. Fin ce cas, l'effort horizontal du rent pourra se décomposer directement suivant les axes de ces arbalctriers, lesquels ne seront soumis i aucun effort tranchant.

Si, au contraire, il s'agit d'une très grande pile, telle que la Tour Eiffel, dans 
laquelle il n’y a plus au sommet la réaction horizontale du vent sur le tablier, mais simplement l'action du vent sur la pile elle-mème, il suffit, pour supprimer l'emploi des barres de treillis, de donner aux montants une courbure spéciale. Cette courbure sera telle, que les tangentes aux montants, menées en des points situés à la mème hauteur, viendront toujours se rencontrer au point de passage de la résultante des actions que le vent exerce sur la partie de la pile inférieure aux points considérés.

Enfin, dans le cas où l'on vent tenir compte, à la fois de l'action du vent sur le tablier supérienr du viadıc, et de l'action exercée sur la pile clle-mème, la courbe extérieure de la pile doit se rapprocher sensiblement de la ligne droite.

" Une haute pile de viaduc, telle que nous la concevons, dit M. Eiffel, serait donc ainsi simplement constituée parquatre montants d'angle, en forme de caissons. Les parois en seraient évidées, afin de diminuer la surface offerte au vent. La base, dont le rapport avec la hauteur serait aussi grand qu'on le désirerait, permettrait de donner à la construction toute la stabilité désirable. Nous avons étudié, dans cet ordre d'idées, une grande pile de viaduc de 120 mètres de hauteur et de 40 mètres de base, aux avantages pratiques de laquelle nous croyons fermement et que nous espérons bien avoir un jour l'occasion d'appliquer à un grand ouvrage. C'est l'ensemble de ces recherelıes qui nous a conduits à étudier une tour ou pylỏne, atteignant la hauteur tout à fait inusitée de 300 mètres.

Conditions de mísistance ET DE STABLITE. - Dans ła conférence que nous mentionnons nu début de ce chapitre, M. Eiffel a exposé scientifiquement les principes sur lesquels il a pu établir les conditions de résistance et de stabilité de la Tour de 300 mètres. Par l'application de ces principes, il arrive que la direction de chacun des éléments des montants s'infléchit de telle manière que la courbe extérieure de la Tour reproduit à une échelle déterminée la courlıe mème des moments fléchissants dus au vent. L'incertitude qui existe sur les effets du vent et sur les données à adopter, tant pour l'intensité mène que pour la valeur des surfaces frappées, a conduit M. Eiffel à se mettre dans des conditions de prudence particulières.

En c qui concerne l'intensité, il a admis deux hypothèses: dans l'une, le vent a sur toute la hauteur de la 'Tour une force constante de 300 kilogrammes par mètre carrí: daus l'autre, cette intensilé va en augmentant de la base, où elle est de 200 kilogrammes, jusqu'an sommet, ò elle atteint 400 kilogrammes.

Ouant aux surfaces frappées, M. Eiffel a admis par exagération que, sur la moitié supérieure de la Tour, tous les treillis du caisson étaient remplacés par des parois pleines; que sur la partie intermédiaire, où les vides prennent plus d'importance, chaque face arıtérieure était complée à quatre fois la surface réelle des fers; qu'audessous (galerie du premier étage et partie supérieure des arcs), la surface antérieure était pleine; enfin, qu'a la hase de la Tour les montants étaient pleins et frappés deux fuis par le vent: ces hypothèses sont assurément plus défarorables que celles qu'on adopte en général pour les viadues.

Cela posé, M. Eiffel a fait ses całculs dans l'une et l'autre hypothèse de répartition de l'intensité du vent, et l'épure prouve que les deux polygones funiculaires auxquels il est arrivé sont à peu de chose près identiques.

Dans thypothèse d'un vent uniforme de 300 kilogrammes sur toute la hauteur, l'effort horizontal total sur la construction est de 3,284 tonnes, et le centre d'action est situé à $92 \mathrm{~m}: 30$ au-dessus de l'appui. Le moment de renversement est donc de : 



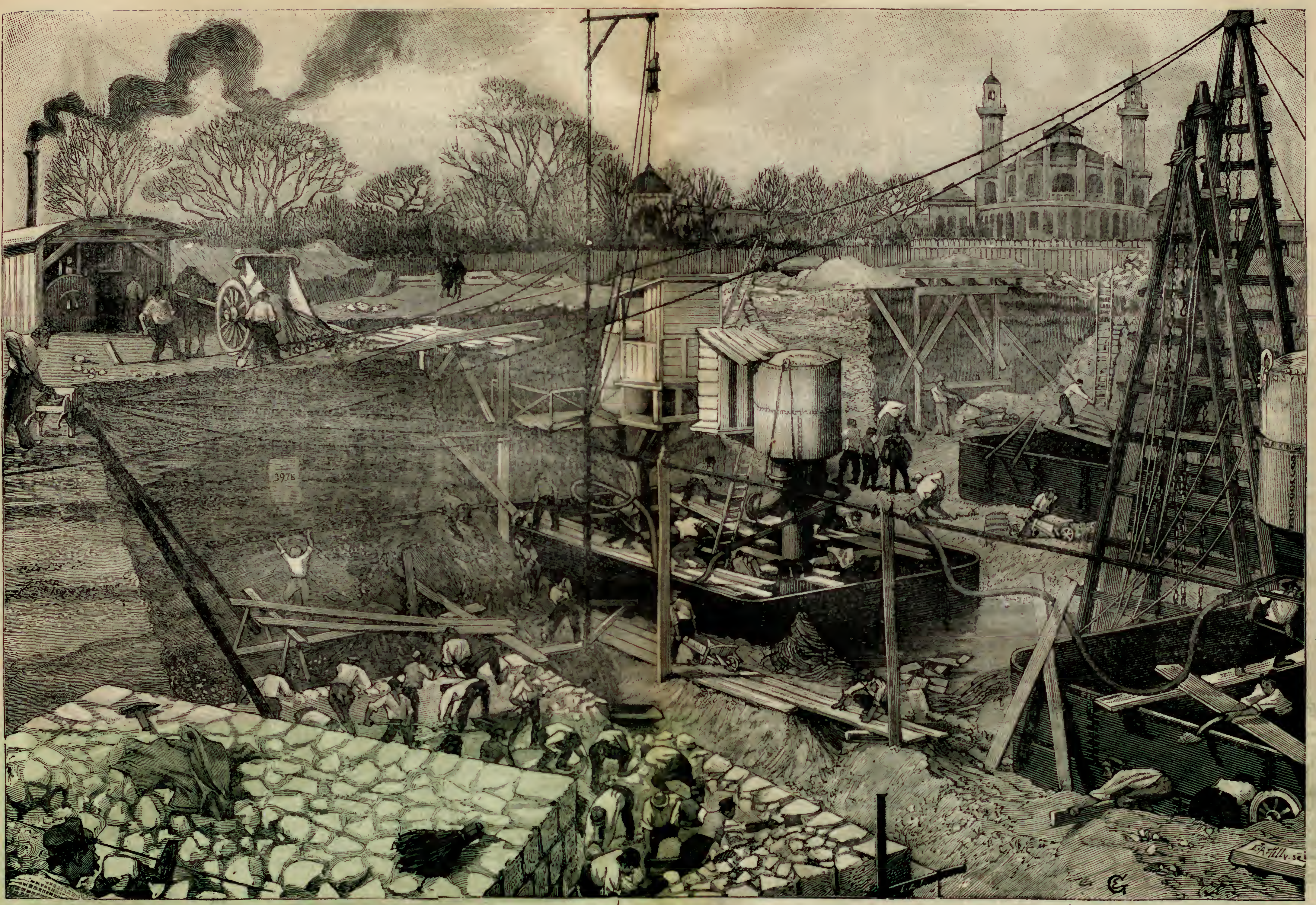

La tour eiffel. - Trayaux de pondation et de CONSOlidation des plles 


$$
\mathrm{M}_{\mathrm{B}}=3,284 \times 92 \mathrm{~m}, 30=30 \%, 113 \text { tonnes mètres. }
$$

Q ant au moment de stabilité, le poids total de la construction est le suivant:

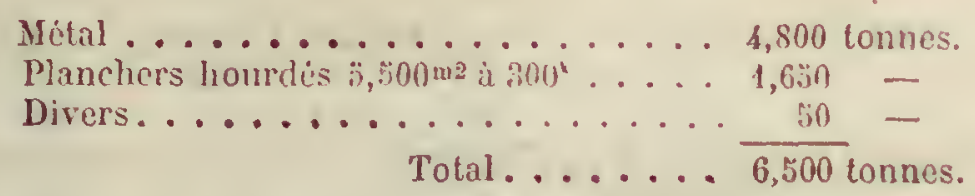

La base de la Tour étant de 100 mètres, le moment de stabilité sera de

$$
M_{\mathbf{s}}=6,300 t \times \frac{100}{2^{-}}=323,000 \text { tonnes inetres, }
$$

qui est supérieur au moment de renversement.

Dans la deuxième hypothèse, celle d'un vent variant de 200 à 400 kurogranmes, l'effort horizontal n'est plus que de 2,874 tonnes, mais le centre d'action s'élève à 107 mètres au-dessus de l'appui, le moment de renversement est donc de :

$$
\mathrm{Mr}=2,874 \times 107=307, \text { öl } 8 \text { tonnes mètres. }
$$

Ce chiffre est presque identique à celui de la première hypothèse et reste inféricur an moment de stabilité.

Mais l'on peut augmenter encore notablement le degré de sécurité en amarrant chacune des quatre membrures des montants au massif du soubassement au moyen de trois tirants de $0^{\mathrm{m}}, 11$ de diamètre qui intéresseront un cube de maconnerie suffisant pour doubler le coefficient de sécurité.

Si nous passons aux fondations, nous voyons qu'elles sont ainsi constituies : (:hitcune des membrures d'angle s'appuie sur un massif carré en maconnerie reposint sur une base en béton. Ces massifs, traversés par des amarrages, sont relićs les uns aux autres par un mur, et il reste entre eux une grande salle vitrée d'environ 250) mètres carrẻs, qui sera utilisée pour les accès aux ascenseurs et l'installation des machines. Dans ces conditions, la charge sur le sol de fondation, dans le cas du vent de 300 kilogrammes, sera la suivante:

$$
\begin{aligned}
& \text { 1. Cliarge due au montant métallirgue : } \\
& \left.\begin{array}{l}
\text { Pour la cliarge propre, } \frac{6,000}{5}=1,625^{\circ} . \\
\text { Pour l'effet du vent } \frac{307,31}{2 \times 100}=1,03 \% \text {. }
\end{array}\right\} 3,162 \text { lonnes. } \\
& \text { פo Charge due aux meçonneries ... . } \\
& \text { Ensemble. . . . . S,862 tonnes }
\end{aligned}
$$

qui se répartissent sur une surface de 3214 mètres crrés, soit par centimètre carré :

$$
\frac{8,262,000}{3,240,000}=2 k, 6 \text { en moyenne, }
$$

et $4 k, 500$ sur l'arête la plus comprimée.

Enfin, quant au travail maximum du fer, il doit ètre établi en vue d'un vent de 300 kilogrammes, lequel est tellement exceptionnel 'qu'il n'y en a pas encore d'cxemple à Paris, et ce coefficient de travail sera fixé à 10 kilogrammes, ce qui, dans les circonstances ordinaires des vents à Paris, correspond à un travial effectif de 6 à 7 kilogrammes. Du reste, ce coefficient de 10 kilogrammes est usuel en Allomnann of on 
Autriche pour les grandes charpentes métalliques qui ne sont pas soumises, comme les ponts, aux trépidalions dues aux trains.

La part du coefficient total, due aux charges propres, est dans la Tour Eiffel de 5 kilogrammes, et la part due au vent de 300 kilogrammes est de 5 kilogrammes également, laquelle se réduira à 1 ou 2 kilogranmes pour les vents violents ordinaires a Paris.

La flèche que peut prendre une tour de cette nature sous linfluence du vent est une question qui ne manque pas d'intérêt, non pas au point de vue de la flèche qui peut se produire dans les limites extrêmes des vents de 300 et 400 kilogrammes, dont on n'a pas à s'inquiéter, puisque le sommet de la tour n'est plus alors abordable, mais il est bon de s'en rendre compte, pour le cas des vents violents ordinaires, afin de savoir si les personnes qui seraient sur la plate-forme supérieure pourraient s'en trourer incommodées.

Si l'on prend les classifications des vents indiqués dans l'ouvrage de Claudel, et si l'on calcule les flèches qui correspondent aux pressions indiquées, on reconnait que ces fleches sont les suivantes:

\begin{tabular}{|c|c|c|c|}
\hline $\begin{array}{l}\text { DLSIGNATION } \\
\text { DES VENTS }\end{array}$ & $\begin{array}{l}\text { VITLSSE: } \\
\text { gAR SECONDE }\end{array}$ & $\begin{array}{l}\text { PRESSION } \\
\text { PAR MÈTRE CARRÉ }\end{array}$ & $\begin{array}{c}\text { FLECHES PRISES } \\
\text { PAB LA TOUR }\end{array}$ \\
\hline Tris furle brise... & $\begin{array}{l}\text { inctres } \\
10.00\end{array}$ & $\begin{array}{l}\text { kil. } \\
13.34\end{array}$ & $\begin{array}{r}\text { in itres } \\
0.038\end{array}$ \\
\hline $\begin{array}{c}\text { Brise faisant serrer les } \\
\text { hautes voiles. . . }\end{array}$ & 12.00 & 19.50 & $0.08 \%$ \\
\hline Fent tres fort ... & 18.00 & 30.47 & 0.086 \\
\hline Vent impètueux & $\begin{array}{r}20.00 \\
-\end{array}$ & 34.16 & 0.133 \\
\hline Tempîte. & 24.00 & 78.00 & 0.221 \\
\hline
\end{tabular}

Ces chiffres sont tout i faits rassurants, et comme les oscillations seront d'une extrime lenteur, en raison de la grande longueur de la partie flèchissante, il cst certain que l'eflet en sera tout a fait insensible, et qu'il sera beaucoup moindre que dans les phares en maconnerie, où l'élasticité des mortiers est la cause la plus déterminante des flèches observées.

Les dépenses de construction de la Tour s'élèveront à 4,905,000 francs, non compris le prix des ascenseurs.

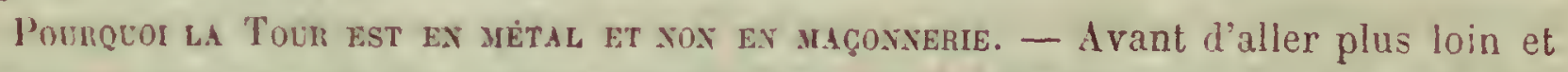
d'indiquer les services que pourra rendre une pareille construction, il y a quelques 
mots à dire sur l'emploi de la matière que M. Eiffel a choisie. L'emploi du fer ou de l'acier semblait tout indiqué par la grande résistance du métal sous un faible poids, par le peu de surface qu'il permet d'ex poser au vent, enfin, par son élasticité qui solidarise toutes les pièces et permet d'en faire un ensemble dont toules les parties sont susceptibles de travailler à l'extension ou a la compression et qui, étant toutes calculables, peuvent donner une sécurité complète.

Après de nombreuses hésitations, M. Eiffel a donné la préférehce au fer sur l'acier, parce que, dans le cas actuel, il était peu important d'avoir une légèreté particulière, laquelle, au point de vue de la résistance au rent, est plutòt nuisible qu'utile, parce qu'avec ces grandes dimensions ta résistance au flambage est, pour la plupart des pièces,

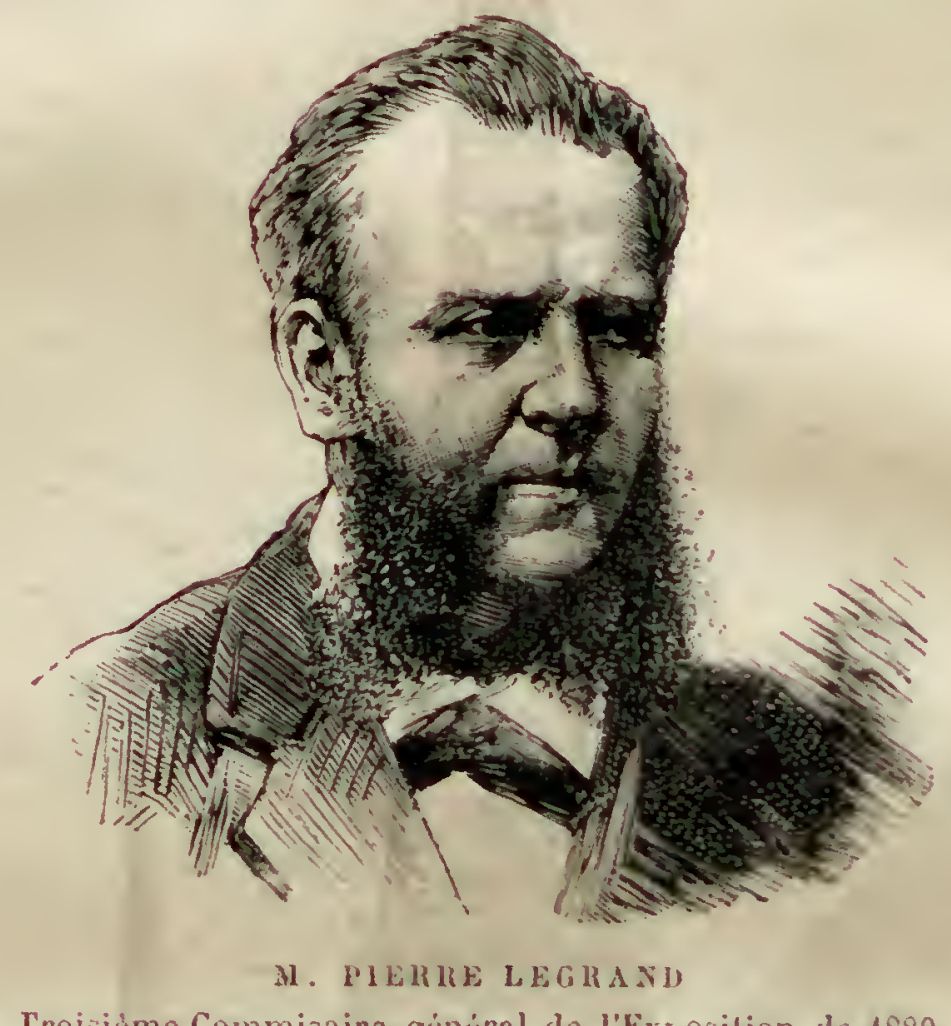

un élément prédominant, et enfin', parce que l'acier travail lant à un coefficient plus élevé que le fer on aurait des fièches et des vibrations plus grandes sous l'effet dn vent.

Le métal présente un avantage particulier : c est que la construction est temorible et qu'il permet, sans frais excessifs, le déplacement de la Tour, dans le cas oì, pour un cause quelconque, on jugerait utile de la transporter en un point de Paris antre que l'Exposition. La dépense de ce déplacernent est évaluéc par M. Eiffel à 6 ou 700,000 francs. D'ailleurs, M. Eiffel avait constaté que les deux solutions dins lesquelles on aurait pu employer la maçonnerie, soit en combinant la maçonneric avec le fer, soit en employiut la maçonnerie scule, donneraient des résultats inférieurs a l'emploi du fer seul, si elles n'étaient mème pas tout à fait irréalisables.

En essayant de combiner l'emploi du fer avec la maconnerie, on rencontre tous les inconvénients d'une solution mixte dans laquelle entrent des éléments tout à fait hétúrogènes comme élasticité. résistance ou dilatation, et sans insister davantage, il suflira de dire que les difficultés étaient telles que l'on ne serait pas parvenu a un projet possible. Par l'emploi de la maçonnerie seule, l'on ne serait parvenu à une chose réalisable qu'en mettant la question de prix tout à fait de củté. Voici quelques développements très sommaires à ce sujet : 


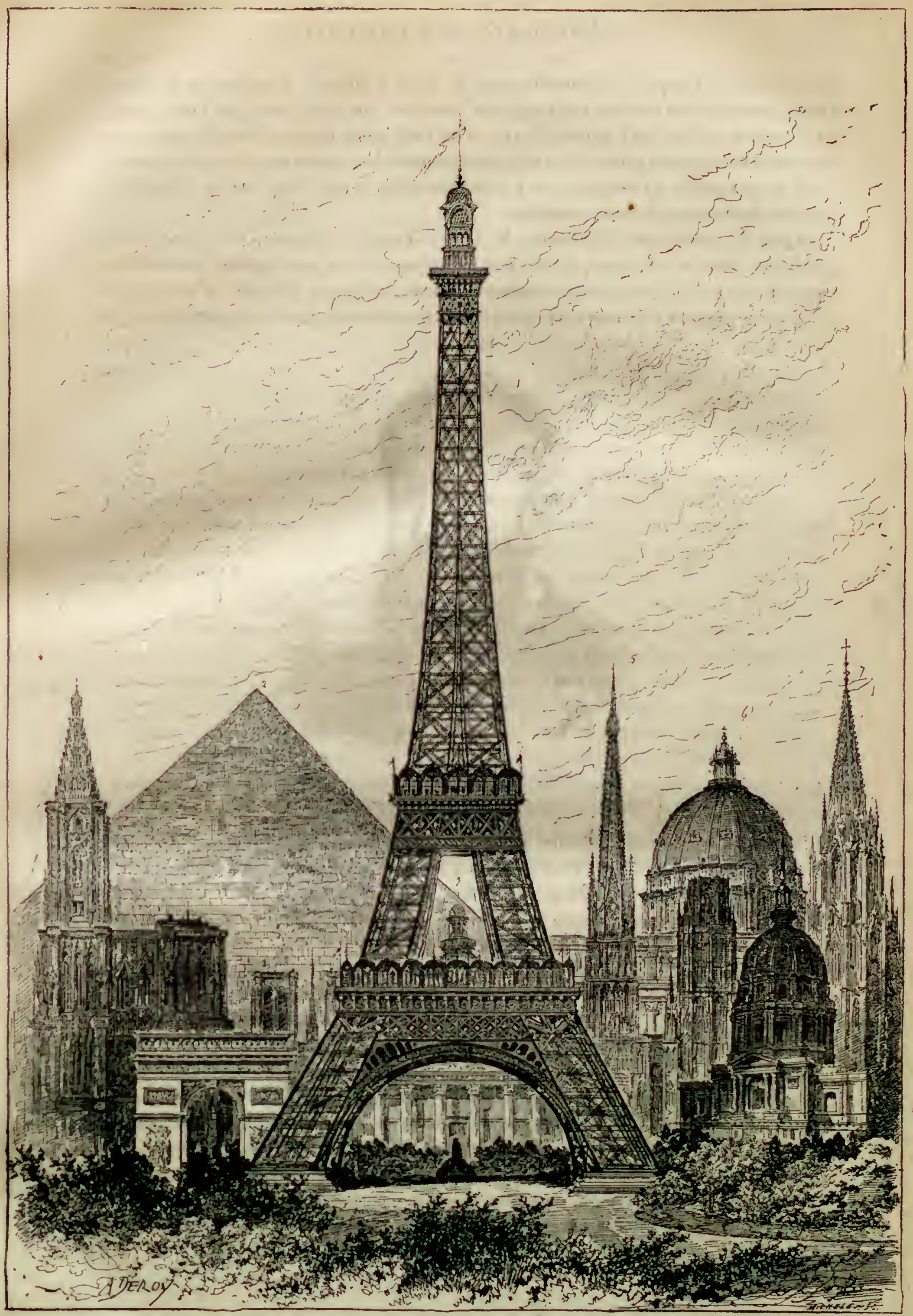

Ilauteur comparée de la tour Eiffel (300 mėtres) et des principaux monunevts du MoNde.

1. Cathédrale de Strasbourg, 142' $\mathrm{m}$. - 2. Grande pyramide, $146 \mathrm{~m}$. - 3. Notre-Dame de Paris, $66 \mathrm{~m}$.

4. Are de triomphe de l'Étoile, $49 \mathrm{~m}$. - : Cathédrale de Rouen, $150 \mathrm{~m}$. - -6 . Saint-P'ierre de Rome, $132 \mathrm{~m}$. 7. Cathédrale de Cologne, $159 \mathrm{~m} .-8$. Dúme des Invalides, $10 \mathrm{~s} \mathrm{~m} .-9$. Panthéon, $83 \mathrm{~m}$. 
"La première chose dont il y ait lieu de se préoccuper est le coefficient de rúsistance par centimètre carré i adopter. Eu effet, ce ne sont pas les considérations du rcnversement par l'effet du vent qui doivent ètre prédominantes dans l'étude d'un griand ouvrage en maçonnerie, mais surtout celles qui sont relatives a la résistance mème. En outre, il faut faire entrer dans cette recherche une considération capilale sans laquelle on serait tout 'a fait en erreur, si on calculait la hauteur possible d'un édifice d'après la seule résistance de la pierre employée à sa construction, comme s'il ćlait un monolithe, et si l'on supposait qu'avec du porphyre ou du granit on pourrait établir pratiquement une tour plus hante qu'avec une bonne pierre calcaire.

a En effet, si l'on ne veut pas faire de simples conceptions matliématiques, et si l'on veut rester dans la réalité des faits, laquelle consiste dans l'édification d'un grrmal ourrage dans lequal les matériaux travaillent à une très forle charge, il ne faut pas oublier que ces matériaux ne seront pas simplement superposés les uns aux autres par des surfaces plus ou moins bien dressées. Ils seront inévitabiement séparés par des lits de mortiers destinés à assurer la répartition convenable des pressions.

"La stabilité de l'ouvrage exige done que ce mortier ne s'écrase pas: aussi ce qu'il faut faire entrer en ligne de compte pour l'exécution d'une telle maçonnerie, s'est la limite de l'écrasement du mortier, bien plutôt que celle de la pierro. laquelie. considérée seule, conduirait à des apparences de possibilité d'exécution loul a fait trompeuses, et a fait croire comme limite pratique a des hauteurs tout à fait fantastiques. La condition nécessaire ast que les matériaux employés soient plus résistants que la mortier, leur excédent de résistance ne servant qu’à donner un excéden! de sécurité qui échappe à l'évaluation. Or, les ouvrages classiques indiquent pour les mortiers en ciment des résistances maxima de 1500 à 200 kilogrammes par zentinètro surré

* En adoptant comme limite pratique le $1 / 10^{\circ}$ de cette résistance, ainsı qu'il est armis habituellement, une maçonnerie en pierre de talle ne tevraıt pas supportar une char de plus de 15 à 20 kilogrammes par centimètre carré. T'out a fait exceptıonnellement. et en allant au delà de la limite de sécurité habituelle, en entrant en quelqua surte diıns la zone dangereuse, on pourrait aller jusqu' 1 g. kilogrammes. La limite de 30 kilogrammes est diffislement acceptable pour l'ensem!)le d'un grand ouvraga; in tuut cas, c'est une limite tout à fait extrêne.

Les éditices dans lesquels la charge est la plus ionsidérable sont, d'aprés Navior, les suivants :

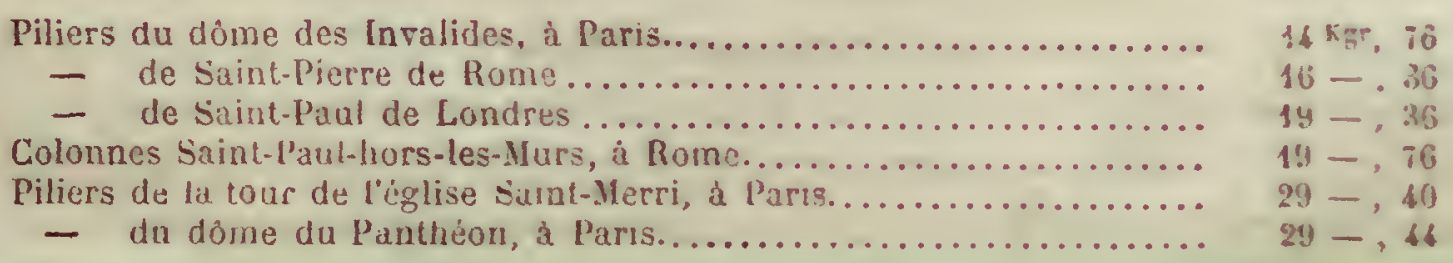

Il résulte de ce tablean que la limite de la résistance des constructions jugées les plus hardies est de 13 à 20 kilogrammes par centımètre carré, et qu'elle s'blève dans deux d'entre elles à 30 kilogrammes.

- Le fer, conclut M. Eiffel, nous semble donc la seule maticre capable de mener it la solution du problème. Du reste, l'antiquité, le moyen agge et la lienaissance ont ponssé l'emploi de la pierre à ses extrèmes limites de hardiesse', et il ne me semble guère yos. sible d'aller beaucoup plus loin que nus devanciers avec les mêmes matériaux, - d'au- 
tant plus que l'art de la construction n'a pas fait de bien notables progrès dans cesens depuis bien longtemps déjà.

"L'édifice - tel que nous le projetons avec sa hauteur inusitée - exige donc rationnellement une matière sinon nouvelle, mais du moins que l'industrie n'avait pas mise ì la portée des ingénieurs et des architectes qui nous ont précédé. Cette matière, c'est le fer, par l'emploi duquel les plus difficiles problèmes de construction se résolvent si simplement, par l'emploi duquel nous construisons couramment soit des charpentes, soit des ponts d'une portée qui aurait paru autrefois tout à fait irréalisable. ”

Quant à la forme de l'édifice, elle ne manque ni de force ni de grandeur. Ses montants, qui semblent jaillir du sol, sont comme moulés sous l'action mème du vent. Son ossature est d'aspect imposant. La galerie qui au premier étage réunit les quatre montants n'a pas moins de 4,200 mètres carrés de surface; ses balcons seront fort appréciés des curieux, qui rencontreront au deuxième étage une seconde galerie de 30 mètres de cóté. Quant à la coupole vitrée du sommet, on devine quel panorama magnifique et grandiose on verra se dérouler autour d'elle.

Entre les quatre piliers de la Tour s'élèvera une fontaine monumentale, due à M. de Saint-Vidal et dont le Bulletin officiel de l'Exposition nous a fait connattre par avance les grandes lignes. Cette fontaine est haute de 9 mètres et le diamètre du socle est de 12 mètres. Autour de la vasque sont cinq statues représentant les cinq parties du monde. "Le motif qui s'élève au milieu de la fontaine, lisons-nous dans le Bulletin, symbolise l'état d'obscurité relative dans lequel notre monde est encore plongé. La nuit nous ntoure encore et ce qu'elle enveloppe dépasse ce que nous voyons, jugeons et apprécions. C'est un état que représenterait assez bien ce mot spirituel d'un savant qui s'écriait : "Quel beau livre on ferait avec ce que je ne sais pas! "

Les ascerseutus de la Toun Liffel. - Lorsqu'il fut question de l'élévation des visiteurs depuis la deuxième plate-forme jusqu'au sommet dela tour, une commission fut constituée pour l'examen des projets qui seraient présentés : elle se composait de MII. Collignon, Contamin, Mascart, Ménard-Dorian, Molinos, l'amiral Mouchez et Philipps.

La commission dut rejeter le projet de M. Backmann parce qu'il présentait de nombreuses difficultés relativement à l'installation au haut de la Tour des organes de. commande et des systèmes mécaniques. Il y avait aussi à craindre le bruit des vibralions produites par les mouvements des trucks moteurs. Enfin, le systeme préconisé par M. Backmann n'avait jamais encore été essayé et la prudence la plus élémentaire conseillait de ne pas profiter pour tenter une expérience aussi importante du moment oì l'Exposition attirerait sur la Tour Eiffel un grand nombre de visiteurs.

Après un mùr examen, la commission se décida pour le projet de M. Edoux, qui réunissait tous les avantages des appareils précédemment proposés sans en avoir les inconvénients, et dont un spécimen fonctionnait depuis plus de dix ans au Trocadéro sans avoir causé d'accident.

Les ascenseurs du système Edoux ont été décrits au point de vue technique par M. Grosclaude, ingénieur des Arts et Manufactures, dans le journal le Génie civil. C'est de cette étnde que nous nous servirons pour donner à nos lecteurs une idée exacte du systime adopté.

a I'appareil ordinaire de M. Edoux, dit M. Grosclaude, consiste essentiellement en un piston métallique ayant pour hauteur celle de la distance à parcourir, se déplaçant 
dans un cylindre vertical et portant à sa partie supérieure la cabine destinée à recevoir les voyageurs; le système ainsi constitué est équilibré par des contrepoids convenablement disposés et calculés. Ce système ne pouvait s'appliquer tel quel à la Tour, puisque l'on imposait la condition de ne faire descendre au-dessous du second plancher aucun des organes destinés à la manœuvre de l'appareil.

- M. Edoux a su vaincre la difficulté d'une façon très ingénieuse, tout en ne changeant pour ainsi dire rien à son appareil-type. La distance verticale à parcourir, comprise entre le second étage et le sommet de la Tour est de $160^{\mathrm{m}}, 40$; supposons-la divisée en deux parties de $80^{\mathrm{m}}, 20$ chacune et établissons par la pensée un plancher intermédiaire à ce niveau. En considérant ce plancher comme point de départ d'un ascenseur ordinaire, ce dernier pourrait franchir toute la partie au-dessus, jusqu'au sommet de la Tour, pendant que son contrepoids, dont le point de départ serait le même plancher, irait de celui-ci jusqu'au second étage.

- Si maintenant on remplace ce contrepoids pal une cabine, on conçoit aisément que l'on pourra franchir de cette façon toute la hauteur des $160^{\mathrm{m}} .40$ qu'il s'agit de parcourir. Tel est dans ses grandes lignes ce projet remarquable, qui résout un problème absolument nouveau, tout en n'employant que des principes établis depuis longtemps et sanctionnés par une pratique de plusieurs années. L'ossature métallique est constituée par une poutre-caisson pleine occupant le centre de la Tour, et d'une hauteur de $160^{\mathrm{m}}, 40$, et par deux autres poutres de section plus petite allant, l'une du second étage au plancher intermédiaire, et l'autre de ce dernier plancher au sommet de la Tour. Ces diverses poutres sont réunies par des entretoises aux parois métalliques et sont destinées à supporter les guidages des cabines."

L'une de ces cabines que nous désignerons par la lettre A, s'appuie sur deux pistons de presse hydraulique fournissant à eux deux une section de 1,600 centimétres carrés. Ces pistons sont articulés à leur partie supérieure sur un palonnier dont le centre supporte la cabine. Celle-ci montera sans secousses, n'élant pas influencée par les variations de vitesse des pistons. Ces variations seront d'ailleurs fort peu appréciables, puisqu'elles ne pourront résulter que des frottements inégaux, aux garnitures des pistons.

Quatre cables partent de la cabine A et des deux extrémités des palonniers et soutiennent la cabine B en passant sur des poulies fixées au sommet de la Tour; deux de ces câbles sont attachés à la cabine mème, les deux autres sont fixés sur le palonnier au centre duquel est suspendue la cabine. D'une surface de 14 mètres carrés, les cabines peuvent recevoir 63 personnes et en monter 750 à l'hcure; la durée de chaque voyage, montée et descente, sera de cinq minutes. Le poids de chaque cabine chargée est de 8,000 kilogrammes, 4,000 kilogrammes pour la cabine elle-même et 4,000 kilogrammes pour les voyageurs. Chaque cabine ne faisant que la moitié du parcours total, un échange aura lieu de l'une à l'autre à la hauteur du plancher intermédiaire par deux chemins distincts, ce qui permettra une grande célérité dans le service.

Sur toute la hauteur de leur parcours, les deux pistons sont garantis par une colonne creuse en fonte offrant une rainure pour le passage du palonnier et munie de plusieurs portées servant de guidage et contre lesquelles le piston pourra s'appuyer. le cas échéant : les cábles de suspension de la cabine $B$ passant dans les mèmes colonnes. Sur toute la hauteur comprise de l'autre côté, entre le second étage et le plancher intermédiaire, les cabines sont guidées par deux colonnes en fonte semblable. 


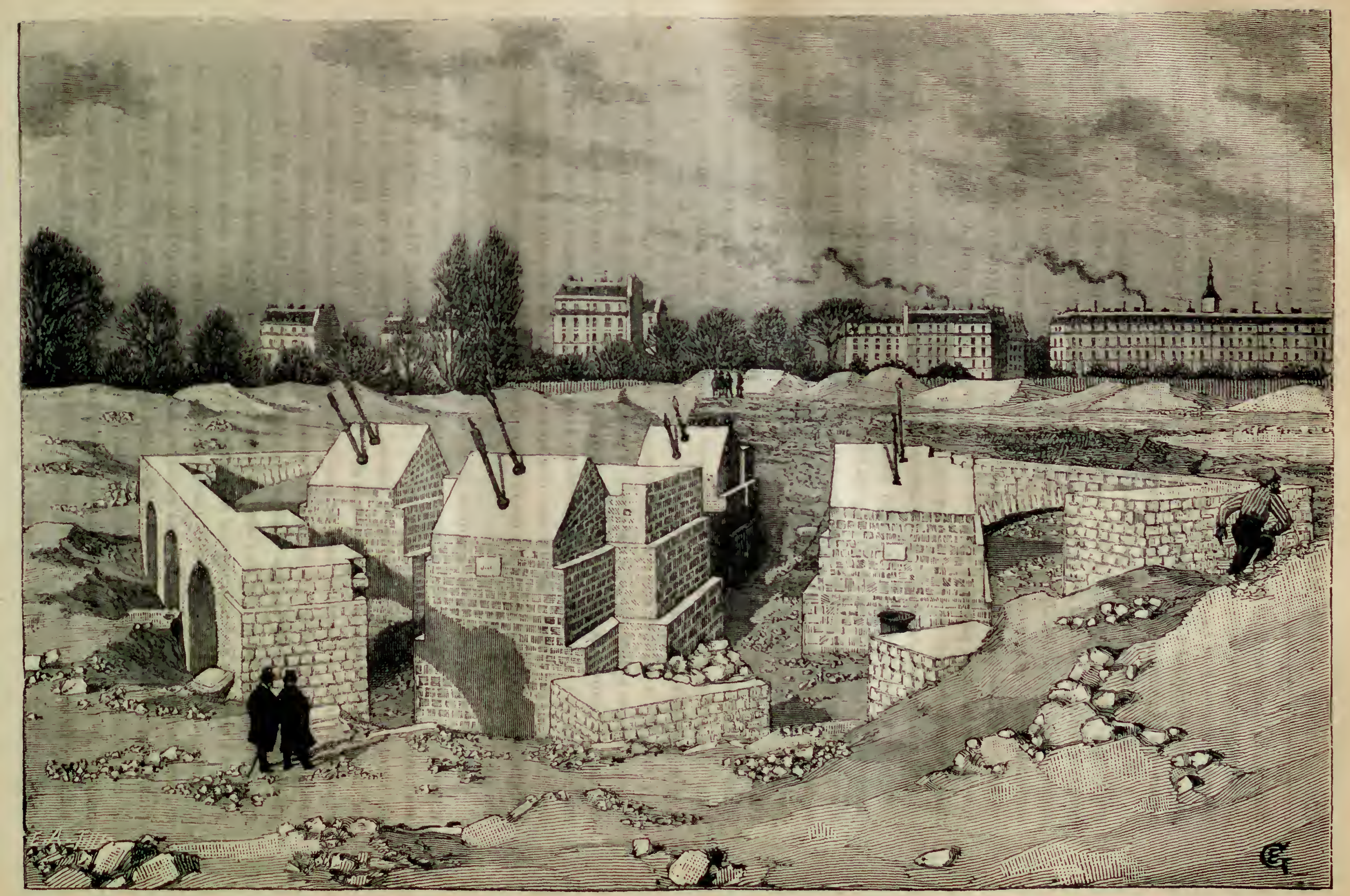

LES FONDATIONS DE TA TOUR ElFFEL. - PILE d'UN PIED du COTÉ de L'Égole MiLITAIRE 
aux précédentes qui renferment aussi et mettent à l'abri du vent les cables de suspension de la cabine $B$.

Comme on le voit, les organes de transmission, pistons et cábles, sont protégés par des gaines, excepté les cables de la cabine B qui seront fixés sur les entretoises de la Tour par des embrasses, dans la partie supérieure au plan d'échange.

Si l'on s'occupe du fonctionnement et de la marche des cabines, on constate avec M. Grosclaude que quatre cas peuvent se présenter $: 1^{\circ}$ la cabine $A$ est vide et la cabine $B$ est seule chargée; $2^{\circ}$ les cabines $A$ et $B$ sont chargées toutes les deux; $3^{\circ}$ les deux cabines sont vides; $4^{\circ}$ la cabine $\mathrm{d}$ est seule chargée. Examinant le premier et le qnatrième cas, seụls intéressants à discuter, II. Grosclaude étudie le poids qu'il faut donner aux pistons, étant admis que le poids de chaque cabine sera de 4,000 kilogrammes, le poids d'eau déplacé par mètre pour les deux pistons de 160 kilogrammes, le poids des voyageurs de 4,000 kilogrammes et les actions dues aux frottements de 2,400 kilogrammes. Dans le premier cas, on sera assuré que le système se mettra en marche avec des pistons de 19,200 kilogrammes; dans le quatriène cas, la section totale des pistons étant de 1,600 centimètres carrés, la pression d'ean devra ùtre de 8 kilogrammes par centimètre carré. \& L'ascension de la cabine B, qui correspond ì la descente de la cabine $\Lambda$, sera réglée par un système. Les pistons seront compusés do deux parties tubulaires, l'une en acier, l'autre en fonto, et ils auront chacun nn poids de 9,600 kilogrammes. Le tronçon supérieur sera formé par un tube en acier de 60 mètres de longueur, pesant 3,900 kilogrammes; la différence 9,600 - 3,900 $=5,700$ représentera le poids des troncons inférieurs en fonte. Les deux pistons auront une grande force de résistance, car les faligues du mélal à la traction et a la compression ne dépassent pas 2 kilogr. כ̧ par millimètre carré. Les cylindres auront un diamètre extérieur de $0^{m}, 38$ et seront faits en tỏle d'acier de 10 millimètres d'épaisseur. Des manchons filetés réuniront les divers tronçons en tôle et assureront une continuité parfaite sur toute la hauteur des cylindres. On s'est représenté, pour calculer le travail de ces pièces à l'éclatement, les pistons presque au bas de leur course et supportant le poids de la cabine a remplic et celui des cables sur la hauteur de 80 mètres. On a ainsi constaté que le fond des cylindres serait soumis à une pression de 16,800 kilogrammes, ce qui correspond à un travail de 3 kilogr. 64 par millimetre carré. Les cylindres étant supportés par le second étage, la fatigue à la traction et à l'éclatement sera par cela même considérablement diminuée.

Le poids des cables de transmission sera la moitié de celui du volume d'eau total déplacé par les deux pistons. Le déplacement d'eau par mètre de chaque piston élant de 80 litres, correspondant à un poids de 80 kilogrammes, chaque cable pesera donc par mètre 20 kilogrammes, ce qui donne une section métallique de 2.563 millimètres carrés. En supposant la cabine $B$ en bas de sa course et chargée, les quatre cAlules auront, en plus de leur poids, à soutenir celui de la cabine et des voyageurs, soit 8,000 kilogr. Chaque cable sera donc soumis à un effort de 5,200 kilogr., et la fatigue du métal par millimètre carré de section sera de 2 kilogr. 020 . Si l'on ajoute à cela la fatigue due à l'enroulement des cables sur les poulies, c'est-à-dire le double de celle due à la traction, on voit que la fatigue totale vaudra 6 kilogr. 07\%, chiffre donnant pleine sécurité. Dans le cas où deux des câbles seulement fonctionneraient, la fatigue atteindrait 8 kilogrammes, chiffre encore très rassurant avec des câbles en fil d'acicr pouvant supporter sans se rompre une charge de 80 kilogrammes par millimètre carré. 
Un meme distributeur alimentera les denx cylindres, assurant ainsi dans chacun d'eux une admission égale, donnant pour le piston des déplacements égaux. Un réservoir d'une capacité d'environ 20,000 litres situé au sommet de la Tour alimentera ce distributeur. L'eau sera amenée dans le réservoir par deux pompes de 20 litres chacune, installées a la partic inféricure de la Tour et élevant l'eau à une hauteur de 276 mètres environ; mais dans le cas actuel, M. Edoux n'aura besoin que de la foree utile pour élever l'eau à 80 mètres de hauteur. En effel, l'eau d'échappement des cylindres retournant aux pompes, arrivera sur les pistons avec une pression correspondant a une hauteur d'eau de 196 mètres; la hauteur réelle à laquelle il faudra élever l'eau ne sera donc plus que $276-196=80$ mètres.

lin réalité, la force à développer sera un peu plus considérable à cause des pertes de charge. Habituellement, les deux pompes fonctionneront ensemble, elles ne marcheront séparément que lorsque les visiteurs seront peu nombreux.

Le mouvement de descente de la cabine li pourra. s'il y a lieu, être arrêté au moyen d'un frein reposant sur le mêne principe hélicoïdal que l'ascenseur système Backmann. " Ce systène de frein, lisons-nous dans le Génie ciril, est à la fois simple et ingénieux. Chaque cage est guirlée vers son sommet par des tetons portant sur des glissières verticales et terminés à leur partic inféricure par des portées coniques. En même temps que la cage, se incuvent dans les cylindres formant l'appui des glissières, des blocs glissant dans des rainures hélicoïdales et présentant à leur sommet un évidement conique correspondant à la portéc conique que nous avons signalée sur les tetons. Les blocs et les tetons étant traversés par les cables, si ceux-ci viennent a se rompre, les - blocs s'arrêtent dans leur rainure et supportent, par l'intermédiaire des tetons, le poids Je la cage.

Avantages phatgues de m Tour. - La principale objection qui a été faite dans le public contre la construction de la Tour Eiffel, c'est son prétendu manque d'utilité. 11 est cependant facile d'établir que cette utilité est réelle, que ses applications sont nombreuses.

Tout d'abord, il est certain, après le succès des précédentes ascensions dans les ballons captifs Giffard et celui des ascensenrs du Trocadéro, que le public aura grand plaisir à visiter les différents étages de la Tour qui présentera un spectacle bien digne d'admiration. Un panorama de 120 à 130 kilomètres pourra être observé comme en ballon, sans fatigue et sans danger, et sans que les premiers plans viennent, comme dans les ascensions de montagne, nuire au sentiment de la distance et de la hauteur. La vue de Paris, la nuit, avec son éclairage si brillant, présentera un aspect merveilleux connu jusqu'd présent par les aéronautes seuls. Cela constituera pendant et mème après l'Exposition une puissante attraction pour les Parisiens et les étrangers.

La Tour, au moins pendant l'Exposition, pourra porter à son sommet un foyer électrique destiné à éclairer le pare et les jardins. En prenant comme surface à illuminer un cercle de 1,000 mètres de diamètre, et en mettant pour condition que la Jumière soit assez vive pour permettre de lire un imprimé, MII. Sautter et Lemonnier, constructeurs de phares électriques, pensent que le foyer placé au sommet de la Tour devra ètre de 3,000 ampères. Ils prennent pour terme de comparaison l'éclairage des quais de Rouen, pour lesquels un foyer fixé à 13 mètres de hauteur, et d'une intensité de 21 ampères, éclairait suffisamment un cercle de 130 mètres de diamètre.

En ce qui concerne la Tour, la distance du foyer au centre de ligure étant à peu 
près dix fois plus grande qu'à Ronen, il faudra un foyer cent fois plus puissant; mais comme il faut tenir compte de l'absorption par l'atmosplière, la source lumineuse devra ètre de $123 \times 24$, soit 3,000 ampères; une force de 400 à 500 chevaux sera nécessaire pour cette production. Jusqu’à présent on n'a obtenu avec une seule lample qu un maximum pratique de 90 ampères; il faudrait done 33 lampes au maximum. II vaut mieux en supposer 48 d'inégales intensités qu'on disposerait autour de la lanterne supérieure, suivant trois étages et éclairant trois zones concentriques.

On n'a pas, avec des fojers a courants continus, à se préoccuper de mattre lis

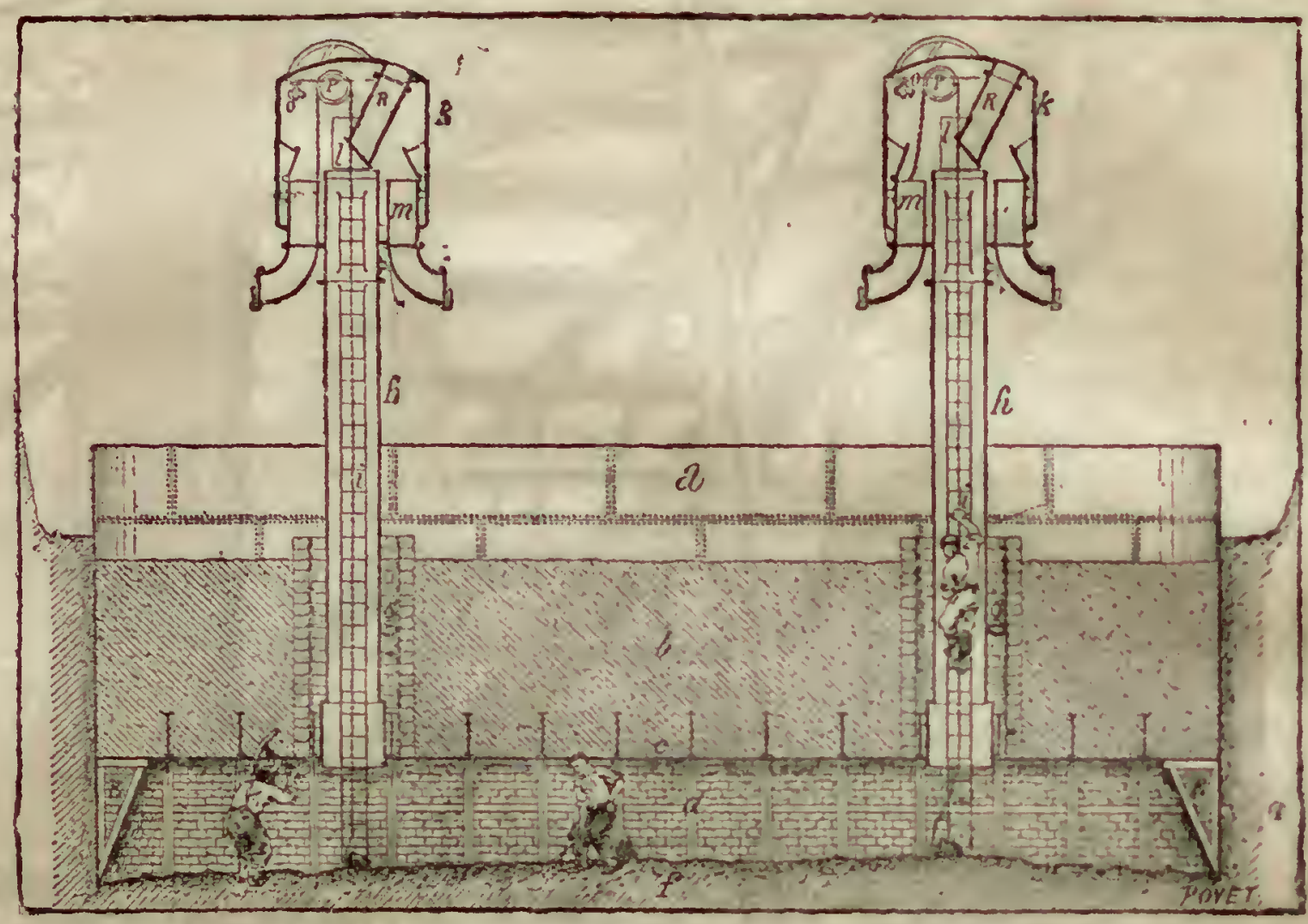

COUPE D UN CAISSON A BETON POUR LES ASSISES DES YONDATIONS IF, LA TULU FIFHEL.

$c$, cloison séparant le caisson en deux parties, l'une a, remplic partiellentent d'une curche de luéton b. l'autre $d$ reposant sur le sol $f$ par les trauches de ses parois margonnées $F, ~ F ; ~ h$, cheminir amenant l'air comprime dans la partic $d ; i$, escalier; $k$, caisse d'air comprimó intermédiaire; $l$. laper: n. toucluen pur la sortie des déblais; $p$, poulie sur laquelle s'enroule la chatne a laquelle sontattachés les seaux a déblats; $R$, bouche pour l'entrée du béton.

lumière vers le sol, puisqu'il a été prouvé par de nombreuses expériences que presque tous les rayons sont projetés naturellement de bas en haut dans un cône dont les génératrices sont inclinées d'environ 45 degrés avec la verticale. Il faudra seulement avoir soin de concentrer la lumière de chaque lampe de façon à ce qu'elle donne son maximum d'intensité dans la fraction de zone qu'elle doit éclairer. Le meilleur moyen pour parvenir à ce but est de pourvoir chaque foyer d'un appareil optique spécial orient: d'une manière différente pour chacun d'eux.

La Tour Eiffel n'offre pas qu'un intérèt de curiosité ; elle a aussi une ntilité scientifique que M. Hervé-Mangon a fait ressortir devant la Société météorologique de France. - Il existe, a-t-il dit, dans plusieurs observatoires, des tomrs eu maçnerie, unais elles présentent, pour l'installation des instruments inétéorologiques, plus d'inconvénients que d'avantages. Au soleil, la masse de la construction séchauffe, les surfaces murales produisent des remous qui rendent difficiles les observations sur la pluie, la brume, la neige et la rosée, faites dans un rayon mème étendu; toutes les indications hygronétriques ou therınométriques deviennent inexactes ou illusoires. 


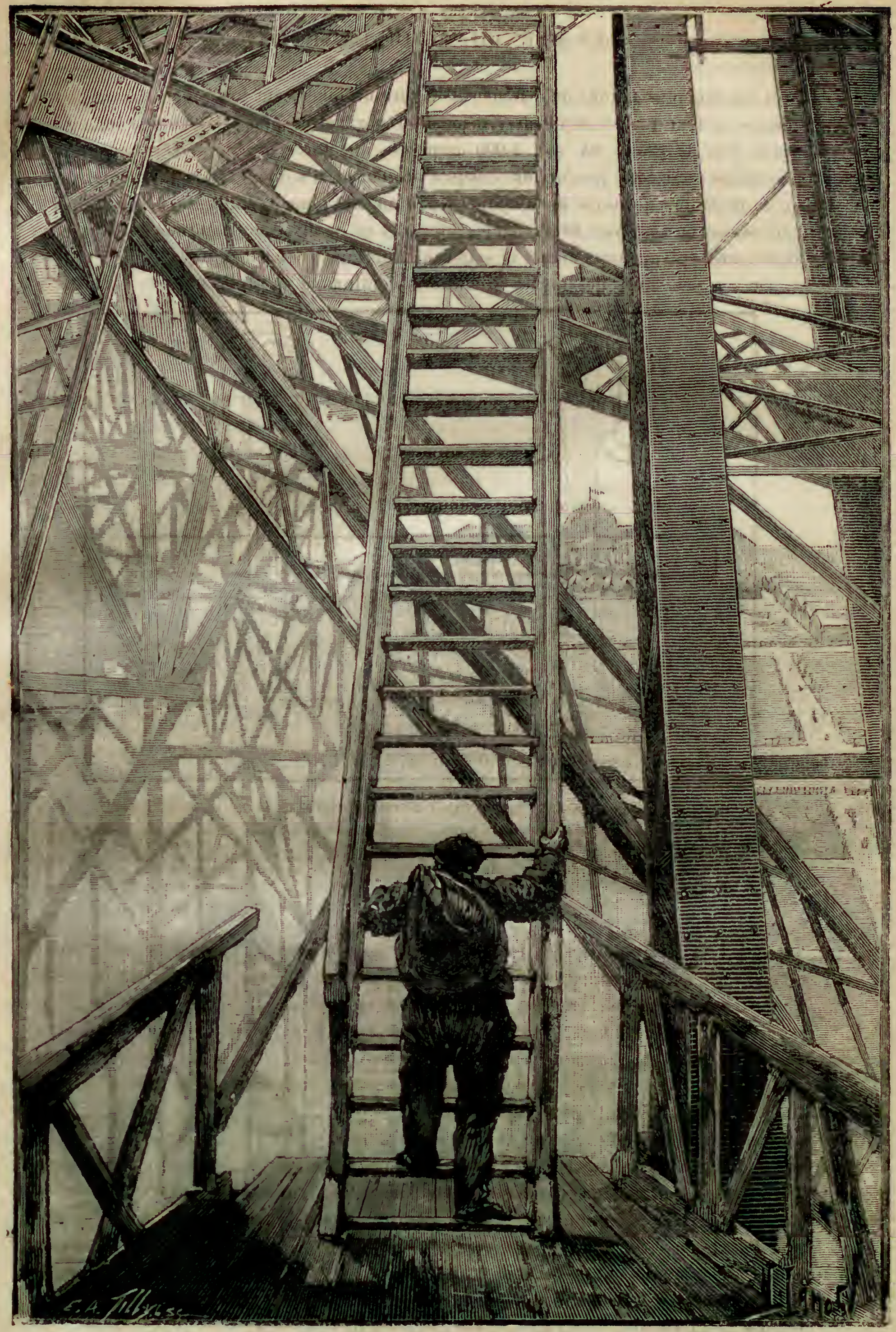

LES TRAVAUX DE LA TOUR EIFFEL. - LA GRANDR ÉchELLR. 
"Le projet de la tour en fer de 300 mètres de hautcur, présente donc pour les inétéorologistes un intérèt des plus considérables. Elle permettrait d'organiser un grand nombre d'observations et d'expériences météorologiques du plus haut intérèt, parní lesquelles nous citerons au hasard les suivantes:

* La loi de décroissance de la empérature avec la hauteur serait facilement observée, et les variations dues aux vents, aux nuages, etc., fourniraient certainement de nombreux renseignements, qui nous font jusqu'd présent complètement défaut. La quantité de pluie qui tombe a différentes hauteurs sur une même verticale a été frès diversement observée. Cette question si intéressante pour la théorie de la formation de la pluie serait résolue par quelques années d'observations faites au moyen d'une quinzaine de pluviomètres régulièrement espacés sur la hauteur de la Tour.

- La brume, le brouillard, la rosée forment souvent i la surface du sol des couches de moins de 300 mètres de hauteur; on pourrait done observer ces météores sur toute leur épaisseur, faire des prises d'air à diverses hauteurs, mesurer le volume d'eau it l'état globulaire tenu en suspension dans chaque couche. Ce volume liquide est benucoup plus considérable que celui qui répond à la vapeur d'eau, et sa connaissance expliquerait comment des nuages d'un faible volume versent quelquefois sur le sol des quantités d'eau si considérables. L'état hygrométrique de l'air varie arec lia hanteur, Rien ne serait plus facile que d'étudier ces changements, si l'on pouvait oluserrer au mème instant des instruments placés a d'assez grandes distances les uns au-dessus des autres. L'évaporation donnerait également lieu à de très utiles expériences. L'électricité atmosphérique, sur laquelle on ne possède encore que des notions si imparfaites, devrait faire à l'observatoire de la Tour l'objet des recherches les plus actives. La différence de tension électrique entre deux points situés ì 300 mètres de distance verticale est probablement très considérable et donnerait lieu à des phénomẻnes du plus grand intérèt.

"La vitesse du vent croit en général avec rapidité en s'écartant de la surface du sol; la Tour permettrait de déterminer la loi d'augmentation de cette vitesse jusqu'a 300 mètres et probablement un peu plus haut. Cette détormination, indépendamment de son intérèt théorique, fournirait à l'aérostation d'utiles renseignements. La transparence de l'air pourrait ètre observée, avee la Toul', dans des conditions exceptionnellement favorables, soit suivant la verticale, soit suivant des lignes d'une inclinaison donnée. Indépendamment des observations météorologiques que je viens de citer et dont je dois exclusivement m'occuper ici, la Tour de 300 mètres permettrait encore de réaliser un grand nombre d'expériences impossibles à tenter aujourd hui. Elle permettrait, par exemple, d'établir des manomètres allant jusqu'à 400 atmosphères, pouvant servir à graduer expérimentalement les manomètres des presses hydrauliques, et d'établir des pendules dont chaque oscillation durerait plus d'un quart de minute, etc.

- Sans développer davantage, fante de tenıs, le programme des études que permettrait d'entreprend̉re une tour de 300 mètres de hauteur, je suis persuadé que la Société s'associera aux vœux que je forme pour la mise à exécution du magnifique édilice projeté par M. Eiffel pour l'Exposition de 1889, et dont l'utilité, comme instrument de recherches scientifiques, ne saurait ètre mise en doute.,

D'autre part, M. l'amiral Jouchez, directeur de l'Observatoire de Paris, a écrit à M.- Eiffel une lettre dont voici les principaux passages : " Je m'empresse de vous faire 
savoir que j’ai vu avec le plus grand intérèt votre projet de Tour de 300 mètres. J'en désire bien vivement la réalisation parce que je crois, qu'outre l'intérêt général que présentera un tel monument, il sera d'une très grande utilité pour diverses questions scientifigues el particulièrement pour l'élude des conches inféricures de l'atmosphère, qui ont une certaine influence sur la précision des observations astronomiques; une hauteur de 300 mètres permettra d'observer régulièrement ces fréquentes inversions de la toi de décroissance de la température avec la hauteur, et dans de meilleures conditions gue sur une montagne. On pourra également śtudier les variations de l'humidité ot re l'électricité atmosphériques, les variations du vent en force et en direction. Quatre collections d'instruments enregistreurs scmblables placés au ras du sol, $\gtrsim 100,200$ ot 300 mitres, donneraient certainement, par leur comparaison, des résultats d'ın grand intérèt. Quant aux obscrvations astronomiques, je ne crois pas qu'il y ait une égale utilité d̀ en tirer. Il est cependant certain qu'au milicu de la ville de Paris, on aurait une atmosphère beaucoup plus pure à cette hauteur que dans nos villes d'obsorvations; oul y laisserait au-dessous de soi la plus grande partic des fumées et des poussieres de la ville.

- Au point de vue des observations mótéorologiques et de l'étude de l'atmosphòro dont je parlais, lit tour en maçonnerie enlèverait une très grande partie de l'exactitude et de l'intéred des observations que donnerait la tour en fer : avec celle-ci les instruments sont entièrement isolés dans l'atmosphère; avec la tour en maçonnerie, ils s'échauffent et se refroidissent avec elle, sont alternativement à l'ombre et au solerl, etc., les conditions sont toutes dillérentes. La tour en fer aurait une très grande et incontestable supériorité pour les observations métécologiques. ๖

M. Pierre Puiseux, astronome attaché à l'Observatoire de Paris, a indiqué au point de vue spécialement astronomique tous les avantages de la Tour Eiffel :

- Il est hor's de doute, fait-il remarquer, que la Tour projetée pourra recevoir des applications utiles aux étude astronomiques. La mobilité de la plate-forme sous linfluence du vent exclut sans doute les observitions qui ont pour but de fixer la position précise des astres, mais clle laisse le champ libre à la plupart des recherches d'astronomie physique. Des spectroscopes destinés à analyser la lumière du soleil et des étoiles, ì constater les mouvements propres des astres par le déplacement des raies, fonctionneraient micux à 300 mètres de hauteur qu'au niveau du sol. L'élimination des poussières et des brumes locales permetlrait de suivre le soleil plus près de l'horizon. De là un séricux avantage pour l'étude des raies telluriques dues à l'absorption de la lumière solaire par l'atmosphère. Un appareil à photographie lunaire ou solaire serait aussi d'un bon usage; son emploi serait surtout indiqué dans le cas de passage de Mercure ou d'éclipses s'effectuant près de l'horizon. Les photographies d'étoiles ou de nébuleuses exigeant une pose appréciable seraient plus exposées à ètre contrariées par le vent et devraient étre réscrvées pour les nuits calmes. Il faut faire attention cependant qu'une translation latérale de l'instrument n'a pas d'influence nuisible; l'essentiel est que l'axe optique reste parailèle à lui-mène. Il semble difficile de décider, avant l'expérience, si les mourement causés par le vent seront bien de cette nalure. En tout cas, les aspects physiques de la lune, des planètes, des nébuleuses, pourront être étudiés et dessinés dans des conditions farorables.

- Un chercheur ou un télescope de grande ouverture, installé au sommet de la Tour, permettra de suivre les astres qui n'atteindraient qu'une faible hauteur sur l'horizon 
de Paris. Ces observations ne sauraient rivaliser d'exactitude avec celles des observa toires fixes, mais elles pourraient ètre effectuées dans des cas où celles-ci deviennent impossibles. Or, on sait que pour les astres nouvellement découverts, il est important d'obtenir le plus tòt possible des mesures mème approchées. Une élude égralement intéressante pour la météorologie et l'astronomie, sera celle de la variation de la température avec l'altitude. Toutes les théories de la réfraction données jusqu'a présent reposent sur des hypothèses gratuites et souvent démenties par l'expérience. ,

Consulté par M. Eiffel sur l'utilité de la Tour au point de vue des applications à la télégraphie optique, M. le colonel Perrier a affirmé qu'elle rendrait de grands services et permettrait des communications qui n'existent pas encore. Il est resté dans une réserve facile a comprendre quant à l'indication des localités, et a indiqué sommairement les questions que la construction de la Tour pourrait aider à éclairer : - Astronomie: loi des réfractions, spectroscopie, raies telluriques; -Chimie régétale : la végéation à 300 mètres, composition de l'air, acide carbonique; - Météorologie : vents, rempérature, hygrométrie, état électrique, foudre, courants supérieurs; - Physique: déviation d'un corps qui tombe, électricité atmosphérique; - Guerre : télégraphie optique. « Le champ des expériences qu'on pourra faire est fort étenclu, a dit M. le colonel Perrier en terminant, et s'étendra tous les jours davantage avec les progrès de la science. Je crois que vous ferez une auvre utile en construisant cette tour gigantesque.

La Tour Eiffel pourra jouer le rôle d'un immense paratonnerre protégeant un très large espace autour d'elle à la condition que sa masse métallique soit en communication parfaite avec la couche aquifère du sous-sol par le moyen de conducteurs capables de débiter la quantité considérable de fluide électrique dont il $\mathrm{y}$ aura lieu d'assurer l'écroulement pendant les jours d'orage. De plus, grace à ces précautions, l'intérieur de l'édifice, avec les personnes qui s'y trouveraient abritées, sera absolument assuréc contre tout accident pouvant provenir des coups de foudre.

La première application de la Tour Eiffel a eu lieu sous la forme d'une expérience de physiologie. On sait que la circulation du sang peut s'observer sur l'animal vivant; grace à la transparence de certaines parties du corps el au moyen d'un petit instrument appelé hématoscope, le $\mathrm{D}^{\mathrm{r}}$ IIenocque est arrivé à mesurer mathématiquement la nature et l'intensité des phénomènes qui se passent dans le sang, lorsque l'oxygène provenant de la respiration se trouve entraîné avec les globules rouges au milieu de nos tissus pour servir à notre nutrition. On sait que ces phénomènes se traduisent par la transformation du sang veineux en sang artériel. En plaçant le petit instrument en question devant l'ongle du pouce, vivement éclairé, on voit, de la mème façon qu'au travers de la patte d'une grenouille, une réaction particulière que M. Ilenocque désigne par les termes de "réduction de l'oxyhémoglobine ", réduction ì l'aide de laquelle on constate la mesure exacte de l'énergie des échanges dans le sanğ et de l'activité nutri. tive. Apprécier les variations de çtte activité dans les ascensions d diverses hauteurs, tel est le problème que s'est posé le Dr Henorque, et, parmi les résultats obtenus, il est à noter qu'une ascension lente et méthodique favorise les ćchanges respiratoires, tandis que la montée brusque les retarde et les diminue.

Le Journal du Ciel a inséré une note de M. Minary, de Besançon, qui donne de curieux détails sur la Tour Eiffel et la rotation de la Terre. "Le sommet de la Tour Eiffel, dit M. Minary dans cette note, situé à 300 mètres au-dessus du sol, va faire en 
un jour, par suite de la rotation de la terre, une circonférence de 300 mètres de rayon, c'est-ì-dire $1,884^{\mathrm{m}}, 96$ de plus que son pied. Une rotation de la terre durant $23 \mathrm{~h}$. 54 ou 1,436 minutes, ou 86,160 secondes solaires, il en résulte que le sominet de la Tour fait par seconde $1,884^{\mathrm{m}}, 96: 86,160$ ou $0^{\mathrm{m}}, 02187$, ou près de 22 millinchlres du plus que son pied. Or, une balle de plomb, pour tomber librement du sommet de la Tour, devant mettre un nombre de secondes égal à la racine carrée du double de la hauleur divisé par l'intensité de la pesanteur'. soit la racine carrée de $600: 98,088$, mellra 7 secondes 8 , et dans cet.intervalle, le sommet de la Tour fera $0,02187 \times 7,8$ on $0^{\mathrm{m}}, 1 \mathrm{i}$ de plus que son pied du còté de l'est, il en résulte que si le plancher de chaque étage de la Tour est percé de trois trous à 930 centimètres de distance sur des lignes ayant la directiou nord-sud. et situées verticalement les unes au-dessous des autres, en faisant passer par les trous extrèmes deux fils à plomb (fils d'acier de un millinc̀tre de diamélre) descendant jusqu'au sol, les extrémités inférieures de ces fils dessineront, sur une large et solide plaque de fonte placée au-dessous, la direction du méridien sur une longueur de 50 centimètres. Les trous du milieu, allongés de plus en plus du cóté de l'est, donneront passage à une balle de plomb de minute en minute et on pourra constater chaque fois la déviation de 17 centimètres vers l'est due d la rotation de la terre par le point où laballe vient frapper la plaque de fonte à l'est des deux fils à plomb. „ .I. Minary ajoute qu'en recevant la balle de plomb dans un vase de forme comvenable, les amateurs auront encore l'avantage de pouvoir constater la transformation du mouvement en chaleur, sans se brùler les mains, car l'échaufement de la balle, quoique bien appréciable, ne dépassera pas 22 degrés.

Édificatiox de la Tour Eiffes. - Les travaux dédification de la Tour Fiffel commen-

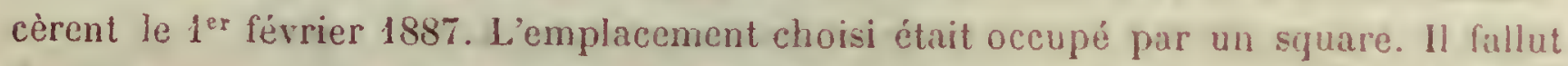
donc commencer par déraciner les arbres et les fleurs, enlever la terre régétale, détourner et reconstruire l'égout raui, du côté de la Seine, traversait les pil ss, enfin aménager le chantier.

M. Eiffel, après avoir pris au moyen de sondages une connaissance exacte de la composition du sol, put s'occuper des massifs de fondation des arbalétriers, ainsi que du mur du pourtour qui devait servir de fondation au soubassement. I.es piliers furent terminés le 31 mars 1887.

Le Bulletin officiel de l'Exposition, qui suit pas a pas les progrès de cetle grande entreprise, a donné des détails intéressants sur la marche des travaux. a Les fondilions de la Tour, dit cette excellente publication, ont été une des acurres les plus cousidérables. Elles se divisent en deux parties : la partie inférieure située au-dessuns de la cote 29 pour les piles 2 et 3 , et 28 pour les piles 1 et 4 , est composére d'un mussif de béton de ciment. Pour les piles 2 et 3 , ce massif a été étahli à l'air libre, et pum les piles 1 et 4 à l'air comprimé, à cause de la profondeur à laquelle il a fallu descrndre au-dessous du niveau des eaux pour atteindre le terrain de fondation. (Hn sint en effel que le niveau de la Seine, a la retenue du barrage de Suresnes, est i lit cute $7^{ \pm}, 06$. la partie supérieure est une maçonnerie cn pierre de Souppes et un mortier de ciment. Lorsque ces massifs ont été élevés et le mur de pourtour conslruit, on a remblayé les fouilles jusqu'au niveau du sol du Champ de Mars sauf pour la pile 3 , où l'on a du laisser un espace vide afin de donner asile aux moteurs des ascenseurs. Ces travaux, ainsi que la pose des pierres de taille couronnant les massifs de fondation étaient terminés le 30 juin 1887 et représentaient les totaux suivants : 


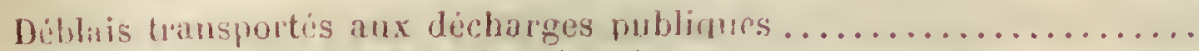

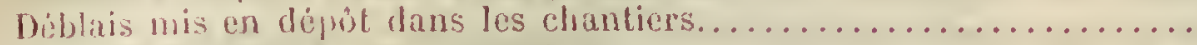

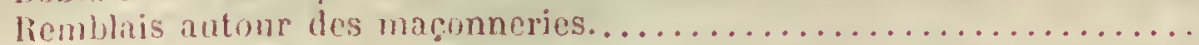

Total des terrassements.

Biton des fondations infërimres, ì l'air libre.

-

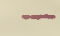

a l'air comprimé

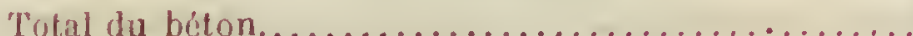

Maçonneries superieures...

Tolal des maconneries de tontes sortes.

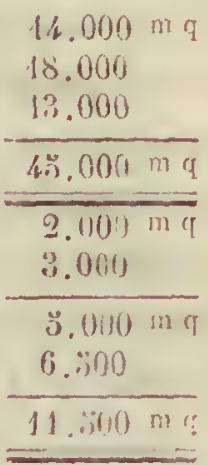

- Le for juillet ont commencé les travaux de montage. Les sabots d'appui des scize atbalétriers (quatre pour chaque montant) et les seize premiers troncons étaient placés. Le montage des premières pièces métalliques s'opérait et pour chacun des quatre montants on taillait d'énormes charpentes en bois destinées au montage des pièces inétalliques supérieures. Ces masses de bois en pylones, devant servir de supports ì chacun des montants à la hauteur de 28 mètres, étaient placés le 30 sepcombre. Quatre vastes charpentes de 403 mètres étaient établies etavaient pour objet de permettre le montage des grandes poutres devant relier les montants entre eux, deux i deux, et servir de première ceinture au plancher du premier étage. "

Après la mise en place de la première ceinture de poutres intermédiaires de 7 mètres de hauteur, on s'occupa de la pose d'une seconde ceinture de poutres également de 7 mìtres de hauteur et destinées a soutenir le plancher du premier étage. Les grues de montage employées par M. Eiffel sont assez puissantes pour élever des pièces de 3,000 lilogrammes. " La flèche en tôle, dit le Bulletin officiel, a une portée maxima - te 12 mètres, c’est-ì-dire que, de la base de la grue à la verticale la plus éloignée, suivant laquelle le crochet de levage peul soulever des fardeaux, il y a 12 mètres. Comme cette llèche étant ì cornière articulée sur un pivot, peut en se levant ou en s'abaissant desservir tous les points intermédiaires entre sa partie maxima (de 12 mitres) et sa base, et comme le tout peut tourner sur un pivot, il s'ensuit que le crochel de levage peut se placer au-dessus de tous les points imaginables dans un cercle énorme ayant $\mathbf{2 4}$ mètres de diamètre. Elle peut donc sur chaque pilier desservir le montage des arbalétriers. " M. Guyennet, ingénieur-constructeur, a utilisé pour l'évevation de la grue li roie mine des ascenseurs.

Le 3 mai 1888 , la commission compétente, sous la direction de M. Contamin, s'assura de l'état des travaux de la Tour. Elle ne put que rendre hommage aux efforts de M. Eiffel pomr établir un lıon système de fondations. Les fouilles et les travaux de macomnerie, commencés dans les derniers jours du mois de janvier 1887, avaient été terminés à la fin de juin, de sorte que cinq mois avaient suffi pour remuer 48,000 mètres cubes de terre et pour construire 14,000 mètres cubes de maçonnerie. La comnission constata que M. Kiffel avait réuni les arbalétriers deux à deux, non seulement dans la partie du second élage, mais aussi sur toute la hauteur du panneau situé au-dessus de cet élage, qu'il avait porté la section uniforme des membrures dans la partie du prenier élage de 188,800 millimètres par arbalétrier à 208.096 mil!imètres pour cerlains panneaux et 220,036 pour d'autres; qu'il avait sensiblement renfurcé les assemblages des barres inclinées aux membrures, coupé les arbalétriers à la base normalement à leur axe moyen et dégagé ces arbalétriers dans la hauteur du rez-de-chaussée de l'archivolte de la voùte. " M. Eiffel a fait plus, disait le rapport de II. Conlamin : pour faciliter son montage et ne pas avoir a se préoccuper de tas- 
sements possibles dans les fondations, il a de lui-mème et sans y etre invité disposé l'appui des arbalétriers sur les culées de manière à pouvoir intercaler entre la base des membrures et le sabot des vérins hydrauliques permettant a tout instant des montages et pendant la période d'exploitation de remédier aux tassements qui pourraient se produire. Il a porté à cet effet le poids prévu pour les appuis de 80,000 kilosrammes à $133,33 \pi$ kilogranmes. Pour mieux assembler le plancher aux membrures

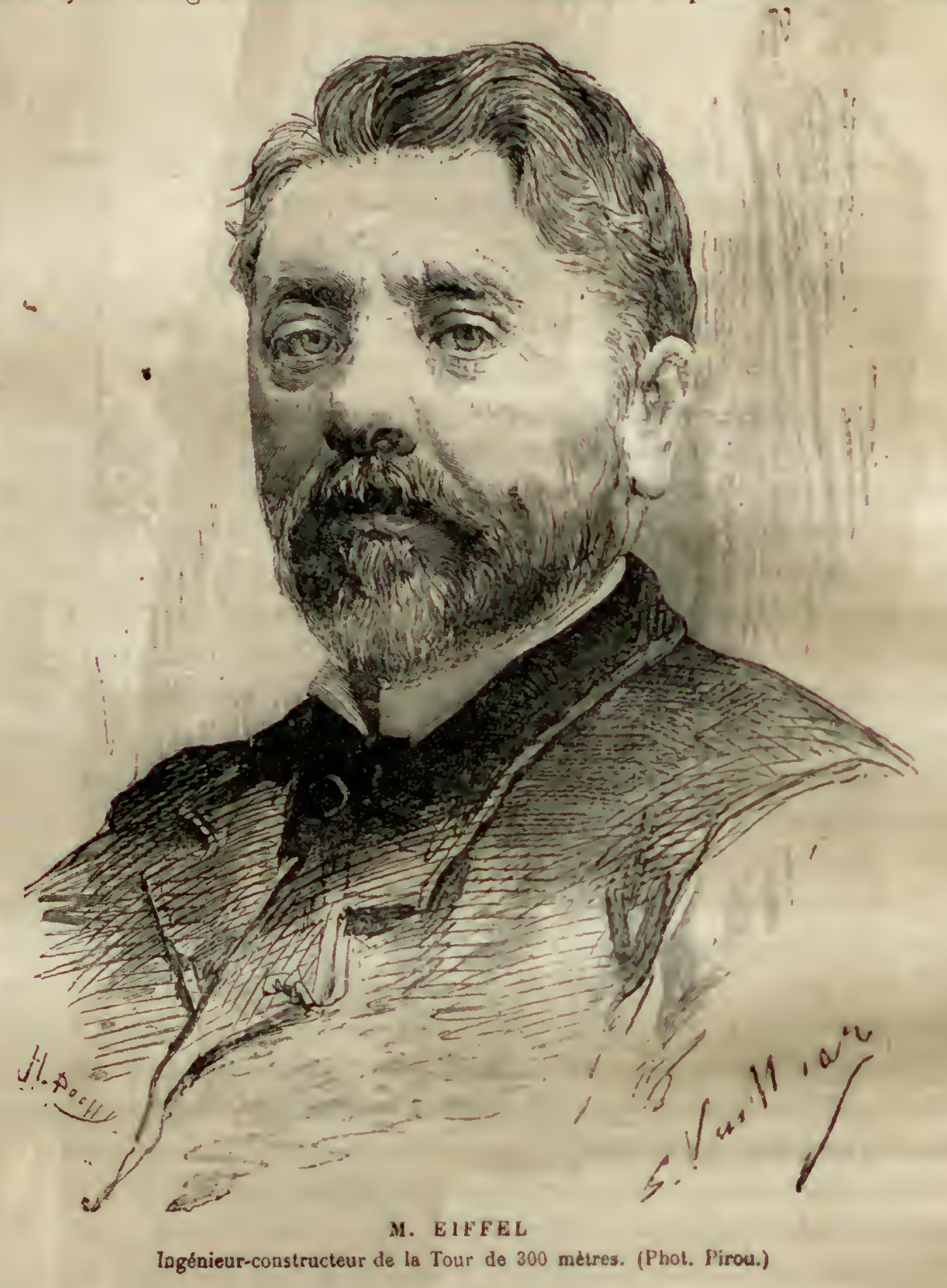

et augmenter les propriétés résistantes de ce dernier aux efforts de compression considérables que les arbalétriers exercent sur lui pendant et après la période de construction, il a remplacé les trois poutres verticales qui, dans le projet primitif, réunissaient les arbalètriers à la hauteur de ce plancher, par deux grandes poutres doubles superposées ayant leurs âmes dans les prolongements des faces des inembrures. Cette disposition, qui ne peut être adoptée qu'it la condition d'avoir les faces supérieures de ces poutres dirigées suivant un plan horizontal, conduit à assembler les plates-bandes composant ces faces aux ames inclinées des poutres par dés cornières 
LES MERVEILLES DE L'EXPOSITION

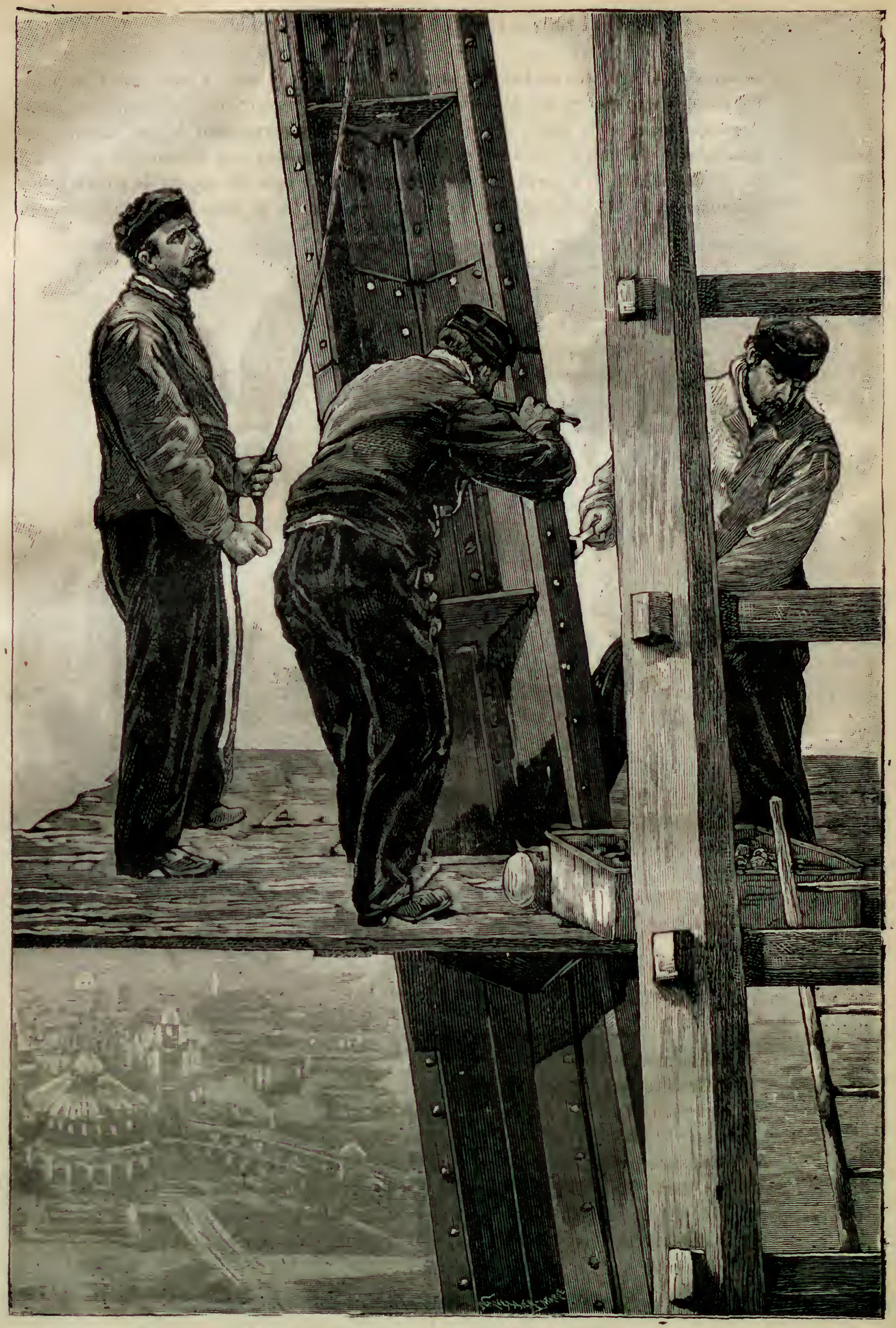

LES TRAVAUX DE LA TOUR EIFEEL.

A 180 MĖTRES EN L'AIR : BOULONNAGE DU JOINT DES DEUX ARBALÉTRIERS. 
à faces elles-mèmes inclinées, et, par suite, d'un prix d'achat trùs sensiblement supéricur a celui des cornières droites, mais elle présente par contre le très grand avantage de placer les âmes de ces poutres dans le sens des efforts de compression auxquels elles ont à résister et à transmettre ces efforts aux arbalétriers suivant le sens mème de ces efforts. Un contreventement extrèmement puissant entre ces poutres, śtudié de manière à reculer le plus possible la limite produisant la flexion latérale, assure enfin à cette partie de la construction une rigidité et une stabilité qu'étaient loin de présenter les dispositions soumises tout d'abord à la commission. Un dernier changensent enfin a été apporté à la disposition du premier étage : il a consisté à placer le planclier de la galerie des tribunes en encorbellementsur les pourtours de cel étage ì un nivcau inférieur à celui des galeries, à supporter ces tribunes par des consoles ayant la hauteur des poutres supérieures, et à les réunir entre elles par un voile plein en tôle. , En résumé, II. Eiffel, loin de se conformer strictement à son plan primitif, s'est efforcé de le modifier chaque fois qu'il a eu conscience d'accomplir une amélioration. Dans ce but, il a employé près de 600 tonnes de fer supplémentaires dans la partie de la Tour comprise entre les fondations et le prenier étage. Les fers et fontes de cet étage représentent un poids de $3,562,800$ kilogrammes.

III

\section{L'EXPOSITION A YOL D'OLSEAU}

La Tour Eiffel étant en quelque sorte le restibule des palais du Champ de Mars, sa description devait servir de préface à notre ouvrage. Ce devoir rempli, il convient maintenant, avant d'entreprendre la description des sections diverses de l'Exposition. de montrer l'emplacement qu'elles occupent, de jeter sur elles un coup d'œil d'ensemble. Commençons par le Champ de Mars.

Le Champ de Mars ne mesure pas moins de 1,028 mètres en longueur, et sa superficie dépasse 42 hectares. On sait qu'il s'étend dans le quartier de Grenelle entre la façade septentrionale de l'École militaire el la rive gauche de la Seine.

Le Champ de Mars a une histoire, et une histoire importante. C'est sur l'emplacement qu'il occupe que le fils de Robert le Fort, Eudes, fit essuyer une terrible defaite a ces farouches Normands qui harcelaient les Parisiens au $1 x^{\circ}$ siècle. Ces Normands avaient établi sur le futur Champ de Mars leur quartier général. Après la victoire d'Eudes, les Parisiens se réunirent à l'endroit mème d'où les pirates menaçaient la ville et célébrèrent gaiement leur départ; mais, voici que survint au milieu de la féte une innombrable armée de moines, suivant un corps enveloppé dans un linceul. l.es Parisiens interrompent leurs jeux et laissent passer sans défiance la procession; mais tout à coup les prétendus moines jettent le froc, le soi-disant mort sort du drap funèbre : c'étaient les Normands et leur chef. Poursuivis jusque dans la cité, les Parisiens étaient perdus si Eudes, dans une rigoureuse sortie, n'avait refoulé les envahisseurs : la place où eut lieu leur défaite fut nommée Champ de la Victoire. Tel est le premier grand souvenir du Champ de Mars.

Jusqu'au règne de Louis XV, le Champ de Mars passa oubié, et loreque, en 
janvier 17301, Ja fondation d'une école militaire en faveur de cinq cents gentilshommes fut décrétée, il ne formait plus depuis longtemps qu'une vaste garenne appartenant à l'ablaye de Saint-Germain. En 17:33, les travaux de l'École militaire commencèrent sous la direction de l'architecte Gabriel, et les élèves, provisoirement installés à Vincennes, l'inaugurèrent en 17506 . Vers 1770 , on expulsa les maraîchers qui s'étaient emparés du terrain situé devant la nouvelle école, et on traça un parallélogramme de 1,000 mètres de long sur 500 de large pour servir de récréation aux jeunes gens. L'ancien Champ de la Victoire devint une vaste esplanade entourée d'un fossé revêtu de pierre qui servait d'avenue à l'école du côtẻ de la rivière; quatre rangées d'arbres plantés sur les colés des fossés formaient de belles allées dont cinq grilles de fer fermaient les entrées. Le régiment des gardes françaises y faisait également ses exercices, le Clıamp pouvant contenir 10,000 homınes rangés en bataille. Le roi, accompagné de lime de Pompadour, inaugura le Champ de Mars par une revue des élèves, des gardes françaises et des suisses. En 1787, l'École militaire fut supprimée et convertie en caserne de cavalerie; le Champ de Mars devint alors et resta júsqu'à maintenaut l'emplacement où se firent les évolutions militaires.

La Révolution survint : Paris, afin de resserrer les liens fraternels qui devaient unir tous les Français, pensa à une grande chose, recevoir la France. La municipalité forma un comité de fédération et décida que les districts des départements seraient invités à envoyer à Paris des députés avec charge de conclure le pacte de la fédération nationale avec les Parisiens, le $\mathbf{1 4}$ juillet 1790, jour anniversaire de la prise de la Bastille. "Dix mois se sont à peine écoulés, disait une adresse aux Français, publiée ell mème temps au nom des habitants de Paris, depuis l'époque mémorable où, des murs de la Bastille reconquise, s'éleva ce cri : "Nous sommes libres! "Qu'au mème jour un cri plus touchant se fasse entepdre: "Nous sommes frères! Les travaux à accomplir étaient éuormes; il fallait relever les terres en talus de chaque còté, de telle façon qu'ils pussent supporter le poids de la foule, creuser le terrain, le retourner. En outre on avait projeté d'élever, entre l'amphithéatre et la rivière, un arc de triomphe, et de construire au milieu du Champ de Mars l'autel de la Patrie. 15,000 ouvriers furent réquisitionnés par l'Assemblée; mais, malgré ce nombre de travailleurs, on desespéra, le 7 juillet 1790, de voir les travaux terminés pour le 14. Un garde national nommé Carthui eut alors une idée qui eut un plein succès. Il fit insérer au journal la Chronique de Paris une lettre faisant appel au patriotisme de la population parisienne et lui demandant de travailler comme des, mancuvres pour que la fète nationale pût avoir lieu avec tout l'éclat qu'elle devait avoir. L’appel fut entendu, et tous, hommes, femınes et enfants se dirigèrent en masse vers le Champ de Mars. "Qu'on se figure, dit un historien illustre, 300,000 volontaires de tout age, de toute condition, revètus des costumes les plus divers, et du matin au soir, dans la douce ivresse d'un commun désir, avec cette harmonie qui nalt d'elle-méme de l'accord des àmes sous la loi d'une cordiale égalité, au bruit des chansons, creusant, roulant, renversant la terre avec autant d'ardeur que des soldats se meltent a ourrir une tranchée. Courage! courage! c'est la féte de la patrie qu'il s'agit de préparer. Que les vieillards se raniment! que les jeunes garçons accourent! que les fiancés viennent par leur présence faire de la fatigue un enchantement et sourire aux plus braves! Ce fut un prodige! "Les étrangers qui se trouvaient à Paris en ce moment restèrent pétrifiés de surprise devant, cette manifestation d'ardent patriotisme. 'J'ai vu, écrivait l'un d'eux, attelés au 
mème chariot, un bénédictin, un invalide, un moine, un juge, une courtisané. " On a trouvé dans les mémoires d'une actrice le récit suivant: " Les thédtres eux-mèmes se signalèrent: chaque cavalier choisissait une dame à laquelle il offrait une bèche bien légère, ornée de rubans, et, musique en tète, on allait au rendez-vous universel. II fallut inventer un costume qui résistat ì la poussière : une blouse de mousseline grise, des bas de soie et des brodequins de mème couleur, une éclıarpe tricolore, un large chapeau de paile, telle fut la tenue d'artiste. "Au chant du Ca ira, les courages s'animaient, on piochait ferme, et en quelques jours les travaux furent terminés. L'autel de la Patrie s'éleva au milieu du Champ de Mars, autel sur lequel prètèrent solennellement le serment civique les députés de toutes les gardes nationales de France et des corps de l'armée. Louis XVI jura aussi d'employer son pouvoir à respecter et à fiare respecter la Constitution décrétée par l'Assemblée nationale. L'endroit où se passa cette manifestation imposante prit des lors le nom de Champ de la Fédération.

Nous n'insisterons pas sur la. fète funéraire gni fut ordonnée au Champ de Mars, après les massacres de Nancy (1790), ni sur le drame sanglant dont il fut le théatre, lorsque la Fayette et Bailly crurent devoir appliquer à ceux qui demandaient la déchéance de Louis XVI, les rigueurs de la loi martiale contre les attroupements. Lorsque l'Europe entière eut déclaré la guerre à la llévolution, un soufle d'enthousiasme anima le peuple français, et c'est au Champ de Mars que se firent les eurülemenis volontaires. Des amphithédtres y furent élevés avec des drapeaux sur lesq̨uels se lisaient ces mots : La Patric est en danger. Les officiers municipaux inscrivaient le nom des engagés sur une table supportée par deux tambours. Un grand nombre de fètes nationales furent célébrées au Champ de Mars, pendant le cour's de la Révolution. Le 20 prairial an III (8 juin 1794), lors de la Féte ì l'k̂tre suprême, une montagne, rappelant celle de la Convention, fut érigée au centre, vis-ì-vis de l'autel, toute la Convention se plaça au faite, tandis que le cortège se massait autour. Quand Bonaparte, alors simple officier d'artillerie, eut repris Toulon aux Anglais, une réunion platriotique se tint au Champ de Mars, et, jusqu'au 3 décembre 1804, il ne s'y passa rien de particulier. Ce jour-lá, lendemain du couronnement de l'empereur Napoléon Ier à NolreDame, on y distribua des aigles impériales. La cérémonie se passa dans cet ordre: l'empereur et l'impératrice Joséphine prirent place sur deux trùnes dressés en face de l'École militaire; les corps d'armée se rangèrent en ligne devant les trônes, musique en tête; les députations des gardes nationales se placèrent dans l'intervalle du centre de la ligne, les colonels se rangèrent sur les degrés du trône, aigles en main. Napoléon se leva ensuite et fit cette proclamation devenue célèbre : Soldats! roilà vos drapeaux; ces aigles vous serviront toujours de point de ralliement; elles seront partout ou votre empereur les jugera nécessaires pour la défense de son trone et de son peuple. Vous jurez de sacrifier votre vie pour les défendre, et de les maintenir constamment par votre courage sur le chemin de la victoire. , La distribution des aigles commença et fut terminée par un défilé général. La période des revers arriva pour l'empereur qui abdiqua à Fontainebleau, s'exila à l'lle d'Eibe et voulut une dernière fuis tenter la fortune. Il revint à Paris sans coup férir, en traversant toute la France. Un banquet colossal réunit le 2 avril, au Champ de Mars, 15,000 convives pour célébrer ce succès. Quelque temps après, il y proclama l'Acte additionnel, promesses de liberté destinẻes à consolider son trône ébranlé. Le 15 juin 1810\%, une fête rappelant celle de la Fẻdération eut lieu au Champ de Mars; toutes les députations des corps d'urmée et des 


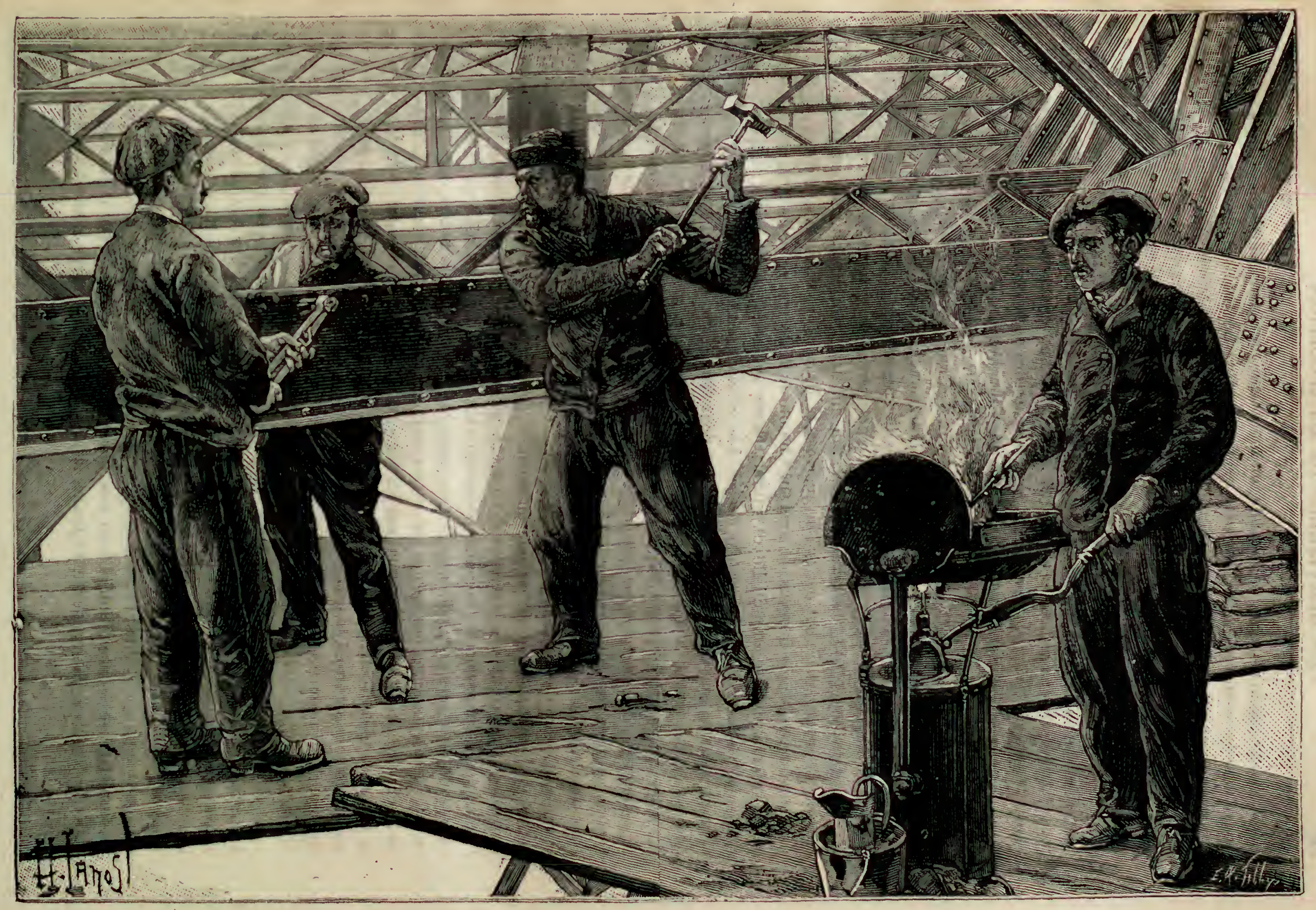

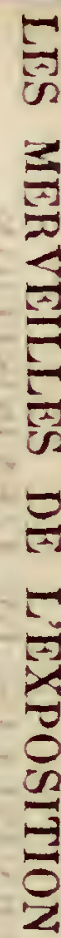

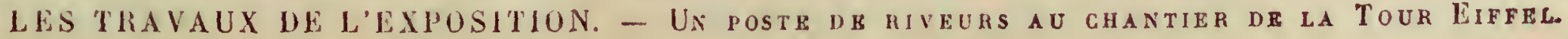


corps d'État furent réunies; cette solennité prit le nom de Champ de Mai, sans doute parce qu'elle avait été primitivement projetée pour le 26 mai.

Sous le règne de Louis XVIII, après le retour du duc d'Angoulème qui avait été remporter en Espagne des succes faciles pendant la guerre qu'on appella guerre du Trocadéro, le gouvernement donna au peuple de Paris l'image de ce qui s'était passé au delà des Pyrénées. Une petite guerre fut simulée, et le Champ de Mars, servit de lielı d'opérations où l'on représenta la prise du Trocadéro et les triomplies du duc d'Angoulême en Espagne, au grand divertissement des spectateurs. Le 9 ' arril $182 \pi$, le roi Charles $\mathrm{X}$ y passa une revue des gardes nationales a la suite de laquelle elles furent supprimées. Voici pourquoi : Il parcourait les lignes lorsque les cris de: " Vive la Charte! Vixe la liberté de la Presse!' se firent entendre. Le roi, fort mécontent, dit d'une voix irritéc: "Messieurs, je suis venu ici non pour recevoir des leçons, mais des hommages: - Puis il ordonna au maréchal Oudinot de commander le défilé qui commença cette fois non seulement aux cris de Vive la Charte! mais encore à ceux de Vive la liberté! A bas les Jésuites! A bas les ministres! Le soir même, le conseil des ministres fut conroqué et la dissolution de la garde nationale prononcée.

En 1830, le Champ de Mars fut agrandi et devint, le 1 ä juin 1837, le théatre d'une catastrophe.

A l'occasion du mariage du duc d'Orléans on donna une fète militaire représentant la prise de la citadelle d'Anvers. On ne sut au juste al quoi attribuer le désastre, mais un grand nombre de personnes furent écrasées, étouffées ou foulées aux pieds. Pendant la République de 1848, une fête dite de la Concorde eut lieu le 21 mai au Champ de Mars.

Le 10 mai 185̋3, Louis-Napoléon Bonaparte, encore président de la République, mais en fait déjà réellement empereur, voulut singer son ancètre et fit la distribution des aigles. Le Moniteur nous donne le programme anticipé de la fête: . Devant l'ícole militaire s'élève la tribune du prince Napoléon, président de la Républiq̣ue; les statues qui sont au pied du grand escalier conduisant a cette tribune représentent la furce, la Victoire, la Prudence, l'Histoire et la Paix. A côté du président de la République se tiendront le prince Jérôme, les ministres, les maréchaux et amiraux, les ambassadeurs français présents à Paris et la maison du prince. Dans les tribunes roisines se placeront le corps diplomatique étranger, les grands corps de l'tetat et tous les corps constitués. Enfin les deux cents mats qui formeront deux lignes et seront garnis de bannières, de trophées, de panoplies, porteront l'inscription de chaque nunéro de régiment avec l'indication des batailles où il a figuré . La cérémonie commença par une revue après la q̧uelle le président prononça ces paroles caractéristiques : "Soldats! l'histoire des peuples est en grande partie l'histoire des armées. De leurs succès ou de leurs revers dépend le sort de la civilisation et de la patrie. Vaincus, c'est l'invasion ou l'anarchic; victorieuses, c'est la gloire ou l'ordre. Aussi les nations comme les armées portent-elles une vénération religicuse a ces emblèmes de l'honneur militaire, qui résument en cux tout un passé de luttes et de triomphes. L'aigle romaine, adoptée par l'empereur Napoléon au commencement de ce siècle, fut la signification la plus éclatante de la régénération et de la grandeur de la France. Elle devait revenir, lorsque la France, relevée de ses défaites, maîtresse d'elle-mème, ne semblerait plus répudier sa propre gloire. Soldats, reprenez donc encore ces aigles, non comme le symbole d'une menace contre l'étranger, mais comme le souvenir d'une époque liéroïque, comme le signe de noblesse de chaque 
régiment. Reprenez vos aigles, quı on sı suuvent conduit vos pères à la victoire, et jurez de mourir s'il le faut pour les défendre. »

Ce fut le dernier événement politique qui se passa au Champ de Mars, qui ne servit plus depuis de théatre qu'à ces grandes manifestations pacifiques que l'on appelle des expositions.

C'est au Champ de Mars que se sont ouvertes et tenues les Expositions de 1867 et de 1878; c'est là que s'ouvrira et que se tiendra la grande Exposition de 1889.

L'heure approche où les travaux vont ètre terminés, où la Tour Fiffel va dominer de sa hauteur' gigantesque les batiments de l'Exposition et mème la ville entière. Autour du Champ de Mar's, dans les rues avoisinantes, c'est un défilé d'exposants, de charrettes remplies de matériaux qu'elles vont déverser sur le terrain mème du Champ de Hars, au milieu d'une nuée d'ouvriers affairés dont les marteaux résonnent sur le fer, tandis que les pelles et les pioches fouillent la terre, là creusant une fosse, élevant ici des remblais. Rien ne saurait donner une idée de cette activité fiévreuse.

Il faut se hiter si l'on veut jouir du spectacle vraiment original que présentent les bitiments en construction de l'Exposition. Leur ossature de fer à longue portée et à grande hauteur oblige à des travanx d'échafaudage qui ajoutent encore à l'étrangeté de leur physionomic. La nef centrale occupera le inilieu des batiments bordant, a 600 inc̀tres en arrière de la Tour Liffel, les jardins de l'Exposition. Son dòme, a 60 mìtres au-dessus du sol, sera surmonté d'une statue de 10 mètres de hauteur. Le poids total de son ossature de fer est de 867,000 kilogrammes. La charpente de hois élevée ì sa droite sert au montage des fermes de la galerie des industries diverses. - Chacune de ces fermes pèse 30,000 kilogrammes. Quant au dôme du Palais des BeauxArts, il ne sera pas, comme celui de la nef centrale, surmonté d'une statue. Sa hauteur est de 56 mèlres. La poutre doublant et l'ossature intérieure destinées à supporter la ceinture de la coupole sont fixées sur des piliers d'une hauteur de 29 mètres. La poutre horizontale. contre laquelle est placée une échelle, indique l'emplacement du plancher du porche d'entrée.

Bien que le gros ouvre de toutes ces constructions ne soit pas complètement achevé, on s'occupe depuis longtemps déjà, avec activité, de la partie décorative. Aussitit qu'une galerie est recouverte, ol installe un atelier de sculpture et de moulage. Chaque architecte a adopté une spécialité. M. Formigé, pour les Palais des BeauxArts et des Arts libéraux, a choisi les ormements en céramique. M. Bouvard, pour le Palais des Industries diverses, a surtout employé le platre. C'est chez lui que l'on modìle les grandes figures allégoriques, femmes, hommes, génies, qui doivent figurer aux angles de la coupole de la nef centrale. M. Dutert, chargé de la galerie des Machines, emploie le staff, sorte de plàtre mèlé d'ocre très fluide qu'on renforce avec des étoupes et qui produit l'effet de la pierre véritable. Enfin, à l'arrière-plan, dans toute la largur du Champ de Mars, la galerie des Machines. Sa toiture vitrée, semblable à une immense carapace, domine celle des palais voisins. On sait que l'architecte, II. Dutert, a exécuté le projet hardi de former cette galerie d'une série de fermes métalliques de 1130 mètres de portée, la plus grande qui ait jamais été appliquée dans les travaux de ce genre. Il s'est produit dans le montage des fermes un fait assez intéressant. Leur exécution avait été confiée moitié à la maison Cail, moitié à la Compagnie de Fives-Lille. Iaquelle des deux arriverait première? Elles sont tout simplement arrivées ensemble. Le poids total de celte prodicicuse couverture de fer, y compris les 
fermes et les fers de vitrage, s'élève a 11,300,000 kilogrammes. Il a été prévu pour ce travail une dépense de $6,496,228$ francs.

Laissons ici la parole à M. Charles Yriarte. « Comme l'artiste qui a concu et dessiné dans toutes ses parties un immense projet architectural en voit nettement la réalisation dans la chambre noire de son cerveau, l'aspect général, avec la perspective, cavalière, les coupes, les abords, les intérieurs et jusqu'aux moindres cellules : l'étude des plans et l'état actuel des constructions permettent de dessiner à grands traits la vue de l'ensemble que le lecteur pourra suivre sur le plan.

- Placé sous le portique circulaire du palais du Trocadéro, au centre mêne, dans l'axe du pont d'Iéna et de la Tour Eiffel, embrassons d'un senl regard le panorama splendide :

"Au premier plan de la perspective, en avant du portique du Palais du Trocadéro, se dressent les statues d'or des parties du monde qui accrochent les rayons du soleil; à nos pieds se déroulent les pentes vertes des parterres, la nappe des bassins, et nons entendons le bouillonnement des cascades. Au delà, le pont d'léna, la Seine, et juste dans l'axe, la Tour Eiffel, dont le sommet de l'arc de base arrive juste a la hanteur dı comble du Palais des Machines, caché demain par le pavillon central des galeries industrielles. Sur l'arrière-plan, ì droite de la Tour, se profile le comble du Palais des Beaux-Arts, à gauche celui des Arts libéraux. Ici, c'est Grenelle et les hautenrs de Chatillon, Meudon, Bellevue et ses collines; là, sur la gauche, le Gros-Caillon et le Paris vivant aux maisons pressées, le dòme d’or des Invalides, le Panthéon tout gris, les tours de Saint-Sulpice boiteuses, puis celles de Notre-Dame, et, an loin, les brumes des horizons.

Les jardins du Trocadéro, qui s'étendent sous nos pieds, sont entierement consacrés à l'Exposition d'arboriculture et d'horticulture, là aussi s'élèvent le Parillon des Foréts et les Serres. A notre gauche, où en $\mathbf{1 8 7 8}$ on accédait à l'aqquarium, s'ouvre une excavation cachée dans des massifs de fleurs : c'est la Tour Eiffel en sens inverse, c'est-àdire le voyage au centre de la Terre; un trou noir dans lequel on descendrat au moyen d'une cage représentant la benne d'un puits de mine. La descente dans cet enfer ne sera qu'illusoire, mais on en aura la sensation par une légère trépidation imprimée à la cage, et bientòt on fera passer successivement sous les yeux des visiteurs de grands tableaux en trompe-l'œil, coupes souterraines montrant les égouts de Paris, une galeric des Catacombes, une excavation des anciemes carrières sous Paris, aujourd'hui consacrées à la culture des champignons; les couches sédimentaires dont la stratification démontrera l'histoire géologique du globe terrestre; enfin une galerie de mine de charbon et de fer, des flons métalliques, des carrières de sel gemme, en pleine activité d'organisation et d'exploitation.

Au bas des jardins, le pont d'Iéna, unique communication avec le Champ de Mars, est couvert d'un velum et orné de kiosques élégants; au débouché du pont, immédiatsment à droite et à gauche, avec façade sur la partie dite le Square de ’a ville de Paris: l'histoire de l'habitation, c'est-d-dire quarante-neuf petites constructions types de l'habitation de l'homme aux diverses phases des temps, de la période préhistorique il la périodle historique; chaque type de demeure de chaque age, de chaque civilisation s'élevant dans son milieu, dans la nature qui l'entourait, avec sa flore, avec sa faune, al lintérieur avec ses accessoires, à l'extéricur avec sa vie propre.

Tout autour de la construction de M. Eiffel s'étend le parc du Chump de Mlurs, avec 


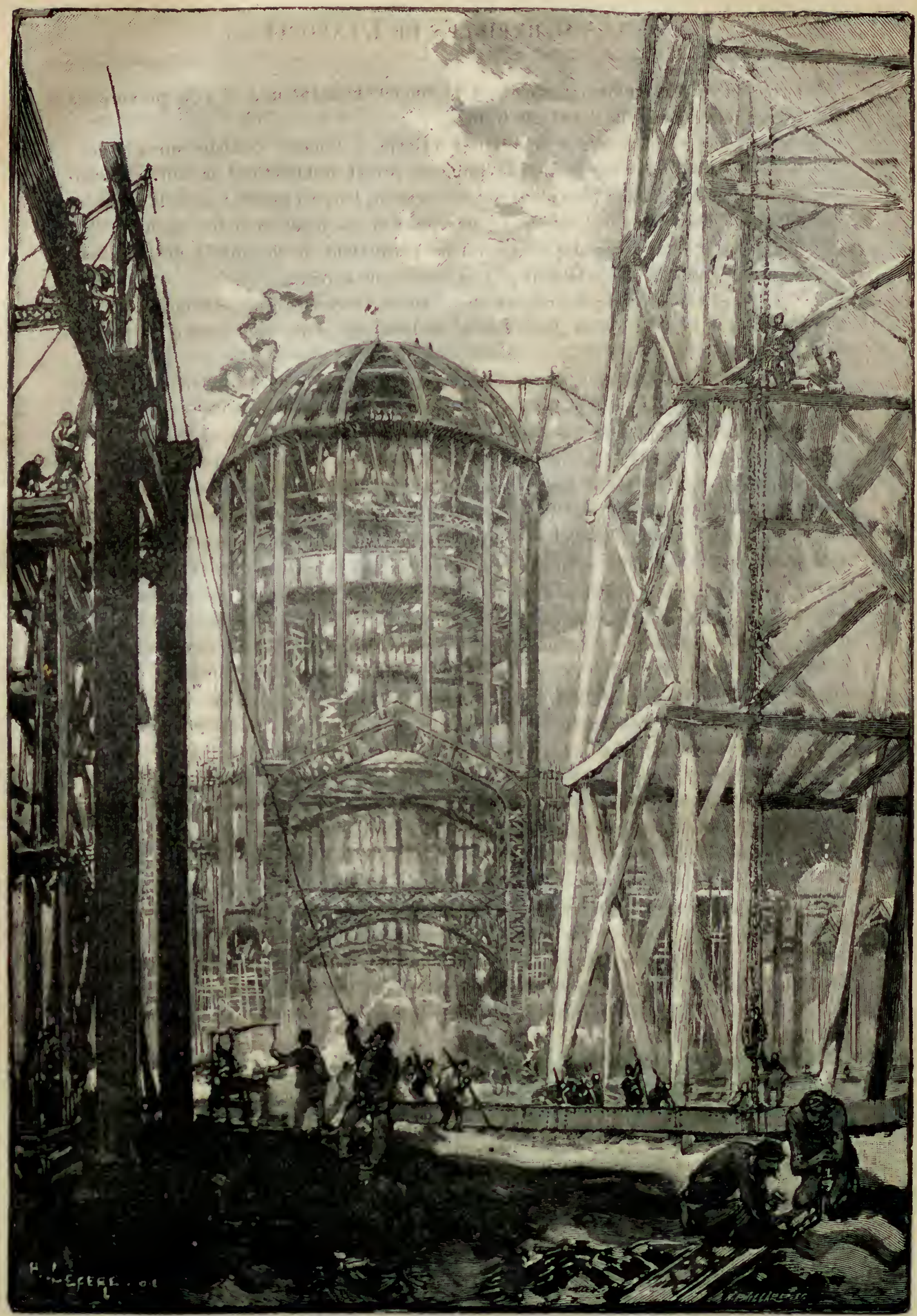

LES TRAVAUX DE L'EXPOSITION UNIVERSELLE DE 1889. - LA YEF GENTALE. 
ses rivières, ses cascades, ses vallonnements, peuplés des pavillons d'exposition de chacun des États de l'Amérique centrale et méridionale. On a aussi réservédans cette partie une grande salle de théâtre au milieu d'un espace de 2,000 metres carrés. où "on trouvera tous les jeux destinés à la jeunesse et où l'on donnera des représentations enfantines. Dans la partie gauche du parc (côlé de Paris) s'élèveront : le Pavillon des Tabacs, la Maison Suédoise, le Batiment des Téléphones, le Pavillon de la Presse, vaste centre où on réunit toutes les informations, et la bibliotheque spéciale nécessaire aux correspondants de journaux. Puis vient l'Exposition du gaz : pavillon combiné spécia lement pour son objet, dont, le soir, les toitures, les tourelles, les frontons, toules les saillies et toutes les ouvertures, seront éclairés par transparence; maison de flanme déjà surnommée par les ouvriers la Maison du Feu. Enfin, dans cette méme partie du parc, on a donné la concession d'un grand café-concert d̀ deux artistes comiques célèbres, Scipion et Daubray, et là viendront concourir et s'exposer toutes les célébrités comiques, les étoiles du chant, les danseuses, les baladines, les divas de Bohême et les Patti du bock et de la limonade, et les Paulus internationaux.

Sortons du parc, revenons d̀ la Tour Eiffel et regardons de là l'École militaire. Nous avons en face de nous, au lieu d'un parc anglais capricieux semé de pavillons, un immense jardin français à deux étages de terrain, avec de beaux parterres rectilignes, richement plantés d'arbres et de fleurs, terminé dans l'axe par des casćades, des fontaines, des jets d'eau qu'on éclairera le soir à l'aide de la lumic̀re électrique colorée. Ces longs jardins français, fermés d̀ droite et à gauche par le Palais des Beaux-Arts et celui des Arts libéraux, et clos par les galeries industrielles, forment une sorte de square autour duquel on a concentré tous les établissements de consommation de tous les pays du monde, sous la ceinture de portiques qui le bordent. Tous soumis a un plan uniforme et se succédant sans interruption, ces restaurants garderont chacun leur caractère indigène dans la décoration, et ceux qui les desservent porteront tous leurs costumes nationaux. Les Mozos, les Manolas, les Kellner, les Moujiks, les Tyroliennes à jupes courtes, les blondes Girls ou les Frisomnes, et autres échantillons de garçons ct de servantes choisis avec soin pour le plaisir des yeux, y débiteront l'orchateria, l'ale, le gin, l'hydromel, le faro, le lambic, le kummel, le curaçao, la slivovitza, les vins de France; même le cidre, le guignolet, et bien d'autres choses plus mauraises encore. C'est la concession nécessaire faite aux divers appétits des visiteurs. Si l'on avait écouté les inventeurs d'apéritifs et les innombrables fabricants de liqueurs aussi digestires que nuisibles d la santé, le Directeur de l'Exploitation aurait da couvrir les parcs et les jardins de kiosques tapageurs et de débits de dégustation, qui auraient fait de l'Exposition un immense bar. Désormais la liste des concessions est irrévocablement close.

L'éclairage par l'électricité date d'hier seulement; c'est elle qui permettra cette innovation de l'ouverture de l'Exposition a la nuit close; aussi, d cette heure nocturne, le carrefour compris entre les palais et les galeries industrielles, scra-t-il le coin le slus pittoresque et le plus virant de toute. l'Exposition. Au vif éclat des feux électriques, on entendra ronfler le panderos, cliqueter les castagnettes, grincer la cithare et pincer 18 guzla; les Tsiganes feront rage avec la marche de Rukoscy; les minstrels de Leicester Square passés à la suie coudoieront le piper écossais qui enverra aux échos le SweetHome, pendant que le négro de la Havane hurlera : A la Ratatomba, muchachos l ', auquel répondront les : Alsa! ola Salero! , des Gitanos de l'Albaycin. 
$\mathrm{Au}$ sortir de ces gaietés internationales, de cette Babel culinaire, on entrera dans le Palais des Ifachines, tout en feu comme un brasier, colossale conception aux proportions démesurées; Exposition unique, la plus grande qu'on aura encore imaginée. Du'on se figure l'effet de celte mise en mouvement de 2,500 chevaux-vapeur, activant des milliers d'appareils, et ce développement d'arbres de transmission de force mesurant 1,400 mètres, avec des ponts roulants a la hauteur de ces arbres, portant les visiteurs d'un bout à l'antre dı palais.

Dans le plan général de l'Exposition, sur les bas-côtés, lout autour des palais, règne un large chemin de ceinture. Là s'élèveront d'un côté le bazar égyptien, les okels de vente, les souks tunisiens, les cafés maures, et une vaste écurie pour 100 anes blancs, bas et commodes, à larges selles, destinés à la location pour transporter les visiteurs d'un parc à l'autre en guise de fauteuils roulants. Plus loin s'élèveront la Maison 'aponaise dans le goût de celle de 1878, les Kiosques Marocains, les Pavillons Persan et Siltmois.

Le bas-côté qui regarde Paris est réservé aux pavillons industriels des grands établissements métallurgiques ou miniers avec leurs petits pares pour les pièces colossales, et les fac-similés des marteaux-pilons démesurés.

Si de là nous redescendons jusqu'au fleuve, sur sa rive gauche, en bordure sur les quais, sont l'Exposition du Hatériel de la navigation, du Sauvetage, de la Péche, de ses engins, et la Compagnie transallantique, qui convie le public à s'embarquer sur une partic, vraic grandeur, du pont d'un transatlantique, la Champagne: L'arrière et l'avant de ces paquebots sont ingénieusement représentés en trompe-l'œil, et l'illusion est complétée par le déploiement d'une toile panoramique représentant la rade du IIavre.

Le groupe de l'Agriculture occupe, depuis le quai d'Orsay jusqu'à l'Esplanade des Invalides, sur la contre-allée, 30,000 mètres de surface jusqu'à l'Esplanade des Invalides, tout entière divisée en deux grandes parties séparées par l'allée qui accède au dôme, et réservée aux Colonies françises, au Ministère de la Guerre, à l'Exposition de l'Économie sociale, et mème à un café de tempérance où on ne boira que du thé, de l'eau claire et de la limonade. Dans un coin, à l'angle, vers l'hôtel de Sagan, s'élèvera le panorama dit Tout Paris, où on verra défiler 1,300 personnes connues, se promenant comme par hasard et meublant la chaussée, les trottoirs, les balcons des clubs et du Grand-Hôtel, les tables de café el les voitures de l'avenue de l'Opéra. Enfin, le long du Ministère des Alfaires étrangères, dans des espaces spéciaux, on nous a ménagé tout un prolongement de la France, un village de chacune de nos Colonies avec leurs types d'indigènes, les habitations, les animaux, la flore, la faune du pays, les monuments les plus curieux.

Voilà le tableau dans son ensemble! Si c'est le soir que vous venez le contempler du haut du portique où nous sommes placé, tout éclate, tout flamboie sous la voùte du ciel : c'est la fète de l'électricité. Tous les systèmes modernes de lampes à air ou à incandescence sont là en pleine activité, et 300,000 becs carcels font de la nuit le jour, dépassant en intensité deux fois la puissance de l'éclairage municipal au gaz de toute la ville.

Si c'est le jour, le ciel est clément, un air transparent et léger enveloppe ce prodigieux panorama, et un gai rayon du soleil de France, le soleil sans morsure, doux comme l'espérance, salue les pavillons de toutes les nations qui flottent au vent.,

Après celte description très remarquable, très brillante de M. Charles Yriarte, nous allons compléter par quelques détails les puints auxquels fait allusion le récit de 
notre distingué conîlère et $\mathrm{y}$ ajouter quelques détails nouveaux. Ce n'est pas en quelques lignes, dans une rue à vol d'oiseau de l'Exposition, qu'il était possible de tout passer en revue.

Voici, par exemple, au centre du jardin de l'Exposition, une vaste rotonde qui marque l'entrée des galeries industrielles françaises, face au pont d'léna et a égale distance des expositions d'art dont les pavillons occuperont les deux cótés du jardin. Cette rotonde sera particulièrement consacrée aux Erpositions de nos mamufuctures d'Etat: Sèvres, les Gobelins, Beaurais et la Mosaïque. la manufacture des Gobolins sera représentée par trente-trois tapisseries de haute lisse et six panneaux en tapis veloutés, dits tapis de Savonnerie. Ce que l'on admirera surtout, e'est une suite de figures allégoriques : les Muses, les Poèmes, et un admirable Pégase, en tout 17 tentures composées par P.-V. Galland et destinées à décorer le salon d'Apollon, au Palais de l'Élysée. Mais on réservera une part de son admiration pour les huit " verdures ^ qui décoreront l'escalier d'lionneur du Sénat et dont on doit la composition à MLM. Desgofles, Flandrin, Curzon, Bellel, Colin, Rapin, Maloisel. Des cinq panneaux d'après F. Ehrmann qui doivent orner la chambre de Mazarin a la Bibliothèque nationale, trois seulcment scront prètes à temps : ce sont des allégories de l'Imprimé, du Manuscrit et des Lettres, Sciences et Arts dans l'antiquité. Joigne\% it cela des pièces isolées de MM. Galland, Mazerolles, J. Lefebrre, Bourgeois, des panneaux d'après Chardin, et vous aurez une idée de l'effet merveilleux que ne manquera pas de produire l'Exposition des Gobelins.

Les pièces dites de. Savonnerie, ne seront pas moins remarquables. On sait ce qu'il faut entendre par cette désignation, mais rappelons cependant son origine. Au commencement du xwı siècle, Pierre Dupont donna a IIenri IV lidée d'établir près de Paris une manufacture de tapis dans le genre oriental. Ilenri IV y consentil, et la manufacture fut établie dans une vaste maison qui avait servi d'abord de fabrique de savon, et qui était située sur le bord de la Seine (quai de Billy). Pierre Dupont et son successeur Simon Lourdet obtinrent de si magnifiques résultats qu'ils rerurent des lettres de noblesse : les tapis de la Savonnerie rivalisèrent avec ceux des Gobelins Cependant, et en dépit de la réorganisation édictée par Colbert en 1663, la manufaclure déchut de son ancienne renommée. Elle eut un nouveau moment daclive splendeur

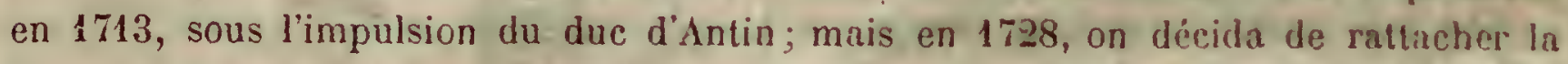
Savonnerie aux Gobelins. Les batiments du quai furent abandonnés : ils scrvent aujourd'hui de magasins de subsistances militaires. Ce rattachement n'empeche pas que les procédés de Pierre Dupont et de ses successeurs soient encore en faveur. On s'en rendra compte à l'Exposition, où les ateliers des Gobelins, à qui l'on a donné la désignation d'ateliers de la Savonneric, enverront six panneaux allégoriques : les cinq premiers, dus a M. Iameire, symboliseront les Sciences, les Arts, I'Industrie, la Guerre et la Marine; le sixième, d'aprìs MM. Merson et Lavastre, représente les Sciences et est destiné à la Bibliothèque nationale.

La Galerie des Industries dixerses est aujourdhui terminée: elle a été mise à la disposition des comités des différentes classes et des commissaires généraux des sections étrangères. A l'entrée est une porte monumentale que surmonte un dóme haut de 70 mètres et élevé d'après les plans de M. Bouvard, architecte de la ville de Paris. Ce dôme est recouvert d'une belle coupole au centre de laquelle se dressera une statue gigantesque. L'ossature du dôme centril a absorbé plus d'un million de kilogrammes 


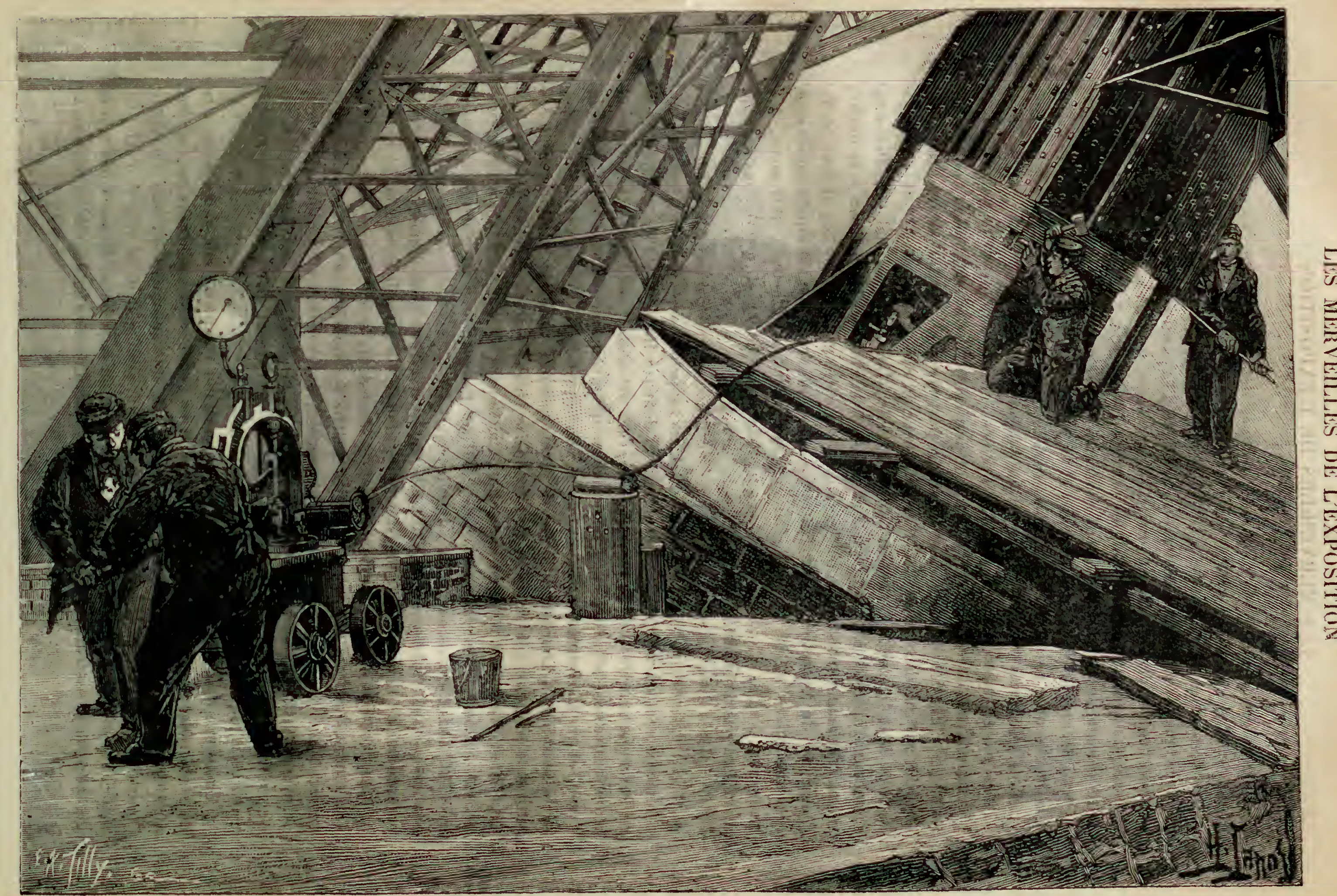


de fer. De chaque côté sont deux pavillons latéraux. La porte est munie d'un balcon en encorbellement et flanquée de deux tours carrées. Le montage a été fait dans des conditions exceptionnellement remarquables par MM. Moisant, Laurent et Savey. C'est encore à M. l'ingénicur Grosclaude que nous emprunterons les détails techniques qui suivent sur l'échafaudage de montage du dôme central. La coupole qui domine la nef centrale se compose de huit demi-fermes principales et de huit demi-fermes intermédiaires; huit grands piliers de 40 mètres de hauteur la supportent el sont reliés entre eux, à des niveaux différents, par trois ceintures circulaires te 30 mètres de diamètre. Ces piliers soutiennent aussi deux à quatre arcs métalliques sur lesquels viennent s'appuyer les fermes intermédiaires; les fermes principales ne sont que la continuation des piliers tubulaires. Toutes les fermes sappuient, à la partie supéricure de la coupole, sur une couronne métallique qui supportera encore un molif de décoration de plus de 10 mètres d'élévation. Un plancher placé à 8 mètres au-dessus du sol divise en deux parties les pavillons latéraux et se continue par un balcon sirculaire qui fait le tour de la nef centrale; il ast soutenu par des consoles en encǫriellement fixées sur la première seinture inféricure. Les pavillons sont constitués au moyon de fermes à deux rampants à entrait surélevé.

Les chargos et surchargos a dmises dans le salcul des fermes de la zoupole sont les suivantes :

Paids de la couverture du dìme par mètre superficiel développé......... 200 liilont.

Hourdis des pans de fer circulaires, par mètre carre................... 200

Action horizontale du vent, par metre carré........................ 120 -

Le calcul des fermes principales a úté fait en considérant l'onsemble de deux demifermes liamétralement opposées, ot les regardant comme articulées à leurs points d'appui sur le sol et au point de rencontre de leur prolongement avec l'axe central du dôme. Les fermos intermédiairæs sont :ombinées avec lappui simple sur les arcs et articulation au faitage. Les piliers des premières ont à soutenir, outie les chargno mentionnées plus haut et communes aux fermes principales et intermediaires, une partie du poids du plancher des pavillons latéraux. Ce poids est fixé a 800 kilugrammes par mètre sarré.

Le poids total de l'ossature métallique et du montage du dủne et de ses pavillons est évalué à 867 lonnes.

- L'échafaudage, dit M. Grosclaude, comprenait deux parties distincles : Ia première, le pylone annulairo, servait au montage de la grande nef jusqu à la partie courbe des fermes de la coupole; la seconde, le pylöne central et les deux plateformes en encorbellement, serraient au montage de la coupole. Le pylône annulaire étail formé de 16 fermes constituées shacune par deux poleaux verlicaux reliés entre eux par des moises horizontales des contrefiches. Les seize fermes élaient reliées jar un double cours de 10 moises chacun, l'un intérieur, l'autre extérieur au pylone. Elles étaient en outre réunies par an contreventernent intérieur et un second extéricur ayant tous deux pour but de résister aux efforts de torsion dus au vent. A la partic supéricure. l'échafaudage se terminait par une plate-forme annulaire située à 4 mètres au-dessus du sol et supportant una double voie circulaire qui servait a la manceurre de l'apparcil de levage.

L'appareil da levage se composait de deux parties essentielles : le chariot et le mécanisma. Le shariot était formśs par deux longernns en fer a double T, réunis d leurs 
extrémités par deux entretoises en fer de mème section. L e système, ainsi constitué, était renciu indéformable par une double diagonale en fer plat. Il pouvait se déplacer au moyen de deux paires de galets de roulement, sur une double voie circulaire en fer d double T, sur laquelle il était guidé par quatre autres galets à axe vertical, fixés aux quatre coins du chariot. L'axe d'une des paires de galets portait une roue d'engrenage en contact avec un pignon denté auquel on pouvait donner le mouvement au moyen de deux roues d'engrenage et d'une poulie à gorge sur laquelle passait une chaîne sans fin qui descendait jusqu'au sol; en agissant sur la chalne, le chariot se mettait en nouvement, guidé par la voie circulaire. Le mécanisme servant au levage des pièces était supporté par deux fers à double $\mathrm{T}$ de $13^{\mathrm{m}}, 42$ de longueur, fixés sur le chariot. Les extrémités de la grue, qui portaient toutes deux une poulie fixe, étaient maintenues horizontales au moyen de quatre barres en fer rond, qui s'opposaient à leur flexion el étaient soutenues par une tige verticale fixée sur le chariot. Sur l'aile supérieure des fer's à double $T$, et pouvant se déplacer à droite et à gauche du chariot, étaient deux trucks roulants constitués par deux paires de galets dont les axes passaient dans des flasques qui portaient les tourillons de deux poulies à gorge; c'est sur ces poulies que passait, en suivant le chemin indiqué sur le dessin, la chaine servant au levage des matériaux. Cette chaine, fixée aux deux extrémités de la grue, de longueur invariable et sup. portant deux poulies à crochet, celui de gauche prenant les pièces, l'autre étant inis en relation avec un treuil à double engrenage situé sur le sol. »

Pour se rendre compte du fonctionnement de l'appareil, il faut supposer, - une pidce devant ètre levée, - que les deux trucks ont été ramenés aux extrémités de la -grue et la poulie de gauche descendue. On fixe le crochet de cette poulie à la pièce qu'on veut lever el que l'on a eu soin de placer sur le sol à $1^{\mathrm{m}}, 50$ environ, en dehors de la paroi verticale du dóme. Quand la pièce est élevée à hauteur voulue, on l'amène en face de son emplacement en roulant le chariot, puis au-dessus de la pièce avec laquelle elle doit s'assembler. C'est à cet effet que les deux trucks portaient chacun une chaine dont les bouts s'attachaient aux flasques des galets, et passant sur les poulies fixées aux extrémités de la grue et sur deux autres poulies dont les axes portent des roues engrenant entre elles. En donnant le mouvement à l'une des roues, les deux trucks s'approchaient ou s'éloignaient de l'axe du chariot, et cela, de telle manière, que la résultante des charges passait toujours par le milieu du chariot. L'arbre de cette roue portait une roue d'engrenage qui actionnait un pignon dont l'axe était muni d'une autre roue a laquelle une vis sans fin pouvait donner le mouvement. a Il convient de remarquer que, pendant le mouvement des trucks, la chaine qui portait les matériaux s'allongeait d'un côté pendant qu'elle se raccourcissait de l'autre; il en résultait que la pièce restait toujours au meme niveau. Quand la hauteur à laquelle on levait une pièce était assez considérable pour que le poids de la chaine à droite, put s'opposer à ce que la poulie de gauche descendit par son propre poids, on ajoutait, avant le montage, un certain nombre de rondelles en fonte destinées à faire équilibre au poids de la chaine de droite.

Ce systène de levage, des plus ingénieux, permet d'amener chaque pièce à son emplacement d'une manière mathématique et assure le fonctionnement des mancuvres sans aucun danger.

Le Palais des Machines. Pour abriter les merveilleuses inventions, les machines colossales que la science a créées depuis la dernière Exposition universelle, il fallait 
élever un palais qui fut à la fois digne de recevoir les premières et capables de contenir les secondes: il fallait faire énorme et beau, c'est-à-dire qu'il fallait résoudre un problème pour ainsi dire insoluble. Celte chose impossible a été tentée sous la haute et remarquable direction de M. Alphand, et, ce qui paraissait n'ètre qu'un rève irréalisable, est presque un fait accompli. II. Dutert, l'éminent architecte, M. Contamin, ingénicur de la Compagnie, professeur à l'École des arts et manufactures, avec NII. J. Chrarton et Pierron, ingénieurs, qu'il s'est adjoints comme collaborateurs, ont exécuté un chef-d'œuvre. Le Palais des Machines sera, au point de vue de la construction, avec la Tour Eiffel, le plus grand attrait de l'Exposition. 11 a 429 metres de

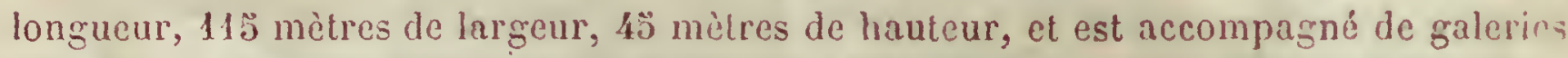
latérales de 15 mètres. Ces galeries latérules comportent un premier étage de 8 mètres de hauteur; elles sont rejointes à leurs extrémités par deux tribunes soutenues par des piliers métalliques. Le premięr étage sera desservi par quatre escaliers.

La charpente est constituce par une série de fermes métalliques d'une portée de $110^{\mathrm{m}}, 60$. Jamais pareille dimension n'avait été atteinte: les fameuses fermes métalliques de la gare de Saint-Pancras, à Londres, les plus grandes qui eussent été construites jusqu'à ce jour, n'ont que 73 mètres d'ouverture. C'est sur ces fermes que s'appuie toute l'ossature de la couverture, en zinc, sur les parties basses de la grande nef et sur les bas-cùtés; le reste du vaisseau central est en verre strié. Les fermes ont la forme d'ogives surbaissées, et sont articulées à leur base et à leur sommet. L'axe des pivots sur lesquels elles sont appuyées est au ras du sol. Des massifs de naçonnerie portent les sabots ou coussinets en fonte qui reçoivent la pression des arcs; ces massifs peuvent supporter une charge verticale de 412,000 kilogrammes et une poussée horizontale de $11: 5,000$ kilogrammes. Cette poussée horizontale, ayant pour but d'assurer le glissement des pieds des fermes, est arrêtée par l'ancrage des boulons des coussinets dans la maçonnerie.

Le terrain élant bon du côté de la Seine, la ligne des puits des piliers a été faite en maçonnerie, et les fondations ont eu lieu sur gravier. Les piles se composent d'un massif rectangulaire de maçonnerie de $7^{\mathrm{m}}, 07$ de long sur $3^{\mathrm{m}}, 50$ de large et $3^{-m}, 70$ de haut, reposant sur un plateau de béton qui a jusqu'à $1^{m}, 35$ d'épaisseur, arec une surface d'appui de $14^{\mathrm{m}}, 20$ sur $6^{\mathrm{m}}, \mathrm{50} 0$, soit une moyenne de 5 mètres de profondeur. Des travaux considérables ont du stre exécutés du côté de l'école militaire, à cause du mauvais état du sol, composé en grande partie de remblais. Dix piles ont été montées sur pilotis. Au-dessous des massifs précédents, on a battu 28 pieux en quinconce, par pile. Ces pieux ont une longueur de 9 mètres, et quelques-uns de 14, c'est-d-dire une moyenne de 20 mètres de profondeur; les boulons fixant les coussinets ont été ancrés dans la maçonnerie. Ces travaux ont été faits très rapidement: commencés le 3 juillet $\mathbf{1 8 8 7}$, ils ont été terminés le 21 décembre suivant.

Les difficultés que présentait le montage des fermes ont été vaincues de façon différente par les deux soumissionnaires, la Compagnie de Fives-Lille et la Société des anciens établissements Cail. Le système employé par la Compagnie de Fives-lille est fort original et fort rapide. L'ingénieur de cette compagnie, M. Lautrac, a imaginé un échafaudage qui se compose de trois grands pylônes. Ceux-ci, montés sur galets et se mouvant avec facilité, malgré leur dimension, permettent de monter chaque ferme en quatre tronçons pesant chacun près de 50 tonnes. On assemble d'abord et on rive sur le sol les morceaux constituant les quatre tronçons. On procède ensuite à la a mise au 
LES MERVEILLES DE L'EXPOSITION

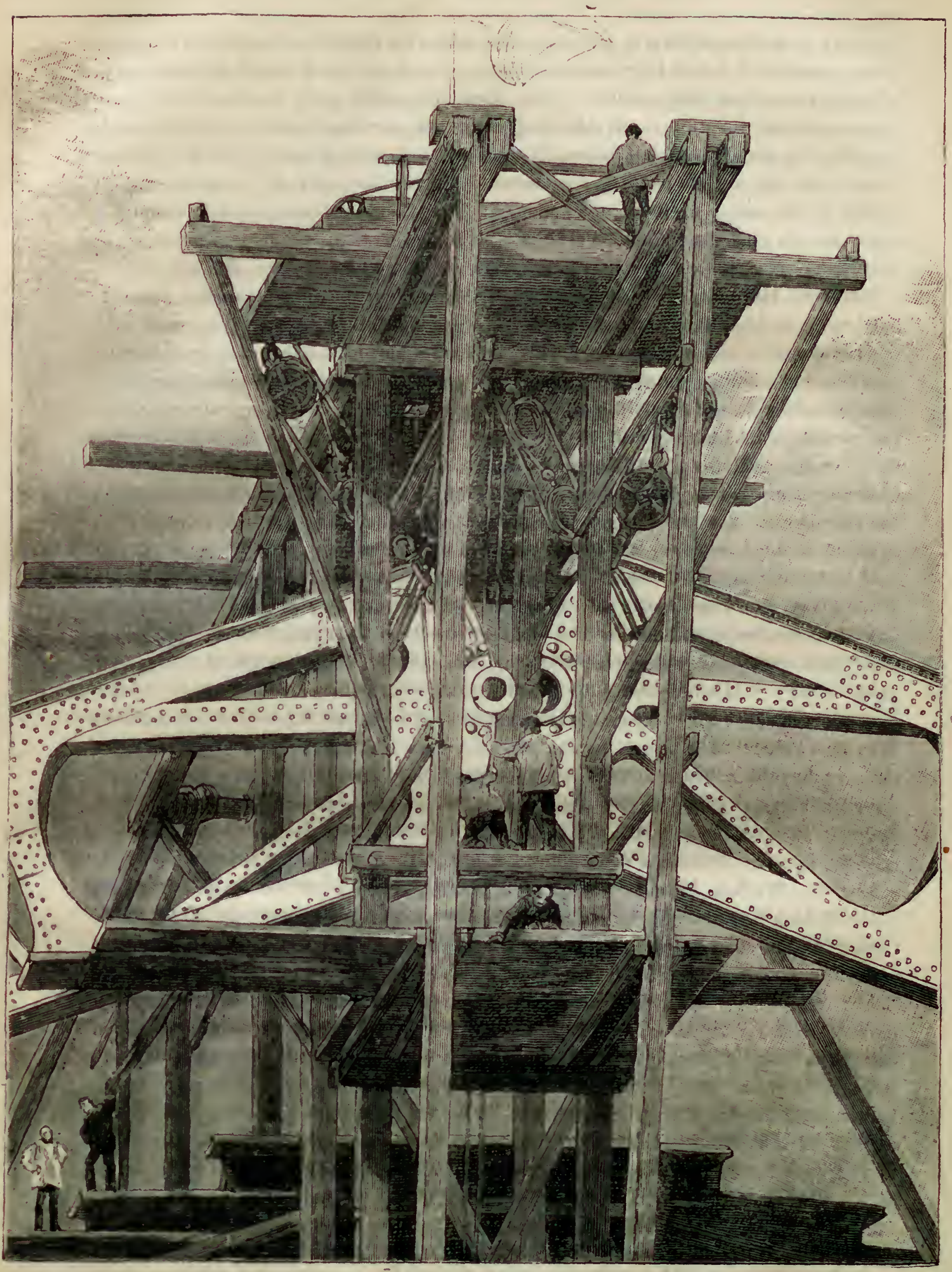

LA GALERIE DES MACLIXES: ASSEMBLAGE DU SOMMET D'UNF FERME.

Liv. 8.

MrRreilles Expositiox. 
levage de côté », c'est-à-dire qu'on soulève les pilier's des deux piesd au moyen de puissants palans, en les faisant pivoter autour de l'articulation inférieure. Quand ces deux masses métalliques sont mises en place dans leur position verticale, on procède à la "mise aù levage du milieu », c'est-ì-dire qu'on élève les deux tronçons de la partie médiane jusqu'à ce qu'ils atteignent le sommet de l'échafandage. Cette opération exige une précision mathématique et une véritable perfection daus tous les engins du levage. La vitesse ascensionnelle de ces tronçons, malgré leur poids considérable, est de dix mètres environ par heure; une fois les pylònes mis à l'emplacement voulu, il suffit donc de quelques heures pour élever dans les airs et faire ressembler à de légères armatures, ces masses de fer d'un aspect si lourd lorsqu'elles gisent sur le sol.

La Société des anciens établissements Cail procède différemment; au licu d'assembler sur le sol les pièces entrant dans la construction des divers tronģons des fermes, elle les assemble par petiles fractions ne dépassant pas trois tonnes environ, sur un plancher continu formant cintre, supporté par sept pylònes; sur ce cintre sont installés tous les appareils et engins de levage dont les dispositions, ainsi que l'échafaulage lui-mème, ont été étudiés par Mr. Barbet, l'ingénicur en chef de la Société. 7 millions 1/2 dekilogrammes de fer ont été employés pour la construction totale de la granle galerie centrale. Des ponts roulants seront installés dans l'intérieur de la galerie centrale et sur les galeries latérales, de sorte que les visiteurs pourront suirre sans fatigue les expositions diverses qui seront établies dans la grande nef.

La décoration intérieure de la partie basse de la couverture a été confiée à Ni. Jambon, de la maison Rubé, Ghaperon et Jambon, qui a composé pour cela 124 panneaux représentant les armoiries et attributs de chacun des départements français, des colonies et des principales capitales des pays étrangers. Ces remarquables peintures couvrent un espace de $\mathbf{1 8 , 0 0 0}$ mètres carrés.

Palais des Beaux-Arts et des Arts lumeracx. - Le Palais des Beaux-irls est situé le long de l'avenue de la Bourdonnais, celui des Arts libéraux s'étend parallelement à l'avenue de Suffren. Ces deux palais sont l'œuyre de M. Formigé, un des trois architectes des buitiments du Champ de Mars, et dressent, à 36 mètres de hauteur, leur élégante coupole. Ils ont chacun une longueur de 230 sur 83 mètres de largeur. Mt. Formigé a voulu que l'ossature des deux édifices restat risible. Seuls. les interstices de fer seront bouchés au moyen de briques, afin d'assurer suftisaminent l'intérieur des palais contre les intempéries. Tous les fers apparents seront revetus d'une teinte bleu-rert pâle, et les coupoles seront recouvertes de briques énaillées, jaunes, blanches, rouges et bleues, dont l'effet sera certainenient des plus agréables. Le Palais des Beaux-Arts offre une aimable hospitalité à tous les artistes des pays étrangers qui participeront à l'Exposition de 1889; ils seront traités sur le pied d'égalité avee les exposants français. Dans le Palais des Arts libéraux, M. Sédille, l'architecte chargé du lotissement et de l'installation des exposants, a construit dans toute la longueur de la nef centrale une sorte de palais intérieur, en bois sculpté. divisé en sections diverses, avec façades, cadres, vitrines, galeries ouvertes et terrasses reliées par des passerelles aux galeries du premier étage. Cette construction élégante est destinée à receviir l'Erprosition rétrospective du tratail et des sciences anthropologiques, qui sera certaimement l'une des curiasités de l'Exposition de 1889. M. Jules Simon, qui a été choisi pour présider la commission chargée de son organisation, en a défini le caractère daus une circulaire dont voici le passage le plus saillant : a L'Expusition rétrusplnctive dn travail 
et des sciences anthropologiques qui est projetéc pour 1889 a pour but, dit-il, d'initier le public à l'histoire des procédés du travail manuel et du travail mécanique qui, à traver's les siecles, ont abouti à l'outillage industriel moderne des arts et métiers. Cette exposition a surtout un caraclère historique et technique; elle est loin d'exclure les objets d'art; car à plusieurs époques, les outils, ceux surtout qui servaient aux arts libéraux, ont été de véritables bijoux, soit par l'élégance de la forme, soit par la richesse des matériaux ou la grace des détails. On trouve des chefs-d'œuvre sur une carte géographique, sur le manche d'un ciscau, sur le canon d'un fusil. Nos ancêtres n'avaient pas la mème passion que nous pour la rapidité et le bon marché. L'industrie y perdait; les arts en profitaient. Notre exposition, en présentant ces chefs-d'œuvre, ne peut que gagner en éclat et en agrément. Les musées d'Ĺtat, les collections municipales, les ugagasins de nos grandes usines, renferment un nombre considérable d'appareils complets ou d'organes d'appareils intéressants, dont la remise en état serait peu conteuse et qui seraient les éléments fondamentaux de l'exposition qui se prépare. L'exposition, à son tour, en appelant l'attention des érudits et des artistes, peut provoquer d'utiles découvertes, et mettre au jour des mervilles oubliées. A côté de l'outil, ¿̀ côté de la machine, pourront ètre exposés des objets d'aspect décoratif, à la fabrication desquels ces outils et ces machines auront concouru, pourvu toutefois que ces objets aicnt une valeur d'art ou une importance historique. o

Arrètons-nous un instant sur cette curieuse exposition du travail et des sciences anthropologiques. Liidée en avait été émise déjà en 1867, et, a cette époque, le ministre d'Étit avait institué une section de l'Fxposition destinée à recevoir les objets produits depuis les temps les plus reculés jusqu'à la fin du xvin ${ }^{8}$ siècle. Prenant en considération cette pensée utile et pratique, l'article 5 du règlement général de l'Exposition de 1889 a institué une Exposition rétrospective de l'histoire du travail. Le programme de l'Exposition rétrospective de 1867 établissait, pour la partie française de celle-ci, un classement correspondant à dix époques bien tranchées :

$1^{\circ}$ La Gaule avant l'emploi des métaux;

2. La Gaule indépendante;

$3^{\circ}$ La Gaule pendant la domination romaine;

4. Les Francs jusqu'au sacre de Charlemagne (800);

$\dddot{3}^{\circ}$ Les Carlovingiens, du commencement du $\mathrm{IX}^{\mathrm{e}}$ siècle jusqu'à la fin du $\mathrm{xi}^{\mathrm{e}}$;

$6^{\circ}$ Le moyen Age, du commencement du $\mathrm{xu}^{\mathrm{e}}$ siècle au règne de Louis XI inclusivement (1483);

$7^{\circ} \mathrm{La}$ Renaissance, depuis Charles VIII jusqu'à la mort de Henri IV (1610);

$8^{\circ}$ Les règnes de Louis XIII et Louis XIV (1610 à 1715);

$9^{\circ}$ Le règne de Louis $\mathrm{XV}$ (1715 a 1773);

$10^{\circ}$ Le règne de Louis XVI et la Révolıtion (1775 à 1800).

Les nations étrangìres étaient invitées à prendre part à cette Exposition, en adıptant un classement conforme au dévoloppement historique de leurs civilisations resper:ives et de Peur travail national. Tout en présentant un intérêt réel, surtout au point de vue alrchéologique et de l'art rétrospectif, celte section de l'Exposition de 1867 ne tint pas tout ce que les principes de son organisation semblaient promettre, car les amateurs qui consentirent à preter leurs objets formant collections ne se soumirent pís volonticrs ì la division que comportaient les prescriptions de l'ordre historique et chronologique: 
En 1878, un nouvel appel fut adressé aux collectionnenrs, pour l'organisation d'une Exposition historique de lart ancien, dans les ailes du palais du Trocadéro. On arriva à grouper des objets anciens très remarquables, lant au point de vue historique qu'au point de vue du mérite récl. On avait adjoint une Errpnstinn ellonographique, conçue dans le but de mettre sous les yeux du public un tahlean de la marche de la civilisation à travers les àges et de ses développements successifs dans les différentes contrées du globe. LExposition historique de l'art ancien et le Musée ethnographique ont formé, en 18 $\mathbf{8}$, un ensemble magistral; le sucès obtenu a été éclatant, gritce ì

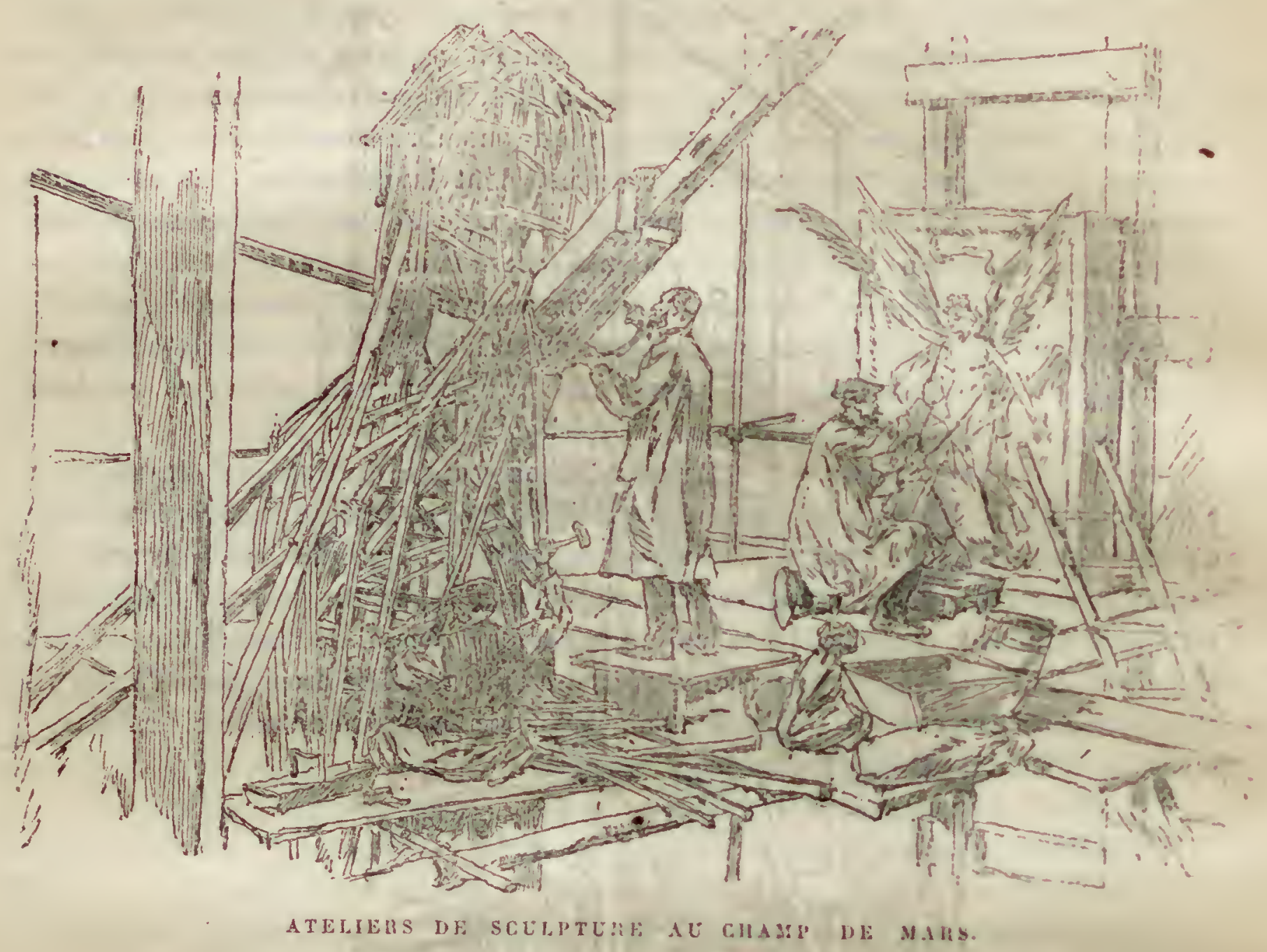

l'empressement des collectionneurs, dont la bonne volontí aurait pu être mise en doute après tant d'expositions rétrospectives de Beaux-Arts, oi leur concours avait été sollicité, depuis la plus importante de toutes, ouverte en 1873, dans les salons de la présidence du Corps législatif, au profit dela Société des Alsiciens-Lorrains. Quoi qu’il en soit, il suffit de jeter les yeux sur la nomenclature ci-après des dix sections entre lesquelles ont été répartis les objets admis en 1878, ponr rester convaincu que cette Exposition eut, de nouveau, pour élément essentiel, l'art rélrospectif proprement dit.

$1^{\text {re }}$ section. - Art rétrospectif et antiquités des Ginllos;

$2^{\mathrm{e}}$ section. - Sculpture antique, du moyen age et de la Renaiss nce; glyplique;

$3^{e}$ section. - Numismalique gauloise el moyen Age; médaillons; sigillographie;

4 e section. - Céramique du moyen ảge, de la llenaissance; faïence; porcelaine;

$3^{e}$ section. - Manuscrits; livres incunables, dessin, reliure;

$6^{\text {e }}$ section. - Armes, armures;

$7^{e}$ scction. - Orfèveric, iroire, cristaux, bijoux; 
$\mathbf{8}^{8}$ section. - Ameublement, étoffes, tapisserie;

ge section. - Ethnographie des peuples étrangers à l'Europe;

$10^{\circ}$ section. - Instruments de musique.

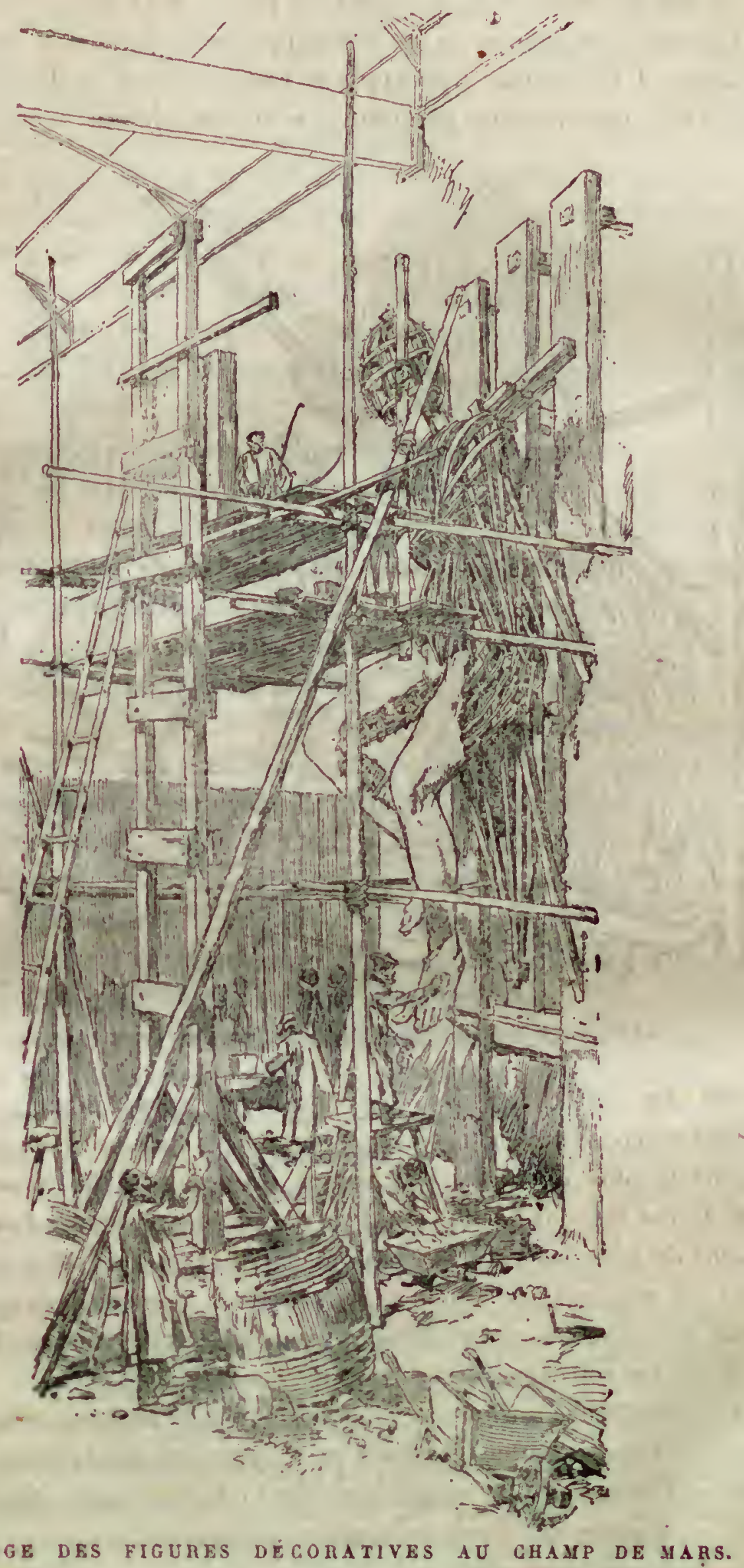

Cette répartition avait été arrètée surtout en vue de l'admission des objets, et ceux-ci devaient ètre rangés dans les salles; suivant des séries surtout chronologiques, comprises entre les temps anciens et le commencement du xix siècle. Liordre 
d'exposition ainsi réglé a été maintenu aussi rigoureusement que possible, mais les comités d'installation se sont trouvés trop souvent impuissants devant la volonté des prêteurs, qui désiraient maintenir leurs collections dans leur intégralité, si disparates d'espèce et d'époques que pussent en être les pièces. Il appartient à l'Exposition de 1889 de réaliser ce qui n’a pu etre accompli avant elle. 11 ne saurait plus être question d'une exposition rétrospective d'œuvres d'art pouvant ètre la répétition, sous une forme quelconque, de ce qui a déjà été fait; il faudrait, en effet, extraire les éléments constilutifs de cette exposition de collections souvent mises a contribution et qui n'ont, pour ainsi dire, plus rien a révéler, parce qu'elles n'ont pas eu le temps de s'enrichir, dans une mesure suffisante, de morceaux nouveaux à montrer.

L'Exposition rétrospective du travail, en 1889, ne saurait avoil qu'un but très défini : celui de retracer à grands traits, au moyen de la production de documents el de monuments authentiques, les étapes du grénie de l'homme. Obéissant successivement au souci défensif de sa vie animale, a la recherche de son bien-être et de sa richesse, it l'idée de l'avancement économique et social, l'lomme a fait parcourir aux moyens et aux méthodes de son travail purement manuel d'abord, secondé ensuite par l'arme, outil des Ages primitifs, et simplifié progressivement, pendant les époques hisloriques, grâce à l'emploi des instruments dont le perfectionnement a abouti a la création des engins mécaniques industriels de notre siècle, une route qu'il importe de suivre sous les yeux de nos contemporains. Pour atteindre ce résultat, il était nécessaire d'associer à l'Exposition rétrospectice du tracail celle des sciences anthropologiques, afin de faire voir, pour commencer, thomme tel qu'il est sorti des mains de la nature, dans les formes physiques des différentes races.

Lhistoire primitive du travail de l'homme sera ensuite retracée au noyen des découvertes de la paléoethnographie ou archéologie préhistorique qui, dans les sciences anthropologiques, forme l'introduction de l'ethnographie proprement dite, classée comme la deuxième division de ces sciences, dont l'anthropologie physique est la première.

L'anthropologie physique ou technique ferait une part auvivant en prisentant les types reproduits par les arts de la plastique et du dessin: bustes, maśjues, etc., cllemontrerait ensuite le crâne, laboratoire de la pensée et de l'esprit de découverte, avec le squelette qui est la machine articulée naturellemiseau service exécutif des conceptions issues de l'enveloppe cérébrale. L'ethnographie associerait ses enseignements aux démonstrations résultant de l'exposition méthodique des organes mécaniques et des objets industriels d'autrefois; elle constaterait ainsi la filiation séculaire rétrospective des produits modernes réunis dans l'Exposition internationale du Champ de Jars.

Les recherches nécessaires pour arriver à constituer matériellement l'Lxposition rétrospective du travail pendant les siècles antérieurs à la publication de l'Eucycloppro die furent longues et pénibles, mais avec le temps, la science et la bonne volonté de tous, on ne pouvait qu'obtenir des résultats très intéressants. Un comité spécial, institué le 12 octobre 1887, prépara et organisa l'exposition projetée.

A partir de 1789 , la tâche des organisateurs devenait plns aisée et la démonstration plus significative. Malggré la différence ou l'antagonisme des institutions politiques les différentes nations, la date de 1889, personne ne peut y contredire, est l'anniversiire d'un fait aussi bienfaisant pour l'humanité que glorieux pour la France. Le principe de l'égalité civile, proclamé en 1789, s'est imposé au monde en fondant nniversellement la richesse industrielle et commerciale, c'est-à-dire en mettant au service du travail 
universel l'intégralité des capacités ct des forces. C'est donc à partir de 1789 qu'il fallait accumuler les leçons de choses, leçons destinées à apprendre aux visitcurs de l'Exposition comment s'est formé par la science et ses applications, par la pratique professionnelle, par le dévcloppement du génie de l'homme, lc merveilleux outillage actuel des arts ct méticrs du monde. En élablissant des séries dont les points de départ seraient les appareils mèmes qui sont sortis des mains des invcnteurs et de leurs successeurs immédiats, appareils dont certains existent encore ou dont la connaissance peut exactement s'obtenir par des documents graphiques de l'époque, on arriva à constituer une sérí centenale d'objets curieux choisis, comme espece et comme nombre, de façon à retrace matériellement et à grands traits la marchc du xrxe siècle dans le domaine de la scicnce appliquée et de l'industrie proprement ditc. Là sera véritablement le vestibule historique de l'Exposition de 1889, vestibule subdivisé en cinq grandes salles: anthropologie t: ctlınographie, arts libéraux, arts ct métiers, moyens de transport, arts militaires.

L'Exposition de l'habitation, préparée par M. Charles Garnier, sera particulièremont intércssantc. Il s'agit, on le sait, de donner les types successifs de l'habitation humainc depuis l'antiquité jusqu'à nos jours : la maison assyrienne s'y montrera à côté de celle du Chinois, celle du civilisé à côté de la hutte préhistorique ou de la cabane du sauvage de l'Afrique ou de l'Océanie. De là, des points de comparaison émincmment suggestifs, non seulement pour le curieux, mais pour le savant en us, qui nc sera pas médiocrement ravi de voir s'élever de toutes pièces la maison dc ces Grecs ou de ces Romains dont il étudie chaque jour les moeurs dans ses livres. Ce sera l'expérience succédant à la science livresque.

Nous nc faisons ici qu'une sorte de revue générale, mentionnant au hasard ce qui nous paraft offrir dès maintenant un intérêt pour nos lccteurs, nous réservant de décrire dans tous leurs détails les sections diverses, françaises et étrangères, de l'Exposition. Disons cependant quelques mots de l'Esplanade des Invalides.

On verra sur l'Esplanade lcs expositions de l'Algérie, de la Tunisie et des pays de protectorat, lc Palais international de l'Hygiène, l'Exposition rétrospective de l'Art militaire organiséc par lc Ministère de la Guerre, les pavillons de l'île Maurice, du Transvaal ou République Sud-Africaine, un village des Indes néerlandaises, enfin ce curieux panorama de "Tout-Paris, dont nous avons parlé plus haut. Le Pavillon gastronomique s'élèvera vis-à-vis du quai d’Orsay, à l'extrémité gauche de l'allée transversale de l'Esplanade. Lcs fondations en sont faites, les pilotis sont posés, et, dans une quinzaine de jours, la charpentc en fer va s'élever sur les madriers d'appui. En face de cc batiment, qui pourra contenir six cents personnes, se dressera le Pavillon des Postcs et des Télégraphes, dont la charpente est déjà suffisamment ébauchée pour permettre de devincr ce que sera la construction.

A la suite se trouve le bdtiment réservé au IInistère de la Gucre, et qui se compose d'un rez-de-chausséc haut de 8 mètrcs et d'un premier étage qui ne mesure pas moins de 7 mètrcs. L'avant-corps principal est dejà presque terminé. Pour l'architecture de cc palais, on s'est inspiré du style Louis XIV. Le fronton du grand portique d'entrée est décoré de bustcs des gucrriers des diffẻrentes époques. Dans la galerie de gauche, on installera unc Exposition de la métallurgie militaire, la première de ce genre. du prenier étage, divers exposants scront autorisés à exposer leurs produits. Au milieu, dans le grand vestibule central, seront tous les objcts d'art et de curiosité ayant trait à l'art militaire. L'ailc droite du pavillon sera exclusivement réservée à l'Exposition 
moderne du Ministère de la Guerre, et à l'étage supérieur sera l'Exposition rétrospective. En facede l'avant-corps principal du Palais central, une porte de style moyen âge donnera accès aux colombiers militaires. Enfin, en arrière du palais, sous les arbres, les hangars de l'aérostation et la télégraphie.

De l'autre cóté de l'allée transversalese dresse le Pavillon de l'Algérie, de style arabe,

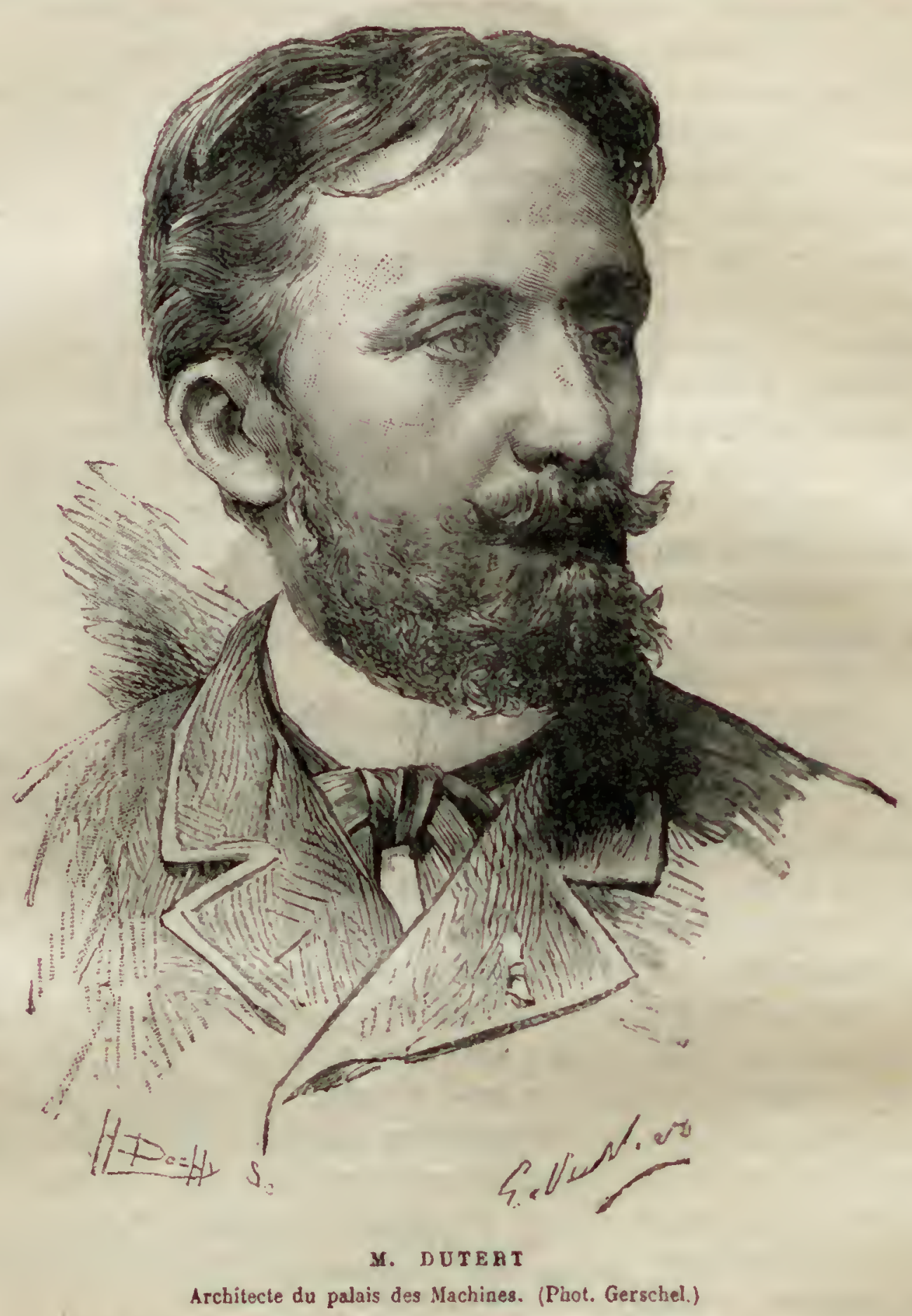

construit de fragments de monuments célebres de notre colonie. Dans la cour d'entrée, d droite, d'innombrables bibelots indigènes formeront un bazar, après lequel un vestibule surmonté d'un dôme mosaïque conduira à la grande salle de réception. Un escalier donnera accès au minaret. - Vient ensuite la section tunisienne, aux blanches tourelles, et le grand Palais central ou figureront les produits des pays exposants, pour lesquels des bâtiments spéciaux n'auront pu être édifiés. Au sein de ce palais se grouperont les pavillons coloniaux.

A gauche du Palais central est le pavillon cochinchinois, élevé par des indigènes, Annamites et Chinois au torse nu, à la peau jaune et à la natte entortillée autour d'un 
crine rasé. Ce pavillon sera peint en rouge, bieu, vert et or, mais avec les teintes spéciales que nous admirons sur les pagodes chinoises, ce qui contribucra à lui donner un aspect d'une originalité saisissante. Les ornements seront absolument surprenants.

A droite du Palais central, les pavillons de l'Annam et du Tonkin. A gauche de la Cochinchine, la pagode d'Angkor, la résurrection de la curieuse architecture khmer;

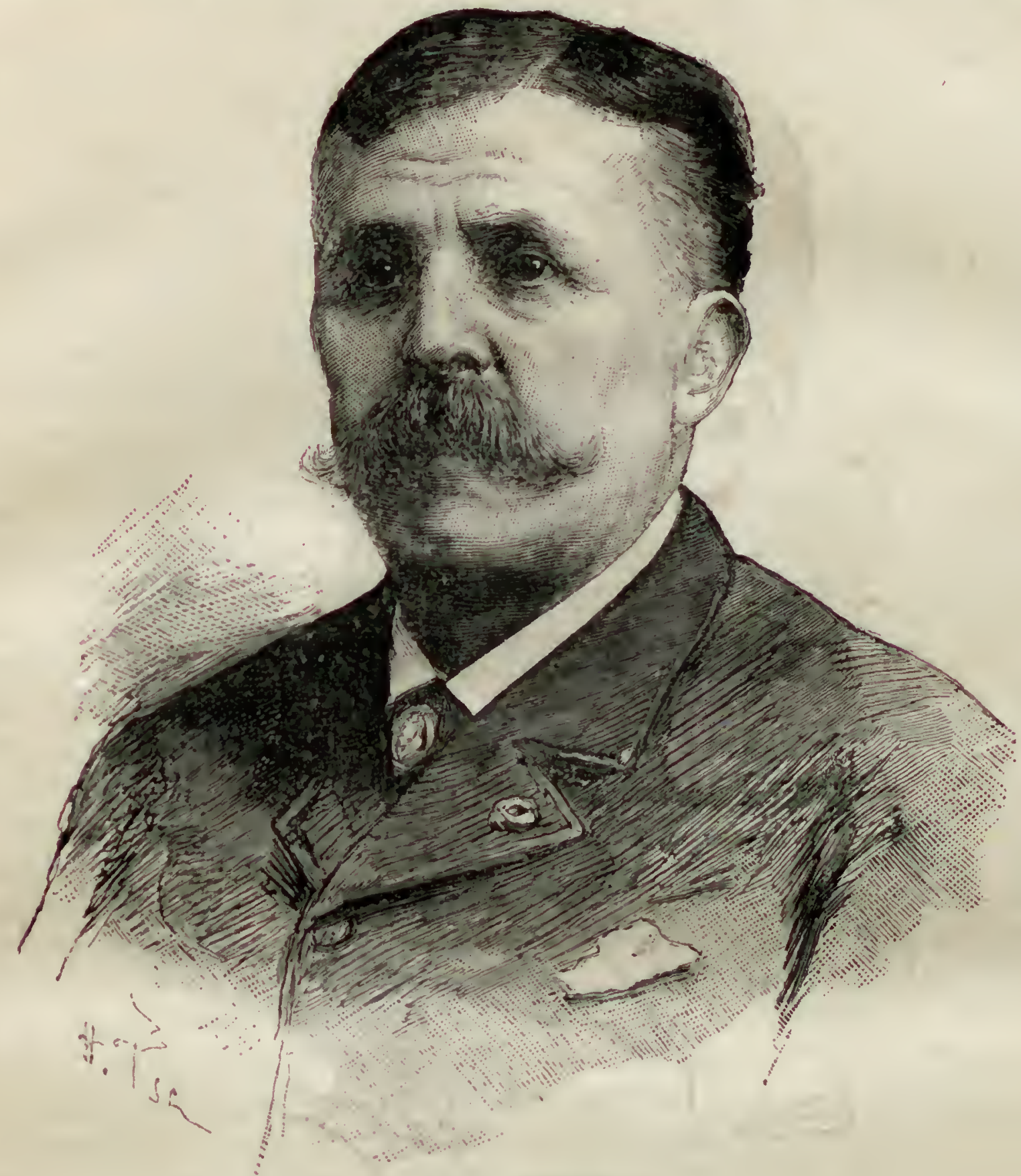

14. G. BERGER

Dírecteur général de l'Exploitation.

puis, un hameau de l'Inde; puis, un restaurant créole; puis, un village sénégalais et des villages du Congo, de la Nouvelle-Calédonie. Comme annexe, on installe un théatre annamite, avec une sallespéciale où l'on jouera sa partie d'échecs, 32 Annamites devant servir de pions!

Décidément, l'Esplanade des Invalides ne sera pas la région la moins attrayante de l'Exposition de 1889.

Les Expositions d'horticulture seront centralisées dans les Jardins du Trocadéro. Le Japon a demandé pour exposer ses plantes et ses fleurs un emplacement de 1,600 mètres !

LI\%. 9 . 
Nous ne saurions mieux terminer ce chapitre qu'en donnant quelyues noles biogrnphiques sur les organisateurs de l'Exposilion.

Trois ministres se sont succédé au ministère du Commerce, et par consé́puent au Commissariat général de l'kxposition, depuis que celle-ci est entrée dans la période d'exécution: M. Lockroy, M. Dautresme et M. Pierre Legrand.

11. Lockroy, né à Paris en 1838, est député de Paris. Il a été le secrétaire de M. Renan. qu'il a accompagné en Phénicie, el il a pris part, sous les ordres de Garibaldi, à l'expédition de Sicile. Journaliste, il fut élu pour la première fois député en 1871 et il ne cessa depuis ce temps de faire partie des Issemblées délibérantes. M. Dautresme es iugalement député, et M. Legrand représente à la Chambre le département du Nord.

La Direction générale des Traraur a à sa léte .I. Alphand. It. J.-Chinles-Adolphe Alphand, administrateur et ingénieur, est né à Grenoble en 1817. Sorti de l'École polytechnique en 183i dans les Ponts et Chaussées, il fut envoyé à Bordeaux en 1839 et pendant quinze ans fut chargé des ponts, des cbemins de fer et des landes dans la réerion. Nommé en 1843 ingénieur ordinaire des Ponts et Chaussćes, il fut appelé en 18.31 ì Paris où il reçut le titre d'ingénieur en chef des embellissements de cette ville. Il cut successivement la direction des promenades el plantations, de l'éclairage, des cuncessions sur la roie publique et des voitures. Dans son service se trouraient les hois de Boulogne et de Vincennes, transformés en pares, les buttes Chaumont si merveillensement aménagées, les Champs-Élysées, la multitude de squares qui ornent anjourl' hui la plupart des quartiers de Paris. Lors de I'Exposition universelle de 1867, .1. Alphand fut chargé de l'importante opération du nivellement du Trocadéro. dont il enrploya les terrains à remblayer le Champ de Mars. En 1878, après la nort de M. Belgrand. il devint directeur des Eaux et des Égouts. Cette méme année, il prit une part considí. rable aux travaux de l'Exposition universelle comne membre de la Commission supérieure des Expositions. Enfin, en 1886, il a été choisi pour les fonctions délicates de Directeur général des Travaux. Comme souvenir des grands travaux exécutís sous scs ordres, M. Alphand a entrepris une luxueuse pulslication intitulée Les Promenalies de Paris 1867- ¡3, 2 vol. in-folio). Comme l'a dit si justement M. Yriarte, son ourre est un livre que tous les Français, à toute heure, peuvent ouvrir et feuilleter, un tahlenu qui se déroule incessamment devant nous : celui du Paris moderne.

M. Bartet, ingénicur en chef adjoint au Directeur gênéral des Travaux, est né en 1842. Sorti de l'École polytechnique, il résida successiveınent comme ingrinteur, it Prades, à Montauban, a Chartres, et en 1872 fut nommé ingénieur de fre classe de la ville de Paris. En cette qualité, il collabora à tous les grands travinx et a tou les embellissements de la capitale. Aussi, en 188?, le Conseil municipal de 'aris étalılit-il exprès pour lui le poste d'ingénieur en chef des promenades et plantations, précédemurent occupé par M. Alphand. Cest lui qui a dirigé les travaux d'aménağement du cimetière de Pantin et les travaux de soutènement de la butte Montmartre. Une mort prématurée l's empêché de prèter à M. Alphand le précieux concours de son activité et de son savoir.

M. Bouvard, architecte, est né dans le département de l'Isère en 1830. Éléve de Cons. tant Dufeux, il fut associé aux travaux exécutés par lui aụ Panthéon, àl'lícole de droit, au Palais du Luxembourg. Inspecteur des travaux de Paris, puis architecte du service de la Ville depuis $\mathbf{1 8 7 9}$, il travialla à l'église Saint-Laurent, al la mairie du X.' arrondissement, au Thédtre Lyrique. Il construisit aussi le pavillon d'expusition de la ville de Paris en 1878 , la caserne de la garde républicaine sur le boulevard Mlorland, l'Ecole 
d'enseignement professionnel de Voiron, le piédestal de la statue d'Alexandre Dumas sur la place Malesherbes. Architecte du gouvernement, architecte-conseil de la Compagnie du chemin de fer Paris-Lyon-Méditerranée, expert près du tribunal civil de la Seine, M. Bouvard a été nommé chevalier de la Légion d'honneur en 1878, et officier d'académie en 1883 .

M. Dutert, inspecteur général de l'enseignement du dessin, qui dirige les travaux du Palais des Machines, est né à Douai en 1840̈. Entré à l'Ĺcole des Beaux-Arts à l'âge de dix-neuf ans, il y eut M. Lebas comme professeur, et ne tarda pas à s'y faire remarquer. L'Académie des Beaux-Arts lui décerna le prix Achille Leclerc en 1866 , et trois ans après il obtint le grand prix de Rome. En 1868, il avait envoyé au Salon un Projet de bains publics et un Projet de tribunal de première instance. Il exposa au Salon de 1869 un projet représentant un Quartier de caralerie. Il s'occupa aclivement d'études archéologiques pendant son séjour réglementaire en Italie. En 1875, lorsqu'il rentra à Paris, il fut nommé auditeur au Conseil général des bâtiments civils et inspecteur des travaux de la rédification de l'llòtel de Ville de Paris. Cette même année le jury du Salon lui décerna une médaille de première classe pour son envoi du Forum romain sous les Antonins, restauré, du Forum triangulaire de Pompéi et des Etudes dé aicoralions antiques. Ces ceuvres remarquables lui valurent encore le prix biennal des hautes études d'une valeur de 4,000 francs, décerné par l'Académie des BeauxArts. En 1876, M. Dutert a exposé un projet d'une Académie de commerce, et en 1877 la Porte Son-Spritilo à Rome et l'Arc de Titus à Rome. En 18is, il soumit au jury d'Lxposition le Forum romain sous les Antonins, les Études de décorations antiques, le Palais public des Césars sur le mont Palatin et une Académie de commerce qui lui valurent une première inédaille. Lors de la réorganisation de l'enseignement du dessin dans les écoles des différents degreés, M. Dutert en a été nommé inspecteur en 1879 et directeur en 1881. Quand le ministère des Arts fit de nouveau partie du ministère de I'Instruction publique, il fut, par suite du remaniement du personnel, nommé inspecteur principal du dessin. En 1886, il fut nommé architecte pour l'Exposition de 1889 à la suile d'un concours dont il avait obtenu le premier prix. En 1876, M. Dutert a publié un intéressant ouvrage intitulé : le Forum romuin et les Forums de Jules César, d'Augusle, etc. (Paris, 1876, in-fol.); il est officier de l'Université et chevalier de la Légion d'honneur.

II. Formigé, architecte de !'Hôtel de Ville, qui a été chargé de la construction des Palais des Beaux-Arts et des Arts libéraux, est né au Bouscat, près de Bordeaux, le 2.4 juillet $18 \%$. Élève de Laisné, il a obtenu une médaille de troisième classe au Salon de 1873 , une de deuxième classe en 1876 et 1878 , la médaille d'honneur en 1881 et lí croix de chevalier de la légion d'honneur en 1883. Parmi ses plus remarquables tritvaux, qui ont figuré aux Salons annuels, nous citerons: la Cheminée du Palais dlu

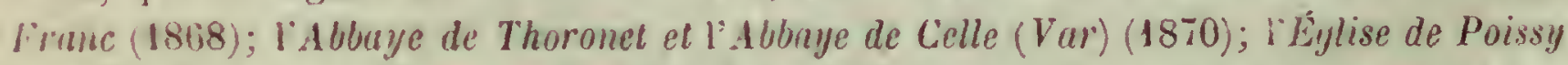
el l'bylise de Suint-Honorien (Seine-et-Oise) (187.t); Projet de restauration de l'éylise de Comques (Aveyron) (1873); I'Abbaye de Saint-ILartin de Canigon (1870); Église etcloitre d'Arles (Pyrénées-Orientules)(1877); Une fontaine monumentale (1878); Restes du temple de Vernègues (Bouches-du-Rhóne) et Pont-Julien (Vauchuse) (1879); Restauration de l'Église de Conques (1880); Eglise de Coustouges et projet de monument commémoratif lle l'Assemblée Constitnante, 1 is! (1881), projet adopté à la suite d'un concours; Restauration de Notre-Dame-la-Grande (Puitiers) (1882); Are de triomphe de Saint-Remy (1883); 
Église de Cormelia del Conflent (1884); Esquisse d'un monument commémorulif de 1789 à ériger an Chump de Mars (188̈̈).

A côté de MM. Dutert et Formigé, nous devons citer II. Bernard, architecte, qui a participé à la construction des palais bordant le Champ de Mirs; M. Contamin,

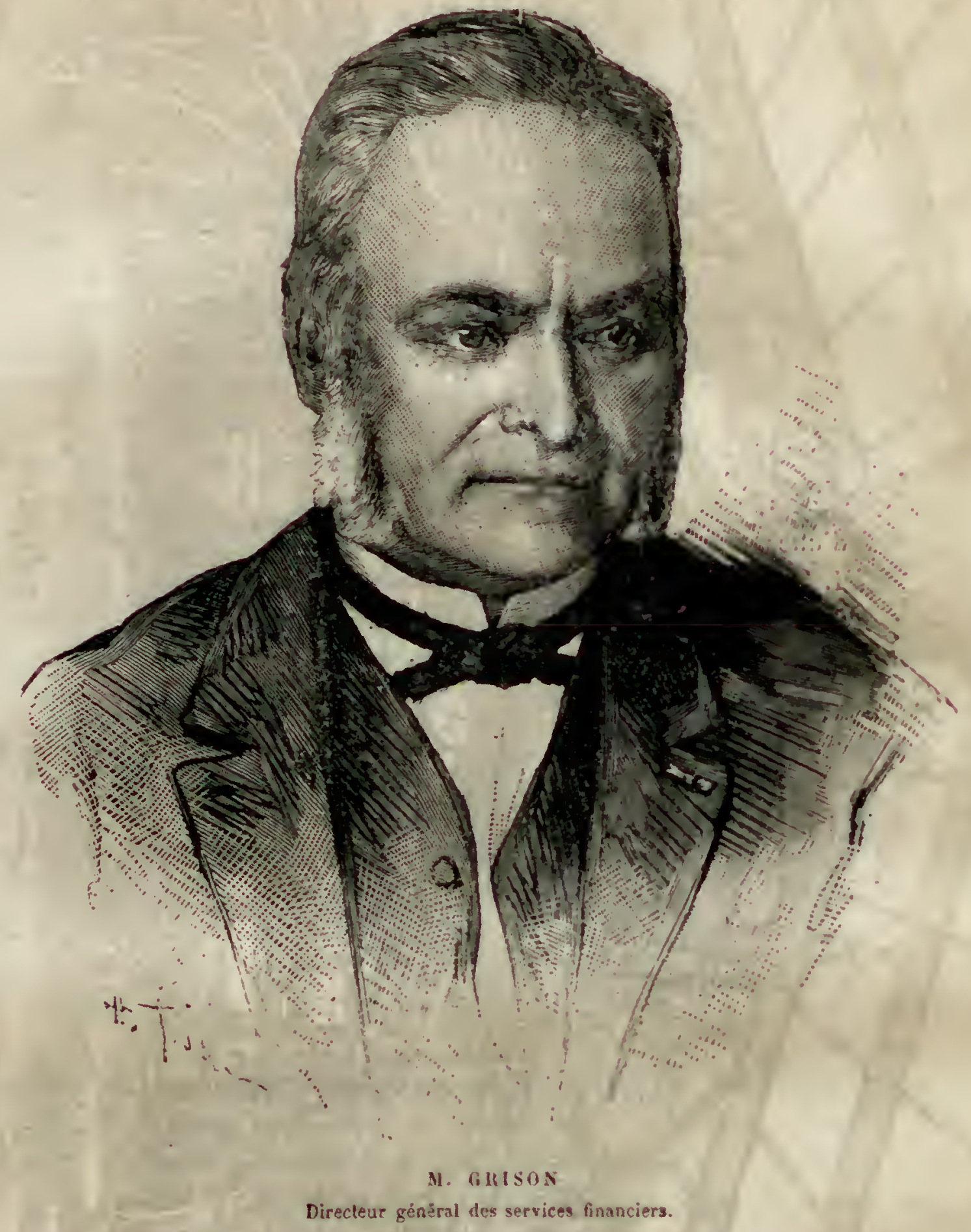

Ingénieur en chef du contròle des constructions métalliques; M. Jules Charton, ingénieur en chef-adjoint dudit contrôle; M. Pierron, ingénieur; MM. Laforcade et Lion, chargés des plantations.

La Direction générnle de l'Explaitution a il sa tete M. Georges Berger. M. Berger, né à Paris en 1834, débuta comme ingénieur des mines, mais il ne tarda pas à délaisser cette carrière pour se vouer aux beaux-arts vers lesquels l'entralnait une irrẻsistible vocation. Ce goút se développa encore á la suite de voyages qu'il fit à plusieurs reprises en Europe et en Orient. II y acquit une érudition très variée, très profonde, et une compétence telle que le Gouvernement lui confia la direction de la section 


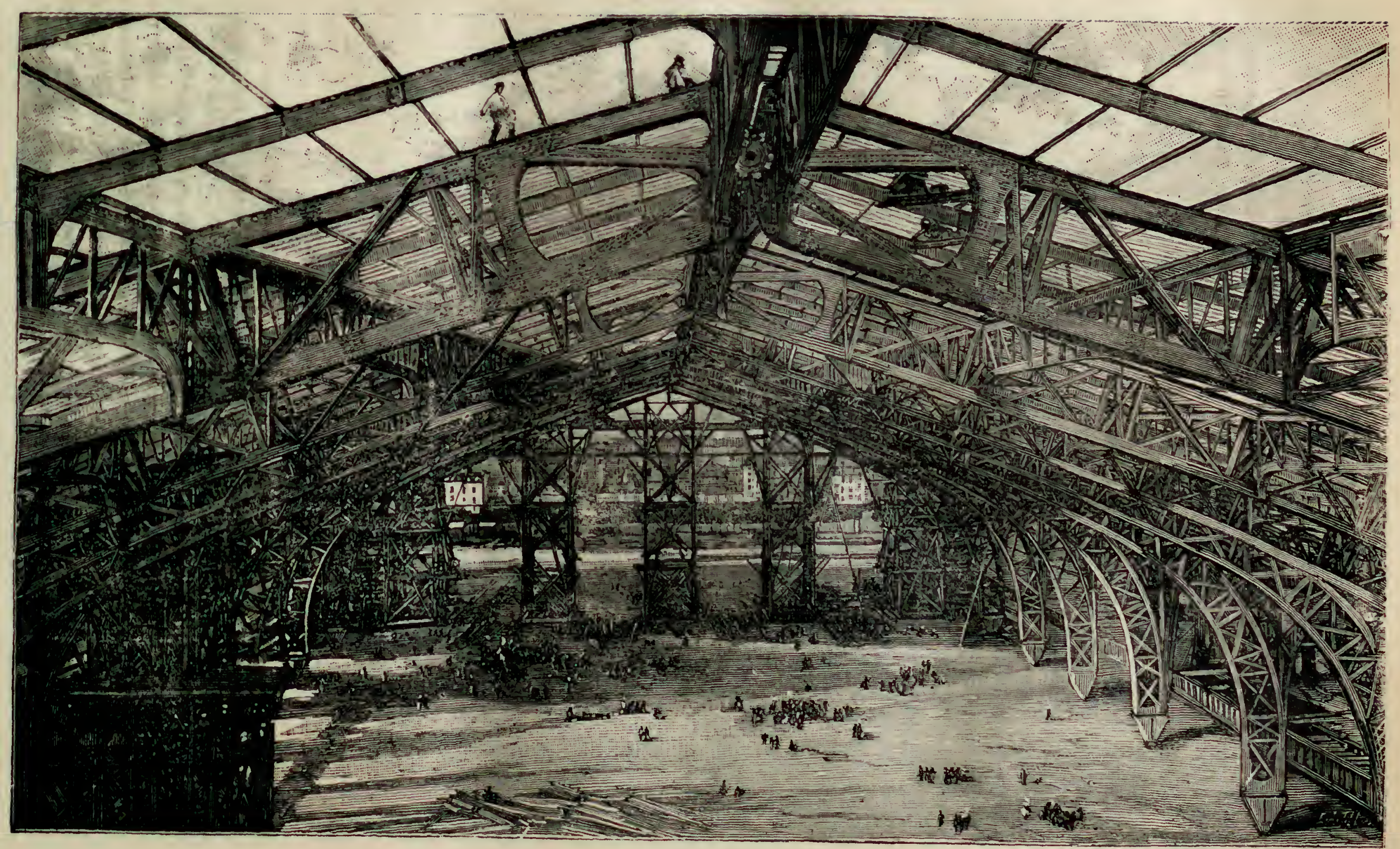


étrangère lors de l'Exposition de $186 \pi$. Il reçut la mème mission en 1878, et enfin en 1889 on lui donna la Direction générale de l'Exploitation. Indépendamment de ces Expositions officielles, il a organisé en 1874 une Exposition artistique au profit des Alsaciens-Lorrains. En 1876-7T, M. Georges Berger a été professeur suppléant d'art et d'esthétique à l'École des Beaux-Arts. Il a publié en $188 \%$ deux volumes dans lesquels il a exposé ses vues relativement it la grande manifestation de 1889 , et on hi doit un remarquable ouvrage sur l'École française de peinture depuis les origines jusqu'a la fin du règne. M. Berger est assisté de MII. Thurneyssen, Ossude, Legrand, Liton, Melehior, Monthiers, Giroud, de Moulignon, de Lacretelle, Halphen, Vigreux, Boumerc, elc., ce qui ne l'empèche pas de se donner corps et atme ì son cuvre et de ne se reposer que sur lui de toutes les affaires importantes. Ingúnieur, économiste et estheticien, voilit de nombreux talents réunis chez un mème homme. Joignez à cela que II. Herger est un orateur accompli.

Le souci et la gestion financière ont été laissés ì M. Grison, administrateur habile. Ce n'est pas la tâche la moins ardue ni la moins délicate.

Nous arrivons à M. Eilfel, né à Dijon, dans la Cûte-d'Or, en 1832. Sorti de l'École centrale en 183̈3. M. Eiffel appliqua à la construction du pont de Borleaux le systime des fondations de piles de pont à l'air comprimé. Il construisit ensuile le pont de la Nive, à Bayonne, et ceux du réseau central, à Capdenac et à Flurac. En 1867, M. Kranlz, Commissaire général de l'Exposition, lui confia les ares de la galerie des Machines, et c'est à ce moment qu'il fixa le module d'élasticité des pièces composées. En 1868, il construisit, sous la direction de $\mathbf{I}$. de Nordling, les viaducs sur piles métalliques de la ligne de Commentry à Gannat; pour les piles, il employa le fer, au lieu de la fonte, de mème que plus tard il chercha à utiliser lacier.

On doit aussi i M. Eiffel des innovations considérables dans le lincane des pouls a poutres droites, et surtout des ponts en ares dont le viaduc de Garalit est le specimen le plus remarquable et le plus justement connu; c'est lui qui a construit la gigautesque ossature de la statue de la Liberté éclairant le monde; cest lui enlin que II. Ife Lesseps a chargé de la construction des écluses du canal de Panama. En accoptant In projet de la Tour de 300 mètres, le Gouvernement était donc certinin de la science et de l'expérience de M. Eiffel.

IV

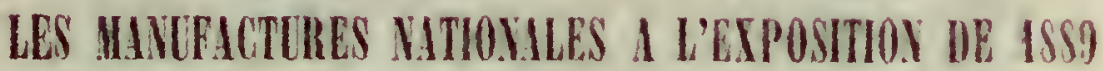

L'une des sections les plus intéressantes de l'Exposition, l'une de celles dont nous aurons lieu d'être le plus justement fiers est celle qui comprendra l'Exposition de nos grandes manufactures nationales: Gobelins, Sèvres, Beauvais et la Savonnerie. Ia, le visiteur admirera les spécimens les plus fameux qui soient sortis depuis un siècle de ces établissements vraiment artistiques; mais en attendant, il sera saus doute heureux de connaitre par avance les merveilles que le Gouvernement se propose, dans cet ordre d'idées, de faire figurer au Champ de Mars. Ces merveilles, nous sommes a mune de les décrire, et aussi de donner dès maintenant la reproduction fidèle de plusieurs tapis, 
vases et tapisseries qui, si rien ne s'y oppose, seront exposés officiellement. En même temps, nous produirons quelques ronseignements sur la fabrication de ces objets, désireux de montrer, à cóté de l'œuvre, l'ouvrier qui la met au jour. Nous commencerons pas les Gobelins.

La manufacture des Gobelins passa oubliée à travers la tourmente révolutionnaire de 1789; le Premier Consul y introduisit des réformes; le gouvernement des Bourbons nomma M. des Riotours directeur de la manufacture; M. Lavocat lui succéda en 1833.

Le gouvernement de la Képublique de 1848 classa les manufactures royales sous la direction du ministre de l'Agriculture et du Commerce, et M. Badin, artiste distingué, fut nornmé administrateur des deux manufactures des Gobelins et de Beauvais. A cette époque plusieurs publicistes, entre autres Émile de Girardin, dirigèrent de violentes attaques contre les manufactures de l'État, en demandant leur suppression comme étant inutiles au développement des industries nationales. En présence d'une telle campagne, le Gouvernement nomma, pour examiner les réformes nécessaires à introduire dans ses manufactures, une commission composée de Ingres, Delaroche, du luc de Luynes, Séchan, Feuchères, Viollet le Duc, Cherreul, Klagmann. Cette commission n'apporta pas grand changement ì l'état de choses existant; sur la proposition de Ingres, elle accepta le principe de la reproduction des tableaux de maitres, en leur assignant préalablement une destination spéciale et en donnant la préférence aux auvres anciennes; elle réclama en outre la restauration de l'école des apprentis tapissiers. lour occuper les ouvriers on entreprit l'Olympe, de la Farnésine, la Psyché, pendentif de la décoration du mìme palais, et l'Éude surprise par la Nuit, d'après Balze, médaillon destiné à la bibliothèque Sainte-Geneviòve.

Sous le second Empire, les deux manufactures furent de nouveau séparées administrativement; M. Badin eut la direction de celle de Beauvais, et M. Lacordaire, ingénieur, celle des Gobelins. La liste civile fut chargée de la direction générale des deux établissements. En 1830ّ, on continua lapplication du système préconisé par Ingres, en faisant repproduire en tapisserie vingt-quatre portraits d'artistes français de la Renaissance, du siccle de Louis XIV et du premier Empire. MM. Larivière, Charvet, Boulanger, Duval-Lecanms, Brisset, E. Giraud, Albert-Lucas Duval, Auguste llesse, Baume, Duverdving, Appert, Lecomte, Tissier, Jobbé-Duval, IIoffer, Marquis. Vauchelet et Biennoury furcnt chargés de l'exécution des modèles. Le tissage de ces curres d'art occupa les ouvriers jusqu'en 1863 et coùta plus de 150,000 francs.

M. Lacordaire se retira en 1860 et $\mathbf{~ I I . ~ B a d i n ~ l e ~ r e m p l a ̨ ̧ ; ~ i l ~ r e ́ u n i t ~ a i n s i ~ e n c o r e ~ u n e ~}$ fois la direction des Gobelins et de Beauvais. Cet lomme de goùt et de talent fit tous ses efforts pour faire entrer un peu d'originalité dans la composition des tapisseries, et ses tentatives furent couronnées de succès.

Après le \& Septembre, la manufacture des Gobelins fut raltachée au ministère de I'Instruction publique et des Beaux-Arts. Pendant la période néfaste du siège de Paris (18i1), presque tous les ouvriers firent leur devoir de Français et combattirent aux avant-postes. Privée de personnel, la manufacture fit office de poudrière, de magasins de vivres et de munitions, et d'hòjuital militaire.

Nous enpruntons a MM. Ilenry Havard et Marius Vachon' le récit des risques que courut la inanufacture pendant la Commune : A Au 18 mars, M. Badin étant ì Beau- 
vais, Raoul Rigault délégua aux fonctions de contròleur et agent comptable, un ancien employé de la liste civile nommé Billoquet, garde-magasin de la manufacture. Le fonctionnaire qui occupait ce poste, M. Gampenon, avait été congédié après plusieurs jours de détention. Enfin un aide-préparateur de chimie. M. Bourgougnou, s'était nommé lui-même conservateur des Cisbalins, et la Cuminuae ratifia spontanément cet

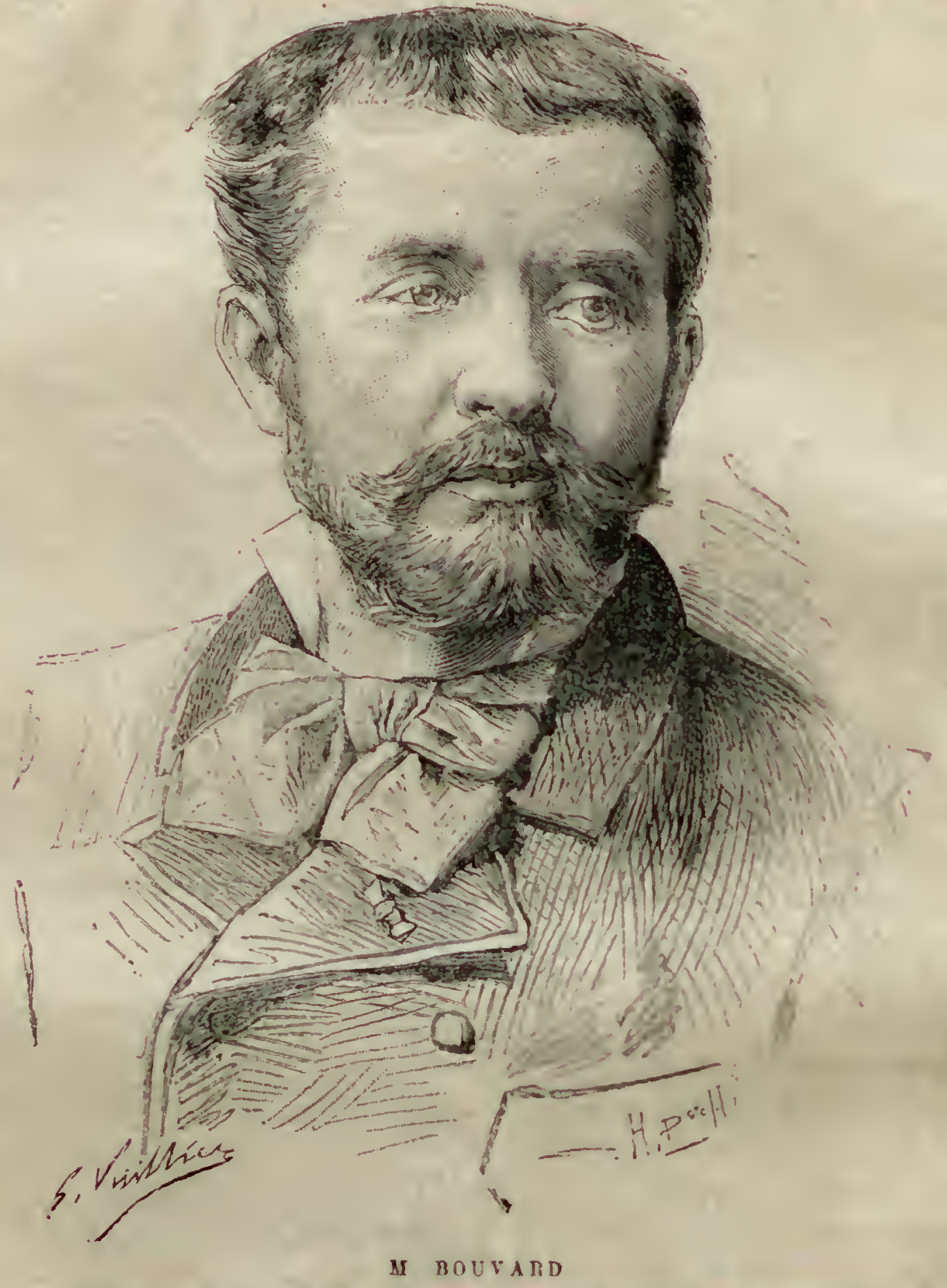

Architecte du Dime central et du Palais des Industries diverses. (Pbol. Truchelut.)

arrêté intime. M. Bourgougnou put ainsi, à plusieurs reprises, faire officiellement les honneurs de l'établissement aux délégués du Comité central et aux membres de la l'édération des artistes. Ajoutons que le personnel sous ses ordres était réduit à sa plus simple expression. La plupart des employés, pour échapper au service de la garde nationale fédérée et ne point prendre part à la guerre civile, avaient abandonné la manufacture et réussi à quitter Paris.

"Ce furent MM. Feyen-Perrin, Aubin et Poitevin, que la Fédération des artistes délégua à la surveillance des Gobelins. Leur mission, très passive, essentiellement 


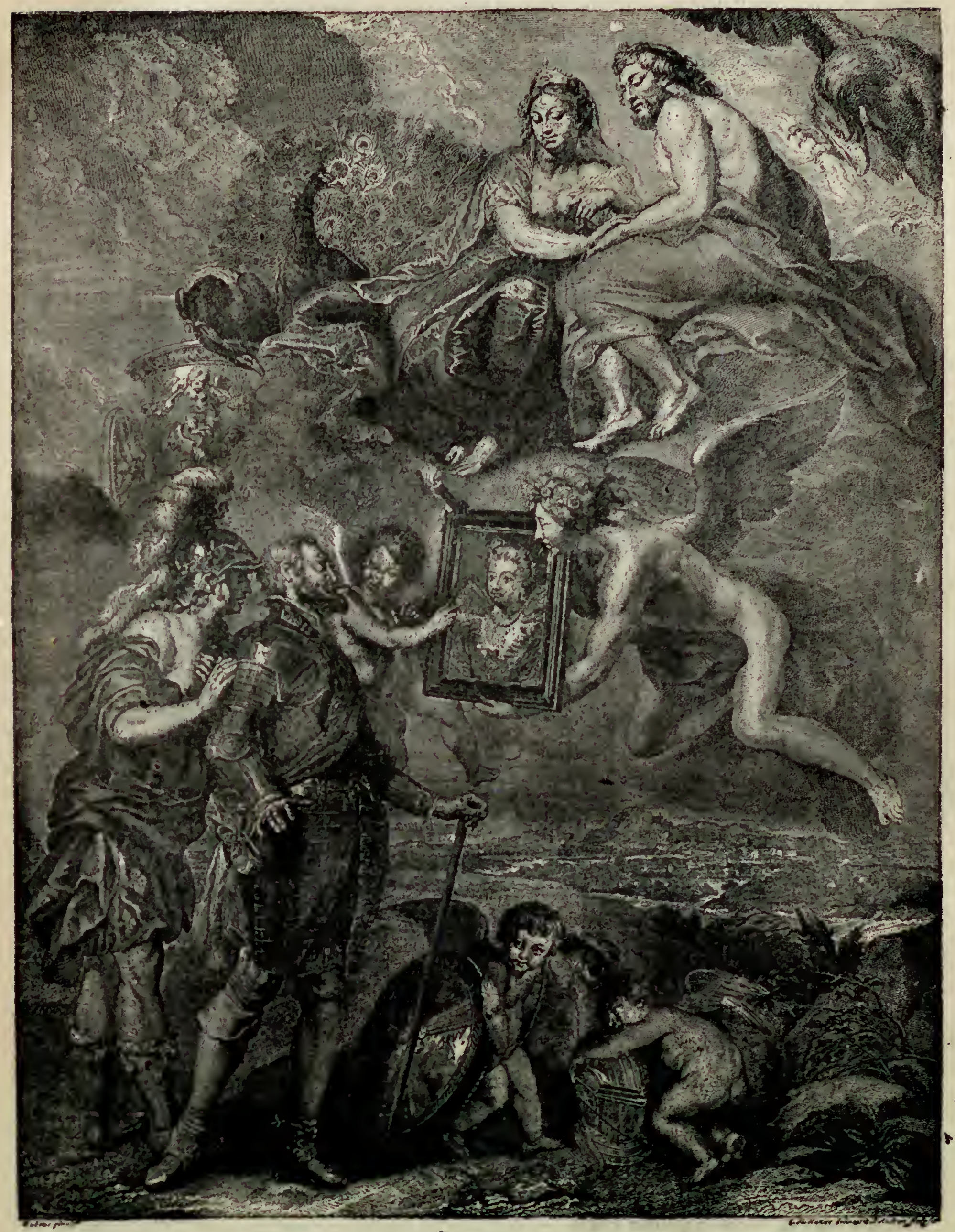

Les Gobeluss. - Henri IV contemplant le portrait de Marie de Médicis (d’après Rubens). 
protectrice et conservatrice, qui ne constitua point, d'ailleurs, aux yeux des eonseils de guerre, une usurpation de fonctions publiques, se borna à des visites très courtes. ayant pour but très louable d'assurer le respect des ateliers et des collections. Toutefois, à ce moment, comme à tous les changements brusques de régime, l'utilité de la manufacture des Gobelins fut mise en discussion, mais les événements ne laissèrent pas au gouvernement de l'Iròtel de Ville le temps de réaliser ses projets. ,

Cependant soixante-scize tapisseries furent brulées, tant dans les magasins que sur les métiers.

Bièn que la manufacture fùt à moilié détruite, les ouvriers qui rentrèrent dans Paris y reprirent leur travail dès Je mois de juin 1871. Le ministre des Beanx-Arts confia momentanément l'adıninistration des Gobelins à M. Chevenl; puis. vers la fiu de l’année, lorsque le calme revint un peu dans la capitale tant éprouvée. M. Marcel (Alfred) fut chargé de la réorganisation de l'établissement. Le nouvel administrateur se préoecupa immédiatement de donner du travail aux ouvriers et d'introduire des réformes utiles dans les ateliers.

Le 28 avril 1879, un arrèté du ministre de l'Instruction publigute et des Beaux-.Irts institua le concours dit " Prix des Gobelins *. Ce concours. en stimulant le goit des artistes, encouragea la production de tapisseries originales et diun fini merveilleux. Lin autre arrèté, en date du 3 février $188 \%$, organisa adninistrativement le Musie de tapisseries et de tapis. L'école de tapisserie reçut le noun d'École fratipue d'an't dicoratif et de tapisserit et comprit : $1^{0}$ J'enseignement des sciences et des arts qui servent de base à lart lu tapissier (cet enseignement est donné dans les trois cours: cours élémentaire, cours supérieur et Académie de dessin); 20 l'Ḱcole spéciale de tapisserie et de tapis. La mème année, M. Gerspach, chef du bureau des Manufactures is la Direction des Beaux-Arts, succéda à M. Dared, nommé conservateur du Musée de Cluny et des Thermes.

Le budget annuel des Gobelins s'élève à 236,000 francs. Les appointements des chefs d'ateliers varient de 4,100 à 5,000 francs; cenx des sous-chefs de 3.000 a 4.000 . Les artistes tapissiers touchent de 1,600 a 3,230 franes et les apprentis de 900 à 1,500 francs. Fn outre, il est accordé chaque année des primes qui varient de 250 francs. Presque tous les ouvriers sont logés dans la manufacture: ceux qui habitent en dehors reçoivent une indemnité de 200 francs. Le travail dure de 8 heures du matin à ŏ heures du soir en été et à 4 heures en hiver, avec une heure de repos pour le déjcuner. Un ouvrier fournit en moyenne dans son année un mètre carré de tapisserie.

Comme les visiteurs de l'Exposition seront a mème de constaler dp risu le fonctionnement des Gobelins, il ne sera pas superflu de le décrire ici, brièrement.

La manufacture nationale des Gobelins compte aujourd'hui qquatre ateliers : un atelier de haute lice, occupé à la fabrication des tapisseries. l'atelier des rentraitures qui fait les réparations, l'atelier des teintures et l'atelier de la Saronnerie, oi su tissent des tentures décoratives; la fabrication des tapis de pien a été abandonnée à cause de son prix élevé.

Dans l'atelier de haute li_ə, 11 méliers fonctionnent: ils se composent d'une paire de cylindres en bois de chène ou de sapin, dits ensouples, disposis horizontalement it une distance de $2^{\mathrm{m}}, 30$ a 3 mètres, et dont le cylindre supéricur est soulenu par des montants appelés cotrets. La chaine de la lapisserie se fixe dans une position 
verticale sur les ensouples, et le fil est retenu par une baguette en bois, le verdillon, qui est contenu dans une rainure. Cette chaîne, soie, coton ou laine à plusieurs brins, se partage en deux nappes, dont la séparation est maintenue par une ficelle de croisure et par un baton en verre ou en bois dit biton d'entre-deux. A chaque fil de la nappe d'arrière se passe la lice - une cordelette en forme de cercle, - et la lice est fixée sur une forte perche, dite perche des lices. C'est en tirant ces lices que le tapissier ramène les fils d'arrière en avant et opère le croisement de la chaine et de la trame, celle-ci étant enroulée sur une broche qui remplace la navette du tisserand. L'artiste a soin de décalquer préalablement sur la chaine les grandes lignes du modèle à reproduire, un trait noir marquant les contours extéricurs et un trait rouge le détail des carnations. "Pour former le tissu de la tapisserie, l'onvrier, placéderrière le métier, à l'envers et devant le modele dont il doit reproduire les formes, saisit une broche chargée de la laine ou de la soie teinte de la coulcur déterminée; il arrète l'extrémité du fil de la trame sur le fil de chaine, puis mettant la main gauche entre les deux nappes séparées par le bdton de croisure, il écarte les fils que doit recouvril la trame de mème nuance. La main droite passint entre les fils va chercher à gauche la broche qu'elle ramène à droite; après ce temps, la main gauche saișissant la lice fait revenir en avant les fils d'arrière et la main droite lance la broche au point d'où elle était partic. Ces deux passées constituent une duile. A chaque duite, l'artiste rapproche avec le bout aigu de la broche des fils de la trame du tissu et au bout d'un certain nomlire de passées, complète l'opération au moyen d'un lourd peigne d'ivoire, dont les dents pénètrent entre les fils de la chaine et compriment régulièrement ceux de la trame. "Le nombre des duites et leur élendue sont indiqués par les contours du dessin et les diverses nuances du coloris à reproduire. La transparence et la légèreté des nuances sont obtenues par le nouveau procédé des hachures, ignoré avant 1812. Ce procédé consiste, au lieu de mèler dans la cuve plusicurs couleurs qui ne se mélangent pas toujours facilement pour teindre les écheveaux, à mélanger plusieurs fils de nuances différentes pour en obtenir un de la couleur que l'on désire.

Les premières tentatives de ce genre furent faites vers 1812 par un artiste de l'atelier de basse lice, nommé Deyrolle et furent continuées par son fils, M. Gilbert Deyrolle, chef d'atelier. En 1826, lorsque l'atelier de basse lice fut supprimé, Ia méthode passa à celui de haute lice. Actuellement, ce procédé est presque uniquement employé.

L'atelier de teintures de la manufacture des Gobelins a eu autrefois une véritable légende. Le peuple, émerveillé de la richesse des coloris obtenue par les artistes tapissiers, attribuait aux eaux de la Bièvre des propriétés particulièrement favorables à la teinture des laines et des soies. Malgré cette croyance populaire, on ne se sert plus depuis longtemps dans l'atelier que d'eau de Scine filtrée ou d'eau de source, et on ne se sert pas de l'eau de la Bièvre à cause de son impureté. Mais, à l'époque où de Comans et de la Planche vinrent s'installer dans le faubourg Saint-Marcel, ils préférèrent laisser s'accéditer cette version fantaisiste qui assurait une réputation solide à leur maison, que de révéler les procédés dont ils se servaient et dont d'autres auraient pu s'enparer. On suppose que le premier atelicr de teintures des associés de Comans et de la Planche fut précisément celui de Nicolas Gobelin qui a laissé son nom à la manufacture. C'est li que durent se teindre toutes leurs laines pendant le premier quart du xvil siècle, les soies. Ieur arrivant toutes prètes de l'Italie. 
La réputation de cet atelier était si stablement établie, que, en 1662, lorsque Colbert eut la pensée de créer sur les bords de la Bièvre une manufacture royale des meubles de la Couronne, il jugea utile le maintien en ces lieux de l'atelicr de Nicolas Gobelin. Il lui donna même une mission professionnelle et, dans l'édit de fondation, il indiqua les teinturicrs comme devant compter parmi les artisans dont la surintendance des

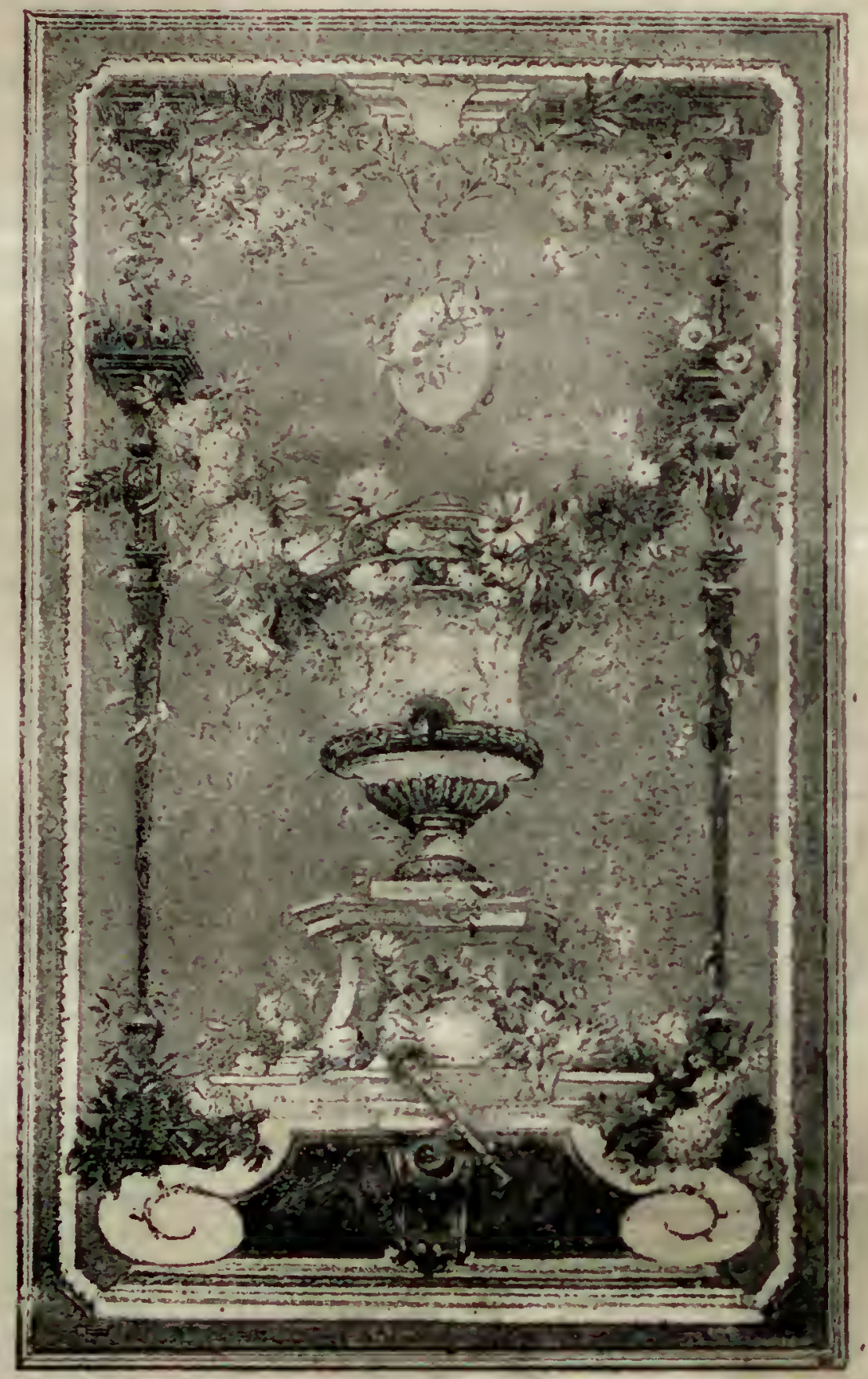

L.ss Gobecixs. - Pannenu dicoratif composè par M. Galland. (Palais de l'Elysie.)

Lütiments et le directeur doivent pourvoir la manufacture. M. Chevreul, dans une remarquable étude sur les Gobelins, dit qu'à côté des éléments artistiques et technologiques que le ministre $\mathbf{y}$ avait introduits, il faut tenir compte de l'élément scientifique dont il avait prévu l'influence et auquel il avait préparé une place capitale. A l'appui de son affirmation, M. Chevreul cite un livre publié par Colbert en 1:31, quatre années après le règlement des Gobelins et intitulé : Instructions génerales pour les teintures des laines et manufactures de laines de toutes couleurs, et pour la culture des drogues on ingrédients qu'on y emploie : Cette instruction, dit-il, renferme plus de vues généralcs 


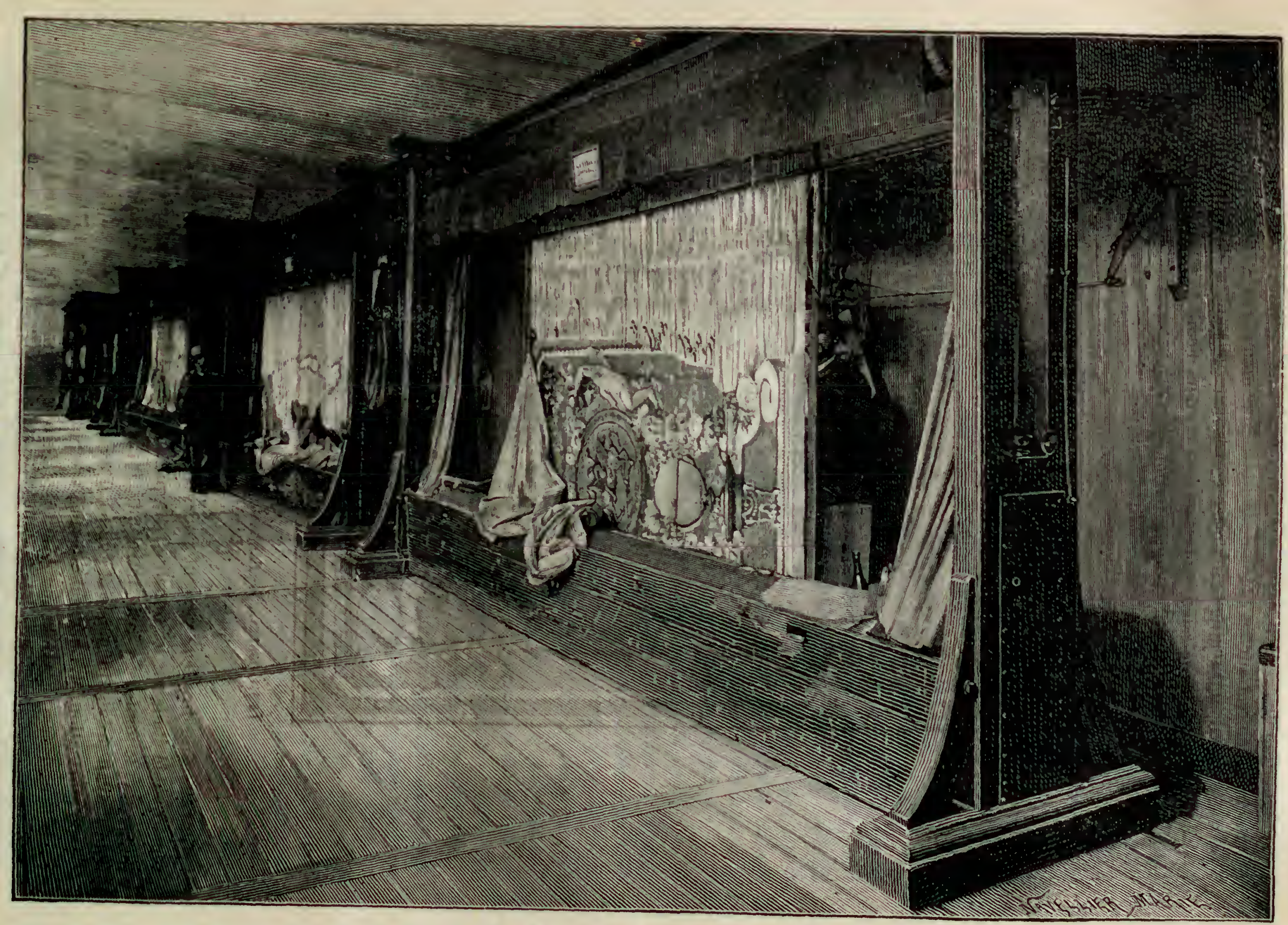

Les Gobelins, - Latelier de haute lice. 
sur l'administration, l'économie des arts et la teinture, qu'on n'en trouve dans la plupart des écrits auxquels cet art a donné lieu dans le xrıle siècle et mème dans le notre, bien entendu, en tenant compte de l'institution des jurandes et maitrises, nécessité des temps où elle parut... Elle montre à tous que l'institution des leux manufactures des Gobelins et de Beauvais, et l'extension de la manufacture de la Savonnerie n'avaient pas seulement pour but de meubler les palais royaux, mais de donner encorc a l'industrie française l'impulsion la plus puissante. "

L'atelier de teinturc était, dès $\mathbf{1 6 6 3}$, pourvu d'une organisation officielle. Josse Kerchove, ou de Kerkhove, fut nommé directeur avec le titre de "teinturier de la maison des Gobelins *, titrc qu'il remplaça en 1669 par celui de t teinturier et marqueur des ouvrages de la manufacture ". Josse Kerchove reçut un traitemcnt de 1,500 livres, soldé par la surintendance des Batiments, et un gage de 50 livres élevé cusuite à 100 livres en qualité de petit officier au service du roi et comme artiste occupé par la Couronne. Plus tard, la direction changea de système et paya a raison de tant par livre de laines teintes. Kerchovc eut pour successeur Cozette; mais lorsque celui-ci vint à mourir, son fils, qui était compagnon avec 600 livres d'appointements par an, refusa la direction de l'atelicr qui n’était plus une situation avantageuse. Il s'établit pour son compte teinturier dans le centre de Paris. Un Ménil, qui alimentait depuis très longtemps les Crobelins de soies teintes et de laines blanches, accepta l'cmploi en s'adjoignant comme compagnon un Kerchove, petit-fils de Jossc Kerchove.

Les laines obtenues à cette époque par les procédés alors en vigucur étaient loin de satisfaire les ateliers de haute et basse lice qui se plaignirent très vivement de la fragilité de certaines nuances qui passaient promptement et rompaient l'larmonie des tapisseries. Cela constituait un véritable danger pour l'avenir de la manufacture. Kerchove n'avait pas le talent nécessaire pour remédier au mal, et de plus sa vie privée était si scandaleuse que Soufflot dut le révoquer. II décida Cozelte, moyennant une indemnité annuelle de 800 livres, dont la moitić était reversible sur la tête de sa veuve en cas de décès, à rentrer aux Gobelins. L'oncle de kerchove, du méme nom que lui, fut adjoint à Cozette en qualité de compagnon.

L'atelier fut entièrement remanié en 1769 ; la direction en fut confiéc par Soufnot à Audran, Cozette et Neilson. Mais les entrepreneurs de la hante et hasse lice naraient pas les connaissances scientifiques indispensables pour surveiller la teinture des laines; aussi Audran et Cozette ne tardèrent-ils pas d̀ donner leur démission, laissant a Yeil. son tout le poids de la tâche à accomplir. Mais cc dernier connaissait son métier et il s’appliqua à le faire progresser. Les ouvriers qui travaillaicnt en ce moment a latelier se heurlaient à de nombreuses difficultćs occasionnécs par les tons clairs mis en faveur par les peintres a la mode, et par la reproduction plus scrupuleuse des modèles par Ics tapissiers. Or, les laines teintes dans les nuances tendres étaient beaucoup moins solides comme coloris que celles employées dans les couleurs vigoureuses. L.es teinluriers avaient done de grands obstacles a vaincre pour arriver à la perfection. Deux excellents collaborateurs secondèrcnt efficacement Neilson dans ses difficiles fonctions : ce furent Daniel-Marie-Neilson, son fils, agréé comme cntreprencur de basse live en survivance de son père, et le savant Quérniset, engagé aux nppointements de 600 livres.

Quémiset travailla pendant dix ans aux Gobelins avec ardeur, apportant aux procédés de teinture tous les perfectionnements qu'il pouvait décourrir. Malheureusement, 
Neilson, en butte à l'envie de ses collegues, ne fut pas soutenu par l'autorité supérieure, bien que 11. de Montucla, chargé, en 1772, avec le célèbre chimiste Nacquer et Soufnot, directeur des Gobelins, de constater les améliorations obtenues par Neilson et (Uuémiset, ait rendu dans son rapport une entière justice aux efforts tentés par les deux collahorateurs. Malgré leurs mérites les denx inventeurs n'obtinrent pas les encouragements qui leur étaient dus pour quatre années d'un travail assidı qui avait donné de précieux résultats. M. d'Angeviller donna à Quémiset une gratification de 2,400 livres el remboursa simplement à Neilson les avances qu'il avaił faites. Découragé, (luémiset quitta la manufacture en $\mathbf{1 7 8 3}$, et mourut peu de temps après dans la plus affreuse détresse. Quant à Neilson, il avait demandé dès l'année 1781, après la mort de son fils, à ètre relevé de ses fonctions; il patienta un peu espérant rentrer dans les fonds qu'il avait avancés, mais il dut quitter les Gobelins ruiné et désespéré pour mourir aussi dans la misère. Audran lui succéda en s'adjoignant le chimiste Cornette; mais malgré leur's efforts réunis, ils ne purent relever l'atelier qui fut supprimé ofliciellement par le ministre Rolland en 1792.

P'enlant son séjour à l'atelier, Quémiset avait dressé un tableau de toutes les couleurs réalisables avec un manuscril explicatif en trois volumes, indiquant les procédés au moyen desquels on pouvait obtenir les nuances marquées sur le tableau. La possession de ces précieux documents amena entre Neilson et l'inspecteur Belle une vive querelle. Neilson les réclamait comme sa proprićté en raison de sa collaboration effective avee (quémiset et les avances d'argent qu'il avait fitites pour les essais. Il lui fut répondu que Quémiset n’arait tenu nul compte de son opinion dans ses travaux et que les fonds nécessaires à l'entretien de l'atelier ayant été dounés par le roi, Sa - Majesté était seule propriétaire des documents. On ne voulut mème pas laisser à Neilson le temps d'achever la rédaction des manuscrits et on consentit seulement à lui abaudonner la copie qu'il en avait faite. Ces documents existaient encore lors du rétablissement de l'atelier en 1794. Augustiu Belle affirme, dans un rapport adressé à la Commission d'Agriculture et des Arts, en 179\%, que le tableau est intact et que le manuscrit était entre les mains de Darcet, ancien inspecteur de l'atelier de teintures de $17 S 7$ a 1792 , qui travaillait à trouver la clef desdits procédés.

La Commission réclama le manuscrit; il dut sans doute être restitué, mais on ne sait plus depuis celte époque ce qu'il est devenu. Quant au tableau, il pourrit dans les greniers de la manufacture. De 1803 a 1816, sous la direction de M. Roard, professeur de chimie et de physique. les teinturiers recherchèrent la perfection des coloris et obtinrent de notables résultats. Ce directeur habile créa une école pratique d'où sortirent un certain nombre d'adroits teinturiers. Le comte de Laboulaye-Marillac succéda, le ter janviel 1817, a Roard, et fut lui-meme remplacé, le 9 septembre 1824, par s M. Chevreul. Cet illnstre savant réorganisa le service des teintures; aux procédés empiriques, antérieurement en usage, il substitua une méthode plus scientifique consistant it tenir comple des effets produits par le rapprochement des couleurs et l'utilisation raisonnéc de leur contraste o: de leur harmonie.

1. Wxposition de la inanufacture des Gobelins sera consacrée spécialement aux auvres produites pendant le $\mathrm{x} / \mathrm{x}^{\mathrm{e}}$ siècle ou plus exactement depuis cent ans. Or, durant ces cent années, les plus belles pièces sorties des ateliers sont les suivantes: lEntio vement de Proserpine, par Vien; la Mort de Duguesclin, par Brenet; la Mort d'Étienne Marcel, par Barthélemy; la célèbre tenture en plus de vingt pièces consacrée à la 


\section{LES MERVEILLES DE L'EXPOSITION}

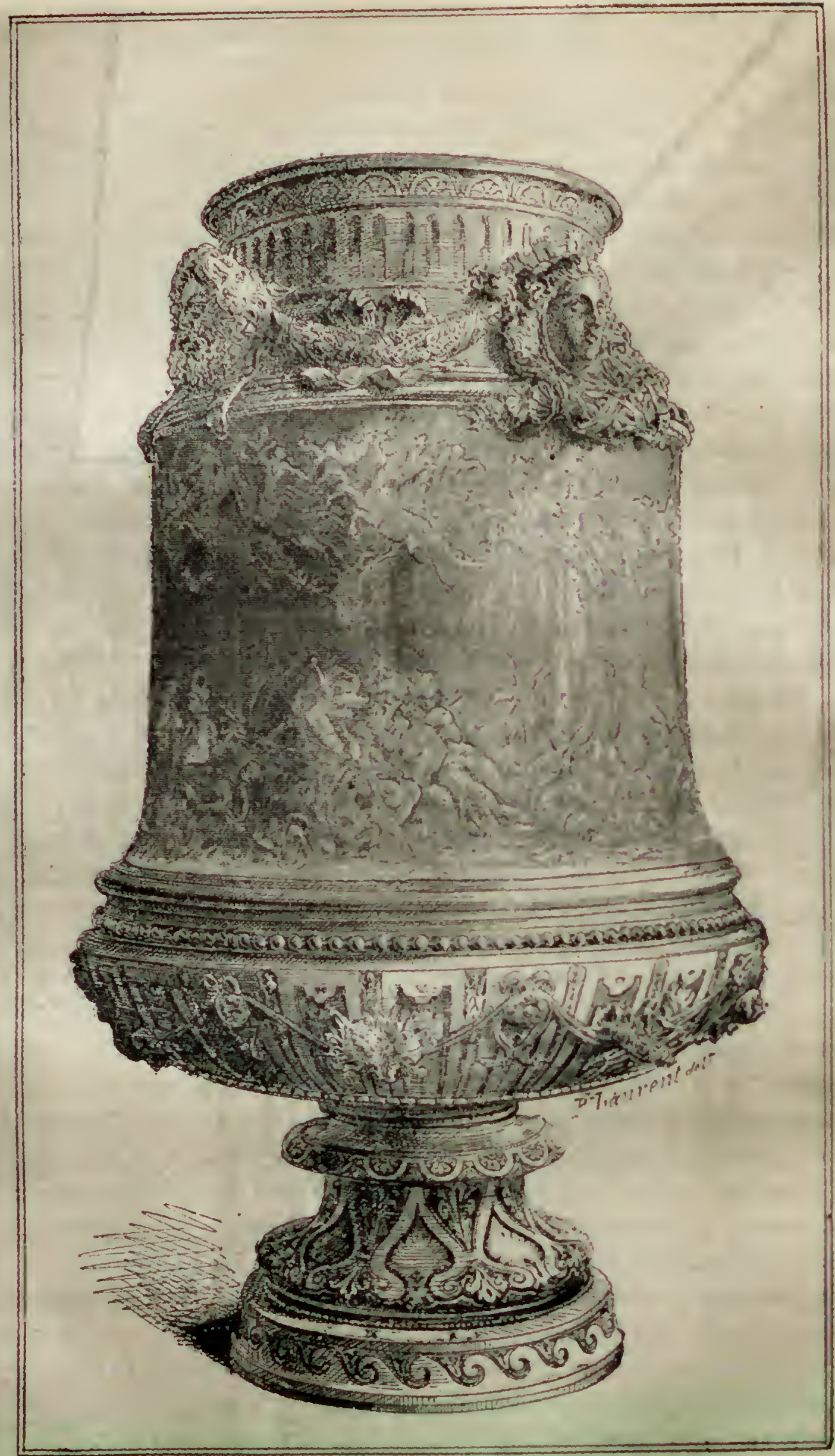

SÈvres. - Grand vase décoré en application de pate sur fulte.

reproduction des principales scènes historiques de l'Empire; Henri IV, Marie de Médicis et Louis IIII, pièce faisant partie de l'histoire de Marie de Médicis, exécutée en tapisserie d'après l'admirable suite des peintures de liubens que possède le Louvre; la 


\section{LES MERVEILLES DE L'FYPOSITION}

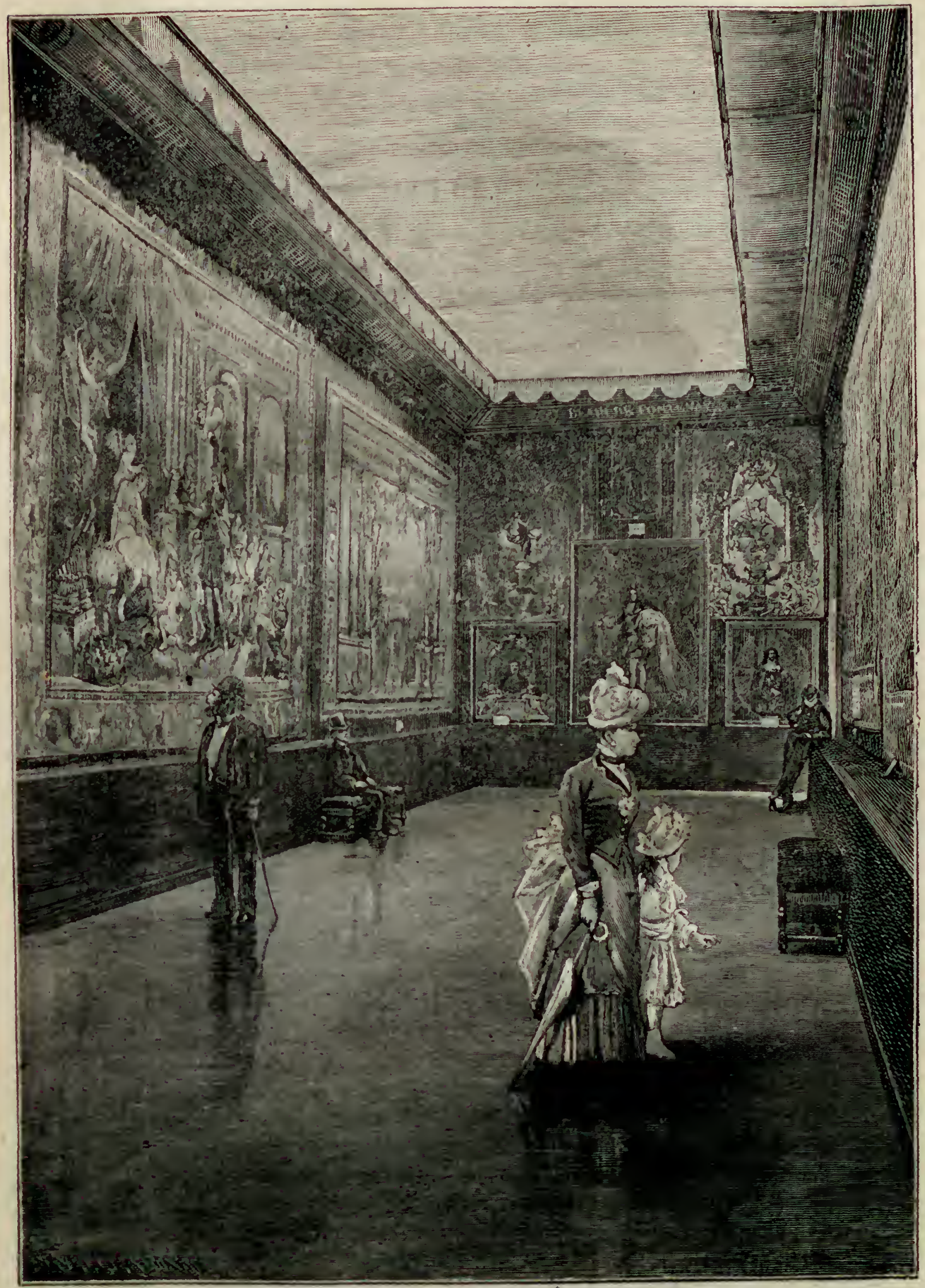

Les Gobeliss. - La grande salle du muséo.

Liv. 11.

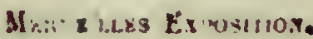


Mort de Duguesclin, par Brenet; la Famille de Darius par Le Brun; Léonidas et Cléombrote, par Lemonnier; le Caar Pierre le Grund sur le lac Ladoga, par Steuben; un nombre considérable de portraits; la Vie de saini Bruno; une suite de llllistoire de Frunce d'apres Fragonard, Vernet, Gassies, etc., les Cinq Sens, comprentut cind panneaux, sept dessus de portes et sept trumeaux; des panneaux décoratifs. Cels que celui de M. Galland, que nous reproduisons: la Filleule des Fies par M. Mazerolle.

Ainsi que nous l'avons dit plus haut, la manufacture de la Savonnerie fnt réunie en 1826 à la manufacture des Gobelins où elle devint un atelier spécial. Dès lors: lí fabrication des tapis de la Savonneric subit linfluence de la production des Gobelins. Sous la monarchie de Juillel, l'atelier exécuta le grand tapis lu chour de Notre-Dame de Paris, qui a près de 200 mètres carrés ot qui fut dessiné par Saint-luge el de Vertus; un tapis pour la salle du Tròne aux Tuileries; un tapis pour la salle de concert des Tuileries; un tapis pour la salle du conseil a Saint-Cloud; un tapis pour te salun Louis XIV aux Tuileries. De 1869 à 1882, l'atelier s'occupa exclusivement d'cxículer deux grands tapis pour le salon ot la shambre à coucher dite du pape, atu palais de Fontainebleau, d'après des modèles de Dieterle. Mais depuis l'avènement de la troisiẻme Irépublique, la Savonnerie n'exécute plus que des tentures décoratives destinées au palais du Président de la République et aux édifices publics. Les ourriers terminent actuellement Les Arts, les. Sciences et l'Industrie, la Guere el la Marine, diuris Ch. Lameire; Les Arts et les Lettres, panneaux et dessus de porte, d'après Lavastre.

Le métier dont on se sert à la Savonnerie a la mème forme que le nétier de liaute lice, mais l'ouvrier procède autrement. A Ayant choisi la broche chargée de laine dont la conleur correspond au coloris du modèle: le tapissier, dit M. Ilavird. saisit atver la main gauche le fil de chaine sur lequel il doil commencer son travail, il lattire a lui et fait passer derrière la broche qu'il tient de la main droite. Au moyen de la lice, is détache de la seconde nappe de chaine un autre fil et l'enveloppe avec dextérité d'un nceud coulant qu il serre vigoureusement. Entre ces deux passées, le fil de trame forme au-devant de la chaine un anneau qui s'enroule au fur et à mesure de la fabrication. sur un tranche-fil dont le manche de calibre varie donne la hauteur du poil de velours. En tirant cet instrument tous les anneaux se trouvent compés et le velours est formi. Lorsqu'une rangée de nœuls ou points se trouve terminée, l'ouvrier les joist par un fil de chanvre très fort appelé duite, posé entre les denx nappes de la chaine, mais cett: duite étant incapable de former un tissu solide, il lie encore entre eux les fils de 1.6 chaine par un fil de chanvre et enchaine pour ainsi dire les points de veluurs, en serram les uns et les autres au moyen d'un peigne. Vient ensuite la tonte, qui se fait an mnyen de ciseaux à branches recourbées. Le métier de tapissier de la Saronneric exige des aptitudes particulières, qui le rendent très difticile et très délicat. L'artiste, tont autant mais plus que celui des Gobelins, doit posséder à fond la seience du coloris et doit ètre un excellent dessinateur. Aussi, cet atelier bi-séculaire, qui complète si heureusement la Manufaeture nationale de tapisseries, a-t-il produit de véritables merveilles d'art. Sa disparition, si elle venait à se produire, comme le fait est à craindre en raison des difficultés de recrutement du personnel, serait un désustre artistique pour notre pays.

Après les Gobelins et la Savonnerie, nous devons nous occuper de la manufacture de Sèvres. La porcelaine de Sèvres se compose d'une pate où entrent du kiaolin, de la eraie et de l'argile plastique. Le kaolin (silice, alumine, chaux et polasse) vient des carrières du Limousin. Dès qu'il arrive à la manufacture, on le purifie, on le mèle avec 
de l'eau, on te broie, et on le décante. Comme il contient alors $500 / 0$ d'eau, et que cette proportion doit être réduite à $150 / 0$, on le conduit dans des réservoirs soulerrains oì elle se dépose, puis dans les presses hydrauliques qui le compriment. C'est alors qu'on le rédnit en poudre après l'avoir séché. Le sable que l'opération du décantage a séparé du kaolin et qui doit introduire dans la pate $30 / 0$ de potașse est, de solk coté, soumis a l'opération du broyage dans un atelier spécial. Aucune parcelle de fer ne doit etre introduite dans la pate. Aussi les ouvriers ne portent-ils pas de souliers munis de clous. Le chimiste de la manufacture choisit un échantillon sur chaque monceau de sable et de kaolin, le soumet ì une analyse et donne au préposé au magasin la fornule du mélange à opérer, mélange qui est soumis aux mêmes opérations que le kiolin: puis, la pate est pétrie et malixée, et enfin enfermée dans des cuves oì elle se repose de six mois à un an. C'est là qu'elle acquiert ses qualités plastiques.

La première opération que subit la pàte à manufacturer est celle du façonnage. Les procédés de faconnage sont au nombre de fuatre: le tournage, le moulagge, le coulage, el le rachevage, ainsi décrits par M. Ilavard:

"Le tournage se compose de deux opéralions principales : l'ébnuchage et le tourmassuge. Lartiste tourneur saisit un bloc de la pate qui doit servir à constituer la pidce dont la confection lui est confice et le place sur le tour à potier classique que cunt le monde connait. Du pied droit, il imprime à la roue un mouvement rapide, en mème temps qu'il saisit à deux mains le bloc de pâte. Sous l'effet de la rotation du tour et de la pression des doights, la pate s'allonge, se rétrécil, monte, descend, se tord en spirales, s'arrondit en panses épaisses, s'effile en fuseaux légers. Tout à coup, la masse mouvante s'abaisse, prend une forme plus certaine qui, peu à peu, accentue ses 'liznes el se dessine avec précision. C'est un vase, une coupe, un gobelet. Aussitút que la pièce apparait nettement, comme évoquée par la caresse de sa main, le potier pousse plus vivement la roue du tour. Ses doigts souples sagitent rapidement autour d'elle, et suivant délicatement les courhes, vont et vienuent a vec agilité du dehors au dedans, du haut en has, rectifiant avec la hausse la forme ébauchée. Le tour s'arrète. L'cenvre se dresse fièrement, toute luisante, dans sa plasticité fraîchement acquise. La pièce séchée, pendint quelques jours sur une forme en bois, passe ensuite au tour a tournasser où l'onvrier muni d'instruments trinchants dénommés tournassins évide les gorges, fait saillir les filets et les moulures, polit les panses et les collets, en un mot donne à l'ébauche la forme définitive de la piece is olstenir. Le façonnage sur le tour de certaines pieces, comme les assiettes, les soucoupes et les plats, nécessite une opération distincte nomnée le calibrage et qui consiste à poser sur lúbauclıe un calibre en acier présentant a son bord le profil découpé de la forme définitive, intérieure et extérieure. Par l'elfet de la rotation, ce calibre donne a la pièce l'épaisseur et les profils qu'elle doit avoir délinitivement. Pour les ouvrages qui reçoivent des moulures compliquées, des gijlons, des oves, etc., le tourneur se sert ensuite du tour a guillocher. La manufacture de sevres possede quinze tours de potier simples a pied et quatre tours i deux places. En ce moment, on s'occupe d'adapter aux tours des moteurs mécaniques. Pour le tournage des pièces communes, l'innovation présentera certainement un prozrès sérieux; rnais pour les pièces artistiques, le tour ì pied restera toujours indispensable, le mouvement de rotation devant être réglé avec soin sur le travail d'ébauchage, qui exige chez l'artiste une vigilance de tous les instants et une habileté peu commune.

Le deurième procédé de façonnage est le moulage, qui exige plusieurs opérations 


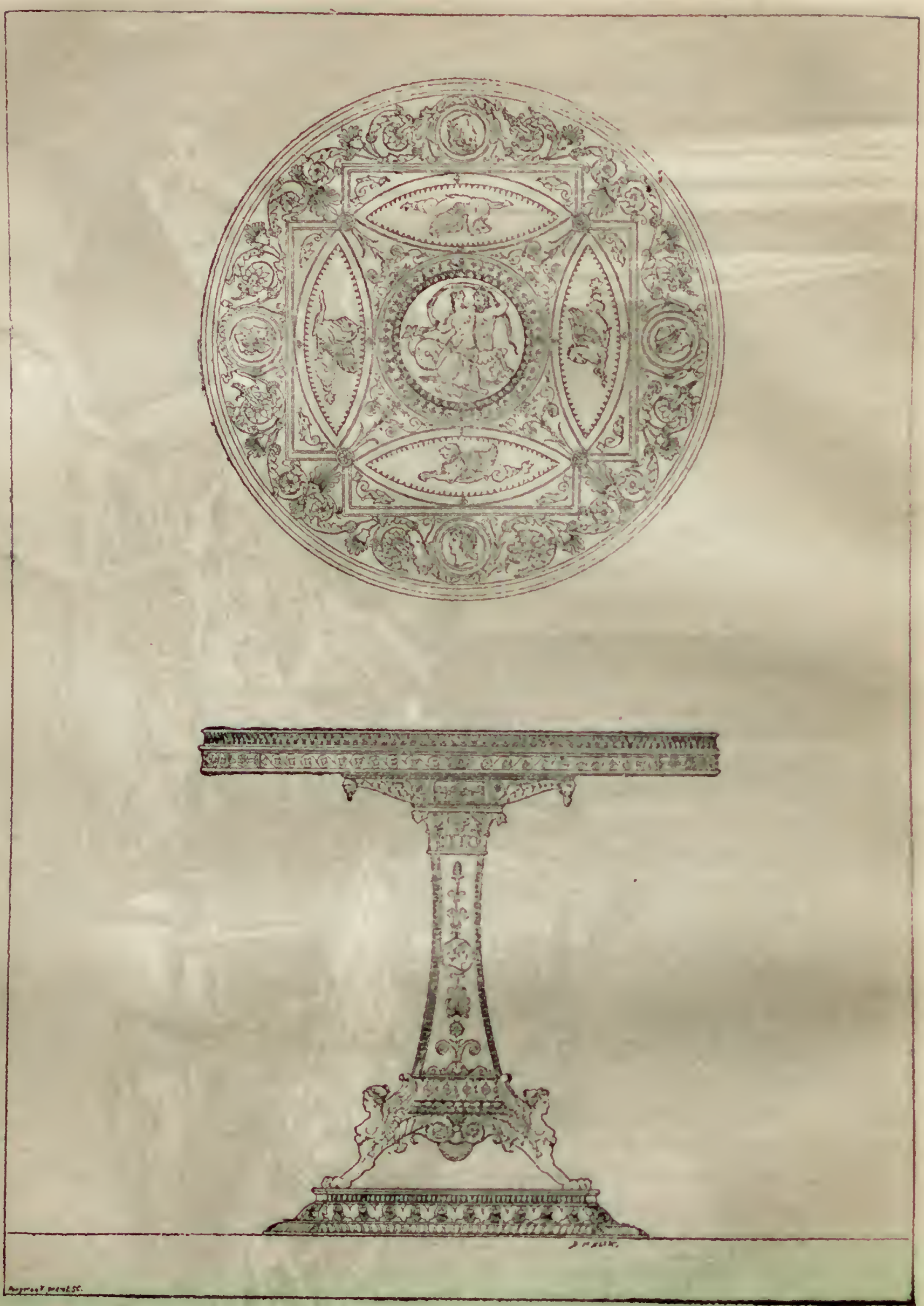

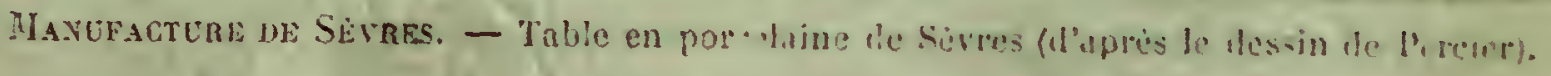

consécutives : l'invention du modèle, la création du moule, at le moulage propreme:.: dit. Lorsque le sculpteur a donné à la manufacture son modèle en terre cuile en plätre ou cn cire, les ouvriers mouleurs le divisent en fragments, dont le nombre varie suivant la mulliplicité des parties saillàles de la piece. Ils revedtent ensuite ces from - 


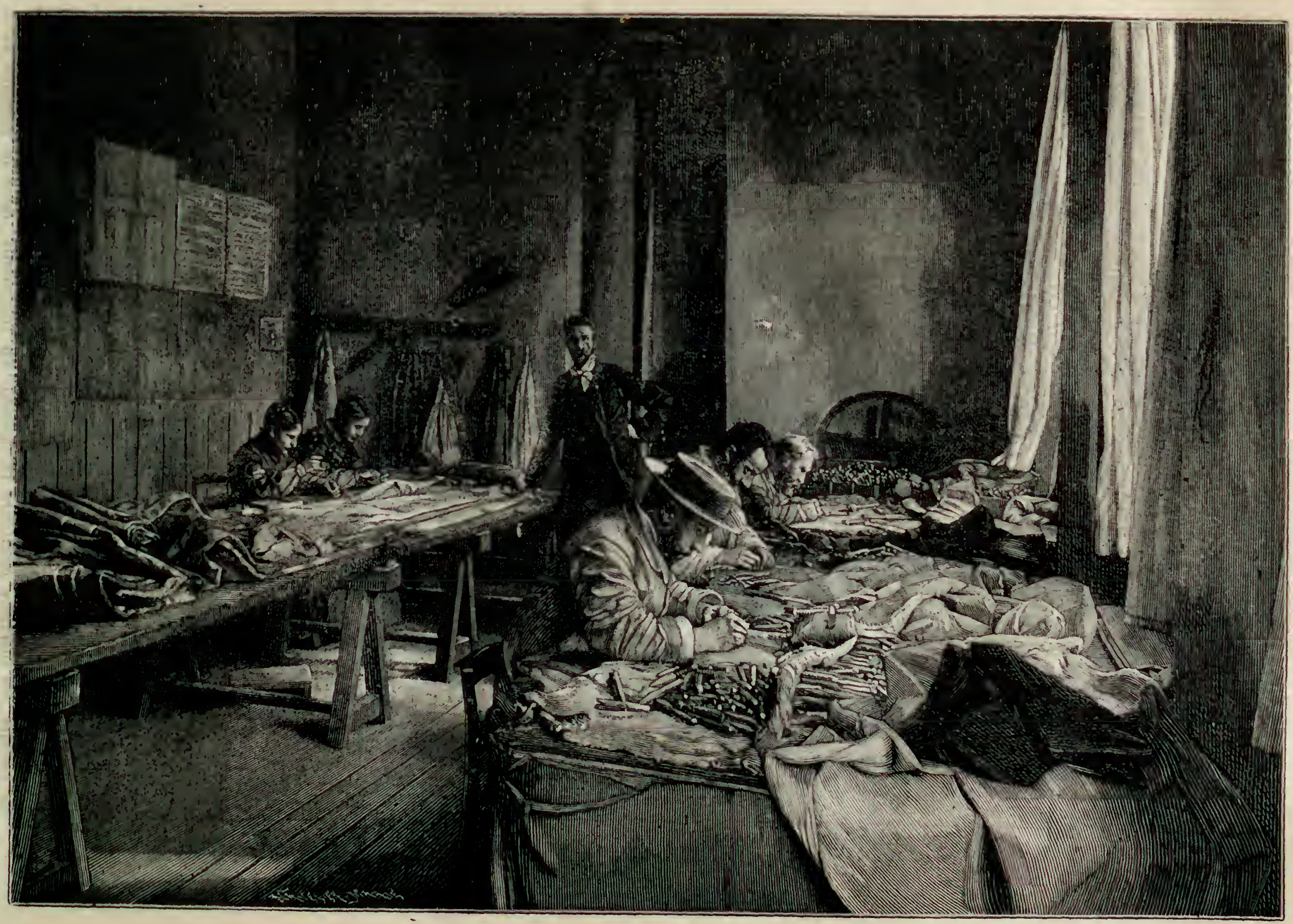

Las Gobeins - Latelier de rentraiture. 
ments d'une chape en platre ou terre cuite, qui en éponse fidèlement toutes les formes. Comme l'ouverture du moule doit etre assez grande pour receroir directement la massc de pate nécessaire, la chape sourre en deux pieces nommées coquilles, qui se partagent à peu près également la pièce moulée. Le moulage consiste a faire prendre à la pièce la forme du moule sur lequel on l'applique. Suivant la nature de l'objot it mouler on prépare la pate en balles, quon insère vigonreusement avec la paume do la main daus la chape, ou en crouite bien égale d'épaisseur et de densité, dont on recourre le moule. Un troisième procédé, celui de la housse, employé pour les pates délicates ct pour les pièces à large ouverture et simples de formes, consiste ì ébancher une pièce comme si elle devait ètre faite au tour, à l"insérer ensuite dans le moule en l'ippliquant arec une éponge contre les parois où elle se fixe et dont elle reproduit fidèlement les formes et l'ornementation.

Le coulage, troisième procédé de faconnage, est le plus employé de tous pour les pièces de production courante et pour les vases de grandes dimcusions. L'honneur de l'application industrielle on revient a la manufacture de Sevves qui en fait un usage constant, st, grice ì l'ingéniosité de son personnel, le perfectionue tous les jours. La pâte de kaolin est amenée par une addition d'eau à l'état d'une fouillie liquide yquon nomme barhotine. Pour les pièces dites de creux, tasses, pots a sucre, jalles, on remplit, au robinet, de barbotine, des moules de platre tris secs. Le plitre alsorbe precyne instantaniment la partie d'eau de la barboline qui adhère à ses parois; l'ouvrier vide alors le moule; une couche de pate de 3 à millimitres j'épaisseur, suffisante comme consistance, se trouve ainsi formée; la piècest posée sur un support le méme forme, s'y sèche et derient propre au tournassage. Pour les vases de petites dimensions, le moule est rempli identiquement de barbotine, et lorsque la couche sest formée, l'eau est décantée par une ouverture spéciale placée au pied du vase et du moule.

Pour le coulage des pièces de grande dimension, la manufacture le Sivres emploie des procédés spéciaux : le coulage à air comprimé et le coulage dans le vide. I.'air comprimé introduit dans le moule maintient contre les parois, par sa force expansive, la couche de pate pendant la décantation et la capillarisation; le vide produil dans le moule conduit, par un phénomène inverse, au même résultat. Grủce à ces procédés, on peut couler d'une seule pièce des vases énornes qui ne soblieudraient jamais autrement. Lorsque la dessiceation est jugce suffisante et lorsque la pâte coulée a la consistance nécessaire au tournassage, le moule est démonté et la pièce installée sur des tours spéciaux où se fait le réparage. Dans des loges, qui occupent une des travées te l'atelier de tournage, sont placés les artistes chargés de réparer les pièces en clu, e'est-à-dire de boucher avec de la pâte les cavités et gergures que le moulage et le loulnassage ont produites, de donner aux figures, aux groupes, par le moyen de l'éliauchoir et de la gouge, leur perfection de formes, leur souplesse de lignes at de contou's, de faire les assemblages des divers fragments du moulage, de garnir les pièces de leurs ornements en saillies, anses, becs, etc., moulés ou ébauchés à part, de coller les diverses parties d'une pièce. Ces opérations très délicales et d'une grande ịnportance exigent de véritables artistes. Les répareurs, à Sevres, sont traités zomme tels; ils marchent avec les sculpteurs et les peintres.

Tournées, coulées ou moulées, les pièces sont, a partir de ce mounent, prules à subir un premier feu, dit de dégourdi, qui a pour but de raffermir la pate, afin qu'on puisse plus aisément lui donner sa couverte et, dans certains cas, la sculpter, la graver ou la 
réticuler. Cette demi-cuisson se fait dans les parties supérieures des fours, où la température ne s'élève jamais beaucoup. Viennent ensuite les općrations de la pose de la couverte en émail translucide qui recouvre la pate de la porcelaine et lui donne cette glaçure si délicate et si chatoyante qui constitue une de ses qualités essentielles. L'énail s'obtient au moyèn de la pegmatite ou feldspath, mélangée de quartz, roclie très dure qui se rencontre parliculièrement dans la régrion des gisements de kaolin. Les cailloux de permatite sont d'abord calcinés, puis concassés dans des moulins Alsing où ils sont réduits en poudre. On mélange de la craie au feldspath pour lui servir de fondant, et la matière définitive de la couverte est placée dans des cures à eau où elle se délaye. A Sèvres, le posage de la couverte a lieu de trois façons: par immersion, par irrorition, et par volatilisation. Dans l'immersion, l'ouvrier trempe purement et simplement la pic̀ce dins la cuve, pleine d'émail liquide, où l'on a versé préalablement une certaine quantité de vinaigre, qui a la propriété de retarder la précipitation des matières en suspension. L'irroration se fait aujourd'hui au moyen de vaporisateurs à air comprimé. Celte irroration très simple permet de poser la couverture sur les gran des pièes avec une facilité et une précision qu'on ne pourrait jamais obtenir de l'immersion toujours fort codteuse et très dangereuse. Où, avec l'ancien procédé, il fallait 100 kilos de couverte, 1 kilo suftit abondamment avec l'irrorateur. Deux ouvriers, au lieu de dix, sont necessaires; l'un mancuvre l'appareil, pendant que l'antre fait tourner la piece sur une rondelle. Enfin, la volatilisation consiste à remplir le four ou les cazcttes d'une vapeur saline ou métallique qui, s'étendant sur les pièces arrivées a l'incandescence, vitrific leug surface. Avant cette dernière opération intervient l'encastage ou placenent des pièces ì cuire dans des étuis dits cazettes, destinés à les protéger et à les supporter dans le four. La fabrication des cazettes se fait dans de conditions peu difrérentes de la pate de porcelaine, mais avec des malières plus grossières et muins fusibles, de l'argile de Dreux, du sable et du ciment. Les pièces encnslíes sont placées dans les fours, suivant des méthodes variables qu'il serait trop lo:ig de développer ici. L'enfournement est une des opérations de l'industrie céramique qui exige le plus de soin et d'habileté; une erreur ou un oubli peut compromettre toute une fournée, dont la valeur est souvent d'une vingtaine de mille francs. Sèvres possède huit grands fours, six à flamme renversée et deux à flamme directe. Ces dernier's sont destinés a disparaitre, le premier système étant plus près de la perfection et plus économique. Un four à namme directe consomme 30 stères de bois par 30 inetres cubes; le four à flamme renversée, la moitié moins. La température du four atteint environ 1,800 degrés, condition indispensable pour que la vitrification du kaolin s'opère intégraleınent et que la pùte devienne de la porcelaine parfaite. Pendant quarante heures, nuit et jour, le chef de la fabrication et les chauffeurs, sous la direction d'un chef, ne quittent point le four, surveillent attentivement, au moyen du pyrometre et des montres en porcelaine, la gradation de la température, activent ou diminuent les quatre foyers, entassent les lourdes bưches de bois sur les alandiers, en tirent la braise qui ressemble d de la neige rosée, ouvrent ou ferment les bouches de cette mer de feu, où l'œil qui observe par les visieres croit voir des tourbillons de lave en fusion parsemée de diamants, de rubis, de topazes, ete. Lorsque les montres ont prouvé que la porcelaine est cuite, le chef ordonne l'arrêt du feu. Le four refroidit pendant huit jours, au bout desquels a lieu le défournement.

Au moment où la première cazette est retirée, lorsque la première pièce en sort, 
les céramistes éprouvent toujours une certaine émotion; mỏme avec les progrès de la science, l'inconnu continue à se mèler à ces opérations, particulièrement délicates. II faut si peu de chose, un grain de quartz ou de calcaire, une vapeur de pyrite, un coup de feu, pour rendre une pièce manvaise. Le moindre défaut d'ébauchage ou de tournassage. la plus légère erreur d'un répareur, dissimulés jusque-li, réapparaissent éclatants. Lorsqu'il s'agit d'une de ces grandes pieces, il laquelle ont travaillé, penlant de longs mois, vingt colliborateurs de talent, sculpteurs, peintres, modeleurs

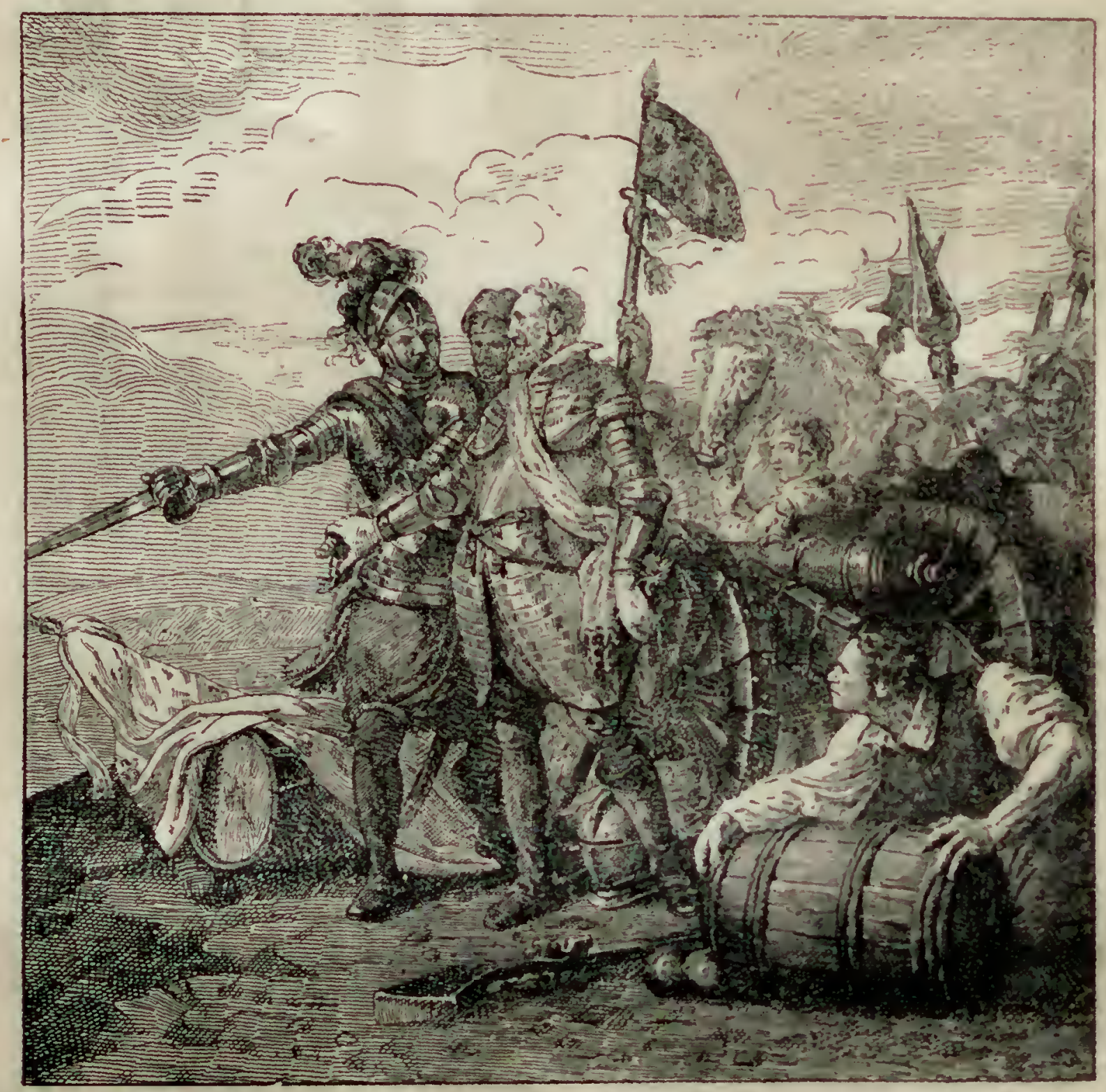

Les Gobelins. - Henri IV fuisunt entrer des tures duns $l$ ants

(tapisserie exẻculée en 1816).

et répareurs, quelle anxiété parmi tous ces artistes qui, vieux on jeunes, aiment passionnément leur métier et tiennent à honneur de conserver à leur manufacture sun grand renom! Ils sont là tous, depuis le plus modeste mancuv'e des moulins jusqu'i l'administrateur, réunis devant la yueule béante du four, guettant la sortie du clicfd'œuvre, et attendant, le cœur serré, son apparition au grand jour.

Chaque défournement est suivi d'une conférence générale des chefs de service, qui étudientavec soin les qualités et les défauts de toutes les picces, analysent minutieusement les accidents et consignent leurs observations sur un registre spécial. Les critiques, les félicitations ou les conseils sont transmis alors directement a l'artiste, à qui incombe la responsabilité des accidents, ou à qui revient l'honneur du succès. II y a 


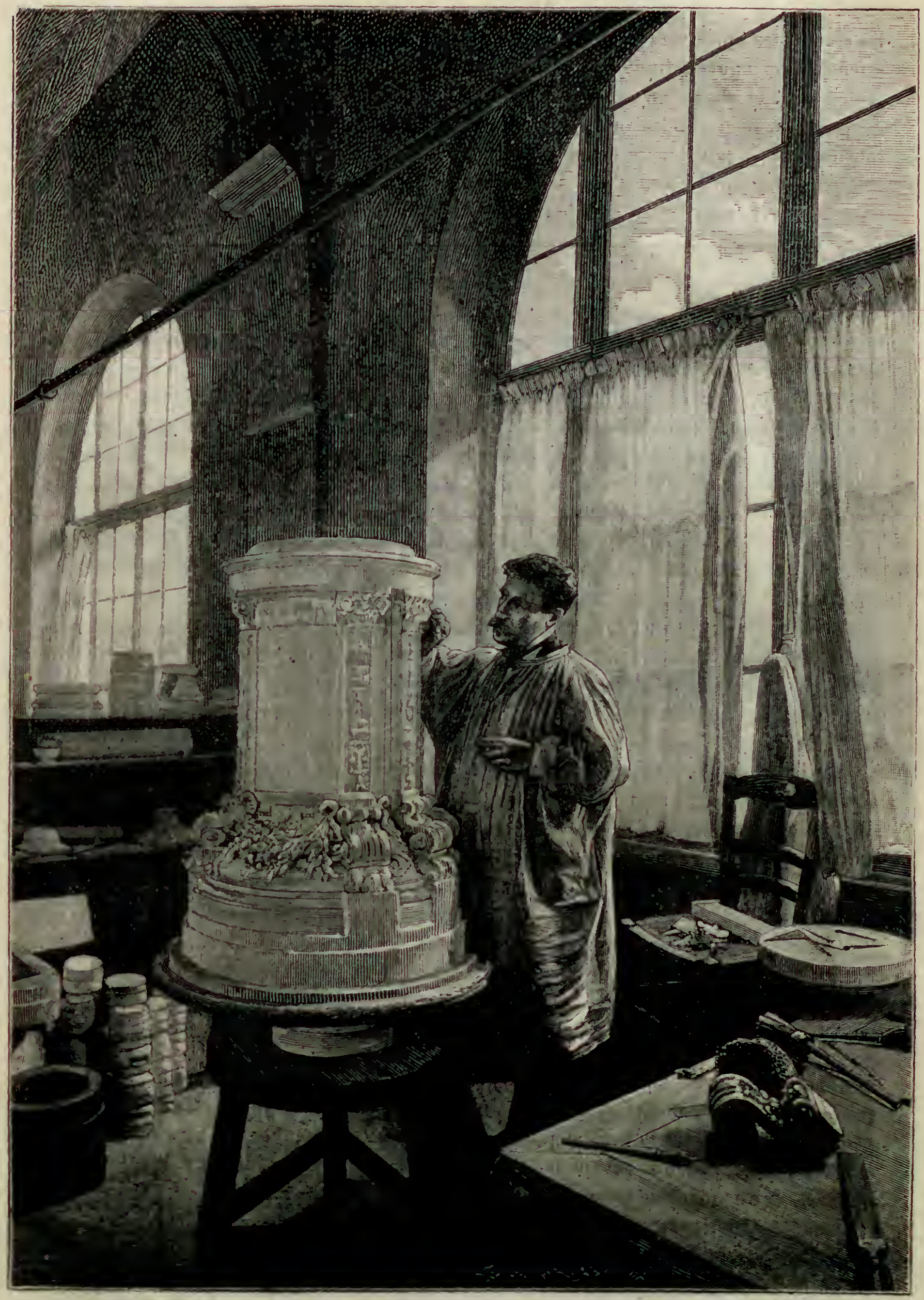

Sèvres. - Atelier des sculpteurs. 
ainsi émulation constante entre tous les ateliers et tous les artistes de la Manufaclure. Le rendement d'une fournée donne les proportions suivantes : 30 0/0 de très bon, $230 / 0$ de bon, $100 / 0$ de passable st $300 / 0$ de maurais; mais cette dernidre qualification est spéciale à Sèvres. Certain produit classé dans la catégorie des mauvais serait considéré comme satisfaisant, dans les manufactures particulières les plus importantes et les plus soucieuses de leur réputation.

En mème temps que des pièces en blanc, les fours renferment aussi de la porcelaine décorće. Deux systèmes sont en usage pour la décoration de la porcelaine : la décora. tion au grand feu et la décoration au feu de moulle. On obtient une grande variété de nuances en employant une suite de procédés intermédiaires. Dans le système du gुrmul feu, la pièce crue ou dégourdie est décorée au moyen de mélanges renformant des axydes sur lesquels on étend la couverte d'émail, par immersion ou par irroration. La pièce est ensuite soumise à l'action d'une température qui s'élève a 1,800 degrés. Les couleurs vitrifiables se développent sous la couverte, samalgament chimiquement avec elle et obtiennent ainsi l'éclat, la profondenr et la transparence qui caractérisent la décoration de grand feu. Dans le système du feu de moufle, on ne se sert que de porcelaine en blanc, c'est-à-dire cuite. Le peintre décore sur la couverte avec dus mélinges d'oxydes colorants et de fondants, puis l'objet est soumis il l'action d'un feu doux inui ne s'élève pas a beaucoup plus de 300 degrés. Les couleurs fondent at adhirent en enduit opaque sur l'émail, sans s'identifier avec lui comme dans le grand léll. Il y a a Sèvres vingt-cinq fours de moufle. Depuis que la nourelle porcelaine de sécress it ité découverte, on peut se servir, sur une matière ayant la résistance de la porcclaine dure, des couleurs qui s’altéreraient au grand feu, et qui, dans les nourelles conlitions te cuisson, font parfaitement corps sous la couverte. Toutes les délicatesses du pinceau se trouvent reproduites très nettement et açuièrent la vibration lumineuse el la Irauslucidité de l'émail.

La manufacture de Sèvres occupe actuellement vingt peintres doreurs el décrateurs, dont plusieurs sont des artistes de talent; des ateliers particuliers sont mis it leur disposition ainsi qu'à celle des sculpteurs qui donnent les modẻles ou décorm los pièces. Lorsque les objets sont retiris du four, ils passent entre les mains des muuleurs et des brunisseurs, puis aux magasins des sous-sols où ils sont classés comme pitce de. vente ou pièce de réserve.

Les ouvriers occupés au montage deviennent de moins en moins nombreux depuis que la fabrication des vases en une seule pièce a rendu inutile la longue et minutiense opération de l'ajustage des fragments. Les nouveaux modeles n'exigent pas non plus autant d'anses et de garnitures en métal que les anciens, oì le bronze tenait une place quelquefois exagérée.

Au-dessus de l'atelier des fours à mouftes est situé le laboratoire de chimie d'où sont sorties tant de combinaisons merveilleuses, de nuances délicates, de découvertes de pates nouvelles et on le travail opiniatre de lacarniste moderne ravit aux poterins chinoises de King-Te-Chin et Nan-Chang-Sao, ainsi qu'aux céramiques japonaises dOwari, de Kisto et d'Hizen, leurs secrets de fabrication. Les savants qui ont contrilmé à établir la réputation da laboratoire de Sẻvres sont Hellot, Macquer, Brongniart, Ebelmen, Salvetat et Lauth; il est maintenant sous la direction d'un des meilleurs élèves de IVurtz, .II. Vogt: qui le gouverne avec autant de talent et d'intelligence que ses prédécesseurs. 
Les procédés que nous venons d'indiquer n'ont pas toujours existé à la Manufacture nationale de Sèvres; ils ont aé employés aussi concurremment avec d'autres : nous expliquerons dans l'historique de la Manufacture leur origine et leurs perfectionnements successifs.

La naissance d'un des plus grands établissements de porcelaines de l'Europe est fort humble: En 1740, la fabrique de porcelaines de Chantilly, dirigée par un nommé Siroux, occupait deux ouvriers du nom de Dubois, dont l'un était sculpteur et l'autre lourneur. Les opérations de la pate, de la couverte et du choix des terres leur ayant clé confiées pendant quelque temps, ils découvrirent le secret de Siroux pour la falrication de sa pate de porcelaine. Poursuivis par leurs créanciers, ils furent a celte époque chassés de Chantilly à cause de leur mauvaise conduite. Ils se réfugièrent au chatenu de Vincennes, dans la tour du Diable, el se servirent sans scrupule des proculés de Siroux. A l'abri de toute poursuite de la part de leur ancien patron qui ignorait leur retraite, ils parvinrent à enlever à Chantilly un ouvrier fort adroit appelé Gérin. Ce dernier construisit un four de son invention destiné a donner un feu doux anx dorures et aux peintures; il leur rendit d'immenses services, et ce fut gràce à lui qu'ili purent exécuter assez bien quelques pièces qu'ils vendirent à Paris. Une fois, un des clients des Dubois, le marquis du Chatelet, montra à Orry de Fuloy, frère du directeur des Bitiments du Roi, quelques échantillons de leur savoir-faire. Celui-ci, qui cherchait vainement depuis longtemps à fabriquer de la porcelaine, fut tres surpris de voir ces spécimens. Il s'intéressa aux travaux des trois réfractaires, leur fit accorder une partie des battiments de l'Intendance et leur promit meme un secours pécuniaire. Vers ce moment, les nouveaux porcelainiers firent la connaissance d'un épicier de Chantilly nommé Gravant, qui prétendait posséder un secret de fabrication pour la porcelaine, ct ils l'associèrent à leur fabrication. Mais le système employé par Gravant ne donnait jas de meilleures résultats, el la porcelaine des frères Dubois resta assez ordinaire.

Malgré la protection effective d'Orry de Fuloy, qui avait fait obtenir aux associés le manere du chateau de Vincennes pour installer leurs ateliers et un logement dans les bitiments de la Surintendance avec une avance de 10,000 livres de la part du roi, la fabriçne ne put réussir à prospérer. Les frères Dubois, menacés de faịre banqueroute, abandonnerent clandestinement Vincemnes, laissant aux créanciers leur fabrique et son matériel. Découragé par cet insuccès, Orry de Fuloy pensa à se désintéresser complètement de la question; le passif laissé par les fugitifs montait a 30,000 livres plus les 10,000 livres avancées par le roi, et il n'osait en prendre la responsabilité. De plus, ils n'avaient jamais voulu lui confier leur molle de procéder, et il n'était pas sưr qu'ils fussent en possession de recettes particulieres. Il allait donc faire ordonner contre eux des poursuites judiciaires, lorsque Gravant lui offrit de continuer encore pendant quelque temps, pour son compte, les experiences, en lui promettant d'obtenir rapidelirent de la porcelaine fine. Gravant, qui arait fort peu de délicatesse, avait profité des moments où les frères Dubois se trouvaient en élat d'ivresse pour prendre copie de lenrs notes sur la fabrication des pates el la cuisson de la porcelaine; il réussit en outre à débaucher plusieurs ouvriers de Chantilly. Vers cette époque, un sieur Caillat vendit à Orry de Fuloy le secret de la composition et de l'application de plusieurs couleurs.

En 1740 , la Manufacture donnait d'assez beaux résultats pour qu'Orry de Fuloy se risụnit à constitucr une Société d'exploitation dont tous les membres utrient intéressés 


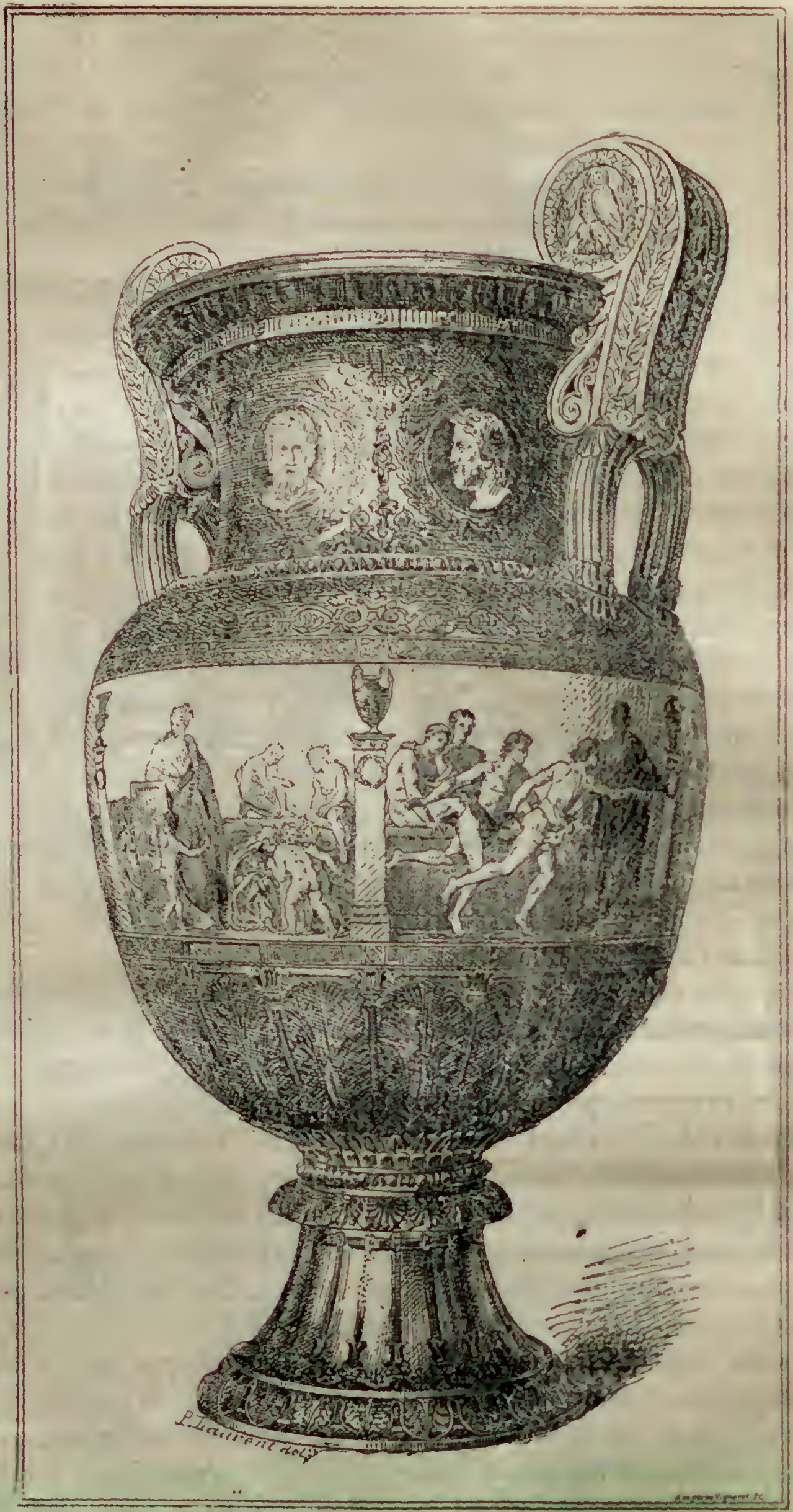

Sèvnes. - Grand vase à décor jaspé, moulé en bronze dore.

dans les Fermes; 90,000 livres constituèrent le fouds social et le roi abandonna les sommes qu'il avait avancées aux frères Dubois. Par l'acle d'association, Cravant sengageait à livrer tous ses secrets de fabrication à Orry de luloy, moyennant quoi, si la Manufacture se soutenait pendant dix années, à compter du $t^{e_{r}}$ janvier 1746 , il lui serait 


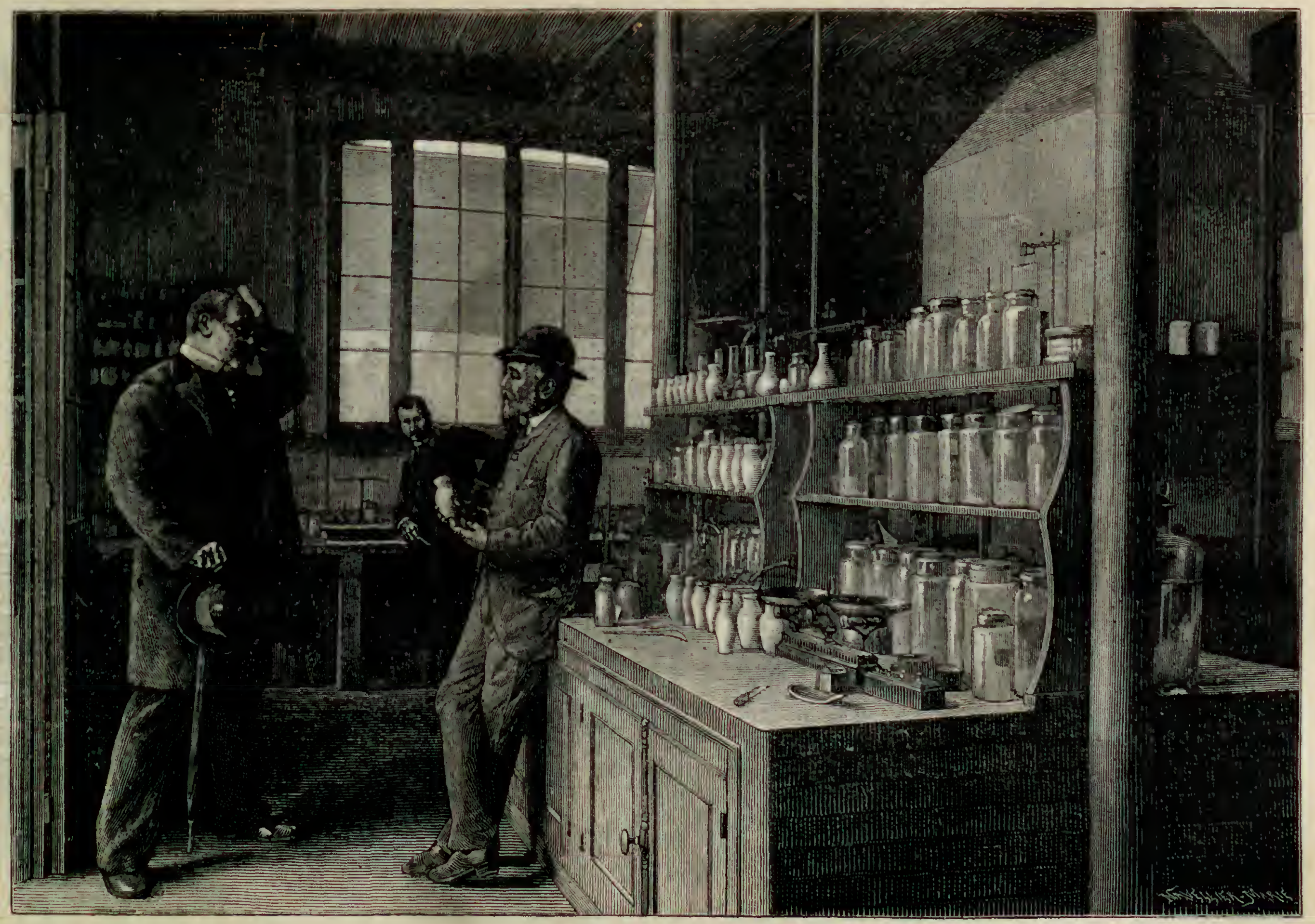

SÈvres. - Le laboratoire de l'udiministrateur. 
payé, à l'expiration des dix années seulement, la somme de 24,000 livres et jusqu'alors, à compter du $1^{\text {er }}$ janvier 1748 , la somme de 1,200 livres par année. Orry de Fuloy obtint de nombreuses facilités d'organisation par l'influence de son frère : le roi octroya à la nouvelle société, le 24 juillet 1745, un privilège exclusif de trente années, au nom de Charles Adam, pour l' " établissement de la Manufacture de porcelaine faron de Saxe, au chateau de Vincennes $\$$. Il donna, en outre, au titulaire la jouissance des batiments de la Surintendance, du manège couvert at de la ménagerie située au Bel-Air.

Orry de Fuloy porta ensuite toute son attention sur la composition de son personnel; mais, malgiré le zèle et l'habiloté des administrateur's, la situation financière de la Manufacture s'aggravait chaque jour, et il fallut que les associés fissent de nombreus sacrifices pécuniaires pour la maintenir.

En 1749 , la Manufacture livra à la vente des fleurs de porcelaine dont la cour s'engona et qui eurent un grand succès, même i l'étranger. Er 17ä3. Louis XV commanda un grand service de table, à fond bleu céleste, décoré de fleurs, service qui couta 60,000 livres et qui fit l'admiration de tous. La Manufacture avait, it ce moment, réussi à trouver la composition régulière d'une très belle matière, se pliant a toutes les formes par sa plasticité et susceptible de recevoir les décorations les plus délicates en opposant aux couleurs sa blancheur laiteuse. Un Mémoire de la direction, datant de cette époque, nous a transmis la composition chimique et le mode de préparation de celte matière nouvelle. Pour faire une cuite de 6,264 livres, est-il dit dans ce mémoire, on mélange :

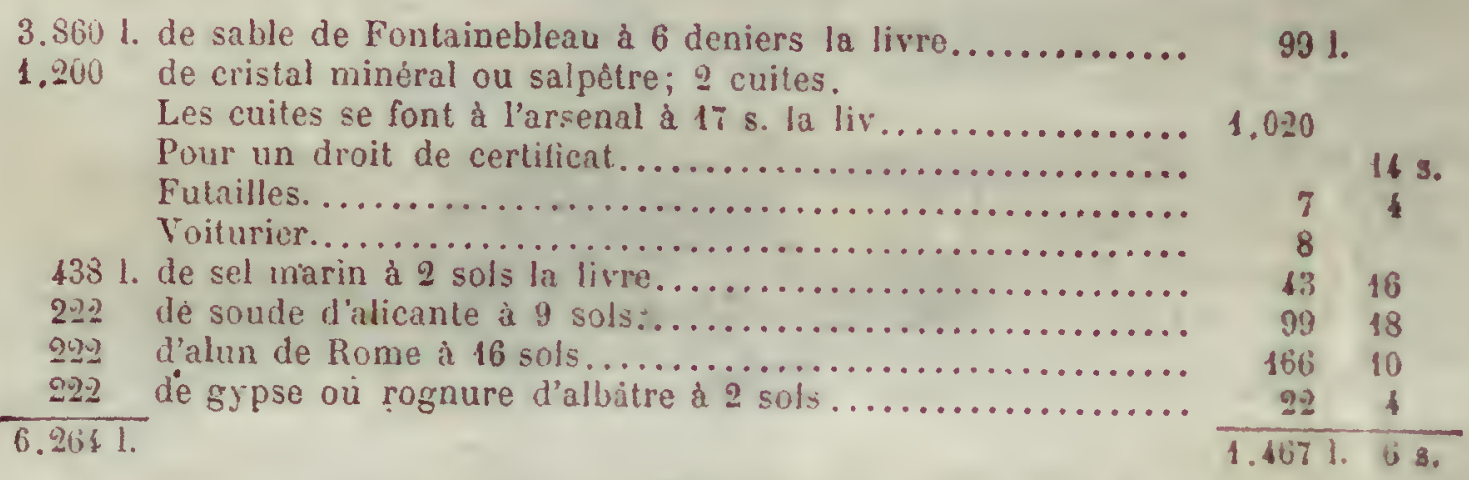

Lorsque le mélange est parfaitement bien fait, explique le Mémoire, on en forme une couche d'à peu près un pied d'épaisseur sur un bane de sable, sous le four de fritte; on fait un feu gradué pendant environ cinquante heures; on pousse le four jusqu'au degré de couleur de citron. Il faut observer de le ménager beaucoup plus lorsqu'il est parfaitement rouge jusqu’à rinstant de le quitter; il faut que la fritte soit bien blanche sans cependant ètre trop vitrifiée; s'il se trouve des parties de frittes rougeâtres, c'est un signe assuré du trop peu de feu qu'elle aurail eu; alors on repasse ces mêmes parties rougedtres au four prochain et on les place sur la nouvelle composition. On pile ces matières que l'on voit suffisamment frittées, el quand elles sont -éduites en poudre, on fait la composition suivante : on prend 900 livres de fritlo en loudre que l'on met dans les tinettes de moulin avec 300 livres de marne d'Argeneuil; le tout étant broyé ensemble, l'espace d'environ trois semaines, forme une pate liquide que l'on fait sécher dans des auges destinées pour cela; lorsqu'clle est seclie, on la porte au blutoir pour l'écraser avec des cylindres a main et la bluter, et ensuite on la porte dans un endroit où on forme des ballons en l'imbibant avec de l'eau scule ment; c'est ce qu'on appelle pâte neure. 
Les partics de patc provenant des répareurs, tourneurs et unisseurs, se réduisent en poudre et pour les faire resservir utilement, on les mêle avec un tiers de patte neuve; pour imbiber le tout et lui donner du liant pour mouler tous les grands oljjets et la platrerie, on se sert de l'eau bouillante et du savon vert; on se sert aussi de ce moyen pour la pale neuve quand on la destine à mouler de grands objets et la plâtrerie ; sans cela, elle n'y serait pas propre. On appelle celte pâte chimisée. Pour la composition de la couverte, on emploic les matières suivantes:

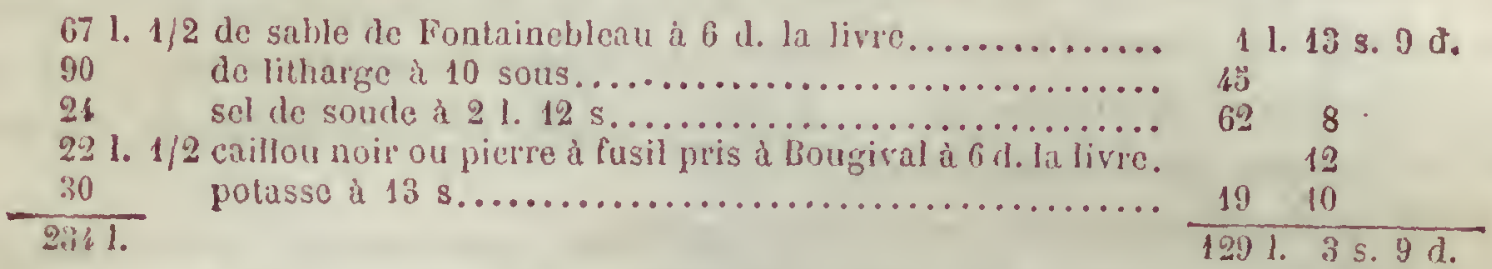

On mc̀le toutes ces matières ensemble, et après les avoir passées au crible, on les met dans soixante creusets; on les place sous le four de biscuit de porcelaine tendre et quand on les retire, on les casse; on épluche bicn scrupuleusement le cristal, on le pile au moulin; ensuite on le broie comme la pate avec de l'eau, et pour l'employer on y met lu vinaigre blane qui le fait adapter ou prendre facilement sur la porcelitine en biscuit.

Ainsi en possession d'une matière première souple, blanche, ductible, transparente, In Société varia rapidement ses objets de production, et composa des modéles originaux, abandonnant l'imitation des porcelaines de Saxe et de l'Extrème Orient. Voici, d'après les documents du temps, la liste des principaux articles fabriqués d Vincennes, avec leurs prix :

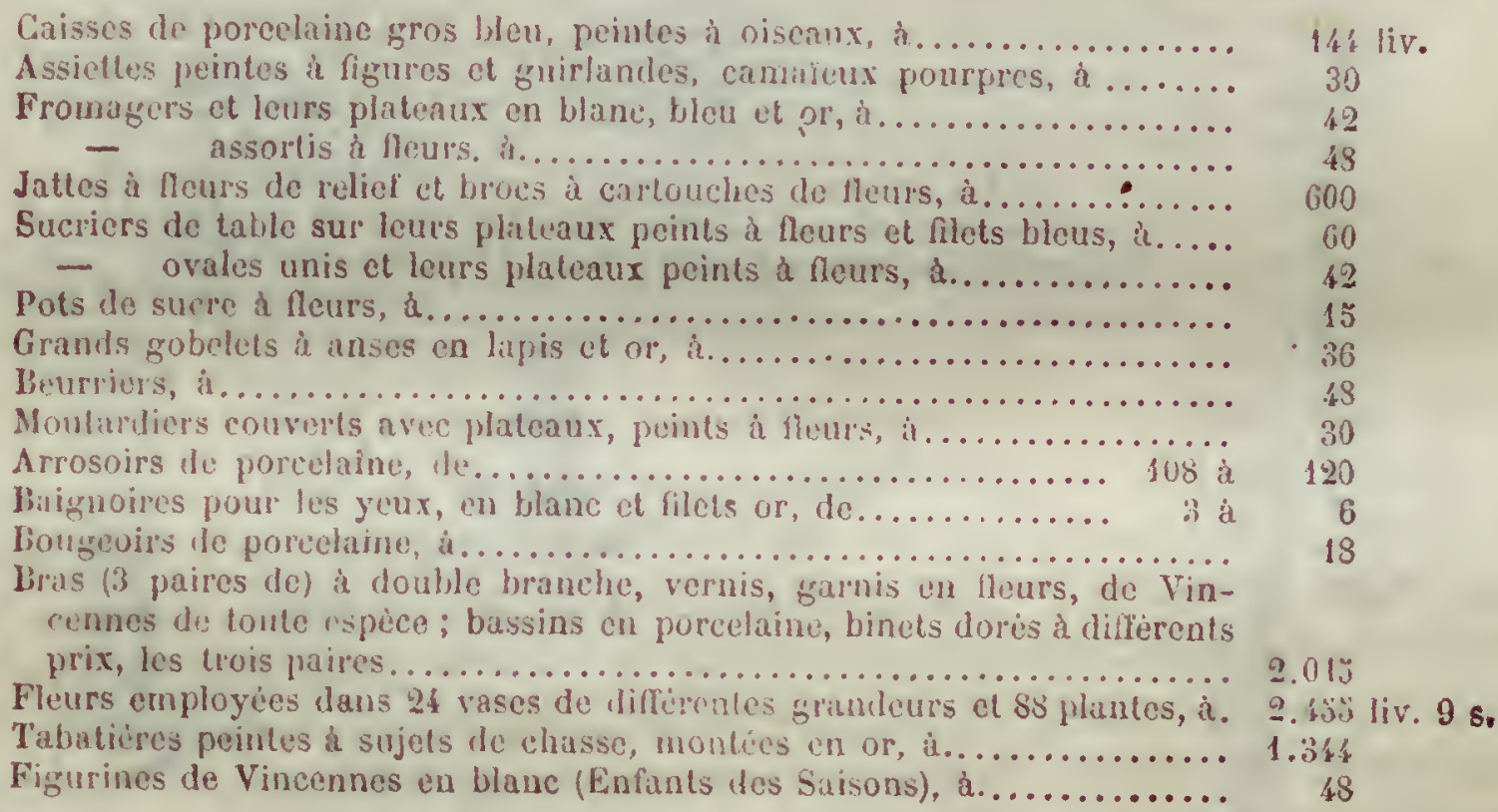

La porcelaine tendre devint promptement ì la mode; il fut de bon ton, du meilleur ton à la cour et à la ville, d’avoir de helles pièces de la Manufacture. En 1 ̈̈ö3, Louis $\mathrm{XV}$ donua le privilège de la manufacture a Eloi Brichard, mais se réserva " le secret des compositions qui entrent dans la fabrication, peinture et dorure de la porcelaine •. La nouvelle Compagnic, trop a l'étroit au chateau de Vincennes, trop éloignée de Versailles et de la Cour, transporta la manufacture à Sèvres. Dès ce moment, et avant meme que $M^{m_{*}}$ de Ponpadour eut couvert la manufacture de sa protection, la pate et la décoration de la porcelaine avaient atteint un haut degré de perfection. On avait créé un style particulier. On était en possession de la formule des principales 
couleurs. " Sur une pâte d'une transparence agréable et d'un aspect velouté, on était parvenu à faire des fonds d'une couleur charmante. D'abord, e'avait été le splentide bleu de roy, marbré, veiné d'or ou uni, et toujours aussi riche de ton qu'une pierre

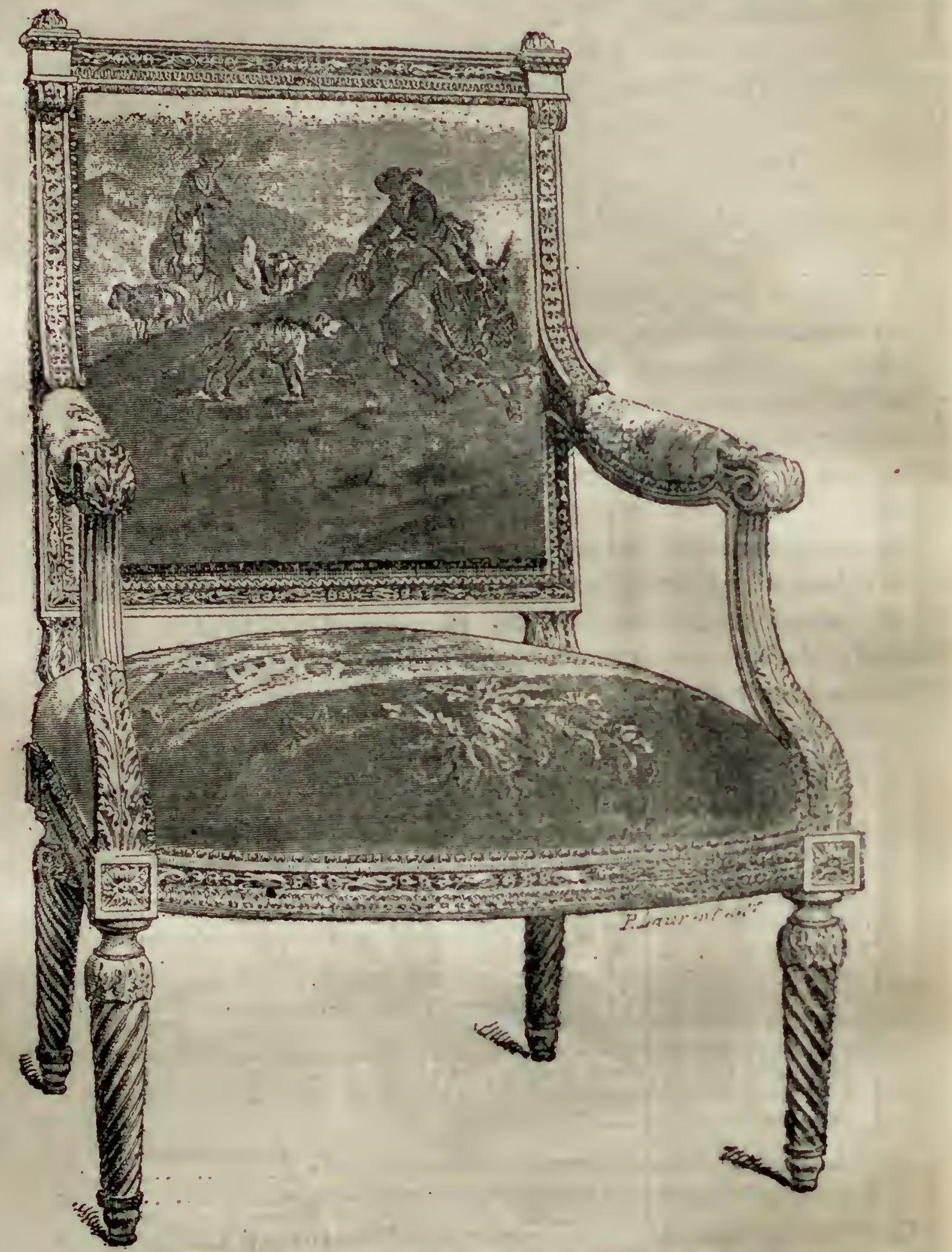

Beacrals. - Fauteuil en tapisserie (dessin de Casadora).

précieuse. Puis en 1732, Hellot avait découvert ce bleu célcste si fin, qu'on nomme bleu turquoise. Longtemps auparavant, la Manufacture avait mis à profit l'inventium de l'orfèvre Taunai, qui permettait d'appliquer sur la porcelaine cinq ou six nuances de rouge, l'incarnat, le pourpre, le rouge cerise, et nous savons également qué la ma. nufacture avait acquis du frère llippolyte des procédés de dorure presque parfints. Sous la directian de Duplessis, il avait été créé une série de modèles charmants, d'une 


\section{LES MERVEILLES DE L'EXPOSITION}

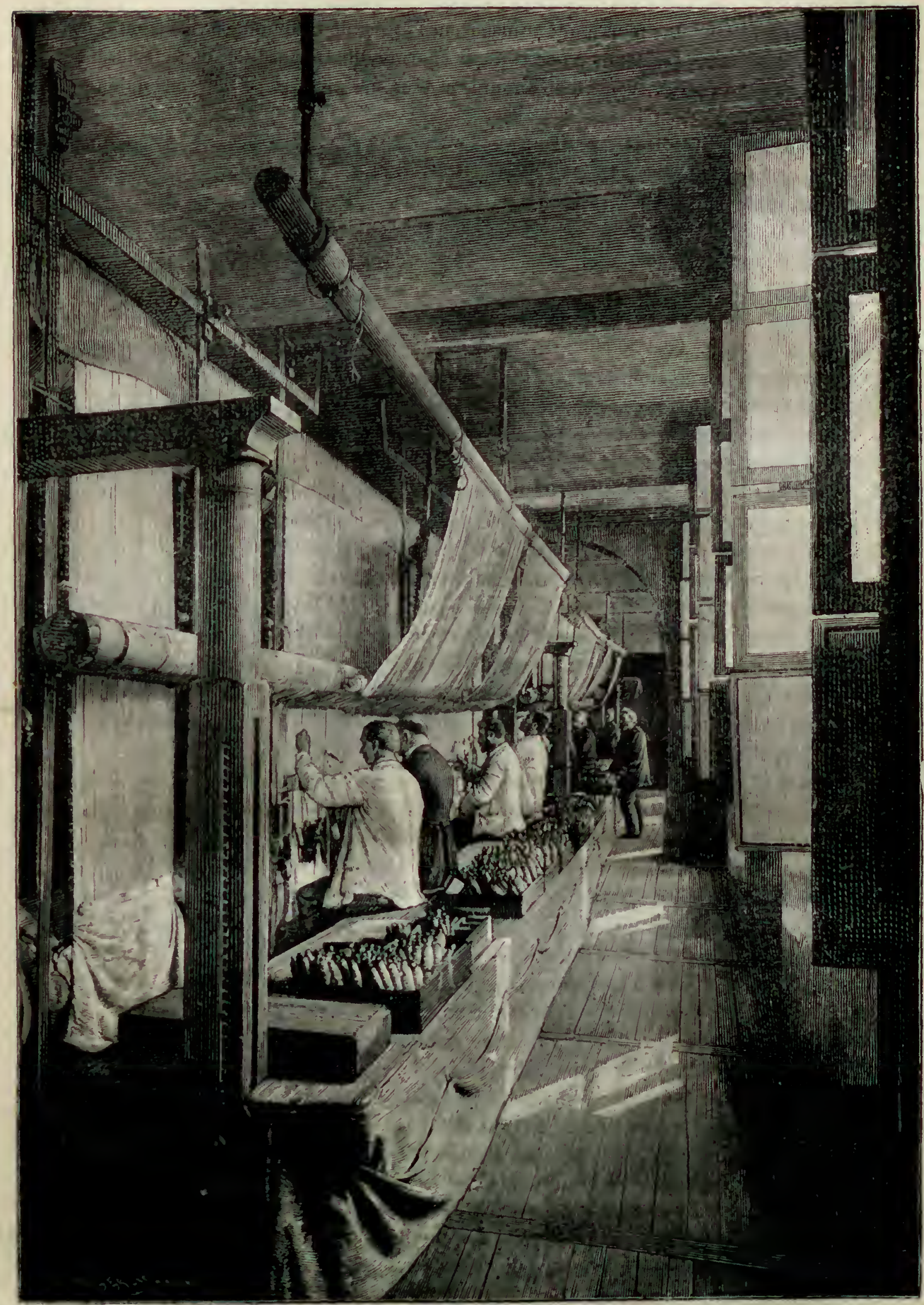

LES MÉTIERS DE LA SAYONNERIE. - Aspect actuel. 
gràce, d'une élégance exquise, auxquels, trente ans plus tard, Bachelier ne tronvait it reprendre que leur forme légèrement baroque et un pcu trop tourmentée. Enfin, n'oublions pas que, dès 1749, Bachelier avait proposé d'exécuter des petits groupes sans couverte.

Du temps de Mme de Pompadour, la mode aidant, la pate tendre de Sevres eut de nombreux acheteurs. Une foule d'artistes de valeur consacrèrent leurs soins à la fabrication de ces précieuses porcelaines. Les rases de grande ornementation et les biscuits de Sèvres passionnèrent l'Europe entièrc. Au bleu de roi s'ajoula le rose carné, dit rose Pompadour, puis le violet pensée, le vert pomme, le vert anglais, le jonquille, permettant d'obtenir des fonds d'une fraicheur exquise, d'une richesse éblouissante, sur lesquels les peintres s'exercèrent à jeter des décorations d'un gont parfait. Jusquelà, on avait pris dans l'orfèvrerie les présents diplomatiques. Louis XV substilua à l'orfèvrerie la porcelaine de Sèvres, et cette innovation reçut le meilleur accieil. lit pourtant, les affaires de la Manufacture étaient en fort maurais état, a ce joint que lo privilège d'Eloi Brichard fut réroqué et deviut propriété royale sous le titre de Manufacture de porcelaine de France.

Au début de la seconde moitié du xrü siècle, la Manufacture entra dans une période marquée par la création de formes alors originales, derenues classifuez diris la suite : le vase Duplessis, ovoïde, avec lètes d'éléphant, qui, partant du col, forment l'anse; le vase Adélaïde, en forme d'cuuf supporté par trois pierls faits do fruilles d'acanthe; le vase Cobelet, d'une forme très typique, la panse eflilée à profondes cannelures et insérée dans une sorte de large corolle dont les branches amineies forment anses ; le vase Gardin, large panse, arec des masques de faunes aux anses et le couvercle surmonté d'une pomme de pin; le vase Choiseul, large coupe náriculairn, à panse godronnée; le vase La liue soutenu par deux tritons enlacés: le vase Bachelier, en forme de tonnelet avec ceinture de médaillon en relief. "Cetle yérisirle de 1669 à 1774 est assurément la plus brillante de l'histoire de Sèvres. L'art y fleurit avec éclat. Toutes les cuvres qui en sortent ont un cachet d'originalité et de haute élégance. Un administrateur dune rare intelligence assure la prospérité financière. Enfin, il n'est pas jusqu'à $\mathbf{I}^{\text {me }}$ Dubarry qui ne se montre aussi des plus passionnées pour les produits de la Manufacture et, afin de ne pas renoncer au titre de protectrice des Arts, dont $\mathrm{Imo}^{\text {me }}$ de Pompadour a fait un des apanages des grandes farorites, elle lui fait des commandes considérables. Pour constater son gout pour ces frazilus ouvrages, il n'est besoin au surplus que de pénétrer chez elle. Dans le salon du pavillon de Luciennes, on voyail sur la cheminée une magnifique pendule à culonnes. ornée de figures de porcelaine; au milieu une superbe table ornée de porcelaines de France, le dessus, qui était le morceau principal, représentant un tableau en niniature d'après Leprince. Une belle commode, richement garnie de bronzes dorés au unat était ornée de cinq panneaux de Sèvres. Il y avait, dans sa chambre d̀ concher, une autre commode plus belle encore, ornée de tableaux de porcelaine d'après Watteru et Van Loo. Plus loin, c'était un secrétaire-armoire, orné de porcelaines de Sivres, fond vert, à fleurs, et dont les bronzes étaient merveilleusement finis. Sur des meubles fournis par Gouthière, se trouvaient deux cuvettes a mettre des fleurs, fond vert i minialures représentant des marines, et trois autres, fond gros bleu, caillouté d'or, décorées de sujets d'après Teniers. La cheminée du cabinet était ornée d'une pendule à rase et serpent en bronze doré d'or moulu, à cadran tournant, dont le pied était garni de 
porcelaines de Sèvres. On admirait dans la même pièce une très jolie table à gradins égilement en Sèvres, fond vert à cartouches de fleurs, sans compter un thermomètre ct un baromètre de Passement, trìs richement montés en bronze, enrichis de panneaux de mème porcelaine et décorés d'enfints en miniature.

Les vases de dimension colossale datent des dernières années du règne de Lunis XVI. II en est de meme des plaques de porcelaine, dont on tend alors a généraliser l'emploi dans l'ébénisterie de luxe. Mlle Laguerre possédait un secrétaire de furme cintrée, plaqué en bois de rose, s'ouvrant dans le milieu par un battant, orné de trois panneaux de porcelaine, dont l'un représentait une corbeille de fleurs soutenue par un noud de rubans, les autres des guirlandes de roses dans les cadres. Après les meubles, on décora de ces plaques les carrosses.

"C'est il la participation du public dans les commandes et les achats, qu'il faut attribuer en grande partie la transformation subie à cetle époque par la production de Sivres. Celle-ci, en effet, se modela sur les sentiments particuliers qui animaient la sociẻté française. L'histoire artistique de Sèvres sous le règne de Louis XVI se divise cn deux périodes très distinctes. Dans la première, qui va environ jusqu'en 1780, le caractère général des porcelaines au point de vue du décor'et de la forme n'est point sensiblement différent de celui que nous avons délerminé pour l'époque de Louis XV. Les peintres continuent d s'inspirer de Boucher et de Watteau; les médaillons sont consacrés à la représentation de sujets galants, de scènes champètres et de galanteries idylliques. L'ornementation gracieuse et légère se compose de guirlandes de fleurs, de bouquets, de fruits aux délicates et claires colorations. Les figurines des biscuits représentent des marchandes d'amour', des baigneuses, de coquettes bergères. Peu à - peu, une formule artislique nouvelle se manifeste. L'allégorie, de galante devient philosophique. Une exécution habile, une pratique savante du métier, appris à l'école des grands sculpteur's du règne précédent, donnent fort heureusement à cette produc. tion d'idées et d'inspirations assez peu plastiques une forme qui a encore de l'élégance el de la gralce. Mais aux sujets historiques et aux mievreries sentimentales, un naturalisme mal inspiré ne tarde pas à associer des compositions grotesques, qu'on ne se serait pas attendu à voir traduire en une matière si précieuse. Les mèmes causes amenent du reste des effets identiques. A Sèvres comme aux Gobelins, on prend peu à peu l'hahitude de créer. Les peintres ne font plus de dessins spéciaux pour la décoratiou céramique; on commence a emprunter aux tahleaux les sujets de composition et les motifs d'ornementation. On copie en porcelaine, comme en tapisserie, les peintures monumentales. Pendant les dernières années du règne de Louis XVI, l'harmonie charmatrte de couleurs et de formes qui donnait aux auvres des Dodin, des Aloncle, des Fragonard, des Bachelier tant d'originalité et de charme tend à disparaitre pour faire place a un amalgame de combinaisons hétéroclites où le sentimentalisme du temps tient une place considérable. "

L'agitation sociale qui résulte de la Rérolution française n'était pas de nature à favoriser le commerce et l'industrie de luxe. Les acheteurs manquaient dès 1789, et l'on songea un moment, en haut lieu, d abandonner la Manufacture; on se contenta de restreindre les frais de l'établissement. La République fut proclamée en 1792. du milieu des troubles intéricurs et extérieurs qui agitaient alors la France - tant est laborieux l'enfantement de la liberté - la Manufacture décrut à vue d'œil, mais le gouvernement ne congea pas un instant à la supprimer. Le 9 floréal an VIII, Bron- 
gniart en fut nommé directeur, sur la désignation de Berthollet, chargé par le ministre de la mission délicate de choisir le nouveau directeur parmi les savants les plus aptes à ces fonctions. Aussitôt après sa nomination, Brongniart se préoccupa de réorganisenr la Manufacture, tant au point de vue artistique qu'au point de vue adninistratif. II pensait qu'une Manufacture nationale ne doit pas vieillir et doit se modifier constamment suivant ic goùt actuel et le progrès des arts. De plus, il voulait introduire dans les atelier's de Sèvres les habitudes d'ordre et de discipline qui distinguent les établissements particuliers, admettre dix apprentis pour former ainsi de bons ouwriers, faire travailler aux pièces et employer des femmes pour les ouvrages de décoration in peinture. Toutes ces réformes furent approuvées par le ministre de l'Inlérieur et lí situation précaire de la Manufacture empècha scule qu'on les réalisalt; elle ctait tellc. qu'on ne pouvait même pás payer les ouvriers. A force de démarches. Brongniart finit par obtenir du gouvernement, pour ses ouvriers, une allocation mensuelle de $\check{3}, 000$ francs, qui fut portée peu après à 150,000 franes. Il organisa la vente vlirecte des produits de la Manufacture, et en fit une exposition publique au Muséum. Grace à ces mesures habiles, le budget de la Manufacture se trouva enfin en équilibre en $\mathbf{1 8 0 1 .}$ Cette année-là, les recettes s'élevèrrent à 221,330 francs et les dépenses ì 221,2930 francs. Non content de ce beau résultat, Brongniart conçut le projet d'étendre l'activité de la Manufacture à toutes les branches de l'art céramique. Il proposa au ministre de l'Intérieur de fonder à Sèvres une fabrique de faience fine et de terre de couleur, en lui faisant observer que toutes les fabriques semblables en France étaient en pleine décadence. La Manufacture de Sèvres devait, dans ce cas, faire une terrible concurrence a l'Angleterre. Mais le ministre ajourna la réalisalion de ce projet par suite de la dépenso nécessaire et pour ne pas introduire à la Manufacture une fabrication nouvelle susceptible de faire supposer que celle de la porcelaine de Sevres n'existait plus ou avait été dénaturée.

La Manufacture passa, le 16 brumaire an XII, dans les attributions du ministère de la Maison de l'Empereur. Napoléon portait un intérèt tout spécial à l'extension et à la prospérité de Sèvres et la visita fréquemment afin de constater par lui-méme l'étut des travaux et les progrès réalisés. II donna également des sujets de décoration, entre autres des motifs militaires. Pendant l'Empire, le budget de la Mauufacture, pris sur Ia liste civile de la Maison de l'Empereur, varia de 270,000 a 314,000 franes, sur lesquels le personnel touchait à peu près 150,000 francs. Les recettes et les dépenecs furent en balance pendant cette période, et de 1810 à 1813 les recettes eurent un excédent de 40,000 francs par année, sur les frais généraux. $A$ près 1806, la Mrnufacture, qui avait pris une grande extension, exécuta des ouvres de grandes dimensions, du plus haut intérèt historique et artistique. Parmi elles il faut citer :

La célèbre table des Maréchaux, de 3 pieds de diamètre, d'un seul hloc, sur le uessin de Percier, où sont reproduits en peinture, Berthier, Bernadotte, Marmont, Davoul. Soult, Ney, Lannes, Augereau, Bessières, le prince Murat, le grand Maréchal du palais Duroc et le grand écuyer, pièce estimée 23,300 francs.

La table rectangulaire, de $1^{\mathrm{m}}, 60$ de long sur 80 centimètres de large, représentant les figures principales du Musée Napoléon, Apollon, Vénns, Minerve, Laocoon et Ilercule, évaluée à 12,000 francs.

Le service Égyptien, comprenant 146 pièces, fond bleu, avec hiéroglyphes en or, et peintures en grisaille de Schweback d'après Jonon, représentant des vues d'Ĺgyple, 
du prix de 44,609 franes; le surtout, en sculpture, figure, au centre, le temple de Phila, sur les cotés, les temples de Teutyris et d'Esfou et deux môles, quatre parties de colonnades relient les temples avec les môles; les images du Sphinx et de Memnon décorent les cxtrémités.

La table des Quatre-Saisons, peintures de Georget.

Presque toutes les œurres d'aṛt exécutées à Sèvres à cette époque sont décorées de sujets à la gloire de Napoléon, soit en représentant les événements historiques ou les personnages de la famille impérialc, ou des sujets se rapportant dune facon plus ou moins directe à l'Empereur. Elles furent, pour la plupart, distribućes à l'étranger sous forme de cadeaux impériaux et de présents diplomatiques. Ainsi, le ministre des Affaires étrangères offrit en 1802 à lord Malmesbury, négociateur du gourernement britannique pour la paix d'Amiens, un service de table, en porcelaine, fond écaille, valant 17,640 francs. En 1808, l'Empereur offrit au czar le service Égyptien; il avait déjà envoyé au mème souverain deux vases, formes fuseau, avec peintures tirées de l'Énéide; un tableau de porcelaine de 40 centimètres de haut sur $\$ 6$ de large, représentant un sujet famand peint par Drölling; une tasse a chocolat, ornée du portrait en miniature de Napoléon, et un autre service, dit service Olympique parce qu'il représentait les dieux, déesses et héros de la Fable, d'une valeur de 60.000 francs. La mème année, l'Empereur fit don au prince Guillaume de Prusse de 20,000 francs de porcelaines, parmi lesquelles il faut remarquer deux rases de Clodion de 80 centimètres de hautcur, peints par Drölling et estimés 10,000 francs. En 1809, Napoléon ofrit au roi de Wurtemberg pour 20,000 francs de porcelaines, services et vases, entre autres le fameux vase du "Triomphe de IEmpercur, et au comte Romanzoff pour 30,000 francs d'objets d'art de Sèvres. Des dons considérables furent aussi faits à l'occasion des mariages et des baptêmes qui eurent lieu dans la famille impériale.

A Sèvres, les produits de la Manufacture n'étaient guère vendus qu'à des visiteurs princiers ou exceptionnellement recommandés. Le reste des produits était absurbé par le service des résidences impériales. Brongnniart, pour soutenir, au milieu de toutes ces exigences, la réputation europécnne de la Manufacture de Sères, s'entoura d'artistes de choix, parmi lesquels nous citerons : larchitecle P'ercier, Lagrenée, Laffitte, Heim, Bergerel, Isabey, Drölling, Demarne, Le Guay, Langlacé, Boquet, Saulnier, Runeau, Coupin, Béranger, Swebach, Salmon jeune, Degault, Robert, Palmieri, Fragonard, Abadie, Chaponay, Buteux, Georget, Parant, Drouet, Sisson, Bouillat, Despérais, Caron, Boullemier, Mre Jacquotot, ctc., qui étaient des peintres. remarquables. Quant aux sculpteurs nous nommerons Cortot, Bosio, Moille, Valois, Chaudet, Petitot, Louis-Simon Boizot. L'ceuvre de ce dernier est considérable; il travailla pour Sèvres presque sans intermittences, de 1765 à 1809 , c'est-a-dire pendant près de cinquante ans. Thomire se fit comme ciscleur en titre de la Manufacture une réputation bien méritée.

En 1814, l'Empire fit place à la IIonarchic, et Louis XVIII remonta sur le trone de ses ancêtres. Le 10 août, le roi risita l'établissement, et accorda aux ouvriers une gratification d'un quart de leur rétribution mensuelle. Brongniart donna sa démission; mais, le 7 novembre, Louis XV111 le confirma dans ses fonctions dadministrateur de la Manufacture royale de porcelaine. L’éminent savant remercia dignement le roi de la faveur qu'il lui faisait, mais sans renier son passé et son attachement à l'Empire Pendant les Cent-Jours Brongniart resta a son poste. Ln 1810, la Manufacture fut 
occupée par les alliés. Brongniart lui-même, dans un rapport adressé à l'Intendant de la Maison du Roi, nous en fait le récit. Nous le reproduisons dans son éloquente simplicité :

"Le 2 juillet, le village de Sèvres à été pris de vive force par les troupes prussiennes; dans la soirée du 2 et dans les trois jours suivants, toutes les maisons de Sèvres ont été pillées et dévastées. La Manufacture a reçu le 2 une sauvegarde prussienne et la protection de MM. les officiers prussiens l'a garantic de tout dommage.

- Le 5 , M. Forster est venu en qualité de commissaire prendre l'administration de la Manufacture au nom du roi de Prusse. Sur 11,000 francs qui se trouvaient en caisse, il en a fait enlever 10,000 qu'il a versés dans la caisse militaire du $4^{e}$ corps.

a Les instructions de M. Forster et celles de M. Kuspch, son successeur, instructions dont ces messieurs m'ont donné copie, portent qu’ils doivent garantir la Manufacture de tout dommage, et verser les produits de la vente dans la caisse militaire, mais après en avoir distrait les sommes nécessaires au paiement des ourriers. La vente rendant très peu dargent et par conséquent ne paraissant pas susceptible de remplir les intentions de l'intendance générale de l'armée, il a été ordonné de faire un inventaire et ensuite de faire emballer toutes les porcelaines pour les transporter a Paris et les vendre au rabais au profit de l'armée prussienne. Cet ordre, donné le 14, a été révoqué le 100 au matin, mais l'inv'entaire a été fait et remis à M. le commissaire Kuspch le 16. Cet inventaire, avec les porcelaines relatives a l'histoire de Bonaparte, monte à 633,000 francs.

" Aujourd'hui 19, l'ordre d'emballer les porcelaines relatives ì l'histoire de Bonaparte pour les envoyer à Berlin s'exécute. Le commissaire prussien a reçu, en outre, l'ordre de réduire tous les prix a moilié; mais, sur les observations que j'ai faites à M. Ribbentropp, cet ordre a été modifié et appliqué seulement aux porcelaines qui seraient livrées à MM. les officiers prussiens, d'après l'autorisation de M. l'Intendant général. M. Ribbentropp, Intendant général de l'armée, m'a expliqué bien formellement aujourd'hui ses intentions qui sont aussi celles du prince Blücher. Les troupes ayant besoin d'argent, la Manufacture du roi ayant été protégée par elles, il demande: $1^{0}$ que la Manufacture contribue pour une somme déterminée; $2^{0}$ que les officiers puissent acheter facilement les porcelaines qu'ils désirent avoir.

- La seconde demande, qui est assez naturelle, est remplie par la mesure mentionnée plus haut. Mais, pour obtenir le premier résultat, M. l'Intendant général menace de vendre au profit de l'armée, à quelque prix que ce soit, toutes les porcelaines confectionnées el il assure que plusieurs spéculateurs s'offrent déjà pour les acquérir. Il se désistera de ce moyen, si le trésor royal veut racheter lui-mème les porcelaines et demander à traiter, mais le plus promptement possible, avec $\mathbf{M}$. le comte de Pradel. C'est dans celle allente qu'il a encore suspendu aujourd'hui l'exécution de la vente de tous les magasins. Je compléterai cet exposé des faits par le bordereau suivant des valeurs livrées jusqu'ù ce moment au gouvernement prussien:

10 En argent . . . . . . . . . . . . 10,000 francs.

¿ En porcelaines livies à des ofliciers et nises à part, suivant un état que je fournirai en son temps. . . . . . . . . . . 24,000 francs.

$3^{\circ}$ En porcelaine relative à l'histoire de Bonaparte........ 53,000 francs. 
" Si on est réduit à la dure et inconsolable nécessité de racheter les porcelaines du roi, et de faire un sacrifice d'argent pour empècher la ruine d'une Manufacture qui a fait quelque honneur, j’ai proposé, dans ma note détaillée du 15̋, les bases suivantes

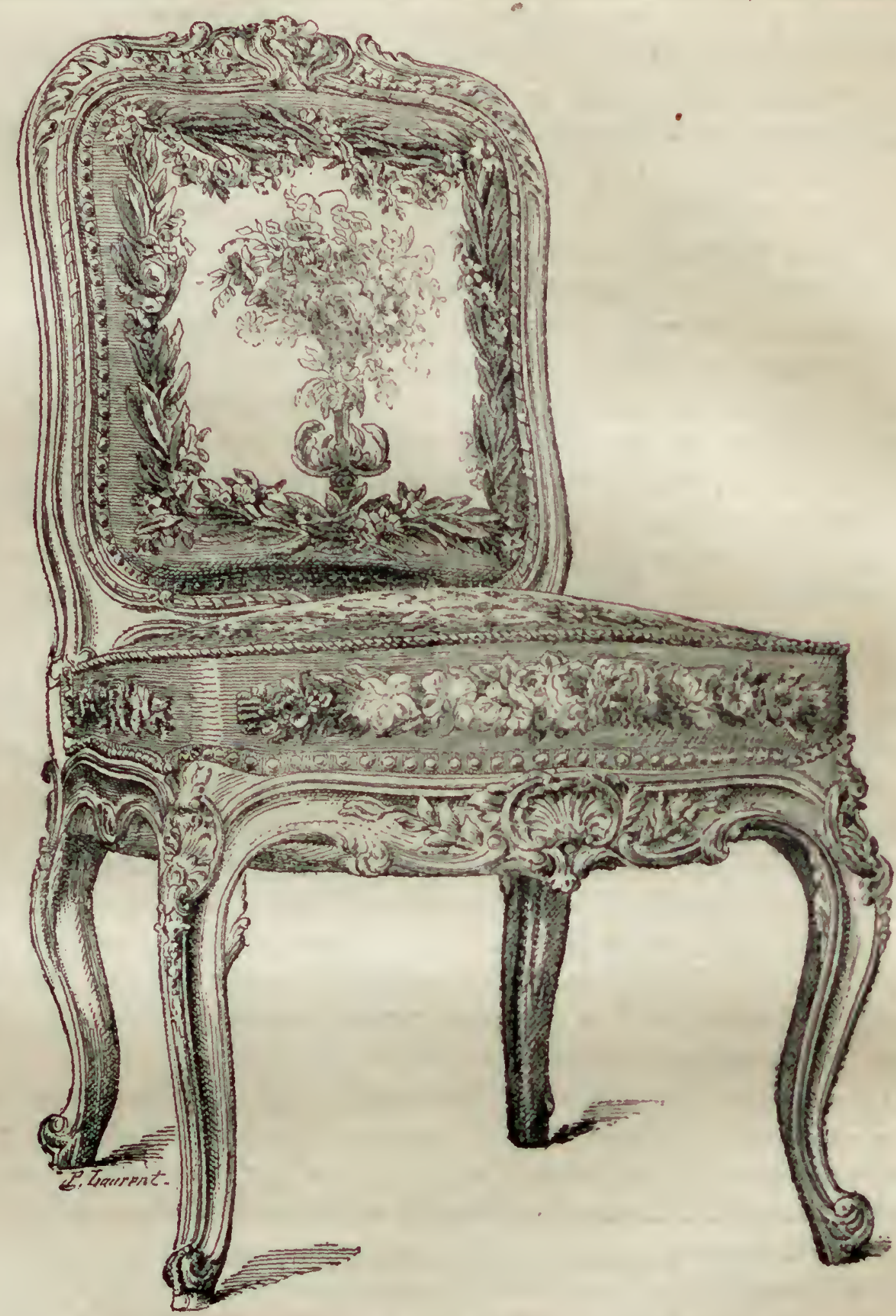

BeAurals. - Chaise recouverte on lapisserie (style Louis XV).

pour ce rachat $: 1^{\circ}$ donner de toutes les porcelaines faites, en y comprenant tout ce qui a été et est à livrer en nature, 150,000 francs; il ne resterait que 60,000 francs à donner en argent; $2^{\circ}$ faire comprendre cette somme dans les contributions de guerre, s'il est possible; on l'empruntera ì des capitalistes en leur assurant un fort bénélice et leur remboursement sur le produit des ventes. Mais ne pourrait-on pas obtenir, en s'adressant directement au roi de Prusse, par l'entremise de $\mathbf{M}$. de Goltz ou de M. de Hardenberg, que Sa Majesté donnat des ordres prompts et formels pour qu'on cessat de 
faire au rol de France la proposition inconvenante de racheter de son allié ses propres porcelaines. Le roi, de son côté, pour reconnaitre les soins que les autorités prussiennes ont pris de sa Manufacture, pourrait offrir tant au roi de Prusse qu'à MM. les officiers employés de l'armée un présent en porcelaine, de la valeur de 150,000 trancs

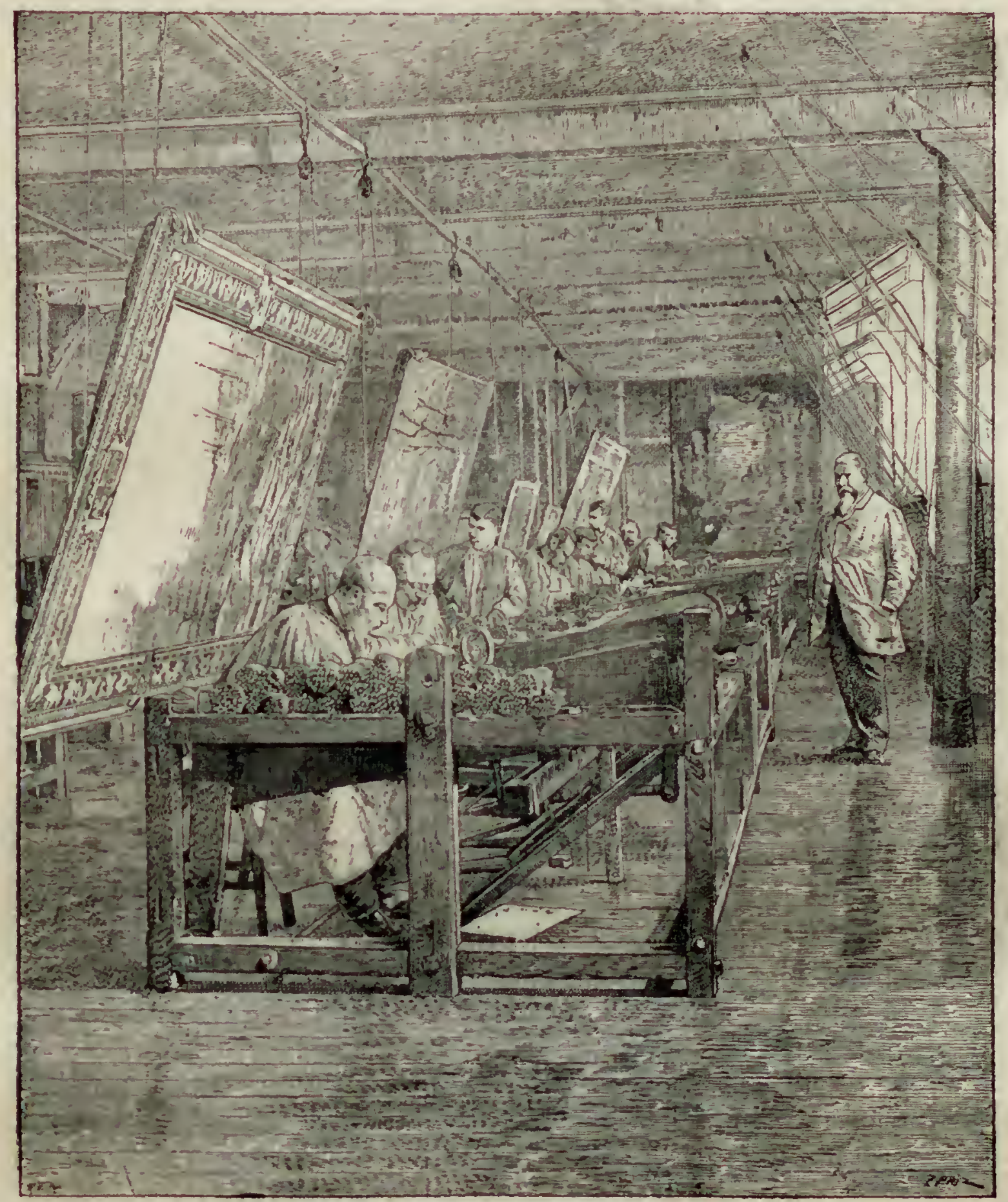

Bratrals. - Intéricur d'un atelier de basses lices.

ou même plus, aux prix de l'étiquette. Ces porcelaines seraient délivrées sur les bons de I1. l'Intendant général de l'armée. Les 86,000 francs de porcelaines déjà livrées feraient partie de ce présent. .

- Sévres, le 19 juillet, 9 beures du soir, 1815.

\section{- Liadministrateur,}

- Alfix. Brongiant.

Le duc de Brunswick fit réclamer ensuite à la Manufacture les porcelaines qui avaient été offertes en 1807 par la Manufacture de Furstenberg et en fit enlever pour Liv. 14. 
environ 1,761 francs. Il laissa ce qui restait de cette série en échange d'un lot de pièces de Sèvres, estimées 4,185 francs. Malgré toutes les réclamations de Louis XVIII lcs Allemands ne voulurent rien restituer de ce qu'ils s'étaient adjugé.

Après le départ des alliés, le roi rétablit la chapelle de la Manufacture et ordonna que l'on recommençat de faire chaque année, au mois de janvier, une exposition des porcelaines de Sèvres dans sa résidence des 'Tuileries, ainsi que cela s'était fait a Versailles au temps de sa jeunesse.

Afin de remédier à la pénurie financière de la Manufacture, Brongniart fit un marché avec trois négociants, MM. Jamard, Islande et Perès, el leur céda, moyennant la somme de 50,000 francs, ce qu'on avait pu soustraire aux Allemands, de porcelaines tendres, tant en blanc qu'en couleur. Ce petit capital permit la reprise des travaux qui furent poussés avec vigueur par l'administrateur.

Brongniart obtint du gouvernement royal que !a Manufacture continuat la filirication des grandes pièces historiques, entreprises sous Napoléon, et chargées de co:sacrer les événements marquants de son règne, en faisant valoir leur intérèt au point de vue de l'histoire technique de la céramique.

La production artistique, à Sevres, ne changea guère de caractère avec l'arènement de Louis XVIII. Les emblèmes, sujets et attributs relalifs à la Royauté furent simplement substitués à ceux qui avaient pour objet la glorification de l'Ermpire, et l'on continua même à représenter les sujets égypticns et antiques si fort en vog̣ue an commencement du siècle. Une tendance funeste menaça, à partir de 1814, d'amener la décadence de la Manufacture: les artistes, au lieu de décorel les pièces de motirs originaux, se contentèrent de faire des copies de tableaux et de représcnter sur les vases, et sur les assiettes, dans les coupes, les portraits du roi, de Monsieur, Ies princes et des princesses de la famille royale. L'art de la décoration perdit ainsi toulu ingéniosité.

Ces travaux de reproduction alternaient cependant avec la fabrication des oljects de fantaisie et de décoration mobilière. En 1822, Percier était chargé d'imaginer les décorations d'une cheminée figurant l'Hirer, avec les signes du zodiaque relalifs à cette saison. Quelque temps après, on exécuta pour le roi, d'après les dessins de Fragonard, une bibliothèque en porcelaine, destince à mettre des lirres religicux. Siır les quatre panneaux de face, en style gothique, étaient représentées les personnalités de la chrétienté. En 1828, un meuble-bureau figura à l'Exposition annuelle des Tuilcries; à l'Exposition de 1830, on remarqua un secrétaire-bibliothègue, ainsi qu'une écriloire ornée des portraits du roi et de la reine d'Espagne, et de scènes rappelant le mariage du roi et de la reine de Naples, objet qui fut donné par la duchesse d'Orléans à la reine de Naples. Nous mentionnerons encore une tabatière faite pour le roi et décorée de

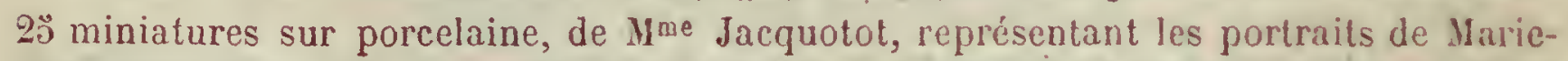
Antoinette, Henri IV, Anne d'Autriche, François Ier, Marie-Thérèse, le roi Louis Xilli à l'áge de 13 ans, Jeanne d'Albret, la princesse de Longueville, Anne de Brelagne, le Dauphin, père du roi, Marie Lecksinsha. Marie de Médicis, Molière, Charles Vill. M. le Dauphin, La Bruyère, Fénelon, Mme de Sévigné, Turenne, Aortense Mancini. l, Régent, Christine de Suède, Mme Dacier. Mme de Maintenon et Bossuet. Cetle tabilitre avait pour écrin un coffret de porcelaine d'une haute valeur. En outre de ces piéces dunt le sentiment artistique n'était guère élevé, la Manufacture exécuta pendant celte frériode un certain nombre d'objets d'un goùt plus recherché, entre autres: un grand vitse 
Médicis, en biscuit, d'une hauteur de 6 pieds avec 4 pieds de diamètre, confectionné pour la glorification de la Sculpture; le sujet représente Phidias venant d'acquérir le inodele de son Jupiter Olympien et le faisant adınirer à Socrate, à Périclès et plusieurs de ses amis; un vase étrusque, peinture camaïeu, représentant Louis XIV prenant les rines du gouvernement, peint par Parault; un vase ovale, fond vert, rappelant le voyages de découvertes des deux Bougainville.

Après avoir indiqué quelques-uns des objets les plus notables du temps de la Restaturation, nous rappellerons les progrès réalisés dans la technique à cette mème époque. En 1818, la Manufacture acheta pour la somme de 1,500 francs le brevet qu'un nommé de Saint-Amand avait pris pour un procédé de moulage dimiruant de moilié les dépenses de main-d'œuvre, et le mit en pratique dans ses ateliers. L'atelier de moulage fut définitivement organisé en 1819. En 1837, un atelier de vitraux peints fut instillé à Sèvres; le gouvernement lui accorda un crédil de 26,000 francs, et M. Robert fut mis a lit tete des travaux. Une commande de 30,000 francs de vitraux pour la sacristie de l'église de Notre-J)ane de Lorelte fut fatte par le préfet de la Seine, en vue de favoriser le développernent de cette production. En 1829, l'atelier livrait à l'ícole polytechnique deux vitraux, sur l'un desquels est ligurée la découverte du verre par les Phiniciens, et sur l'autre un bouquet de fleurs dans lequel on a épuisé toutes les cuuleurs pouvant itre employées par les veriers. L'atelier cessa d'exister avec la monarehie de Juillet.

Sous la Rostauration, les dépenses de la Manufacture atteignirent en moyenne environ 3 millions de francs, ef le produit de la vente 110,000 franes par année. De plus, un inventaire, dressé au mois d'avril 1830, révélait en magasin l'existence de 47,701 pièces représentaut une valeur de 1,209,63̈1 francs. La réputation universelle de Sevres s'était maintenue comme au temps de l'Empire, et le roi fit de nombreux présents, d'une grande valeur; aux monarques étrangers et aux personnages de distinction. En 1817, il offrit au duc de Kent 14,833 francs de porcelaines. En 1821, il fit don au luc Decazes d'un service dit des Fruits. En 1822, le roi décida qu'on offrirait à nos ambassadeur's des spécinıens de la fabrique de Sèves, afin qu'ils les fissent admirer L Ins les pays où ils représenteraient la France. Pour satisfaire à ce désir, on expédia lus vases décorés et des services de table à M. de Chateaubriant, ambassadeur à Lundres; au marquis de Moustier, ambassadeur en Suisse; au duc de MontmorencyLaval, ambassadeur à Rome; au marquis de Gabriac, ambassadeur à Stockholm; à M. de Rayneval, ambassadeur à Berlin. En 18zö, Charles $X$ fit envoyer, par l'intermédiaire du baron de Mackau et dn capitaine de va sseau de Melay, un service de Lable, d'une valenr de $33,: 320$ franes, décoré de fleur's et de fruits, au président d'Haïti. Le roi de Naples reçut, ver's cette époque, pour $ّ 2,400$ francs de porcelaines, et le prince de Saxe-Cobourg une table de porcelaine sur laquelle étaient peintes plusieurs vues du Musée du Louvre. A loceasion de son sacre, lo nouveau roi des Français offrit des porcelaines au duc de Northumberland, ambassadeur extraordinaire d'Anglelerre; au prince Wolkonski, ambassadeur extraordinaire de Russie; au prince Estherazy, ambassadeur d'Autriche; au duc Villa-Hermoza, ambassadeur d'Espagne. En 1826, ('arles $\mathbb{X}$ ottrit au pape un bureau-secrétaire estimé 30,000 francs, une pendule en biscuit d'un merveilleux travail coutint 9,000 francs, plus deux vases valant 7.000 francs.

Les artistes et les gens de lettres reçurent souvent des cadeaux royaux sortant des 


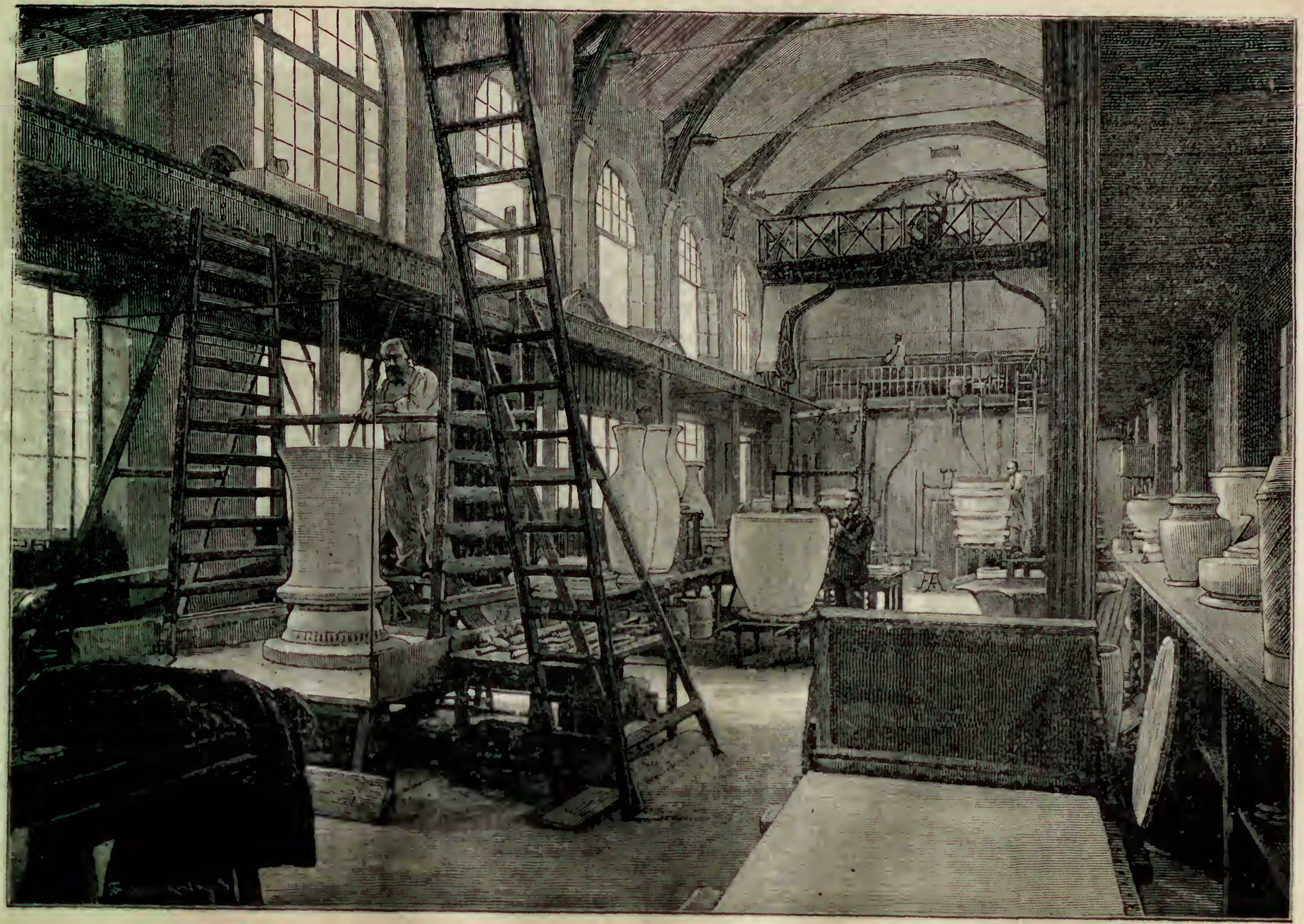

Sévaes. - Atelier de moulage des grands rascs. 
ateliers de Sèvres, et parmi les favorisés nous cilerons: Rossini, Ancelol, Guiraud, Summet, Boïeldieu, Victor Hugo, Scribe.

Les principaux artistes occupés à la Minufacture sous la Restauration furent comme sculpteurs: Renier, Boquet, Alexandre Brachard, Mascret et Marchind pere; comme peintres: Le Guay, Béranger, Constantin, Georget, Develly, Robert, Le Bel, Poupart, Langlacé, Drouet, Philippine, Sisson, Jacobber, Chaponet, Huart, Schilt, Barbin, Didier, Riton, Weidinger, Godin et $M^{\text {me }}$ Jacquotot.

Sous le règne de Louis-Philippe les progrès furent aussi plus techniques qu'artistiques. C'est à cette époque que la Manufacture inaugura la fabrication des fonds de grand feu. En 1838, on put, pour la première fois, admirer à Sivres des vases de porcelaine dure ornés en vert céladon, en vert émeraude, en vert bleuatré, en brun chocolat, en jaune Isabelle, etc. L'honneur de cet accroissentent de la richesse des couleurs revient à Bunel et à Paul Noualhier. La décoration des vitraux se perfectionne notablement, et leur fabrication prend, dans les premières amnées du règne, un développement insportant.

De plus, les chimistes attachés à la Manufacture recherchèrent arec acharnement les procédés de fabrication de la porcelaine de Chine. Un instant, M. Robert crut aroir trouvé le secret, mais il dut abandonner ses travaux. En 1842, Brongniart adressa an général de la congrégation de Saint-Lazare qui enroyait ses missiomaires au CélesteEmpire, une instruction minutieuse, afin de se procurer, par son entremise, des données précises sur la fabrication de la porcelaine de Chine, et des spécimens de matières premières et de produits en cours d'exéculion. Le père Ly expédia i la Manufacture, le $\mathbf{1}^{\text {er }}$ novembre 1844, une coltection répondant aux souhaits de Brongniart. Les chimistes Ebelmen et Salvetat analysèrent ces pièces, et complétèrent leurs observations par l’étude des échantillons faisant partie de la collection de l'ḱcole des Mines de Paris, composée sur la demande du sinologue Stanislas Jullien, et de celle de M. Isier.

- En mème temps qu'on s'efforcait de surprendre les secrets des Chinois. une curieuse tentalive était faite pour retrouver la formule de la pate tendre. que les cér.tmistes du commencement du siècle avaient laissée se perdre. En 18 ĭ Ebeluren déc surat dans les caves de la Manufacture 1,300 kilogrammes de celte pate, préparéc en 1781. Il s'efforça, après l'avoir analysée sévèrement, d'en reproduire une imilation; il dut y renoncer en présence de ses insuccès rẻitérés. De son cùté, le chef des ateliers, Régnier, s'était livré à des recherches semblables; il avait trouvé une pâte plastique quii] dénomma pâte chinoise, à cause des analogies qu'elle présentait avec la vraic pate chinoise, au modelage, par sa ténacité au dégourdi, et sa couleur un peu grisitre. Mais toutes ces expériences et ces inventions fort intéressantes, el qui allaient, par la suite, ouvrir des voies nouvelles à la céramique, restèrent, pour le moment, sans application pratique. Il n'en fut pas de mène pour la décoration en pite sur pile qui devait, à courte échéance, amener une transformation dans l'ormencutation des grandes pièces. En 1840, Régnier exposait la célèbe coupe, dite de Ileuri II, décoriè par ce procédé, qui fut complété par Robert, en 1849. La me̊me amnée, l'Lxpurition contenait les premières productions de l'atelier d'émaillage, établi sur la demande de Louis-Philippe et dont lii direction avait été confiée an célèbre peintre d'úmax, MeyerHeine. La pièce principale, qui obtint un très grand succès de curiusité, était un pretit tableau sur plaque de porcelaine, de $0^{\mathrm{m}}, 28$ de hauteur sur $0^{m}, 29$ de largeur, reprisen- 
tant, d'après le tableau du peintre de Bacq, Palissy brûlant ses menbles pour fubriquer son premier vase. Le tableau étail entouré d'un riche cadre, composé d'ornements en cuivre émaillé sur fond de paillons, avec figurines en biscuit el en bronze doré, dont Ḱlagmann avait fail la sulpture et Armand Feuchère la monture. Cette pièce était cotée 4,500 francs. On voit que peu de périodes offrent au point de vue technique une moisson plus variée et plus abondante.

« Malheureusement, au point de vue artistique il n'en est pas ainsi. La production de Sc̀vres, sous le règne de Louis-Philippe, présente à peu près le mème caractère que sous la Restauration. Des genres identiques y sont cultivés, la même mode y lleurit, el les mèmes hérésies artistiques se manifestent avec éclat. On continue de fabriquer des pendules il sujets symboliques et historiques, de styles variés, turc, arabe, roman, gothique, espagnol, efc., créations d'un gout au moins doutcux, dont le Musée de la Manufacture contient des spécimens fort étranges, et cette fabrication occupe plus de la moilié du personnel. On exécute aussi de nombreux tableaux en porcelaine. Les meubles de tous genres, aux architectures inattendues, alternent avec les miniatures. On peint sur les fonds d'assiettes, sur les panses des vases, des coupes et des tasses, les portraits du roi, de la reine, des princes, de la reine d'ingleterre, du prince consort, de Dunois, des chevaliers illustres, des grands éducateurs de l'humanité, des épisodes empruntés à la vie des peintres espagnols, etc. Le moyen àge, que Notre-Dame de Victor Ilugo avait achevé de mettre en vogue, et auquel les tableaux de l'école romantique, et les travaux des Mérimée, des Vitet, des Viollet-le-Duc, a vaient conquis toute une légion d'admirateurs, fait sentir son infiuence à Sèvres et provoque l'éclosion d'un art tourmenté el bizarre, d'un sentimentalisme puéril et d'un symbolisne mélancolique, qui exerce plus de ravages encore que ne l'avait fait, quarante anc plus tôt, l'invasion du Romain et de l'Égyplien. Le Gothique, en effet, achève de ruiner la tradition de grace, d'élégance el de coloris harmonieux, crééc par le xrine siccle.

- L'Empire avait bénéficié d'un reste de traditions aimables de ce siècle. En outre, la représentation symbolique de nos gloires militaires donnait une certaine grandeur, une originalité pittoresque aux couvres de ce temps. Sous Louis-Philippe, les imitations bumales d'un autre ìge, n'éroquant aucune idée généreuse el ne se rattachant à aucune manifestation de l'esprit moderne, ou de la puissance nationale, ne pouvaient qu'aboutir a un art bitard, atrophié, incapable non seulement d'enfanter de grandes cuvres, mais simplement de donner naissance à une production élégante ou spirituelle. Aussi Sèvres se traina-t-il, pendant toute cette période, dans l'ornière de la Restauration. Les nouveaux artistes qui collaborent avec les anciens sont : les architectes Fontaine, Dubreuil, Bouchet; les sculpteurs et ornemanistes, Armand et Léon Feuchère, Klagmann, Lejour, Combettes, Antonin Noine, Triqueti; les peintres et dessinateurs Moriut, Leloy, Chenavard, Hyacinthe Régnier, Desbouf, Jules André, Laurent, Dauzats, Garneray, Julienne, Delahaye, Ferdinand Régnier, Demoulins, Mme Ducluzeau et Itme Turgan. En dépit du manque de gout et des applications singulières qu'on fit alors de la porcelaine, la renoınmée de Sèvres était encore si universelle, qu'il fut question de créer à Bruxelles une Manufacture royale de porcelaine, sur le modèle de la Manuficture de Sèrres. Le roi Léopold, très enthousiaste de cette idée, arait demandé à Brongniart de se charger de cette organisation et de fournir un directeur compétent à la nouvelle Manufacture. Sur la recommandation de J.-B. Dumas, 
il choisit pour cette importante fonction un jeune chimiste, nommé Decaux, et le fit travailler auprès de lui, pendant deux ans, pour le préparer à sa tache nouvelle. Mais le projet fut abandonné, et-le futur directeur de lia Manufacture royale de Belgique entra aux Gobelins, dans le service de M. Chevreul, auquel il a succédé, il y a quelques années, comme chef des travaux chimiques."

Au cours de la Révolution de 1848, la Manufacture fut classée dans les attributions du ministère de l'Agriculture et du Commerce. Vainement, Mérimée, se faisant l'interprète de la Commission des monuments historiques, avait-il demandé son rattaclicment au ministère de l'Instruction publique. Le 9 fóvrier 18.49, le ministre prit un arrèt, qui ne fut heureusement pas longtemps maintenu, anx termes duquel il était prescrit au directeur de Sdrves de ne commencer ancun travail nouveau sans en avoir demandé et obtenu l'autorisation. Les chefs de chaque département devaient aussi adresser chaque mois un rapport au ministre sur les travaux de chaque artiste, sur la fabrication des pièces, sur leur valeur, sur la date prévue de leur achèvenent et sur les projets en préparation. Ces dispositions eussent apporté un grand ralentissemont dans la production de Sères si elles eussent été longtemps mises en viguteur.

La Commission des Manufactures nationales s'inquiéta également de Sèvres pendant plusieurs mois, et reconnut la nécessité du rétablissement de la fabrication de la porcelaine tendre ainsi que la création d'un atelier de faïence. Elle se préoccupa du moyen le plus sûr pour obtenir de bons modèles, et repoussa le concours public des crainte que les artistes de talent ne voulussent pas se soumettre aux dícisions d'un jury et aux risques d'un concours. L'organisation d'un personucl fixe n'obtint pas un grand nombre de partisans bien que la Commission ne rejetat pas exclusivement ce projet, mais elle demanda que certains artistes délite fussent libres de continuer leurs travaux personnels et, sans ètre engagés à la llanufacture, y pussent apporter leur précieux concours. Paul Delaroche proposa de nommer à l'établissement un dessinateur de figures; ce vœu fut écarté. Une difliculté se souleva un peu plustard entre le ministre de l'Agriculture et du Commerce et la Commission. Le ministre avait signé avec M. Sallandrouze d'Aubusson, une convention par laquelle celni-ci acquérait is: droit d'établir dans ses galeries à Londres, un magasin de vente des produits de Sirres et des Gobelins. La Commission protesta contre cette convention et en obtint l'annulation, " les Manufactures nationales ne devant pas, disait-elle, se laissel entralner a faire du commerce».

Sèvres prit part à l'Exposition de 18:31, et le jury de lExposition lui accorda la plus haute récompense. Pendant la seconde Répubiique, le budget de la IIanufacture varia entre 320,000 et 350,000 francs; le chiffre de ses receltes alleignit 80,000 francs par an.

Le coup d'État du 2 décembre $180 \% 1$ modifia essentiellement l'organisation de Sèvres qui fut placé dans les charges de la Maison de l'Empereur. Lá liste civile fut responsable de son entretien, et ses produits furent presque entièrement destinés a l'embellissement des résidences impériales. M. Ebelmen, qui avait succédé à Brongniart, fut enlevé par une terrible maladie; il fut remplacé par un savant chimiste, II. Regnault, membre de l'Institut. Le premier soin du nouveau directeur fut de s'occuper activement de la fabrication de la faience. M. Vital-Roux, chef de la fabrication, fut chargé par lui d'inspecter minutieusement toutes les fabriques de faience. Liatelier de faience fut mis en activité en 183 et fonctionna jusquaen 1870. En 1833, une enquête sur le pré- 
tendu mauvais état de la Manufacture fut faite et surve d'un projet de restauration qui fut abandonné. En octobre $18 \% 6$, l'architecte de l'établissement, M. Landin, soumit à

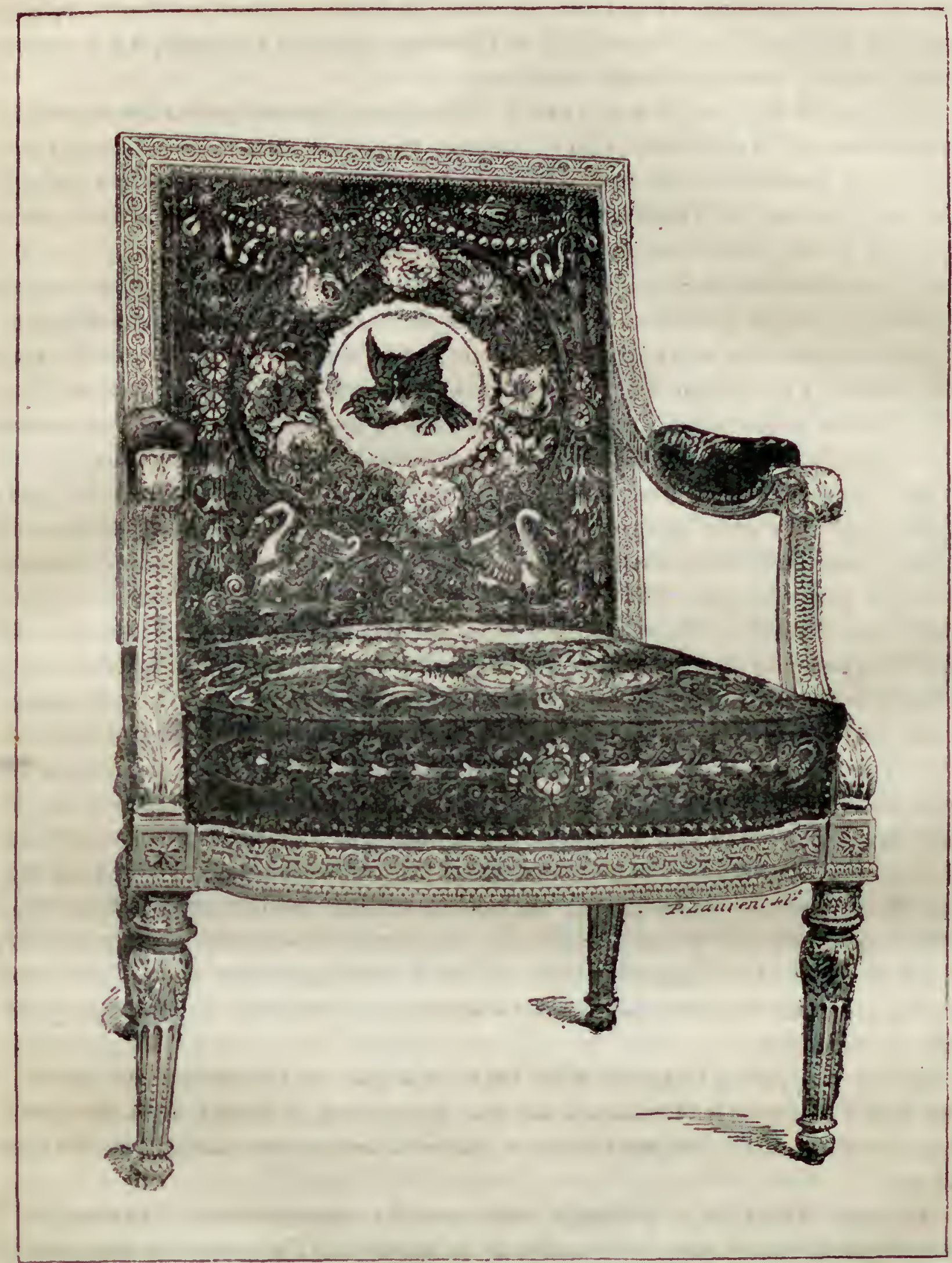

Beauvals. - Fauteuil en tapisserie (style Empire).

l'administration supéricure un projet d'édification d'une nouvelle Nanufacture, sur les bords de la Seine, dans le parc de Saint-Cloud, près du pont de Sèvres. En 18ä8, le Conseil d'Ĺtat, et l'année suivante le Conseil des Bàtiments civils adoptèrent ce projet. La Chambre des députés vota les premiers crédits le 27 juillet 1861 , et les travaux LIV. 10. 
furent entrepris an mois d'aout de la mème année. L'ancienne Manufacture existe encore, et sert anjourd'hui d'école normale secondaire de jeunes filles.

Si Sevres fabriqua beaucoup sous le second Empire, l'art ne fit qu'y perdre, et la Manufacture entra dans une période de décadence. Pour faire grand, on fit monstrueux, le bronze et le cuivre se mêlèrent en dimmenses proportions dans la composition des coupes et des vases et les artistes clıargèrent la matière première de lourdes compositions et d'ornements exagérés d’or et d'argent. Vers la fín du règne, le goùt fort vif de l'impératrice pour Marie-Antoinetle ramena le gout ver's l'ar't gracienx de la fin du xrmi siècle, mais cette réaction n’aboutit guère qu'à la reproduction servile des formies et des peintures de cetle époque.

Arec le 4 septembre, la Manufacture nationale de Sèvres fut réintégrée dans les services du Ministère de l'A griculture et du Commerce, et ne subit ancune modificalion administrative. Le moment était critique; le 6 septembre, le ministre ordonna au garde général des magasins de prendre les mesures nécessaires pour faire transporter à Paris les produits, le musée et la bibliothèque de la Manufacture, Sèrres menạ̣int d'ètre nccupé par les Allemands. Cet ordre fut immédiatement exécnté : les pièces du musée céramique furent emballées dans 14́ caisses, la bibliothèque, les livres et les tableaux furent mis dans des roitures spéciales. Les porcelaines furent placées au Garde-Meuble: les livres et les tableaux al'hùtel du ministre, situé 78, rue de Yarennes: le musée fut partagé entre les caves du Lourre et le Ministère de l'Agriculture et du Commerce, 60, rue Saint-Dominique-Saint-Germain. Il était grand temps : le 18 septembre, dans la soirée, la dernière voiture remplie des pièces du musée partil. et l'on n'eut pas le temps d'enlever les livres de comptabilité. les archives, el deux caisses contenant des pièces du musée. Dans la. nuil, le génie faisait sauler le punt dr. Sèvres et le lendemain natin les Allemands étaient dans la ville et occupaiout la Manufacture. Une centaine d'ouvriers et dartistes restèrent à Serres; les autres, au nombre de 141. faisant partie de la garde nationale et de lat garde mobile, entrèrent dans Paris. L'administration se trouva par. ce fait dirisée en deux. M.M. Megnault, directeur; Salvetat, chimiste; Robert, chel des travaux; Riocreux, directeur du musée, n'avaient pas quitté la Manufacture. MM. Nicolle, administrateur adjoinl, et Anlsroise Milet, chef des fours et pâtes, qui avaient gagné Paris, furent installés au Collège de France et furent chargés des intérèts de la Manufacture. Plusieurs artistes périrent aux avant-postes ou dans les ambulances; Henri Regnault, le célèljre peintre, tur a Buzenval. était le fils du directeur de la Manufacture.

Après la paix de Francfort, les artistes de la Manufacture revinrent ì Sirres oủ les travaux reprirent le 3 juillet, sous la direction de $\mathbf{M}$. Ilobert. Le 26 du ineme mois, I. gouvernement créa une commission chargée de perfectionner au point de vue artistique les travaux céramiques de la Manufacture et composée de MM. Duc, Guillaume, Mazerolles, Dubouché, Charles Blanc, Champfleury. Lameire. La commission comprit parfaitement l'objet en vue duquel elle avait été nomuée par It. Jules Simon, ministre de l'Instruction publique et des Beaux-Arts. L'industric privée veut rarement faire des essais vrament artistiques, parce quils sont couteux el que le gout de lourrin? a été souvent, il faut bien l'avouer, faussé par une production esscutiellment mercantile el hâtive. La Manufacture, au contraire, n'a pas à sinquiéter de lit mode du jour, de la question de vente immédiate, mais de diriger el d'élever le nivean de l'ar. Elle possede dans son sein, comme le faisait remarquer M. Duc, tous lus bincints 
nécessaires pour la maintenir au niveau de sá réputation européenne. Sa fabrication est supérieure, elle peut fournir ce qu'on peut rêver de mieux sous le rapport de la matière, des émaux et des couleurs. Ses artistes ont, pour la plupart, une virtuosité inimitable, et l'on trouve réunies chez eux au plus haut point les qualités de grâce et de délicatesse qui sont l'apanage du tempérament français. Mais jusqu’ici, la Manufacture avait servi presque uniquement à fournir aux souverains les objets mobiliers, des objets de décoration, des présents diplomatiques. Sous la troisième République, une transformation radicale se produisit. La commission nommée en 1871 se proposa de donner à la Manufacture de Sèvres le caractère d'un établissement professionnel et pratique, d'en faire une véritable école céramique qui produirait, à côté d'œuvres trop considérables pour pouvoir ètre exécutées par l'industrie privée, des formes nouvelles et des décorations inédites propres à servir de modèles aux fabricants particuliers.

Pour répondre à cel objet, la commission institua, en 1879, une école spéciale. annexée aux ateliers, et oì se recrutèrent désormais non seulement les artistes de Sèvres, mais encore des ouvriers éminents dans l'industrie privée. Le nombre des élèves fut fixé à vingt, choisis par le ministre des Beaux-Arts, parmi les ouvriers de la Manufacture. En mème temps, un concours annuel national, dit prix de Sèves, fut institué dans le but d'ouvrir la Manufacture aux artistes du dehors et de renouveler d'une manière constante " l'atmosphère artistique des ateliers de production ". La commission s'occupa enfin d'établir le programme des travaux de la Manufacture : "Sèvres, en devenant une école de céramique, avait pour devoir de favoriser surtout le développement de l'industrie nationale par l'exemple Jैune production nationale conforme à ses traditions artistiques et à son but d'enseignement. Les souverains étaient disparus; mais la nation avait conservé avec soin les palais et les chateaux qui, sous le titre de bâtiments et édifices nationaux, étaient devenus des musées publics. Leur entretien et leur décoration incombaient directement à l'État. Les museies, les bibliothèques, les mairies pouraient être considérés désormais comme les palais du peuple. On devait les orner comme le furent autrefois les résidences impériales et royales. La République, aussi bien que l'Empire et la Royauté, nouait des alliances politiques et commerciales avec les autres pays clu monde, recerait des ambassadeur's des puissances étrangères, des personnages éminents par leur science, par leur situation politique; elle derait continuer la tradition des présents royaux. Enfin, Sèvres derait fournir à l'industrie privéc et au public des modèles élégants et de bon goût. „En conséquence, la commission énuméra ainsi les divers genres de production de la Manufacture : rases de faste destinés it des souverains, des ambassadeur's et des grands personnages; vases destinés a l'ornementation des musées, des palais et des établissements publics; vases destinés à des loteries et couvres de bienfaisance; vases destines à des artistes, hommes de lettres et industriels en reconnaissance de services rendus; rases de jardins pour perrons et parterres; vases destinés a l'ornementation des riches habitations privées; vases décoratifs où les souvenirs de l'art oriental peuvent prendre une grande part; petits vases d'appirtement pour garniture de cheminées et meubles; vases bijoux; pièces fines et cilpricieuses ne relevant que du goût et de la fantaisie; services a thé et à café; rases trépied et pièces de surlout de table; jardinières potiches et cache-pots; soupières, salières, assiettes; coupes, buires, vidercomes, cornets, 


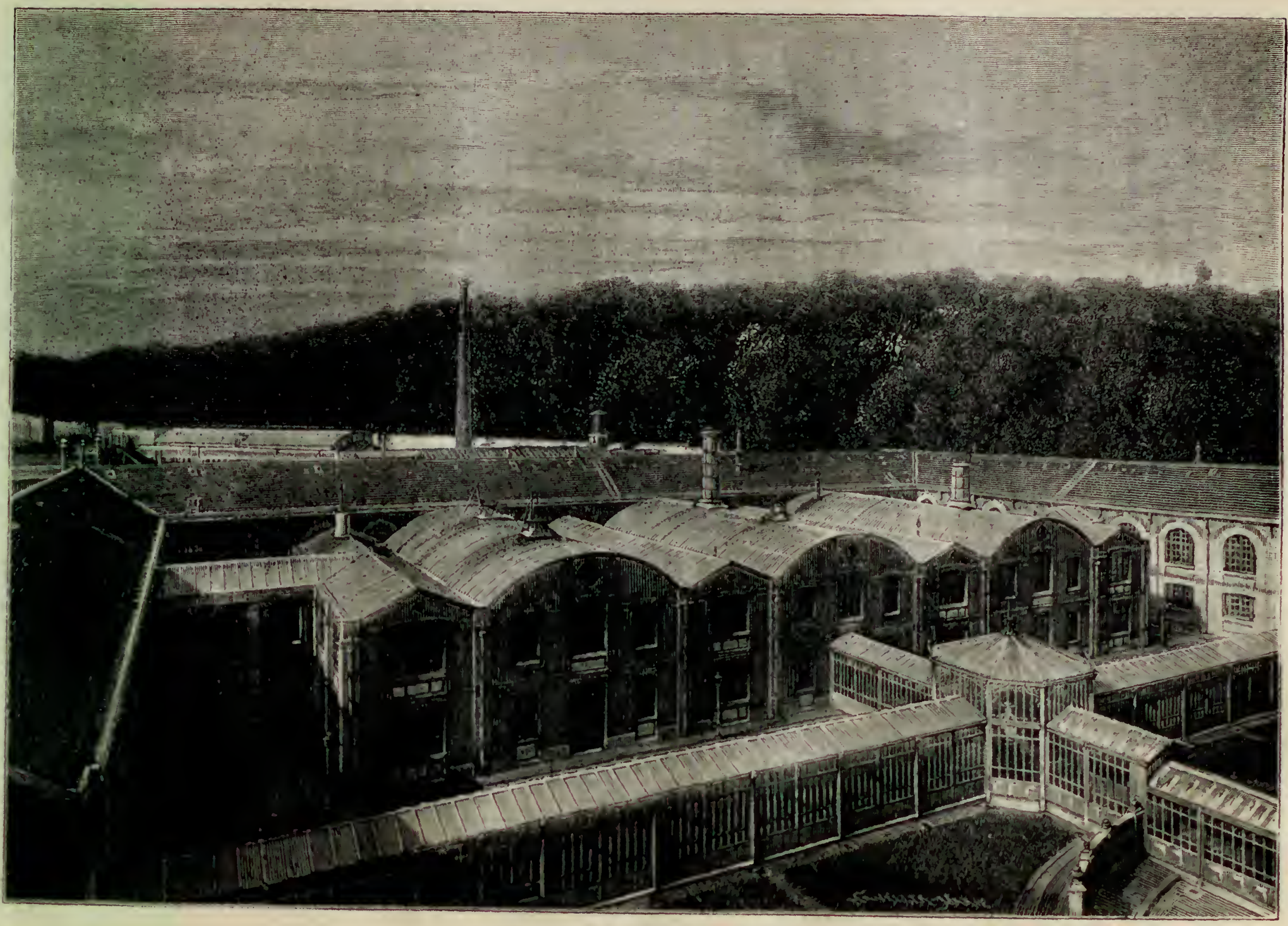

Sávars. - Les ateliers a vol d'oiseau. 


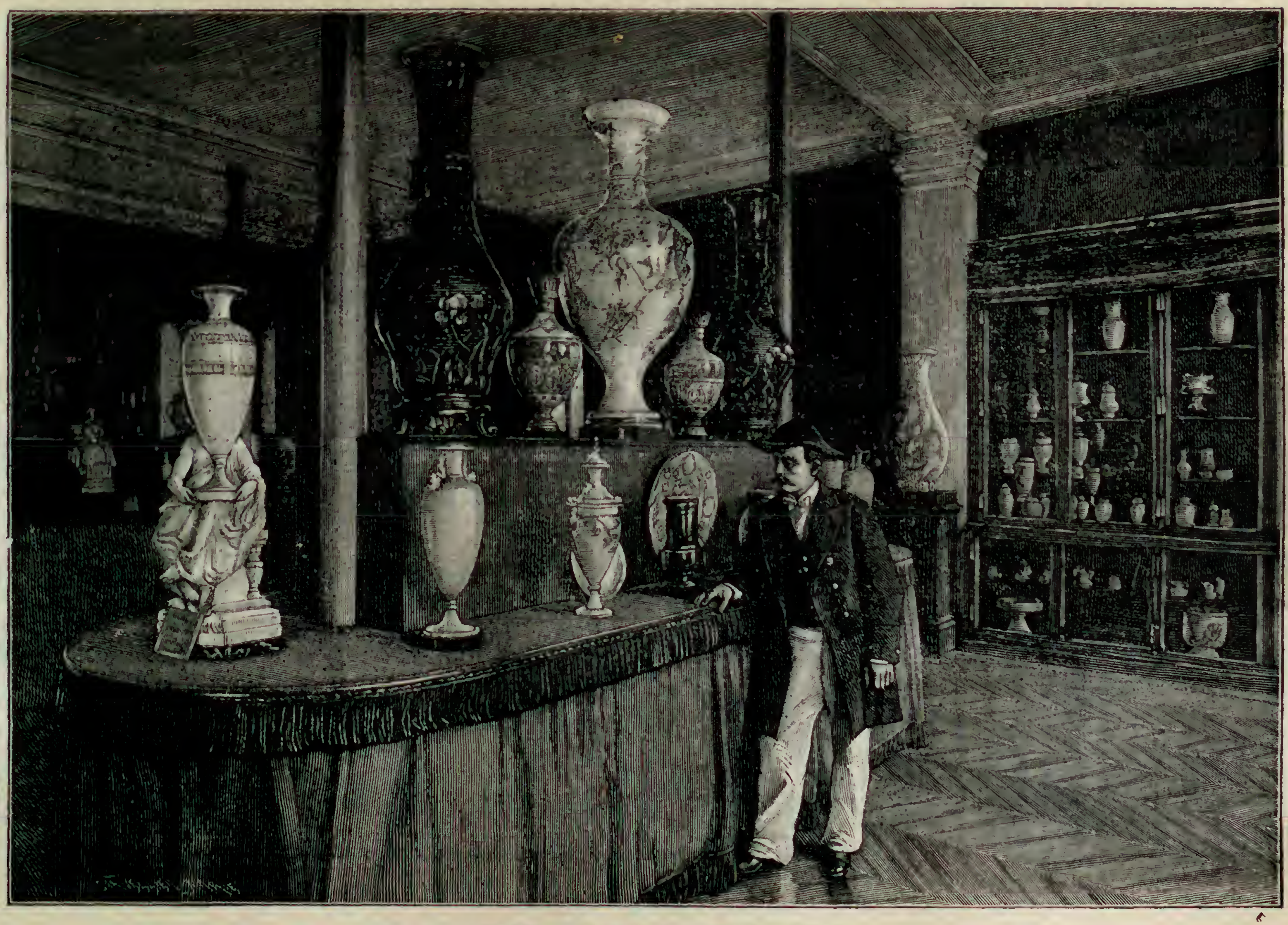

Sèvhes. - Le musée des produits modernes. 
bouteilles; bassins et jattes; grands plats décoratifs pour dressoirs; fontaines, lavabos pour vestibules et salles à manger; grandes pièces d'ornementation pour dessus de cheminées; médaillons, cartels sculptés et coloriés pour l'ornementation de l'architecture à l'intéricur et à l'extérieur; bustes avec entourage orné, consoles, crédences et supports; carreaux et frises d'ornementation pour salles a manger et salles de bains, plaques décoratives formant tableaux; décorations rustiques pour grottes et salles fraîches dans les chiteaux. C'est en se conformant à ce programme que Sèvres produisit des vases pour le Louvre, l'Opéra, la Légion d'honneur, les tir's régionaux, les présents diplomatiques, etc. Mais, par une innovation heureuse, l'administration des Beaux-Arts décida que, désormais, la sortie comme vente t comme don ne pouvait porter sur un certain nombre de pièces réservées ì la Manufacture mème comme modèles pour l'industrie.

C'est aussi sous la troisième République que fut inventée la porcelaine nouvelle do Sèvres. Brongniart avait substitué la porcelaine dure a la porcelaine leudre, et des essais avaient été faits pour découvrir la formule de la porcelaine chinoise. En 187i, M. Salvetat put soumettre au chef du service une pate de porcelaine dure modifíe ayant l'avantage de recevoir sur couverte les émaux de la pate tendre; deux ans plus tard, le mème chimiste produisit des spécimens de porcelaine dure exécutés d'après les procédés chinois. Mais sur cent pièces, quatre ou cinq seulement étaient vraiment satisfaisantes. Sur ces entrefaites, M. Salvetat dut, pour cause de maladie, abandonner ses recherches. La commission de perfectionnement de La IIanufacture proposa alors: $1^{0}$ de créer une porcelaine propre à recevoir des couvertes colorées de grand feu et à être décorée de fonds et de peintures en émaux de demi grand feu; 20 de trouver la compasition et le mode de cuisson des céladons et des rouges flambés des Chinois. Les essais de MM. Lauth et Vogt aboutirent a des résultats remarquables, c'est-il-dire a l'invention de la porcelaine nouvelle de Sèrres. Cette porcelaine, essentiellemint kaolinique, est solide, blanche et transparente; sa pate, d'une grande plasticité, remplit toutes les conditions désirables pour le moulage et pour le modelage; sa cuisson se fait régulièrement et s'opère complète à une température qu'il faut développer pour cuire la porcelaine dure; sa couverte blanche, bien glacée et d'une parfaite transparence, adhère en couche plus épaisse que la couverte de la porcelaism dure, ce qui lui donne la douceur des pates tendres, et multiplie les reflets et les jeux de lumière sous les couleurs et les émaux. Lacuisson a lieu aux environs de 1,300 degrés. La nouvelle porcelaine de Sèrres acquiert toutes les qualités de la poreelaine dure en cuisant à une température moins élevée, puisque la cuisson de la porcelaine dure a licu à plus de 1,500 degrés. Enfin, cette propriété de cuire à un feu relativement moins destructeur, permet l'emploi d'un certain nombre de couleurs, notamment celles qui dérivent du cuivre, dont l'une est précisément le rouge flambé des Chinois. En étendant leur méthcde, les chimistes, obtinrent la couverte céladon, le violet aubergini. toute la série des bleus turquoises. A ce moment, la commission de perfectionnement émit le vou'que, pour compléter la fabrication, la Manufacture s'occupal désormais de la pâte tendre. Ce vœu fut exaucé, car la Manufacture a en effet repris aujourd'lui la fabrication d'une nouvelle porcelaine tendre qui, bien que différant complétenent comme composition de l'ancienne porcelaine tendre de Sevres, offre les mèm's avantages au point de vue de la décoration.

II. Deck qui, dans l'intervalle, était entré à la llanufacture comme administrateur, 
s'occupa de trouver le moyen de faire acquérir la translucidité à la faïence et celui de la décorer au moyen des couleurs de la porcelaine, grand, moyen et petit feu. Comme picces typiques de la production de Scivres pendant celle période, nous citerons : les deux vases de l'Opéra, par II. Chéret; les vases Paris, dits des Peintres el Sculpteurs; le vase d'Entrecolles, de l'Exposition de 1878, gravé en réserve en pleine pâte, par 11. Lambert; le vase du passage de Vénus devant le Soleil (prix de Sèvres 1879), par 11. Chéret, aujourd'hui a la Bibliothèque nationale; le vase Brongniart, qui décore la salle IIenri II, au Louvre; le vase Novi de la Science, exécuté en pâtes d'application par M. Barriat ; les vases Clodion des Eléments, composition et exécution de M. Gober't; la grande jardinière Philibert Delorme, modèle de M. Carrier-Belleuse, ornéments de M. Bélet; le vase de la Vendange, exécuté pour le Louvre par M. Derischweiler, d'après une composition de M. Avisse.

- La physiononie caractéristique de la production de Sèvres, depuis 1871, est un éclectisme artistique complet, dans le choix des formes et dans la décoration. On réédite les anciens modèles, ceux du xvur siècle, si délicats, si charmants, mais en les décorant de molifs nouveaux, pour les adapter au gout du jour. Les innovations de la Rrnaissance française, sur lesquelles l'érudition a appelé l'attention des curieux et des artistes, sont remises en faveur. Les créations nouvelles empruntent leurs éléments variés à tous les styles, à toutes les fantaisies des maitres du passé, et manquent souvent, par ce fait, de simplicité et de cohésion. Nais l'art de l'Orient surtout exerce sur les artistes de la Manufacture une influence puissante. Elle eut été fort utile, si, au lieu d'imiter servilement les ouvres des potiers du Japon, de la Chine et de la Perse, on s'en était inspiré avec discrétion. Nalheureusement, on imagina de mêler à - Ia fantaisie orientale l'ornementation classique de l'Occident. Les rinceaux, les acanthes les termes et les bucranes enguirlandés s'associèrent aux vols de libellules et de cigognes, aux semis de chrysanthèmes et de fleurs de pêcher. Ces premiers essais ne furent pas toujonrs heureux. Plus tard l'adaptation devint plus habile, plus ingénieuse. Insensiblement, sous l'effet d'une édication plus développée, les décorateur's de la Manufacture acquirent un meilleur sentiment de l'esprit artistique de l'Extreme-Orient. Ajoutons que cet éclectisne leur était, pour ainsi dire, imposé par l'impulsion artistique donnée à leurs travaux. La commission de perfectionnement ne recominandait-elle pas, dans son rapport de 187̈, d'inculquer aux jeunes artistes, par des études spéciales, la pureté et la grace de l'art grec: la sévérité et la vigueur de l’art étrusque; le brillant et l'origrinalité de l'art persan; la varicté infinie, la coloration merveilleuse de l'art chinois; les effets frappants du décor de l'art japonais; la grice et les combinaisons ingenineuses de l'art arabe; l'abondance et le richesse de l'art italien; la légèreté gracieuse des arabesques de Rouen, de Never's et de Delft; la noble élégance et la distinction du vieux Sères de Louis XVI? A cette encyclopédie de connaissances et de théories on a heureusement substilué peu a peu l'enseignement plus fécond et plus logique de la nature. L.es dernières couvres exécutées à Sèvres témoignent nettement de cette évolıtion, qui peut ètre l'aurore d'une renaissance nouvelle de la céramique. Souhaitons qu'on nous délivre des Grecs, des llomains, des Japonais el des Persans. pour que nous puissions en revenir à l'éclosion resplendissante d'un art rraiment français ayant sa source dans l'observation ingénieuse de la flore et de la faune de notre patys.

La Manufacture est dirigée par un administrateur, secondé par un sous-administra- 
teur, un chef de travaux d'art, un chef du service de la fabrication et un chimiste, chef du service de la décoration et des moufles. L'administration compte vingt-sept fonctionnaires, employés ou gagistes. Les ateliers sont divisés en trois départemenls : $1^{\circ}$ les fours et pàtes; $2^{\circ}$ la peinture et la sculpture; $3^{\circ}$ la chimie et les moufles. Le

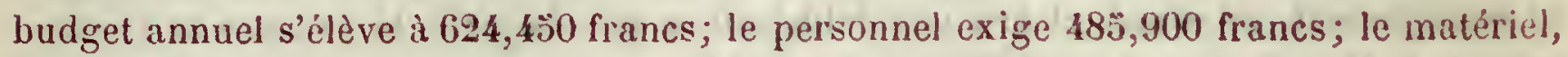
138,ว̈3̈0 francs.

De ce moment, le personnel de la Nanufacture est ainsi composé : MM. Théodore Deck, administrateur; Champfleury, sous-administrateur, conservateur du musée et de la bibliothèque; Gobert, directeur des travaux d'art; Auscher, chef des ateliers de fabrication; IIallion, chef des ateliers de décoration; Voght, chef des travaux chimiques. - Modeleurs et sculpteurs : MM. Doat, Briffault, Forgeot, Roger, Larwe, Celos, Archelais, Blanchard, Legay, Lucas Maugendre, Sandos. - Peintres : MII. Ciobert. de Courcy, Brumel, Caban, Bulot, Lambert, Fromont, IIme Anoil, MI. Belet, Einile Richard, Barriat, Merigot, Goddé, Derischweiler, Rejoux, Bonnuit, Engène Ilallion. Guillemain, Paillet, Henri Renard, Sieffet, Mme Moriot. - Dessinateurs : MIM. Avisse et Émile Renard.

Tous les Parisiens connaissent la nouvelle Manufacture de Sèvres, si admiral,hment située au milieu du parc de Saint-Cloud; elle na ni le cachet artistique qui lui conviendrait, ni le confortable nécessaire à un élablissement industriel. Le public a accès dans la Manufacture par le parc; au rez-le-chaussée, à gauche, sont les bureaux de l'administration et la bibliothèque céramique; à droite les magasins de vente. La vente est fort peu importante aujourd'hui, elle ne dépasse pas annuellement le chiffre de 100,000 francs sur une production de 300,000 francs environ. Le musis córamique occupe tout le premier étage et renferme quelques-nnes des pic̀ces colussales sorties des ateliers Ue Sèvres : le vase Nicolle de l'Exposition de $180 . \vec{z}$. qui mesure $3 m$, 15 de haut; le vase Barriot, de l'Exposition de 1878; le vase Béranger, dont lis peinture représente: Le transpart des depouilles opinues artistiques de l'armite dillulie nu musée Náapaléon. Les collections sont divisées en quatre sectious : 10 les poleries mates, peintes et lustrées; 20 les poteries vernissées; $3^{\circ}$ les fä̈nces; $4^{\circ}$ les porcelaines.

L'Exposition de 1889 comprendra de nombreux modeles de chacun des genres dont nous venons de décrire la fabrication et de montrer la richesse. Les renseignements que nous avons donnés permettront aux visiteurs d'apprécier comme elles doivent l'ètre les merveilles de l'Exposition spéciale de Sèvres. II nous r'este ì dire quelques mots de la Manufacture de tapisseries de Beaurais.

Cette Manufacture date du xrme siecle. Nous n'avons pas a en faire l'histoire, mais seulement à rappeler ce qu'elle a été depuis cent ans. A celte époque, elle était aux mains du sieur de Menon. Par suite de troubles politiques, la production décrut rapidement et de Menon donna sa démission le 24 novembre 1790. Aucun candidat ne s'étant présenté pour prendre sa succession, il resta à la tête de l'entreprise, sur la demande du comité de cornmerce et de la municipalité de Beaurais, jusqu à ce qu'une décision fut prise pour l'organisation de la Manufacture. Le 17 brumaire, la Convention rendit un décret plaçant Beauvais sous la surveillance directe du district de Beauvais. L’administration se préoccupa aussitôt de venir en aide aux ouvriers tombés dans la plus atroce misère par suite du manque de travail. De Menon, dont la position était devenue intolérable, redonna sa démission et se retira définitivement le 23 nivôse. En présence de la phase critique que traversait la Manufaclure, le Directoire du dis- 
trict de Beauvais demanda sa suppression. Mais devant les protestations des habitants de Beauvais et de de Menon, cette résolution ne fut pas mise à exécution. Le Conseil permanent du district de Beauvais, sous l'influence de la municipalité et du birectoire du département, se réunit, et prit une délibération par laquelle la vacance de l'entreprise de la Manufacture devant être rendue publique, une commission était constituée pour inventorier les magasins et les ateliers. Cette décision n'améliora pas la situation : personne ne se présentait au poste que de Menon venait d'abandonner, et, de guerre lasse, les comités du Commerce, d'Agriculture et des $\Lambda$ rts confièrent par un arrèt la gérance provisoire de ia Manufaclure au peintre Camousse.

L'année suivante, le gouvernement asssura l'existence de la llanufacture et lui

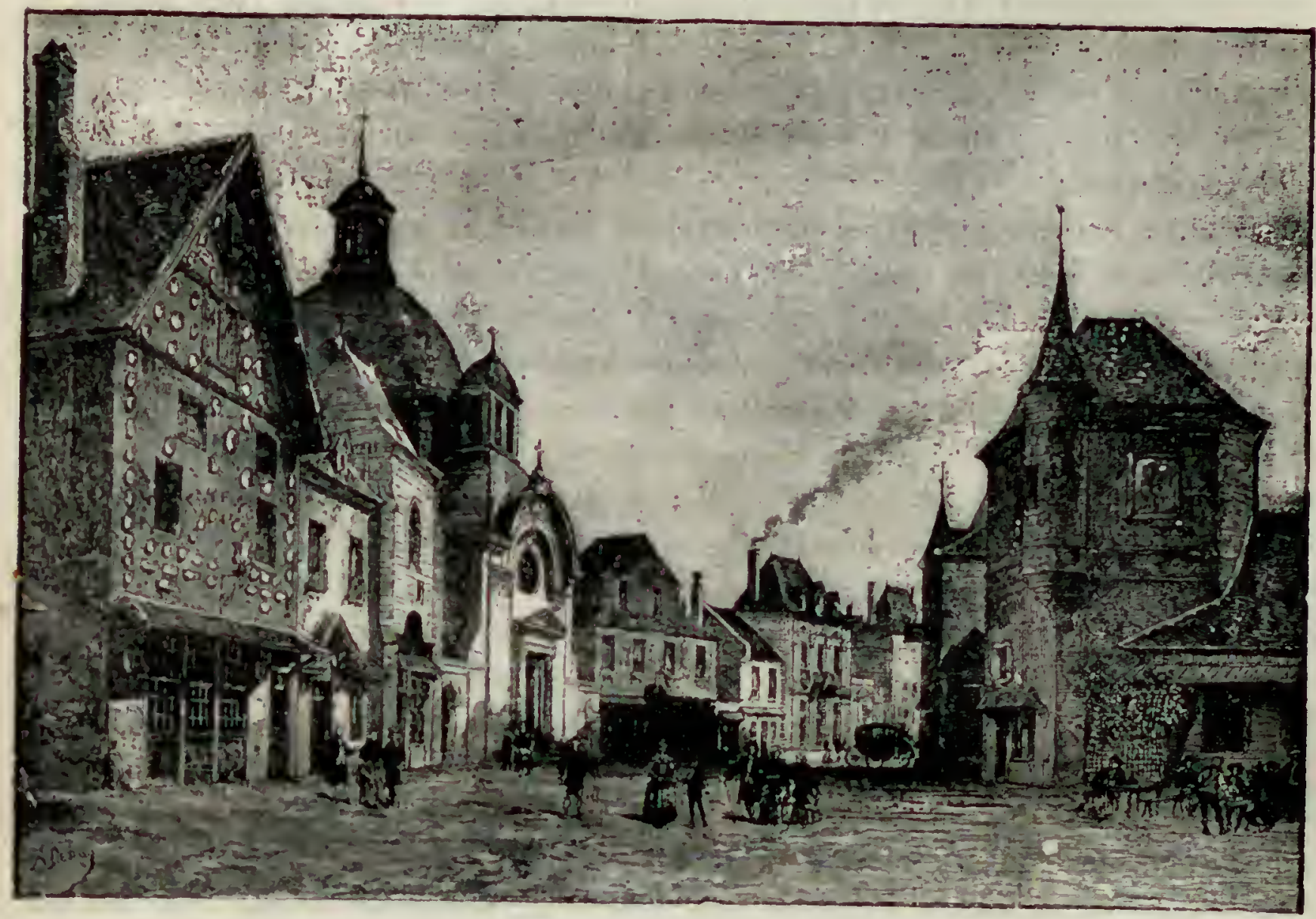

la rue Saixt-Axtolve, heconstitule pah M. Perhusson, au Chanp de Mars.

donna une organisation plus régulière. Camousse mourut au commencement de l'an VIII, et Lucien Bonaparte, alors ministre de l'Intérieur, nomma pour le remplacer le citoyen Hnet, homme d'une haute valeur qui élait depuis longtemps dans la division des Manufaclures. Le premier Consul accorda au nouveau directeur les fonds nécessités pour le renouvellement du matériel et la mise en train de nouveaux travaux; malgré ce secours, la situation financière de Beauvais resta en soufrance, son budget ne pouvant suffire aux frais occasionnés par la réorganisation des ateliers.

La loi du 28 floréal an XII classa les Manufactures dans les attributions de la Maison de l'empereur, et des commandes de ineubles furent faites à Beauvais pour restaurer les anciennes résidences royales. Quant Huet mourut, le 26 mars 1814, a l'age de quatre-vingts ans, la Manufacture commençait à se relever. Son fils ainé lui succéda et lorsqu'il ınourut à son tour, son plus jeune frère lui succéda, le 1er février 1819. Le mauvais état de sa santé l'obligea neuf mois après d donner sa démission. 
Le 18 octobre 1s19, Guillaumot, chef de bureau de la comptabilité dans liuministration de la Maison du roi fut nommé directeur. Pendant neuf ans, il gouverna sagement la Manufacture et $y$ introduisit bien des améliorations.

Épuisé par un travail constant, Guillaumot donna sa démission au mois de décembre 1828, et fut remplacé par le marquis d'Ourches. Nommé ì la faverr. sans aucune des connaissances nécessaires pour remplir ces hautes fonctions, 11 . d'Ourches causa par sa mauvaise administration un grave préjudice à la Manufacture; le 1 er avril 1831, il quitta Beauvais sans y laisser un bon souvenir. Le fils de Guillaumot ful chargé de continuer l'œuvre de réorganisation entreprise par son père, mais il mourut le 2 novembre 1832. M. Gran de Saint-Vincent recucillit sa succession et s'appliqua de tout son pouvoir à remédier à la mauvaise gestion du marquis d'Oulches.

En 1848, la Manufacture de Beauvais fut un instant réunie aux Gobelins et M. Badin fut nommé directeur des deux fabriques; mais l'Empire vint redonner son indépendance à Beauvais qui fut comprise dans les attributions de la Maison de l'empereur et garda à sa tète M. Badin. En 1860, les deux Manufactures furent de nouveau réunies sous la direction de M. Badin, auquel il fut adjoint à Beauvais un inspecteur, remplacé deux ans après par un simple agent comptable. Lempereur donna aux ateliers une vive impulsion en faisant d'importantes commandes pour ses résidences, et se réserva presque tous les produits de la Manufacture.

Pendant la guerre de 1870 , Beauvais fut pillé et cinquante pièces de lapisserie furent enlevées et emportées à Berlin; mais, dès 1872, elles furent restituées à la Manufacture. Après la paix de Francfort, Beauvais fut rapidement réorganisé, et dès 1872. à l'Exposition de Londres, ses travaux furent admirés, ainsi qu'í l'Lxposition universelle de Vienne. Le gouvernement de la République ordonna la reprise des travaux au commencement de 1873 , et le 21 janvier de la mème année, le ministère autorisait la mise sur métiers: $1^{\circ}$ des pièces complémentaires du menble Louris $\mathbb{R}^{\circ} \%$, fond blanc et bordure bleue, détruit en partie en 1811; d'un meuble fond blane, bordure rose, en soie, modèle de M. Chabal-Dussurgey, comprenant un grand canape, un canapé moyen, deux causeuses, quatre fauteuils, six chaises, un écran; $3^{\circ}$ d'un canapé

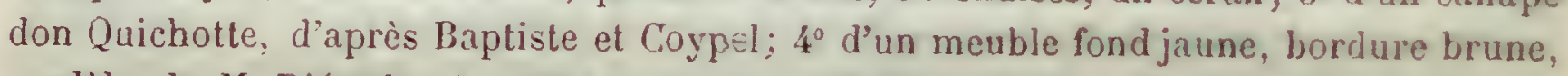
modèle de M. Diéterle. Le 28 mars, on mettait en train un meuble à bouquets de fleurs sur fond jaune, entouré d'une guirlande de lilas et d'une bordure brunc. P'eu de temps après, le budget de la Manufacture atteignait 109,3 30 francs, chifre aussi élevé qu'aux temps les plus prospères de Beauvais, sous le second Empire.

Parmi les principales œuvres produites depuis 18\%1, nous citerons : la Lice et $s a$ compagne, le Lion devenu rieux, le Loup deremu Berger; le Cog el la Perle, panneaux d'Oudry; le Lion et l'Ane chassant, de Godefroy et Desroy, actuellement au palais Farnèse; un panneau de la galerie d'Apollon, au Louvre; le Médaillon de Nephme, par Arbant, également au palais Farnèse; une copie d'un panneau du cabinet de Sully a l'Arsenal; un panneau, dit des Oiseaux, d'après Oudry, lar Godefroy et Desroy; quatre panneaux décoratifs, fleurs, vases et architectures, far Mne Lscallier, MM. Maisiat, Petit et Tony Faivre, destinés à l'escalier d'honneur du Luxembourg. De plus, un certain nombre d'œuvres importantes ont été mises sur les métiers pour figurer' i l'Expro. sition de 1889, dont elles seront une des curiosités artistiques les plus appréciées.

"La Manufacture de Beaurais est située dans la Grande-Rue; qui de la gare conduil au centre de la ville. Elle se compose de deux corps de batiments : le premier, cons- 
truit en 1818, donnant sur la rue, est affecté à l'administration. Il comprend un rezde-chaussée, un premier et un deuxième étage, avec greniers au-dessus, et, sur la cour, deux pavillons en retour; l'un à droite, servant de logement à l'administrateur, et l'autre ì gauçe, à l'agent comptable et au chef d'atelier. Le second, entre cour d'honneur et jardin, construit en pierre de taille sur la cour et sur le jardin, en pans de bois et briques, a un rez-de-chaussée et un étage; à droite et à gauche sont deux grandes ailes, en retour sur le jardin, également construites en pans de bois, à un étage, et surmontíes d'un toit énorme, en tuiles. Ce batiment, qui date de la fondation de la Manufacture, et qui a conservé le caractère de l'architecture industrielle de ce temps, contient les ateliers de tapisseric qui, au rez-de-chaussée et au premier étage, prennent jour sur le jardin. L'aménagement n'a rien de luxueux, ni de monumental; mais il présente des dispositions et un éclairage très favorables au travail des artistes. En été, les croisées des ateliers, qui s'ouvrent en auvent, laissent entrer à flots l'air rafraîchi par les grands arbres et la verdure du jardin; en hiver, la lumière pénètre partout, abondante et limpide. II y a cinq ateliers qui contiennent $\mathbf{4 0}$ métiers de basse lice, dont un tier's est toujours en activité.

- Le métier de basse lice diffère sur beaucoup de points, dans son organisme et dans sa disposition, du métier de haute lice en usage aux Gobelins. La chalne, au lieu d'etre verticale est horizontale; les lices sont mises en mouvement, non plus par la main de l'artiste, mais au moyen de pédales placées sous le métier; le carton ou décalque du modẻle à suivre est fixé au-dessous de la chaine. L'ouvrier de basse lice a, ainsi, ses deux mains constamment libres pour conduire sa duitée, c'est-à-dire pour prendre ses flite's de couleur's, et les introduire a traver's la chaine. Le travail du basse-licier est donc bien plus rapide que celui du haute-lieier, sansque la différence des résultats soit très appréciable au point de vue de la perfection artistique et de la solidité du tissu. Néannoins, la tapisserie de haute-lice a toujours passé pour avoir plus de beauté et plus de style, et c'est à cette considération qu'elle doit d'avoir été conservée avec un soin spécial et d'ètre pratiquée exclusirement dans la manufacture des Gobelins. Le métier en usage à Beauvais est le métier ancien, transformé par Vaucanson, à la demande de Soufflot et de Neilson. On a simplement modifié la nature des organes qui, pour les petits métier's, sont aujourd'hui de fonte et de fer, au lieu d'ètre en bois. Pour les grands, on a continué de les faire en bois parce que, de l'avis des tapissiers, le bois possède, exclusivement, l'élasticité nécessaire pour former de bonnes ensouples de grande dimension, donnant à la cliaine une tension et une souplesse uniformes.

Aetuellement, la Manufacture comprend 31 artistes tapissiers, dont voici les noms: Desroy, chef d'atelier; Lacroix, Vérité, Souflier et Livier (Émile), sous-chefs; Senan, Błaucousin, Léveque (Charles), Mahn (Alexandre), Dérécusson, Cantrel, Lévêque (Jules), Fontaine, Langlois, Pinchon, Lalonde, Rohant, Mahn (Paul), Piet, Roussel, Carbonnier, Livier (Edmond), Lecolle, Aimont, Pruvot, Warin, Pecheret, Y vorel, Tillcul, Boulie et Dangoisse, tapissiers.

Hans le jardin planté d'arbres superbes, se trouve, a droite, un berceau abritant une table de pierre rappelant une visite de Louis XIV. De l'autre côté du jardin, à l'ouest, s'élevaient autrefois plusieurs constructions qui servaient de logements aux ourriers de la Manufacture: elles ont été abaltues en $183 \overline{\text { I el }}$ 1838. Les jardinets qui en dépendaient sunt à l'usage de l'administrateur, du chef des ateliers et de l'agent coinptable. On a élevé, il y a quelques années, un bàtiment qui contient actuellement 
l'école de dessin et l'école primaire des élèves tapissiers, fondée en 1879. Au premier étage du bảtiment industriel, sur la cour d'honneur, a été installé récemment un muséeexposition, dont l'organisation est inspirée des mèmes principes d'éducation professionnelle pour les ouvriers et d'enseignement artistique pour les visiteurs, qui ont provoqué la création du musée des Gohelins.

Beauvais est dirigé aujourd'hui par M. Jules Badin, fils de l'ancien directeur sons le second Empire, et gendre de M. Diéterle, qui avait succédé à celui -ci en 1875. Peintre de talent, administrateur habile, M. Badin a maintenu la Manufacture dans la situatiou de prospérité et de progrès où son père et M. Diéterle l'avaient laissée. Comme les Gobelins, Beaurais fait honneur a la France par les auvres qu'il produit. Ses basseliciers continuent fièrement les traditions artistiques des maitres du xrum" siècle, ct les artistes qui fournissent ses modèles marchent glorieusement sur les traces des Bérain, des Oudry, des Boucher, des Coypel, des le Prince et des Casanova.

\section{LA BASTILLE}

L'Exposition universelle devant coïncider avec le centenaire de la Révolution de 1789, il était naturel de faire revivre le Paris d'il y a cent ans.

Parmi les idées qui ont été mises en avant, nous devons une mention spéciale à celle qui consistait à restaurer la Bastille et le faubourg Saint-Antoine. La prise de lis Bastille, c'est le premier acte matériel de la Révolution, c'est le premier défi jeté par les Parisiens à l'absolutisme, dont la célèbre prison était en quelque sorte le symloole édifié. Nous nous proposons, en conséquence, de décrire la restitution qui a élé faite de la Bastille; mais, auparavant, nous donnerons un court aperçu historique du monument, nous ferons une brève description de son cachol el du régime des prisonniers, puis nous raconterons, d'après les sources de l'époque, les incidents qui signalèrent la prise de la Bastille, dont l'anniversaire a été choisi par la troisième République comme date de la fète nationale.

Ce fut Charles $\mathbf{V}$ qui jeta les fondements de la Bastille. Ce n'était d'ahord que deux tours jointes par une arcade et destinées à défendre l'entrée de Paris. Ces deux premières tours étaient celles du Trésbr et de la Chapelle. Quelque temps après, on en fit éleverdeux autres qui furent nommées depuis la lour de la Liberté et la tour de la Bertaudière. Vers l'ạn 1383, Charles VI fit construire les quatre autres, les réunit entre elles par un mur, les entoura d'un large fossé, détourna le chemin a gauche, el d'une simple bastille qu'elle était dans l'origine, on en fit une véritalle forteresse, composée de huit grosses tours rondes et jointes par des massifs de maçonnerie de neut pieds d'épaisseur. En 15 כ̈3 on y ajouta un bastion entier à orillons,

Nous ne nous étendrons pas en dissertations sur l'origine des noms donnés à ces tours. Quelques-uns sont évidemment tirés de leur usage, tel que celui des tours de la Chapelle et du Trésor. On sait que Henri W fit déposer dans cette dernière les sommes inmenses qu'il rẻservait pour l'exécution de ses grands desseins. D'autres, telles que 


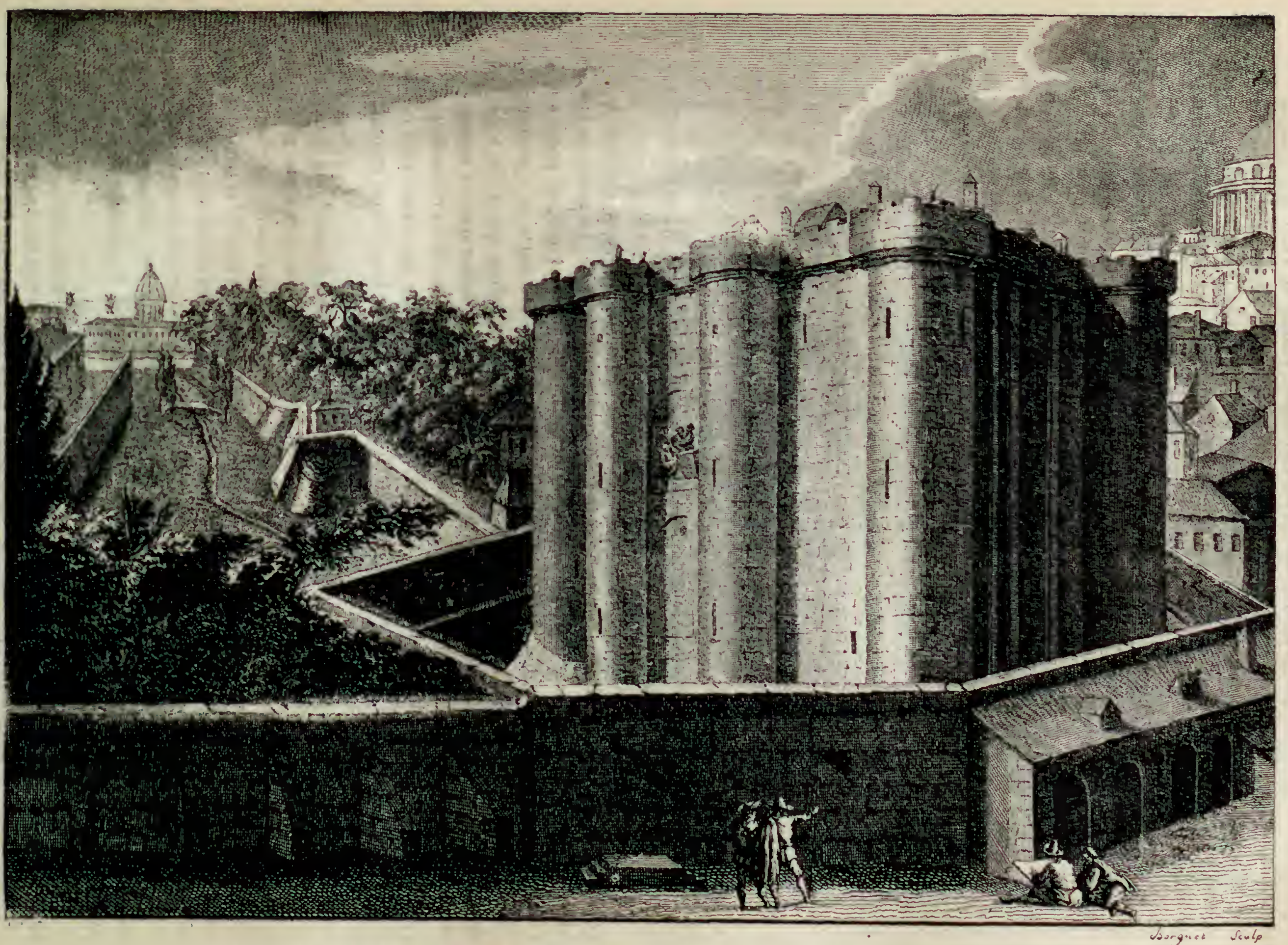

LA Bastille, EN 1789, VUE DU GOIN DU BOULEVARD. - (D'aprés une estampe de Gudin.) 
celles de la Bazinière et de la Bertaudière, furent nommées du nom de ces denx prisonniers. Ouant à la tour de la Liberté, elle fut sans doute ainsi qualifice par dérision. Il parait qu'elles ne tardèrent pas longtemps ì servir de prisons, car llugues Aubriot. prévôt des marchands, qui en posa la première pierre le 22 avril 1370 , y fut enfermi: en 1381 et $y$ finit ses jours, selon plusieur's historiens. En 1389, Bussy-Le-Clerc y mena le Parlemènt. Les troupes de cette compagnie s'en emparìrent olles-mèmes en 1649, pendant la guerre de la Fronde, et le fameux conseiller Broussel en eut le gonvernement.

Chaque tour était une prison a cinq étages. Les cachots et les calottes, on appelait ainsi les chambres placées immédiatement sous les plates-formes, étaient les flus affreuses de toutes. En śté, une chaleur brûlante; nn hiver, un froid excessif en renditient le séjour également insupportable. Un ancien créneau, qui servait de fenètre, pratiqué dans un mur épais de six pieds, assez large en dedans, mais se rétréci-saut vers le dehors, au point de n’avoir pour ouverture sur les fossés qua une longue fente de deux à trois pouces de large, et fermée à son extrímité la plus étroite par de grosses grilles de fer, laissait ì peine pónétrer dans ces chambres une faible lueur. l'resque toutes les prisons des autres étages des tours étaient des polygrones irréguliers, de quinze à seize pieds de diamètre, sur quinze à vingt pieds d'élévation; quelques-unes méme avaient plusieurs fenètres, mais elles étaient presque ontièrement masquées par lépaisseur des murs. Cette épaisseur, augmentant ì mesure que l'on se rapprochait du sol, allongeait les embrasures, et le prisonnier recevait d'autant moins de lumière qu'il était plus éloigné de leur ouverture. Ces espèces de meurtrières étaient de plus gárnies, à différents points de leur profondeur, de deux, et quelquefois de trois grosses trilles de fer. Chaque prison était fermée par deux portes épaisses de denx à trois pouces, dont quelques-unes avaient des guichets. L'intérieur de plusieurs était recouvert de fer, el elles étaient fermées par des verrous et des sertures énormes. Chacune de ces prisons était numérotée, et les infortunés étaient appelés du nom de la tonr oì ils étiriunt enfermés joint au numéro de leur chambre. Lientrée de charque tour était fermée comme celle des prisons. 11 y avait mème des portes de sùreté dans les escaliers, de distance en distance.

Les cachots étaient enfoncés de dix-neuf pieds au-dessous du niveau de la conr, cinq pieds environ au-dessus du niveau des fossés. Ils n'avaient d'autre muverture qu'une ètroite barbacane donnant sur les mèmes fossés. Le détenu, privé d'air et de lumière, plongé dans une atmosphère infecte et humide, ne tardait pas à mourir: une pierre énorme, recouverte d'un peu de paille, lui servait de lit et composait lout l'ameublement.

Excepté les cachots, toutes les prisons avaient ou des poêles ou des cheminíes; mais elles étaient très étroites, fermées au bas, à l'extrémité supérieure. et quelquefois de distance en distance, par de grosses barres de fer. Leurs meubles orrinaires étaient un lit de serge verte avec rideaux, paillasse et matelas: une ou deux tables, deux cruches, un chandelier; fourchelte, cuiller et gobelet d'étain; deux ou trois chaises, l'assortiment d'un briquet, rarement, et, par faveur, de petites pincettes et une pelle à feu très faibles, enfin, deux très grosses pier'es an heu de chenets. Les unr's étriient - nus et seulement variés çà et lì par des noms de prisonniers, des dessins au charhon ou a l'ocre, des vers, des sentences et autres expressions du long ennui des habitints de ces sinistres lieux. 
La Bastille pouvait contenit environ cinquante prisonniers logés séparément: elle pouvait en contenir jusqu'à cent, en en róunissant plusieurs dans la mème chambre. Quand il n'y avait pas d'appartements vacants, on donnait aux nouveaux venus un simple lit de sangle que l'on plaçait dins de petites cellules pratiquées auprès des fusses d'aisance, jusqu'à ce que le cómmissaire de la Bastille en eùt ordonné autrement. Le bitiment neuf qui séparait la cour du puits de la grande cour, était destiné an lugement de l'état-major; le bas était occupé par les cuisines, offices, laverie, etc., qui avaient une sortie dans l'arrière-cour, et par des logements d'officiers subalternes el de porte-clefs, $\Lambda$ droite, au premier, sur la salle du conseil, était l'appartement du lieutenant du roi; au second celui du major; au troisième celui du chirurgien. Le reste de ces trois étages était oceupé par un certain nombre de chambres destinées aux prisonniers très distingués, et aux malades qu’on voulait ménager. C'est là qu'ont demenré le cardinal de Rohan et M. de Saint-James. Dans les temps de presse, toutes les pièces de ce corps de logis. les antichambres, les chambres, les cahinets mème des ofliciers de l'état-major, étaient remplis de prisonniers. Dans le fond de la tour de la Liberté se trouvait la chambre des oubliettes. Le prisonnier qui devait périr par ce supplice était tiré de son cachot et conrluit par le gouverneur dans la chambre dite le dernier mot. Cette vaste pièce n'étail éclairée que par une lampe, et les murs étaient garnis de poignards, de piques, d'épées et d'énormes chaînes. On cherchait alors, par des questions caplieuses à faile nommer au condamné ses complices ou prétendus tels. Après cette formalité le patient élait remis entre les mains du gouverneur qui, sur un signe d'intelligence, le conduisait, aux Oubliettes. Cette chambre n'offrait rien de sinistre ni d'efrayant; elle était éclairée par plus de cinquante bougies; des fleurs odpriférartes y répandaient un parfum délicieux. A peine le prisonnier et son conducteur élaient-ils arrivés dans ce nouvel appartement qu'ils s'asłeyaient l'un et l'autre. La conversation était adroitement amenée sur un sujet intéressant, la détention du prisonnier; le gonverneur lui laissait entrevoir qu’il jouirait bientôt de sa liberté. Mais, quanfl l'espoir venait d'entrel dans l'àme du captif, le signal était donné par le gouverneur, et une bascule, pratiquée dans le parquet, s'ouvrait et faisait disparaître l'infortuné.

Yous emprunterons à M. de Mirabeau, qui a été captif à la Bastille, le récit de l'entrée d'un prisonnier dans la. prison : "C'est ordinairement la nuit, dit-il, que le millieurcux y est plongé; car on s'accoutume en France ì lit méthode espagnole, qui dı moins est une sorte d'hommage que le despotisme rend a l'opinion publique et a l'épuité. Il craint d'exciter trop souvent l'indignation ou la terreur; il craint que le soleil n'éclaire ses violences. La faible lueur d'une lampe vraiment sépulcrale éclaire les pas du captif. Deux conducteut's guident sa marche. Des verrous sans nombre fiappent ses oreilles et ses regards; des portes de fer tournent sur leurs gonds énormes, el les vontes retentissent de cette lugubre harmonie. Un escalier tortueux, étroit, escarpe, allonge le chemin et multiplie les délours; on parcourt de vastes salles; la lumière tremblante qui perce avec efrort dans cet océan de ténébres, et laisse apercevoir partout des cadenas, des verrous et des barres, augmente l'horreur d'un tel spectacle et l'effroi qu'il inspire. Le malheureux arrive enfin dans son repaire; il y trouve un grabat, denx chaises de paille et sourent de bois, un pot presque toujours élréclıé, une table enduite de graisse... et quoi encore?... Rien. Imaginez l'effet que produit sur son àme le premier coup d'œil qu'il jette autour de lıi. Mais bientùt le 
gouverneur fait une utile diversion. Il commande aux porte-clefs de fouiller le nouveau venu, et leur en donne l'exemple, afin qu'ils le fassent avec plus de zèle et d'exactitude.,

Le patient était dépouillé de tous ses effets; argent, montre, bijoux, dentelles, tout lui était enlevé, de peur qu'il ne les employat à corrompre quelqu'un. On lui otait aussi son couteau, ses ciseaux, de crainte qu'il ne se suicidat ou qu'il n'assassinat ses geóliers. Suivait une injonction laconique d'éviter le bruit le plus léger : C'est ici la maison du silence, disait le commandant. Quatre geoliers ou domestiques étaient au service des prisonniers, service qui se bornait à leur porter à manger; on les appelait porte-clefs. "Une physionomie austère, dit Mirabeau, un imperturbable silence, un cour inaccéssible à la pitié, sont les vertus de cet état; mais il faut en convenir, le chef l'emportait sur eux en perfection de ce genre comme en autorité. En vain le prisonnier interrogeait-il : une négation simple était l'unique réponse qu'il recevait. « Je n'en sais rien „; voilà la formule des porte-clefs, comme : C'est ou ce n'est pas la règle était celle du maître geòlier. Il est impossible de se peindre la situation d'un homme en ces premiers moments. La réalité porte sa mesure avec elle; un malheur connu navre le cœur; mais enfin on s'efforce d'y remédier ou de prendre son parti; mais un malheur vague ouvre un champ sans bornes aux égarements de la doulcur, qu'aggrave en quelque sorte l'espoir, en nous empèchant de nous en affranchir. l'incertitude tourmente et déchire sans relache, et la solitude et l'ennui enveniment la blessure.

Les heures des repas étaient sept heures pour le déjeuner, onze heures pour le diner, six heures pour le souper. Ces trois époques étaient ordinairement les seuls instants qui interrompissent la solitude des prisonniers, et ces instants étaient des plus rapides, car les porte-clefs ne faisaient guère que déposer promptement leur fardeau, couper à la hate, s'il le fallait, les morceaux et partaient au plus vite. Une livre de pain, une bouteille de mauvais vin, une soupe fade et sans gout, des mets au beurre fort ou à l'huile rance, le tout servi sur une vaisselle d'étain malpropre, tel était l'ordinaire de la Bastille.

Le gouverneur touchait, outre de forts appointements, quinze places mortes a 10 livres, ce qui faisait 150 livres par jour de bénéfice net. Un tarif réglait la dépense des prisonniers pour la table, le blanchissage et la lumière selon leur état. Un prince du sang était à 50 livres par jour; un maréchal de France à 36 livres; un lieutenant général à 24 livres; un conseiller au Parlement à 15 livres; un juge ordinaire, un prèlre, un financier, à 10 livres; un bon bourgeois, un avocat à 5 livres; un petit hourgeois a 3 livres, el les membres des moindres classes à 2 livres 10 sous; c'était le taux des gardes et des domestiques. Voilà ce que chaque prisonnier coutait au roi, selon sa condition. Le gouverneur retirait encore d'immenses revenus de la location des fossés de la Bastille et des boutiques qui les environnaient.

Il y avait à la Bastille une bibliotbèque léguée aux prisonniers par un étranger qui y était mort au commencement du xvıue siècle. On en prütait des livres à quelques-uns, et l'on permettait aux plus recommandés d'y aller en choisir eux-memes. Mais on refusait à certains ce soulagement de l'esprit. Avant que le régime de la Bastille fat porté aux excès de rigueur où il parvint sous le règne de Louis $X V$, on accordait aux prisonniers tous les adoucissements compatibles avec la sureté de la prison. On allait à peu près quand on voulait se promener sur les tours. Le jardin du bastion offrait une 
autre promenade également en plein air, et où la vue, sans être bien variée, laissait moins de prétexte et de crainte à l'inquiète et soupconneuse politique des gouverneurs. On écrivait, on recevait des lettres et mème des visites du dehors. Les gouverneurs et

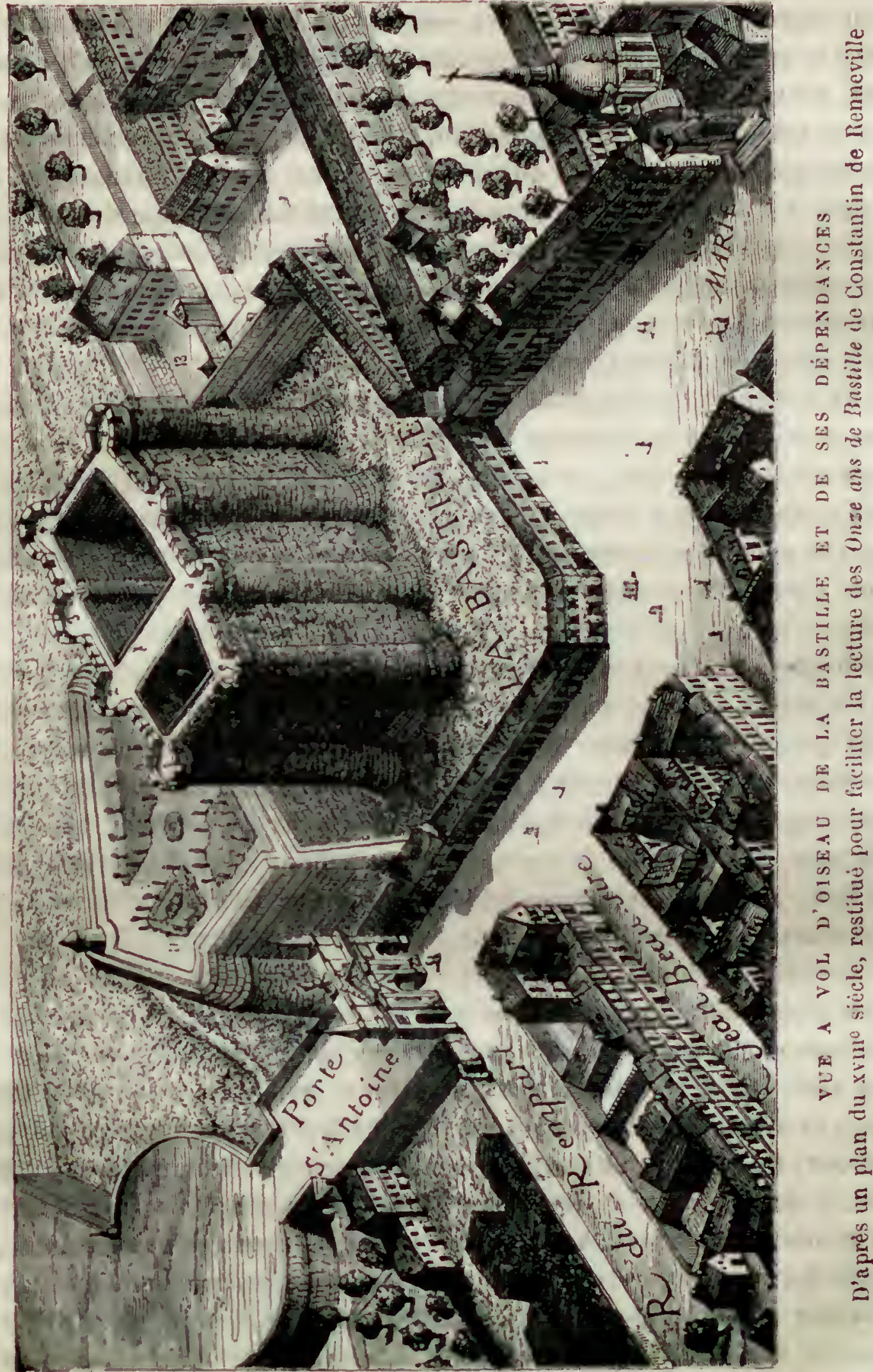

les ofticiers de l'état-major allaient visiter les prisonniers, dinaient dans leur chambre ou les invitaient à venir dans la leur; ils étaient presque leurs amis : ils les gardaient mais ne les tourmentaient pas. C'est qu'alors la plupart de ceux qui y étaient détenus étaient des ennemis du gouvernement, qui s'en assurait mais ne les hařssait pats. Mais. sous ce règne, la forteresse fut remplie non d'ennemis de l'État, mais d'ennemis des ministres, de leurs favoris, de leurs maltresses ou de leurs commis. De cette différence 
dans les motifs de l'emprisonnement, en résulta une très grande dans le traitement. I a méfiance naquit à la suite des abus d'autorité; dès lors, toute communication avec le dehors fut interdite: toute conversation, mème avec ses compagnons et ses employés subalternes, devint criminelle. Les officiers cessèrent de visiter leurs captifs; toutes les lettres durent passer par les mains du major, quiles envoyait a la police, el c'était après avoir subi un nouvel examen qu'on les remeltait a leur adresse, ou qu'on les supprimait. Les réponses devaient de inème être adressées a la police, qui les faisait tenir au major, et celui-ci en donnait communication au prisonnier. Les visites étaient irrévocablement interdites avant l'interrogatoire qui ne se faisait parfois qu'au bout de plusicurs semaines et mème de plusieurs mois. On faisait descendre l'accusé dans la salle du conseil. Il y trouvait des commissaires tels que le lieutenant de police, un conseiller d'État, un maitre des requètes, etc. Souvent le premier n'arrivait qu'à la fin de l'interrogatoire; des faits hien constants prouvent míme que fréquemment il s'en dispensait totalement, et cependant il signait toujours.

On employait les menaces, les insultes, les promesses, selon les personnes et les circonstances, pour arracher aux prisonniers des aveux. Quelquefois on joignail la cruauté à la fourberie. Ainsi le cardinal de Richelieu, voulant tirer de Laporte, valet de chambre de la rcine Anne d'Autriche, ce qu'on prétendait qu'il devail savoir de cette princesse, on lui donna un billet qu'on avait eu l'insolence d'arracher it rette malheureuse reine, par lequel elle lui marquait qu'elle avait dit la vérité. yu ainsi il pouvait en faire autant. Ensuite on lui fit subir un interrogatoire. Le magistrat, ipjris avoir essajé en vain les promesses et le ton de l'intérèt, passa tout à coup aux menacrs. tira un papier de son sac, et le lui montra en disant: "Voila un arret qui vous ion. damne à la question ordinaire et extraordinaire; c'est ce que vous vaut rotre opimtreté. Et sur-le-champ, il le fait descendre à la chambre de la question : on lui fait voir en détail tous les instruments; on lui explique au long l'usage des ais, des coins, des cordages; on lui dépeint les cruelles douleurs, le tiraillement des chairs, les craquements des os, l'aplatissement des genoux, etc. C'est ainsi qu'à plus d'une époque on a préparé les prisonniers de la Bastilie à l'interrogatoire qu'on leur faisait subir.

Le chevalier de Rohan, grand veneur de France, ayant été arréé en 1674, sur le soupçon qu'avaient donné des lettres surprises dans ses équipages, qu'il voulait livrer le Havre aux Anglais, fut mis à la Bastille. Un nommé de la Tuanderie, son entrenrutteur, dont on voulut aussi se saisir, se défendit, fit feu et fut tué sur place. Des gerrs attachés au grand veneur allèrent plusieurs fois le soir crier autour de la Bastille dians des porte-voix : La Tuanderie est mort et nia rien dit. Mais le chevalier de Rohin ne les entendit pas; cependant il n'avoua rien. Les commissaires n'en pouvant rien tirer, lui dirent que le roi savait tout, qu'il n'attendait que son aveu pour lui accrerder sa grace. Liinfortuné se fia à cette promesse, convint de son crime et ent la late tranchée.

Dans le temps de l'affaire des Parlements, un homme est arrete; il est soupgruné d'avoir des complices qu'il ne veut pas révèler. On le précipite dans un earhot. L'horreur de ce lieu où il n'avait d'autre société que d'énormes rats, lui fait avourr tont ce qu'il sait, peut-etre mème ce qu'il ne sait pas, et, sur sa simple déposition, quatore [r'rsonnes sont conduites le lendemain à la Bastille.

Après les interrogatoires, on permettait quelquefois de recevoir des visites a ceux 
pour qui des parents et des amis puissants sollicitaient cette faveur avec de grandes instances. Celui qui avait la permission de voir un prisonnier arrivait muni d'une lettre du lieutenant de police, adressée au gouverneur, au lieutenant du roi ou au major, dans laquelle le nombre et la durée des entrevues étaient fixés. Elles se faisaient en présence d'un ou deux témoins qui se tenaient entre le prisonnier et la personne qui venait le voir. Cette personne ne pouvait lui parler d'aucun objet relatif a sa détention, hors le cas d'une proeédure entamée, dans lequel on obtenait quelquefois un conseil a vec qui l'on pouvait conférer. Si, par une faveur particulière, on accordait à un prisonnier un domestique pour le servir, si par quelque raison de défiance on lui donnait un garde pour le surveiller, le domestique, le garde lui-mème, partageait dès lors les rigueurs d'e sa prison, et sa captivité n'avait d'autre terme que celle du malheureux ave qui on l'enfermait. Quelquefois cet adoucissement n'était qu'un piège que l'on tenlait au captif. Les malheureux ont besoin de s'épancher; la seule vue d'un homme qui sonffre les mèmes maux inspire la confiance. On plaçait donc auprès du prisonnier un espion adroit qui, par une feinte compassion, s'emparait de ses confidences et allait ensuite le trahir.

P'resque tout à la Bastille était l'objet d'un honteux trafic; le gouverneur de Launay n'apportait pas dans ses fonctions les scrupules qu'il aurait dú avoir. Ainsi, lorsque le roi donnait un garde à un caplif, soit pour le surveiller, soit pour le servir, il lui allouait une solde de 30 sous par jour; de Launay ne lui en allouait que 2. . Le bastion ofrrait aux habitants de la Bastille une promenade agréable et un air salubre. Le guvverneur s'en fit un potager, et ayant calculé qu'il lui rapporterait davantage lorsqu il ne servirait plus de jardin d'agrément, l'entrée en fut interdite aux prisonniers. lientòt la plate-forne leur fut également fermée. Il fallait qu'ils y fussent accompagnés par un subalterne ou un porte-clefs qui ne pouvaient pas toujours ètre à leur disposition. Restait donc pour toute ressource la cour intérieure. C'est là que le captif, cntouré de sentinelles, environné de inurs, dans un morne silence, venait pendant une heure braver le soleil ou la pluie, une chaleur étouffante ou un froid insupportable et respirer un air sans circulation. Encore, dans ces courts moments de distraction, lui faisait-on ressentir l'influence da pouvoir arbitraire. Dans un des massifs qui réunissaient les tours, élait auprès de la chapelle un étroit boyau que l'on nommail le cabinet. Comme lout prisonnier devait ètre invisible aux étrangers, et réciproquement, dès que quelqu'un était sur le poinl de traverser la cour: a Au cabinel! * s'ćcriait aussitôt une sentinelle, et il fallait s'enfermer dans la prison décorée de ce nom. La cour étant devenue l'unique chemin de la cuisine et des logements de l'état-major, les pourvoyeurs, les ouvriers de toute espèce, les personnes qui venaient voir les officiers, tuut passait par cette cour, que unl autrefois ne traversait sans nécessité, passé l'heure où s'y rendait le premier promeneur qui, par ce moyen, n'était pas retenu sans cesse dans le cubinet.

Un mémoire de .1. Linguet a sa sortie de la Bastille, et le ridicule qu'il jeta sur ces nsages anena plusieurs changements. Les cuisines furent placées dans une cour extérieure ainsi que la salle de bain, le la gouvernante, ce qui produisait autrefois un vaet-vient perpétuel de porteurs d'cuu, de femmes rle chambre qui forçait les prisonniers a rester des heures entières dans le cabinet. Ce ne fut pas la seule réforme que produisit ce mémoire. Deux figures enchainées par le cou, par le milieu du corps, par les mains et par les pieds servaient d'ornement au cadran de l'horloge du chateau, et 
leurs fers, après avoir couru tout autour du cartel en manière de guirlande, venaient au bas former un nœud énorme. Pour prouver qu'elles menaçaient également les deux áges, l'artiste, guidé par le génie du lieu, ou par des ordres précis, avait en soin de modeler un homme dans la force de l'age, un autre accablé sous le poids des années. Linguet s'éleva avec force contre cette cruauté ingénieuse qui meltait sans cesse sous les yeux des prisonniers des emblèmes de leur triste situation, et les deux figures furent supprimées.

Ces promenades n'étaient accordées qu'd un petit nombre de prisonniers privilégiés; les autres, séparés de l'univers entier, privés de toute communication, dans l'ignorance la plus profonde et du sort des personnes qui leur étaient chères et de leur propre destinée, vivaient dans les angoisses et le chagrin. Il y avait une chapelle à la Bastille, et l'on y disait la messe, mais c'était une faveur que d'être admis a l'entendre, et cette faveur n'était accordée qu'à douze. Dans le mur d'un des cótés de cette chapelle, étaient pratiquées six petites niches, dont chacune ne pouvait contenir qu'un prisonnier, et ceux anxquels on accordait la permission de s'y rendre n'y avaient ni air ni jour. Du commencement du canon à la communion du prétre, on ourrait un rideau qui couvrait une étroite lucarne vitrée et grillée, a travers laquelle, comme dans un tuyau de lunette, on entrevoyait le célébrant. Le chapelain disait tous les jours la messe à neuf heures, et six prisonniers pouvaient y aller. Les dimanches et fetes, il $y$ en avait une seconde à dix heures où il pouvait $y$ avoir six autres assistants. Enfin,. entre midi et une heure, se disait celle du gouverneur, où des prisonniers privilégiés seuls obtenaient la grîce de se rendre. Du moment où le prêtre montait à l'autel jusqu’à celui où il en descendait, on plaçait une sentinelle à la porte de la chapelle. La confession n'était pas interdite aux prisonniers, mais le confesseur de la Bastille était un membre de l'état-major, à 900 livres de gages.

Les détails que nous venons de donner expliquent l'espèce de terreur que faisait naitre dans les esprits, sous l'ancien régime, la crainte de la Bastille. Aussi tous les effurts du peuple se portèrent-ils sur la vieille forteresse, le 14 juillet 1789. Cette date, qui marque le premier triomphe de la population parisienne sur le pouroir absolu, est celle que la République a choisie pour la célébration de sa fète nationale. Il n'est donc pas hors de propos de rappeler les circonstances dans lesquelles s'est accompli ce grand événement, il y aura bientôt un siècle.

Pendant que l'Assemblée nationale paraissait s'abandonner avec une sorte de sécurité aux sentiments d'amour et de confiance que les Français de ce temps accordaient sans réserve à Lonis XVI, ce prince, jouet des intrigues qui se nouaient autour de lui, fut sur le point, dès les premiers jours de juillet 1789 , de couvrir de son nom un des actes de rigueur les plus violents dont un gouvernement puisse se rendre responsable. L'Assemblée nationale devait ètre dispersée, ses arrêts déclarés sédilieux, ses membres proscrits, le Palais-Royal et les maisons des " patriotes, livrés au pillage, les électeurs et les députés aux bourreaux. La nuit du 14 au 13 juillet avait été fixée, dit-on, pour l'invasion de Paris. Les Invalides devaient faire résistance et s'opposer a l'enlevement des armes et du canon en faisant feu sur le peuple. Au mème instant, les brigades campées au Champ de Mars, composées des régiments de Salis-Samade, Chateau-Vieux et Diesbach, suisses; des hussards de Bercheny, Estherhasy et Royal-Dragons, devaient courir au secours des Invalides avec de l'artillerie, tandis qu'un autre corps de troupes légères aurait fondu sur l'Hôtel de Ville et enlevé les magistrats et les échevins. Au 


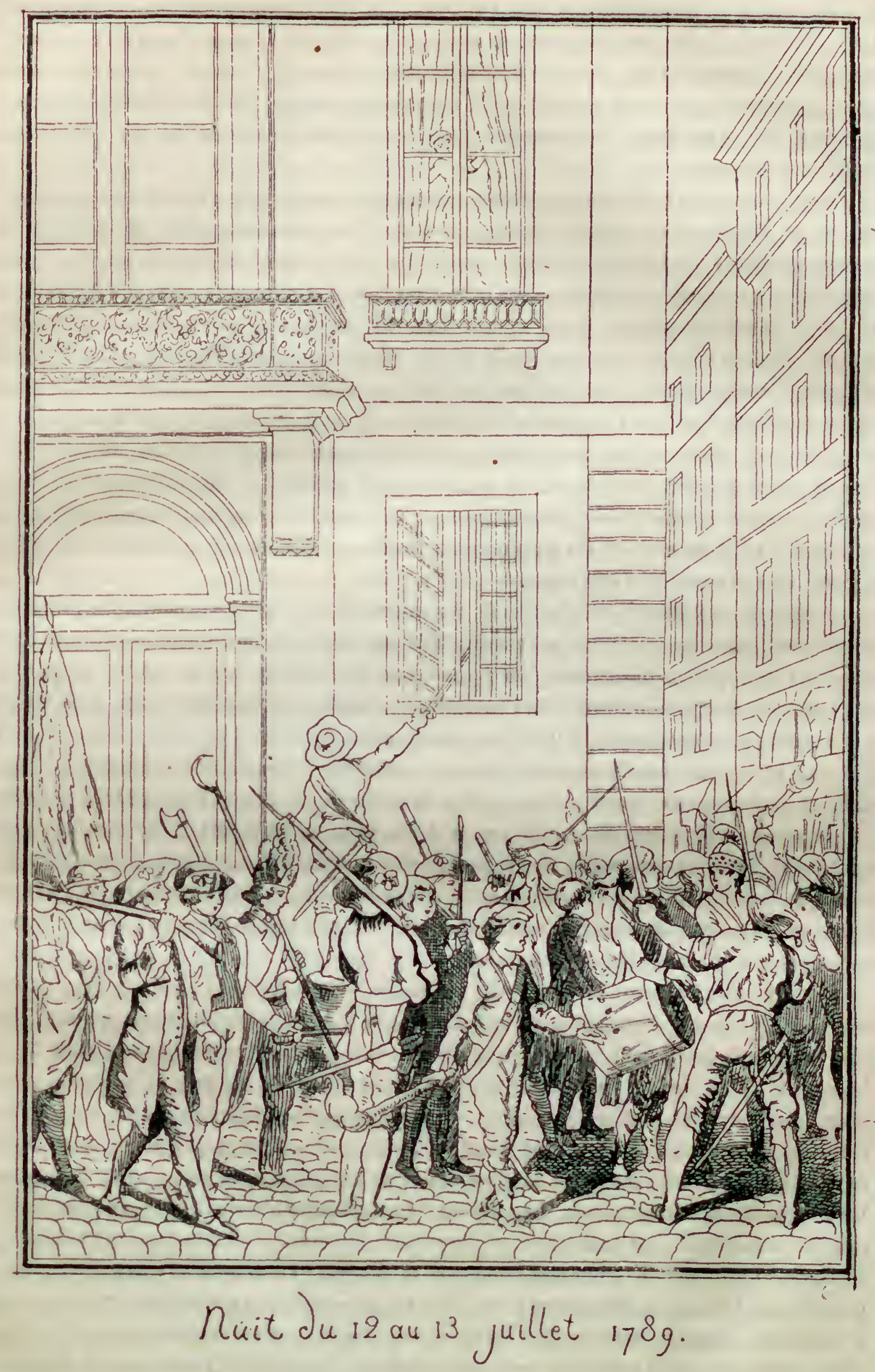

boest? 
premier coup de canon, le prince de Lambesc se serait transporté daus la rue SaintHonoré avec le régiment lioyal-Allemand et les autres régiments de cavaleric, le sabre à la main, avec ordre de charger tout ce qui se présenterait et de s'emparer de la place de Grève. Ce coup de canon étant le signal pour toutes les troupes qui investissaient Paris, les régiments de Provence el de V'intimille seraient accourus de Neuilly; cenx de Royal-Cravatte, Melmstadt el Royal-Pologne, de Sevres et de Mendun aturaient éte suivis de quatre régiments de chasseurs destinés pour la porte Saint-Intoine; trois régiments allemands, avec leurs canons, se seraient rendus it la porte d'Linfer: six mille hommes auraient parcouru la ville, forgant et bouleversant les maisons des "patriotes", et le pillage du Palais-Royal aurait été la récompense des hussards. L'incendie de l'hotel de Bretonvilliers ot de quelques maisons de la freme iturail augmenté le désordre. Dans le mème temps, les régiments de Besancon et de la Firro auraient foudroyé Paris des hauteurs de Nontmartre avec cinquante pidecs d'artillerie. Cette expédition faite, les troupes se seraient retirées à tontes les barrières pour s'en emparer, et des batteries y auraient élé dresșées pour intercepter loute communication avec les provinces. Le lendemain matin, le roi se serait transportí it l'issemblis natio. nale pour la dissoudre. On peut se tromper sur quelques détilis de ce projul: mitis toutes les disposilions prises pour en assurer la réussite, le commencement dexécution qu'il a eu, ne permettent pas de douter de son existence. Un cnsemble de circonstancé empêcha la réalisation de ce plan.

La disgrâce de Necker était un des premiers actes nécessaires ì l'exécution de co projet. Elle fut résolue et fixée à la nuit du 14au 13. Mais ceux des conjurés qui entonraient le roi crurent faire un grand pas en précipitant le départ du ministre, et dès le 11, M. d'Artois, secondé de M. de Breteuil, obtinrent du monarque le r'envoi de Necker, qui reçut l'ordre de sortir du royaume dans les vingt-quatre heures, avec tout le secret et toute la célérité possibles. Il était encore à table lorsque II. de la Luzerne, comme le dernier des ministres en rang, lui apporta la lettre du roi. Sans être troublé d'un message auquel il devait si peu s'attendre, il eut la présence d'esprit de lui dire on le rquittant: Sans adieu, nous nous reverrons ce soir au conseil, et continua de s'entretenir librement avec l'archevèque de Bordcaux et les autres personnes qui dójemnaicnt chez lui. Sur les cinq heures, il dit à IIme Necker, en présence de tout le monde, qu"il se sentait la tète embarrassée, et qu'il désirait faire avec elle un tour de promenade: ils montèrent en voiture. Au bout de l'avenue de Saint-Cloud, le ministre dit au cocher' d'aller plus vite et a Saint-Ouen; c'est dans ce lieu, près de Saint-Denis, qu cétait siture sa maison de campagne. Il y passa la nuit à faire les préparatifs de son départ, et le lendemain à six heures du matin, il en partit pour se rendre à Bruxelles, route la plus courte pour gagner la frontière. Ce fut alors seulement qu il instruisit de ce qui lui arrivait son beau-frère et $\mathrm{M}^{\mathrm{me}}$ la baronne de Staël, sa fille, en présence desquels il aviait reçu la veille l'ordre de quitter la France. Paris ne sut la nouvelle que le lendemain. La consternation fut générale. Les théatres furent aussitôt fermés en signe de deuil ; Ir peuple s'assembla au Palais-Royal où l'agitation croissait d'instant en instant. Dans ce moment, Camille Desmoulins monte sur une tahle, crie : Aurarmes !' tire l'épée, nontre un pistolet et une cocarde verte. La foule étonnée, électrisée par cet appel, pousse tout à coup de violentes clameurs. On s'anime, on s'excite, et les feuilles des arbres arrachées en un instant servent de cocardes a plusieurs milliers d'hommes et donnent le premier signal de l'insurrection dans tous les quartiers de la ville. 
Un gros de citoyens se rendit au calinet de Curtius ${ }^{1}$; on enleva, du consentement de cet artiste, le buste de Necker et celui du duc d'Orléans, que l'on disait alors partagnt' sa disgrace; on les couvrit de crèpe et on les porta dans les rues, au milieu d'un cortège nombreux accompagné d'hommes armés de bàtons ferrés, de haches, de pistolets, marchant sur plusicurs files et formant une procession tumultucuse. Cette eérémonie, en mème temps funèbre, triomphante et grotesque, traversait la place Louis $\mathrm{XV}$, lorsqu'un détachement de Royal-Allemand et de dragons vint, le sabre haut, charger cette foule de manifestants. La eour, prévoyant l'impression que ferait sur les esprits le départ de Neeker, avait envoyé ses satellites pour prévenir l'effet des premiers mouvements, et avait fitit avancer Royal-Allemand et le réginent des gardes-suisses, précédé de ses canons, sous les ordres de M. Bezenval, chef de cette expédition. Le buste de Necker fut brisé, eelui du duc d’Orléans échappa avec peine au sabre d'un dragon. Un gardefrançaise sans armes fut tué, et quelques personnes blessées. Le prince de Lambese, colonel de Royal-Allemand, était alors avec sa troupe sur la place Louis XV. Le peuple l'assnille d'une grêle de pierres. Il perd la tète, s'élance dans les Tuileries avec quelques cavaliers, et d'un coup de sabre blesse un vieillard. Quelques coups de fusil et le bruit d'un eoup de eanon répandent la terreur parmi la population qui quitte précipitamment le jardin.

A cette vue, les cris redoublés : "Aur armes! aux armes!" se répètent successivement du Pont-Royal dans tout Paris. Le tocsin sonne dans toutes les paroisses; on court à l'Hotel de Ville, on se rassemble, on enfonce quelques boutiques d'armuriers; des gardes-françaises s'échappent de leurs casernes, se mẻlent avec le peuple. Rassemblés en force près du dépòt, sur le vieux boulevard, ils s'avancent en bon ordre, astaquent un détachement de Royal-Allemand, et tuent trois cavaliers à la première décharge. Ceux-ei, quoique assaillis, essuient le feu de leurs adversaires sans riposter, et se replient sur la place Louis XV, où était le gros de leur régiment. Sur les onze lieures du soir, les gardes-françaises se rendirent au Palais-Royal, au nombre d'environ douze cents, et sans officiers ni artillerie, se déeidèrent à se porter sur la place Louis $\mathrm{XV}$ pour en chasser les troupes réglées qui l'oceupaient. Cette petite armée se mit en marche a la lueur de flambeaux et de lanternes. Les troupes de la place n'opposèrent aucune résistance et se retirèrent ì Versailles. Leur exemple fut suivi par tout ce qu'il y avait de troupes réglées dans la ville qu'elles évaeuèrent en même temps.

Des malfaiteurs profitèrent des ténèbres de la nuit pour parcourir la ville et les faubourgs, mettant le feu à la barrière Blanche et à plusieurs autres. Des divisions de soldats du guet. de gardes-franģaises, des eorps de bourgeois armés et des patrouilles parcouraient les rues, achevant ainsi de troubler la population. On n'était pas plus tranquille à Versailles : deux cents députés se réunissent a sept heures du soir, mais l'Assemblée étant ineomplète, sans président et ajournée seulement au lendemain, ne s'oceupa que de ses soucis et de ses inquiétudes. Les communications avee la capitale furent interrompues: ni les courriers de la poste, ni les piétons, ni les voitures ne purent frauchir les barrières. Le chemin de Versailles fut aussitòt couyert de troupes; les gardes du corps cux-mèmes passèrent la nuit en bataille; le pont de Sèvies fut gardé avec du canon, et loordre fut donné de le rompre, si l'on ne pouvait le défendre

1. Scuphtear qui montrait au public, dans les lieux les plus fréquentes, des cabinets remplis de diverses effigies en cire, et particulierentent des contemporains capables de fixer l'attention et de piquer la curiosites. 
avec avantage. Un faux avis de l'attaque de ce pont vint encore augmenter l'alarme du parti des conjurés royaux. Pendant ce temps, Paris s'occupait de sa défense. Dès le point du jour, des troupes d'ouvriers armés de batons et de fusils, de piques, sabres,

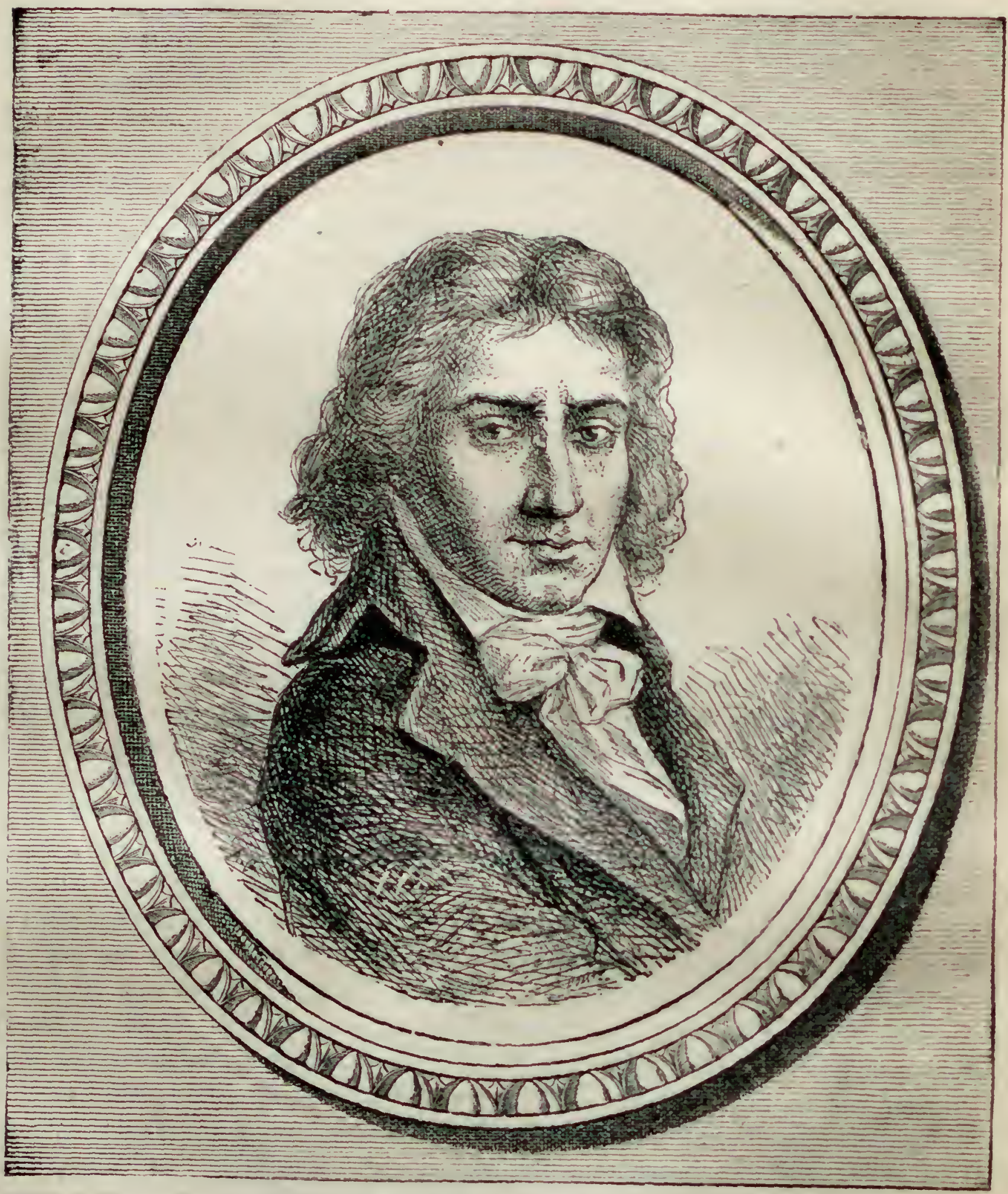

CAMILLE DESMOULINS.

lances et pistolets, s'étaient répandus dans divers quartiers, menaçant de brôler les hôtels des familles aristocratiques. Une heureuse idée venue à un Parisien sauva la capitale. Paris avait deux cent mille bras pour la défendre, mais il n'y avait pas de tête pour commander. A la requête de ce citoyen, les électeurs sont convoqués; ils s'emparent de l'autorité et ils sont écoutés avec confiance.

Le dimanche 12 juillet, à six heures du soir, les électeurs, ayant appris que l'Hotel 
de Ville était rempli par la foule, s'y rendirent pour prendre provisoirement le gouvernement de la ville. Les électeurs étaient d'abord en trop petit nombre pour prendre une délibération. Ils réunirent leurs efforts pour calmer leffervescence du peuple, et pendant quelques moments, la multitude fut contenue dans l'enceinte réservée au

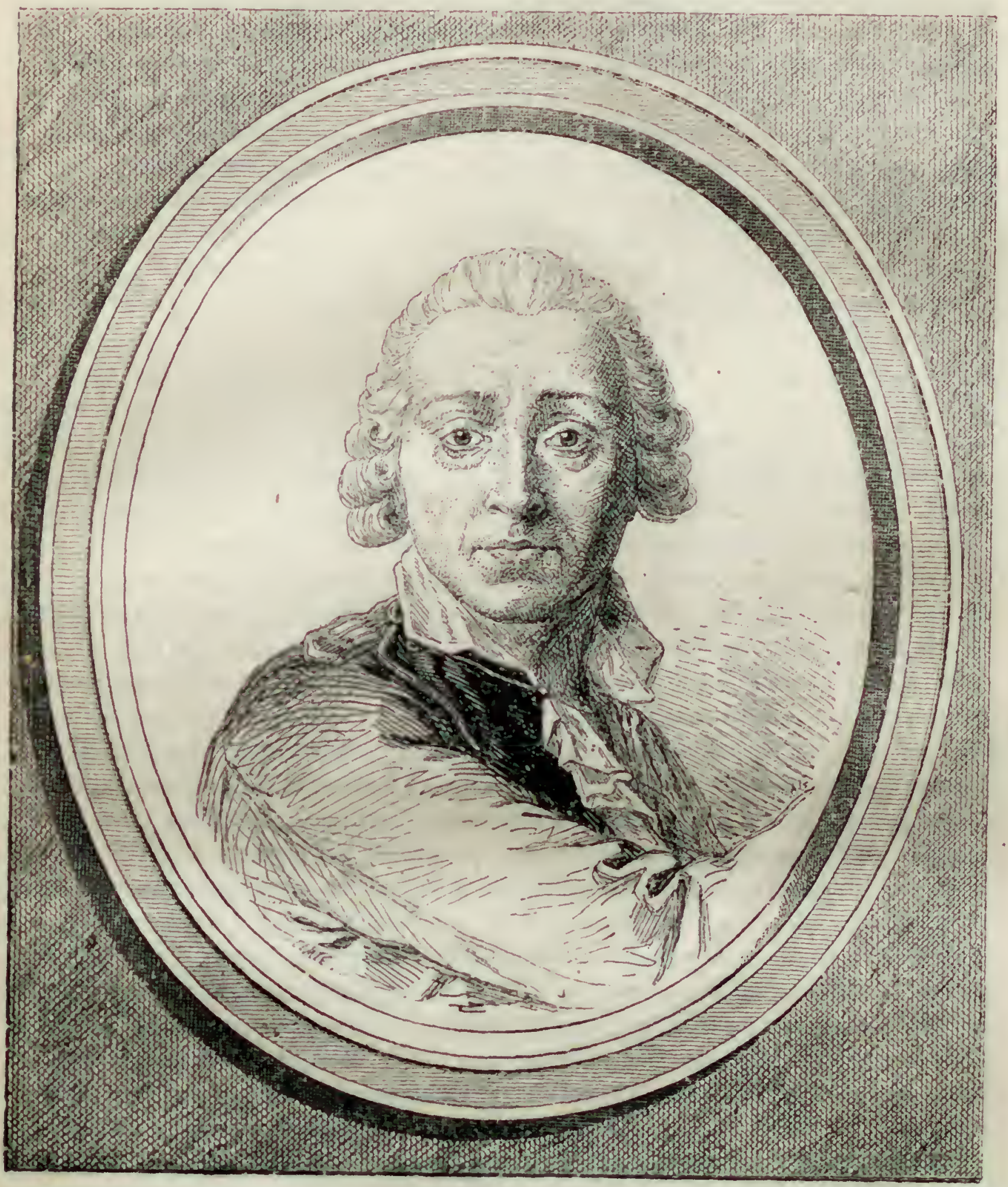

LATUDE, PRISONAIRR DE LA BASTILLE.

public, personne n'osint encore franchir la barrière qui séparait, dans la grande salle, cette enceinte de l'autre partie de la pièce occupée par les électeurs. Mille voix confuses demandaient des armes et l'ordre de sonner le tocsin. Sur les huit heures, une patrouille du guet à pied rentra au poste établi sur la place de l'Hôtel de Ville. La multitude pressée sur cette place désarma les soldats; les cris pour obtenir des armes 
redoublèrent, et les menaces de mettre le feu à l'ilotel de Ville éclatèrent de tontos parts. Ces cris, parvenant jusque dans la grande salle, augmenterent l'agilation qui y régnait. La barrière fut bientôt franchie, et les électeurs furent pressés jusıune sur lo bureau autour duquel ils s'étaient rassemblés. On leur demaudi impéricuscment n' ordre en vertu duquel les citoyens fussent aulorisés à s'armer pour repousser le dinger qui menaçait la capitale. Dans ce moment redoutable, et pour cacher l'incendie dont la menace devenait plus vive à chaque instant, les électeurs ordonnèrent au concieräc de délivrer les armes qui pouraient se trouver daus l'llùlel de Ville. Cet orile ne s'exécutant pas assez promptement au gré du peuple, il chercha lui-mdinc, et bientit il décourrit le dépót des armes des gardes de la ville. Les portes furent enfoncica et les armes pillées. Un instant apres, on vit un homme en chemise, jambes nues ct sans souliers, le fusil sur l'épaule, prendre la place d'un garde de ville désarmé, rt monter fièrement la garde à la porte de la salle. Le tumulte était toujours le mu na dans cette salle; on demandail le tocsin, des armes et la convocation des districts.

Cependant, le nombre des électeurs s'tant successivement augnuenté, ils parviurmt enfin à se faire entendre, à obtenir quc!ques intervalles de tranquillité, et, apres il: longs débats, ils prirent à onze heures du soir l'arrêté suirant: "Sur les lemamin: pressantes de nombre de citoyens alarmés qui se sont rendus a l'Hùtrl de Ville. ct qui ont témoigné leur appréhension aux électeurs alors assemblés; pour tacher de privenir le tumulte, lesdits électeurs ont arrèté que les districls seront sur-le-champ convoqués, et que les électeurs seront enroyés aux postes des citoyens armés, pour les prier de s'opposer, au nom de la Patrie, à toute espèce d'attroupement et roie de fait. - Signé: Debin de Loxchamp, Damecve, Fortix, Soluis, Sint-Fílix, Damelve fils, de Luigxé, Bourdon. Duport du Tertre, Crchet, de Bosieville.,

Les électeurs confirmèrent, par acclamation, la nomination du p̧révòt des marchands, des échevins, du procureur du roi, et des autres officiers composant le burean ordinire de l'Hôtel de Ville. Ils prirent les mesures les plus sages pour assurer les subsistances et le bon ordre. Sur la proposition d'un électeur, on cráa un comité pernunent (ainsi nommé parce que son service devait durer sans interruption, jour et nuil), et immediatement furent nommés, pour le composer, le prévôt des marchands, M. listhis de Comy, procureur du roi, les quatre échevins, le greffior de la Ville, deux conseillers, un quartenier, MM. le marquis de la Salle, l'abbé Fanchet, Tassin, Delentre, Cuatremère, du Mangin, Ducloz-Dufresnoy, Moreau de Saint-Méry, des Issarts, Ilyon, Leczrant de Saint-René, Jeannin, Gressé du Verrier, de La Vigne, Bertholio, Boucher, Dusaulx, Chignard, Leconteux de Lanvraye, Ganilh, Perrier et Pérignon. Comme le plan diune milice bourgeoise et d'une garde nationale avait déjà été arrèté, on nomma, pour la commander en chef, le marquis de la Salle, et le chevalier de Sandray pour le commandement en second. Le soir, l'Assemblée générale, ou plutòt toute la commune convoquíc, confirma et ratifia ce qui avait été fait. Pendant que quelques-uns s'occupaient ainsi du danger présent et s'efforçaient de le conjurer, toutes les bouliques restèrent fermies; le peuple, armé de batons, de poignaids, de lances, de piques grossières et infurmes que les maréchaux avaient forgées à la hate pendant la nuit, se divisa et se porta en mème temps sur différents points pour attaquer les hủtels des princes. Un peloton, supposant que les religieux de la congrégation des lazaristes avaient dublé emmagasiné, s'achemina vers le couvent dont il enfonça les portes à coups de hache. La communauté fut saccagée du grenier à la cave. Les tonneaux ayant élé défoncés, une trentaine d'indi- 
vidus, lant hommes que femmes, furent trouvés le lendemain noyés ou expirants dans les flols de vin. On incendia une grange; on chargea cinquante-deux voitures du grain un des farines qui garnissaient les magasins. On ne vola rien pour l'emporter ou pour Ir plaisir de voler, car un de la troupe ayant élé pris en flagrant délit, justice en fut fiite sur-le-champ. Deux des plus grands et des plus forts ayant appuyé leurs lances sur leurs épatules, le voleur y fut inmédiatement accroché et étranglé. Le reste escorta les voitures qui furent conduites ì la halle. Un groupe se présenta dans la mème matinée au Garde-Meuble de la Couronne, enleva des armes, deux canons et plusicurs al'mures très précieuses et d'un grand prix. Dans l'après-midi, on découvrit au port Sinint-Nicolas un bateau rempli de poudre; il fut déchargé et mis sous la sauvegarte des bourgeois. Sur les six heures du soir, un convoi considérable, destiné aux troupes du Champ de Mars, ajouta aux provisions de bouche qui devenaient nécessaires. M. de Crosue, lieutenant de police, fut mandé à l'Hôtel de Ville; il annonça qu'il avait donné sit démission au roi et assura qu'il y avait à Paris des approvisionnement pour quinze jours.

La population passa une nuit un peu plus calıne que la précédente, toujours veillant cependant, les hounnes armés, les femmes assises sur des monceaux de pavés arrachés dans les cours el transportés dans les appartements pour s'en servir en cils d’agression des tronpes régulières. On apprit, dès le commencement de la nuit, qu'une portion des soldats étrangers et que tous les régiments nationaux devaient refuser le service ì leurs chefs. Pendant la mème nuit, la garde bourgeoise arrèla et désarma une quarantaine de gens sans aveu, la plupart faisant partie de la troupe de ceux qui, dans la matinée, avaient pillé la maison de Saint-Lazare; ils furent condnits dans les prisons. Au milieu du trouble général, les églises se remplissent en un clin d'ail, les citoyens se rendent précipitamment dans leurs districts. On députe à l'llùtel de Ville, on se concerte avec le comité des électeurs qui s'y était assemblé dès la veille. La commune se forme; on dépose le prévòt des marchands et les autres officiers municipaux et on les recrée anssitòt. Tous les hommes se font inscrire sur la liste des « défenseur's de la Patrie et se décorent de la cocarde verte. Il est statué que chaque district formera des patrouilles pour garder la ville, que le prévòt des marchands avisera aux moyens de fournir promptement des fusils et des munitions de guerre.

Après cet arrèté, les drapeaux de la ville furent déployés, on fit des décharges de canon pour tenir tout le monde en éveil, on établit des tranchées, des barricades dans les fanlourgs et dans quelques rues du centre, on posta partout des corps de garde. kn moius de trente-six heures, Paris présenta l'image d'une ville assiégée et vit dans son enceinte au moins cent mille hommes armés qui se divisèrent par compagnies, nommèrent des conmandants, et auxquels vinrent s'adjoindre environ trois mille gardesfrançaises. Sur ces entrefaites, on surprit un convoi de farine destiné au Champ de Mar's: il fut conduil ì la halle pour ètre distribué aux boulangers. Sur les cinq heures et demie de laprès-midi, la comitó de la Ville nomma une députation pour aller rendre compte ì l'Issemblée nationale de ce qui se passait à Paris. Les districts redoublèrent d'activité, firent distribucr clracundans leur arrondissement des patrouilles nombreuses "l tirent falıriquer cinquante mille piques; la place de Grève fut encombrée d'hommes de toutes les conditions, de députations de toutes les parties de la capitale. La nuit se láşa sans événement; le jour parut. Les régiments campés aux Champs-Élysées s'étaient retirés pendant la nuit; on ignorait le vrai motif et le lieu de leur retraite. On 
salteadait it chaque instant i une altaque, on ne parlail que le troupes venant assaillir la capitale. A deux heures du matin, on était venu donner l'alerte il l'llotel de Ville. $10 \%, 000$ hommes, disait-on, descendent de la rue Saint-Antoine vers la place de cirèce et l'Hôtel de Ville ne peut manquer d'ètre forcé. "Il ne le sera pas, répondit un des électeurs, Legrand de Saint-René, car je le ferai sauter à temps. „Aussitôt il ordonne aux gardes de la ville de lui apporter six barils de poudre et le les déposer dans le cabinet voisin de la salle commune. La garde nationale, quoique fornée de la veille, comptait déjà près de 150,000 hommes, mais la plupart étaient sans armes. Le 14 juillet trouva Paris dans un état d'effervescence difficile ì décrire; la foule se portait avec une curiosité inquiète des districts ì l'llòtel de Ville, de l'llótel de Ville aux distriets : le tumulte, la méfrance, l'agitation, l'incertitude régnaient dans toutes les assemblées; au I'alaisRoyal, les motions les plus violentes se succédaient avec une efrayante rapidité, díposées par de véhéments orateurs; le tocsin sonnitit sans interruption dans la cathédrale. au Palais et dans toutes les paroisses; des tambours battaient la générale dans tous les quartiers et les cris “A Ax armes! aux armes! » retentissaient par toute la ville. Le conité des électeurs était permanent nuit et jour à l'Hôtel de Ville. Ir. de la Salle fut nommé commandant des forces nouvellement organisées, sur le refus du duc d’amont. Les cocardes vertes furent proscrites en haine du comte d'Artois que l'on considériat comme un des principaux chefs de la conjuration et dont la maison portait cette conleur. Les rubans rose et bleu, couleurs de la Ville, furent adoptés pour marque distinctive par tous les enrollés volontaires.

Les capitaines et officiers furent désignés; on se rassembla sur les places, dans les jardins; on s'y forma en troupes qui furent appelées, les unes, volontaires In PalaisRoyal; les autres volontaires des Tuileries, de la Bazoche, de l'Arquebuse. Mais on manquait toujours de fusils et de munitions. Des députations continuelles accouraient demander qu'on distribuat les armes qui se trouvaient dans les dépóts publics. I.e prévòt des marchands prodignait les promesses, mais n'en réalisait aucune. Le peuple prit le parti de se procurer lui-même ce qu'on ne voulail pas lui accorder. Plus d: trente mille hommes suivirent aux Invalides M. Ethis de Corny, chargé par le comité d'en demander au gouverneur. Dès le dimanche, cel officier général avait recu l'orilre de se tenir prêt, et, toute la journée du lundi, ses soldats restèrent sous les armes. N'ayant, depuis, reçu aucun ordre ultéricur, il leur permit le mardi matin de prendre quelques heures de repos.

Ce fut dans ce moment qu'arriva le procureur du roi. Il fit part au gouverneur de l'objet de sa mission; M. de Sombreuil répondit qu'il n'avait pas d'armes, et, tout en causant avec M. de Corny, le reconduisit à la grille. A peine fut-elle ouverte, que le peuple se précipita en foule dans l'hôtel et courut à la recherche du magasin qui derait contenir les armes. Mais quelques jours arant, elles en avaient été soigneusement enlevées et cachées sous le dỏme et dans d'autres réduits secrets. Un hasard en déconvit une partie à la multitude, et d'actives recherches la mirent en possession du reste. (In se précipita avec fureur dans le souterrain qui recélait le dépôt principal : fusils, sabres, baionnettes et pistolets furent enlevés en un instant. On se porta aussi à tons les corps de garde, et on s'empara de toutes les armes qui s'y trouvaient. Vingt-luuil mille fusils et vingt pidces de canon furent le fruit de cette expédition; plusieurs hommes furent étoulrés dans la foule, victimes de la violence avec laquelle on : dispula les arnes. 


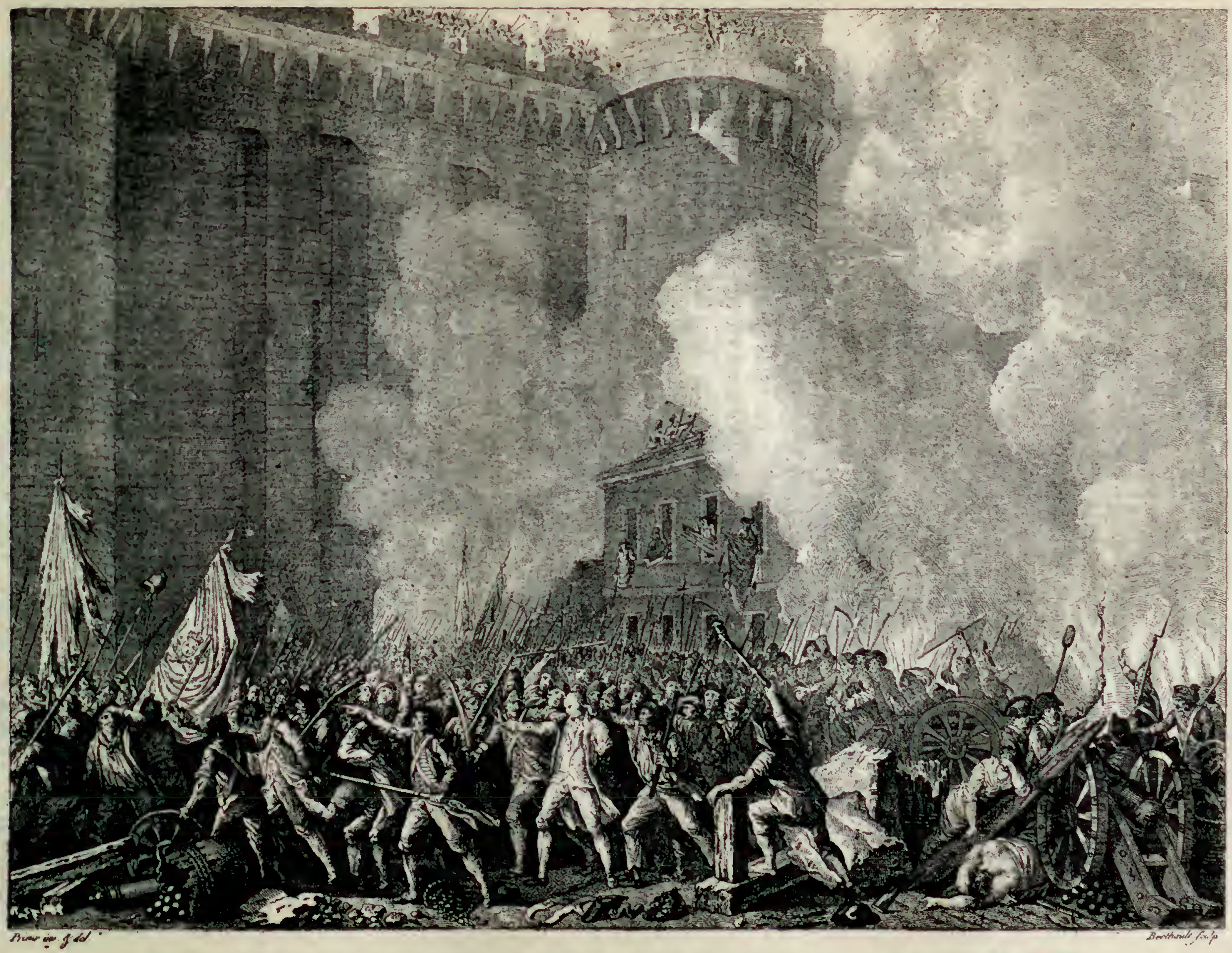

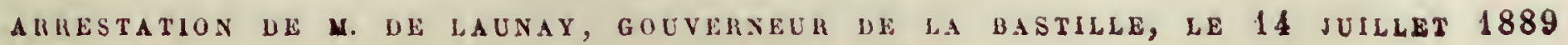

(D'après l'estampe de Prieur.) 
Le gouverneur avait des soldats et de l'artilleric; il aurait pu, avant de se rendre, se défendre à outrance, mais il aurait fini par succomber. Il prit donc le parli d'éviter' l'effusion du sang et ne tenta pas une résistance inutile. Cependant, 11. de Sombrenil ayant eu le courage de refuser les clefs, disant que son devoir de gomverneur l'obligeait à les garder, le peuple lui sut gré de sa fermeté, et ne fit aucun dégàt aux luvalides. Üne garde nombreuse y fut mène laissée pour prévenir les désordres que la multitude, toujours croissante, pourait occasionner. On distribua sur-le-champ les canons à différents postes; on en traina quelques-uns à l'llütel rle ville, et on leus laissa à tous des sentinelles. Au mème instant, des légions d'hommes armés inondèrent la place des Invalides, le boulevard et les rues voisines; une partie s'avança en corjps d'arméc dans le centre de la ville, l'autre resta immobile el rangée en bataille en face des troupes campées au Champ de Mars.

Mais la Bastille était toujours debout, et cette forteresse excitait depuis longtemps la haine du peuple parisien qui résolut d'en avoir raison. Depuis l'émeute du faubonrg Saint-Antoine, le gouverncur de Launay, qui se sentait menacé, s'occupait sans relâche de ses préparatifs de défense. Quinze pièces de canon furent installées sur les tours du donjon, et trois pièces de campagne furent placées dans la grande cour en face de la porte d'entréc; 400 biscaiens, 14 cofrets de boulets sabotés, $1,: 00$ cartouches. des boulets de calibre, et 2.00 barils de poudre du poids de $12 \%$ livres cliacun, telles étaient les munitions du gouverneur. Cette poudre arait été transportée de l'Arsenal a la Bastille par les Suisses du régiment de Salis-Samade, dans la nuit du 12 au 13 juillet. Dès le 10 du même mois, il avait fait monter sur les tours six voitures de pavés. de vieux ferrements, et des boulets qui n'étaient pas de calibre, pour défendre les approclie. du pont, dans le cas où les munitions viendraient à manquer, et où les assiégeunt s'approcheraient assez pour que le canon ne pùt plus les alteindre. Quelques nuits auparavant, il avait eu la précaution de faire tailler d'un pied el demi les embrasure-. pratiquer des meurtrières, réparer tous les pont-levis, et enlever tous les garde-fous, pour qu'ils ne pussent pas favoriser le passage du fossé lorsque les ponts seraient levés. Dans son logement même, une fenêtre felmée par des madriers de chine assemblés, à rainures et languettes, offrait six ouvertures propres it recevoir le canon d'un fusil; une jalousie baisséc en dérobait la vue. Il avait r'etiré du magasin d’armes douze fusils de rempart, portant chacun une livre et demie de balles, et en avait fait prépareı six pour sa défense. Quatre-vingt-deux soldats, invalides, dont deux canonniers de la compagnie de Monsigny, et trente-deux Suisses du régiment de Salis-Samade, commandés par le lieutenant de grenadiers Louis de Flue, composaient sa garnison. Tel était l'état de ses forces le mardi 14 juillet. Mais les munitions de gucre avaient fait oublier au gouverneur les provisions de bouche : elles consistaient en deux sacs de farine et un peu de riz. Il ne manquait pas de pois, mais il n'avait d'autre four qu'un petit four à patisserie, et d'autre eau que celle que fournissaient des canaux par le moyen d'un bassin extérieur, faible ressource dont on pouvait facilement le priver. Il est nécessaire, pour l’intelligence des détails, de donner une idée de la forteresse à cette époque.

Le chàteau de la Bastille était composé de huit grosses tours, dont les murs avaient environ six pieds d'épaisseur; elles étaient jointes par des massifs de maconnerie épais de neuf pieds. L'entrée se trouvait à droite de l'extrémité de la l'ue Saint-Antoine: audessus de la première porte était un magasin considérable d'armes de difrérentes espèces, 
qui depuis peu avaient été transportées aux Invalides, à la réserve de 600 fusils que le gouverneur fit rentrer dans l'intérieur mème de la Bastille, et quelques armures anciennes qui furent pillées par le peuple. A côté de celte porte élait un corps de garde où l'on plaçail chaque nuit deux sentinelles pour répondre et ouvrir aux personnes qui se présentaient. Celte porte conduisait à une première cour extérieure dans laquelle ćtaient les casernes des invalides, les écuries el remises du gouverneur. On pouvait exalement arriver à cette cour par l'Arsenal; une porte à côté de laquelle élait un aulre corps de garde, un fossé et un pont-levis, qu'on appelait le pont de l'A cuncé, la sćparait d'une seconde cour dans laquelle se voyait l'hôtel du gouverneur. En face de cet hôtel élait une avenue longue de 17 toises, dont le côté droit élait bordé par un corps de logis vù se trouvaient une cuisine et une salle de bains. Ce baliment était construit sur un pont dormant qui traversait le grand fossé et sur lequel s'abaissait un pont-levis. Au deli, était encore un autre corps de garde; e'est par là que l'on arrivait ì la grande cour intéricure, après avoir franchi une grille de fer qui servait de retranchement à la sentinelle qui devait ne pas laisser approcher delle les prisonniers à la distance de trois pas. Celle grande cour avait 102 pieds de long sur 72 de large; elle était environnée des tour's dites de la Liberté, de la Bertaudière, de la Bazinière, de la Comté, du Trésor et de la Chapelle, et des massifs qui joignaient ces six tours qui s'élevaient à la hantenr de 73 pieds 3 pouces en dedans. Celte cour élait terminée par un bàtiment yu'une inscription en lettres d'or sur un marbre noir annonçait avoir été construit sous le rigne de Louis XV et le ministère de M. de Saint-Florentin, par M. de Sarline, alors lieutenaut de police, pour le logement des officiers de l'état-major, el qui séparait la Grunde Cour de la cour du P'uits. Cette dernière cour était environnée des tours du Puits etolu Coin, et des massifs correspondants, et avait 72 pieds de long sur 42 de large; c'itait la hasse-cour du chateau. Un bastion qui servait autrefois de promenade aux prisunniers, et depuis quelques années de polager au gouverneur, élait joint au fort par une espèce de galerie qui communiquail an chemin de ronde. La forteresse était environnée entièrement dun large fossé toujours à sec excepté dans les temps pluvieux ou lorsque la rivière étail haute. Une forte maçonnerie de 36 pieds de hauteur couvrait sa surfice lalérale extérieure, à laquelle était scellée une galerie de trois pieds et demi de largeur qui régnait dans tout le contour de celle espèce de contrescarpe. On y arrivait par des pas de souris ou par des escaliers placés à droite et à gauche du pont. Cette galerie formait ee qu'on appelait le chemin de ronde, parce que des officiers et des sergents y faisaient de fréquentes rondes, surtout la nuit, pour sassurer de la vigilance des quatre sentinelles qui y étaient placées. Au sommet des tours était une lerrasse prolongée le long des massifs par lesquels ces tours se communiquaient et au bord de laquelle régnait un parapet.

M. de Launay fit prendre les armes a la garnison le lundi 13, à deux heures du matiu, el la fit reutrer dans l'intéricur. Les portes du quartier furent fermées : la compagnie y laissa ses effets. Deux soldats invalides sans armes furent chargés de veiller à louverture et i la fermeture des portes donnant sur l'Arsenal et la rue Saint-Antoine. On établit des factionnaires a tous les postes, et douze hommes furent placés sur les tours pour observer ce qui se passait au dehors. Entre onze heures et minuit, on tira sept coups de fusils sur ces observateurs, ce qui donna l'alarme; mais elle n'eut pas de suite. Dans la matinée du 14, plusieurs députations vinrent demander au gouverneur des armes et la paix. Il les assura de ses bonnes intentions et les reçut au gouverne- 
ment, après avoir donné au peuple des otages pour leur sưreté. Une grande partie de l'état-major était d'avis qu'il ne prît aucune mesure hostile. Mais excité par les conseils de Louis de Flue, commandant des Suisses, par les ordres de M. de Bezenval et"les promesses de M. de Flesselles, il se décida ì employer la force.

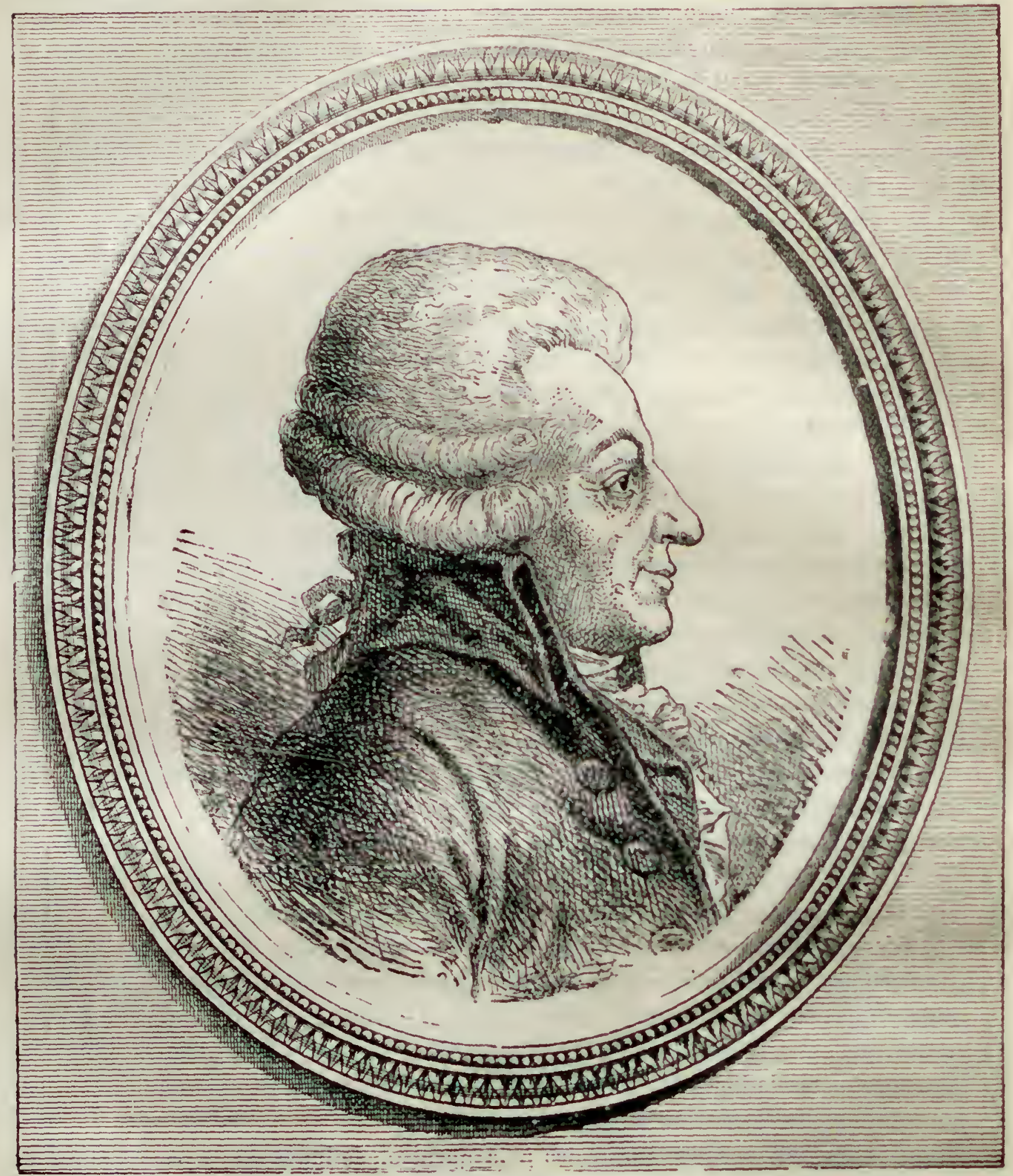

YIAABRAO.

A midi, on vint annoncer au district de Saint-louis-de-la-Culture que la direction des canons placés sur les tours de la citadelle jetait l'alarme dans la capitale; on assura en mème temps que le siège était décidé et qu'il allait commencer. M. Thuriot de la Rosière, député par le district vers le gouvernement, s'y rendit aussitot accompagné de deux "soldats citoyens, qui s'urrêtèrent au pont de l'Avancé. Il entra seul 
et lui dit: "Je viens, au nom de la nation et de la patrie, vous représenter que les canons que l'on voit braqués sur les tours de la Bastille causent beaucoup d'inquiétude et répandent l'alarme dans tout Paris. Je vous supplie de les faire descendre, et

$$
\text { Se Révell Jutiers Etat }
$$

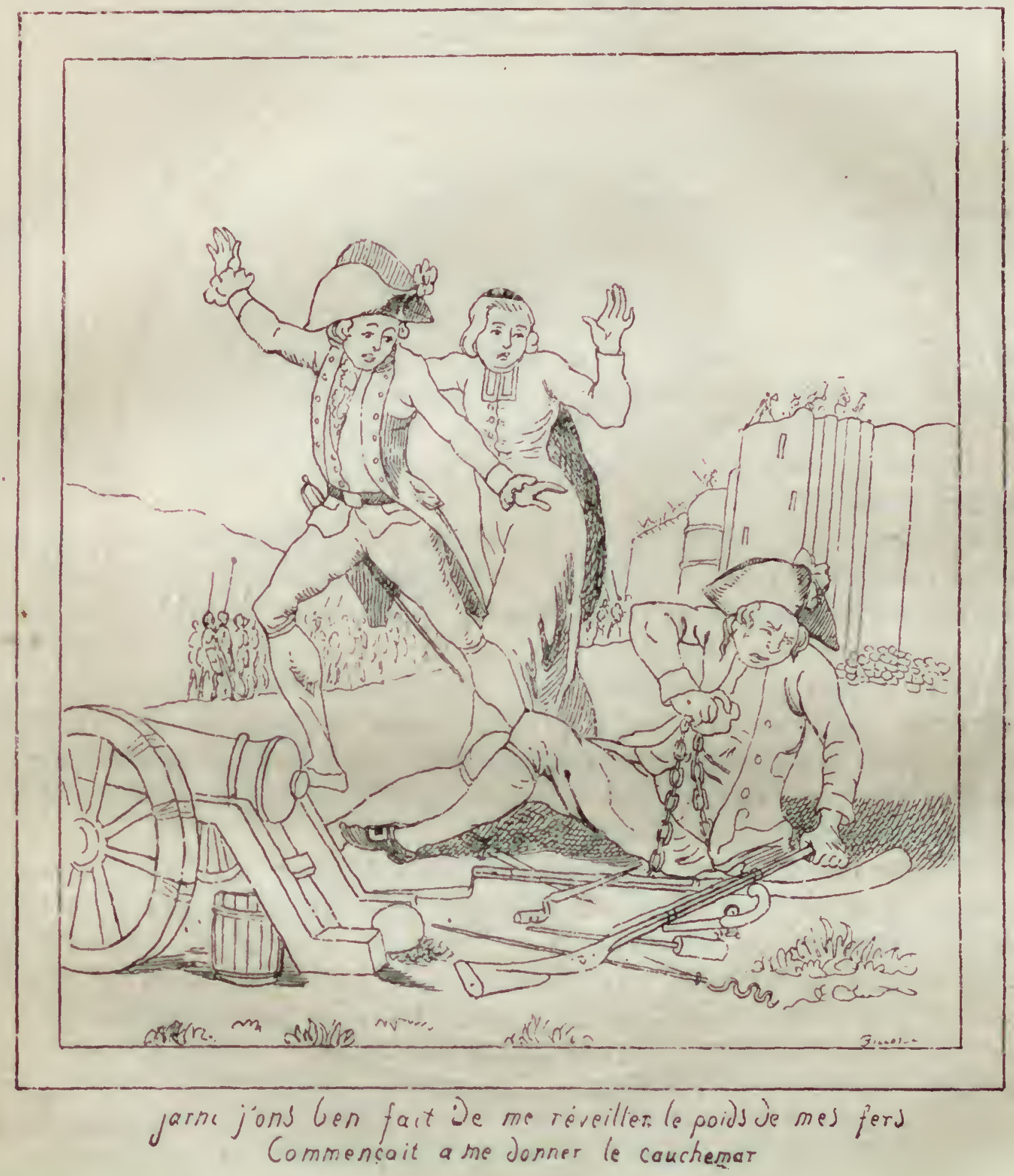

CARICATURB PUBLIÉ EN 1789, APRÉS LA PRISE DE LA BASTILLE.

j'espère que vous voudrez bien acquiescer à la demande que je suis chargé de vous en faire. - Cela n'est pas en mon pouvoir, lui répondit le gouverneur, ces pièces ont de tout temps été sur les tours, je ne peux les en faire descendre qu'en vertu d'un ordre du roi. Instruit déjà des alarmes qu'elles causent dans Paris, ne pouvant pas les faire ôter de dessus leurs afruts, je les ai fait reculer et sortir des embrasures. 
Le député ayant obtenu, à la prière de M. de Losme, major de la place, la liberté d'entrer dans la cour intérieure, il supplia les officiers et les soldats de faire changer la direction des canons et de se rendre. Tous, sur l'invitation meme du gouverneur, jurèrent de ne faire aucun usage de lenrs armes si on ne les attanuait. M. Thuriot monta ensuite sur les tours avec M. de Launay: parvenus au sommel de celle qui dominait l'Arsenal, ils découvrirent un peuple immense accourant de toutes parts et le faubourg Saint-Intoine qui s'avangait en masse. Le gouverneur pillit, et, saisissint M. Thuriot par le bras: "Que faites-vous, monsieur? vous abusez d'un titre sacré pour me trahir? - Lt vous, monsieur, si vous continuez sur le meme ton, je vous déclare que liun de nous va bientòt tomber dans ce fossé. "De Launay se tut. Mors. la sentinelle qui était sur cette mème tour vint leur dire que l'on se préparait à allapur. le Gouvernement, qu’il n'y avait point de temps à perdre, et conjura .M. Thuriot dis se montrer. Celui-ci s'avanga sur le rehord, et de nombrenx applandissements partirent du jardin de l'Arsenal. Il jeta ensuite un coup d'oil sur les canons; on les avait retirós environ de quatre pieds des embrasures, mais il observa que leur direction était la même et qu'on les avait masqués. Descendu de la tour avec le grournernour, il le prosir de nouveau, lui et ses soldats, de se rendre au voeu de la population. Les soldats cédaient, mais leur chef, éperdu de ce qu'il venait de voir et d'entendre, fantit les retenait, tantòt hésilait. M. Thuriot de la Rosière, désespérant de vaincre sa résistance, et craignant de perdre des moments précieux, prit le parti de se relirer l'aburd à son district, ensuite ì l'llòtel de Ville.

Un nombre assez considérable de citoyens vint alors se présenter devant la Bastilla pour demander des armes et des munitions de guerre. Comme ils étaient la plupart sans défense, et n'annonçaient aucune intention liostile, M. de Launay les accueillit ct fit baisser le premier pont-levis pour les recevoir. Les plus déterminés s'avancìrent pour lui faire part du motif de leur mission. Mais a peine furent-ils entrés lans la première cour, que le pont se releva, et qu'un feu roulant de monsqueterie et l'artilleris tua une partie de ces parlementaires qui ne purent ni se défendre ni s'enfuir. Ceux qui les attendaient au dehors coururent sur-le-champ il l'llutel de Ville rendre compte et demander vengeance de cette action.

Au mème instant, une multitude armée de fusils, de sabres, d'épées, de haches, se précipita dans les cours extérieures en criant : La Bastille! la Bastille! i bas la troupe! s'adressant aux soldats placés sur les tours. Denx hommes, dont l'un eut Louis Tournay, ancien soldat au régiment Dauphin, montent sur le toit du corps-degarde qui était à côté du petit pont-levis, malgré les cris et les menaces de la garnison de la forteresse. Tournay descend seul dans la cour du Gouvernement et va all corpsde-garde chercher les clefs du pont-levis. Ne les trouvant pas, il demande une hache, brise les verrous et les serrures, pendant que de l'autre cỏté on travaillait avec la mème ardeur ì enfoncer les portes. Les ouvrages de l'Avancé cèdent ì leurs efforts. tet les deux pont-levis sont baissés. Deux invalides, qui étaient sortis le matin ponr aller prendre les vivres que leurs femmes leur apportaient, essaient en rentrant de les rele. ver. Mais Tournay et Aubin Bonnemire, ancien soldat d'infanterie de Royal-Comtois, qui l'avait secondé dans l'enfoncement des portes, fondent sur eux et les melleut en fuite. L'énorme machine retombe avec fracas et, dans sa chute, écrase un homme et en blesse un autre.

A la première nouvelle de l'attaque de la Bastille, dont le nom réveillait les idćes 
de lettres de cachet et d'oppression, les têtes s'allumèrent et l'audace s'éleva soudain au nivean de la terreur imprimée si longtemps par ce nom redouté. La foule des assaillants augmentait de moment en moment; elle se grossissait de personnes de tout age, de toutes conditions, de femmes, la plupart sans armes. Le faubourg SaintAntoine, placé sous l'artillerie du furt, plus animé encore, en raison de sa proximité, y affuait tout entier. On combattait autour du pont-levis avec un acharnement égal de part et d'autre. Le peuple se jeta en foule dans la cour du Gouvernement et conrut au second pont pour s'en emparer, en faisant une décharge de mousqueterie sur la troupe. Elle riposta par un feu vif et soutenu qui forç les assaillants à se retirer en désordre, les uns sous la voúte de la porte de bois de la cour de l'Orme, les autres sous celle de la grille, d'où ils ne cessent de tirer sur la plate-forme, sans oser s'approcher pour attaquer le second pont. Il y avait une heure que durait cette attaque, larsqu'on entendit du côté de l'Arsenal le hruit du tambour et de grands cris. On vit entrer à cet instant, dans la cour de l'Orme, par la cour des Poudres et Salpêtres, un drapeau escorté par un gliand nombre de citoyens armés. Une grosse troupe s'avança vers la cour du Gouvernement et cria aux assiégés de suspendre leur feu, que c'étaient des députés de l'Hòtel de Ville qui voulaient parler au gouverneur. Aussitôt, on arbora un pivillon blane sur la plate-forme des tonrs, el les signes de paix et d'appel se multiplièrent par les chapeaux. Sur cette invitation amicale, M. de Corny, accompagné de MIM: Francotay, La Fleurie, Milly, Beaubourg, Piquot de Sainte-IIonorine, Boucheron, Coutans, Six, Joannot, qui portait le drapoau, et, précédé d'un tambour, se mit en marche vers la voute qui conduisait au pont del'A vancé. Un homme du peuple leur fit remarquer une pièce de canon qui s'avançait dans une embrasure des tours et que l'on poingrit sur la cour de l'()rme; tout le monde leur cria de ne pas se fier aux promesses yu'on semblait leur faire.

M. Francotay seul s'ivança avec le tambour et le drapean jusqu'an pied du fossé, timdis que M. Je Corny el ses collègues restèrent sous la vonte. Plusienrs des assaillants le conjurèrent avec les plus vives instances de ne pas s'exposer ainsi au feu de l'ennemi. Mais lrancotily les pria aussi vivement de s'éloigner eux-mèmes, leur observant qu'ils ne pouvaient rien contre la forteresse dont l'artillerie allait les foudroyer; qu'il pouvait demeurel scul et ne présumait pas avoir quoi que ce soit à craindre. - Non, lui répond un de ceux qui etaient présents, nous ne voulons pas vous abandonner. Les assiégées lui firent assuyer une décharge de mousqueterie qui étendit deux hommes à ses cótís, et lobligea à se retirer au milieu du sifllement des balles qu il voyait pleuvoir sur lit muraille attenant i la voute sous laquelle il alla rejoindre la députation. Pénétrée d'horreur et d'indignation, elle reprit le chemin de l'Hòtel de Ville avec une très petite partie de ceux qui l'avaicnt accompagnéc. Le peuple furieux courut au pont en poussant de grands cris; mais le feu de la place l'en écarta promptement. Une partie de la multitude se retira à peu de distance, et tandis que ceux qui avaient de: fusils liraient sins reliche sur les officiers postés sur la plate-forme, une autre troupe bri-ait a coups de lıache les portes du quartier qui fut livré au pillage.

Ene seconde députation de la ville vint présenter au gouverneur le vou du comilé permanent, et ticha d'alribler l'effusion du sang. Elle portait le décret qui ordonmait au commanlant de remettre, sans verser le sang des citoyens, cette place sous la garde de la cité. L'ablé Fauchet était à sa tête et se présenta sous le feu de l'artillerie. On lui répondit par des décharges. La députation s'avanģa trois fois au milieu du mème 
danger. Une autre députation, avec un signal plus intelligible encore, avec un drapeau incliné, n'eut pas plus de succès. Les députés, ne pouvant se faire entendre des assiégés au milieu du tumulte du combat, donnèrent aux citoyens armés lecture de l'arrêtẻ suivant :

a Le comité permanent de la milice parisienne, considérant qu'il ne doit y avoir à Paris aucune force militaire qui ne soit sous la main de la ville, charge les députés qu'il envoie à M. le marquis de Launay, commandant de la Bastille, de lui demander s'il est disposé à recevoir dans cette place les troupes de la milice parisienne, qui la garderont de concert avec les troupes qui s'y trouvent actuellement, et qui seront aux ordres de la ville.

- Fait double, à l'Hôtel de Ville, ce 14 juillet 1789.

- Signé : DE Flesselles, prérôt des marchands et président du comite; DE LA VIGNe, président des élecleurs.

L'abbé Fauchet se retira ensuite avec MII. de la Vigne, Chignard et Bossidont qui l'avaient accompagné, et vint à lHôtel de Ville rendre compte de sa mission. Les assaillants, furieux, amenèrent trois voitures de paille, mirent le feu au corps-degarde avancé, au Gouvernement et aux cuisines. Les assięgés tirèrent un coup de canon à mitraille; la plate-forme et les créneaux retentirent du bruit de la mousqueterie, et les officiers de l'état-major eux-mêmes firent le coup de fusil. Les Suisses, qui étaient demeurés dans la cour, avaient pratiqué un trou dans le tablier du grand pontlevis, d'où ils faisaient sur les assaillants des décharges continuclles d'un fusil de rempart, qui tua à lui seul plus de combattants que toutes les pièces d'artillerie et de mousqueterie ensemble. L'incendie durait encore lorsqu'on vit arriver dans la cour un détachement de gardes.françaises composé en grande partie des grenadiers du régiment de Rufleville et des fusiliers de la compagnie de Lubersac, commandés par les sergents Wargnier et Labarthe, et une troupe de bourgeois sous les ordres de M. Hullin. C'est ce dernier qui avait décidé la marche des gardes-françinses, occupés depuis une heure des moyens d'attaquer la Bastille avec succès. "Mes amis, leur avait-il dit, êtes-vous citoyens? Narchons à la Bastille; on y égorge nos amis, nos frères; nous avons la patrie à venger, des traftres à punir ; pourrions-nous douter de la victoire? A A ces mots, les soldats se précipitèrent sur ses pas et se dirigèrent vers la forteresse avec trois pièces de canon; ils les renforcèrent de deux autres qu'ils rencontrèrent près de l'Arsenal. Quelques invalides, qui avaient rendu les armes le matin, se joignirent à eux, et ils arrivèrent dans la cour de l'Orme. Deux pièces de 4, un canon plaqué en argent, venant du Garde-Meuble, et un mortier, furent dressés en batterie et dirigés sur les embrasures du fort pour empecher ses manouvres. On en plaça deux autres près de la pompe et du passaģe de Lesdiguières. Bientòt, on les amena à la porte qui communiquait au jardin de l'Arsenal, et l'on entra dans la dernière cour, malgré le feu continuel des assiégés.

L'épaisse fumée de l'incendie des bàtiments et celle qui s'élève de la paille enflainmée avait été quelque temps favorable aux Parisiens qu'elle enveloppait de ténêbres. Mais les charrettes qui avaient amené la paille, se trouvant à l'entrée de la seconde cour, en face du pont dormant, fermaient l'entrée du fort et coupaient le passage aux assiégeants. M. Elie, officier au régiment de la reine, suivi de trois ou quatre autres 


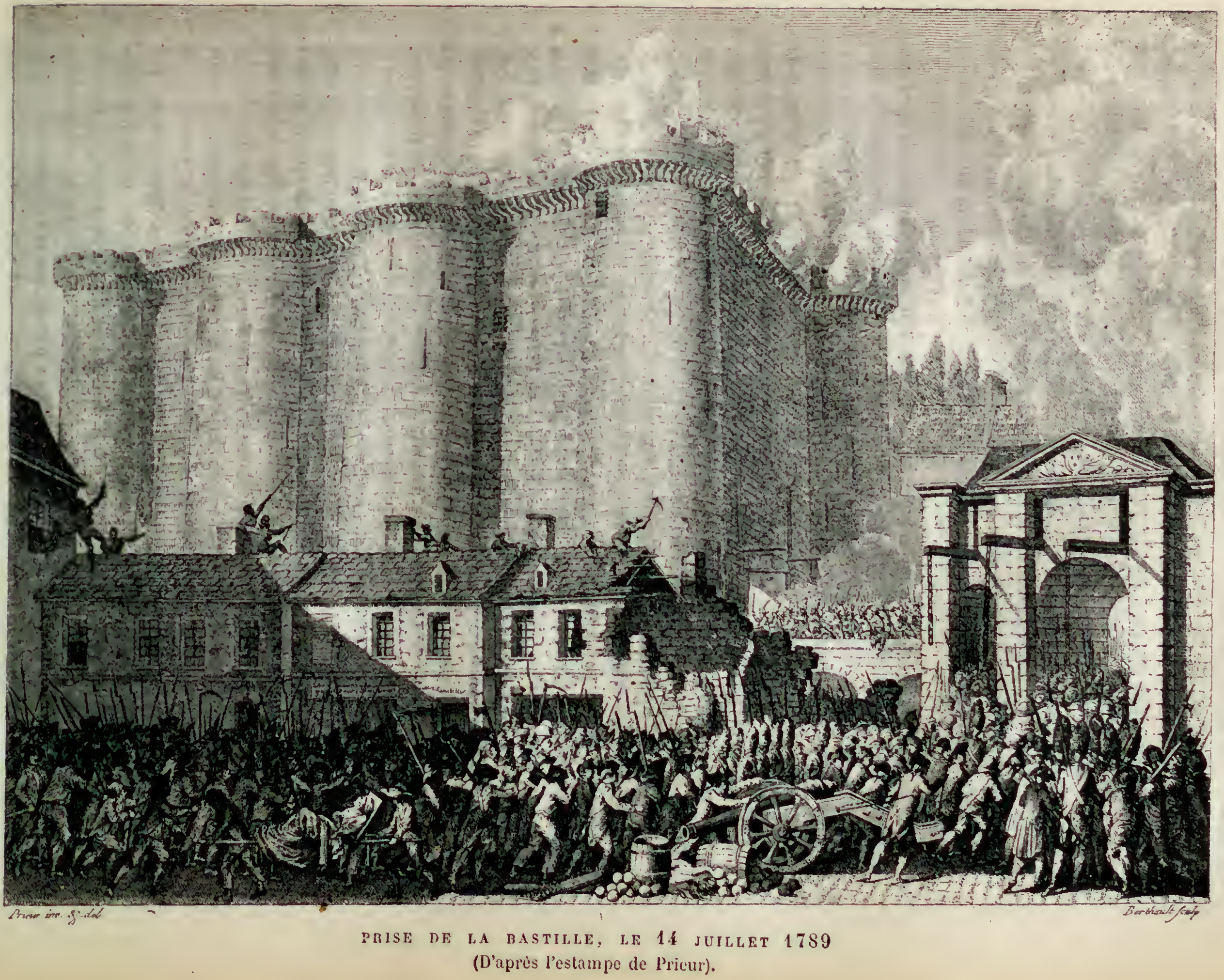


citoyens, s'avanģa hardiment au milieu du feu et parvint à en écarter une; la seconde résista à leurs efforts. Un nommé Réole, marchand mercier près de Saint-l'aul, retira lui seul cette voiture brûlante, après avoir vu tomber morts à ses cótés deux de ses ca. marades. Deux canons furent aussitot braqués en face du girand pont, et l'attaque recommença avec une nouvelle fureur. Pendant ce temps, une fraction du peuple forcait l'hòtel de la régie des poudres el salpètres, brisait des caisses de munitions et en portait aux combattants. 11 . Clonet, régisseur, est arrêté; son uniforme le faisait prendre pour M. de Launay; on allait le tuer à l'instant mème sans l'intervention dn citoyen Cholat, qui parvint ì suspendre les premiers moments de la fureur populaire. On le traina à l'llótel de Ville, où M. de Sandray ne lui sauva une seconde fois la vie qu'au péril de la sienne, et en recevant sur la tête un coup de sabre dont il fut grièvement blessé:

Tandis que les uns croient le gouverneur entre leurs mains, d'autres semparent, dans l'une des cours de la Bastille, d'une jolie jeune fille. Layant amenée près lu premier pont: "C'est la fille de 11 . de Launay, s'écria-t-on; qu'il rende la place ou qu'il voie sa fille expirer dans les flammes. Une paillasse va lui servir de lucher; on y met le feu, l'infortunée s'évanouit. Le père de Mlle de Monsigny (c'était le nom de la jeune personne) voit du haut des tours sa fille près d'ètre brùlée vive; il allait se précipiter, lorsqu'il fut atteint et renversé de deux coups de feu. Indigné de cet attental, Aubin Bonnemère quitte son poste, écarte la foule homicide, enlève la victime, la remet en mains surres et retourne au combat.

Une scène émouvante se passa aussi à l'Arsenal. Un perruquier, ivre ou forcené, muni de deux tisons enflammés, s'occupait à mettre le feu au magasin des salpétres, quand il fut aperçu par J.-B. Ilumbert, qui le premier monta sur les tours de la Bastille. Il arrivait de l'Hòtel des Invalides, et accourut aux cris poussés par une femme, frappa le forcené d'un coup de crosse de fusil, et le terrassa. Puis, saisissant avec intrépidité un tonneau de salpêtre déjà enflammé, il le renversa, réussit a léteindre, et, après avoir chassé quelques malfaiteurs qui avaient forcé les archives et lırisí les armoires, sous prétexte de chercher de la poudre, il courut rejoindre les combattants de la Bastille. Le découragement commençait à devenir général dans la forteresse. Les Suisses exhortaient cependant le gouverneur à la résistance; mais l'état-inajor le sollicitait vivement de rendre la place, il sentait lui-mème qu'il était impossible d:

- la défendre, la disette absolue de vivres ne lui permettant pas de soutenir le siézr plus longtemps. Les assaillants ayant abattu le premier pont et amené leurs canons en face du second, ne pouvaient manquer d'ètre vainqueurs. De Launay perdit la tète dis qu'il se vit bloqué par ce peuple exaspéré et se réfugia derrière la masse énorme des bastions oủ il espérait pouvoir attendre en sûreté les secours qui lui étaient promis pour le soir même par M. de Bezenval et M. de Flesselles. Inquiet et incertain, il n’osait prendre aucun parti, ni capituler, ni se défendre à outrance. Trompé dans son attente, effrayé des efforts incroyables de la multitude, il ne prit plus conseil que de son désespoir, et au moment où un porte-clefs distribuait du vin aux soldats, il saicit la mèche d'une des pièces de canon de la cour intéricure et alla droit à la sainte-barlue pour y mettre le feu. Un sous-officier lui présenta sa baïonnette et le reponssa. II descendit alors à la tour de la Liberté, où l'on avait mis en llépot une partie des poudres qu'il avait fait venir dans la nuit du 12 au 13, mais un autre sous-ofticier l'obligen a se retirer et prévint un acte de désespoir qui aurait fait sauter la Bastille ainsi qu'une 
partie du faubourg Saint-Antoine. Le gouverneur, hors de lui-même, demanda alors par grace un seul baril de poudre. Enfin, il s'adressa a la garnison, et lui demanda s'il ne valait pas mieux se faire sauter que de s'exposer a la fureur du peuple auquel on ne pouvait plus se promettre d'échapper. "Remontons, dit-il, sur les tours, et s'il faut mourir, rendons notre mort funeste à nos ennemis; écrasons-les sous les débris de la Bastille. "Mais les soldats lui répondirent qu'ils aimaient mieux mourir que de faire périr un si grand nombre de leurs concitoyens, et qu'une plus longue résistance étant désormais impossible, il fallait faire monter le tambour sur la plate-forme pour appeler, arborer un drapeau blanc et capituler. On battit donc la chamade et on arbora le drapeau blanc sur la tour de la Bazinière. C'était trop tard. Le peuple, irrité contre le gouverneur qui avait fait tirer sur ses députés, ne vit qu'un nouveau piège dans ces démonstrations de paix, et s'avanȩa toujours, faisant des décharges, jusfu'au pont de l'intérieur. L'officier suisse, adressant la parole aux assaillants à travers une espèce de créneau qui se trouvait auprès du pont-levis, leur demanda à sortir avec les homneurs de la guerre. "Non, non! lui cria-t.on. " Il fit passer alors par la même ouverture un papier que l'éloignement empècha de lire, en criant que l'on voulaí bien se rendre, si on promeltait de ne pas massucrer la troupe.

Un particulier courut chercher une planche, on la posa sur le parapet, plusicurs per'sonnes se mirent dessus pour faire le contrepoirls; l'inconnu s'avança et allait saisir le papier lorsqu'il tomba dans lo fossé, frappé, selon quelques-uns, d'un coup de fusil, et mourut victime de son zèle. M. Maillard, fils d'un huissier au Chitelet, sans s'effrayer de cette mort s'avança courageusement sur cette planche longue et étroite, prit le papier et le remit entre les mains de M. Ilullin qui le lut à haute voix. Voici ce qu'il tontenait: "Nous avons vingt milliers de poudre, nous ferons sauter la garmison et tout le quarlier, si tous n'acceptez pas lu cupitulation. - Foi d'officier, nous l'acceptons, dit M. Ilullin, Guissez ros ponts. "Mais le peuple se récria au seul nom de capitulation et fit avancer trois pièces de canon. On allait tirer, déjà les rangs s'ouvraient pour laisser passer les boulets, lorsque les assiégés, voyant que l'on voulait abattre le grand pont, firent baisser le petit pont-levis de passage qui était sur la gauche de l'entrée de la forteresse. Malgré le nouveau danger qui naissait de cette manœuvre, Mu. Élie, Hullin, Maillard, Réole, Ilumbert, Tournay, François, Louis Morin et plusieurs autres le remplirent à l'instant, après l'avoir fixé en fermant les verrous. Les gardes-françaises, conservant leur sangr-froid au milieu du péril, formèrent une barrière de l'autre côté du pont pour empecher que la foule des assiégeants ne s'y portât. Cet acte de prudence sauva la vie à des milliers de personnes qui se seraient précipitées dans les fossés. Environ deux minutes après, un invalide vint ouvrir la porte située derrière le pont levis et demanda ce quon voulait : "Qu'on rende la Bastille », lui répondit-on. Alors, il laissa entrer. Les vainqueur's firent à l'instant baisser le grand pont; il n'était pas encore à son repos, que le nommé Arné s'y élança, au risque de se briser les jambes, pour faire contrepoids et empécher qu'on ne le relevat.

Les invalides étaient rangés à la droite et les Suisses à la gauche; leurs armes étaient déposées le long du mur. Ils ôtèrent leurs chapeaux, battirent des mains et crièrent braro aux assiégeants qui acconraient en foule dans le fort. Les premiers entrés aborderent les vaincus avec humanité, sautèrent au cou des officiers de l'état-major en signe le paix et de réconciliation, et prirent possession de la place comme rendue par capitulation. Mais ceux qui les suivaient la traiterent comme prise d'assaut. Quelques 
soldats placés sur les plates-formes, ignorant leur défaite, ayant à ce moment fait quelques décharges, le peuple se précipita sur les invalides et les accabla de mavais traitements. In d'entre eux est massacré. Le sous-ofticier béquart, qui arait si bien

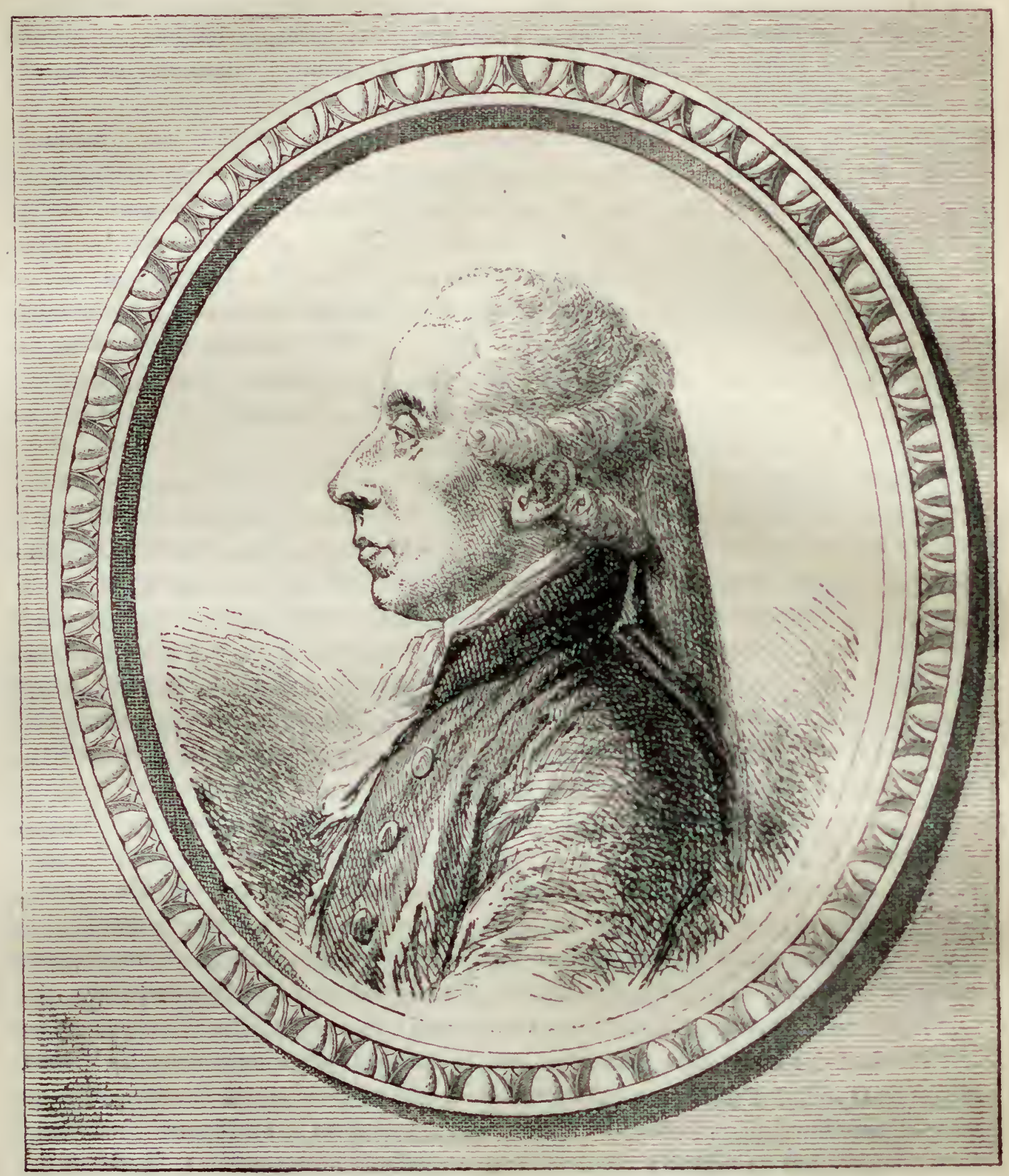

BAILIY, MAIIE DE PAHIS.

mérité de la ville de Paris, en arrétant le bras du gouverneur lorsquill voulait faire sauter la Bastille, et qui n'avait mẻme pas tiré un coup de fusil dans la journée, fú atteint de deux coups d'épée et frappé d'un coup de sabre qui lui abaltit le poignet. On porta en triomphe, dans toutes les rues de la ville, cette main a qui beaucoup devaient la vie, et Jiéquart fut enlevé et trainé à la place de Grève. La multitude 
aveuglée, qui le prit pour un canonnier, l'attacha à un gibet où il expira avec le nommé Asselin, victime comme lui de la mème erreur. On fit prisonniers tous les offciers de l'état-rnajor, on se jeta en foule dans leur logement, on en brisa les meubles, les

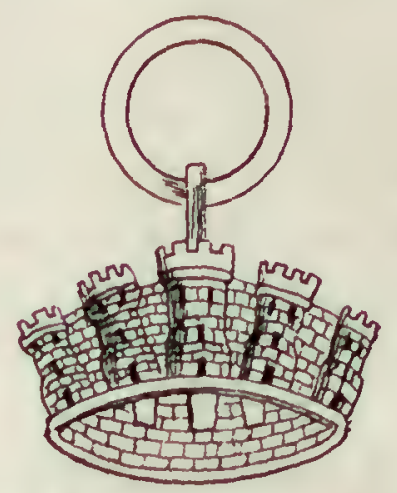

Couronne murale portée à leur boutonnière, dans les fétes publiques par les vainqueurs de la Bastille.
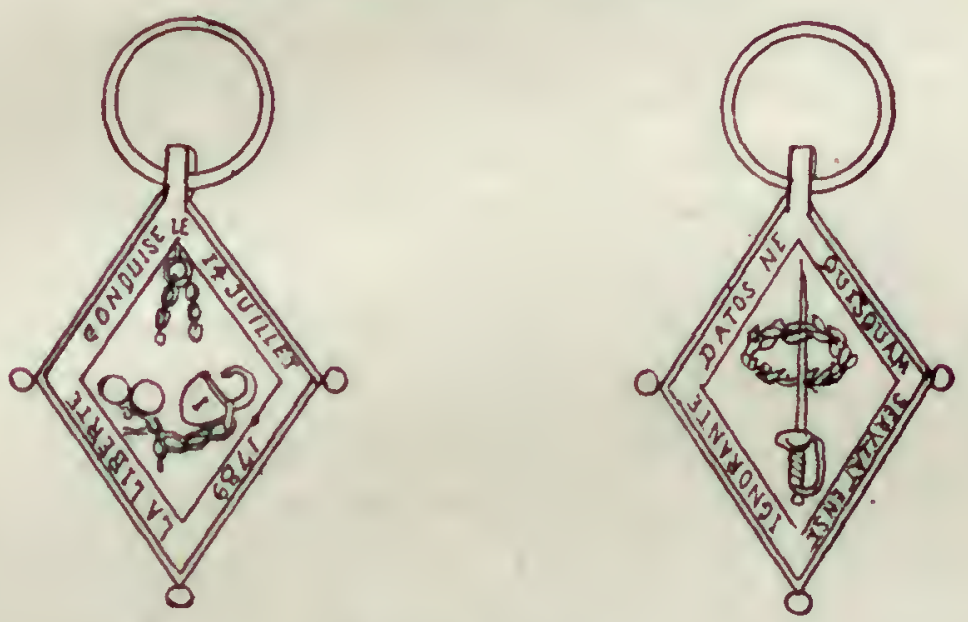

Boucles d'oreilles.

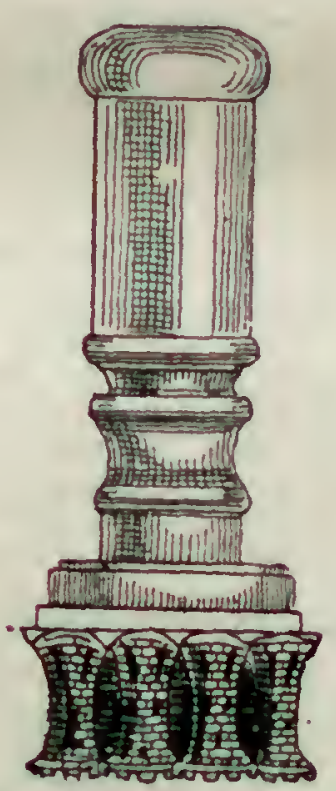

Cacbet en cuivre des vainqueurs de la Bastille.

portes, les fenètres. Dans ce désordre général, ceux qui étaient dans la cour tirèrent sur ceux qui étaient dans les appartements et sur les plates-formes; plusieurs furent tués. Humbert reçut un coup de fusil sur la plate-forme; un de ses amis fut tué dans ses bras. Alurs le brave Arné, élerant sur sa baïonnette son bonat de grenadier, se LIV. 2J. 
présenta au bord du parapet et s'exposa lui-méme à recevoir la mort pour faire cesser le feu.

MM. Maillard, Cholat, le grenadier Arné et plusieurs des assaillants se disputèrent l'honneur d'avoir arrêté M. de Launay. Il n'était point en uniforme, mais vêtu d'un frac gris avec un ruban ponceau; il avait en main une canne à épée dont il roulait se frapper, et qui lui fut enlevée par Arné. M. Ilullin, Élie et quelyues autres se chargèrent de sa garde et parvinrent à le faire sortir de la Bastille, non sans éprouver les mauvais traitements du peuple, dont le cri général le condamnait a mort. Ils prirent le chemin de l'Hòtel de Ville, escortés d'une foule nombreuse. II. Gilie, en uniforme, ouvrait la marche, portant la capitulation à la pointe de son épée; après lui venait M. Legris, garde des impositions royales; ensuite M. Maillard, portaut le drapean; puis le gouverneur, tenu par M. Hullin et Arné. Immédiatenent aprés manchait M. de l'Épine, clerc de M. Morin, procureur au Parlement. Presque tous ceux qui cosnposaient l'escorte de M. de Launay faillirent être vichimes de l'acharnement de la multitude contre leur prisonnier et de leur zèle à le défendre contre la fureur généralé. Les uns lui arrachaient les cheveux, les autres le menaçaient de leurs épécs. Le nlilheureux, voyant le danger auquel il était exposé, disait d'une voix éteinte à II. IIullin :

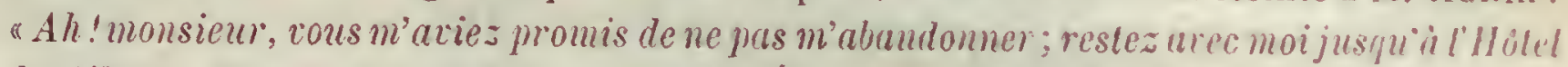
de Ville! "D'autres fois, s'adressant à M. Élie : "Est-ce lie ce que rous m'urit'z promis" oh!monsieur, ne mabondonnez pas! " Mais la fureur de la foule allait toujours croissint. et son ressentiment n'épargnait pas ceux qui accompagnaient le gouverneur. II. We l'Épine reçut sur la tète un coup de crosse de fusil, et fut contraint d'abandonner l'cscorte à l'Orme Saint-Gervais. Hullin lui-mème, malgré sa viğueur et sa grande taille. ne put résister à la violence de la multitude. Épuisé par les efforts qu'il arait faits frrur défendre son prisonnier, accablé de mauvais traitements, il fut obligé de le quitler ì la Grève pour prendre un peu de repos. A peine était-il assis, que retournant les yeux, il aperçut la tète de M. de Launay suspendue au haut d'une pique. Les dernìres paroles qu'il prononça furent: "Ah! mes amis, tuez-moi sur-le-chump, ne me frile's jus languir. „Le peuple, craignant qu'on ne lui enlevat sa victime, l'arait égorgé sur les marches de l'Hûtel de Ville.

M. de Losme, son major, homme plein d'humanité, aimé el respecté de tous les prisonniers, partagea son sort. Le malheureux major était déjà sur la place de Girève et était entrainé par la foule, lorsque tout a coup un jeune homme se précipita dans ses bras: "Arrêlez, s'écrie-t-il, arrêtez, vous allez immoler le meilleur lles hommes; iali été cinq ans à la Bastille, où il fut mon consolateur, mon ani, mon père. " C'était M. de Pelleport qui, renfermé dans cette prison, avait trouvé dans l'humanité de M. de Losme un adoucissement à sa captivité. Frappé des paroles et de l'action du jeune homme, le major leva les yeux, et lui dit avec un sang-froid héroüque: "Jenue homme, quinllezvous faire? Retirez-tous; rous allez vous sacrifier suns me santer. , M. de Pelleport. oubliant qu'il était sans armes, écarta la foule avec ses måins et s'écria : Oui, je le défendrai envers et contre tous. A ces mots, un forcené lui déchargea un cuup de hache qui lui fit au cou une large blessure; il allait lui en porter un second sur la léte, lor'squ il fut renversé lui-même par le chevalier de Jean, qui avait accompagné .I. de Pelleport. Mais celui-ci fut assitót assailli de toutes parts, frappé de coups de salore, percé de baïonnettes; il saisit enfin un fusil et renversa tout ce qui se présentait devant lui ; on le lui arracha, et ce n'est que par des prodiges de force el de valcur qu'il parvint à 
échapper a la rage du peuple et à la mort. Il gagna avec peine l'escalier de l'Ilôtei de Ville où il tomba sans connaissance. MI. de Losme fut massacré en face de l'arcade Saint-Jean; sa têie fut coupée et mise au bout d'une pique, comme celle du gouverneur, et fut aussi promenće par toute la ville. M. de Miray, aide-major, fut tué dans la rue des Tournelles, et M. de Persan, lieutenant de la compagnie des Invalides, sur le port au Blé. C'est dans la poche de cet officier que l'on sauva la croix de SaintLouis, qui fut attachée à la boutonnière du fusilier aux gardes-françaises Dubois. Ce soldat la fit rendre le 3 septembre par son district à M. de la Fayette.

Le reste de la garnison de la Bastille attendait en tremblant la décision de son sort. Les Suisses avaient échappé au premier mouvement dú ressentiment populaire. Comme ils étaient couverts de sarraux de toile, on les prit pour des prisonniers. D'ailleurs, pendant le combat, ils étaient restés dans la cour et on ne les avait pas vus sur les tours; c’est ce qui les sauva de la colèrè des assiégeants. Elle tomba touí entière sur les invalides. Ils furent conduits a la place de Grève. Saisis d'horreur à !a vue de deux de leurs camarades suspendus au gibet, accablés d'injures, abreuvés d'humiliations, ils furent présentés à un officier de ville: “Vous avez fait feu sur vos concitoyens, vous méritez d'être pendus, et vous le serez sur-le-champ. "Un cri universel prononça le mème jugement contre tous les défenseurs de la Bastille et demanda leur supplice. Les gardes-françaises supplièrent alors le peuple de leur accorder, pour prix de leurs services, la vie de leurs prisonniers. On applaudit i cetle générosité : la vengeance publique el particulière fut désarmée; tout céda i la voix de ces braves, et les cris rípétés "Grice, grice!" firent retentir la place de Grève. Magné, sergent des grenadiers des gardes, couronna par un nouveau trait d'humanité cet acte de clémence; il fit placer au milieu du détachement qu'il commandait vingtdeux invalides et onze Suisses, et, pour les soustraire aux clameurs insultantes de la multitude, les conduisit par la place des Victoires jusqu'aux casernes de la NouvelleFrance, malgréle peuple qui voulait qu'on les promenât dans le Palais-Royal. Ils trouvèrent sous les tentes de leurs vainqueurs de la nourriturs et du repos, et partirent le lendemain matin pour aller rejoindre leurs corps respectifs.

Cependant le peuple réclamait de nouvelles exécutions. M. de Montharey, ancien ministre de la guerre, fut conduit de l'Arsenal à l'llòtel de Ville. Là, poussé d'une extrémité de la salle jusqu'au bureau des électeurs, il y est pressé de manière à pouvoir à peine respirer, et vingt hommes armés le retiennent immobile. Vingt autres appuient leurs baïonnettes sur la poitrine de $M$. de la Salle qui lui tendait les bras. Ce digne commandant ne désespère pourtant pas de le sauver. Il sollicite tour à tour ceux Gui serraient si étroitement leur proie et ceux qui l'assaillaient lui-mème; il parvint ¿ fitre lacher prise aux uns, à relever les baïonnettes des autres et, saisissant à própos ce moment, d'un bras vigoureux enleva M. de Montbarey du milieu de ceux qui l'cntouraient et lui fit un rempart de son corps. Ce coup de théatre fit tant d'impression qu'on les applaudit tous deux et que les clameurs firent place aux acclamations redoublées.

De son cùté, le brave Élie, du haut de l'espèce de trophée où l'avaient placé ses compagnons, tendait la main à ceux qui imploraient son secours. Tous les regards étalient fixés sur lui, on ne perdait pas une de ses paroles. "Citoyens, dit-il, gardezvaus surtout d'ensanglanter les lauriers dont vous venez de ceindre ma tète, ou reprenez vos palmes et vos couronnes. Avant d'aller voir tomber les créneaux de 
la Bastille, car le soleil les verra crouler demain, que tous ces prisonniers, plus malheureux que coupables, jurent ici d'ètre fidèles à la nation. o Le serment fut aussitôt prêté solennellement, au milieu de toute l'assemblée. Les assiégeants restés dans la

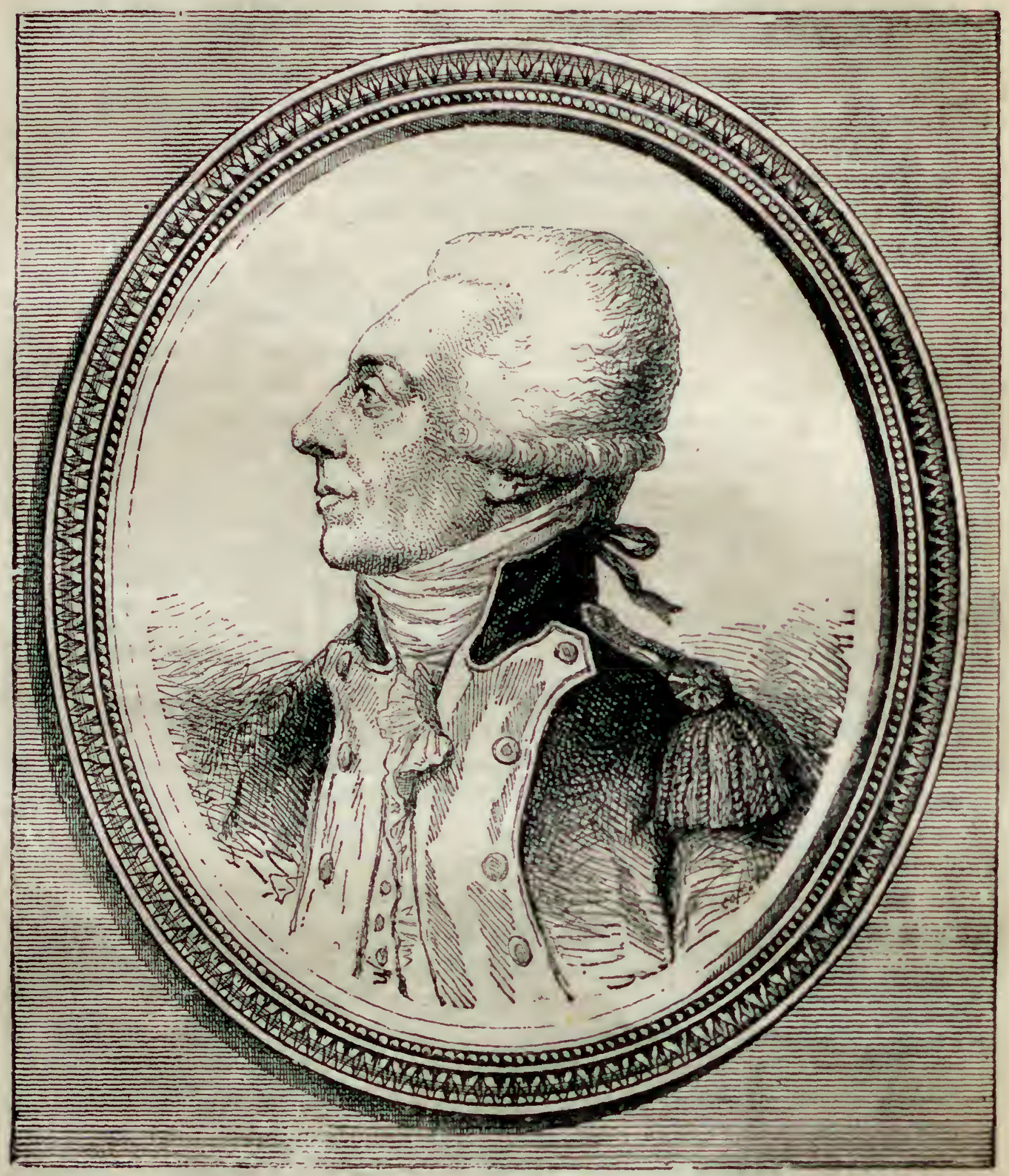

J, A $F$ Y F, T TE.

place se dispersèrent dans la forteresse; ils parcoururent les prisuns, descendirent dans les cachots, en ébranlèrent et forcèrent les portes: car, dans 'ivresse de la victoire, on avait oublié les prisonniers et l'on portait en triomphe les clefs des verrous qui les enfermaient. Tout fut dévasté; une foule de documents, de manus. crits, de registres, furent jetés dans les fossés, dans les cours. On trouva sept prison- 


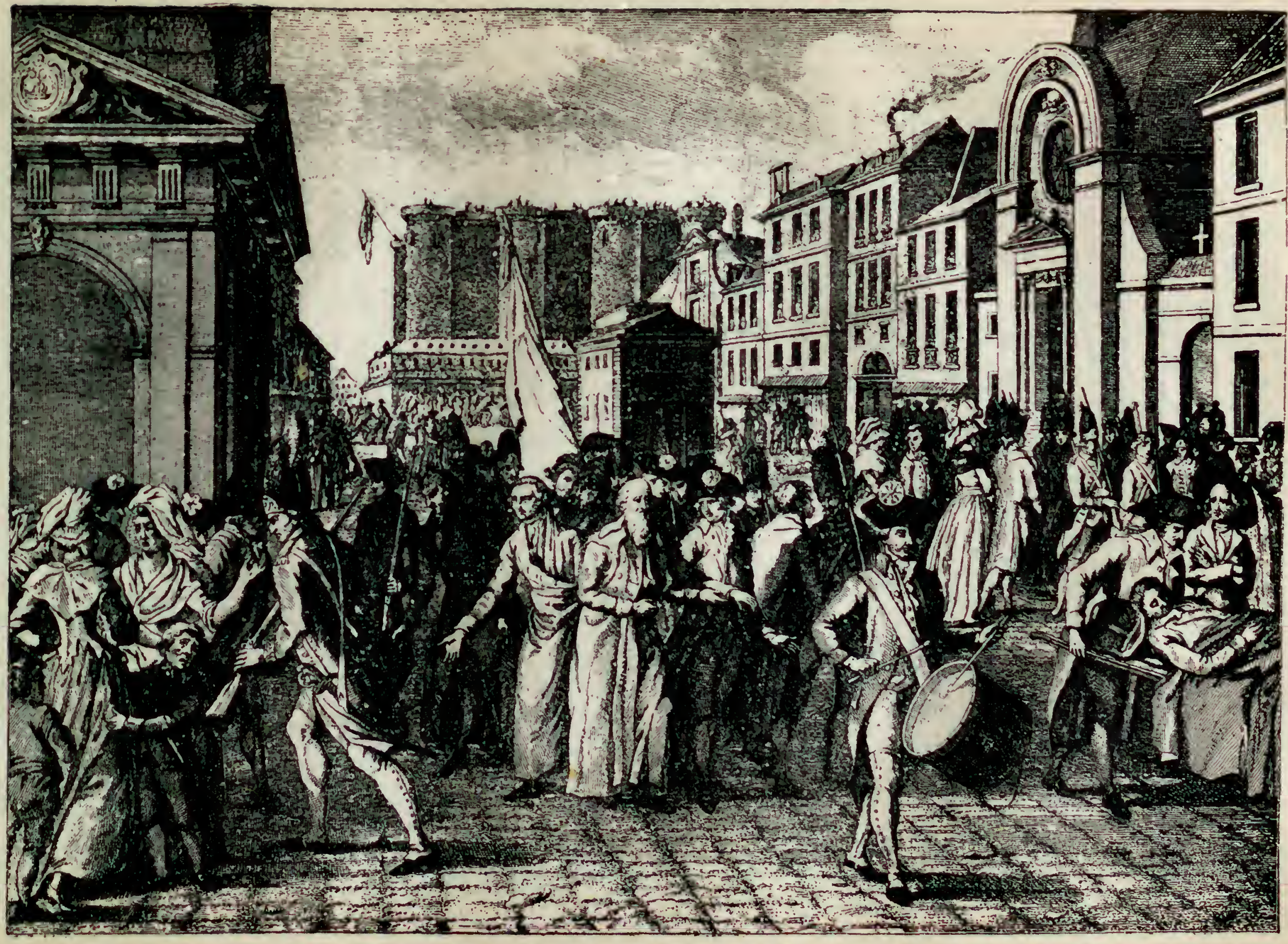

DÉLIVRANGE DES PRISONNIERS DE LA BASTILLR (JUILLET 1789)

Fae-similé d'une estampe du temps. 
niers que l'on conduisit en triomphe au Palais-Royal. C'étaient M. Pujade, Béchade, la Roche, la Camège, accusé de falsification de lettres de change; M. de Salages, arrîlé en 1782, à la réquisition de son père, pour dérangement d'affa:res, enfermé d'abord a Vincennes, et transféré à la Bastille. Pendant ces sept ans, il n'avait pas reçu une seule lettre de sa famille, ni de ses amis, quoiqu'il écrivît fréquemment. Il ignorait que son père fùt mort, qu'il y avait eu une Assemblée de notables et que les États généraux se tenaient à Versailles. Ayant demandé à son porte-clefs la cause des coups de fusil qu'il entendait de sa chambre, on lui dit que le peuple était révolté à cause de la cherté du pain. Le district de l'Oratoire, où il fut conduit. le prit sous sa sauvegarde et en répondit. M. Tavernier, fils naturel de M. P'Aris-Duverney, y élait détenu depuis le 4 aout 1739. Enfin M. Whyte, conduit à la Bastille lors de l'éra. cuation du donjon de Vincennes. On ne put savoir depuis combien d'aunces durait sa détention, ni savoir au juste qui il śtait. Il fut promené dans toutes les rues de Paris. Il avait perdu la tète ainsi que le précédent, et les b́lecteurs furent obligés de les faire transfírer à Charenton quelques jours après leur délivrance.

Les clefs de la forteresse furent remises à Mrissot qui, peu d'années auparavant, avait lui-mème été prisonnier à la Bastille, et trois mille hommes furent envoyés pour garder les tours en attendant qu'un arrèté de la ville eùt confirmé le veu du peuple qui demandait leur destruction. La prise de la citadelle conta la vie à quatre-vingt-dixhuit des assiégeants; soixante-treize furent blessés plus ou moins gravement. Les assiégés ne perdirent qu'un homme pendant le combat; quatre officiers et qualre soldats furent pendus ou égorgés après l'action.

Le 16 juillet, un Comité permanent, installé à l'IJòtel de Ville et formé par l'élection, arrèta que la Bastille serait démolie immédiatament par les soins des districts. L'ordre de démolition fut proclamé par les trompettes municipales tans la conr de l'llutel de Ville et dans tous les carrefours de Paris, su nom de la Fayette, comman. dant la garde nationale. L'Assemblée nationale ralifia celte técision.

Les travaux de démolition furent longs et pénibles, sarce ne fut seulement çu'en 1790 que les « volontaires de la Bastille » vinrent offrir à l'Assemblée nationale la c dernière pierre des derniers fondements " de l'édifice. Le maçon Palloy fut chargé de la direction des travaux, et commença par visiter minutizusement les souterrains que la rumeur publique prétendait remplis de prisonniers que l'on tenait cachés a lous les yeux. Aucune découverte de ce genre ne fut faite au cours de celte inspection. Le 10 aoùt un terrible dccident répandit l'émoi parmi les travailleurs : une femme était entrée dans la forteresse; une pierre, se détachant d'une des tours l'atteignit et la tua. Le 14 du mème mois, cinq cents ouvriers, précédés d'un tambour, marchant sur deux rägs, et tenant de longues branches d'arbre, traversèrent Paris, se dirigeant vers le Palais-Royal. C'étaient les travailleurs occupés à la démolition de la Bastille qui apportaient trente-sept boulets trouvés dans un mur du donjon. Une foule immense accourut autour d'eux et répondit généreusement a la quête qqu'ils firent. L.es matériaux de l'ancienne citadelle furent mis en vente le $t^{\text {er }}$ décembre et de nombreux amateurs se disputèrent les débris du donjon qui pendant plusieurs siècles avait été la terreur du peuple.

a 'Tandis que l'on démolit la Bastille, dit M. Georges Lecoq, les jolies femmes, promenées dans la forteresse par le comte de Mirabeau, prennent une pierre sur la plate-forme et la jettent en criant: "Liberté. "En bas des tours, tout Paris ramasse la 
pierre précicuse. La livre de pierres se vend aussi cher que la meilleure livre de viande. La chevalière d'Éon envoie quelques livres de ces reliques à lord Stanhope. On porte des bagues avec des pierres de la Bastille enchássés. Mme de Genlis sorne comme parure d'une de ces pierres, polie, enrichie de symboles et d'une légende (liberlé) en diamants, entourée de lauriers d'émeraudes et placée au milieu de rubans aux trois couleurs."

Palloy créa sous le nom d'Apôtres de la liberté un corps de voyageurs pour porter dans toute la France des matériaux provenant de la démolition.

On eut, peu après ces événements mémorables, l'idée d'en perpétuer le suuvenir par un monument commémoratif. Dès le mois d'avril 1792, le citoyen Marnois, dans une lettre publiée dans les journaux, proposait "d'établir sur les ruines de la Bastille une nouvelle place publique. Au centre de cette place serait élevé, disait-il, une colonue telle que celle de Trajan a liome; cette colonne porterait une statue qui symboliserait la liance, foulant à ses pieds les abus de l'ancien régime, désignés par des emblèmes, tels que le cude des droits féodaux, une table des bénéfices ecclésiastiques et la liste des pensions.

a Lat colonne serait ornće de bas-reliefs qui retraceraient les principaux événements de notre Révolution; on y verrait le génie de la Liberté, invitant toutes les nations à hriser les fers du despotisme; des inseriptions répandues autour du monument annonceraient que depuis l'an 1789 la Frarce est devenue la patrie commune de tous les hommes libres. "

Le maçon Palloy, qui avait dirigé les travaux de démolition de la forteresse, proposa a l'Assemblée l'érection, sur l'ancienne enceinte de la Bastille, d'une colonne à lıt Liberlé, faite avec les matériaux provenant de la démolition. Le 16 juin 1792, l’Assemblée législative rendit un décret approuvant la proposition Palloy et disant que plusieurs de ses membres seraient députés pour assister a la pose de la première pierre le 14 juillet, et donna a la place de la Bastille le nom de place de la Liberté. La cérémonie se célélnra au jour convenu. "On plaça dans une boìte de cèdre la Déclaration des Droits, gravée sur une table d'airain; une copie authentique de la Constitution; des médailles fondues avec des fers de la Bastille; des monnaies et des assignats; la liste des patriotes morts au siège de la Bastille, etc. Tous les outils employés pour l'opératron sout faits avec les arbres du jardin; le mastic dont on se sert pour sceller est fait avec les cendres des anciens titres de noblesse. Au moment de poser la première pierre, la députation de l'Assemblée ayant remarqué que ces mots : i en présence de Lauis XVI , étaient gravés sur le couverele, et que le roi n'avait pas voulu assister à la cérémonie, le président biffa ces mots. Le projet de Palloy, comme un grand nombre d'autres, a été gravé. Il comportait une colonne élevée sur une bastille. En cela, il est trés différent de celui que nous fait connaitre une monnaie, émanant du même patriote; le fùt repose non plus sur l'ancienne forteresse. mais sur un double soubissement à l'antique accosté de statues accroupies. Le revers porte l'hommage snivant: c Législateurs, ce métal provient des chaînes de notre servitude que votre serment du 20 juin 1789 a fait briser le 14 juillet suivant par Palloy, patriote. " Ni le projet de .Marnois, ni celui de Palloy ne furent exécutés. Napoléon songea à y sulstituer un éléphant gigantesque, mais Louis-Philippe préféra ériger une colonne a l'houneul des victimes de la liévolution de 1830. La colonne de Juillet, qui existe encore aujourd'hui, est l'ceurre des architectes Maroine el Duc. Elle est surmonté: 
du Génie de la Liberté (en bronze doré), par Dumont, et sur la base sont des sculptures de Barye.

L'anniversaire du 14 juillet devait être, on le conçoit, l'occasion de fètes patrio. tiques et nationales. La plus célebre est celle du 14 juillet 1790 , plus connue sous le nom de Fête de la Fédération. En 1791, l'anniversaire de la prise de la Iastille coîncida avec la translation des cendres de Voltaire au Panthéon. En 1792, la fiste se passa aussi tranquillement que possible, contre l'espoir de ceux qui auraient eu de l'intérèt à la troubler. De 1793 à 1800 , l'anniversaire fut célébré régulièrement, mais en 1800 Bonaparte est déjà le maitre : il n'est plus question de la Bastille.

Quatre-vingts ans après, la troisième République choisit pour la Féte nationale l'anniversaire du $\mathbf{1 4}$ juillet 1789. C'est M. Benjamin Raspail, député de la Seine, qui, le 21 mai 1880, en fit la proposition, qui fut adoptée le 8 juin. La promulgation est du 6 juillet. On n'a pas oubliẻ cette magnifique journée et l'enthousiasme des Parisiens la première fois que la troisième République célébra la Fète nationale. Par une coïncidence heureuse, on avait le mème jour distribué à l'armée ses nouveaux drapeaux, et cette circonstance ne pouvait que réjouir les patriotes; car, si dix ans plus tôt la France s'était trouvée aux prises avec les pires difficultés, la distribution des drapeaux a nos régiments était comme le symbole de notre régénération militaire. Donner des étendards à ces jeunes gens, qui défilaient devant les représentants du gouvernement et de la nation, c'était leur dire en quelque sorte: "Depuis dix ans, nous n'avons rien épargné pour nous mettre en mesure de faire respecter la patrie; ì vous de défendre ses drapeaux, qui sont l'incarnation de notre honneur national.

La prise de la Bastille joue donc un très grand rôle dans notre histoire nationale et il est aisé de comprendre le puissant intérèt qui s'attachait a la restauration de celte vieille forteresse, devenue pour nos ainés de 89 un objet de haine et de terreur. Et il ne s'agit pas ici d'une restauration minuscule, mais d'une construction en maçonnerie, de sorte que le visiteur aura l'illusion la plus complète lorsque, sortant du Champ de Mars, il entrera dans le monument élevé par MM. Perrusson ct Colibert, à l'angle des avenues de Suffren et de La Mothe-Piquet.

Les travaux, commencés le $1^{\text {er }}$ avril 1887, furent completement acherés un an après.

On pénètre dans l'intérieur par la porte de la Conférence, construite en briques et en pierre, ornée des armes de la ville, surmontée de la toiture traditionnelle el flanquée de deux guichets latéraux. On entre de plain-pied dans la rue Saint-intoine, avec ses maisons curieuses, ses boutiques aux enseignes bizarres, ses réverbères tout primitifs, ses clochetons ardoisés, ses auberges; on remarque surtout l'hotel d'Ormesson, l'auberge des Enfants de Bacchus, l'église Sainte-Marie, une boutique d'orfévre a l'enseigne diı "Grand Dagobert ", une boutique de savetier où s'étalent des boltes dc tout âge et de toute dimension. Au bout de la rue Saint-Antoine s'élève la Bastille. La clef de la serrure d'entrée et l'une des portes du cachot sont authentiques. Puis, l'are triomphal de Henri II dresse son élégante silhouette à còté de la lourde prison.

Des panoramas, des résurrections des scènes les plus émouvantes de l'histoire de la Bastille, notamment l'évasion de Latude, donneront la vie et l'animation au quartier du vieux Paris reconstruit par $\mathbf{M}$. Colibert, et à la rue Saint-Antoine, où s'agitera une foule de marchands, de soldats, de bateleurs et de musiciens velus comme au temps de Louis XVI. 


\section{L'IIABITATION IIUHAINR}

L'Exposition de 1878 offrait dans la "rue des Nations " un ensemble de façades diversement décorées et donnant une idée assez complète des procédés architecturaux adoptés par chaque peuple, en mème temps que de la mise en ouvre des matériaux fournis par son sol. Pour l'Exposition de 1889, M. Charles Garnier a imaginé de rëmplacer cette série de conceptions décoratives des habitations modernes par us

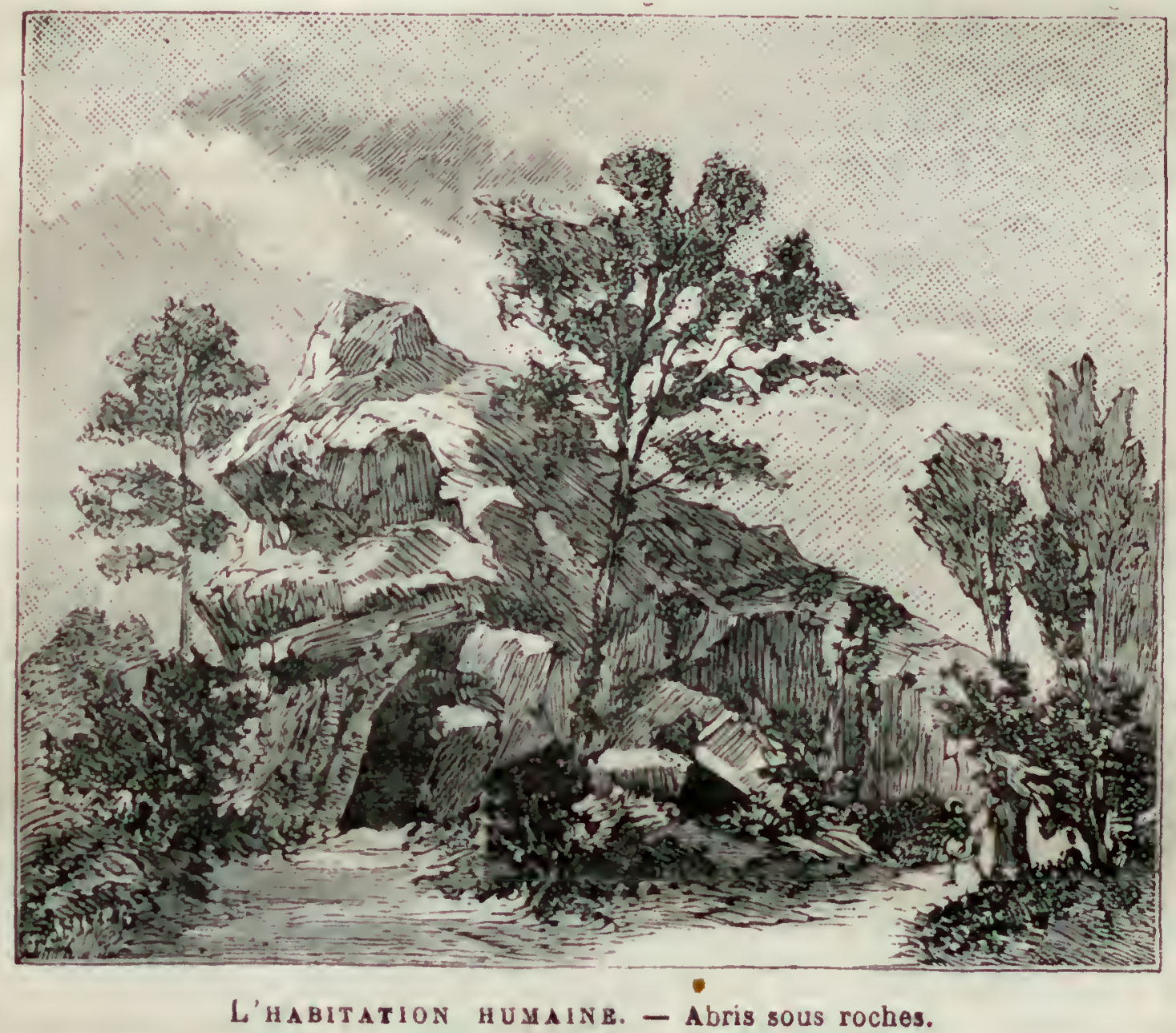

ensemble de constructions représentant l'histoire de l'habitation : le terre-plein qui borde le quai d'Orsay en avant de la Tour Eiffel leur est consacré.

Ce projet, pour lequel un crédit de cinq cent mille francs a été ouvert à M. Garnier par la commission des finances de l'Exposition, comporte une cinquantaine de petits edifices affectant, sous des dimensions plus ou moins restreintes, les caracteres principaux des demeures successives de la famille humaine. En même temps que l'évolution complete de l'art architectural, il reflète les mœurs et les conditions de la vie pendant les périodes qui nous ont précédés. Nous y verrons l'homme, après s'être contenté de chercher un refuge contre les intempéries et un abri contre les betes féroces, accroftre progressivement ses besoins, faire de son habitation un séjour d'abord simplementagréable, puis approprié à tous les raffinements exigés par les civilisations avancées. En un mot l'bistoire de l'habitation constituera une véritable leçon de choses 
qui offrira de nombreux rapports avec l'histoire des civilisations et des arts chez tous les peuples.

M. Charles Garnier a réparti son programme en deux groupes principaux : l'un relatif a la période préhistorique, l'autre à la période historique.

L'habitation prichistorique. - On appelle méhistorique ou paléoelhnologie l'étude de Porigine et du développement de l'humanité, lorsque cette étude est faite en dehors des documents écrits ou traditionnels à l'aide desquels on écrit l'histoire. L'homme préhistorique, c'est donc l'homme avant l'histoire, l'homme tel que nous le font connaitre les découvertes géologiques. En prenant pour caractéristique la matière principale qui a servi à fabriquer les armes et les ustensiles usuels, les savants ont divisé les temps préhistoriques en trois ages : l'age de la pierre, pendant lequel l'usage de métaux était inconnu; - l’àge du bronze; -.. l'dge du fer. Mais ces divisions étaicnt insuffisantes, et il a fallu recourir a des subdivisions. C'est ainsi qu'on a, dans l'age de la pierre, distingué la période de la pierre polie (néolithique) et la période de la pierre taillée (paléolithique).

Ces notions préliminaires étaient indispensables pour faire comprendre neltement ce qu'a voulu faire M. Garnier. L'éminent architecte a choisi, pour la période préhistorique, les types d'habitations suivants : sur terre, les abris sous roches ou dans les grottes (age de la pierre); sur l'ẹu, les cités lacustres (în de la pierre polie et age du bronze); sur terre, les huttes et menhirs.

A l'origine, l'homme n'a pour outils que des silex plus ou moins grossierement appropriés aux usages les plus primitifs de la chasse et de la guerre. Cet outillage imparfait suffit à lui.procurer des éléments indispensables, nuais ne lui permet pas d'édifier de toutes pièces une habitation. Il choisira donc pour abri les excarations naturelles formées par la superposition des roches ou les grottes. Il en défendra l'entrée soit par de grosses pierres roulées à bras, soit par des troncs d'arbres abattus a l'aide de haches de silex. "L'homme a de tout temps, dit M. G. de Mortillet, occupé plus ou moins des grottes et des cavernes. On a constaté l'existence d'instruments chelléens ' dans une grotte de Portugal et dans une d'Algérie. Nombreuses sont les grottes qui ont fourni l'industrie moustérienne et solutréenne; plus nombreuses encore sont celles qui ont donné du magdalénien. Elles şont mème si nombreuses que plusieurs paléoethnologues on* donné à l'époque de la Madeleine le nom d'époque des cavernes. Il en est mème qui ont étendu ce nom jusqu'au solutréen et au moustéricn. Le terme est très impropre: d'une part, l'homme à toutes les époques s'est plus ou moins réfugié dans les cavernes ct les grottes; d'autre part, pendant le magdalénien il a plus fréquentó les grottes que les cavernes, dont l'entrée seule était utilisée. Enfin, il n'a jamais habité exclusivement des cavernes, grottes et abris. "En dehors des grottes naturelles. on rencontre aussi des grottes artificielles, creusées par l'homme, dont les plus anciennes datent de l'époque robenhausienne (pierre polie).

Il y a plusieurs sortes de grottes : la caverne, succession de salles ou de chambrcs communiquant entre elles par des couloirs; - la grotte proprement dite, s'ouvrant d l'extérieur; - le surplomb, paroi de rocher dont les couches supéricures avancent sur les inférieures. Le surplomb est un véritable abri sous roche. M. Garnier nous repré-

1. M. de Mortillet subdivise la pèriode de la pierre taillée en quatre époques successives : vlielléenae, coustẻrienne, solutréenne, magdalénienne. 
sente un abri sous roche formé par superposition. Il n'a pas cru devoir édifier une grotte. car il est aisé de se rendre compte encore de nos jours de ce que peut être une pareille habitation. Dans certains villages, des grottes servent de caves, de magasins, de bergeries, et celle de Scacchietti, près de Civitella del Tronto (Italie), était habitée naguère par un berger qui y demeurait avec son troupeau la plus grande partie de l'année.

Mais cette demeure primitive est exposée à la visite des bêtes féroces et à l'attaque de l'ennemi, qui peut entasser d'autres pierres pour fermer les issues. Aussi le riverain des lacs a-t-il imaginé de fonder son habitation sur des pilotis : c'est l'origine des cités lacustres.

Ce fut pendant l'hiver 1833-5̌, époque à laquelle les eaux du lac de Zurich attei gnirent le plus bas niveau connu, que les pilotis qui durent servir de base aux habitations des premiers habitants de l'Ilelvétıe furent aperçus, près d'Obermeilen, par Ferdinand Keller. Les pècheurs avaient depuis longtemps remarqué ces pilotis qui bien souvent leur déchiraient leurs filets, mais nul n'avait songé à faire part de cette découverte curieuse. Du jour ou Ferdinand Keller comprit l'importance de ces ruines, il s'occupa activement de reconstituer la vie des premiers Helvétiens

- A l'aide des ruines qu'elles ont laissées au fond des eaux reconstruisons par la pensée, dit M. Joly, ces antiques demeures qu'un savant célèbre, cette fois malavisé, soutenait avoir été baties et habitées par les castors. Qu'on se figure une multitude de pieux de 15 à 30 pieds de longueur sur un diamètre qui varie de 3 à 9 pouces, et s'élevant de 4 a pieds au-dessus des eaux tranquilles. Quel'on se représente ces pieux plus ou moins espacés, rangés les uns parallèlement, les autres perpendiculairement au rivage, et, formant par leur ensemble un cercle ou un rectangle. Le plus souvent enfoncés dans la vase du lac au-dessus duquel ils s'élèvent, ils sont parfois soutenus (quand la nature du sol n'a pas perinis de les y faire pénétrer) par des amas de pierres ou steinbergs, déposés à leur base. Relions par la pensée tous ces pieux au moyen de traverses, fixées elles-mêmes par des chevilles de bois I ne s'agira plus que d'y établir une uspece de plate-forme, destinée à supporter les habitations, et construite au moyen de planches épaisses et de trones d'arbres refendus, grossièrement équarris et rattachés entre eux par de forts liens, des chevilles de bois, ou mème par des éparts et des rainures en queue d'aronde. Enfin, plaçons sur cette charpente des cabanes ovales, arrondies ou rectangulaires, de 10 à 15 et mème 27 pieds de diametre, dont les parois seront formées de poteaux perpendiculaires, reliés ensemble par une espèce de clayonnage en branches, revetu a l'intérieur d'un ciment argileux. Recouvrons chaque cabane d'un toit d'écorce, de chaume, de joncs, de roseaux, de fougères ou de mousse; laissons une porte pour l'entrée; pratiquons à l'intérieur une trappe communiquant avec le lac.

- Pour siege et pour table, un tronc d'arbre; pour lit, un tas de mousse. Enfin, entourons chacune de ces rustiques demeures d'une rangée de pieux ayant leur extrémitó libre à fleur d'eau, pour empêcher l'abordage des pirogues ennemies; établissons une espèce de pont ou de passerelle en bois, qui reliera les cabanes au rivage, et nous surons une idée suffisamment exacte des habitations lacustres qui existaiøat en Suisse et ailleurs aux époques préhistorisques. Le nombre de ces habitations jusqu'a présent connues ảans ce pays, s'élève à plus de 200. Le seul lac de Neufchâtel en a fourni 40 Chaque bourgade se composait, en moyenne, d'environ 300 cabanes. ' 
On ne sait, au juste, quelle était la destination des palafilles. Quelques écrivains

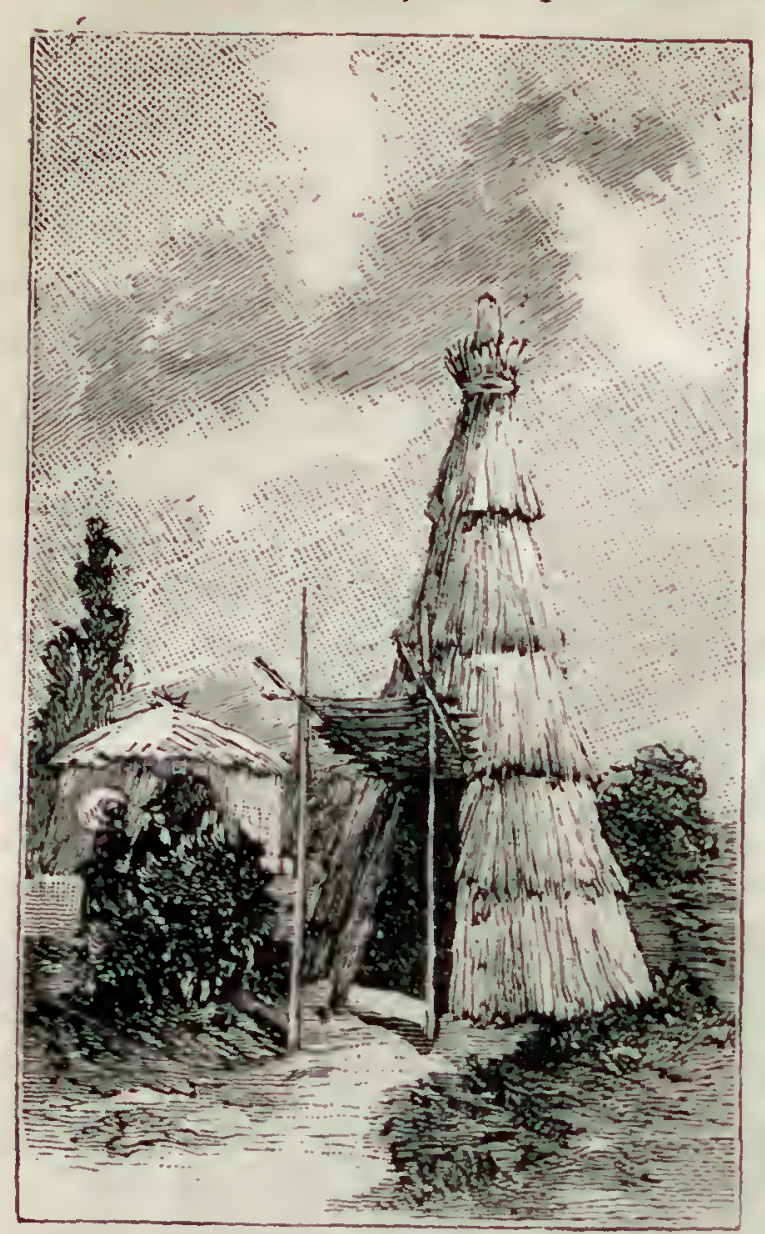

Hutte.

ont prétendu que c'étaient de simples établissements de pèche ou bien des magasins pour déposer des provisions de bouche. Celle hypothèse est peu probable, car les objets de toutes sortes que l'on a trouvés parmi les pilotis semblent lui donner un démenti formel. D'autres ont affirmé, sans plus de preuves, que c'étaient des lieux d'assemblée et des temples consacrés au culte des eaux. D'après les récentes découvertes, tout semble prouver que ces lieux étaient des bourgades habitées par une popula tion qu'on a estimée, dans quelques régions, a 12 ou 14,000 individus. Les plus anciennes palafittes paraissent remonter à la période néolithique, et disparaitre dans les premiers temps de l'Age de fer, c'est-d-dire un peu avant l'invasion des Romains. Les cités lacustres de Moosseedorf, de Wranger, de Robenhansen, de Meilen de Concise, de Saint-Aubin appartiennent à l'age de la pierre polie; celles de Geneve, Bienne, Sempach, Morat, Cortaillod, Annemier, Neufchâtel remontent à l'age de bronze. Celles de

Neufchatel et de Bienne ont existé jusque dans les premiers temps de l'âge de fer. Quelques bourgades contiennent des vestiges appartenant d deux et même trois ages; la bourgade d'Estavager a fourni des débris de l'age de la pierre et du bronze, et celles de Neufchatel et de Nidan des débris des âges de la pierre, du bronze et du fer. Les cités lacustres disparaissent dans la Suisse orientale à l'époque de l'âge de fer; dans la Suisse occidentale, elles subsistent jusqu'à l'àge de fer, mais il est impossible d'indiquer d'une façon précise le moment de leur apparition. Quelques auteurs le font remonter ¿ 5,000 et même 7,000 ans; Troyon le fixe a 2,000 ans avant notre ère. M. Bülimeyer pense que les cités lacustres constituent en Suisse les demeures de ses premiers habitants. Cette conclusion est rendue invraisemblable par la découverte à Verrier, près de Genève, d'une sta: tion humaine remontant à l'âge du renne. La Suisse a donc été habitée par les hommes des cavernes avant de l'ètre par ceux des palafittes.

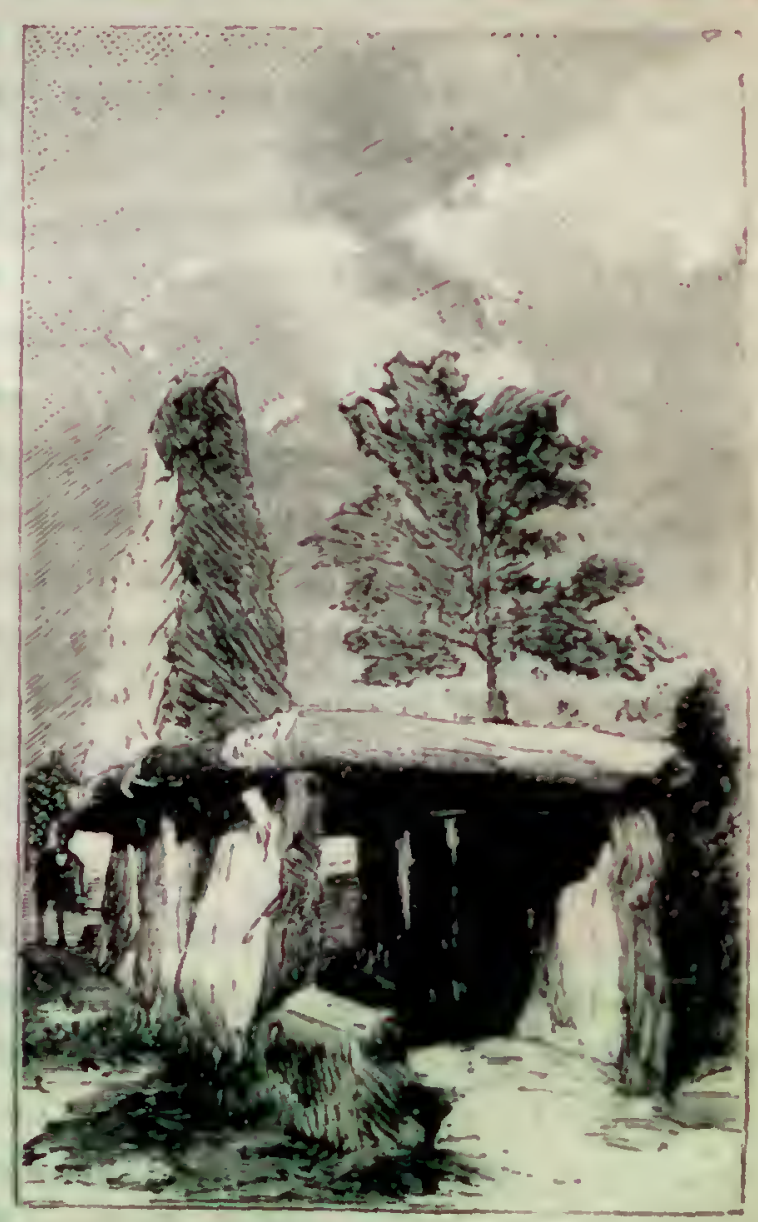

Menhirs.

On n'a pas non plus de renseignements très précis sur ceux qui ont habité les pala. 
fittes. M. Worsaë, et avec lui les archéologues du Nord, prétend que les habitants des cités lacustres étaient aborigènes de l'ouest et du nord de l'Europe, et d'origine celtique; leur race se serait perpétuée pendant toute la durée des palafittes et se serait perfectionnée dans les arts et l'industrie sur les lieux mèmes qu'ils habitaient. Virchow, Desor et F. Keller sont du même avis. M. Troyon et ses disciples pensent, au contraire, que des peuplades de différentes races ont occupé tour à tour les palafittes, en imposant aux vaincus leurs costumes et leur civilisation. La grande ressemblance des constructions lacustres de toutes les époques, l'analogie des objets usuels faits avec l'argile, la pierre, le bronze et le fer, semblent donner un démenti formel à cette assertion. Une théorie nouvelle, soutenue par Carl Vogt, établit un rapport entre les procédés agri-

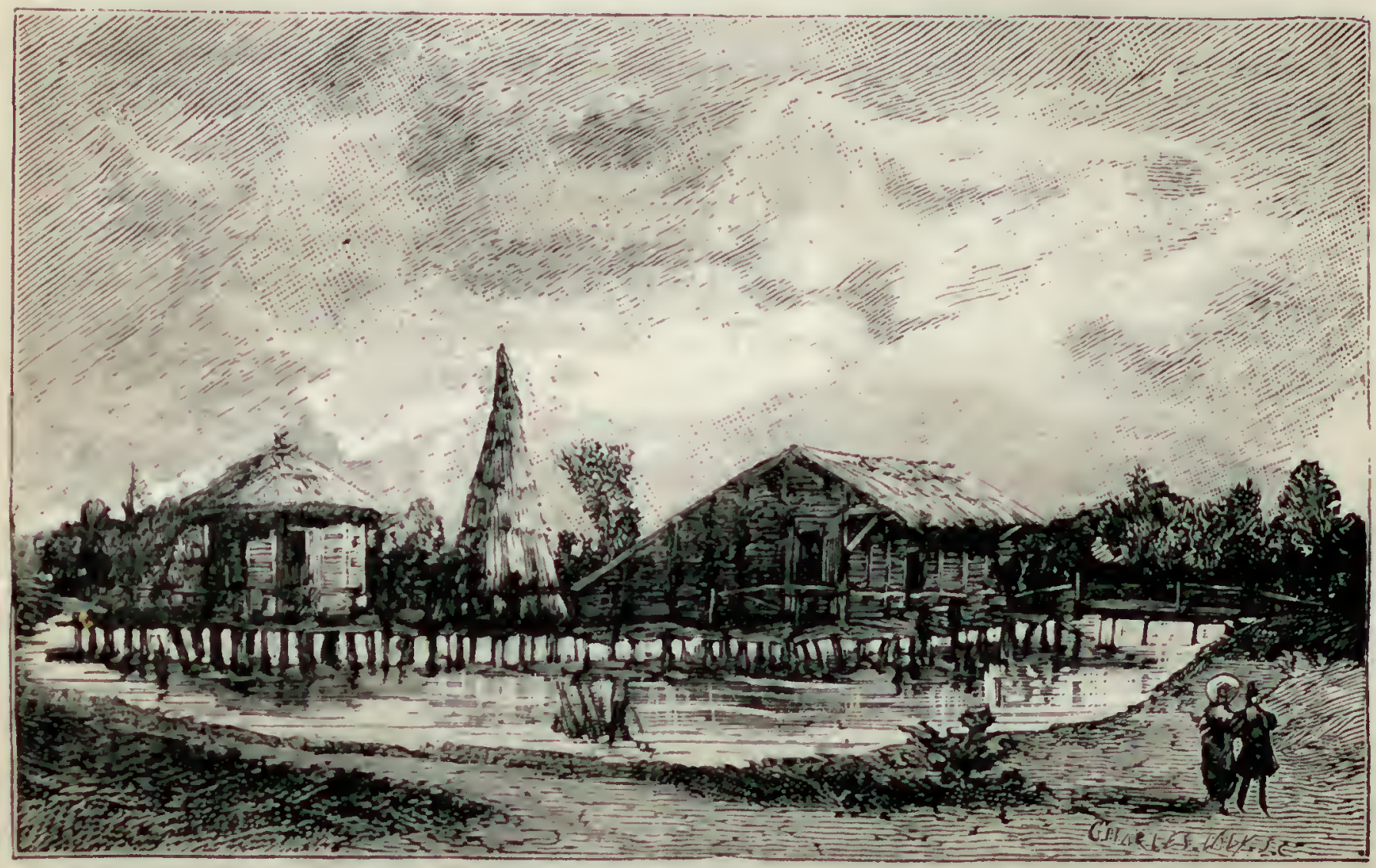

L'Habitation HuaANR. - Cité lacustre.

coles en usage en Suisse pendant l'ảge de la pierre polie et ceux employés en Égypte environ cinquante siècles avant la période étrusque. De ce que ces procédés sont à peu près identiques, il en conclut que les constructeurs des palafittes vinrent des bords du Nil avant les émigrations aryennes et avant l'emploi des métaux dans cette contrée. Ces assertions ne s'appuient pas sur des données assez certaines pour être admises sans discussion.

Les objets trouvés dans les lacs suisses, parmi les ruines des palafittes de l'âge de pierre, ont une grande ressemblance, avec ceux que l'on a découverts dans les groltes de l'époque néolithique. Ils se composent d'ustensiles divers et d'armes en argile, en os et en pierre, tels que haches, marteaux et ciseaux en pierre polie et emmanchés dans une corne de cerf travaillée; de polissoirs, pierres à aiguiser, meules à moudre le grain; de tranchets ou lissoirs, dont plusieurs en néphrite et montés avec une corne de cerf; de pointes de lances, de flèches, de couleaux en silex. On a trouvé aussi des scies en silex d'une petite taille ( 2 ou 3 pouces) et assujetties dans une lame en bois et 
fixées par un masic de coulenr foncée dont on n'a pu retrouver la formule; des couteaux, ciseaux, haches, marteaux, flèches, harpons, tranchets, poincons et aiguillns en os ou en corne. Des épingles à cheveux en mème matière, et presque semblables a celles en métal employées de nos jours, ont été recueillies ainsi que des bagnues et des bracelets en os ou en pierre, et des grains de colliers fabriqués avec l'ambre de la Baltique, avec des cornes de cerf, sciées en petits morceaux, et méme avec des noiseltes percées d'une extrémité à l'autre. A Moosseedorf et à Concise, on a retrouvé des vascs et des coupes à boire de petite dimension, fabriqués en corne ou en bois.

Des débris de poterie grossière nous ont donné un spécimen de cet art rudimentaire; des cordes d'écorce d'arbres, du fil de lin, de la toile lissée ont été retirés des lacs de Constance et de Pfeffikon, dans les stations de Wangen et de Robenhausen. A Wangen, on a remonté du fond des eaux quelques branches d'osier entremèlées avec de la paille et que l'on suppose ètre les débris d'un panier ou d'une corbeille. Dans une des plus anciennes palafittes du lac de Bienue, celle de Locras, datant de l'ige de la pierre polie, M. V. Grass a trouvé des écuelles et des jatles en bois, et des petits coffrets en écorce de bouleau dont le couvercle se meut au moyen de charnières en ficelle. D’ailleurs, ce n'est pas seulement en Suisse qu'on a rencontré des cités lacustres. 11 y a des palafittes en Italie, en Autriche, en llongrie, en Prusse, en France.

Quel était l'état social des habitants des palafittes? Nous trouvons à ce sujet, dans le livre de M. Joly, l'Homme avant les métaux, des donnćes fort intéressantes. - D'immenses forêts, dit M. Joly, peuplées déjà des essences actuelles, couvraient alors les flancs des montagnes de la Suisse et descendaient quelquefois jusqu'nu bord de ses lacs. Là erraient en liberté l'urus, l'aurochs, le cerf élaphe, le daim, le chevreuil, le sanglier, le loup, le renard, etc. La loutre se jouait au sein des eaux limpides, le castor y construisait sa cabane, l'ours brun se blottișsait dans sa caverne perudant que le lominergeyer (vautour des agneaux), épiant sa proie, planait au haut des airs. Le chien derenu dès cette époque le compagnon et l'auxiliaire de l'homme poursuivait avec lui les hôtes des forèts, dont la chair devait servir a les nourrir tous les deux. Outre le chien, les habitants des lacs avaient soumis a leur empire la plupart des animaux maintenant domestiques : le bœuf, la chère, le mouton, le porc, peut-ítre meme le cheval, progrès immense et qui rendait possibles les travaux de l'agriculture. Aussi cultivaient-ils la plupart de nos céréales. La chasse, la péche a la nasse et au filet, le laitage, les fruits de toute espèce complétaient leur alimentation. A en juger par certains de leurs objets d'art ou d'ornement (colliers de corail, perles d'ambre, néphrite, etc.), il paraitrait quiils ont entretenu des relations commerciales par voic d'échange avec les peuples de la Méditerranée, de la Baltique, des lles Cassilerides (Sorlingues), peut-ètre même de l'Orient. Pour vétements, ils portaient des peaux cousues ou non cousues et des étoffes de lin et de chanvre, artistement tissées. Les étoffes de laine leur étaient inconnues, ou du moins on n'en a jusqu'd présent truuvé aucune trace. L'art du vannier, du coldier, du passementier méme arait alteint chez eux un certain degré de perfection relative. Leurs poteries, toutes fiçonnes sans l'aide du tour, ne manquaient pas d'une certaine élésance. Cependant les arts du dessin étaient chez eux dans un état d'infériorité notable, si on les compare à ce qu'ils étaient, à l'ẻpoque du renne, chez les habitants des cavernes du Languedoc ou du Périgord. Leur architecture était des plus simples et des plus modestes; mais leurs charpentiers 
avaient imaginé d’ingénieux procédés d'assemblage, qui ne le cédaient en rien a plusieurs de ceux qui sont adoptés de nos jours. Enfin avec le seul secours du feu, de la hache et de la scie en silex, les lacustres de l'age de pierre savaient se construire des canots dont la dimension et la solidité nous étonnent. Quant a la vie morale des lacustres de l'llelvélie, sur ces points importants comme sur tant d'autres nous en sommes réduits a de simples conjectures. Ceux de l'age néolithique rendaient probablement un culte a la nalure, mais il ne le souillaient point par de sanglants sacrifices. Ils avaient, dit-on, pour autels les blocs erratiques si abondamment répandus dans tous les pays de montagnes à glaciers. Jusqu'en ces derniers temps, on ignorait completement si, où et cominent les habitants des cités lacustres ensevelissaient leurs morts. Une découverte tout a fait imprévue est venue dissiper ces incertitudes : je veux parler de la découverte récente faite à Auvernier, non loin des bords du lac de Neufchatel, d'une sorte de caverne funéraire renfermant au moins une douzaine de cadavres de lout age et de tout sexe, qui avaient été inhumés dans une caisse de pierre où gisaient leurs débris osseux. Cette caisse, tout à fail du mème type que les stonecusts de l'Angleterre, n'avait guere que $1^{\mathrm{m}}, 90$ de longueur sur une largeur de $\mathbf{1}^{\mathrm{m}}, \mathbf{1 2}$ et une profondeur de $\mathbf{1}^{\mathrm{m}}, 80$. Elle était formée de grandes dalles de granit posćes de champ el reconvertes par d'aulres pierres à la manière des dolmens, avec cette différence pourtant que les sépultures d'Auvernier ont été creusées dans la terre et entourćes d'une enceinte de dalles graniti (jues. De plus, la caisse ou chambre principale était précédée du côté sud par une sorte de petit couloir sans dalle de recouvrement qui communiquait avec elle. Une autre chambre accessoire, construite du còté nord, renfermait deux crânes et quelques ossements. A cette époque (fin de l'àge néolithique), les liabitants des palafiltes confiaient donc leurs morts à la terre, et les entouraient d'un certain nombre de dalles en pierre formant le cercueil et rappelant ainsi les monuments mégalithiques que l'on connait sous le nom de dolmens. Le mobilier funéraire, quoique très pauvre, ressemblait beaucoup aussi ì celui des dolmens. Ilaches en serpentine percées d'un trou de suspension, dents d'our's et de sangliers, disques en os également percés, etc., etc. A en juger par les ossements, malheureusement en trop petit nombre, trouvés dans tous les lacs suisses, la taille de leurs habitants était peu élevée et leurs membres sans grace. Mais, si nous voulons savoir l'origine ethnique de ces populations étranges, iciles doutes commencent, la nuit se fait autour de nous, et nous ne marchons plus qu'd pas très incertains dans le domaine des conjectures. İt cependant ce peuple inconnu, quel qu'il soit, nous a laissé au fond de ces lacs limpides des documents aussi authentiques, aussi précis dans leur signification que peuvent lètre les pyramides, les statues et les sphinx égyptiens. Il ne sera pas superflu de dire que de nos jours, il existe encore des peuplades qui vivent sur des constructions analogues. Tels sont les Papous de la Nouvelle-Guinée.

L'une des habitations élevées par II. Garnier nous montre une hutte de l'àge de fer. Le progrès est sensible a l'vil : la hulte que représente notre figure est vaste, percée d'ouvertures, qui y laissent pénétrer la lumière mème quand elle est close. Elle est élablie an besoin sur un petit monticule qui domine la plaine, et on y accède par un petit escalier grossierement taillé.

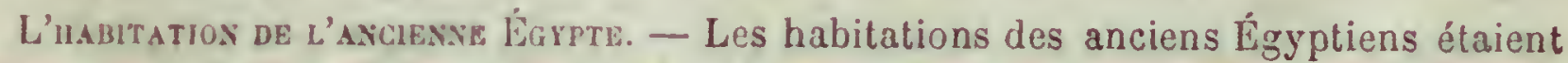
généralement luxueuse : tout particulier cherchait, dans la mesure de ses ressources, 
a avoir une habitation qui se rapprochât autant que possible par son aménagement et ses agréments du palais même des pharaons. On ne sait quel aspect avaient les villes égyptiennes, comment les maisons y étaient groupées, et l'on n'a que peu de renseignements sur les édifices eux-mêmes, qui à la différence des tombeaux et des temples étaient construits en matériaux très fragiles. La patience des érudits permet cependant de restituer avec de grandes chances de fidélité la maison égyplienne.

Comme la plupart des agglomérations urbaines étaient construites non loin du Nil, on avait jugé prudent de les rehausser artificiellement au-dessus du niveau des crues annuelles. Sur l'emplacement du quartier qu'on voulait batir, on commençait par élever des murs épais en brique crue qui se croisaient en forme de damier; on remplissait les

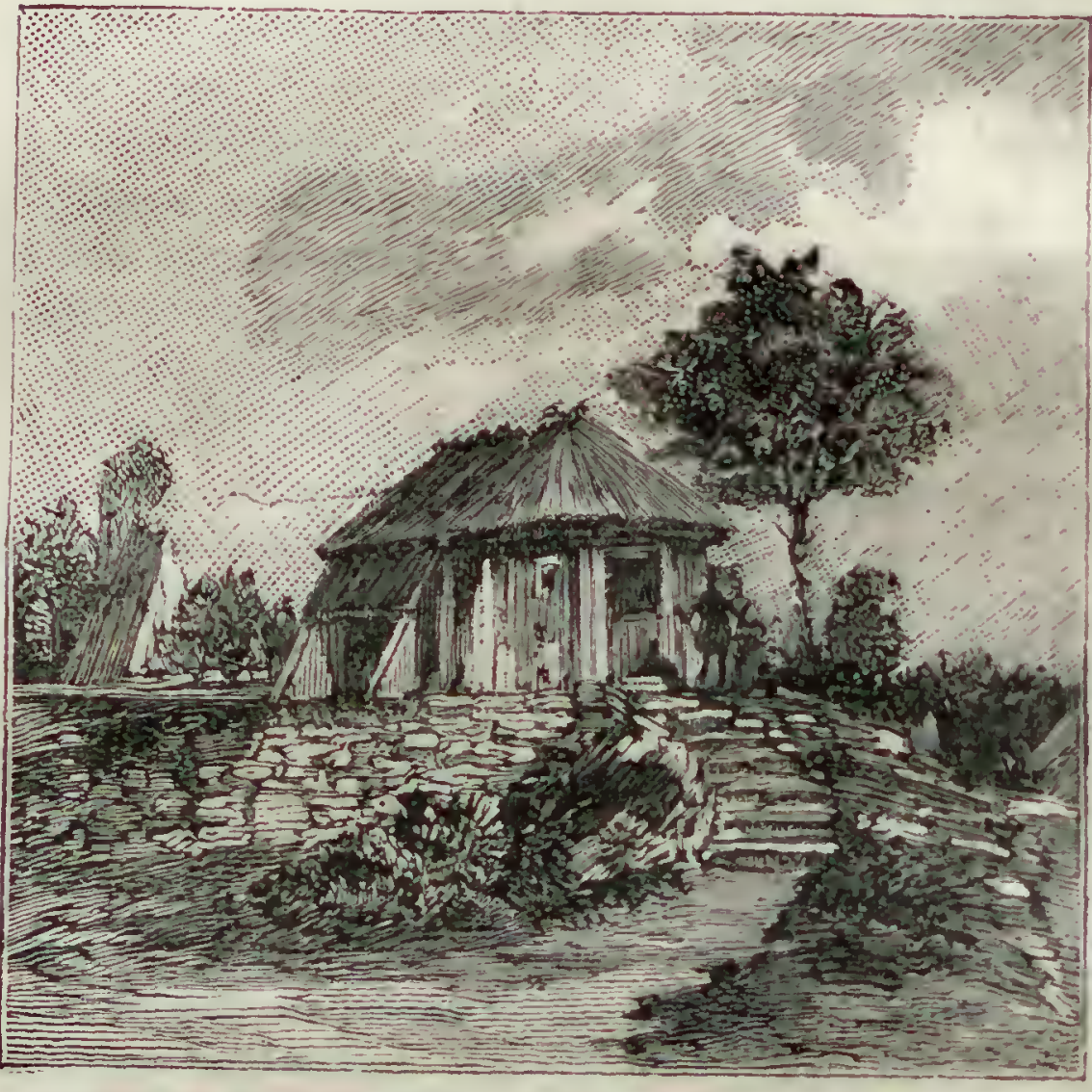

L'habitation humaing. - Hutte de l'époque du fer. intervalles avec de la terre, de la pierre, etc., et c'est sur cette base que l'on disposait les fondations de l'édifice. Généralement, les maisons élaient basses (un rez-de-chaussée, un premier étage et une terrasse couverte); elles s'élevaient au milieu d'une cour et d'un jardin. Les chambres étaient rangées autour d'une cour, régulièrement distribuées sur deux ou trois de ses cótés, ou bien elles ouvraient sur un long corridor. \& Celles du rez-de chaussée servaient aux besoins du ménage, tan. dis que celles des étages su. périeurs étaient habitées par la famille. Au sommet de l'édifice était une terrasse, souvent garantie du soleil par un toit léger, soutenu par des colonnettes de bois et peint de couleurs brillantes. La partie de la terrasse qui n'élait pas couverte portait un large auvent en planches, espèce de ventilateur dans le genre des mulcafs arabes et qui servait comme eux à établir un grand courant d'air dans la maison. Quelquefois, une partie de la maison faisait une saillie en manière de tour. Enfin, certaines habitations sont couronnées par un parapet surmonté d'un cordon de créneaux arrondis. Dans les grandes maisons, la cour était précédée d'une sorte de porche soutenu par deux colonnes à bouton de lotus que, les jours de fetes, on décorait de banderoles. Le nom du propriétaire était peint sur le linteau de la porte. D'autres fois, on $\mathrm{y}$ lisait une sentence hospitalière.

Gailhabaud nous apprend que les maisons étaient construites en briques crues, c'est-à-dire en terre grasse broyée avec de la paille hachée, ayant un pied de long sur un demi-pied de large. Les plafonds des grandes pièces étaient en bois indigenes ou étrangers; les petites pièces étaient souvent voilées. Les portes et les fenétres étaient 
d'ordinaire deux battants; elles s'ouvraient en dedans et se fermaient à l'aide de verrous et de loquets. Quelques-unes avaient des serrures en bois, dans le genre de celles qui sont usitées de nos jours en Égypte. La plupart des portes intérieures n'avaient qu'une simple tenture d'une êtoffe légère. Les murs étaient revêtus de stuc et peints de scènes religieuses ou domestiques. Les galeries ou colonnes étaient coloriées de manière à imiter la pierre ou le granit. Des entrelacs, méandres et ornements de

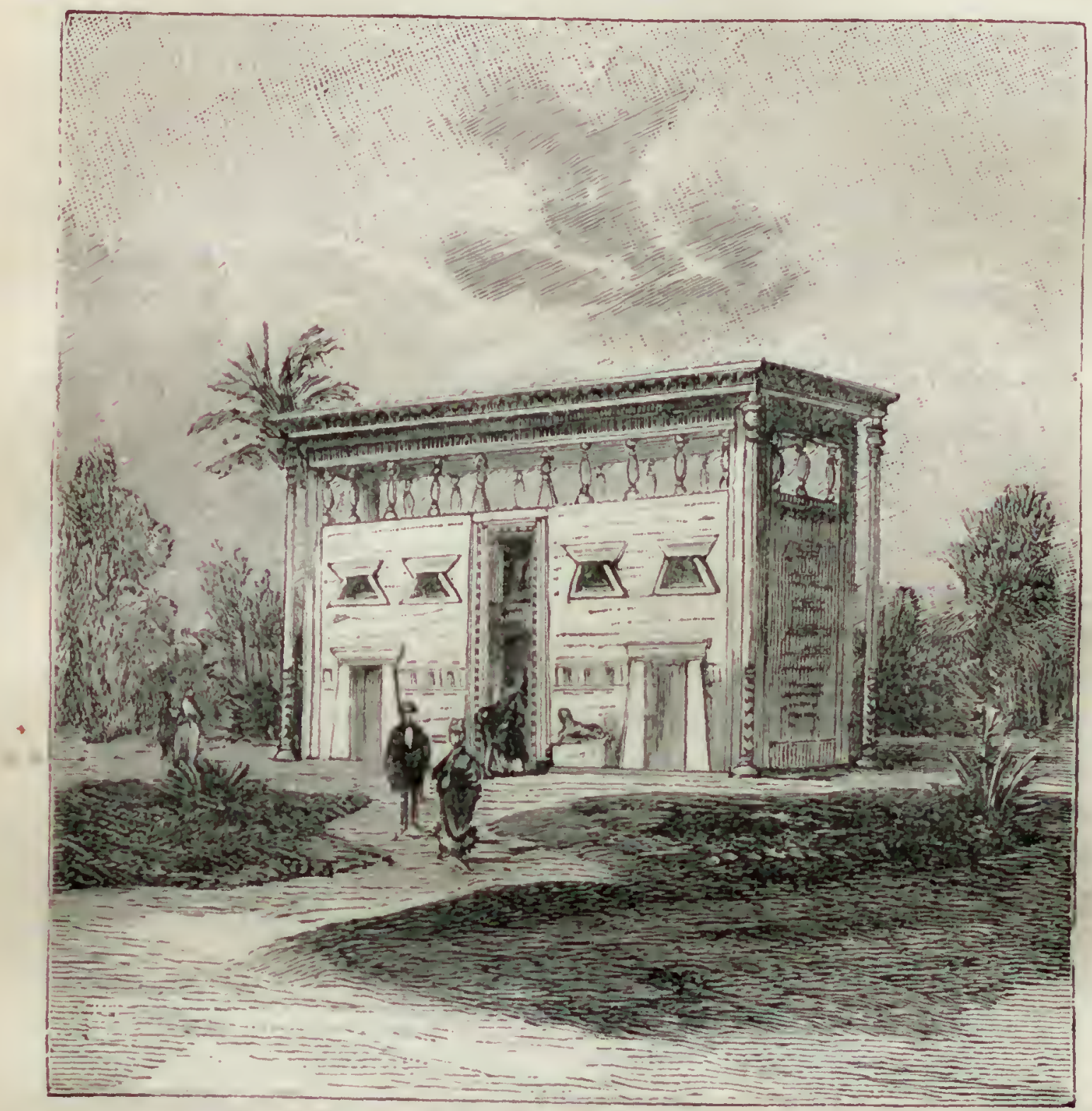

L'Habitation Huyainz. - L'habitation dans l'ancienne Égypte.

toute espèce ornaient les plafonds, tandis que sur les planchers étaient étendues des nattes tressées en jonc de couleur.

Suivant MM. Perrot et Chipiez, on employa presque toujours le toit plat qui avait l'avantage d'agrandir la maison, en fournissant aux habitants un lieu commode de rendez-vous tant pour s'y reposer le soir que pour y dormir en certaines saisons. Inférieure à l'architecture grecque pour ce qui est de l'unité et de l'harmonie du plan, de l'élégance des proportions, du choix des ornements, l'architecture égyptienne n'a pas de rivale pour la solidité, pour l'ampleur, pour la simplicité grandiose. a Notre architecture actuelle, a dit Théophile Gautier, offre peu de points de comparaison a vec ces constructions immenses, dont les ruines ressemblent plutot à des éboulements de montagnes qu'd des restes d'édifices. , L'énormité l'aspect trapu et ramassé,

Liv. 23. 
voilà en effet le caractère distinctif de l'architecture égyptienne. Les premiers habitants de la vallée du Nil auraient, suivant certains auteurs, établi leurs demeures dans des excavations naturelles ou creusées par eux-mêmes dans le flanc des rochers, et ces habitations souterraines auraient servi de type pour les constructions sombres et massives qui s'élevèrent dans la suite en Égypte. Tout dans l'architecture égyptienne, a remarqué Quatremère, nous retrace cette première origine : la grande simplicité, pour ne pas dire monotonie, l'extrème solidité, pour ne pas dire pesanteur, qui en forment les deux principaux caractères, l'absence absolue de profils ou de membres, le peu de saillie des moulures, qui s'y trouvent plutot renfoncées qu'en relief, le manque d'ouvertures, l'énorme diametre des colonnes, assez semblables aux piliers de support qu'on laisse dans les carrières, la forme pyramidale des portes et de beaucoup d'auires objets, l'absence de toits et de toutes les parties des combles et des frontons, la privation de voutes ou la forme imparfaite de celles qu'on y remarque, l'usage constant des plafonds plats. Cette appréciation de l'architecture égyptienne offre plusieurs erreurs. Les constructeurs égyptiens avaient été amenés tout naturellement \&̀ construire des abris assez obscurs pour protéger les habitants contre les ardeurs du soleil, assez élevés pour ne pas être engloutis par les sables du désert ou par les débordements du Nil, assez épais et assez solides pour résister aux grands vents et aux tremblements de terre, si fréquents en ces contrées. Les théories formulées après coup, les systèmes au moyen desquels on prétend assigner à ces constructions des modèles, des prototypes fournis par la nature elle-mème, ne reposent que sur les conjectures les plus vagues. M. Ramée les a vivement critiqués : I Il ne peut y avoir d'hésitation sur l'origine des formes de l'architecture égypticnne, a-t-il dit. Cette architecture n'est nullement une imitation des cavernes qqu'on suppose avoir été habitées par les troglodytes (habitants des eavernes); elle résulte du développement et du perfectionnement naturel des constructions primitives de terre et de charpentes. 'L'explication donnée par M. Ramée n'est pas une conjecture; elle est fondée sur des exemples de constructions qui figurent dans les bas-reliefs de quelques édifices de l'antiquité la plus reculée. Dans ces constructions, les angles et le sommet des murs de terre ou d'argile étaient terminés par une sorle de chássis ou batti composé de roseaux rassemblés et maintenus ensemble au moyen de ligatures transversales. Dans un climat où il ne pleut jamais, on pouvait donner à ces murs, vers l'intérieur de la batisse, une légère inclinaison destinée à en augmenter la force. La couverture de ces constructions primitives était plate, car on n'avait nul besoin de se garantir de la pluie. On plaçait horizontalement, soit en longueur, soit en travers de la maison, selon sa dimension, des pièces de bois formant plancher et, sur ce plancher, on disposait des joncs, des roseaux ou des branches de dattiers, que l'on recouvrait d'une légère couche de terre réduite ou boue. Cette couverture formait une légère saillie sur les murs de face et de côté. Ce fut de ces constructions primitives que les Égyptiens prirent dans la suite l'ensemble et les parties de leurs temples el de leurs palais, en modifiant toutefois avec talent les détails, pour les approprier aux nécessités du climat et aussi a la nature de la matière dure qui remplaça la terre et le bois. C'est ainsi que, le soicil ardent de l'Égypte exigeant des habitations où l'on punt trouver de la frafcheur, on fit des murs et des toits épais, des fenetres ne recevant qu'indirectement les rayons du soleil; d'autre part, la nature des matériaux de construc tion, en Égypte, porta les architectes à couvrir les salles d'immenses et épaisses dalles 
supportées par des colonnes; ces dalles demandaient de leur coté des masses verticales capables de les soutenir dans l'espace: de là l'épaisseur des murs et le diamètre considérable tes colonnes. Indépendamment des pièces destinées à l'économie domestique, des chamb es d'habitation, des salles d'honneur et de grande réception, i' fallait des lieux aérés et cependant abrités de la chaleur, où l'on pùt se terir et se promener. C'est ce que les architectes égyptiens réalisèrent au moyen de la construcwon de vastes galeries couvertes. D'un autre côté, comme il n'y a point de plaines en ligypte, les toits n'avaient pas besoin de rampants, et ils étaient effectivement plats comme une terrasse. L'ornementation des plus anciens monuments de l'égypte parait avoir été empruntée aux divers dessins employés dans les nattes, fabriquées avec des filaments de bois et d'écorce d'arbres. Cette ornementation est toujours rectangulaire dans tous ses détails; on y trouve le chevron, le damier, le méandre, les étoiles. Plus tard, on introduisit dans la peinture et dans les étoffes la ligne courbe, le cercle, les guillochés, les enroulements ou volutes, etc. On développa ensuite les divers éléments de cette ornementation primitive, qui n'était pas uniquement due au caprice, mais qu'une imagination saine et brillante métamorphosa a l'infini.

L'intérieur des familles égyptiennes dénote des mœurs douces et des habitudes d'affection. Dans un tombeau de Gournah, on voit représentée une scène de famille, fort instructive d ce point de vue. Une dame rentre chez elle avec ses trois filles d'age diférent, suivies d'un vieux serviteur et d'une servante. Après avoir traversé une première piece, elles se trouvent dans la seconde, qui en précède plusieurs autres; trois jeunes femmes de service viennent au-devant d'elles et leur présentent respectueusement des fruits et des rafralchissements; dans l'antichambre une des trois filles se désaltire, pressée par la soif, tandis que la servante distribue des fleurs et des joujoux à une petite fille et à un petit garçon sans vètements, accourus vers la porte à la rencontre de leur mire. On vait dans une piece de grands approvisionnements de comestibles variés, empilés sur des tablettes; ailleurs, le sol est recouvert d'une natte tressée en joncs de couleurs diverses; de petites fendtres grillées éclairent les pic̀ces du rez-dechaussée, et au premier étage, habitation pour la nuit, on ne remarque que de très petites croisées. Ces fenctres sont a deux vantaux, garnis de carreaux en verres de couleur. Un grenier ouvert sur les côtés et une terrasse terminaient le battiment. Dans les jardins avoisinant d'ordinaire la maison, on distingue des arbres fruitiers en plcin vent, des grenadiers, des citronniers, des arbres d'agrément de forme pyramidale, des bosquets de verdure et des bosquets de vigne. Ces vignes étaient régulièrement arrosées, et l'on vendangeait pour cueillir les raisins que la consommation journaliere avait épargnés. Le raisin coupé était transporté avec des paniers dans une cuve placée entre deux palmiers; il y était immédiatement foulé par des hommes qui se soutenaient à une corde tendue d'un palmicr à l'autre. Il y avait dans la maison des pièces destinées a recevoir toutes sortes de provisions, notamment des fruits.

L'ameublement intérieur des maisons était sinple, unais élégant et commode. Dans les pays d'Orient, on recherche la ventilation, la fralcheur et l'on évite tout ce qui yeut encombrer et échauffer. Pas de coussins moelleux, point de matelas. On se bornait ù étendre des tapis ou des peaux sur le cannage, les sangles ou les courroies entrecroisées qui en garnissaient le cadre. Au lieu d'un oreiller, on se servait, pour appuyer sa tète eu dormant, d'un chevet de bois en forme de croissant, monté sur un pied. Ce grenre de chevet est encore en usage, comme l'a remarqué Fr. Lenormant, chez les Nubiens, et. 
en Extrême-Orient, chọz les Japonais. - En tenant la tète soulevée et éloignée du lit, il permet tout autour une circulation d'air qui rafralchit le dormeur et rend son sommeil plus paisible. Mais il faut que les muscles du cou y soient habitués dès l'enfance; pour ceux qui n'y sont pas faits, l'usage er est fort douloureux. "

L'habitation indoue. - L'Inde renferme un nombre considérable de monuments

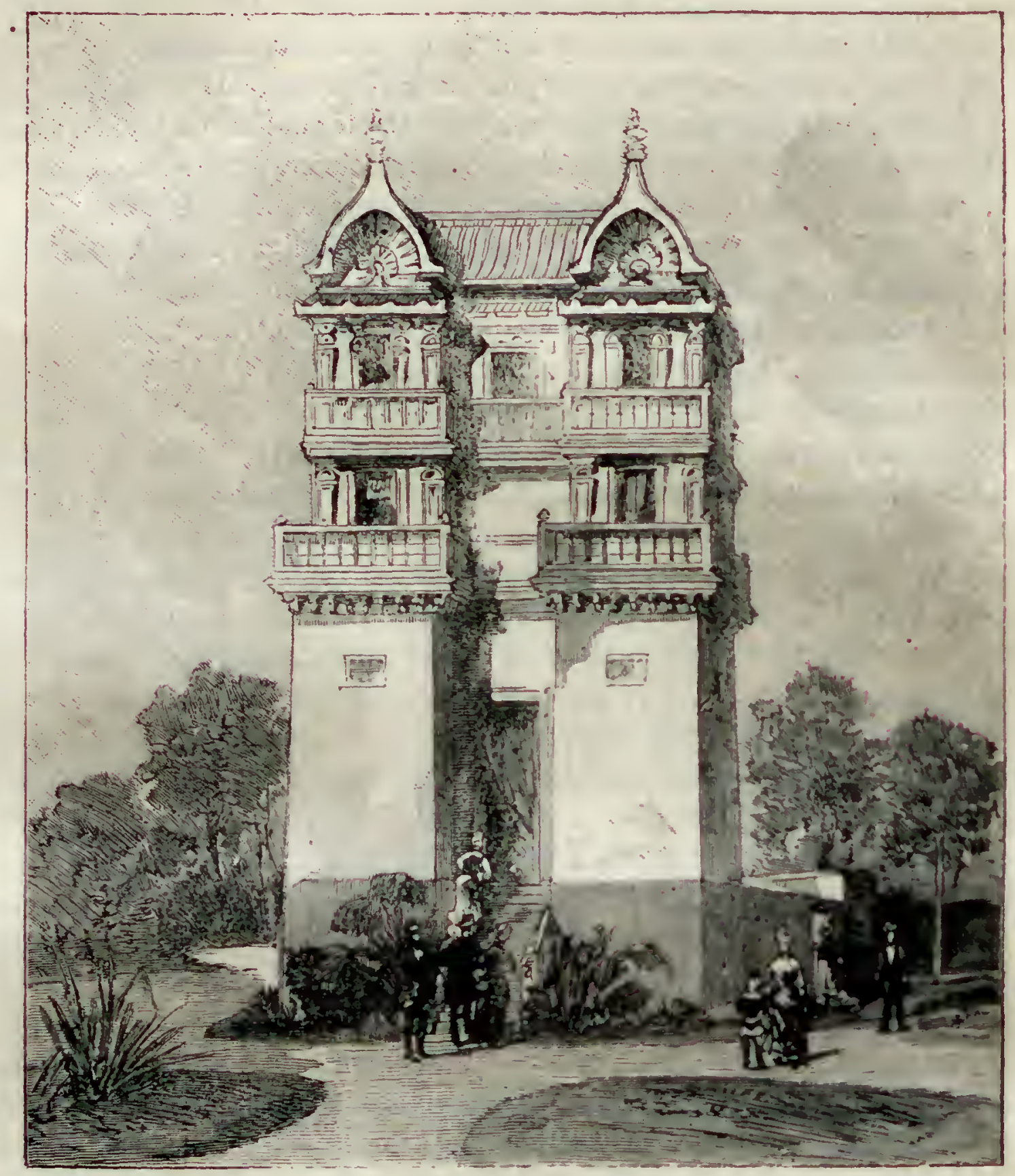

L'habitation humaine. - Typo indou.

religieux du caractère le plus grandiose, qui suffiraient pour attester combien la civilisation fut jadis florissante dans cette contrée. Les érudits de France et d'Allemagne. depuis une einquantaine d'années, ont cru reconnaltre que ces monuments n'avaient pas l'antiquité reculée que certains archéologues s'étaient plu a leur assigner, et que les plus anciens datent de trois ou quatre siècles avant Jésus-Christ.; d'autres seraient du commencement de notre ère; la plupart ne remonteraient pas au delà de notre moyen áge européen. En général, les premiers sont creusés sous terre, les secunds sont taillés dans le roc, au-dessus de terre; les troisièmes sont formés de matériaux rapportés. Ces fixations de dates sonl évidemment approximatives. 
L'architecture des Indous, comme celle des Grecs et des Romains, a ses règles et ses canons. Il y a quelque cinquante ans, un brahmane savant, nommé Ram-Raz, publia en langue anglaise (Essay of the architecture of the Hindus) un traité dans lequel il reproduit d'anciennes lois sur l'art de construire. Ce traité indique les lieux convenables pour élever les cités et les bourgs, détermine leur configuration, désigne la place que doivent occuper les palais et les temples, donne les proportions des colonnes et fixe la disposition des moulures qui les décorent. Dans chaque ordre, on

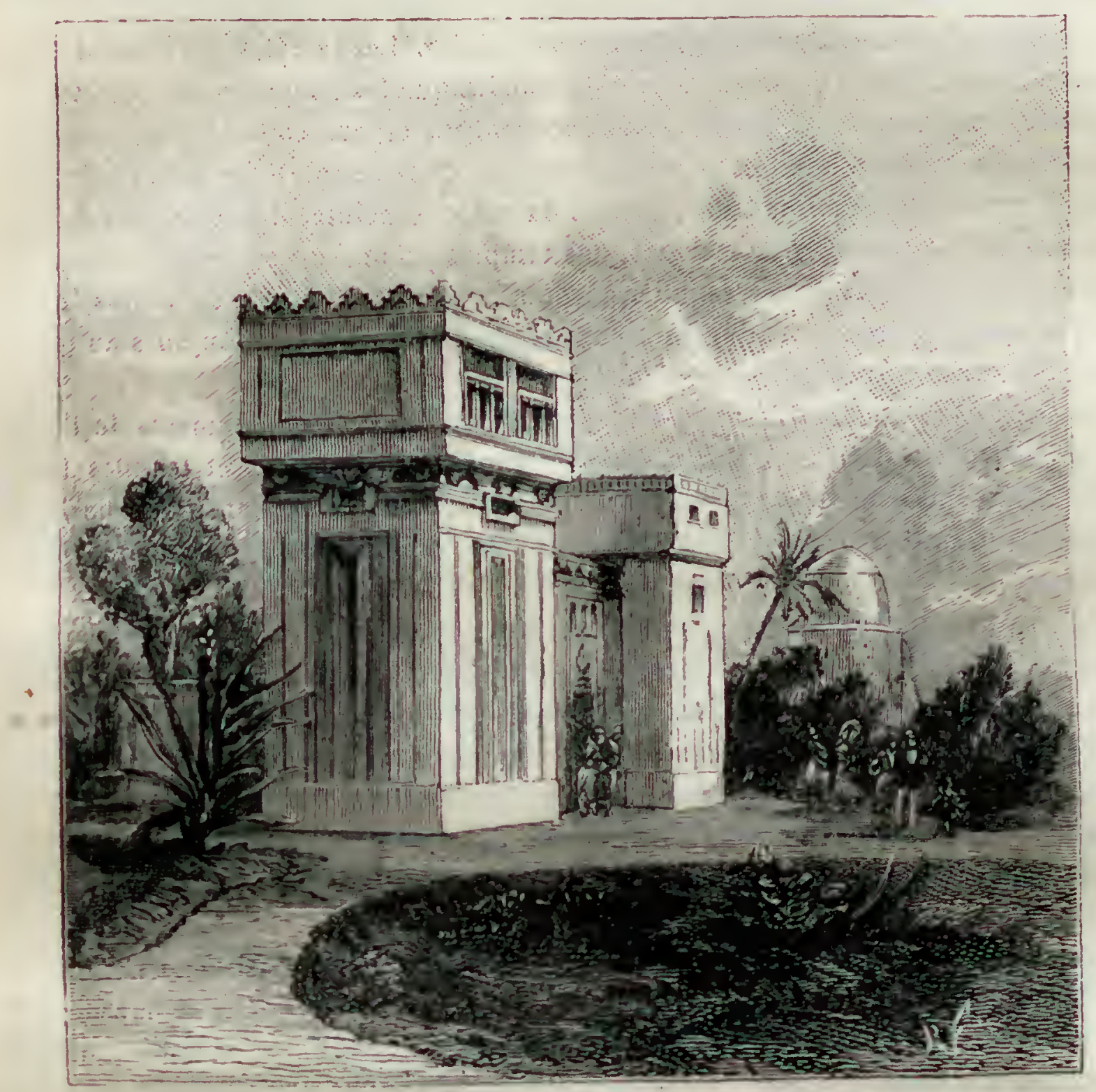

L'Habitation Husaing. - La maison assyrienne.

distingue quatre parties : le piédestal (repapitha), la base (adhistana), le pilier (stamba), l'entablement (prastana). Le nombre des moulures est assez considérable; mais elles sont toutes currées ou rondes et ne different que par les dımensions proportionnelles. Le lotus, qui est notre cymaise droite ou renversée, est très employé dans les ordres de l'Inde, auxquels il donne un caractère tout particulier.

- En examinant les monuments de l'Inde, dit il. Batissier, on remarque que, malgré la variété de leur décoration, ils ont entre eux la plus grande affinité et qu'ils ont un caractère d'originalité tout à fait national. Dans les proportions que comportent les ordres de l'architecture indoue, il y en a qui sont à peu près les mèmes que celles qu'on retrouve dans les ordres grecs ou romains. Cette analogie est mème si frappante 
qu'or pourrait la regarder comme n'étant pas seulement l'effet du hasard, s'il n'y avait chez les Indous des espèces de colonnes, les unes plus trapues que le toscan, les autres plus élancées que le composite. La forme des colonnes est toujours ronde chez les Grécs; elle est souvent carrée et à pans coupés chez les Indous, et surchargée d'ornements et même de sculptures de ronde bosse. "Une encyclopédie contemporaine nous apprend que les villes et les bourgs de l'Inde présentent ordinairement plusieurs rues se coupant à angle droit. Leur mur d'enceinte est percé d'une porte à chacune de ses faces et à chacun de ses anģles. Aux angles, à l'intérieur, s'élèvent les halles, les marchés, les collèges et autres établissements publics. Les temples des grands dieux ont leur place marquée au centre de la ville, tandis que les chapelles des petites divinités sont hors des murs. Les forteresses occupent un espace considérable; elles renferment tout à la fois l'habitation des souverains et les temples des dieux. Celle de Madoureh a un mille de circuit et contient, dans son enceinte, des bois, des étangs, des jardins, des galeries, des maisons, des temples et une magnifique pagode. Les maisons particulières sont très régulièrement alignées et sont plus ou moins hautes suivant le rang des personnes qui les occupent. La porte n'est pas toujours au milieu de la façade, mais un peu plus sur la gauche.

Nous n'aurons pas à nous ćtendre ici sur la description des monuments de l'Inde, que l'on peut diviser en trois catégories : 10 Temples souterrains et temples taillés dans le ruc au-dessus de terre; 20 Topes ou stoupas et dagobas, constructions bouddhiques d'un caractère particulier; $3^{\circ}$ Pagodes. Nous nous bornerons a quelques notes sommaires.

Les temples souterrains et les temples taillés dans le roc se trouvent fréquemnzent accouplés, notamment à Ellora. Dans l'lle d'Éléphanta, sur la côte occidentale du Decar, sont des grottes considérables, que précèdent des portiques soutenus par des colonnes et des pilastres. Le principal sanctuaire, consacré a Siva, est taillé dans le roc le plus dur; il est divisé en plusieurs nefs et contient une figure de la Trinit: indoue, haute de ${ }^{\mathrm{m}}, 57$ et entourée de plusicurs statues de moindre dimension.

Dans l'lle de Salsette, les souterrains de Kennery forment unc véritable ville tro. glodyte, ornée de portiques et de sièges taillés daus le roc. Le principal sanctuaire, dédié à Bouddha, est divisé en trois nefs par deux rangrs de colonnes; la nef centrale se termine en hémicycle, comme celle de la basilique romaine. On pénétre dans ce lemple par un portique élevé, où l'on remarque un énorme pilier isolé el octogone, dunt le chapiteau est formé de trois lions couchés et se tournant le dos. Entre Bombay et Pouna sont situées les célèbres grottes, qui communiquent entre elles par des escaliers, des corridors et des galeries. A peu de distance de Pouna et de Sattara, la forteresse de Mhar contient un temple taillé dans le roc, dont le style se rapproche de celui des temples de Salsette. A l'extrémité orientale du sanctuaire est une figure colossale, laillée dans le roc et assise sur un trône entre deux statues plus petites. A lhoumnar, dans le nord de la province de Malva, le colonel Todd a complé jusqu'a 170 souterrains formant une grande ville troglodyte. Il y a une galerie de 100 pas de longueur sur 4 de largeur, qui aboutit à une piece rectangulaire longue de $30^{\circ}, 4 \mathrm{i}$, large de $21^{\text {n }}, 33$ et haute de $10^{m}, 66$, au milicu de laquelle est un petit temple isolé, consacré à Vichnou et décoré de figures de dieux, de démons et d'animaux. Todl dit avoir reconnu dans ce monument deux styles de sculpture, l'un propre au bouddhisme, l'autre spécial aux ouvrages consacrés à Siva et Vichnou. Les 'auch-Paudou, grotles 
voisines de Baud, dans le sud de la province de Malva, sont surtout intéressa ntes à cause des peintures qu'elles renferment. Sur la côte de Coromandel, au sud de Madras, on voit les restes d'une ancienne ville taillée dans le roc, connue sous le nom des Sept-Pagodes; ce sont des temples monolithes, ornés seulement à l'extérieur. Tout auprès, dans le versant septentrional de la montagne, il existe une pagode taillée dans le roc, haute de $5^{m}, 48$, et contenant une grande quantité de sculptures qui, au dire de brabmanes, représentent des scènes tirées du Mahabhârăta. A Banian, cité jadis très prospère, appelée aujourd'hui Mubalik (la Ville désolée), dans la partie la plus sauvage de l'Indou-Khou, d'innombrables excavations sont pratiquées sur une étendue de 12 kilomètres et forment une ville immense habitée encore par une population assez considérable. Elles sont creusées dans un terrain argileux mêlé de cailloux, et forment pour la plupart des espèces de chambres carrées, dépourvues de tout ornement architeclural; quelques-unes cependint sont voútées en dômes et ornées d'une frise sculptée à l'endroit où la coupole prend naissance. Les traditions qui se raltachent a ces grottes sont des plus extraordinaires; on assure, notamment, que ce fut dans l'une d'elles que le fameux Vyasa composa les Véllas. Ritter pense que c'est à Banian qu'il faut placer la grotte rendue célèbre par la fable de Prométhée. Près de ces excavations s'élèvent deux figures gigantesques, taillées dans le paroi verticale de la montagne. L'ile de Ceylan renferme des monuments d'architecture bonddhique, moins anciens mais non moins intéressants que ceux de la presqu'ille. A Damboulla ou Damboulnu-trallé, au sud des ruines d'Anouradjapoura, l'antique capitale, s'élève un rocher de $18: 3$ mètres de hauteur, dans lequel sont tailís les plus beax et les plus anciens sancluaires de lile. Une galerie couverte conduit a une large plate-forme plantie d'arbres et séparée de l'entrée des souterrains par un mur de 122 mètres de longueur, percé de plusieurs portes et d'une multitude de fenètres. Le temple principal se conpose de quatre grottes admirables pour l'élégance de leur ordonnance, la richesse et la perfection de leur ornementation. La plus grande de ces grottes a 58 mètres de longueur; lit plus petite n'a que 22 mètres. De nombreuses statues colossales, dont plusieurs sont peintes, peuplent ces sanctuaires ornés aussi de bas-reliefs exécutés avec une véritable habileté.

lies topes ou stupas, répandus dans les diverses provinces de la péninsule hindoustanique, mais plus particulièrement dans le kaboulistan, sur la rive occidentale de I'Indus, jusqu'à Peschawer et Jellalabad, sont des monuments funéraires ou, selon quelques archéologues, des trophées érigés en commémoration des conquêtes du bouddhisme. Les dagobas ou dlıagobs, qu'on rencontre en grand nombre à Ceylan, ont veaucoup d'analogie avec les topes. Ce sont ou des constructions à coupole, ou des espèces de tumuli en forme de cône, composés de monceaux de terre recouverts d'une majonnerie de brique ou de pierre. A l'intérieur est un espace libre destiné à renfermer des reliques. Ces édifices qu’accompagnent presque toujours de nombreux piliers isolés. varient beaucoup de dimensions. Les plus connus sont voisins du temple de Mahintala ou Mahintélé, à quatre ou cinq lieues d'Amouradjapoura.

Le iype d'habitation indou choisi par M. Garnier, pour figurer à l'Exposition de 18\$9, se compose de deux tours d'une hauteur considérable et qui constituent à peu près tout l'édifice, car elles ne laissent entre elles qu'un corps de batiment extrêmement étroit. Ici le soubassement prend une importance prépondérante : sa hauteur est, en effet, supérieure à la moitié de celle de la construction. Mais s'il alourdit par sa masse 
l'ensemble de l'édifice, la partie supérieure des tours présente un caractère de légèreté relative, relevé encore par l'abondance et la richesse de l'ornementation. Celle-ci comporte des balcons pleins à balustres saillants, auxquels accèdent les baies intérieures; des colonnettes établies sur le premier supportent le second par leurs chapiteaux, et se continuent par d'autres, pour servir d'appui à un entablement élégamment mouliné.

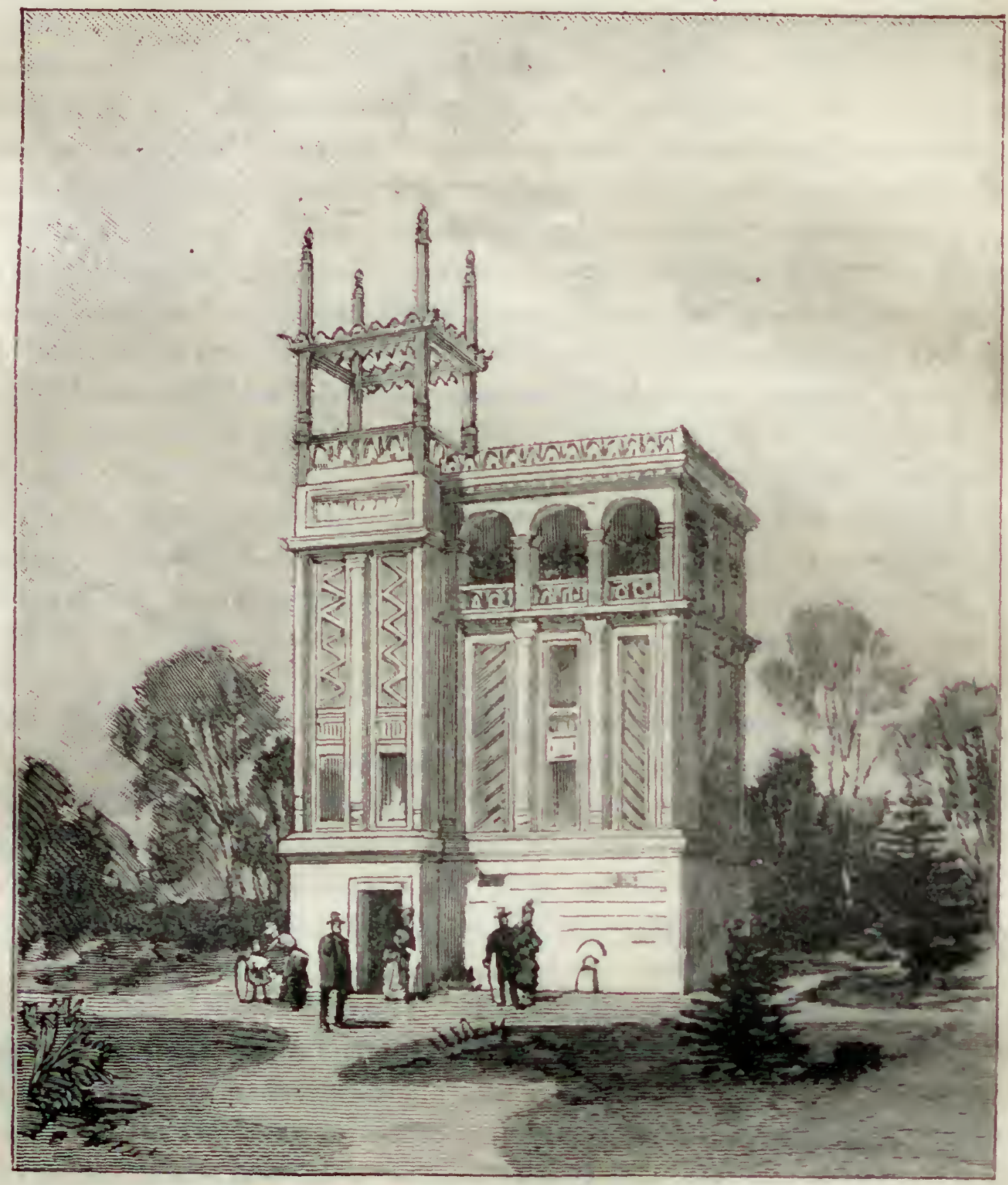

L'habitation humaing. - Type phénicien.

Chaque tour est couronnée par une sorte de pignon à contour neltement ogival; l'inté. rieur présente une décoration encoquille, et le pignon s'effile vers la partie supérieure et donne à l'ensemble un aspect à la fois riche et grasieux. C'est, comme on le voit, dans ce type de demeure, que la ligne courbe fait pour la premiere fois son apparition dans l'architecture ancienne.

L'habitation assyrienne. - Lorsqu'on étudie l'histoire de l'ancienne Asie, il n'ost pas de peuple plus intẻressant à étudier que le peuple assyrien. Ces monarques ninivites, toujours en guerre, toujours assoiffés de sang et de carnage, sont bien les spécimens 
les plus typiques de ce que peut produire de sauvage et de barbare une civilisation exclusivement guerrière. Dans un bas-relief, qui malgré les injures du temps est parvenu jusqu'ì nous, on voil un roi d'Assyrie assis dans un bosquel à côté de la reine. Sur une table, des mets et des coupes; en haut, dans le feuillage, la tête salée et préparée du monarque vaincu par les troupes assyriennes! Ce trait, tout répugnant qu'il est, est significatif. Les $A$ ssyriens vécurent de la guerre : le jour où ils cessèrent de combattre, c'en fut fini de leur puissance.

Un pareil peuple, on le comprend, ne songeait guère aux tranquilles jouissances de l'art, et ce n'est pas sur les bords du 'Tigre que l'on doit chercher ces restes grandioses qui, en Égypte par exemple ou en Grèce, dénotent une race vraiment civilisée et le sans

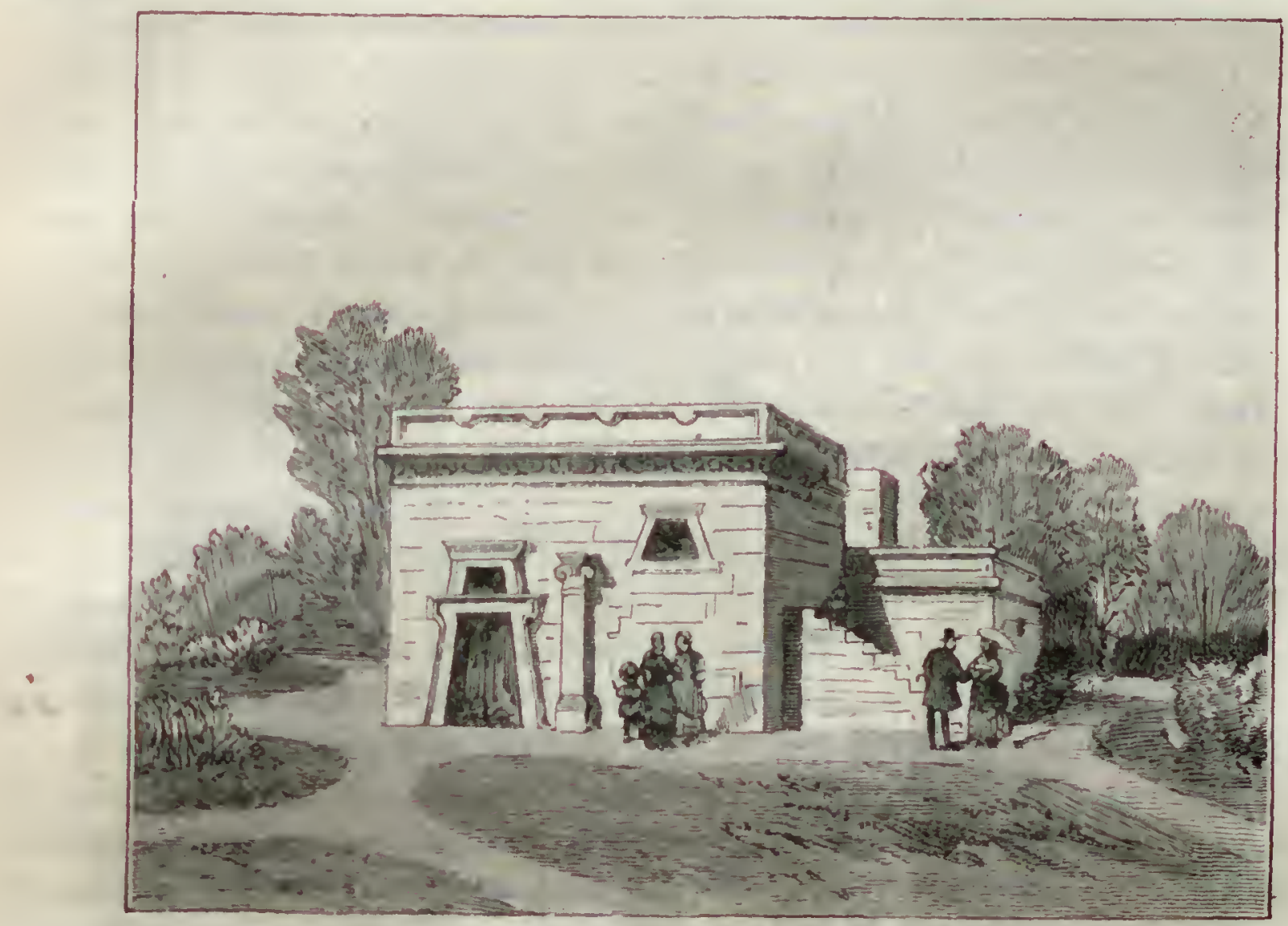

L'haвiтation hunatse. - Type hébreu.

de l'art. L'art ne peut se développer là où la guerre étend ses ravages, là où les hommes ne songent qu'à s'entretuer. En fait d'architecture, on trouve surtout chez les nations guerrières une architecture purement militaire : des fortifications, des remparts, des tourelles. Sur les monuments, des bas-reliefs se détachent, mais ils représentent surtout des scènes sunglantes, de longues trainées de captifs, des chars remplis d'archers et des malheureux écrasés sous les roues. Aucun symbole de paix, de travail, d'art, de jouissance intellectuelle, de civilisation dans le sens noble du mot.

La reconstitution de l'habitation assyrienne présentait de grandes difficultés. Tandis que le sol de l'Égypte est couvert de ruines imposantes, et qu'il suffit d'ouvrir les yeux pour connaltre l'architecture ancienne de la vallée du Nil, en Assyrie comme en Chaldée, il n'y a que des ruines informes, si l'on peut donner ce nom aux matériaux écroulés enfouis sur les bords du Tigre et de l'Euphrate. Cette différence entre les ruines des bords du Nil et ces dernières provient de la diversité des matériaux employés par les Égyptiens et les Chaldéo-Assyriens dans leurs édifices. La pierre se trouve abon- 
damment en Égypte, tandis qu'en Assyrie on dut employer à son défaut l'argile., que l'on fit cuire pour la rendre solide. Pour que ces briques pussent être convenablement cuites, il fallait qu'elles fussent de dimensions restreintes. Les constructions élevées avec de telles matières premières donnèrent, on le conçoil, plus de prises aux raváges des siècles, aux éboulements et aux crevasses. Du temps mème des Assyriens on devait souvent réparer les édifices endommagés. 11 existait deux sortes de briques, la brique crue et la brique cuite. La première était séchée au soleil sans être soumise a l'action du feu et n'offrait qu'une résistance médiocre; la seconde était mise dans des fours comme nos tuiles modernes et avait apres la cuisson une teinte rougedtre, tandis que la brique crue était blanchatre. Pour les préparer, on pétrissait l'argile avec de l'eau et de la menue paille, puis on mettait cette pate dans des moules en bois et on l'exposait pendant tout l'été au soleil brûlant, ou on la faisait cuire dans les fours. Plus grossière et moins couteuse que l'autre, la brique crue servait surtout d la construction des terrasses et des murs intérieurs et ne résistait pas a l'action des eaux. Les inscriptions de ces temps reculés mentionnent fréquemment des éboulements produits par la liquéfaction des briques des fondations. La brique cuite était plus en faveur à cause de sa plus grande solidité, et on émaillait parfois la face extéricure quand elle devait servir à la construction d'édifices de luxe. Les briques offraient en général l'aspect d'un cube rectangulaire d'un pied chaldéen de côté $\left(0^{\mathrm{m}}, 315\right)$ sur $0^{\mathrm{m}}, 10$ centimètres d'épaisseur. Pour les constructions particulières, telles qu'une voute ou un fut de colonne, elles présentaient la forme de nos voussoirs en pierre. Sur l'un des côtés on gravait, au moyen d'un timbre en métal que l'on appliquait sur la pâte avant la cuisson ou la disseccation, une formule en caractères cunéiformes en l'honncur du monarque qui faisait élever l'édifice. Souvent aussi elle était tracée à l'aide d'un stylet. Les ouvriers plaçaient toujours en dessous le côté qui portait l'inscription, et l'on avait soin de ne pas cacher le texte avec le mortier que l'on disposait tout autour de la formule.

- A Ninive et à Babylone, dit M. Lenormant, la pierre ne fut employéc qu'd l'état d'exception pour des travaux extraordinaires, des dallages, des soubassements et surtout pour les bas-reliefs. C'est ainsi qu'Hérodote et Diodore disent formellement que, tandis que les quais de l'Euphrate étaient enbriques, le grand pont qui seul faisait communiquer l'une avec l'autre les deux parties de la ville, fut bati en très grandes pierres, que reliaient des crampons de fer noyés dans du plomb. Ninive plus rapprochée des montagnes eût pu avoir de la pierre en quantité, et de fait on y rencontre des constructions en moellons appareillés, mais la capitale de l'Assyrie ne fit, au point de vue architectural, que copier Babylone. Elle n'eut point d'art original, et clle ne cessà de demander à la Chaldée des ouvriers et des artistes qui, habitués à batir avec la brique, ne changèrent pas souvent leurs habitudes. Il en est de mème pour le bois de charpente qui manque absolument a la Babylonie, mais qu'on eut pu se procurer à Ninive en exploitant les forêts du Masios ou du Kurdistan; on ne le fit que rarement, et ce ne fut que lorsque de grandes conquêtes lointaines eurent livré pieds et poings liés aux Ninivites des armées d'esclaves, qu'on se décida à leur faire transporter jusque sur les bords du Tigre les poutres de cèdre, de pin et de chene des montagnes de l'Amanus, voire mème du Liban. Souvent on employait comme inortier de l'argile grasse, ou un composé de cendres et de chaux; parfois aussi, comme duns les constructions de Birs-Nimroud et du Kasr de Babylone, c'est un mortier de chaux si solide qu'on ne peut détacher les briques les unes des autres sans les réduire en menus 
morceaux. Enfin, on a surtout eu recours au bitume. On s'en est servi dans la construction des temples d'Our dont le nom actuel Mugheir signifie encore a la bitumée . Il a été mis en usage pour les murs de Babylone, et outre les récits des voyageurs modernes, nous avons sur ce point le témoignage d'Hérodote. Dans le mur d'enceinte, on retrouve aujourd'hui les couches de briques noyées dans le bitume, et de distance en distance, des lits de ces roseaux gigantesques qui naissent en abondance dans les marécages de la Basse-Chaldée. "

Si, par la pensée, on dépouille les édifices chaldéo-assyriens de leurs ornements, et de tous leurs accessoires, ce qui constitue le corps mème du batiment, c'est le parallélipipède rectangle. En d'autres termes, la maison assyrienne a l'aspect d'un coffre gigantesque, dont toutes les faces sont horizontales ou verticales. Les Assyriens n'ont pas fait usage de la disposition en talus, car la brique étant la seule matière mise en auvre, les pentes auraient eu de nombreux inconvénients. L'eau descend moins vite sur un talus que sur un mur droit, et d'autre part les joints sont nombreux dans une muraille de briques. Le seul moyen d'éviter les effets des trombes et des tourmentes c'était l'emploi des murs verlicaux; et encore cela ne suffisait-il pas toujours contre les violents orages et lé déluge des pluies d'hiver. "Sans doute, dit M. Chipiez, les parois verticales élaient revétues de briques cuites au four et soigneusement jointes que recouvrait souvent encore un impénétrable émail; mais pour arriver au sommet de l'édifice, il avait fallu tout autour pratiquer des rampes en pente plus ou moins douce. Lorsque éclatait une tempète, ces rampes, que bordait sans doute un petit mur a hateur d'appui, se changeaient tout de suite en autant de lits de torrents; les eaux, glissant rapidement sur les dalles inclinées, venaient frapper avec violence les angles de la construction. Rejeter tonte cette eau au dehors, il n'y fallait pas songer; elle serait toujours tombée sur quelque face droite ou sur quel que terrasse qu'à la fongue elle aurait dégradée. Grossissant dans son cours, lavant à grands flots toutes les esplanades et tous les escaliers, laissant derrière lui des flaques plus ou moins profondes là où il y avait un creux produit par l'usure de la surface ou le fléchissement de l'appareil, le fleuve se précipitait sur la plate-forme inférieure; quelques précautions qu'on cút prises pour lui ménager une issue, il risquait toujours de produire des affouillements sur un point quelconque de la base. Pour lutter contre les dégâts causés par les eaux, il fallait un entretien continuel et de fréquentes réparations. Dès que la surveillance se relachait pour peu que quelques briques du parement extérieur se fussent détachées, la pluie pénétrait sans obstacle jusque dans le monceau d'arģile tendre qui formait le corps mème de l'édifice; elle dissolvait, elle entrainait la terre; elle avait bientot creusé quelque brèche béante qui s'élargissait d'année en année. Ainsi s'explique l'åspect que présentent aujourd'hui toutes ces ruines; comme l'attestent les voyageurs, elles ont l'aspect de tertres irréguliers que les eaux ont profondément ravinés. Ces sillons sont plus nombreux ct plus marqués sur ceux des côlés du monticule que viennent de préférence hattre les ouragans et les trombes qui dévastent souvent la Mésopotamie. Avec de pareils matériaux et un semblable système de constructions, on ne pouvait avoir qu'une architecture fermée, où les pleins l'emporteraient sur les vides. De plus, pour supporter les rigueurs du climat, on donnait aux murs une épaisseur considérable, à ce point que certains palais avaient des murs d'une épaisseur de huit mètres d travers lesquels les rayons solaires ne pouvaient se faire sentir. On ne songea point à per

es ouverture dans de pareilles masses, car on 
n'aurait obtenu que bien peu de jour. On prit le parti d'éclairer les édifices par le haut, par le plafond, et la fenètre fut presque inconnue en Assyrie, ì moins que l'on ne veuille donner ce nom aux espèces de meurtrières que l'on pergait au sommet de certains édifices.

Les Chaldéens ont beaucoup employé la voùte, dont la retombée était supportée par les épaisses murailles dont nous venons de parler. L'architecte ne s'en servit pas seulement dans les substructions, dans les égouts qui conduisaient au fleuve les eaux de pluie et les eaux-vannes, mais aussi sur les façades les plus grandioses. a Portes de ville, portes de palais ou de temples, la plupart des entrées monumentales sont surmontées d'un arc dont la courbe est dessinée et comme soulignée par une archivolte souvent émaillée de vives couleurs. Ces voùtes en bercean se continuent d'un bout à

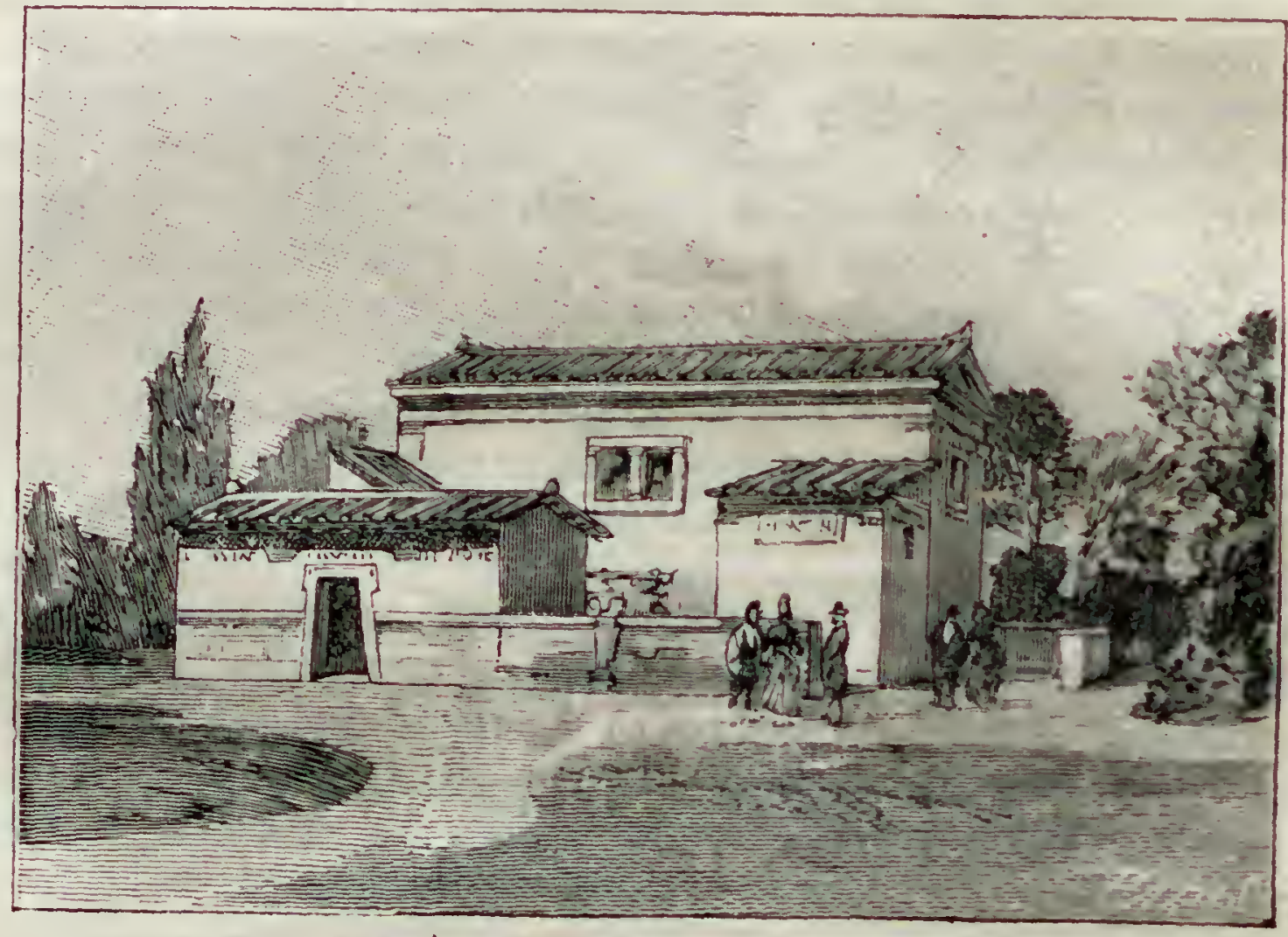

L'habitation himaing. - Type örec.

l'autre du passage parfois très long qui conduit dans l'intérieur; là, selon toute apparence, on les retrouverait, si tout le haut du batiment n'était pas détruit, au-dessus de beaucoup de ces salles étroites qui sont si nombreuses dans les palais assyriens, On a cru même pouvoir affirmer que des chambres de ces palais étaient couvertes de voûtes en berceau. . Par quel procédé les Assyriens établissaient-ils ces voútes en brique crus? Il nous est difficile de le dire, mais l'argile étant presque la scule matière dont disposat l'architecte assyrien, il avait appris, par une longue habitude, à en tirer un parti que l'on n’aurait pas mème soupçonné avant l'exhumation des édifices ninivites. Grâce à ses qualités naturelles et à une préparation savante, l'argile prenait entre ses mains une vertu plastique et une ténacité que les explorateurs ont constatés non sans surprise en plus d'une occasion. Les excavations souterraines en forme de voate ou d'ogive, pratiquées aux cours des fouilles, étaient parfois hautes et larges de plusieurs mètres et n'auraient pu dans toute autre especce de terre se soutenir sans ctre fortement étançonnécs. ' 
Si la Chaldée n'a pas employé la pierre, comme l'Assyrie, c'est elle qui a précédé Ninive dans l'art des constructions légères, dont le bois et le métal fournissent les éléments.

L'habitation phéNiciense. - Les temples et les diverses constructions phéniciennes ont presque totalement disparu, mais les écrivains et les médailles du temps nous en ont transmis la reproduction, ainsi que la description détaillée. Les villes de la Phénicie étaient entourées de fortes murailles destinées à les protéger contre les surprises de l'ennemi; l'enceinte de Tyr est particulièrement célèbre dans les textes anciens, mais il n'en est resté aucun vestige. Pour trouver un rempart de ville phénicienne qui n'ait subi aucune transformation postérieure, il faut aller jusqu'aux environs de Banias, vers l'extrémité nord du pays qui dépendait jadis d'Arad. M. Camille Faure

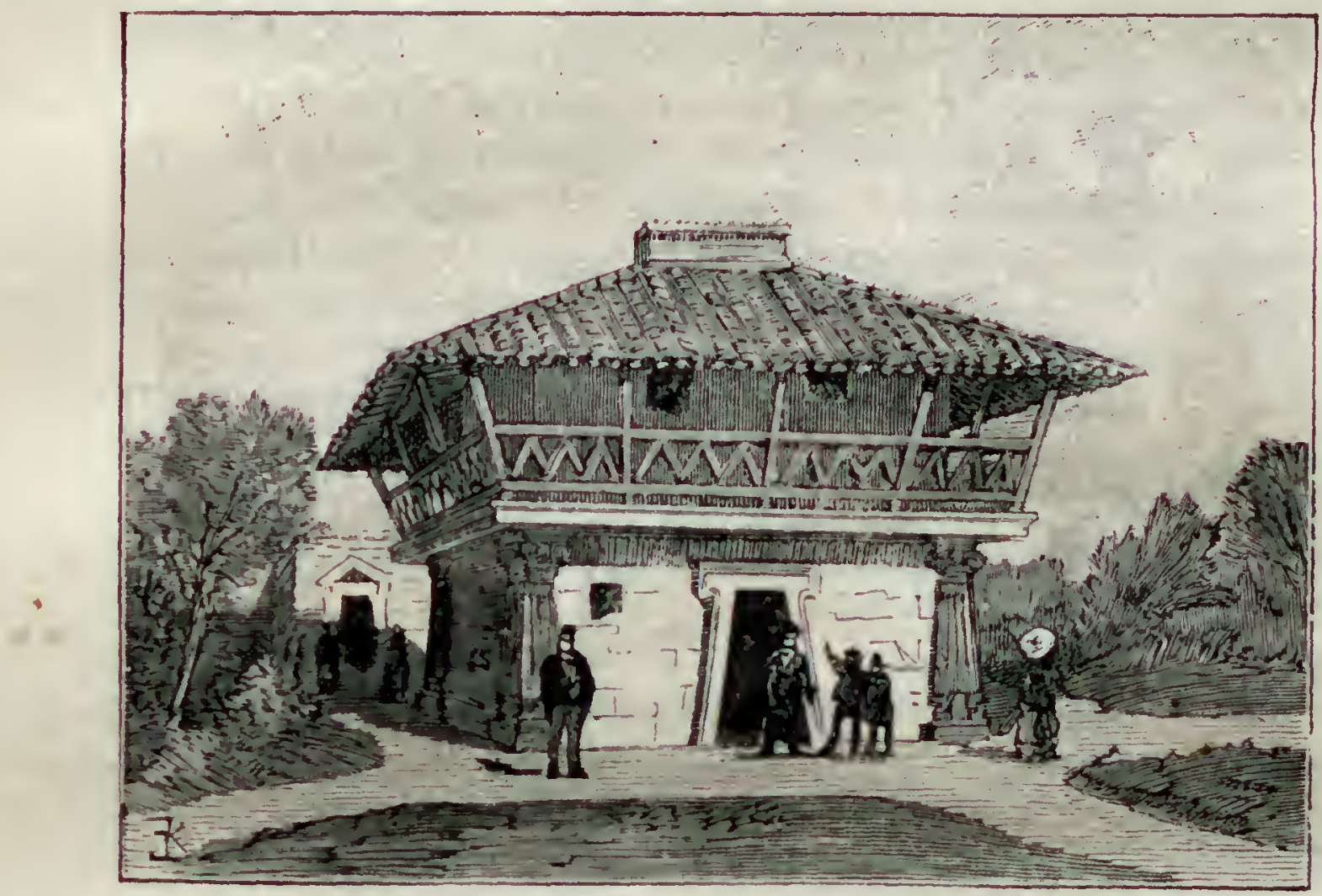

L'Habitation humaise. - Type iltusque.

sn a récemment décrit les ruines et c'esi a lui que nous en demanderons la description. La muraille a, non compris les saillants, à peu près 600 mètres d'étendue. A ses deux extrémités, elle prend pied sur un précipice par une sorte de urochet en retour. La lortification est coupée en trois endroits par des baies larges de 8 a 10 mètres qui devaient être closes par des barridres en bois, où étaient insércés des portes de chène ou de cedre garnies de ferrures. Ce mur, dont la hauteur actuelle varie entre 5 et 10 mètres, est composé de blocs de calcaire gris, très sommairemeni épannelés. Les plus considérables nont guère plus de 1 mètre de long sur $0^{\text {w }}$, SO de liaut. Ils sunt appareillés sans ciment, et les intervalles sont remplis par des pierres plus petites; le mur a une épaisseur variant entre 5 et 8 mètres. Ne nombreux écrils nous ont transmis la description des fortifications de Carthage, mais on n'a pas encore assez de documents archéologiques pour en reconstituer exactement les remparts.

11 ne reste pas non plus grand'chose des villes phéniciennes. Dans certains centres, le rocher garde encore l'empreinte des maisons qui y étaient adossées, et dont quelques 
pièces étaient parfois creusées dans le roc même. Cette disposition n'existait que dans les faubourgs où le sol n'avait pas été nivelé. Bans l'intérieur de la ville, pressću entre des remparts, on avait donné aux maisons une grande hauteur, afin de pouvoir loger toute la population, et les rues étaient très étroites afin de ménager un espace très restreint. Les riches négociants avaient hol's des murs des maisons de ca npigne, où, le terrain ne leur manquant pas, ils pouvaient prendre leurs aises

Toutes les villes phéniciennes, privées d'eau courante, avaient construit des citernes destinées à recueillir l'eau de pluie. Les maisons élaient pourvues de terrasses bétonnées, d'où l'eau descendait dans les citernes particulières. La ville avait les citernes publiques, et, pour recueillir l'eau du ciel, les rues étaient dallées en large.s plaques de calcaire, et des conduits menaient l'eau aux réservoirs situés dans la basse ville. "Les citernes de Carthage, dit M. Daux, avaient une disposition particulière: aux quatre angles du vaste parallélogramme qu'elles formaicnt, ainsi qu'au milieu étaient six filtres circulaires recouverts par six dùmes ou coupoles, dont l'effet gracieux rompait à l'ail la monotone uniformité des extrados des voûtes en berceau, voutes qui s'arrondissaient au-dessus de deux rangs de longs bassins paralleles. "Certains archéologues ont refusé à ces citernes l'origine carthaginoise, en se detrandant si lit vo:ite avait été usitée en Afrique avant la conquête des Romains. D'auties affirment que les Carthaginois n'ont guère employé la voute appareillée, mais qu'ils y ont sulystitué des voutes faites d'une sorte de béton a de pelites pierres noyées et tassées dans un bain de mortier à sable tamisé si fin, que l'on en voit à peine le đrain •, mortier dont la chaux a été produite avec la mème pierre, et auquel l'action des siècles a jonné une consistance et une homogénéité égale, voire souvent même supérieure à celle de la pierre employée.

En 1883, des ouvriers travaillant à une tranchée pour l'écoulement des eaux découvrirent près de la ville de Béja un caveau vouté qui contenait des ossements humains, une lampe et une urne funéraire. Des fouilles furent alors organisées et amenèrent la découverte de cent vingt tombeaux, ayant approximativement la forme d'une botte. On arrive dans la chambre au moyen d'un puits rectangulaire, dont les parois sont maçonnées en forts moellons. Les orifices des puits ont une largeur de io à 750 centimètres; la profondeur varie entre $1^{\text {m }}, 0$ o 0 et 3 mètres. Dans leur partie inférieure, ces puits se confondent avec la chambre à larjuelle ils conduisent. Ces caveaux, taillés dans la maçonnerie en béton sont grossiers et fort irréguliers. Ils renferment des poteries communes et un certain nombre de pièces de monnaie carthaginoise, en bronze, aux types du cheval et du palmier. W'après toutes ces indications, il est j!!ns que probable que cette nécropole remonte à la période de l'indépendance et de la domination carthaginoise. On suppose, d'apres les renseignements fournis par cetle nécropole, que, avant l'invasion romaine, les Phéniciens d'Afrique employaient le béton par grandes masses, et l'on peut en conclure qu'ils aient construit survant le même mode des coupoles pour couvrir les citernes, ou les diverses pièces de leurs édifices.

Les données manquent pour reconstituer exactement l'intérieur des maisons où les riches Phéniciens avaient réuni, soit en Orient ou en Occident, les objets destinés a leur procurer une vie matérielle agréable. Autant qu'on peut le conjecturer, les, haules maisons des villes phéniciennes et carthaginoises avaient des cours intéricures entourées de portiques et, aux étages supérieurs, des galeries en bois convri : 
forme de loggia. Le type représenté par M. Garnier pour l'Exposition se distingue particulièrement par le role important attribué au bois dans la construction et l'ornementatiör. La décoration ne manque ni d’élégance ni de légèreté. Une tour carrée forme l'angle gauche de l'édifice avec une terrasse supéricure à toiture supportée par de petites colonetles à section carrée. La façade du corps de batiment reproduit l'ornemientation de celle de la Tour, et ses pilastres à chapiteaux ornementés soutiennent li balustrade d'une sorle de loggia sur laquelle s'ouvrent les appartements de l'étage supéricur.

L'inabitation nébraïque. - La maison des Israélites était faite de briques crues et d'un plafond en poutres de palmicr ou de sycomore que recouvrait une couche de terre ballue. Murs el toits, dit M. Perrot, devaient être épais, pour que la température de l'intérieur se ressentît moins des variations du dehors. Ce n'est pas tout à fait la maison du fellah syrien d'aujourd'hui; la demeure de celui-ci est souvent surmontée d'une coupole qui lui donne plus de hauteur et de solidité. Chez les Hébreux, toutes les habitations, comme beaucoup encore de celles qu'on rencontre dans les villages syriens, se terminaient par une terrasse sur laquelle on passait la nuit dans certaines maisons; aussi, ces lois religieuses qui prennent souvent le caractère de ce que nous appelons des règlements de police, avaient-elles recommandé d'entourer cette terrasse d'un parapet, pour que les dormeurs et les enfants ne risquassent pas de rnuier à terre. La plupart des maisons n'avaient qu'un rez-de-chaussée; pourtə?t certaines demeures, celles des riches, étaient pourvues d'un étage supérieur. Dans ces mêmes maisons, certaines fenètres, sans doute surtout celles de l'appartement des femmes, étaient munies de treillis analoğues à ceux des moucharabiehs de la maison arabe contempoinine. Le type hébreu n'ofre pas un caractère architectonique bien tranché. La construction emprunte au type égyptien sa forme générale, massive et carrée, mais sans faire usage des colonnes qui, dans les monuments anciens de l'Égypte, jouent un sı grand rôle, et qu'on retrouve également dans ceux de la Phénicie.

L'habitation grecque. - Elle se distingue par l'élégance et la sobriété des lignes et de la décoration. Dans le modèle de M. Garnier, une sorte de vestibule rectangulaire à rez-de-chaussée avec un soubassement en pierre de taille et une porte encadrée par une moulure continue précède la cour intérieure sur laquelle il s'éclaire ainsi que le reste du batiment. Les baies de ce dernier sont géminées. La colonnette intermédiaire qui porte le linteau a reçu la même ornementation que les jambages. Les bardeaux des deux édifices sont supportés soit en leur milieu, pour le premier, soit à leurs angles pour le second, par de légers encorbellements qui accusent le mode de construction et lui empruntent un motif de décoration suivant les principes bien connus de l'art grec.

Cet art comprit daus son essor et dans ses développements le luxe et les dispositions des habitations privées. A Après les premières maisons remontant à environ deux mille ans avant notre ère et découvertes par M. Fouqué sous les cendres volcaniques dans l'lle de Thérasia, après le palais d'Ulysse à Ithaque, palais que décrit l'Odyssée et au sujet duquel les trouvailles faites par M. Schliemann à Tirynthe et à Mycènes confirment l'exactitude des assertions du poète; après ces petites maisons antiques, dont le plan a été relevé par M. Lug. Burnouf, sur le versant oriental de l'acropole 
d'Athènes, maisons qui montrent bien comme à certaines époques tout le luxe de la cité se portait sur les temples et les autres édifices publics, on peut constater par les ruines du palais macédonien ou Prytanée royal de Palatiza, édifice attribué aux rois macédoniens prédécesseurs de Philippe et d'Alexandre le Grand, tout le luxe d'un palais grec au vo siècle avant notre ère, coinme on peut, après les relevés d'une des rares maisons anciennes de Délos, relire Vitruve et y chercher avec confance la description d'une riche habitation grecque de la période alexandrine. Mais ce n'est pas en Grdce mème ni sur les còtes de l'Asie Mineure ou dans une fle de l'Archipel, c'est sur la cote occidentale de l'Italie, c'est à Pompéi, ceth ville plus grecque que romaine de la Campanie, et dont l'éruption du Vésuve de l'an iú nous a si admirablement conservé sous

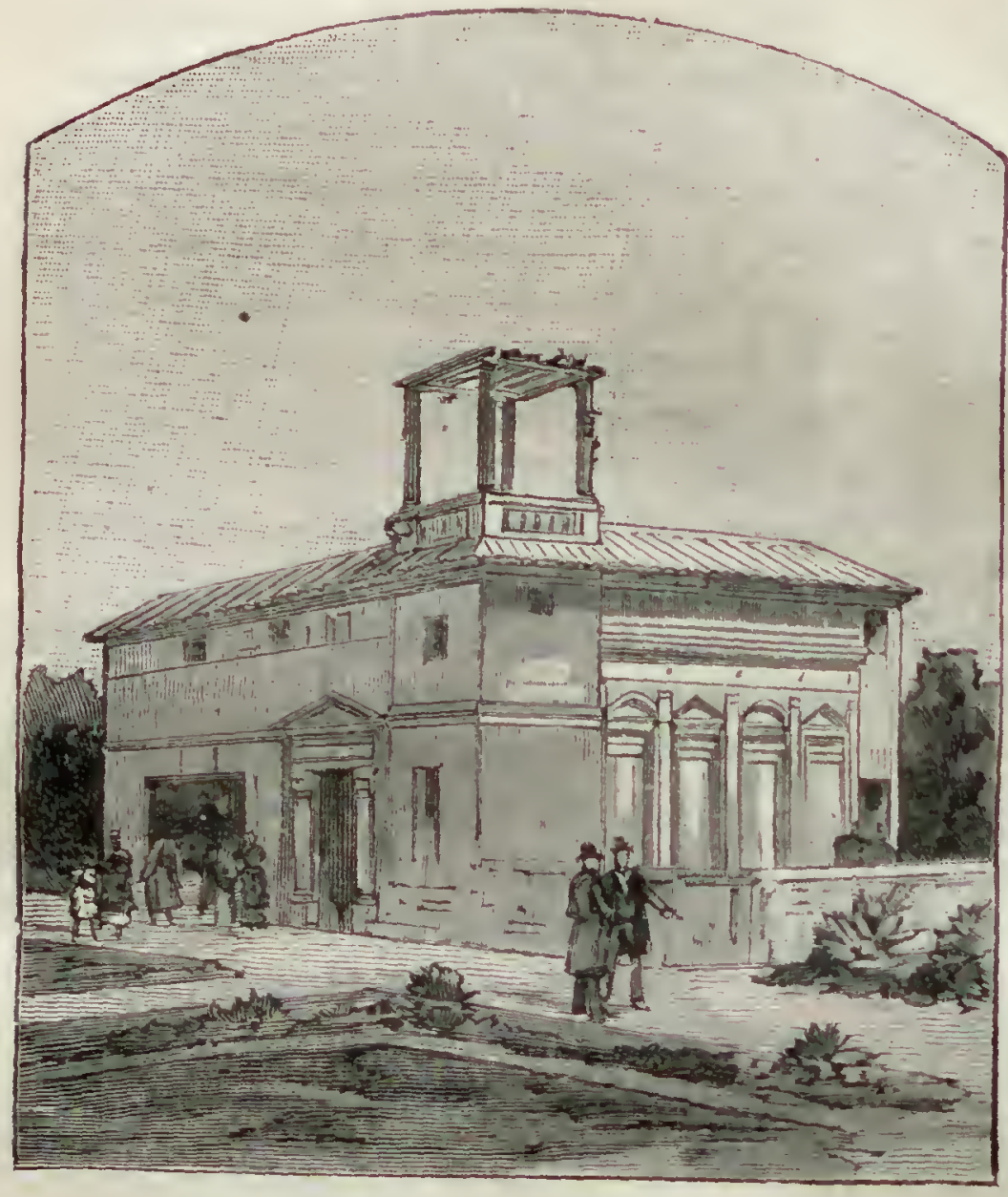

L'habitation humaine. - Type romain. une pluie de cendres la civilisation gréco-romaine, c'est à Pompéi qu'il faut chercher le dernier mot de l'habitation grecque, non tant peut-etre pour la disposition du plan que pour les gracieux détails d'ornementation; c'est à Pompéi que, à côté de la colonne doriquue atteignanl une rare élégance et se pliant aux exigences de l'habitation privée, il fnut chercher ces gracieuses fresques et ces cxquises figurines toules empreintes d'une saveur hellénique et rappelant bien plus la mollesse efféminće de Corinthe que la rudesse de Rome ou le décoruin de l'Étrurie. ' Chanles Lucas.' Sans remonter aux ages hérol. ques de la frèce, nous rappellerons simplement que l'architec. ture dorique et celle des Ioniens d'Asie se développerent parallilement, n'offrant de différence que dans les proportions ct la décoration des parlies constitutives de l'édifice. La première fut sévère et sobrement ornée, la seconde élégante et gracieuse. Le progrès se fit rapidement sentir à partir de la première Olym. piade, dans la Grèce continentale, mais aussi sur la côte d'Asie el dans la Grande Grèce. Les monuments de ce temps étaient en bois et en pierre. Ils étaient ornés de péristyles en marbre et de sculptures.

Après la défaite définitive des Perses, une phase nouvelle se produisit pour l'art grec, et l'on vit se produire le plus beau mouvement intellectuel et artistique auquel l'humanité ait jamais assisté. C'est le moment où Callicrate, Iktinos, Mnésiclès, Corœbus, Eupolème, Métagène, Polyclète et Xénoclès élevaient ces monuments superbes, dont le Parthénon d'Athènes est le plus sublime spécimen. "Toutes les parlies de l'art de batir élaient en progrès et alleignaient à lcur plus haut point de perfection. On 
n’employait que des matériaux de choix, dit $\mathbf{M}$. Batissier, qui étaient travaillés avec le plus grand soin et ajustés avec une rare précision. L'ordre dorique et l'ordre ionique recevaient l'un et l'autre les plus belles proportions qu'ils avaient jamais eues. Les moulures étaient profilées avec hardiesse, et les différents membres d'architecture disposés avec une symétrie réglée par le goût le plus irréprochable. Les ornements appliquẻs aux édifices étaient toujours bien motivés et ne leur enlevaient rien de leur aspect male et sévère, de leur caractère de force et de solidité. Nous voyons pendant celle période prendre naissance plusieurs ordres dont les Grecs empruntèrent peut-être l'idée première aux monuments égyptiens, bien que Vitruve leur ait assigné une origine différente: nous voulons parler de l'ordre persique et cariatidique, où les colonnes sont remplacées par des statues de barbares ou

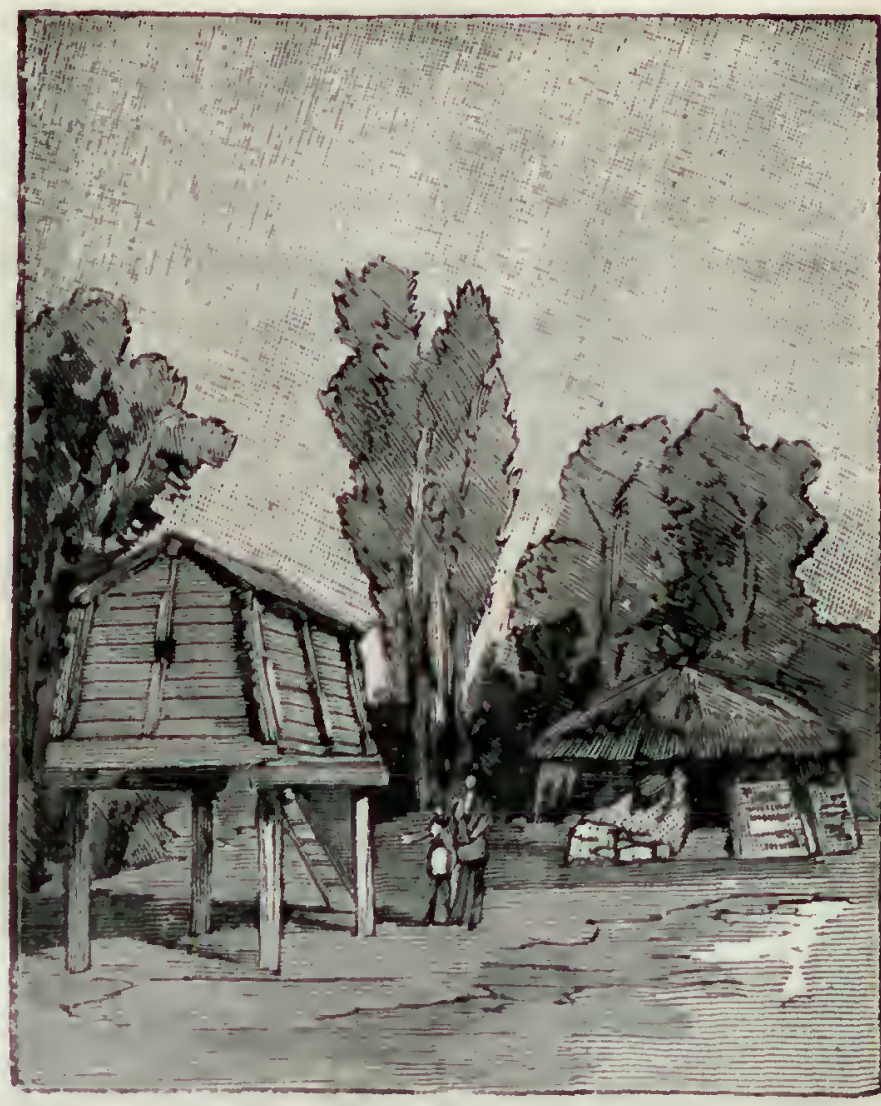

L'nabitation huzaise. - Types germain et gaulois. de femmes. L'ordre corinthien dont on a attribué l'invention à Callimaque commence aussi à être en honneur. , La décadence de l'art grec commença avec la domination

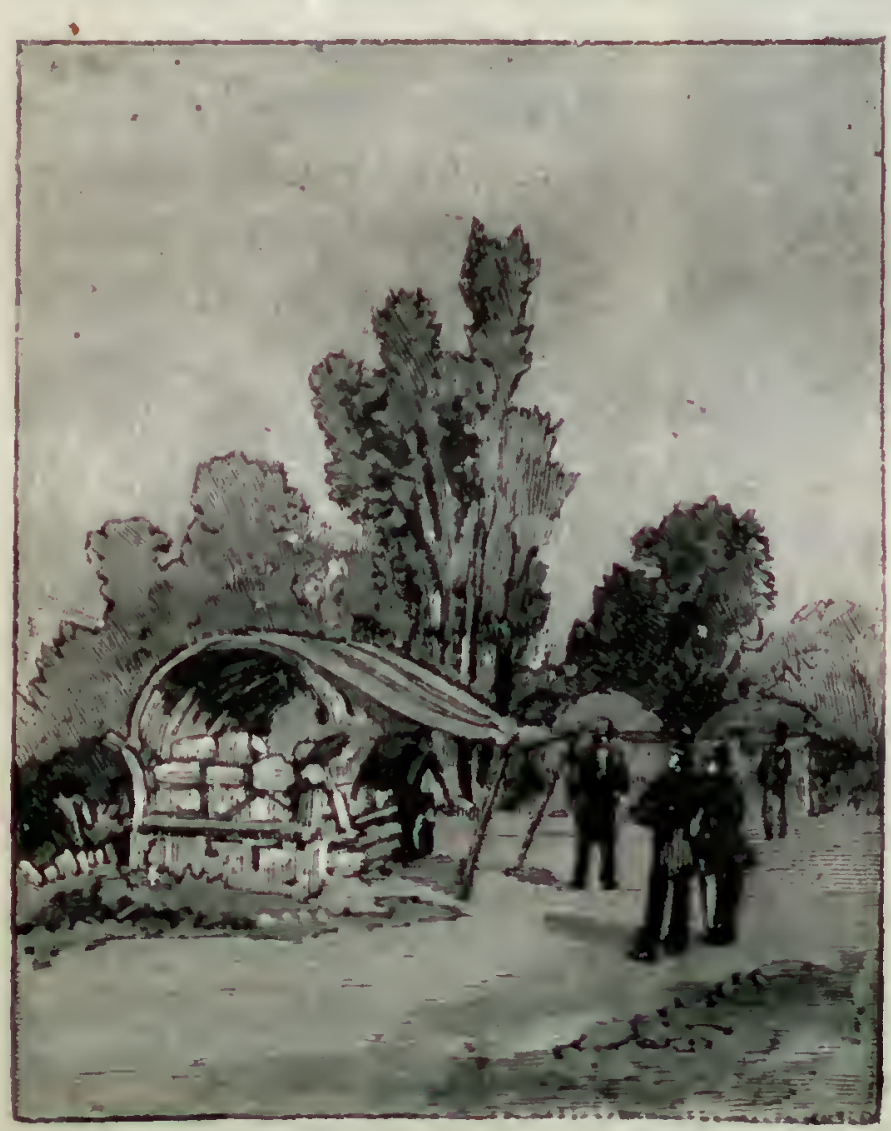

L'babitation humaing. - Type hunique. macédonienne. Si les ordres ne s'altèrent pas immédiatement, on sent que le goût devient moins pur. Bientôt, la Grèce fut abandonnée de ses meilleurs artistes qui allèrent rejoindre en Égypte et en Asie les successeurs d'Alexandre. Là, ils perdirent la sévérité, la simplicité ct la noblesse des anciens temps.

L'Habitation étrusque et l'habitation nomane. - Les plus antiques con. structions que l'on rencontre en Étrurio sont des fortifications qui, par leur puissance, rappellent les murailles pélasgiques de la Grèce, et des travaux d'art rendus nécessaires par le climat malsain de leur pays et le besoin d'écouler les eaux stagnantes. Mais ce que l'on connait le mieux de l'architecture étrusque, c'est l'architecture funéraire. Les tombeaux étaient généralernent élevés sur des monticules ou creusés dans le roc et maçonnés. C'est avec les renseigne- 
ments fournis par l'architecture funéraire et par les œuvres de Vitruve que l'on a pu reconstituer l'habitation étrusque. Cette maison n'a aucune ressemblance avec la cabane ronde et couverte de chaume des populations de l'Italie primitive, elle est rectangulaire. Le toit est en bois et se compose de quatre auvents inclinés vers l'extérieur et laissant entre eux, au sommet, une ouverture carrée, faite pour laisser passer la fumée. Dans les maisons des riches, il y avait deux ou plusieurs chambres, avec une petite cour (atrium) au centre. L'atrium n'était jamais couvert, et les eaux pluviales tombaient dans un bassin par l'intermédiaire d'auvents inclinés vers l'intérieur, et qui protégeaient les chambres contre le grand jour et contre la chaleur. Les chevrons qui supportaient ces auvents étaient supportés par deux poutres parallèles allant d'un mur à l'autre. Il y avait peu d'ouvertures sur le dehors, et sous le toit

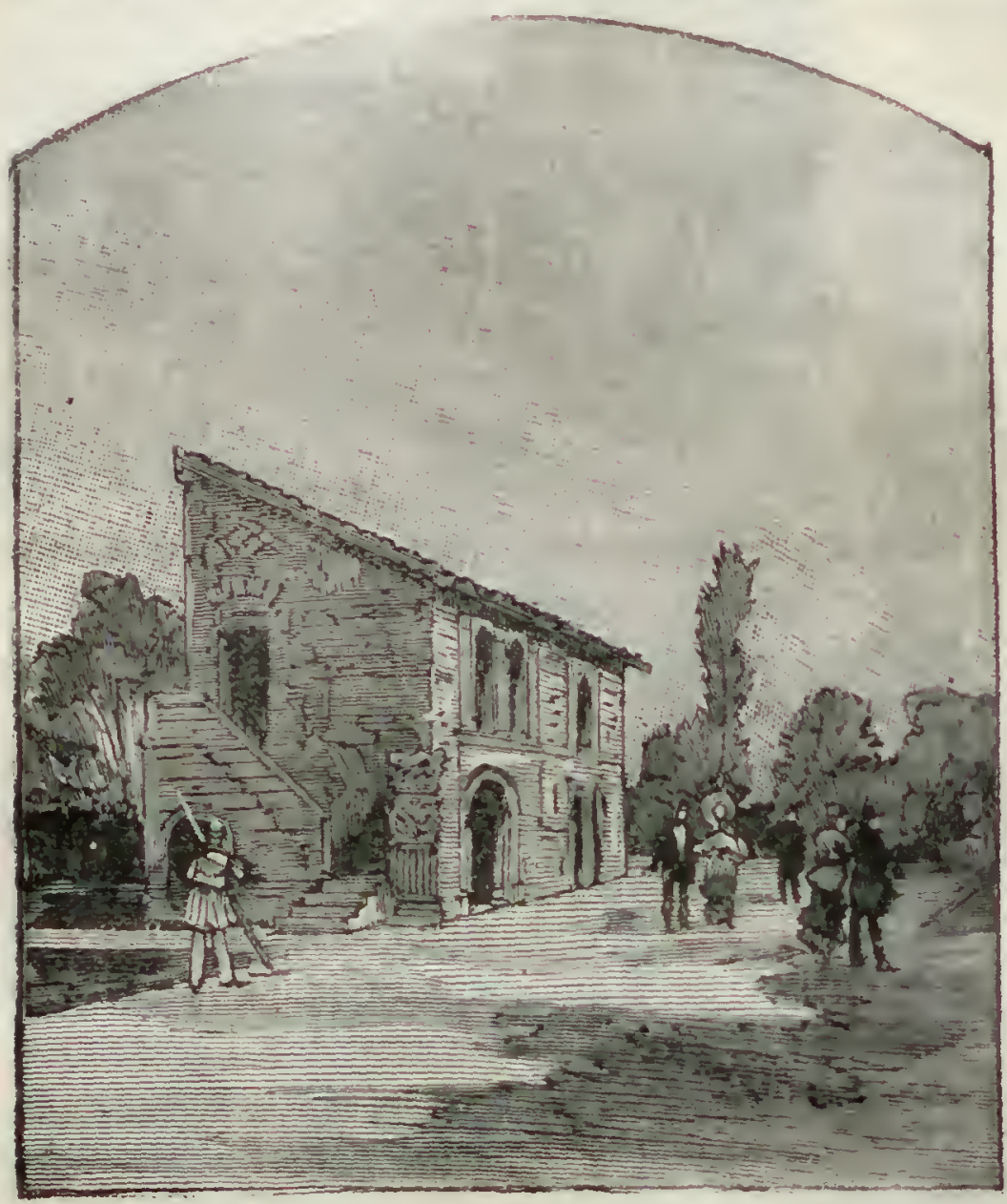

L'HAUITATION HUMAINE. - T'ype gallo-romain. régnait une sorte de loggia, ou, si l'on veut, un balcon couvert. Nous n'avons pas besoin de rappeler que les titrusques ont exercé sur le développement primitif de liome une influence considérable et qu'ils ont implanté dans la Ville Éternelle le goct du luxe et le bon goût.

Au début, Rome n'a connu d'autre architeclure que celle de ses voisins, mais cette architecture se modifie peu à peu a travers les siècles, car si le géule du peuple romain n'était pas essentiellement artistique, il n'etait pas non plus assez incapable de sentiment artistique pour se borner à copier servilement.

Les Étrusques n'araient employé la voate que dans leurs travaux de voirie. Les Romains eurent le mérite de comprendre qu'on pouvait tirer un grand parti de ce mode de construction, et ils lui flrent jouer un rỏle principal, qui eut pour conséquence nécessaire le renforcement des supports verticaux. Ils employèrent avec prédilection la forme ronde, et aucun peuple n'a laissé plus de monuments sur plan circulaire ou demi-circulaire. Mais nous ne saurions nous occuper ici de tous les monuments de l'architecture romaine : temples, théâtres, aqueducs, thermes, basiliques, cirques, amphithéatres, arcs de triomphes, colonnes commémoratives. Les principaux types de chacun de ces genres sont présents à toutes les mémoires. C'est de l'habitation privée que nous nous occuperons, et c'est à M. Martha que nous demanderons nos renseignements. "Pendant plusieurs siècles, jusque vers la fin de la république, la inaison romaine ne fut qu'une reproduction de la maison étrusque. Le centre en élait l'atrium comme en Étrurie. Le type de cet atrium variait peu. Parfois il étaił entière- 
ment couvert (testudinatum), mais le plus souvent il était éclairé par une ouverture carrée que laissaient entre eux les quatre auvents da toit inclinés vers l'intérieur (compluvium); au-dessus de cette ouverture, un petit bassin peu profond recueillait les eaux de pluies et les déversait au dehors par une rigole. Suivant. que les auvents reposaient sur deux traverses horizontales ou sur quatre supports verticaux, l'atrium était dit tuscanicum ou tetrastylum. Tout alentour de cette petite cour à demi couverte se groupaient quelques chambres plus ou moins nombreuses, plus ou moins grandes selon la condition des habitants. Dans toutes les maisons de quelque importance, on était sûr de rencontrer, en d'autres annexes, deux ailes latérales, sortes d'alcôves ouvertes, situées vers le fond de l'atrium à droite et à gauche, et entre ces deux enfoncements, un troisième, le tablinum, le tout disposé comme les trois branches supérieures d'une croix.

Les alce servaient à garder, rangés sur des rayons, des portraits des anccilres et ces masques de cire moulés sur la figure du mort qui, portés par des acteurs, représentaient les aỉeux aux funérailles de leurs descendants. Le tablinum complétait ce musée héréditaire en conservant tous les écrits et lous les documents qui pouraient intéresser l'histoire de la famille, les comptes, les tessères d'hospitalité, les extraits d'annales, les éloges func̀bres, des copies des décrets honorifiques, en un mot les archives domestiques. Au début de la période impériale, le goât du bien-être et du confortable, joint au désir de jouir des raffinements de l'art grec, vont modifier considérablement l'habitation romaine. Le Romain a ne délaisse pas l'antique maison, car il est, de sa nature, fidèle au passé, mais il ajoute à cette vieille demeure, faite pour un autre temps et d'autres mœurs, les aises, les agréments, les élégances plus modernes de la maison grecque,.

La maison romaine était peu ouverte sur l'extérieur et une enceinte presque continue de boutiques l'entourait. . Sur le péristyle s'ouvraient les fenêtres des chambres ou plutot les portes, car les portes étaient souvent les seules ouvertures. Aussi quelles attenitions pour faire de ce péristyle un gentil cloitre! Il faut avoir vu de près ce qui reste encore de toutes ces colonnades garnies de stucs et peintes, de ces petites groltes en rocaille, de ces fontaines en coquillages ou en mosaïque, de ces pavements multicolores, de ces statuettes en marbre, en bronze ou en terre cuite, enfin de ces mille riens indescriptibles et charmants qui décoraient les péristyles pompéiens, pour se figurer la coquetlerie du bourgeois romain amoureux de sa maison et naĩvement ingénieux à l'embellir. Dans cette jolie cour intérieure si fraîche, si parée, impénétrable aux indiscrétions ou aux importunilés, il se sentait bien chez lui. Lor'squ'à l'heure de midi, suivant un usage qui dure encore et que le climat commande, il se reposait étendu sous les auvents de son péristyle et s'abandonnait à une douce somnolence, aucun bruit ficheux ne troublait la paix de la sieste. De larges stores tendus, analogues à ceux qu'on peut voir dans mainte ville italienne, tamisaient la lumière trop vive et se balanfaient au moindre souffle, entrelenant comme une brise autour de lui, tandis que le jet d'eau de son bassin le bergait de son murmure. Naturellement la maison de campagne differait de la maison de la ville et le luxe de la demeure variait avec la fortune de l'habitant. C'est au marbre, au marbre multicolore, que les riches empruntaient les éléments principaux du décor. " Les plus modestes chambres n'avaient que des peintures a fresque, comme à Poınpéi. Ici, les pavements étaient en simples briques ou en carreaus; là c'étaient des mosaïques. S'il faut en croire les anciens, il y avait de 
ces habitations dont le luxe raffiné avait quelque chose d'oriental et qui étaient comme des demeures enchantées. "

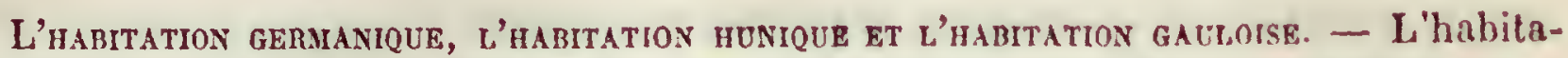
tion des races germaniques, telles que nous la verrons restituée, comporte deux types se rattachant l'un à la cabane, l'autre à la hutte. La cabane est constituée par une grossière charpente en bois de grume horizontalement superposée. Cette disposition était générale chez tous les peuples barbares du nord et de la vallée du Danube. Elle s'est, du reste, conservée jusqu'à ce jour chez certaines peuplades asiatiques. L'en-

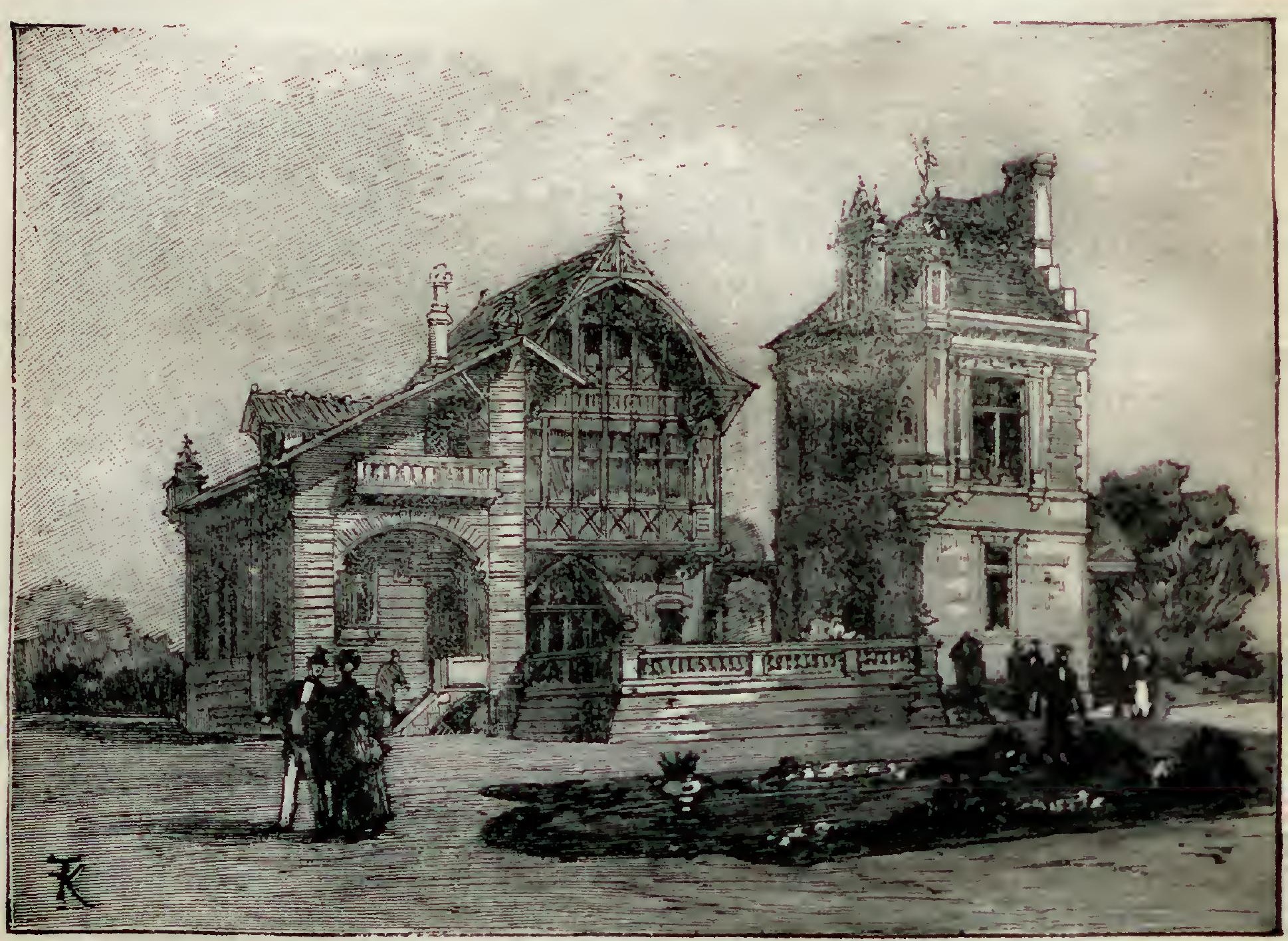

L'habttation humalne. - Types roman, moyen age, renaissance.

semble repose sur des poteaux fichés dans le sol, sans doute pour élever le plancher au-dessus des marécages qui, concurremment avec des forets, formaient alors la plus grande partie de l'Allemagne actuelle, ou pour se protéger plus aisément contre les attaques des bêtes féroces qui hantaient ces immenses espaces boisés. A côté de la cabane, figurent plusieurs huttes, toutes de forme arrondie et à enveloppe extérieure de roseaux. Cette enveloppese pose sur une légère ossalure constituée par des perches de bois non équarries, relićes entre elles par de légers clayonnages. Ces huttes ne difréraient que par la couverture, pyramidale pour l'une, sphérique pour l'autre.

L'habitation de ces autrés Barbares, qui donnèrent le signal des invasions en se ruant sur l'empire romain d'Orient, nous voulons parler des Iluns, a un aspect tout particulier : on dirait un chariot privé de ses roues et recouvert d'un léger batis en 
berceau qui s'appuie sur des montants obliques. C'est bien là la demeure qui convient à ces farouches nomades, ne vivant que de rapines et de déprédations. Il n'y a qu'à remettre des roues sous cette construction rudimentaire pour qu'elle soit prête à porter au loin le a fléau de Dieu , et ses hideux sectaires.

Voici un peuple qui nous intéressera davantage et dont nous nous occuperons plus longuement. Nous nous rappelons tous avoir lu sur les bancs de l'école des descriptions plus ou moins étendues du pays gaulois. Ce pays était couvert de forêts et de paturages, et sur les plateaux, dans les clairières, au bord des eaux, s'élevaient une multitude de grandes bourgades. Dès les temps les plus reculés, des Gaulois se sont

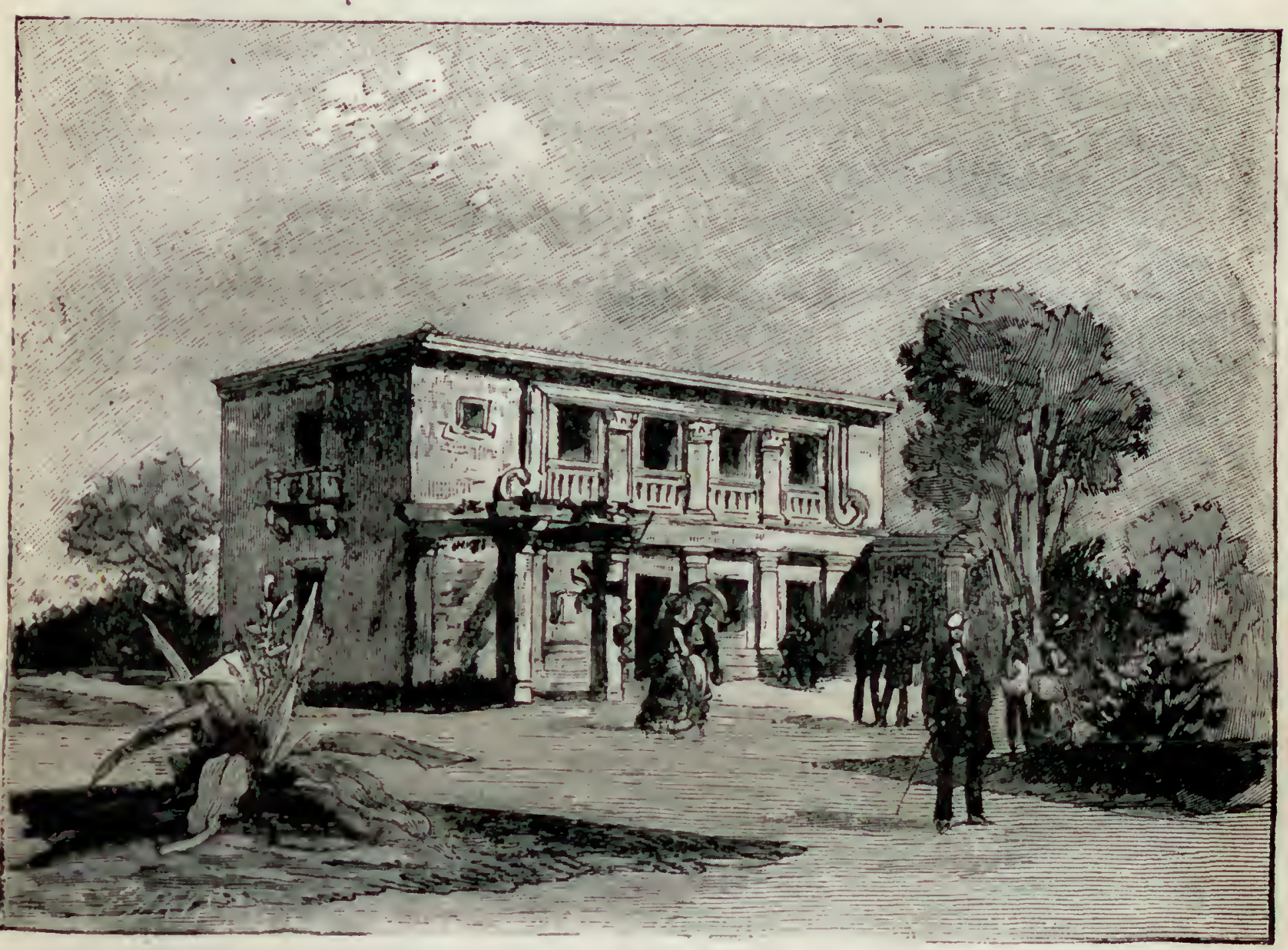

L'habitation humaine. - Type byzantin.

groupés partout où l'a permis la nature des lieux. \& Les maisons, spacieuses et rondes, sont, dit Henri Martin, construites avec des poteaux et des claies revêtues en dedans et en dehurs de terre battue : leurs toits élevés sont formés de bardeaux de chène et couverts de chaume où de paille hachée et pétrie dans l'argile. Des tables en bois, des peaux de luetes servant de lits, de sièges el de tapis, sont à peu près tous les meubles de ces demeures vastes et nues. Parfois, des vases d'argent, contrastant avec cette simplicité, révèlent la richesse minérale du pays. Cette richesse apparait bien mieux encore au cou, aux bras et aux doigts des hommes et des femmes. Les colliers, les bracelets, les anneaux d'or étincellent de toutes parts chez les guerriers de renom : l'or, l'argent et le corail ornent leurs sabres et leurs boucliers; leurs saies, de laine épaisse ou légère suivant la saison, sont bariolées de carreaux aux vives couleurs ou semées 
de paillettes ou de fleurons éclatants. Les Gaulois aiment tout ce qui est vif et brillant, tout ce qui réjouit l'œil et l'imagination "

Le voyageur qui, sortant des brillantes cités de la Grèce ou de la basse Italie, arrivait en Gaule, étaít frappé de l'aspect sauvage et dur de la ville ou du village gaulo is. Il apercevait des têtes d'hommes clouées aux portes de la ville et àcelles des maisons, à côté des hures et des mufles d'animaux sauvages, trophées de la guerre rapportés au cou des chevaux et mèlés aux trophées de la chasse. Mais les manières franches et ouvertes de ses hôtes, leur cordiale simplicité, la propreté, l'espèce d'élégance rustique des habitations et des vêtements remettent le cœur de l'étranger, et il linit par s'habituer à regarder sans trop de répugnance au fond d'un'grand coffre ouvert solennellement par le chef gaulois, d'autres tètes embaumées, qui sont comme les archives de la famille, dépouilles choisies des chefs, des héros ennemis tombés sous les coups du guerrier ou de ses ancètres. Ces titres de noblesse, le guerrier qui les céderait pour leur pesant d'or serait déshonoré dans toute sa nation.

La maison gauloise participe à la fois de la hulte et de la cabane. Mais au lieu d'ètre établie directement sur le sol naturel, comme les huttes germaines, elle présente une excavation circulaire : quatre énormes pierres, placées debout au sommet d'un carré, forment les colonnes sur lesquelles s'appuyaient deux poutrelles non équarries se superposant à angle droit vers le centre de la hutte. En ce point, elles soutiennent une sorte de poinçon auquel viennent aboutir des chevrons rudimentaires. Ceux-ci reçoivent une couverture en chaume de forme conique; l'intervalle entre les colonnes est comblé par des murs en pierres sèches. L'usage de la pierre et l'emploi d'une charpente à peu près rationnelle constitue un sérieux progrès sur les constructions informes des Germains et des IIuns.

L'Habitation galdo-romaine. - Nous abordons maintenant les types d'habitationqui relèvent de la civilisation romaine en Occident, c'est-à-dire les types gallo-romain, moyen àge et renaissance.

Le type gallo-romain nous conduit à une époque de décadence. II n'y a plus d'unité ni dans la disposition générale de la construction ni dans l'usage des matériaux. La première n'offre ni symétrie ni régularité. Des baies accolées en plein cintre qui éclairent la façade latérale, l'une est entièrement ouverte, l'autre, au contraire, presque complètement fermée, ne donne naissance qu'à une petite ouverture rectangulaire. Les ruines qui s'accumulent en Gaule sousl'influence des exactions de la métropole, des révoltes incessantes, des premières invasions des Barhares à grand peine repoussées, forment des carrières où l'on va puiser les matériaux sans en tirer le moindre prarti d'ulnementation. A l'un des angles, on trouve un fùt de colonne avec chapiteau corinthien et un débris d'entablement. Les linteaux de la porte du rez-de-chaussée ont été arrachés à quelque temple, et d'autres moulures incorporées çà et là dans l'épaisseur des murs témoignent du peu de soin qui a présidé à l'édification du batiment. On retrouve aussi dans les murs cette alternance de lits de briques-plaques posées sur d'épaisses couches de ciment, avec la pierre de taille de petit échantillon, et d'appareillage irrégulier que nousprésentent les thermes de Julien. Mais le moment approche où l'art, sous les influences sociales et religieuses, va sortir de la pénombre où il végète depuis des années.

L'habitation romane et du MOYEx Age. - L'architecture romane a ses origines bien 
a dela de la fin de la domination romaine. Pour en trouver les sources, il faut étudier les basiliques civiles que les fidèles transformèrent en églises dès les premiers temps du christianisme, non seulement en Italie, mais encore dans l'empire d'Orient ou byzantin.

Le style roman, élaboré dans les cloîtres où seules se conservèrent au moyen âge les traditions architecturales, marque d'une ineffaçable empreinte la période qui s'étend du $x^{\circ}$ au $x^{\prime} 11^{\circ}$ siècle. L'habitation de cette époque atteste une intelligence complète des ressources de la pierre et du bois. La création de la vie en commun, de la vie de fitmille qui ouvrait a la femme toutes les parties de l'habitation, donne à la maison un aspect nouveau. Elle commence d prendre directement jour sur la rue : si une grande arcade, constituant une sorte de porche analogue a ceux des églises, si développées à cette époque, s'avance encore sur les baies du rez-de-chaussée, l'étage supérieur est plus découvert, surtout les faces latérales, et s'éclaire du côté de la rue à l'aide d'une galerie formée par un balcon. L'apparcillage est régulier : les fenêtres géminées tirent leur ornementition de l'arcade qui les enveloppe et du chapiteau des colonnettes qui les séparent. Ces chapiteaux ne présentent encore qu'une ornementation empruntée à des figures géométriques ou composées de rinceaux lourds et sans grâce, les processions de personnages, lns têtes bizarres, les monstres étant surtout réservés aux chapileaux des grands édifices, où ils peuvent se développer plus librement. Du xıı" au $x v^{0}$ siecle, la France voit s'effectuer l'affranchissement des communes, le rôle social de la bourgeoisie s'accuse de plus en plus, les corporations de métiers reçoivent leur organisation à peu près définitive, et la construction civile vient former une branche spéciale de l'architecture. On voit alors apparailtre les maisons à façade surmontées de pignons, dont quelques curieux spécimens ont fait la réputation des vicilles rues de Rouen et de Reims. Le rez-de-chaussée et le soubassement sont construits en pierre; le reste de la construction est en bois. A cóté d'une porte étroite qui donne accès dans l'habitation, une large arcade ogivale divisée par des traverses et des montants moulurés, éclaire la grande salle commune. Les salles de chaque étage prennent jour par une fenêtre continue. La façade se termine par un pignon de forme aiguë dont la saillie, supportée par deux pièces de bois recourbées en ogive, abrite les ¿lages inférieurs. La charpente apparente constitue d'abord l'unique motif de décoration. Les poteaux corniers, les montants, les traverses sont sculptés ou peints, et mème dorés; plus tard, leurs remplissages se couvrent de carreaux de fäence ou se décorent d'un élégant briquetage. Les spécimens de cette architecture sont fréquents. Dans le midi de la France, on voit encore des maisons romanes aux façades percées de fenêtres en plein cintre. Dans le nord, elles sont beaucoup plus rares, mais elles ne manquent cependant pas complètement.

L'étude attentive des monuments permet de distinguer deu= ,ériodes dans l'architecture romane: le roman primitif et le roman secondaire. Dins le roman primitif, c'est le romain qui prédomine. Les églises sont, à l'intérieur, divisées en trois parties inégales dans le sens de la longueur, par deux rangs parallèles de colonnes ou de pilastres. Les f́nétres offrent d l'extérieur l'aspect le plus simple: le cintre qui les courunne repose sur les pieds-droits de la maçonnerie, et ce cintre se compose luimème d'un rang de pierres symétriques sans moulures. Les moulures sont lourdement imitées des motifs antiques : ce sont des rosaces a lobes arrondis, des bordures formées de perles allongées et de torsades, mais beaucoup plus que les moulures les incrustations en terre cuite, en pierre ou en marbre concourent à la décoration extérieure. A 
¿'intérieur, les murs sont plaqués de marbre, couverts de peintures, incrustés de mosaïques en pate de verre. Mais si les sculptures provenant des monuments romains ou faites à leur imitation donnent de l'éclat à l'édifice, elles ne lui donnent pas la solidité. Le désir de remédier à ce défaut décida la transformation de l'art roman primitif, vers le commencement du $\mathrm{x}^{\circ}$ siècle. La partie de l'édifice la plus soignée à cette époque fut incontestablement la porte. Les portes sont ornées d'un nombre considérable de moulures, de figures végétales ou animales. Le chapiteau assoupli a bientot une com. position plus libre qui permet d'y dérouler tan tôt une scène entière de l'histoire sacrée, tantôt une série de figures d'une prodigieuse bizarrerie et d'un symbolisme souvent monstrueux, dont les archéologues n'ont point encore trouvé l'énigme. La partie faible

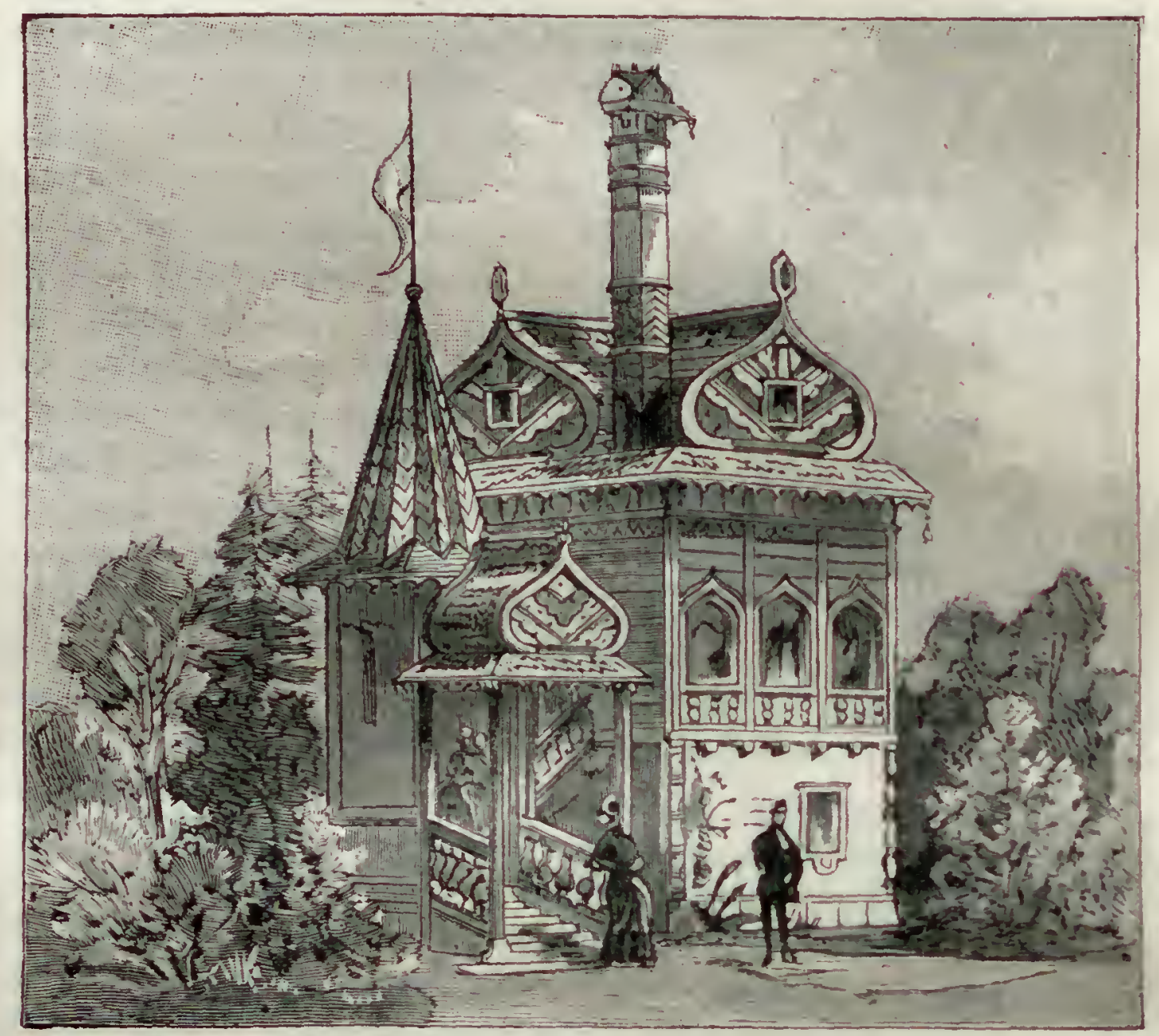

L'inabitation humaine. - Type russe.

de l'architecture romane, c'est la voùte. L'artifice le plus hardi employé par l'architecte consistait à diviser les voûtes par petites parties carrées, à diriger lapression sur des points correspondant d des piliers et a former ainsi ce qu'on appelle la voate d'arete.

L'architecture romane participe du vieux monde et procède, comme nous l'avons dit, de l'art romain et de i'art byzantin. Tant que le christianisme s'organise et se constitue, elle convient à cette civilisation naissante. Dès le moment où le christianisme règne incontestablement, l'art roman ne répond plus ni à son idéal ni à ses besoins, ni aux sentiments ou aux idées que la pierre devait rendre sensibles. Un style nouveau apparut, le style ogival, qui est proprement le style du moyen ige.

- On ne peut, dit M. Émile Soldi, citer tous les édifices dont l'art roman a enrichi l'Europe. Après les beaux monuments de l'Italie, citons : en Belgique, Tongres, Tournai; en Allemagne, Bonn, Nayence, Trèves, Spire et Cologne; en Angleterre, 
Exeter, Norwich, Londres. En France, Caen, le Mans, le Puy, Poitiers, en sont restés les modèles. Le roman occidental était court, sombre, lourd; sous l'effort du génie français, l'emploi de l'arc brisé ou ogival est généralisé, les ares-boutants intérieurs sont rẹietés à l'extérieur et, se superposant comme ui immense échafaudage de pierre, permettent d'en hausser les murs, d'agrandir les fenetres, d'élever les voutes dans le ciel. Le caractère général du roman était horizontal; dans le gothique, la verticale domine. Alors Strasbourg lance la dentelle ajourée de sa flèche à la hauteur des lourdes et massives pyramides d'Égypte. A P’aris, Notre-Dame, la vaste métropole, toujours grande et toujours fière, présente ses nobles proportions, son chour svelte, ses belles

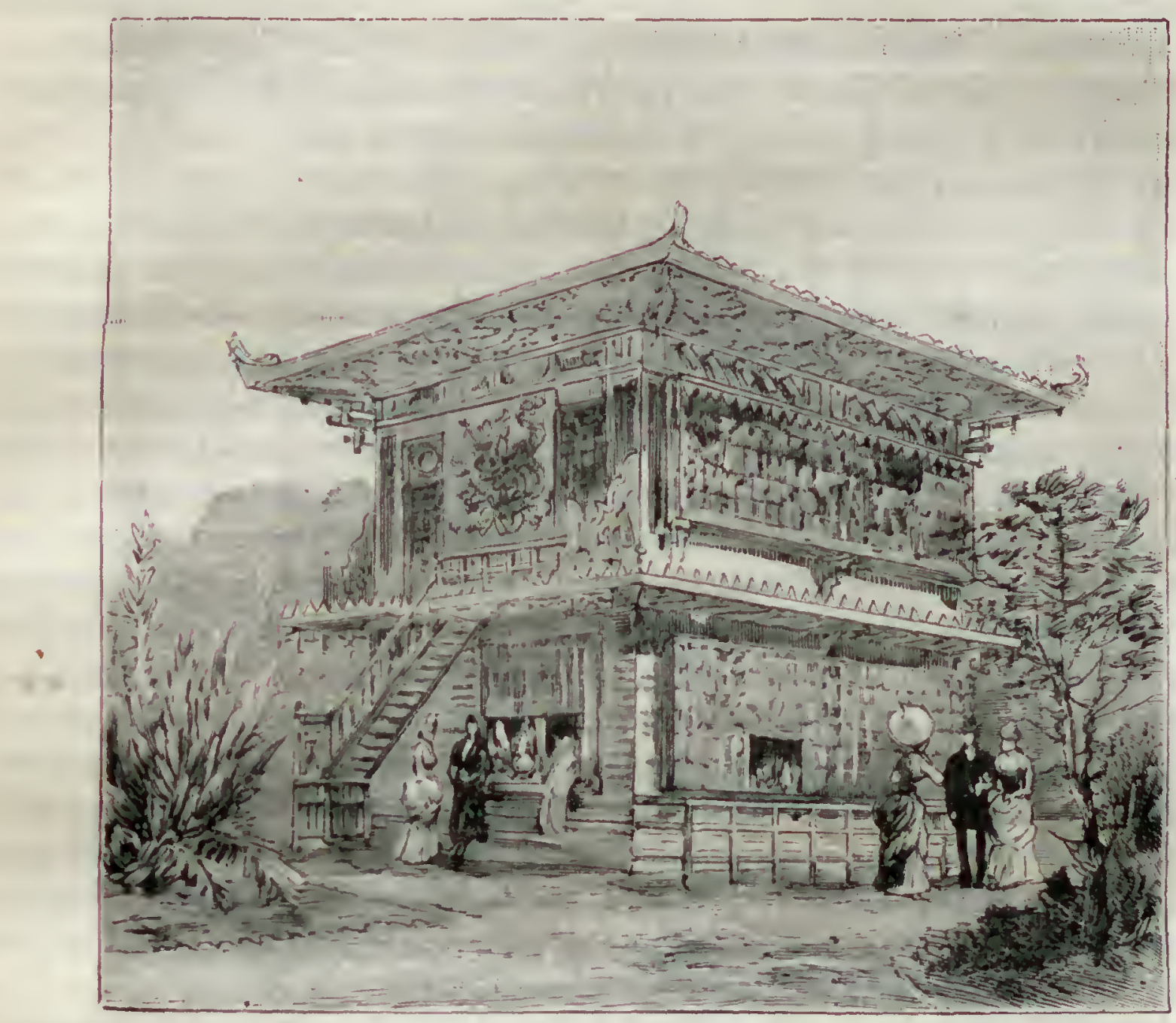

Limamtatox momas. - Type scimdinave.

sculptures, ses deux tours superbes au milieu de la cité; les monuments modernes enserrent la vieille cathédrale sans plus la dominer que les chétives masures qui l'enlaçaient au moyen age; elle les domine encore de sa grandeur, les abime dans son immortelle beauté, les écrase sous sa haute majesté, sous son incomparable solennité. Et quelle diversité dans le style gothique! Non seulement la date de chaque monument se reconnalt immédiatement, mais encore en Angleterre, en Espagne, en Allemagne, en Italie, en France, bien plus, dans chaque province de chacune de ces contrées, le gothique a un style, un ordre particuliers. ,

Lee style ogival, improprement appelé gothique, puisque les Goths n'eurent aucune part à sa genèse, régna souverainement de la fin du x ${ }^{\circ}$ siècle (ou du commencement du xim॰) jusqu'à la Renaissance. Ce qui le caractérise, c'est l'emploi systématique de l'ogive, c'est-d-dire la substitution de l'arc en tiers-point au plein cintre roman, 
mais son règne a franchi trois étapes successives : période primitive ou période du style à lancette, période secondaire ou de l'ogival rayonnant, période tertiaire ou période de l'ogival flamboyant ou du gothique fleuri. Dans la premiere, l'aspect du monument fut transformé par l'introduction des arcs-boutants qui, projetés en l'air, s'appuyaient d'un côté sur les contreforts des collatéraux, et allaient, de l'autre, soutenir les murs du grand comble. " Du moment, dit M. de Caumont, que les arcsboutants formèrent des arcades aériennes, les contreforts s'élevèrent comme des tours au-dessus des toits des ailes. On les couronna de clochetons tantot oclogones, quelquefois d'un fronton aigu ou d'un toit à double égout. Sur les pieds-droits de ces contreforts pyramidaux, on pratiqua des niches zarnies de colonnes dans lesquelles on plaça des statues. Et un autre archéologue ajoute : Le $\mathbf{x}$. $^{\circ}$ siècle introduisit une naïve et exquise décoration architectonique. Plus de ressouvenirs gauches et maladroits de l'ornementation byzantine et de la flore orientale; c'est la végétation des vallées de la Seine et de la Loire, des forêts teutones et des bords du Rhin qui vient, docile, s'enrouler autour des chapiteaux. La feuille de vigne, la feuille de chêne, la feuille du rosier, la feuille du saule, la feuille du fraisier, celle du nénuphar, s'étalent gracicusement à la cime des chapiteaux du $\mathrm{x}_{11}{ }^{\ominus}$ siècle artistiquement disposées et découpées dans le style ornemental de l'acanthe classique. L'entablement ne fut pas moins unodifié que l'ornementation. On ajouta les balustrades, on couronna les corniches avec des rampes en pierre. Les balustrades furent portées sur des arcs ogivaux ou sur des arcs trilobés avec ou sans colonnes. Artifice ingénieux des maltres macons, grands hommes humbles et inconnus, ces minces colonnettes, prodigieusement hautes, sont liées en faisceau et déguisent ainsi la lourdeur du pilastre autour duquel elles montent dans leur jet sublime, recevant les arceaux des voutes en plein ciel bleu étoilé d'or Quelquefois ces colonnettes sont détachées; le füt n'est parfois que d'un seul morceau. Dans tous les cas, il a fallu pour obtenir quelque solidité se servir de très grandes pièces; le chapiteaux de ces petites colonnes sont d'une grace exquise, légère couronne à ces légers monuments. Les voutes sont tout aussi admirables. On en truuve qui ont juste six pouces d'épaisseur et qui sont jetées d'un mur à l'autre, à plus de 100 pieds d'élévation avec une hardiesse étonnante. Faites de petites pierres mêlées d'une grande quantité de mortier, elles ont, malgré leur faible apparence, une telle solidité qu'clles résistent à travers les siècles aux efforts de l'homme et à ceux du temps.

La période de l'ogival rayonnant (xıve siècle) apporta des modifications architecturales dans la forme des églises. Le chapiteau devient moins naïf, les feuillages moins capricieusement solidaires de la pierre. Aux fenètres, les lancettes sont remplacies par la combinaison suivante: deux ogives géminées, surmontées d'une rose polylobée, occupant toute la fenètre, et chacune des deux ogives décomposée en deux baics surmontées d'une rose trilobée. La sculpture prend un caractère de plus en plus satiri jue et symbolique.

La période de l'ogival flamboyant est plus nettement reconnaissable. L'ornementation est en quelque sorte anguleuse; les pétales des trèlles et des qualre feuilles se terminent par une pointe ou par une sorte de flamme. L Lornementation végétale se rigidifie et se régularise. Les arcatures sont presque toujours surmontées d'un fronton pyramidal, portant des impostes, qui est souvent garni de crochets et couronné d'un bouquet de feuillages frisés. Les murailles se garnissent de pelites arcades trilobécs, ordinairement superposées les unes aux autres, et séparées par des lignes horizontales, 
qui ont été figurées sur les murs durant les $\mathrm{xv}^{\bullet}$ et $\mathrm{xvI}^{\mathrm{e}}$ siècles. Les portes deviennent flamboyantes; elles ont souvent de chaque côté des pilastres divisés en plusieurs panneaux et surmontés d'aiguilles. A l'extrados court une bordure d'élégant feuillage orné de crochets, dont le sommet s'élève verticalement; puis, s'il ne se termine pas en fleur de lis, il s'épanouit en piédestal et porte une statue. Parfois la porte ne s'ouvre pas en ogive pure; les lignes se relèvent subitement près du point de jonction en forme d'accolade. Il y a aussi des portes en arcs surbaissés, des portes Tudor, comme on les nomme, ce qui caractérise le temps et le lieu où elles furent employées. . Les arceaux sont plus saillants. Les tours se découpent avec beaucoup de grâce et de légèreté. Enfin, la statuaire s'humanise, si l'on peut dire. C'est la Renaissance qui approche, et uvec elle la Réforme. Le christianisme a exprimé son idéal avec toute l'ampleur désirable. $\Lambda$ un nouvel état social va répondre un art nouveau.

Lihabitation de la Renaissance. - Un simple coup d'œil montre la différence de l'habitation du moyen age et de l'habitation de la Renaissance. La pierre et la brique remplacent le bois. Les pignons triangulaires sur la rue tendent à disparaitre. L'ornementation et la décoration présentent une variété infinie de motifs s'appliquant, soit aux pilastres accusant les étages ou accompagnent les fenétres rectangulaires ou cintrées et le plus souvent à meneaux. Jes cartouches délicats surmontent les linteaux des portes : des têtes gracieuses, des mascarons, des médaillons rompent la monotonie des moulures droites; une corniche accentuée couronne l'édifice et l'un de ses angles s'agrémente d'une tourelle carrée, en encorbellement, qui contient l'escalier destiné aux étages supérieurs, mais contribue par son ornementation et sa coupole surmontée d'un épi à l'heureux effet de l'ensemble. Le toit lui-mème, dont la hauteur écraserait les motifs élégants des étages, dissimule cet inconvénient grâce à ses grandes fenêtreslucarnes à meneaux analogues aux fenètres inférieures et à ses cheminées décorées avec gout et richesse. L'art de la construction civile atteint ici son apogée, au moins en ce qui concerne la décoration extérieure de l'habitation; car la distribution laisse encore à désirer et ne trouvera la perfection qu'd notre époque.

Lorsque se produisit le beau mouvement de la Renaissance, le premier des arts qui revint à l'antiquité fut l'architecture. Le célèbre Brunelleschi, après une étude approfondie des antiques monuments de Rome, eut l'intuition d'un art nouveau, naturel, simple et logique, fondé sur les justes rapports des proportions et n'admettant l'ornementation que comine un moyen élégant d'accuser à l'extérieur les divers membres de la construction. Dans ses cuvres et dans celles de ses élèves, des proportions antiques, grandes et sévères, s'unissent à l'esprit de l'ar't antérieur. Bramante crẻa l'architecture romaine, au style pur, à l'ordonnance simple, régulière, étrangère à tout ornement fantastique, se rattachant par son ensemble aux traditions de l'architecture du temps de l'Empire, et restée l'expression la plus haute, la plus classigue de l'art moderne. A Venise, le style de la Renaissance fut dès l'origine modifié dans le sens du génie national et de ses affinités avec l'Orient. En France, la transition de l'ancien style architectural au nouveau se fit assez lentement, notamment dans les édifices religieux. - L'architecture gothique, épuisée par la plus splendide efflorescence, à bout de moyens pour produire des effets surprenants, emprunta quelques éléments décoratifs à la Renaissance italienne, mais elle conserva longtemps encore sa construction, son procédé de tracé, ses dispositions d'ensemble. La combinaison, l'amalgame des deux 
¿

systèmes produisit au xvr siècle un style particulier a la France. Nos grands architectes du $\mathbf{x v l}^{\bullet}$ siècle surent combiner avec une adresse remarquable les vieilles et bonnes dispositions de l'architecture française avec les formes nouvellement admises. S'ils employèrent les ordres antiques et s'ils crurent imiter souvent les arts romains, ils respectèrent dans leurs édifices les besoins de leur temps et se soumirent aux exigences du climat et des matériaux. Une des modifications les plus importantes que subit au début de la Renaissance la construction des habitations seigneuriales consista dans l'adoption des dispositions symétriques, mais les distributions antérieures, les tourelles d'angle à toits pointus et beaucoup d'autres détails des anciens chateaux féodaux furent conservés longtemps encore. Mais ce respect des premiers constructeurs

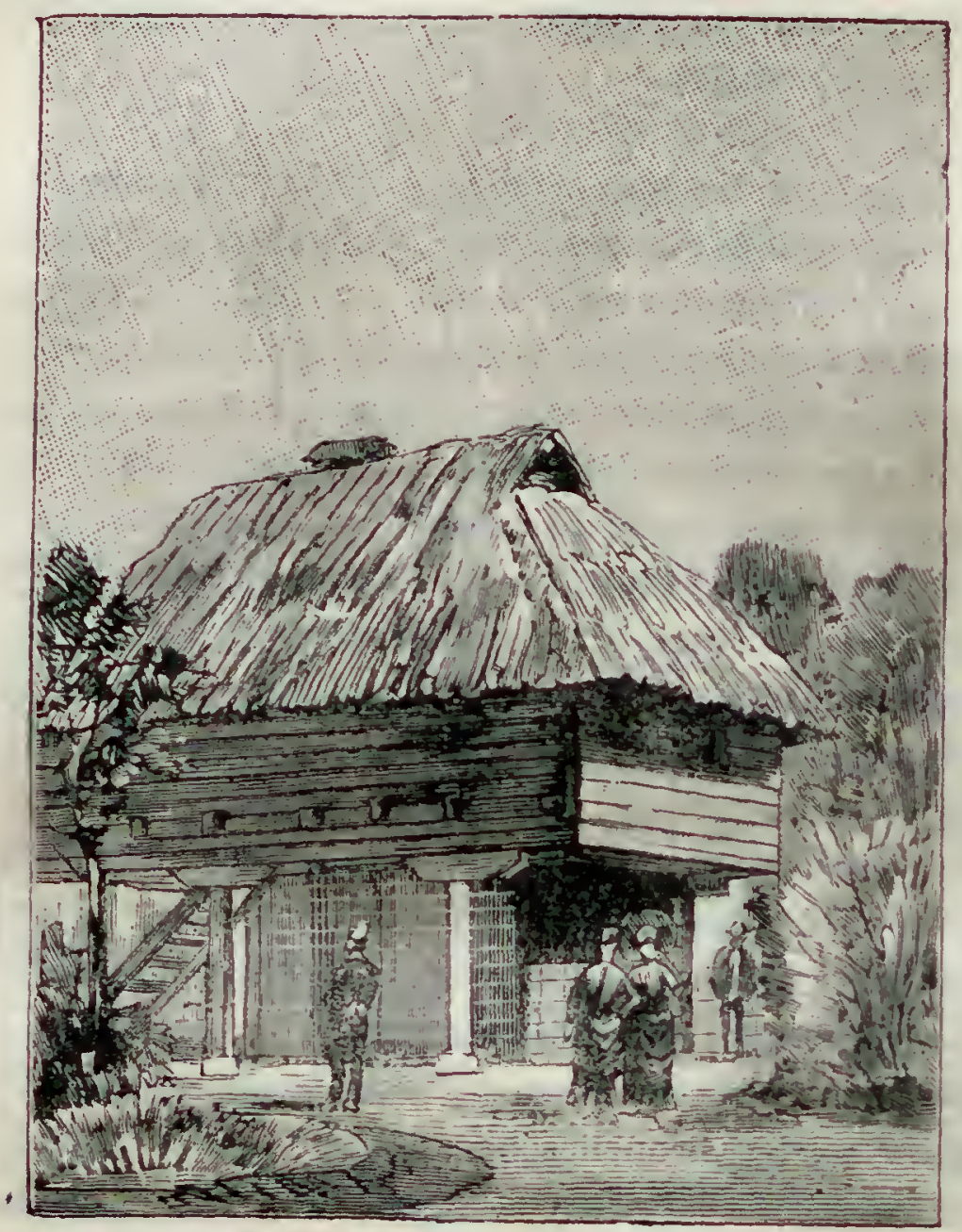

Lihabitation humaine. - Type slave. de la Renaissance pour nos traditions nationales devait peu à peu faire place à une admiration plus exclusive des formes savantes de l'antiquité. D'heure en heure, le public s'accoutuma à voir altérer, puis élaguer, puis proscrire tout élément décoratil suspect d'avoir appartenu de loin ou de près à la fimille de l'ogive. , Bien qu'engaźce sur le terrain de l'imitation, larchitecture française garda en somme une physionomie originale, et la seconde période de la Renaissance dans notre pays est ineme lc plus souvent dégagée de toute attache. Les chateaux de Blois, d'szay-le-Rideau, de Chenonceaux, d'Amboise, de Maisons, les Tuileries, Fontainebleau, etc., sont les plus riches productions de l'épo. que. Comme le fail remarquer un critique, dans ces demeures, il ne subsiste plus rien de l'ancien manoir féodal, plus de donjon, plus de tours, plus de créneaux, plus de passages détournés : ce sont de vastes palais ouverts, faciles d'accès, entourés de magnifiques jardins, décorés à l'extérieur de statues et à l'intéricur de peintures, offrant unc application pleine de goût des formes antiques, mais conservant un caractère essentiellement original et français. .

L'habitation byzantine. - L'art byzantin est de ceux que l'on a le plus discutés. Pendant longtemps, on l'a flétri des épithètes les moins oblizeantes, et le mot de byzantin a pris une signification ficheuse. Ce discrédit, malheureusement, n'a d'autre origine que l'ignorance mème de ceux qui l'ont fait naltre, et depuis quelque temps ceux qui ont pu étudier sur place l'art byzantin ou pour mieux dire l'art néo-grec ont cherché à modifier une opinion qu'on pouvait croire invétérée. La période de formation 
de l'art byzantin s'étend de Constantin à Justinien. Ce dernier monarque, qui fut un grand constructeur, donna à l'architecture une impulsion telle qu'elle atteignit brusquement l'apogée de son développement. On sait que le type par excellence de l'art byzantin, c'est l'église de Sainte-Sophie de Constantinople. "Vue de l'extérieur, dit M. C. Bayet, Sainte-Sophie ne produit qu'une impression médiocre et la coupole mème, si hardie qu'en soit sa construction, parait déprimée. C'est à l'intérieur de l'église qu'il faut pénétrer pour en bien comprendre l'originalité et les splendeurs. En avant du temple s'étend l'atrium. Du côté de l'église se trouve un double narthex qui communique avec elle par neuf portes. Si l'on en excepte l'abside orientale, l'église est renfermée dans un ešzace rectangulaire de 77 metres de longueur sur $76^{\mathrm{m}}, 70$ de largeur, y compris l'épaisseur des murs. Cet intéricur est divisé en une partie centrale, la nef, et deux parties latérales. $\mathrm{Au}$ centre de l'édifice s'élève une coupole de 31 mètres de diamètre inscrite dans un carré. Elle s'appuie sur quatre grands arcs d'une ouverture égale à son diamètre, lesquels reposent sur quatre gros piliers. D'immenses pen. dentifs sphériques se projettent sur le vide, remplissent l'espace entre les grands arcs el viennent saisir la coupole. Sur les deux ares perpendiculaires a la nef, l'arc oriental et l'arc occidental, s'ap-

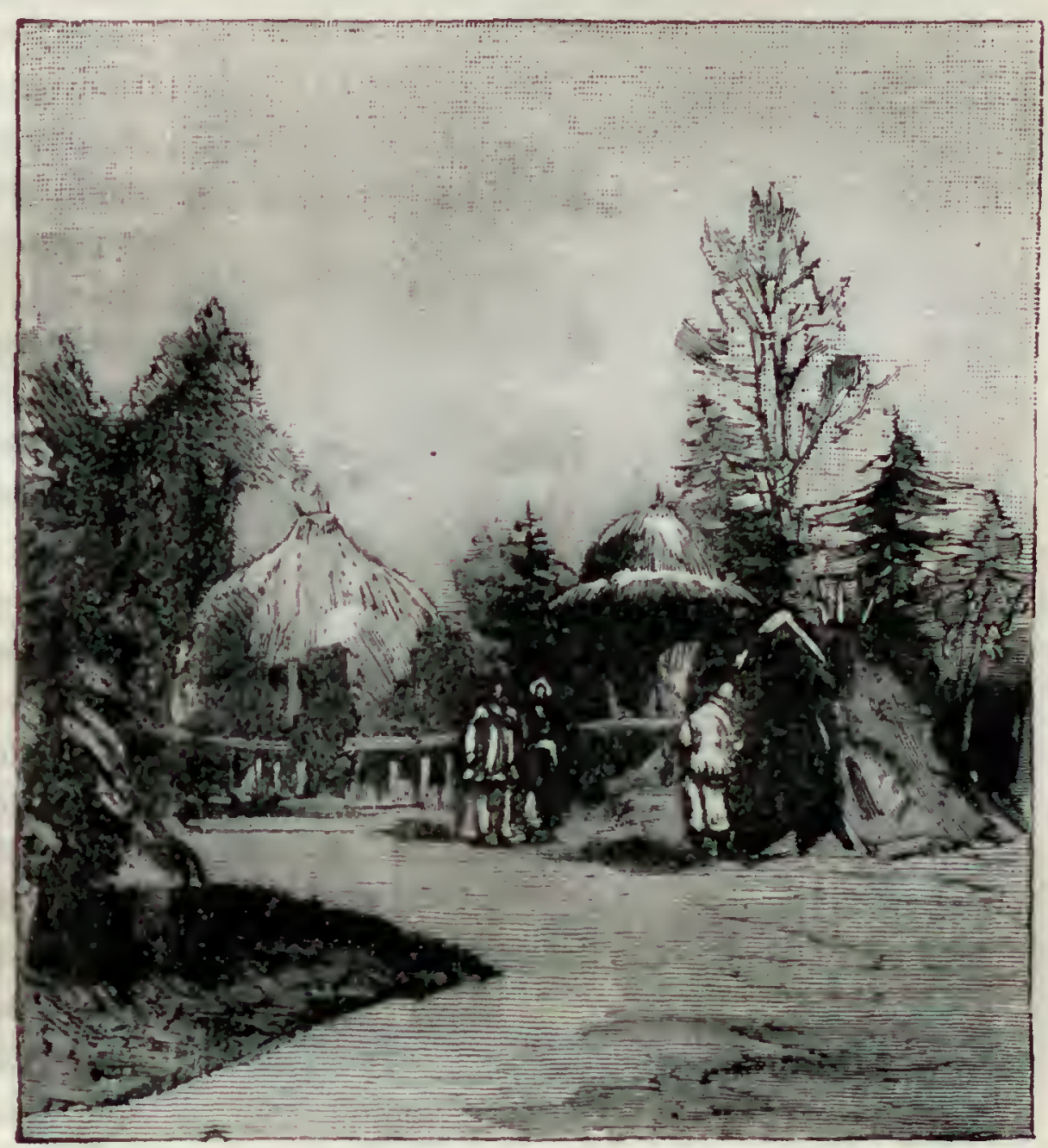

L'Habitatho. humaine. - Ilabitation des Esquimaux. puient deux demi-coupoles; au contraire, au nord et au midi de la grande coupole, les grands arcs sont fermés par un mur plein que soutiennent des colonnades. Autour de l'hémicycle que recouvre la grande demi-coupole orientale s'ouvrent trois absides : au centre, l'abside principale, qui se prolonge à l'orient et se termine par une voúte en cul-de-four, et deux absides secondaires à droite et à gauche de l'abside principale. Le fond des deux absides secondaires est ouvert sur les bas côtés et leur voâte est soutenue dans cette partie par deux colonnes. Le pourtour de l'hémicycle occidental est pénétré de la mẻme manière, mais l'arcade centrale n'est pas terminée en cul-de-four; la voûte se prolonge jusqu'au mur de face dans lequel sont percées les trois portes qui coinmuniquent avec le narthex. Les bas côtés, depuis le sol jusquà la naissance des arcs, sont divisés en deux étages; l'ẻtage supérieur portait le nom de gynécée. La lumière pénètre dans tout l'édifice par un grand 
nombre de.baies; quarante fenètres s'ouvrent a la base de la coupole, d'autres sont percées dans les murs pleins des grands ares du nord et du midi, dans les demi-coupoles et dans les absides. "M. Garnier ne pouvait songer à nous donner la réduction de Sainte-Sophie, mais le spécimen qu'il a fait élever n'en est pas moins instructif. Ce spécimen rappelle la tradition grecque par l'emploi a peu près exclusif de la platebande. Les coupoles caractéristiques de l'architecture byzantine sont réservées aux grands édifices el n'apparaissent point dans les habitations privées. Un portique intérieur, constitué par des piliers massifs à section carrée supporte une plate-bande sur laquelle viennent s'appuyer des colonnes plus élégantes et à chapiteaux orne-

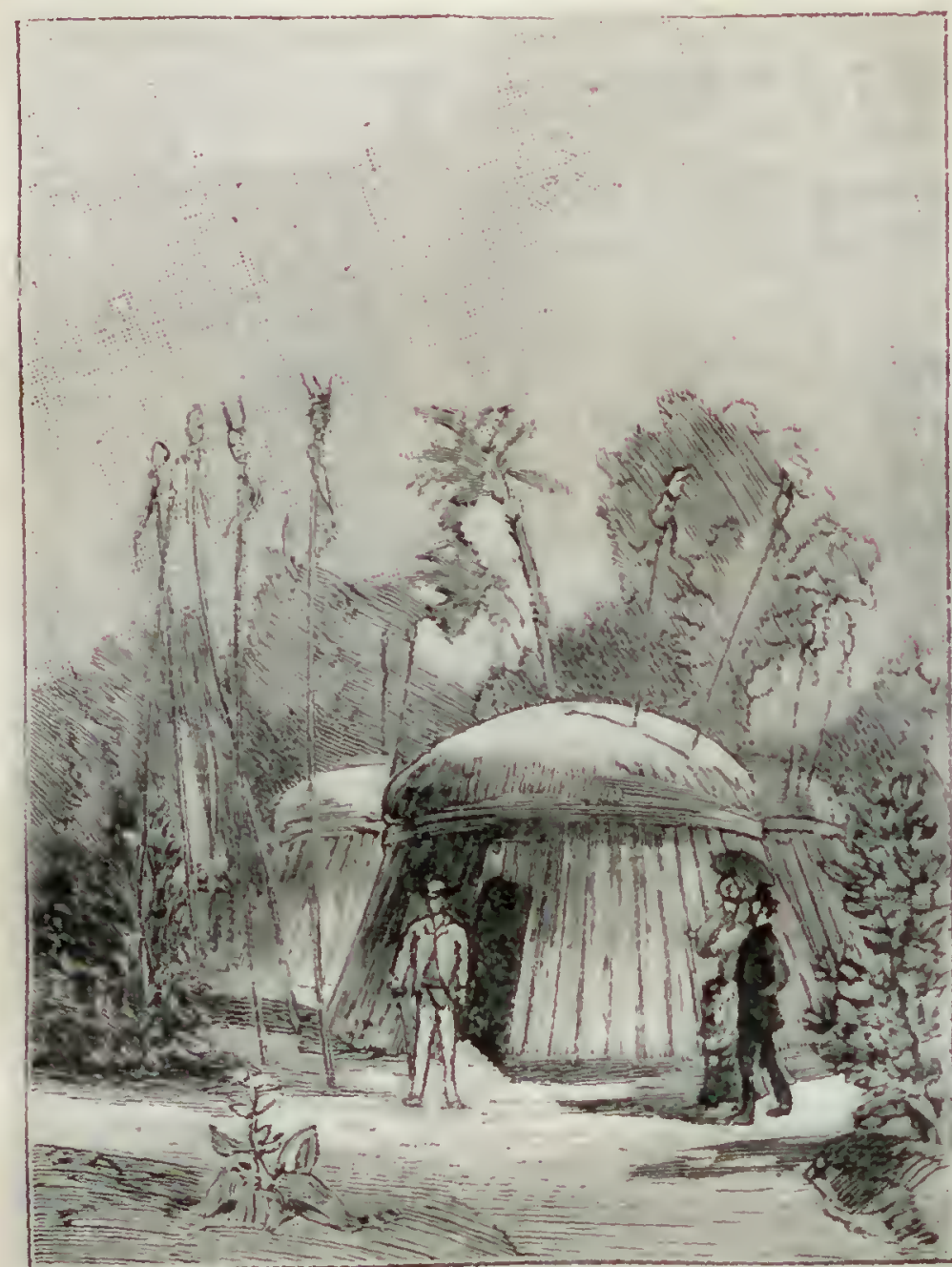

Lihamition humaine. - Iutte de Peaux-Rouges. mentés qui lui font une sorte de loggia. Toute la décoration des fenêtres, des balcons de la loggia, est empruntée d des figures de forme géométrique, à la croix grecque et au monogramme sacré.

L'Habitation russe et sLave. Sous la domination mongole. les arts furent fort négligés en Rus. sie; ce ne fut guère que sous le règne du czar İvan III, qui détruisit Saraï et secoua le joug tartare, qu'ils reçurent une impulsion nouvelle. Ce monarque ct ses successeurs dotèrent Moscou, devenue leur capitale, de plusieurs monuments, parmi lesquels il faut distinguer la cathédrale de l'Assomption. Cet édifice présente beaucoup d'analogic avec les constructions des Saxons et des Normands; l'are de la porte méridionale rappelle ceux que l'on vort dans les plus anciennes églises de l'Angleterre et les fenètres étroites et arrondies, ainsi que la rangée de petites arches qui fait le tour du batiment, à une hauteur élevée, appartiennent a la mème architecture. La nef presque carrée, la voûte du sanctuaire soutenue par quatre piliers énormes, - semblent indiquer un plan byzantin. En 1487, Ivan III confia aux architectes Marco et Pietro Antonio et Aleviso la construction du Kremlin. Les deux premiers élevèrent le palais Anguleux, vaste et unique salle voùtée, soutenue par des piliers, où les czars reçoivent le serment de fidélité des grands après leur couronnement. Aleviso construisit le palais des Czars ou du Belvédère, dont une galerie entoure le premier étage, ainsi que les cathédrales de l'Annonciation et de l'Archange Saint-Michel, et les églises de Saint-Jean, des Saints Athanase et Cyrille, du Saint-Sauveur, etc. L'église de là I'rotection de la Vierge, qui fut élevée en $133 y^{4}$ par les ordres d'Ivan le Terrible pour célébrer la prise de Kazan, est une des plus belles de Moscou. Elle renferme dix-neuf 
chapelles et est dominée par une flèche d'une forme étrange et par une masse de coupoles bulbeuses dont aucune ne ressemble parfaitement aux autres. L'église de SaintNicolas, qui date de la fin du xvi', siècle a de grands rapports avec l'église de l'Assomption, mais elle est plus décorée. L’église du Sauveur, comprise dans le palais des Czars au Kremlin, fut fondée dans le $\mathrm{xvI}^{\circ}$ siècle, et restaurée sous le règne de l'impératrice Anne. Elle a deux étarges, et ses neuf coupoles dorées forment un effet pittoresque au milieu des constructions voisines. Sous le règne de Boris Godonnof, le clocher d'IvanVélikoi qui contient trente-deux cloches fut élevé; ruiné en partie par l'explosion de la mine qui fut placée sous le Kremlin en 1812, il fut reconstruit depuis et surélevé. Dans ies vieilles églises russes, le clocher est le plus souvent indépendant du vais. seau principal, à tel point qu'il semble parfois n'en pas farre partie. On prit ensuite l'habitude de le placer sur la face occidentale, et de le faire commu. niquer a l'église par un petit passage auquel son étage intérieur sert de vestibule; ce vestibule et le prolongement du sanctuaire a l'orient, formèrent une croix assez semblable a celle du vaisseau des cathédrales des autres pays chrétiens. Ce qui attire surtout les regards dans les églises moscovites, c'est la guantité de leurs bizarres coupoles. - Jusqu'à présent, dit le comte da Ia veau, l'on n'est point tombé d'acc'rit sur l'origine de cet ornement. Le prutotype de ces colonnes bulbeuses ne $e$ trouve ni a Sainte-Sophie de Constartinople, ni dans les plus anciennes églises qui subsistent dans la Grèce, l'Asie Mineure et l'Archipel. Quelques historiens en ont voulu chercher l'origine dans la Chine; mais, c'est ne pas prendre

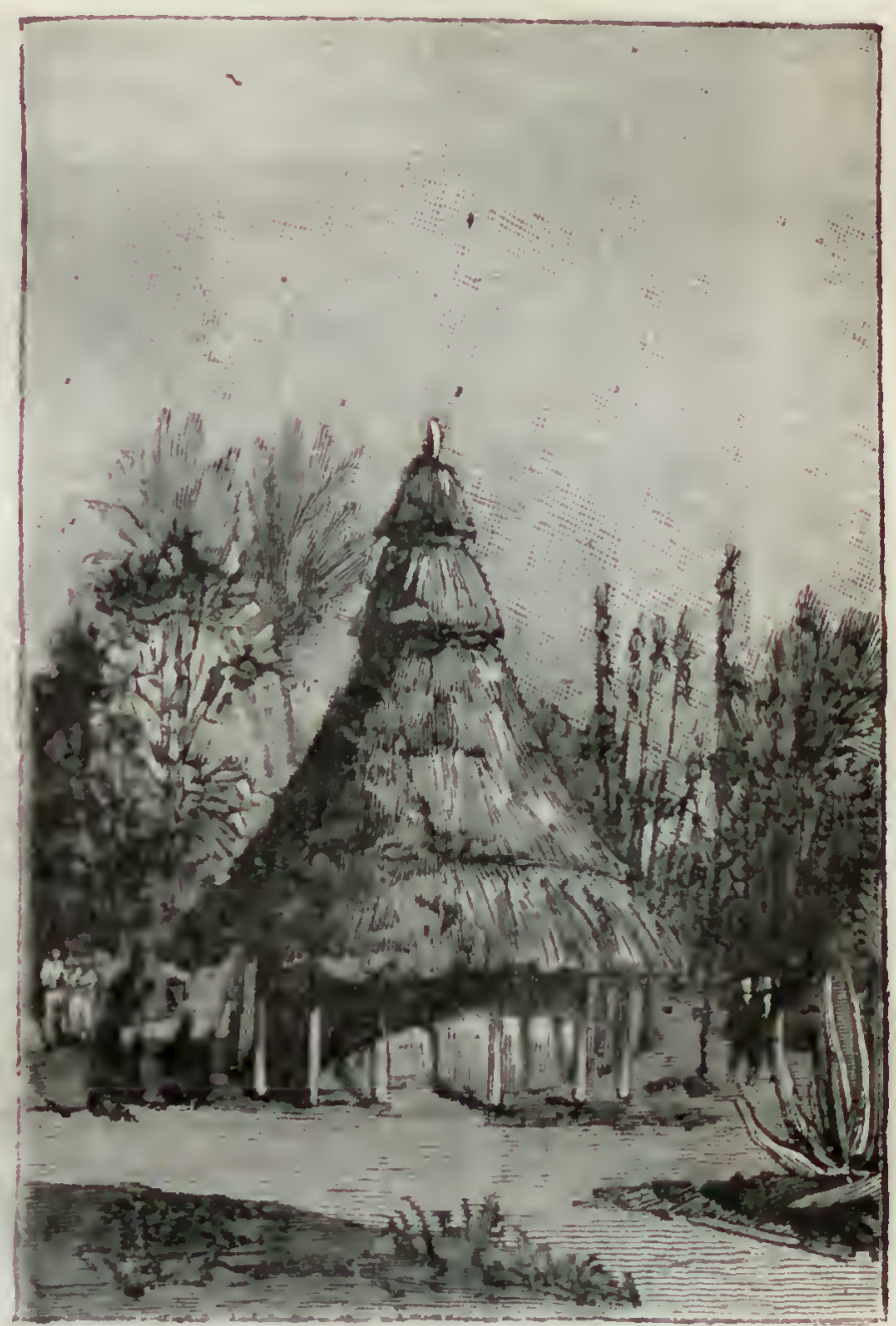

Lihabitatign hcmane. - Hulte des sauvages de l'Afrique. garde aux concavités que présente l'architecture des Chinois, tandis que les coupoles russes sont remarquables par un excès de convexité.

- D’autres ont supposé, avec quelque vraisemblance, que c'était dans l'Asie que devait s'en trouver le modèle, et c'est peut-être à tort qu'on leur a objecté que les Tartares, conquérants et nomades, habitants des camps et non des villes, n'avaient guère été en état d'enseigner l'architecture aux peuples qu'ils subjuguaient. Il est certain qu'on voit en Perse des tombeaux surmontés de cylindres environnés de coupoles fdont la forme se rapproche de celles de la Russie. Si celles-ci sont un peu plus convexes, c'est peut-être par suite du calcul des effets du climat, car, si elles l'étaient moins, le poids et l'infiltration de la neige qui $\mathrm{y}$ eât séjourné auraient accéléré la dégradation des édifices. Enfin, en résumant tout ce qui a été dit sur l'architecture des églises de Moscou, on peut conclure que le vaisseau de ceś églises 
est byzantin, que les coupoles ont été empruntées a l'Orient, et que les ornements forment un genre mixte qui a été modifié suivant le goût du siècle auquel appartiennent les architectes italiens ou allemands qui construisirent ces édifices. " De nos jours, les constructions religieuses élevées en Russie se rapprochent beaucoup plus du style byzantin que les anciennes. Dans leurs monuments civils, les Russes imitent volontiers les monuments classiques de la Grèce et de l'Italie. Le marquis de Custine, dans ses Lettres sur la Russie, fait sur les matériaux employés des réflexions sévères, mais assez justes. a Les anciens, dit-il, batissaient avec des matériaux indestructibles sous un ciel conservateur; ici, avec un climat qui détruit, on élève des palais de bois,

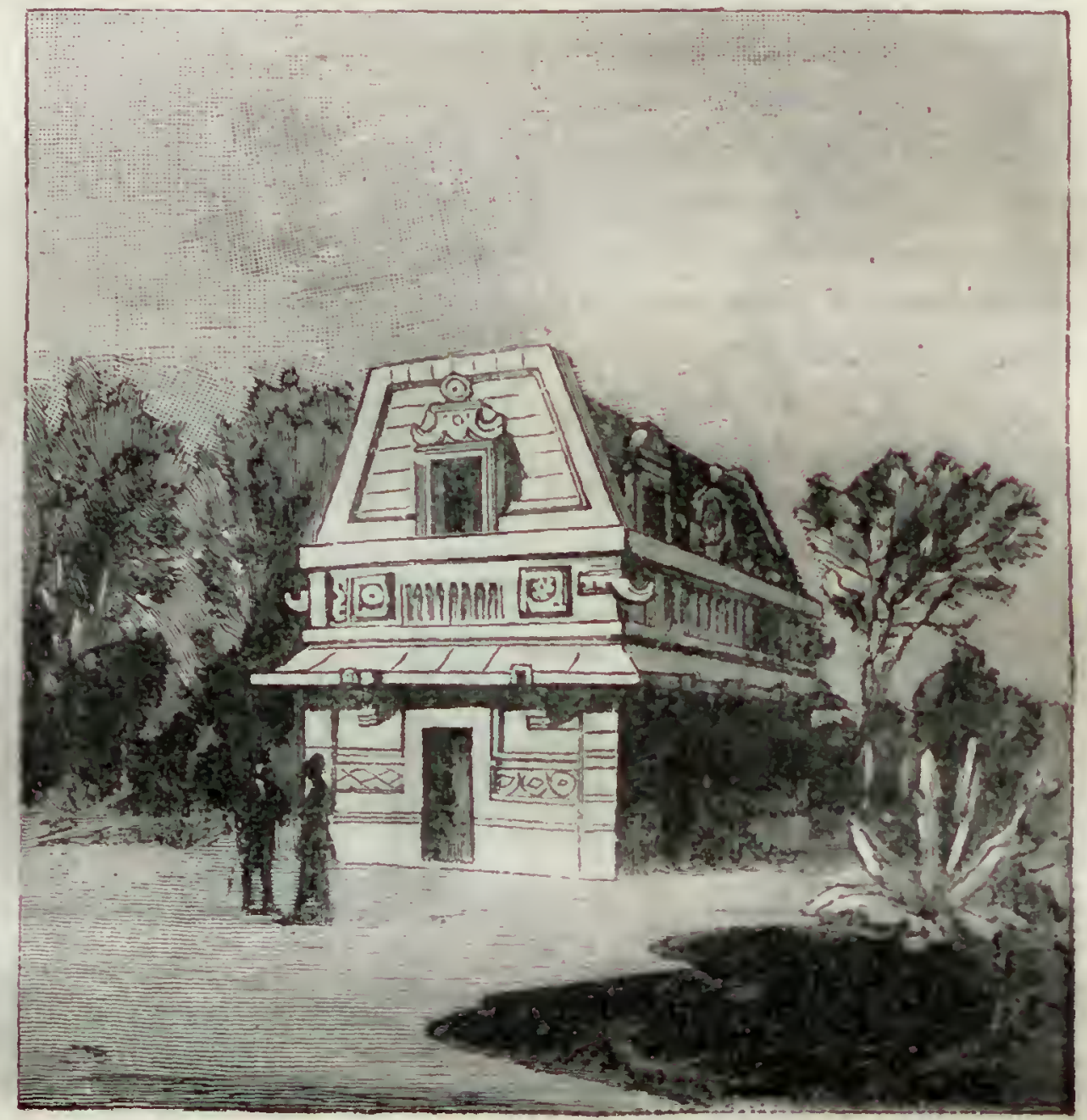

L'habitation humaing. - Type aztéques.

des maisons de planches et des temples de platres; aussi les ouvriers russes passentils leur vie à rebâtir pendant l'été ce que l'hiver a démoli. Rien ne résiste à l'influence du climat; les édifices, mème ceux qui paraissent les plus anciens, sont refaits d'hier; la pierre dure ici autant que le mortier et la chaux durent ailleurs.,

Le spécimen élevé par M. Garnier se fait remarquer par sa hauteur au-dessus du sol et l'élégance de ses proportions. La pierre dure étant très rare en llussie et d'un t'ansport difficile, c'est au bois que cette construction emprunte ses éléments. Élevée sur un faible soubassement en pierre, elle s'appuie sur des piliers moulinés, et les vides extérieurs sont remplis par des rondins simplement écorcés. Le rez-de-chaussée, à l'aspect rustique, porte un premier étage dont les baies assez étroites règnent sur tout le périmètre et sont séparées par des potelets moulurés. Elles se terminent par des ogives évasées au-dessus desquelles s'étend une frise richement ornementée. La 
toiture constitue une partie importante et caractéristique de la décoration générale: on y distingue spécialement les ogives largernent évasées encadrant les petites baies supérieures, ogives dont le profil est celui des coupoles en forme de bulbes adoptées dans l'architecture religieuse. Une haute cheminée en briques émaillées, et surmontée d'un chapeau qui rappelle les motifs de décoration de l'ensemble, contribue à donner à l'habitation russe un cachet de distinction très remarquable. L'accès au premier étage se fait par un escalier extérieur en bois, dont une partie est découverte, tandis que l'autre s'abrite sous un élégant pavillon dont les auvents superposés sont reliés sur chaque face par une des larges ogives dont nous venons de parler.

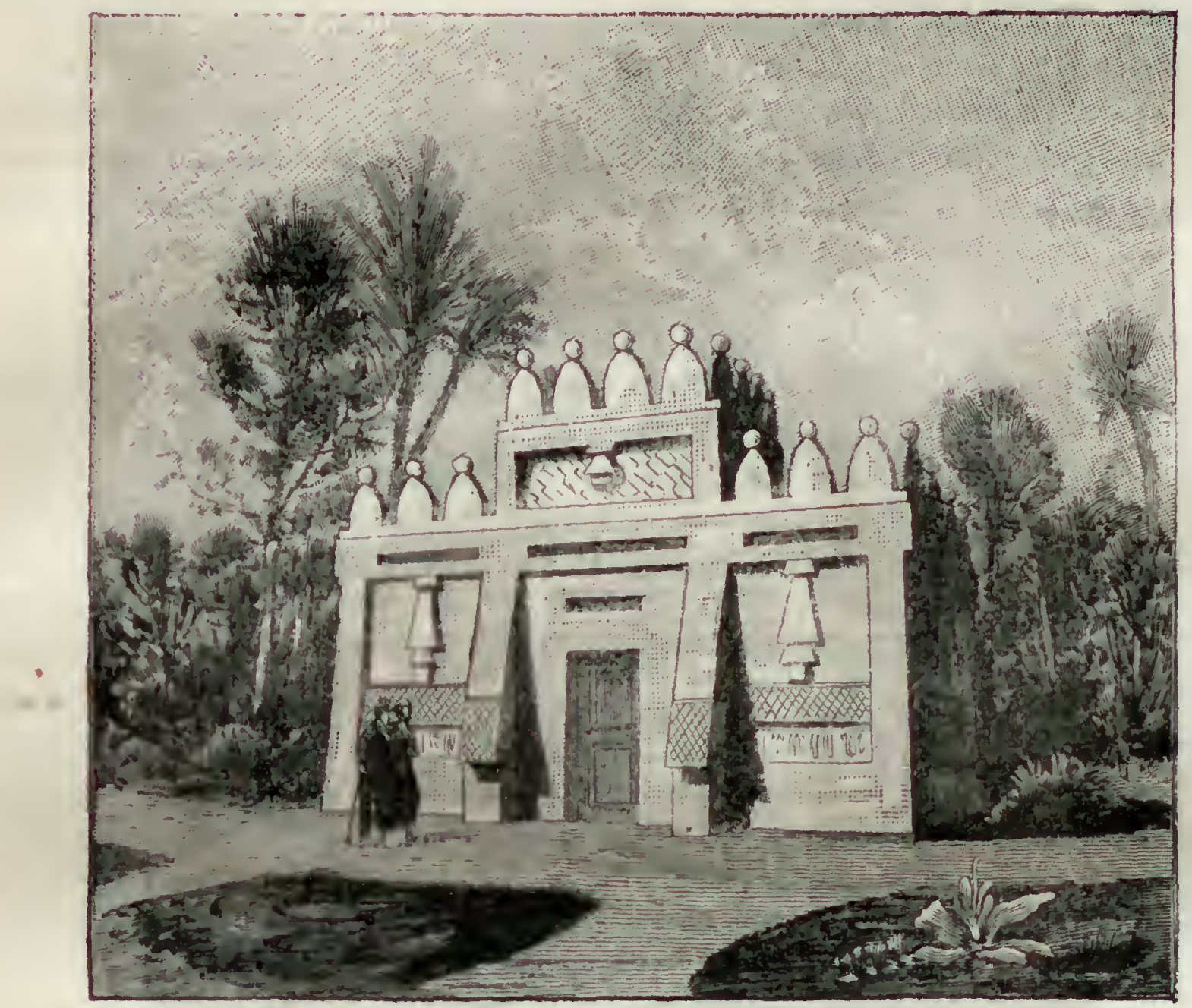

LiHAHTATION IIUMANE. - Typo soudanien.

Le type d'habitation slave témoigne d'une civilisation beaucoup plus rudimentaire que le précédent et exclut toute idée d'élégance architecturale. C'est une construction massive en charpente grossière, dont le premier étage paraît seul destiné à l'habitation. 11 s'établit partie sur des murs, partic sur une séric de piliers en bois simplement équarris. Une épaisse couverture en chaume accuse encore la lourdeur de l'immeuble.

L'uabitation scavisave. - Avec l'habilation scandinave, nous retrouvons le témoignage de l'habileté avec laquelle les peuples du Nord savent traiter le bois, tant au point de vue de la construction que de la décoration. Un soubassement en pierre assez élevé nécessite un escalier latéral à balustres, sur le palier duquel des potelets ornementés soutiennent l'auvent qui abrite la porte d'entrée. Près d'elle et lẻgèrement surélevées, deux fenêtres accolées séparées par un montant éclairent l'inlérieur. Les abouts, les chevrons de la toiture sont curieusement moulurés, et la fal- 
tière se décore à ses extrémités de sculptures reproduisant des animaux fantastiques.

Les peuples scandinaves, nom générique sous lcquel il faut comprendre les Suédois, les Norvégiens et les Danois, éxcellent, nous le répétons dans l'emploi du bois comme élément de construction. Un des types les plus connus de cette architecture cst l'église de Ringeloo, en Norvège. Elle est en bois goudronné et peint en brun. a Sa haute tour, dit M. Enault, exiguë comme une flèche, est couverte de planchcltes hcrmétiqucment imbriquées comme la tuile de nos couvertures, et d'un rouge vif qui tranchc nettement sur la verdure sombre des bois environnants et sur lc bleu léger du ciel; quatre petits clochetons triangulaires couronnent la base, et l'aiguille jaillit de leur bouquet comme le pistil d'une fleur s'élance de son calicc. L'église est percée de grandes fenètres blanches et carrées, dont la forme lourde et le ton criard heurtent la délicatesse de la construction et troublent cctte gamme de couleurs harmonieuses. , Les maisons des paysans norvégiens sont en sapin. \& Pour les murailles cxtérieures, on prend des troncs d'arbre dans la forêt voisine, on les équarrit, on les superpose le plus exactement possible. Une mous̉se sèche et pressée bouche hermétiquement lcs interstices. A l'angle des murs, les grands troncs s'adaptent les uns dans les autres au moyen d'entailles profondes. Quand on veut percer une fenetre, on scie la muraille. La première qualité d'un architecte, c'est d'ètre menuisier. A l'intérieur, des planches bien unies et solidement jointes remplacent les murs de refend; toutes les pieces ont un parquet sec et luisant. Parfois un superbe balcon, fincment ourragé, circule autonr de la maison, dont le toit, qui fait saillie, domine ct surplombe. Ces balcons, dont la haute balustrade monte jusqu'à la poitrine d'un bomme, sont de vrais chefs-d'œuvre de menuiserie; les piliers des encoignures se tordent conme les colonnes de nos baldaquins de la Renaissance: les barreaux, soigneusement tournés, sont sculptés et fouillés d'arabesques que donnent la patience et l'habileté du ciseau. Le toit a une inclinaison assez douce. Tantôt il est en bois et alors on le recouvre d'une couche de terre que la mousse et le gazon rendent bientủt impénétrable. Parfois aussi on rencontre des couvertures en tuileou en ardoise. La feuille de l'ardoise mince et délicate, verte ou rougeâtre, a des reflets d'un éclat métallique, la tuile est petite, souvent octogone ct disposée de manière à former des dessins d'une capricieuse élégance. , Dans ces inté. rieurs on remarque des lits d'une solidité à toute épreuve et d'une grande hauteur; ils ont deux ou trois étages, avec la place pour deux personucs, atteignent jusqu'au plafond, et sont munis de porte sur le devant et ressemblent à une armoire.

En Suèdc, pour les habitations bourgeoises, on emploie le bois dans les villes scptentrionales, et la brique ou la pierre dans les villes du Sud.

L'habitation des Esquimaux. - Les Esquimaux habitent l'extrême nord de l'Amérique, depuis la côte sud du Labrador, en passant par le nord de la baie d'Iludson et en longeant les côtes, jusqu'à l'embouchure du Frascr à l'est du continent. On cn trouve aussi dars le Groënland et les archipels polaires. Ils vivent de peche, et leur gibier ordinaire, c'est le phoque. Cơmme le combustible est infiniment rarc dans ces régions, ils combattent le froid surtout par leur genre de vie et de nourriturc. Ils prennent de l'huile de poisson pour activer la combustion du sang. Ils boivent le sang encore chaud des phoques ou des animaux qu'ils tuent à la chasse. On vante leur hospitalité, mais quel régal pour le voyageur que la tasse de sang frais qu'ils lui offrent en manière do poiitesse ! La chair crue ne les effraie pas non plus. 
Leurs demeures sont, l'été, des tentes de peau facilement transportables, car ils sont nomades. Mais durant la plus grande partie de l'année ils se construisent des cabanes avec des blocs de neige qu'ils taillent très habilement. Le Dr Bordier, dans les Mémoires de la Société d'anthropologie, décrit ainsi cette hutte : a Leur maison est composée d'un monticule en terre gazonnée, de forme carrée et rappelant assez nos travaux de fortifications: on y entre par une porte basse donnant accès dans un couloir étroit et fort bas, dans lequel le Groënlandais lui-même, malgré sa petite taille, est forcé d'entrer en rampant. L'unique chambre dans laquelle ce couloir aboutit, et dont le sol se trouve plus bas que le sol environnant, est aérée par un orifice placé a la partie sıpéricure; elle est éclairée par deux ouvertures hermétiquement fermées par des bandes cousues ensemble d'une sorte de baudruche, faite avec l'intestin du phoque. Cette sorte de vitrage immobile tamise dans la chambre une lumière très suffisante et semble du dehors complètement opaque. „On devine que l'odeur la moins agréable s'exhale de ces taudis dont le sol est recouvert d'un mélange infect de sang caillé, de détritus et de lambeaux de poisson pourri.

L'ilabitation des Peaux-Rouges. - Il y a peu de chose à dire sur cette habitation. La hutte des Indiens de l'Amérique du Nord est tout à fait primitive. Elle est établie directement sur le sol et constituée par des madriers inclinés et jonctifs. Ceux-ci, disposés sur un périmètre arrondi, se relient à l'intérieur par une grossière charpente qui soutient une couverture rudimentaire en chaume et branchages. Des perches portant les tètes scalpées des ennemis tués à la guerre se plantent vis-à-vis de l'entrée et mène dins la couverture. Un trou de côté sert de porte. Au sommet un autre trou donne issue a la fumée. Notons que parmi les Peaux-Rouges, il est des tribus qui sont arçivées à un certain développement industriel. Elles ont construit de vastes habitations fermées de toute part, où l'on peut tenir à l'aise deux ou trois cents et où l'on ne pénètre que par les fenètres au moyen d'échelles. D'autres ont élevé des refuges au summet des gorges de la montagnne, dans des anfractuosités. Ce sont des nids aériens d'où les Indiens défient leurs ennemis.

Prupades dF l'Afringet du Suldan. - Lelogis des tribus sauvages de l'A frique équatoriale consiste en une cabane en torchis portée sur un énorme pilier et présentant la forme circulaire. Une charpente en bois légèrement taillé forme le cadre sur lequel s'appuie le torchis et supporte une couverture conique en grosse paille ou en jonc. L'aspect général est celui d'un gros champignon, et ce qui y contribue encore, c'est la présence d'une sorte de gouttière basse destinée sans doute à recueillir les eaux de pluie et qui est supportée par Je pilier central à peu près à la hauteur du seuil.

L'labitation soudanienne se présente sous l'aspect d'une construction à rez-dechaussée massive et carrée, surmontée d'une terrasse à créneaux en ogive. La pierre de taille et le bois en forment les éléments; l'ornementation et la décoration y sont rudinentaires. La façade est divisée en trois parties séparées et limitées par des pilastres presque nus, en ressaut sur le mur extérieur et supportant un large bandeau. Les créneaux de la partie centrale, dans laquelle est pratiquée la porte d'entrée, sont surélevés par rapport aux autres. Les façades latérales ne comprennent que des baies extrèmement petites, de manière à intercepter le jour et la chaleur.

Il y a bien d'autres types a signaler. Dans le Sennaar, on rencontre des chau- 
mières arrondies en cercle, sur une construction inférieure en argile, en pierre et en paille, et surmontées d'un toit conique couvert de paille. Le fondement est formé par des poutres, des bambous, des roseaux. L'endroit où l'on se couche est isolé par des nattes. Dans le pays d'Ouganda, la hutte a la forme d'une ruche. Ailleurs, elle est a base carrée, et son toit íncliné à pignon est uni ou bilatéral. Les Mombouttous élèvent des constructions très hautes, très légères avec des tiges de palmier. Les cabanes de la Guinée sont à toits inclinés. Sur le lac Mohrya, Stanley a vu des chaumières sur pilotis, et des cavernes servent de demeure à certains indigènes africains. Partout où domine l'islamisme, le style de presque tous les incubles est asiatique. Au Magreb et

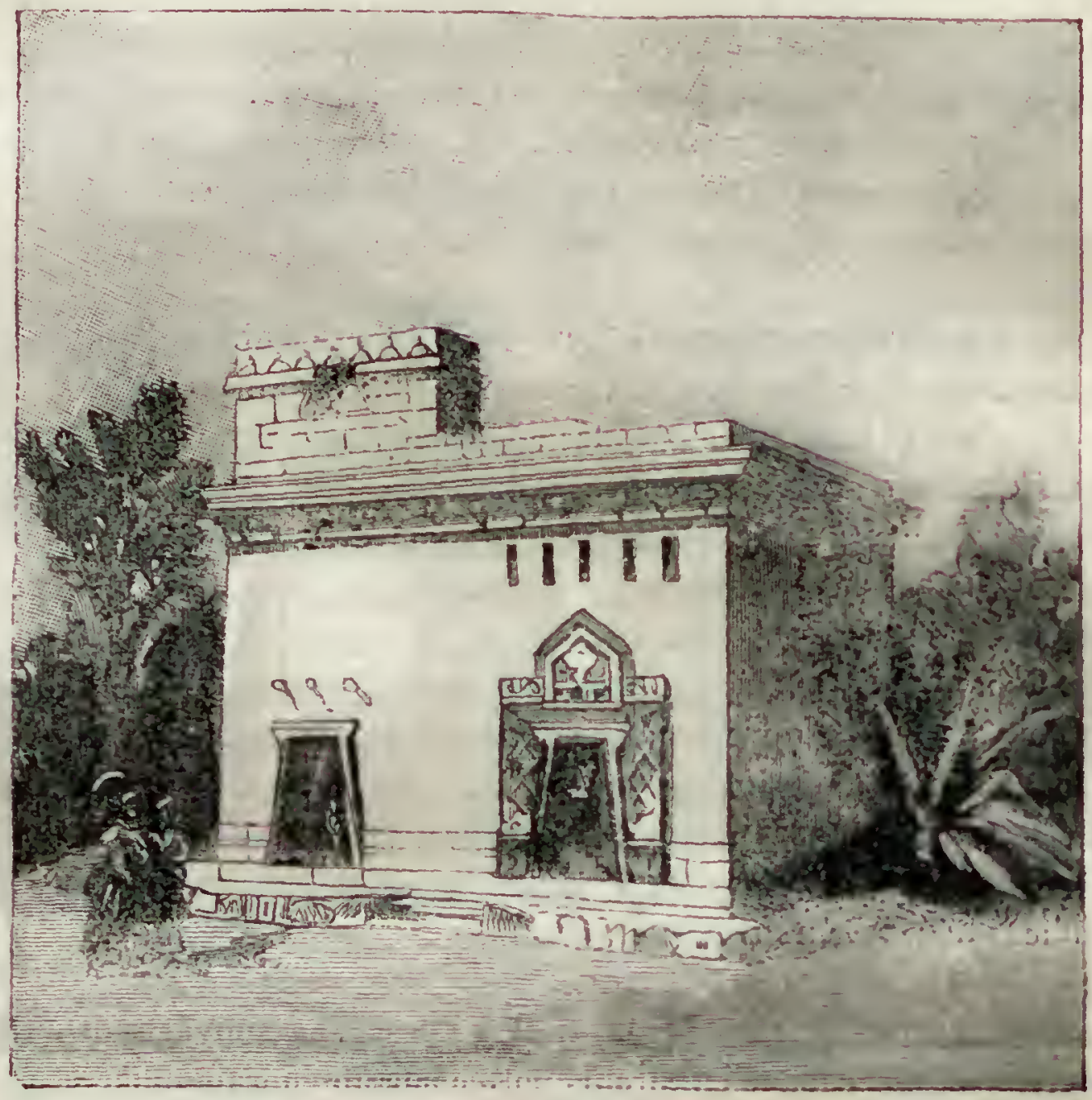

L'habitation humaine. - Type inca.

En Egypte, on retrouve la même profusion de sculptures, de broderies et peintures qu'en Turquie, en Perse et en Arabie, ainsi qu'un grand nombre de tapis aux dessins riches et variés. Dans le pays qui s'étend entre la mer Rouge et la côte de Sénégambie, in retrouve chez plus d'un chef indigène ce même luxe d'ameublement. Dans le Soudan central et occidentall'industrie locale ne manque pas de grace et de richesse; on y fabrique des objets en bois, en vannerie, en cuir et en terre. Les llaoussus produisent des coussins en cuir aux couleurs variées avec goât, qquoique un peu ternes, les Touaregs ont acquis une certaine renommée avec la confection de vases à orifices multiples, et les Berabras, les Fundjés, les habitants des oasis algériennes, les Marocains, confectionnent de charmants objets avec des brins de jonc, de la paille, des feuilles de palmier, des fils de lin ou de laine, des lanières de cuir peints des plus vives couleurs. 
Dans le Sennaar, on fabrique des poteries grossières, qui ont une forme arrondie, rappelant celle de nos vases préhistoriques. Les Gallas et les Abyssins sculptent dans des cornes de bouf des coupes semblables à celles autrefois en usage en Allemagne. Des cuillers, artistement sculptées, sont en usage chez un grand nombre de tribus africaines, telles que les Baris, les Somalis, les Wasnahelis et les Amazoulous. Dans l'Afrique tropicale, la gourde est très employée pour les usages domestiques; ces gourdes possèdent un étui en cuir ou en paille tressée, et sont recouvertes d'un couvercle décoré avec élégance. Les Africains du sud et de l'ouest de l'Afrique se servent

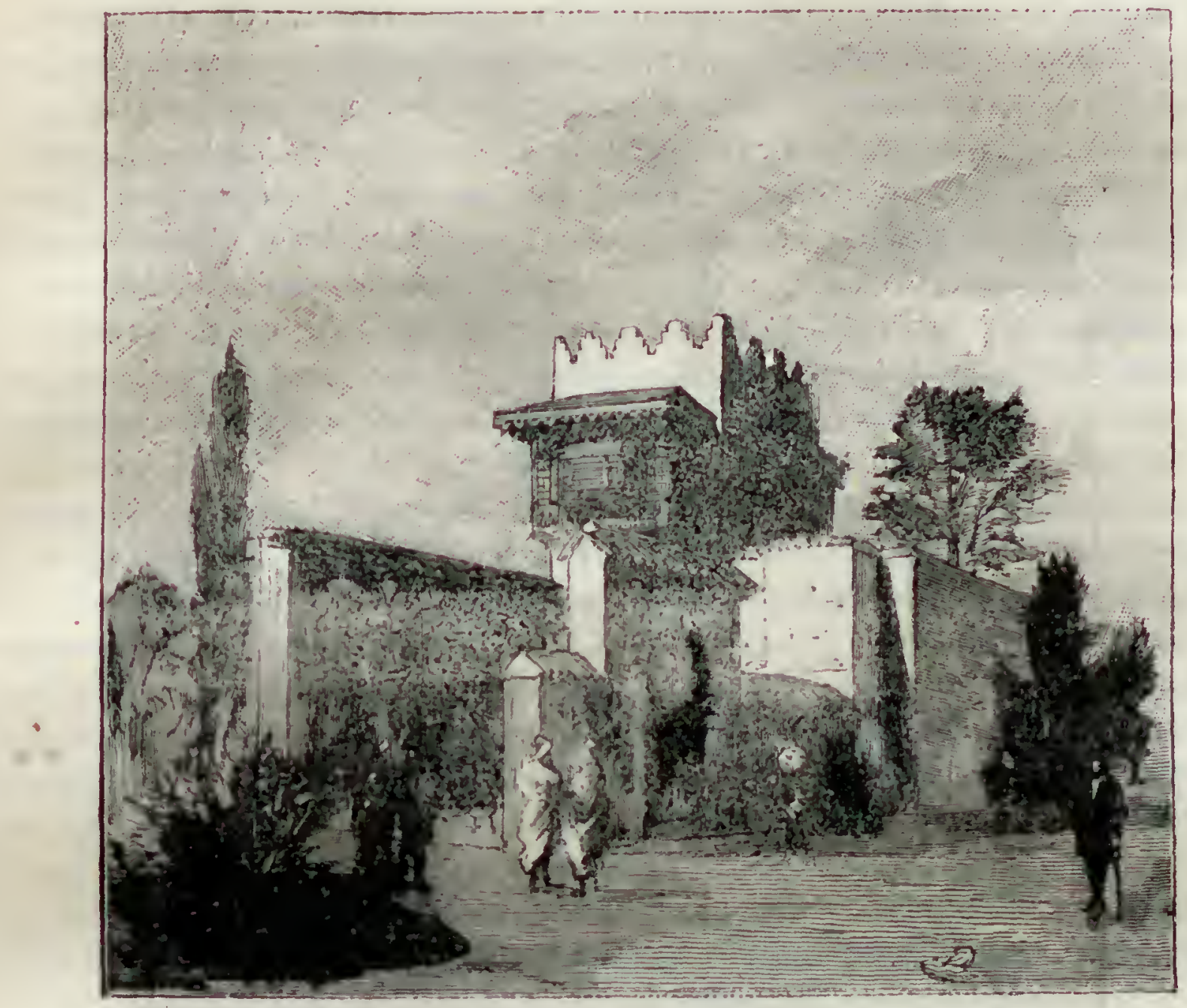

L'habitation humaine. - Type arabe.

de coupes ornées et gravées avec art. Les écuelles de terre et de bois, en usage chez les tribus nigritiennes, sont confectionnées avec le plus grand soin. Le plus souvent l'Africain couche sur la terre nue, sur des branches d'arbre, sur des peaux, sur des nattes, mais certaines peuplades ont des lits de bois plats ou des espèces de sangles.

L'maritation aztèque. - Il élait intéressant de parler de l'habitation des sauvages africains après avoir décril celle des Peaux-Rlouges. Revenons maintenant en Amérique et occupons-nous d'une civilisation disparue : celle des Aztèques.

Les Aztéques, dont la civilisation nous a été récemment révélée, connaissaient l'art de construire. Tout d'abord, à leur arrivée au Mexique, ils se contentaient de cabanes dont les murs étaient faits de boue et de roseau, mais celte habitation peu confortable ne pouvait leur suftire lorsqu'ils arrivèrent à un certain degré de développement social. Les pauvres avaient des maisons en bambous et en brique sèche ou en pierre; 
le toit était formé de feuillages. Il n'y avait qu'un rez-de-chaussée, où l'on vivait en commun lorsque le propriétaire n'était pas assez riche pour avoir plusieurs pièces. Les nobles n'avaient que des demeures en pierre, à deux étages, avec un toit it terrasse en charpente; les murs étaient blanchis et luisauts. Les portes étaient toujours ouvertes, ou, plus exactement, les ouvertures n'avaient pas de portes: les lois étant tris sévères, les Aztèques se trouvaient suffisamment protégés pour n'avoir pas à craindre les voleurs.

Les Aztèques connaissaient l'usage de la voute. "Ils ornaient, dit M. Lucien Biarl, leurs édifices de corniches, et ils en encadraient volontiers les ouvertures d'arabesques. Dans certains palais, on voit ramper sur la façade un serpent prèt à se mordre la queue, après avoir entouré toutes les fenètres de ses anneaux. Les murs qu'élevaient les mafons mexicains étaient droits, bien perpendiculaires, mais on ignore de quels outils et de quels moyens ils faisaient usage. On croit que dans les constructions importantre, ils suppléaient à nos échafaudages en amoncelant de la terre de chaque củté des nur's qu'ils construisaient. Les Aztèques employèrent certainement cet artifice; toutefois, rien ne démontre qu’il ait étẻ mis en œuvre par les Mexicains. Les colonnes à l'aide desquelles ils soutenaient leurs constructions étaient cylindriques ou carries, sans luases ni chapiteaux. Ils les taillaient toujours d'un seul bloc et les ornaient de bas-reliers. $A$ Mexico, ru le peu de solidilé du sol, ils donnaient pour assises i leurs édifices des pilotis en bois de cèdre. En général, c'était à la mème famille d'arbres qu'ils emprun. taient les charpentes de leurs toits, et les colonnes à l'aide desquelles ils les soutenaient étaient de pierre pour des maisons ordinaires, de marbre on d'albatre pour les palais. Jusqu'au règne d'Ahmizotl, ils se servirent de pierres ordinaires, mais ayant découvert près du lac des carrières d'une substance dure, poreuse, légère, facile à unir ņar le mortier, ils l'employèrent exolusivement. Celle pierre, nommce tetzontli (ammydılö̈de poreuse), sert encore aux modernes architectes du Mexique. Le pavé des temples et des palais se composait de larges dalles en marbre de dilférentes couleurs.

- Bien que l'architecture aztèque n'ait pas enfanté les merveilles qui placent l'lu. rope au premier rang, il est certain que les Espagnols furent si surpris de la beauté des palais de Mexico que Cortez, dans ses lettres à Charles-Quint, ne Irouve pas d'expressions assez forles pour les vanter. "Le roi Montézuma, écrit-il, posside à Mexico - des maisons si vastes et si merveilleuses que je ne puis en mieus faire comprendre la " beauté qu'en déclarant qu'il n'y en a pas de pareilles en Espagne. ,

Dans la demeure aztèque, que l'on verra reconstituée au quai d'Orsay, il n'y a d'autres malériaux mis en œuvre que la pierre de taille; le bois, insuffisamment préparé, n’aurait pas résisté à la destruction par les insectes, si fréquents dans la rízlon équatoriale. La décoration est empruntée uniquement aux formes géométriques of affecte une raideur particulière. Comme disposition architecturale, on peut signaler la forme trapézoïdale de la façade antérieure de l'élage, correspondant a celle de la converture constituée par une série de plates-bandes en échelons. Une sorte d'auvent en pierre est établi au-dessus de la porte d'entrie et règne tout autour de l'édifice; il c:l soutenu de distance en distance par des consoles également en pierre et dont les abouts sont grossièrement moulurés.

L'HABITATIOA DEs InCAs. - On retrouve quelgues-uns de ces caracteres dans le type 
l'habitation des Incas, notamment l'emploi exclusif de la pierre de taille, et la décoration à l'aide de moulures géométriques. Mais l'édifice est beaucoup moins massif; l'ornementation y est aussi plus sobre et se restreint à une frise générale régnant tout autour de l'entablement qui porte la terrasse supćrieure et à l'encadrement des portes. Celui-ci présente cette particularité que le inur extérieur est évidé au pourtour de la porte, et que toute la décoration fait saillie sur cet évidement au lieu de former ressant sur lui-mème. L’édifice est élevé sur marches.

Les anciens Péruviens étaient un peuple agriculteur. Pour favoriser l'agriculture, les Incas firent exécuter de grands travaux publics, tels que des murs de soutènement pour prévenir l'érosion des pentes, des magasins de guanos, des canaux d'irrigation soigneusement entretenus. Le bien-ètre matériel favorisa la naissance d'une classe nombreuse d'artisans et de citudins. De grandes routes, partant de Cuzco el larges de 5 a 8 mètres, rayonnaient dans toutes les directions. Pour franchir les cours d'eau, il y avait des ponts en pierre, en lianes solidement tressées, en cordes. Sur les routes des réservoirs d'eau potable étaient établis de distance en distance. C'est une civilisation curieuse que celle des Incas, et M. Garnier aura renclu un service a l'érudition en appelant sur elle l'attention des nombreux visiteurs de l'Exposition universelle.

Linamition anabe. - Les Arabes ont conquis tant de pays divers que les matériaux employés dans leurs constructions ne sont pas les mes partout. Ils se servirent de la brique, de la pierre, d'un béton formé de chaux, de sable, d'argile et de cailloux. Commeils trouvèrent un grand nombre de monuments dans les régions où ils s'étihlirent, ils utilisèrent d'abord des colonnes et des chapiteaux grees, romains, byzalitins, mais plus tard ils devinrent vrainent architectes et donnèrent à leurs constructions un cachet vraiment personnel. M. le Dr Gustave Le Bon, qui a entrepris une histoire conıplete des civilisations, a pris la peine de parcourir l'Orient musulman, de relever partout des indications et de restituer à l'architecture arabe, par des comparaisons multiples, son vérilable caractère. "L’ogive, de mème que l'arc outrepassé, forment deux caractéristiques de l'architecture arabe que l'on rencontre dans leurs premiers monuments. J'ai, dit M. Le lion, trouvé l’ogive employée concurremment avec le plein cintre dans les plus anciens monuments arabes que j'ai cu occasion d'étudier en Europe, en $A$ sie et en Afrique. La brisure de l'arc à son sommet, de mème que l'étranglement d sa base, qui s'accentuera dans les monuments postérieurs, sont d'abord très faibles, et il faut quelque altention pour les reconnaitre. Ils existent cependant et suffisent à donrer à la courbe une forme très gracieuse. Liogive s'accentua de plus en plus en Égypte, mais le retour de l'arc à sa base ne fut jamais très prononcé. Lin Espagne, en Afrique, il s'exagéra au contraire au point de donner à l'ouverture cette forme particulière que l'on a désignée sous le noun de fer à cheval ou arc outrepassé et qui fut la caractéristique de l'art arabe dans ces deux contrées à une certaine époque.,

La forme des minarets, dont l'usage est partout le meme, varie comme les matériaux selon les pays; ils sont coniques, carrés, cylindriques, etc., et couronnés de crénuaux en forme de trèlles, fers de lance, fers de hallebardes, etc. Ils donnèrent aux. coupoles une forne nouvelle élancée au sommet, rétrécie à la base. M. Le Bon fait remarquer justement que les Arabes eurent une profonde antipathie pour les surfaces unies, aingles et rectangles. Afin de combler les coins des murs se coupant à angle 
droit et pour relier par des transitions insensibles des voutes circulaires aux salles carrées qui les supportent, ils ont fait usage de petites ruches en encorbellement ayant la forme d'un triangle sphérique. On les a nommés pendentifs, parce qu'elles pendent sur le vide. Ces petites voutes leur paraissant trop géométriques, ils les ont superposées par séries graduelles, et sont arrivés à former un ensemble qu'on a nommé stalactites et dont l'aspect rappelle celui d'une ruche d'abeilles. L'usage des stalactites en pendentifs est spécial aux Arabes et n'a été retrouvé jusqu'à présent chez aucun autre peuple. \$ Quant à l'ornementation, elle est formée de dessins géométriques connus sous le nom d'arabesques. La décoration est le plus souvent polychrome.

Les maisons particulières, dont M. Garnier nous donne un modele remarquable, sont constituées par une construction massive surmontće d'une terrasse. A l'un des

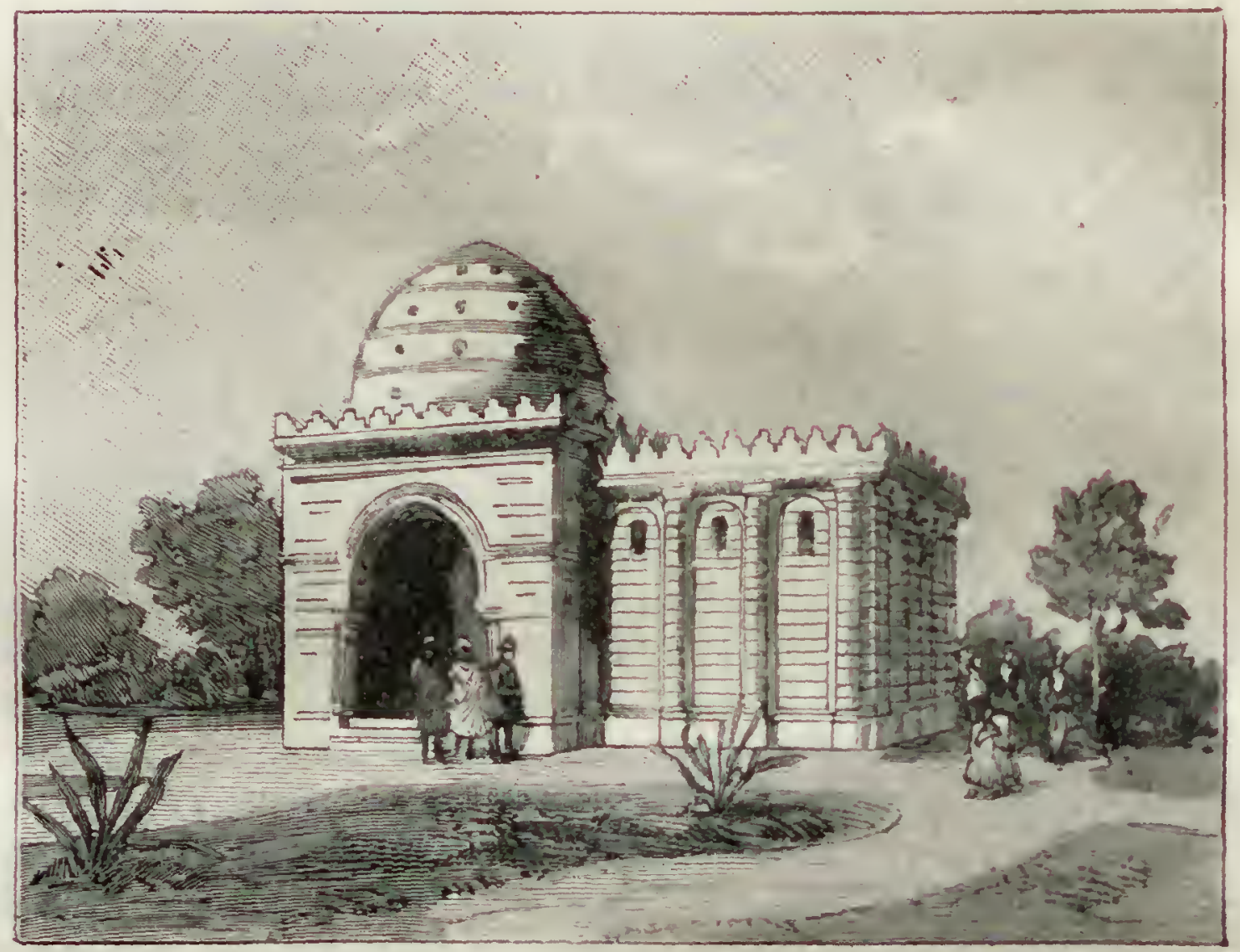

L'habitation humaine. - Type persan

angles se dresse une tour carrée avec un terrasse à créneaux aigus et ne prenant jour sur la rue que par un élégant moucharabieh. La conception de la vie intime conduit l'Arabe d éclaircir les appartements habités par des baies s'ouvrant sur une vaste cour entourée d'élégantes colonnettes et richement décorée de faĩences vernissées à tons clairs et brillants. L'accès de l'extérieur se fait par une porte à arc outrepassé. Les bois, le stuc et la faïence jouent un grand rôle dans ces constructions, et tous les murs de supports isolés sont reliés par un système de charpente horizontale.

Le rez-de-chaussée des maisons arabes est réservé aux domestiques et serviteurs. On arrive à la salle du divan par un grand escalier en bois. Après avoir gravi cet escalier, on pénètre dans un corridor menant aux pièces réservées aux hommes et qui se prolonge sur trois côtés de la cour. Des kiosques, ornés d'une masse d'arabesques, s'élèvent à chaque angle, et servent de salles d'attente pour les étrangers qui ont demandé une audience. C'est là aussi que les serviteurs de service se tiennent à la dis- 
position de leurs maltres. Le principal corps de logis comprend deux parties : la première est habitée par le maitre de la maison, ses enfants et le personnél nécesssaire et accessible aux étrangers; la seconde est réservée aux femmes et les maris ont seuls le droit d'y pénétrer : c'est le harem. Les chambres du salem-lit sont larges, mais d'une hauteur médiocre; elles sont meublées de tapis et de sofas, et les murs sont peints d'une couleur unique. Un précepte du Coran est tracé au-dessus de la porte d'entrée et sur toutes les parties du mur on lit les noms vénérés de Dieu et du Prophète. Dans la salle du divan, les tentures sont plus riches, les fenêtres sont décorées avec recherche et peuvent produire à volonté tous les degrés de lumière. On y vient

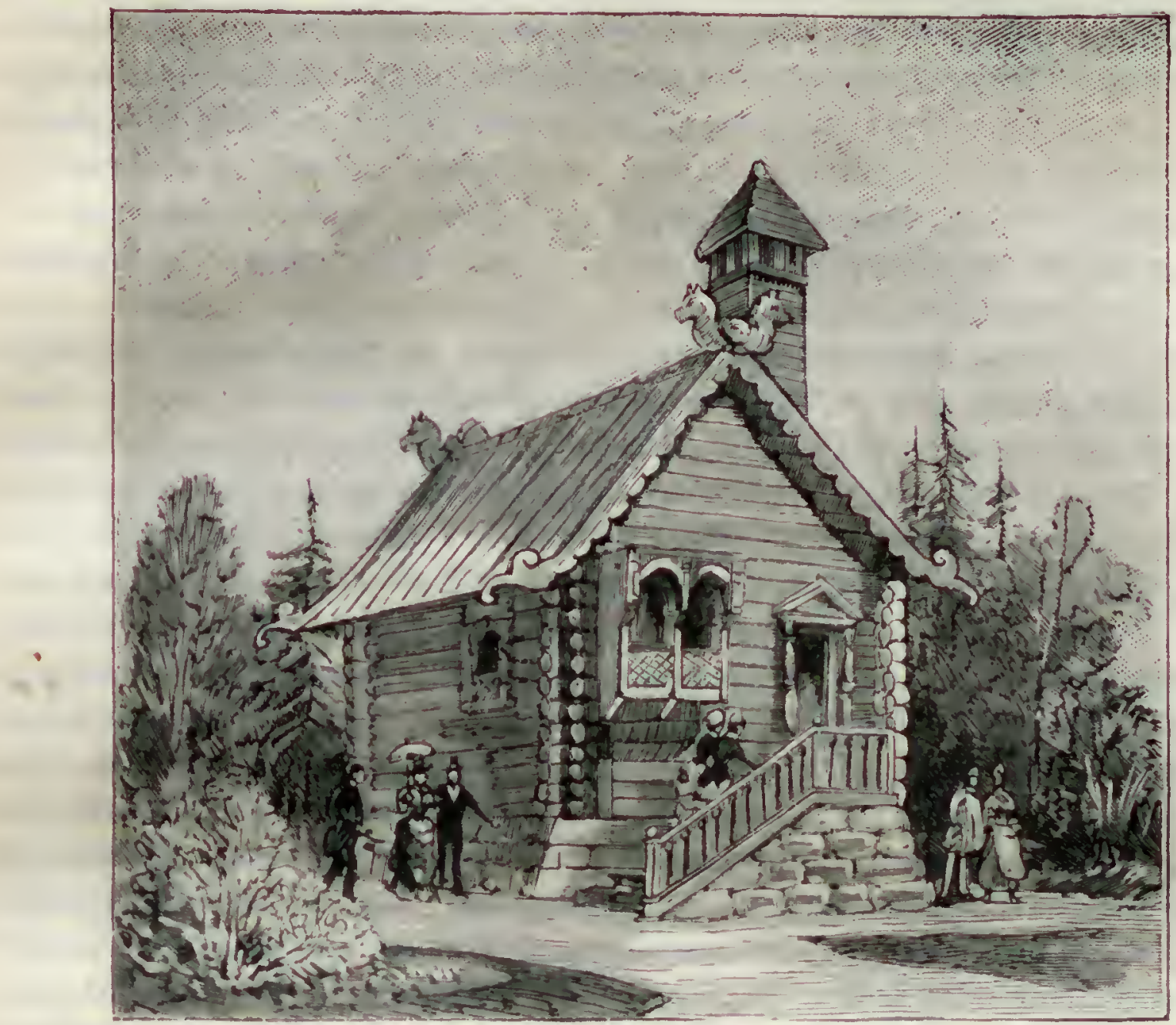

L'habitation humake. - Type japonais.

pendant les lourdes chaleurs de l'été respirer un air moins fatigant. Les boiseries constituent une des plus importantes décorations des habitations musulmanes et quelques-unes sont de véritables chefs-d'œuvre.

L'inabitation pensane. - On.remarque dans l'halitation persane l'arcade ogivale de la baie d'entrée, arcade qui se rattache à la verticale des pieds-droits par une courbe brisée. Une innovation l'accompagne, c'est celle du dùme, peu élevé, il est vrai, car il est lourd et écrasé. Ici, l'on ne rencontre plus la pierre de taille, sauf dans le socle et les marches de l'escalier. Les briques cuites au soleil et les briques vernissées sont les éléments les plus importants de la construction: seules, d'ailleurs, elles ont permis l'édification du dôme à une époque où la coupe des pierres était inconnue. Elles se prêtent aussi très facilement à l'ornementation, les unes par les ressauts des moulures 
et des colonnes prises dans l'épaisseur des murs, les autres pour l'exécution de ces décorations polychromes dont la Perse sait encore aujourd'hui tirer des effets si riches et si variés.

Linabitation japoratse. - L'habitation japonaise, comme l'habitation chinoise, donne à la charpente qui en constitue l'ossature une importance considérable, et cotle préférence s'explique par la fréquence des tremblements de terre, auxquels résisteraicnt diflcilement des constructions en matériaux moins élastiques. Mais les vides qu'elle laisse ne sont pas remplis par une maconnerie plus ou moins épaisse. De petites lattes forment par leurs croisements de légers appuis sur lesquels on élend le papier hnilé qui sépare l'intérieur de la rue. .Des pans de sapin très minces et mobiles dans des coulisses forment les cloisons intérieure et extérieure. Le toit, en bambon dans les campagnes et en tuiles dans les villes, s'élève sur un premier étage desservi par un balcon qui règne sur son périmètre et dont les supports soutiennent une véranda abritant l'entrée de l'habitation. Telle qu'elle est représentée, l'habitation japonaise évoque par sa gràce et par sà légèreté, l'idée d'une jolie volière qui n’allend plus que des oiseaux pour s'animer.

Qu'on ne s'imagine pas que M. Garnier ait construit un type d'habitation plus ou moins fanlaisiste. Un des derniers vuyageurs qui ont visité le Japon, M. Raymond de Dalmas, dit dans sa description de Tolio: " Malgrẻ les énormes différencas de température existant dans les diverses lles du Japon, les maisons sont partout semblables, au nord comme au sud, et paraissent exclusivement faites pour les pays chauds; elles sont uniquement cons'suites en bois, en paille et en papier, et ne sont pourvues d'aucun sérieux moyen de chauffage. Est-ce négligence de la part des habitants, ou routine pour suivre les anciennes coutumes de leurs pères? Dans tous les cus. le fait parait difficile à expliquer. Les tremblements de terre, il est vrai, leur interdisent la construction des édifices solides et les forcent à avoir des habitations basses, très légères et très flexibles, pouvant se prèter et suivre sans s'écrouler les oscillations du terrain, atteignant fréquemment une grande amplitude. 'our cette raison, les maisons ont en général un seul étage peu élevé; quatre poutres supportent un toit recouvert de chaume épais ou de minces planchettes dans les campagne et les villages et souvent de tuiles et même de feuilles de zinc, dans les grandes villes; il est formé de quatre plans peu inclinés et déborde de tous côtés comme les toits des maisons turques. Le plancher, élevé de 50 à 60 centimètres au-dessus du sol pour préserver de l'humidité, est couvert. mème dans les habitations les plus pauvres, de tatani, paillassons très fins et très épais retenus dans des cadres de bois rectangulaires; les tatani ont des dimensions constantes et sont désignés dans la vie usuelle comme mesure de surface. Ces nattes forment un sol assez moelleux et servent à la fois de lit, de siège et de table. Sur une seule ou sur deux des faces de la maison, le mur est fermé par n treillis de bambous masliqués avec de la terre. "Les autres côtés sont fermés par des châssis de bois très légers glissant dans des rainures en haut et en bas, et recouverts de papier blanc. Ils sont censés garantir du froid et du vent, et font en mème temps l'office de portes et de fenêtres; mais leurs carreaux de papier ne laissent pénétrer à l'intérieur qu'nne lumière tres insuffisante et en revanche sont rarement intacts; de plus, ces chassis ne firment jamais bien et ne sont munis daucune serrure ni verrou. A l'intérieur, les chambres, pelites et carrées, sont separées les unes des autres par des feuilles de paravents 
engages aussi dans des rainures; de cette façon, les habitants d'une même maison sont forcés de mener une vie absolument commune. A l'extérieur règne un couloir qui, fermé la nuit par deş panneaux, protège les habitants contre les voleurs et contre les intempéries. Quant d l'arneublement, M. de Dalmas nous raconte qu'il est rudimentaire: quelques tableaux en papier, une armoire de très petite dimension, une sorte de réchaud l'hiver, un allume-pipe, des bibelots, quelques plantes. La cuisine se fait dans un hangar qui touche a la maison et est muni d'un âtre de pierre. Il y a aussi, pour chaque maison, une cour exiguë ou un tout petit jardin, avec un bassin de poissons rouges.

Les façades demeurent ouvertes le jour. C'est là que sont établies les boutiques. Le marchand est accroupi au milieu mème de son étalage et les clients s'assoient sur le parquet. Il est vrai de dire que depuis quelques années, on a construit dans les principales villes du Japon des magasins à l'européenne.

L'habitation cunorse. - Plusieurs archéologues affirment que les premiers édifices élevés par les Célestes furent construits sur le modèle des tentes qu'habitait primitivement ce peuple pasteur : Les nombreux piliers de bois, sans base ni chapiteaux, qui supportent le plafond des édifices chinois, dit Hope, représentent les pieux primitifs. Les toits, qui de ces piliers semblent projeter au loin leur dos et leurs côtes, en conservant la forme convexe, sont les peaux et les étoffes pliantes étendues sur les cordes et les lambous. Dans les pointes recourbées qui bordent ces toits, nous voyons les crochels qui retenaient les peaux déployées. Enfin, dans l'étendue, le peu de hauteur et l'agglomération des différentes parties, nous reconnaissons toutes les formes et le caractère distinctif des habitations de ces pasteurs dont les Chinois sont descendus. Les maisons chinoises semblent altachées à des pieux qui, plantés en terre, auraient fini par y prendre racine et par s'inmobiliser. Les palais ressemblent à un certain nombre de tentes réunies; les pagodes elles-mêmes, les tours les plus élevées, ne sont rien autre chose que des tentes amoncelées, empilées, pour ainsi dire, l'une dans l'autre, au lieu d'ètre placées côte a côte. Toute agglomération de maisons, depuis le plus petit villıge jusqu'à la résidence impériale d̀ Pékin, ne présente dans sa distribution que l'image d'un camp, et, quand lord Macartney, après avoir traversé tout l'empire de la Chine, dans sa plus grande étendue, de Canton à la Grande Muraille, fut arrivé aux confins de la Tartarie et reçı par l'empereur dans une véritable tente, à peine pútil apercevoir une différence entre cette dernière et les milliers d'édifices qu'il avait vus. , Ce qu'il y a de sưr, et quels que soient les mocieles dont ils se sont inspirés, c'est que les architectes chinois ont voulu avant tout rendre leurs constructions gracieuses. Les villes sont généralement construites avec symétrie, et peu de capitales présentent autant que Pékin, dans leur ensemble, une régularité aussi parfaite. Les maisons n'ont rien de grandiose, mais elles plaisent à l'œil. Elles tendent, le plus souvent, dit 1I. Batissier, vers la forme pyramidale, et se composent pour la plupart de plusieurs étages de toils dont les angles sont relevés et ornés de cloches ou de figures fantastiques. Leurs colonnes sont de bois, presque toujours, et appuient sur une base de pierre; leur extrémité supérieure, au lieu d'avoir un chapiteau, est traversée par des poutres. Les murs sont revetus de briques séchées ou cuites et vernissées. Les tuiles des-toits sont demi-cylindriques. Quant à l'appareil dont les Chinois se servent, c'est à pruprement parler l'emplecton des Grecs; il n'emploie que des matériaux de petites dimensions. 
En général, tous les édifices sonł peints et produisent un effet charmant. La résidence. impériale est une vaste agglomération de palais, surtout remarquables par le nombre considérable des appartements qu’ils présentent et le luxe excessif de leur clécoration intérieure : partout des objets d'un luxe inouï, des trésor's, des antiquités, des entassenents de porcelaine du beau temps de Nankin, des vases de hauteur d'homme en argent et en or massif, des émaux cloisonnés des $x{ }^{11^{e}}$ et $x v 11^{\circ}$ siècles, des boltes, des meubles, des cassettes en laque rouge de Pékin, des jades verts et blancs et des agates. des festons de santal, des bronzes, des perles de Ceylan et de Jolo.

Les palais des mandarins sont plus grands, plus somplueux que les autres habitations : ils sont souvent précédés de mats vénitiens d'une grande hauteur auxquels flottent des banderoles à fond jaune, figures de li puissance impériale; souvent aussi la cour d'honneur est décorée de figures de lions, de dragons et autres bètes symboliques. Enfin tout le monde a entendu parler de ces édifices si nombreux en Chine comme au Tonkin, que nous zonnaissons sous le nom de pagodes et que les indigènes appellent taas. Ce sont des tours polygonales, très élancées, divisées en étages dont le nombre mystique est toujours impair, et qui vont en diminuant de diamétre; elles sont munies d'une galeric extérieure avec balustrade à jour et d'une corniche sur laquelle s'applique un toit concave. Le plus célèbre de ces édifices était le taa de Nankin, la Tour de porcelciine, qui eut malheureusement beaucoup ì souffrir de l'insurrection des 'Tä̈-pings. Elle avait neuf étages, mesurait à sa base près de trente mètres de diametre et avait cent sept metres de hauteur, y compris une espece d'aiguille de vingtsept mètres, qui la dominait.

Lorsqu'on entre dans une ville chinoise, on éprouve d'abord une impression de monotonie, comme si l'on avait sous les yeux, malgré les apparences, un type architectural unique. Cette impression est conforme aux faits. Dans son beau livre sur l'Ar chinois, M. Paléologue s'exprime en ces termes : La Chine n'a eu à toutes les éporjues de son histoire et pour tous ses édifices cịvils ou religieux, publics ou privés, qu'un seul modèle d'architecture. Én ce qui concerne l'antiquité chinoise nous sommes obligés de nous en référer aux documents écrits et aux reproductions grapliques, car il n'existe pas dans tout l'Empire du .Iilieu de monument antérieur au $\mathrm{xI}^{\mathrm{e}}$ sidcle de nutl. ère. Quatre ou cinq cents ans avant Jésus-Christ, les Chinois construisaient dêjà leurs monuments et leurs maisons sur le plan dont ils se servent encore aujourd'hui. La brique et le bois ont été de tout temps les principaux, presque les seuls matériaux de construction usités en Chine. Il est difficile de déterminel les raisons pour lesquelles les Chinois ont fait si rarement usage de la pierre dans leurs édilices. Ce n'est pas la rareté de la pierre: on en trouve, en effet, en abondance dans toutes les provinces: d'ailleurs la plupart des villes ont des quartiers entiers pavés de larges ralles. L unique raison qui nous paraisse justifier l'emploi presque exclusif que les Chinois ont toujours fait des matériaux légers est l'idée, toute différente de la nùtre, qu'ils ont conçue de la durée à assigner aux constructions. Avec leur esprit éminemment positif, sans grande vue ni ambition, ils estiment qu'un édifice qui est demeuré debout autant que la génération qui l'a vu élever a satisfait à sa destination. , M. Paléologue croit que cle toute antiquité les Chinois ont connu la voùte, mais qu'ils s'en sont rarement servis, si ce n'est pour les ponts et les remparts. La formule de l'art chinois, c'est le t'ing, c'est-idire le toit recourbé reposant sur des colonnes courtes. I Le t'ing, avec ses extlémités recourbées comme le sont les angles d'une tente relevés par des piques, avec celte 
incurvation du milicu de la pente qui rappelle le creux formé par la souplesse pesante de la toile, présente en effet une ressemblance frappante avec une tente : l'absence du plafond, des fenêtres latérales, et généralement aussi d'ćtage supéricur, est un trait commun de plus. Qu'il s'agisse de palais, d'arc de triomphe, de maisons particulières, c'est toujours sur le type du t'ing que la construction a été batie. Il y a en effet en Chine une réglementation officielle dont personne ne songe à s'écarter.

Tels qu'ils figurent au pied de la Tour Eiffel, les divers types qui constituent l'histoire de l'habitation forment une remarquable leg̣on de choses et donnent une idée très complète des procédés de construction et d'ornementation architecturales usités chez les divers peuples à un grand nombre d'époques de la civilisation. Un puissant élé-

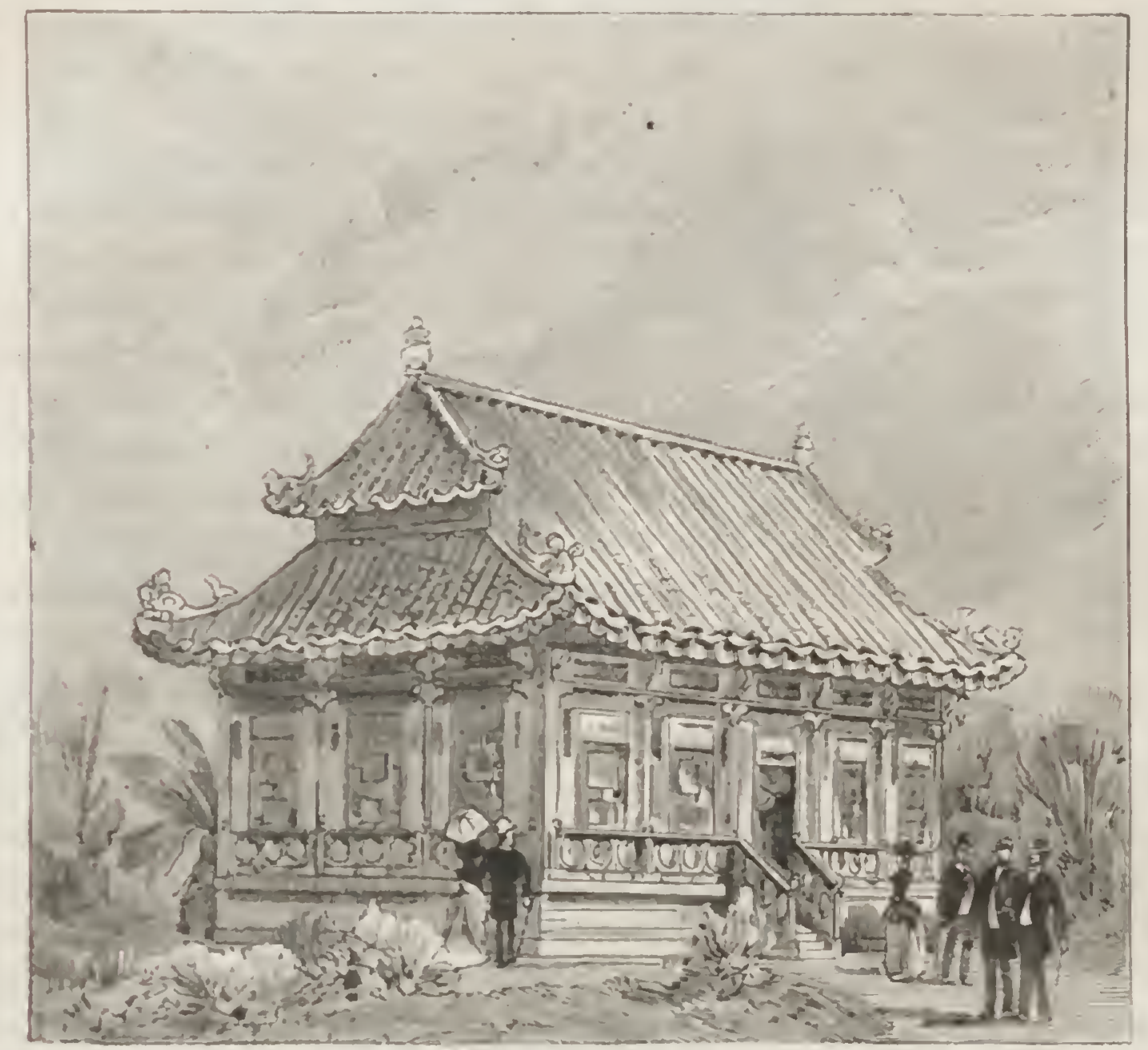

Linamiation hicmani. - Type chinois.

ment d'intérết va y être ajouté par des motifs de décorations savamment combinés et multipliés autour des habitations, tels que places, jardins, puits, fontaines, citernes, tous relatifs aux divers époques étudiées. Des inscriptions faisant connaitre la provenance des types seront rédligées en langue française et aussi selon l'écriture du temps. M. Garnier a également l'intention de peupler ces constructions de personnages portant les costumes conformes aux tỵpes et aux époques représentées. Il ne serait pas inutile, croyons-nous, surtout pour des édifices relatifs aux cirilisations primitives, d'indiquer sommairement les dimensions réelles qu'ils présentaient et que l'exiguité de l'espace et des ressources a naturellement obligé à réduire. En terminant, il nous reste à féliciter M. Charles Garnier de l'heureuse idée qu'il a fait adopter à la direction de l'Exposition et a ses collaborateurs, MM. Amman, professeur agrégé d'histoire au lycée Louis-le-Grand, et Darvant, sculpteur, qui l'un pour la partie historique, l'autre 
pour la partie décorative, ont contribué puissamment a la réalisation de cette conception originale. L'histoire de l'habitation, c'est en somme le résumé des efforts de l'homme pour se préserver de mieux en mieux des atteintes de la nature; c'est une partie importante de l'économie politique, en mème temps qu'une œuvre d'art.

\section{VII}

\section{L'ACHEVENETT DE LA TOLR EIPFEL}

Nous avons, au début de cet ouvrage, donné sur les premiers travaux de la Tour Eiffel les renseignements les plus circonstanciés. Il nous reste à compléter notre précé. dent chapitre, c'est-à-dire à conduire la tour de 300 mètres jusqu'à son achèvement.

Ceux qui ont suivi attentivement les travaux ont été frappés de la régularité avec laquelle les chantiers successifs se sont installés et organisés. Le public s'imaginait que les grandes hauteurs influenceraient le moral des ouvriers. Il n'en a rien été. Montant incessamment et régulièrement, avec la construction mème, ces équipes disciplinées et entièrement dévouées à leur besogne n’ont éprouvé aucune défaillance sérieuse. A כ̌7 mètres, elles ont trouvé dans le plancher du premier étage comme un nouveau sol audessus duquel les ouvriers se sont élevés avec confiance; 115 mètres, ils en ont trouvé un second. Dailleurs, ils n ont point couru des dangers extraordinaires dans ces chantiers aériens. L'œuvre s'est inontée par panneaux successifs, formant un assemblage complet et rigide. Or, aucun panneau n'est placé dans ces conditions sans qu'un plancher provisoire ait été établi, muni de claies et de garde-fous. Ae plancher, dit M. Max Nansouty, monte avec l'ouvrier, le défendant contre le vertige et lui assurant tout à la fois la plénitude de ses facultés et la sécurité de ses mouvements. Une équipe de six charpentiers de premier ordre établit, tout d'abord, cette plate-forme volante que viennent ensuite occuper les monteurs et les riveurs; eux seuls pourraient ètre exposcis à des chutes, et il ne s'en est produit qu'une seule parmi ces ouvriers spéciaux, tout à fait au début du travail. En ce qui concerne la différence de température entre le bas de la tour et les parties élevées, à partir de 200 mètres, on n'a guère relevé pendaut l'hiver, assez clément à la vérité, de 1888-1889, que ă à 6 degrés de différence. Souvent mème, lorsque le brouillard enveloppait Paris, la partie de la Tour émergente était à une température supérieure à celle de ses assises, car elle recevait directement l'action des rayons solaires, alors que les parties basses étaient plongées dans les brumes et

l'humidité. Cette constatation donne d'avance un réel intérêt aux expériences oúrentıfiques concernant la physique du globe et la météorologie qui seront faites au sommet de la tour. Les riveurs, placés auprès de leurs forges et livrés à leur travail mouvementé ne paraissent pas avoir souffert du froid pendant celte campagne d'hiver déci.sive. Ils en avaient vu bien d'autres sur les chantiers des viaducs de Garabit et de la Tardes et ont refusé de faire usage des vètements chauds en peau de mouton que M. Eiffel avait mis a leur disposition.,

Les escaliers à étages inclinés et les palier qui mènent de la base de la Tour a a 
premier étage sont trìs doux. On y passe aisément trois de front du premier au second étage et, au dela, il n'y avait plus de place pour une pareille installation, et M. Eiffel a employé des escaliers à vis dont chacun s'enroule autour d'un tuyau de fer d'un diamètre extéricur de 40 centimètres. Ces divers tuyaux sont maintenus verticalement par de solides traverses en fer reliées aux montants de 11 en 11 mùtres. Les marches mesurent 60 centimètres de largeur. Tous les 9 mètres, l'escalier s'incline pour regagner la verticile.

A partir du second étage (115 mètres), le travail de montage au moyen de grues subit des modifications importantes. Tout d'abord, il y avait eu quatre grues de montiage s'élevant sur les chemins de roulement inclinés des ascenseurs. A partir de 115 mètres, le systène d'ascenseurs est remplacé par le système Édoux vertical, et des lors non seulement il n'y avait plus de chemin utilisable pour la montée des grues, mais en raison de la diminution de section horizontale de la Tour, les quatre grands pieds se réunissent pour former la pyramide finale quadrangulaire à faces courbes. Au lieu de quatre grues de montage, on n'en a plus employé que deux. Au chemin de ronlement des ascenseurs, M. Eiffel substitua pour le montage les piliers verticaux étabilis depuis le second étage jusqu'au sommet de la Tour et qui servent de guidage aux -censeurs Édoux fonctionnant verticalement dans cette partie de la Tour; le point d'appui ne fut donc plus le mème. Les grues furent modifiées de façon à se hisser contre un support vertical, au lieu de griffer sur un support incliné. Fixées sur les deux faces opposées du pilier central des ascenseurs, elles se firent respectivement équilibre sans tendre au déversement. Elles purent monter tout un panneau de la Tour sur une hauteur de 10 à 11 mètres, et leur relevage à bout de course ne demanda que quarantehuit heures de travail.

Les ascenseurs de la Tour déposent les visiteurs sur un plancher situé exactement à $309^{\mathrm{m}}, 03$ au-dessus du niveau de la mer et à $273^{\mathrm{m}}, 13$ au-dessus de la base de la construction. A $2^{\mathrm{m}}$, כo 8 plus haut, $\mathbf{1 1}$. Eiffel a tout fait préparerpour les expériences scientifiques. Autour de cette région élevée règne un balcon octogonal que dominent quatre grands arceaux de fer constituant le campanile. Un escalier tournant s'enroule autour de l'axe du campanile; il conduit sur un nouveau plancher circulaire à balcon situé a $290^{\mathrm{m}}, 815$ au-dessus de la base de la Tour et au-dessus duquel un phare électrique avec feu fixe de premier ordre donnera des éclats bleus, blancs et rouges, pendant que des projecteurs enverront sur Paris leurs faisceaux lumincux. Le sommet de la calotte du phare est à 300 mètres au-dessus du sol, à $333^{\mathrm{m}}, 50$ au-dessus du niveau de la mer. Un grand paratonnerre le surmonte. Le plancher de $273^{\mathrm{m}}, 13$ peut contenir 800 visitcurs; il mesure $16^{\mathrm{m}}, 50$ de côté et fait partie d'une galerie à châssis vitrés et mobiles. Les arceaux à treillis qui constituent le campanile se coupent suivant les diagonales de la scction carrée de la Tour. Le phare lancera des feux dans un rayon de 70 kilomètres.

Ceux qui voudront avoir par avance une idée de l'impression que produira l'ascension de la Tour jusqu'd la hauteur de 1150 mètres n'ont qu’à aller au musée Grévin, dont les organisateurs leur offriront sous forme de panorama le mème spectacle et la mème impression. Ce panorama représente la Tour au moment où elle est parvenue ì une hauteur de 115 mètres, un pen au-dessus de la deuxième plate-forme. La maquette a en réalití 12 mètres d'élévalion, le dixiène à peu juès de celle à laquelle le spectateur se croira placé. Laspect général est le suivant. Les équipes d'ourriers monteurs et 
riveurs sont au travail, dirigés par $M$. Eiffel et ses ingénieurs, qui font constater aux directeurs de l'Exposition, MM. Alphand et Berger, l'avancement des travaux. Les

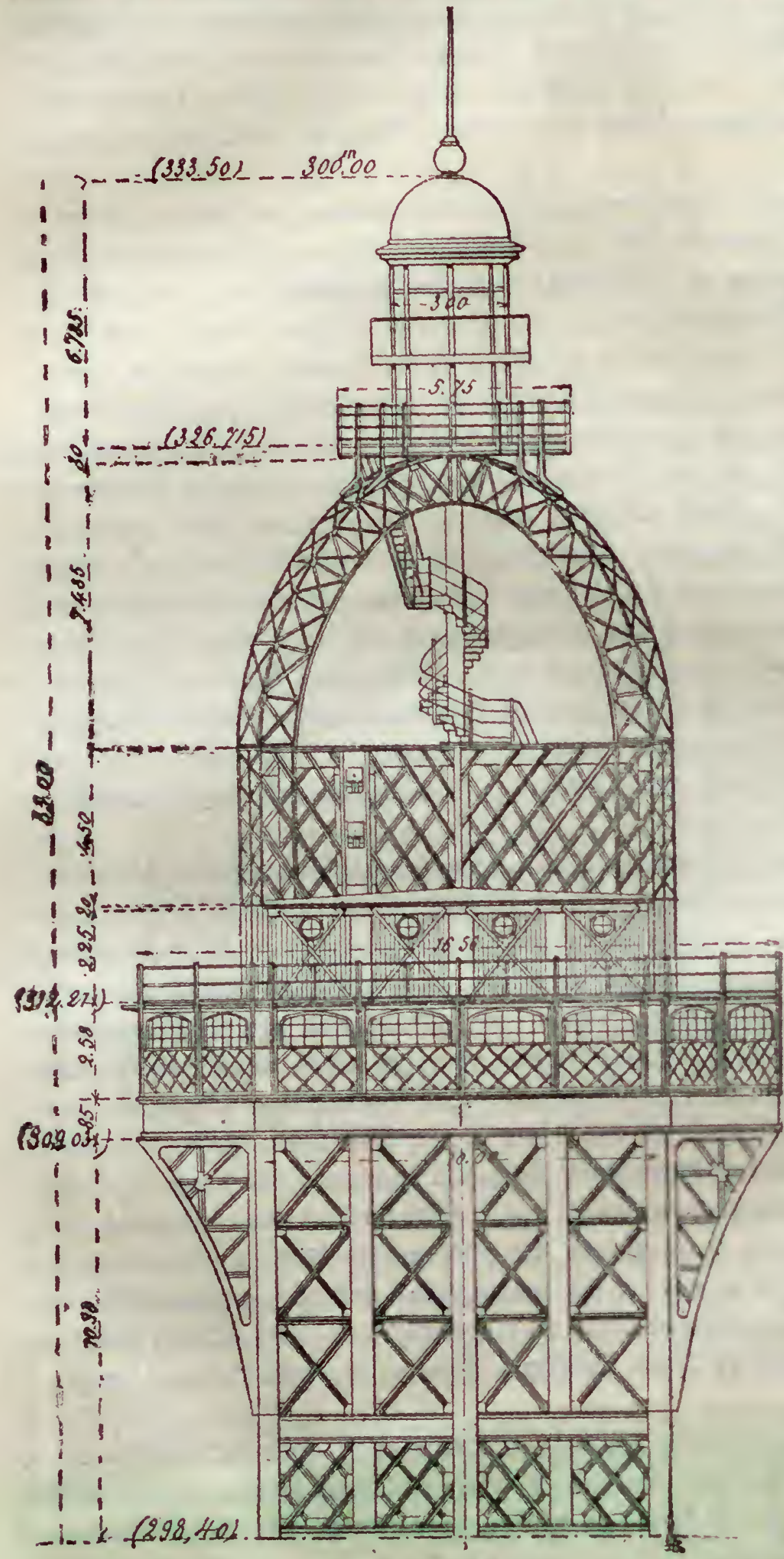

Le couronnement de la Tour et le campanile. passages aboutissant au panorama ont été disposés de manière à donner au public l'illusion du plein air. Des tons sombres et une pénombre graduée lui réservent la surprenante découverte d'une énorme étendue do terrain se développant sur une toile de $40 \mathrm{me}-$ tres de longueur et 14 mètres de hauteur, peinte par MII. Rubé, Chaperon et Jamboin. Les pièces de la charpente de la Tour ont été exactement reproduites, en bois, et peintes de la couleur mème qu'elles avaient à l'époque du montage; les forges, les outils, l'allure des ouvriers ont été reproduits arec une rigoureuse exactilude. La physionomie des principaux personnages est d'une ressemblance frappante

Des expériences intéressantes ont été faites par la Direction générale des travaux et par M. Eiffel pour vérifier, à l'aide du théodolite, la verticalité de la Tour, et s'assurer que les plans médians de la Tour (plans partageant les quatre faces en deux parties égales) étaient rigoureusement dans des plans verticaux, c'estd-dire coincidaient exactement avec les plans principaux passant par le centre du carré de base et jerpendiculaire à ses quatre côtés. "Il fallait avant tout, dit M. l'ingérieur Grosclaude, que le 


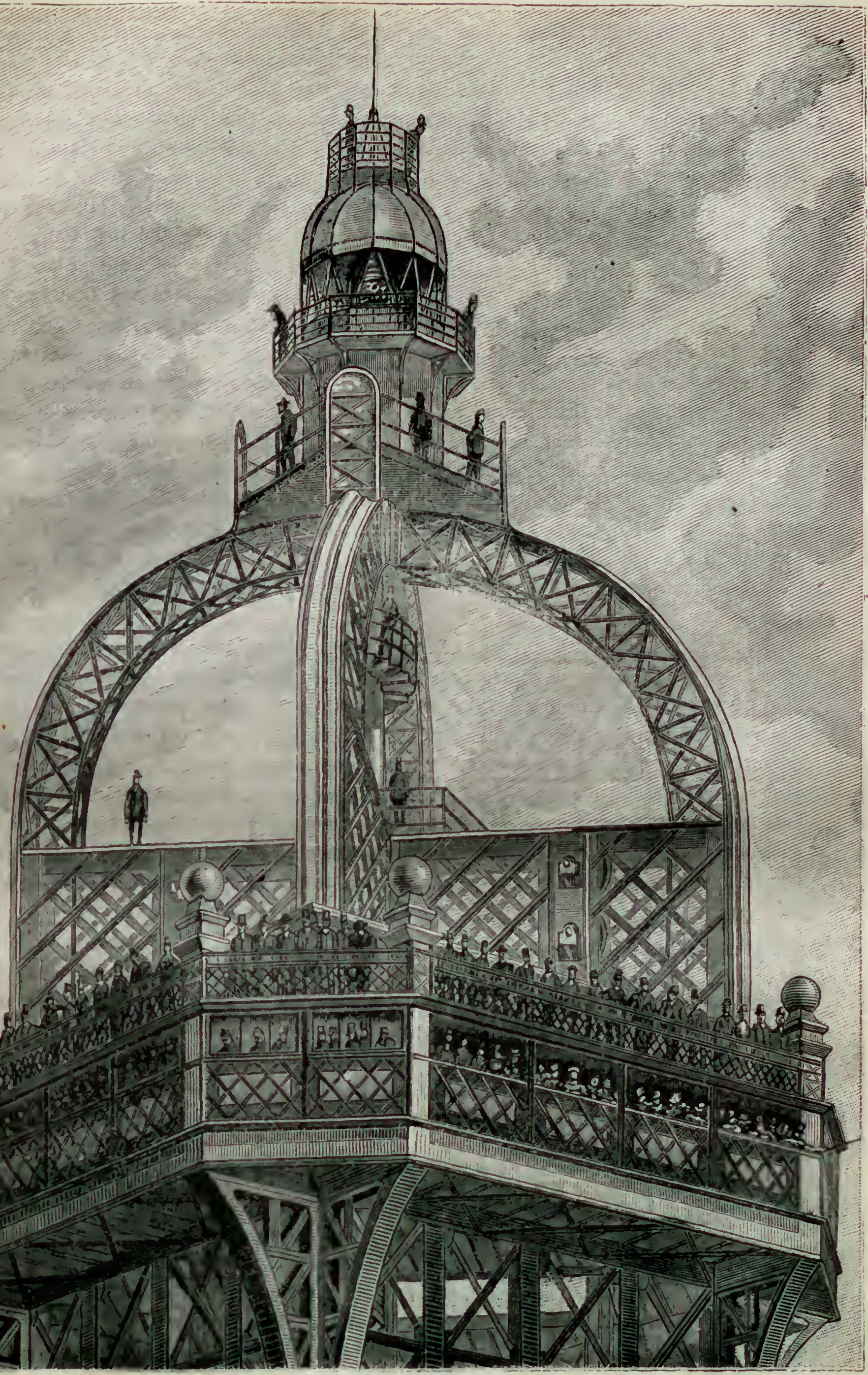

L8 CAMPANULE ET LE PUARE DE LA TOUR EIFFEL.

Lr. 28. 
théodolite, dont le fil vertical du réticule devait donner la verticale, fủt situé dans les plans principaux. Cette opération n'a pu, dans deux cas, se faire qu'avec une certaine difficulté. Quant aux plans médians, ils étaient assez bien définis au moyen de points singuliers bien tracés sur chacune des quatre faces. "Quatre expériences successives furent faites de quatre postes différents par M. Thuasne, ingénieur attaché à la Direction des travaux, et M. de Seilhac, ingénieur de la maison Eiffel. Le premier poste était situé sur le port d'Iéna, à 250 mètres environ du centre de la Tour. L'opération consista, le théodolite ayant été bien réglé, à le placer à peu près dans le plan principal, puis à faire varier à droite et a gauche dans un déplacement horizontal la position du fil vertical du réticule. Le second poste était situé à 160 mètres de la Tour, dans le voisinage du théatre des Folies-Parisiennes, et le troisième ì 300 mètres du centre de la Tour: Enfin, dans la quatrième expérience, le théodolite fut installé dans le voisinage de l'avenue de Suffren, à 200 mètres environ du centre de la Tour De tout cela, dit M. Grosclaude, on peut conclure que dans ces diverses phases le montage a toujours été effectué avec la plus grande précision, ne donnant lieu, non seulement à aucun infléchissement général et progressif, mais aussi à aucune déviation partielle qui eut été des plus préjudiciables pour le bon fonctionnement de l'ascenseur vertical Edoux. On peut déduire également ce point intéressant entre tous a constater, à savoir qu'il n'y a pas eu le plus léger tassement dans les maçonneries à la base des piles, bien que les fondations eussent été établies dans un mauvais terrain.

De tous les points de la France et de l'étranger, de nombreux touristes vont accourir avec l'idée bien arrêtée de voir la Tour Eiffel et d'en entreprendre l'ascension. Iront-ils jusqu'au bout? La crainte salutaire du vertige les arretera-t-elle à mi-chemin? Cela dépendra du tempérament de chacun, mais nous gagerions que le nombre de ceus qui graviront la Tour jusqu'au bout et qui contempleront Paris d'une hauteur de trois cents mètres ne sera pas considérable. Déja, quelques curieux ont obtenu de M. Eiffel l'autorisation d'opérer l'ascension de la Tour : les sensations qu'ils ont éprouvées sont curieuses à signaler. L'un d'eux, M. Hugues Le Roux, a fait une relation humoristique de son voyage - car c'est bien un véritable voyage que cette ascension. C'était le 24 février, par un temps neigeux. Le thermomètre marquait $1^{\circ}, 5$ au-dessus de zéro, et le baromètré 763 ; le vent soufflait du nord-nord-ouest. A deux heures, M. Eiffel, M. Hugues Le Roux et quelques autres invités, en tout une quinzaine de personnes, entrent dans le pilier de droite, où s'ouvre un des escaliers. Trois cent cinquante marches, et l'on arrive à la première plate-forme. Là s'élèvent quatre pavillons : une brasserie flamande, un restaurant russe, un bar anglo-américain et un cabaret Louis XIV, dont les caves se trouvent à 58 mètres au-dessus du sol. Quatre mille deux cents personnes pourront y diner à l'aise. Déjà, a la ville a pris l'immobilité d'un panorama. $\mathrm{La}$ vie et le mouvement cessent. Les silhouettes des passants et des fiacres font dans les rues de petites taches d'encre, très noires, très nettes. Elles ont l'aspect figé des foules qui se pressent, des chevaux qui stoppent dans les dessins autour des magasins de nouveautés. Seule la Seine vit toujours, par les moires qui courent sur sa face limoneuse. L'impression est une toile gonđée par un coup de vent. , 13 heuses 25 , la petite troupe s'engage dans un étroit escalier en vis, qui s'élève parallelement aux ascenseurs verticaux. > Pour échapper a l'étourdissement de cette ascension circulaire, on fouille le paysage a travers l'enchevêtrement des croix de Saint-André dont la 
tour est batie. Et l'on a la sensation surprenante, à chaque tour de vis, de la rapide montée de l'horizon. Le Trocadéro descend, il ne dépasse plus la ligne géométrique que de la pointe de ses paratonnerres. Les masses sombres du bois de Boulogne - éclaircies par la tache fraiche des pelouses de Longchamp - entrent en coin dans Paris, repoussent la ville vers l'est., A 125 mètres, on arrive à la seconde plate-forme, où sontinstallés un petit chemin de fer circulaire pour faciliter et hater les travaux, des longues-vues, des rouffs, une cantine où les ouvriers ont pris leur repas jusqu'à l'achèvement de la 'Tour. On domine l'Exposition dont on a sous les yeux comme un plan en relief. " Par une fente du plancher où monte en grinçant une chấne à crémaillère, je regarde l'abîme. Cette coupe est verticale. Là-bas, à une distance inconnue, les petits canards continuent de nager sur le bassin gelé. Le frisson vous vient de la chute possible. Il vous grimpe des reins a la nuque. Joignez à cela que le froid des fers cause une longue brûlure cuisante.

A 200 mètres, arrivée sur la plate-forme, dite plancher intermédiaire. " C'est vraiment à cette hauteur qu'on entre dans le vide. Les quatre membres de la Tour, sensiblement rapprochés, donnent à cette plate-forme l'apparence d'une nacelle de bálon. L'air, la lumière vous assaillent aux quatre points cardinaux. Et, en l'absence de constructions qui masquent, on a pour la première fois la sensation de la suspension, de l'isolement. Dans la perspective, le Mont-Valérien est descendu sous l'horizon... le Trocadéro sous le bois de Bou logne... la presqu’lle de Genneviliers apparait... voilà Saint-Denis... voilà la Seine qui fait son lacet entre ces hauteurs et ces abaissements. Je puis compter ses méandres comme sur une carte: un, deux, trois, quatre. A ma gauche, les collines de Meudon se sont presque affaissées. Par-dessus leurs épaules, j’aperçois trois rangées de,mainelons que la brume, dans l'éloignement progressif, teinte en decrescendo de gris pale. A droite, Montmartre, déja couvert d'ombres, entre comme un éperon de navire dans le flanc de la galère parisienne. A ses pieds, les maisons sont de plus en plus nettes, peut-être parce qu'on voit quatre de leurs faces, que trouent des fenêtres, symétriques comme des points de dés à jouer - si bien que de ces hauteurs Paris a l'air d'une vaste partie de biribi jouée par un géant sur un tapis vert. ' $\Lambda$ cinq heures, M. Eiffel, M. Hugues Le Roux et les rares visiteurs qui ont eu le courage de braver le froid et les giboulées pour venir jusque-là, se disposent à gagner le faîte de la Tour; mais au dernier moment quatre personnes seulement se décident : Mr. Eiffel, M. Le Roux, M. l'ingénieur Richard et le guide. Plus de planchers, plus de balcons; des échelles posées sur des madriers qui ' chevauchent dans le vide, et liées en haut avec des cordes. Après la troisième échelle, les quatre intrépides atteignent la plate-forme de 273 mètres, où souffle un vent du diable. M. Hugues le Roux veut s'appuyer à quelque objet stable et saisit un câble qui pend à portée de sa main, mais aussitôt cette rorde cède et descend sous sa poussée : M. Eiffel n'a que le temps de lui crier : Lâchez toni: - J'obéis bien vite, mais j'ai perdu l'envie de m'approcher du fin bord pour regarder à mes pieds. J'éprouve au contraire comme une sensation rassurante à appuyer mes regards aux collines qui. surgissent en ceinture autour de Paris. De leur fafte, encore éclairé, les ombres descendent sur la ville. La nuit noie les quartiers. Elle submerge tout. On dirait l'engloutissement d'Ys la Fabuleuse, descendant au fond de la mer avec sa rumeur d'honmes et de cloches. - Cinq heures et demie du soir ! Nous roici assis tous les trois devant des boissons chaudes au second étage, sous le toit de la cantine. M. Richard nous rapporte les péripéties de son ascension au mont Blanc. 



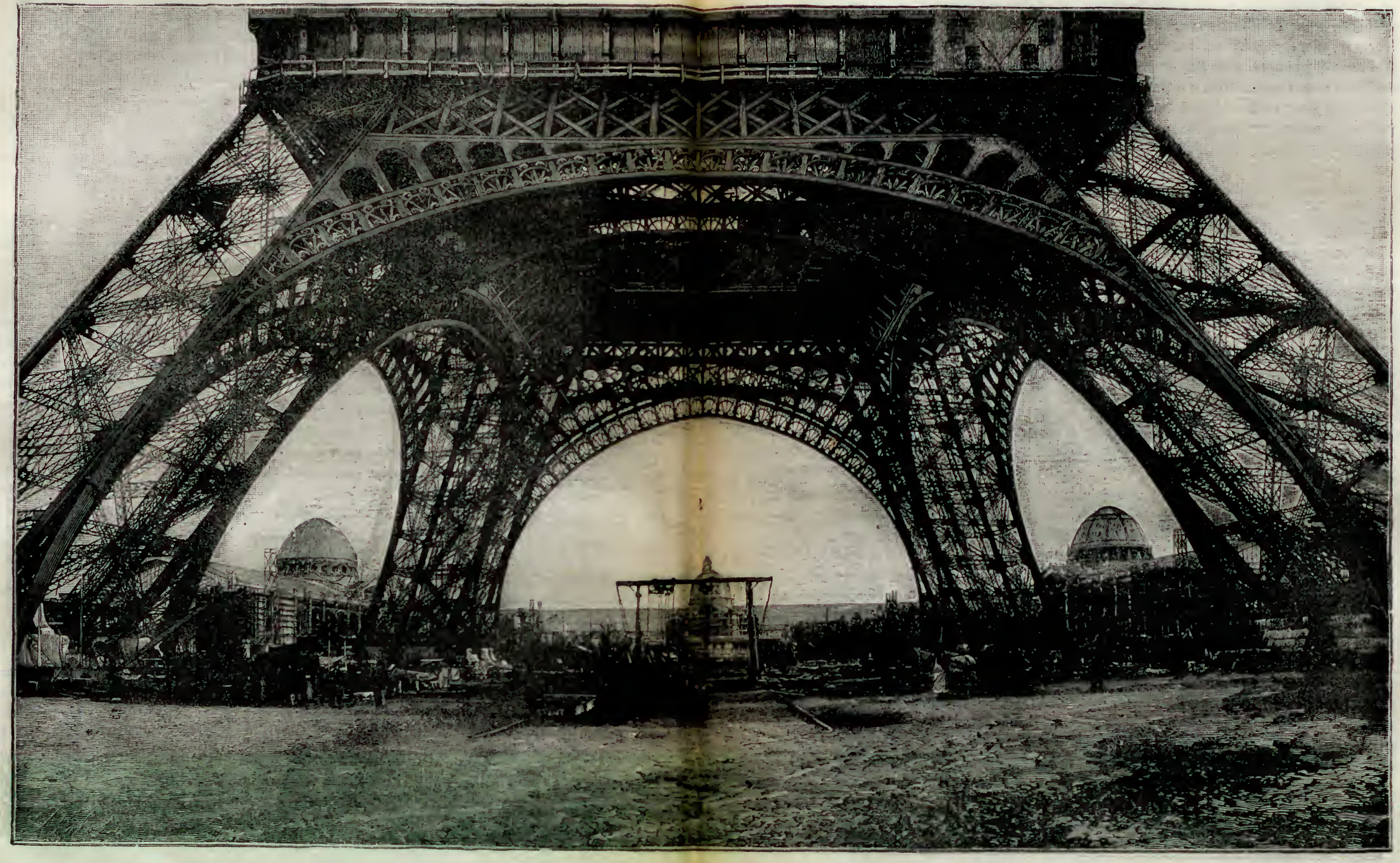


M. Eiffel conte que de toutes parts les 1élicitations lui arrivent. Nombre des artistes signataires de la fameuse protestation au ministre ont déjà fait amende honorable. a Il n'y a que trois ou quatre gens de lettres, qui s'entetent. Je ne comprends pas - pourquoi! - Croyez, cher monsieur Eiffel, que vous héritez des haines sous lesquelles - M. Georges Ohnet a plié. En somme, votre Tour, c'est un piédestal de 300 mètres élevé * à la gloire de l'ingénieur, c'est l'apothéose du Maitre de Forges." On sourit et la conversation se prolonge, séduisante, avec une paresse que personne n'avoue à quitter la tiédeur de l'abri pour rentrer dans le vent qui déferle, qui pleure avec des sanglots humains dans ces 300 mètres de fer tendus de la terre aux nuages comme un harpe éolienne. "

\section{LACHÈVEMENT DE LA TOUR EIFFEL}

La Tour de 300 mètres a pris dans les préoccupations du Parisien une trop grande importance pour que la fète de famille que II. Eiffel y a donnée le 31 mars n'ait pas revêtu aussitôt le caractère d'une rẻjouissance publique, dont nous devons fixer le souvenir.

Dès une heure et demie, à la tête de deux cents invités parmi lesquels se trouvaicnt M. Berger, directeur général de l'Exposition, et la plupart de ses chefs de service, M. Contamin, M. Chautemps, président du Conseil municipal, etc., etc., M. Eiffel avait commencé l'ascension. Trois quarts d'heure après seulement le cortège débouchait, à 273 mètres de hauteur, sur ce que l'on peut appeler la quatrième plate-forme, un plancher intermédiaire ayant été établi pour le service des ascenseurs entre ce dernier point et le deuxième étage de la Tour.

Mais l'ascension n'est pas terminée. Un étage encore, et l'on se trouve sous la coupole ronde partagée en quatre chambres, dont trois seront réservées aux savants et la quatrième à M. Eiffel. Au-dessus de la coupole, un phare. Ici, déjà, plus d'escaliers. Un énorme mât de fer creux d'un diamètre de 60 centimètres environ, et à l'intérieur duquel sont scellés des barreaux de fer servant d'échelle, conduit au sommet. C'est par là qu'une dizaine de personnages officiels, seuls admis dans cette partie de la Tour, ont accédé à la dernière plate-forme, une étroite terrasse circulaire d'oủ l'cil se perl. émerveillé, aux quatre coins de l'horizon.

Notre gravure représente celte terrasse au moment mème où $\mathbf{M}$. Eiffel hissait an sommet de la Tour le drapeau national. A ce moment 21 coups de canon sont tirés sur la troisième plate-forme. C'est alors que M. Contamin s'avance vers l'éminent ingénicur et le félicite chaudement.

Quelques minutes après, le groupe officiel, traversant la troisième plate-forme, toastait au champagne, en l'honneur de M. Eiffel, et regagnait bientot le pied de la Tour où les ouvriers étaient réunis pour le lunch.

La Tour Eiffel, n'en doutons donc pas, c'est le grand succes, c'est le clou de l'kxpo. sition. Ne vous contentez point de regarder de loin le monument géant. Approchez. ou mieux encore, placez-vous au centre de la Tour, entre les quatre piliers de fondation. Vous demeurez comme écrasé par celte masse, vous vous demandez comment l'homme peut arriver à édifier des ceuvres semblables, auprès desquelles il n'est qu'un 
nain, qu'un infiniment petit. Devant un tableau ou une statue, vous éprouvez cette impression de trouble heureux, cette émotion bienfaisante que la vue du beau détermine chez les hommes qui savent regarder. Ce n'est pas la même impression que produit la Tour : c'est un sentiment d'admiration qu'on éprouve, un hommage qu'on rend spontanément au merveilleux travail de l'homme, une joie qu'on ressent à voir le triomphe de l'esprit sur la matière.

Ne terminons pas sans appeler l'attention sur l'ornementation des consoles et des panneaux de la première plate-forme. Outre la décoration courante, d'un joli style malgré sa simplicité, comme on le verra par un de nos dessins, M. Eiffel a donné l'ordre d'écrire en lettres d'or les noms de plusieurs hommes illustres. Quant au sien, il n'a pas besoin d'etre écrit en toutes lettres sur un panneau : il se lit du haut en bas de la Tour géante, des fondations au campanile.

\section{VIII}

\section{DRRIRR COUP D'BIL D'BNSEMBLE SUR L'EXPOSITION}

L'activité qui régna au Champ de Mars depuis le commencement de l'année nécessita sur plusieurs points l'ouverture de chantiers de nuit. On dut recourir au syndicat des électriciens pour leur éclairage par l'électricité; et ce fut un coup d'œil merveilleux que ces travailleurs opérant comme en plein jour, grâce à quarante-cinq lampes à arc d'une intensité moyenne de 100 carcels, réparties dans les divers Palais du Champ de IIars. Dı haut en bas de l'échelle hiérarchique, de l'ingénieur au simple tâcheron, chacun fit les plus louables, les plus sérieux efforts pour mener à. bien la grande entreprise qui s'appelle l'Exposition.

Que pense l'étranger de cette entreprise? Quoi qu'on dise, il en pense beaucoup de bien. Dans un journal anglais, le Pall Mall Gazette, M. Julius Price disait l'autre jour: - Ce sera la plus colossale et la plus extraordinaire que le monde ait jamais vue. Les Français aiment a faire grand : ils sont en train de prouver une fois de plus qu'ils s'y entendent. Leur Exposition du centenaire de 1789, comparée surtout aux misérables déballages que nous sommes accoutumés de voir à Kensington, est déjà absolument stupéfiante. Ni les peines ni l'argent n'ont été ménagés. Rien de mesquin n'afflige le regard. Jusque dans la plus petite charpente de fer, le sentiment artistique et le goût éclatent. Le résultat est de nature à démontrer à l'univers que la France est toujours la plus laborieuse et la plus artiste des nations, et qu'une fois résolue à faire une chose, elle sait s'y mettre corps et Ame. Si les nuages dont l'horizon politique est chargé, n'éclatent pas en orage, l'Exposition va attirer à Paris la moitié du monde civilisé, et certes, à bon droit, car c'est la plus belle que le globe ait jamais vue. Voilà qui est encourageant.

L'entrée principale de l'Exposition au Champ de Mars, pour toute la rive gauche, c'est la porte Rapp, qui donne directement accès, à gauche, dans les galeries d'Expositions diverses, et à droite, dans le Palais des Beaux-Arts. Mais nous allons commencer notre visite par la Galerie des Machines, parallèle à l'École militaire, et nous continuerons notre excursion jusqu'au Trocadéro et jusqu'à l'Esplanade des Invalidés. Ceux 
qui sont rebelles à la marche, et qui ne voudront pas se fatiguer à parcourir à picd 90 hectares auront divers moyens de locomotion. Ils trouveront des fauteuils roulants, des anes venus tout exprès du Caire avec leurs aniers; mais lorsqu'ils voudront se rendre à un point déterminé de l'Exposition, ils trouveront mieux encore : un chemin

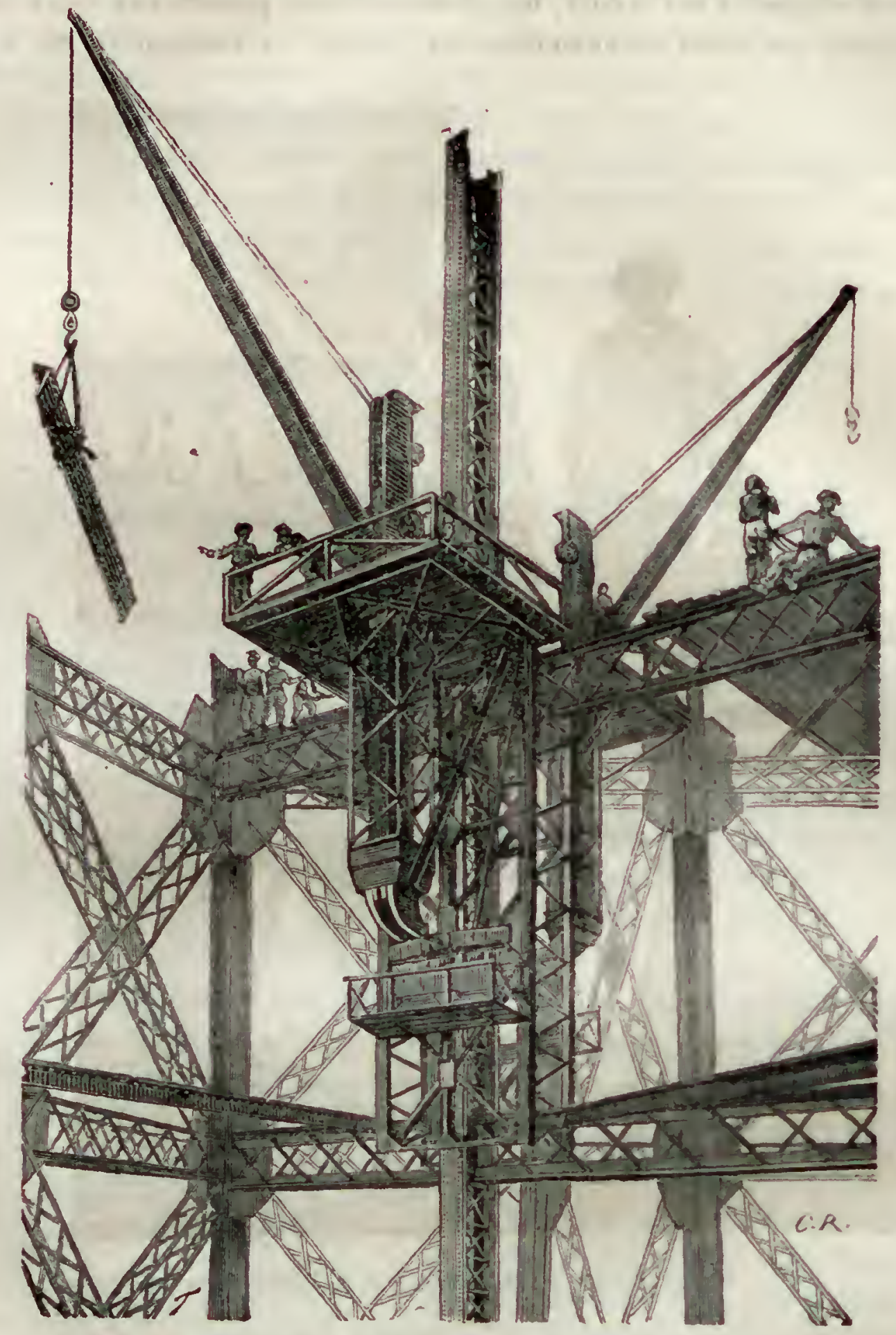

LES GRUES DE MOXTAGE DE LA TOUR AU DELA DU 2 ÉTAGE.

de fer-tramway de plus de 3 kilomètres, longeant l'Esplanade, le quai jusqu'au pont d'léna et l'avenue de Suffren, avec stations au carrefour Malar (Galerie de l'Agriculture), au Palais des Produits alimentaires et à l'angle du quai et de l'avenue de Sufren. M. Frédéric Moreau, auteur d'une étude sur le chemin de fer-tramway de l'Exposition. nous apprend que le profil en long de la voie est peu accidenté, ne comporte que de très faibles travaux de terrassement, que les rampes sont peu nombreuses, que les courbes ont un rayon minimum de $\mathbf{4 0}$ mètres, et que la voie est courbe avec une entrevoie de 2 mètres. "Le mode de traction adopté en principe est la vapeur. Les locomo- 
tives sont de plusieurs modeles. L'une des plus intéressantes est celle du capitaine Péchot. Cette machine, dite locomotive Duplex, a été combinée spécialement, pour les usages de l'armée, et en particulier pour l'armement de siège et de place. Elle est symétrique par rapport à deux plans perpendiculaires et est munie de deux foyers avec portes de chargement sur le côté; les cheminées sont placées aux deux extrémités de la machine. Le corps de chaudière est unique. La locomotive est à quatre

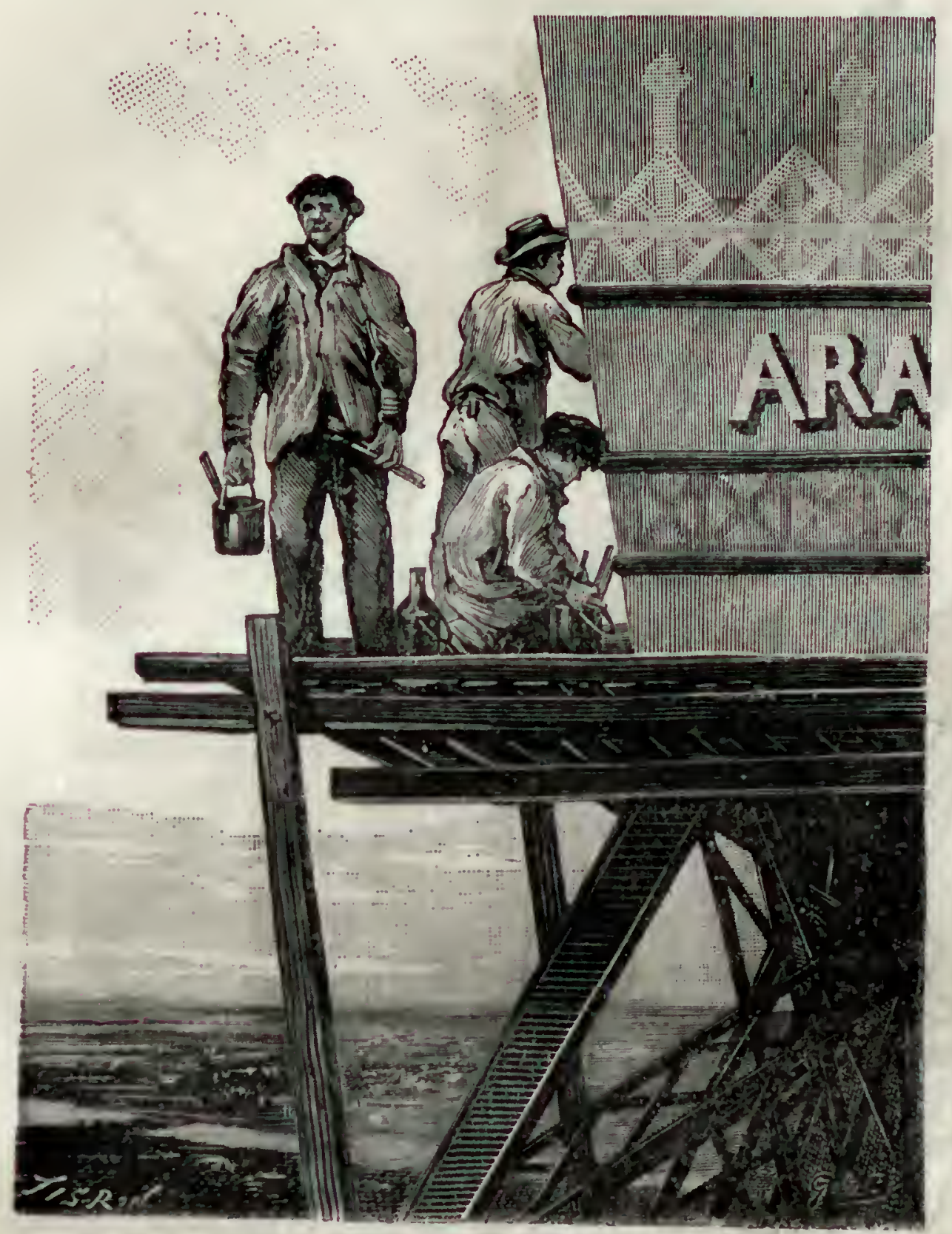

PEINTURE DES IXSCRIPTIONS SUR LA TOUR.

essieux et pdse 9 tonnes $1 / 2$ à vide et 12 tonnes en service; elie peut remorquer 13 tonnes sur des pentes de $0 \mathrm{~m}, 10$ par mètre, et 480 tonnes en palier. Elle passe dans des courbes de 20 mètres de rayon. Cette mobilité est obtenue, malgré la longueur relative de la machine, grace à l'emploi de deux bogies porteurs. Comme ceux-ci renferment les essieux moteurs, il a été nécessaire d'articuler le tuyau de vapeur au moyen d'une rotule, ce qui d'ailleurs ne semble pas présenter d'inconvénients dans la pratique. On emploie également des locomotives du type Mallet, bien connu et justement apprécié, appelées à servir dans les mêmes conditions que les précédentes. Elles sont Compound, et comportent un seul bogie à l'avant. On fait valoir en leur faveur que les petits Liv. 29. 
cylindres à haute pression étant placés près des essieux d'arrière, c'est la vapeur de détente seule qui passe par le joint articulé conduisant aux grands cylindres portés par le bogie. ,

Les trains partiront toutes les dix minutes, de chacune des stations terminus, depuis 9 heures du matin jusqu'à minuit. Bien que la voie soit presque sur tout son parcours inaccessible au public, la vitesse ne sera que de 10 kilomètres à l'heure; cette vitesse, quoique très faible, devra encore être réduite à 4 kilomètres aux passages à niveau où chaque train sera en outre précédé d'un pilote. Chaque train possédera un frein à arrêt instantané, et il n'aura pas une longucur de plus de 50 mètres. Le prix des places est de 25 centimes par personne, quelle que soit la longueur du trajet.

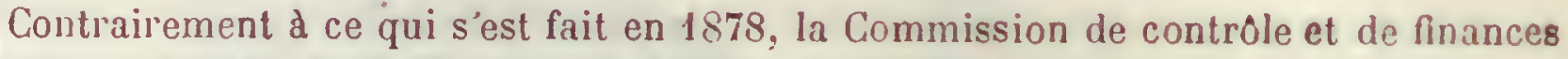
a demandé à la fin de 1887, que l'Exposition de 1889 restat ouverte le soir. L'éclairage devait être fait par l'électricité, dont les progrès, depuis plusicurs années, ont perınis d'obtenir des résultats si remarquables. Le Ministre du Commerce a passé un traité avec les exposants électriciens syndiqués, qui se chargent du Champ de Mars et cloivent recevoir en remboursement de leurs dépenses, moitié des droits d'entrée du soir, fixés à 2 francs pendant la semaine et à 1 franc le dimanche. En réalité, c'est une exposition collective d'éclairage électrique qui est organisée par les exposants et pour laquelle l'Administration laisse percevoir des droits d'entrée. Pour que le caractère d'csposition collective fut nettement établi, il fallait que le syndicat des électriciens restat ouvert à tous les exposants sans distinction de nationalité : les statuts donnent à cet égard toute garantie. Chaque exposant pourra ne s'engager qu'à installer un matériel électrique nécessaire à l'utilisation d'une force motrice de 10 chevaux. Or, la force motrice nécessaire pour l'éclairage de l'Exposition est de 3,000 chevaux; c'est donc la possibilité garantie de faire entrer dans le syndicat jusqu'a 300 exposants d'appareils producteurs d'électricité. Le Comité fondateur du syndicat prend en meme temps vis-dvis de l'État la responsabilité de l'œurre à laquelle il convie les électriciens de toutes les nations, et s'engage à suppléer aux défections qui pourraient se produire parmi les syndicataires. La surface éclairée à l'électricité sera de 30,000 mètres, avec une intensité totale d'environ 150,000 becs carcels, qu'on a supposée a priori devoir être répartie en 20,000 lampes à incandescence et 1,000 appareils à arc voltalque.

A côté de l'électricité, les expériences des autres modes d'éclairage sont également garanties. Les bas-côtés de l'Exposition, le long des avenues de Suffren ct de La Bourdonnais, ainsi que tous les jardins du Trocadéro, avec la cascade, sont réservés pour être éclairés au gaz.

Le Syndicat international des électriciens, constitué par arrêté du 15 février $\mathbf{1 8 8 8 ,}$ s'est mis rapidement à l'œuvre. L'éclairage du Champ de Mars esl assuré par trois groupes de stations centrales offrant un ensemble complet des divers systèmes de distribution de force électrique: le premier dans le jardin d'isolement (cóté de l'avenue de La Bourdonnais), le deuxième sur la berge de la Seine, en aval du pont d'léna; le troisième le long de lavenue de La Bourdonnais, à cỏté du pavillon de la Presse. Un certain nombre de postes d'électricité sont en outre installés par le Syndicat en différents points du Palais des Machines pour compenser l'exiguîté des stations du jardin d'isolement et faciliter l'éclairage du Palais.

Les organisateurs de l'Exposition avaient été frappés du grand succes ohtenu par 
les fontaines lumineuses installées a l'Exposition coloniale de Londres en 1886, a Manchester en 1887, à Glascow et enfin à Barcelone. En s'appuyant sur les curieuses expériences de réflexion totale, on est arrivé à donner l'illusion d'un jet de feu, et en modifiant, au moyen de verres spéciaux, la coloration de la lumière et en faisant varier en mème temps la pression de l'eau, on obtient des effets merveilleux, donnant l'illusion d'un feu d'artifice sans fumée, sans odeur et sans danger. Un projet a été mis à l'étude, et on s'est arrêté à l'idée de reproduire la gerbe telle qu'elle existait à Glascow, etc., en la complétant par des effets d'eau et de lumière nouveaux destinés à la marier avec la décoration générale du Parc. La fontaine est reliée, par un canal allongé, d la gerbe, pour constituer une pièce d'eau unique, rappelant celle du parc de SaintCloud. Le soir, tandis que la grande gerbe viendra jeter au milieu de l'Exposition sa note éblouissante, tous les effets d'eau de la fontaine décorée et du canal s'illumineront en mime temps. Aucune partie ne restera dans l'ombre, et on produira ainsi un effet décorati absolument différent de ceux obtenus jusqu'à ce jour. L'eau de la fontaine est poussée avec une forte pression entre deux troncs de cônes qu'éclairent les lampes électriques placées dans des chambres sous les bassins. La lame liquide cylindrique sur laquelle se produisent les réflexions n'a pas plus de deux ou trois millimètres d'épaisseur, ce qui permet d'éclairer le jet d'eau jusqu'd une hauteur de quatre à cinq mètres. Celle-ci prend successivement toutes les teintes, grâce aux verres colorés par lequels passent les faisceaux de lumière.

Ceux qui ne veulent pas se contenter de voir les choses superficiellement pourront assister aux Congrès et conférences qui auront lieu en grand nombre dans l'enceinte de l'Ex position sur les sujets les plus divers. Un des Congrès des plus intéressants au point de vue patriotique, sera le Congrès organisé par l'Alliance française, et qui s'occupera de l'organisation de l'enseignement de la langue nationale dans nos colonies, ainsi que de la réforme de l'orthographe. Si cette réforme pouvait aboutir, on ne saurait trop en féliciter la compagnie qui en a pris l'initiative et qui a toute qualité pour la réaliser. - Il y aura aussi des auditions musicales. Cinq grands concerts seront donnés dans la salle du Trocadéro par la Société des concerts du Conservatoire, la Société des concerts du Chàtelet, l'orchestre Lamoureux, l'orchestre de l'Opéra et l'orchestre de l'OpéraComique. On n'y exécutera que des airs français; mais, sous certaines conditions, la salle du Trocadéro sera mise à la disposition des Sociétés étrangères.

Cela dit, parcourons les constructions de l'Exposition, de manicre à ce que nos lecteur's puissent s'y diriger sans embarras.

Au haut du Champ de Mars, parallelement a l'teole militaire, nous trouvons le Palais déjà célebre des Machines. Les installations mécaniques ont été dirigées par M. Vigreux, professeur a l'École centrale, assisté d'un Comité technique. Pour le service de la force inotrice, dont les exposants se serviront gratuitement, on a eu a installer les généra. teurs de vapeur, les machines motrices, la transmission principale de mouvement, les canalisations d'eau froide, de vapeur et d'eaux chaudes de condensation, les machines élévatoires et le réservoir. Deux ponts roulants d'une portée de 18 mètres el d'une puissance de 10 tonnes chacun ont servi a la manutention pendant l'aménagement du Palais des Machines et servent au transport des visiteurs pendant l'Exposition. Ils roulent sur des poutres en treillis, reliant chacun deux lignes de support de transmissions, et se déplacent d'un bout à l'autre du Palais, mus au moyen d'un transport de force par l'électricité; des ascenseurs installés aux extrémités de la galerie donnent 



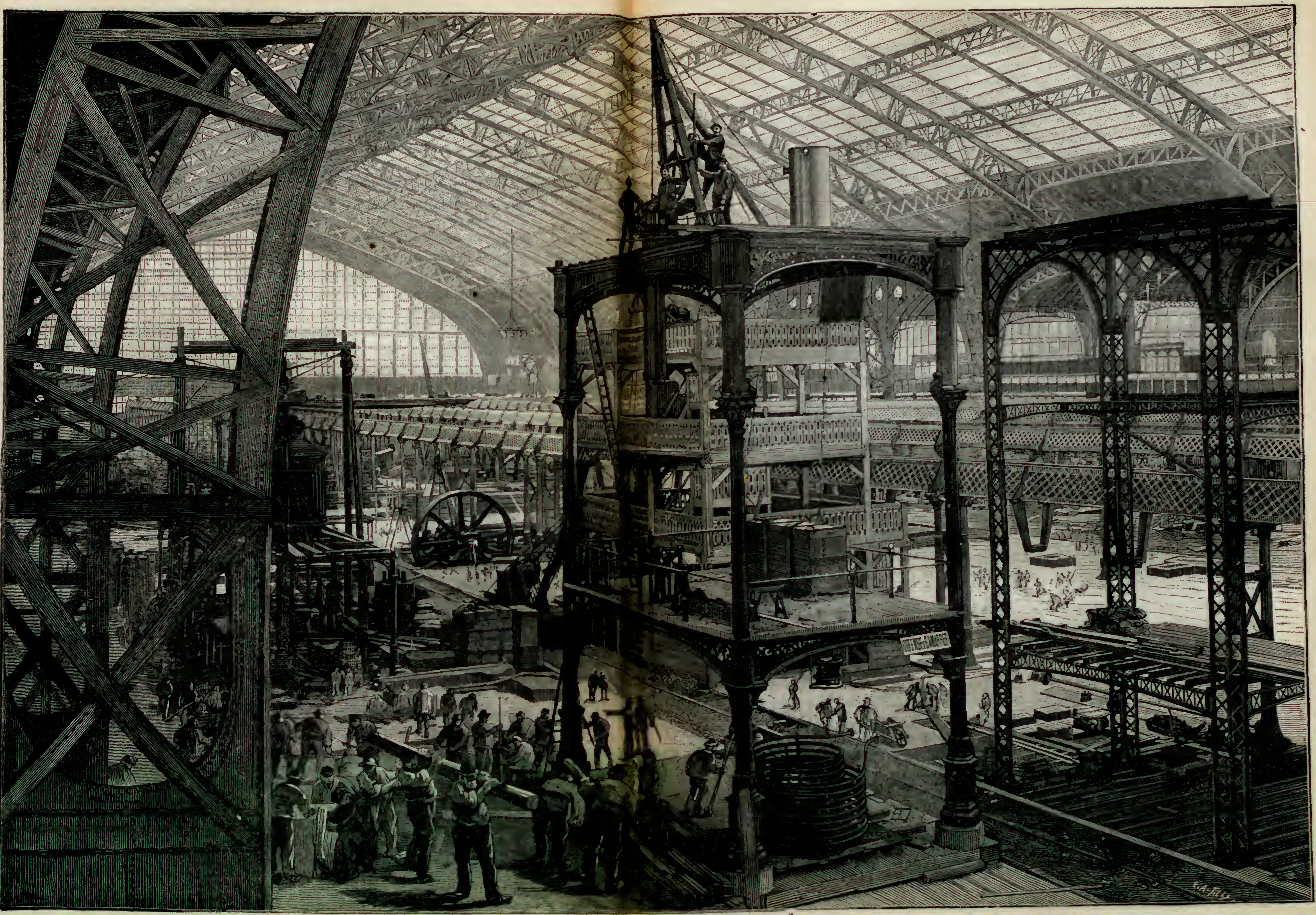


accès aux ponts roulants. L'eau nécesaire au service de la force motrice est puisée à la Seine; à cet effet, sur la berge du fleuve, en aval du pont d'léna, est installé une usine de machines élévatoires. Chaque jour un matériel spécial peut élever 600 mètres cubes d'eau (200 litres par seconde), soit, au total, environ deux millions de metres cubes pour la durée de l'Exposition. La transmission principale du mouvernent comprend quatre lignes d'arbres qui vont d'un bout à l'autre du Palais des Machines.

La peinture des grands ouvrages métalliques présente de grandes difficultés, surtout lorsqu'il s'agit de véritables monuments comme le Palais des Machines. M. Rondeau, chargé de peindre le dessous des chevrons, les petits fers et une partie du vitrage supérieur, a imaginé dans ce but un ingénieux système d'échafaudages volants, se déplaçant sur des cables métalliques auxquels ils sont suspendus. "Ces cadres, dit M. Eugène Flachat, formés par la réunion de fils d'acier tordus en hélices sont tendus fortement à l'aide de tendeurs analogues à ceux des attelages des wagons de chemins de fer, et solidement fixés parallèlement a la surface d̀ peindre. Sur chacun de ces cables se meut une poulie à gorge dont la chape supporte l'échafaudage volant par l'intermédiaire de moufle. Le déplacement de cette poulie, et par suite de l'échafaudage volant, a lieu au moyen de deux moufles doubles fixées chacune aux extrémités du câble en acier, et dont les deux extrémités du brin sont fixées a la chaple du galet de roulement et diamétralement opposées. L'altache des cables métalliques se fait, dans le cas qui nous occupe, aux treillis mêmes de la ferme, au moyen de chatnes a maillons entourant les treillis, en ayant soin d"interposer des coins de bois entre les chaînes et les treillis pour empêcher tout glissement des chaines. Ce mode d'attache donne une sécurité parfaite aux peintres qui se trourent sur l'échafaudage volant. ,

L'aspect général du Palais est imposant et agréable. On avait pu un instant craindre que le visiteur n'éprouvât comme un sentiment de vide sous celte nef immense et que les machines disséminées à l'intérieur ne fussent disproportionnées par leur pelitesse relative avec les proportions du local. Il n'en est rien, et, comme le disait M. de Nansouty, le Palais des Machines est équilibré au point de vue artistique dans toute ses parties, satisfaisant à l'œil el si bien proportionné que sa puissance se devine bien plus qu'elle ne se voit; rien ne disparait dans son immensité, et si l'on ne prenait gal el la de certains repères donnant l'échelle et permettant de juger des dimensions relatives, on $s^{2}$ figurerait difficilement que l'on se trouve sous une voute qui pourrait contenir l'Arc de Triomphe de l'Étoile et dans laquelle une brigade de cavalerie ferait aisément scs évolutions. M. de Nansouty rappelle dans les termes suirants les bases sur lesquelles repose cette importante construction métallique : "La section de la ferme, dans toule son étendue, est celle d'un double caisson en fer ouvert vers l'intéricur. Chacun de ces caissons est constitué par deux âmes écartées de כొ 4 centimètres et une semelle réunie par quatre cornières; la semelle supérieure d'extrados a 77 centimètres de largeur. celle d'intrados a 90 centimètres. L'épaisscur des semelles est variable aux différents points du développement de l'arc selon les nécessités de la résistance du métal. et augmente progressivement vers la partie la plus cintrée où la compression est la plus forte. Aux points les plus chargés, elle atteint huit épaisscurs superposées de Wles de 1 centimètre d'épaisseur; les rivets qui les assemblent ont jusqu'ł 22 millimètres de diamètre. Ces grandes fermes présentent les particularités remarquables suivantes: 10 l'existence de deux rotules en fonte solidement fixées sur les fondations el sur lesquelles repose la ferme aux naissances de l'arc; $2^{\circ}$ la jonction des deux moitiés aux 
sommets par l'intermédiaire d'un axe en acier formant articulation supérieure. On n'avait jusqu'à présent trouvé d'exemples de cette disposition que dans l'établissement des ponts. Grace aux beaux calculs de M. Contamin, pratiquement vérifiés par cette gigantesque application, l'art des charpentes en fer s'est enrichi d'une méthode nouvelle très remarquable. Un seul regret est à exprimer, c'est que ces belles fermes du Palais des Machines n'aient pu, pour des considérations budgétaires, être exécutées en acier, le métal de l'avenir. Plusieurs motifs sérieux justifient l'emploi des articulations de ces fermes au faîtage et aux retombées : d'une part la commodité qui résulte pour le calcul de l'introduction de ces éléments dans la construction; d'autre part, la petitesse de la surface d'appui par laquelle passent les efforts, ce qui simplifie beaucoup le calcul des résistances. Il est en effet très difficile, sinon impossible dans la pratique, de déterminer exactement en quel point passe la réaction d'un arc dont la base est très large; or, il peut résulter de cette hypothèse que l'on fait, à ce sujet, de très grandes incertitudes sur la façon dont le métal travaille dans les différentes parties de l'arc. Avec l'emploi des rotules articulées cet inconvénient disparâ̂t. La rotule détermine le point absolu du passage des réactions. De plus, le montage par parties est ainsi facilité : la ferme peut être rigoureusement calée en place au moyen de coins d'acier chassćs entre les talons qui bordent la plaque et le sabot. Enfin, la dilatation du métal est facilitée : pour un écart possible maximum de $50^{\circ}\left(-15^{\circ}\right.$ hiver à $+35^{\circ}$ été), chaque demi-ferme s'allonge de 4 centimètres. Rien ne s'oppose, avec les rotules, à un léger soulèvement du faitage et à une petite oscillation des pieds-droits sur les rotules, mouvements qui s'exécutent en soulageant les assemblages sans les fatiguer. En résumé, la ferme ainsi constituée peut être considérée comme un triangle curviligne, dont les trois sommets seraient les trois articulations et dont le sol formerait la base. C'est de lagiomitrie réalisée avec les ressources d'une science parfaite de la résistance des matériaux."

La poussée de la ferme sur chaque articulation des pieds-droits est de 115,000 kilogrammes, en y comprenant les charges normales et accidentelles : couverture, vent, neige, etc. Une ferme courante pèse environ 196 tonnes, et une demi-travée de pannes, chevrons et fers a vitrage 62 tonnes; le poids des pieces formant paroi verticale, sablière, chéneau et arc d'une demi-travée est de 23 tonnes. Les fermes de tête sont plus larges et pèsent chacune $\mathbf{2} \mathbf{4 0}$ tonnes. Le poids total métalliqure de la grande nef du Palais des Machines s'élève à 7,400,000 kilogrammes. La surface d'appui de chaque rotule au-dessous du coussinet n'étant que d'environ 68 décimètres carrés, cette énorme charpente ne repose que sur une surface de fonte de 28 mètres carrés.

En sortant de la galerie des Machines, on pénétrera dans les galeries des Industries diverses dont le nom est suffisamment clair pour dispenser d'explications. Elles sont au nombre de deux, à droite et a gauche, et au milieu sera le Pavillon de la Ville de Paris. On trouvera ensuite en se dirigeant vers la Seine: à droite le Palais des Beaux-Arts, a gauche le Palais des Arts libéraux. Nous décrirons en détail ce Palais des Beaux-Arts dans un chapitre spécial, mais nous pouvons dès aujourd'hui décrire l'aménagement du Palais des Arts libéraux.

Ce Palaiz comprend 2 grandes nefs de 87 mètres de long sur 50 mètres de large, reliées par un dủıne central ayant 32 mètres de diamètre à la base et 56 mètres de hauteur; autour rèznent une galerie et un balcon. La charpente est métallique et, extérieurement, on a adoplé une décoration céramique d'un bel effet. Le pourtour intérieur 


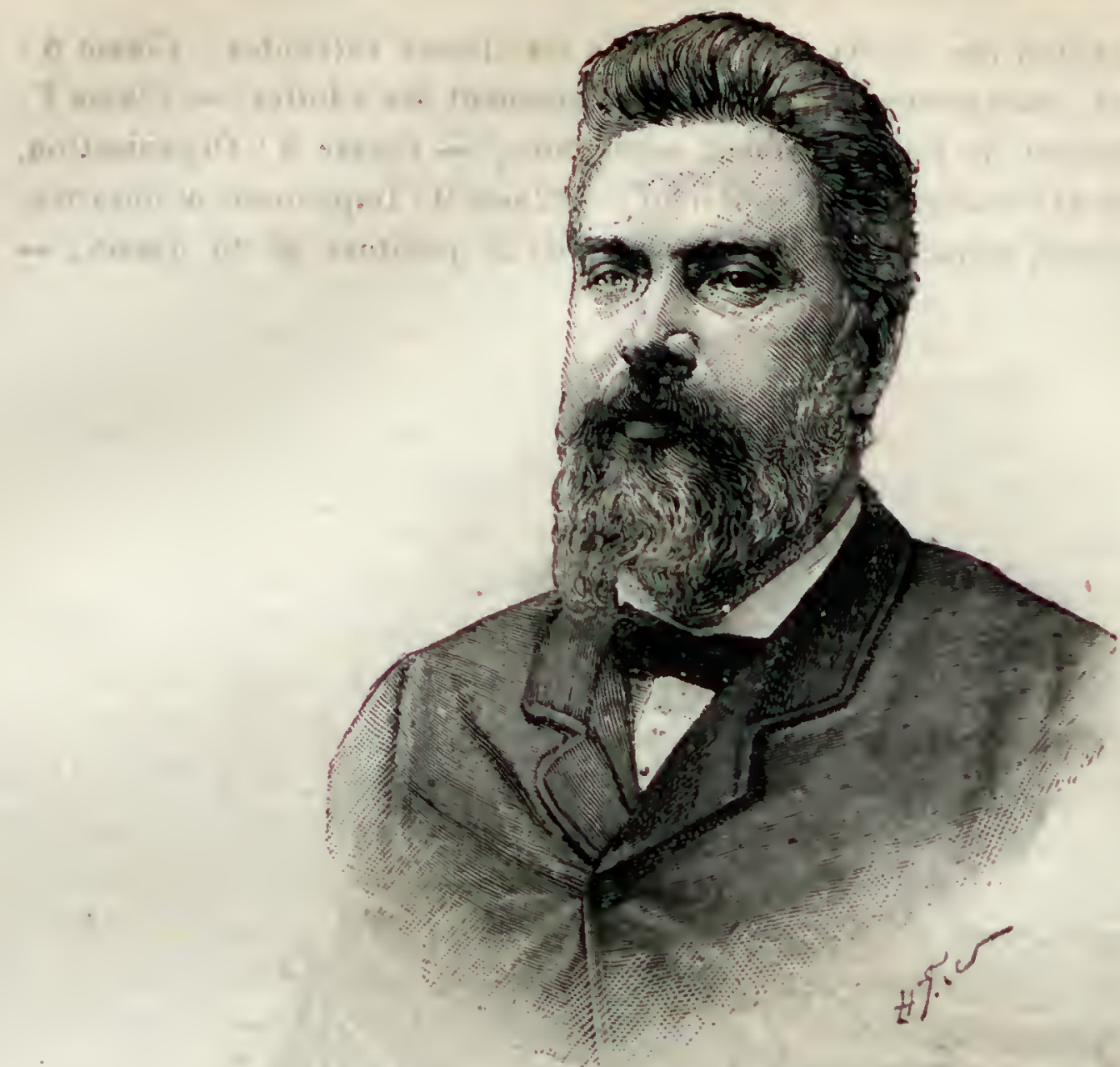

15. Contamin

Ingénieur en chel. (Cleroy, phot.)

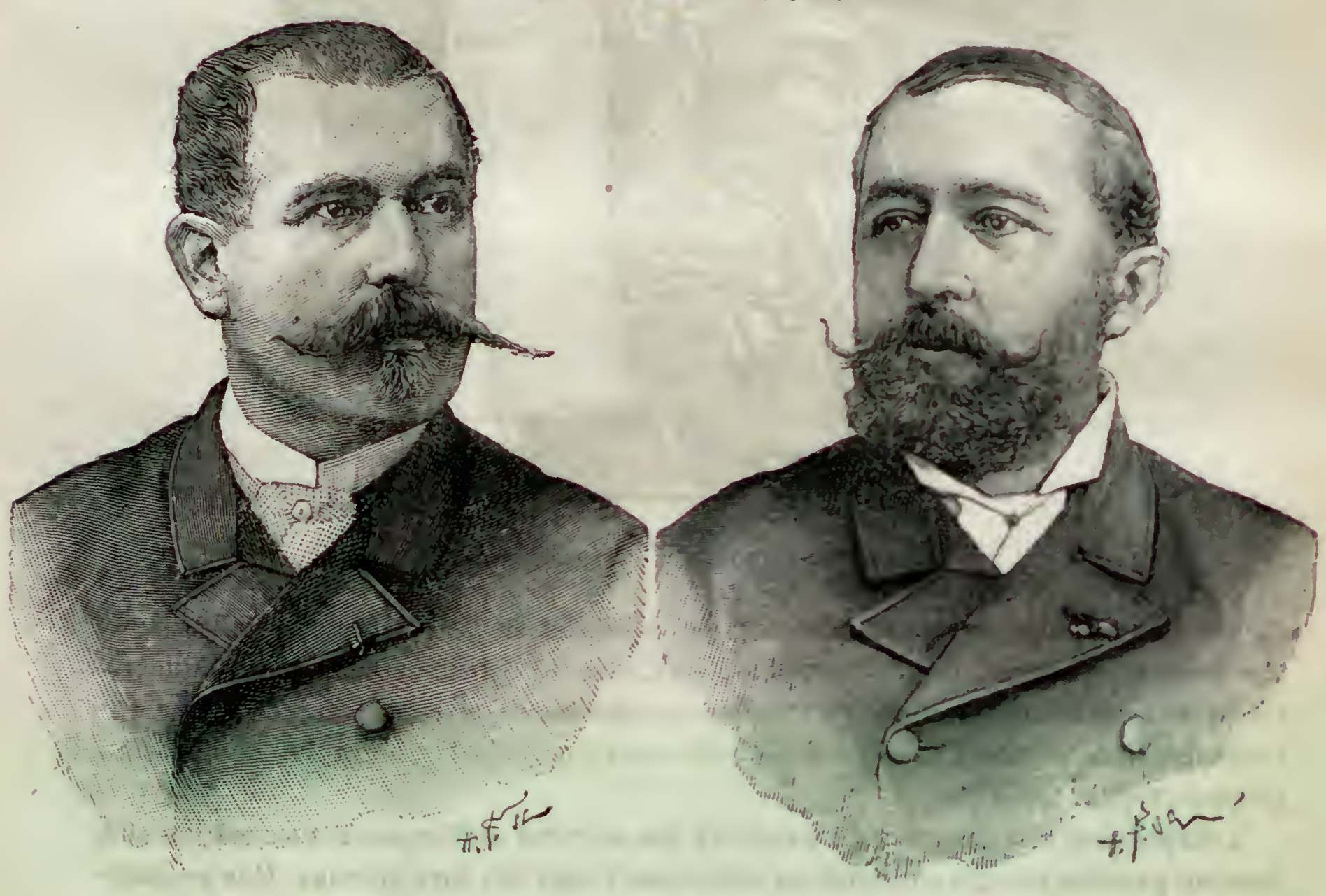


est réservé a l'exposition des olyjets renlrant dans les classes suivantes : Classe $\mathbf{b}$ : Éducation de l'enfant, enseignement primaire, enseignement des adultes; - Classe 7 : Organisation et matériel de l'enseignement secondaire; - Classe 8: Organisation, méthodes et matériel de l'enseignement supérieur; - Classe 9 : Imprimerie et librairie; - Classe 10 : Papeterie, reliure, matériel des arts de la peinture et du dessin; -

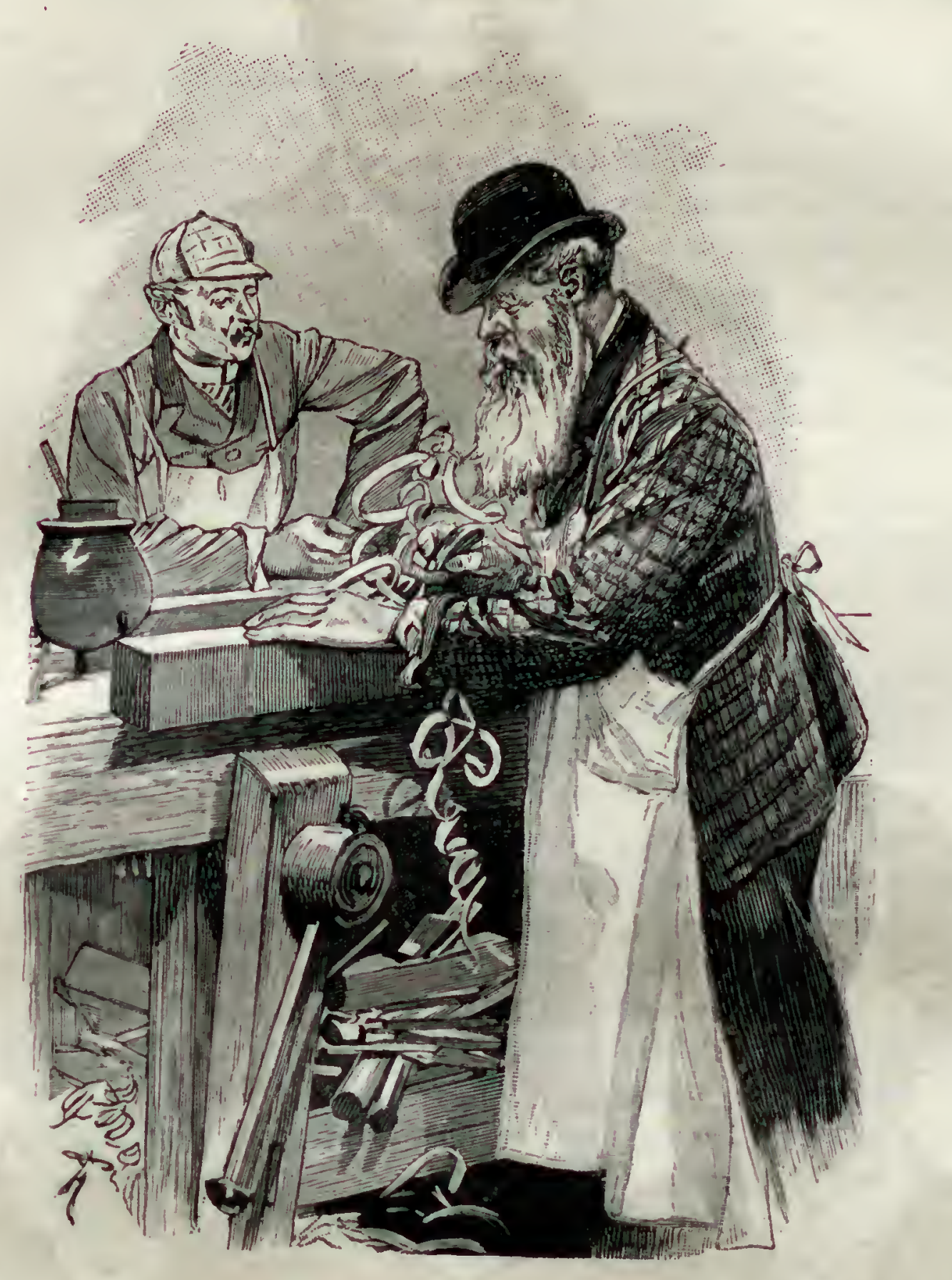

OUVRIERS ANGIAAS A L'EXPOSITION.

Classe 11 : Application usuelle des arts du dessin et de la plastique; - Classe 12 : Épreuves et appareils de photographie; - Classe 13 : Instruments de musique; Classe 14: Médecine et chirurgie, médecine vétérinaire et comparée; - Classe 15 : Instruments de précision; - Classe 16 : Cartes et appareils de géographie et de cosmographie, topographie.

L'Exposition rétrospective du travail et des sciences anthropologiques est installée dans un pavillon en bois construit au milieu du Palais des Arts libéraux. Une première section est chargée de l'anthropologie, de l'ethnographie et de l'archéologie. Tous les 
documents relatifs au travail dans les temps antiques ou chez les populations sauvages y sont exposés, et l'on y voit fonctionner un atelier de fabrication d'émaux cloisonnés de Chine.

Dans la section des Arts libéraux, on trouve des reconstitutions d'observatoires chinois, hindous, égyptiens, d'Ulughbey et d'Uranienborg, des anciens cabinets de physique, de chimie et d'alchimie, et notamment du laboratoire de Lavoisier. Le Musée Plantin a fourni ses documents relatifs a l'histoire de l'imprimerie. Les outils de reliure, les types de papiers et de livres, de journaux, d'affiches et d'images, ainsi que le matériel des librairies seront exposés de manière à mettre en évidence leurs variétís et leurs perfectionnements. L'histoire de la musique s'y trouve tout entière, tant au point de vue des instruments que des œuvres musicales. Une maquette représente une série de décors, de costumes, de masques, de programmes, d'affiches de théatre, et l'histoire complète des arts du dessin, architecture, peinture, sculpture, médailles et pierres fines artistiques, gravures, d'art, lithographies et chromolithographie d'art.

La section des Arts et Métiers réunit tous les documents relatifs a la photographie, l'électricité, la chasse, la pêche, les minéraux; un matériel d'outillage pour la fabrication des terres cuites, céramiques, faïences, de la verrerie et cristallerie, des ćmaux et des mosaïques; à l'industrie des matières textiles, du papier, des dépouilles animales, enfin de l'art de se vêtir, de bâtir, de se chaulfer, de s'éclairer, et à toutes les interventions de l'art de l'ingénieur pour les satisfactions des besoins de l'homme vivant en société.

Les collections de l'École des Ponts et Chaussées, du Conservatoire des Arls et Métiers, de la Galerie des Phares, de l'École centrale, des Compagnies de chemins de fer, ont fourni une mine inépuisable de matériaux à la section des moyens de transport. L'Exposition comprend des reproductions de tous les ouvrages d'art intéressants : ponts, barrages, écluses, ports, rades et avant-ports; des reconstitutions, des types des véhicules employćs pour le transport maritime, depuis l'antiquité jusqu'à nos jours: batcaux de peaux, trirèmes, galères; l'historique de l'architecture navale, des paquebots à voiles, de la machinerie d̀ vapeur marine et des bateaux sous-marins; de tous les modèles de voitures : thensa, chars, litières, carrosses, calèches, diligences, omnibus, tramways; l'histoire de l'aérostation; enfin, le matériel et l'organisation des chemins de fer.

Entre le Palais des Beaux-Arts et celui des Arts libéraux s'étend un jardin intérieur, qui aboutit à la Tour de 300 mètres. Traversant le pont d'Iéna, on arrive au Trocadéro. Dans le parc du Trocadéro est organiséc une Exposition d'Horticulture, qui a nécessité des travaux de règlement du sol, de drainage, de transplantations d'arbustes et de semis, et aussi l'Exposition des Forets, pour laquelle on a construit un Pavillon d'un hel aspect et réservé un emplacement de 3,500 mètres carrés. La façade du pavillon est composée de panneaux constitués par la simple juxtaposition de bois non écorcés: chène, hẻtre, orme, acacia, mélèze, charme, frêne, ormier, merisier, en un mot, toutes les essences qui viennent dans le domaine forestier de la France.

Repassons maintenant le pont d'Iéna et revenons le long de la Seine, du cúté du Champ de Mars. Le visiteur tourné vers le Trocadéro trouve a sa gauclıe, cest à-dire, à la gauche de la Tour Eiffel, une série de charmants pavillons, qui sont ceux des t́tats de l'Amérique du Sud. A droite s'étend l'œuvre de M. Garnier, l'Exposition de l'Hahitation humaine, dont nous avons décrit déjà tous les types en détail. A l'extrémité de 
cette série si curieuse, des maisons de tout pays et de tout age, un grand bâtiment rond attire les regards : c'est le Panorama de l'Exposition transatlantique. Le Parisien aura l'illusion d'un voyage à travers l'océan et, embarqué sur un des paquebots de la Compagnie, il entrera triomphalement dans la rade de New-York sans avoir quitté Paris. Ce panorama est très réussi; il sera, avec le Panorama du a Tout-Paris ", un des attraits de l'Exposition.

Nous trouvons ensuite l'Exposition des produits alimentaires.

Le Palais des Produits alimentaires est construit aux frais des exposants. II se compose de deux galeries supérposées: l'une sur la berge de la Seine, qui a l'aspect d'un chais, et où seront groupés tous les échantillons de notre production vinicole et de notre industrie des liquides; l'autre, au niveau du quai et où sont exposés les produits de la patisserie, des conserves, etc. Quant aux galeries de l'Agriculture, elles s'étendent entre l'avenue de la Bourdonnais et l'Esplanade des Invalides.

Nous voici à l'Esplanade des Invalides, véritable nid à surprises pour le visiteur. C'est la qu'est disposée l'Exposition des Colonies sur un espace rectangulaire de 230 metres de long sur 110 de large, soit une superficie totale de $\mathbf{2 7 , 5 0 0 ~ m e ̀ t r e s ~ c a r r e ́ s . ~}$ En pénétrant par la porte d'entrée de la rue de Constantine, on trouve, à droite et à gauche, deux pièces d'eau pour les embarcations indigènes des peuples soumis à notre domination. En face, se dressent le palais central, puis derrière ce palais, des villages néo-calédonien, alfourou, sénégalais, palıouin et cochinchinois. Les postes iortifiés dı sénégal sont représentés par une reproduction de la tour de Saldé, et l'architecture khmer (Cambodge) par la pagode d'Angkor. Vous pourrez goûter, au café Bambara, un café vraiment exquis, et vous régaler de mets aussi alléchants qu'inconnus à nos palais dans les restaurants créole et annamite, où vous serez servis par des indigrènes, des indigènes authentiques.

Le Pavillon de l'Algérie, élevé sur les plans de MM. Ballu et Marquette, représente fidèlement un spécimen darchitecture algéro-arabe, pur de tout alliage, de toute inflence européenne. L'escalier intérieur du minaret est merveilleusement léger et fini. Des bazars al'abes et juifs sont installés dans les batiments en aile sur le quai et l'allée centrale.

Le l'alais Tunisien, dont M. Saladin est l'architecte, est le digne pendant du précédent. Ses ormenentations, ses décors, sont fidèlement empruntés à ceux qui existent a Tunis, a liaîrouan, en un mot dans les principales villes de la Régence. Le Palais est surmonté du ininaret de Sidi-Ben-Arrouz, autour duquel viennent se grouper une maison du pays de Djelrid, la galerie des Souks (boutiques), le Pavillon forestier, des cafés divers, etc.

Le Palais de l'Annam et du Tonkin est entièrement orné, avec des bois qui arrivent tout sculptés d'Indo-Chine. Là sont exposés les arachides, l'huile d'arachide, la farine du riz, la soie grège, les bois, les cotons égrenés, l'étain, l'huile à laquer, le sucre, les bronzes, les meubles sculptés, les étoffes brodées. Les matériaux einployés sont les brignes, avec un revètement en platre et charpente en bois. Au milieu d'une cour intérieure, un atrium couvert abrite une statue gigantesque de Bouddha, et la façade est ornée de panneaux décoratifs en bois ou en faïence, d'attributs symboriques, de figures d'hommes et d'animaux. - Il y a aussi un théatre annamite, où d'autres motifs d'ornementations attirent les regards. Les spectateurs sont assis sur des gradins, sur trois côtés d'un rectangle dont le quatrième forme la scène; les artistes 

LES MERVEILLES DE LEXPOSITION

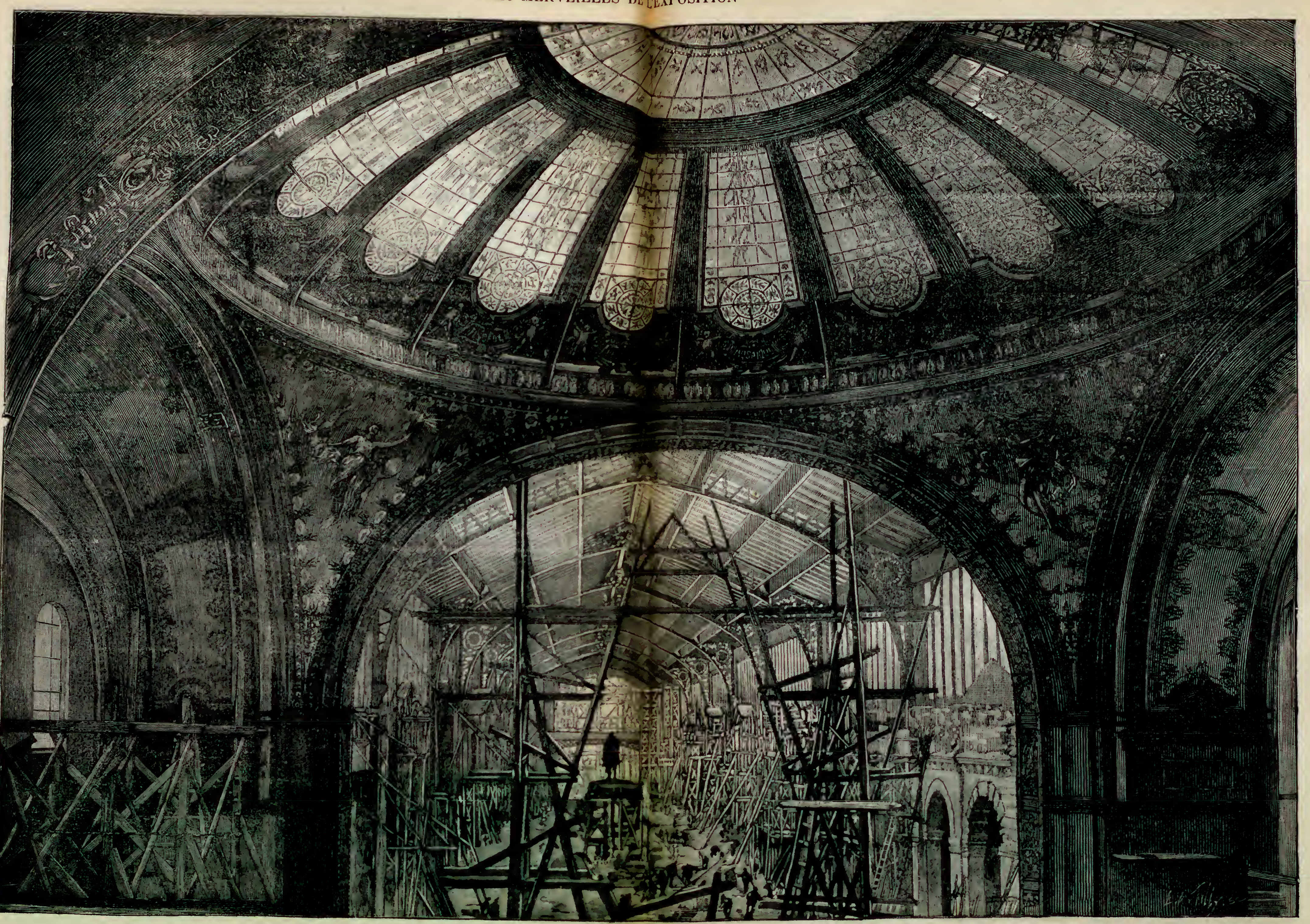

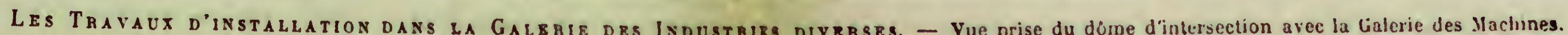


engagés sont, naturellement, des Annamites venus tout exprès de Hué ou d'autres villes de l'empire.

Parmi les nombreuses attractions que présentera la section coloniale à l'Exposition universelle de 1889, il convient de citer deux idées dues à M. Louis Henrique : 1 l'établissement d'un bureau de renseignements commerciaux où importateurs et expor. tateurs n'auront 'qu'à s'adresser pour être en mesure de connaître les prodnits de l'industrie nationale qu'il est possible de répandre dans nos colonies, et les produits indigìnes qu'ils pourront sé procurer sans passer par les marchés étrangers; $2^{\circ}$ une vaste bibliothèque coloniale, qui sera mise à la disposition des visiteurs. Ils y pourront puiser tous les renseignements désirables sur les mœurs et coutumes des habitants de nos possessions d'outre-mer et y connaîtront les ressources de chaque pays, le commerce et la culture à y entreprendre. Grâce à ces facilités, le colon désireux de fonder une maison aux colonies, partira mun ide renseignement sérieux, qui, jusqu'a un certain point, lui éviteront un apprentissage onéreux. Du reste, l'Exposition Coloniale n'a pas été seulemeni faite pour intéresser, pour amuser le visiteur. Sans doute, il sera fort agréable de voir une représentation du Théatre Annamite, de monter sur le minaret du Palais Algérien et de se représenter le muezzin appelant les fidèles a la prière, de prendre une tasse de café brúlant au cabaret Bambara, d'entendre la musique bizarre de tous ces indigènes venus des quatre coins de nos possessions pour nous faire touclier du doigt leur civilisation; mais ce n'est point pour cela que l'Esplanade des Invalides a été couverte sur un large espace de constructions coloniales. A côté des civilisations, on veut nous faire connaitre les ressources des pays. On veut montrer au comnergant, écrasé quelquefois sous le poids de la concurrence étrangère, qu'il peut trouver daus nos possessions une précieuse matière première; que cette matière, il pourra l'échanger non contre des espèces sonnantes et trébuchantes, mais contre les produits français, car une fois connu le gout de telle race, de tel peuple, qui l'empechera de fabriquer des objets qu'il exportera en Asie ou en Afrique? L'Exposition Coluniale a donc une importance sur laquelle il faut, dès maintenant, insister. On y fera des conférences. Des hommes qui ont vécu dans nos possessions d'outre-mer, qui en con naissent les besoins économiques, qui ont vu là-bas ce qui encombre le narché el ce qui y est introuvable, des hommes en un mot qui savent par expérience, auront toutes les facilités du monde pour s'éclairer, pour s'instruire, pour acquérir une connaissance exacte de notre domaine colonial et ne pas exposer, en conséquence, leurs capitaux a tout hasard.

Les administrations publiques avaient à retracer, dans leur Exposition, les progrds considérables accomplis dans les ministères depuis 1878. Pour montrer les résultats acquis, il était nécessaire que chaque ministère groupat ensemble, au lieu de les disséminer dans leurs classes respectives, les divers objets qu'il exposait.

Le Ministère de l'Instruction publique montre les transformations apportées a l'enseignement de tous les degrés depuis plusieurs années. Les nouvelles facultés, des laboratoires de zoologie marine, de météorologie, les muséums, les nouvelles écoles de médecine, les établissements types d'éducation, Janson de Sailly et Lakannl, les collèges de jeunes filles, les résultats des fouilles archéologiques el les royages d'explorations, enfin les spécimens de matériel scolaire et les travaux desécoles norinales ont fourni une série de documents dignes d'attirer l'attention des visiteurs, et qui pourrout devenir les bases d'un musée rétrospectif de la science et d'une histoire de l'Úniversité. 
Il faut citer encore une exposition ethnographique retraçant les usages, les instruments de travail, les costumes des provinces en 1789, et l'Exposition des Beaux-Arts, qui relèvent de ce ministère.

L'Exposition du Ministère de la Guerre comprend, à côté des produits qui se rapportent à l'art de la guerre, les parties du matériel qu'il n'y a pas intérêt à tenir cachécs au point de vue de la défense du pays, et en outre une exposition rétrospective et artistique de l'art militaire. Dans la partie moderne figurent le service géographique, le service des communications par réseaux télégraphiques, téléphoniques et aériens, de nombreux modèles se rapportant à l'armement, à l'équipemeit, des documents sur les services administratifs et de santé, ainsi que sur les poudres et les poudrèries. La construction du batiment du Ministère de la Guerre a une façade de $\mathbf{1 5 0}$ mètres. Ses trois portes monumentales et ses larges baies lui donnent un aspect des plus imposants Elle est précédée d'une porte moyen Age crénelée à pont-levis, flanquée de deux tour's dont la charpente est entièrement montée.

L'Exposition de la Marine et des Colonies occupe une surface de 2,500 mètres et se compose d'un palais central et d'une série de pavillons spéciaux. Le pavillon central abrite les collections de l'État, les expositions de travaux publics, les envois des écoles coloniales et des établissements pénitentiaires, des documents géographiques et statistiques. Outre les pavillons spéciaux des colonies, dont nous avons longuement parlé, une serre contient les spécimens des plantes coloniales les plus rares.

L'Exposition du Ministère de l'Agriculture comprend une exposition permanente, présentant le résumé complet des progrès agricoles accomplis depuis 1789 jusqu'à nos jours et mettant en lumière les modilications apportées à l'enseignement agricole; : In concours universel d'animanx reproducteurs; un concours d'animaux de l'espèce chevaline; une exposition de service de l'hydraulique agricole, et enfin une exposition forestière destinée à mettre sous les yeux du public les nombreuses variétés de produits forestiers, les divers procédés de culture et le reboisement des montagnes.

Le Ministère des Travaux publics expose dans un salon spécial, à l'aide de modèles et de dessins, les ouvrages les plus importants exécutés par les ingénieurs de l'État. Le Ministère de la Justice expose les statistiques de la justice civile et criminelle, les modèles de croix et diplỏmes de la Légion d'honneur et des anciennes décorations françaises, les travaux des élèves des Écoles de la Légion d'honneur et le matériel de l'Imprimerie nationale. La participation des Affaires étrangères consiste uniquement en une exposition des produits de Madagascar, pays de protectorat. Le Ministère des Finances présente les dessins, tableaux et appareils relatifs au service de la Statistique, des Contributions directes et indirectes, de l'Enregistrement, des Domaines, du Timbre, des Jouanes, des Monnaies et des Manufactures de l'État. Le Ministère de l'Intérieur expose la carte de France, le service vicinal, les établissements pénitentiaires et les services de l'Assistance publique. Enfin, l'Exposition spéciale du Ministère du Commerce et de l'Industrie comprend le matériel, les travaux et méthodes d'enseignement des écoles professionnelles, des écoles d'Arts et Métiers, de l’école centrale, l'exposé comparatif de la situation économique de la France en 1789 et en 1889, un album gra. phique des mouvements de la population française d'après les derniers recensements Les services de l'hygiène, des eaux minérales et des établissements thermaux ont été transportés pendant la préparation de l'Exposition au Ministère de l'Intérieur et détachés du Alinistère du Commerce; par contre celui-ci s'est augmenté du service des 


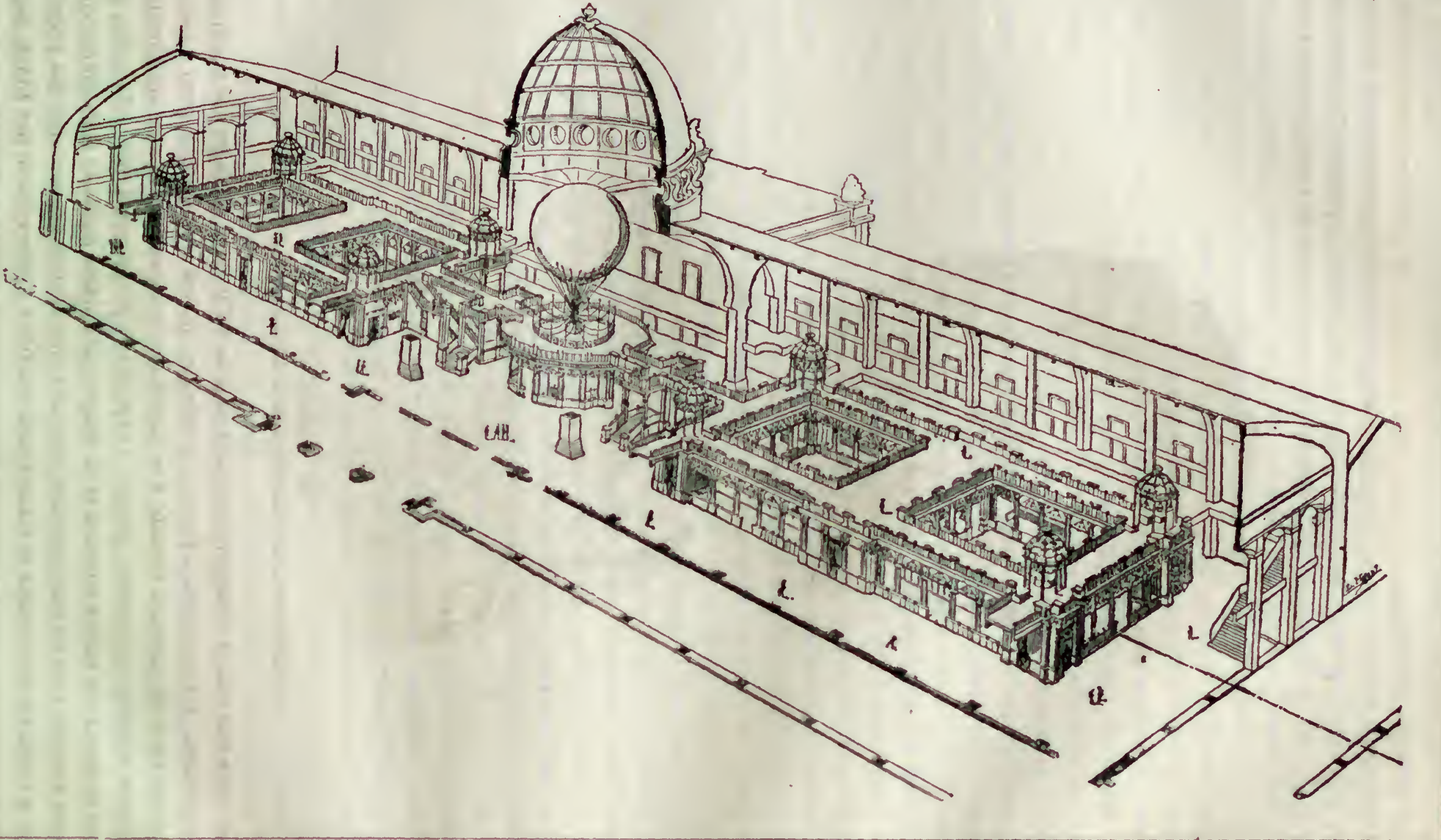


Postes et Télégraphes, dont l'exposition, des plus attrayantes, occupe un pavillon spécial sur l'Esplanade.

Tout au bout de l'lisplanade, près des Invalides, on s'arrêtera certainement au Panorama du Tout-Paris, dont nous avons parlé au début de notre ouvrage. En face, lèlong de la rue Fabert, l'Exposition des secours aux blessés nous montre les ambulances modèles, les trains sanitaires, les bateaux et voitures pour le transport des blessćs;

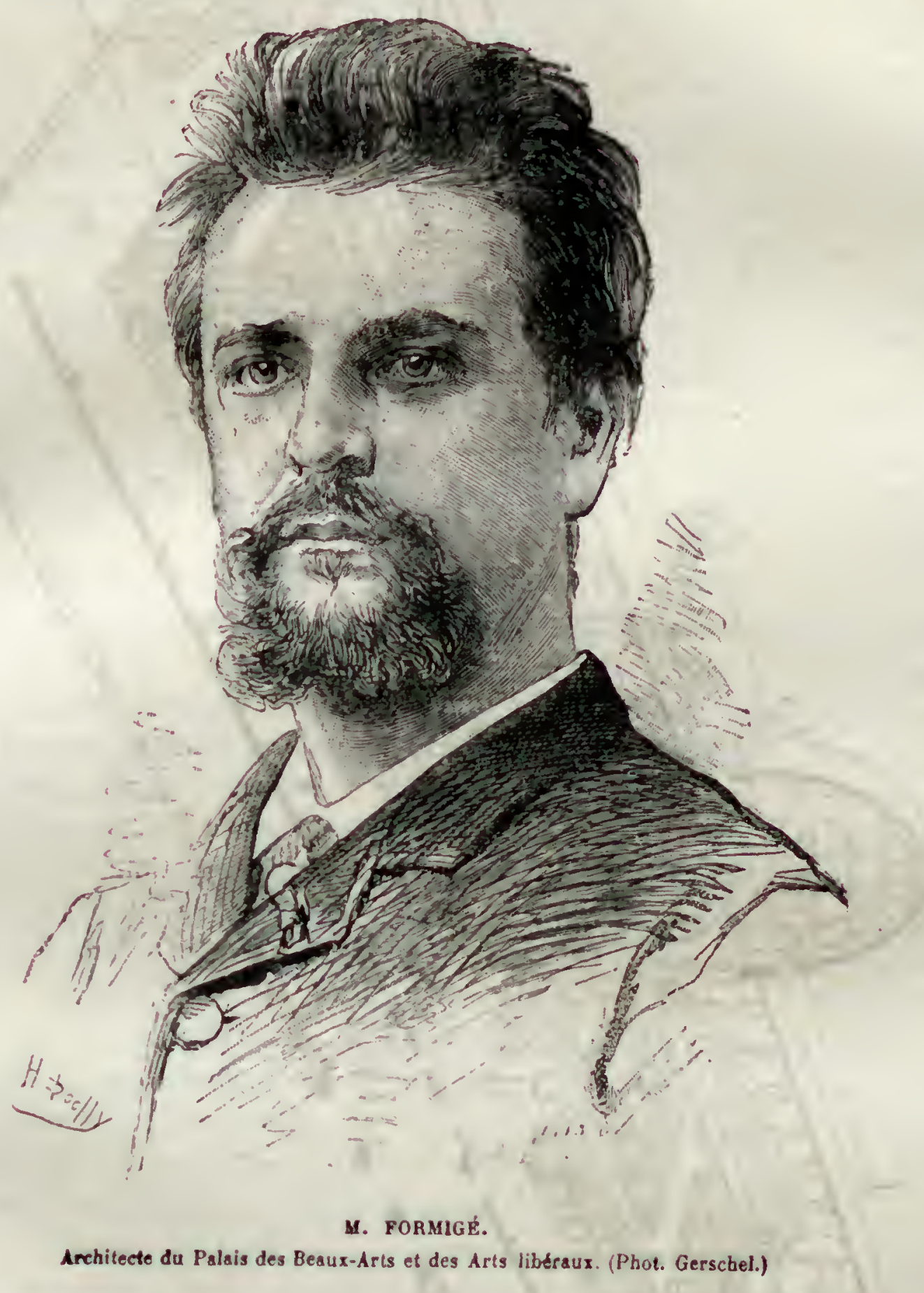

elle témoigne des efforts considérables faits depuis $18 \% 0$ pour soulager les souffrances des belligérants. L'Exposition d'Économie sociale, qui est contiguë, a pour base une enquéte sur les faits sociaux relatifs à la condition des ouvriers et aux améliorations susceptibles d'y être apportées; quant a l'exposition proprement dite, elle a lieu sous forme de tableaux, de cartes murales et de graphiques placés dans des maisons ouvrières d'un type spécial. Une section spéciale, celle de l'intervention économique des pouvoirs publics, a réuni les documents et statistiques relatifs à l'intervention des États, départements et communes dans les services habituellement confiés à l'initiative privée des 
citoyens. On ne verra pas sans intérêt les modeles de maisons ouvrières menblées et ornées de plans, un cercle ouvrier, un restaurant populaire et un dispensaire. Ce sont lì des documents tout a fait nouveaux.

- Nous devons signaler enfin, toujours sur l'Esplanade, l'Exposition de l'Ily giène, qui contient un parillon spécial à l'hygiène de l'habitation. Ce ne sera pas la partie la moins instructive de l'Exposition. Que de maladies seraient évitées, que de santés demeureraient robustes et florissantes si l'on observait scrupnleuscment les règles de. l'hygiène! La médecine guérit parfois les maladies, mais l'hygiène les prévient; nous conseillons à nos lecteurs une longue station a cet endroit. Comme on ponvait le prévoir dès le commencement de l'année dernière, la totalité des espaces réservés aux exposants étrangers s'est trouvée rapidement occupée. Les pays qui ont une section nationale à l'Exposition de 1889 peuvent être classés en deux catécories : d'une part, ceux qui sont représentés par des commissaires nommés par leur gouvernement; ces pays dont la participation est officielle sont: En Europe: la Grèce, la Norvège, la Serbie, la Suisse, Saint-Marin et Nonaco; - en Asie : le Japon, la Perse et le royaume de Siam; - en Afrique : le Maroc et la République Sud-Africaine; - en ncéanie : Victoria, la Nouvelle-Zélande et la Nouvelle-Cialles du Sud; - en Amérique : les Chtats. Unis, la République Argentine, la Bolivic, le Chili, la Colombic, l'Équateur, le Guatemala, Haiti, le Mexique, le Nicaragua, le Paragnay, Saint-Domingue, le Salvador, l'Uruguay, le Venezuela.

D'autre part, les pays dans lesquels l'initiative privée s'est substituée au gouverne. ment pour constituer des comités qui ont demandé à être reconnus officiellement. Ces pays sont :

En Europe: l'Autriche-Hongrie, la Belgique, la Grande-Bretagne, le Danemark, les Pays-Bas, la Russie, l'Italie, la Roumanie, l'Espagne, le Portugal et le grand-duché de Luxembourg; - en Afrique : l'Égypte; - en Amérique : le Brésil. Parmi ces comités plusieurs ont obtenu d'importantes subventions de leur gouvernement. Ainsi le Parlement belge a voté 600,000 francs pour faciliter la participation de l'industrie belge a l'Exposition de 1889; les Chambres espagnoles ont roté de ineme 500,000 francs; le gouvernement portugais a accordé $13 \pi, 000$ francs; le Comité roumain a reçu 200,000 francs; le Comité danois 140,000 rrancs et le Comité brésilien 750,000 francs.

On voit done que la participation des étrangers à l'Exposition de 1889 sera aussi large que possible, et il est bon de constater que les surfaces totales, mises i la disposition des différentes sections étrangères, sont supérieures à celles qqu'elles occupaient en 1878. On a réservé aux étrangers, dans l’enceinte même des palais, plus de 87,000 mètres carrés; néanmoins ils se plaignnent de l'insuffisance de place, malgrés les annexes créées dans les parcs et l'autorisation accordée aux pays de l'Amérique de réunir leurs expositions dans des palais et pavillons situés dans les jardins. Les Com. missions officielles et les Comités nationaux ont promptement complété leur organisation, et sont représentés par des commissaires spéciaux. Les sections étrangères occupent, dans le Palais des Industries diverses, les deux ailes symétriques qui s'étendent le long des avenues de Suffren et de la Bourdonnais, et la galerie de 15 mètres, dite Galerie des Pays du Soleil, qui borde le côté de l'avenue de Suffren. Denx enclaves prolongeant 'es ailes des sections étrangères ont été prises dans la section française pour' placer l'Autriche-Hongrie et la Russie. 
AUtriche-Hongrie. - L'Autriche-IIongrie occupe un emplacement de 2,291 mètres carrés dans le Palais des Industries diverses et un compartiment de plus de 300 mètres pour l'exposition de ses produits agricoles et alimentaires. Neuf travées lui sont affectées sur le vestibule de 15 mètres. Le Comité général austro-hongrois a provoqué et recueilli les adhésions d'un grand nombre d'industriels de l'Autriche et de la Bohême, si bien qu'il a été obligé de refuser les adhésions des retardataires.

Belgique. - En Belgique, un grand mouvement s'est produit en faveur de l'Exposition de 1889. Dès les premiers jours de l'année 1887, un comité provisoire, présidé par M. le comte d'Outremont, adressa un appel aux industriels belges. Les exposants belges occupent une surface de 11,000 mètres carrés, et la façade de leur sectien, sur le vestibule de 15 mètres, offre un modèle très caractéristique de l'art flamand. M. Berger a accordé à la section belge l'extension de 3,900 mètres carrés qu'elle demandait au delà de l'ensemble de la superficie déja accordée. On a également concédée à la Belgique un surcrôt de force motrice pour l'établissement de son compartiment mécanique. Sur 40,000 kilogrammètres de vapeur disponibles, la Belgique en réclamait 15,000. Pour satisfaire à cetle demande, on a dû porler la force motrice de 40,000 à 50,000 et même a 60,000 kilogrammètres. C'est une augrmentalion de plus de 100,000 francs de frais, mais on n'a pas hésité.

Pays-Bas. - Malgré l'absence de toute subvention, la Commission qui s'est constituée pour organiser l'Exposition des Pays-Bas a conduit à bien ses travaux, et la section néerlandaise n'est inférieure ni en intérêt, ni en importance, à celle de 1878. L'Exposition des Indes néerlandaises, avec ses habilations javanaises, sera l'un des principaux attraits de cette section.

Danemark. - La section danoise a commencé à s'organiser depuis le mois d'octobre 1888, et, grace a la subvention de 140,000 francs dont elle peut disposer, elle promet d'etre particulièrement brillante.

Grande-Bhetagne. - Une commission s'est formée à Londres, au mois de janvier 1888, sous la présidence du lord-maire, et a demandé au Commissaire général un vaste emplacernent pour l'Exposition de l’industrie anglaise. Près de $\mathbf{2 0 0 , 0 0 0 ~ m e ̀ t r e s ~ c a r r e ́ s ~ o n t ~ e ́ t e ́ ~}$ mis, dans les divers palais de l'Exposition, à la disposition du Comité exécutif. Dans le Palais des Industries diverses, la section anglaise s'est installée avec une rapidité remarquable et la façade de 10 mètres touchant au grand vestibule Rapp forme un carlre ornemental d'une originalité intéressante. Les colonies anglaises ont suivi l'exemple de la métropole, et le cap Victoria, la Nouvelle-Zélande, l'île Maurice et les Indes anglaises ont demandé des emplacements qu'il a été nécessaire de réduire. La deux dernieres colonies ont trouvé place dans des pavillons spéciaux du Champ de Mirs.

Lexemiourg. - L'Exposition du grand-duché de Luxembourg occupe une surface de $3 \subset 0$ mètres carrés environ. Le succès de l'entreprise a été facilité par le Gouvernement qui a pris à sa charge tous les frais incombant à ses nationaux. 



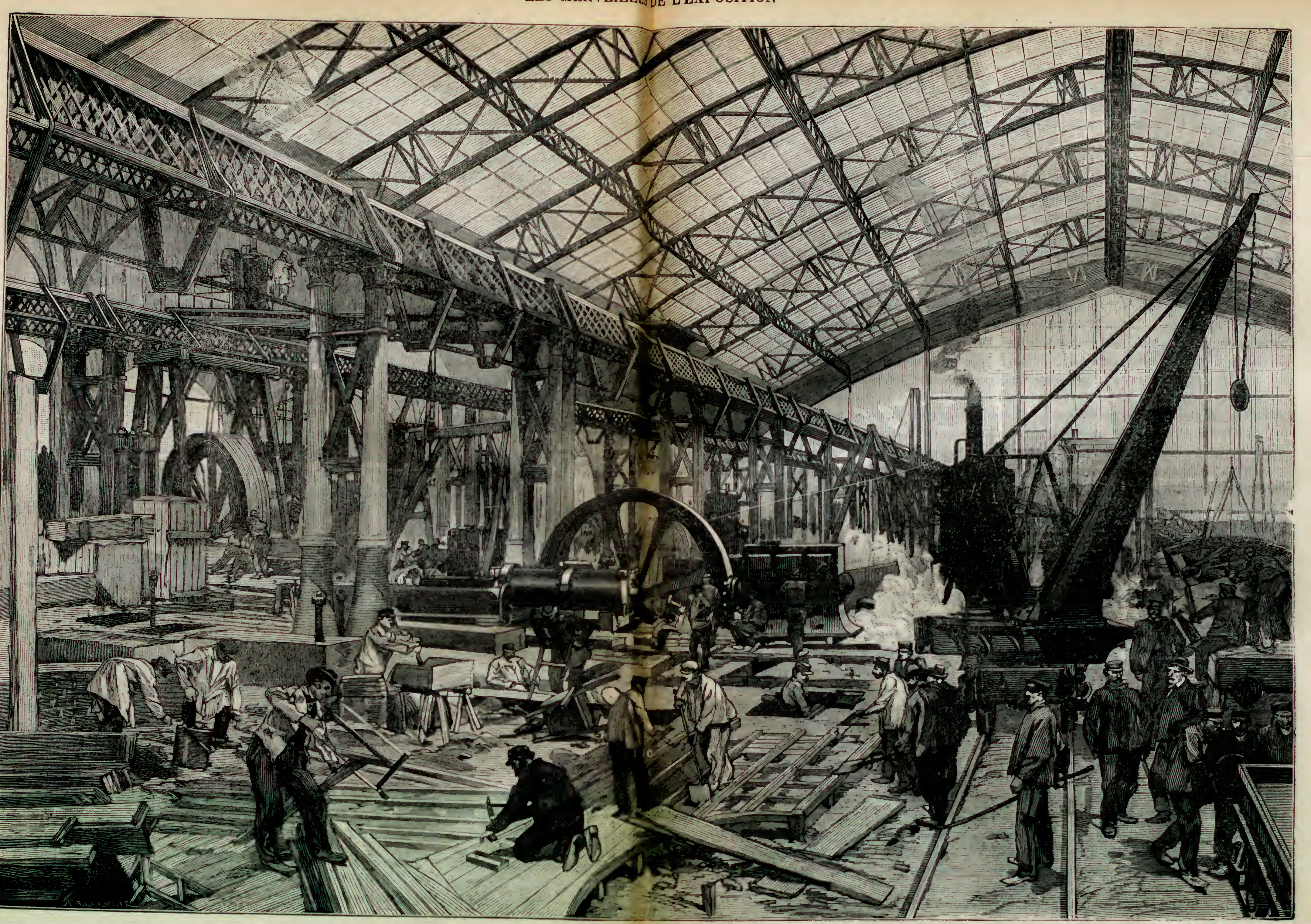


NorvèGe. - La participation de la Norvège à l'Exposition est officielle, et au mois de mai 1888, l'Assemblée nationale a voté une subvention de 140,000 francs pour venir en aide aux exposants. La section norvégienne occupe un espace total de 1, 2:0 mètres carrés.

Roumane. - Gráce à la puissante intervention du prince Georges Bibesco, un comité roumain s'est formé pour assurer la participation de la Roumanie à l'Exposition, et la Chambre roumaine a voté dans le meême but une subvention de 200,000 francs. L'industrie roumaine se trouve ainsi trè: dignement représentée, et son exposilion occupe 420 mètres carrés dans les galeries des Industries diverses, et plus de 200 mètres dans les galeries du quai d'Orsay.

Russie. - L'Exposition de la Russie ne fut décidée que fort tardivement, et c'est seulement au milieu de l'année dernière que fut formé à Saint-Pétersbourg, par un grand nombre de notabilités, un bureau des représentants des exposants russes. Bientôt le gouvernement ayant autorisé le fonctionnement de ce comité, une Commission fut constituée à Paris pour servir d'intermédiaire entre le Commissariat général et celui de Saint-Pétersbourg. Le mouvement, d'abord restreint a la capitale, s'est rapidement propagé et un plus granả nombre d'exposants qu'en 1878 sont venus non sculement de Saini-Pétersbourg, mais de Varsovie, de Riga, de Moscou. En outre, dans le grand-duché de Finlande, les industriels se sont syndiqués, avec l'autorisation du gouverneur général, pour prendre part à l'Exposition, et ils se sont décidés à grouper leurs produits dans un pavillon spécial. La Russie occupe, en tout, près de 3,000 mètres carrés dans les divers palais de l'Exposition. La section industrielle aboutit au vestibule de 150 mètres où elle dispose de neuf travées. Sa façade reproduit, dans ses lignes générales, l'entrée du Kremlin; elle est, en outre, surmontée d'une grande décoration peinte montrant les coupoles de l'ancien palais des czars, et forme un ensemble très caractéristique.

Mi. Tatistchef a examiné, dans une brochure intéressante, la question de la participation de la Rinssie à l'Exposition de 1889. Il déclare tout d'abord que l'agriculture el l'industrie russes ont tout intérèt à y être représentées. A Il suffit de connaitre tant soit peu l'histoire des rclations politiques de la Russie et de la France pour se convaincre que de tous les gouvernements qui, dans le cours des deux derniers siècles, se sont succédé dans ce pays, pas un n'a témoigné a la Russie une amitié plus loyale que le gouvernement de la troisième République. Les sympathies de la France contemporaine et républicaine a l'égard de la Russie sont un fait indéniable et que viennent corroborer fréquemment non seulement les actes du gouvernement, mais aussi les manifestations spontanées, unanimes et parfois si touchantes du peuple francais. II n'existe point de pays au monde où le nom russe soit tenu en plus grand honneur qu'en France aujourd'hui. Tout ce qui nous est cher y est respecté, nonolstant la diversité des principes politiques et des tendances sociales des deux nations. Sciences, arts, lettres russes jouissent en France de l'estime générale. Seuls, parmi les peuples de l'Occident, les Français ont reconnu les titres du peuple russe a la qualité de membre de la grande famille européenne apte a jouir de tous les droits de ses alnés. Le sentiment leur a dicté ce verdict, et la raison l'a ratifié.

- La Russie doit d'autant plus apprécier l'amitié de la France que, dans leurs 
rapports avec nous, les. Français font exception parmi toutes les autres nations occidentales. Par calcul politique, tel gouvernement étranger peut, d un moment donné, chercher a se concilier les bonnes graces du cabinet impérial, mais nous serions impardonrables de faire semblant de ne pas nous apercevoir de la haine implacable et ardente qui se fait jour sans cesse et par les moyens les plus variés à l'égard de notre pays dans les manifestations de l'opinion en Allemagne et en Autriche, en Angleterre et en Italic.

* En présence de la soi-disant Ligue de la paix constituée au centre de l'Europe et s'appuyant d'un côté sur les forces maritimes de la Grande-Bretagne, de l'autre sur les petits Élats chrétiens de la péninsule balkanique créés par la Russie et comblés de bienfaits par elle, la France se trouve être la seule des grandes puissances qui, uon seulement ne nous honnit pas ni ne nous témoigne de l'hostilité, mais qui cherche à se rapprocher de nous, a s'entendre avec nous, non dans des vues de revinche ou de conquates, mais pour sauvegarder, de concert avec nous, la paix et l'éruilibre de l'Lurope. L'Exposition universelle qu'elle organise en ce moment dans sa capitale n’est-elle pas la preuve la plus évidente de la sincérité de ses intentions pacifiques?

"Néanmoins, ce n'est pas au nom de la paix de l'Europe, c'est surtout dans son propre intérit que la liussie doit attribuer une haute valeur à l'amitié de la France, cal sans elle, elle se trouverait bientòt dans un isolement complet, face à face avec une coalition générale des forces hostiles de l'Occident. ,

II. Tatistchef conclut de là que la participation de la Russie à la solennité nationale de la France est réclamée tout autant par les intérêts de sa politique que par les besoins de son art, de son industrie et de son commerce.

- Ne serait-il pas étrange, dit-il, que nous nous tinssions à l'écart de l'Exposition - aujourd'hui qu'une amitié sincère relie à la Russie le gouvernement et le peuple en France et cela après que nous avons pris part sans hésiter à des expositions pareilles en 1867, quatre années après la campagne diplomatique inaugurée contre nous par la France des Bonaparte à la tête de l'Europe coalisée, ou bien en 1878, lorsque les représentants de la jeune République s’associaient, dans leur inexpérience, au Congrès de Berlin, aux votes si hostiles à la Russie de toutes les autres grandes puissances. Au point de vue des intérèts de la Russie, dans leur acception la plus large, sa participation a l'Exposition de $18 \& 9$ se présente comme une exigence politique de premier ordre qui n'admet ni doute ni contestation.

M. Tatistchef se pose ensuite cette question : Étant donnée cette nécessité, pour. quoi ne pas la satisfaire? Et pour y répondre, il cite un extrait du document ćmané de M. de Bismarck, et où le chancelier fait observer que, antérieurement à la Rérolution française, l'idée ne venait pas à un homme d'État de subordonner les rapports extérieurs de son pays à la crainte de se mettre en contact avec la Révolution à l'étranger, bien que les principes de la Révolution américaine ou anglaise fussent presque identiques à ceux qui avaient déterminé en France une interruption dans la continuité du droit. Après avoir rappelé que les actes de la Révolution de 1789 nont été sévèrement jugús par l'opinion monarchique qu'en tant qu'ils se sont produits en France, M. de Bismarck arrive d nier que la Révolution française ait pris source dans ce pays. "Si l'on vẹt à tout prix, nous apprend-il, lui attribuer une origine terrestre, il faudrait la rechercher, non pas en France, mais plutot en Angleterre, ou mème antérieurement en Allemagne ou d Rome, selon que l'on voudrait reporter la culpabilité sur les ramifications de la 
Réformation ou bien de l'Église romaine, conjointement avec l'introduction dans le monde germanique des principes du droit romain. "

- Nous nous plaisons, continue M. Tatistchef, à rendre justice a la profondeur, mais surtout à la stricte objectivité du jugement porté par l'éminent homme d'État sur l'une des plus grandes époques de l'histoire qui emprunte son nom a la Révolution

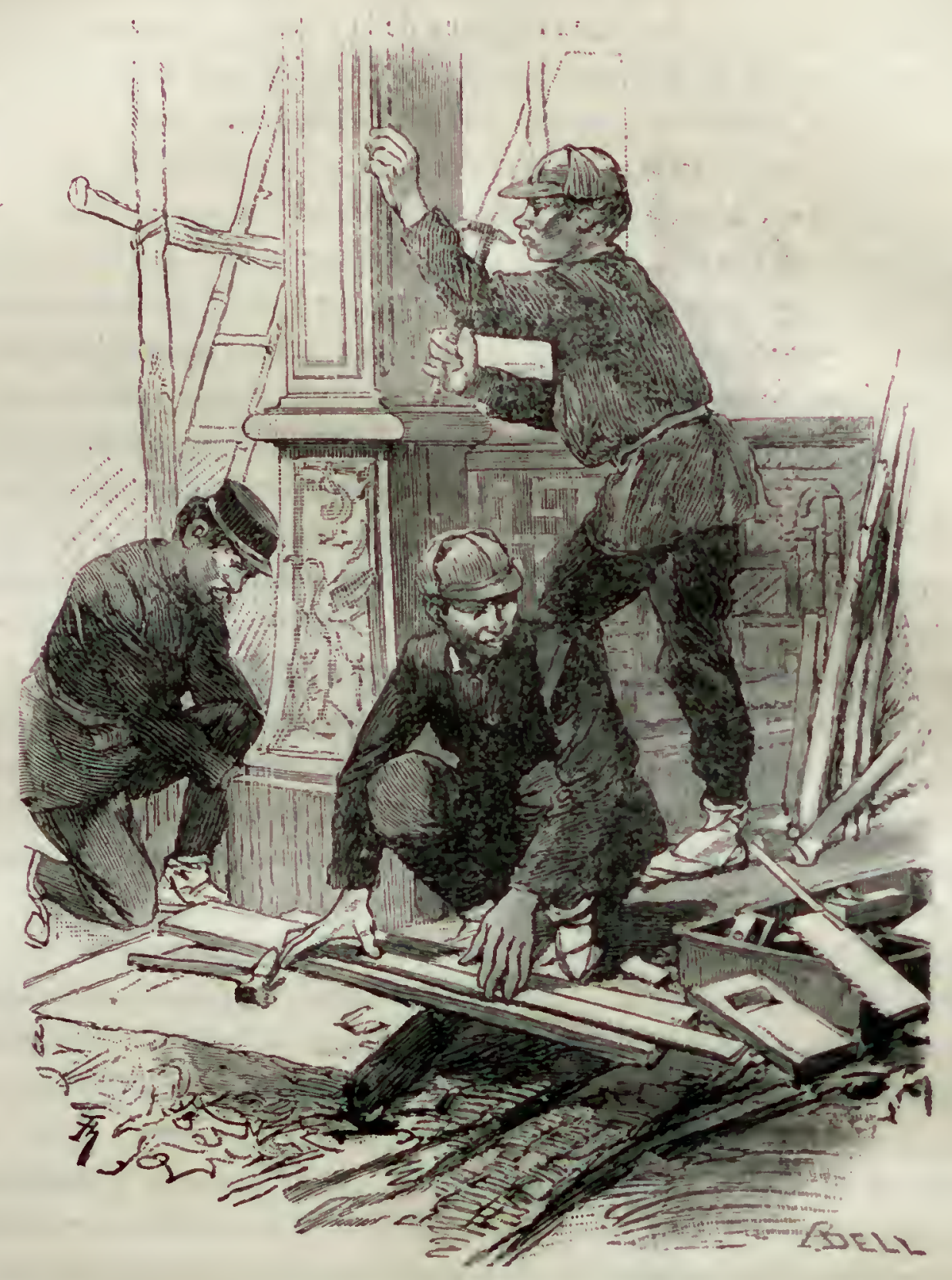

OUVRIERS IAPONAIS A L'FXPOSITION.

française. La Russie a été plus d'unc fois dans le cas de se convaincre de l'inanité de cette abstraction politique de la légitimité à laquelle elle a, depuis le commencement de ce siècle, si souvent et si généreusement fait le sacrifice de ses intérèts et de ses droits. Et qu'en est-il résulté? De même que pendant la guerre de Crimée les sympathies des États-Unis d'Amérique offraient un contraste frappant avec l'hostilité que nous témoignaient toutes les grandes puissances monarchiques, aujourd'hui encore, nous voyons quatre monarchies former une coalition redoutable qui, tout en s'intitulant la ligue de la paix, n'a pour but que de mettre fin à la croissance 


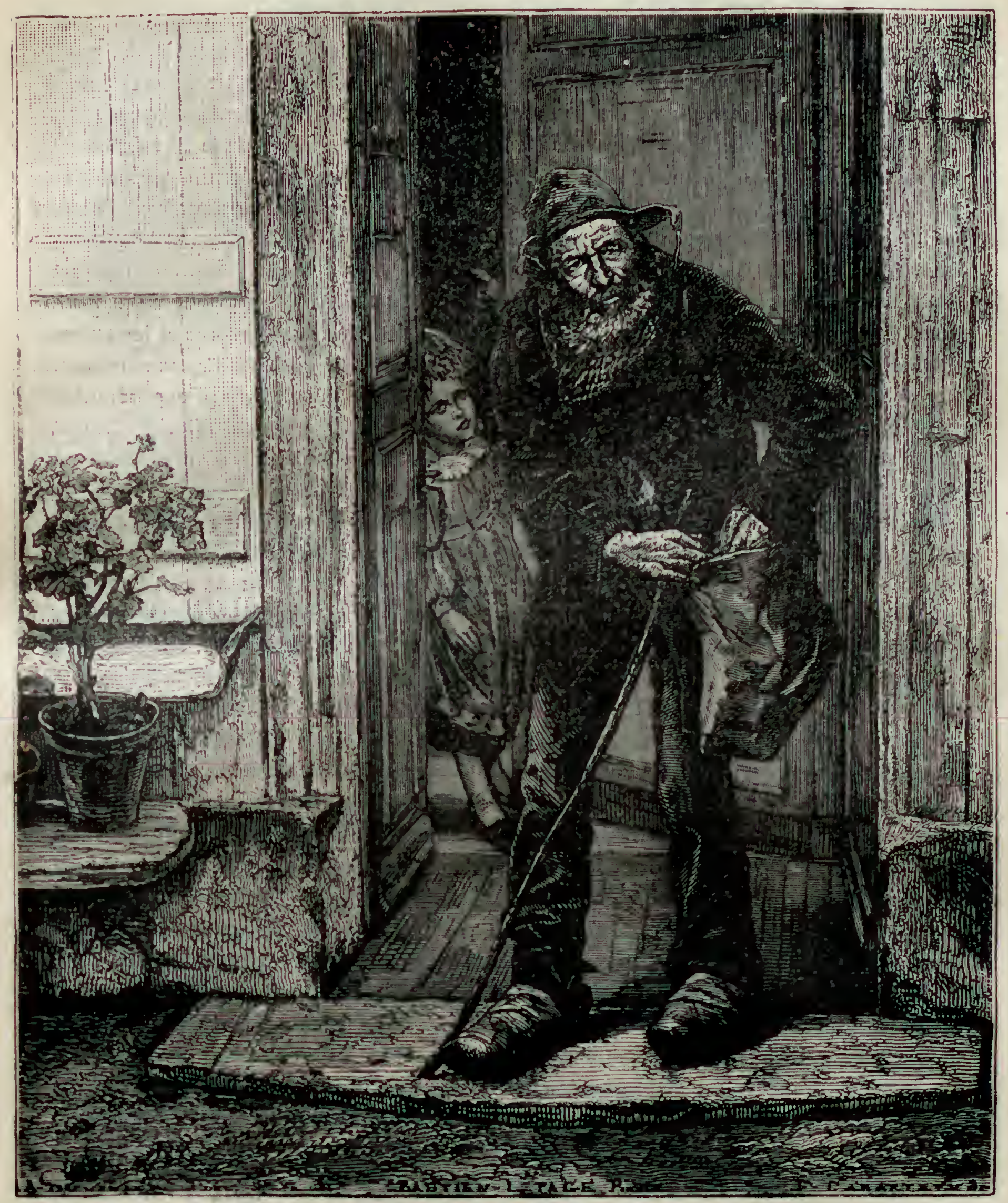

BвAUX-ARrs. - Le Mendiant, par Bastien Lepage.

politique de la Russie et, en dehors de cette ligue, la lépublique franģaise seuls: nous témoigaant une constante el loyale amitié.

- Il n'en faut pas davantage pour nous auturiser a prendie une part ufficielle à la célébratiun du jubilé républicain en Franıce, toul comme il g a ciny uns nuus n'avons pas hérité à nous faire représenter à l'Expusition de Philitlelphie, orgauisce en 
l'honneur du centenaire de la fondation de la grande République transatlantique. A mes yeux, la poussée vigoureuse imprimée par 1789 au développement politique de la France, a eu des conséquences incalculables et, en majeure partie, bienfaisautes, non seulement pour ce pays, mais pour tous les États, de l'Occident européen. Ces derniers ont subi, sans trop s'en ressentir, la tempête des guerres de la Révolution at de l'Empire, mais les germes des idées de 1789 y trouvèrent un terrain préparé par un travail séculaire et produisirent en fin de compte la renaissance morale et l'unité politique tant de l'Italie que de l'Allemagne. C'est aux Français qu'Italiens et Allemands sont redevables de la chute de l'antique édifice féodal avec toutes ses difformilés et tous ses abus servant de prison à leurs aspirations nationales. lin refusant de prendre une part officielle đla commémoration de la Révolution française, les uns et les autres font acte d'une ingratitude que l'on ne peut s'empecher de qualifier de monstrueuse.

" La Russie, dont la vie politique et sociale s'est développée d'une maniere absolument indépendante des grands événements qui ont bouleversé l'Occident, prut apprécier avec d'autant plus de justice et d'impartialité les résultats d'un mouveneut dans lequel on est forcé de reconnaitre un progrès immense dans la voie du développement intellectuel de l'humanité. Admettons que ce mouvement n'ait fait que glisser sur la vaste surface de notre pays et n'ait exercé qu'une influence indirecle sur ses destinées, mais tout ce qu'il contenail de juste, de bon et de véritablenent utile a été introduit dans notre législation par nos autocrates, l'impératrice Catherine II et les empereurs Alexandre Ier, Nicolas Ier et Alexandre II. Disuns plus: l'acte immortel du dernier de ces souverains, l'émancipation des serfs, présente une analogie frappante avec les réformes de 1789. Il y a cent ans en F́rance, comine en Russie de nos jours, une animation patriotique s'étail emparée de tous, poussant tout le monde à faire des sacrifices volontaires au bien commun de la patrie. Confondre les glorieux débuts de 1789 avec les excès de 1793 et déduire les premiers des seconds, n'est-ce pas la mème chose que de chercher à établir une causalité étroite entre la date radieuse du 19 février 1861 et le crime abominable dont une bande de forcenés n'a pas craint, vingt ans plus tard, d'ensanglanter le sol russe.

- Telles sont les considérations qui nous permettent d'affirmer qu'en prenant une part officielle à l'Exposition universelle organisée en l'honneur du centenaire de 1789 la Russie n'entrerait nullement en contradiction avec elle-meme, avec son bistoire, avec les bases fondamentales de son existence politique, et ne porterait certainement pas atteinte à sa dignité. L'autocratie, qu'il est bon de distinguer de l'ancienne monarchie française, est inébranlable chez nous précisément parce qu'elle est légale et nationale tout conme l'est en France la République, de par les décrets de l'histoire. Et ceux-là ne sont pas fermes dans leur foi, et ils ne croient guère à la puissance et ¿ la vérité du pouvoir absolu en liussie, qui se permettent d'exprimer la crainte insensée que la présence des représentants, officiels russes à la fête nationále d'un peuple ami pourrait'saper par la base les fondéments de l'ordre politique si chers a tous les cœurs vraiment russes. ,

Serbie. - La Serbie participe officiellement à l'Exposition. Elle est représentée par un commissaire générá et par un commissaire général délégué, qui est le conseil général du royaume de Serbie à Paris. La sectioñ serbe occúpe près de 300 mètres càrrés. 
Suısse. - Dès la fin de l'année 1887, la Suisse avait décidé de participer officiellement à l'Exposition et la Chambre fédérale avait voté un crédit de 425,000 francs. Près de 6,000 mètres carrés ont été mis à la disposition de la Suisse, dont la section présentera un réel intérêt; la façade sur le vestibule de $\mathbf{1 5}$ mètres a un caractère très original.

ITALle. - Le comité national italien, qui, sous la présidence de M. Villa, s'était constitué en 1887, a poussé activement ses travaux dans les derniers mois de l'année dernière. $\Lambda$ u 15 novembre 1888, plus de douze cents producteurs italiens avaient déjà demandé des emplacements et ce nombre a doublé depuis. Aussi le commissaire général a-t-il réservé aux exposants italiens près de 3,500 mètres carrés, sans parler des espaces importants de la Galerie des Machines.

Esingne. - Au mois de juin 1888, le Congrès votait à Madrid un crédit de 500,000 francs pour la participation de l'Espagne à l'Exposition. Immédiatement après ce vote, la Chambre de commerce espagnole de Paris s'occupait de l'organisation de sa section nationale qui fut activement poussée. L'Exposition espagnole occupe, en dehors de la Galerie des Machines, près de 4,000 mètres carrés.

Pontugal. - Ce fut l'Association industrielle portugaise, présidée par M. Mélicio, pair du royaume, qui se chargea d'organiser la participation du Portugal à l'Exposition. Depuis lors, le gouvernement portugais a alloué, pour venir en aide aux exposants du royaume, une somme de 137,000 francs. L'espace réservẻ au Portugal, dans les seules galeries des Industries diverses et sur le quai d'Orsay, dépasse 2,000 mètres carrés.

GıĖck. - La Grèce avait fait connaftre, dès 1887 , son intention de prendre part officiellement à l'Exposition universelle. L'espace demandé par M. Vlasto, ingénieur, commissaire général, et mis à la disposition de la section grecque, est de 560 mètres.

Monaco. - Le prince de Monaco a également accepté l'invitation officielle du gouvernement français. La principauté a fait construire au Champ de Mars un pavillon spécial, flanqué de quatre tourelles carrées; une serre y est adossée.

Sarnt-Manis. - La participation officielle de la République de Saint-Marin a été, dès les propositions faites, assurée à TExposition. La section spéciale occupe, dans les galeries des Industries diverses, une superficie de 230 mètres.

Axporre. - Le gouvernement d'Andorre s'est également fait représenter à l'Exposition où le visiteur se rendra compte avec intérêt de l'industrie de ce pays.

États-Unis. - Au mois de juin 1888, la Chambre des représentants et le Sénat ayant roté un crédit de 225,000 dollars pour la participation des États-Unis à l'Exposition unirerselle, M. le général Franklin fut désigné comme commissaire général, et M. Bailly-Blanchard comme secrétaire délégué à Paris. Dès son entrée en fonction, le 

LES MERVEILLES DE L'EXPOSITION

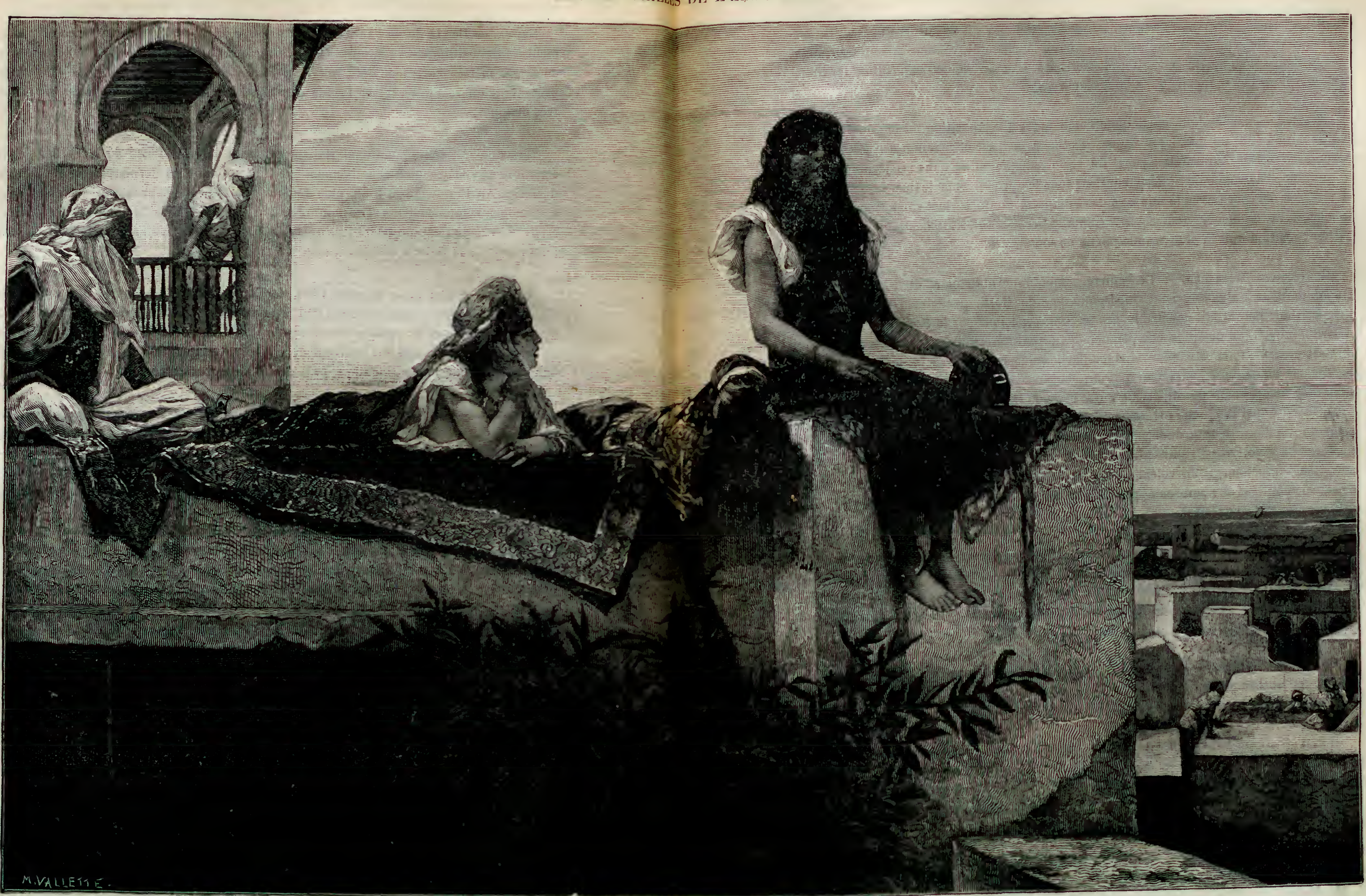

BEAUX-ARTs. - Le Sorr sur les terrasses tableau de M. Benjamin Constant. 
comité américain demanda l'augmentation des espaces qu'on lui avait réservés, surtout dans la Galerie des Machines. De son côté, le célèbre inventeur Edison a organisé une brillante et complète exposition d'électricité. L'ensemble de l'exposition des lítatsUnis n'occupe pas moins de 8,000 mètres carrés.

MexiQue. - Le Mexique participe officiellement à l'Exposition, et le gouvernement a alloué un crédit de 2,500,000 francs, destiné à faciliter et à rehausser l'éclat de la section mexicaine. Un palais spécial du style aztèque, situé dans les jardins entre la Tour Eiffel et l'avenue de Suffren, contient tous les produits mexicains. Le ministre du Commerce, d’accord avec le ministre des Finances, a autorisé la dégustation des tabacs mexicains instamment réclamée par le commissaire général, M. Diaz Mimiaga, à laquelle cette exposition doit la plus grande partie de son succès.

Guatemala, Nicaragua. - Les gouvernements de Guatemala, du Nicaragua, de la République de Salvador, de Saint-Domingue, de Haîti, participent officiellement à l'Exposition; ils ont fait construire des pavillons spéciaux sur la terrasse du Palais des Arts libéraux. L'un des plus complets et des plus intéressants est certainement celui du Salvador. Cette construction, dirigée par le goût artistique de M. le consul général Pector, est embellie à l'extérieur par une curieuse corniche de faience, sur laquelle sont inscrits les noms des différents mois et le millésime 1889, en caraclères nahuad (on appelait ainsi la langue originaire de l'Amérique centrale et du Mexique). A l'intérieur du pavillon, deux grands panneaux représentent des cérémonies religieuses indigènes. On y voit aussi l'entrée du port de la Libertad et le merveilleux lac Nilopango, au milieu duquel surgit un volcan. Dans une annexe au pavillon, une sorte de serreorangerie contient de nombreux produits agricoles et forestiers, notamment des plantes médicinales fort appréciées.

RÉpubulque Argentine. - Sur la proposition du gouvernememl argentin qui proposait d'organiser officiellement une section spéciale à l'Exposition universelle, le Congrès a voté $3,200,000$ francs; aussi un espace de 1,600 mètres carrés a-t-il été mis à la disposition du président de la section argentine pour l'édification d'un palais très réussi.

Bolrvie et Colombie. - Les gouvernements de la Bolivie et de la Colombie, désireux de prendre une part officielle à l'Exposition, ont fait bâtir à frais cummuns, près de la Tour Eiffel, un bâtiment d'une surface de 800 mètres carrés.

BréSIL. - Depuis les premiers mois de l'année 1888, la participation du Lrésil a été assurée, et grâce aux efforts de M. d'Albuquerque, chargé d'organiser la section brésilienne, gràce aussi au crédit considérable dont il a pu disposer, le palais a été promptement édifié. Le comité a utilisé les jardins autour du palais pour y exposer les plus beaux spécimens des plantes du Brésil.

Républiqu Sud-Africaine. - Cette république participe officiellement a TExposition. L'Assemblée nationale a voté une somme de 75,000 francs pour subvenir aux dépenses; son pavillon spécial figure sur l'Esplanade des Invalides. 
CumL. - Dès que le gouvernement du Chili eut exprimé son désir de prendre part officiellement à l'Exposition, un emplacement de 60 mètres carrés fut mis à la disposition.de M. Antunez, ministre du Chili et commissaire général. On admire dans le pavillon du Chili une collection de minerais, la plus riche et la plus complète qui ait été réunie jusqu'à ce jour.

Énuatelr, Paraguay, Pérou, Unuguar, Venezuela. - Tous ces pays sont officiellement représentés par des commissaires généraux et des emplacements spéciaux lui ont été accordés pour la construction de leurs bâtiments d'exposition. Le Venezucla, en particulier, occupe un emplacement de 600 mètres carrés dans les jardins avoisinant la Tour Eiffel.

ÉgYrte. - Le comité égyptien, qui s'était formé au Caire en 1887, a délégué à Paris M. le baron Delort de Gléon en qualité de commissaire général. Il s'est entendu avec l'Administration pour la création d'un quartier Égyptien, dont la a rue d" Caire * est le centre et constitue certainement l'une des attractions les plus pittoresques de l'Exposition.

Maroc. - Le sultan du Maroc, qui avait décidé de participer officiellement, a délégué plusieurs commissaires, qui ont organisé la section marocaine. Un pavillon impérial, destiné au sultan, est élevé au centre; il ne coûte pas moins de 100,000 francs et contient de riches collections.

Chune. - A la fin de l'année dernière, le chargé d'affaires de Chine à Paris annonça le désir d'un certain nombre de négociants de venir à l'Exposition et demanda pour eux un emplacement. Un espace de 300 mètres carrés a été mis à leur disposition.

JAPON. - Le gouvernement japonais participe officiellement à l'Exposition universelle. Le nombre des exposants de la section japonaise dépasse celui de 1878; ils occupent une surface de 1,650 mètres carrés. En outre, le Japon occupe une surface de 1,100 mètres dans les galeries d'Agriculture.

Pense. - M. Nazare-Aga, ministre de Perse à Paris, a été chargé d'organiser l'exposition de son pays; on a mis à sa disposition un emplacement dans les galeries des pays d'Orient; en ontre, la maison persane, qui figure dans "l'Histoire de l'habitation *, sert de pavillon à S. M. le schah de Perse.

Sinm. - L'exposition siamoise, qui a un caractère officiel, emprunte un éclat particulier aux collections royales que le roi a envoyées à Paris; elles sont exposées dans un pavillon spécial construit dans le pays mème et qui occupe 250 mètres carrés de superficie.

On voil, par le résumé qui précède, que les étrangers sont représentés d'une façon exceptionnellement brillante. Plusieurs d'entre eux se sont adressés, pour la construction de leurs pavillons ou de leurs palais, aux architectes français les plus distingués, et, pour leur décoration, à nos meilleurs artistes. Ces constructions sont de trois types: 
ou bicn elles sont la reproduction de monuments nationatx existants (pavillons mexicains), ou bien elles sont inspirées par des monuments de la renaissance espagnole (palars du Venezuela), ou bien elles sont dues à la seule fantaisie de larchitecte. Toutes ont un cacliet d'originalité qui attire en foule le public dans la partie des jardins du Champ de Mars où elles se trouvent reunies.

Rien donc ne pouvait arrèter le succès de l'Exposition. Les comités départementaux, dont la fornation avait été achevée avant la fin de lannće 1587, ont rendu lous les

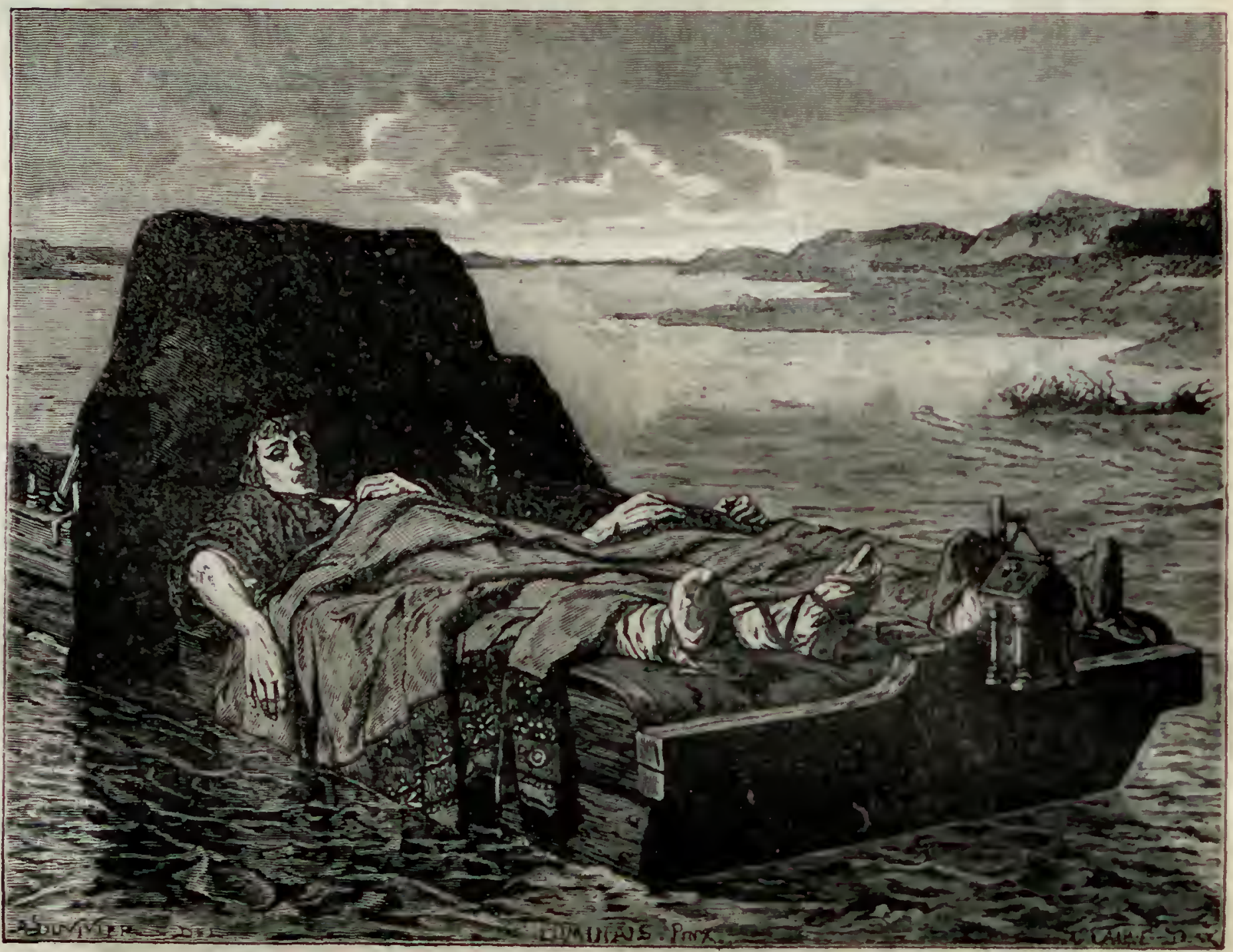

BEAUX-ARTs. - Les Énervés de Jumièges, par Luminais!.

services qu'on était en droit d'en attendre; ils ont, avec l'aide des autorités locales, recueilli et transmis les demandes d'admission, organisé les expositions collectives, et fait naftre en faveur de l'Exposition de 1889 un mouvement qui a contribué à en assurer le succès. Les demandes d'admission affluèrent et leur nombre dépassa 22,000. A leur côté, les comités d'installation se sont préoccupés de répartir entre les exposants l'espace attribué à chaque classe, de dresser des plans d'installation, d'établir le devis général des dépenses d'installation et de décoration des salles et des frais de gardiennage et d'entretien, et de s'entendre pécuniairement arec les exposants. Les exposants n'ont reçu leurs certificats d'admission qu'après s'être engagés \& payer les frais qui leur incombent; néanmoins, il eât été injuste d'écarter par la nécessité dẹ cet enga-

1. Pour rendre l'aspect de la publication plus varié, les reproductions de lableaux ont été placées indifferemment, sans observer l'ordre chronologique. 
gement préalable les ouvriers et les petits inventeurs dont les prodnits peuvent être d'un réel intérêt pour les industries qu'ils représentent : de là est venue l'idée d'exonérer ces exposants des frais d'installation qui auraient dú être mis à leur charge. Le

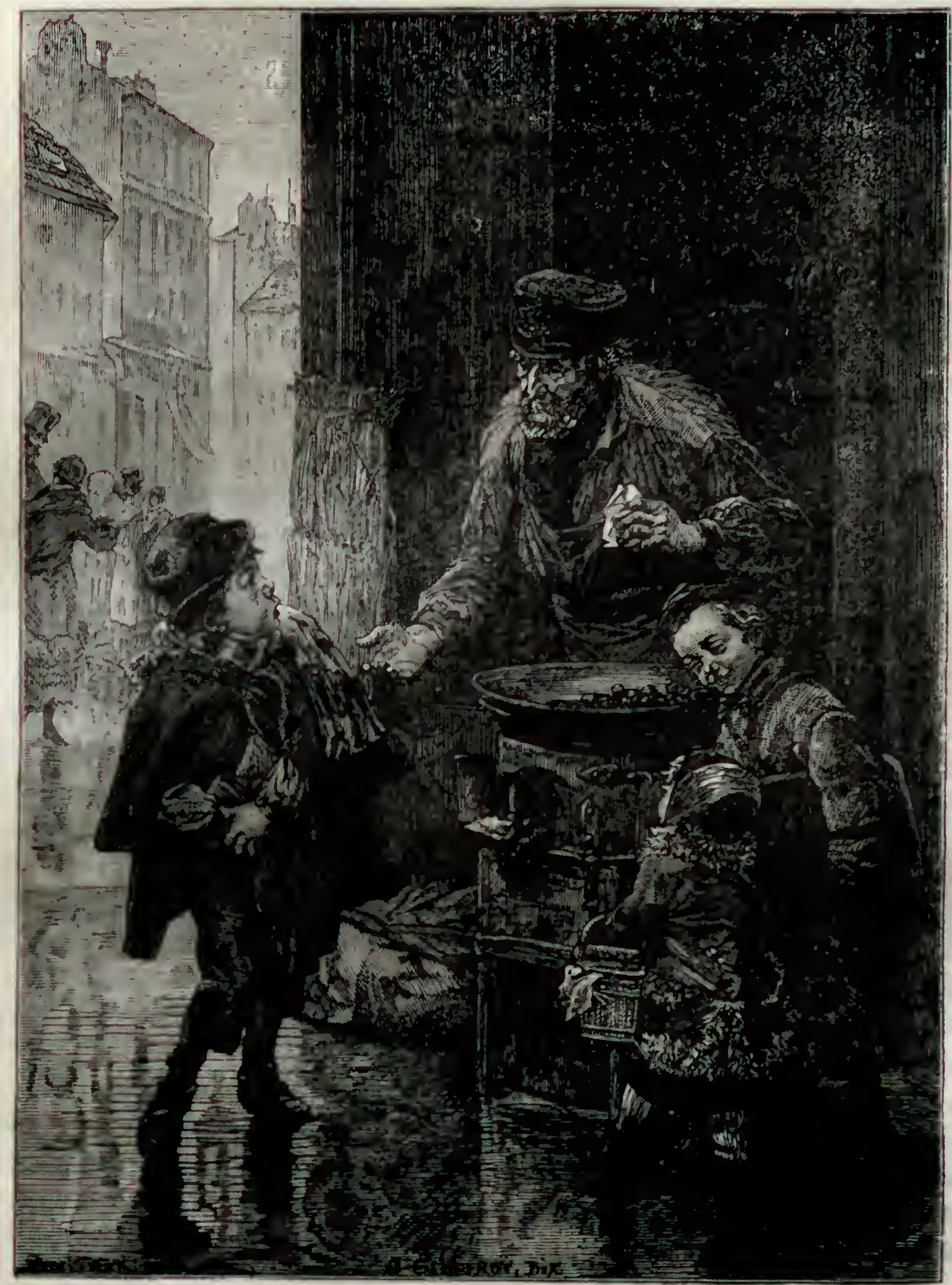

BEAUX-ARTS. - Le Quart d'heure de Rabelais, par Geoffroy.

Conseil municipal de Paris ayant accordé la jouissance du Pavillon de la Ville pour l'installation d'une Exposition ouvrière proprement dite, le Commissariat général consentit à recounaltre cette exposition spéciale comme annexe de l'Exposition universelle. 
IX

\section{L'EXPOSITION DES BEAUX-ARTS}

Le groupe des œuvres d'art qui figurent a l'Exposition universelle comprend des peintures sur toile, sur panneaux, sur enduits divers; des miniatures, des aquarelles; des pastels et dessins de tous genres; des peintures sur émail, sur faience et sur porcelaine; des carfons de vitraux et de fresques; des sculptures en ronde-bosse, en bas-reliefs, repoussées et ciselées; des médailles, camées et pierres gravées, des nielles; des études d'architecture, projets et restaurations; des gravures en noir et polychromes; des lithographies en noir, au crayon et au pinceau; enfin, des chromolithographies.

L'Exposition des Beaux-Arts se compose de deux grandes sections, l'une est une exposition centenale et comprend, autant que possible, les œuvres des maltres depuis la fin du $\mathrm{xvIII}^{\mathrm{e}}$ siècle; l'autre est une exposition en quelque sorte contemporaine. Nous avons donc à passer en revue l'évolution de la peinture française pendant cette longue période.

Il y eut au xvm ${ }^{\mathrm{e}}$ siècle toute une pléiade de peintres légers, gracicux, brillants, ne relevant que de leur caprice, n'écoutant que leur inspiration. Cetle école, a laquelle on commence à rendre justice, parce qu'on en comprend mieux l'esprit, procède du besoin qu'on éprouva de réaģir contre lá tutelle bigote de $M^{\text {ne }}$ de Maintenon. A l'austérité, à la gravité succédèrent, avec excès malheurcusement. la gaieté, l'amour, la coquetterie. On s'engoua de la nature : les lettres et les arts l'idéalisérent, montrèrent dans les prairies et dans les bois, dans les grottes et les bocages, des marquises sentimentales transformées en paysannes et des marquis langoureux roucoulant des idylles sous les habits du berger. Quelques peintres surent rendre en artistes ces séduisantes fantaisies et ces gracieux mensonges; beaucoup tombèrent dans un maniérisme fade et impuissant.

Le peintre le plus connu, le.plus estimé du xvme siecle, c'est Watleau, né à Valenciennes. Antoine Watteau (1684-1721) commença par peindre des plafonds, des trumeaux et des dessus de porte chez un décorateur nommé Audran, qui demeurait près du Luxembourg. C'est en travaillant d ces divers ouvrages qu'il prit l'habitude de la touche légère, vive et spirituelle qui est un des charmes de sa peinture, en méme temps qué les ombrages du. Luxembourg lui fournissaient de beaux sujets d'étude. II devint peu à peu le peintre le plus aimable, le plus spirituel, le plus original de son temps. Comme l'a fait remarquer W. Burger, Watteau est une singulière el brusyue révolution dans l'École française. Il arriva au moment où allaient disparaftre Mignard et Le Brun, qui emplissent le xvir siècle, oủ venaient de mourir Poussin el Claude, où l'École n'avait plus qu'une valeur d'apparat, manquait d'aspiration, de caractère, d'esprit. "Il semblait que la société française en füt à ce point te je ne sais quelle comédie italienne, où le personnage chargé du grand role, après beaucoup d'embarras, 
s'avance majestueusement au bord de la scène et demeure immobile et morne sous son masque et ses amples draperies. Qu'y-a-t-il ? L'acteur caché sous le mannequin et qui l'avait fait mouvoir, s'esquivant par une trappe inférieure du théatre, a laissé la défroque vide, et il reparait subitement... en arlequin. N'est-ce pas Watteau jaillissant tout a coup derrière le fantome de Charles Le Brun? Cette comparaison est on ne peut plus juste. Si maintenant, on veut une appréciation merveilleuse de brio et de raffinement du talent d'Antoine Watteau, il suffira de lire les lignes suivantes, empruntées a MM. Edmond et Jules de Goncourt : Le grand poète du xvı1 siècle est Watteau. Une création, toute une création de poème et de rêve, sortie de sa tête, emplit son œuvre de l'élégance d'une vie surnaturelle. De la fantaisie de sa cervelle, de son caprice d'art, de son génie tout neuf, une féerie, mille féeries se sont envolées. Le peintre a tiré des visions enchantées de son imagination un monde idéal, et, au-dessus de son temps, il a bati un de ces royaumes shakespeariens, une de ces patries amoureuses et lumineuses, un de ces paradis galants que les Polyphile batissent sur le nuage du songe pour la joie délicate des vivants poétiques. Watteau a renouvelé la grâce. La gràce chez Watteau n'est plus la grâce antique : un charme vigoureux et solide, la perfection de marbre de la Galatée, la séduction toute plastique et la gloire matérielle des Vénus. La grace de Watteau est la grâce. Elle est le rien qui habille la femme d'un agrément, d'une coquetterie, d'un beau au delà du beau physique. Elle est cette chose subtile qui semble le sourire de la ligne, l'ame de la forme, la physionomie spirituelle de la matière. Toutes les séductions de la femme au repos : la langueur, la paresse, l'abandon, les adossements, les allongements, les nonchalances, la cadence des poses, le joli air des profils penchés, les retraites fuyantes des poitrines, les serpentements et les ondulations, les souplesses du corps féminin, et le jeu des doigts efflés sur le manche des éventails, et les indiscrétions des hauts talons dépassant les jupes, et les heureuses fortunes du maintien, et la coquetterie des gestes, et le manège des épaules et tout ce savoir que les miroirs du siècle.dernier ont appris a la femme, la mimique de la grace. Et cette grâce, si Watteau l'anime, s'il la délie du repos et de l'immobilité, s'il la fait agissante et remuée, il semble qu'elle s'agite sur un rythme, et que sa marche balancée soit une danse menée par une harmonie. Quel décor a la femme, a la grâce! Une terre complice, des bois galants, des champs emplis de musique, des bosquets propices aux jeux d'Écho, des arbres en berceaux où pendent les paniers de fleurs, des déserts, loin du monde jaloux, rafraichis de fontaines, peuplés de marbres et de statues, et de naïades, que tache l'ombre tremblante des feuilles! jets d'eau jaillissant soudain du milieu des cours des fermes ! Soleil d'apothéose, belles lumières dormantes sur des pelouses, verdures pénétrées et translucides! Délices champêtres, décorations murmurantes et parées, jardins empuissonnés de ronces et de roses, paysages de France plantés de pins d'Italie ! Villages égayés de noces et de carrosses, de cérémonies, de toilettes et de fètes, étourdis de violons et de futtes ! Et quelle mode adorable nait de ces modes alliées et brouillées, la mode de Watteau ! une mode d'aventure et de liberté errante et bénie, qui attrape le neuf, le piquant, le provocant; des ciseaux d'artiste qui trouvent en se jouant la négligence et la parure, l'abandon du matin et le bel habillé des aprèsmidi, ciseau de fer, courant el coupant en pleine volupté dans l'argent du satin, ne ménageant ni l'étoffe ni l'oil des galants; jolis retroussis de jupes, ravissante rocaille des plis, étroits corsages, prisons friponnes, corbeilles de soie d'où se 



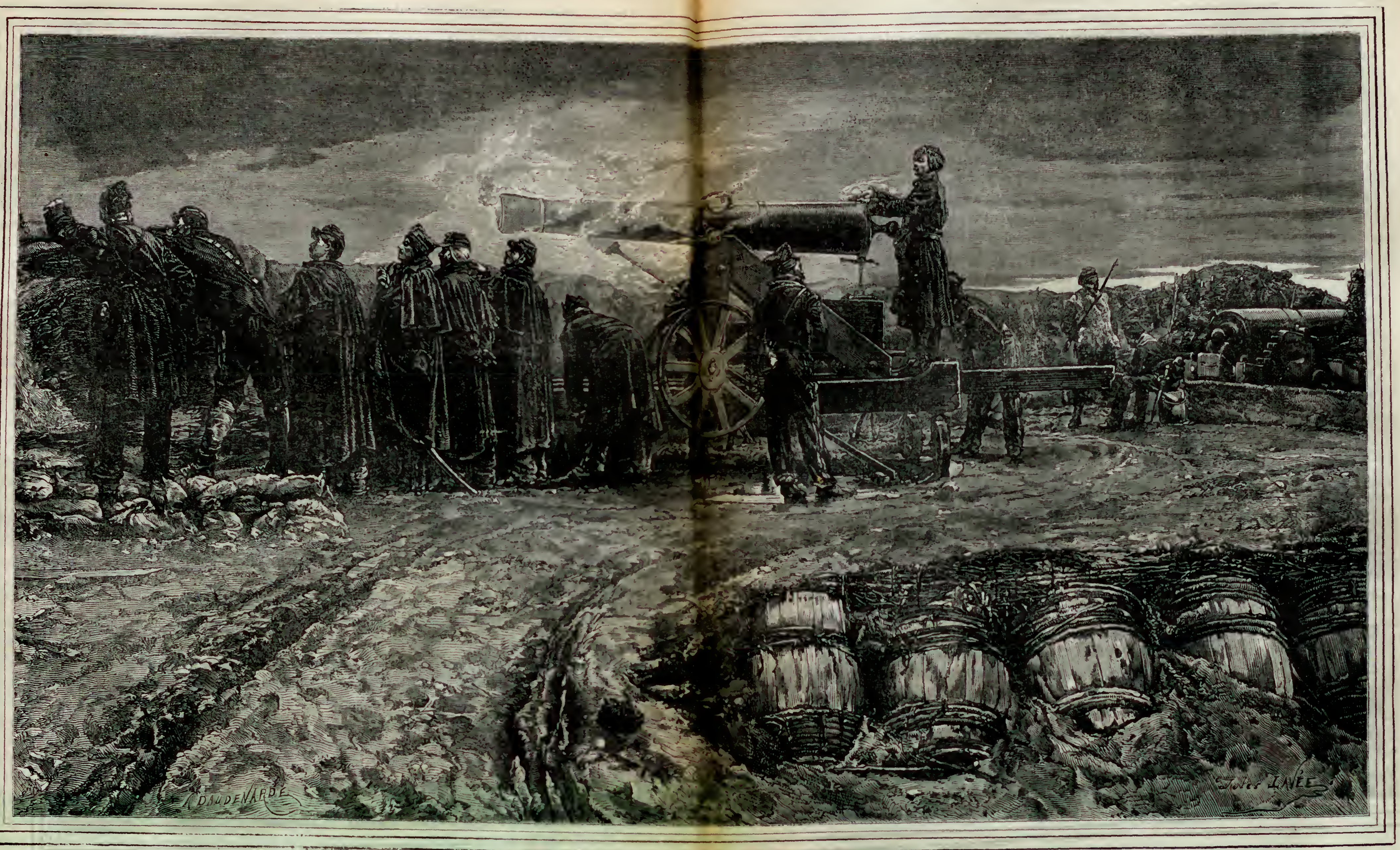

BeAUX-Aris. - Un coup de canon, tableau de M. Berne-Bellecour. 
sauvait la chair fleurie! o ciseaux enrubannés de Watteau, quel joli royaume de coquetterie vous tailliez dans le royaume embéguinée de la Maintenon! Nier le maniérisme de Watteau serait puéril, mais il ne le serait pas moins de refuser au peintre de l'Embarquement pour Cythère, au peintre des fétes galantes, l'esprit, l'originalité, la grâce, le gout, le coloris, une touche d'une légèreté inimitable, un dessin exquis. Ses draperies sont bien jetées, l'ordre des plis est vrai, parce qu'il les dessina toujours sur le naturel, ne se servant jamais de mannequins. Quoiqu'on ait longtemps soutenu le contraire, il est de la famille des grands maitres.

La gaité de Watteau inaugura donc le xvm siècle et réveilla l'École française qui dormait depuis les derniers temps du règne de Louis XIV. En dépit de ses fantaisies, il exerça sur les peintres de genre et les paysagistes une influence incontestable, leur montrant les avantages du naturel et leur apprenant à peindre les chairs. Il eut un collaborateur qui fut un continuateur, François Lemoyne (1688-1737), le décorateur aux inventions savamment capricieuses, le coloriste qui enseigna à l'École française les séductions du ton rose. C'est ainsi que le caractérise M. Paul Mantz qui, après avoir fait ressortir que Lemoyne s'est attaché à la recherche du problème de la décoration claire, s'exprime en ces termes : C'est en effet en ce point que Lemoyne représente dans l'École une force nouvelle et qu'il fut un initiateur. J.orsqu'il songeait à suspendre aux soffites des palais de souriantes mytloologies, a égrener des figures aériennes dans un ciel fluide, il n'avait pas encore vu l'Italie. Il put cependant, avant de quitter Paris, apprendre quelque chose de l'art léger auquel les faveurs de la morle étaient promises, et il s'éprit de ces tons frais, de ces tons d'éventail, que la France ignorait encore. Watteau, qu'il faut toujours citer le premier parıni les inventeurs, avait trouvé dans le satin de ses robes aux reflets changeants et aussi dans ses yerspectives chimériques, des bleus argentés, des gris adorables; mais, pour les carnations, il cherchait volontiers la note chaleureuse et ombrée à la Giorgione. On pouvait peut-ètre peindre plus clair. Lemoyne y pensait, lorsque l'Italie de la décadence vint au devant de lui. „Sébastiano Ricci et Antonio Pellegrini avaient déja préparé son esprit à subir l'influence de cette décadence, lorsqu'il passa les Alpes en compagnie de Berger et de Groizil. A son retour, il peignit son tableau de l'A mour et Céphule, sa Vénus au bain, son Hercale et Omphale. Si l'on se place au point de vue de l'art sévère, cette dernière composition pourrait être condamnée sans appel, mais M. Paul Mantz fait judicieusement remanquer que ce serait là une cruauté irréfléchie. . Historiquement, dit-il, cette composition a de l'importance, car elle marque une élape dans la marche de l'art français; elle précise un point de départ. Nulle apparence de gravitê : Lemoyne imagine que la coquetterie remplace tout. Hercule est assis, tenant la quenouille d'une main et de l'autre le fuseau. Près de lui est un pelit amour grassouillet et sans charme. Omphale, à moitié nue, se penche avec des attitudes caressantes sur l'épaule du héros qu'elle a dompté; elle l'enveloppe de ses câlineries, elle veut ètre bien certaine qu'il ne lui échappera pas. Le pauvre Hercule ne fait pas trop bonne figure dans ce duo galant. Il est vraiment trop apprivoisé, el pourquoi est-il dessiné d'une façon aussi approximative? Faire un Hercule en coton, c'est mauquer de respect à la mythologie. Et pourtant, dans ce tableau, qu'il est difficile de prendre au sérieux, l'Omphale est charmante Ici encore le dessin est fort négligé, mais cette jeune femme penchée et nue a une sorte de gråce amoureuse; elle s'inflécliit comme une arabesque vivante; sa sveltesse déroule la ligne serpentine dont llogarth doit fairo 
un élément de beauté. En outre, les chairs de la reine de Lydie ont cette morbidesse, très rare alors, que Watteau avait enseignée à ses contemporains. L'Omphale de Lemoyne devint pour quelques années (car l'idéal change toujours) le type authentique de l'élégance sans vêtement. Pour le choix des colorations, le tableau ne présentait pas moins de nouveauté. $\Lambda$ son début, Lemoyne avait paru croire aux tons roux qui alourdissent les peintures de Galloche et de La Fosse, mais dans Hercule et Omphale son pinceau s'était fort éclaircı. Jamais le trouble heureux de la transition, jamais l'amusante recherche d'une mode inédite n'ont été mieux marqués. L'artiste garde I toujours de la chaleur dans les ombres, il multiplie les demi-teintes ombrées et un peu cuites; mais l'ensemble est clair, les carnations ont des fralcheurs fleuries, et çà et là on voit au milieu de tons blonds jouer des tons roses. Le rayon rose n'était sans doute pas de l'invention de Lemoyue puisqu'on le trouve dans Luca Giordano et dans Ricci, mais c'est Lemoyne qui l'introduit dans l'École française, c'est grace a lui que, de l'aveu de l'Académie elle-mème, le rose devient la coleur à la mode au xviı ${ }^{\ominus}$ siècle.

Parmi les élèves de Lemoyne, deux surent conserver une indépendance qui les a sauvés de l'oubli : Nonotte et Natoire; un autre, François Boucher, parvint au premier rang. Donat Nonotte (1707-1785) fut employé par Lemoyne à peindre les fonds et accessoires de l'église Saint-Sulpice et se fit aider par lui dans les peintures du salon d'Hercule a Versailles. Son tableau, la Surprise de Besancon par les protestants, est remarquable par la disposition de l'ensemble et du coloris, mais on lui reproche une vérilable profusion de personnages allégoriques. Nonotte fonda à Lyon une École de dessin gratuite, qui est devenue le modèle de toutes les institutions de ce genre. Il se fit aussi remarquer comme portraitiste. Charles-Joseph Natoire (1700-1777) sut disposer ses compositions avec habileté. A côté de ses créations rosées, il mit comme Eemoyne des ombres chaudes. Ennemi du contraste des couleurs, il adopta pour sa coloration une gamme d'un gris bleuâtre. Il eut des qualités, en un mot, et des qualités sérieuses, mais pour le juger équitablement, il faut replacer ses œuvres dans leur milieu, à coté des décorations qu'elles ont complétées, car Natoire fut surtout un décorateur. Son dessin est loin d'être impeccable, mais sa peinture vaut beaucoup mieux que son dessin. Il manque de relief, de netteté, de précision; il est mou dans son élégance; il a en quelque sorte, comme coloriste, atténué les atténuation de son: maftre. Sa justesse d'exécution le fit rechercher pour la décoration, et en ce genre' ses meilleures cuvres sont les panneaux du Cabinet des Médailles, ceux des appartemants du premier étage à Versailles, et la décoration d'un salon de l'hôtel de Soubise.

François Boucher, né à Paris (1703-1770), fils d'un pauvre dessinateur de broderies, débuta par des dessins d'encadrement pour diplônes, armoiries, emblèmes, etc., et par des illustrations de livres. Tout en s'occupant de ces travaux, où l'art n'entrait pas pour grand'chose, Boucher cultivait la peinture et remportait en 1723 le prix de peinture de l'Académie. En 1727, il fit un voyage à Rome, d'où il rapporta un pinceau plus vigoureux, plus male, et sept ans plus tard, la célébrité étant venue, l'Académie lui ouvrit ses portes. Sa fécondité était prodigieuse. On l'appelait le peintre des Grâces, mais ces Graces étaient maniérées. C'était un mattre bien dangereux pour les jeunes gens, que séduisaient le piquant et la volupté de ses tableaux, et qui ne réussissaient, en voulant l'imiter, qu'à devenir détestables et faux. C'est une question très uiscutée de savoir si son séjour en Italie lui a été utile ou non. Certains critiques, moralistes rigoureux, aflirment a priori que les chefs d'œuvre de Rome le laissèrent 
froid, parce que ses instincts l'éloignaient tróp de la grande peinture pour qu'il pût rien comprendre ì ces chefs-d'œuvre. $A$ cela on peut opposer une critique dont l'opinion s'appuie sur des arguments d'une justesse évidente: "Ceux qui parlent ainsi, et le nombre en est grand, montrent peu de sentiment artistique s'ils ignorent que les conditions de mise en scène, d'arrangement, de couleur et de forme, indispensables à une œuvre hien entendue, sont les mèmes absolument dans un sujet religieux que dans un

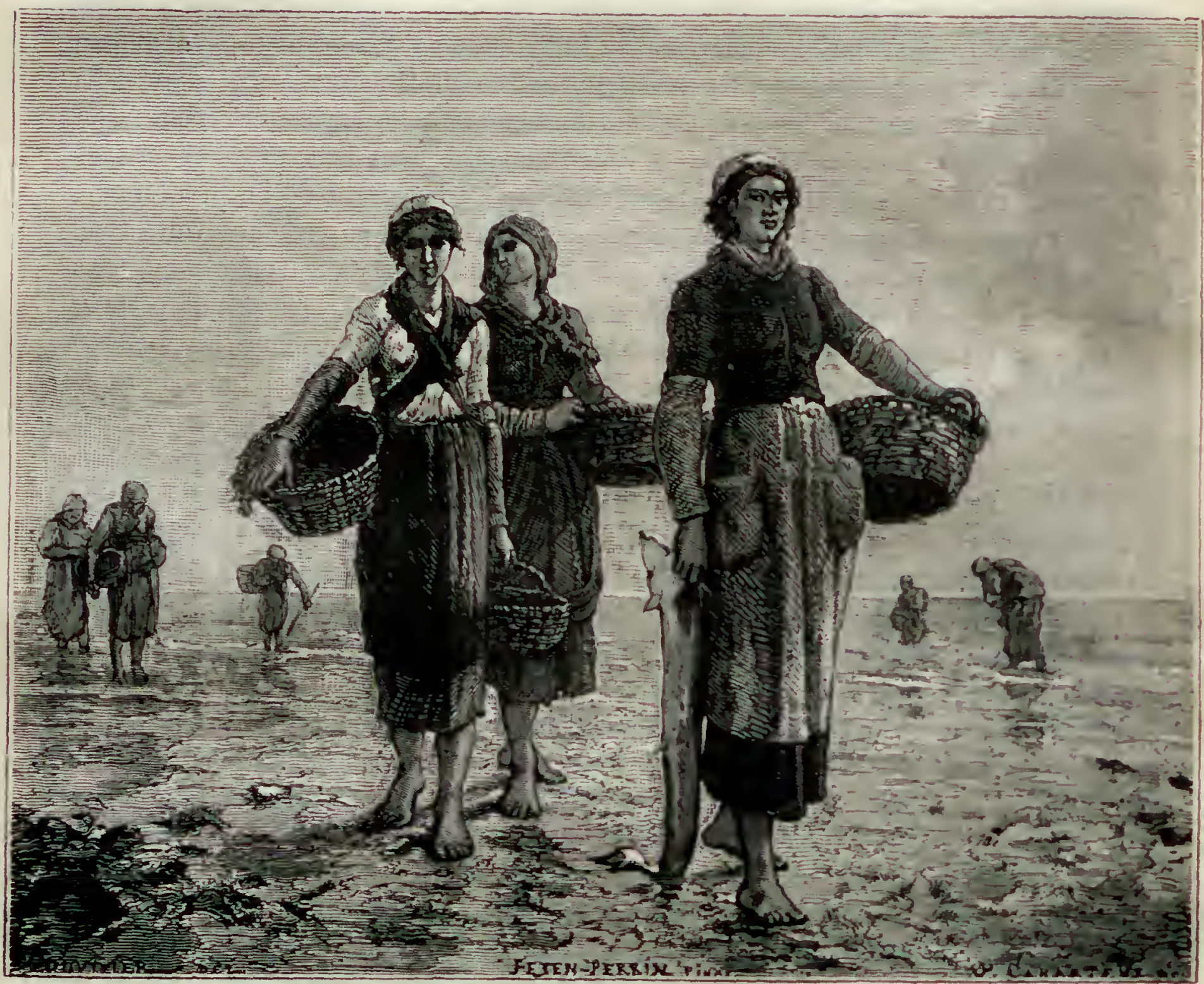

Bia UX-A Rts. - La Pèche a pied, par Feyen-Perrin.

sujet érotique; que pour développer un thème licencieux, ordurier si l'on veut, il faut savoir dessiner, composer, exécuter avec autant de puissance que pour traduire la plus sainte inspiration. Est-ce à dire qu'un souper du Régent, avec des abbés et des filles, des fauteuils renversés, du champagne qui mousse, des chansons grivoises, des baisers impudiques, doit être rangé sur la mème ligne que la Cène de Léonard de Vinci ? Évidemment non, ce serait un blasphème. Mais si le peintre avait dessiné des femmes et des marquis, les avait groupés avec autant de science et de bonheur que l'a fait Léonard de Vinci dans son chef-d'curre sublime, ce peintre serait aussi remarquable que lui dans son genre, quelque blàmable que ce genre püt être d'ailleurs. 
Bien supérieur est Nicolas Lancret (1690-1743), né à Paris et mort dans la mème ville. Il commença par s'adonner à la gravure, puis reçut des leçons de peinture de Pierre Ulin et de Gillot, eut pour condisciple Watteau, dont il devint l'ami et s'assimila tellement la manicre de cet artiste que, dans une exposition publique, on attribua à Watteau une de ses toiles. Lancret débuta par une Féte galante qui cut un très grand succès, et il ne tarda pas à devenir un des peintres de son temps dont les ouvres furent le plus recherchées. En 1719 , il fut nomnté membre de l'Académie de peinture sous le titre de peintre des Fètes galantes et devint ensuite peintre du roi. Bien qu'il ait prétendu ne rien faire sans consulter la nature, Lancret est tombé dans le maniéré, dans le faux, car s'il étudiait la nature, comme l'a dit un biographe, e'est surtout celle de l'Opéra qu'il aimait à fréquenter et il où il allait puiser des sujels de tableaux. Ses auvres sont riantes, agréables, mais en général entachées d’affectation et son coloris manque de naturel. Doué d'une imagination primesautière, il a composé un grand nombre dc tableaux, parmi lesquels la Marmotte, les Douze Mois, les Quatre Éléments. Au sujet de ce dernier tableau, Charles Blanc fait les considérations suivantes:

- Le marquis de Beringhem, premier écuyer du roi, voulant orner son beau cha. teau de Jouy, chargea Lancret de peindre dans le salon les Quatre Éléments. En homme d'esprit, Lancret s'abstint des pesanteurs de l'allégorie et de la banalité des attributs traditionnels. Le siècle de Louis XV ne se perdait pas dans les symboles. L'Eau représentera donc une scène de bain; le Feu sera, je suppose, une conversation sous le manteau de la cheminée; mais que pensez-vons qu'aura peint Lancret sur le panneau destiné à l'Air? Peut-être une marquise qui s'abandonne au mouvement d'une balançoire et livre sa robe de satin aux indiscrétions de l'élément flıide? Précisément. ,

Il ne faudrait cependant pas croire qu'il se laissat aller, mème dans les sujets égrillards, au delà de certaines limites. Ces choses légères, il les effleurait seulement comme d'un sourire. Affable, poli et d'un commerce agréable, Lancret n'était pas homme à se laisser séduire par l'appat du gain lorsque les moyens qu'on lui ófrait pour gagner de l'argent ne lui semblaient pas honorables. Un brocantenr lui ayant proposé une somme importante pour donner à une vieille peinture un aspect plus négociable, il lui répondit froidement :

- J'aime mieux courir le risque de faire de mauvais tableaux que d'en gaiter de bons.

"Il mourut, dit M. Paul Lacroix, en 1743, à l'age de cinquante-trois ans et n'cut pour imitateur que des peintres médiocres ou détestables, qui dégradèrent l'École de Watteau, en lui attribuant l'emploi exclusif de fournir des dessus de porte à la décoration des intérieurs bourgeois. Mais, depuis la fin du règne de Louis XIV, l'lécole française avait brillé dans un genre qui semblait lui ètre acquis el qui la plaçait sous ce point de vue à la tête de toutes les écoles modernes. C'est dans le portrait qu'elle pourait revendiquer celte incontestable supériorité; presque tous les peintres d'bistoire avaient fait des portraits, mais les véritables peintres de portraits furent ceux qui se renfermèrent à peu près dans ce genre magistral, qui convenait si bien à la nature mème du talent français. Pierre Mignard, qui exécnta un si grand nombre de grandes compositions historiques et religieuses, était avant tout 11 portraitiste accompli, et l'on peut affirmer que c'était là son principal talent. Il le savait bien et ne refusait jamais d'ajoutẹ un nouveau portrait à l'innombrable collection de ceux qu'il avait faits dass le cours de sa longue carrière. Un portrait, le plus beau et le plus travaillé, était un 
jeu pour lui ; il avait fait, en trois heures, un portrait de Louis XIV âgé de vingt et un ans, portrail envoyé par Mazarin à l'infinte d'Espagne, que le roi devait épouser. Depuis, Mignard eut à faire dix ou douze portraits de Louis XIV à différents âges et en costumes différents; plusieurs de ces portraits sont des chefs-d'œurre, et, parmi les deux ou trois cents portraits peints par Mignard, d'après nature, on en citerait cinquante qui méritent les plus grands éloges sous le rapport de la ressemblance et de la vérité de l'image, comme sous le rapport de l'ordonnance et de la couleur. On doit leur reprocher toutefois un peu de trivialité et de froideur. Mignard, dont les portraits avaient eu si longtemps la faveur des princes et des gens de cour, dut éprouver dans sa vieillesse un vif sentiment de jalousie en voyant s'élever en face de lui plusieurs peintres de portraits qui n'appartenaient nullement à son école et qui semblaient déjà de redontables concurrents : c'était François de Troy, Nicolas Largillière et Hyacinthe ligaud. Ce dernier fut celui qui inspira le plus de jalousie à Nignard, d'autant plus que Le Brun avait pris sous sa prolection cet excellent portraitiste, ainsi que ses deux amis de Troy et Largillière Ceux-ci furent reçus à l'Académie royale long. temps avant Rigaud qui, bien qu'appuyé comme eux par Lee Brun, fut repoussé obstinément par Mignard, lequel sembla même avoir légué à quelques académiciens le soin de faire encore obstacle ì ce rival triomphant. »

liigaud naquit à Perpignan le 20 juillet 1639 et il mourut à Paris à la fin de launée 1743. Orphelin de bonne heure, il vint à Montpellier dès lage de quatorze ans, reçut les leçons de Pezet, Verdier et Antoine Ranc, passa quatre années à Lyon et, en 168!, se rendit à Paris pour se perfectionner dans son art. Il remporta presque aussitòt le r.emier prix de peinture proposé par l'Académie sur un sujet mythologique. Ayant fait un portrait de Girardon, Le Brun lui conscilla de s'adonner exclusivement à ce genre de peinture, sans aller en Italie profiter de la pension accoráée aux élèves couronnés. Rigaud suivit le conseil et s'en trouva bien. Reçu à l'ilcadémie comme peintre d'histoire et de portraits, il eut désormais une réputation inataquable. Ce fut à qui pourrait avoir son portrait peint par Rigaud, qui, en 1709, fut admis par les consuls de Perpignan au nombre des citoyens nobles de sa ville natale. Rigaud est un des premiers peintres du genre.

- Ses tètes sont vivantes, pleines de caractère et d'expression: sa touche est à la fois hardie et délicate, et sa couleur quoique gaie noffre pas de tons éclatants. Dans lit composition de ses figures, toujours conformes, soit par les attitudes et le port, soit par le jet des draperies, au caractère des personnages, il déploie une noblesse qui lui est propre, un peu éludice, mais en rapport avec le goùt de l'époque.»

Fraucois de Troy (1643-1730) reçut a Paris les leçons de Loir et de Claude Lefebrre et fit. comme Rigand, un grand nombre de portraits, remarquables par le fini de l'exécution, la pureté du dessin, la noblesse et la beanté des poses, l'expression des figures, l'éclat du coloris. Comme il nattait ses modẻles et qu'il les représentait dans des costumes mythologiques d'un hel effet. il ne tarda pas ì devenir le peintre favori des dames.

Son tils, Jean-Francois de Troy (1680-1732!, s’adonna plus spécialernent à la peinture décorative. Il n'a pas un gout très pur. mais la composition est harmonieuse el le coloris des plus brillants. Nicolas Largilliere (1656-174ti), que ron surnomme le Van Dyck français, fut d'une fécondité qui, par bonhenr, ne nuisit pas à la valeur de ses productions. On ne saurait compter les minois bourgeois et nobles qu'il reproduisit sur la toile, mais il ne se contenta pas de gagner ainsi des milliers et des milliers de livres, 

ICS MER VEILLES II L'EXPOSITION

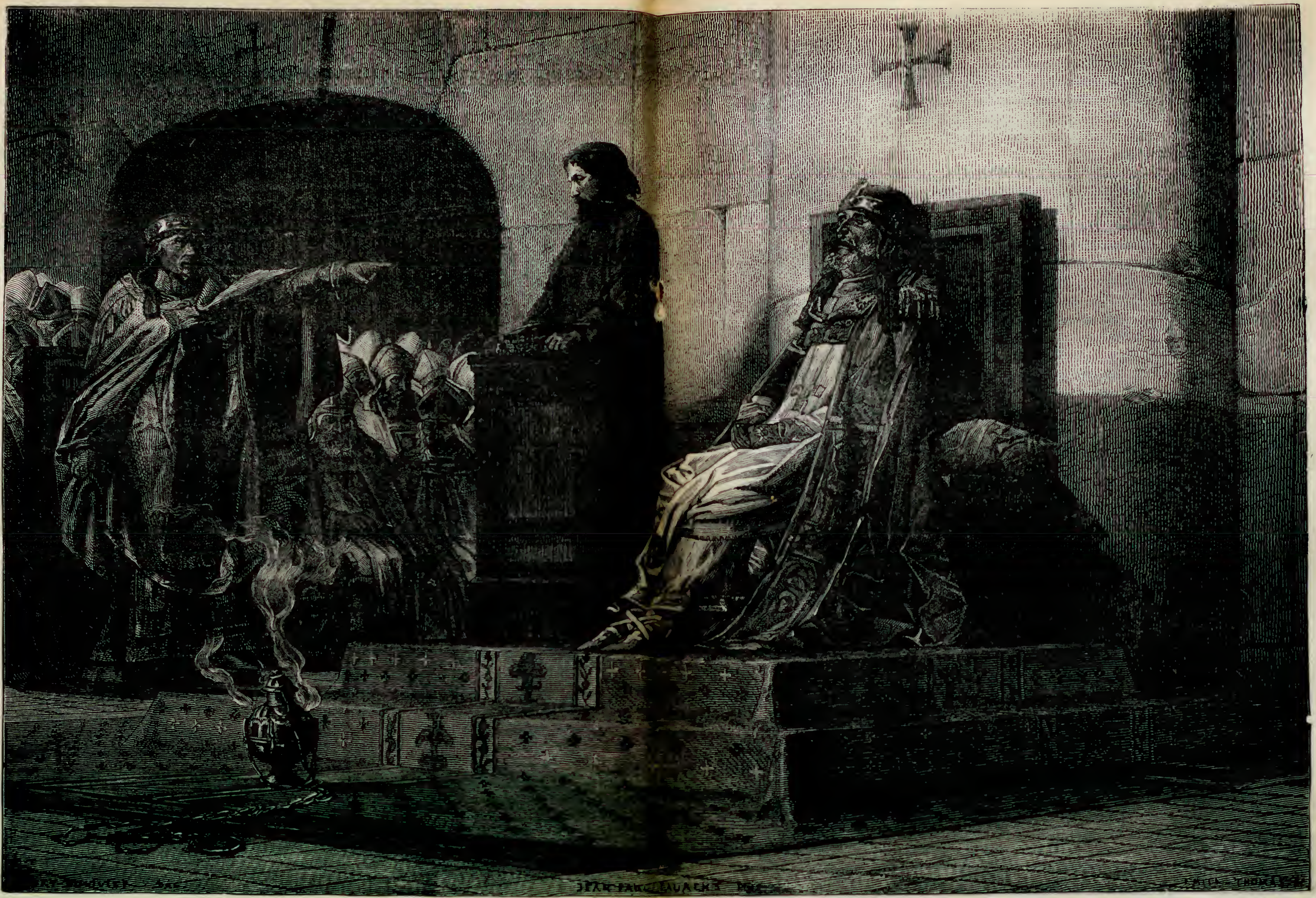

Braux-Arts. - Le Pape Formose dE Elienne VII, tableau de J.-P. Laurens. 
de meubler avec une élégance raffinée son hôtel de la rue Geoffroy-Langevin. Il peignit aussi des tableaux de genre, des animaux, des fleurs et des fruits. Vérité du coloris, frâ̂cheur de ton, légèreté de touche, correction du dessin, voilà ses qualités essentielles. Ajoutez à cela que ses draperies amples et souples sont savamment jetées, qu'il exécnta les têtes et les mains dans la perfection, et que la gràce féminine trouva en lui un interprète presque impeccable.

Si les portraitistes qui vinrent ensuite n'eurent pas le talent de leurs maítres, plusieurs d'entre eux réussirent pourtant à se rapprocher des initiateurs : Rigaud, de Troy et Largillière. Jean-Marc Nattier (1683̈-1766) remporta à quinze ans le premier prix de dessin à l'Académie, et il commença par copier les Rubens de la galerie du Luxembourg que l'on voulait faire graver. Indécis entre le portrait, le paysage, la peinture d'histoire, il se fit un nom dans le premier de ces genres en faisant le portrait de Pierre le Grand, tsar de Russie, et des grands personnages de la cour de ce monarque. Il refusa d'ailleurs de s'établir en liussie, et l'Académie lưi ouvrit ses portes. Ruiné par la banqueroute de Law, il travailla avec une ardeur incroyable pour réparer la brèche faite à sa fortune. Les femmes surtout s'engouèrent de Nattier, ce dont Casanora donne une explication piquante : a Il faisait, dit-il, le portrait d'une fenme laide; il la peignait avec une ressemblance parfaite et, malgré cela, ceux qui ne voyaient que son portrait la trouvaient belle, alors que l'examen le plus ininutieux ne faisait découvrir dans le portrait aucune infidélité; mais quelque chose d'imperceptible donnait at l'ensemble une beauté réelle et indéfinissable. "On remarque dans ses toiles une certaine grâce efféminée et une tendance précieuse vers l'allégorie; aussi Gresset le surnomma-t-il l'élève des Gràces et le peintre de la Beauté. Sa Madeleine, qui est au Musée du Louvre, est sans doute le portrait d'une dame de la cour, d'une amoureuse repentie, avec une robe de soie blanche ei des cheveux pondrés. - Joseph Ared (1702-1766), né à Douai, vécut d'abord en Ilollande, vint ensuite à Paris où il se lia avec Boucher et Carle Vanloo, qui le firent recevoir à l'Académie. Sa peinture a un aspect vigoureux; l'effet est large et bien senti, l'exécution habile et souple, mais ainsi que le fait remarquer M. Olivier Merson, la couleur est généralement lourde, sans transparence, et le dessin peu correct. - Robert Tournières (1668-1752) était le fils d'un tailleur de Caen, qui fut frappé de ses dispositions artistiques et lui fit apprendre les éléments du dessin. Entré dans l'atelier de Bon Boulongne, Tournières ne tarda pas à se distinguer dans le portrait et forma à son tour de bons élèves. - Citons enfin Louis Tocqué, élève de Nattier (1696-1772), portraitiste d'un dessin correct, d'unc touche lègère et d'un coloris agréable.

Dans la peinture de nature morte, le xvure siècle compte aussi des peintres remarquables. Ciest d'abord le Champenois François Desportes (1661-1743), fils d'un laboureur, qu'un de ses oncles, établi à Paris, fit entrer dans l'atelier de Nicasius, peintre flamand et élève de Snyders. "Desportes reçut dans son atelier les enseignement3 sévères de la saine et forte peinture. Bien qu'il se sentît entrainé par goùt à représenter des chasses, des animaux, la nature morte, genre intéressant dont il fut pour ainsi dire le créateur en France, il ne négligea rien pour acquérir toutes les cornatissances nécessaires à un peintre de figures. Il débuta par des portraits : celui du roi de l'ologne, Jean Sobieski; celui de la reine, et ceux des plus grands seigneurs de cetle cour, ou l'avaient présenté quelques gentilshommes de ses amis qui, pressentant sa gloire future, auraient sans doule voulu le fixer en Pologne. Cependant, en dépit des avan- 
tages de cette brillante existence, le mal du pays le prit, et un beau jour, il revint en France, après une absence de deux années. Presque sans ressources, ii accepta d'abord tous les travaux qu'on voulut bien lui confier : plafonds, décorations de théatre, ornements, peinture d'animaux; il aida ensuite Claude Audran, habile peintre d'ornements, à embellir le chateau d'Anet et la ménagerie de Versailles. I déploya partout un génie fécond, enjoué, une grande vérité d'expression, une touche légère en même temps qu'un ton de couleur admirable. Ces divers travaux lui valurent de brillants succès, et Louis XIV le jugea digne d'être peintre de sa vénerie. Il lui accorda une pension avec un appartement au Louvre. Le peintre devait suivre les chasses et a portraire o les animaux rares envoyés à la ménagerie de Versailles. De célèbre qu'il était, grâce à son talent, il devint bientôt illustre, grâce à la protection du roi. Aussi l'Académie royale de peinture s'empressa-t-elle de lui ouvrir ses portes, le 1or août 1699. Malgré les distractions bruyantes occasionnées par la somplueuse existence qu'il avait à la cour, Desportes travaillait heaucoup. Ses études d'après nature témoignent hautement de sa passion pour les chasses, qu'il peignait avec une science profonde. Les amateurs sont encore à la recherche de ses dessins à l'huile sur papıer griö, qu'il exécutait durant l'action, sous les yeux du roi, dessins pleins de feu, grands d allure et superbes de ton. " Après avoir décoré l'une après l'autre les diverses résidences, il fut chargé de huit grandes compositions pour les Gobelins, et acheva en même temps pour Compiègne cinq vastes toiles, dont l'une, le Cerf aux abois, compte parmi ses chefsd'œuvre. En somme, depuis un siècle et demi que florissait l'École française, il n'y avait pas eu encore de peintres animaliers, comme nous dirions aujourd'hui. Desportes eut la gloire de fonder en France le genre de Snyders en Flandre, de Benedetti en Italie.

Jean-Baptiste Oudry (1686-1763), fils d'un marchand de tableaux qui était en mème temps un peintre médiocre, apprit de son père les premiers éléments du dessin. Largillière le prit en affection, le fit travailler dans son atelier, et, jugeant qu'il rendait beaucoup mieux les accessoires que les portraits, l'engagea à peindre les animaux et la nature morte. Les débuts d'Oudry furent pénibles, mais sa persévérance triompha de tous les obstacles, et un tableau, l'Abondance avec ses attributs, lui ouvrit les portes de l'Académie, en même temps qu'elle le mit en relation avec le premier écuyer du roi, qui le présenta à Louis XIV. Il plut au roi, en lui peignant ses chiens favoris, conserva la faveur du souverain, et en obtint la direction de la manufacture de Beauvais. Ses nombreux tableaux dénotent une composition facile, mais il manque de chaleur et de légèreté dans le coloris. Il est, quoique célèbre, bien inférieur à Desportes.

A près les chasses, les batailles. Charles Parrocel (1688-1752), peintre de batailles comme son père Joseph Parrocel (1646-1704), le surpassa par une plus grande fermeté de pate, une couleur plus variée et plus fraîche, une exécution moins étudiée. Il peint d'après nature, avec un sentiment très vif de la réalité. C'est en effet sur les champs de bataille qu'il prenait ses inspirations, et non dans le silence de son atelier JeanBaptiste Martin (16:7-173\%), dit Martin des Batailles, reçut des leçons de Van der Meulen. Il accompagna le grand Dauplin dans ses campagnes, assista aux siègés de Mons et de Namur, et obtint, à la mort de son maitre, le titre de peintre des conquètes du roi et la direction des Gobelins. 11 a peint pour Versailles des scènes de batailles et des vues de places fortes. Un de ses parents, Pierre-Denis Martin, peignit des chasses, des batailles, des résidences royales.

lirançois Casanova (1727-180כ), frère du célèbre Casanova de Seingalt, se signala 
de bonne heure par de hardies pochades, qui exciterent l'admiration des amateurs. II se fixa assez tard à Paris, où en 1763 il entra à l'Académie. En dépit des distractions d'une existence agitée et mondaine, il produisit beaucoup. Ses ceurres ont de la couleur, de la touche, de l'action; la composition est généralement bonne, parfois excellente; joignez à cela de la fougue, de l'imagination. a Il sort de son cerveau, a écrit

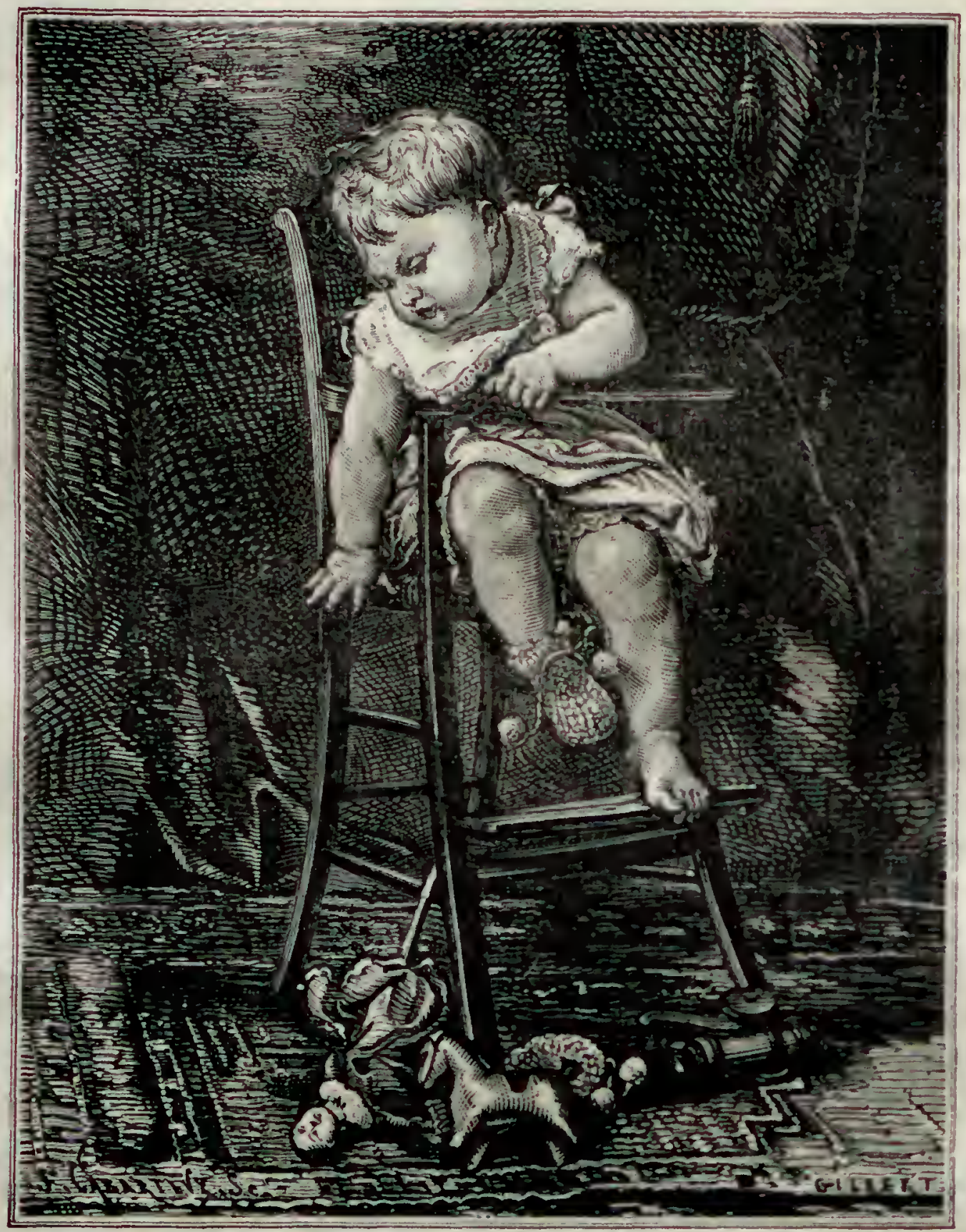

BeaUX-ARTs. - Le Supplice de Tunlale, par Lobrichon.

Diderot, des chevaux qui hennissent, bondissent, mordent, ruent et combattent, des hommes qui s'égorgent de cent manières diverses; des cranes entr'ouverts, des poitrines percées, des cris, des menaces, du feu, de la fumée, du sang, des morts, des mourants, toute la confusion, toutes les horreurs d'une melée. . Et ce qu'il y a de curieux, c'est que ce coureur de ruelles et de salons ne parut jamais sur les champs de bataille, tenant bien trop à sa personne pour l'exposer. Mais nous n'avons pas ici à nous occuper de l'homme. L'artiste seul nous intéresse, el il fut hor's de pair par l'origi- 


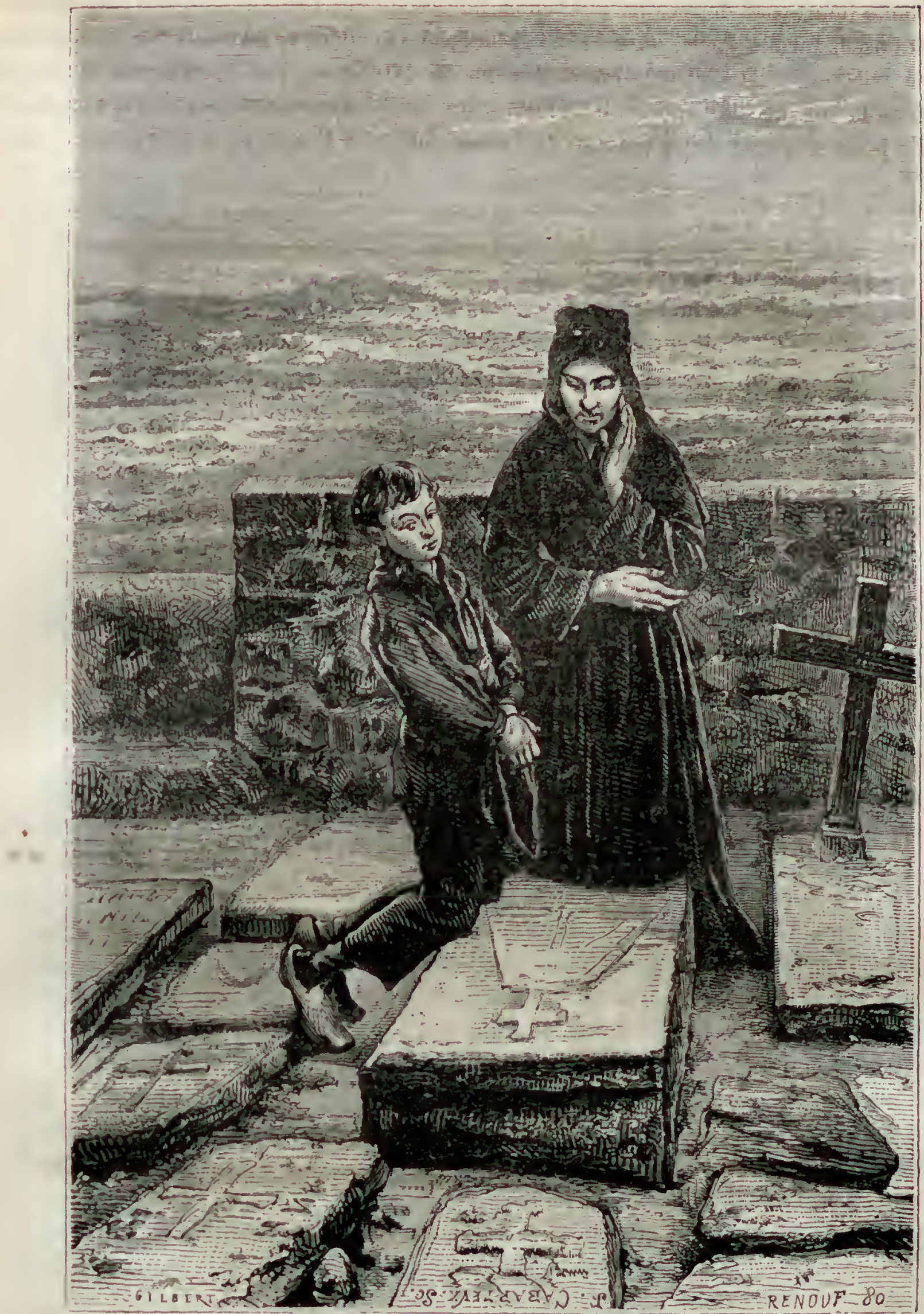

BeAvX-Alits. - La Veuve, par Renouf.

nalité de son invention, par le pittoresque et le brillant de son imagination féconde, par un instinct artistique prodigieusement développé.

Si l'on veut saroir ce qu'élait le paysage au xrme siècle, il faut se reporter aux Lix. הij. 
critiques de Diderot. Parlant de Boucher: "Je vous défie, dit-il, de trouver dans toute une campagne un brin d'herbe de ses paysages. "Parlant de Vernet, le ton change : * Allez à la campagne, tournez vos regards vers la voute des cieux, observez bien les phénomènes de l'instant; et vous jurcrez qu'on a coupé un morceau de la grande tuile Iumineuse que le soleil éclaire pour le transporter sur le clicvalet de l'artiste. On, fermez votre main et faites-en un tube qui ne vous laisse apercevoir qu'un espar: limité de la grande toile, el vous jurerez que c'est un tableau de Vernet qu'on a pris sur son chevalet et transporté dans le ciel. Il est impossible de rendre ses compositious, il faut les voir. Ses nuits sont aussi touchantes que ses jours sont beaux, ses purls sont aussi beaux que ses morceaux d'imagination sont piquants. Éralement mervoil leux, soit que son pinceau captif s'assujettisse à une nature donnéc, soit que sa mun? dégagée d'entraves soit libre el abandonnée ì elle-même; incompréhensible, sort quii emploie l'astre du jour ou l'astre de la nuit, la lumière naturelle ou les lumières artificielles, à éclairer ses tableaux; toujours harmonienx, vigourenx el sage, tel que ces grands poètes, ces hommes rares en qui le jugement balance si parfaitement la verve qu'ils ne sont jamais ni exagérés ni froids. Ses fabriques, ses édifices, les rêtements, les actions, les hommes, les animaux, tout est vrai. De près, il vous frappe; de loin, il vous frappe plus encore. On dirait qu'il commence par créer le pays et qu'il a des hommes, des femmes, des enfants en réserve, dont il peuple sa toile comme ou peuple une colonie; puis il leur fait le temps, le ciel, la saison, le bonheur, le inalleur quil lui plait.

Joseph Vernet, né à Avignon (1714-1789), peignit d'abord avec son père des dessus de porte, des écrans, des panneaux de voitures et de chaises a porteurs. Il s'embaryua à dix-huit ans à Marseille pour l'Italie et fut, chemin faisant, assailli par une tenuphte furieuse. Il se fit attacher au grand mat pour ne rien perdre du spectacle grandiose qui s'offrait à lui. Entré dans l'atelier de Fergioni, il étudia les ruines et la campagne de Rome, les côtes de la Méditerranée, le golfe de Naples, dédaiguant l'art conventionnel et ne voulant d'autre source d'inspiration que la nature. Ses marines dénotaint une telle vérité, les effets de lumière étaient rendus avec une telle puissance que de hauts personnages de Rome lui demandèrent des paysages qu'il peignit aduirablencnt. Sa réputation passa les Alpes; il fut de l'Académic de Paris; il exposa aux Salons, et ses toiles arrachèrent a Diderot les cris d'enthousiasme que l'on a lus plus haut. A vrai dire, Diderot exagère un peu, mais cela s'explique par ce fait que Vernet créait dans le paysage une véritable révolution. En 1753, il fut chargé de composer une série de toiles représentant les principaux ports de France. Ces toiles, outre leur mérite artis. tique, ont un intérêt documentaire de premier ordre. Nous devons aussi mentionner deux Nuits, dont l'une est illuminée par un feu d'artifice, à la lueur diquel on aperçoit une ville, et nous terminerons par une appréciation de M. Henri Delaborde qui, pour être moins enthousiaste, est plus exacte que celle de Diderot: an a dit avec raison que Poussin était le peintre des hommes sérieux; on peut dire de Jospph Vernet qu'il est le peintre des gens d'esprit, mais d'un esprit un peu superficiel. Ses tableaux doivent satisfaire sans doute les intelligences pressées qui veulent comprendre une ceuvre d'art au premier coup d'œil et y lire tont de suite à livre ouvert; il est moins probable qu'il contente les intelligences amies du recueillement et de l'étude, celles qui aiment à voir au deld du fait, et qui préfèrent les intentions profondes aux intentions facilement exprimées. On recounaitrait peut-ctre dans le 
talent de l'artiste plus d'adresse que de science, plus de sagacité que d'imagination, plus de magie que de vraie puissance, mais on ne saurait en tout cas refuser a ce talent l'estime qui lui est due et contester la légitimité du succès attaché depuis un siècle aux ouvrages de Vernet.

Simon-Mathurin Lantara (1729-1778) a laissé un petit nombre d'œuvres, mais qui attestent un talent fier et original. Orphelin à huit ans et berger chez un échevin de la ville de Paris, le fils de ce dernier, frappé de ses dispositions, le plaça dans un atelier de Versailles. Lantara, venu a Paris, devint le domestique d'un peintre pour compléter gratuitement son éducation artistique, mais il se crut bientôt assez fort pour voler de ses propres ailes. Il ne réussit qu'd mener une vie misérable, déréglée, passant ses jours au cabaret ou dans une mansarde, donnant une toile pour un diner, dessinant sur un bout de table, à côté d'une bavaroise au chocolat et a la lueur fumeuse d'un quinquet, des clairs de lıne, des couchers de soleil au crayon blanc sur papier bleu. Teintes, oppositions, accidents, rien ne manque à ces improvisations. Il mourut à l'hôpital de la Charité. Quelques instants avant sa mort, l'aumônier lui ayant dit: - Vous êtes bien heureux, mon fils; vous allez voir Dieu en face pendant l'éternité. * Lantara répondit : " Quoi! mon père, tonjours de face, jamais de profil! " Aujourd'hui les amateur's recherchent et couvrent d'espèces les moindres croquis de ce bohème d'un autre siècle.

Avant Vernet et Lantara, le genre du paysage était dédaigné. Poussin et Claude Gelée, dit le Lorrain, avaient sans doute créé un art estimé depuis longtemps en Italie, et ils avaient nème surpassé $\Lambda$ nnibal Carrache, mais ils n'avaient point créé un mouvement d'opinion favorable. Les deux Patel, dont les vues d'Italie ne manquent point de valeur, passèrent inaperçus; ils moururent l'un et l'autre dans l'indigence. Étienne -Allegrain (1653-1736), malgré son titre d'académicien, avait grand'peine à vendre aux brocanteurs, à un prix dérisoire, les paysages qu'il peignait; et pourtant, ces paysages sont tels qu'on les a souvent pris pour des Millet. Ce qui contribua à mettre le genre en évidence, ce fut l'usage des Salons de peinture. Ces Expositions, qui sont aujourd'hui une des habitudes de notre vie moderne, ne devinrent annuelles que depuis 1673. Elles eurent d'abord peu de retentissement et furent peu suivies. Peu à peu, on y prit goût. Vers 1745 , la peinture de genre détrôna au Salon la peinture d'histoire, puis le nombre des tableaux insignifiants augmentant dans des proportions dérisoires, on décida que le Salon serait biennal, décision qui fut nbservée jusqu'en 1791. La critique d'art naquit, avec Bachaumont, Saint-Yenne, Charles-Nicolas Cochin, Diderot et Grimm; elle n'eut pas, le prime ahord, la sévérité et la justesse de nos bonnes critiques actuelles, mais toute chose a ses débuts, sa période de tâtonnement, et d'ailleurs, il y a dins les Salons de Diderot, plus d'une page où l'on ne trouverait rien ì remanier, plus d'une page dont se serviront sans doute les critiques qui écriront des éludes spéciales sur l'Lxposition centénale de 1889.

Le chef de l'illustre dynastic des Vauloo fut Jacques Vanloo, né à l'Ecluse, près de la llaye. en 1614, et mort à Paris, en 1670. Son père, Jean Vanloo, était lui-mème i:n peintre distmgné. Il trivailla d'abord sous la direction de son père; il acheva ses études ì Amsterlan, où il ncquit une certaine célébrité avec quelques esquisses, introuvables aujourdhui. On lui attribue, au "lusée de Rotterdam, divers tableaux, entre autres un Portrait d'homme, ın Portrait de femme, datés tous deux de 16ä3, et une fitude de mu, connue suus le nom du Conurher. faisant astuellemant partie de la colle:- 

LES MERVEILIPB DE L'EXPOSITION

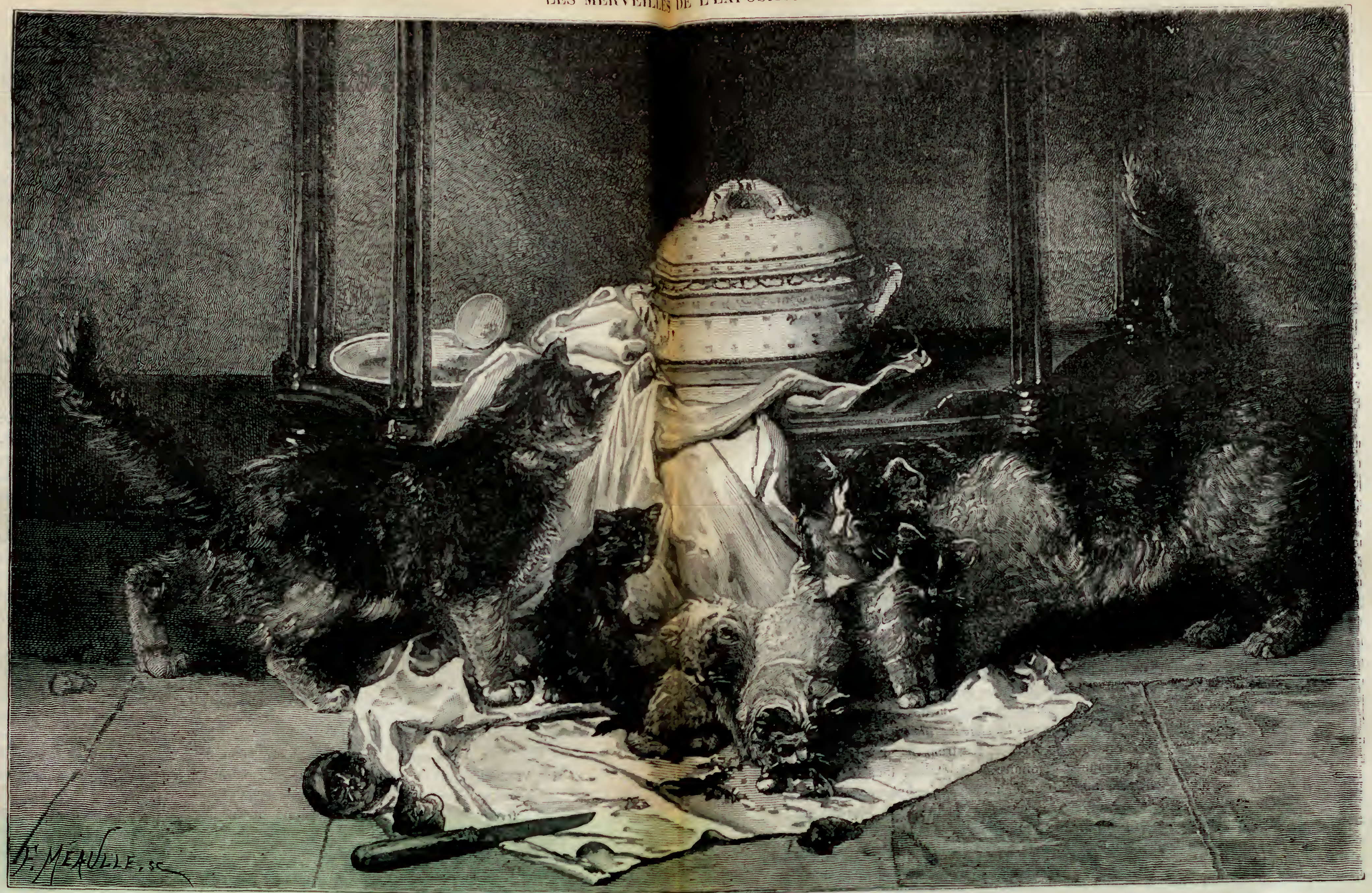



réussis ne firent qu'accroître sa réputation. Vanloo possédait à ce moment une fortune considérable, mais fut ruiné par les spéculations de Law. Il dut se remeltre activement au travail. Le duc d'Orléans lui avait fait espérer la protection du roi, mais il mourut avant d'avoir réalisé sa promesse. Vanloo, pressentant que la fortune lui serait de nouveau acçuise s'il parvenait à faire le portrait du roi, s'en alla chaque jour it Vel'sailles se mèler à la foule des courtisins. Quand, sans ètre remarqué, il pouvait saisir la tète du roi dans un moment favorabic, il reproduisait sur une esquisse les traits de Louis XV. Il put ainsi faire un portrail du roi de grandeur naturelle et le lui euvoya. Flatté et surpris, le roi fit appeler le peintre, le complimenta ef lui commanda son portrait en pied. Celle premiere eommande lui en valut une seconde, Louis XV à cheval, œurre qui lui altira les bounes graces du souverain. L'Acadénie ouvrit alors ses portes a Vanloo, qui présenta sa Diane et Endymion, maintenant au Louvre (2:; février 1731). Peu après, l’artiste cxécuta pour le prévôt des marchands une allégorie sur la Nuissance du dauphin. puis un Henri III recerant le comte de Gonzalés parmi les cheraliurs du Saint-Esprit, pour l'église des Augustins. Ce dernier Lableau causa une grande idniration dans le monde artistique. L'Académie venail de le nommer professeur (1733), mais sa mauvaise santé le força a prendre trois ans de repos a $\Lambda$ ix, sa ville ratale. Diss son retonr dans la capitale, il fut áppelé a Londres par le ministre Robert Walpole dont il fit un portrait resté célèbre. Vanluo fut ensuite chargé d'exécuter les portraits de la famille royale et ceux rle presque lous les personnages de la cour d'Angleterre. Le climat ne lui fut pas favorable, et la perte d'un de ses fils, survenue pendant san sújour à Londres, lui porta un coup mortel. Il rentra en France et voulut revoir sa ville natale; il y mourut peu après son arrivée, à l'àge de soixante ans.

Charles-André, dit Carle Vanloo, frère du précédent, naquit a Nice en $170 \ddot{\text { et }}$

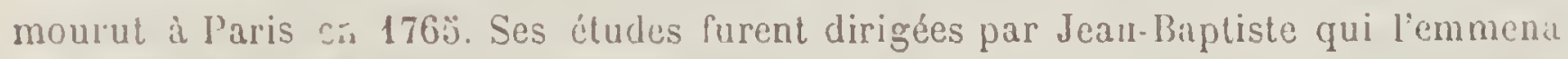
avec lui à liome chez le prince de Carrignan. Il entra dans l'atelier de Benedetto Luti. où il se lia avec un sculpteur, alors en vogue dans la capitale italienne, nommé Legros. Se croyant une véritable vocation pour la sculpture, Carle abandonna la peinlure pour travaller avec son nouvel ami, mais il ne tarda pas a rentrer dans l'atelier de son frère. Cedernier l'emnena avec lui à Paris, et là, il se mit séricusement à l'ceuvre.

Il cullabora avec Jean-Baptiste a la restauration des peintures du l'rimatice, à Fontainebleau, oci il donna la mesure de la délicatesse de son talent. Il obtint le prix de Irome en 172\%, en traitant le sujet demandé : Jacob purifunt sa maison arant ie partir pour Belhel, oic il alluil offrir un sacrifice au Seigneur. II partit pour Rome en emmenant ses leux neveux, loouis et francois. Dès son arrivée, Il obtint le prix annuel de dessın à l'Académie de Saint-Luc. L'A pothéose de saint Isidore, pour l'église de ce nom, lui attira l'admiration des connaisseurs; une Sainte . Warthe et un Saint Francois furent exćcutés aussitót après el furent achetés par le général des Cordeliers de Tarascon, qui était en ce moment à Rome, et altirèrent à l'artiste la faveur du cardinal de Polignac, qui demanda et obtint du roi de France une pension pour le peintre. Le Pape lui-mène s’intéressa à Carle, le créa chevalier, et il vécut au milieu du clergé qui le combla de faveurs. L'Angleterre lui fit demander un tableau par l'intermédiaire de son ambassadeur, et paya royalcment unc étude de femme, la Femme oricntale à sı toilette, qui a ité longtemps célèbre sous le nom de Femme an bracelet, parce quiun cercle d or lui cntoure la cuisse. Lorsqu'il revint en France, un malheur terrible le frappa à Turin : son neveu François périt d'une chute de cheval, plongeant son oncle 
dans une cruelle désolation. La cour tout entière súmut de cetle catastrophe et combla Carle Vanloo de marques de sympathie. Remis de cetle pénible secousse, le peintre essaya doublicr son chagrin dans un travail acharné. On doit citer parni ses cuvres les plus remaryuables à eelie éponue les neuf panneatux de la Jérusulem drili. vrée, commandés pour le Cabinet du roi. Ilépousa alor's une cantatrice célèbre, la belle Christine Somis, et revint avec elle à Paris, où il mena une existence princidre tont en produisant des cuvres capitales et où il mourut en 176.3. Carle Vanloo, comme quelques peintres de sccond ordre, cut ses élaus de génie. "Quoiyue fuyant et mou, dit Arsène lloussaye, son ćessin était agréable, son pinceau élait moelieux; il variait avec beaucoup de talent le style du crayon et du pinceau; il passait sans effort de l'effet énergique et sévère au ton argentin et suave. Sa couleur, quoique un peu rouge et hlanche, a du charme et de l'attrait, mais en visant à l'écliat, il touche souvent au clinquant. Ses airs de tète sont aimables, trop peu variés: cést toujours la mène figure comme dans l'œurre de Watteau avec moins d'esprit. Maintenant que la critique moderne a répandu une grande lumière sur l'art français, tout le monde voit Vanloo sans prisme, tel qu'il fut: un peintre très habile arrivant presque au génie par hasard, conme d'autres y arrivent naturellement.

Louis-Michel Vanloo (1707-17il), fils de Jean-Baptiste Vanloo, se distingua daus le genre mythologique et fut le peintre favori du roi d'Espagne Philippe $V$. II eut moins d'originalité que son oncle Carle, mais on ne peut lui refuser le coloris, le mourement et mème une certaine puissance, sans parler d'une brillante inagination. Dans la seconde moitié de sa vie, il fit surtout des portraits, et il se montra bien supéricur a ce qu'il avait été dans le genre mythologique. Sa peinture vigoureuse était exempte de la gamme et du parti pris des Espagnols, et Diderot ne trouva pas d'assez louangenses épithètes pour exprimer son enthousiasme. Les autres memlıes de la famille lanloo qui ont laissé un nom dans la peinture sont François. né à Aix (1711-173:3): Philiple, né à Turin (1718-1796); Denis, né à Paris (1743-1821).

A côté de la familie des Vanloo, l'histoire de l'art signale la famille des Restunt, dont deux représentants appartiennent au xvilo siècle : Jean Restout (1692-1768) et Jean-Bernard Restout (1732-1793). Ni l'un ni l'autre ne méritent d'attirer notre altention, mais il n'en sera pas de mème de Greuze.

Jean Greuze (1720̈-1803), fils d'un maitre couvreur de Tournus, cut dis l'enfince un goût prononcé pour le dessin. Son père, qui voulait faire de lui un archilecte, lui défendait de dessiner, et il devait prendre sur son sommeil pour contenter ses gouls, mais la vue d'une copie, que Jean offrit au couvreur le jour de sa fete, modifia la première résolution de ce dernier, qui enroya le jeune homme à Lyon, dans l'atelier de Grandon, un fabricant de tableaux plutôt qu'un artiste Greuze fit des proģrès rạpides. Ayant la conscience de sa valeur il vint a Paris ayant déja peint une magnifiłue toile : Un Père de famille expliquant la Bible. La, il lulta, il travailla seul, ne trouvant aucun appui chez ses ainés, obligé de firire de pelites peintures pour gagner sis vie. II ne fut agréé par l'Académie qu'à l'àge de trente ans, grice à la proteclion de syłrestre, l'ancien maltre à dessiner des enfants de france. Le fère de famille, exposé chez un amateur avant de l'ètre au Salon de 1730 , valut brusquement un triomplie a sou auteur: enfin, on découviait Greuze. Loin de se laisser griser par la renommée, sentant le besoin de compléter son éducalion artistique, il partit pour litalie, étudia surtout les nuvres du Tition, mais il " lezla Françars en Ilalie. Ce n'est pas daus ses grandz 


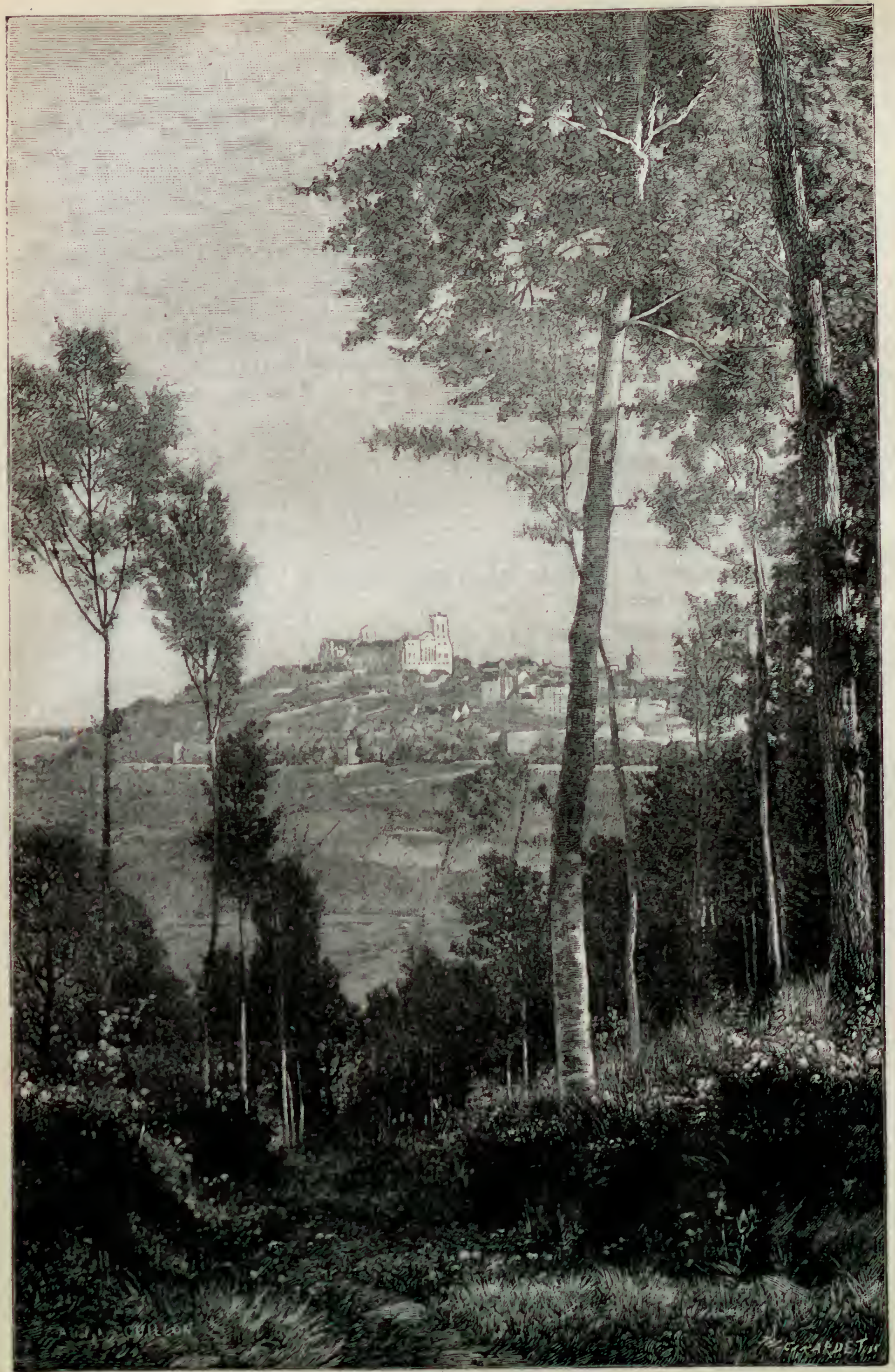

BeAUX-ARTs. - Vézelay, tableau de N. Adolphe Guillon. 
tableaux qu'il est admirable, c'est dans ses petites toiles, lorsqu'il peint des tetes enfantines.

- Onsent, comme disent les Goncourt, que la main, la main inspirće d'un véritable peintre a passé sur ces joues fouettées par le pinceau du rouge de la santé, a bombé et lissé ce petit front, où le jour vit, a mis dans cet œil un regard bleu, l'éclair et le ciel, a jeté une caresse d’ombre sur le sourcil ébauché, a fait de l'arc de la bouche, pressé par les deux joues, la moue d'un chérubin. Rien de plus frais, rien de plus vivement et de plus légèrement touché : le ton est tendre et comme tout mouillé d'huile, l'empate. ment fleurit la chair en l'effleurant; la physionomie naissante, les formes a peine dégagées semblent, sous le frottis qui badine avec elles, trembler comme les choses i l'aube. Peintre de l'enfance, Greuze est un maître lorsqu'il touche à la lête de la jeune fille. Il excelle à représenter cette beauté de la femme qui se lève et flotte encore dans les traits de la petite fille. Il a des finesses, des tendresses de ton adorables pour lies chevelures, à peines retenues par un ruban, envolies, foudroyantes pour le rayonnement doré que la naissance des cheveux fail au haut d'un front, pour le réseau des petites veines bleues ramifiées à la tempe. Il donne à l'œil de la jeune fille la profondeur et la flamme voilée; il sait rendre le noyé du regard, en altendrir l'expression, en mouiller la lueur, faire trembler l'émotion ou la passion dans la douceur d'une larme arrêtée par les cils. Il anime tout de jeunesse : la narine est flémissante, un souffle entr'ouvre la bouche, les lèvres pleines se tendent et s'avancent dans un rague mouvement d'aspiration. Des glacis relevés de martelages de pàte sèche, des trafnées de lumière jetées sur des demi-teintes fluides et qui éclatent sur l'inconsistance des dessous, il n'en faut pas plus à Greuzo pour faire sortir de la toile tous ces jolis visages, ces teints rosés, cette chair blanche, douillette et chaude, vivante de sang. baignée de suleil, ces cous effilés, ces épaules rondissantes et caressantes à l’œil comme un couple de colombes, ces petits seins gonflés d'hier. sur lesquels passe et joue le reflet d'une gare; bonnes fortunes du coloriste, morceaux peints d'instinct, enlevés de verve, qui parfois rappellent le grand maitre dont Greuze, grimpé sur une échelle, au Luxombourg, interrogeait le génie, dont il flairait la peinture, le nez sur la toile pendant de longues heures : Rubens!,

L'Accordée de village, exposée au Salon de 1761, acheva de porter à son comlsle la réputation de Greuze. On admira dans cette toile bien plutôt que la peinture, la vérité de l'expression, le mouvement, la délicatesse des détails, et Greuze comp̧rit que sa voic était trouvée: il serait le peintre des inœurs bourgeoises et populaires. Greuze, il faut le dire hautement, n'est pas un artiste hors pair, mais autant il est excessif de le placer au premier rang, autant il est injuste de ne pas reconnaltre la place éminente qu'il occupe dans l'art français. En dépit de leurs défauts, ses compositions sont de petits drames de famille, d'une expression qui est souvent touchante (car on serf ce qu'a voulu Greuze), et qui furent une réaction salutaire contre les irnmoralités de Boucher. Ses personnages sont sien groupés.

Chardin (1699-1779), fut lui aussi un peintre de mours, mais bien supérieur a Greuze. Chez Cazes, dans l'atelier duquel il débuta, il n'apprit rien, à ce qu'il paralt, mais chez Nicolas Coypel il commença à dessiner d'après nature. Une enseigne qu'il peignit pour un chirurgien et qui fut un vrai petit chef-d'œuvre, une scène éblouissante de vie et d'action, attira d'abord les yeux de la foule, puis le regard des académiciens. Mais comment se faire agréer de ces hauts et redoutables personnages? Chardio, désirant 
pressentir leur opinion, se permit un innocent artifice: il plaça dans une 'petite salle, comme au hasard, ses tableaux et se tint dans la seconde. Largillière vient à passer, s'arrête, les considère, et entrant dans la seconde salle de l'Académie où était Chardin - Vous avez la, lui dit-il, de très beaux tableaux; ils sont assurément de quefque bon peintre flamand, et c'est une excellente école pour la couleur que celle de la Flandìe. A présent, voyons vos ouvrages. - Monsieur vous venez de les voir. - Quoil ce sont ces ableaux que. - - Oni, monsieur - Oh! conclut Laigillière, présentez-vous, mon ami, présentez-vous. , Aussi Chardin fut-il agréé à l'approbation générale.

Il y avait, parmi ces tableaux exposés, un buffet chargé de fruits et d'argenterie, et une raie avec quelques ustensiles de ménage. Chardin fut en effet le a grand peintre de la nature morte , MM. Edmond et Jules de Goncourt, qui se sont efforcés de rendre à l'art du xvine siècle la place qui lui revient et qu'on lui a si longtemps refusée, sont peut-être les premiers qui aient dil de Chardin qu'il est un grand peintre. Laissons-leur donc une fois encore la parole: "La nalure morte, ld en effet, est pour ainsi dire la spécialité du génie de Chardin. Il a élevé ce genre secondaire aux plus hautes comme aux plus merveilleuses conditions de l'art. Et jamais peut-être l'enchantement de la peinture matérielle, touchant aux choses sans intérêt, les transfigurant par la magie du rendu ne fut poussée plus loin que chez lui. Dans ses tableaux d'animaux, ses lières, ses lapins, ses perdrix, dans ce qu'on appelait au $\mathbf{x} v \mathrm{r}^{\mathrm{e}}$ siècle des retours de chasse, quel maître n'égale-t-il pas? Fyt lui-mème, plus spirituel, plus piquant, plus amusant ì l'œil, plus détaillé de plume et de poil, lui cède en force, en solidité, en largeur de travail, en vérité d'effet. Les fruits, les fleurs, les accessoires, les ustensiles, qui les a peints comme lui ? Qui a rendu, comme il la rend, la vie inanimée des choses? Qui a donné aux yeux une areille sensation de présence réelle des objets? Chardin semble entrer comme le soleil dans la belle et sombre petite cuisine de Wilhem Kalf. C'est une magie à còté de laquelle tout palit et tous faiblissent. Sur un de ces fonds sourds et brouillés qu'il sait si bien frotter, et où se mêlent vaguement des fraícheurs de grotte à des ombres de buffet, sur une de ces tables à tons de mousse, au marbre terreux, habituces à porter sa signature, Chardin verse les assiettes d'un dessert : voici le velours pelucheux de la peche, la transparence d'ambre du raisin blanc, le givre de sucre de la prune, la pourpre humide des fraises, le grain dru du muscat et sa buée bleuatre, les rides et les verruqueux de la peau d'orange, la guipure des melons brodés, la couperose des vieilles pommes, les nœuds de la croùte du pain, l'écorce lisse du marron, et jusqu'au bois de la noisette. Tout cela est là devant vous, dans le jour, dans l'air, comme à portée de la main. Chaque fruit a la saveur de ses couleurs, le duvet de sa peau, le pulpe de sa chair: il semble tombé de l'arbre dans la toile de Chardin. Puis, au travers de ce bouquet d'été et d'automne, ce seront des soupières de Saxe ì fleureltes, de massives argenteries, des bocaux d'olives, des bouteilles trapues, remuant dans leurs flancs de verre l'or des liqueurs ou les lueurs de sang du vin, mille oljets de table sur lesquels le peintre fera jouer, en un petit carré lumineux barré d'ombre, le jour et la croix de la croisée. Chardin fait tout ce qu'il voit. Rien n'humilie ses pinceaux. II touche au garde-manger du peuple. Il peint le vieux chaudron, la poivrière, l'égrugeoir en hois avec son pilon, les meubles les plus humbles. Nul morceau de nature qu'il méprise.

Chardin s'était cantonné exclusiveinent dans la nature morte, lorsqu'une question d'amour-propre le fit s'attaquer à la nature vivante. Il peignit d'abord des singes, puis 

LES MERVEIL DE L'EXPOSITION

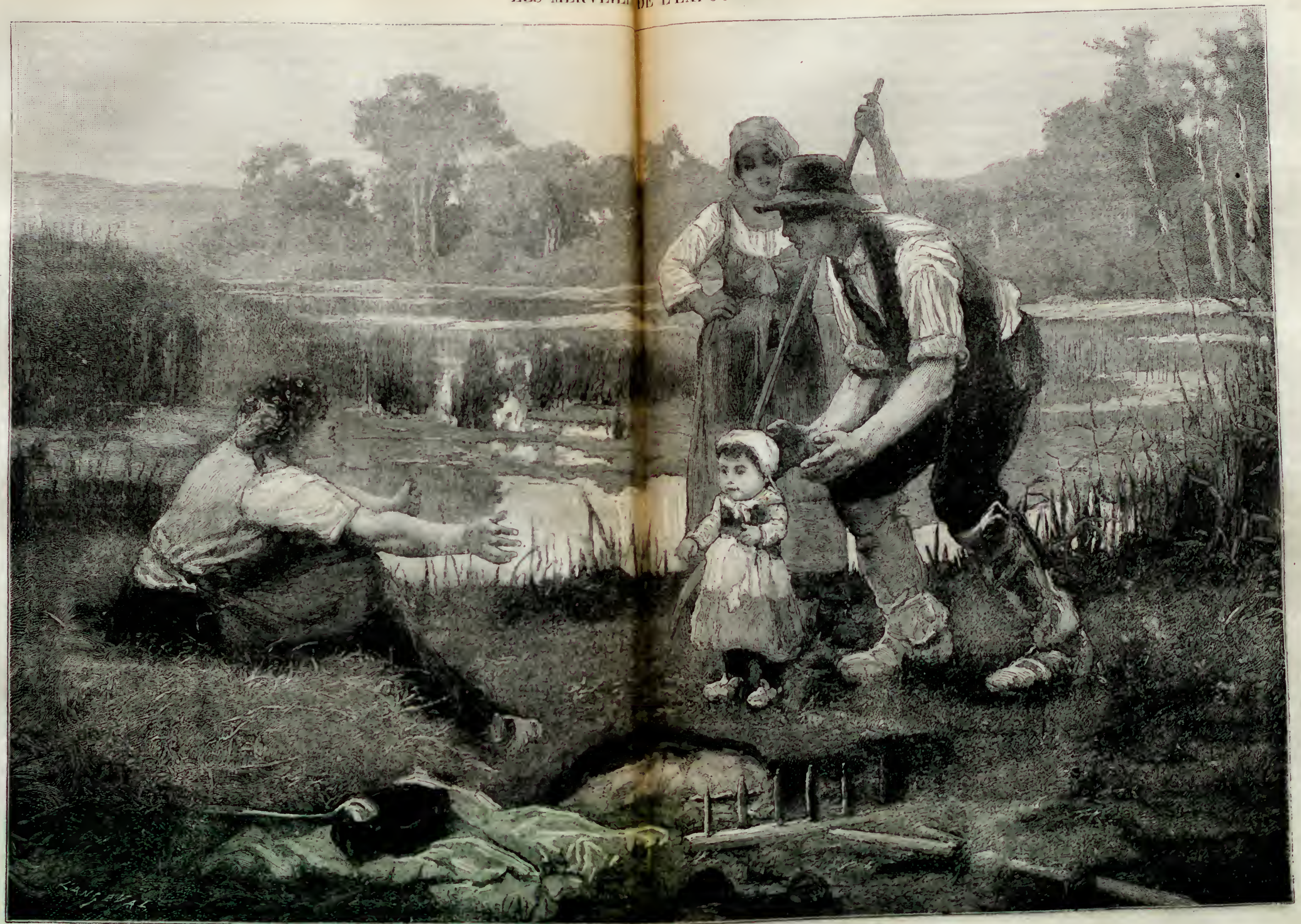

Bravz-ARTs. - Les Prenurs Pus, lableau de M. Georges Laugéo. 
Ine gracieuse et coquette petite toile de figure, un adolescent, une petite fille jouant avec un épagneul, la Fontaine, la Blanchisseuse, etc., et sa peinture familière cut un succès qui rendit l'artiste populaire, qui le cousacra comme le peintre bourgeois de la petite bourgeoisie. De 1737 à 1779, il exposa aux Salons qui se succédèrent cent donze tableaux, où il est toujours le modèle inimitable de la gráce simple, de l'observation naîve, de la fine bonhomie. On a dit que dans l'cuvre de grenre de Chardin, il y avait du la Fontaine, et cela n'est pas exagéré. Quelle saveur, quel caractère dans le Bénédicité! Une femme debout, près d'une table sur laquelle est servi un repas, fail riciter le bénédicité à deux petites filles assises et qui joignent les mains. Le sujet est aussi simple que possible, mais il est traité avectant de naturel et de bonhomie qu'il impressionne vivement le spectateur. Jusqu'à son dernier jour, Chardin travailla sans tomber, sans survivre à son talent, et, chose curieuse, ses dernières œuvres sont des portraits aú pastel.

Sur ce terrain, il fut en concurrence avec Maurice Quentin de la Tour (1704-1783). Il étudia dans l'atelier de Louis Boulongne, mais il préféra à la peinture l'emploi des crayons de couleur pulvérisés connus sous le nom de pastels et qui est comme un intermédiaire entre le dessin et la peinture. Dès que ses premières ouvres furent connues, la cour et la ville s'engouèrent sans bornes de ce révélateúr d'un art nouveau. Tout le monde voulut avoir son portrait peint pas la Tour, et comme il ne pouvait portraiturer tous ceux qui le désiraient, sa vogue s'accrut de la difficulté quil y avait à ètre honoré de son pinceau. Né avec des idées indépendantes, la Tour ne s'en dịarlit jamais, mème lorsqüil se transportait à Versailles.

Depuis la fin du règne de Louis $X V$, l'École française se divisait très nettement cn deux catégories de peintres procédant plus ou moins directement les uns de Wallean, les autres de Poussin et de l'art antique. Tel est Fragonard dans la premicre, tels suat Vien, Pierre, Deshays, Doyen et Peyron dans la seconde.

Jean-IIonoré Fragonard (1732-1806), né à Grasse, est le peintre méridional frar excellence. On ne saisit bien tous les détails de son talent qu'en sc rappelant le wilicu où il est né, qu'en songeant à cette terre ensoleillée et parfumée, avec ses verger - ses orangers, ses plaines, ses montagnes et son ciel bleu. Fils d'un négrociant ruiné, il dııt entrer à $10 ّ$ ans comme petit clerc chez un notaire, qui ne tarda pas a conseiller de mettre l'enfant chez un peintre et non chez un homme daffaires. Boucher refis: Je prendre Fragonard, ne pouvant se charger d'apprendre le rudiment i ses ileves. Ciardin le prit pour charger sa palette, mais il affirma à ses perents que jamais il ne ferrit rien de bon en peinture. Chardin ignorait que Fragonard passait presque tout son (rmpla, non à jouer, mais à courir dans les églises, à y regarder les tableaux et à en fairc des croquis qu'il alla un jour présenter à Boucher. Cetle fois le peintre le reçut de grund cœur dans son atelier, l'occupa à de grandes toiles destinées aux Gobelins, et en 17.:. à lâge de vingt ans, il obtenait le prix de Rome sans avoir jamais été admis aux cutirs de l'Académie. Les grands artistes de l'Italie l'effrayèrent par leur sévérité. . L'ẻicrzie de Michel-Ange m'effrayait, disait-il; j'éprouvais un sentiment que je ne pouris rendre; en voyant les beautés de Raphaël, j'étais ému jusqu'aux larmes, et le crayon ine tombait des mains; enfin, je restai quelques mois dans un état d'indolence qu: je n’étais plus le maître de surmonter, lorsque je m'attachai d l'étude des peintres qui me donnaient l'espérance de rivaliser un jour avec eux. C'est ainsi que Baroche, l'iètre de Cortone, Solimène et Tiepolo fixèrent mon atlention. , Ces mattres de second plan, il 
les copie, il dessine leurs œuvres à satiété, mais en même temps, il apprend à copier la nature, les paysages, les ruines, les curiosités. Il occupe même ses loisirs à graver des Tintoret, des Carrache, des Lanfranc. On pense bien qu'il revint à Paris fortifié et comme transformé, mais qui se serait aperçu de cette transformation? Personne, dans le public parisien, ne connaissait Fragonard : il fallut le tableau de Callirhoë pour enlever les suffrages et en mème temps la célébrité. Mais quel début! Quels piquants effets de lumière, quelle habileté d'exécution, quelle chaleur, quel mouvement! "Et pourtant Fragonard n'était pas fail pour la grande peinture, comme on le vit par son tableau de la Visztution, qui suivit Callirhoë, et que l'artiste n'avait pas composé sous l'impression immédiate de son voyage en Italie. Il jura de ne plus recommencer, puis se donna tout entier à la peinture légère de Boncher. Ses scènes d'amour et de volupté firent de lui le peintre à la mode : on se les arracha à coups de deniers, et, libertinage à part, il n'était en effet rien de plus joli que ces petits poèmes qui s'appellaient le Serment d'amour, le Sacrifice de la rose, le Verrou. Une verve indescriptible, une forme exquise, un arrangement merveilleux, une suavité ravissante, voilà ce qu'on y voit, ce qui saute aux yeux du spectateur.

Quand éclata la Révolution et que le goùt de l'érotisme eut disparu avec la société corrompue de la fin du siècle dernier, Fragonard tomba dans une affreuse misère, n’ayant rien conservé des millions qui avaient couvert ses toiles. Il mourut désespéré et malleureux, regrettant sans doute de n'avoir pas persisté dans la peinture d'histoire après et malgré l'échec de la Visttition.

La réforme que David devait réaliser dans l'École française fut préparée par le peintre Vien (1716-1809). Il montra de bonne heure un gout passionné pour le dessin, découpant dans du papier des fleurs, des oiscaux, ou copiant nerveilleusement des estimpes. On voulut pourtant faire de lui un procureur, et c'est seulement en 1740 qu'il entra dans l'atelier de Natoire. Le genre faux et maniéré de la plupart de ses camarades d'atelier le frappa et lui donna l'idée d'étudier de près la nature, de la prendre pour mo lèle, ce qui lui valut nombre de quolibets. Prix de Rome en 174k, il composa, pendant la traversée de Marseille en Italie, la magnifique esquisse du Massacre des Innocents, fortifia sa conviction artistique en contemplant les chefs-d'ouvre des mattres, se présenta à l'Académie en 1730 et fut écarté une première fois sous prétexte qu'il ne savait pas peindre! L'Emburquement de saınte Hurthe plut aux académiciens, qui l'admirent en 1732 . " Dès lors, dit un critique, la révolution était accomplie dans la peinture française; l'École classique était fondée. Ce n'était lì, il est vrai, qu'un còté de l'innovation de Vien. Si on le suivit dans la reproduction des formes harmonieuses et savantes des modèles antiques, on refusa d'admettre cette sorte de réalisme, cette imitation scupuleuse de la nature qui s'est manifestée dans ses tableaux d'histoire; il était réservé au xıx siècle de s'emparer de ce genre et de l'exagérer en le fécondant. Vien eut donc la gloire d'être aussi le père de l'école romantique. Le premier, il établit dans son atelier l'étude du modèle vivant. 'A côté de la louange, il n'est pas hors de propos de placer la critique. M. Charles Blanc reconnait que Vien fut ot le maitre et le précurseur de David, mais il ajoute : " La grande réforme que David devait opérer dans l'École française, Vien l'avait pressentie et préparée, mais n'ayant pas la force de l'accomplir lui-meme, il demeura toute sa vie entre deux principes, celui qu'il voulait détruire et celui qu'il aurait voulu restaurer. De là, le côté mixte et batard de son talent. , Le chef-d'œuvre de Vien, Saint Denis préchant dans les Gaules, décore l'église 
Saint-Roch à Paris. Marie Reboul, femme du peintre (1728-180\%), peignit arec une délicatesse et unc exactitude remarquable des neurs, des fruits et des oiseaux, et son fils, Joseph-Ilarie (1761-1848) cultiva arec succès la miniature ct le portrait.

Donc, Vien fut le précurseur de David, et David, chacun le sait, fut le peintre de la Révolution. Arec lui, c'en est fini de l'art galant et pastoral du xrü siècle, dont nous avons passé en revue les représentants les plus connus. Depuis que les philosophes avaient mis à la mode les mots de liberté et d'égalité, qui passèrent bientôt à l'état de réalités palpables, on s'était peu à peu engoué dans les salons des mœurs antiques. Après la prise de la Bastille, on accrocha aux murs des appartements les portraits de Brutus, de Lycurgue, des citoyens farouches de l'antiquité. M. Spire Blondel fail à ce propos de curieuses réflexions. "Par suite d'une erreur trop longtemps et trop généralement accréditée, dit-il, l'adoption des modes et des costumes antiques a élé tenue pour une des manifestations républicaines de l'époque, lorsque c'était tout simplement la conséquence de l'éducation monarchique. Thémistocle, Aristide, Epaninondas, Solon, Cicéron, Caton, Cincinnatus, Scipion étaient les modèles qu'on proposait depuis des années à la jeunesse. Les institutions étaient monarchiques, et les habitudes républicaines; les prétentions et les privilèges étaient aristocratiques, les opinious et les mours devenaient démocratiques. Le Voynge du jeune Anacharsis en Grèce, par l'ablié Barthélemy, exalta encore ladmiration pour l'antiquilé. Ce livre, publié en 1788, fut l'événement et le triómphe littéraire de l'époque. Les artistes contribuèrent aussi par leur influence à ce mouvement qui, encore une fois, ne fut pas plus républicain qu'il ne fut local; si la France avait son David et ses disciples fervents, l'Angleterre avait son Flaxmann, l'Italie son Canova, et ces maitres des imitateurs partout. Nos pères de la liévolution se trouvèrent donc tout naturellement portés vers l'antiquité; ils le furent aussi vers l'allégorie, comme le prouve le calendrier républicaiu, fondé sur l'observation de la nature et de la vie agricole autant que sur les données scientifiques. Aussi l'art révolutionnaire fut-il particulièrement allégorique. "Ou assiste, dit M. Paul Rouaix, à une violente réaction contre les tendances de Boucher et celle réaction se proclame elle-mème un retour à la nature. Sans doute ces Romains, celle mythologie romaine, ces Horaces, ces Spartacus, ces Marius ont quelque chose de froid et de convenu; mais avec eux, avec leurs costumes de draperies, dans lesquelles le corps se devine et se dessine, c'est le nu qui rentre dans l'art; non plus le nu enjoliré, le nu séduisant et mutin de Louis XV, mais la nudité robuste, saine et morale, si l'on peut dire. Outre que l'art recherche le nu, il redevient en effet moral. Chaque tableau est une leçon, un exemple de dévouement civique. Les arts de la Révolution sont moraux et patriotiques. Cette union de l'art et de la morale, union chère aux plilosophes de l'antiquité, passe dans le fait, se formule dans le décret.

Le peintre par excellence de la Révolution, tout le monde le sait, c'est David. Jacques-Louis David naquit à Paris le 31 août 17.18. A l'age de neuf ans, son père, un marchand de fer du quai de la Mégisserie, fut tué en duel, et son oncle Buron, qui se chargea de son éducation, le mit au collige des Quatre-Nations. Au lieu d'étudier, Louis couvrit avec obstination ses livres classiques de croquis qui révélaient sa vocation; mais, lorsqu'il déclara qu'il roulait être peintre, sa famille s'ellorga de l'en détourner et le supplia de faire un architecte. Il refusa avec une ténacilé devant laquelle on s’inclina. Le voilà dans l'atelier de Boucher, lequel, se sentant trup ágé et trop occupé pour veiller sérieusement à l'éducation artistique du jeune homme, lo 


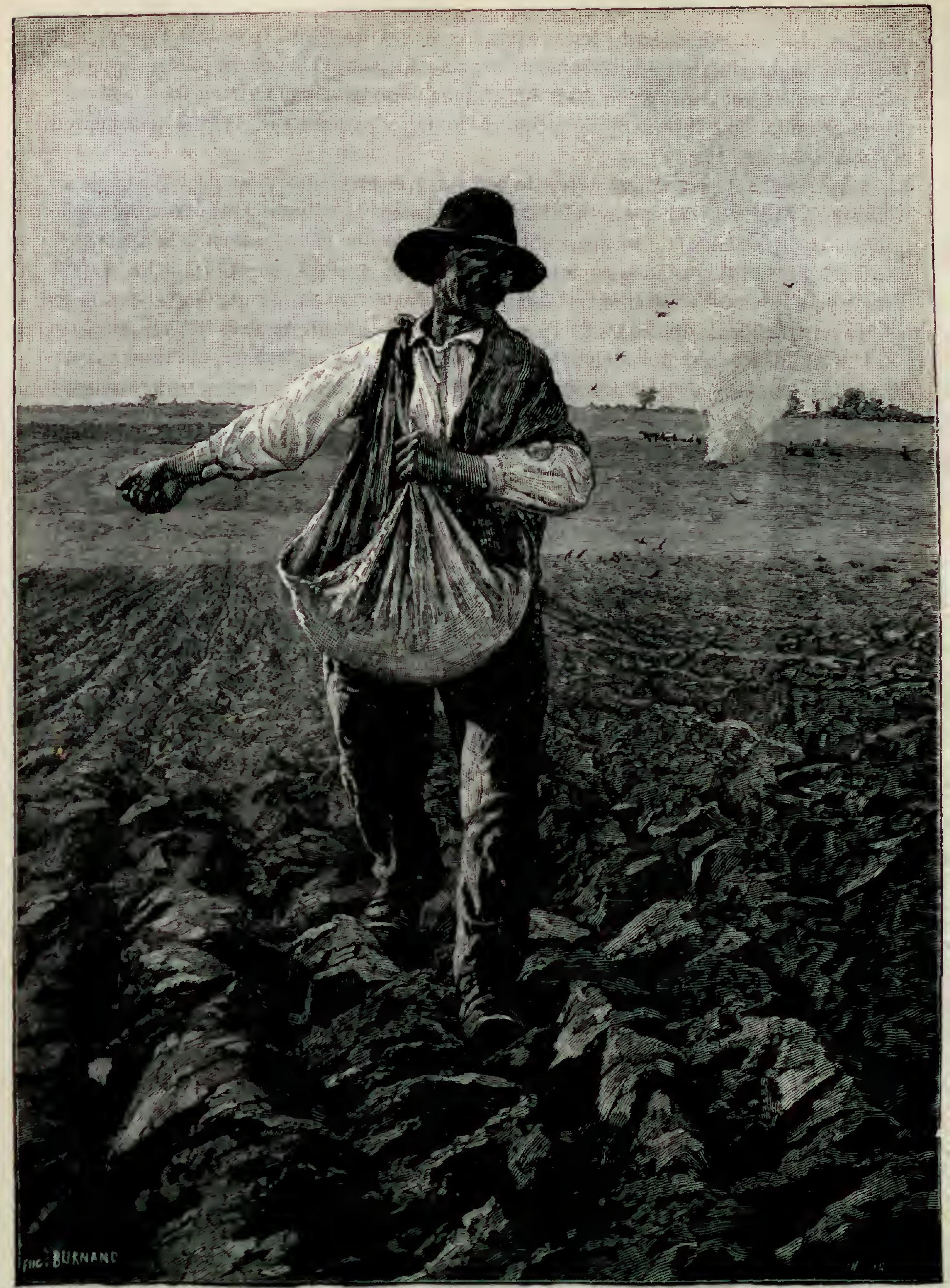

Beavi-Arts. - Le Semeur, tableau de M. Eugène Burnand. 
confia à Vien. Cependant, les progrès de David ne furent pas très rapides : il dut concourir cinq fois avant d'obtenir le prix de Rome (1775), et ses échecs successifs lui avaient été si sensibles qu'il résolut un jour de se laisser mourir de fiin. Sedaine, son parrain, eut beaucoup de peine à le faire revenir sur cette détermination pessimiste.

Lorsque Natoire mourut, Vien le remplaça dans la direction de l'Académie de France à Rome. Il enmena avec lui David, qui demeura enthousiasiné devant les chefsd'œuvre de la peinture italienne, qu'il ne connaissait que pour les avoir entendu décrier à Paris; il fit d'abord des copies, puis des études vigoureuses et originales d'après nature, et il revint en France en 1780. complètement transformé par un commcrce de cinq ans avec les monuments de l'art antique et les grands maftres italiens, résolu d se consacrer à la peinture historique. Son Bélisaire lui valut d'ètre agréé par l'Académie (1781), et son Andromaque pleurant la mort d'Ilector (1783) se fit remarquer par la simplicité des attitudes, le naturel des draperies, la vérité. Revenu une seconde fois à Rome, il y exécuta le Serment des Horaces, où les défauts ne manquent point, mais qui constitue un immense progrès sur les tableaux du genre. linfin. en 1787, on admira dans la Mort de Socrate la grandeur de la pensée, la clarté de la composition, le naturel de l'expression, la noblesse des attitudes. Son talent, désormais, ne fit que s'affirmer. Le gouvernement de Louis XVI lui commanda les licteurs rapportant à Brutus le corps de son fils. "Si ce tableau, dit Delécluze, soutint plutôt qu’il n'augmenta la réputation déjà très étendue de David, il eut sur le goût et les modes, et même sur les mœurs, une influence qui se fit sentir à l'instant mème.,

En 1789, David exposa au Salon les Amours de Paris et d'Héléne, un Brutus, une Vestale couronnée de flewrs, une Psyché abandonnée (étude non terminée), une dizaine de portraits, un tableau représentant Louis X VI entrant dans le lieu des séances de l'A ssemblée constituante (ouvrage dont on a perdu la trace), et un magnifique dessin a la plume, lavé au bistre, immortalisant le Serment du Jeu de paume. Ce dernier ouvrage obtint un tel succès que, sur la proposition de Barère, la Constituante décréta qu'il serait reproduit en peinture par David, aux frais du gouvernement, et placé dans la salle des síances de l'Assemblée. Le peintre entreprit ce travail sur une toile de 30 pieds de largeur sur 20 pieds de hauteur, mais les importants événements qui se succéderent ne lui permirent pas de l'achever. Cette ébauche se trouve actuellement parmi les des. sins du Louvre. Dès lors, David devint le peintre des événements de la llévolution et prit en outre une part active à la politique. Il entra de bonne heure au club des Jacobins et fut le principal organisateur de la fête célébrée en l'honneur du régiment suisse de Châteauvieux. En septembre 1792, la section du Muséum le nomma menbre de la Convention. Comme député, il se montra toujours d'un républicanisme cxalté et ne prit guère la parole que pour traiter les questions se rapportant aux arts, aux artistes et aux grandes fètes républicaines, dont l'organisation lui était généralement confiẻe. La Convention supprima, sur sa proposition, la place de directeur de l'Académie de Ṙome, et, peu après, l'Académie elle-méne. Pendant la période révolutionnaire, David eut la haute direction des arts; il fit exécuter à ce moinent plusieurs projels, entre autres celui d'un monument d'assez mauvais goat représentant . l'image du peuple géant, du peuple français . Il organisa un grand nombre de fetes patriotiques, telles que celle qui célébra la reprise de Toulon sur les Anglais, celle qui fut donnée en l'honneur du jeune Bara, et celle qui cut lieu au Champ de Mars en l'honneur de 
l'Être suprème. Emprisonné au Luxembourg le 9 prairial, il dessina beaucoup pendant sa captivité, esquissa son tableau des Sabines, où il revint au pur style antique que la Révolution lui avait fait perdre de vue, car le Serment du Jeu de paume, Lepelletier, Marat et Bara marquent une phase spéciale et comme une parenthèse dans les tableaux de David. Amnistié par le Directoire, il ne se mêla plus aux luttes politiques, termina le tableau des Sabınes (1799), œuvre compassée et sans beaucoup de sentiment, mais où brillent au suprême degré la perfection du détail anatomique, la pureté du dessin, la fermeté du modelé. Quand Bonaparte commença à devenir toutpuissant, il combla David d'attentions, et le peintre exécuta le portrait célèbre où le vainqueur de Marengo est représenté à cheval gravissant le mont Saint-Bernard. Nommé premier peintre de Napoléon, il peignit le Couronnement et la Distribution des aigles. De 1800 a 1814 , if fit de nombreux portraits, et termina l'année même de la chute de l'Empire son Léonidas aux Thermopyles. Exilé par la Restauration, il s'établit à Bruxelles, admiré et choyé de tous, mẻme du roi, et il semble avoir subi là, si l'on en juge par ses œurres d'exil, l'influence des coloristes flamands. C'est à Bruxelles qu'il mourut le 23 décembre 182:. Le gouvernement de Charles X, malgré les instances les plus pressantes, refusa de laisser entrer le .corps en France, mais le gouvernement belge, plus humain et plus intelligent, fit inhumer les restes du grand artiste dans la cathédrale de Bruxelles.

Le Comité de salut public avait, après la suppression de l'Académie, invité les peintres à représenter les épisodes de la Révolution et à exposer leurs projets. Des prix furent distribués, l'an III, à Gérard, Vincent, Carle Vernet, Lagrenée, Lethière, Prud'hon, Demarne, etc. Vincent, qui figure parmi les lauréats, est un peintre de valeur, mais son nom est peu connu, parce qu'il se tint en dehors de l'agitation révolu- tionnaire, contrairement à Hennequin qui, en peinture comme en politique, prit modèle sur son maitre David.

Pierre-Paul Prud'hon (1760-1823) est un exemple mémorable de ce que peut produire un travail assidu. Obligé de fabriquer pour vivre toutes sortes de dessins, de portraits et de vignettes, il ne put se donner qu'assez tard a la grande peinture, objet de ses vœux les plus ardents. Il est l'aiteur du Christ en crowx, de la Justice et la Veng'ance poursuivant le crime, de Vénus et Adonis, de l'Enlèvement de Psyché, du Zéphir se balansant au-dessus de l'eau, de Diane implorant Jupiter (plafond de la salle des Antiques, an Louvre), etc. M. Victor d'Ilalle fait remarquer que Prud'hon s'est créé une place à part entre l'École classique de David et le romantisme naissant, qu'il tira parti de l'antique d'une manière vraiment inédite. Il fut aussi le peintre de la grâce. a Il a créé une grìce nouvelle, dit Théophile Gautier, et trouvé une veine de beauté inconnue. Sa manière de comprendre l'antique diffère complètement de celle de ses contemporains. Les statues que David dessinait avec une sécheresse sculpturale, il semble les voir au clair de lune argentées de molles lumières, baignées d'ombres et de reflets, ondoyantes, effumées sur les contours, enveloppant et noyant leurs lignes dans une vague brune. A la mythologie de l'Empire, il applique le flou du Corrège. Il a la vapeur, le mystère, la rèverie, il a aussi un divin sourire qui n'appartient qu'à lui ., On a dit de lui qu'il était bien plutỏt que David le peintre par excellence de la Révolution. Cela dépend du point de vue auquel on se place, et la vérité nous paraît être dans l'opinion de $\mathbf{M}$. Spire Blondel, d'après laquelle les générations, habituées à chercher dans l'art le signe le plus rivant des idées et des hommes, trouveront chez Prud'hon c la plus idéale 



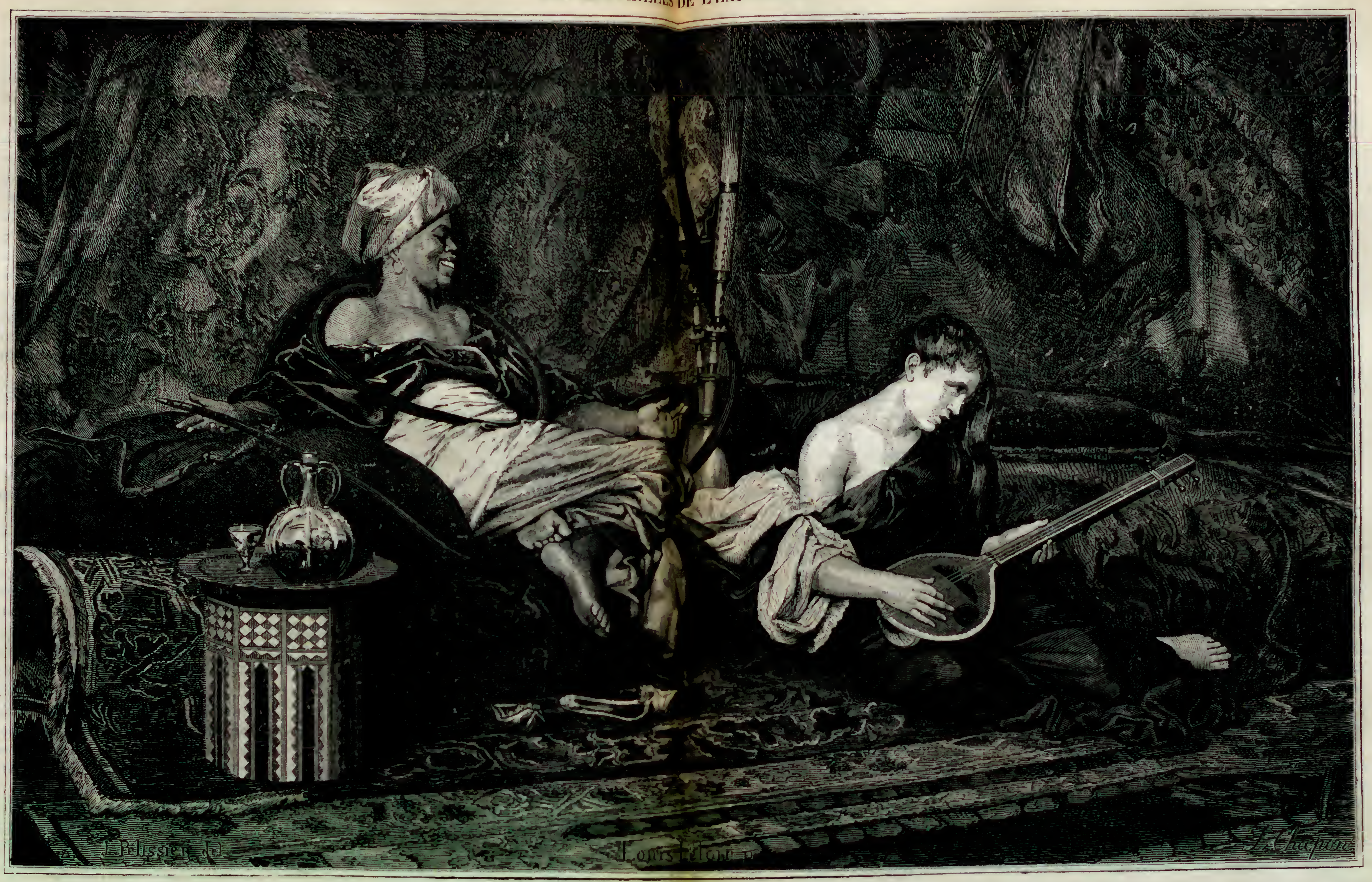


expression de l'époque révolutionnaire, comme ils trouveront dans David l'expression de sa plus grande énergie».

* Prud'hon, artiste d'un caractère tout intime, n'exerça qu'une influence latente et ne prit pas de son vivant la place qui lui était due, mais il représentera la Révolution dans les régions primordiales des plus grandes Écoles. Dans sa manière aussi neuve qu'antique, c'est-à-dire pénétré de l'esprit mème d'une renaissance et caressé d'un baiser de la nature, il donne la main aux maitres sublimes de l'Italie et résume l'élément possible de l'art de son temps. Après en avoir conçu le type au moment le plus expansif de 1789 et l'avoir nourri aux jours les plus misérables de 1793, ii l'éleva an plus haut degré de beauté. Que cette beauté nous soit toujours présente et nous fortilie au milieu des infirmités trop nomḅreuses que présente l'art de la Révolution. L'histoire doit son attention à ces infirmités, car ce sont encore des conditions esthétiques: IA, caducités prolongées des corruptions de l'ancien régime; ici, étiolements amenés par l'instabilité des gouvernements nouveaux.

Théodore Géricanlt (1791-1824), élève de Carle Vernet et de Guérin, eut de bonne heure la passion des chevaux, au point qu'il s'engagea quelque temps dans le corps des mousquetaires lors de la première Restauration (1814). Il peignait d'après nature, et David, voyant un jour son Officier de chasseurs chargeant, s'écria : "Mais d'où cela sort-il? Je ne reconnais pas cette touche!, Dans le Cuirassier blessé, son originalité s'accentue encore, mais dans le Radenu de la Méduse, il arrive à la perfection. . Tout concorde à l'effet général, s'écrie avec enthousiasme II. d'Ilalle; le ciel sombre, la mer déchainée, les mourants et les cadavres amoncelés. Le radeau même et le mat ont des teintes sinistres, des tons de chair en putréfaction. C'est l'horreur dans l'horreur. Et comme facture! c'est magistral! Le dessin est puissant, la touche large et hardie., On devine l'étonnement que provoqua chez les classiques cette audacieuse peinture, qui ne s'inspirait que de la réalité. Exposé au Salon de 1819 , le Reudeau fut généralement trouvé détestable, tant il est vrai que l'éclosion d'un génie original n'est jamais immédiatement saluée.

- En Angleterre, où l'attira son éternelle passion pour les chevaux, il peignit quelques tableaux et des aquarelles. A son retour à Paris, il exécuta la Forge au village, l'Enfant donnant à manger à son cheral, l'Écurie, etc. Enfin, comme sculpteur, Géricault est l'auteur de ce cheval écorché, dont tous les ateliers ont le moulage et qui est bien le plus beau quadrupède que l'art ait produit en l'espèce. Une chute de cheval le conduisit au tombeau en 1824 et cette mort prématurée fut un immense malheur. S'il en avait eu le temps, Géricault aurait pu exercer une influence plus durable'sur les paysagistes et les peintres de genre, mais cette influence se reconnait néanmoins chez Delacroix, Decamps, Barye.

Girodet (1767-1824), dont on voulut faire un architecte, puis un soldat, entendait étre peintre et n'ètre que cela. Conseillés par David, ses parents finirent par céder et par le mettre dans l'atelier du chef de l'École classique. A l'age de vingt ans, il concourut pour le prix de Rome, mais il fut rayé de la liste des prétendants pour avoir apporté dans sa loge les études de ses figures, ce que le règlement interdit formellement. L'année suivante, il prit part au concours sur le sujet suivant : Tatins ussrassiné au milieu d'un sacrifice ì Lavinium, en présence de Romulus; il n'obtint que le second prix. La troisième fois, il remporta un succès complet avec la composition de Joseph vendu par ses frères, belle ourre qui se trouve actuellement dans la salle des grands 
prix de Rome, à l'École des Beaux-Arts. Ce tableau rappelle tout à fait la manière de Dilvid, au point qu'il semble peint par le maître lui-même. Girodet arriva à Rome à l'ige de vingt-trois ans et se mit au travail avec acharnement, et composa pour l'École des Beaux-Arts son Sommeil d'Endymion, un de ses meilleurs morceaux. Il exécuta ensuite Hippocrate refusant les présents des Perses, toile dont la couleur a beaucoup de sécheresse, mais dont la composition et le dessin sont très remarquables. Forcé d'abandonner Rome pendant les troubles de la Révolution, Girodet s'installa à Naples avec le paysagiste Péquignot. Là, il composa une série d'études dont on retrouve quelques-unes dans les tableaux qu'il exécuta plus tard, puis il alla jusqu'à Gènes où il prit encore une masse de croquis. De retour à Paris, Girodet obtint un logement au Louvre et peignit pour l'hôtel de M. Gaudin une Danaé, et pour le roi d'Espagne les Quatre Saisons. En 1799, il exposa au Salon une autre Danaé qui était le portrait d'une actrice de la Comédie-Française; cette dernière avait refusé son portrait prétextant que la ressemblance nétait pas exacte. Tout le monde reconnut pourtant la comédienne et l'hilarité fut générale parce que le peintre avait substitué à la pluie d'or traditionnelle une pluie de gros sous. Un Fingal au inilieu de ses descendants, exécuté pour le Premier Consul, n'eut aucun succès. L'artiste résolnt alors de faire un chef-d'œu vre qui furcerait l'admiration géuérale et se consacra pendant quatre ans à la Scène du déluge quil exposa au Salon de 1806 et qui obtint le premier prix.

En 1810, la lérolle du Caire. De 1810 à 1819, sa santé, gravement altérée, ne lui permit pas de réaliser une œuvre de longue haleine; il fit seulement quelques dessins et une Títe de V'ierge très remarquable. En 1819, il rentra en scène avec une toile chirmante, Pyymalion et Galatée, qui fut fort goutée du public. Depuis ce moment, j'isqu'à celui de sa mort, il u'exécuta plus que des portraits, entre autres ceux de Culfrelineau, de Bonchamp, de Merlin de Douai et de Mme Reizet.

- Le baron François Gérard (1770-1836) est lui aussi un élève de David. Son tableau de déluut, Bélisaire, impressionne par sa simplicité mème. L'année suivante, il donna la P'syché du Louvre. Il exposa, au Salon de 1810, la Bataille d'A usterlitz, qui consacra sa réputation. Il fit plusieurs portraits remarquables: Moreau, Me Récamier, Talleyrand, toute la fanille impériale, l'empereur Alexandre, le roi de Prusse, Wellington, Louis XVill et tous les membres de sa famille, Charles X et Louis-Philippe. En 181ö, Gérard entreprit, sur la demande de Louis XVIII, un tableau qui ne fut achevé qu'en

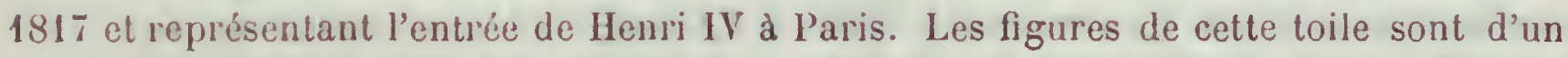
dessin très pur et ont longtemps servi de modèle daus les écoles de peinture. Corinne au cap) de Alisène figure parmi les meilleur's productions du maftre. Après la révolution de juillet 1830, Gérard exécuta pour la Chambre des députés le Duc d'Orléans acceptant lit lieutenance générale du roxaume. Il composa pour le Panthéon quatre pendentifs remiriuables: Ia Mort, la Patrie, la Juslice et la Gloire (1832-1836). Nous citerons encore parmi ses meilleures couvres : les Trois Ages (1806), Ossian (1810), le Tombeau de' Sainte-llélène (1826), l'Extase de sainte Thérèse, le Sucre de Churles $X$ (1829), Yupolion dens son cabinet (1831), la Patrie en danger (1831). Moins exclusivement attaclié que David aux traditions de l'antique, il sut imprimer à ses compositions une plysionomie expressive, une touche vigoureuse et une grande richesse de coloris.

Le haron Antoine-Jean Gros, un des meilleurs élèves de David, né à Paris en 1771, se suicida le 2uj juin 1833. Il avait élé nommé membre de l'Irstitut en 1816. Dès l'àge de 14 ans, il fut admis dans l'atelier de l)avid, obtint la première médaille au concours 
de l'Académie des Beaux-Arts, et résolut d'aller se perfectionner à Rome. N'ayant pas de ressources, il fit le voyage par étapes, s'arrêtant dans les villes importantes pour se procurer l'argent nécessaire en faisant des portráts. Parvenu à Gẻnes en 1796, il dut satisfaire au service militaire, fut incorporé dans un régiment et ne tarda pas a devenir officier d'état-major. De passage à Gènes, Joséphine eut l'occasion d'admirer plusieurs portraits de Gros, et emmena l'officier a Milan afin qu'il fit celui de son époux. Là, il représenta le général en chef de l'armée d'Italie s'avançant sur le pont d'Arcole un drapeàu à la main. Comme remerciement, Gros fut nommé adjoint à la commission chargée de recueillir dans les villes soumises les objets d'art destinés au inusée du Louvre, et plus tard inspecteur aux revues. Les insuccès de nos troupes au delà des Alpes en 1799 ramenèrent en France le peintre qui se consacra alors tout entier à son art. Son premier tableau d'histoire, la Peste de Jaffa, qu'il exposa au Salon, excita l'admiration générale; le Combat de Nazareth parut peu après. A l'origine, cette toile devait avoir 15 mètres de largeur, et le ministre Chaptal avait mis pour son exécution la salle de l'ancien Jeu de paume de Versailles à la disposition du peintre. Junol, un des lieutenants de Napoiéon, était le héros de cette bataille; vexé peut-ètre de n'étré pas le principal acteur de la scène, Napoléon fit réduire de moitié le tableau sous prétexte d'économie. En 1806, il exposa la Bataille d'A boukir qui ent un immense succès. Suivirent la Bataille d'Eylau (1808), la Prise de Madrid et les hatailles des Pyrumides et de Wagram (1810). En 1812, l'Empereur chargea Gros de peindre dans la coupole du Panthéon les figures de Clovis, de Charlemagne, de saint Louis et celle de Napoléon lui-mème. Le retour des Bourbons modifia cette donnée, et l'image de Louis XVIII vint remplacer celle de l'Empereur. Ces admirables peintures furent ache. vées en 1823 et valurent à l'artiste 100,000 francs et le titre de baron. La conception de ces compositions est grandiose; le dessin est d'une pureté remarquable et le coloris riche, bien fondı et d'une variété harmonieuse. Gros fut profondément troublé ì l'ap. parition de l'École romantique et ses derniers œuvres annoncent la vieillesse. En 1822, son tableau de Saïl fut vivement critiqué par la nouvelle école : - Laissez-les fitire, lui écrivait alors David : vos ouvrages resteront et leurs critiques feront un jour pilié. , Aux Salons de 1831 et de 1833, les attaques furent encore plus violentes. Peu de temps après, on retrouvait son corps dans la Seine, près de Meudon. Reconnaissons du muins que Gros a perfectionné, dans la inesure du possible, la méthode et le genre de son maitre David. De son temps, tout ce qui n'était pas grec ou romain, tou héros qui ne figurait pas au premier plan du De Viris paraissait indigne de tenter la palette des peintres et ce n'était ni un mınce mérite ni une mince audace que de s'attaquer à des héros vivants sans les habiller comme César ou comme Miltiade, sans les armer d'une pique ou d'un bouclier.

Le Retour de Marcus Sextus, le premier tableau exposé par Guérin (17:4-1833), eut une vogue qui s'explique par une cause toute politique. Dans cette scène d'un Romain proscrit et trouvant à son retour sa femme morte, on vit une allusion aux émigrés qui commençaient à revenir en France. Vinrent ensuite Phèdre et Hippolyle, l'ofrande d'Esculape, Clytemnestre, l'Amour enlerant Céphale, Didon et Énée, où l'on reconnait encore l'influence de David, dont l'archaisme, exagéré par ses imitateurs, produisait dans l'art une dégénérescence complète. On en était arrivé à ne plus voir que l'antiquité, une antiquité de pierre; yn ne peignait plus des personnages en chair et en os, mais des statues. Sauf Gros et Prud'hon, on ne s'inquiétait plus de la nature, de la vie, ce qui 
amena la réaction du romantisme. Boilly (1761-1845), qui avait débuté par des toiles d'un genre léger, fut bien supérieur à ce point de vue à ses contemporains de l'époque révolutionnaire. Il a beaucoup d'imagination, mais il sait, malgré sa touche un peu dure, rendre ses personnages avec vérité, leur donner des poses naturelles. Vers la fin de sa vie, il peignit un grand nombre de portraits, - environ cinq cents, - et se rendit populaire par ses lithographies, où il déploya une verve, un esprit, une originalité incontestables. Parmi ses toiles, il faut citer: l'Amour vénitien, Petite coquette,

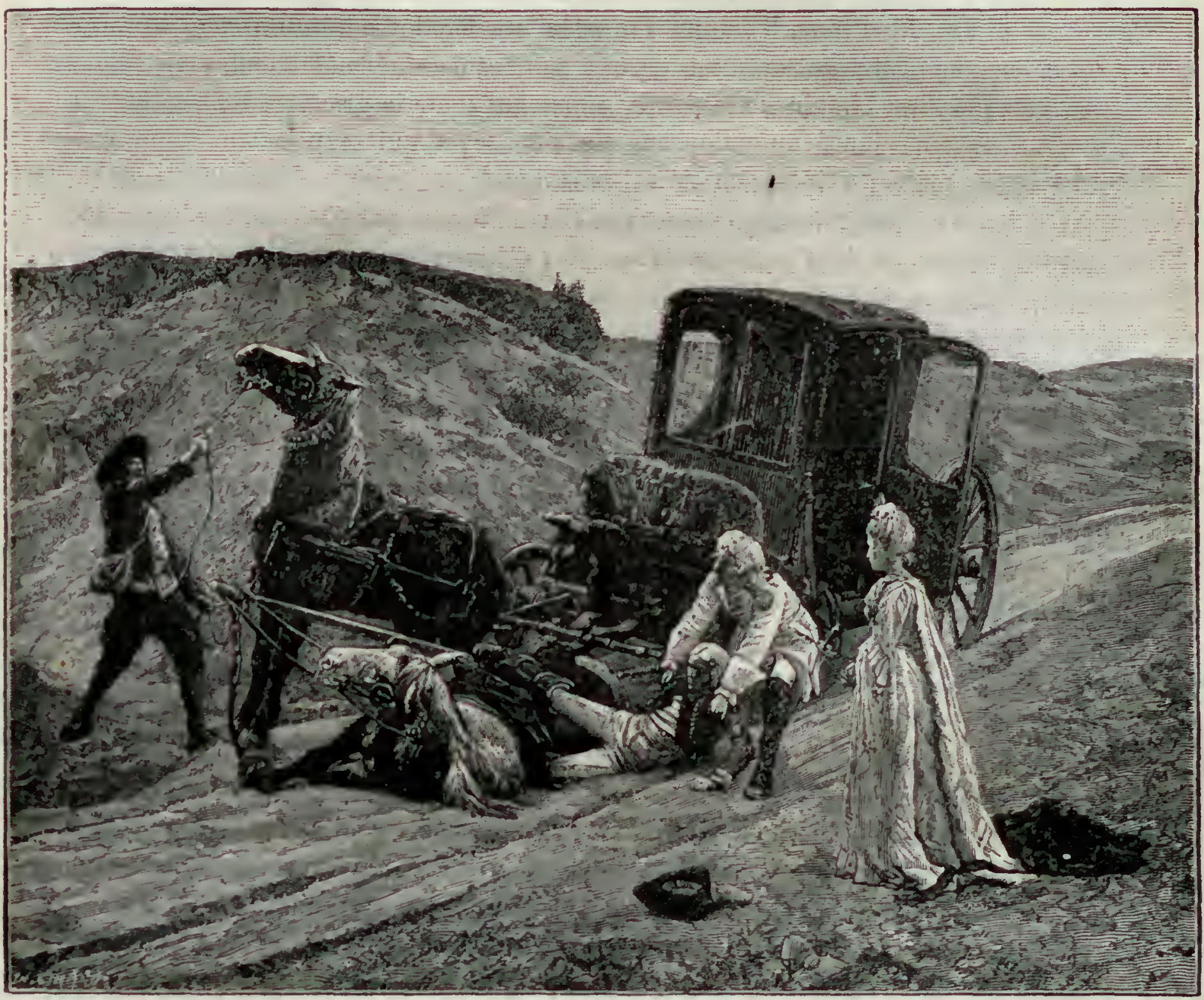

BEAUX-ARTS. - Parlie manqué, par Jules Girardet.

l'Écanouissement, l'Arrivée de la diligence, le Triomphe de Marat après son acquittement.

Nous retrouvons maintenant un nom que nous avons eu l'occasion de rencontrer. Joseph Vernet eut un tils, Carle, qui fut célèbre dans l'histoire de la peinture (17581833̈). Il ne lui plut pas de peindre des marines et il ne resta que peu de temps dans l'atelier de son père. II vint à Rome, où il étudia particulièrement les peintres de bataille, comme Salvator llosa, et il peignit le Mutin d'A usterlitz, le Bombardement de Madrid, la Butaille de Rivoli, la Bataille de Marengo, etc. A Plus hardi que Van der Meulen, moins gêné par l'étiquette, dit L. Lagrange, c'est au cœur de l'action qu'il se plaçait, montrant aux spectateurs non plus seulement les disposilions générales des lignıes, mais le mouvement réel des troupes, le drame passionné auquel concourent les 
honmes et les chevaux, les généraux et les soldats. Ce cadre vivant était si bien approprié à ce qu'il fallait peindre que, malgré les efforts épiques de Gros, l'art n'a plus changé depuis, et tous les peintres de batailles modernes, à conmencer par Horace Vernet, n'ont pu faire mieux que de se conformer au programme tracé par la Bataille de Marengo. Afin de se rendre plus familier les différents personnages du drame, Carle étudiait dans des tableaux de moindre dimension les actions particulières qui forment comme le réseau de l'action générale. C'étaient des marches, des combats singuliers, des trains d'artillerie. La encore il inaugurait une peinture toute nouvelle, le genre militaire. Bien plus, il fut un des premiers à y introduire un élément qui y joue un grand rôle, l'élément oriental. Carle a peint et dessiné le Mameluk dans toutes les positions difficiles, témoin cette Sortie, popularisée par la gravure, où l'on voit le malheureux cavalier lancé au galop sur un pont-levis qui se brise; ou bien il le montre au repos, sous sa tente, son cheval près de lui; car le cheval arabe, devenu un type classique de l'art contemporain, c'est Carle Vernet qui l'a peint le premier, donnant ainsi le branle à ce mouvement qui devait entrainer vers l'Orient et son fils Horace, et Decamps, et Delacroix.

Marie-Louise-Élisabeth Vigée, femme du critique Lebrun et connue sous le nom de $M^{\text {me }}$ Vigée-Lebrun, naquit à Paris en 1750 dans l'atelier d'un peintre qui s était fait un nom en peignant des portraits au pastel et des tableaux dans le style de Watteau. Des l'âge de six ans, la petite fille crayonna sur les nurs de son pensionnat des têtes qui dénotaient un goût très vif, des dispositions exceptionnelles, et à onze ans, elle entra dans l'atelier du peintre Davesne, ami de son père. A treize ans, après avoir reçu les conseils de Vernet et des peintres les plus illustres du jour, elle exécuta un portrait de sa mère, qui eut à Paris le plus grand retentissement. Orpheline à quinze ans, elle travailla courageusement pour venir en aide a sa famille : le prix de ses premiers tableaux paya la pension de son frère dans l'une des bonnes institutions de Paris. - Pendant toute son enfance, dit un de ses contemporains, elle avait été laide de figure et faible de corps, à la grande désolation de sa mère; vers cette époque, 1770, elle prit insensiblement une si grande beauté que c'était merveille, et que tous les marquis et les seigneurs de la Cour voulaient être peints par elle afin de voir en face son gracieux visage et son gentil minois. "C'est alors que sa mère épousa un ancien joaillier, araı'e et brutal, qui s'emparait sans scrupule de tout l'argent que gagnait la jeune artiste. - Ce qui froissilit surtout le cœur de la pauvre enfant, remarque le contemporain anonyme déjà cité, c'était de voir le malotru se goberger dans les vêtements de M. Vigre sans le moindre respect pour le souvenir de sa femme et de sa belle-fille. " La fortune, cependant commençait à lui sourire. La duchesse d'Orléans, qui avait entendu vanter son talent et sa gentillesse, lui commanda son portrait et l'introduisit à la Cour. Malheureuse chez elle, tlle accepta sans enthousiasme la main de certain Lelorun, amalcur de tableaux, bien fait de sa personne, mais joueur et débauché. En moins de trois ans, il engloutit la somme d'un million que sa femme avait gagnée en peignant les portroits de toutes ies illustrations de la naissance, du talent et de la beauté. Bllo vivait quotidiennement dans le commerce des poètes, des arlistes, des grands seigneurs. Quatrevingt-neuf vint mettre un terme à ces réjouissances, dont on parlait un peu partont. $\mathbf{M}^{\mathrm{me}}$ Lebrun s'enfuit de Paris arec sa fille, vint en Italie et fut successivement nommée sociétaire de l'Académie de Saint-Luc, comme elle l'avait été de l'Académie de Paris en 1783 sur la présentation de Joseph Yernet. Elle parcourut ensuite l'Allemagne, la 
Russie où elle maria sa fille, et la Prusse, partout fètée, partout heureuse. Elle entra à l'Académie de Saint-Pétersbour's en 1800, et à l'Académie de Berlin en 1801. La même année, elle revint en France après une absence de douze ans, ayant déjà à son actif le nombre incroyable de six cent soixante-deux portraits. Dans les dernières années de si vie (elle mourut en 1842 ), elle réunissait autour d'elle, à Lucienne, près Marly, tous les débris de la vieille société. $M^{\text {me }}$ Vigée-Lebrun tient un rang très honorable dans la peinture de portraits : tout le monde a vu celui qu'elle a fait d'elle-même avec sa fille dans ses bras et qui est exposé au Louvre. Elle avait une parfaite intelligence du clair-obscur et savait jeter les draperies avec grace. Ses carnations sont toujours vraies, malgré leur variété. Les caractères ont une expression vive et franche, et l'ensemble a quelque chose de délicat, de tendre, sans être fade ou maniéré.

Voici encore un élève de David, Abel de Pujol (1785-1861), né à Valenciennes. Un pinceau facile, un faire large, un dessin correct et un bon choix de la forme, sans toutefois s'élever jusqu'à l'idéal; un coloris brillant et harmonieux; une bonne entente de l'ordonnance; enfin, la sage retenue d'un esprit judicieux, réglant à propos les élans trop vifs de l'imagination, sont les qualités distinctives que présentent les œuvres de cet habile et laboricux artiste. "A la mort de Gros, Abel de Pujol le remplaça à l'Académie (1835). Il fut le dernier élève de David, dans le sens étroit de ce mot élève, et en 186t, date de sa mort, on n'aurait peut-ètre trouvé aucun représentant du pur art classique.

Avec Delacroix, nous arrivons en pleine période romantique. Le classicisme, nous l'avons vu, était né du besoin de réagir contre les mièvreries du xvıu siècle. David fut le chef de cette réaction; il avait voulu chercher dans l'étude exclusive de l'art antique un joint de départ nouveau, mais il alla trop loin.

Le mal vint de l'excès du bien. A la vraie noblesse, les classiques substituèrent la froideur. Lapparition des Pestiférés de Jaffa fut le premier indice de la révolution dont devaient périr les classiques, et c'est à partir de l'exposition de cette belle œuvre que des jeunes gens, touchés de la couleur éblouissante et de la vérité si étudiée du tableau de Gros, songèrent a abandonner les héros classiques pour les passions vivantes, pour la réalité. Une fois David exilé, la réaction s'accentua peu à peu. Géricault exposa au Salon de 1819 son célèbre Radeau de la Méduse. ¿ Cette révolution, dit Delécluze, fut aussi subite et aussi complète que l'est dans un État le passage de la monarchie à un gouvernement populaire. "Il est de fait que les quarante ans de gloire dont s'enorgueillissait David furent, je ne dirai pas oubliés subitement, mais tournés en ridicule. Géricault mourut alors que la bataille entre romantiques et classiques était à peine engagée, et la nouvelle école se trouva privée de son chef avant de s'ètre organisée, d'avoir pris position. Heureusement, un nouveau maitre surgit, le peintre de la Barque du Dante.

Eugène Delacroix est né à Charenton Saint-Maurice, près de Paris, le 26 avril 1799. On raconte que sa roeation lui fut révélée un jour de sortie qu'il était allé, alors élève du lycée Louis-le-Grand, visiter le musée Napoléon, rempli des chefs-d'œuvre artistiques pris en Italie et en Hollande. Il entra à dix-huit ans dans l'atelier de Guérin, qui le trouva trop indépendant et ne daigna pas s'occuper de lui, mais Géricault, dont il fit la cunnaissance, lui confia l'exécution d'un tableau qui lui avait été commandé. En 1822. il exposa sa prenière toile, Dante et Virgile, plus connue sous le nom de Barque du Dante, que nous avons appréciée plus haut. M. Thiers, l'homme politique, qui 



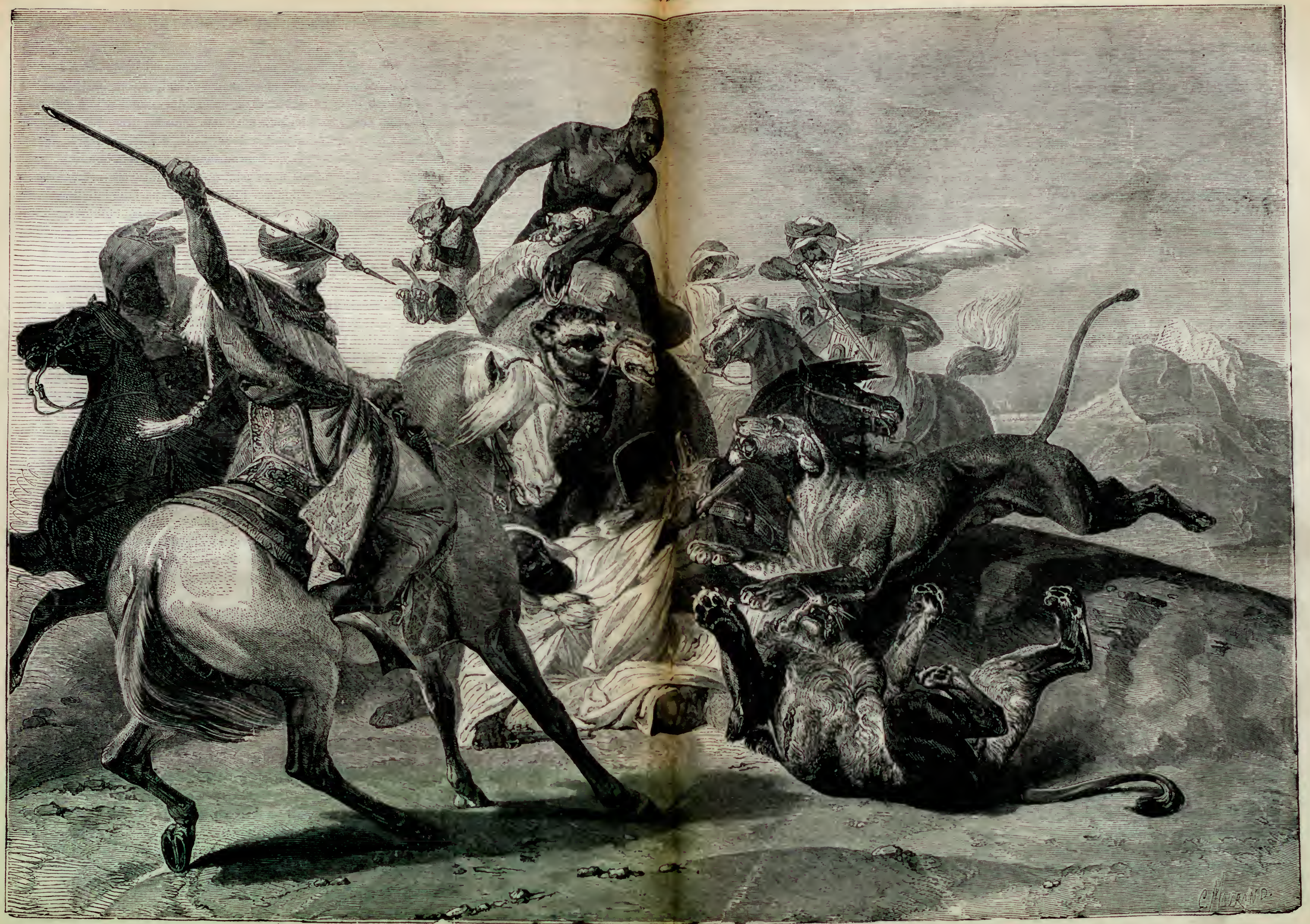


faisait à ce moment le Salon dans le journal le Constitutionnel, ne craignit pas de se mettre en contradiction avec les classiques : "Je ne crois pas m'y tromper, écrivait-il, M. Delacroix a reçu le génie. Qu'il avance avec assurance, qu'il se livre aux immenses travaux, condition indispensable du talent; et ce qui doit lui donner plus de confiance encore, c'est que l'opinion que j'exprime ici sur son compte est celle de l'un des grands maitres de l'école. Ce grand maitre, c'était Gérard. Mais si l'influence de Géricault apparaissait avec évidence dans l'œuvre de début de Delacroix, l'artiste se montra original et personnel dans le Massacre de Scio, exposé en 1824. Les classiques rugirent. Ils reprochèrent à Delacroix de rechercher particulièrement les sujets bizarres, d'etre - trop voisin du bas et de l'ignoble o, tout en reconnaissant dans son cuvre de la verve, de la chaleur, une composition originale, une exécution profondément caractérisée. Du côté des jeunes artistes, las des poncifs académiques, ce fut un tout autre concert; on ne trouva pas d'épithètes assez louangeuses. La querelle s'envenima tout à fait au Salon de 1827. Les uns traitèrent Delicroix d'ambitieux sectaire, et ses œurres d'ébauches grossières admises par le jury avec une funeste complaisance; d'autres, moins possédés de l'esprit de parti, reconnurent que Delacroix avait de l'originalití, de la fougue, de l'imagination, de la puissance, un coloris chaleureux et énergique, un je ne sais quoi de saisissant et de troublant.

Les événements de 1830 , bien faits pour réjouir un peintre qui avait failli être poursuivi en 1822 comme conspirateur, furent favorables au mouvement romantique. Delacroix peignit pour le gouvernement la Liberté sur les barricades, qu'il exposa au Salon de 1831, en mème temps que l'Assassinat de l'écéque de Liège, le Cardinal de Richelieu, Cromwell à Windsor, Raphaël dans son atelier, un Indien, une étude de Tigres. Jusque-là, on avait particulièrement reproché à Delacroix de ne pas apporter assez de conscience et de sincérité dans l'exécution de sa peinture. Sa Liberlé sur les barricades donnait à la critique, sur ce point spécial, un éclatant démenti, mais le jury ne trouva pas la toile suffisamment académique el ne la récumpensa pas. 11 est vrai que le gouvernement donna à l'auteur la croix de la Légion d'honneur.

Delacroix ne visita jamais l'Italie, mais le Maroc fut pour lui l'occasion de magnifiques études qu'il traduisit plus tard, dans des œuvres d'une resplendissante coloration. Il exposa aux Salons de 1833, 1834 et 1833: Charles-Quint à Saint-Just, les Femmes d'Alger, la Bataille de Nancy, la Rue de Méquinez, l'Intéricur d'un courent, le Christ en Croix, le Prisonnier de Chilon, les Nalchez, les Arabes dOran, et Alexandre Decanjus, le frère du peintre, disait à ce sujet: Il y a un artiste qui embrasse a lui seul, avec la variété et la fécondité du génie, tout le domaine des arts; aucune époque ne lni parant trop vieille ou trop jeune; aucune poésie ne lui est étrangère; aucun peuple, ancun costume n'est à ses yeux indigne de l'art. Doué d'une imagination passionnée, pleine de chaleur et de sentiment, il est frappé vivement par toutes les impressions qu'il regoit, et c'est toujours une émotion qu'il produit en exprimant ses impressions sur la toile. II n'a aucun système exclusif, il s'identific avec tous les temps, avcc tontes les croyances, il comprend toutes les poésies, parce que sa croyance it lui, sa poésie, sont celles de son art qui peut embrasser toutes les autres. Quand il traduit par la peinlure une persée religieuse ou poétique ou un fait historique, c'est loujours dans l'intelligence de l'époque ou dans l'inspiration du poète qu'il a puisé les véritables éléments de son cuvre. Quant à la manière d'exprimer, quant ì la forme ou d̀ l'effet qu'il adopte, il ne s'en rapporte qu'à son propre sentiment; il n'y a en lui ni recherche ni étude de tel ou 
tel maitre, ni concession à telle exigence ou telle opinion de ses contemporains; son ouvre est la sienne en propre, tout entière, tout originale, toute personnelle; qu'il se trompe ou qu'on lui donne raison, il est toujours lui-mème. Le jury continuait de lui donner tort : il acceptait le Saint-Sébastien, mais il refusait une Scène d'Ilamlet au Salon de 1836.

Thiers, qui avait été l'un des premiers à comprendre et à féliciter l'artiste, le vengea du jury en le faisant charger la mème année de peindre le Salon du Roi à la Chambre des Députés, et Delacroix prouva nettement qu'il savait, lorsqu'il le fallait, mèler à l’imagination la plus sobre sévérité. Sa peinture décorative est large, puissante et les sujets allégoriques sont choisis avec une grande distinction.

Tout en travaillant au Salon du Roi, il prétendait ne pas renoncer aux Expositions annuelles. Il exécuta donc sa remarquable Bataille de Taillebourg, une Médée, les Convulsionnaires de Tanger, le Caïl marocain, un Intérieur de cour, la Dernière scène de Don Juan, une Cléopatre, Hamlet et ses fossoyeurs, la Justice de Trajun, la Prise de Constantinople par les Croisés, la Noce juive dans le Maroc, un Christ en croix, des Exercices militaires au Maroc, des Naufragés abandonnés, et tant d'autres toiles non moins brillantes, où il se maintenail toujours à la hauteur de son génie, traitant toutes les époques de l'histoire, allant de l'Europe à l’Orient et de l'antiquité au moyen àge, ne restant élranger à aucun genre : religion, poésie, politique, allégorie, vie intime et familière. Dans la Bibliothèque de la Chambre des Députés, il peignit deux toiles superbes, deux allégories relatives à l'origine et à la ruine de la civilisation : Orphée enscignant aur Grecs les arts de la paix, et Attila foulant aux pieds de son cheral l'Ilalie conquise ct ses monuments. Rien de plus saisissant que ce contraste entre la trancjuillité de la première scène et la violence de la seconde. Le gouvernement de 1848 lui confia la décoration du plafond de la galerie d'Apollon, au Louvre, et il y représenta A pollon vainqueur du serpent Pithon, restant original et inventif méme dans ces scènes inythologiques incurablement ennuyeuses a force d'aroir été reproduites. Delacroix, qui n'avait pu encore rallier tous les sufrrages, résolut de frapper les regards (le tous par la vue de son œuvre complète, ou du moins de la plus grande partie de son ceuvre. A l'lixposition universelle de 183̈3̈, il réunit une quarantaine de tableaux, depuis la Barque du Dante jusqu'à sa Chasse au lion; comme Ingres, il eut du jury une grande médaille et le gouvernement le nomma commandeur de la Légion l'honneur. Edmond About. toujours spirituel, répondait aux critiques de quelques irréconciliables. - rarinantes : Il est bicn vrai que M. Delacroix ne dessine pas aussi correctement que M. Flandrin ou M. Lehmann et qu'il ne reinporterait pas même un accessit dans la classe de M. Ingres. Il serait placé dans les dix derniers avec Rubens et quelques autres artistes immortels qui ne dessinaient pas mieux que lui. Il le sait et il s'en console. Il est également certain que M. Delacroix possède une couleur inimitable et qu'il manie la lumière comme s'il avait passé un marché avec le soleil. Mais ce n'est pas cela qu il faut louer en lui. M. Delacroix est plus qu'un peintre, c'est un créateur. Il est celui qui donne la vie. Soll génie consiste à prèter un corps aux récits de l'histoire et aux fietions de la poésie. Je vous défie. après que vous aurez regardé ses œuvres, de concevoir un autre Hanlet, une autre Marguerite, un autre Dante et d'autres Foscari que ceux de Delacroix. Relisez Shakespeare, Gothe, Byron, la Ditine Comédie : toutes les images qui s'agitaient naguère, confuses et incolores dans votre esprit, prendront un corps déterniné par Delacroix, une couleur déterminée par Delacroix. Ce génie 
impérieux qui ne vous a point séduit, qui vous a presque effrayé au premier coup d'œil, vous impose le joug. Notez bien, s'il vous plait, que Delacroix n'est ni le peintre d'une époque, ce qui serait une faiblesse, ni l'interprète d'un poète, ce qui serait une infériorité : tous les temps sont de son domaine, tous les pays relèvent de son talent, tous les poètes ont passé par ses mains, et il parcourt en moissonneur le vaste champ de l'imagination. Une fécondité incroyable, une conception rapide, une exécution fou-

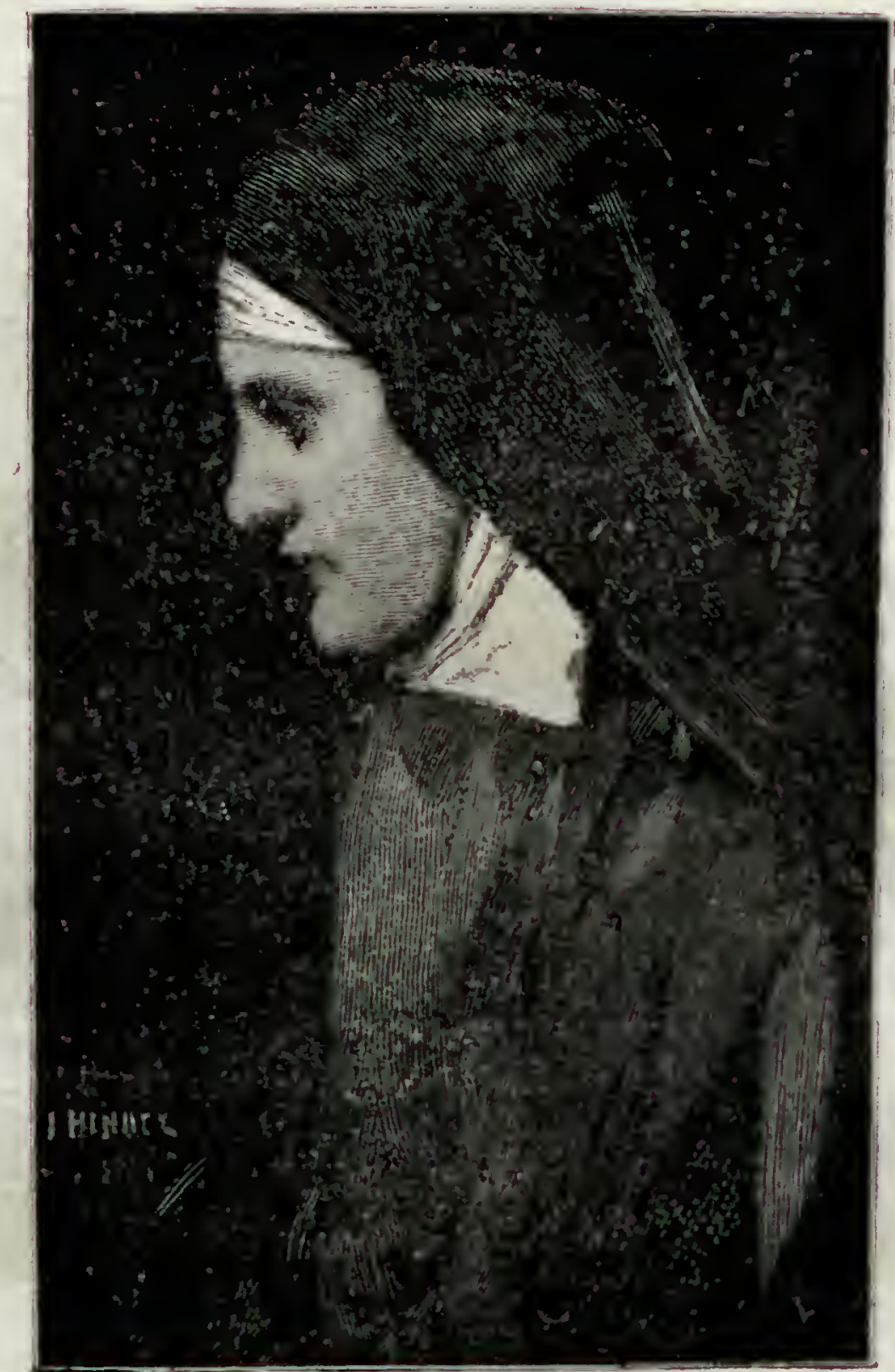

BEAUX-ARTs. - La Religieuse, par Henner.

droyante, un travail obstiné qui ne s'attarde ni à discuter la critique ni à savourer le succès, lui ont permis de produire une cuvre immense sans vieillir ni s'épuiser. ,

L'entrée de Delacroix à l'Académie des Beaux-Arts (18\%̄i) porta à son comble le triomphe d'un artiste que l'on arait jusqu'alors considéré sous la coupole de l'Institut comme un réfractaire. Et ce qu'il y a d'almirable, c'est que Helacruix ne cessa point de produire jusqu'd la fin de ses jours. Vous vous rappelez, dans l'oécure d'Émile Zola, ce type si étudié de Bongrand, le peintre qui, sur le déclin de sa vie, doutait de lui-même et de son talent; il veut en avoir le cœur net, savoir ce qu'on pense de lui dans le public qui a acclamé jadis sa première toile. Jusque-lí, la peur de sa déchéance l'a dévoré, mais ce n'était qu'un doute; il expose, et alors, devant l'indiffé. 
succès, Ingुres ne put aller en Italie. Épuisé par les guerres continuelles, le budget de la France ne pouvait suffire aux dépenses de l'École de Rome. L'artiste dut rester cinq années à Paris, vivant péniblement de dessins et d'illustrations de livres. Il occupait une des cellules de l'ancien couvent des Capucins, ou plusieurs peintres et sculpterrs s'étaient réfugiés. Il s'adonna à l'étude des antiques du Louvre et des estampes de la Bibliothèque, et un goùt prononcé pour les maitres du xvie siècle se développa en lui. Durant ces cinq années, Ingres exécuta le portrait en pied du Premier Consul, celıi de Napoléon en costume impérial, un tahleau allégorique, Napoléon passant le pont de Kehl, une esquisse peinte, Vémus blessée par Diomède; les portraits du sculpteur florentin Bartoloni, de M. Ingres père, de M. Gélibert, de Montauban; son propre portrait; un dessin représentant la famille Forestié, et une composition au crayon, Philémon et Baucis. Le peintre put enfin partir pour Rome où il resta jusqu'en 1820 , et étudia spécialement les œuvres de Raphaël, auquel il voua un véritable culte. A Rome, Incres peignit OEdipe et le Sphinx, la Buigneuse, Jupiter et Thétis, Raphaël et la Fornarina, Romulus vainqueur d'Acron, grande composition à la détrempe, pour la galerie de Monte-Cavallo; le Songe d'Ossian, pour le plafond de la chambre à couclier de Napoléon dans ce palais romain; Virgile lisant l'Enéide, Francoise de Rimini, la Chapelle Sixtine, l'A rétin, Arétin chez Tintoret, Don Pedro de Tolèle baisant l'épée de IJemri IV', Rnjihuël et le cardinal Bibiena, l'odalisque, commandée en 1813 par la reine de Naples: Philippe $V$ et le duc de Berwick, Henri $1 V$ et ses enfants. Ia Mort de Léonard de Vinci, Roger délirrant Angélique; vient ensuite Jésus-Christ remettant les clefs du ciel à suint Pierre, exécuté pour la Trinité-du-Ifont, à Rome. Malgré ce travail acharné. le peintre n'acquit pas de renommée. L'OEdipe et le Sphin.r, l'Odalisque et Thétis suppliant Jupiter, envoyés aux expositions de 1812 et 1819, furent peu appréciés. Moins encore que la renommée, la fortune souriait au courageux artiste et il dut subrenir aux besoins de son existence en peignant et en dessinant simplement à la mine de plomb une certaine quantité de portraits, parmi lesquels nous citerons ceux de la reine de Naples, de Mme Ingres mère, de Senones, de Vaujü, do Éšcot, de Marcotte, de M. de Pressigny et de M. de Norvins. Malgré ces cruelles déceptions. Ingres ne se découragea pas; il alla se fixer à Florence, où il produisit de 1820 à 1824 : Charles V faisant son entrée à Paris, une variante de la Chupelle Sixtine, et le Vau de Louis IIII. Ce dernier tableau, commandé par le gouvernement français, fut envoyé au salon de 1824, où il obtint un immense succès; deux ans plus tard, l'Apothéose d'Homère conquit tous les suffrages.

Ingres revint à Paris et y resta jusqu'en 1834; pendant ce laps de temps, il ourrit un atelier d'élèves et exécuta le Martyre de Saint-Symphoren et les portraits de Charles X, du marquis de Pastoret, du cardinal de Latil, de My. Galteaux, Hittnrf, Baillot, Bertin, du comte Molé. Puis il retourna à Rome avec le titre de directeur de notre Académie de peinture. Très occupé par les exigences de sa direction. Ingrea produisit peu pendant son nouveau séjour en Italie. Néanmoins il donna la Stratanice. un de ses meilleurs ouvrages, exécuté pour le compte lu duc d'Orléans; la lieryi is l'Hostie pour le prince Alexandre de Russie; l'Odalisque et son esclare et le purtiait allégorique de Chérubini. Dans cette dernière composition, le célebre compusiteur cot assis, le menton appuyé sur la main droite, le regard reveur. Derrière lui, une couronne de laurier a la main, la Muse de l'harmonie est debout. Ce tablcau est merveilleux; c'est un véritable chef-d'œurre; le rlessin est d'une allure magistrale qui fait 
oublier la couleur. Ingres revint à Paris en 1841. Presque tous les artistes présents dans la capitale: peintres, sculpteurs, graveurs, architectes, se réunirent pour faire une ovation au maître, et lui donnèrent une fète brillante. Le duc de Luynes l'appela d̀ celte époque au chateau de Dampierre où il commença dans une des galeries deux grandes peintures décoratives, l'Age d'Or et l'Age de fer ; il laissa ces deux ouvrages inachevés et ne les termina jamais. Depuis 1841, Ingres a donné : le portrait du duc dOrléans, celui de M ${ }^{m}$ d'Haussonville, les vingt-cinq cartons coloriés qui servirent de modèles aux vitraux de la chapelle de Saint-Ferdinand, à Sablonville, el de la chapelle de Dreux; les portraits de $\mathrm{M}^{\mathrm{m} \theta}$ la baronne de Rothschild, de la princesse de Broglie, de $M^{\text {mes }}$ Reiset et Moitessier; la Naissance de Vénus, entreprise à Rome en 1807, achevée en 1848; l'A pothéose de Napoléon I ${ }^{\mathrm{er}}$, pour le plafond de l'une des salles de l'Hòtel de Ville; Jeanne d'Arc au sacre de Charles VII, la Naissance des Muses, exécuté sur le postrium d'un modèle de temple grec imaginé par M. Hittorf; la Source, dont le succès a été immense. La mort surprit Ingres à son chevalet; il avait achevé pour le $1^{\text {er }}$ janvier $\mathbf{1 8 6 7}$ le portrait de sa filleule, M ${ }^{H_{0}}$ Hippolyte Flandrin, et pendant la semaine qui précéda pour lıi le dénouement fatal, il acheva l'ébauche d'une nouvelle Strutonice, et refit son Ossian. Il expira le 14 janvier.

Eugène Devéria (1803̆-1863̈) débuta dans les arts par une œuvre de génie, alors qu'il n'était à peine ágé que de vingt-deux ans. Ce chef-d'œuvre, la Naissance de IIenri IV, est malheureusement sa seule toile vraiment remarquable. La reine de Navarre, pâlie par les souffrances, est couchée tout habillée sur un lit d'apparat exhaussé de quelques marches. Henri d'Albret, un vieillard, présente le prince aux courtisans assemblés. Paul de Saint-Victor a porté sur le jeune artiste le jugement suivant: "Un jeune Véronèse semblait aussi naître à la France dans cette peinture harmonieuse et chaude, élégante et vive, où l'esprit des figures rehausse encore la pompe de la mise en scène et le chatoiement des costumes. Cette flamme de couleur s'éteignit presque subitement; ce talent, qui débutait par un coup d'éclat, se perdit dans l'obscurité. Il n'en reste que cette grande page, préface sans livre, prélude sans concert. ๖ En effet, comıne si ce chef-d'œuvre eut desséché l'imagination et la palette de l'artiste, les ouvages médiocres qu'il donna ensuite parurent d'autant plus ternes que le début avait été plus brillant. La chute fut terrible, et Devéria ne put s'en relever, malgré ses lutles énergiques et les encouragements de ses nombreux amis, de la presse et de la famille régnante.

Alexandre Gabriel Decamps (1803-1860) entra, après avoir achevé ses études, chez le père d'un de ses amis, M. Bouhot, où il reçut les premiers éléments de géométrie, d'architecture et de perspective. II n'y resta que peu de temps et entra dans ratelier d'Abel de Pujol. Il voyagea ensuite beaucoup en Suisse, dans le midi de la France, et visita l'Orient pour lequel il prit un goùt très vif et dont la plupart de ses toiles sont inspirées. Au Salon de 1827, il exposa, pour la première fois, une Chasse aux vannenux et un Soldat de la garde d'un vizir, qui furent bien accueilis par la critique. M. A. Jal les apprécie ainsi daus ses Ĺsquisses sur le Salon de 1897: . 1I. Decamps n'a fait que deux petits ouvrages, mais je les aime mieux que cent des plus grandes productions historiques, comme disent MM. tels et tels de leurs compositions, où l'his. toire, la nature et la raison sont trahis dans chaque figure. La Chasse aux vanneaux et le Soldat de la garde d'un rizir sont des morceaux remarquables par le ton local, la franchise et la finesse de la touche. Vers la fin de la Restauration, Decamps visita la 



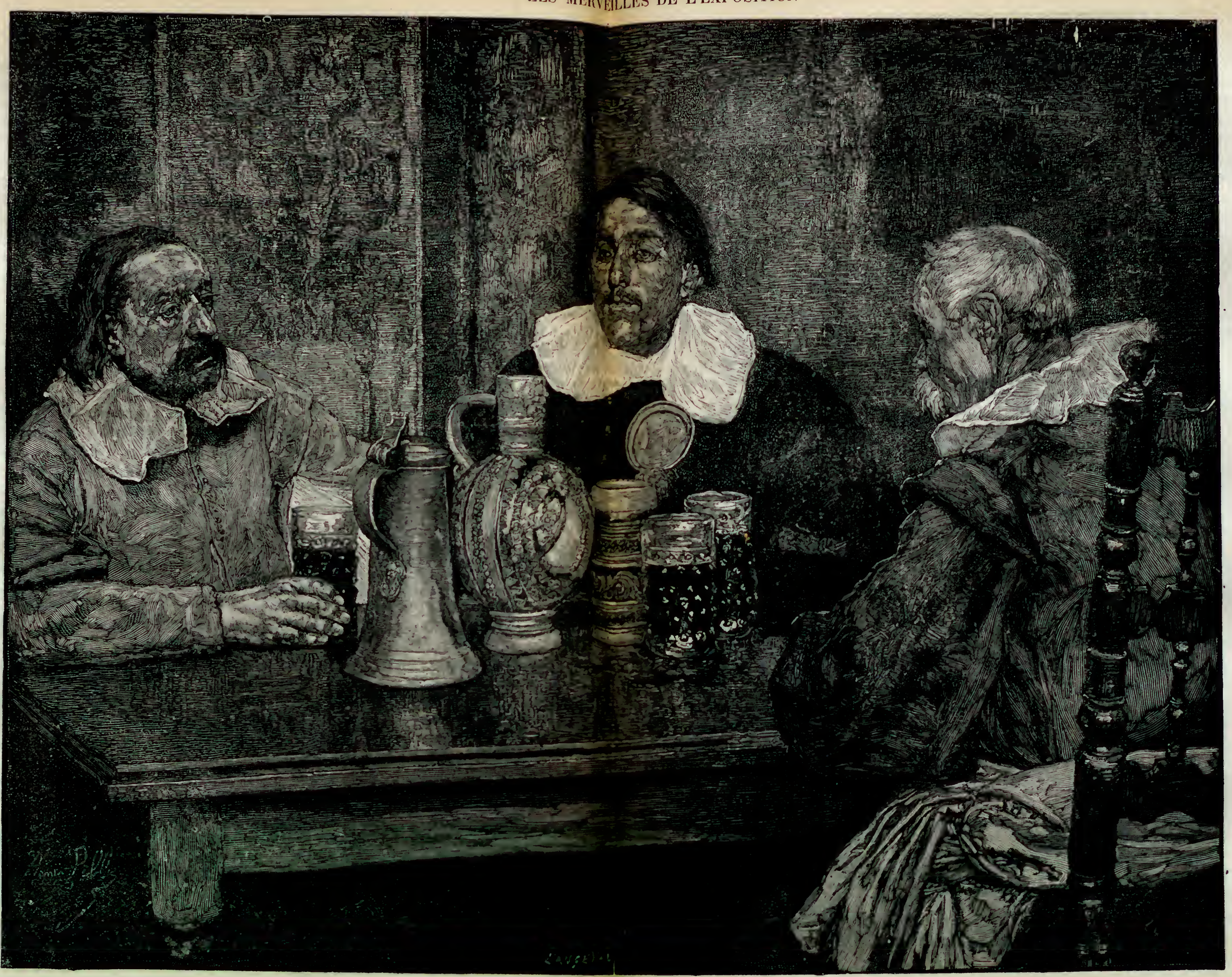

BEAUX-ARTs. - Trois Ciruches, tableau de H. Pille. 
Grèce et les côtes de l'Asie Mineure d'où il rapporta des vues et des scènes d'une réalité saisissante qui surprirent et charmèrent le public. En 1831, il exposa la Maison turque, et la Patrouille turque ou Ronde de Smyrne, à propos desquelles Gustave Planche a dit : "N. Decamps est un grand artiste, qui ne fait suite à personne, à qui personne ne pourra faire suite, qui ne se rattache ni aux Flamands, ni aux Anglais, aussi loin de Wilkie et d'Allan que de Terburg et de Metzu. Explique qui voudra ce talent original, tellement original, tellement lui qu'il ne pourra mème pas fonder d'école. Il aura des singes, mais pas un élève. Il donna également une Halte d'animaux et Une Caravane. Ce dernier tableau, qui n'est qu'une esquisse, est superbe d'éclat et de vérité. Dans le mème temps, Decamps collaborait au journal la Caricature, où son crayon composa un grand nombre de pièces satiriques contre le gouvernement de la liestauration. Ces fantaisies contribuèrent à attirer l'attention sur les œuvres sérieuses de l'artiste.

Voici comment Paul de Saint-Victor a apprécié le sympathique artiste : Decamps, a-t-il dit, est en art un panthéiste de l'école de Goethe. L'homme et le mur auquel il s'adosse, l'enfant et la tortue avec laquelle il joue, le pacha et le narguilé qu'il fume, le chameau et le chamelier sont égaux devant son pinceau; il les peint arec le même luxe et le même détail. Son dessin a généralement horreur de l'action; il se complâtt dans l'immobilité des physionomies et des poses. La couleur a l'éclat de la mosaĩđue; il ne joue pas avec la lumière comme d'un accompagnement idéal, il l'étale avec l'ostentation d'un prodigue, ou il obtient, en l'opposant aux ombres, des résukats qu'on dirait empruntés à des calculs de géométrie. 11 est midi, encore midi, et toujours midi dans son cuvre., Un autre critique de talent, M. Thoré a aussi très favorablement accueilli ses œuvres; voici ce qu'il en pense : Contrairement aux peintres organisés comme Ary Scheffer et qui tàtonnent l'expression de leur poésie, Decamps est un homme qui voit tout de suite ce qu'il veut faire et qui n'hésite point.' L'image lui saute aux yeux et glisse aussitót au bout de son pinceau pour s'étaler brulante sur la toile. C'est là certainement la nature de Decamps, quelles que soient ses ficelles d'exécution. Il est spontané, vivant, pittoresque, original ; il a l'instinct de la beauté, de la tournure et du mouvement; il a la passion de la lumière et de la riche couleur. Aussi quitte-t-il rarement le pays du soleil, et des campagnes éblouissantes, et des murs blancs, et des visages brunis, et des étoffes splendides... Nous qui demandons à l'art une valeur morale, nous déclarons yue les tableaux de Decamps nous ont toujours fait aimer les hommes et la nature. L'impression que le peintre lui-même a ressentie devant le monde extérieur est si vivement traduite dans l'effet et dans la tournure, que la nature nous apparaît avec toute sa poésie : il y a de quoi faire rèver et penser comme devant une belle figure vivante ou devant les splendeurs du paysage. ' La plupart des critiques d'art ont ainsi été favorables à Decamps, et parmi ceux qui l'ont le plus sévèrement jugé, pas un ne lui a refusé l'originalité qui a fait de tous ses ouvrages des pages inimitables et de lui le fondateur de la jeune école orientaliste, l'un des mailres du paysage moderne.

Prosper Marilhat (1811-1847) avait comme Decamps visité la Grèce, la Syrie, l'Égypte, et c'est seulement au retour de ce voyage en Orient qu'il commença a exposer. Lorsque l'on vit au Salon la Place de l'Esbékieh au Caire, cette toile étrange, d'une originalité naîve et violente, émut les artistes et le public. Marillat, d'abord élève de Roqueplan, n'eut pas de ces débuts brillants qui du premier coup mettenl en 
relief les littérateurs et les artistes vraiment doués. Il se sentait attiré vers l'Orient, et c'est avec joie qu'il y accompagna un riche seigneur étranger. Débarqué à Alexandrie, il ne peut retenir des cris de joie, des exclamations enthousiastes, al la vue de cette foule "si pittoresquement drapée, si sale et si brillante, si bariolée et si diverse s, des cahutes, "mamelonnant la plaine, comme autant de verrues ", des femmes, - fauves comme des statues de bronze, vêtues à pcine d'une chemise bleue 》, entrant dans ces tanières en courbant la tète on sortant avec un vase de terre et trainant quelque enfant nu. En Syrie, la nature est désolée, le pays aride, mais, écrit Marilhat, - qu'on se figure au milieu de cette désolation trois ou quatre mille chameaux blancs, roux et noirs, mangeant gravement les herbes sèches et dispersés dans la plaine, comme autant de petites taches; un camp de Bédouins, composé de vingt ou trente tentes noires, toutes noires, en poil de chameau, agglomérées sans ordre, quelques fernmes ayant pour tout vêttement une chemise bleue et une ceinture en cuir; puis près de vous, si vous voyez un homme poussant ses chèvres et ses moutons, c'est quelque chose de sec et de fier, couleur de pain bis, avec une chemise autrefois blanche, serrée d'une ceinture de cuir, recouverte d'un manteau en laine à trois larges raies bleues du haut en bas, la tête enveloppée d'un mouchoir de soie jaune et entourée d'une corde en poil de chameau .. On peut voir par ce court extrait que Marilhat n'est pas seulement un peintre et qu'il aurait pu devenir un écrivain de talent; il décrit à merveille, caractérisant d'un mot les hommes et les choses.

Decamps, lui aussi, étail un peintre orientaliste, mais l'un et l'autre, malgré leurs affinités, savent rester originaux. Decamps est meilleur coloriste, mais le dessin de Marilhat est plus élégant. Après la Place de l'Esbékieh, viennent le Tomberu du cheik Abou-Mandour, la Vallée des tombeaux ì Thèbes, le Jardin de la mosquée, les Ruines de Bulbeck, tous éclatants et puissants. Son chef-d'œuvre, exposé au Salon de 1844, c'est Sourenir des bords du Nil.

Ary Scheffer (1795-1858), ainsi que le remarque M. Alfred Rambaud, est très français par la perfection du goût, par la netteté de l'idée et du dessin, mais il tient de son origine hollandaise quelque chose de la rèverie du Nord. Ses débuts datent de l'époque féconde qui vit éclore en mème temps les Delacroix, les Devéria, les Decamps, tous ces peintres en un mot qui revendiquèrent la souveraine liberté de l'art. La guerre que soutenaient les Grecs pour reconquérir sur le Turc leur indépendance attirait alors les regards anxieux de l'Europe. Scheffer chercha dans la terre traditionnelle de l'art les éléments de son tableau les Femmes souliotes (1827), qui avaient été précédées de la Mort de Gaston de Foix et des Bourgeois de Culnis. Dans les Femmes souliotes, on admira la fougue du coloris, la netteté du sentiment et, pour tout dire, l'inspiration, qui est, selon le mot de Balzac, l'occasion du génie. Il subissait l'influence de lord Byron, de Gœthe, des poètes de l'dllemagne qui donnaient l'élan au mouvement romantique. 11 ne prenait pas directement la nature pour modèle, mais il cherchait à rendre sur la toile les impressions de ses lectures. Sous l'influence des poètes, il peignit la Marguerite de Faust, vaporeuse et idéale, une forme de femme plutôt qu'une femme, . l'ombre d'une ombre '; il donna le Roi de Thulé, Eberhart le larmoyeur. Un peu plus tard, l'étude des chefs-d'œurre d'Ingres lui donna le désir d'une plus grande correction de dessin, d'une plus granle netleté de contours; mais ce n'est pas quand un artiste arrive au sommet de sa carrière qu'il pent revenir sur ses pas, reprendre le rudiment, cesser d'ètre lui-mème. Ary Scheffer, en voulant perfectionner sa manière, n'aboutit qu'à 
perdre une partie de son originalité. Dans Francesca et Paolo, le modelé est à peine suffisant. La Mignon de Scheffer n'est pas celle de la tradition: elle est idéalisée, spiritualisée outre mesure. Ary Scheffer est un a romantique de la littérature plutôt que de la peinture ", un " poète transposé ». Celui qui n'étudierait ses œuvres que sur les gravures verrait en lui un artiste impeccable, car les gravures traduisent surtout l'idée d'un tableau, et dans les toiles de Scheffer il ne faut chercher que l'idée. Étrange et merveilleux artiste, à tout prendre! Certes, si nous avions une édition de Goethe ou de Byron illustrée par lui, nous serions probablement en possession d'une œuvre unique, car nous ne voyons guère que Gustave Doré pour avoir pénétré comme lui dans la conception des ourres littéraires, pour avoir fait vivre les personnages nés de l'imagrination d'un auteur.

Roqueplan (1802-1853), l'élève d'Abel de Pujol et de Gros, n'emprunta rien ì leur manière et conserva des idées originales. Il se garda également des exagérations de la nouvelle école romantique, resta gracieux et charmant alors que les autres faisaient souvent disgracieux en voulant faire imposant. Il débuta au Salon de 182. avec un Soleil couchant et un Roulier dans une écurie; en 1827, il exposa la Marée l'énuinore et la Mort de l'espion Morris, drame poignant, dont loutes les figures sont merveilleu. sement étudiées On le retrouve au Salon de 1833 a vec un Épisode de la vie le J.-J. Rousseau, un Moulin à eau, la Promenade dans le parc. Au Salon de 1834, l'A uliquare olutint un succès universel et contribua puissamment à établir la réputation du peintre. Le Lion amoureux rappelle, par son exécution, la manière de Prud'hon et du Corrège. Roqueplan donna successivement la Bataille dElchingen (1837), Van Ilyck it Londres, les Deux petites scurs, les Plaisirs du soir (1838). A celte époque, Roqueplan, très sonffrant, alla redemander au Midi un peu de forces. II reparut au Salon de 18.17 avec les Paysans de la vallée d'Ossau, Espagnols des environs de Penticosa, Paysage. En 18:i(), il exposa Léda, Jeune fille portant des fleurs; en 183̈2, la Fontaine du Grand-Figuier, d'un coloris chaud et vibrant. En 1830 , il donna sa derniere cuvre, les filles ditre. Roqueplan fut un peintre de genre et excella dans son art; ses toiles réjouisseut l'esprit et charment les yeux. Théophile Gautier a porté sur lui ce jugement bien mérité - Aux premiers moments de sa fureur contre le poussif classique, la jeune école seın. blait avoir adopté la théorie d'art des sorcières de Macbeth sur la bruyère de Dunsinane: " Le beau est horrible, l'horrible est beau. 'Roqueplan ne prononça pas la formule sacramentelle et resta fidèle à la gràce, dont le romantisme, à ses débuts, fit peut-être trop bon marché. Quand tous voulaient être formidables, gigantesques et p rodigieux, il se contenta d'ètre charmant. Là fut son originalité; du reste, il se monii a, autant que personne, nouveau, inattendu, plein de hardiesse. ,

Louis Boulanger (1806-1868), débuta dans la carrière artistique pal un tableau remarquable, son chef-d'œuvre, exposé au Salon de 1827. Mazepla plaça immédiatement l'artiste au premier rang des peintres de l'école romantique. De vigoureux Tartares attachent Mazeppa sur le dos d'un cheval indompté qui se cabre. Le inari offensé assiste inexorable aux préparatifs de l'expiation atruce qu'il a commandée. Au loin, le château féodal se détache en noir sur un ciel chargé de nuaçes. "Cétait, dit Théophile Gautier, une peinture fougueuse, pleine de fierté, d'une couleur superise. d'un maniement de brosse très habile qui cherehait Rubens et Titien, et dont l'aspect éblouissaii les yeux habitués aux palcur's de l'école classique. , Cette ourre enthonsiasma la critique, et Victor Hugo prit l'artiste en amitié et lui dédia quelques-unes de 
ses plus belles poésies. Boulanger ne donna jamais aussi bien que ce morceau superbe et l'Assassinat de Louis d'Orléans par le duc de Bourgogne (1833), le Cantique de Judith (1853) sont loin d'approcher de cette merveille de coloris. Le T'riomphe de Pétrarque et les Trois amours poétiques rappellent la facture de Mazeppa par la couleur et la composition. Boulanger donna successivement : les Bergers de Virgile et les Baigneuses (1845), la Douleur d'Hécube, Ugolin et ses fils (1855), le Roi Lear et son fou (1858), Saint Jéróme et les Romains fugitifs (1855), Roméo achetant du poison (1857), Othello, Macbeth (1859), la Réverie de Velléda (1861), Concert picaresque, etc. Il composa en outre un certain nombre de peintures religieuses et de portraits. En 1860, Boulanger

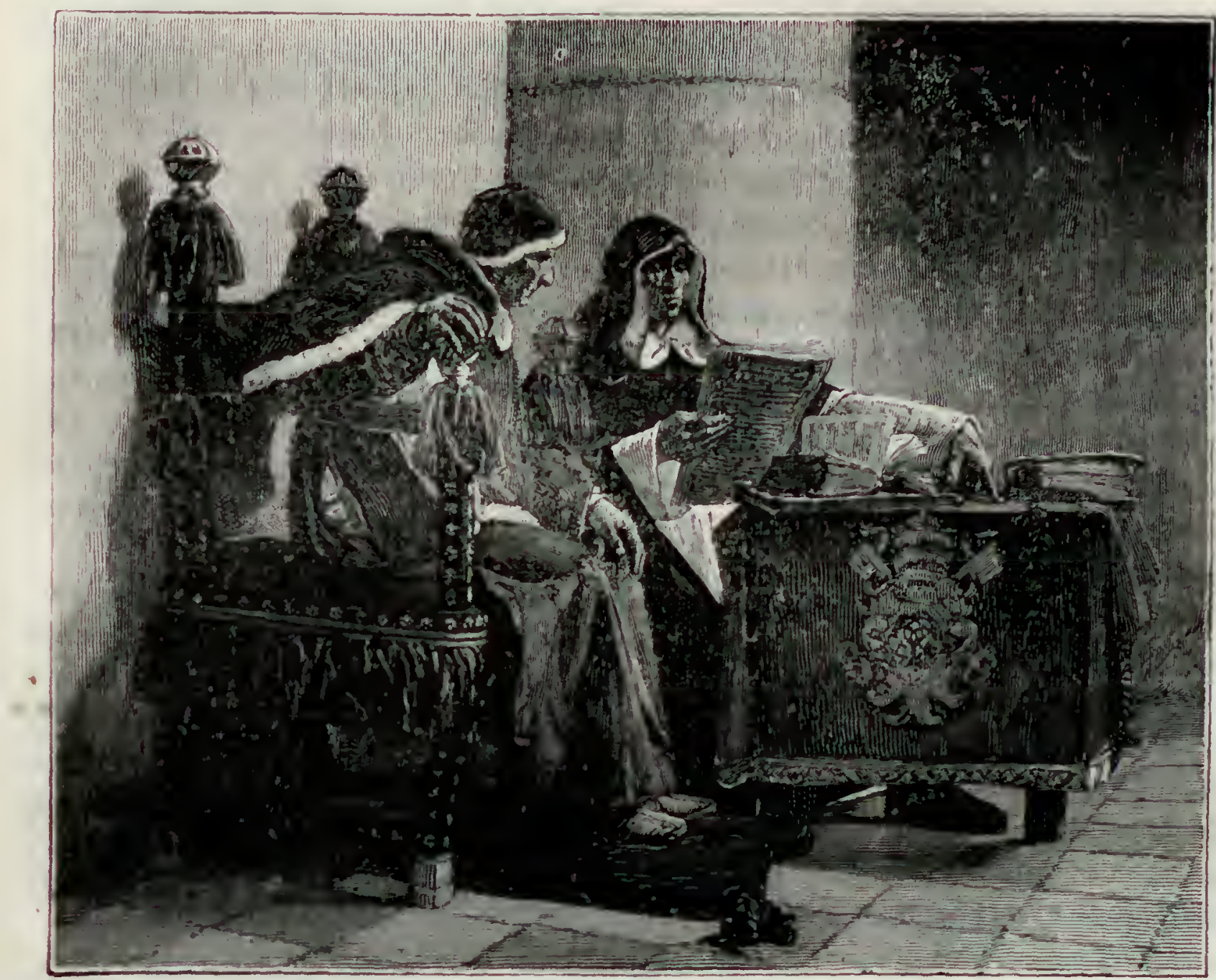

BeAUX-ARts. - Le Pape et l'Inquisilcur, par J.P. Laurens.

$(c$

fut nommé directeur de l'école des Beaux-Arts de Dijon, et mourut à peu près oublié après avoir excité à ses débuts l'enthousiasme de la critique et du public.

Xavier Sigalon (1788-1837), fils d'un pauvre maitre d'école, fit ses études à l'école de dessin de Nimes et reçut ensuite des lę̧ons de Monrose. Après avoir peint en province quelques tableaux religieux, il vint à Paris (1817), entra et resta quelque temps dans l'atelier de Guérin et exposa successivement: la Jeune Courtisane, Locuste essayant des poisons, Athalie faisant massacrer les enfants du sang royal, et, beaucoup plus tard, une magistrale copie du Jugement dernier. A côté de défauts que la critique signala avec quelque dureté, Sigalon a révélé dans ses toiles un tempérament plein de vigueur et d'audace, épris du grand et puissamment original.

llippolyte Flandrin (1809-1864) ، s'est toujours tenu dans la plus haute sphère de Ls. 40.

MxrysuLes Exposition. 
l'art, dit Théophile Gautier, et c'est sur les murailles des églises qu'il faut chercher les témoignages de son génie. Il était digne d'ailleurs d'a voir le sanctuaire pour atelier, car jamais talent plus pur, plus chaste, plus élevé, ne fut mis au service d'une inspiration plus religieuse. Disciple bien-aimé et fervent d'un maltre austère devant lequel il se tint toujours dans la modestie d'un éleve, quoique depuis bien des années la gloire lui fùt venue, il a, fort de ses savantes leçons, tendu vers l'idéal d'un effor't qui nes'est jamais lassé. Ce n'était pas assez pour lui de chercher le beau, il cherchait le saint, et la forme humaine épurée sans cesse lui servait à rendre l'idée divine. Il arait, dans sa nature, quelque chose de cette timidité tendre, de cette délicatesse virginale el de celte immatérialité séraphique de Fra Beato Angelico; mais sa naîveté de sentiment pouvait s'aider d'une science profonde. Chrétien d'une piété convaincue et pratique, il apportail à la peinture religieuse un élément bien rare aujourd'hui, la Foi. Il croyait sillcèrement à ce qu'il peignait, et n’avait pas besoin de se mettre l'esprit dans la situation voulue par un entraînement factice; c'était son élément, son air respirable; il y voguait d'une aile accoutumée et confiante. Aussi nul peintre moderne ne s'est plus approché des vieux maitres sans imitation archaïque . Hippolyte Flandrin a été l'élève favori d'Ingres, et, de bonne heure, son gout pour la peinture religieuse se révéla. On a de lui, entre autres morceaux : Saint-Clair guérissant les aveugles, Jésus appelant à lui les petits enfunts, Mater dolorosa, Jeune homme assis au bord de la mer, Euripide écrivant se's tragédies, Dante dans le cercle des entieux, et un certain nombre de portraits. Mais un des plus sérieux titres de gloire de Flandrin est la série de chefs-d œuvre qu'il a exécutés comme peintures murales, particulièrement dans les églises de Saint-Vincenl-de-Paul et de Saint-Germain-des-Prés.

Pour rendre complet le tableau artistique de la France depuis David jusqua'a la fin de la période romantique, il faudrait étudier les œuvres d'un certain nombre d'autres peintres dont nous ne ferons que citer ces noms : Léopold Robert (1794-1835); Cranet (1775-1849); Picot (1786-1868); Léon Cogniet (1794-1880 '); Horace Vernet (1789-1863), le peintre de batailles de la monarchie de Juillet "; Alfred Johannot; Couture, l'auteur des Romains de la décadence; Oudin, le peintre de marine; Karl Girardet; Philippoteaux; Joseph-Robert Fleury, l'auteur du Collogue de Poissy, de la Saint-Burthélemy, du Pillage d'une Juiterie, de Charles-Quint au coutent de Yuste; Amaury-Duval; Brascassat, etc.

Sous le second Empire, la peinture d'histoire prit un essor remarquable. Horace Vernet peint la bataille de l'Alma, Philippoteaux la charge de Balaklava et le siege de Puébla, Pils les batailles de la Crimée, Félix Barrias le débarqueınent en Crimée, Yron la prise de Malakof, Solférino et Magenta, Protais la bataille d'Inkermann, la prise du Mamelon Vert et tant d'autres. A coté de ces peintres de bataille, qui tiennent le premier rang, une belle place revient encore a Chenavard, à Muller, à Langée, a Boulanger, à Gérome, à Paul Baudry, à Giacomotti, à Tony-Robert-Fleury, à Ilamon, d̀ Isabey, à Meissonier, à Frère, à Fromentin, à Henri Regnault, à Cabanel, d Bouguereau. Le portrait a été cultivé, de notre temps, arec un véritable bonheur par Winterhalter, Cot, Hébert, Dubufe, Paul Baudry, Bonnat, Paul Dubois. Un trouvera sur ces artistes des détails précis dans l'. Histoire de la eivilisation contemporaine ,, de

1. Auteur de Marius sur les rubines de Carthage, du Massacre des Innocenls, du Tintorel peignant sa fille morte.

\&. Auleur de la Prise de la Smala d’Abd-el-haler. 
M. Alfred Rambaud, excellent ouvrage auquel nous emprunterons ce qui suit sur l'école réaliste et sur les impressionnistes : C C'est surtout, dit l'auteur, la vogue de MM. Cabanel et Bouguereau qui provoqua l'insurrection réaliste, comme la domination de l'école davidienne avait suscité la révolution romantique. Le chef du mouvement réaliste, ce fut Courbet (1819-1877), un peintre franc-comtois qu'on appelle le maitre d'Ornans, qui n'a pas eu de maître, mais qui a eu de nombreux disciples; un artiste qui s'est formé lui-mème et qui s'est trouvé, dès le début, en révolte contre toutes les écoles. C'était une nature de paysan fruste et madré et l'un des originaux du siècle. Il méprłsait également les classiques et les romantiques. A tous il reprochait de ne pas voir la nature telle qu'elle est ou telle qu'il la voyait. Des Vénus, des Nymphes, des Amours, cela n'existait pas : ce qui existe, ce sont des etres humains que leur laideur rend intéressants pour l'artiste, des paysans aux costumes fripés, aux bottes crottées; des paysannes vêtues de droguet, aux pieds nus et d'une propreté douteuse; de larges figures aux nez camard et rouge, aux poils hirsutes : voilà ce qu'il fallait reproduire, si l'on voulait être dans le vrai. Alors Courbet donna l'A près-dinée à Ornans, l'Enterrement a Ornans, les Paysans de Flagney revenant de la Foire, les Casseurs de pierres (1800), des Baigneuses qui ne ressemblaient pas du tout à celles de M. Bouguereau, des Lutteurs qui n'avaient rien de la nudité et de la beauté antique, le Retour d'une Conférence de curés (1863), l'Ilomme à la ceinture de cuir, etc. En mème temps, il peignait les admirables paysages du Doubs, avec une réalité saisissante, une puissance étrange de vision, des effets de neiges aveuglants, des verts d'une intensité étonnante. Courbet suscita parmi les peintres à aspirations idéales des colères semblables à celles qu'avait déchainées Delacroix parmi les peintres classiques. Si les critiques n'armaient pas sa main d'un a balai ivre ,, ils l'accusaient de peindre avec sa barbe, qu'il avait fort longue et touffue. A chaque Salon, les jurys de peintures refusaient obstinément ses tableaux d'insurgé. Alors il ouvrit une exposition particulière, où une foule accourut, les uns pour se moquer, les autres pour protester contre l'ignorance des jurés, contre l'incompétence de ces • fouetteurs de crème à la vanille ». A la suite de Courbet, il y ext, sinon une école, du moins une foule de peintres et même de rapins singulièrement plus mèlée que celle qui avait pris Delacroix pour porte-drapeau, les uns sincères et d'un talent novateur, les autres prétendant justifier par les hardiesses du inaître leurs propres témérités, les incohérences de leur dessin ou l'étrangeté de leur coloris.

Les choses allèrent si loin que le jury, pour se justifier, et le gouvernement, pour donner une satisfaction à l'opinion, se décidèrent à ouvrir un Salon des refusés (1863). Ce second Salon fut aussi couru du public que celui des reçus. On y vit des toiles épouvantables, devant lesquelles tout Paris s'esclaffa de rire; mais on en vit d'autres qui firent réfléchir même les maîtres, des tableaux de genre et de scènes familières d'une vérité frappante et d'une âpre poésie dans leur vulgarité. L'école réaliste eut donc son influence salutaire sur les écoles établies, les rappelant à plus de vérité et de sincérité, et, quand ses meilleures toiles eurent désarmé les rigueurs du jury et eurent été admises aux honneurs officiels, elle renonça aux exagérations de la première heure.

Au Salon des refusés s'était révélée une section de l'école réaliste, qui est restée intransigeante : l'école impressionniste. Elle eut pour chef Manet (1833-1880). La théorie impressionniste consiste à soutenir que la réalité agit sur notre appareil visuel, non par des formes, mais par des couleurs. Ce qui impressionne notre rétine, ce sont, 

LES MERVEILLES DE L'EXPOSITIU.V

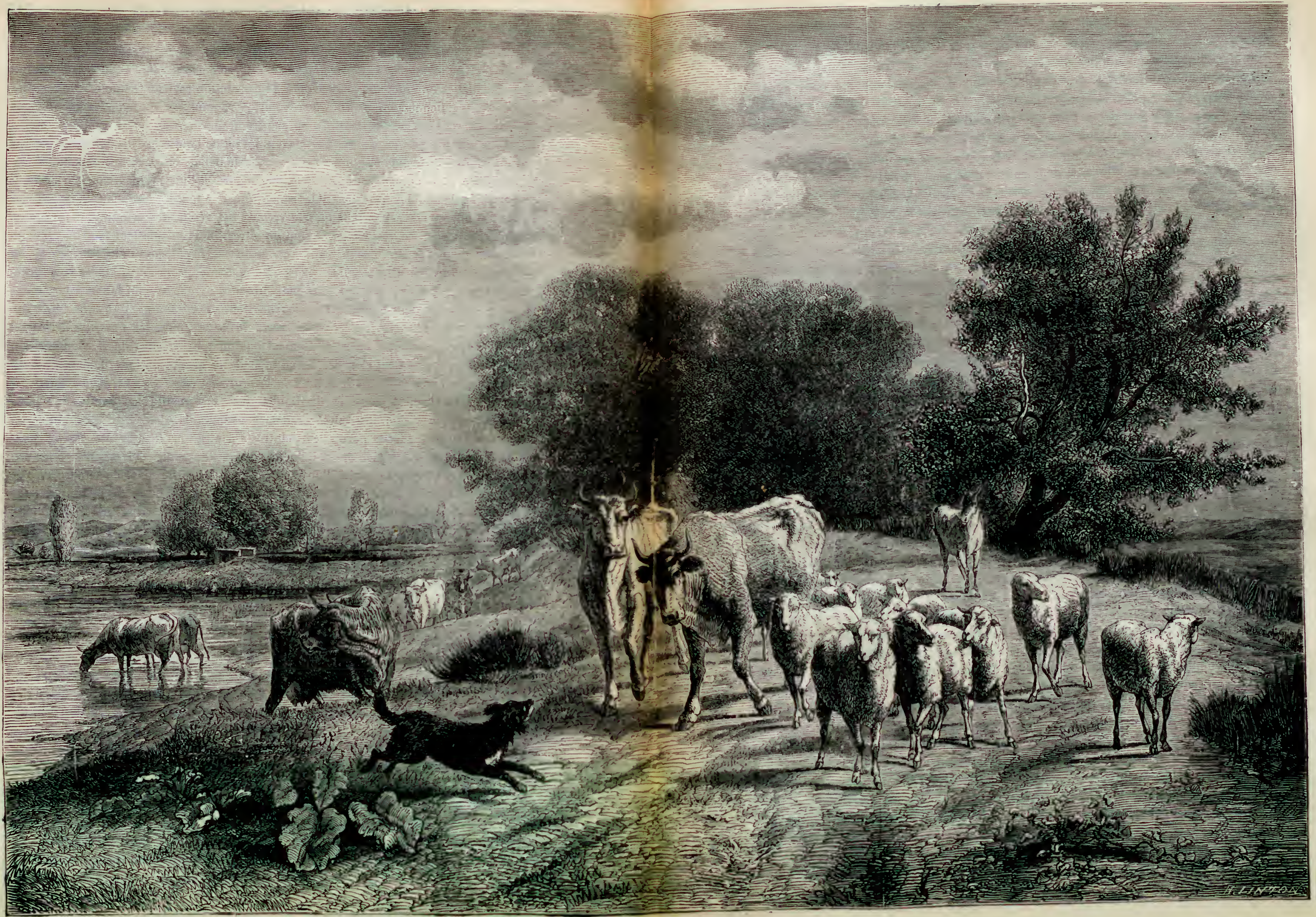

Liscix Ints. - Le fellour a la ferme, tableau de Trovon. 
non des contours, mais des rayons lumineux. Dès lors, il est inutile de dessiner : il suffit d'appliquer sur les toiles des tons, des touches, des frottis. Comme certains impressionnistes paraissent avoir un appareil visuel conformé d'une facon particuliere, on peut arriver aux plus étranges résultats; des visages zébrés de touches violettes, jaunes, oranges; des vêtements noirs qui prennent une teinte d'azur; des arbres qui sont bleus, des mains qui ressemblent à des pattes de homard, etc.

Nous arrivons, on le roit, à la période tout à fait contemporaine. Ici, nous devons être très sobres d'appréciations, et nous nous contenterons d'emprunter au deuxième supplément du Grand Dictionnaire Larousse un tableau d'ensemble du mouvement actuel. De 1872 a 1889, l'activité de nos compatriotes a fait de la France le foyer artistique de l'Europe. Sous l'influence des événements de 1870-71. il s'est formé toute une pléiade de peintres militaires ajant pour chefs Detaille et Neuville, à côté desquels MM. Protais, Armand Dumarescq, Berne-Bellecourt, Dupray, Georges Bertrand, Beauquesne, Bontigny, Conturier, Médard, Lançon, Marot et Delahaye tiennent une place très honorable. - La tendance générale de cette pléiade n'est pas d'embrasser de vastes ensembles, de donner comme Raffet et Bellangé la ressemblance d'un combat dans son entier; ils se bornent à raconter l'épisode d'une bataille, sans négliger aucun détail, avec un constant souci de l'exactitude historique. Le souvenir de l'Alsace et de la Lorraine est resté présent à l'esprit de tous à chaque Salon, grâce aux œuvres de peintres presque tous originaires de l'Est, qui ont rappelé les provinces perdues, tantôt par des figures symboliques, comme celles de MM. Henner, Lix, Jean Benner, tantôt par de vivantes et patriotiques allégories, par des tableaux de mœurs; qui ont pour auteurs MM. Brion, Marchal, Jundt, Bapst et Beltannier.

a Pendant cette période, l'État et la ville de Paris ont contribué fortement au déreloppement de l'art décoratif. C'est depuis 1872 qu'ont été entrepris les plafonds de la Comédie-Française, de l'Odéon, du musée de Saini-Germain-en-Laye, la décoration du Panthéon, du Palais du Luxembourg, de la Sorbonne, du Palais de la Légion d'honneur, de l'Hotel des Archives nationales, du Palais de Justice, du Ministère de la Guerre, du Muséum d'histoire naturelle, de l'École de Médecıne, de l'École de Mlarmacie, des différentes mairies de Paris: ceci pour la capitale. J sand à la province, les commandes, presque toutes très importantes, sont nombreuses encore. Il suffira de rappeler les travaux exécutés à la salle du Jeu de paıme de Versailles, au Palais des Arts et à l'École de Médecine de Lyon, aux Facultẻs des Lettres el des Sciences de Bordeaux, au Palais de Justice du Havre, à l'Hotel de la Préfecture et à la Cour d'appel de Montpellier, à l'École Nationale des Beaux-Arts de Bourges, au théatre de Cherbourg, au musée d'Amiens, à la catbédrale de la Rochelle, au Palais de Justice de Rouen, à la Faculté des Lettres de Nancy, aux hôtels de ville de Limoges, de Beauvais, de Nancy, de Dieppe, de Saint-Quentin. Tandis que des peintres d'un renom consacré, MM. Baudry, Cabanel, Delaunay, Lenepveu, J.-P. Laurens, Henry Lévy, Mazerolle, Cormon, Benjarnin Constant, Dubufe, attestaient. leur conscience par l'habileté de l'ordonnance et de la facture, qu'ils montraient des compositions fort iutéressantes en soi, mais dénuées de lien avec l'édifice appelé à les recevoir, il se trouvait des maitres pour s'imposer comme règle de renouveler la décoration ou plutôt de la mieux comprendre. C'est leur grand mérite d'avoir su plier leur talent aux exigences de la destination, et l'on ne sallait s'étonner que le plus éminent d'entre eux, M. Puris de Chavannes, ait rencontré en MM. Humbert, Lagarde, 
François Flameng, des admirateurs disposés à imiter sa manière avec un indéniable talent, mais peut-ètre sans raisons aussi soigneusement déduites. Plusieurs peintres, MM. Gervex, Humbert, Blanchon, Baudoin, ont introduit dans la décoration l'élément moderne, ne craignant pas de montrer sur les murs d'une mairie des scènes contemporaines dans toute leur réalité : un manège, une déclaration de naissance, le travail des forts de la Halle et des ouvriers du bassin de la Villette, le retour des lahoureurs et les fiançailles aux champs.

" Les décorateurs ne pouvaient d'ailleurs se soustraire d un mouvement qui, se produisant d'accord avec les changements politiques, affranchissait le goût des formules conventionnelles, suggérait aux artistes un besoin de vérité, de franchise, qui les portait ù l'étude approfondie de l'hoinme et de la nature. De là, de ce courant moderne, venaient, malgré les efforts de MM. Boulanger, Gérôme, Hector Leroux, Sylvestre, Matte, l'abandon progressif des sujets empruntés à l'antiquité classique, de là aussi la décadence de la peinture religieuse, cultivée suivant la tradition par MM. Bouguereau, Merson, Lehoux, II. Martin, et la rénovation de ce genre par des artistes de la nouvelle école, MM. Bastien-Lepage, Duez, Dinet, Girardot, qui s'attachèrent à humaniser la légende, à ranimer leurs visions rétrospectives par une observation franche et hardie de la réalité; pareillement, la peinture historique dans laquelle MM. J.-P. Laurens, Maignan, Luminais, Maillart, François Flameng, Mélingue, Schommer, avaient trouvé l'occasion de plus d'une louange, devait un certain regain de faveur au souci d'exactitude documentaire dont témoignaient les œuvres de MM. Rochegrosse, Tattegrain, Bloch et Le Blant. Examine-t-on les tableaux de chevalet, le changement qui s'est produit sous l'action des doctrines récentes s'accuse plus nettement encore : MII Meissonier, Vibert, Worms, Delort, Fichel, Lanis et Maurice Lelou, Boybet, Kaemmerer, Jacquet, Pille, Boyard, Adrien Moreau, continuent bien à peindre des sujets à costumes, mais le public s'intéresse plutôt aux cuvres de MM. DagnanBouveret, Perrandeau, Fourié, Buland, Degas, Gœeneutte, Jeanniot, Bérand, Gilbert, à ces scènes de mœurs prises sur le vif, notées dans leur milieu, abondantes en détails profitables pour l'esprit. MM. Fantin-Latour et Bonvin avaient déjà repris et continué la tradition de Chardin, des maltres du xvuı siècle, et fait revivre le goùt si français des intimités. Ils développèrent avec éclat leur système; puis, la curiosité vint à MM. Dantan, Carrière, Thévenot, Friant et Gueldry, de fixer l'image des intérieurs d'ateliers d'artistes et d'ouvriers; à MII. Dawant, Moyse, Paul Salzédo, de montrer dans leur ressemblance animée les sacristies, les synagoğues et les tribunaux. Ainsi se réalisaient les théories naturalistes émises depuis longtemps déjà par Castagnary, Auguste Comte et présentées par Proud'hon sous cette forme de programme: " Peindre les hommes dans leurs fonctions civiques et domestiques, avec leur physionomie habituelle, et surtout sans pose, non pour le plaisir de railler, mais comme but d'éducation générale et à titre d'avertissement esthétique. Dès la fin du second Empire, Mu. Jules Breton et leyen Perrin avaient laissé prévoir ce retour à la nature. Mais ces images de l'existence champètre et maritime étaient poétisées, idéalisées presque, et l'homme n'y paraissait pas, le plus souvent, dans sa proportion véritable. La génération suivante aborda la réalité sans réticence d'aucune sorte. A cet égard, le rôle de Manet dans l'école fut décisif. Il traita des sujets contemporains jusqu'alors conspués, réagit contre les embrunissements de la palette, et, en doniant l'exemple d'une perception plus exacte de la lunière et des ambiances, il apprit à lécole le "plein air ", l’obligea à voir la 
nature comme les Japonais, d'une façon directe, et à traduire vivement dans toute sa vérité l'inıpression ressentie. Son action ne se reconnait pas seulement chez MM. Degas, ỉaflaëlli, qui ont traité, en ajoutant le bénéfice d'une vision personnelle, les sujets que Manet n'eut pas dédaignés : les gens du peuple, les intérieurs de thédre ou de brasserie, le travail des danseuses à l'Opéra; elle est évidente dans les œuvres de MM. Bastien-Lepage, Roll, Duez, Gervex, Lhermitte, Lerolle, Ulysse Butin, qui ont honoré le plus grandement l'école nationale et propagé à l'étranger l'influence française en montrant avec une absolue sincérité les épisodes courants de l'activité quotidienne dans les centres ou d la campagne.

- L'elfort des peintres était si visiblement tendu vers la représentation rigoureuse et sincère des types, l'idéal contemporain se montrait tellement fatigué des à peu près généralités prétentieuses que les maitres les plus réputés du portrait, M. Delaunay, Cabanel, Bonnat, Baudry, J.-J. Lefebvre, Paul Dubois, Carolus Duran, J.-J. Henner, Jean Gigoux, Gaillard, Jalaben, $M^{110}$ Jacquemart, s'essayèrent à rajeunir leur manière par un procédé plus personnel ou par une simplicité plus saisissante, tandis que les partisans de l'indépendance, MM. Ribot, Raffaëlli, Bastien-Lepage, Dagnan-Bonveret. Roll, Fantin-Latour, Besnard, Carrière, Ilenri Pille, s’ingénièrent à ne pas séparer le sujet figuré de son milieu, de l'entour coutumier de son existence. Parmi les peintres de la chair, il s'en rencontre un, $\mathbf{M}$. Roll, pour faire avec éclat la tentative du uu en plein air, tandis que les autres, MM. Henner, Kaphaël Collin. Lefebvre, Marot, Courtat, faisaient montre de puissance ou de délicatesse à peindre le corps humain. Si de l'homme on passe à la bète, puis aux fleurs, et enfin aux objets inaninés, on rencontre chez les animaliers, MM. Lambert, Chaigneau, Brissot de Varville, John Lewis lirown, Goubies, Max Claude, Grandjean, Van Marcke, de Vuillefroy, Barillot, Vayson, et pareillement chez les peintres de fleurs comme MM. Quost, Jeannin, lireyder, Rivoire, Schuller, Thomas, $\mathbf{M}^{\mathrm{m}}$ Madeleine Lemaire, ou de nature morte comme MII. Vollon, Ph. Rousseau, Bergeret, J. Bail, Desgoffe, une ambition égale d'arriver à traduire avec plus de conscience et de logique la réalité. A l'exception de MM. Guillaumet et Dinet, les orientalistes semblent seuls se refuser à céder à ce mourement, et c'est plus souvent un Orient composé pour le plaisir des yeux que nous montrent M. Benjamin Constant, Clairin, Bida, Luguet, Berchère et Frère. Néanmoins, partout pénétrait la tendance moderne. Dans la peinture de paysage, la cause du romantisme est bien encore victorieusement soutenue par MI. Jules Dupré et Ziem; mais la tradition classique languit, pour bientôt s'éteindre avec MM. Cabat, Bellel, Bénouville et Flandrin; MN. Français, Busson, Veyrassat, Rapin, Zuber, servent de lien de transition entre l'école de 1830, et MM. Harpignies, Guillemet, Lansyer, Desbrosses, qui se montrent moins soucieux de la composition qu'inquiets de la vérité. La recherche de l'exactitude absolue, la notation des ambiances et des transparences aériennes, est le principe d'art des impressionnistes proprement dits, MM. Monet, Siley, Renoir et Pissard, qui, contestés à leur début, ont pris maintenant rang définitivement dans l'école; ils procèdent de Manet et de Corot, tandis que les harmonistes, MM. Cazin, Poitelin, Lavieille, Billotte, Baran, Victor Binet, Boudin, Lépine, semblent plutot descendre de Corot seul. Notons enfin que le symbolisme littéraire a trouvé son équivalent en peinture dans les œuvres de MM. Hébert, Sellier, de Beaulieu, Puvis de Chavannes, Besnard, Agache, Gustave Moreau. ,

Avant de terminer notre description de l'Exposition des Beaux $A r$ ts, où la peinture 
tient la première place, nous devons résumer brièvement l'histoire centenale de la sculpture, qui est représentée au Champ de Mars par David d'Angers, Houdon, Pajou, Pradier, Préault, Rude, Barrias, Cain, Chapelain, Chapu, Dalou, Delaplanche, P. Dubois, Falguière, Frémiet, Eugène Guillaume, Injalbert, Lanson, Mercié, Millet, Rodin, Saint-Marceaux, Thomas, et, pour l'étranger, par Antokolseki, Argenti, Boëhm, P. de Vigne, P. d'Epinay, P. Leighton, Montverde.

Sous le règne de Louis XV, la sculpture était devenue maniérée, outrée, sans nerf. - La nature paraissait pauvre, l'antique froid et sans caractère. Diverses raisons

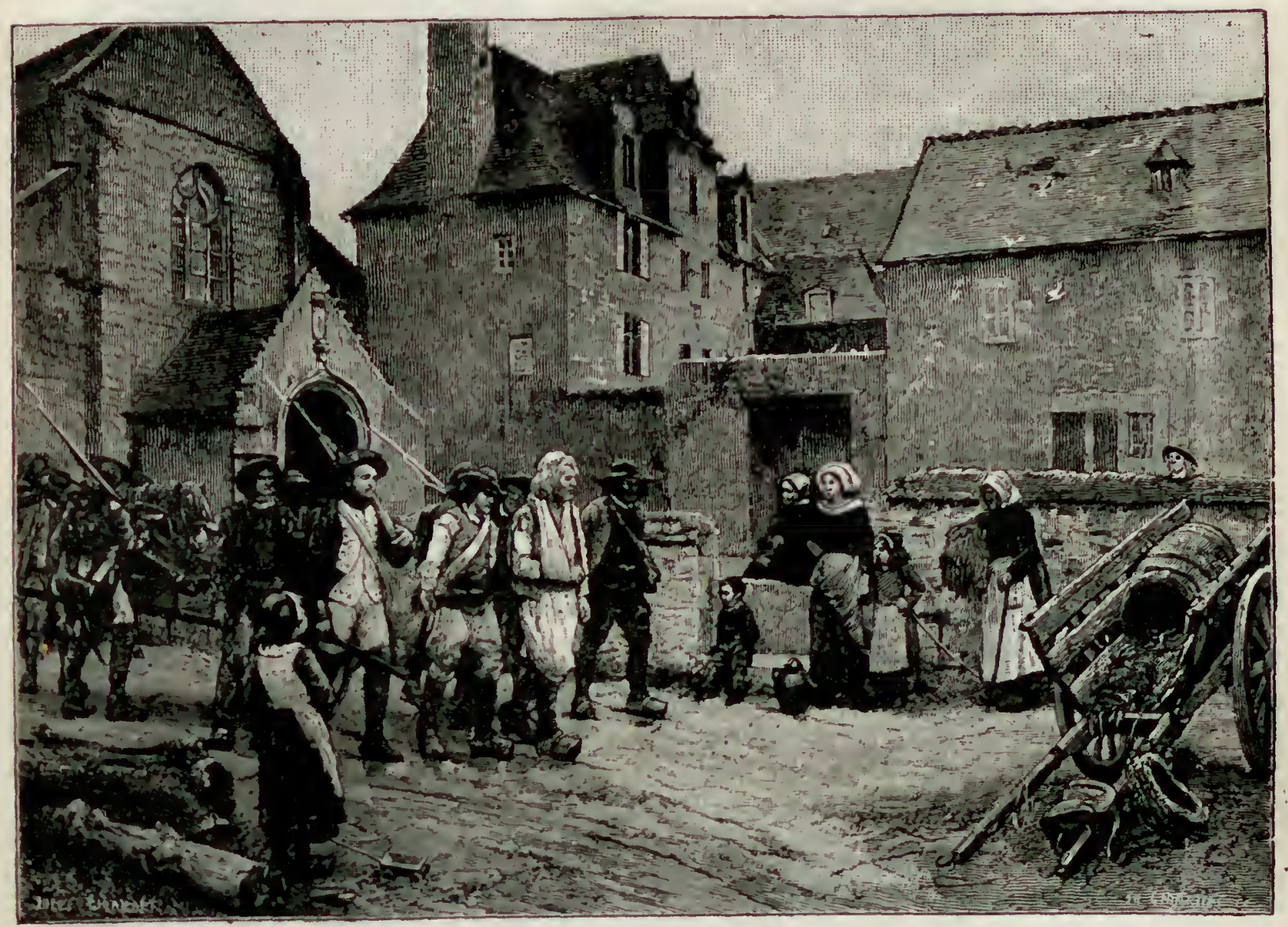

BEA UX-ARTS. - Les Révollés de Fouesnant ramenès a Quimper par la garde munzeipale, tableau de M. Jules Girardet.

contribuèrent à remettre l'école française dans la bonne voie, notamment les découverics archéologiques en Italie, diverses publications relatives à l'antiquité. Pigalle, animé d'un profond sentiment de la vérité que lui avait donné l'étude minutieuse de l'anatomie, et, avec lui, son parent Allegrain furent les promoteurs de la réaction contre le maniérisme sans toutefois rompre complètement avec le faux gout. Nouchy, JeanGuillaume Moitte, Dupré, Baquet, Le Brun continuèrent la nouvelle tradition. Houdon fut un observateur profond, mais il rend les nuances de la physionomie bien plutôt que celles du caractère. Quatremère a dit de lui : . On ne dira pas que Iloudon ait porté dans l'art du portrait ce profond caractère de simplicité qui, sous le ciseau des anciens et par la seule vertu d'un petit nombre de traits énergiquement écrits, nous révèle la constitution à la fois physique et morale des personnages, leur humeur, leurs affections, leur ame tout entière. Houdon suivait l'autre route. C'est par le nombre et 
la finesse des détails qu'il imprimait à ses portraits une vive ressemblance. "Nous trouvons ensuite Pierre Julien, Clodion, Depoux, Berruer, Stouf, Boichot, Delaistre, Gois père, Baccari, avant d'arriver à la période classique, car en sculpture comme en peinture, il y eut une école académique représentée par J.-B. Giraud, Cliaudet, Roland et Bosio, Lemot. Dupaty, Cartellier, Beauvallet, Ramey, Gois le fils, Calamard, Lemire, et Mil homme. Leurs exagérations faisaient dire a Guizot : Nos statuaires modernes, ceux du moins qui exécutent des figures nues et de leur choix, semblent prendre a tache d'outrer les belles formes: trop peu sürs du charme de leur ciseau pour donner au marbre une beauté simple, facile et animée, ils croient y suppléer en exagérant la beauté telle que la déterminent les règles; ainsi ils rendent les paupières plus longues, les lignes du front èt du nez plus droites, et se flattent peut-être davoir crée ainsi de belles têtes.

La sculpture contemporaine commence à proprement parler avec Pradier et David d'Angers. David d'Angers, né à Angers en 1789, fils d'un modeste sculpteur sur lois, fut de bonne heure entralné par une vocation irrésistible vers l'art où il devait acquérir la célébrité la plus méritée. Il arriva à Paris avec neuf francs dans son portemonmaie (1808), travailla pour vingt sous par jour aux corniches du Louvre et aux ornements de l'arc du Carrousel, et fit heureusement la connaissance du sculpteur Roland qui l'admit gratuitement parmi ses élèves. Plusieurs artistes éminents, frappés de ses dispositions, denandèrent et obtinrent pour lui de sa ville natale une subvention annuelle de 500 francs, et dès lors David marcha de succès en succès. Ses ceuvres furent saluées avec enthousiasme par les romantiques, avec sympathie par les classiques euxmèmes, ou du moins par beaucoup d'entre eux. "Toutes ses œuvres, a dit un de ses biographes, sont marquées du double cachet qui caractérise l'artiste supérieur : l'originalité et la fécondité. David posséda au plus haut degré ces deux qualités qui se confirment l'une l'autre et sont comme le trait ineffaçable qui sépare le génio de la médiocrité. En parcourant la liste de ses ouvrages et en voyant la sévérité yu'il apportait à chacune de ses compositions, on comprend a peine que la vie d'un homme ait pu suffire à une pareille tảche. La personnalite puissante de son talent s'y retrouve toujours; ce qui la distingue, c'est la vigueur et l'intention inorale. Repoussant toute inspiration qui ne vient que des énervantes beautés de la plastique paienne, il se cor:sacra de préférence à immortaliser les grandes figures de l'histoire contemporaine; son but était de retremper les âmes par le sentiment de leur puissance et non de les amollir. "Le crilique Du Pays fait remarquer que David d'Angers ne modelait pas a froid, mais qu'il s'inquiétait de passionner l'art, de lui imprimer une signification vivante, el qu'il a le premier rehaussé le portrait sculpté à costume moderne, fait de la statuaire par la seule puissance de la physionomie et du geste. I lin sculptant les hommes illustres des trois derniers siècles, David leur a mis leur propre flamme au front, les a glorifiés par eux-mêmes; il en a fait de poétiques statues, où l'on sent le génie, la vertu ou l'héroïsme. Pour arriver a ce grand résultat, il lui a fallu aussi l'habitude de l'art antique et le pouvoir de plier chaque costume, chaque individualité aux graves conditions dé la statuaire. C'est là la grande originaliié et la grande force du talent de David. Dans celte audacieuse entreprise de faire accepter à la statuaire la convention du vètement officiel et des modes du temps, a l'art les excentricités des personnes et des mœurs, il réussit toujours grâce à ses grandes études classiques, à ce grand goût du maître formé par les anciens. 11 redresse, modifie, élargit tout et par 
lintclligence des masses, par les grandes indications du nu, il rend dignes de la statuaire, sinon tous les détails du costume contemporain et de l'action individuelle. du moins l'aspect et l'ensemble de la figure.

"Personne comme Pradicr, ainsi que le remarque Louis de Cormenin, n'a compris la chasteté du nu et revetu le corps humain d'un pareil idéal de beauté. La volupté mème s'épure; elle n'a pas d'attaches grossières, de tentations malsaines, elle ne provoque pas le désir; elle sollicite l'admiration par la touchante ingénuité de sa grâce, par le charme pénétrant de ses suaves contours. La femme s'ennoblit dans la déesse et garde je ne sais quelle distance de majesté froide que l'œil le plus hardi ne saurait franchir. Il n'a pas la pruderie et le rigorisme, mais il a la pudeur et la réserve du beau. Sous le ciseau de Pradier, le marlıre s'assouplit comme une chair, il prend le grain, la transparence les jeux de lumière et les tiédeurs de l'épiderme. Plus que tout autre, il maitrisa le marbre. Puget raconte que les blocs frémissaient sous sa main; devant Pradier, je m'imagine qu'ils devaient sourire.

Maindron et Préault ont été en sculpture les représentants accrédités du romantisme, mais ils ne sont pas les seuls. Il faut au moins nommer Ottin, qui a sculpté Acis et Galatée au Luxembourg, Aimé Millet, Cavalier, Carrier-Belleuse, Louis Brian, Arnaud Toussaint. Rude fut un maltre, un artiste hors pair. Nul au xix siècle n'a montré plus de hardiesse vigoureuse, plus de monvement, plus de vie, plus d'inspiration que l'auteur du Départ, cette page merveilleuse qui se lit sur l'Are de Triomphe, et ses élèves eux-mèrnes se sont particulièrement distinguẻs, car il a formé Carpeaux, Christophe, Chatrousse, Leveel, Ch. Cordier, Cabet, Schroder, Marcellin, Garraud, Franceschi, etc. Dans la sculpture d'animaux, Barye, Caïn et Frémiet ont donné des chefsd'œuvre, et dans des genres divers, il y a lieu de citer encore Jouffroy, Perraud, Guillaume, Chapu, Falguière, Paul Dubois, Cambos, etc. Après la guerre de 1870 la reconstruction des édifices detruits, les monuments commémoratifs, les nombreuses érections de stalues ont donné aux statuaires l'occasion d'exercer leur talent. Tout en travaílant pour eux-mèmes, MI. Chapu Dubois, Guillaume, etc., ont formé des élèves comme Mercié, Gautherin, Marqueste, Lauson, Albert Lefeuvre, Daillon, Suchetet. Un école nouvelle, qui veut simplement se préoccuper de la vérité des mouvements et des formes, est très dignement représentée par les sculpteurs Dalou, Falguièr, Saint-Mlarceaux, Aubé, Carriés, Boncher, Turcan, Injalbert, Etcheto, Auguste llodin.

Nous croyons ètre agréable à nos lecteurs en leur donnant ici une liste des principales cuvres qu'ils feront bien d'examiner dans la section de sculpture, car ils ne retrouveront jamais sans doute une occasion semblable de trouver en dehors des musées autant de chefs-d'œuvre réunis en un mème endroit.

Banye (1795). - Le Lion de la colonne de Juillet (moulage); Lion et serpent de la colonne de Juillet (moulage); Jağuar dévorant un gavial (bronze).

Baubaut (1828). - Le Premier Miroir (marbre).

Just Beçuet (1829). - Ismä̈l (marbre).

Bonassizux (1810). - L'Anour coupant ses ailes.

Bos10 (1768-1815). - Henri IV (statue marbre); la Nymphe Samalcis (moulage). 



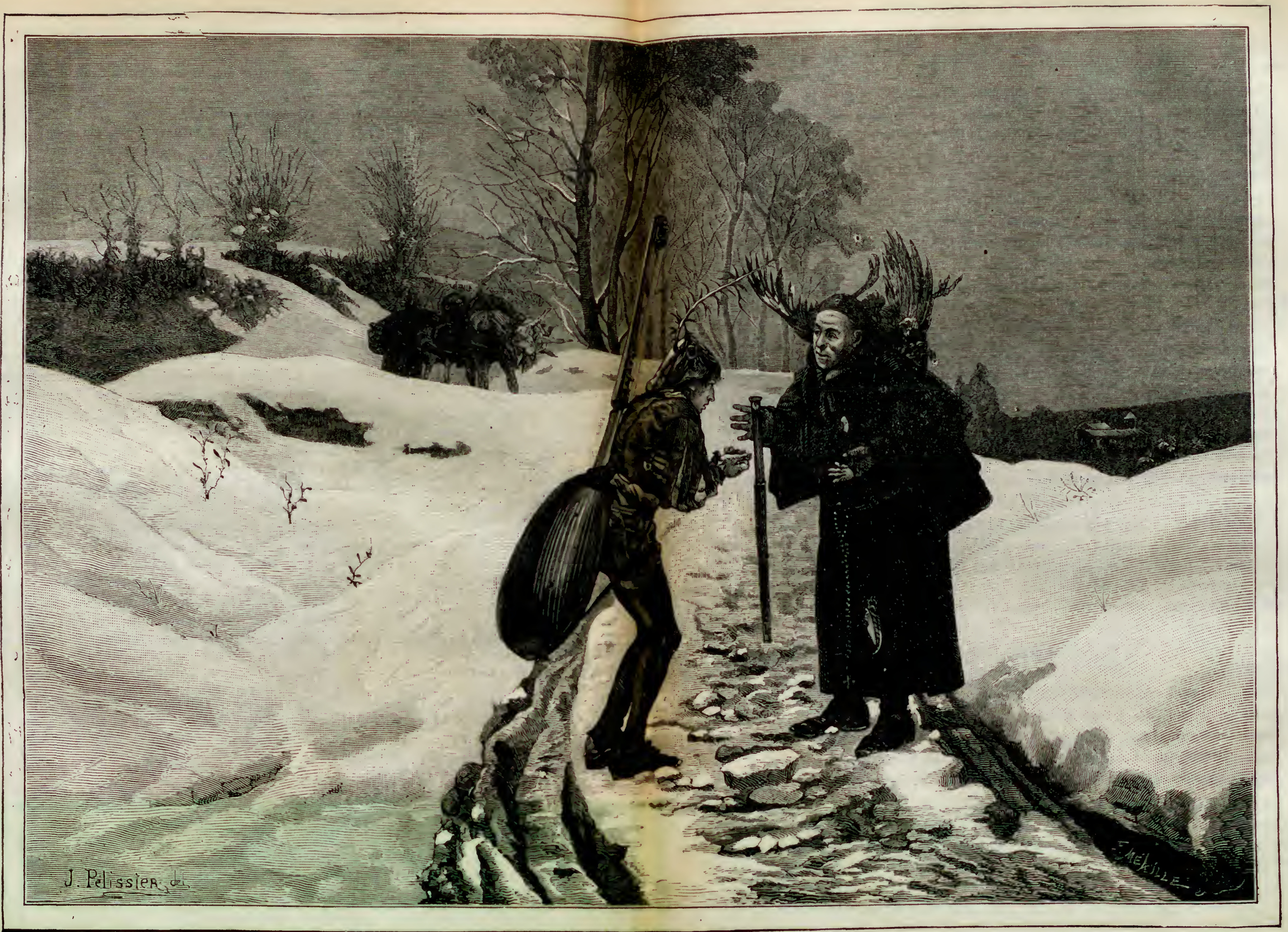

B\&AUX-AKrs. - La Cigale el la Fourmi, Lableau de M. J.-G. Vibert. 
Caffiér (1720̈-1792). - Buste de Pingré; Buste de Marivaux; Buste de liclloy (marbres).

Carv. - Vautour (bronze); Lion de Nubie et sa proie (bronze).

Carpeaux (1827). - Le Prince Impérial (marbre); Flore (moulage); Bustes; la Fontaine du Luxembourg; le Moulage du groupe de la Danse, à l'Opéra.

Cavelier (1814). - L'Odysséc.

Chapu. - La Jeunesse.

Ciraudet (1763-1810). - L'Amour prenant un papillon (moulage).

Cícésinger (1814). - Cléopatre; Un combat de taureaux; Léda.

Corbet (1758-1808). - Buste du général Bonaparte.

Cortot (1787-1843). - Le Soldat de Marathon.

David DArgers (1789-1856). - Bustes; Moulage du tombeau de la comtesse de Boureq.

Delaplanche (1836). - L'Éducation maternelle; Message d'amour.

DiÉBolt (183دั-1861). - Sapho.

Paul Dubors (1829). - Chanteur florentin (bronze).

Francisque Dunet (1804-1865). - Le Danseur.

Espercietx (1758-1840). - Baigneur (moulage).

ETEx (1808-1888). - Caïn; Buste d’André Chénier.

Falguère (1831). - Le Vainqueur du combat de cogs; le Nartyr.

Feuchère (1807-1852). - L'Ange déchu.

Forater (1793-1S63). - Spartacus.

Frémet (1824). - L'Age de pierre; Chien blessé (moulage).

Gullaume (1822). - Buste de Mgr Darboy (marbie); les Gracques.

Hounow (1741-1828). - Bustes de Louis XVI, Lafayette, Napoléon Irr. Nechor, Marat; Apollon (statue bronze).

JALEY (1812-1866). - Louis XI.

Maindion (1801). - Velléda.

Mène (1810-1880). - Le Fauconnier arabe (cire); Chasse en Ficosse (circ); Hallali de cerfs (cire).

MERclé. - David vainqueur de Goliath.

Aimé Mrllet (1819). - Ariane; Baudin.

Mathurin Moneau (1822). - Fileuse.

Pradier (1792-1862). - Atalante à sa toilette (moulage); le Duc d'Orléans.

Préault (1810-1879). - Le Silence (moulage); Jacipues Cocur (bronze).

Rodix (1840). - L'Ilomme au nez cassé (buste); l'Age de fer.

Rude (1784-1855). - Le Maréchal de Saxe; l'Mmour dominateur du monile (statue marbre); Moulage du tombeau de Godefroy Cavaignac; le Pècheur uapolitain (moulage). 
Ces œuvres appartiennent à l'Exposition centenale; dans l'Exposition décennale nous trouvons :

A. Mercik. - Quand mène (groupe marbre); le Monument funéraire de II ${ }^{\text {me }}$ Charles Ferry (moulage); le Souvenir pour un tombeau (figure, marbref; Génie pleurant (figure, platre); Marie-Antoinette (buste, marbre); $M^{110}$ G... (buste, marbre); Tombeau du roi Louis-Philippe et de la reine Amélie (groupe, marbre).

Sucherer. - Aux vendanges (groupe, marbre); Claude C... (buste, marbre); la Biblis (statue, marbre).

Alcound. - Molière mourant (marbre); Héloïse au Paraclet (marbre); Lutinerie (groupe, marbre); Faustin Hélie (buste, marbre); Mes enfants (médaillon, marbre); Beaumarchais (buste, marbre); IIm Buloz (buste, marbre); M. Buloz (buste, marbre).

IIugues. - Tentation (figure, platre); OEdipe a Colonne (groupe, marbre); Torchère; Asie; Femme jouant avec son enfant (groupe, marbre); les Sciences (fronton en pierre a l'École des arts industriels de Roubaix); David (buste, marbre); Groupe principal du Pavillon de la République Argentine, a l'Exposition universelle de 1889; l'Immortalité (stitue platre, Pavillon de la Compagnie de Suez, à l'Exposition universelle de 1889); Monument du chevalier Rose (a Marseille).

E. Gulladue. - Mariage romain (groupe, marbre); Andromaque(groupe, marbre); Monument élevé a la mémoire de Duban (bronze et marbre); Marc Seguin (buste, marbre); le Prince Napoléon (buste, marbre); François Buloz (buste, marbre); Jules Ferry (buste, marbre); Thiers (buste, marbre teinté).

CanLÈs. - Abel (statue, marbre); Retour de la chasse (bronze); la Cigale (statue, marbre); Candide (buste, mirbre); la Jeunesse.

- Albert Lafeurre. - Le Pain (groupe, marbre); Après le travail (platre); Bara, (platre); lirère el sour (groupe, pierre).

Aızux. - Marguerite; Mignon; Japon; Vestale; la Paix (statues, marbre).

Peci. - Gui d’Arezzo (statue, marbre); J.-B. Dumas (statue, plàtre).

Graxer. - La République française (statue, platre); Jeunesse et Chimère (statue, plitire).

Manoton. - Frères d'armes (groupe, platre); Chactas (statue, marbre).

Fnsimet. - Gorille (groupe, platre); Capture d'un éléphanl par un nègre (groupe, platre); Ourse et homme de l'age de pierre (platre).

Bovcier. - Les Coureurs (bronze).

Bécisa. - David (marbre).

LEDUC. - Cerf, biche et faon (bronze).

Caruar. - L'Aveugle et le Paralytique (bronze).

VAltox. - Lion et Lionne (bronze).

D.sMPT. - Diane (marbre).

Rısiger. - La Marche de Rackoski (bronze); la Saga.

Bovcher. - L'Auscultation (platre).

Defaplaxche. - La Danse (marbre).

Blavchand. - La Surprise (marlore). 
L'Exposition de gravure, par laquelle nous terminerons ce chapitre, mérite bien de nous arrèter un instant. La France compta de tout temps depuis le $\mathrm{xvi}^{\mathrm{e}}$ siècle des graveurs remarquables et parfois hors pair. $A u \mathbf{x} \mathbf{v m}^{\mathrm{e}}$ siecle, on publia de vastes et nombreux recueils d'estampes, et Watteau, Boucher, Lancret, Beaudoin, Vanloo, Greuze eurent des interprètes habiles, qui rendirent leurs œuvres populaires. Citons Nicolas Larmessin, François et Jacques Chéreau, Louis Desplaces, Charles et Nicolns Dupuis, Nicolas-IIenri Tardieu, Charles-Nicolas Cochin, Louis Surrugue, Bernard Lépicié, Laurent Cars, Jean Daullé, Pierre Aveline, Jean Moyreau, Jacques-Philippe Le Bas, Baléchou, Jacques Aliamet, Robert Gaillard, Flipart, Lempereur, J.-J. do Boissieu, Étienne Ficquet, Beauvarlet, Lavasseur, Babel, Canot, Louis Moreau et J.-M. Moreau, Saint-Aubin, Le Prince, etc. Dans notre siècle, grâce au goùt de plus en plus répandu de l'illustration des livres, de nombreux graveurs ont pu se mettre en relief. Les salles 7 et 8 du Salon des Beaux-Arts, au Champ de Mars, sont consacrées exclusivement à la gravure; on y peut voir les cuvres marquantes des graveurs français depuis cent ans, quel que soit le procédé qu'ils aient employé : camaïeu, eau-forte, burin, etc. Nous y relevons les noms de Regnault, Desnoyers, Gaillard, Waltner, Salame, Jacquemart, Raffet, Henriquel-Dupont, Daumier, Bervic, Tardieu, Tissot, Gavarni, Jacques, Legros, Flameng, Daubigny, Bracquemond, Méryon, Baude, Chauvel, Le Couteux, Courty, Boilvin, Chaigneau, Desmoulin, Champollion, Lalauze, Laguillermie, Desboutin, Lunois, etc. Le Larousse, dans son second supplément, qui est un excellent inventaire de la vie contemporaine, donne d'intéressants détails sur la gravure tout à fait contemporaine: " La concurrence des moyens chimiques de reproduction n'a pas été sans atteindre la gravure française. Cependant, il convient d'établir que ces procédés n'ont réussi à entraver en aucune façon la carrière des grands artistes, qui ont placé la gravure nationale au-dessus de celle des autres pays. Si la production est peut-être plus restreinte chez ceux qui usent des procédés les plus lents, chez les lithographes et les graveurs sur bois le nombre des maltres dans l'un et l'autre genre s'est plutôt accru; on doit à MM. Siroux, Gilbert, Emile Vernier, Fantin-Latour, Jacott, Jules Laurens, Vernes, Thornley, Cheret, Mauron, Lunois, Bahuet, un ensemble de lithographies, dignes de prendre place à côté des meilleures productions connues. Quant à la gravure sur bois, elle a été affranchie des formules qui entravaient son développement grâce à MIM.Pannemaker, Georges et Clément Bellenger, Dutheil, Hugot, Roussot et surtout à MII. Baude, Lepère et Léveillé. Les publications illustrées, livres et revues, qui avaient si puissamment aidé à cette transformation de la gravure sur bois devaient contribuer plus encore a favoriser la renaissance et à répandre le gout de l'eau-forte. La rapidité d'exécution du procédé était d'ailleurs bien faite pour convenir à notre époque fiévreuse, toujours pressée, et cette rapidité explique encore comment l'eau-forte a été choisie de préférence par les artistes désireux de graver eux-mèmes leurs propres inventions, tels par exemple que MM. Falguière, Besnard, - Rodin, Ribot, Tissot parmi les sculpteurs et les peintres; MM. Bracquemond, Boilvin, Buhot, Desboutin, Gœeneutte, Guérard, Boulard, Hédouin, Lalauze parmi les graveurs. ' C'est un artiste français, C.-F. Gaillard, qui a renouvelé l'art du burin en remplaçant les hachures régulières par une gravure c variée et fouillée , d'un effet vif et saisissant. 


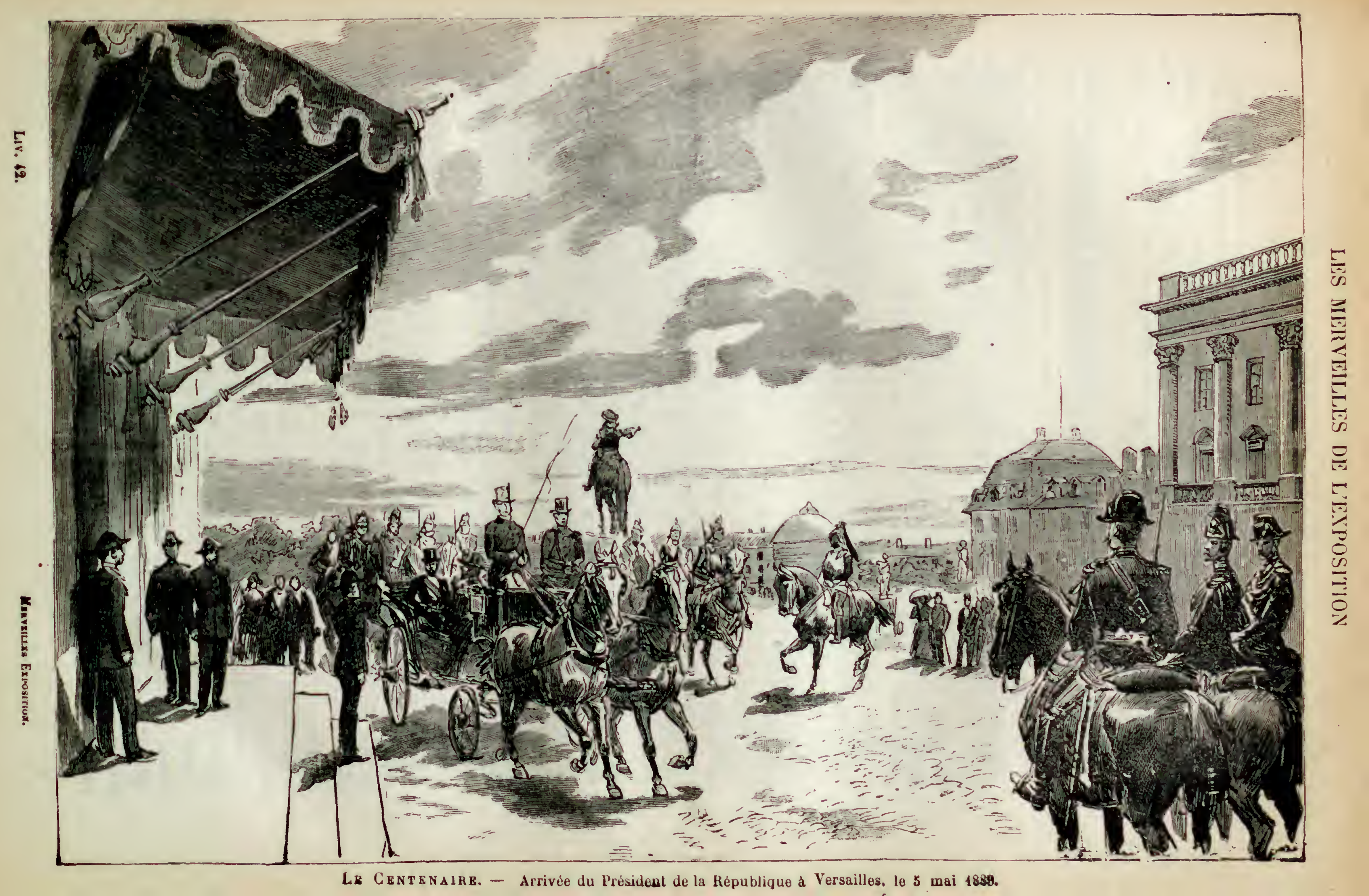




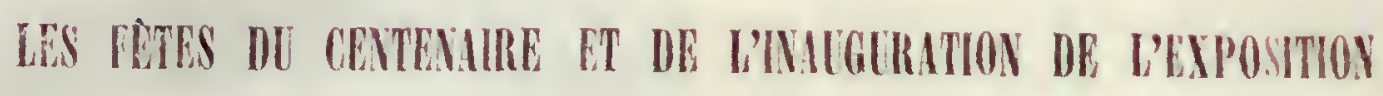

Le 5 mai 1889 , cent ans juste s'étaient écoulés depuis l'inauguration des ĺtats généraux qui devaient, après s'ètre constitués en Assemblée nationale, modifier l'état politique et social de la France, et par contre-coup celui de l'Europe. Tous ceux que n'aveugle pas l'esprit de parti comprirent l'importance de cette date, dont il y a évidemment quelque puérilité à nier la place capitale qu'elle tient dans l'histoire du monde.

Dès le matin, Paris prend son air de fète. De nounbreux drapeaux pavoisent les rues, et les Parisiens se rendent en foule a Versailles et dans la banlieue. A midi, la voiture qui devail transporter le Président de la République à Versailles quitle l'Ẻlysée, suivie par les équipages des ministres, et le passage de M. Carnot souldve de bruyantes acclamations. Au coin de la rue des Saussaies, un individu tire sur le premier magistrat de la France un coup de feu qui jelte l'émotion dans la foule, mais le revolver n'était pas chargé à balle, et cet altental n'était qu'un moyen d’altirer l'altention des autorilés sur une affaire privée. Le plus grand calme n'abandonne pas un instant le président, qui donne l'ordre de reprendre la marche. Les cris rénélés de : Vive Carnot! Vive la République! * se font de nouveau entendre, et une véritable ovation est laile au corlège pendant la trarersée de Paris jusqu'à Billancourt. De Billancourt a sèrres, Ia route est bordée de måts ornés de drapeaux et reliés entre eux par des zuirlandes de verdure. A une heure le Président arrive au pont de Sèvres; une salve de vingt et un coups de canon annonce larrivée du cortège, puis la musique municipale joue la Marseillaise. Devant la grille du parc, le cortège s'arrète, el le préfel de Séne-et-Oise affirme les opinions républicaines de la population sévrienne. A Chaville, a virollay, le même accueil enthousiaste est fait à M. Carnot.

Versailles, dont l'aspect triste et morne est resté proverbial, a ce jour-la un air animé qu'on ne lui connaissait guère; les rues sont pavoisces, une foule énorme circule sur tous les points de la ville. La place d'Armes est ceinte d'un double cordon de troupes qui remonte, bordant la chaussée de l'avenue de Paris, jusqu'à la grille de l'octroi, où les autorités départementales el municipales de Scine-et-()ise attendent l'arrivée du président de la République. Derrière les soldats, la fonle parisienne s'est installée dans les contre-allées. Adossé à l'hotel des Menus-Plaisirs, s'élève un pavillon recouvert de toile rayée blanc et rouge, sous lequel des sièges ont été préparés pour le Président de la République, les ministres et les corps constitués. Den dejutés et des sénateurs venant de Paris annoncent qu'un coup de feu a été dirigé sur le l'résident, et cette nouvelle cause une profonde émotion. Bientót M. Carnot arrive, salué par de nombreux vivats auxquels il répond avec affabilité. Le cortège descend l'avenue de Paris el, à denx cents mètres environ de la grille de l'octroi, la voiture passe an pas a travers le motif décoratif élevé par les sapeurs du gẻnie. 11 comprend quatre grands pylônes de branchages placés de chaque côté de la route. La base de cliacun est formée 
par quatre pièces de canon. Au-dessus sont disposés en éventails des timons de prolonge, des écouvillons, des refouloirs; des panoplies de cuirasses de carabiniers en cuivre, autour desquelles rayonnent des lames de sabre et de baïonnettes d'acier bleui; des médailles militaires faites avec les diverses pièces de fusils, plaques de couches, pontets de sous-garde, etc., le tout entremèlé de drapeaux et de flammes tricolores. A l'arrivée du Président, les tambours battent, les clairons sonnent, les troupes présentent les armes, les salves d'artillerie éclatent, des acclamations enthousiastes se font entendre, et, dominant les bruits, les cloches de toutes les églises de la ville sonnent à grande volée. La voiture présidentielle s'arrète près de l'hôtel des MenusPlaisirs, M. Carnot en descend; tout le monde se découvre, et la musique du $1^{\text {er }}$ régiment de génie, placée dans la cour de l'hòtel, attaque la Marseillaise pendant que le Président et sa suile prennent place sur l'estrade.

Le coup d'ocil est véritablement grandiose.

Dans l'avenue, entre les épais feuillages des grands arlıres, se prolongent à droite et à gauche les lignes étincelantes des baïonnettes de l'infanterie. Au bout de l'avenue se détache la masse imposante du chateau, pavoisé aux trois couleurs. Devant l'estrade, formant un contraste saisissant avec les uniformes éclatants des généraux et les robes rouges, jaunes el violettes de la Cour d'assises, de l'Université et des Facultés, se tient la masse compacte des habits noirs, dont la sévérité n'est pas sans grandeur; elle fait songer à ces messieur's du tier's, si maltraités, il y a cent ans, par 1 . de Dreux-Brézé, et dont la cérémonie du 5 mai 1889 constate le triomphe. Sur un signal du préfet, le rideau qui voilait la plaque tombe el des discours sont prononcés. M. Tirard, président du Conseil, retrace l'état des esprits au moment de l'ouverture des Élats géiéraux

a Que de grandes choses accomplies, Messieurs, en ces années, aussi fécondes que des siècles, dit .1. Tirard. La declaration des droits de l'homme el du citoyen, votée le. 26 aout 1789, est comme le programme, écrit en style lapidaire, des travaux de nos grandes Assemblées. La Constituaute nous donne l'égalité religieuse, par la liberté des cultes; l'égalité dans la famille, par la suppression du droit d'alnesse; l'égaiité civile, par l'abolition des classes et des privilèges, par le règne équitable et l'autorité souveraine de la loi.

- Sur ces grands principes qui seront les fortes assises de la société nouvelle, elle fonde la liberté de conscience, la liberté de penser el d'écrire, le droit de réunion, la liberté du träiail et la garantie de la propriété.

- Elle établit la souveraineté de la nation; elle substitue par la conscription une armée nationale à l'armée du roi; elle institue la justice française, une et invariable; elle organise l'ordre dans les finances et crée le Grand-Livre de la delte publique; enfin elle affranchit d jamais le cultivateur de la terre en lui donnant la propriété du so! fécondé par ses bras.

- Le paysan, travailleur sacré, nourrisseur.des nations, en quel pays est-il plus libre que chez nous? Ah! qu'il a bien justifié, l'admirable paysan français, le grand acte d'émancipation qui lui a rendu ses droits d'homme et de citoyen I Sobre, patient, économe, gardien fidèle des vertus modestes et silencieuses qui sont la force des peuples, infatigable au travail, admirable sur les champs de bataille, n'est-il pas vraiment la nation elle-mème?

- La bourgeoisie se recrute chaque jour dans ses langs, et ses meilleures qualités sont celles qu'elle a su garder de cette origine. L'épargne lentement accumulée du paysas 
est la réserve inépuisable et sans cesse renouvelée de la fortune française; cette race puissante et vivace est le sol fécond où germent incessamment et d'où s'élèvent a la lumière les grands esprits et les ames d'élite qui sont la fleur, l'ornement et la gloire de la patrie!

- Tel est, Messieurs, dans ses traits essentiels, l'aspect de la France au sortir de la Révolution.

- Sommes-nous résolus, comme ceux qui prètèrent, à quelques pas d'ici, le grand serment du Jeu de Paume, à rester unis dans l'amour de la patrie et de la liberté, a donner, chacun dans la mesure de nos forces, le concours le plus désintéressé a la tache commune, à sacrifier à la paix sociale et au bien public nos vues particulières, nos impatiences même les plus généreuses, nos ambitions et nos intérèts, à ne former enlin qu'un parti : celui de la République et de la grandeur nationale?

a S'il en est ainsi, mes chers concitoyens, nous ne pouvons que bien augurer de l'avenir. La République française poursuivra sa carrière däns la paix et dans la gloire, et la postérité dira peut-ètre que les grands Français de 1789 n'ont pas eu en nous des héritiers trop indignes d'eux!,

Les discours terminés, le Président de la République descend de l'estrade et se dirige à pied vers le chateau, suivi par les ministres, les autorités de Seine-et-Oise, les officiers de sa maison militaire et la masse des invités. Un détachement de troupes, barrant toute l'avenue sur quatre rangs de profondeur, marche derrière le corlige, le séparant du public. Une musique militaire joue une marche triomphale. De tous côtés, on entend les commandements lancés à pleine voix par les officiers des réggiments, qui rompent la haie pour aller prendre l'emplacement qui leur est assigné avant le défilé. A trois heures, le Président de la République prend place sur une estrade placée devant la grille d'honneur. Autour d'elle sont ménagées pour les invités des enceintes comme celles qui se trouvaient devant les Menus-Plaisirs. Le général commandant les troupes vient saluer de l'épée le Président, se place en face de lui, et le défilé commence, aux cris de : Vive l'armée! Vive la République! Vive Carnot!"

Au moment où les dernières troupes s'avancent, vers 4 heures, le Président de la République traverse la cour d'honneur; le cortège se déroule entre les deux files des colossales statues de héros, Bayard, Duguesclin en tète, Condé et Turenne en queue; passant au pied de la statue équestre de Louis XIV, il pénètre dans la cour royale, entre les deux attiques sur le fronton desquels est gravée en lettres d'or cette inscriplion: - A toutes les gloires de la France!, Des fenétres tombent de lourdes draperies de velours rouge à crépines d'or. Devant l'attique du Midi, celui de gauche, par lequel entre le Président de la République, est tendu un velum du Garde-Ileuble. M. Carnot pénètre dans le vestibule de l'escalier de Marbre, où il est reçu par l'administration du palais, monte l'escalier de Marbre aux couleurs chatoyantes, tourne d droite, et se trouve dans la salle des Gardes des grands appartements de la Reine, où furent massacrés les gardes du corps dans lesjournées d'octobre, traverse les grands appartements de la Reine, et arrive au salon de la Paix, d'où il passe dans la galerie des Glaces. La réception commence. Pendant qu'elle a lieu, les musiciens du Conservatoire et les chœurs, placés dans le salon de la Guerre, et invisibles derrière les tentures, se font entendre. Lorsque les corps constitués occupent chacun la place qui leur a été désignée dans la galerie des Glaces, les discours commencent. M. Le Royer, président.du Sénat, prend le premier la parole: Ce ne sont plus, dit-il, d'humbles députés du tiers, à qui l'on conteste le droit 


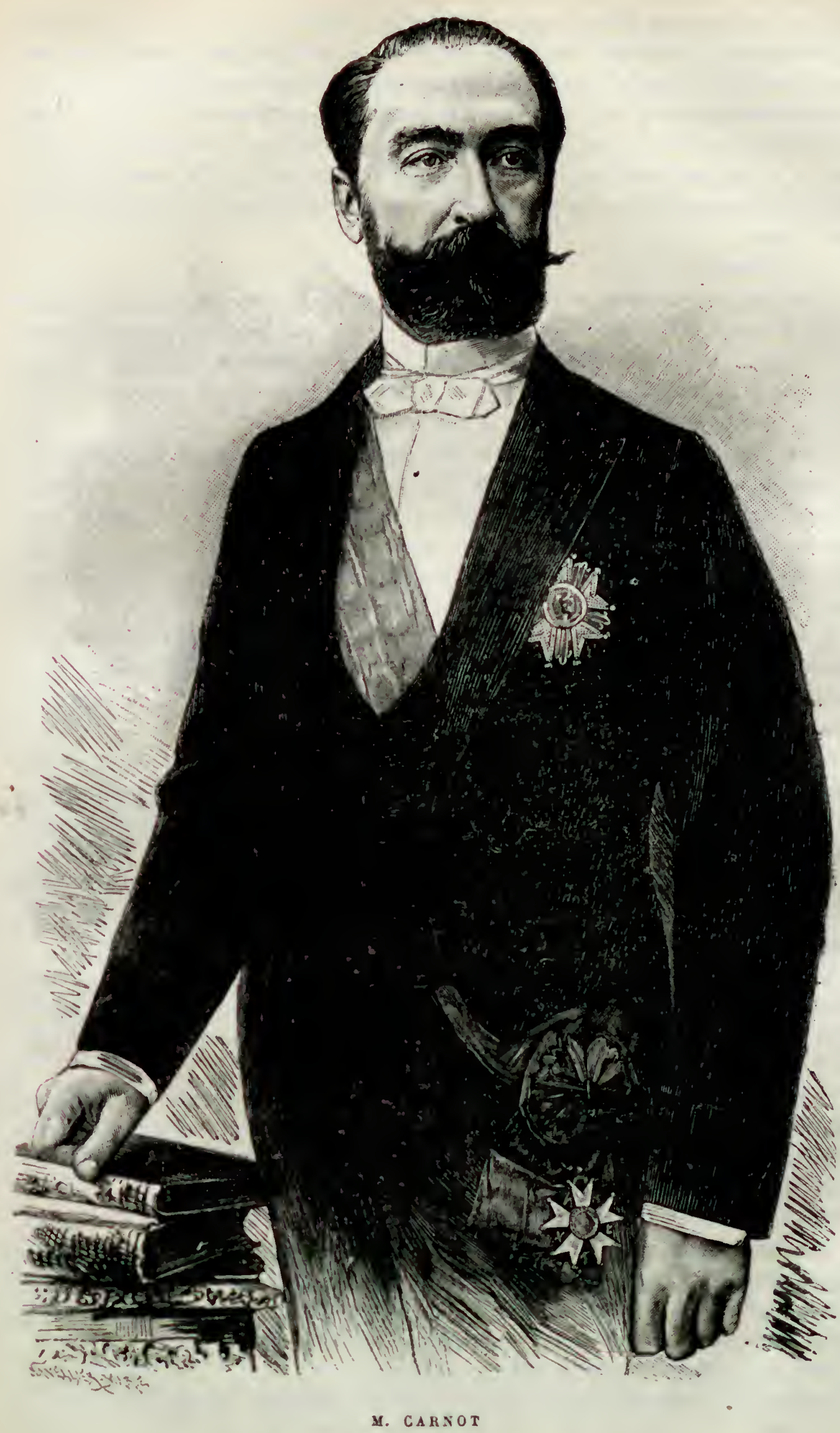

Président de la République française. 
mème de se tenir debout, venant supplier un maître; ce sont les représentants, librement élus, de la nation, s'inclinant devant un chef d'État - d'autant plus respecté qu'il est, lui aussi, un élu - et unis à lui, dans un solennel hommage aux grands morts auxquels nous devons cette liberté dont vivent aujourd'hui jusqu'à ses détracteur's. ' Après lui, M. Méline, président de la Chambre des députés, fait l'éloge de la souveraineté nationale, le mot magique, la grande formule de la Révolution , et l'évêque de Versailles prononce une allocution patriotique. M. Carnot se lève alors et prend la parolo en ces termes:

a Messicurs,

- C'est avec une émotion profonde, c'est le cœur pénétré de gratitude envers nos ancètres et rempli d'une ardente espérance en l'avenir que je salue, eomme premier magistrat de la République; dans ce palais élevé par l'ancienne monarchie, les représentants de la nation française, en pleine possession d'elle-même, maitresse de ses destinées, et dans tout l'éclat de sa force et de sa liberté.

- Notre première pensée, dans celte réunion solennelle, doit s'élever vers nos pères, vers cette immortelle génération de 1789 , fille du xvil ${ }^{e}$ siècle, qui, à force de courage et de persévérance, au prix de tant d'efforts et de sacrifices, nous a conquis les biens dont nous jouissons et dont nous transmettrons à nos fils le précieux hérilage. Janais notre reconnaissance, jamais celle de notre postérité n'égalera la grandeur des services rendus par nos pères à la France et au génie humain.

- D'illustres penseurs avaient proclamé les principes de justice, d'égalité et d'indépendance qui contenaient en germe la Révolution française. Nos pères assumèrent la táche héroïque de faire de ces principes la base nême de la société et de fonder un régime nouveau sur la raison et sur la justice.

- Gloire d eux! gloire à ces généreux lutteurs! Ils surent affronter tous les périls, supporter toutes les épreuves pour laisser à leurs descendants un précieux patrimoine qui n'est le monopole.d'aucun parti, dont tous les Français peuvent revendiquer leur part et qui est devenu le domaine commun du monde civilisé!

- Le 5 mai 1789, les États généraux, convoqués à Versailles pour la première fois depuis cent soixante-quinze ans, étaient invités à pourvoir aux besoins financiers de la monarchie française.

- Mais telle n'était pas la mission que le pays leur avait confiée. La résistance aveugle des privilégiés, paralysant les meilleures intentions de la royauté et les efforts éclairés d'un grand ministre, avait fait échouer toutes les tentatives de réformes. L'heure de la Révolution avait sonné.

- On le vit bien dès la réunion de ces élus de la nation qui, écartant les anciennes appellations, se déclarèrent membres de l'Assemblée nationale et jurèrent de ne se séparer qu'en laissant à la France une Constitution de ses droits et de ses libertés.

- Le pays lui-mème avait dressé le programme de leurs travaux.

- Il est, tout entier, inscrit dans ces cahiers approuvés par six millions d'électeurs, où la modération du langage fait resșorlir la force et l'élévation de la pensée, où l'ou voit apparaitre cette belle devise de "Liberté, Égalité, Fraternité, qui est devenue celle de la fiépublique, et dont la surprenante unanimité atteste a la fois la clairvoyance et l'unité morale du peuple français, en dépit de la division des provinces.

- Plus de provinces, disait-on déjà, la patrie!

- Faire une nation forte, unie, respectée, vivante et libre en abaissant les barrières 
qui découpent le territoire de l'ancienne lirance, en supprimant des privilèges incommodes et blessants; assurer à cette nation un droit uniforme, un gouvernement représentatif exercé au nom de tous et contrôlé par les élus du peuple; fonder l'égalité devant la loi, garantir la liberté individuelle et l'indépendance des liberlés religieuses et politiques, et effacer toutes les traces de la féodalité et du servage.

a Ainsi se résument les principes de 89, épars dans les cahiers et coordonnés dans la déclaration des droits de l'homme. Tàche grandiose devant laquelle nos pères n'ont pas reculé et qu'ils ont su accompliravec une admirable persévérance, sans se laisser ébranler par les plus redoutables obstacles.

- Condamnéc à soutenir contre l’ancien monde une lutte gigantesque, la France a traversé des temps doulourcux, où tous les partis ont successivement cédè à des entraînements a jamais regrettables. Elle n’a pas dévié de la voie qui, dès la première heure, lui fut tracée par les hommes de 89 : Constituante, Légrislative, Convention, autant d'étapes, autant de relais sur la route du progrès; constitutionnels, girondins, montagnards, tous architectes du mème édifice qui s'est achevé à travers les régimes successifs et qui abrite aujourd'hui tous les Français sans distinction d'opinions ni de partis.

a Duêne cour, avec la inème reconnaissance, nous devons tous nous retourner vers ceux qui, il y a cent ans, ont gravé dans les institutions de notre pays l'égalité des citoyens devant la loi et des enfants devant l'héritage, l'abolition des privilèges et le droit pour tous les Français d'accéder aux emplois publics et a': x grades de l'armée, la liberté du travail, l'équitable répartition de l'impòt annueliement consenti, l'indépendance de la pensée, la liberté des opinions religieuses et la souveraineté de la nation, d'où émane toute autorité légitime.

- Ces grands ancêtres ont fait notre France d'aujourl'hui : celle que nourrissent nos laborieux agriculteurs devenus inviolables dans la propriété du sol qu'ils cultivent; celle qu'enrichissent nos industriels, nos commerçants, nos ouvriers, délivrés des entraves des corporations et des jurandes; celle qu'illustrent nos écrivains et nos artistes; celle que nos braves soldats défendent et qui est pour tous ses fils, de près comme de lom, aux heures d'adversite comme aux jours de triomphe, l'objet d'un amour saus bornes et d'une indéfectible espérance.

- La Révolution dont nous célébrons l'aurore a fait éclore en un jour les germes féconds accumulés par un labeur dix fois séculaire et échauffés par le souffe des grands penseur's du $x^{2}{ }^{\circ}$ et du xvil' siècles.

- Elle a ouvert une ère nouvelle dans l'histoire. Elle a fondé la société moderne sur d'immuables assises; elle a créé la France démocratique, inébranlable dans son attachement aux principes de 89, à travers les régimes politiques qu'elle a vus se succéder depuis un siècle.

- Il étail réservé à notre génération de donner à cette démocratie son gouvernement nécessaire, une organisation politique assurant a la nation l'exercice de la souveraineté qui réside en elle, offrant à la liberté, à l'ordre et au progrès les garanties qui sont la condition première du travail et de la paix.

- La fundation de celte République est le couronnement de l'œuvre inpérissable qui a été commencée ici il y a un siècle. Elle est le but que devait atteindre, après bien des secousses, apris de cruelles épreuves, qui lui laissaient une inconsolable douleur, cetle généreuse nation française, si passionnée pour l'égalité et si jalouse de sa liberté. 
LES MERVEILLES DE L'EXPOSITION

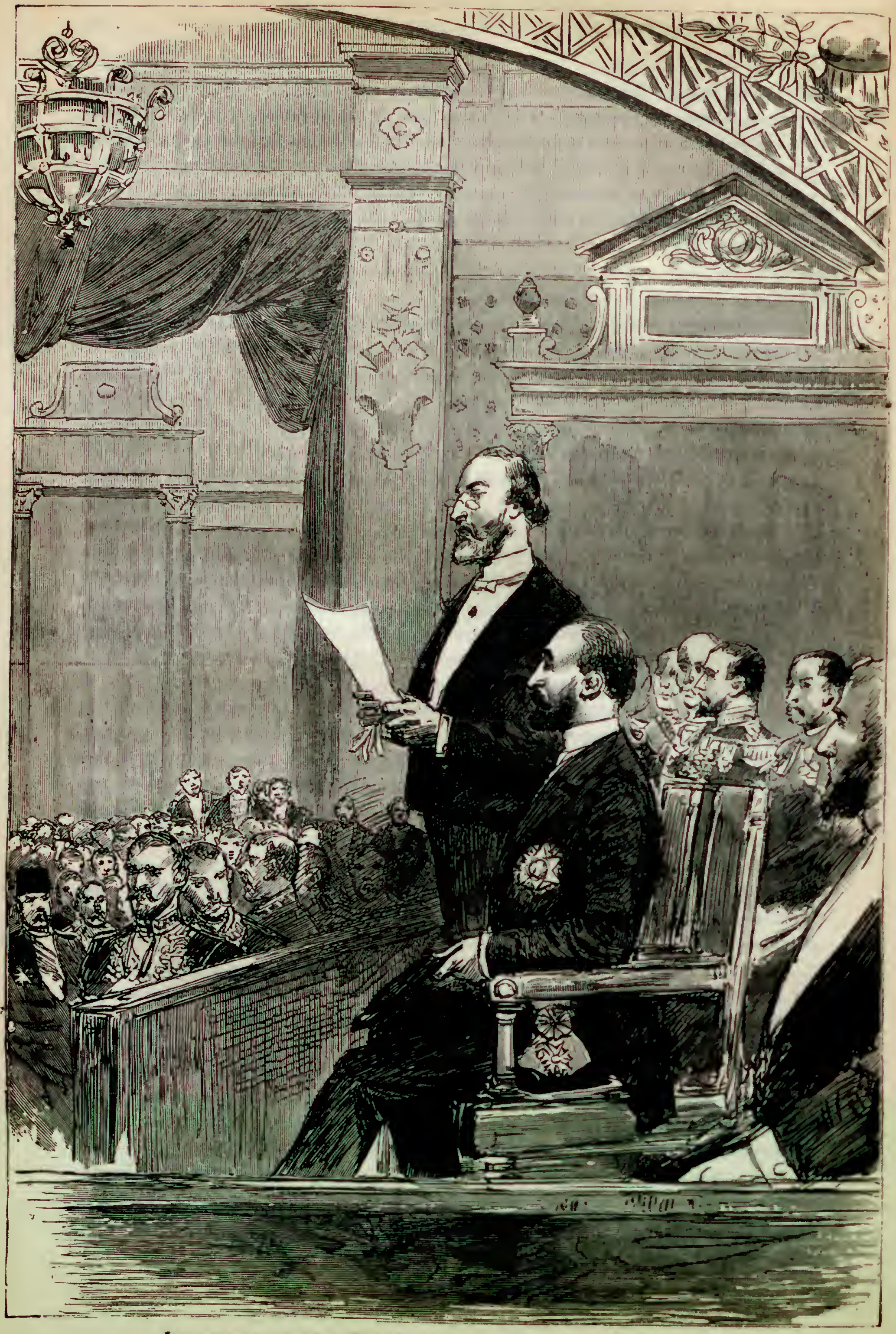

INAOGURATION OE L'EXPOSITION. - M. Tirard lisant son discours. 


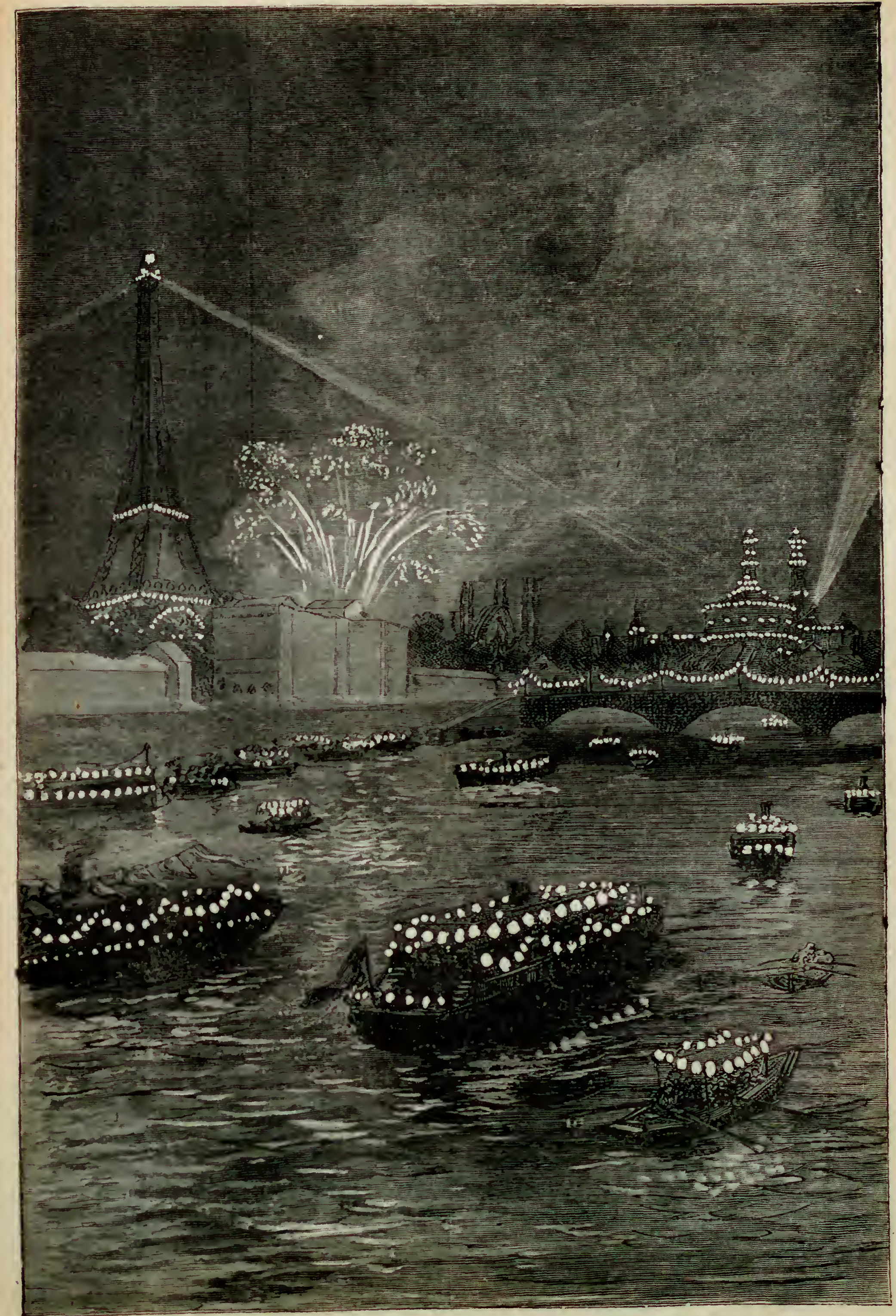

IXAUGURATION OE L'Exposition. - Fète vénitienne sur la Seinu. 
* Elle a définitivemént rompu avee le pouvoir personnel d'un homme. quelque titro qu il prenne, et ne reconnait plus d'autre souverain que la loi délibérée par les élus du peuple dans leur pleine indépendance.

- Telle est, Messieurs, l'œurre d'un siècle, le résultał acquis par cent années de travail politique, de réflexion et d'expérience.

- Qu'il nous soit permis, en ees lieux mêmes oì nos glorieux ancêtres ont apporté les premières revendications de la France, d'élever vers eux nos cœurs reconnaissants, de mesurer du regard le cliemin parcouru, de comparer la patrie a cent ans de distance, de montrer ce qu'ont pu réaliser les efforts d'un grand peuple, armé des vivifiants principes dont 89 a éclairé le monde.

- J'en appelle à vous tous, Français de 1889, à vous représentants, a qui le suffrage universel a confié la haute mission de faire les lois dlu pays.

" A vous, grands corps de l'État français, qui avez la charge d'appliquer ces lois, d'assurer le respecl de nos institutions. de garantir les droits et la liberté de tous :

" A vous, offieiers et soldats de l'armée nationale, qui portez si haut le sentiment de vos devoirs, et ce respect de la discipline qui fait la foree de la patrie.

- A vous, chers élèves de nos grandes écoles, filles de la lRévolution; à vous, 'élite de notre jeunesse; à vous, généreux initialeurs de toutes les cuvres de prévọ̆ance et de bienfaisance qui sont nées de la liberté de la pensée; à vous. écrivains et artistes; à vous, travailleurs de tout ordre qui nous montrerez demain les merveilles enfantées par l'esprit fécondant de 1789; à vous tous, je fais ici un appel qui sera entendu de votre patriotisme!

Ce que nous sommes, nous le devons à eeux que nous venons glorifier aujourd'hui. Ils nous ont laissé d'admirables exemples dont nous devons savoir nous inspirer. Soyons prêts a parfaire leur œuvre. Sachons retrouver les élans génèreux de celte grande époque, nous élever au-dessus des mesquines passions, des querelles de partis, des divisions d'écoles.

- Sous l'égide de la République, qui est le droit constitutionnel, elterehons dans l'esprit d'apaisement, de toléranee mutuelle, de coneorde, cette roree irrésistible des peuples unis.

- Le siècle glorieux que nous célébrons dans cette pieuse el grandiose cérémonie doit être couronné par la réconeiliation de tous les Français dans la commune passion du bien public au nom de la liberté, au nom de la patrie.

- Et la France aura toujours son rang à l'avant-garde des nations.

- Honneur à nos pères de 1789 !

- Vive la France!

- Vive la République!,

La réception terminée, le Président de la République se rend à la galerie des latailles, où est servi un lunch. Il repasse par les appartements de la Reine et les grands appartements du Roi, et se rend dans le pare, où le spectacle des grandes eaux est absolument féerique. A 5 heures et demie, le Président monte dans sa chaise de poste, attelée de quatre ehevaux. Une foule immense l'acelame, et le cortège, composé d'une dizaine de voitures escortées par un escadron du $6^{\mathrm{e}}$ cuirassiers, se met en marche. A Paris, tout le long des avenues du Bois-de-Boulogne, des Champs-Elyscies et de Marigny, une foule considérable attend le cortege présidentiel, qui à 8 heures arrive devant l'Arc de Triomphe et descend au grand trot l'avenue des Cilamps- 
Elysées. C'est au milieu d'une ovation unanime que M. Carnot rentre à l'Élysée. - Én somme; la fète qui eut lieu à Versailles pour la commémoration séculaire de l'ouverture des ĺlals généraux de 1789 fut digne des grands souvenirs qu'elle avait pour but d'évoquer. 'Tous les discours prononcés montrèrent que, dans l'esprit du gouvernement, elle était célébrée dans un esprit de paix et de solidarité patriotique que personne ne saurail récuser.

La fête d'inauguration de l'Exposition, qui eut lieu le lendemain, 6 mai, fut peutêtre plus unanimement joyeuse. Paris avait voulu une Exposition qui surpassât en richesses et en éblouissements de toute sorte toutes les précédentes, et il s'était tenu parole. Tous les partis, sauf de rares exceptions individuelles, firent taire leurs récriminations pour s'incliner devant le génie de la France, et les nécessités de la vie économique amenèrent en foule au pied de la Tour Eiffel les citoyens de ces gouvernements étrangers qui avaient cru devoir manifester leur défiance en s'abstenant de prendre une part officielle à l'cuvre de paix et de concorde à laquelle nous les avions conviés.

Le Clıamp de Mars fut, pendant la semaine qui précéda l'ouverture de l'Exposition, le théâtre d'une fiévreuse activité. Chacun voulait ètre prêt pour ce grand jour, et tous travaillaient avec un admirable zèle. Aussi, l'Exposition était-elle aux trois quarts prête le jour meme de l'inauguration.

Le 6 mai, a 1 heure et demie, l'équipage du Président de la République sortait de la cour de l'Élysée, et tout le long de l'avenue Marigny et des Champs-Élysées, M. Carnot recevait comme la veille les manifestations de la plus vive sympathie. Le cortège s'engagea sous la Tour Eiffel, dressée là comme un arc de triomphe gigantesque, puis longea la terrasse du Palais des Beaux-Arts, acclamé par une foule compacte. A 2 heures précises, le Président parvient devant le dòme central. Là, le service d'hollneur est fail par des soldats de la ligne, par des tirailleurs annamites et par des soldats noirs de nos diverses colonies. Le président du Conseil, entouré de tous les ministres et des trois chefs de service de l'Exposition, attendait le Président de la République devant la porte d'honneur. Au moment où M. Carnot descend de sa voiture, des vivats frénétiques s'élèvent de toutes parts et se renouvellent à son entrée dans la salle. Les places réservées au corps diplomatique sont au grand complet, et la galerie circulaire qui court autour du dòme est occupée par les dames; au centre, M Me Carnot préside.

Au milieu d'un profond silence, M. Tirard, président du Conseil, qui, en sa qualité de ministre du Comınerce, est en mène temps le commissaire général de l'Exposition, prend la pirole et rend hommage aux hommes qui sont parvenus, en si peu de temps, a élever une ouvre qui, dans son genre, ne saurait ètre comparée à aucune autre.

- Bien qu'il dépasse toutes.les espérances, dit II. Tirara, ce magnifique résultat n'a rıen qui nous doive étonner : le progrès ne ralentit pas sa inarche; les générations nouvelles remplacent incessamment les forces épuisées ou disparues; la science puissance souveraine de notre siècle - n'arrète pas le cours de ses conquètes; chaque jour elle pénètre plus avant dans les secrets de la nature; la vapeur et l'électricité ont déjà révolutionné l'ordre économique de l'univers; qui saurait dire les prodiges et les surprises qu'ellus ménagent encore à nous et a nos descendants? Les inventions, les découvertes, les perfectionnements se succèdent avec une rapidité vertigineuse; nul ne peut résister à cet entraínement: les usines, les ateliers, les manufactures, stimulés par la concurrence, encouragés par le succis, sont soumis à d'incessantes transformations, dont il faut se féliciter, puisqu'elles ont pour conséquence l'abondance de 



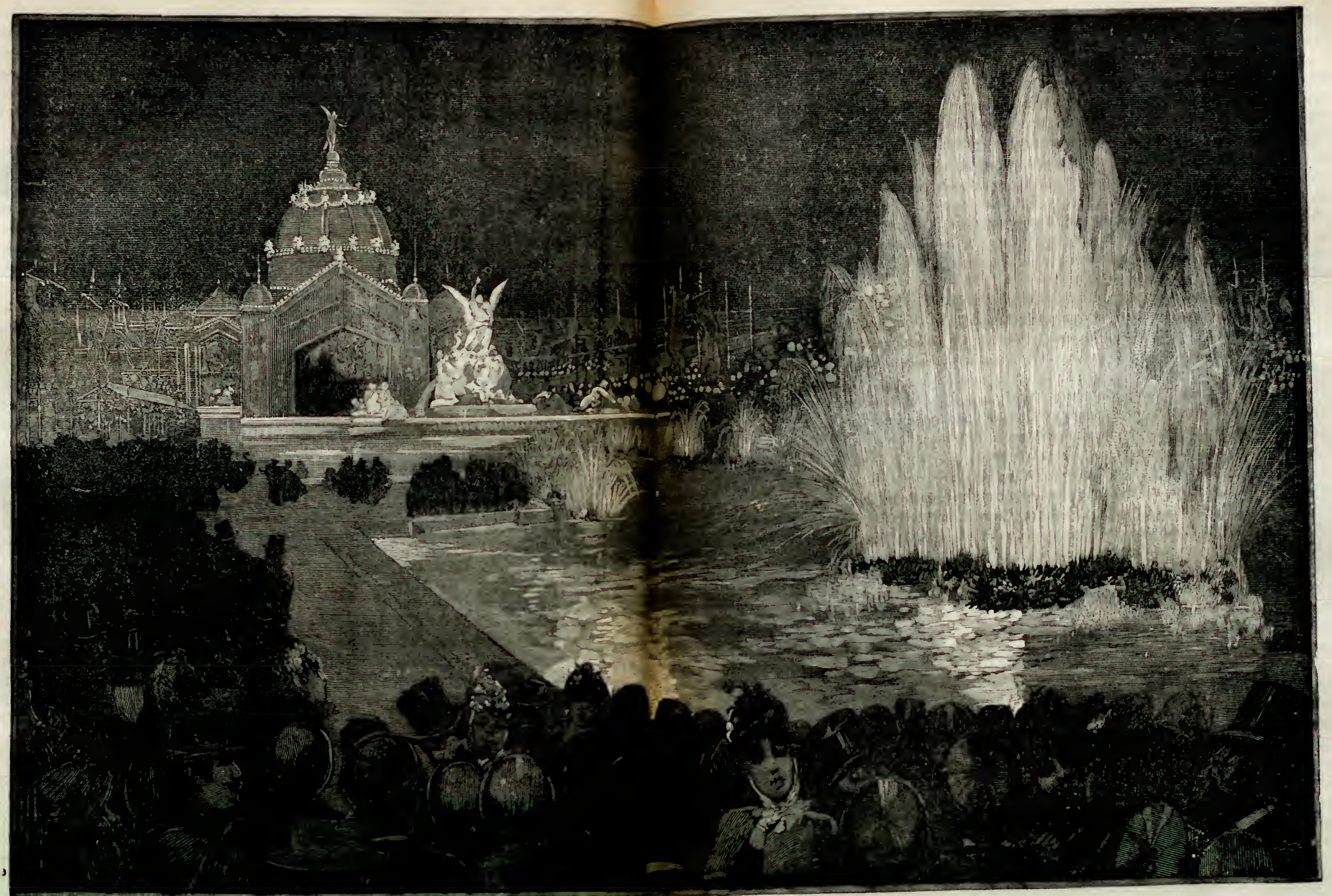

Inaugunation De 2. Expositiox. - Fite de nuit dans le Pare du Champ de Mars. 
choses nécessaires à la vie, l'abaissement de leur prix et, par suite, l'augrnentalion du bien-ètre général.

" Nos agriculteurs, laborieux, sobres, économes, patients, et si cruellement éprouvés par les đéaux et les intempéries, luttent courageusement et sont entrés résolument, eux aussi, dans la voie du progrès, en appliquant à leurs procédés de culture et d'élevage les méthodes scientifiques enseignées par des guides surs etéclairés. Nos artistes, glorieuse pléiade, dont à juste titre nous sommes si fiers, ne s'endorment pas non plus sur les lauriers conquis; tout en respectant les traditions et les enseignements des maitres qui les ont devancés, ils s'efforcent d'imprimer à leurs cuvres un caractère vraiment personnel, en associant de plus en plus intimement l'idéal de l'art aux vérités de la nature. La très remarquable exposition ouverte en ce moment aux ChampsElysées, aussi bien que la collection des dix dernières années contenue dans l'un de nos plus beaux palais, marquent une nouvelle et brillante étape dans la marche ascerldante de l'art français.

- Industric, agriculture, science, beaux-arts, partout le triomphe de l'élude et du travail! Spectacle réconfortant, et qui prouve combien ils se trompent ceux qui, se hatant de la juger superficiellement et sous l'influence des polémiques quotidiennes, croient la France exclusivement absorbée par les agitations stériles et les querclles des partis. Sans doute elle n'est point indifférente a la marche des affaires publiques; éclairée par les leçons de l'histoire, elle entend ne plus être dupe d'aucune aventure; plus que jamais elle est attentive à la conscrvation des libertés gloriensement el chèrement conquises par nos pères et au maintien de nos institutions.

- La France est libre, elle entend rester libre et ne subir la tyrannic de personne. pas mème celle qui pourrait naitre de l'abus des libertés si largement octroyées par la République; mais, quelque souci qu’elle prenne de ces graves intérêts, la France conserve les qualités essentielles de sa race, elle est toujours ce que l'ont faite ses ancitres: la grande nation honnête et laborieuse! Sa passion dominante est tonjours la passion du travail; elle y consacre son intelligence, sa science, son génie souple et fécond, son humeur joyeuse et franche, ses immenses ressources, en un mol le meilleur de ses forces, dont elle ne distrait que ce qui est néressaire à la défense du pays, et c'est ainsi que, malgré l'intensité de la crise économique qui, depuis plusieurs années, pèse sur le monde entier, elle a pu entasser tant de richesses artistiques, agricoles et industrielles dans le superbe domaine que nous inaugurons anjourd'hui.

- Ce phénomène n'est pas, d'ailleurs, spécial a la France. Le précicux et brillant concours que les nations étrangères ont bien voulu nous prèter, et qui ajoute tant d'éclat à notre Exposition, le prouve surabondamment: en toutes matieres, leurs prodiris rivalisent avec les nôtres, souvent mème ils les surpassent, et leur comparaison donnera lieu, comme précédemment, a d'intéressantes et profitables études. Si tous les gouvernements n'ont pas pris une part officielle à ce concours, la plupart d'entre eux ont secondé le généreux effort des initiatives privées par des encouragements el des subsides, el ont ainsi contribué au succes d'une participation qui, dans son ensemble, est supérieure à celle des précédentes expositions.

- Je n'en finirais pas, Messieurs, si je voulais décrire tout ce qui s'olfre ici volre admiration; je pourrais le faire sans offenser la modestie, car celui qui a l'honneur de parler en ce moment n'est qu'un ouvrier de la dernière heure; mais cela m'entralnerait trop loin. Ne suffit-il pas d'ailleurs, pour s'en rendre compte, de lever les regards sur 
la superbe coupole qui nous abrite, puis de les porter sur la vaste galerie qui s'étend devant nous et conduit à cette autre merveille, déjà célèbre, le Palais des Machines, grandiose chef-d'œuvre de construction mélallique, dont les proportions gigantesques el pourtant harmonieuses rivalisent avec les hardiesses de la tour de 300 mètres, que le public a baptisée du nom de son éminent constructeur, M. Eiffel.

a Et tout cela, Messieurs, s'est exécuté avec un ordre, une rapidité et une régularité qui étonneraient, si l'on ne connaissait l'homme qui a dirigé tout cet ensemble de travaux. C'est l'ingénieur habile qui, depuis quarante ans, travaille à l'embellissement et à l'assainissement de Paris et qui en a fait, je n'ose pas dire la plus belle, mais assurément l'une des plus belles villes du monde. Oui, M. Alphand a couronné sa laborieuse et utile carrière en construisant le plus splendide cadre d'exposition qui ait jamais été fait, et il a ainsi conquis un titre de plus à la reconnaissance de ses concitoyens.

- Pour organiser et conduire a honne fin une aussi vaste entreprise, il ne suffisait pas d'un grand constructeur, il falliait un administrateur habile et très expérimenté : c'est M. Berger, qui déjà s'était si ǵnalé dans maintes expositions en France et à l'étranger, qui a bien voulu se charger de la direction de l'exploitation.

- Je ne saurais assez louer le zèle et le dévouement qu'il a déployés dans ces ingrates et difficiles fonctions. C'est lui qui, par son ardente activité, ses nombreux voyages dans nos départements et à l'étranger, ses conférences, ses connaissances techniques, a donné l'impulsion première et vigoureusement contribué au grand succès que nous pouvons constater dès aujourd'hui. Que M. Berger reçoive donc le tribut d'éloges que méritent si bien les nouveaux services qu'il vient de rendre à l'industrie française l

- Enfin, par une heureuse disposition réglementaire due à l'initiative de l'un de mes prédécesseurs, l'honorable M. Lockroy, le contrôle financier des travaux et de toutes les dépenses a été assuré par la création d'une direction spéciale, à la tête de laquelle a été placé un comptable de premier ordre, dont la carrière adṃinistrative au ministère du Commerce se trouve ainsi brillamment complétée par un travail minutieux et compliqué qui assure la régularité de toutes les opérations, de tous les comptes, et qui fait le plus grand honneur à M. le directeur Grison...

- Et maintenant, Messieurs, félicitons-nous d'avoir ouvert une fois de plus les portes de la France aux produits du monde entier. Félicitons-nous de cette grande et pacifique manifestation des forces productives de notre cher pays, qui continue sa marche fièrement assurée dans la voie du progrè̀s et de la civilisation.

- Accueillons et fètons avec joie les étrangers dont la foule se presse déjà dans nos murs; prouvons-leur que la France républicaine est hospitalière et généreuse, qu'elle -aime et honore les travailleurs de tous les pays et voit en eux, non des rivaux qu'elle jalouse, mais des collaborateurs qui travaillent avec elle au bonheur de l'humanité et à la paix du monde. :

Le discours de H. Tirard fut particulièrement applaudi quand il attesta les intentions de la France de vivre libre, et quand il rendit hommage au zèle des principaux chefs de service de l'Exposition. Mais un grand silence se fit à la voix de M. Carnot, qui prononça l'allocution suirante :

- Messieurs, la France gloriliait hier l'aurore d'un grand siècle qui a ouvert une ère nouvelle dans l'histoire de l'humanité.

"Aujourd'hui nous venons contempler, dans son éclat et dans sa splendeur, l'œuvre enfantée par ce siècle de labeur et de progrès. 
- Nơss venons saluer les travailleurs du monde entier qui ont apporté ici le fruit de leurs a forts et les productions de leur génie. Nous venons tendre une main amie d tous ceux qui se sont faits nos collaborateurs dans l'œuvre de paix et de concorde a laquelle nous avons conviẻ les nations.

- Nous venons souhaiter la bienvenue aux visiteur's qui, déjà, de tous les points de l'ho rizon, en deçà ou au delà des frontières, arrivent sans compter les distances pour prendre part à nos fètes.

- lls trouveront ici une terre hospitalière, une ville heureuse de les accueillir, et verront ce que valent les calomnies dictées par des passions aveugles auxquelles le respect mème de la patrie ne sait pas imposer silence.

- Notre chère France est digne d'attirer à elle l'élite des peuples. Elle a le droit d'être fière d'elle-mème et de célébrer, la tête haute, le centenaire économique comme le centenaire politique de 1789.

c Elle a su se relever, a vec une indomptable énergie, après les plus cruelles épreuves, et n'a jamais désespéré de la fortune. Par sa bonne foi dans les engagements publics et par sa loyauté, elle a inspiré une juste confiance; elle a trouvé dans ses institutions la force de vivifier le travail, de ranimer l'activité du commerce el de l'industrie, de rendre courage à l'agriculture atteinte par de redoutables fléaux; l'épargne nationale a reçu la plus admirable impulsion, et jamais il ne s'est produit plus de généreuses initialives, plus de recherches passionnées dans toutes les branches de la bienfaisance publique et privée.

- Je le répète avec fierté : la France poursuit dans le calme et dans la paix son œuvre de progrès, et le siècle laborieux qui s'achève laissera dans son histoire une trace lumineuse.

- Quel chemin parcouru, Ilessieurs, depuis que François de Neufcliateau installait, en 1798, cent dix exposants dans le Temple de l'Industrie!

- Quel admirable essor a pris l'activité humaine afranchie de toutes les entraves du passé! Quel développement de la richesse publique sous l'influence du travail émancipé, du commerce libéré, des douanes intérieures supprimées!

- Au point de vue social, on peut traduire le progrès par cette éloquente formule : la vie humaine accrue, la mortalité abaissée.

- Dans l'atmosphère fortifiante de la liberté, l'csprit humain retrouve son initialive, la science prend son essor, la vapeur et l'électricité transforınent le monde.

- Un siècle qui a vu de pareils miracles devait ètre célébré.

- On ne saurait mieux le faire que par cel admirable concours des peuples, qui, venus de toute les parties du monde, se donnent rendez-vous pour rassembler les merveilles de l'industrie et les splendeur's de l'art de notre époque.

- C'est dans ces fètes grandioses du travail que les nations peuvent se rapprocher et se comprendre, et que doivent naître les sentiments d'estime et de symputhie qui ne manqueront pas d'influer heureusement sur les destinées du monde en avangant l'heure où les ressources des peuples et le produil de leur travail ne seront plus consacrés qu'aux œuvres de la paix.

- Aussi, Messieurs, l'appel de la France a été entendu et le concours spontané et indépendant que les peuples eux-mèmes ont voulu apporter à cette manifestation de fraternité internationale vient encore ajouter a la grandeur morale de cette fête.

c Son éclat matériel, vous en jugerez tout à l'heure. Vous verrez quelles surprises 


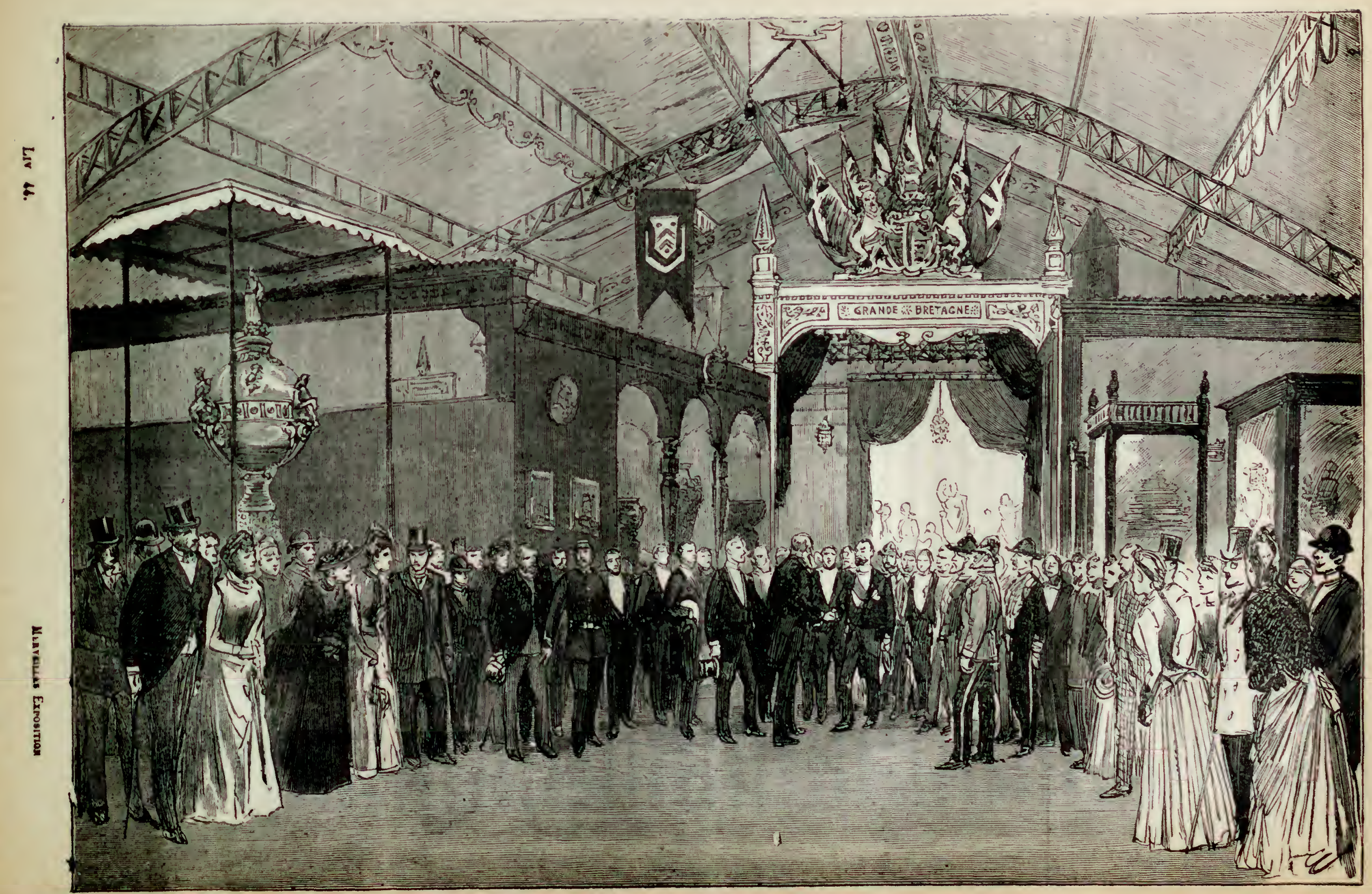

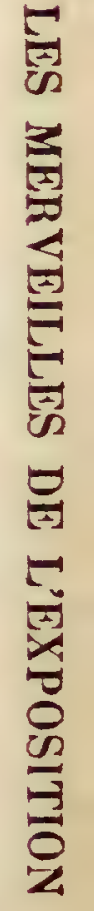

INaUgunation dis L'Exposition. - M. Carnot traversant la Section anglaiso. 
ménageaient d̀ notre génération les merveilleux progrès de la science, comme les ressources inépuisables de l'industrie humaine et les trésors artistiques qui jettent sur notre époque un si brillant éclat.

- Vous connaissez déjà le cadre où se déploient ces merveilles. Vous avez pu apprécier en entrant ici la belle ordonnance de cette grande Exposition, où ingénieurs. architectes et constructeurs ont rivalisé de science, d'activité, de dévouement pour présenter au monde une ouvre digne du génie de leur pays.

" Au nom de la France, je les remercie, eux et leurs collaborateurs. Ils n'ont pas vaincu sans combat; il leur a fallu triompher et du temps et de la matiere, et pardessus tout, des mauvais vouloirs persistants à ne pas comprendre que l'Exposition n'est pas une œuvre de parti, mais l'œuvre de la France. Ces hommes de cœur ont su répondre à la confiance de la République et tenir fidèlement tous ses engagements. Après avoir été à la peine, ils ont droit d'ètre à l'honneur.

- Et maintenant, Hessieurs, nous allons visiter enscmble les trésors que le monde a accumulés dans ces palais et ces jardins, en donnant à notre pays un si éclatant témoignage de confiance et de sympathie.

- Après avoir, de nouveau, souhaité une cordiale bienvenue aux hótes de la France, je déclare ouverte l'Exposition de 1889. ,

A 2 heures et demie, M. Carnot terminait son discours au miliell diune qiadruple salve d'applaudissements et commençait sa promenade à travers l'Exposition. [] parcourut d'abord la gralerie centrale du Palais des Industries diverses, ou les comités des groupes étaient rangés, chacun devant sa façade, et arriva dans le grand vestibule, à l'entrée du Palais des Machines. Dix mille personnes s'écrasaient pour le suivre Les machines, que le Président domine de la galerie du premier étage, ronflent formidablement. Le cortège, après avoir traversé d'un bout à l'autre le palais de M. Dutert, s'engage dans les galeries des Arts libéraux, où les commissaires des sections étrangères installées de ce còté, viennent saluer M. Carnot à son passage.

Dans le programme primitif, le Président devait recevoir les commissaires des Républiques américaines au Palais des Arts libéraux. Ceux-ci, dont les pavillons remplissent l'angle ouest du Champ de Mars, protestèrent contre cet itinéraire. Ils firent observer que leurs peuples étaient latins comme le nôtre, qu'ils viraient sous une forme de gouvernement semblable à la nôtre, quils étaient tous officiellement représentés à l'Exposition et que les relations commerciales et artistiques les plus suivies existaient entre eux et la France. A tous ces titres, ils croyaient aroir droit à la visite du Président de la République. Ils voulaient le voir au milieu de leurs expositions.

M. Carnot s'empressa de déférer à un væu aussi légitime. Le cortège se dirigea donc vers ce groupe de pavillons si attirant par la variété de ses architectures, avant de se rendre devant la fontaine monumentale de M. Coutan, qui comporte une quinzaine de personnages beaucoup plus grands que nature. Une femme symbolisant le Progrès est assise sur un trône qu'une barque emporte. Un coq sonne une fanfare a l'aviant; l'Alı, l'Industrie, le Commerce et l'Agriculture se pressent autour du trone; la liêpublique est au gauvernail, la liontine et l'Ignorance sont culbutées par cet équipage. Dans le bassin des personnages marins jouent avec des tritons.

M. Antonin Proust, qui attendait le cortège sous la porte principale du Palais des Beaux-Arts, l'introduisit sous le dôme. Pendant qu'une collation est servie au Président 
de la République, l'orchestre de Danbé joue un morceau fait pour la République de 1848 et retrouvé dans l'œuvre d'Adam.

En sortant du Palais des Beaux-Arts, M. Carnot acheva la visite du Palais des Industries diverses et revint par la galerie centrale jusqu'au dôme, où l'attendait sa voiture qui allait le conduire au 'Trocadéro et au quai d'Orsay.

Le long du quai d'Orsay se développent, sur une longueur de 2 kilomètres, les baraquements destinés a l'agriculture française et étrangère, le Palais des Produits alinentaires, et un Palais espagnol.

L'Esplanade des Invalides était éblouissante pour la cérémonie d'inauguration. Les façades indo-chinoises avaient arboré sur leurs piliers des planches à inscriptions laquées de rouge vif. Le Palais Algérien, les batiments de la Tunisie resplendissaient. La Pagode d'Ang-Kor, toute dorée, brillait sous le soleil, et le long du Palais central des Colonies des soldats indigenes se tenaient l'arme au pied. La musique arabe des turcos jouait avec un zèle très louable, sans couvrir les bravos frénétiques de la foule.

A sa sortie du Palais, M. Carnot reçut des bouquets de tulipes et de lilas que lui offrirent les négresses de la section. A l'Exposition du Ministère de la Guerre le général Coste lui présenta tous les membres du Comité militaire de l'Exposition.

Après le départ du Président, le Champ de Ilars offrait un spectacle des plus animés. L'heure du diner arrivant, la foule prit d'assaut les restaurants, faisant main basse sur les provisions qui surchargeaient les comptoirs. Il fut bientôt impossible de trouver une table, ni même une chaise, et les restaurateurs, petits et grands, durent déclarer qu'il leur était impossible de faire un second service. Les affamés durent se contenter de sandwiches, de brioches; mais bientôt le pain mème vint à manquer. Un restaurateur, ayant de la farine dans sa cave, eut l'idée de faire cuire du pain et le servit chaud à ses clients. Un certain nombre de personnes sortirentet, après des incursions chez les boulangers du voisinage, rapportèrent triomphalement des pains de quatre livres. Plusieurs fournisseurs des environs songèrent à tirer parti de la situation et se mirent en devoir de ravitailler la place. Sur des voitures de marchands des quatre saisons, dans des hottes, dans des paniers, ils amoncelèrent des provisions de toute nature et vinrent camper le long des palissades du Chan̈p de Mars; de l'intérieur, les personnes qui n'avaient pas voulu quitter l'enceinte de l'Exposition, pour ne pas avoir à donner trois tickets à la rentrée, mirent les comestibles aux enchères. Le saucisson faisait prime un morceau bien petit a trouvé acquéreur à deux francs, et un pain de quatre livres a été vendu quatre francs. Des hommes et des femmes étaient assis en cercle autour des caisses non encore déballées, qui leur servaient de tables. On pense bien que dans Paris, sur les boulevards, il y avait fort peu de monde. Toute la population s'était portée au Champ de Nars ou aux abords, malgré les illuminations qui étaient magnifiques. Les tours, les frontons, les dômes de la Trinité, de Saint-Augustin, de la Madeleine resplendissaient dans la nuit. Au bout de la rue Royale, un embrasement général : les façades des maisons sont colorées en rouge vif par le reflet des splendides illuminations de la place de la Concorde. Le ciel est entièrement couvert de nuages empourprés qui se renouvellent sans cesse emportés par la brise. D'innombrahles rampes de gaz se croisant et s'enchevitrant en tous sens forment commo les mailles d'un immense filet lumineux a travers lesquelles passent les gerbes des jets d'eau. De place en place. des torchères immenses lancent des nappes de flammes. 
Le pont de la Concorde est entièrement couvert d'ifs lumineux, au bout le Palais Bourbon est magnifiquement décoré.

Sur la Seine, on admirait les barques pavoisées et couvertes de lanternes véni-
tiennes.

Mais tout cela n'était rien à côté de l'Exposition où plus de 333,000 tickets avaient été reçus par le contrôle! Si vous ajoutez à cela les entrées gratuites, vous aurez une idée de la foule qui se promenait dans les jardins et les palais du Champ de Mars. Un. de nos confrères du Temps, qui a pu contempler la fête de nuit du haut de la Tour Eiffel, en donne une description enthousiaste. c La magnifique soirée d'hier! dit-il. Comment la décrire? Et surtout comment donner une impression à peu près exacte du spectacle qui s'est déroulé sous les yeux des quelques personnes admises à faire l'ascension de la Tour de 300 mètres? De la cage du phare, où nous avons pénétré, Paris. s'étend, semble-t-il, jusqu'à la ligne d'horizon; sa masse sombre et vivante se ponctuepeu à peu de points lumineux qui bientôt deviennent légion. L'architecture des principaux monuments, de l'Opéra, de Saint-Augustin surtout, qui est si joliment illuminé, de l'Arc de triomphe, des Invalides, le dessin des places et des jardins, sont déterminés, dans leurs lignes principales, par des traits lumineux. Mais, ce qui est une merveilleuso surprise, c'est de contempler la courbure tout entière de la Seine, à travers Paris, entre la double haie des girandoles et des candélabres allumés sur les quais. En outre, une autre surprise, c'est de constater, du haut de la Tour Eiffel, que certains points de. Paris se sont, par un phénomène d'optique, étrangement rapprochés de nous. C'est ainsi que la place de la Concorde apparait presque au pied de la Tour.

- Mais, si le spectacle de Paris s'étendant au loin est surtout émouvant et presque auguste, celui de l'Exposition est féerique. A gauche, la passerelle de Passy est une longue dentelle d'or; en face, le Trocadéro, avec son énorme carapace centrale et ses deux ailes qui se prolongent, admirablement illuminé de diverses couleurs, nous aveugle de sa clarté. A droite, les ponts tendent de distance en distance des réseaux de feux sur la Seine, où passent lentement des bateaux chargés, comme de beaux fruits, de lanternes vénitiennes. Et derrière nous le Champ de Mars, avec le dòme central, et surtout ses fontaines multicolores. Ces fontaines ont élé saluées hier soir par les acclamations des deux cent mille personnes qui se trouvaient dans l'intérieur de l'Exposition. Le grand bassin de la fontaine Coutan est bordé, sur chacune de ses deux lignes longitudinales, d'une série de jets d'eau qui, tour à tour, lancent des gerbes jaunes, vertes, rouges, violettes ou bleues. En outre, à l'extrémité inférieure de ce bassin, du centre de la grande vasque circulaire, s'élance, à une hauteur qui, mẻme de la Tour Eiffel, semble considérable, une sorte de dôme formé par des jets d'eau combinés. Ce sont les mèmes couleurs du prisme que revêtent ces gerbes d'eau, mais atténuées un peu, tandis que celles des jets simples ont une merveilleuse pureté.

- Dans les jardins du Champ de Mars, comme dans ceux du Trocadéro, les bosquets sont chargés de lanternes vénitiennes jaune rouge. Et tout cela, toutes ces couleurs lumineuses se mèlent en une indéfinissable harmonie qui donne une idée véritablement grandiose de fète.

- A 10 heures, le feu d'artifice est tiré à l'île des Cygnes.

- C'est pendant une demi-heure une véritable canonnade, a laquelle répondent les cris de la foule, le canon de la Tour Eiffel, et, dans le lointain, d'autres fusées, qui éclatent en gerbes dans le ciel., 


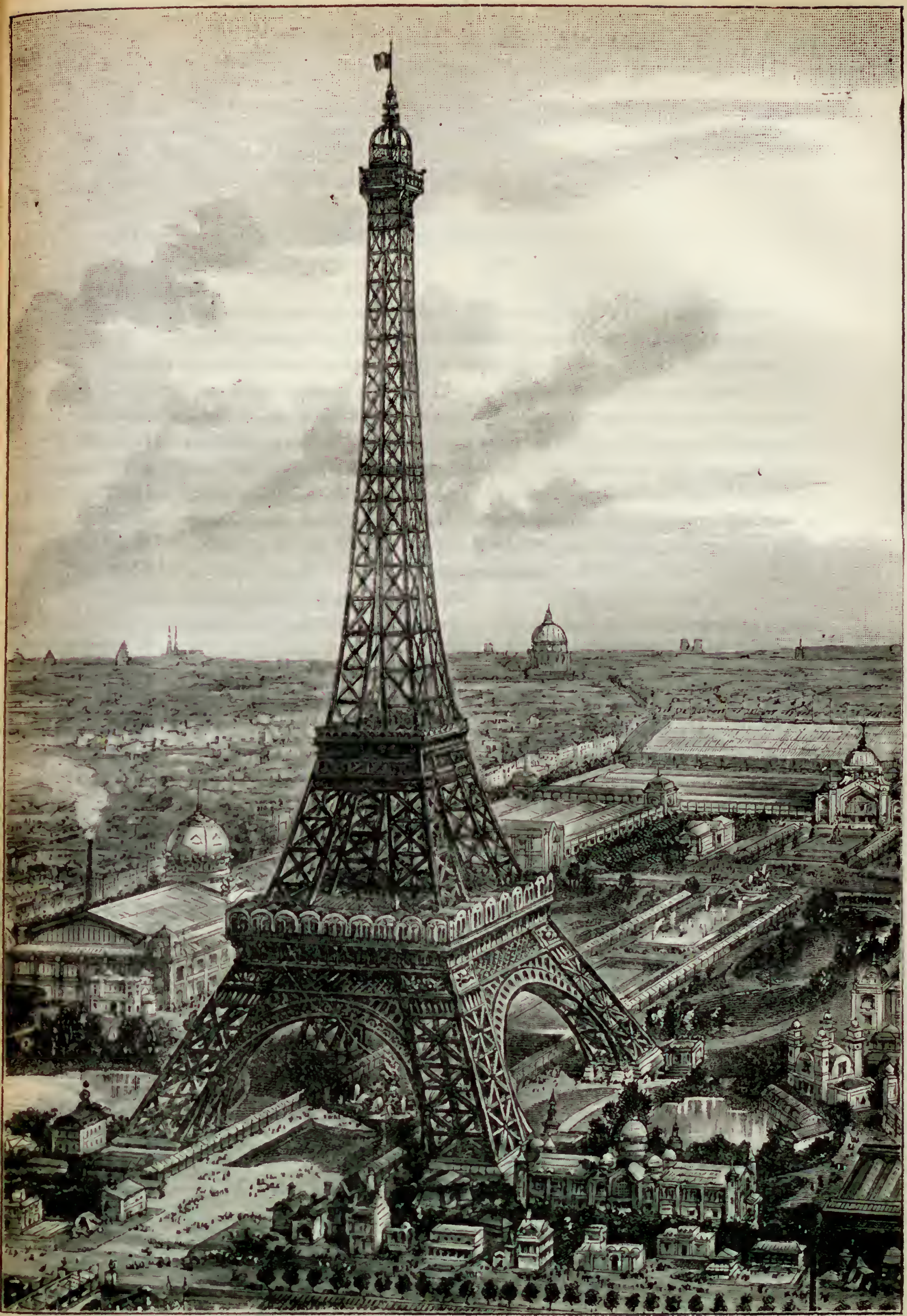

L'Exposition Unipehsele. - Le Champ de Mars vu du pare du Trocadéro. 


\section{$\mathbf{X} \mathbf{I}$ \\ LA FOMTAIN LuHINEUSE}

Entre la Tour Eiffel et le Dỏme central, le sculpteur Coutan a édifié une fontaine qui a été l'une des premières et l'une des plus curieuses attractions de l'Exposition.

Dans le plan primitif de M. Alplıand, le parc central devait etre orné de quatre pièces d'eau, dont la plus importante serait disposée de manière à racheter la différence du niveau entre les parties haute et basse du parc; les trois autres pièces d'eau, de moindre étendue, devaient se composer de bassins de forme allongée avec effet d'eau au milieu, analogues à ceux des Champs-Élysées en face du Palais de l'Industrie. Quand fut formé le syndicat international des électriciens en vue de l'éclairage de l'Exposition le soir, M. Alphand résolut d'installer plusieurs fontaines lumineuses analogues at celles qui avaient fonctionné avec beaucoup de succès aux Expositions de Londres (1884), de Manchester (1887) et de Glascow (1888). Après avoir entendu les observations de MM. Beckmann et Formigé, les trois petits bassins dont il avait été question furent supprimés, et l'on décida qu'oll construirait une seule pièce d'eau, ornée d'une fontaine à gerbe lumineuse et sculptée par M. Coutan.

La fontaine lumineuse monumentale qui s'étend au bord de la terrasse du Palais Central est une des grandes attractions de l'Exposition, celle qui, le soir, captive le plus l'attention des visiteurs. Le jour, elle est déjà très imposante avec ses innombrables gerbes qui jaillissent dans tous les sens. Le soir, elle prend des proportions et un aspect vraiment féeriques, quand les jets s'embrasent, relombent en pluie de reu, passent brusquement d'une couleur à l'autre ou combinent leurs nuances délicates. - Le succès de la Fontaine lumineuse, dit J. Cardane, a été d'autant plus vif que la plupart des visiteurs, prêts à crier à la magie, essaient vainement de découvrir le secret des transformations instantanées subies tantôt par la totalité, tantôt par une partic seulement des jets en fonctionnement. Quand un jet éparpille dans l'espace une pluie de goutteleltes, celles-ci sont très nettement colorées et semblent ctre des rubis, des sineraudes, des topazes, selon que le jet est coloré en rouge vif, en vert, en jaune, en lilas, ctc. La coloration n'est donc pas extérieurement produite par une projection quelconque; elle fait corps avec l'eau. , La Fontaine lumineuse est, en effet, l'application d un principe découvert en 1841 par le physicien suisse Colladon. M. Cardaue rappelle que Colladon eut un jour l'idée de placer dans l'ouverture d'un vase, opposée au trou d'écoulement du liquide, un verre grossissant derrière lequel il avait placé une lampe. Les rayons lumineux rendus convergents par la lentille se trouvèrent absorbés pal le liquide et y restèrent emprisonnés, illuminant non seulement la colonne de liquide, mais aussi ses moindres gouttelettes. Il suffisait donc de remplacer la lampe par un foyer électrique puissant et la lentille par un verre de couleur. La projection des rayons lumineux ne pouvant se faire horizontalement par des jets d'eau, les constructeurs de la Fontaine du Champ de Mars placèrent le foyer sous le jet d'eau, de manidre a projeter des rayons verticalement, et ils interposèrent une lame de verie simple entre le jet 
et le foyer électrique. "Dans ces conditions, il ne reste plus qu'd faire glisser entre le foyer lumineux of la plaque de verre incolore, des plaques rouges, bleues, vertes, etc., pour donner immédiatement à l'eau qui s'échappe du jet, l'une de ces teintes." Notre Fontaine lumineuse, établie d'après le principe de Colladon, perfectionnée par te colonel Bolton, est due à MM. Beckmann et Meker, ingénieur's du service des eaux it I'Exposition. MM. Beckmann et ILeker font passer le faisceau lumineux, non directement dans la masse du jet liquide, mais dans le vide central de ce jet obtenu par la disposition spéciale du bec de lancement.

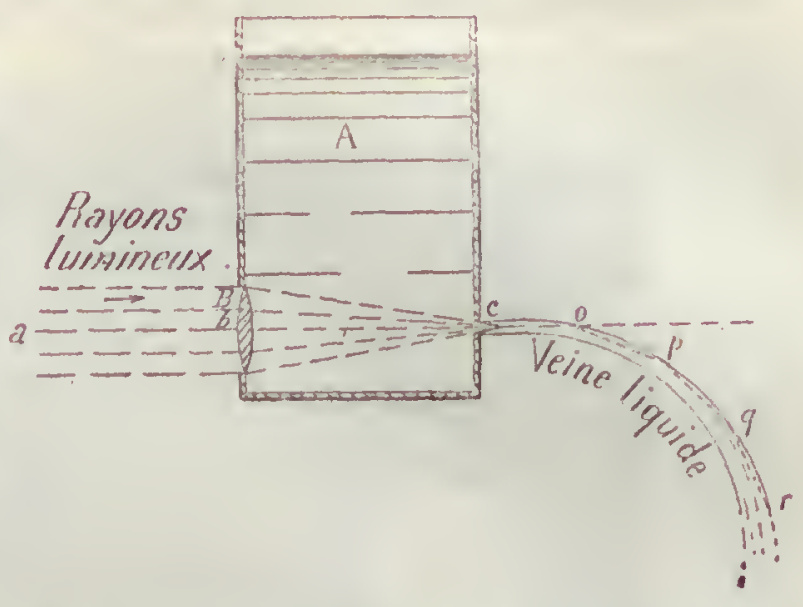

Pour bien faire comprendre à nos lecteurs le mécanisme de la Fontaine lumineuse, nous leur mettrons sous les yeux la description qui en a été donnée par un ingénicur français, M. Arthur Good:

a C'est dès iS4, dit M. Good, qu'un physicien suisse, Colladon, imaginait la fontaine lumineuse représentée sur la figure ci-dessus

- A est un vase dont les parois opposées sont percées de deux ouvertures: l'une par où s'écoule le liquide, l'autre où se loge un verre grossissant. Si l'on approche une lampe de celui-ci, les rayons lumineur, rendus convergents par la lentille, sont absorbés par le liquide et $\mathrm{y}$ restent emprisonnés, illuminant non seulement la vcine principale, mais jusqu'à ses moindres gouttelettes, qui se transforment en autant d'étincelles. Notre figure montre la marche du rayon lumineux ab ainsi absorbé, qui, au lieu de sortir du vase suivant la ligne co, comme si celui-ci était vide, est successivement réfléchi suivant les lignes op, $p q$, $q r$, etc., d'où le nom de réflexion cotale, donné au phénomène.

- Nous venons de supposer le jet liquide projeté horizontalement; s'il est vertical, l'expérience réussit tout aussi bien; il suffit de placer le foyer lumineux sous l'ajutage de maniise à projeler les rayons verticalement aussi, et d'interposer une lame de verre entre le jet et le foyer; enfin, si au-

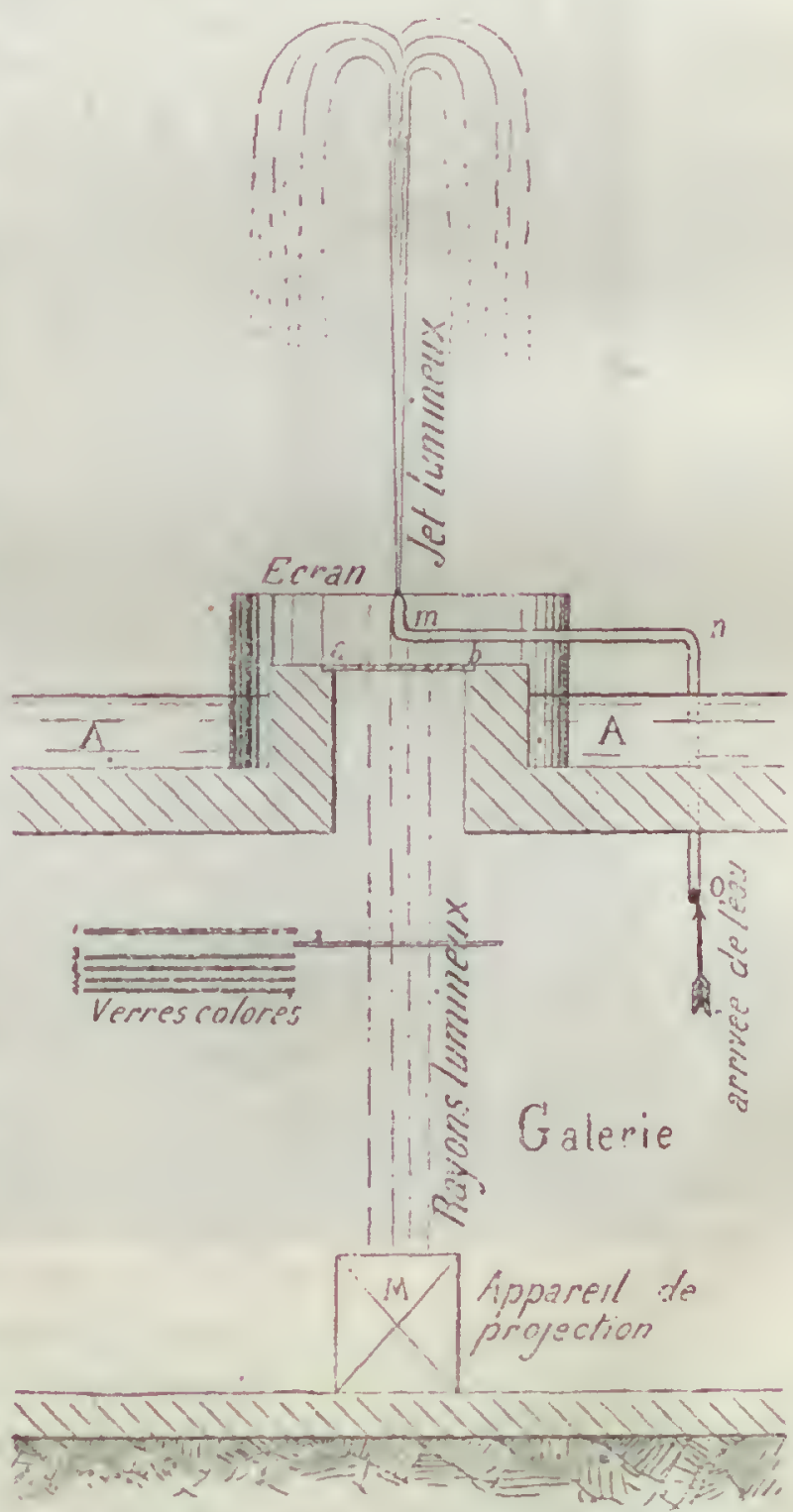
dessous de la lame de verre incolore on en fitit glisser une seconde, colorée en rouge ou en bleu, le jet d'eau se teintera de rouge, de bleu, ou de violet si les verres ronges el bleus sont superposés 
Remplaçons maintenant la lampe à huile de Colladon par un puissant foyer électrique renfermé dans un projecteur M. et nous pourrons éclairer non plus sculement un filet d'eau, comme dans une expérience de laboratoire, mais des jets de 20 mètres de hauteur, comme à l'Exposition.

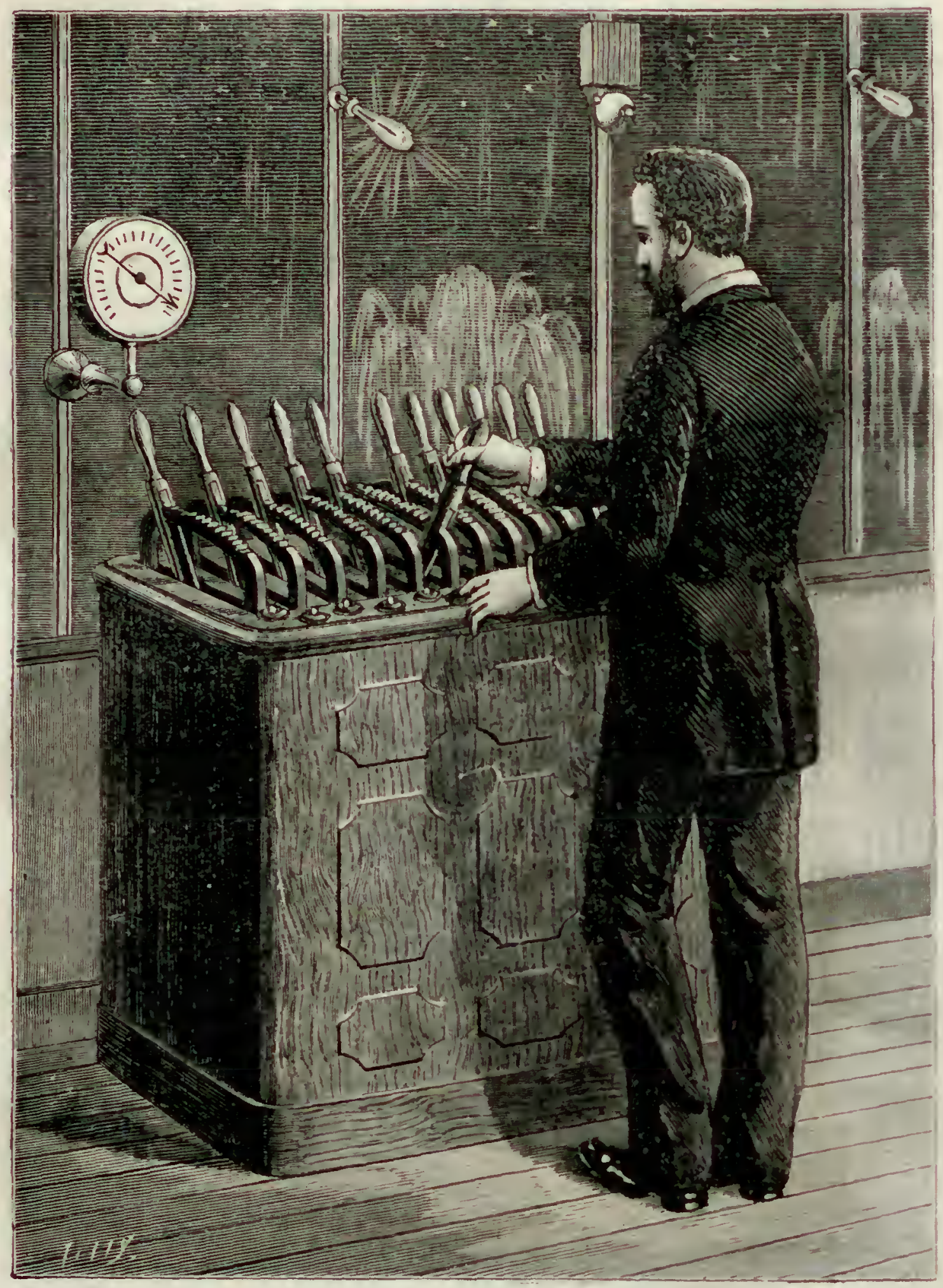

LA FOXTAIXE LUMLXEUSE.

Nै 1. Interieur du biosque d'observation.

- Telle est la théorie : pour en comprendre l'application, entrons, d'abord, dans lo kiosque vitré situé à quelque distance de la fontaine, et dont la gravure $n^{0} 1$ nous montre l'intérieur. Un opérateur y manœuvre des leviers analogues aux pompes a bière des cafés-restaurants : ce sont les robinets modérant ou augmentant le débit des différents jets, de manière à varier les effets; en mème temps que ces robinets, notre 
homme fail agir des signaux indiquant aux machinistes placés dans le sous-sol quelles sont les colorations à obtenir. C'est dans ce sous-sol que nous transporte notre gravure n० 3. Au sommet des voûtes courent les fils électriques alimentant les iampes placées

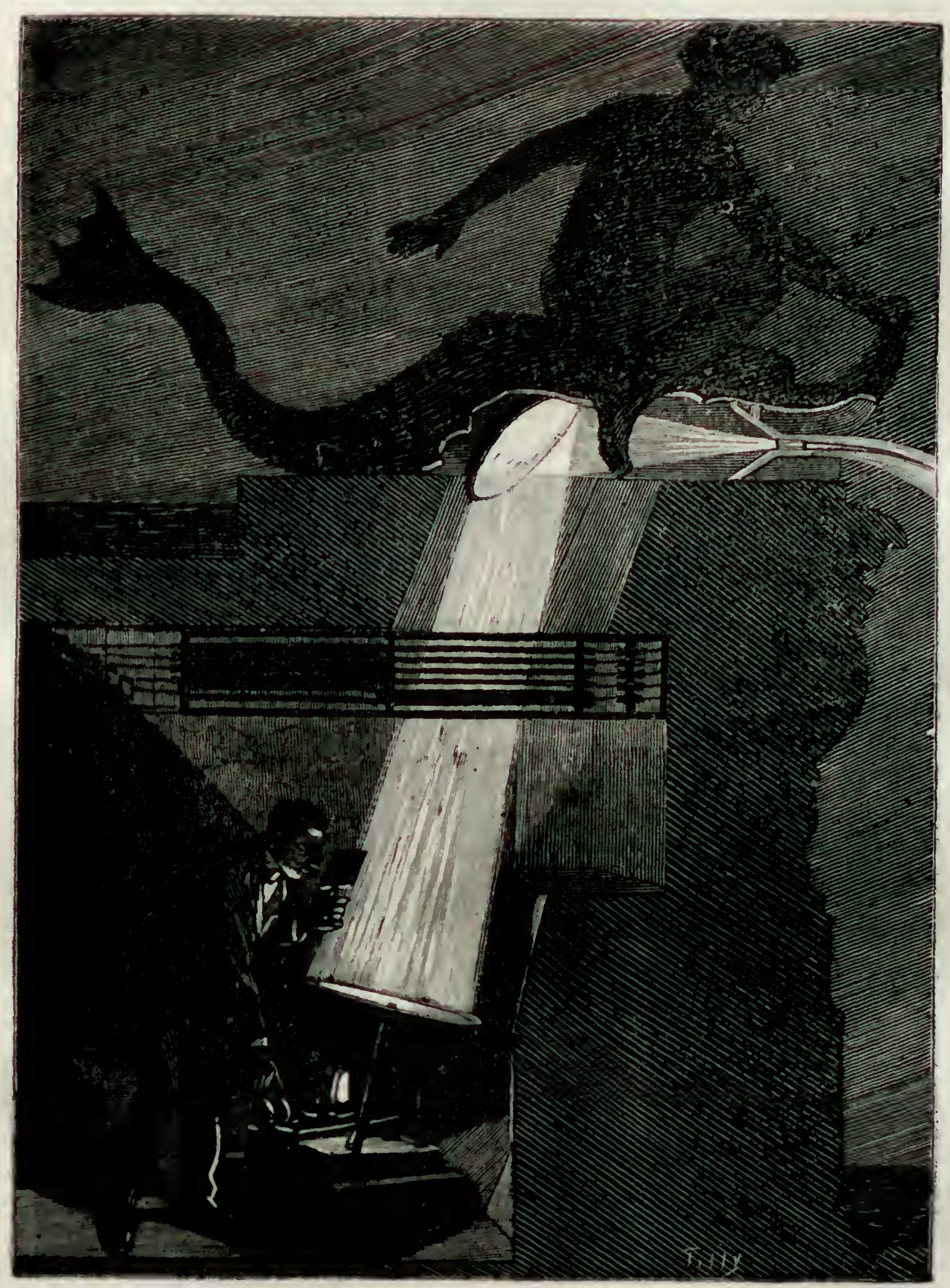

LA FONTAINE LUMHNEUSE.

N०2. Disposition des projecteurs éclairant les jets horizontaur.

sous les jels d'eau; d'autres fils, passant sur des poulies, aboutissent à une série de leviers semblables à ceux des signaux de chemins de fer; ces leviers et ces fils mettent en mouvement les glaces colorées.

- Celles-ci peuvent entrer en jeu soit séparément, soit en même temps; certaines d'entre elles ont une position inclinée qui permet de ne colorer que la partie supérieure Liv. 45. 
d'un jet, dont le bas est d'un ton diTérent; de là une variélé infinie de combinaisons dans les couleurs, l'intensité et la force des jets, que l'opérateur, du haut de son kiosque d'observation, règle à sa guise comme un peintre fait ses tons sur sa palette, ou comme un organiste joue des registres de son instrument

" L'appareil rudimentaire de Colladon se transforme ici en une inslallation indus-

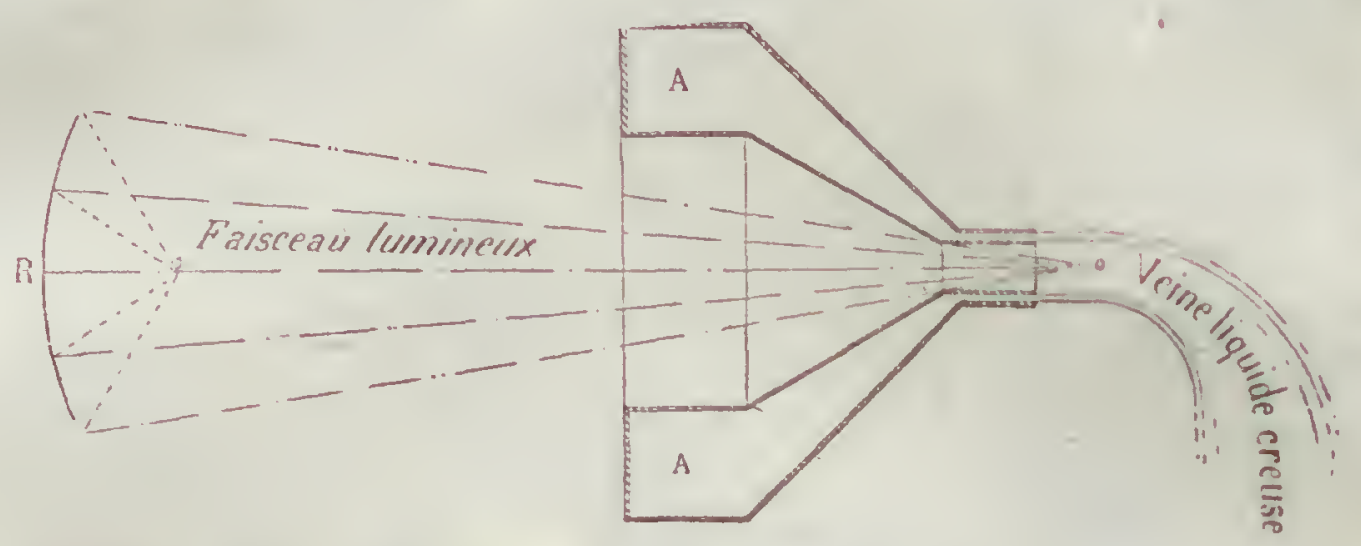

trielle; l'honneur d'avoir imaginé cette organisation revient à un Anglais, le colonel Bolton, dont la fontaine lumineuse fonclionna en 1884 a Londres, puis a Manclicstor et a Glasgow. MM. Beckmann et Meker, ingénieurs du service des eaux à l'Exposition, ont encore perfectionné le système du colonel Bolton en faisant passer le faisceau lumineux, non plus directement dans la masse du jet liquide, mais dans le vide formé au centre de ce jet par un entonnoir à parois réfléchissantes, $\Lambda \Lambda$, ou les rayons sont renvoyés par un miroir concave $R$.

- Quand la réflexion ne peut se faire directement, on emploie d'abord un projecteur

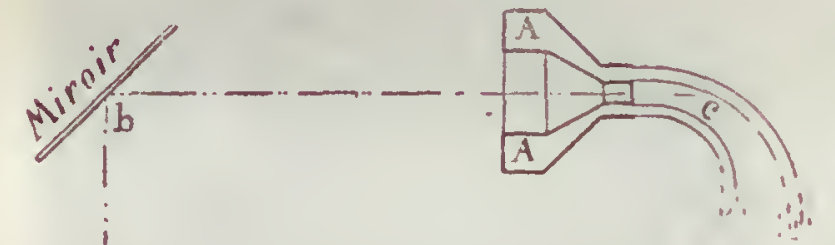

M situé dans le sous-sol; les rayons qui en émanent sont projetés verticalłment à travers les glaces colorées $X, Y$, puis ils sont délournés à angle droit en 6 , pour entrer dans l'entonnoir el dans le jet. Telle est la disposition qui est adoptée pour les jets sortant de la guenle des dauphins. Elle est représentée throriquement dans la figure ci-contre.

Notre gravure $n^{\circ} 2$ la montre lelle qu'elle existe au Champ de Mars. On $y$ voit le projecteur placé dans le sous-sol; les rayons qui en émanent sont tellement aveuglants que l'ouvrier chargé de la manceuvre doit se protéger les yeux au moyen d'un verre noirci. Grace aux perfectionnements de MM. Beckmann et Mcker, on épargne uas a eavle quelals de lumière; mais, malgré celte éconoare, il fact eccore plos de ago eberaix-ra-

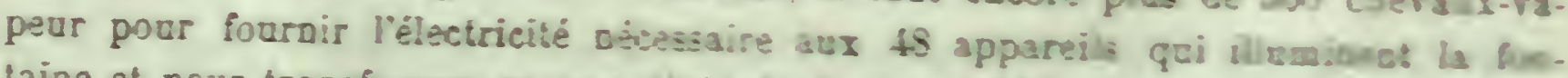

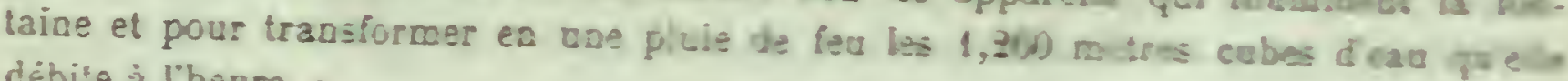
débite à l'heure. ,

le fonctionnement de la Foataine hurarcec-e est. on le run, des ples sumple, we... eimple que l'ễet produit est imposant et grandiose. 
XII

\section{LRS ASCENSEURS DR LI TOUR RIPPBL}

Ceux qui voudront faire l'ascension de la Tour et jouir du superbe panorama que l'on voit se dérouler à ses pieds, à mesure que l'on s'élève dans la gigantesque colonne, pourront recourir, d̀ leur choix, à deux moyens de locomotion : leurs jambes et les ascenseurs. L'ascension de la Tour par les escaliers est fatiganle, on ne saurait le nier, mais aussi quel superbe panorama, et quels raffinements I Avec l'ascenseur, vous ètes brusquement transportés sur la seconde ou la troisième plate-forme. Avec les marches, vous avez le plaisir de voir peu à peu, à mesure que vous montez, la zone du panorama s'étendre, s'élargir; les obstacles qui tout à l'heure voilaient à vos yeux telle ou telle partie de Paris disparaissent l'un après l'autre, et vous finissez par n'avoir au-dessous de vous qu'un énorme plan en relief de la capitale et de ses environs.

Des escaliers droits de 7 mètres de largeur ont été construits dans les piles Est et Ouest. Des paliers, de distance en distance, permettent de prendre haleine, et l'on arrive sans trop d'efforts à la plate-forme du premier étage. Les restaurants qui s'y trouvent sont fort achalandés. Pour gagner le second étage, vous avez à votre disposition, dans les quatre piles, des escaliers hélicoïdaux de 60 centimètres de largeur : deux pour 3 descente, deux pour l'ascension. Du second au troisième étage, il n'y a plus qu'un seul escalier hélicoïdal haut de 60 mètres. La galerie-promenade à arcades qui règne autour de la première plate-forme a plus de 280 mètres de développement sur une largeur de $2^{\mathrm{m}}, 60$; la gálerie du second étage n'a que 150 mètres de développement, avec la même largeur. Enfin, au troisième étage, une salle vitrée de 18 mètres de côté reçoit les visiteurs.

Chacun voudra, s'il n'est trahi par ses jambes ou par le vertige, faire au moins une fois l'ascension par les escaliers. S'il tient a s'offrir de nouveau le spectacle de Paris vu d'une liautcur de 300 mètres, il recourra sans doute aux ascenseurs. Les ascenseurs sont de trois systemes différents :

10 L'ascenseur Roux-Combaluzier et Lepape;

2० L'ascenseur Otis;

$3^{\circ}$ L'ascenscur Édoux.

On ne s'est arreté à ceux-là qu'après de nombreuses expériences, qu'après avoir essayé les ascenscurs à crémaillère, à vapeur, à eau sans pression, à moteur électrique. On fut sur le point d'adopter les ascenseurs hélicoïdaux à crémaillère, système Backmann-Guyenet, mais pour des raisons de stabilité on fut amené à les écarter.

Du sol au premier étage, quatre ascenseurs fonctionnent : deux du système RouxCombaluzier, deux du système Otis. Du premier étage au second, deux ascenseurs Otis élèvent les visileurs. Du deuxiène élage il la plate-forme supérieure fonctionne l'ascenseur Édoux. Dans une excellente étude qu'il a publiée sur la Tour Eiffel, M. Max de Nansouty décrit dans les termes suivants l'ascenseur Roux-Combaluzier et Lepape: - L'ascension mécanique par impulsion n'a été appliquée jusqu'à ce jour que pour des hauteur's relativement faibles, et le système généralement adopté a presque toujours été celui dit à tige ou à piston plongeur, avec les diverses variantes connues. Pour 


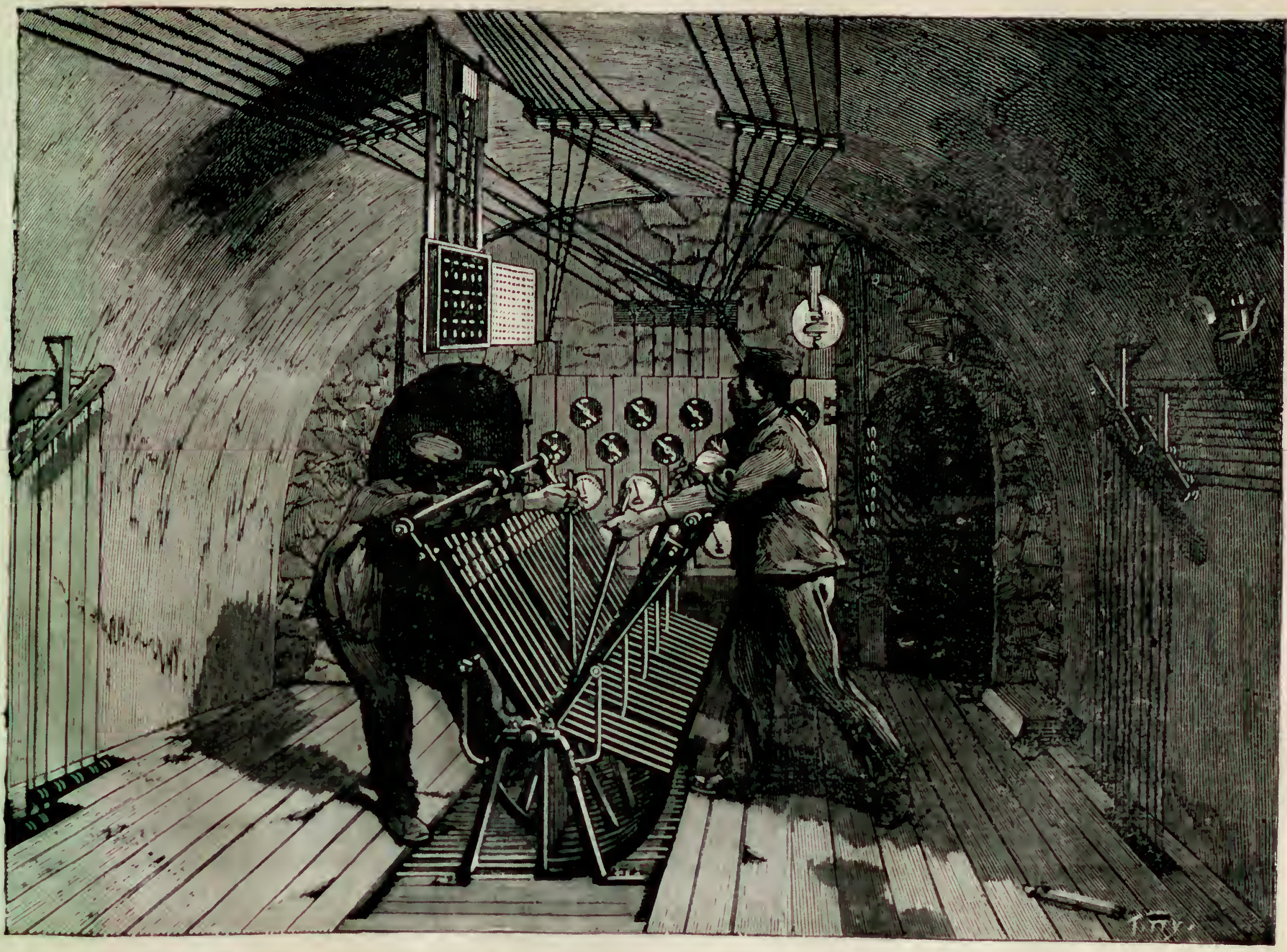

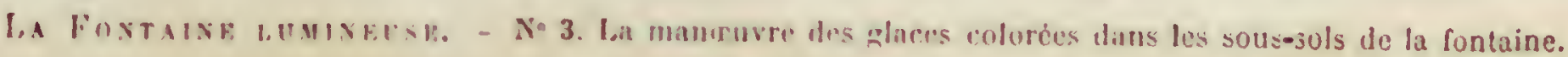




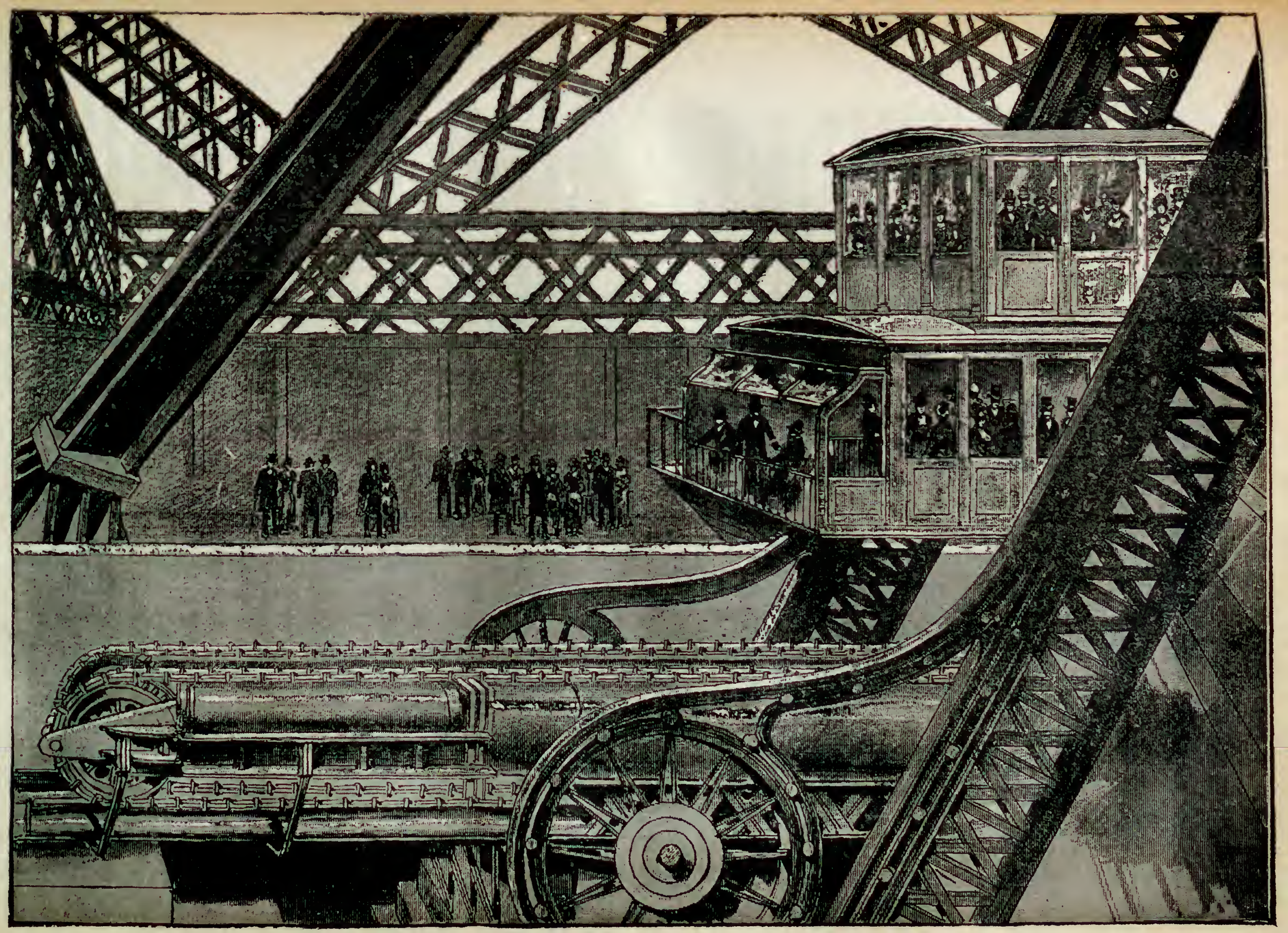


obvier aux inconvénients qu'il présente, tout en conservant le principe du système d impulsion, MN. Roux-Combaluzier et Lepape ont songé, en étudiant un projel d'ascenseur pour la Tour Eiffel, a remplacer cette tige par un organe analogue, et, tronçonmant le piston rigide, ils ont imaginé le piston articulé. Cet organe agit par compression, comme dans les ascenseurs à tige unique et peut itre assimilé à une sorte de colonno vertébrale. Il est en effet formé par une série de vertebres ou petits pistons, ayant la forme de bielles a fourches. Ces pistons sont en outre munis de deux galets en chaque point d'attache. Le piston, ainsi articulé, étant introluit dans un conduit à section circulaire ou carrée, le parcourra aisément si l'on vient agir sur lui par refoulement, et, se courbant facilement, il serpentera sans difficulté en suivant les sinuositis de ce conduit, comme le ferait une chaîne sur laquelle on agirait par traction. Lin lixant le premier maillon de ce piston au plancher d'une cabine ordinaire d'ascensenr et en sectionnant ce piston par une roue à cmpreintes, unie par un moteur quelconque, silué à la partie inférieure de la cage de l'ascenseur, on conçoit aisément qu'il sera facile de faire suivre à la cabine le chemin que l'on voudra, pourvu que le concluit daus lequel sera logé le piston, suive lui-mème le chemin à parcourir. En joignant les deux extrémités de ce piston flexible, ou en faisant une chatue sans fin, à maillons de bielles, se mourant sur deux poulies à empreintes, celle inférieure donnant le inouvement et celle supérieure servant de simple poulie de renvoi, M. de Nansonly expose ensuite que le problème de l'ascension dans la Tour de 300 mètres consistait à b́levr cent personnes à la fois avec une vitesse de 1 mètre à la seconde en suivant un cliemin courbe jusqu'à $113^{\mathrm{m}}, \mathbf{4 0}$, puis verticalement pendant $1: 0$ mètres. La charge à soulever (18 tonnes) portant sur deux pistons, c'est une charge de 9 tonnes qui s'exerce sur chacun d'eux. "Ceux-ci, prolongés au delà de la cabine, passent à la partie supéritrie sur de grandes poulies de renvoi et constituent de véritables chaines sans fin avec cette différence toutefois qu'au lieu de travailler à la traction, elles travaillent à la compression, la chalne ayant du mort dans toute la partie distendue. Celte dispositior présente l'avantage d'éviter à la partic supérieure la nécessité d'un point d'appui destiné à supporler la charge totale des 18 tonnes. La partie supérieure n'a, en efTet, dans ce cas à supporter que son propre poids et celui des huit maillons qui l'entourent. Un contrepoids vient équilibrer partiellement le poids mort de la cabine. Ce contrepoisls n'est que de 3 tonnes, de manière à laisser a la caljine uue surcharge de 2 tonnes, lorsqu'elle est à vide, pour en permettre la descente spontanée. , Des roues à empreintes transmettent le mouvement aux pistons. Chaque cabine, haule de 5 mètres, comprend àeux étages et peut renfermer 100 voyageurs.

Les ascenseurs des piles Nord et Sud, qui sont lu type employé en Amérique et connus sous le nom d'ascenseurs Otis, reposent sur le principe de la grue hydranlijue Armstrong. Supposons un cylindre perpendiculaire, aux arbaletriers, et dans ce cylindre un piston actionné par l'eau opère dans un des réservoirs du second étage de la Tour, et actionnant à son tour un chariot portant six poulies mobiles de $1^{m}, 40$ de diamètre. Chacune de ces six poulies correspond a une poulie fixe de meme grossenr. et l'on a ainsi un immense palan, grice auquel tout mouvement d'un mietro du piston déplace de 12 mètres l'appareil élévatoire. La cabine, soutenue par six puissants câbles en fil d'acier, monte et descend sur des rails le long d'un plan incliné, elle pent être brusquement arrètée par des freins ì màchoire. Les ascenseurs otis, qui fonctionnent, comme nous l'avons dit, jusqu'al second étage, ont une vitesse de 2 mètres 
par seconde et emportent cinquante personnes à la fois. Ils ne mettent qu'une demi minute pour accomplir ce trajet. Les cables en fil d'acier qui suspendent la cabine sont au nombre de six. Leur force est telle que, si cinq d'entre eux venaient à se rompre, le seul restant pourrait supporter le poids de la cabine remplie de voyageurs.

Les ascenseurs Édoux transportent le visiteur du second étage à la plate-forme supérieure. Nous avons eu l'occasion, dès le début, d'en expliquer en détail le mécanisme, et nous n'avons qu'à y renvoyer le lecteur.

Lon emploie constamment les expressions pilierno 1 , pilier no 2, elc. Il ne sera pas superflu d'expliquer que le pilier no 1 se trouve à gauche, près de la Seine, pour les visiteur's arrivant par le pont d'Iéna. Le pilier qui se trouve derrière celui-ci, du côté de Paris, porte le $n^{\circ}$ 2. Le pilier de droite, le plus rapproché de la Seine, est le no 4 , et celui qui se trouve derridre lui le $n^{\circ} 3$. L'escalier de montée est dans le pilier $n^{\circ} 4$, celui de descente dans le pilier $n^{\circ} 2$. Ces deux escaliers, et ceux qui conduisent au deuxième étage, aboutissent aux angles extérieurs des piliers. Il s'ensuit que chaque plan de pilier, au premier étage, porte une amorce d'ascenseur en dedans et une amorce d'escalier en dehors. Les deux autres angles sont occupés par des boutiques Derrière les escaliers, un bureau de tickets.

Nous voici sur la plate-forme du premier étage. Sachez d'abord que le pourtour extérieur de cette plate-forme est un immense carré de $70^{\mathrm{m}}, 69$ de côté, enfermant près de 5,000 mètres superficiels.

.Je suppose l'arrivée au premier étage par le pilier n 4, par ascenseur ou par escalier. On remarque aussitot que le premier étage a deux niveaux : celui des restaurants, balcons et terrasses, et celui des galeries du pourtour, plus bas d'un mètre environ. Cette différence est rationnelle et ingénieuse, en ce qu'elle permet aux visiteurs des galeries de circuler sans obstruer la vue de ceux des restaurants et des terrasses. Douze escaliers mettent ces deux plans en comnunication.

Dès que vous mellez le pied sur le premier étage, vous avez la sensation de l'entrée dins une ville. Arrivant par le pilier 4, vous avez, \& gauche, le restaurant Flamand. à droite le restaurant Anglo-Américain; en face, la façade si gracieuse du restaurant Russe et celle du restaurant Français. Si vous vous avancez sur la vaste terrasse qui s'étend devant vous, vers l'intérieur, vous arrivez devant une ouverture immense, biante; a traver's vous voyez, comme au fond d'un abime, la fontaine de Saint-Vidal, les jardins, les lacs, le départ rles piliers de la Tour; tout en raccourci, tout petit, ainsi que Pantagruel devait voir Paris du haut de sa grandeur. Au milieu de ce paysage vu à vol d'oiseau, les hommes circulent comme des êtres lilliputiens. On s'identifie tellement avec le colosse de fer qui vous porte, que l'on voit tout, au-dessous de soi, avec des yeux de géant.

Chaque façade de restaurant a son caractère national. Devant chacun d'eux règne un balcon arrondi, partant des pans coupés des terrasses intermédiaires et formant un gracieux dessin d'ensemble. Le gouffre béant a environ 23 mètres d'ouverture.

Comme le montre le plan, chaque restaurant occupe un rectangle de 24 mètres de façarle et $14^{\mathrm{m}}, 90$ de profondeur.

Dans l'intérieur de chacun, c'est une vaste salle richement décorée selon le style national du restaurant. Cette salle occupe toute la surface du batiment, moins deux escaliers conduisant à deux terrasses de premier étage donnant vers l'intérieur de la Tour. Sous ces escaliers sont ménagés les offices et des water-closets. 
La façade extérieure de chaque restaurant donne sur une longue terrasse de plainpied avec la salle, dominant, comme je l'ai dit, la galerie du pourtour, ct d'où la vue est merveilleuse à quelque restaurant que l'on soit. Il faudra consommer quatre bocks pour se rendre compte du plaisir qu'il y aura à s'asseoir sur chacune de ces terrasses si différentes de l'une à l'autre. Ici c'est l'admiration et l'extase qui pousseront à la consommation.

Les caves et les cuisines au sous-sol sont vastes et commodes. En sous-sol, a

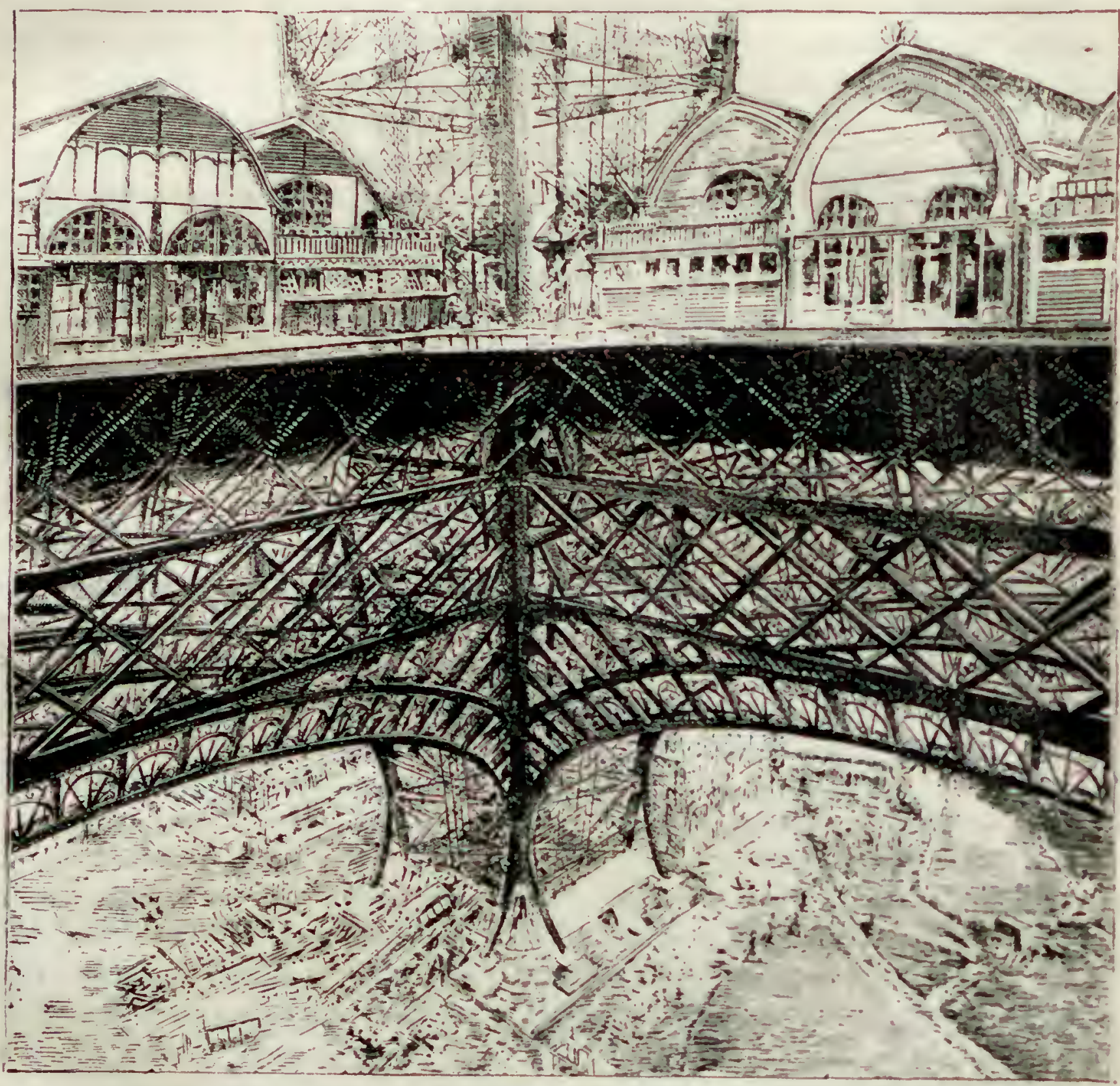

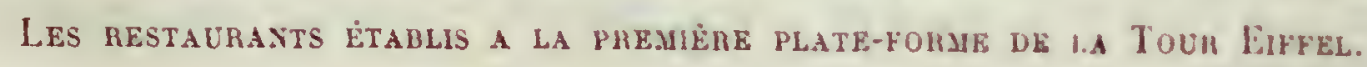

53 mètres au-dessus du sol du Champ de Mars! Lorsque vous monterez et que vous verrez, vous direz que les phrases que vous venez de lire ne sont ni baroques, ni fantaisistes. M. Eiffel vous élève à des hauteurs où les termes terre-à-terre de cette terre sur laquelle nous rampons ont besoin d'ètre corrigés, modifiés, élargis.

Sur la seconde plate-forme, on trouve la gare de transbordement entre les ascen. seurs inférieurs et les ascenseurs Édoux, limprimerie et la rédaction du Figaro. Sur la troisième, où l'on ne peut se rendre qu'en ascenseur, il y a des lunettes, des télescopes et une carte qui montre au visiteur les points où sont braqués ces divers instruments. - La vue est très curieuse, dit M. Gaston Calmelle. A une telle hauteur tout mouve. 


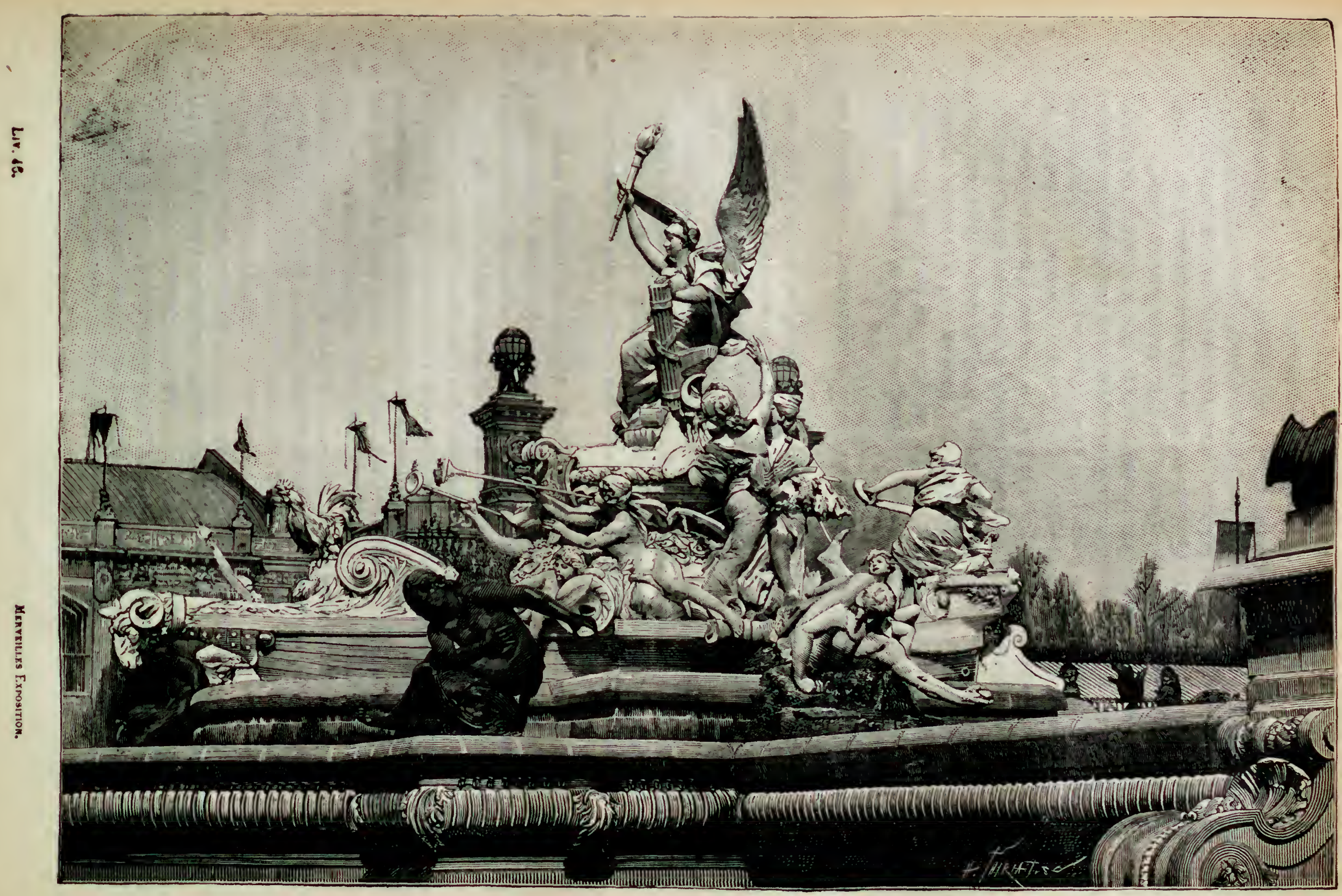


ment disparait et Paris semble un décor de carton avec ses rues étroites, ses toits carrés, ses façades alignées. Cetle grande ville, la ville de l'agitation fiévreuse, de la vie intense et remuante, semble frappée de mort. Aucun bruit ne révèle l'activité de ce peuple qui est en dessous. On plane sur un désert de pierres inertes et silencieuses. Cette impression est très grandiose. Quant à l'ampleur du ciel, elle est infinie."

Le phare électrique installé dans la rotonde aménagée au sommet de la tour Eiffel est parcil aux plus puissants des phares qui ont été installés sur les côtes de France. La lampe électrique placée au centre à une force de 100 ampères. Une particularit\&, légitime par le but patriotique de l'Exposition, la signale toutefois à l'altention du public. Elle porte trois lentilles colorées en bleu, blanc et rouge, de sorle que les coujeurs nationales font lentement le tour de la coupole. De l'enceinte de l'Expusition, il est impossible de voir le phare. Ce n'est que de 1,500 mètres environ qu'on peut l'apercevoir : par exemple, de l'esplanade des Invalides, de la place de la Concorde, du palais de I'Industrie. Portant à 97 kilomètres, el par conséquent visible de très loin, lorsque le temps est favorable, ce phare permet de déterminer les lois de la réfraction atmosphérique.

Sa partie tournante est mise en rotation par un courant accessoire venant du bas de la tour, comme le courant principal.

On a également mis en place deux projecteurs électriques, qui, de la tour, promènent sur Paris de puissants rayons lumineux. Ces projecleurs n'ont pas moins, chacun, de 90 centimètres de diamètre. Placés à 290 mètres, près des appartements de M. Eiffel, au-déssous du phare, ils portent, par les temps clairs, jusqu’à lì distance de 10,000 mètres environ. Ils sont identiques à ceux en service sur les cuirassés de notre flotte. Leur puissance lumineuse égale celle de 10,000 becs Carcel, et l'intensité totale de leur rayon lumineux équivaut à environ $8,000,000$ de carcels.

En concentrant les deux faisceaux sur un mesme objet, on peut donc alteindre à une intensité de 16,000,000 de carcels.

Ce sont ces projecteurs qui, à la demande de M. Janssen, ont été dirigés un soir du mois de mai sur l'observatoire de Neudon, car le directeur de cet utile établissement a vu là un moyen d'étudier dans des conditions spéciales la question de la composition du spectre solaire. On sait que II. Janssen est monté au sommet du Mlont. Blanc pour tacher de reconnaître l'origine des raies dues à l'oxygine dans le spectre du soleil. Ayant reconnu dans ce spectre plusieurs groupes de raies fournies par l'oxygène de l'atmosphère terrestre, on devait rechercher si ces groupes proviennent seulement de l'air qui nous enveloppe et si l'atmosphère du soleil n'y entrait pour rieu, uu bien si l'origine de ces groupes est double. L'une des méthodes les plus certaines pour résou. dre cette question est celle de la vibration, assez difficile à appliquer. On peut aussi observer la diminution d'intensité que subissent les groupes, a mesure qu'on s'éléve dans l'air, et si cette diminution permet de conclure à leur complète disparition aur limites de l'atmosphère. C'est la méthode employée au Mont-Blanc. On peut cncore procéder par une comparaison d'égalité, au moy"n d'une puissante lumière a spectre continu à une distance de l'analyseur telle, que l'épaisseur de l'air traversé représente l'action de l'atmosphire terrestre sur les rayuns solaires aux environs du zénillı. Celle dernière pirconstance s'est réalisée par les situations respectives de la tour litin et de l'observatoire de Meudon. La distance entre ces deux momuments est de 7,700 mètres, représentant à peu près l'épaisseur d'une couche gazeuse de inème poids âue l'atmo- 
sphère terrestre et d'une densité uniforme égale à celle de la couche d'air voisine du sol. Une lentille collective a été placée de manière à amener le spectre à avoir une inteasité comparable à celle du spectre solaire. Le spectre s'est ainsi fait voir avec une vivacité extrène. Aucune bande de l'oxygène ne s'est montrée dans le spectre visible. L'expérience prouve que, pour l'oxygène, les raies obéissent à une tout autre loi que les bandes. Qui donc disait que la Tour Eiffel ne rendrait aucun service à la science?

Les fils conducteurs de l'électricité qui doit éclairer les projecteurs et le phare sont aménagés dans l'armature de la Tour. L'exécution de ce travail aura duré près d'un mois environ. Le moteur est installé dans la base de la pile 3 , où sont déjà logés les appareils hydrauliques.

\section{XIII \\ LEIPOSITION COLONILB}

Il n'y a pas à dire le contraire, l'Exposition compte un si gran nombre de clous qu'on ne sait auquel donner la préférence. La galerie des Machines est une merveille, la tour liffel est un objet d'étonnement pour qui la regarde avec attention; mais connaissez-vous rien de plus charmant, de plus attrayant, de plus éblouissant que les pavillons de nos possessions lointaines, avec leurs multiples annexes? C'est un mélange d'architecture de tout ordre et de tous pays, de couleurs pàles, claires, vives, miroitantes, chatoyantes; de costumes imprévus dans leur coupe et dans leur tonalité. Eı arrivant sur l'esplanade, on ne manque pas d'ètre attiré par des soldats dont l'uniforme n'est pas de ceux que nous sommes habitués à voir. Il y a là, en effet, vingi-quatre tirailleurs tonkinois, vingt-quatre tirailleurs saïgonnais avec deux sousofficiers indigìnes, huil cipayes de l'Inde française avec leur sergent-major, six spahis africains avec un maréchal des logis, huit Sakalaves avec un caporal, plus trois officiers indigènes. Ces honnètes militaires nous font assister à toute la gamme des colorations foncées; leur visage varie du cuivre au noir cirage, et le regard a chez quelques-uns un éclat extraordinaire. Les Annamites, dont quelques-uns sont décorés de la ncidaille du Tonkin, ont une physionomie rèveuse, triste, résignée. Tous ces soldats coloniaux qui montent là garde a la porte des pavillons sont casernés à l'École militaire. On a remarqué qu'ils avaient presque tous un gout passionné pour la musique : l'accordéon et le flageolet jouissent de leurs préférences, et c'est avec respect qu'ils sortent de lour inalle l'un de ces instruments. Pendant la période de construction et d'organisation, rien n'était plus curieux que de voir au travail des ouvriers indigènes: gais, souriants, charpentiers et décorateurs rivalisaient de zèle.

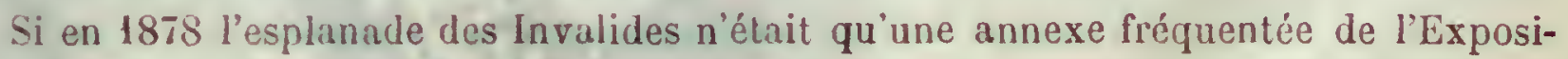
tion, il n'en est donc plus de mème cette année. On aime beaucoup les exhibitions exotiquea, et chaque fois que le Jardin d'acclimatation importe quelques naturels de l'Afrique anstrale ou de l'Amérique, il y a foule au bois de Boulogne. Or, cette fois, on passe en revue sur l'esplanade des Algériens, des Tunisiens, des Sénégalais, des Gaboaais, des Malgaches, des Taîilens, des Canaques, des Indo.Chinois, dont l'authenticité 

LES MERVELLLB DE L'EXPOSITION

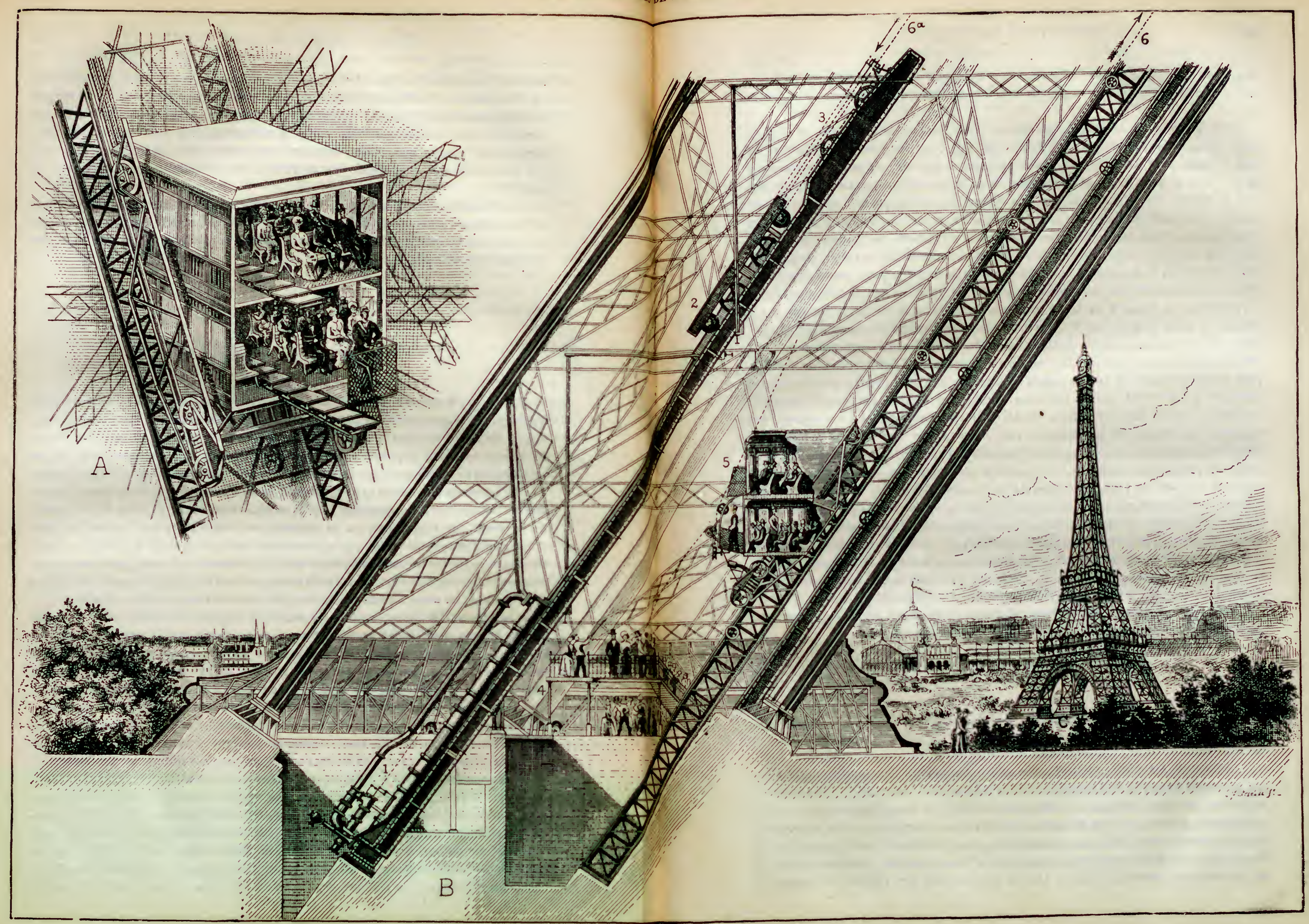

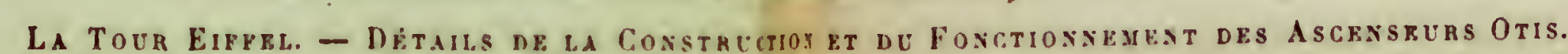

A. Vue intírieure d'une caline. - B. Vue générale d'une des piles avec 
ne saurait être suspecte. Nous commencerons notre excursion coloniale par le Palnis centrá, des Colonies, où l'on a groupé tous les produits qui n'ont pas de pavillon spécial.

C'est un batiment de style composite, dủ à II. Sauvestre, architecte en chef de l'Expoition coloniale, et ì M. des Tournelles, ingénieur commissaire-adjoint. Il est tont en bois, sauf l'ossature du dôme central, et il a $75^{\circ}$ mètres de longneur sur 18 mòres de largeur. Les soubassements sont en briques et mortier. Le dôme, que l'on voit du dehors, est juste au-dessus de la salle centrale, de chaque cóté de laquelle sont deux grandes salles latérales; le sommet du dôme a 50 mètres en hauteur, et les salles latérales sont flanquées de tourelles contenant les escaliers qui mènent au premier étage. Le dòme est flanqué de deux campaniles. A l'entrée, tout au bout de l'avenue qui conduit sous le dòme, on a construit deux corps de garde pour les miliciens indigènes qui stationnent à la porte du Palais. Les tniles émaillées sont de deux tons. Gráce a l'élévation du dôme, à la forme originale des toitures, à la disposition des baies, l'édifice est léger et gracieux. M. Sauvestre avait voulu en quelque sorte confondre les styles des colonies sans laisser dominer aucun d'cux, et il a parfaitement réussı. Les teintes adoptées pour la décoration sont hardies, mais d'un bel cffet: rouge éclatant pour le bois et la surface murale, quelques lignes jaunes, et du rouge foncé et du vert émeraude pour le toit. En entrant, nous trouvons en face de nous une sollection de Bouddhas; abrités par des palmes et des bambous énormes, et tout autour, des trophées, des laques, des incrustations mervelleuses, des meubles, des tentures. Un fronton annamite très original surmonte la porte qui conduit au bureal des commissaires de l'Exposition coloniale. Les produits que nous remarquons dans les salles latérales viennent de l'Inde française, de la Nourelle-Calédonic, de la Réunion, des dépendances de Madagascar, de la Guyane française, de la Martinique. Comme nous allons passer en revue toutes les colonies, nous parlerons a part des produits de chacune d'elles. Rappelons, pour n'y plus revenir, que la France possède en Arrique : l'Algérie, la Tunisie (protectorat), le Sénégal et ses dépendances, le Gabon et le Congo français, la Réunion, Madagascar (protectorat), Nossi-Bé, les Comores, Mayotte, Sainte-Marie, Obock; - en Asie, l'Inde, l'Indo-Chine française (Cochinchine, Annam, Tonkin, Cambodge); - en Océanie, la Nouvelle-Calédonie, les lles Taïti, ctc.; - en Amérique, Saint-Pierre et Miquelon, la Guadeloupe, la Martinique, la Gujane.

\section{L'ALGÉRIE ET LA TUNISIE}

Les Palais de l'Algérie et de la Tunisie sont remarquables sous tous rapports. Ceux qui ont visité l'Afrique septentrionale sont d'accord pour reconnaltre que les architectes leur ont donné un cachet d'authenticité rrappant : ce qui s'explique d'ailleurs par ce faì qu'ils ont emprunté les éléments essentiels des constructions à cies $1 r^{2}$ muments du pays. Prenez le Palais Algérien, considérez-en successivement toutes les parties. Si vous avez visité Alger, vous reconnaitrez dans le grand vestibule à arcades le plafond de l'archevêché; dans le minaret et dans la porte tournée vers l'esplanade, le minaret 
et la porte de Siui-Abd-er-Rhaman; dans l'encadrement de cette porte, le mirhab de la moscuée de la Pècherie, avec ses arabesques gravées dans le stuc; dans la façade tournée vers la Seine, une loggia de la Kasbah. Comment, avec des documents semblables, M. Ballu, inspecteur des édifices diocésains d'Afrique, et M: Marquette, architecte ¿̀ Alger, n'auraient-ils pas élevé quelque chose de merveilleusement réussi?

Le Palais Tunisien, du à M. Itenri Saladin, a été construit suivant la mème méthode. C'est à Kíairouan, la ville sainte de la Régence, que M. Saladin a demandé la plupart de ses inspirations, el le grand dôme de la façade postérieure reproduit fidèlement celui de la mosquée de Sidi-Okba, de mème que les arcades en marbre du patio sont copiées sur celles de la mosquée de Sidi-Saheb. Il serait superflu de dire que les traditionnelles boutiques, avec leur's cordonnicrs, leurs pàtissiers, leurs tisserands, leurs vanniers, abondent sur l'esplanade el complètent l'illusion du visiteur, qui se rappelle avec plaisir une excursion dans les rues d'Alger ou dans celles de la Régence, et l'illusion' est d'autant plus complète que l'on a tenu ici encore à ètre vrai, puisqu'on a copié le Souk de la rue des Etoffes, à Tunis.

On a fait venir d'Algérie une caravane composée d'une soixantaine de personnes, avec des chevaux pur sang de toute beauté. Il sera facile au visiteur de se rendre compte des divers aspects de notre colonie : icı, il voit campé sous deux tentes les Arabes nomades; ailleurs, le Kabyle industrieux exerce son métier sous l'œil du public dans une ferme qui est une copie exacte de la demeure kabyle; là, des ouvriers arabes fabriquent des babouches, brodent de menus objets, enluminent les étagères de tons crus, peigneat sur roseanx: plus loin, c'est un café maure où, au son monotone d'une musique étrange, des Fiatmas dansent la danse du ventre, pendant que, tout a côté, résonne la nouba des Turcos.

Toute cette population indigène, on la désigne communément sous le nom - d'Arabe. Jamais dénomination ne fut plus fausse, cal il n'y a pas en Algérie un million d'Arabes, alors qu'on y rencontre deux millions de Berbères. Tous ces conquérants qui nous ont précédés dans l'Afrique du nord: Phéniciens, Romains, Vandales, Byzantins, ont été absorbés par la race berbère, cette race si vieille qu'elle paraît être autochtone, si pleine de vitalité qu'elle survit a toutes les vicissitudes et à berbérisé les Arabes eux-mèmes. En résumé, les Arabes ont apporté et fait triompher en Agérie leur langue, leur architecture et, pendant un temps, leur organisation politique et sociale, incis la prépondérance ethnographique appartient aux Berbères. C'est à la race berbère, et non a la race arabe, qu'il faut rattacher ces Kabyles, dont un village tout entier a été reconstitué sur l'esplanade des Invalides. C'est à la race berbère que se rattachent aussi ces Touaregs qui, prisonniers sous leur tente rayée en poil de chameau, vous lancent des regards de mépris et de haine; car les Touaregs ne nous aiment guère, et on n'a pas oublié les circonstances douloureuses du massacre de la mission Flatters. Le village kabyle intéressera peut-ètre le visiteur plus que le palais algérien el tunisien, parce qu'il offre au regard quelque chose de moins connu. Quel dommage que l'on n'ait pu, par exemple, copier le rocher et la piltoresque ville de lialéa! Cár les agsglomérations kabyles couronnent la plupart des saillies du Jurjura, défiant les agressions et économisant la terre cultivable, qui est rare dans cette région. Puisque les Kabyles sont une des curiosités de l'esplanade, demandons des renseignements à l'homme qui les a le mieux connus, au général Hanoteau. Le peuplekabyle, dit.il, confiné daus d'étroiles limites territoriales, s'est fixé résolument 
au sol qu'il devait défendre, pendant une série de siècles, contre les efforts envahissants des races conquérantes. La vie pastorale et errante des Arabes était impossible aux Kabyles, en raison du blocus auquel les soumettaient des voisins hostiles et vigilants. Ils se sont donc solidement retranchés dans leurs montagnes, et y sont devenus essentiellement agriculteurs, industriels et commerçants. Sollicités d'ailleurs par lesintempéries du climat, ils ont construit des habitations, et les ont agglomérées dans un but de mutuelle assistance. Le voyageur qui traverse la Kabylie est frappé par la situation pittoresque des villages qui couronnent la plupart des saillies anguleuses des contreforts du Jurjura. Le blanc ininaret d'une mosquée domine souvent desmaisons de pierre, recouvertes de tuiles. Les villages ont nécessairement la confi guration des crètes sur lesquelles ils sont construits; ils sont généralement longs et étroits. Les maisons sont rangées assez régulièrement suivant une voie principale, à laquelle aboutissent des ruelles strictement assez larges pour laisser passage dे un mulet chargé. La situation des villages sur les crêtes avait sa raison, avant l'occupation française, dans la nécessité, pour chaque tribu, ou chaque fraction de tribu, de repousser facilement les attaques ordinairement fréquentes des voisins querelleurs. Chaque hameau, chaque village, était une petite place de guerre. La mosquée, crénelée et barricadée, servait de réduit aux derniers et plus vaillants défenseurs. La position des villages a encore un autre motif : la terre cultivable, suffisant a peine aux besoins d'une nombreuse population, est ménagée autant que possible; les créles dénudées, rocheuses, inutiles à l'agriculture, sont réservées à l'assiette des habitations, rour peu qu'elle; soient abordables par des sentiers muletiers.

- Dans lá plus grande partie de la Kabylie, les centres de population se présentent sous un aspect pittoresque et riant; mais cette apparence d'un bien-être décevant est loin de s'offrir partout aux yeux de l'étranger. On trouve souvent de grossières huttes de pierre et de boue, recouvertes d'une charpente primitive, revétue elle-même de plaques de liège irrégulièrement assemblées; dans certaines vallées du littoral, on voit des gourbis de branches entrelacées et réunies entre elles par un mortier de terre et d'excréments d'animaux. Dans les beaux villages, les maisons, construites en pierre et en mortier de terre, ${ }_{2}$ sont réunies à angle droit par deux ou trois, de façon à ménager entre elles une cour intérieure. Dans chaque corps de logis habitent non seulement les mem.bres d'une famille humaine, composée en moyenne de trois ou quatre individus, mais encore toute la domesticité animale: l'âne ou le mulet, la vache, la chérre ou le bouc. Tout ce monde vit, respire, au moins pendant la nuit, dans un espace que l'on peut à peine évaluer à 60 mètres cubes, et dans !equel le renouvellement de l'atmosphère semble soigneusement prévenu. La quantité d'air contenue dans cet espace suffirait à peine à alimenter la respiration d'un adulte pendant dix heures, en admettant avec Pictet que le volume d'air à fournir dans les habitations doit être égal à 6 mètres cubes par individu et par heure. L'intérieur de la maison kabyle est in rariablement distribué de la manière suivante. La porte, seule ouverture capable de donner au réduit de l'air et de la lumière, est assez basse pour qu'un homme de moyenne taille soit obligé de se baisser pour y passer : elle se trouve à peu près au milieu d'use des longues faces du corps de logis. L'unique piéce d'habitation est divisèe en deux parties inégales par un petit mur, qui s'élève à un demi-mètre au-dessus du sol. La portion la plus vaste est habitée par la famille; son étendue est égale đa peu près aux deux tiers de la capacité de la chambre; clle est un peu élevée au-dessus du sol 
par un pavé de mą̧onnerie. La portion la plus étroite est réservẻe aux bestiaux; c'est une écurie assez mal tenue, dans laquelle s'entasse une litière malpropre, et où séjournent les déjections animales. Sur le mur qui sépare ces deux compartiments sont rangées de grandes jarres de terre, où on conserve les provisions de fruits secs, de grains et de farine. Au-dessus de l'écurie se trouve une sorte de soupente sur laquelle sont emmagasinés la provende des bêtes et les ustensiles de toute espèce. Dans l'espace

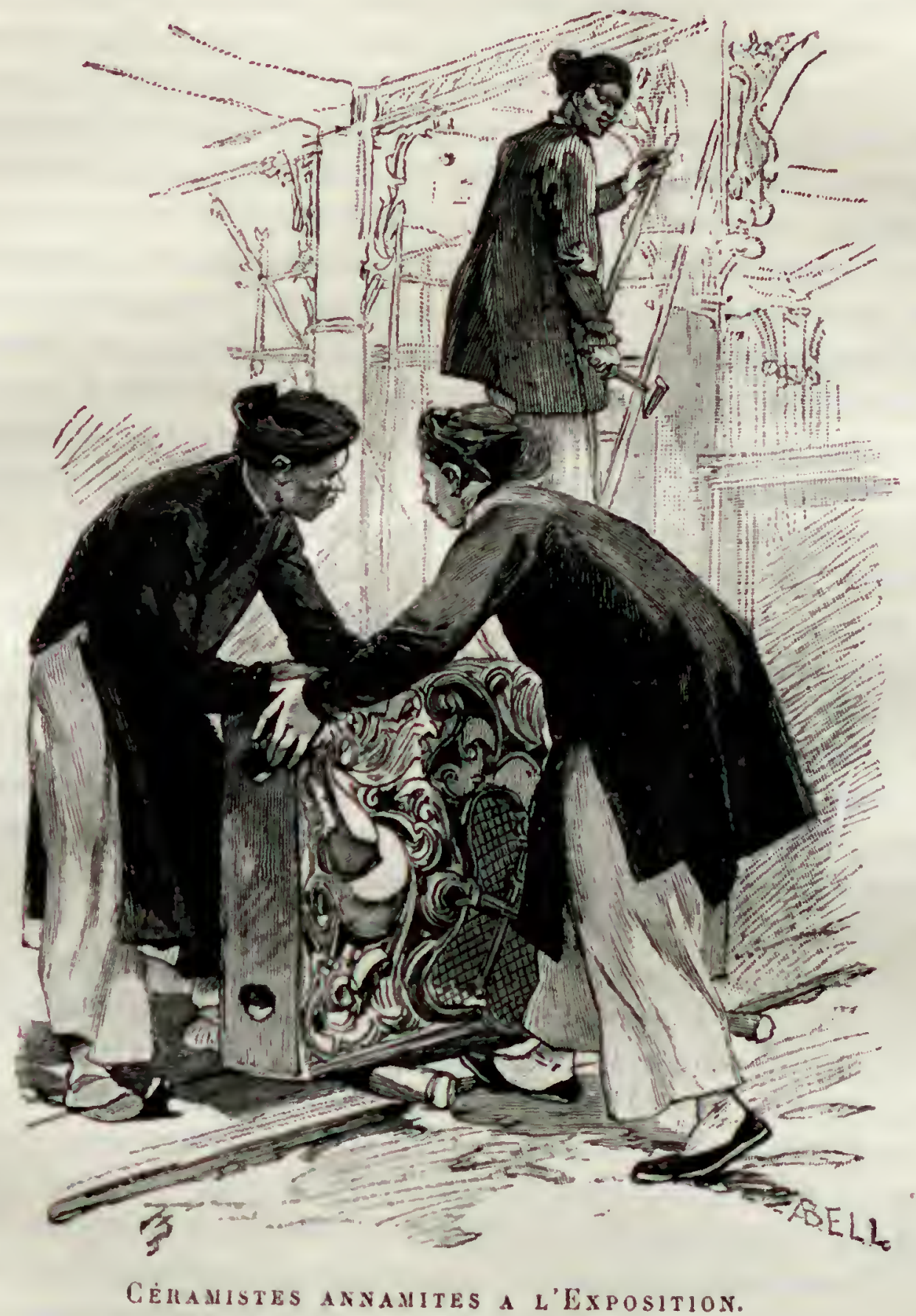

réservé à la famille se rangent des nattes et des tapis, que l'on transforme en lits, en les étendant le soir sur le sol, des coffres et des vases culinaires. $A$ une distance de $0^{\mathrm{m}}, 30$ ou $0^{\mathrm{m}}, 10$ de la muraille et au fond de la chambre, une cavité circulaire de quelques centimetres de profondeur à son centre est creusée dans le sol : c'est le foyer domestique.

"Le kiabyle est donc placé, dans son habitation, au milieu des conditions les plus déficrorables à la conservation de la santé. Les vapeurs ammoniacales de l'écurie se mélant à la fumée du foyer, qui ne s'échappe que lentement par les interstices de la 
toiture, constituent une atmosphère des plus infectes et des moins propres à la respiration. Si l'on joint à ces circonstances le renouvellement insuffisant de l'air, l'absence de la lumière, l'humidité, l'encombrement, on complète la liste des causes les mieux reconnues de la détérioration des constitutions les plus robustes, le développemcut de certaines affections générales, telle que l'anćmie, la scrofule; d'accidents locaux, comme les ophthalmies; enfin de l'origine et de la transmission de maladies infectieuses, telles que le typhus et la fievre typhoïde. Quelques villages sont assez proprement tenus, ce sont les plus rares: dans le plus grand nombre, les rues sont encombrées par les dépôts d'immondices, et reşoivent directement les liquides qui s'écoulent des écuries par un petit chenal. Les fumiers, les débris de toute espèce s'amoncellent autour du village, et constituent à la. Iongue un humus fertile. Le rocher disparaît bientòt sous ces amas dont la végétation s'empare. Des figuiers, des frênes, des pampres cncadrent alors coquettement les habitations et leur donnent par une frafche verdure un air d'aisance et de gaité. Le voyageur qui s'engage dans ces riantes oasis en est bientot repoussé par une foule de sensations désagréables. Quelle que soit l'altitude qu'il habite, et malgré les variations de température, le liabyle est uniformément vêtu et pour ainsi dire d̀ demi-nu. Les hommes portent une large chemise de cotonnade ou de laine grossière; par-dessus cette chemise, un ou deux burnous. Leur tête est couverte d'une ou plusieurs calottes de laine tricotée; leurs bras, leur cou, leurs jamlses sont nus. La chaussure perfectionnée est objet de luxe en Kabylie: les gens les plus riches portent des babouches comme les Arabes; les paurres, lorsqu'ils ont ì faire de longues routes, enveloppent leurs pieds dans un morceau de cuir quadrilatère et oblong, dont les angles, repliés derrière le talon et sur les orteils, sont fixés par des cordes de sparterie qui s'entrecroisent sur le cou-de-pied. Dans la saison des pluies ou de la neige, le habyle clausse le kobkab, espèce de patin de bois d'une seule pièce. Ce patin consisle en une semelle ovale et plane, de laquelle se détachent deux tasseaux verticaux, d'une hauteur de $0^{\mathrm{m}}, 5$ a a $0^{\mathrm{m}}, 10$; par cette disposition, la semelle est complètement isolée du sol et préservée de l'humidité.

"Les femmes ne sont pas vètues d'une façon plus hygriénique que les hommes. Une grande pièce d'étoffe de laine ou de coton fait, le plus souvent, tous les frais de leur habillement; pliée en deux suivant la longueur, elle se dédouble sur l'un des côtés du corps; les deux chefs sont réunis sur les épaules par deux fortes broches de fer ou d'argent, et serrés autour de la taille par une ceinture de soie ou de laine. L,es bras passent par des échancrures ménagées dans les plis de ce vêtement, qui a quelque analogie, par la façon dont il est drapé, avec la tunique de la statuaire grecque. La coiffure des femmes est un capuchon de lin ou de soie, serré autour de la tête par des mouchoirs et flottant en arrière du cou et sur les ćpaules.... Les vètements des hommes et des femmes kabyles, lorsqu'ils sont propres et convenoblement ajustés, présentent à l'œil un ensemble original, qui ne manque pas d'une cerlaine grace; mais, le plus souvent, les déchirures, la crasse et la boue leur font subir une transformation défavorable a leur élégance. Les Kiblyles portent leurs véleunents jusqu'd une.usure avancée sans les passer au savon ni a la lessive; les plus riches sculs mettent quelque vanité a se revetir d'un burnous blanc les jours de grande rête ou de démarches officielles.

"Le couscous est en Kabylie, comme en pays arabe, la base de l'alimentation; il y porte le nom de selssou ou lacim. Le taâm n'est autre chose que de la farine granuléo. 
Placée dans un vase en terre dont le fond est criblé de trous, elle subit une sorte de coction par la vapeur qui se dégage d'un récipient inférieur qui contient de l'eau, de lit viande, des légumes et des plantes aromatiques. Les individus qui sunt dans l'aisance mangent le tadm fabriqué avec la farine de froment; les pauvres, le taûm de farine d'orge, de sorgho ou de glands. Lorsque la pate est arrivée a un degré de cuisson convenable, on la renverse sur un grand plat de terre vernissée; la viande est mise par-dessus; charque convive creuse dans la pate avec sa cuiller une cavité dans laquelle on verse le bouillon. Ce bouillon, très relevé en goùt par une assez forte proportion de poivre et de piment, coloré en rouge par de la poudre de tomates, constitue la sauce du taàm ou la merkâa. Tous les convives sont rangés autour du mème plat, comme nos soldats d̀ la ganelle. La viande que l'on met à la marmite pour la préparation du couscous est tantôt la chair de mouton, tantót celle de bœuf. Malheureusement, la viande n'est pas, pour un grand nombre de Kabyles, la nourriture habituelle; beaucoup n'en mangent qu'une fois par semaine, le jour du marché; les plus pauvres, seulement lorqu'un événement important devient l'occasion d'une timecheret ou distribution à laquelle participent tous les membres du village, riches ou indigents. Le lait est versé dans presque tous les repas. Les principaux légumes qui entrent abondamment dans l'alimentation sont l'artichaut, les pois, haricots, fèves, auxquelles il faut joindre le gland doux. Le pain, préparé avec des farines imparfaitement blutées, a un aspect assez grossier. Les fruits abondent en Kabylie. Le figuier est cultiví partout où la nature du sol le permet; ses fruits séchés pour ètre conservés pendant l'hiver, sont, par la grande abondance de leur production et par leur prix peu élevé, une grande ressource pour les gens nécessiteux. Un colporteur kabyle quelconque part pour Alger en n'emportant, comme provisions de bouche pour l'aller et le retour, que deux ou trois galettes de son pain le plus noir et a peine un kilogramme de figues sèches. Les fruits du cactus opuntia, que nous appelons figues de Barbarie, et que les Kabyles appellent, par opposition, figues de chrétiens, sont aussi très communs; ils se donnent plutôt qu'ils ne se vendent. Les jardins fournissent aussi presque tous nos fruits européens: dı raisin délicieux, des poires, des pommes, des melons, des pastèques. "

$\Lambda$ côté des Kabyles, on trouvera sur l'Esplanade des Arabes nomades, grands, minces, élincés, musculeux, avec un regard vif et des dents éclatantes, une peau d'un beau bronze. La demeure de ces nomales, c'est la tente formée de felidj (laine et poil de chameau cousus ensemble et supportés par des pieux fichés en terre). Les dames qui pourront pénétrer dans une de ces demeures sommaires (car la religion musulmane défend aux femmes de se montrer) n'envieront certainement pas le luxe du mobilier, qui n’ẻveille rien moins que l'idée du confortable. Mais, luxueux ou non, tout est à voir dans l'Exposition de l'Algérie, depuis l'élégante construction de M. Ballu jusqu'aux tentes arabes des liabyles, depuis les bazars algériens jusqu'au café maure. Dans l'intérieur du palais, les produits des départements d'Oran, d'Alger et de Constantine sont méthodiquement exposés et les artistes algériens ont tenu à avoir leur exhibition spéciale au caur mème de la section africaine.

si nous passons au souk tunisien, nous nous trouvons en présence d'un bazar universel, d'une sorte de Bon-Marché oriental, où l'on fabrique et où l'on vend des chechias (bonnets rouges), des tissus de laine ou de soie, des objets de sellerie, des ouvrages en cuir, des broderies, des tapis, des bijoux, des parfums. Le souk de l'Espla- 



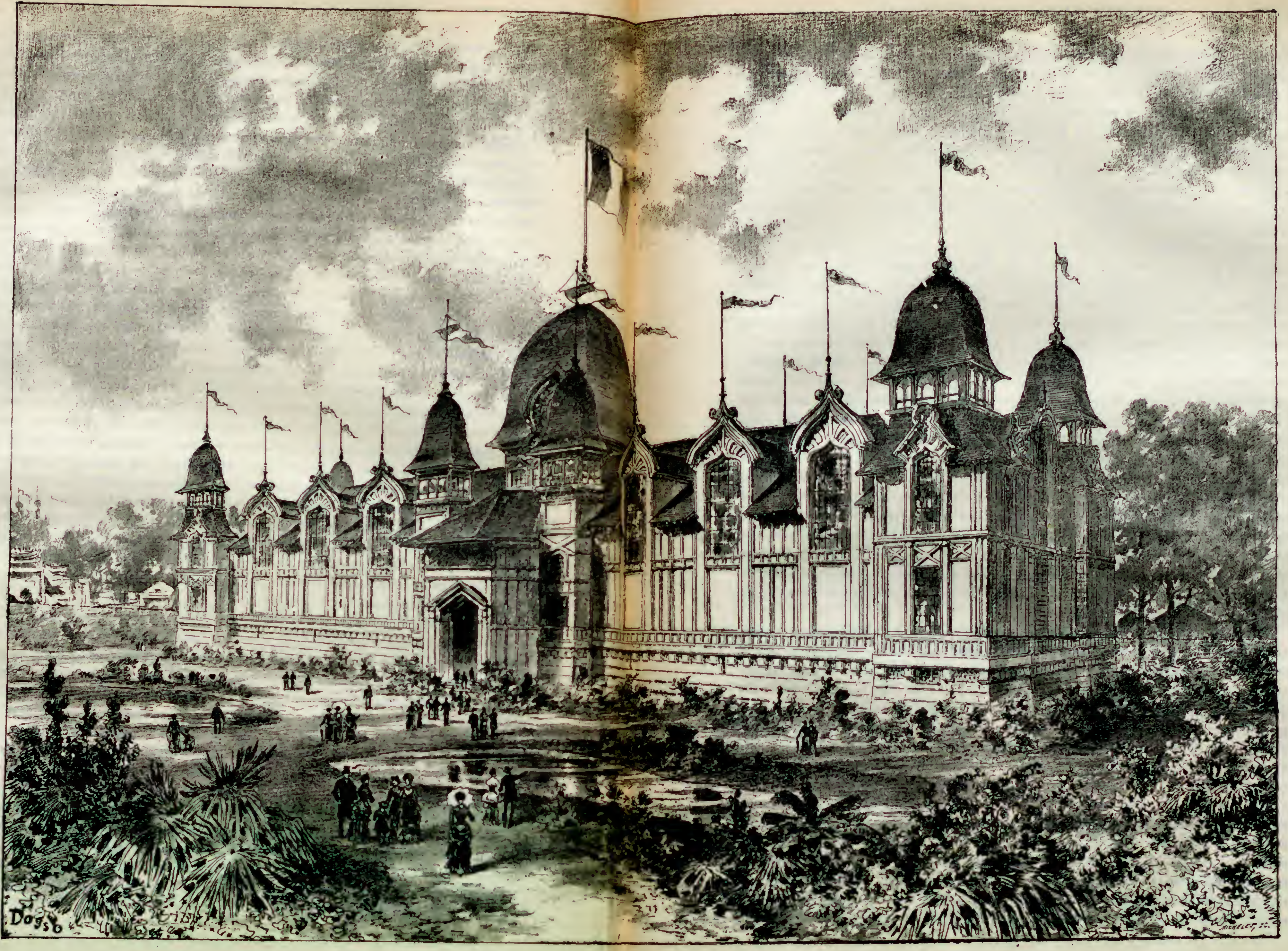

Le palais des Colonirs. 
nade reproduit partiellement et fidèlement le quartier même des Souks a Tunis, quartier dont M. J. de Grozals a donné dans la Revue Bleuc une description bien vivante. - C'est assurément, dit-il, une des plus curieuses choses qui se puissent voir. Imaginez un ensemble de galeries se succédant, mais sans ordre, sous les angles les plus dirers, au hasard de la fantaisie la plus déréglée; juxtaposées, mises bout à bout, s'entrecroisant, hautes et basses, voûtées ou plafonnées, complètement recouvertes ou laissant voir le ciel par endroits, en contre-bas avec le sol environnant ou en saillie, en bois ou en pierre, mais toutes délabrées, sales et d'un piteux aspect. Dans l'épaisseur des murs s'ouvrent, par une large baie cintrée, les boutiques; elles sont toutes sur le méme plan et dans les mèmes proportions. On n'y a pas facilement accès, car elles s'ouvrent a 75 centimèlres ou un mètre au-dessus du sol; mais l'acheleur n'y pénètre pas; il est comme au balcon pour voir les marchandises qu'on lui présente. Tout autour de celte sorte de caveau, des rayons ménagés dans l'épaisseur des murs servent de dépût; quelquefois, dans le fond, s'ouvre une arrière-boutique, qui prend le jour par le haut en dehors du souk et qui verse un flot de lumière blanche el crue jusque vers le milicu de la voùte. En avant des boutiques règne une sorte de marche-pied en pierre qui en facilite l'accès au propriétaire et aux familiers. Les dalles en sont usées et luisantes: recouvertes de nattes, elles servent de bancà la population oisive qui remplit les soulis dès le matin. Le visiteur défile donc entre deux galeries de boutiques et une double haie de curieux accroupis, assoupis, attentifs pourtant, qui jouent avec leur pipe vidée ou avec l'ombre de leur chapelet, les jambes replices, leurs sandales à terre devant eux. Tous les souks ne sont pas voútés: quelques-uns sont recouverts d'une sorte de toiture en planches. Ce sont les plus misérables. Il manque une planclse sur deux ou trois, et de ces hauteurs pendent de larges toiles d'araignées comme on n'en voit en France que dans les antiques étables des hameaux perdus. Lellet en est bizarre: le soleil, jouant dans ces lambeaux grisatres, les colore de reflets inatlendus et leur préle un éclat singulier; quand la brise les agite, on dirait des drapeaux qui frémissent. On n'est qu'à demi rassuré sous cette décoration: une de ces toiles se détachant suffirait à envelopper un homme. Le pittoresque, il est partout. Le pavé des souks est plus irrégulier encore que celui de la rue.

* Comme on ne remplace pas les pierres qui s'ébranlent et sont enlevées, il y a jar endroits presque autant de crevasses que de traces de chaussée; on inarche sur la terre battue, qui devient, a la première pluie, un vrai bourbier. Betes et gens traversent les souks, en battent le sol, en pétrissent la fange. C'est dans ce inilieu cependant que sont accumulées les principales richesses de l'industrie tunisienne. Chaque souk a unè destination particuliẻre; les märchands d'étoffes en occupent plusieurs, les chapeliers et les fabricants de chechias en ont un autre; les bijoutiers et les marchands d'essences forment l'aristocratie marchande et sont établis au centre; les armurier's vivent avec eux en bons voisins. Les cuirs et les onvages de sellerie ont leur quartier à part. Il y a aussi les tourneurs, les fabricants de petits mobiliers, et, ça el la, sur la lisière de ce monde a part, quelque moulin à blé on à huile que met en monvement dans une cave sombre un mulct aux yeux bandés. Il n'y a de vraies richesees, a notre sens, que dans les souks réservés aux étolfes ou aux soieries. Les Juifs règnent en maitres dans ce monde du commerce; c'est naturellement dans leurs bontiques yue s'entassent les plus riches tissus. On reconnait de loin la bontique juive, a l'empressement affairé du vendeur qui va au-devant du client, le presse, lenlace, en fait 
sa chose. Il faut n'ètre plus novice pour échapper de ses mains sans être allégé de quelgues piastres. Aussi bien la tentation est-elle forte souvent; les soieries de Tunis sont célèbres et valent leur renommée. Il y a beaucoup de soie de Lyon dans le nombre; cependant l'industrie indigene produit encore, et ses tissus se reconnaissent a lenr éclat. Ce sont des burnous, des haiks, des blouses de femmes juives aux vives conleurs, aux larges raies d'un très bel effet, des couvertures de laine de Djerba et du Djerid. La broderie d'or et d'argent formant le complément obligé de tout vêtement oriental, les atcliers de broderic ne sont pas éloignés des magasins où se fait la vente. Ce sont les hommes qui brodent. Ils manient l'aiguille avec une dextérité admirable. Quand ils défont un écheveau de soie dont ils retiennent l'extrémité avec le gros orteil de leur pied nu, c'est plaisir de voir l'agilité de leurs doigts et leur jeu insaisissable. De leurs mains sortent ces lourdes et riches broderies qui revêtent comme d'une cuirasse la veste d'intérieur des femınes arabes, la trame d'or qui enrichit leur toque. Le gout n'en est pas toujours parfait; c'est trop surchargé, c'est épais pour notre délicatesse française. Il y a là néanmoins un art indigène qui mérite d'ètro loné. Il y a plus d'origrinalité dans le travail des cuirs et la fabrication des ouvrages de sellerie; c'est l'industrie vraiment africaine; on la retrouve partout, depuis le littoral jusque dans le Soudin, et elle est bien représentée à Tunis. La visite au souk des cuirs est assurément l'une des plus intéressantes. On y trouve tous les obyets de harnachement, ces sacs en cuir de différentes couleurs avec plusieurs poches qui funt partie intégrante du mobilier arabe.

- Lactivitè s'éveille assez tard dans les souks; avant sept heures et demie ou huit heures, on trouve portes closes. Les industries qui, de près ou de loin, tiennent à l'or, affirınent leur aristocratie en retardant; les enchères où se vendent les métaux précieux et les pierres fines ne s'ouvrent pas avant dix heures. On n'a rien vu des souks si on n'y est pas revenu plus d'une fois dans le milieu du jour, de midi à trois heures. C'est alors, dins ces étroits couloirs, un entassement et une cohue inimagrinables. On est vraiment payé de sa fatigue par le régal d'un spectacle sans pareil. Le pavé disparalt sous la multitude des pas; l'éclat, la variétć des costumes étonne et charme le regard. Maures, Juifs, Arabes du désert, nègres à la peau luisante, à la jambe sèche et nue, négresses flétries et ridées, femmes arabes empaquetées sous leurs voiles, Juives en inaillot, tout se donne rendez-vous sous ces voùtes. L'activité commerciale allumée par les Beni-Israël donne à cette population un mouvement, un air de fièvre quon nelui connaît pas. On se presse, on se coudoie, on se bouscule; les courtiers juifs enlèvent au passige l'acheteur européen qui se présente; la foule curieuse le suit. On fait cercle autour de lui; les marchands rivaux font bonne garde. On est en partie sauvé des grifles d'Aaron, qui velat cinquante francs, par la générosité intéressée d'Ahmed, qui laisse à trente. Surviest Ismaël, qui offre à vingt; enfin, grace aux bons soins de ce nez de vautour, qui vante sa propre probité, on a pour dix francs l'objet en litige. N'oublions pas, pour laisser au tableau tout son caractère, que, nème à cette heure d'encombrement, bètes, chariots et portefaix ont toujours droit de passage. ún se ligure le remous que produit, dans ce flot humain, l'arrivée d'un cavalier. Recouvert de son large chapeau de paille ruhaussé de garnitures en cuir, orné de pom pons, de ce chapean qui n'a pas moins de $1^{\text {m}}, 10$ d'envergure, l'homme campé sur ses vastes étriers, le fusil jeté en travers de la selle, domine la foule d'un air superbe. Le cheval choisit ses pas, lentement, l'œil étonné. Le courant humain se 
divise, frole les flancs de la bête et se referme sur sa croupe. On y me plus d'empressement quand un Maure passe sur sa mule qui va l'amble. On ne saurait rien voir de plus gracieux que la mule tunisienne: c'est la fleur du règne animal dans cette contrée. Mais elle se sait belle, elle a ses caprices, il faut se ranger à son approche. Le petit ane passe inaperçu: on se sent un peu poussé par un être minuscule; c'est un bourriquot qui s'ouvre un passage; un grand nègre le suit et cogne sans pitié. Le spectacle de cette activité variée, multicolore, bruyante est chose tout à

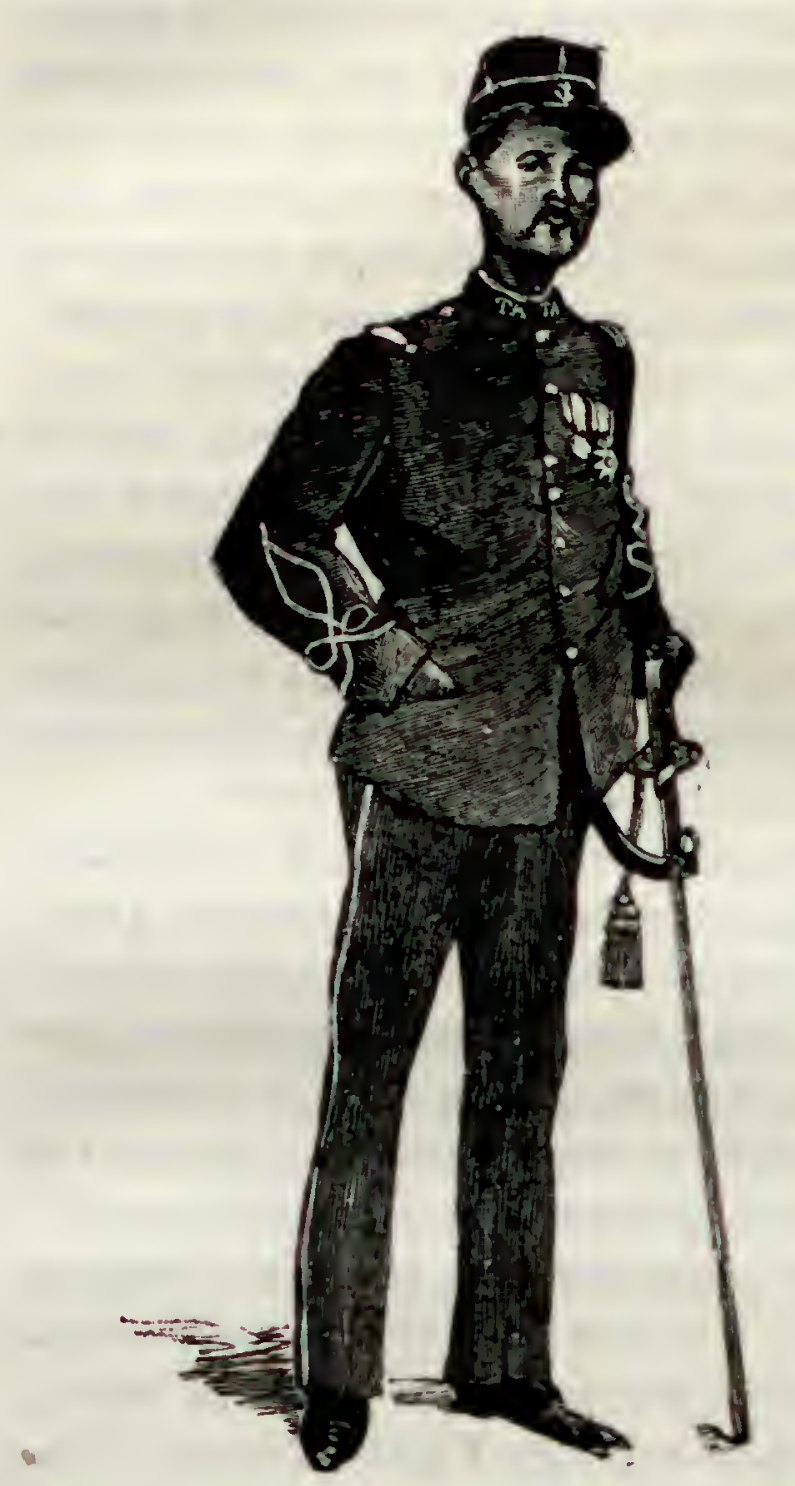

NGUN. - Lieutenant de tirailleurs annamites

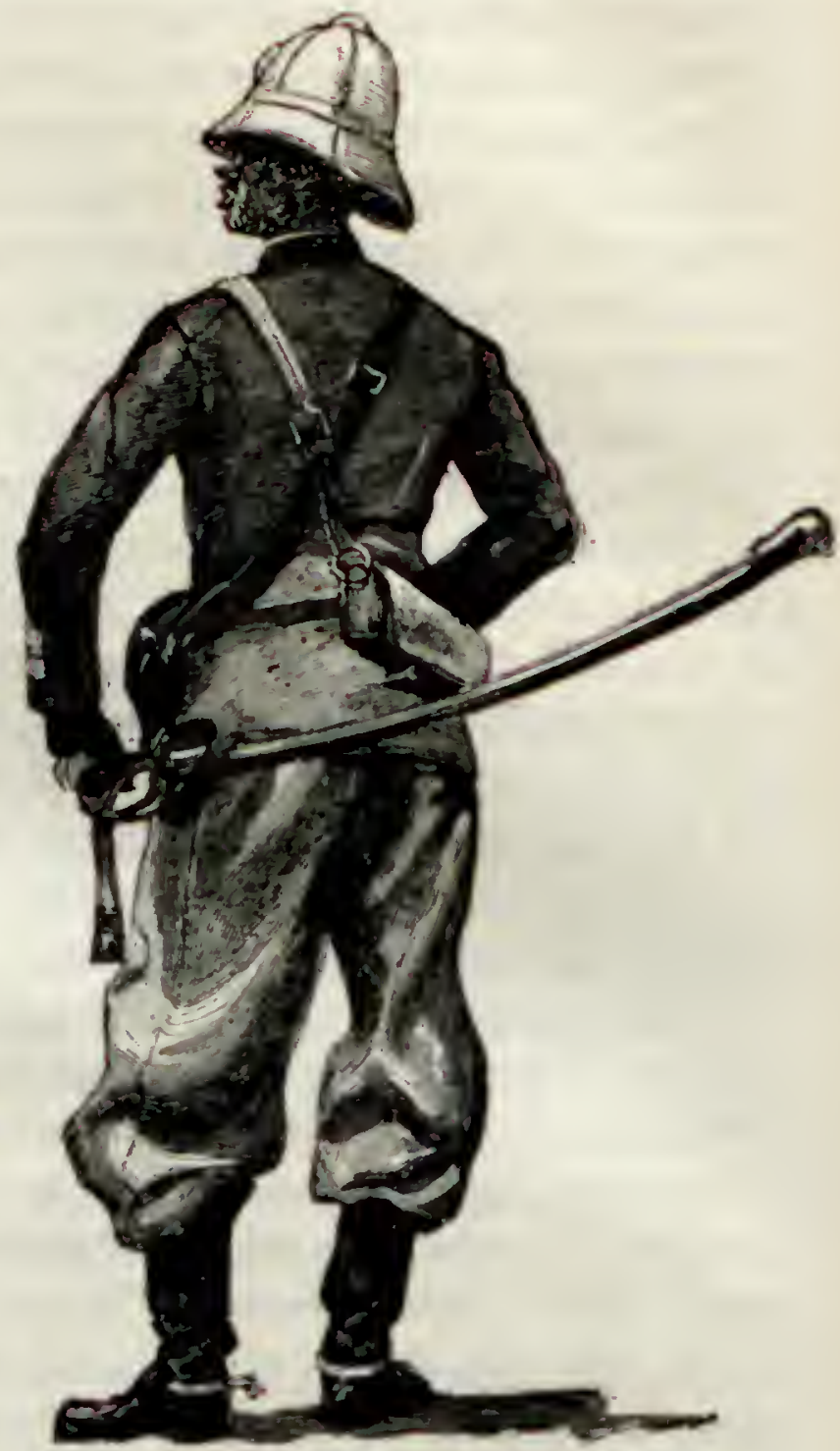

Cavalier de spahis sénégalais.

LES TROUPES COLONIALES A'EXPOSITION UXIFERSELLE.

fait nouvelle pour l'Européen; il doit en rassasier ses yeux, car, sans doute, nulle part ailleurs, il ne retrouvera rien de semblable, et ce flot humain s'écoule rapidement. Vers quatre heures, tout reprend l'aspect calme et languissant de la matinée. II faut bien entendre que cette cohue ne se produit pas dans tous les soulis; la population de Tunis n'y suffirait pas. Les souks de la soierie et de l'or sont surtout fréquentés; le mouvement est moins intense dans les autres. Il en est même qui ne perdent jamais leur physionomie de ruelle écartée de village.,

Une mention toute particulière est due à la section archéologique de l'Exposition tunisienne. On y apprendra comment les Romains, par d'admirables travaux hydrauliques, surent combattre victorieusement la sécheresse, le grand ennemi des colons français en Tunisie. Depuis l'occupation française, des recherches archéologiques ha- 
bilement dirigées ont donné de précieux résultats. Le gouvernement français a envoyé en mission MM. Cagnat, Saladin, Letaille, Salomon Reinach et Ernest Babelon, qui ont fait des fouilles à Bou-Ghara, l'ancienne Gightis; a Ziam, l'ancienne Ciparca; a El Kantara, l'ancienne Meninx, où l'on a trouvé une belle statue d'Auguste voilé, en pontife. Des fouilles ont été exécutées à Carthage, dans l'antique Byrsa, et ont fourni d'intéressantes pièces au nouveau musée de Tunis et à celui du P. Delattre, au cou-

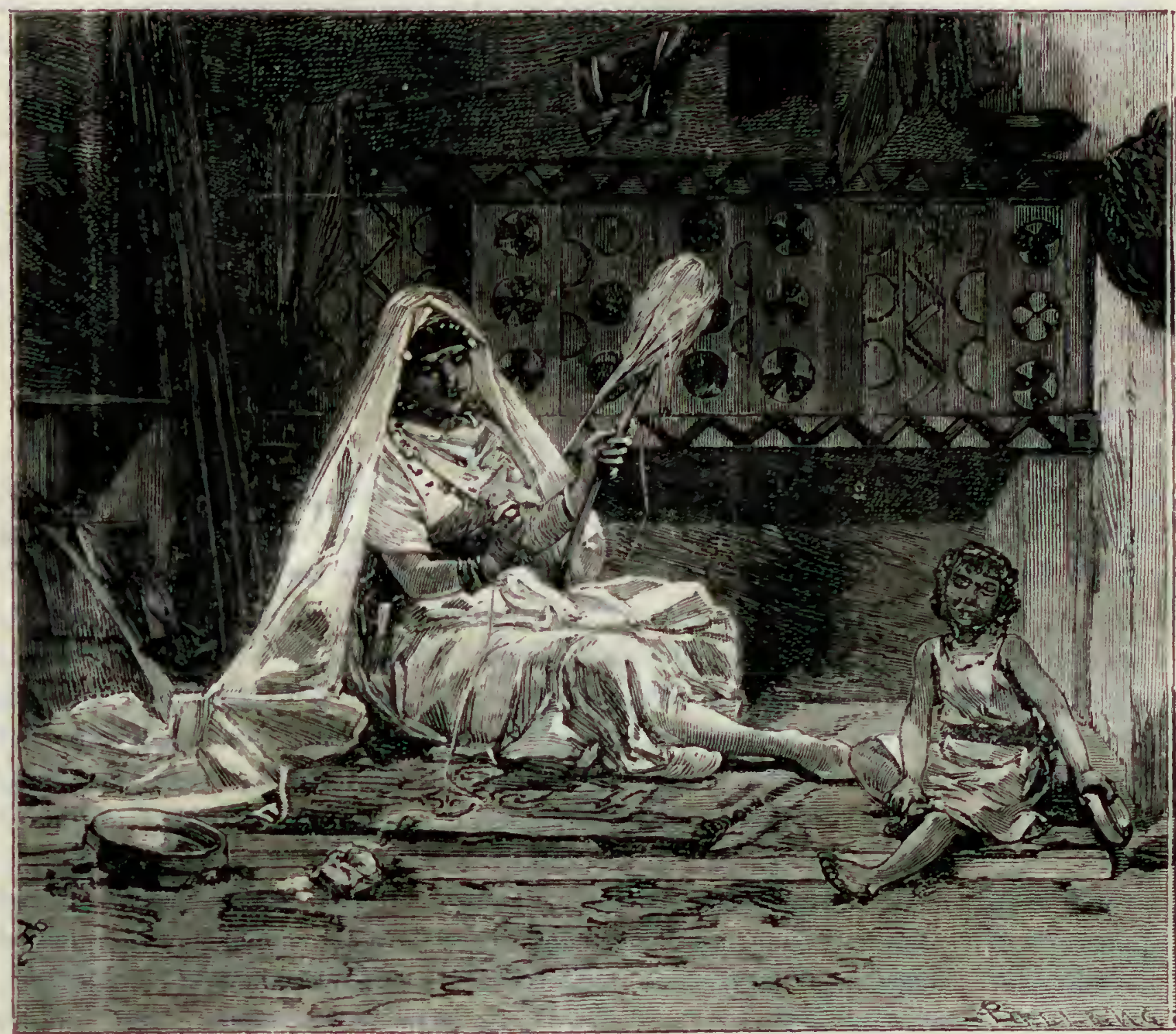

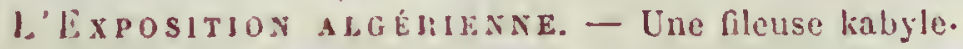

vent des religeux de Saint-Louis de Carthage. Les officiers du corps d'occupation ont eux-mèmes contribué au succès de ces entreprises, soit en relevant des inscriptions, soit en sopposant à la destruction de ces curiosités.

Les produits exposés montrent que l'agriculture tient une grande place dans la vie économique du pays, puisque les produits du sol entrent pour 77 0/0 dans le commerce d'exportation de la liégence. El pourtant l'agriculture tunisienne est encore dans la période de l'enfance. La petite propriété est très rare en Tunisie, où la plupart des terres dépendent de l'administration des Habouss ou appartiennent à de grands propriétaires, qui les font exploiter par des locataires ou des métayers. a Les locations, dit M. de Lanessan, ne sont faites d'ordinaire que pour un an, parfois pour deux au trois années au plus. Le locataire n'a aucun intérèt à améliorer la terre do 
son propriétaire; son insouciance à cet égard est si grande qu'il ne se donne pas la peine d'arracher ou de couper les broussailles; il les contourue avec la charue, sans y toucher plus que si elles étaient sacrées. Si les broussailles sont formérs de plantes que respectent les moutons, les bœufs et les chèvres, comme les jujuljiers épincux et les lentisques, elles se multiplient a leur aise, envahissant chaque aunée une portion nouvelle du champ, qui ne tarde pas à etre tout entier impropre a la culture." Les palmiers viennent à merveille dans la région des oasis, c'est-d̀-dire dans le sud de la Régence, dans l'île de Djerbah et dans le voisinage des Chotts. Les monlirgres du sud sont couvertes d'alpha. Suivant M. de Fleurac, la seule culture importante dans le sud est celle du dattier, qui n'est possible que dans les terrains irrigués des oasis sahariennes. Le palmier se plante généralement en damier. 11 y a, dans le lijérid, 102 espèces de dattes dont.les plus recherchées sont les deglat-en-nom. Presque tous les arbres fruitiers d'Europe viennent dans les oasis, mais ils ne poussent pas tous également bien. C'est vers la viticulture que se sont portés, dès l'établissement du protectorat, presque tous les efforts des colons européens. Ẻn 1886, l'étendue du vignoble était de 2,140 hectares, dont 1,300 dans leur première année de plantation. 830 dans la deuxième, 250 dans la troisième, et 40 hectares sculement attrignatent un dipas. saient l'âge de quatre ans.

Les régions vinicoles sont au nombre de 6 : Mornag, Cap Bon, Tunis, Mlerjurara, Zaghouan et Enfida. M. Gastine, délégué par le gouvernement pourétulier te vignohle tunisien, est arrivé a des conclusions encourageantes pour la colonisatiun. On lira avec intérèt les conclusions d'un aussi éminent agronome sur l'avenir vilicole de la Tunisie française. M. Gastine vante d'abord l'extrême abondance des lerres propres à la culture des vignes dans les meilleures conditions d'économie. Partout la charrue peut être employée, tant pour la préparation des terres, le défonçage, que pour la culture proprement ditc. Les terres en coteau offrent des pentes douces, développées dans de longues vallées larges et ouvertes; elles équivalent comme facilıté de travail aux terres de plaine. C'est donc à bon droit que l'on a dil que la Tunisie ofrail un milieu presque partout favorable à la création des vignobles. ,

En second lieu, M. Gastine rend justice a l'entrain admirable des colons qui ont apporté dans le pays leur énergie et leurs capitaux. " Ce n'est pas en Tunisie que l'on pourrait trouver des arguments pour démontrer notre inaptitude a la culonisation, thèse soutenue avec une inconsciente ironic par les Français eux-uérnes, mais que les étrangers plus clairvoyants n'acceptent pas encorc. Je ne crois pas qu'aucun pays nouveau puisse offrir le tableau d'une parcille activité. Or elle est loute framaise celle activité colonisatrice, car, parmi les propriétaires qui ont quelque iuportance, on chercherait vainement des acquéreurs étrangers.

Les forêts tunisiennes, qui sont représentées a.l'Exposition par un pavillon spécıal, couvrent un espace d'environ 500,000 hectares : chenes-zeen, chenes-lieges, cheneskermès, chênes verts, genévriers, pins, tuyas, lentisques, oliviers sanviges. Le service forestier, institué en Tunisie en 1884, s'est préoccupé d'abort do la inise en valeur des forèts de la Kroumirie; il a construit une route avec pont sur la Medjerda pour faire communiquer Ghardimaou avec la station forestiede d'li-fienda, plus un grand nombre de sentiers muletiers.

L'industrie minière tient enfin une place honorable dans la section, ainsi que les produits marins: sel, corail, éponges. 
Il nous reste, avant de quitter la Tunisie, à dire quelques mots des éléments qui forment la population tunisienne et dont on voit sur l'Esplanade plusieurs lypes authentiques. Cette population n'est pas homogène, ce qui s'explique par la diversité des races qui se sont succédé dans ce coin de l'Afrique. Aussi loin que nous puissions remonter, nous trouvons les Lybiens, qui furent treize siècles avant notre ère vaincus et supplantés par les Sanhaga, les Gétules des Latins. Beaucoup plus tard, les Zénatas Berbères viennent se fondre avec les deux couches ethniques précédentes, et ni les Carthaginois ni les Romains ne purent anéantir la race née de cette fusion. Enfin les Arabes couvertirent les Indigènes a leur religion. Si vous ajoutez à cette énumération une foule d'envahisseurs secondaires, vous comprendrez qu'il n'y a pas à proprement parler de type tunisien. On y trouve des Arabes, des Berbères, des Français, des Italiens, des Maltais, etc., appartenant aux religions mahométane, israélite, catholique, protestante.

\section{L'ANNAM, LE TONKIN ET LA COCIINCHINE}

Olı a tellement parlé de l'Annaın et du Tonkin depuis les événements qui ont abouti a l'établissement du protectorat français dans cette partie de l'Indo-Chine, que les organisateurs de l'Exposition coloniale devaient ètre naturellement amenés à faire une place assez large ì l'architecture, aux productions et même aux mours annamites. Parmi les soldats indigènes que l'on fait venir de nos colonies (de celles, du moins, où des corps de tirailleurs sont organisés), les Indo-Chinois sont de beaucoup les plus nombreux. Ils sont de taille noyenne etimberbes; leurs cheveux noirs et abondants sont relevés en chignon et euveloppés d'une sorte de foulard noir que surmonte, en guise de képı, une simple rondelle plate retenue par des cordons. La face est plate, osseuse, le front large à la partie inférieure, le teint chocolat clair, les yeux a fleur de tète, les paupières épaisses, les mains longues et les doigts noueux, le corps trapu, le bassin large. Leur's dents sont noircies par la mastication de feuilles de bétel enduites de cliaux.

Les Pavilluns de l'Indo-Chine française (Cochinchine, Annam et Tonkin) ont été construits pal des ouvriers indigènes au nombre de vingt et un: un Chinois, un Annamite et dia-neuf Tonkinois.

Le Chinois est un maitre compagnon charpentier qui a travaillé à la préparation de toutes les picces de bois, taillées et sculptées en Cochinchine; il a assisté à leur numérotage et a leur emballage, et a dirigé les ouvriers français chargés de les assembler et de les mettre en place.

L'Annamite est un peintre extrèmement habile, qui est employé aux décorations délicates el vraiment artistiques.

Les dix-neul 'lonkinois ont été occupés à des ouvrages divers dans les Palais de la Cochinchine el Iu Toukin; mais la plupart sont des peintres décorateurs, plusieurs ne manquent pas d'un certain talent. Yous les avons vus a l'œuvre; ils unt décoré la façade du l'avillon Cochinchinois; ils ont peint, dans chaque panneau de celte façade, des paysiges 11 des scènes de la vie annamite, et fait de charmants encadreinents de fleurs, de dragums el d'ornements aux couleurs vives. Rien n'est plus amusant que de suivre leur travail: ils se mettent plusicursả la décoration du même panneau, ils tracent 


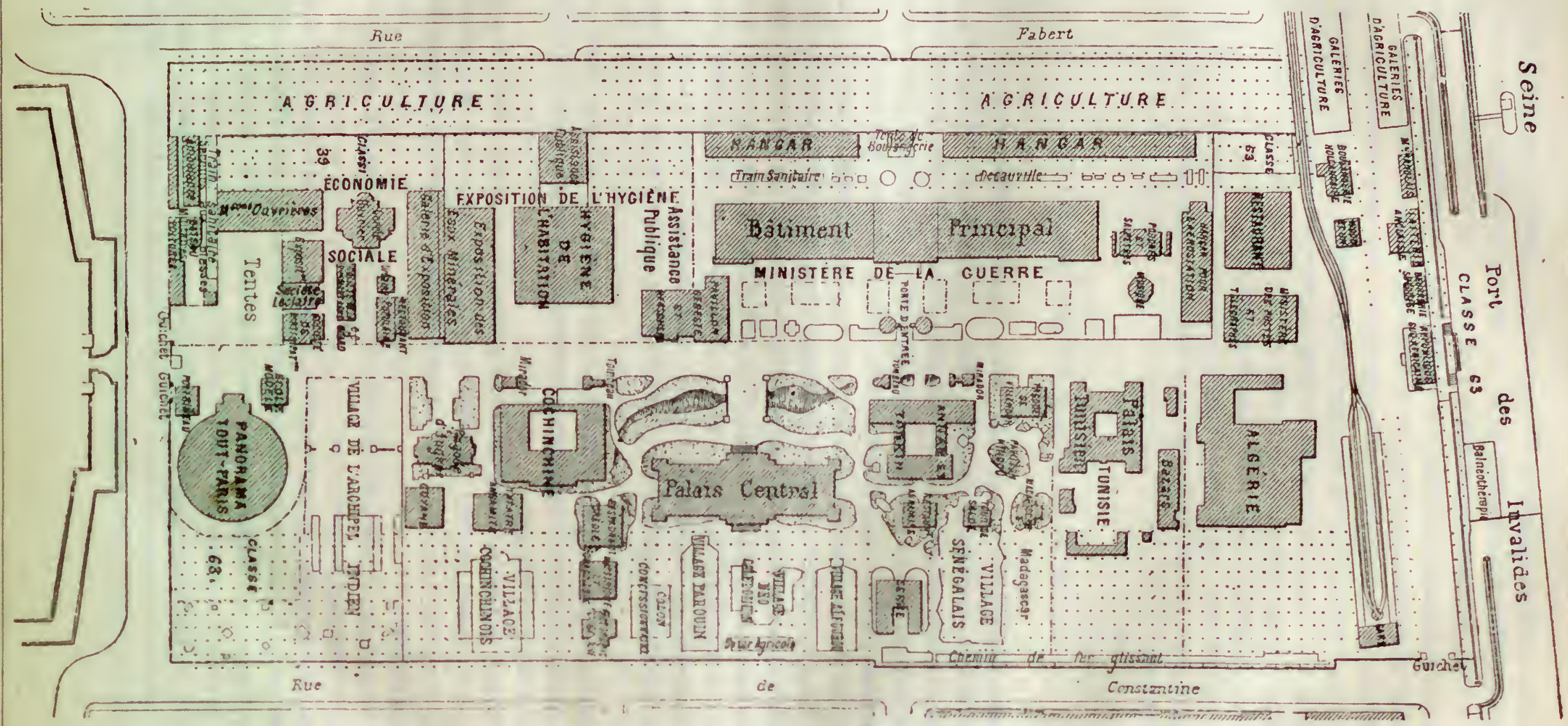




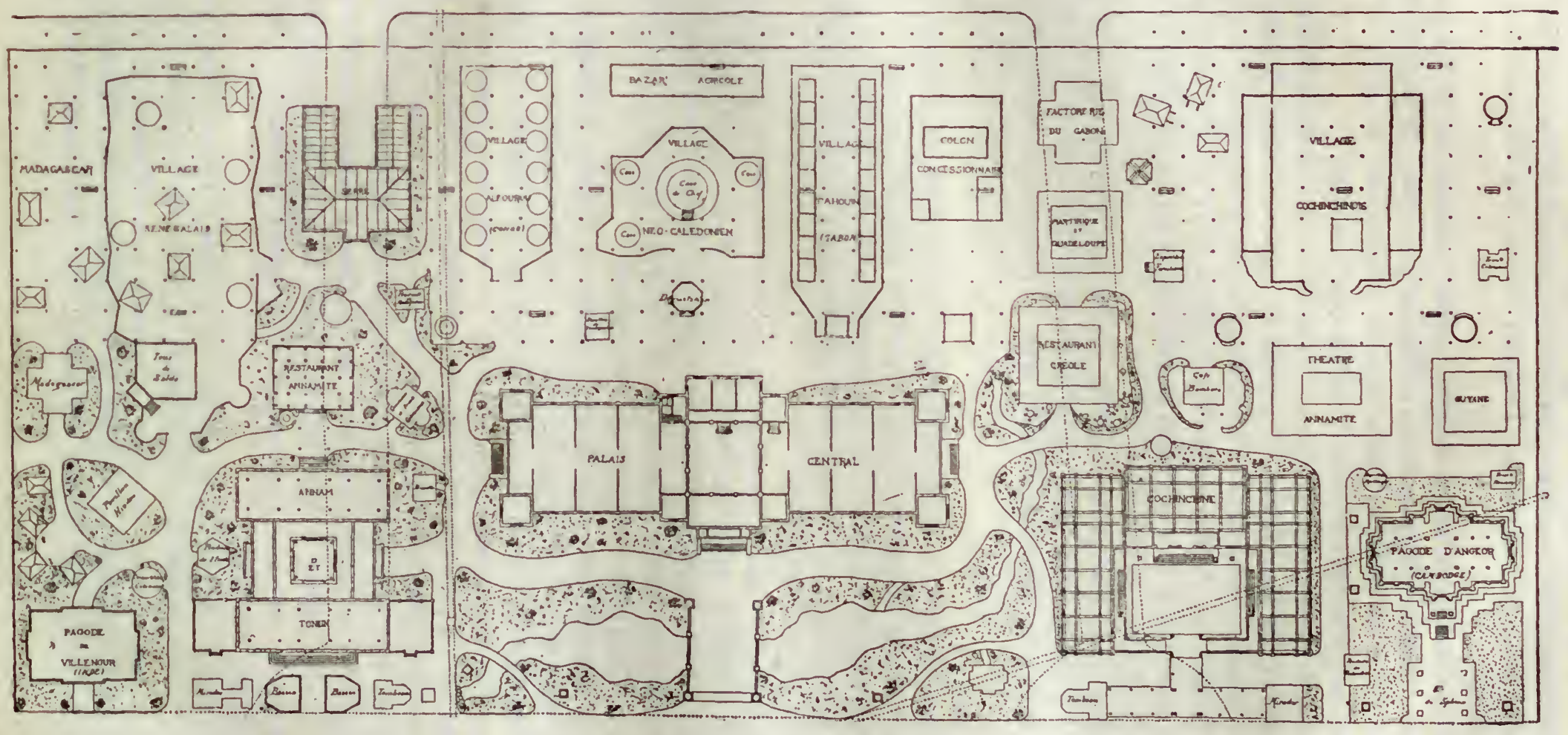

D'LAX SPÉCIAL DE L LXPOSITION COLONIALE. 
ensemble le dessin de leur sujet qu'ils composent et exécutent sans modele, et, une fois la composition terminée, ils passent le panneau à une autre équipe, qui met en caractères annamites le titre de son ceuvre. Tout cela est fait très vite, avec une süreté de main surprenante.

Ces ouvriers sont d'Hanoï ou des environs; cesont presque tous de très jeunes gens, au type chinois: yeux bridés, pommettes saillantes, peau jaune. Ils portent une sortede blouse longue, noire ou verte, serrant la poitrine et fendue sur les côtés, un pantalon blanc très flottant, et sur la tẻte un petit turban noir à ailetles.

Ils sont sobres, dociles et polis; lorsqu'ils rencontraient l'un des ingénieur's surveillant leurs travaux, ils s'arrêtaient, et, portant la main au turban, faisaient le salut militaire. Nous avons pénétré dans le réfectoire qu'on leur avait organisé sous la pagode d'Ang-Kor, au moment oú ils prenaient leur repas; à notre arrivée tous se sont levés, puis, sur un signe, ils se sont accroupis de nouveau, assis sur les talons autour d'une longue planche qui leur sert de table.

Ils prennent deux repas qu'ils préparent eux-mémes, l'un de viande et l'autre de poisson, et toujour's avec une forte ration de riz. Ils avaient apporté un approvisionnement de riz et de poissons séchés et salés; mais le poisson s'est détérioré pendant le voyage, et il a fallu le jeter; du reste, ils ne s'en plaignent pas, car on l'a remplacé par du poisson frais.

Les gardiens chargés de les surveiller leur donnaient les plus grands soins; un médecin leur a fait de fréquentes visites, et prescrit loutes les précautions nécressaires pour éviter les fluxions de poitrine à redouter pour des gens accoutumés à un clinnat plus doux; toute l'équipe a été vaccinće; l'opération ne s'est pas faite sans causer une certaine émotion parmi les patients.

L'administration n'a reculé devant aucun sacrifice: bons repas, bon gile et le reste. On leur a fait connaltre les curiosités de la capitale; ils ont passé une soirée au Nouveau-Cirque et se sont particulièrement intéressés aux écuyères, très curieux de savoir si elles portaient des maillots. Émerveillés de ce qưils avaient vu, ils ont passé une partie de la nuit à se communiquer leurs impressions.

Le Palais Cochinchinois auquel ils ont traraillé est une très intéressante construction conçue dans le pur style annamite. Tout en rez-de-cliaussée, il se compose d'un pavillon central qui contient la pagode, et de deux galeries annexes qui entourent une cour intérieure; au milieu, une vasque et des jets d'eau ornés de porcelaines et de terres cuites. Cette cour est précédée d'une remarquable galerie à colonues et is gradius, a laquelle on accède par un portique, qui est la reproduction exacte de la porte de la pagode de Quan-Yen, près IIäphong. Il y a partout une profusion de colonnettes et de poutrelles sculptées, de panneaux ajourés, de chapiteaux finement fouillés et de moulures fantaisistes et dorées. A l'extérieur on a placé des mâts de pagodes, des orinammes, des statuettes, des vases gigantesques, des animaux fantastiques. C'est d'un effet aussi gracieux que saisissant.

Le missionnaire Legrand de la Lyraye qui a vécu si longlemps parusi les Anuamrtes, et qui les connaissait on ne peut nieux, a publié sur les mours el coutumes de ces Asiatiques une curieuse brochure, à laquelle sont empruntés les détails qu'on va lire. Le visiteur appréciera combien les organisateurs de l'Exposition coloniale ont fait d'efforts pour lui donner un tableau scrupuleusenent fidile de la vie annamite : 
- Les habitations, dit le P. Legrand de la Lyraye, sont pour la plupart des constructions de peu d'importance et d'une apparence très misérable. On voit d'abord une petite cour carrée de terre battue qui est très unie et très soignée, qu'on appelle san. Autour de celte cour qui sert aux besoins du ménage sont plantés des aréquiers, et, à quelques pieds de ces arbres, est élevé le remblai de terre qui sert de plateau ou d'assise à la maison principale et aux constructions de décharge. Elle est faite ordinairement de quelques colonnes de résistance et de pieux de bambou chevillés très ingénieusement avec du bois et non avec des clous, difficiles à se procurer partout. Les colonnes étant posces, on fait des treilles de pieu à pieu, on les enduit de terre battue avec de la paille et de la balle; on laisse quelqutes ouvertures pour donner le jour nécessaire. Ces ouvertures ont des volets tressés qui se ferment quand on n'a plus besoin de voir clair; on a une toiture couverte de jones, de feuilles ou de paille, et ainsi on a une maison qui n'est pas un palais, mais qui devient le sanctuaire domestique, qui suffit aux besoins et qui finit par la coutume à ètre trouvée belle.

"Les maisons des gens riches ont d'assez belles colonnes de beau bois; un péristyle de 3 ou 4 pieds de large fait le tour de la maison, et la colonnade, qui forme proprement la conștruction, se repose sur la colonnade du péristyle par des bouts de poutre, d'ordinaire sculptés en tête de dragon, qui ressortent un peu en dehors. Les cloisons alors sont de planches par derriere, et, par devant, de chaux battue avec du papier; elles sont peintes souvent de différents sujets de la vie champètre.

- bans ces maisons riches, outre la salle de réception, on remarque un petit salon pour boire le thé (nha-che), fumer et converser à l'aise. Au fond de ce petit salon est une ouverture à coulisse qui donne sur un petit bosquet ou sur un petit monticule, fait avec art, de pierres venues du littoral de la mer. Devant se trouve le réservoir où se jouent de petits poissons, et l'on remarque quelquefois autour une allée pavée de coquillages.

- L'hospitalité chez ce peuple est naturellement généreuse, mais méfiante, à cause du despotisme auquel il est soumis et du paupérisme, causé partont par l'excédent de la population. On a toujours a craindre de recevoir chez soi un émissaire des avides mandarins, ou un avide aventurier qui a perdu au jeu, ou un voleur de profession. Quand on s'est assuré qu'il n'est rien de tout cela et qu'on a affaire à un simple voyageur éloigné de son foyer domestique, alors on le voil avec plaisir, on partage généreusement avec lui l'ordinaire du ménage et on lui fait le plus d'honneur que l'on peut.

- Nous voici arrivés à l'examen de la vie de famille proprement dite; cette vie de famille, où les rapports de mari et femme, de parents el enfants, et réciproquement, m'ont paru très raisonnables et d'un grand bon sens, sauf quelques formes provenant de la législation chinoise; car il me faut distinguer ici la vie de famille ofticielle ou autorisée par les lois, de la vie de fumille vraie et réelle, telle que l'ont faite l'usage, la force des choses et le caractere de la nation.

- Daprès le code chinois, le chef de famille n'a, pour ainsi dire, point de devoirs à remplir à l'égard de sa femme et de ses enfants; ils sont abandonnés à son bon sens et ì son intérủt. II est regardé comme le propriétaire de sa femme, qu'il a achetée, et de ses enfants qui sont son bien.

- Cependant j'affirmerai que la femme anamite n'est point esclave, qu'elle jouit au contraire d'une grande autorité dans le ménage et qu'elle y est toujuura honorée quand 
elle s'y conduit bien; j'affirmerai aussi que les enfants sont élevés comme il faut chez un peuple aussi pauvre et aussi nombreux. Une grande preuve de ce que j'avance, c'est que la vieillesse des vieux parents (père aussi bien que mère) est heure use et prospère, et qu'on leur rend, je crois, avec plus d'affection et de dévouement que chez aucun peuple, sur le retour de leur age, ce qu'ils ont dépensé de peines et de sueurs pour l'éducation de leurs enfants.

- Les femmes, au Tonkin et en Cochinchine, ne sont pas à petits pieds et retenues.

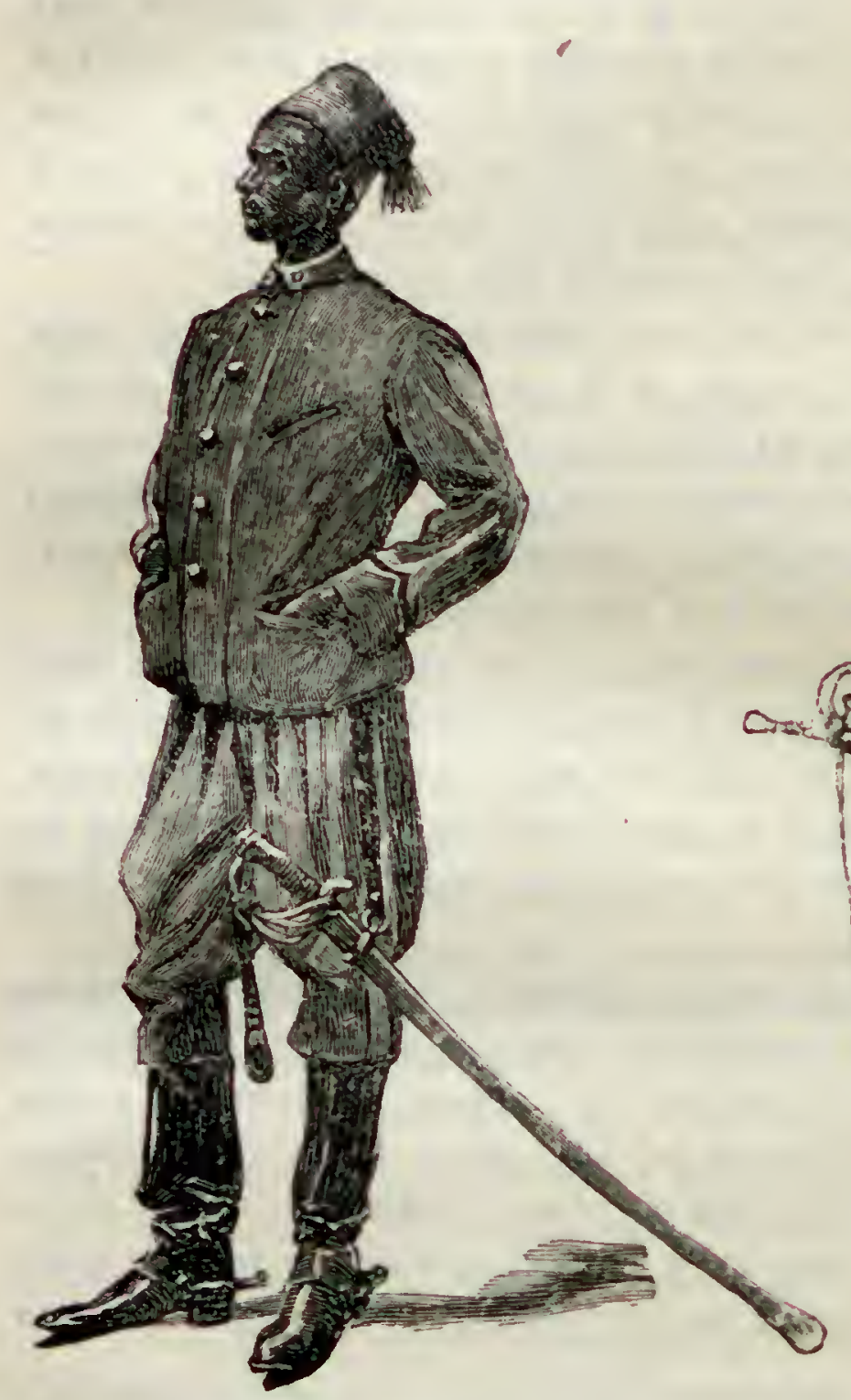

SAMBA'DAYE.

Maréchal des logis de spahis sénégalais.

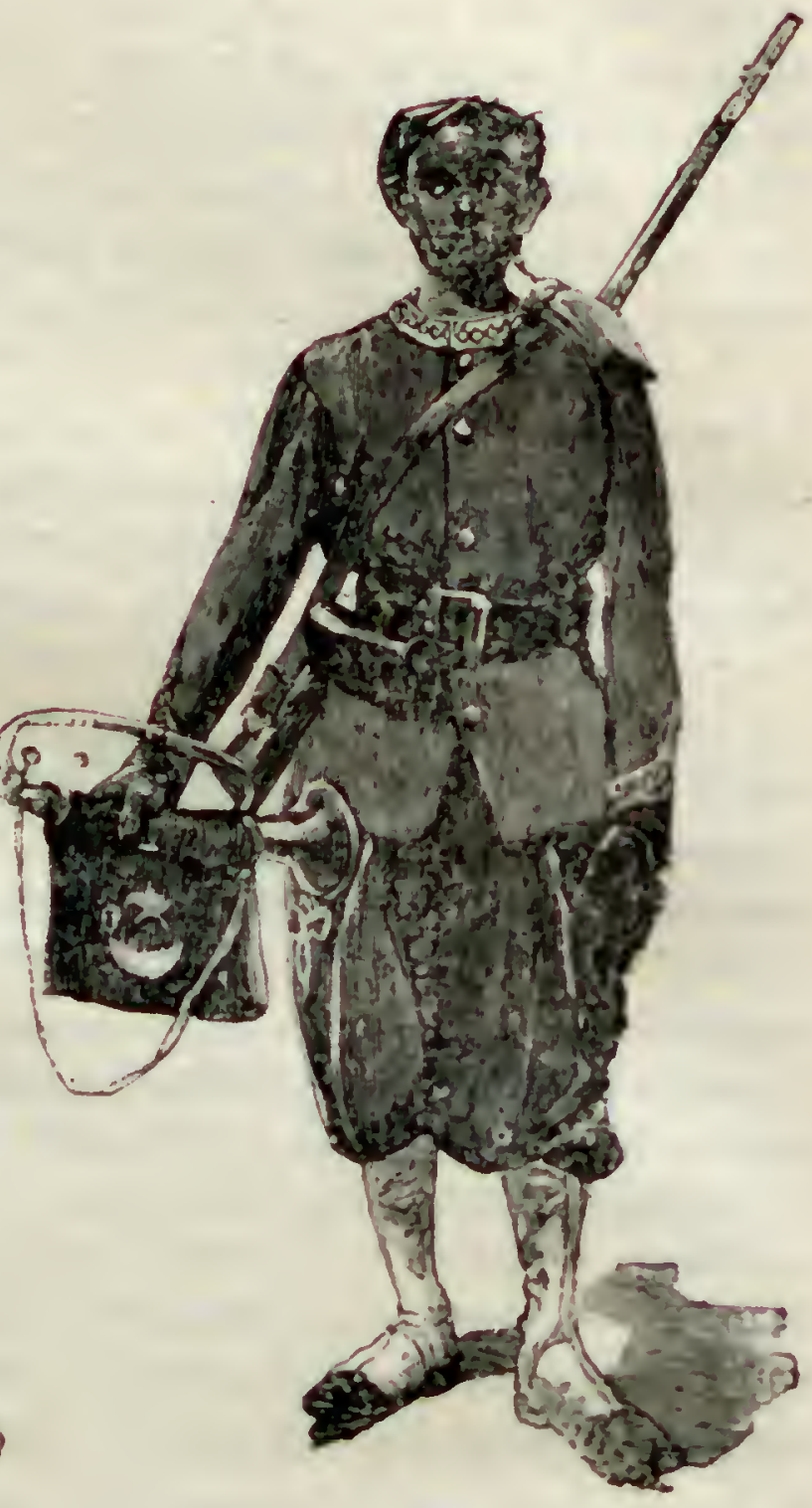

บกAMENUAÉ.

Clairon de tiralleurs sénégalais.

\section{LES TROUPES COLONIALBS L'EXPOSITION.}

comme en Chine, à la maison. Elles ront aux champs dont elle font en grande partie la culture, les hommes étant dérangés par le service de la milice et les corvées du roi, des mandarins et de la commune. Elles vont presque journelleınent aux marchés de la con. trée pour vendre leurs petils produits, acheter ce dont elles ont hesoin et entretenir ainsi le ménage. Elles se donnent une peine infinie et inzessante pour tout cela; elles sont très laborieuses et, sans elles, il serait impossible a la grande majorité des fanilles de virre tant soit peu honorablement.

- La vie extérieure qu'elles minent leur donne une habitude de réflexion, de retenue 
et de force de caractère qui relève ordinairement leurs brillantes qualités de l'esprit et du cœur.

"Les Annamites sont moins orgueilleux que les Chinois, et ils sont plus courageux et meilleurs soldats. Ajoutons que les qualités de l'Annamite sont la sagacité, un grand fond d'intelligence et de discernement et un tact remarquable : voilà pour l'esprit; une grande générosité et un fidèle attachement : voilà pour le cœur.

- L'Annamite est méfiant et, en général, il n'aime pas les nouveautés, mais il les

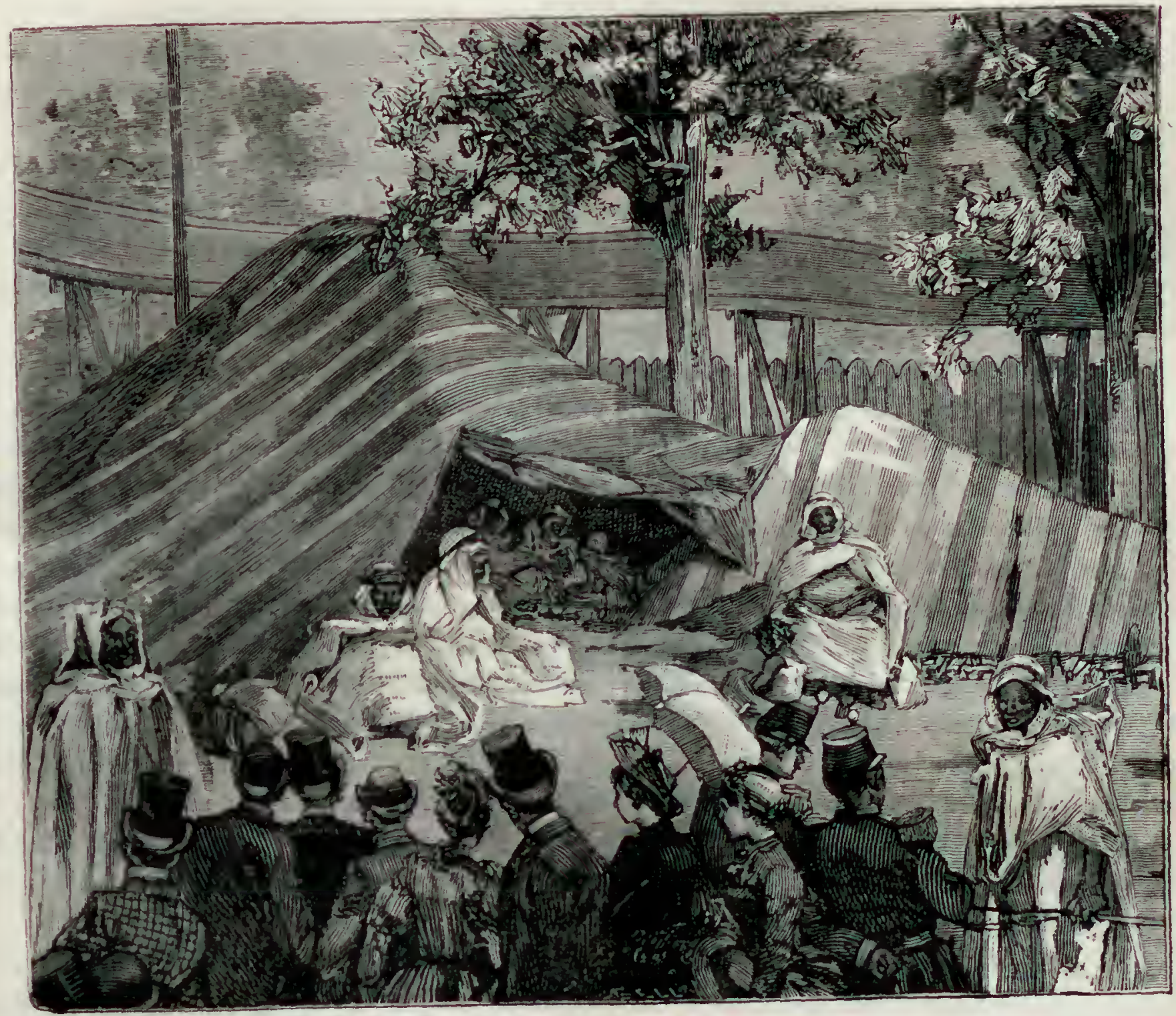

L'CXPOSITION ALGERIEXE. - Un campement de tribus nomades.

accepte quand il en voil bien la raison. Il y a des superstitions auxquelles il se livre, souvent sans frein, mais il n'est pas fanatique; il craint les étrangers, mais il ne les hait pas. Il se soumet volontiers à la plus grande tyrannie et aux plus pénibles travaux de la corvée, pour le bon ordre et le bien public, mais il a en horreur l'esclavage.

- Enfin, il est timide, mais de celte timidité, je dirai bretonne, qui résiste peu à peu et longtemps à la force brutale qu'il ne peut affronter en face. Son cœur est bon ct compatissant, ct, pour lui, l'homme sans affection (vo-tam) est un monstre (nguoi vo-lo); quand il a prononcé cette expression de nguoi vo-tam, c'est le dernier terme de son mépris.

- Les défauts de ce peuple sont la légèreté, et la vanité qui en est la source. Liv. 43. 
- Il aime le brillant, il aime a se vanter, a etre brave quand il n'y a pas lieu de craindre. Je ne vois que la population de IIanoï, au Tonkin, qui offre cette solidité de caractère qui tient un juste milieu entre la trop grande crainte et la trop grande confiance. Les autres défauts proviennent de la pauvreté qui engendre la ruse et le mensonge, la gourmandise, le jeu et l'ivrognerie, une certaine rapacité et l'esprit de vengeance.

Les Annamites de l'Esplanade n'ont pas seulement construit et décoré les pavillons; ils ont tenu ì édifier un village entier, où ils sont établis au nombre de 97. Ce village, qui représente exactement la place du Marché-Brûlé, à IIanoï, est rectangulaire et comporte 26 ou 30 cases de $4^{\mathrm{m}}, 50$ de large sur $4^{\mathrm{m}}, 23$ de haut. Le batiment où se tiendra le marché occupe une surface de plus de 10 mètres.

Parmi les ouvriers qu'on y verra, on trouvera des laqueurs, des incrusteurs, des fondeurs, des brodeurs, des sculpteurs, sans parler des coolies qui, moyennant une rétribution minime, vous promènent dans leurs pousse-pousse, la voiture tonkinoise. Ils portent un uniforme composé d'une blouse et d'un pantalon large bleu marine, avec appliques rouge orange.

Les industries indigènes, que l'on verra fonctionner à loisir, ne manquerout pas d'attirer l'attention. L'Administration de la Marine et des Colonies, dans de substan. tielles notices éditées à l'occasion de l'Exposition coloniale d'Anvers, a exposé le fonctionnement de ces industries d'après les rapports des fonctionnaires el commerçants. Ces notices nous expliquent les procédés de 7 filatures, qui sont très curieux. La fileuse s'installe n'importe où, sous un hangar ou dans la maison. Elle est accroupie sur ses talons, devant une bassine en fonte ou en cuivre de 30 à $3 a ̊$ centimetres de diamètre, posée sur un petit fourneau en terre où l'on fait un feu de bois, que l'on alimente aussi avec de la balle de riz. Ce feu produit parfois de la fumée qui gêne le travail de la fileuse. L'eau de la bassine est presque bouillante. La filcuse jette dans l'eau une poignée de cocons, trente environ, qu'elle agite arec deux baguclles en bois. Klle prend le frison de la main gauche, fait tomber les cocons avec les bagueltes et, en les trempant dans l'eau bouillaute, détache la tète du frison qu'elle jette de côté, étire le frison dont elle passe ensuite l'extrémité à son aide, un petitgarçon ou une petite fille, qui est chargé de tourner le dévidoir.

L'appareil à dévider se trouve en face de la fileuse, de l'autre coté de la bassine. La pièce principale de cet appareil est un cylindre grossier, soutenu sur des coussinets posés sur un cadre plat et composé de quatre pièces de bois assemblées et présentant une circonférence d’à peine 15 à 25 centimètres, dans la plupart des cas. Cependant il y a aussi des cylindres présentant une circonférence de š centimètres, donnant de plus grandes flottes. C'est sur ce cylindre servant d'asple que vient s'enrouler la soie pour former des flottes. Il a environ 0 centimètres et peut recevoir plusieurs flottes de soie côte à côte. Ilest mis en mouvement au moyen d'un rouet à ficelle el coinposé de deux roues de différents diamètres, l'une d'elles ayant 5 à 6 centimètres et l'autre 25 centimètres, ce qui permet au tourneur d'imprimer au cylindre servant d'asple un mouvement de rotation très précipité. Entre la bassine et le cylindre, et un peu audessus de ce dernier, se trouve une baguette horizontale portant des crochets ou passent les fils de soie et à laquelle un excentrique, fixé au cyliudre, imprime un mouvement de va-et-vient qui sert à régrler le dévidage de la soie autour du cylindre et détermine la largeur de la lotte. 
Enfin, plus en avant du cylindre et près de la bassine, mais à une hauteur de 50 centimètres au-dessus du cylindre, se trouve un axe horizontal supportant une sćrie de petites tavelles, sur chacune desquelles s'enroule une fois le fil de chaque flotte à son passage, avant d'arriver au cylindre. Ces tavelles servent à la croisure et fonctionnent absolument comme les tavelles de la filature italienne. Ordinairement, trois de ces tavelles se trouvent à portée de la main gauche de la fileuse et servent a la soie; une ou deux supplémentaires sont vers la droite, séparées des tavelles à soie par le poteau qui supporte l'axe horizontal, et servent au frison.

Lorsque la filcuse tient son frison en main, après avoir agité les cocons avec ses baguettes, elle en passe une extrémité au tourneur, qui lui fait d'abord faire un tour sur la tivelle et l'altache ensuite au cylindre auquel il imprime un mouvement lent de rotation. Ce frison affecte ainsi la forme d'une flotte grossière, de même que la flotte de soic.

Quand la fileuse juge qu'elle a assez produit de frison et que ses brins de soie ou bouts sont assez purgés, elle arrête la filature du frison, réunit tous les brins de soie entre ses doigts, en fait trois faisceaux composés par conséquent chacun des brins de dix cocons environ, et elle passe alternativement l'extrémité de chacun de ces fais. ceaux au tourneur, qui, après avoir préparé la croisure sur les tavelles et les avoirfait passer dans les crochets du réglage, les attache comme pour le frison au cylindre et commence à tourner, lentement d'abord. Quand il voil que tout marche bien, il imprime au cylindre un mourement très précipité, puis le ralentit sur un signe dela fileuse, ou de lui-mème, s'il le juge nécessaire.

P'endint ce temps, la fileuse a pris une nouvelle poignée de cocons, qu'elle a battue, purgée, et, après que le frison a été filé comme précédemment, elle se sert des cocons nouveaux, dunt elle a les brins en mains, pour garnir les trois bouts déjà en marche - suivant leurs besoins et remplacer par des cocons neufs les cocons qui ont donné toute leur soie.

De la frçon dont file la fileuse, la grosseur du fil de soie ne peut pas être très réguliire, car les cocons ne tenant pas bien lontemps, elle n'a pas le temps, pendant qu'elle bat et purge ses cocons, de remplacer ceux qui ont fini de donner leur soie au fil tonjours en marche, et souvent, pour gagner du temps, elle ajoute les brins de pluEion...s cocons à la fuis et mème par poignée.

'I oulefois c'est une question d'adresse de sa part et certaines fileuses filent des soies de 10 i 12 deniers assez régulières.

(1) n voit que la fileuse mène ordinairement trois fils à la fois, mais il peut arriver qu'elle n'en mène qu'un ou deux, suivant son habileté personnelle ou la quantité des cocons.

La soie la plus fine est la meilleure; celle dont les Annamites, à Hanoï et à NamDuih, se selvent pour tisser leurs étolfes, se file en petites flottes de 15 centimètres à peine de circonférence et de 3 centimètres de largeur. Une de ces flottes pèse environ 18 -rammes.

line bonne filcuse file trois de ces flottes à la fois en vingt minutes environ et M. irunat a vu filer ces trois flottes entierrement, sans qu'un seul bout ait cassé.

Lorsque la fileuse juge la grosseur des flottes suffisante, elle coupe les bouts; le tourneur enlève le cylindre, fait tomber de chaque extrénité une clavette qui donnait un petit écart aux quatres rices du cylindre, lesquelles, en se resserrant, permettent 

LES MERVEILLES DE L'EXPOSITION

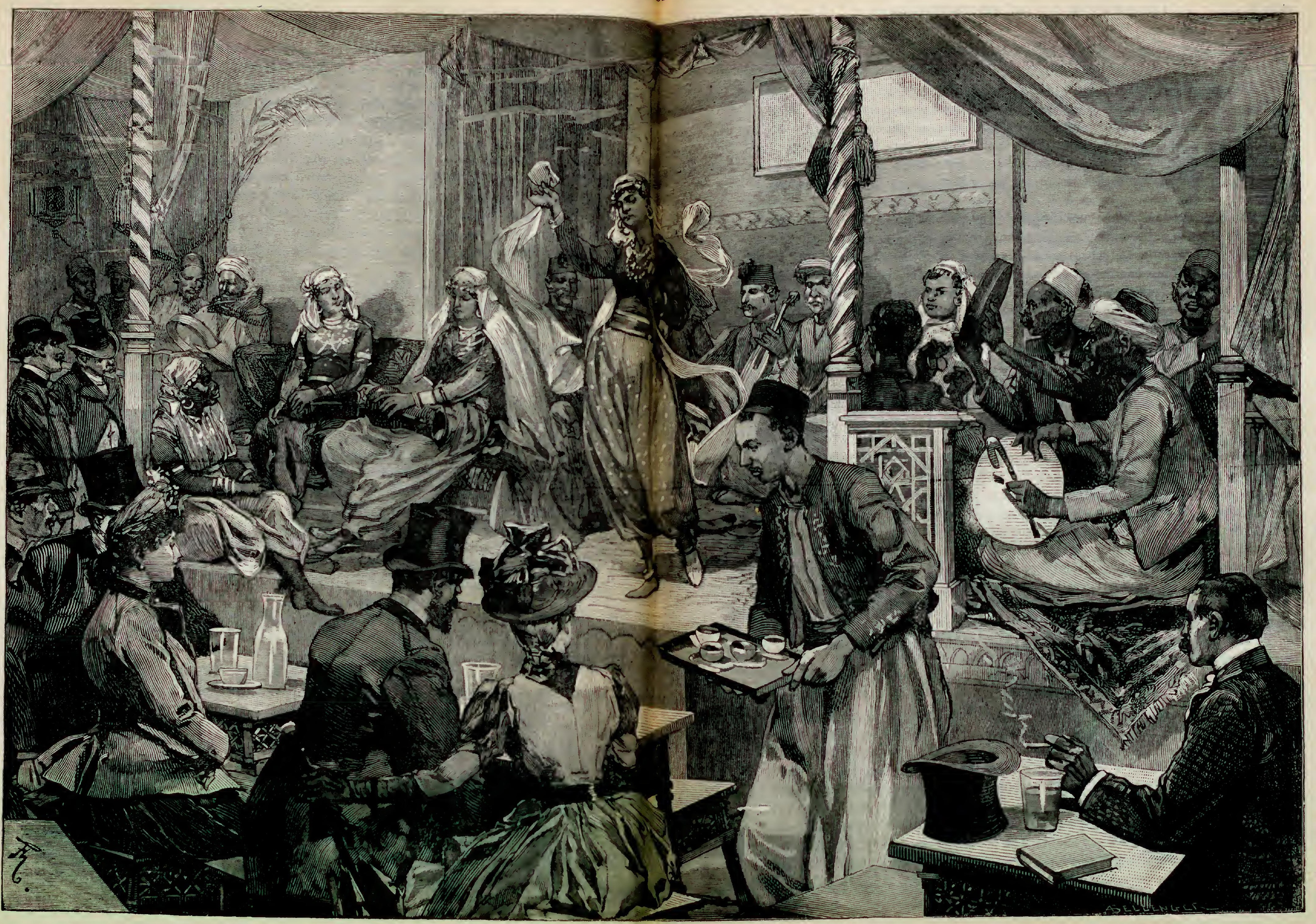


de retirer la flotte. Ces flottes sont ensuite redévidées pour servir à la fabrication des étoffes.

On trouve au Tonkin des fonderies de bronze, de lingots d'argent, de sapdques. Chaque catégorie a sa méthode spéciale, généralement assez primitıve. On fond quelques belles cloches et certains bouddas assez réussis; on cite comme modèle du genre l'énorme et belle statue de la pagode du Grand-Boudda, tout en bronze, qui ne mesure pas moins de $3^{\mathrm{m}}$, $ّ 0$ de haut. Il est évident que cetle pièce a du ètre coulée dius le pays; mais nous ne savons si les indigènes pourraient anjourd'hui répéter ce tour de force.

L'incrustation est une des industries spéciales au Tonkin. Le principe en est très simple : on prend la nacre fournie par des coquillages marins, on la découpe en petits morceaux, et on la colle sur des morceaux de bois préalablement taillés suivant les sujets que l'on veut représenter. La meilleure nacre est celle qui provient des coquillages que l'on trouve sur la côte du Binh-Dinh, du Binh-Thuan et aux environs de PouloCondore. La nacre commune est fournie par des espèces de moules que l'on trouve dans les arroyos du haut Thaï-Binh. On fabrique des meubles, tables, plateaux, etc., incrustés de nacre, assez jolis comme coup d'œil, mais dont la menuiserie laisse toujour's beaucoup à désirer. La vente en a considérablement augmenté par suite de l'arrivée du corps expéditionnaire et le prix en a déjà presque doublé.

La laque est universellement employée dans le pays, et il s'en exporte une cerlaine quantité en Chine et au Japon. Les laques qui se fabriquent au Tonkin sont loin de valoir celles de ce dernier pays. Les Annamites font cependant des progrès sensibles dans cette industrie et pourraient peut-être rivaliser un jour ou l'autre avec leurs voisins.

La laque s'extrait d'un arbre assez commun dans les forèts de Hung-Hoa. A rant de passer les couches de laque, l'ouvrier polit avec soin l'objet et remplit tous les trous avec une terre à grain fin qui se trouve dans le pays, en guise de mastic. On passe ensuite une première couche, on polit avec la pierre ponce, pris on donne une deuxième et mème une troisième couche, suivant le brillant que l'on veut obtenir. Les couleurs les plus usilées sont le rouge, le brun foncé et le noir; elles s'obtiennent: le rouge, par un mélange de minium; le noir, par l'emploi de masse de fer que l'on agite dans l'huile à laquer pendant plusieurs jours; le brun foncé, par le mélange de minium et de noix. Pour les laques de prix, on fait souvent une application de feuilles d'or et d'argent après la dernière couclie lorsqu'elle n'est pas encore tout à fait sèche. On fait même des applications de feuilles d'étain.

Pour donner à l'argent et à l'étain la teinte de l'or, on emploie l'écume qui surnage sur l'huile à laquer.

La broderie est encore une sorte de spécialité du Tonkin; elle se fait sẹnéralement sur flanelle ou sur étoffe de soie. Les dessins se font à l'aide de modeles faits d'avance et que l'on applique sur l'étoffe choisie, on se borne parfuis à reproduire le dessin a l'encre de Chine : l'artiste tonkinois montre dans ce travail une véritable habileté.

Une fois ce travail préparatoire terminé, l'étofe est tendue sur un encadrement en bois; plusieurs personnes, femmes et enfants, y travaillent généralement it la fois : on emploie des soies de couleurs variées enroulées sur un bambou et où l'on choisit succes. sivement les fils dont on a besoin. Les fils sont les uns en écheveaux, les autres en tresses; ces dernières sont appliquées sur le dessin et fixées de distance en distance : ce n'est plus alors de la broderie proprement dite. 
Tous les ouvrages de ce genre sont donc généralement un mélange de bróderies et d'applications de tresses de soie.

En Annam comme au Tonkin, tout village a son esprit protecteur, tout esprit son temple, et l'on ne peut parcourir le pays sans rencontrer à chaque instant des pagodes plus ou moins luxueuses, dédiées a la divinité, aux génies, au roi ou à d'illustres personnages. Généralement, les édifices sacrés sont entourés d'un mur percé en avant d'une porte principale, et, si le monument a des dimensions suffisantes, de deux ou quatre portes secondaires. Ces portes, surmontées d'ornements ou de lanternes bizarres, donnent accès dans une cour spacieuse, au fond de laquelle des hangars précèdent parfois la pagode proprement dite, dont le toit, en tuiles rouges et terminé aux angles en forme de sabot, est surmonté d'oiseiłux et de dragons baroques. L'autel est sculpté, laqué, incrusté. Devant lui est une grande table autour de laquelle les bonzes, entourés de leurs aides, officient les jours de cérémonies et qui se couvre durant l'office de fleurs, de fruits, de bougies allumées par les fidèles. On n'oubliera pas, quand on l'aura vue sur l'Esplanade, l'architecture des pagodes. Leur forme spéciale et leurs couleurs voyantes entrent dans l'esprit pour n'en plus sortir. On fera bien de donner aussi quelques minutes au mirador et au tombeau annamites qui se trouvent en face du pavillon le plus rapproché de la Seine.

Une largre place a été faite aux produits annamites, et avec raison, car le meilleur moyen de rendre avantageux' notre établissennent au 'Tonkin, c'est de faire connaître les ressources du pays aux innombrables commerçants qui se sont donné rendez-vous à l'aris cette année. La basse Cochincline et le Tonkin sont très favorables a l'agriculture, et sur la frontière laotienne, on a signalé de riches forêts. Le riz, nourriture par excellence des indigènes, est aussi abondant que possible; mais on verra dans les Davillons annamites qu'on récolte aussi dans l'Indo-Chine orientale le maïs, l'ígname, l'igname-patate, la patate, le millet, l'ananas, le chinchou, l'arbre à thé, les bourgeons d’aréquier, le bambou, la pastèque, le melon, le manioc, le haricot, l'aubergine, plusieurs especes d'épices, des fruits variés, des plantes industrielles, des plantes médicinales et des plantes d'ornementation. Les intéressés pourront éludier des échantillons de produits minéraux. La principale production du sol tonkinois, on le sait, c'est le riz qui est la grande culture du pays; tous les terrains argileux du Delta, toutes les cuvettes de la région des plateaux, tous les fonds de vallée en pays de montagnes sont consacrés aux rizières; elles contiennent une superficie d'environ 1 million dhectares.

On fait deux récoltes par an dans la plupart des terrains, les six dixièmes environ, mais chacune donne un rendement inférieur à la récolte unique de la Cochinchine: l'une environ la moitié, l'autre les trois quarts. Isa première se fail vers le quatrième mois: c'est la moins fructueuse; la seconde au dixième mois : c'est la meilleure, comme qualité el comme quantité. Si la comparaison était possible, on pourrait dire que l'une correspand da la récolte du riz hàtif de notre possession du sud et l'autre à celle du riz de saison. C est à peu près la mème portion commè rendement et qualité.

Les rizières étaient autrefois divisces en trois classes, avec un impòt afférent à chaque classe; une ordonnance du roi Tu-Duc les a réuniesen une seule et les a imposées à 20 thang de riz le mau, un peu moins de 1 hectolitre un quart à l'hectare.

II y a deux especes principales de riz: le riz sec et le riz gluant; le premier ne sert 
qu'à l'alimentation, le second est surtout employé pour la fabrication de l'alcool de riz, la seule boisson capiteuse des Annamites.

Il sert également pour les gateaux, les nougats, dans les fêtes et les cérémonies, etc...

Ces deux espèces de riz, surtout la première, se subdivisent en un nombre infini de variétés, dont il est difficile de fixer le chiffre et qui proviennent surtout des différentes

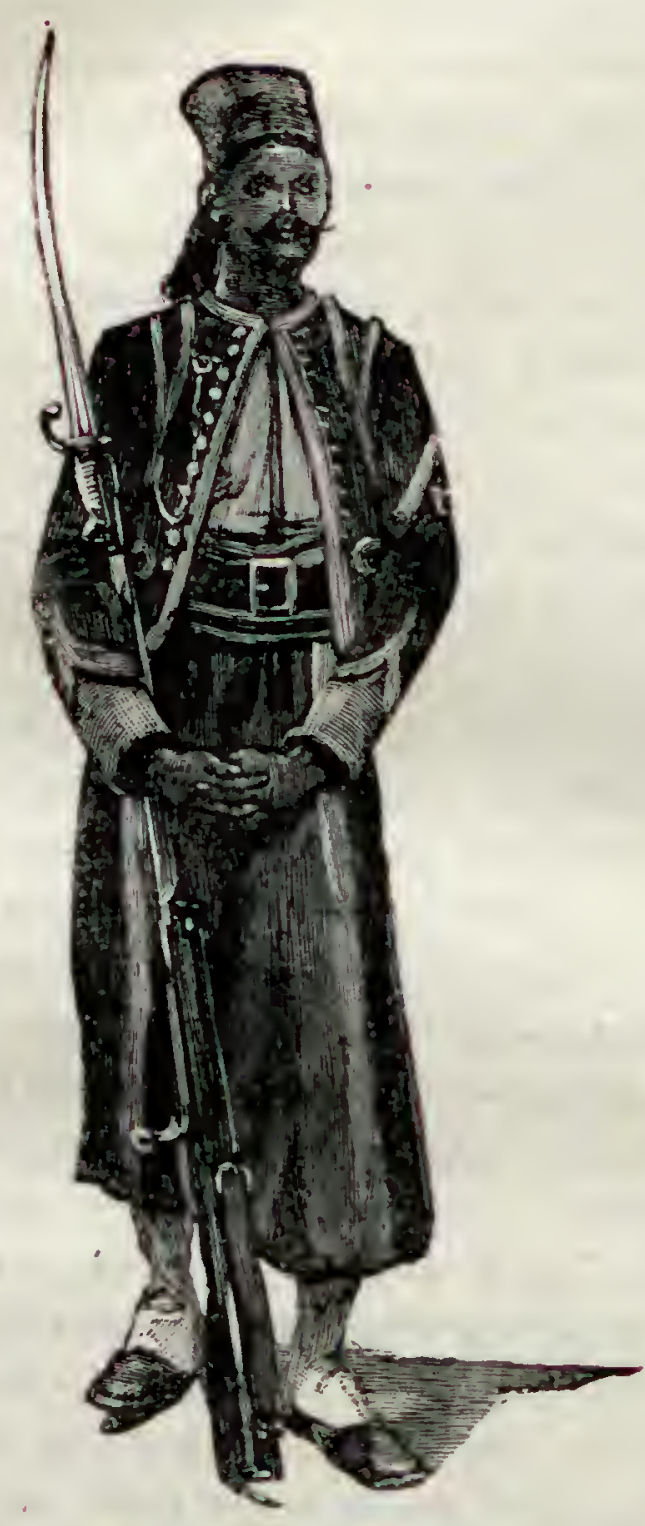

Daniel. - Tirailleur cipaye.

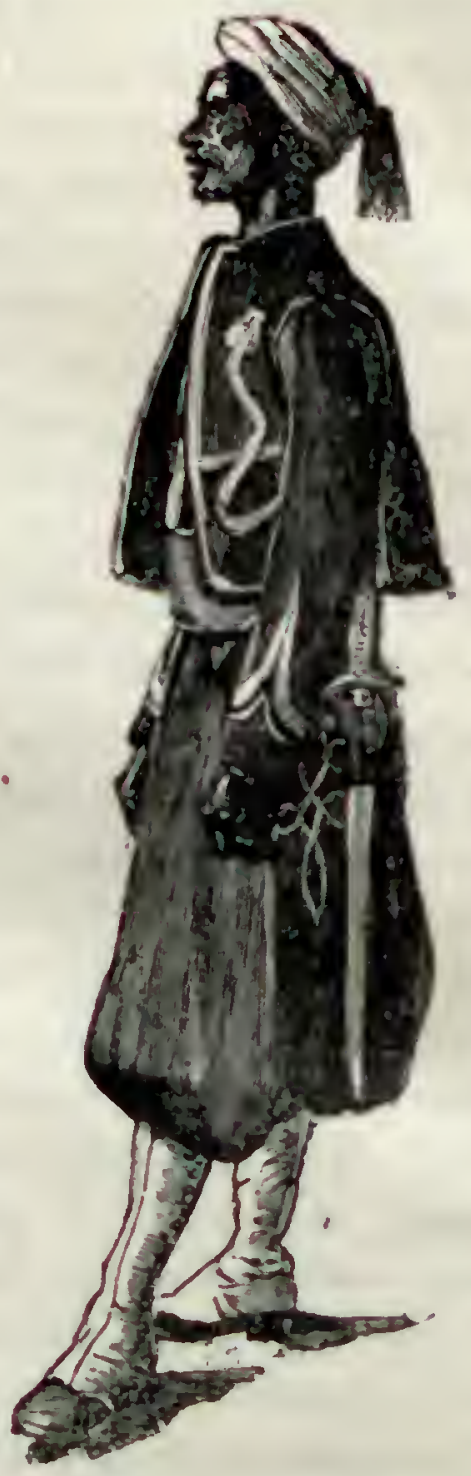

Bramexdao. - Sergent de lirailleurs sénégalais. LES TROUPES COLONIALES L'Exposition.

propriétés des terrains où ils sont cultivés : il n’y a guère que les cultivateurs indigèncs qui puissent bien les distinguer entre elles.

Ce produit fournit peu à l'exportation; la population dense du pays suffit presque dे son absorption, dans les années moyennes; dans les cas rares d'une succession de deux ou trois mauvaises années, la disette peut se faire sentir.

Lexportation, depuis le traité de 1874 , a été autorisée plusieurs fois pendant des périodes de trois à quatre mois; mais les moyens de transport, dans l'intérieur du pays, sont si insuffisants qu'il a été à chaque fois matériellement impossible d'en exporter plus de 300,000 piculs.

Ceux qui préféreront les arts à l'économie politique assisteront sur l'Esplanade d l'une des distractions favorites du peuple annamite: le thédtre. 


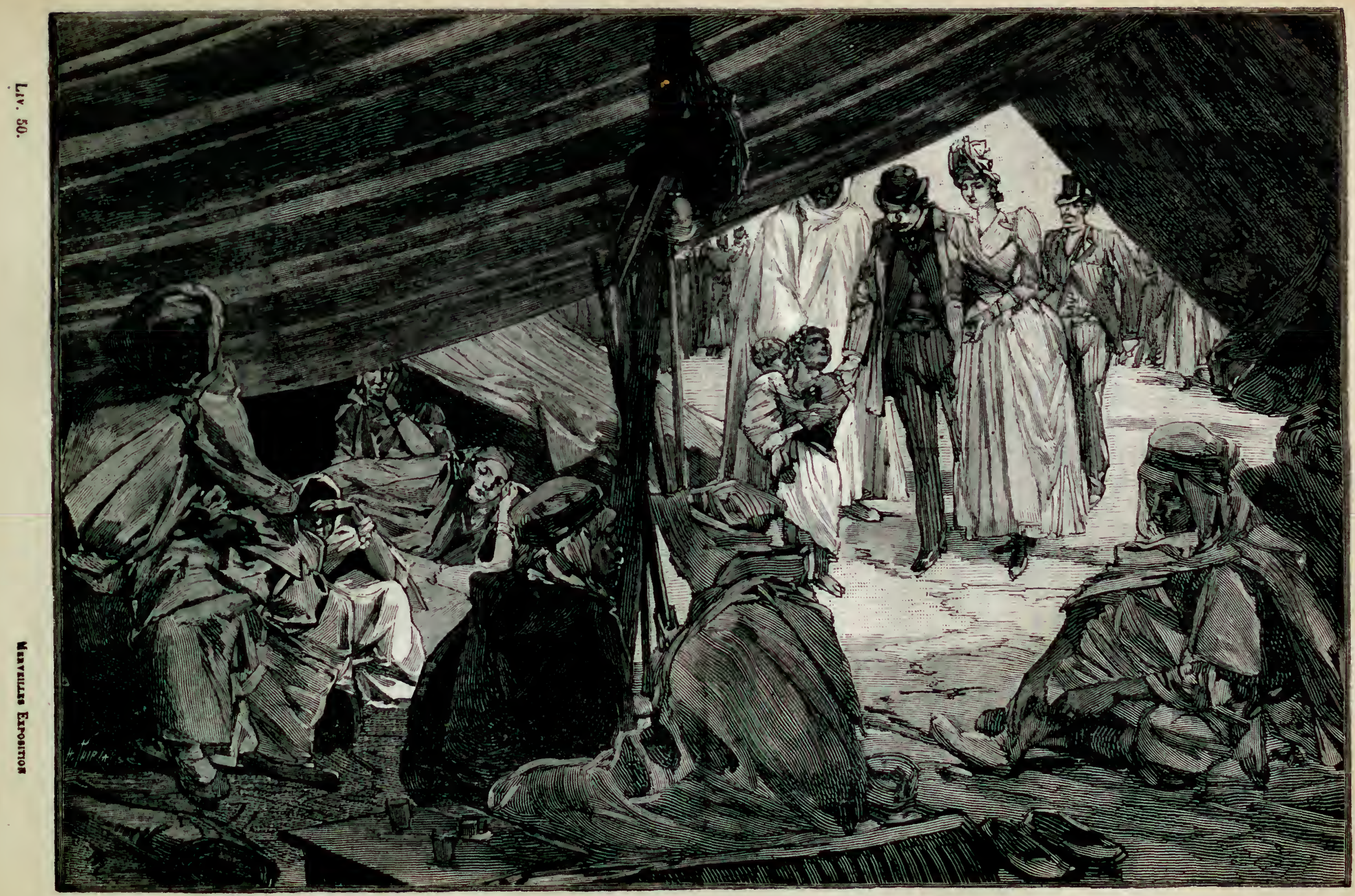

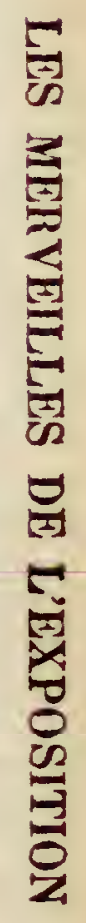

L'Exposition ALgEHENNE. - Intérieur d'une tente. 
La salle est rectangulaire et peut contenir environ 300 spectateurs.

Sur trois côtés sont disposés des gradins derrière lesquels s'étend une galeriepromenoir. Le parterre est occupé par plusieurs rangées de banquettes. II n'y a pas de place réservée à l'orchestre. Les musiciens se tiennent sur un des colés du rectangle. C'est une estrade élevée au-dessus du sol d'environ $1 \mathrm{~m}, 50$; elle est coupée en deux parties inégales dans sa longeur par une sorte de cloison en papier, percée de deux portes ornées de draperies éclatantes.

Pas de décors. Le lieu de l'action est figuré par quelques accessoires très modestes construits en bois et en papier coloré.

La cloison qui se dresse au fond de la scène est partagée en trois grands panneaux occupant la partie supérieure, et ornés de scènes empruntées au répertoire des dranes les plus célèbres.

La troupe se compose de trente-neuf personnes, y compris les musiciens et les danseurs pour les intermèdes. Aucune femme n'est admise à prendre part aux représentations dramatiques. Leurs rôles sont tenus par des jennes gens. Leurs costumes sont fort riches. Ils ont couté une somme assez considérable aux entrepreneurs du Théâtre Annamite de l'Exposition. Ils sont composés de soies éclatantes paillelées d'or.

Les pièces à la mode sont de grands drames militaires. Beaucoup de batailles. de meurtres, de duels, de vengeances, de guet-apens; le tout, entrecoupé de scines d'amour et de passion des plus expressives.

Les Annamites ne sont pas bons musiciens. Ils n'ont pas l'idée de nos tons el de nos demi-tons, de nos gammes majeures et mineures. Aussi le théatre s'en l'essent-il. L'orchestre inaugure la représentation par une cacophonie intense où viennent se fondre les bruits du gong, du tam-tam, du violon a une corde et de la trompelte; et tout le temps que sejoue la pièce, il continue sa musique barbare, car il accomplerneon devrait dire il couvre - la voix des malheureux acteurs qui s'époumonnent. loiei, d'après un de nos confrères, le scénario de la première pièce représentée :

Un jour, Chieu-Ou invite son beau-frère, le roi de Duong, ly-Tieng-Vuong, it venir assister à un festin qu'il donne, en vassal respectueux, it son maltre et à son parent.

Mais voici que quatre mandarins pervers conseillent à Chieu-0u de se léharrasser du roi et de monter sur le trône. La convoitise chuchote aussi ses con-cils dans l'esprit de Chieu-Oú, qui consent à tramer dans l'ombre un attentat horrihle contre la personne sacrée du roi.

Au loin, les fanfares éclatent en notes joyeuses et triomphales, annonçant l'arrivée. de Ly-Tieng-Vuong, qui descend devant le palais au milieu de l'allégrusse et des honneurs.

Mais Ly-Tieng-Vuong a trois mandarins fidèles et fervents qui veillent sur leur maitre. Ils ont surpris les allures suspectes des ma) larins Tiet-Hoai, Tiat 110 , TietLong et Tiet-Phuon, et ils implorent le roi de fuir une hospitalité qui caclie des traltrises et peut-être des meurtres silencieux.

Le roi, pris de crainte, s'enfuit avec ses mandarins, et les voild errants dans Ins rızières bleutées; en passant sur le lleuve, A uh Trung (le hasard meurfrin) fitit quo l'un des mandarins se noie et Ly-Tieng-Vuong reste avee ses deux seuls amı.

Chieu-Ou, voyant ses projets dévoilés et son ambition mourir al'aubede la réusite. 
envoie les quatre mandarins, accompagnés d'innombrables guerriers, à la poursuite du roi.

Il ne faut pas que Ly-'Tleng-Vuong regagne son royaume et la demeure paisible où ses épouses désolées attendent son retour.

Tiet-IIoai, Tiet-IIô, Tiet-Long et Tiet-Phuong arrivent avecleur troupe, le roi est cerné et les régicides mettent le feu aux plaines infinies pour faire mourir le roi.

Dans l'incendie, 'Tiet-Phuong perd la vie.

Mais, ne voyant pas revenir le roi, le fils adoptif de Ly-Tieng-Vuong rassemble aussi des troupes et accourt au devant de son mattre.

11 rencontre les armées du traître; la bataille s'engage, terrible; les hommes tombent. Enfin, le roi est sauvé et revient au milieu de l'allégresse générale, précédé des armes étincelantes des guerriers, sous le chaud soleil qui fait miroiter les co aux plis ondoyants et dans le concert des lay de joie de tout un peuple prosterné.

Le Palais de la Cochinchine a eu pour architecte M. Foulhoux. C'est l'image fidèle d'une habitation saïgonnaise, de pur style annamite, composée d'un pavillon central et de constructions latérales auxquelles conduisent des galeries formant une cour dans laquelle sont des vasques et des pièces d'eau. Les colonnes et les fermes sont recouvertes de sculptures peintes ou dorées, et des vitraux garnissent les baies. Il ne faudrait cependant pas croire que toutes les maisons du Saïgon soient aussi luxueusement aménagées. Là-bas, en réalité, la population indigène occupe autour de la ville de grands faubourgs où elle vil à sa guise dans de simples paillottes baties le long des cours d'eau, autoul des marchés ou au milieu de jardins plantés d'arbres fruitiers.

La Cochiuchine est un pays rizier par nécessité et par nature. On verra que le grain de riz cochinchinois est petit et régulier. C'est l'espèce ronde dite ga-cong qui s'expédie en Europe pour les blanchisseries. Pour la distillerie, on récolte le riz long, dit wishlong, mélangé et nettoyé de paddy. Pour la table, on conserve une sorte de riz long et régulier, dit pychow. On récolte aussi en Cochinchine le cardamome, le coton, la gomme-gutte, l'indigo, le poivre; l'on en exporte de la colle de poisson, des cornes et peaux de buffle, de bœuf et de cerf. Le pays produit peu de soie. Les industries indigènes sont de peu d'importance, chaque producteur exploitant et vendant lui-même. Le Cochinchinois est plus agriculteur qu'industriel, et le commerce est aux mains des Chinois immigrés. Nous mentionnerons cependant parmi les petites industries locales la bijouterie, la vannerie, la poterie, la teinture, la distillerie, la briqueterie, les nattes, les décortiqueries de riz, la sucrerie, la filature, la blanchisserie.

\section{LE SÉNÉGAL}

Nous arrivons au Sénégal, non moins brillamment représenté que l'Algérie et la Tunisie sur l'Esplanade des Invalides. Une grande tour attire d'abord nos regards, c'est la Tour de Saldé, élevée par Faidherbe en 1859 au village de Tebekout, sur les bords du fleuve, pour maintenir dans le devoir les Toucouleurs. A côté s'élàve un tata, nuraille d'argile séchée, construite par assises horizontales et destinée à prut ger les villages indigènes. Il y a aussi la case ouolof, la case toucouleur, la case bambara, la case du Cayor, etc., en un mot des spécimens nombreux de l'ethnographie et de 
l'industrie sénégalaises. Les populations du Sénégal sont aujourd'hui bien connues. II y a d'abord les "Maures, de race berbère, habitant la partie du Sahara comprise entre le Maroc au nord, le fleuve Sénégal au sud, le pays des Touareg à l'est. Ce sont des hommes de race berbère, et bon nombre d'entre eux présentent des types d'une beauté vraiment remarquable. Leurs femmes sont petites et admirablement faites. Malgréces avantages physiques, les Maures n'inspirent guère la sympathie; l'aspect des hommes est sauvage, leur regard est dur, enfin leur cruauté et leur rapacité ne sont pas faites pour attirer. Actuellement, nous sommes en relations commerciales avec leurs trois tribus les plus puissantes, qu sont : les Trarzas, les Braknas et les D suaïchs.

Les Maures fréquentent nos escales du fleuve, apportant leurs gommes, leurs plumes d'autruche, leurs chevaux et leurs moutons, en échange de nos calicots, de nos pacotilles de toute sorte et du mil récolté par les noirs sénégalais.

La limite géographique des pays directement placés sous l'influence des tribus maures est constituée par le Sénégal jusqu'à Bakel, et, au delà de ce poste, par une ligne idéale allant contourner le Guidimaka, le Nioro, le Bakhounou, et rejoignant le Niger à la hauteur du Macina. D'après cela il est aisé de voir que nous n'entrerons en luttes d'intérêts avec les Iaures que lorsque notre effort, ayant franchi les pays nègres, se portera vers la région du Niger moyen, c'est-à-dire un peu avant Timbouctou.

En résumé, les Ilaures ne constituent pas en ce moment une préoccupation sérieuse pour nous, et dans l'avenir on peut dire que, gràce à leur intelligence et à leur amour du lucre, on pourra avoir avec eux des relations sérieuses et durables.

Les Négres sont les possesseurs du sol; ce sont eux qui peuvent l'exploiter. On divise généralement les nègres en quatre races: les Ouolofs, les Peuls, les Soninkís et les Mandingues. Les divisions que nous donnons de ces races ne sont pas arbitraires; elles résultent des études anthropologiques, des traditions existant dans le pays et aussi des noms de famille qui se perpétuent malgré les croisements sans nombre qui se sont produits. Ce dernier moyen de classer les individus est presque infaillible; le premier nègre venu sait le nom de ses ancètres, et peut en reconstituer la généalogie assez avant dans les âges en laissant cependant de côté toute question de date.

Les Ouolofs habitent le littoral maritime de Saint-Louis au Cap-Vert, et la rive gauche du Sénégal jusqu'à notre poste de Richard-Toll. L.es États principaux qu'ils ont constitués sont le Cayor, le Oualo et le Djolor. Les Ouolofs ont la peau noire et luisante. Bien qu'ils aient le nez aplati et les lèvres épaisses, on rencontre parmi eus et surtout chez leurs femmes des visages à traits fins et réguliers.

L'établissement de la voie ferrée de Saint-Louis à Dakar nous donnera une action prépondérante et définitive sur les Ouolofs du Cayor et nous assisterons avant peu à une véritable transformation de ce pays.

Le seul obstacle sérieux qui puisse gèner notre action sur les Ouslofs est leur conversion à peu près générale à l'islamisme. Cette religion les rend rebelles à notre civilisation. Cependant nous espórons que les générations futures se rapprocheront de nos idées de travail et de progrès. Déjà la ville de Saint-Louis nous fournit des ouvriers d'art, et la création de nouveaux débouchés vers le Soudan activera la transformation que nous désirons.

Les Peuls sont connus sous divers noms: Foullies, Fouls, Fouless, Fombas, Fellahs, Fellatahs, etc... Cette race est celle qui intrigue au plus haut point les géographes et les ethnographes. Les recherches historiques sont à peu près d'accord pour faire 


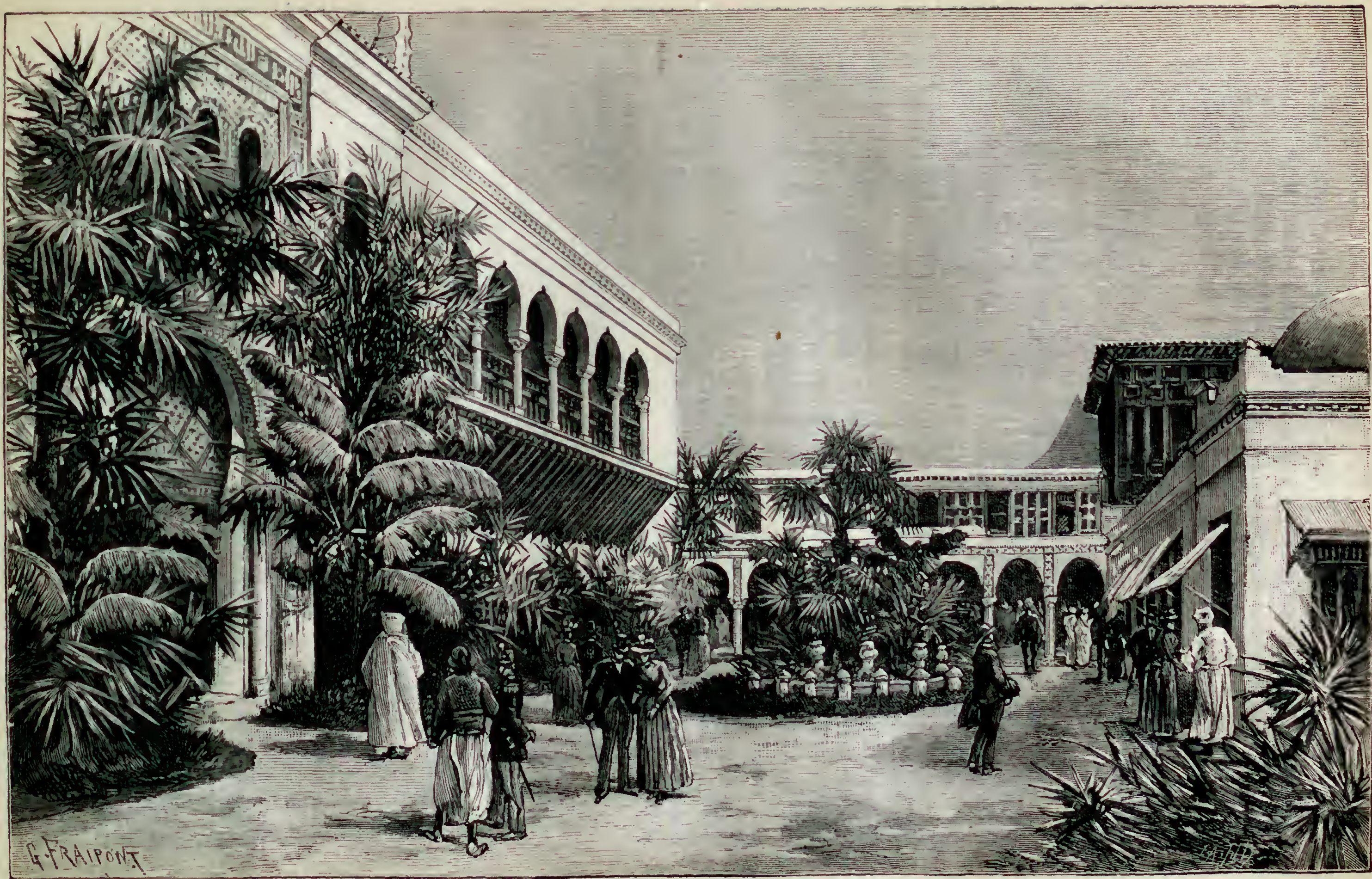

氙

Pavillon de l'Algérie. - la cour intérieure. 
venir les Peuls de l'est en conquérants. Leur berceau semble être la Lybie, et on doit constater que les Peuls sont la race la plus remarquable du Soudan. Ils ont 'es traits fins et réguliers, et on trouve parmi leurs femmes de véritables beautés.

La religion de cette race est l'islamisme. Leur langue est fort belle. On sa parle dans les tribus nomades de pasteurs, dans le Fouta, ou elle a reçu quelques mots Ouolofs, dans le Ségou, le Nioro, le Macina.

Les Peuls sont actuellement répartis dans le Soudan de la façon suivante:

Dans le Cayor, la banlieue de Saint-Louis, le Oualo, le Dimar, le Fouta, le Ferlo et le Ségou, ils sont pasteurs et à peu près nomades.

Dans le Khasso, le Fouladougou, le Birgo et le Ouassoulou, les Peuls se sont si intimement liés aux habitants du pays, que leur langue, leur religion, ont à peu près disparu. Les seuls ḱtats absolument Peuls du Soudan sont le-Fouta-Djallon, le Bakhounou et le Macina, et encore le chef nominal de ce dernier pays est-il un descendant des Toucouleurs. Les Toucouleurs, tel est le nom donné aux métis Peuls, originaires du Fouta sénégalais. Les Toucouleurs, dès qu'ils auront cessé d'ètre nos adversaires politiques, nous rendront de très grands services.

Les Soni-n'kés ou Soninkés sont encore connus sous le nom de Son'rhaĩs, Sarracolets et Markankés. Ils sont aujourd'hui dispersés dans le Soudan. On en trouve de Bakel à Ségou et dans le haut Niger. Ils vont de chez les Maures du Sahara aux marchés les plus reculés du Soudan faire des échanges. Les États Sonirnkés du Sénégal sont sous notre protectorat.

Les Soninkés parlent une langue particulière, cle sarrakoulé ', mais en raison de leurs fréquents voyages, ils connaissent presque tous les idiomes répanlus dans le Soudan. Leur religion est l'islamisme, mais ils ne semblent pas animés d'un grand esprit de prosélytisme.

Les Mandingues sont ces populations noires qui couvrent les vastes territuires compris dans le haut Sénégal, le haut Niger et le versant occidental des montagnes du Fouta-Djallon.

Les Mandingues comprennent: $1^{\circ}$ les Mandingues proprement dits, habitant le Manding ou Mandi;

$2^{\circ}$ Les Mali-n'kés répandus dans le Bambouk et le Bouré;

3. Les Bambaras ou Bamanas peuplant le Kaarta, le Bélédougou, les confins du Bakhounou, la rive gauche du Niger jusqu'au Macina, le Ségou, le Ouassoulou et tons les pays jusqu'aux montagnes de Kong. En général, les Mandingues sont laids. Leurs femmes sont, à de rares exceptions, fort disgracieuses. Les Mandingues sont fétichistes. Lorsque la fréquence des rapports aura augmenté la confiance, nous pourrons certainement établir avec ces noirs un commerce durable.

L'organisation sociale de ces populations doit nous arrêter quelque temps, puisque des industriels sénégalais travaillent à l'Exposition sous les yeux du visiteur. On y trouvera entre autres un forgeron, un tisserand, un bijoutier, un cordonnier, un berger. On y trouvera mème des griots. En tout, une trentaine d'indigènes sous la conduile de Samba-Lambé-Thiam, un bijoutier de Saint-Louis. On ne lira donc pas saus intérêt la curieuse étude suivante empruntée à la France dans l'Afrique occidentalr, remarquable ouvrage récemment publié sous les auspices du ministre de la Marine :

a Les diverses populations du Soudan ont une organisation sociale identique; c'est 
à peine si on constate entre elles quelques nuances que nous ferons ressortir dans le présent examen.

- Tout d'abord la société se divise partout en deux classes d'hommes bien distinctes : les hommes libres et les esclaves.

"Les hommes libres, comme dans toutes les sociétés, même les plus avancées dans la civilisation, comprennent plusieurs castes que nous désignerons par la nature de leurs occupations.

- Les membres des familles anciennes qui ont gouverné leurs compatriotes, ou qui ont leurs noms illustrés par quelque fait de guerre, constituent la classe des guerriers. Ce sont eux qui commandent les contingents lors des invasions chez les voisins ou dans la défense des foyers de la tribu. Ces hommes sont l'objet de la considération générale et ils sont eux-mêmes assez dédaigneux des autres castes, surtout de celles qui ont des professions manuelles. Cependant, l'agriculture étant fort en honneur, le gue rrier va aux champs, ne serait-ce que pour surveiller ses captifs. On comprend l'intérêt qui s'attache aux travaux agricoles; ces peuples imprévoyants seraient dans la plus profonde misère si une année s'écoulait sans semailles. Cette manière de voir est si accréditée que les opérations militaires sont généralement suspendues pendant l'époque des cultures.

- Les guerriers assistent aux palabres et prennent les décisions intéressant le village ou la peuplade. Ils forment une sorte d'aristocratie, qui a pourtant besoin d'être généralement étayée par la possession d'un certain nombre d'esclaves; une grande renommée ne suffirait pas toujours à asseoir une influence effective.

- Après les guerriers viennent les agriculteurs. Nous désignons ainsi les hommes qui sont maltres de maison, possèdent des champs à cultiver et des captifs pour les aider dans leurs travaux. Ils représentent la majorité de la population. Ce sont eux qui, comme les paysans d'Europe, constituent la base solide de la ňation. Ils travaillent beaucoup de juillet à décembre, et le reste de l'année ils s'occupent encore à divers travaux d'intérieur : édification et réparation des cases, confections de sékos, etc., etc Ces hommes assistent également aux palabres, peuvent y prendre la parole, mais en général ils usent peu de ce droit et laissent agir les guerriers, la classe dirigeante par excellence. Les agriculteurs sont combattants et suivent à la guerre des chefs de leur choix; en temps de paix, ils se servent de leurs armes pour chasser.

- On désigne sous le nom de griots une classe singulière de citoyens libres, jouissant d'une médiocre considération, mais puissante et redoutée. Leurs principales fonctions consistent à chanter, à danser et à jouer des instruments de musique qu'ils ont su inventer. Ils vivent du produit de ce travail, car il leur est interdit de se livrer à aucune occupation manuelle. Ils se gardent bien d'enfreindre cette agréable prescription. Les chefs qu'ils adulent, les guerriers qu'ils exaltent, les autres hommes libres qu'ils couvrent de louanges plus ou moins méritées, les rémunèrent largement de leurs flatteries. Après les récoltes ils passent dans les cases et chacun leur fait un don en nature proportionné à sa fortune. Malheur à celui qui oppose un refus à cette mendicité! il est exposé aux injures les plus grossières.

- Les chefs et les homnies riches attachent toujours à leur maison un certain nombre de griots qui augmentent par leurs discours leur popularité et leur influence.

- A la guerre le rôle des griots est d'évoquer dans leurs chants les hauts faits des héros de la tribu morts dans les combats et d'exciter par'leurs tans-tams le courage 
des combattants; ils sont également employés à transmettre les ordres des chefs. Cette caste est redoutée, car les griots colportent toutes les indiscrétions; ils sont effrontés et menteurs. Dans les villages, leur influence est grande; on est sûr de trouver un bon accueil si l'on est généreux à leur égard.

" Les griots des chefs de village sont crieurs publics.

- Malgré leur situation importante, les griots sont méprisés comme caste: un guerrier, un agriculteur ne s'alliera pas à une famille de griots. On ne les adme

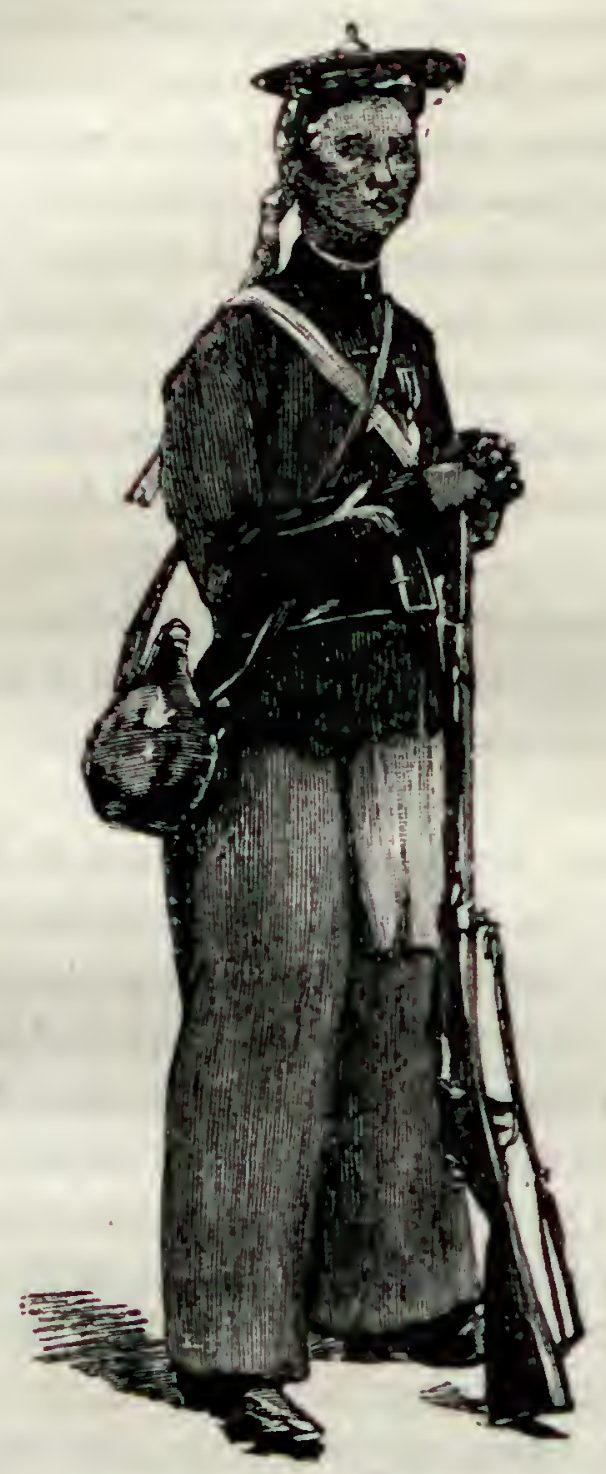

KNovg. - Tirailleur annamite.

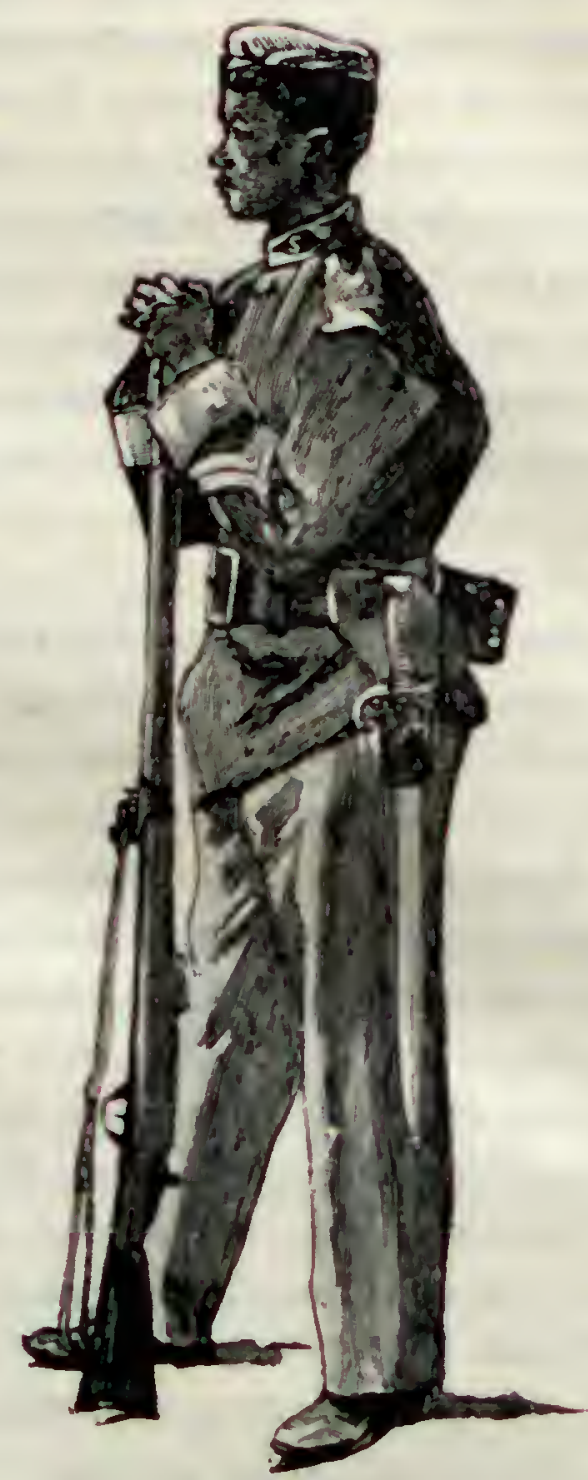

Locis. - Caporal de tirailleurs tamataves.

LES TROUPES COLONIALS L EXPOSITIOX.

jamais à l'exercice d'un commandement quelconque, et s'ils arrivent à influer sur les décisions de la peuplade, c'est qu'ils parlent toujours au nom de quelque chef autorisé. On nait et on meurt griot. A leur mort, ils ne sont pas enterrés dans le cimetière commun. La dépouille mortelle de ces hommes est chose infinme.

- Les ouvriers, dans la société nègre, occupent le bas de l'échelle. Nous trourons parmi eux quatre corps de méliers principaux :

- $1^{\circ}$ Les forgerons. Ces ouvriers travaillent les mélaux et exploitent les mines d'or. Ils fabriquent les outils aratoires, les armes, réparent les fusils, etc. Malgré les grands services qu'ils rendent, ils sont peu appréciés .comme individus. Ils ne s'allient pas avec les hommes libres des castes supérieures. Comme les griols, ils se conflnent dans leur profession et, eux aussi, ils s'altachent volontiers à la personne des grands chefs. 


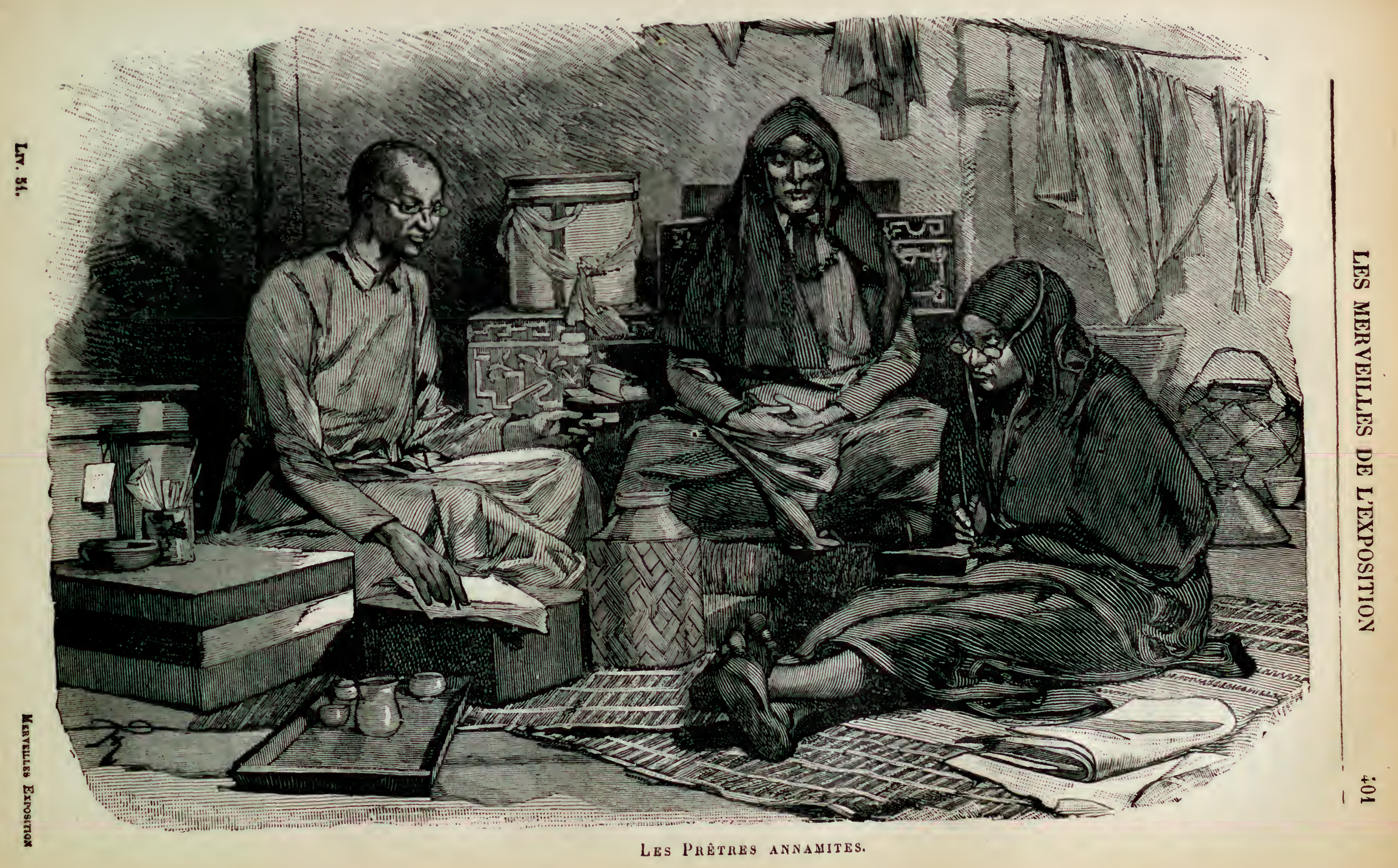


Ceux-ci marchent toujours entourés de leurs griots et de leurs forgerons. II est mème résulté de là une elasse assez singulière de forgerons qui ne forgent pas et qui ne sont plus que les conseillers et les courtisans des chefs et les exécuteurs de leurs tentatives de pillage.

- 20 Les ouvriers en cuir portent le nom de Sakés en toucouleur. Leurs principales oceupations sont de préparer les peaux, de les tanner et d'en fabriquer des harnachements de chevaux, des équipements militaires et des chaussures. Ils ont acquis dans ces travaux une certaine habileté. Ils nous ont paru plus considérés que les forgerons.

- $3^{\circ}$ Le corps de métier qui travaille le bois prend le nom de laobés. Ces ouvriers vont dans les forêts abattant les arbres propres à leur industrie qui consiste surtout a confectionner des pilons, des mortiers, des sièges et autre menu mobilier. Les laobés ont peu d'importance dans les tribus.

- $4^{\circ}$ Les mabos ou tisserands fabriquent les toiles de coton du pays. Ils ont des métiers analogues à ceux en usage en Europe, avant les derniers progrès de cette industrie. Ces métiers sont trop primitifs pour leur permettre d'obtenil des tissus à grande largeur; ils donnent des bandes de toile de $0^{\mathrm{m}}, 03$ a $0^{\mathrm{m}}, 10$ de largeur que l'on coud ensuite l'une contre l'autre. Le travail des tisserands est solide et un boubou en pagne du pays dure plus longtemps que nos fragiles guinées. Cette circonstance devrait engager nos commerçants à envoyer dans le Soudan de la marelandise meillenre, quitte à la faire payer plus cher.

- A Ségou, à Sansandig et au delà les tisserands fabriquent des dampés (sortes de tapis), ornés de dessins obtenus par le tissage mẻme. Ces produits sont assez remarquables. Ce corps de métier teint les étoffes qu'il confectionne, soit avec l'indigo, soit avec dautres plantes tinctoriales fort abondantes dans le pays. Nous avons vu, dans certains jours de fètes, la population se revètir d'étoffes multicolores dı plus agréable effet.

- Les tisserands soninkés sont les plus habiles de tout le Soudan.

- Ce corps de métier, comme les autres, se perpétue dans les mèmes familles.

- Dans les tribus riveraines des grands cours d'eau, on rencontre une catégorie d'hommes qui sont de elasses ouvrières : nous voulons parler des pechenrs. Leur nom est tiouballo en toucouleur, somonos en mandingue. Ils possedent des pirogues, remplissent les fonctions de passeurs et pratiquent la péche sur une grande échelle. Leurs poissons sont rendus frais ou desséchés dans les marehés de l'intérieur. Lcur industrie constitue dans certains pays un monopole pour lequel ils payent des redevances.

- La pêche apporte dans le Ségou un appoint sérieux a l'alimentalion. Le Niger cst très poissonneux.

a Les pêcheurs forment une caste ayant ses chefs mais relevant toujours des aulres chefs politiques.

a A côté des hommes libres et sous leur dépendance absolue vivent les esclaves. On a dit justement que l'esclavage était la plaie de l'afrique et que tous les efforts des nations civilisées devaient tendre a faire disparaitre eette institulion sociale it la fois vicieuse, immorale et improductive.

* Cependant nous pouvons aftirmer, après un long sẻjour dans le Soudan oceidental, que bien des inexactitudes, bien des exagérations ont été émises sur cette question de l'esclavage dans la société nègre.

- Nous n'hésitons pas à avancer que l'esclavage des noirs n'a plis son caractere 
cruel ct sauvage que lorsque la race blanche s'est occupée de la traite; tel que nous l'avons constaté dans la société africaine, il perd ce caractère. Le présent exposé 'modifiera peut-être bien des opinions à cet égard.

- On distingue plusieurs sortes d'esclaves : $1^{\circ}$ les captifs faits d-la guerre; $2^{\circ}$ les esclaves de case; $3^{\circ}$ les esclaves de trafic.

" Au Sénégal, les industries diverses répondant à certains besoins locaux' ne font pas défaut aux indigènes et, en certains cas, aux Europẻens.

" Les industries de luxe telles que l'orfèvrerie et les tissus du pays comptent des artisans habiles. En ce qui concerne la première, on pourrait presque dire que les bijoux fabriqués sortent des mains de véritables artistes, étant donné surtout l'outillage primitif employé.

- Le dessin est correct, les filigranes sont délicats et parfois ne laissent rien à désirer comme fini et comme goût.

"La fabrication des tissus du pays qui servent à la confection du pagne, partie principale du costume indigène, est entre les-mains de tisserands noirs dont les métiers et l'installation ne le cèdent en rien aux outils primitifs des bijoutiers. Et cependant la chaine et la trame sont irréprochables; les passées avec des fils de différentes coulcurs produisent des dessins d'une régularilé parfaite. Il n'y a rien à redire au bobinage, ¿ l'ourdissage et au passage, si rudimentaires que soient les procédés en usage. Ordinairement, le fil blanc provient du colun récolté dans les champs. Le fil de couleur est toujours d'importation européenne. Le tissage se fait par bandelettes de deux mètres de longueur, qui, réunies ensuite, forment le pagne.

- Bon nombre de pagnes sont tissés en fil de coton blanc, sans mélange ue fils de couleur, pour être ensuite teints en bleu avec l'indigo sénégalais. Les teintes obtenues, soit en marbré, soit en bleu uni, d'un coloris parfois brillant, résistent à des lavages Inultipliés.

- Les forgerons, et notamment les individus de race lawbé, confectionnent les poignards, les fers de lance et le hilaire, le seul outil agricole employé. Le hilaire a la forme d'un croissant à bords tranchants et a cornes arrondies et rentrantes. Légèremer: bombé vers le centre, il est muni dans son milieu d'un manchon qui reçoit le baton servant de manche.

- Les cordonniers font non seulement la chaussure, babouche ou botte en cuir rouge ou jaune, mais encore les fourreaux de sabres, de poignards, les hausses de selle, etc. Le cuir du pays, tanné et colorié avec le fruit du soump et avec le sorghum rubens, qui donnent les teintes très vives, est employé par les cordonniers; ils en forment des dessins en mosaïque très variés et du meilleur effet, ainsi que le prouvent d'ailleurs les envois faits en France sous la rubrique d'objets de collections, qui sont l'objet d'un commerce de 200 a 230,000 francs en chiffres ronds.

- Depuis quelques années, la France a pu s'étendre daus la direction du Soudan et dans le haut Sénégal les cercles de Médine et de Boummaka sont régulièrement organisés. Les différentes races, occupant le territoire du cerle de Médine, conprennent:

- $1^{\circ}$ Les Sarakholés (en Gadaika); $2^{\circ}$ les Khassoukés (en Khasso); $3^{\circ}$ les Malinkés (en Logo et Natiaga). On y trouve également un certain nombre de Maures et de Peuls, quelques Toucouleurs, des Bambarras disséminés un peu partout et en petit nombre, et entin des Yolofs sur les points de commerce et d'échange. Les aptitudes spéciales 



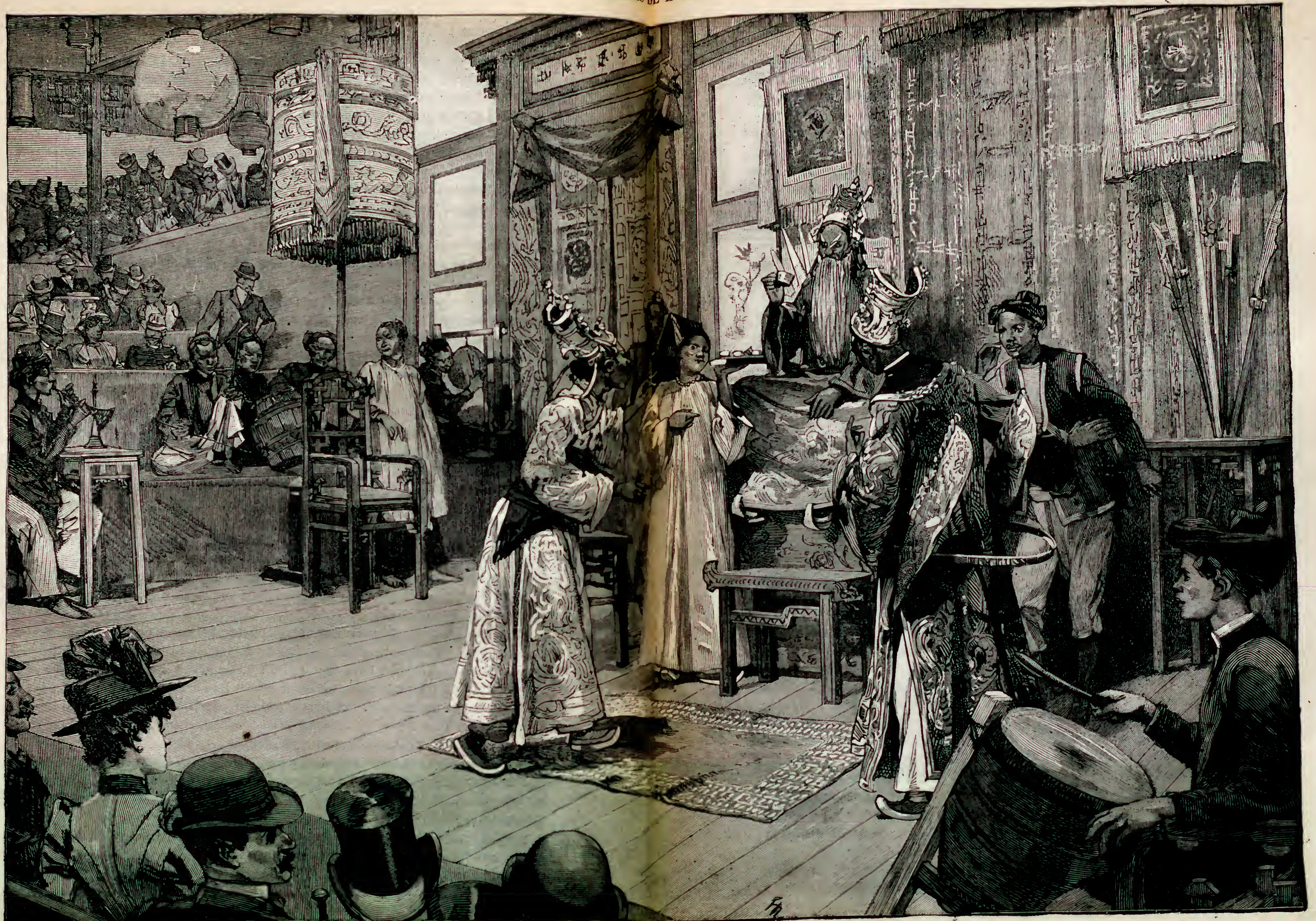

LE TuÉatRE ANNAMITE. 
des trois races du cercle sont bien distinctes: le Sarrakholé est commerçant par excellénce, et au besoin très bon guerrier. Le Malinké ne s'occupe guère de cultur:, et le Khassouké, paresseux à l'excès, ne fait pour ainsi dire rien, se livrant au pillage toutes les fois qu'il en trouve l'occasion.

«La question du Soudan français ou du haut Sénégal a élé posée paur ln première fois par le général Faidherbe, alors gouverneur du Sénégal, dans la letlre en date du 7 aout 1863 par laquelle il chargeait le lieutenant de vaissenu Mage d'explorer la ligne - qui joint nos établissements du haut Sénégal avec le haut Niger et spécialement avec Bammako. Le général Faidherbe songeait déjà à réunir le haut Sénégal au haut Niger par une chaine de postes et à faire passer par cette voie les objets d'importation européenne pour trafiquer sur le Niger. La mission de llage eut des résultats satisfaisants, mais le gouvernement ne s'en occupa point, et c'est seulement le 26 avril 1879 que M. de Freycinèt, alors ministre des Travaux publics, reprit l'idée du général et forma une commission, qui se prononça pour l'ouverture d'un chemin de fer reliant : $1^{\circ} \mathrm{l}^{\prime} \mathrm{\Lambda}$. gérie au Soudan; 20 le Sénégal au Niger. La question passa désormais de la spécuration dans la pratique. En 1879, on construisit la poste de Bafoulabé et la route de Médine à ce point; puis, le 13 novembre 1880, le gouvernement demanda aux Chambres 'un crédit de $8,35 \%, 73$ I francs pour l'établissement d'une voie ferrée entre Médine et Bafoulabé. Une période d’activité féconde succéda à l'engourdissement presıue ininterrompu qui avait suivi le départ du général Faidherbe, et quelques années plus tard, le drapeau français flottait à Bammako. Quel est l'avenir de cette colonie, qui, il n'y a pas à le nier, nous a couté et des hommes et de l'argent? Avons-nous quelque profit à en attendre pour l'avenir? Serons-nous indemnisés de nos avances? Précisément. Faidherbe, qui de 18304 à 18630 a gouverné le Sénégal avec une sagesse rare, avec un sens profond des intérêts de la métropole, a voulu, il y a quelques semaines, publier un aperçu d'ensemble sur le Sénégal, un acte de foi dans l'œuvre qu'il a inaugurée. Il maintient, appuyant son avis sur l'expérience et la réflexion, que le Sénégal est une de nos colonies les plus prospères, un cliamp d'activité susceptible de s'étendree presque à l'infini, et un champ tel qu'il nous en faut, car si nous n'avons pas à rechercher des colonies de peuplement, nous devons porter tous nos efforts sur les colonies de commerce. Le général fait remarquer ensuite que nous avons tout intéròt à continuer par le Sénégal notre œuvre de pénétration au caur de l'Afrique, au moment où les Allemands et les Anglais se disputent la prépondérance sur la cote orientale.

- Et maintenant, quelle politique devons-nous suivre pour assurer la liberté et la sécurité de la navigation sur le Niger, en amont de Bammako? Un document ofliciel répond qu'en amont, comme en aval, nous devons faire surveiller le lleuve par des avisos et des canonnières, mais cela seul ne suffira sans doute pas. La région dı haut Niger est en partie sous la domination des partisans de Samory, en partie sous celle des Toucouleurs, en partic sous celle de peuplades qui sont nos alliees. Les Toucouleurs ne sont pas très redoutables, mais il n'en est pas de ineme des Musulnam, qui ont lié leur cause à celle de Sanory et sur lesquels une surveillance continuelle doit être exercée. En outre, les avisos et les 9 canonnieres devront trouver un refuge at des ravitaillements en avant de Bammako, par exemple, au confluent du Niger avec le Milo ou avec le Tankisso.

« Cette question du haut Niger a plus d'importance qu'on ne pourrait le croire au premier abord. Nais qu'on songe aux efforts fait par les peuples européens pour se 
partager les marchés du grand continent, et l'on comprendra de suite combien il y a lieu de ne pas abandonner l'œuvre conçue et inaugurée par le général Faidherbe. Les Allemands se sont établis dans le golfe de Guinée, à Angra-Pequena et à Zanzibar, d'où ils cherchent chaque jour à pénétrer dans l'intérieur. Les Anglais, établis çà et là sur la côte occidentale, dans l'Afrique australe, en Égypte, tendent à s'emparer, par l'intermédiaire d'une grande compagnie coloniale, de la région des Grands Lacs. Les Italiens ne perdent pas de vue l'Abyssinie. De toutes parts, l'Europe se jette sur l'Afrique, poussée par cette nécessité économique qui oblige le vieux monde, encombré de produits, à les écouler dans les pays neufs et à leur demander en échange des articles d'importation. Ne négligeons rien de ce qui peut rendre moins aiguë la crise dont souffre depuis $\mathbf{1 8 7 0 - 7 1}$ le commerce français. ,

\section{LE CAMBODGE}

Le Cambodge, partie de l'Indo-Chine, est borné au nord par le petit royaume de Bassac et par les provinces siamoises, au sud et au sud-est par la Cochinchine, a l'ouest par le golfe cle Siam. Du côté de l'est s'étend une zone de tribus plus ou moins indépendante. Sa superficie est de 100,000 kilomètres carrés, soit à peu près le cinquième de celle de la France.

Le Cambodge septentrional, montagneux et très brisé, renferme des mines de fer et des carrières de grès. La région des plateaux est très pauvre. Les terrains qui bordent le Meï-Kong sont au contraire très fertiles. Tous sont de formation récente et d'origine alluvionnaire. Le climat varie entre $20^{\circ}$ et $30^{\circ}$ centigrades, en temps normal. La grande artère du pays, le Meï-Kong, sort du Thibet et traverse le Cambodge du nord-est au sud-ouest. Il n'est pas navigable pendant toute l'année au delà de la frontière, mais pendant la saison des pluies, des officiers de notre marine ont pu remonter jusqu'aux fles de Préapasang.

Pnom-Penh, la capitale, est le centre de transit des produits siamois, birmans et laotiens. On commence à y batir à l'européenne, mais on y trouve encore des vieilles paillottes sur pilotis au milieu de terrains marécageux et fétides, à côté du palais du roi, de l'habitation du chef des bonzes, de pagodes originales et des bâtiments français. Dans les 30,000 àmes qui forment la population de Pnom-Penh, les Chinois fournissent un appoint considérable.

Le Cambodgien est brachycéphale. Il ne faut pas le confondre avec l'Annamite, qui est de moindre taille et moins musclé. Il est de caractère sombre, d'humeur sournoise, orgueilleux, lâche, paresseux et fourbe. L'homme a pour vêtement une veste très étroite, qui boutonne droit et tombe sur les hanches. "L'abdomen et les cuisses, dit M. IIondière, sont couverts par le sampot ou langouti. C'est une pièce de soie ordinairement longue de 3 mètres, haute de 1 mètre, qu'on enroule autour de la taille. Les deux bouts supérieurs sont tordus et croisés un peu au-dessus de l'ombilic : les deux bouts inférieurs passés entre les jambes sont ramenés en arrière et fixés à la ceinture. Pour les femines, une longue robe en fourreau, échancrée jusque près de. la naissance de la gorge, mais ne laissant pas voir celle-ci; elle passe commę une chemise; les manches sont étroites. Dessous, noué à la ceinture, une sorte de jupon étrøit tombant au-dessus 
de la cheville. Dans les fetes, souvent, le torse n'est recouvert que d'une grande écharpe de soie laissant le bras droit et l'épaule à découvert. M. Mondière, qui a été à même de se faire une opinion solide en exerçant au Cambodge des fonctions judiciaires, se porte garant de l'immoralité des indigènes, mais aussi de leur ferveur bouddhique et de leur tempérament superstitieux. Parmi les superstitions qu'il a observées, il cite : l'embarquement des mauvais génies et le bol de riz que les ménagères jettent sur leur passage au moment où ils sont censés s'embarquer dans lé bateau en papier qu'on lance à l'eau, afin qu'ils s'y noient; - l'eau de la chandelle sainte contre les maladies, et surtout le cholẻra. Je possède un manuscrit cambodgien sur feuilles de palmier, qui donne les prières et les préparations de cette eau; - les promenades d'un thaumaturge sur un lit de charbons allumés, long de 5 à 6 mètres, et que l'éventail des dévots maintient incandescents.

L'exploration du Cambodge présente de grosses difficultés, dont la principale est la maladie qui vous menace perpétuellement dans les forêts pendant la saison des pluies. M. Delaporte, lieutenant de vaisseau, a eu le courage de s'aventurer en pleine région inexplorée, et plus que ses prédécesseurs, y compris Moubot, il a contribuẻ à appeler sur ce pays l'attention du public savant qui comprend maintenant l'intérét de l'élude historique et archéologique de l'ancien empire Khmer. En partie détruits par les guerres, en partie abandonnés depuis plusieurs siècles, les monuments khmers sont dans un état de délabrement auquel on a peine à croire. Les indigènes ont peur de ces ruines, où ils croient voir errer des esprits, absolument comme dans des pays plus civilisés, on a longtemps craint, dans les campagnes, l'apparition nocturne des sorciers au milieu des châteaux en ruines. Une végétation si puissante les obstrue et les enlace qu'il faut marcher la hache en main pour ètre en mesure d'avancer. M. Delaporte eut du courage, mais quelle moisson! En feuilletant le livre qu'il a publié apris son voyage, on s'arrête des heures entières sur les reproductions de ces mervilleux monuments d'Angkor-Wât et de Beng. Mélea. On admire la finesse des motifs d'ornementation, les fleurs, les feuillages, les arabesques, les oiseaux, les animaux et les scènes les plus variées. Les figures, sérieuses ou bouffonnes, ont une expression frappante. Sur les entablements des portes courent des ornements gracieux ou fouillés d॥ plus rare mérite. Et dire qu'il y a quelque cinquante ans, toutes ces richesses architecturales étaient ignorées en Europe! Il a fallu le dérouement dont sont capables nos officiers de marine pour les décrire, pour montrer qu'il y a eu au Cambodge une civilisation aussi curieuse à étudier que celle des autres États de l'Asie.

Comme l'Annam et le 'Tonkin, le Cambolge est placé sous le protectorat de la France. Au lieu de construire un pavillon quelconque, les organisateurs de l'Exposition ont eu l'idée de reconstituer un fragment des ruines d'Angkor, c'est-ḋ-dire de nous donner un spécimen de l'architecture khmer. Depuis la révélation des cités enfouies de l'Assyrie, la découverte des villes ruinées du Cambodge est peut-être le fait le plus saillant qui se soit accompli pour l'histoire de l'art en Orient.

- La plus importante des capitales du royaume khmer, dit M. Binile Soldi, qui a exécuté avec M. Delaporte une réduction d'Angkor pour le musée du Trocadéro, la ville sacrée porte encore le nom d'Angkor la Grande, Ingkor Thous, la citadelle ou ville royale, et son enceinte, de près de seize kilomètres de tour, est bordée d'un fossé de cent vingt mètres de large. Cinq portes monumentales y donnent accès et celles-ci présentent peut-être le meilleur exemple de la puissance d'imaginaticn des Orientaux, 
LES MERYEILLES DE L'EXPOSITION

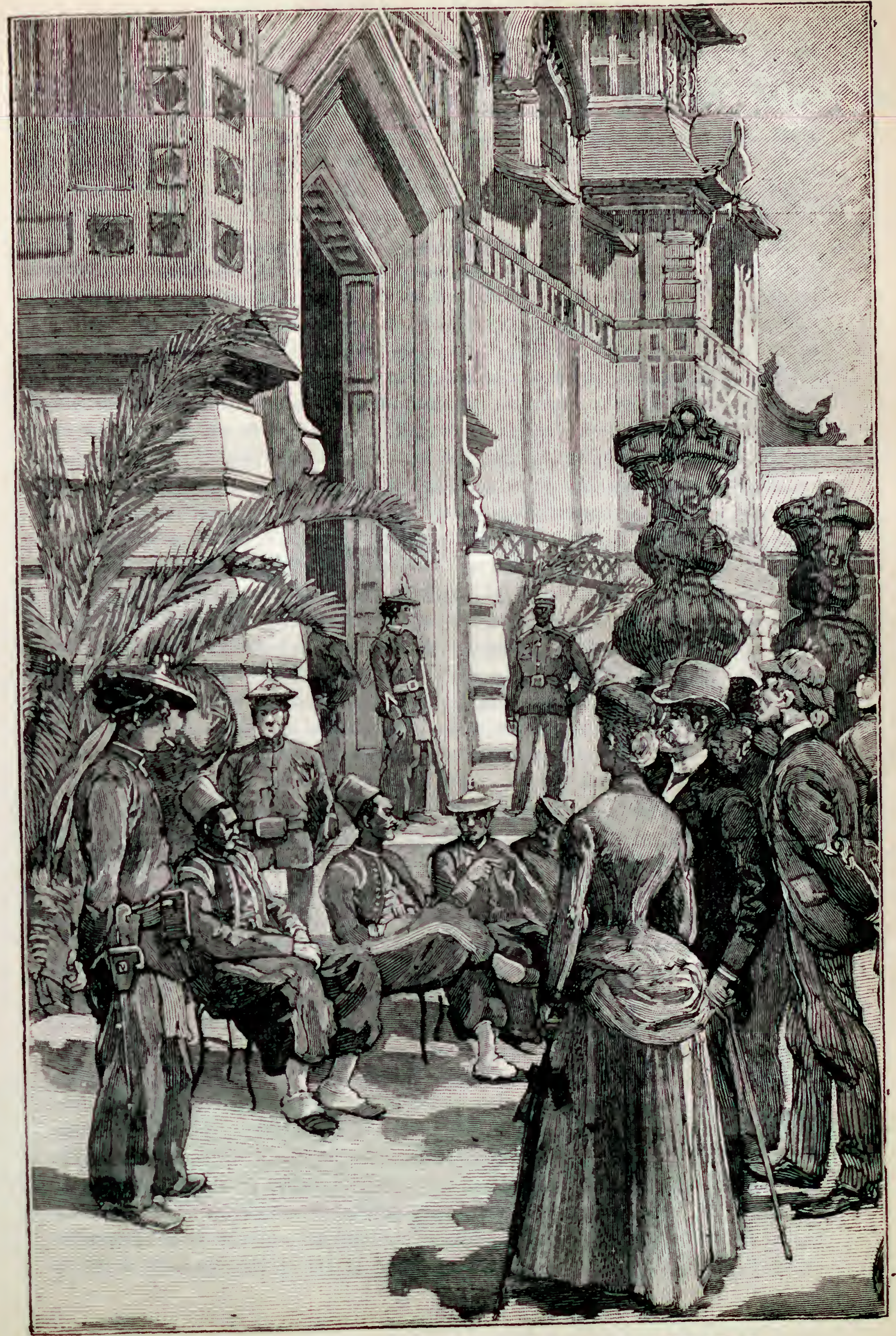

Les Soldats indigexes devart le Pavillon des Colonirs. 
du gout de l'art délical du Khmer et du fini précieux de l'arliste indou. L'alléc qui conduit a la porte khmer consiste en une longue chaussće, pont gigantesque traversant le fossé qui entoure la citadelle. Le parapet de cette chaussée est formé par un alignement formidable de cent vingt-huit géants (Yacksas) portant comme un cordon le divin serpent (Nogas), dont l'énorme tète heptacéphalique tenue par un Yaclisıs polycéphale se redresse, se déploie comme un éventail, et forme une immense courbe de cinq mètres de hauteur du plus majestueux effel. A l'extrémité du pont, encadrée dans cette perspective solennelle, apparait la porte monumentale, véritable arc triomphal, qui sert d'entrée a la ciladelle. Il semble que tout l'olympe brahmanique, tontes les divinités hybrides, tous les habitants de la ville se soient rassemblés, alient escaladé toutes les parties de l'immense portique. Au fronton, la guerre, la poursuite de l'ennemi sur la terre et dans les airs, les dieux et les hommes se confondent daus la meclie; les côtés de la porte sont fanqués de douze éléphants montés par des divinités; sur tous les murs sont sculptés des combats contre les monstres, des apparitions surnaturelles, un monde de statues, de bas-reliefs, dornements. Au-dessus de cet cnsemble, apparaissent d'immenses tètes de Brahma, dont les tiares dentelées représentent trois tours aux sommets dorés. Le tout forme une entrée d'une archilecture aussi puissante que gracieuse, où les profusions sculpturales masquent la massivité du monument, dont le détail est aussi admirable que l'ensemble. Partout la grace s'allie a la force, la grandeur à la douceur. Il semble que, comme dans les cent mille distiques du Muhuhharna l'immense poème religieux dont il est l'expression - l'art khmer ail accumulé dalls un immense pandémonium architectural, les globes qui habitent le paradis d'lndra, lenus en échec par la main caressante d'un enfant, lavalanche des mille chars de guerre et toutes les épouvantes arrètés court à la vue dune Devadassy somiante sortant de la fleur de lotus. Tout étrange que paraisse la conception de ce morrument, on y reconralt instantanément une science de l'art et de l'archilecture, une imagination, un fuyer d'idées d'une telle richesse que d'autres pays considérés comme supérieurs pourraient largement y puiser. On a parfois comparé avec raison les monuments de l'lud., surchargés de sculptures, aux façades de nos cathédrales gothiques, oi la Trinité et tous les saints du ciel et de la terre, les démons, les anges et les archanges, le roi et l'esclave, se superposent, s'amoncellent et s'encadrent dans les ligues roulues. Aussi, dans la porte d'Angkor, les tours, les figures, l'ornementation excessive, la richese inouïe, rappellent nos plus beaux monuments du xm sidcle. Seulement, les avantares sont pour l'art du Cambodge, qui n'a pas à traduire les sévères lígendes de la féodilifi. mais des aventures souvent aussi gracieuses et aussi légères que celles des mytles grecs. L'artiste cambodgien, qui possède une pierre d'un grain tendre el fu, un habileté d'outils, une dextérité de main incomparables, excelle dans ce détail si délicat nt si plein de charme qui rappelle notre Renaissance. A u milieu de la porte d'Allghor s'épanouit le sourire de Brahma, son grand masquue bienreillant est entouré de jeunes filles qui jettent des fleurs. L'art qu'il a enfanté est lui-ndme nne immense floraison, mue luxuriante verdure; il palt et disparait arec le penple klumer comme une strite de bouquets et de gerbes d'artifices se répandent dans les airs et s'éranouissent comme dans un enchantement. L’art du mojen âge seétait révélé de méme instantarément; seulement, né dans les larmes et l'angoisse, son rayonnement fut sumbri d'éclats comme ses vitraux. L'art khmer ressuscite aujourd'hui, mais avec le charme de lous les arts de l'Orient, en rappelant et en présentant lout ce qui est magique, les fleurs, la 
jeunesse, l'imagination, la grace naïve, la richesse et le sourire! " Nous ajouterons que les ruines d'Angkor sont situées, non plus sur le territoire cambodgien, mais sur le territoire siamois, et que ce groupe fameux comprend la pagode d'Angkor-Wat, la ville d'Anglior-Thom, les monuments du mont Cròm, d'Athvéa, de Takéo, de Ta-Prohm, d'Edkey, de Leley, de Bacong, de Préacon, de Méléa, de Pnom-Bachey. On croit pouvoir l'attribuer à la période archéologique qui s'étend entre la fin du rve siècle et le $\mathrm{x}_{11}{ }^{\mathrm{\theta}}$.

Le Cambodge était jadis beaucoup plus pıissant qu'aujourd'hui et beaucoup plus étendu au point de vue du territoire puisqu'il comprenait le Binh-Thuan (aujourd'hui province annamite) et s'étendait le long de la côte jusqu'au Siam. Il dominait dans le Laos. Les ruines imposantes que l'on trouve dans ses forèts, ruines dont la pagode de l'Esplanade montre assez la haute importance, témoignent assez du degré de civilisation de l'empire khmer. D'où venaient les Khmers ou Cambodgiens primitifs ? Probiblement des bords du Gange. Leur histoire est encore mal connue, mais il est certain qu'au xแ० siècle le tiers de la péninsule leur appartenait. Les guerres malheureuses qu'ils soutinrent avec leurs voisins rétrécirent peu à peu les frontières du Cambodģe qui, en 1863, lourna ses regards vers la France, se sentant incapable de secouer l'oppression des Annamites et des Siamois. Le gouverneur de la Cochinchine, l'amiral de la Grandière, sentit que laisser le Siam dominer au Cambodge, c'était la certitude de voir les produits laotiens passer par le Meinnam au lieu de passer par le Meïkong, au grand détriment du commerce saïgonnais; il dépêcha donc Doudart de la Grée auprès de Norodom, qui, habilement circonvenu, accepta notre protectorat et nous accorda une concession sur le Meïkong. En 1884, une nouvelle convention fut imposée a Norodom, qui accepta l'intervention de notre gouvernement dans toutes ses affaires (douines, fisc, travaux publics, etc.), et consentit à abolir l'esclavage.

Lin 1877, Norodom a l'endu une oldonnance concernant les réformes à introduire dans le royaume. Il a restreint pour l'avenir les prérogatives du preci-moha obbarach (second roi) et de la reine mère, fixé la dotation des membres de la famille royale, établi un Conseil de gouvernement de cin q membres, modifié l'administration des provinces, le mode de perception du fisc, l'administration de la justice, déterminé les mesures à prendre pour l'extinction de l'esclavage. Avant les derniers événements qui viennent de s'accomplir au Cambodge, le roi était maitre absolu, et les lois dépendaient de son caprice. Cette autorité excessive s'arrètait devant les choses saintes, car les bonzes sont indépendants, et leur chef a droit aux mèmes prérogatives que le roi. Après le roi venaient plusieurs dignitaires sans influence dans le gouvernement. En premier lieu était l'obbaionréach ou roi qui avait abdiqué, puis l'abbaréach (le premier frère du roi porte ce titre). Chacun de ces persónnages avait une petite cour semblable à celle du roi. D'après les diverses conventions passées entre Norodom et le gouvernement francais, depuis l'établissement de notre protectorat, cinq grands mandarins devaient aider le roi dans l'administration du royaume et prendre part aux délibérations gouvernementales. Le premier d'entre eux, président du Conseil, était le luc-chaufea, appelé depuis quelque temps luc-akamahasena. Le second ministre était le luc-ymerck, chargé d'assurer la police des prisons et de juger les affaires de vol. Venait ensuite le luc-veang, sorte d’intendant chargé de l'administration intérieure du palais et de la perception des impo̊ts. Le luc-kralahom s'occupait des transports par eau, de l'entretien des voies navigables et de la surveillance des postes de douane. Enfin venait le luc-cheliey, 



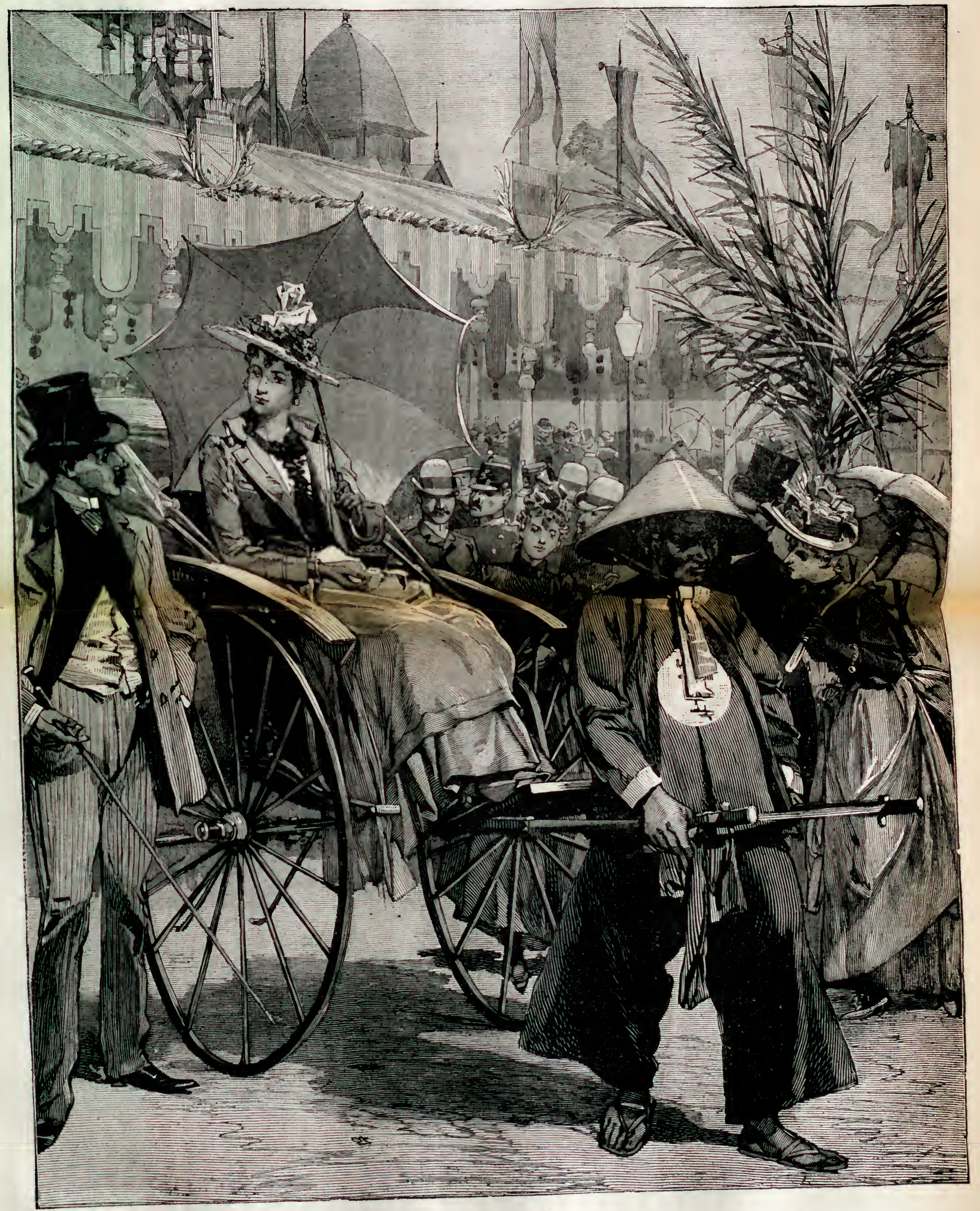


chargé des transports par terre, des éléphants, des boufs et des buffles. Ces mandarins avaient sous leur autorité un certain nombre de provinces où ils levaient des corvées, ce qui leur constiluait de forts revenus. Le royaume du Cambodge úlait divisi en 73 provinces, dont 41 relevaient directement du roi qui les administrait par l'entremise de ses cinq grands mandarins entre lesquels elles étaient partagées. Sept étaint données en apanage à l'abbiliouréach; cette dignité étant actuellement vacante, elles ont fait retour à la couronne. Cinq formaicnt l'apannge de l'obbaréach, frère du roi. La reine-mere avait un apanage de trois provinces qu'elle faisait gouverner par ses mandarins. Enfin, le premier ministre avait sous sa dépendance directr la province de Chœung-Prey, moyennant une redevance annuelle qu'il payait au roi. La convention du $1 \bar{\imath}$ juin 1884 a modifié considérablement le mode d'administration interieure du pays. Le roi, au lieu d'avoir un pouvoir absolu, n’a plus que les attributions d'un monarque constitutionnel. Le Conseil de gouvernement est investi des pouroirs d'un conseil des ministres joints à ceux d'un Conseil d'État. Le résident général tient la place de ministre dirigeant, en mème tenıs quil représeute le gouvernement de la Cochinchine investi, au nom du gourernement de la République française. du contrôle du Protectorat. Le royaume a subi de nouvelles divisions et a éti partage en huit grandes provinces, à la tète de chacune desquelles a été placé un résident français. Ce réident dirige la province au point de vue politique et administratif, contrule les antorités camboảgiennes, et assure le maintien de l'ordre et tous les services publirs. 11 préside le tribunal provincial dont la compétence en dernier ressort est limitće, pour les affaires commerciales, d une valeur de cent piastres. Ce tribunal juge en premier ressort toutes les affaires criminelles ou correctionnelles, toutes les aftaires civiles, quelle qu'en soit l'importance. Les provinces se divisent en arrondissements, et les arrondissements en cantons, administrés chacun par un fonctionnaire indigine.

Il est à souhaiter que l'Exposition marque le point de départ d'une ire économique pour le Cambodge, où le commerce intérieur est insignifiant, parce que les roies de communication manquent et que la monnaie est rare. Liagriculture est plus prospere. Les terrains en bordure du Mékong sont trés cultivés, les quatre cinquiẻmes de la population étant agglomérés dans celte zone, mais au centre du pays le manque de bras fait que le sol reste inculte. L'indigo, le coton, le mürier, le riz, le taluar sont d'une belle venue; il en est de mème du cacaoyer, du vanillier, du maìs. du palmier sucré. La principale des industries du pays est la peche, à laquello le pays se prile merveilleusement. A la fin de la saison des pluies, lorsque l'eau a envihi toutes les dépressions, il suffit, lisons-nous dans une notice fournie par le gourernement de la Cochinchine, de barrer les arroyos secondaires pour avoir, lorsque les eaus baissont, une quantité considérable de poissons que l'on peut prendre presque à la main, tellement leur nombre est considérable. La saison de la pêche commence au mois d'octubre dans les precks et pelits arroyos qui se vident presque de suite pour finir vers le muis de juin dans les arroyos les plus longs à écouler leurs eaux. Le droit de peiche afpriptient au gouvernement qui s'en dessaisit chaque annee au prulit des particuliers. Autrefois le roi traitait de gré à gré avec un fermier (généralement chinois) pour toutes les pècheries du royaume, lequel Chinois rétrocédait les pécheries par provinces ou régions. Aucun cautionnement n’élait exigé. Ce mode de procéder était défectueux et entrainait souvent pour le roi des pertes d'aryent considérables; c'ést ce qui est

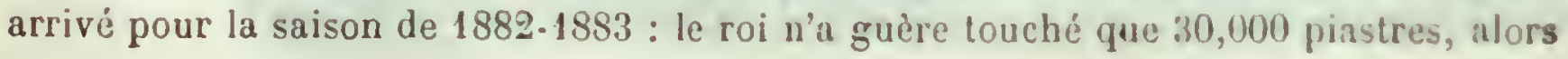


qur: le prix fixé était de 50,000 pinstres. Pour éviler le retour de ces inconvénients et sur la demande expresse du roi, les pẻcheries ont été mises en adjudication pour la campagne 1884-1883 par le représentant dı protectorat; elles ont été concédées à différents adjudicataires, Cambodgiens, Malais, Chinois et Annamites, pour la somme totale de 62,000 piastres. Deux cautions solvahles étaient exigies de chaque acquéreur qui devait de plus verser au comptant le tiers du prix d'adjudication. Le produit obtenu, bien que supérieur à celui des années précédentes, sera sans doute de beaucoup, dépassé lorsque le morcellement des fermes et leur distriluution rationnelle permettront à uo plus grand nombre de concurrents de prendre part aux adjudications. Ce que nous venons de dire ne s’applique pas au Grand Lac, oì la piche a été déclarée libre par le traité de $186 i$ entre la France et le royanme de Siam.

Au mois de novembre, 20,000 individus, pècheurs, femmes et enfants, montent de la Cochinchine et du Cambodge au Roulisap, emportant avec eux les paillolles nécessaires it la construction de leurs cases sur le bord de l'eau; les bambous leur sont fournis par les forêts roisines. Les pècheur's vont s'établir au point où ils feront leur saison. Bicn que les eaux soient encore hautes, ils enfuncent les pilotis qui supporteront leurs maisons et leurs séchoirs. En avant et plus au large, en un endroit où l'eau sera toujours en assez grande quantité pour permettre aux barques d'accoster, sont établies des palissades pour sécher les filets. Ainsi se forment des villages temporaires de pècheurs qui trouvent dans leur réunion plus de facilités pour se protégel contre les attaques des pirates et se prèter une mutuelle assistance dans les inoments où le poisson abonde et ou il est nécessaire de meltre en ocuvre et avec ordre un grand nombre de filets a la fois.

Dans ces derniers cas, les produits de la péche sont répartis proportionnelleneut entre les pècheurs, suirant les règles traditionnelles et spéciales du Grand Lac.

- La formation des villages, dit M. Bouinais, provient de ce que le poisson, le noir surtout, c'est-à-dire celui qui est le plus estimé dans le pays, abonde plus dans certains endroils que dins d’autres. Immédiatement après la pẻche, on décapite les poissons, puis, de retour au village, on les ourre longitudinalement, on les vide, on les lave avec soin et on les saupoudre de sel sur tout le corps. On les expose ensuite au soleil pour les faire síclier. Une fimme armée de brosses les frotte de temps à autre pour faire tomber les petits vers qu'y déposent de grosses mouches. Le poisson, une fois salé et séché, est bon pour la rente. Les principales espèces employées pour la fabrication du nuoc-mam (condiment liquide formant arec le riz la base de la nourriture des indigènes) sont le ca-mau ou mai-ngu. le ca-nop ou hach-dan-ngu, le ca-nom-bien ou hai-phanngu. Le poisson est tassé avec du sel dans un granil cuvier de bois et abandonné pendant deux mois a la putréfaction. Il se forme une masse pateuse exhalant une odeur infecte et au milicu de laquelle pullutent des vers blancs; puis un liquide se dépose, offraut l'aspect de l'huile de poissun mal épurée. On recueille ce liquide au moyen diune ouverture percée latéralement vors le fond du cuvier, on le fait bouillir, puis on le rait déposer dans des vases de terre cuite.

sur les autres industries cambodgiennes, la notice citée plus haut donne aussi des renseignements : La fabrication des alcools de riz est principalement faite par les Chimois qui achètent le droit au fermier général. On use des mêmes procédés de fabrication qu’en Cochinchine: ils ont été si sourent décrits que nous n’y reviendrons pas. 
La notice fait remarquer que la consommation de ce produit est loin d'être proportionnellement aussi grande qu'en Cochinchine.

L'industrie sucrière est peu développée, bien que la canne à sucre du Cambodge nous paraisse devoir donner de meilleurs résultats que celle de Cochinchine. $A$ cóté de la canne existe le palmier à sucre dont les indigènes tirent une grande partie du sucre qu'ils consomment. Ils le récoltent en pratiquant a l'arbre une incision à laquelle ils adaptent un tube en bambou.

Les forêts du Cambodge pourraient facilement alimenter des scieries mécaniques. En certains endroits mème de la forêt on trouverait des torrents d'eau fort suffisants pour les faire marcher, mais, en général, les bois sont débités par des scieurs de long chinois et annamites. Il y a quelques années, une scierie, établie à Pnom-Penh, n'a pas réussi faute de fonds et aussi à cause du mauvais choix de l'emplacement.

Les Cambodgiens sont assez experts dans la fabrication des barques de toute sorte, et, malgré cela, par suite de leur paresse, les embarcations sont presque toutes faites par les Annamites. La fabrication des produits céramiques, au Cambodge, comprend principalement la fabrication des briques et celle des poteries. L'industrie des briques est de première nécessité dans ce pays où l'absence de voies de communications rend si difficile le transport des pierres qui n'existent que dans les montagnes. C'est avec des briques que sont construites presque toutes les maisons en maçonnerie dans lesquelles le granit n'entre, quand il y en a, que pour les fondations et le pied des murs. C'est principalement sur les rives du Bras-du-Lac, entre Pnom-Penh et Kompong-Luong, que se trouvent les briqueteries les plus importantes, presque toutes aux mains des Chinois. Les poteries de toute sorte, comme nous avons déjà eu occasion de le mentionner, se font principalement dans les environs de Kompong-Chnang (rivage des marmites), à l'entrée des lacs. Elles comprennent les vases de toutes formes et de toutes dimensions et des ustensiles de cuisine, fourneaux et marmites. Le procédé de fabrication en usage parmi les potiers du pays est des plus primitifs : les vases sont fabriqués à la main, sans tour. "Quant à la cuisson, dit M. Paire, ils procédent de la façon suivante : sur un lit de fagots épais d'un pied, les vases préalablement séchés au soleil, sont déposés l'ouverture en bas; lorsque la combustion du bois est avancée, que la flamme a disparu, le tout est recouvert d'une couche épaisse de paille qui elle-méme est vite consumée, mais dont le manteau de cendres maintient suffisamment la chaleur pour que le refroidissement ne soit pas trop rapide. .

\section{GUYANE}

Il y a peu de chose à dire de l'Exposition de la Guyane, et nous serons très brefs. Notre colonie de la Guyane est une portion de cette vaste contrée de l'Amérique du Sud qui s'étend entre l'Orénoque et le fleuve des Amazones. Elle n'est pas cultivée, mais elle pourrait l'ètre avec fruit. L'agriculture n'existe pas : on choisit un terrain, on y met le feu, plus rarement on abat les arbres : on plante et l'on attend la récolte, et c'est tout. Il n'est question ni d'amendements, ni de fumure, ni d'assolement, ni de drainage; à peine pratique-t-on de temps à autre quelques sarclages à la houe; la charrue est pour ainsi dire inconnue. Les cultures de la Guyane répondent d'une manière 


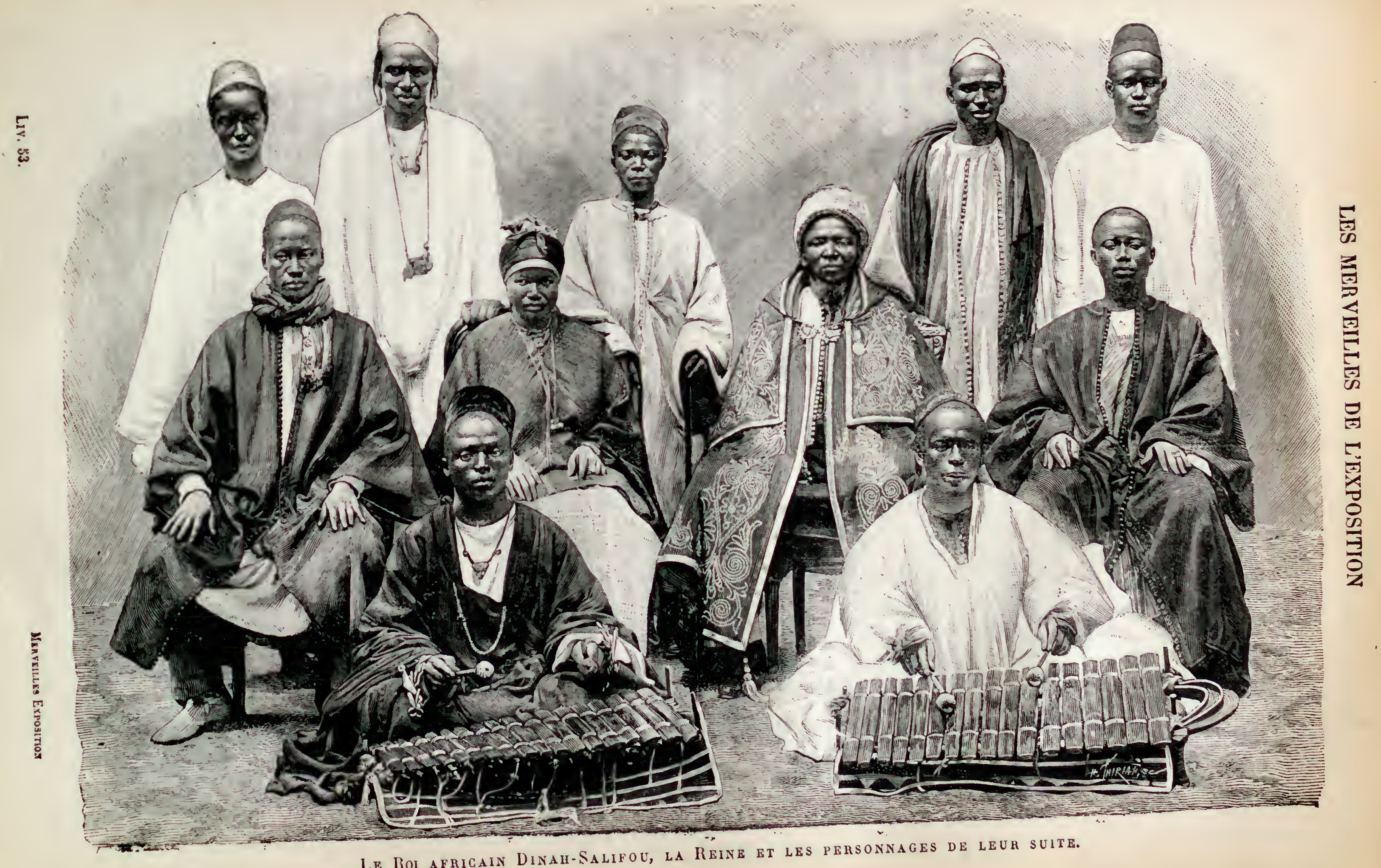

I. Rol AFricaIN DINAII-SALIFOU, LA REINE ET 
tris insufisante aux besoins de la population. Le conac, par exemple, qui donne le manioc du pays, ne sufit pas à la nourriture du pays. et l'on est obligh do reconrar au territoire contesté el au Para. El pourtant, que de richesses fournurait ici l'agriculture : entre autres produits, qui ne demandent pour donner une riche production que quelques soins bien compris, nous citerons : le bananier, la palite, le collac, l'igname, le mais, larbre a pain, le cocotier; des fordts vierges u'altendent que des travailleurs pour donner au commerce des bois de toutes sortes. Le coton, la ramie, l'indigo, le bois de campeche, la gomme-gutte, les plantes pharmaceutiques, la canne à sucre, le caoutchouc, les épices. la vanille, le mùrier ne demandent qu’à pruspérer; l'élevage da anim:aux domestiques pourrait donner aussi de bons risultats. Les gisments auriferes existent à la Guyane, ainsi que de grandes quantités de roches feluspanthinues, dont la décomposition donne en abondance le kaolin. La notice ofticielle pullibesur la Guyane attribue au manque de bras sa situation économiłue peu favorable. Tuus les jeuncs gens sunt aux mines dor, et les directeurs de placers sont obligis d'avir recours aux immigrants hindous, aux Annamites et aux . Aricains. Le truvailleur du pays, le nour, est fort et actif; bien stimulè, il devient tres adroit : les menuisiers, les charpentiers, les maçons et les couvreurs sont presque tous indigènes. Le cnolie hindon pourrait atre utilisé pour la culture des terres : plus nerveux que le noir du pays, plus économe, il pourrait fournir un bon travail si on arait soin de le tenir éloigué des díbils de bois. sons.

Le noir Senégalais, trop rare à la Gugane, est d'une force herculiennt el a est mullement incommodẻ par le climat; sobre, laborieux, il pourrail etre diune grande utulıté dans l'exploitation agricole. Le mulatre est actif et intelligent; il sait diriger les travaus, est affable et poli et fournirait d l'élément comnerģaut el inclustriel un sérieux appoint. L'Annamite n'a qu'une idée : gagner et repartir; il ne s'alluclse pas au sul, c’est le pècheur par excellence. Industrieux. sobre, économe jusqu is la parcimonie, excellent cultivateur. il serait précicux si on pourait le décider á rester. Si la liugane ne manquait pas ainsi de trarailleurs, elle serait destinée à un grand arenir, mais espârons qu une colonisation graduée le lui assurera par des efforts sagement dirigé.

Il est impossible de parler de la Guyane sans dire quelques mots de ladunustration pénitentiaire. La colonic pénitentiaire de la Guyane se compose d'diabes et de condamnés de nos autres possessions; elle est done peu consid'rable, mas on v'en est pas moins parvenu à en retirer des services apprícialsles. La main-d'ipuvre pénale es: employée aux traraux industriels et aux traraux agricoles. Les tranfports qui sont ouvriers de profession entrent à leur arrivé dans les ateliers pénitentiaires; dautres sont employés ì la construction des routes, digutes et canaux ou au batelage; le surplus est consacré à l'agriculture, à l'élevage du bétail et à l'exploitation forestière. II s a quatre centres pénitenciers : $1^{\circ}$ le pénitencier \&̀ torre de Cagenne, qui a puur annexe le ponton La Truite; $2 \circ$ les lles du Salut; $3 \circ$ Kivunou; so Saiul-Laurent du Maroni avec quelques anneres. Lidẻal aurait éte, au mugen de production de la ma nutururre pénitentiaire, de dégrever le budget de la Guyane. et on y serait peul-étre paruenu, mais on jugea quon ne devait pas exposer les crimuels aux risques du clunat de cetle partie de l'Amérique. 


\section{GUADELOLPE ET MARTINIQUE}

A l'occasion de l'Exposition universelle, le gouvernement de la Guadeloupe a publié une notice géographique et historique sur la Guadeloupe, notice qui nous a été remise all Pavillon de celle colonie et qui nous éclaire très exactement sur ce que nous avons ¿̀ en attendre sous le rapport économique.

On sait que la Guadeloupe comprend deux lles bien distincles que sépare un bras de mer conuu sous le nom de Rivière-Salée; lille située à l'ouest de la Rivière-Salée s'appelle Guadeloupe proprement dite ou Basse-Terre; celle qui s'étend à l'est porte la dénomination de Grande-Terre. La population est de 150,000 habitants, d'après le recensement de 1884, le dernier qui ait eu lieu. De la Guadeloupe dépendent la Désirade, Mirie-Galante, Les Siniutes, Saiut-Martin et Saint-Barthélemy.

La Martinique est distante de la Guadeloupe de 110 kilomètres. Du nord-ouest au sud-ouest, elle est traversée par la ligne de faltes antillienne, longue chaine à vallées et a gorges profondes, et se divise en deux vastes péninsules. Elle ne compte pas

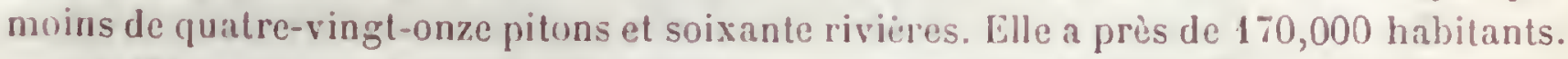

La Martinique entretient des relations commerciales avec la France et les putres colonies françaises, avec les États-Unis d'Amérique, avec l'Angleterre et ses co!onies, avre les Intilles espagnoles, avec Haïli et avec le Vénézućla. Elle nous envoie du sllere d'usine, du sucre brut, du rhum, du tafia, du vin d'orange, des liqueurs des flles, du cacao en fèves, du cacao simplement broyé, de la vanille, du café, de l'ambrelte (graines de gombo musqué), la rocou, des confitures, du bois de campéche, du colon, des peaux lrutes, des cornes el os de bétail bruts, des écailles de caret, de la fécule de manioc, des conserves d'ananas, de la vanneric. La culture principale est celle de la canne a sucre, qui couvre un peu plus du quart de la superficie totale de l'ile. Les cannes à sucre sont livrées à des usines centrales ou exploitées sur l'habitation qui les a produites, on compte actuellenent 310 habitations sucrieres, les unes livrent leurs cannes aux usines, d'autres opérant d'après les vieux procédés ne produisent que du sucre brut et du rhum; quelques-unes seulement ont modifié lour outillige et fournissent du sucre turbiue. , Les cultures vivrières (patate, ignanes, manioc, banane, clıou caraïlıe, légumes el fruits) sont faites en vue de la consommation de l'ile et non en rue de l'exportation. Quant aux cultures dites secondaires elles comprennent le cacao, le café et la casse. Les documents officiels sont daccord pour reconnaitre que si les cultures secondaires étaient encouragées, clles donneraient pent-ètre lle bons résultats, mais les cultivateurs sont arrètés par la difficulté de se procurer les petits capitaux dont ils amtaient besoin pour attendre les premiers produits, soit trois ou quatre ans. II faudrait aussi instituer des clıamps d'expérience.

Les deux principales industries sont la fabrication du sucre et du rhum, dont on verra des échantilluns sur l'Esplanade. La Martinique ne compte pas moins de dix-sept usines centrales i sucre, et chaque habitation sucriere falorique du rhum. Lexportation du rhum et du tafia est de $1: 3$ millions de litres par année, et celle du sucre de près de $\{7$ millions. Mentionnons aussi une machine spéciale dont le fonctionnement repose sur la rotition diaimants électro-magnétiques, se mouvant au-dessus d'une toile sans fin sur laquelle est répandu du sable de mer; les aimants enlèvent de ce sable un 



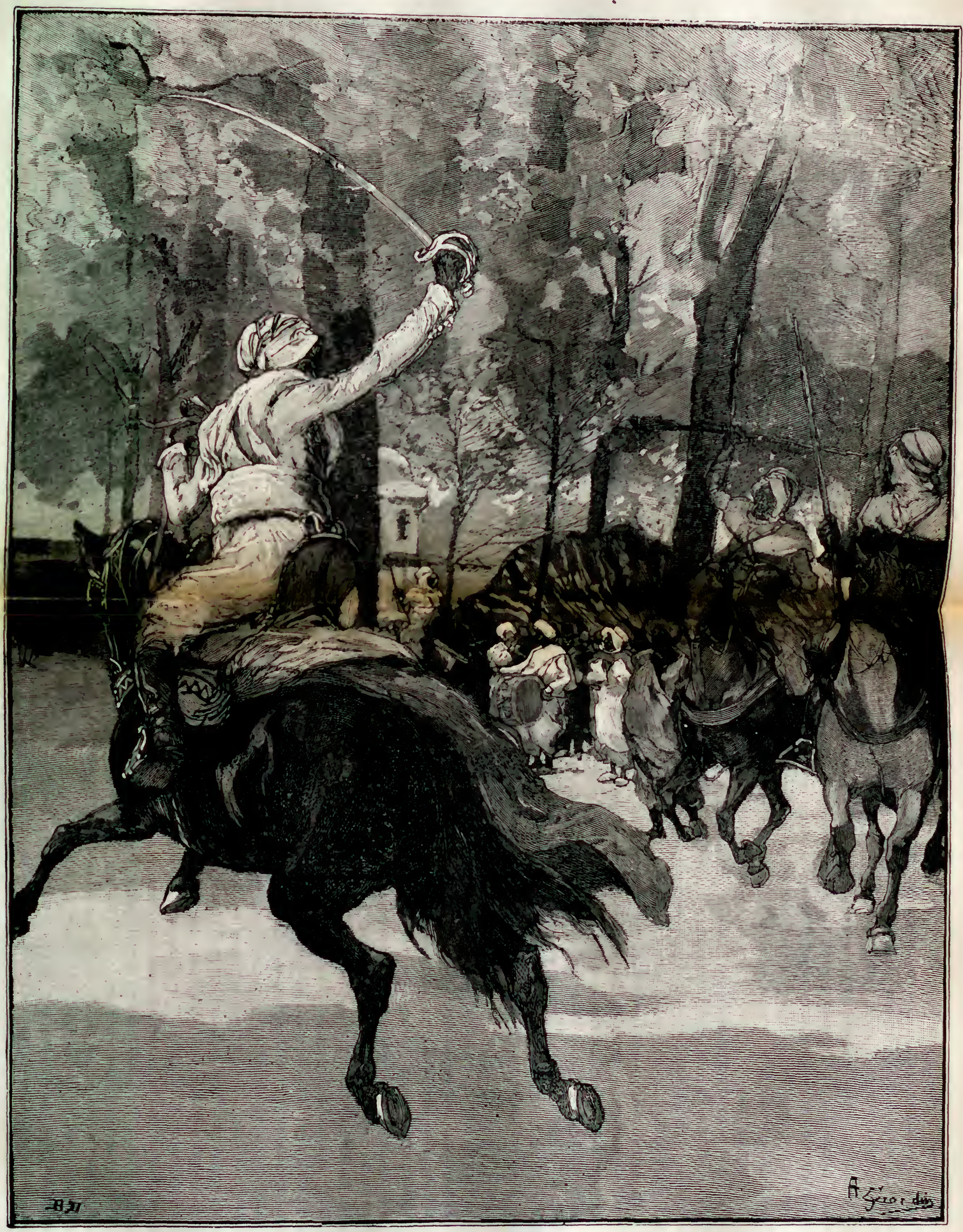


minerai de fer et le laissent tomber dans une trémie. Le minerai ainsi recueilli contient $60 / 0$ d'acide titanique, 0,10 de magnésie, des traces de chaux, $100 / 0$ de quart\%, S3,60 d'oxyde de fer magnétique (d'où 60,53 de fer métallique). . Ce mineriai est donc très riche. Seulement sa forme granuleuse le rend difficilement exploitable par la plapart des hauts fourneaux, et cette industric minière ne pourra ètre réellement lucrative à la Martinique que si, en installant une fonderic, on arrive à produire dans l'ile même de la fonte aciérée, dont le prix de vente normal serait de 200 francs la tonne.

Revenons maintenant à la Guadeloupe, et demandons à la brochure quon nous a remise au Pavillon de cette colonie de nous renseigner sur les produits agricoles et industricls que nous royons exposés.

Les cultures adoptées dans les colonies sont, selon l'ordre de leur élendıe, de leur rendement, de leur importance et du nombre de cultivateurs qui y sont employés. les suivantes : canne à sucre, caféier, roucou, manioc, virusz d̈un pays cacayer, colonnier, vanille, tabac, épices, maïs, plantes à fécule, légumes, elc.

La canne à sucre, dont la culture a toujours prédominé, est aujourd'hui cultivée intensivement dans l'ile. C'est sur elle que devront probablement reposer lonetemps encore la fortune et le bien-itre de la vic coloniale.

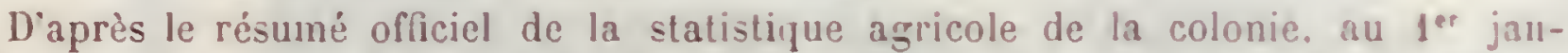
vier 1888, la culture de la canne à sucre s'étendait sur $22,9 \% 8$ hectares $\% 0$ ares et employait 71,229 cultivateurs repartis sur 6,920 propriétés rurales.

La récolte 1887-1888 a prodnit 110,000 barriques de sucre. Le caféier est après la canne a sucre la plante dont la culture est la plus répandne à la fiundeloupe. Eille occupe principalement les endroits trop montueux ou ifficiles d'accès pour y permutre celle de la canne qui varient en altitude de 200 à 600 mètres.

La culture du cafẻier est aujourd'hui presque entièrement disparue de la Martınique et des îles anglaises avoisinantes; elle a diminué pendant un certain nombre d'années à la Guadeloupe, mais elle tend aujourd'hui à prendre un plus grand direloppement. Le nombre des habititions, grandes ou pelites, où l'on s'adunue a catte culture, était, selon les données officielles, au $1^{\text {er }}$ janvier $1 S S S$ de ensemble une superficie de 3,140 hectares, et il s'y employait 6,030 cultivateurs.

La culture du caféier est facile et agréable, mais elle est lente. Il futut huoin-lruis à cinq années avant qu une plantation de ce genre soit bien étalulie et au moins de lınit a dix ans avant qu'elle soit en plein rapport. Les plantations, une fuis lich élablies, sont de longue durée. On voit dans l'ile des caféiers qui sont certuinement centenairis.

A la Guadeloupe proprement dite, se trouvent presque toutes les caféières. Les principales communes productrices de café, sont la Capesterre, les Trois-liviph s, le VienxFort, Gourbeyre, Saint-Claude, le Baillif, les Vicux-llabitants, Bonillante, la I'vinteNoire et Deshaies. Cette culture a entièrement disparu de la lirande-Terre à l'exception peut-être de quelques petites plantations éparses qui lablitent eucure dans les grands fonls des communes de Gosier et des Alymes.

Il existe en ce moment a la Guadeloupe trois varintés de cafiier : le cafiicr nndinaire, le cafëier moka et le caféier de la Libérie.

Le roucouyer (Bixa orleana) est cultivé sur 331 hectares far 1,131 cultiratenrs. répartis sur 28 propriétés rurales. Il n'existe gupre dans liile, en ce monuent. que quatre à cinq grandes exploitations où la graine est réduite en pulté (Piğnentun urucu) qui sert à la teinture. Après avoir atteint des prix excessifs et fait la fortune de quelpues 
planteurs, le roucouyer, dont la culture sétait étendue rapidement dans l'lle, causa la ruine de beaucoup d'habitants. La découverte des couleurs d'aniline fit un tort considérable à la culture du roucouyer en abaissant au-dessous du prix de revient la valeur de son produit.

La culture du roucouyer est facile et de rapide production. La plante, qui est très ornementale, commence a produire au bout de dix-huit mois ou de deux ans. Les plantations une fois bien établies sont de longue durée, et d'un entretien relativement peu couteux. On en fait deux récoltes par an; la première est la plus considérable. Outre les cultivateurs attachés aux cultures, la récolte du roucou donne de l'emploi à beaucoup de personnes de la campagne qui sont alor's occupées a la cueillelte et à l'égrenage des gousses; ce travail se fait généralement à la tache.

Le cacaoyer (heobroma cacao) est une plante d'avenir pour la colonie, mais elle a été beaucoup trop négligée jusqu'à présent, sanș doute à cause du temps qu'il faut arant qu'elle commence à produire. Il existe aux Antilles plusieurs variétés de cacaoyer, celles de la Trinidad et de Caracas sont les plus renommées. Des semences de ces variétés ont été demandées par les jardins botaniques de la Basse-Terre où elles sont cultivées de manière à les propager plus tard dans la colonie.

Le cotonier (gossypium herbaceum). - Tandis que dans les États-Unis de l'ainérique du Nord où on le cultive si largement, le cotonnier n'est considéré que comme plante herbacée et annuelle, il prend aux Intilles les proportions de l'arbuste et mème de l'arbre. A la Guadeloupe, il n'est guère cultivé que pour la consommation locale; son produit, le coton, ne sert qu'à la confection des matelas.

On peut din que l'exportation en est nulle.

Le vanillier (epidendrum vanillı, vanilla aromatica vel Mexicana). - La culture du vanillier ne tend pas à augmenter à la Guadeloupe à cause du prix avili de la vanille. A l'exception de celles de quelques préparateurs soigneux, la vanille de la colonie a peu de renom, préparée généralement en petite quantité par les cultivateurs du pays qui s'y entendent peu ou point, et qui, pour hater les revenus de leur récolte, font la cueillette des gousses avant la maturité voulue, il est rare de voir des lots de vanille ayant une apparence homogène et sans défauts.

Il y a dans l'ile deux variétés de vanillier: le vanillon ou vanille indigène, qui crolt naturellement dans les forèts, et le vanillon du Mexique qui a été introduit dans l'lle. Cette dernière variété est celle qui aujourd'hui est la plus recherchée, son produit étant plus fin et plus aromatique. Le vanillon trouve cependant un placement sur les marchés des États-Unis, oủ il est inèlé largement au tabac à chiquer.

La culture du vanillier est facile et rapide. La plante se propage par des boutures et produit au bout de deux ans.

Le manioc (jatropha manihot). - Cette plante, dont le produit principal, la farine de manioc, n'entre pour aucune part dans l'exportation générale de la colonie, est néanınoins, après la canne à sucre, celle qui est le plus généralement cultivée; la farine de manioc remplace le pain pour le plus grand nombre des cultivateurs, et se voit journellement, par habitude, fantaisie ou nécessité, sur la table des plus pauvres comme des plus riches habitants de l'ile; dans d'autres pays, à la Guyane par exemple, elle est remplacée par la cassave qui n'est que la râpure de manioc, agglutinée et séchée au feu en forme de galette et de giteaux.

Des racines tuberculeuses du manioc, on extrait encore une fécule abondante, 
connue dans les Antilles françaises sous le nom de moussache(fecula braziliensis). Cette fécule ne sert presque entièrement qu'à remplacer l'amidon dans l'empesage des vêtements. On peut cependant en confectionner des mets et des patisseries assez agréables. Quand, encore humide, on la granule, elle prend le nom de tapioca.

A l'exception du manioc doux (yatropha radice dulce), dont les racines peuvent se manger sans préparation préalable, crues, bouillies, ou cuites sous la cendre, celles des autres variétés cultivées qui sont assez nombreuses et connues sous le nom de manioc amer, sont toutes excessivement vénéneuses et causent des symptỏmes d'empoisonnement et une mort assez rapide, chez l'homme et les animaux, quand elles sont employées avant la cuisson; l'action du feu en détruit entièrement les principes vénéneux.

Vivres du pays. - Sous la dénomination de vivres du pays, sont compris non seulement le manioc, mais encore toutes les autres racines alimentaires qui sont cultivées dans la colonie, comme l'igname, la patate, le malanga, le madere, la coussecouche, etc., et qui servent largement à la nourriture journalière des habitants, sans compter cependant parmi les produits d'exportation.

Il existe peu d'habitations où l'on ne cultive exclusivement que le manioc ou les autres racines; mais sur presque toutes celles où l'on récolte du café, du roucou, ou du cacao et mẻme de la canne à sucre, il y a toujours une quantité plus ou moins grande de terrain qui est affectée à la production de ces vivres. Chez les petits propriétaires ou sur les terres occupées par des colons partiaires, hors des grands centres oú l'on ne cultive que la canne à sucre, on voit un mélange confus de cultures diverses qui n'est pas sans charmes, à cause de la variété qu'on trouve dans les plantations d'arbres fruitiers, de caféiers, de cacaoyers, de bananiers, de manioc et de toutes les racines du pays. Le produit qu'en retirent ces humbles cultivateurs n'est pas à dédaigner, car ce sont ces produits variés qui servent en partie à la nourriture des travailleurs et des ouvriers des usines et des grandes propriétés, et aussi à approvisionner les marchés des villes et des bourgs. Presque tous ces petits propriétaires ou fermiers s'adonnent en même temps à l'élevage des bestiaux et de la volaille; ce sont cux qui fournissent aux habitants des villes le lait et les œufs ainsi que la viande de petite boucherie et les légumes qui leur sont utiles.

Les arbres fruitiers de toute sorte poussent partout en profusion dans la colonie et ne contribuent pas peu parleur exubérante végétation à l'aspect verdoyant qu'ofrrent de la mer certains abords de l'île. On n'y voit cependant point de plantations régulières d'arbres fruitiers auxquelles on pourrait donner le nom de verger, chacun plante à sa manière et à sa fantaisie, çà et là, sur sa petite propriété, les semences des bons fruits qui lui tombent sous la main; hors de la localité, aucun produit appréciable n'est liré de la quantité considérable de fruits que fournit le pays; tout y est consommé sur place, il ne s'y fait point d'exportation régulière d'oranges, de figues, de bananes, comme dans les lles anglaises qui en exportent de grandes quantités aux Elats-Uuis.

\section{MADAGASCAR}

Le Pavillon de Madagascar n'est pas des plus remarquables; disons-le, on n'a pas accordé à la grande île africaine la même sollicitude qu'au Tonkin, a l'Algérie ou il la Tunisie. C'est un pavillon en bois, orné aux quatre coins de drapeaux hovas. Nous y 


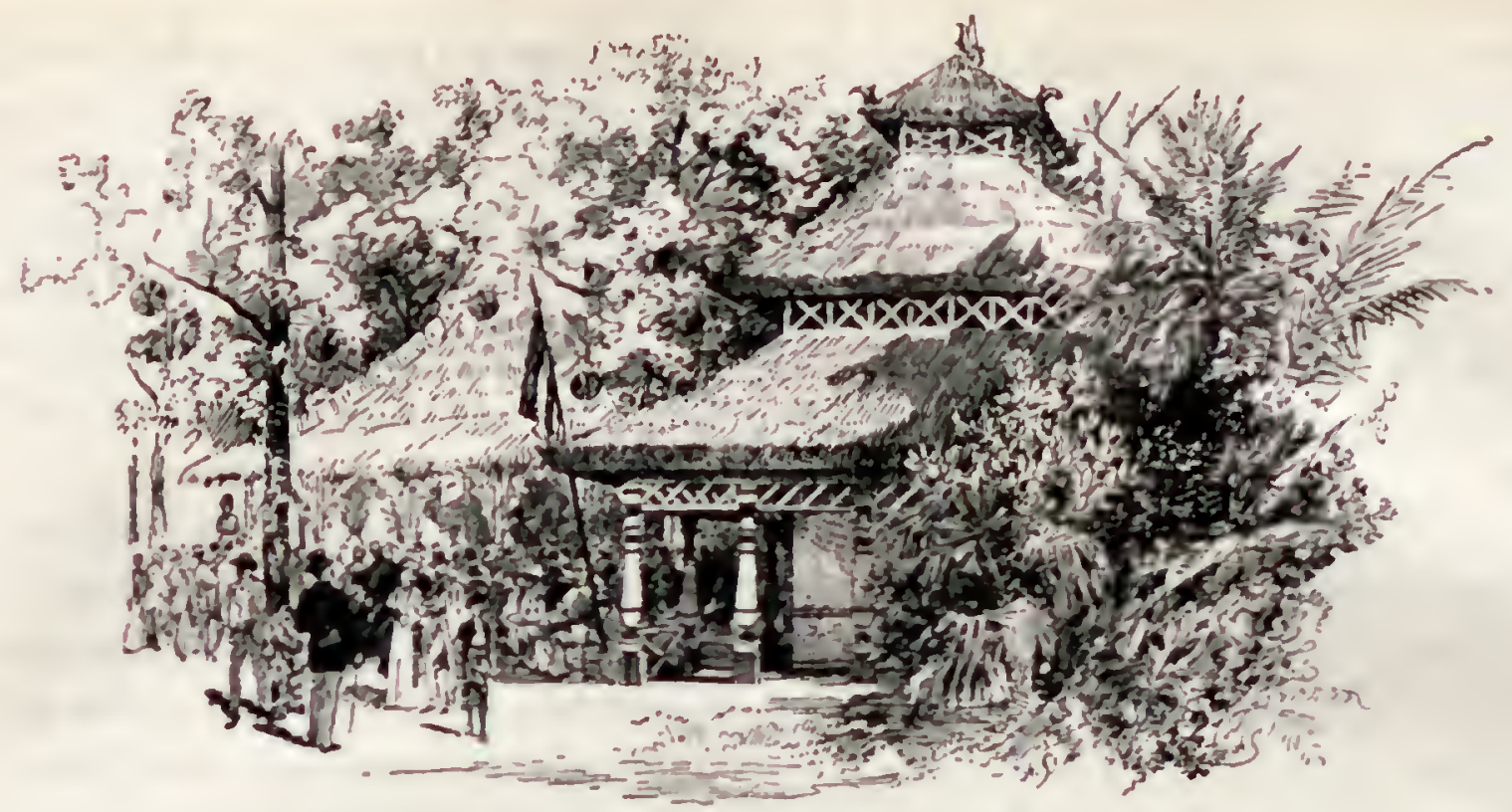

La buvelte, construite sur le modele des pagodes javanaises.

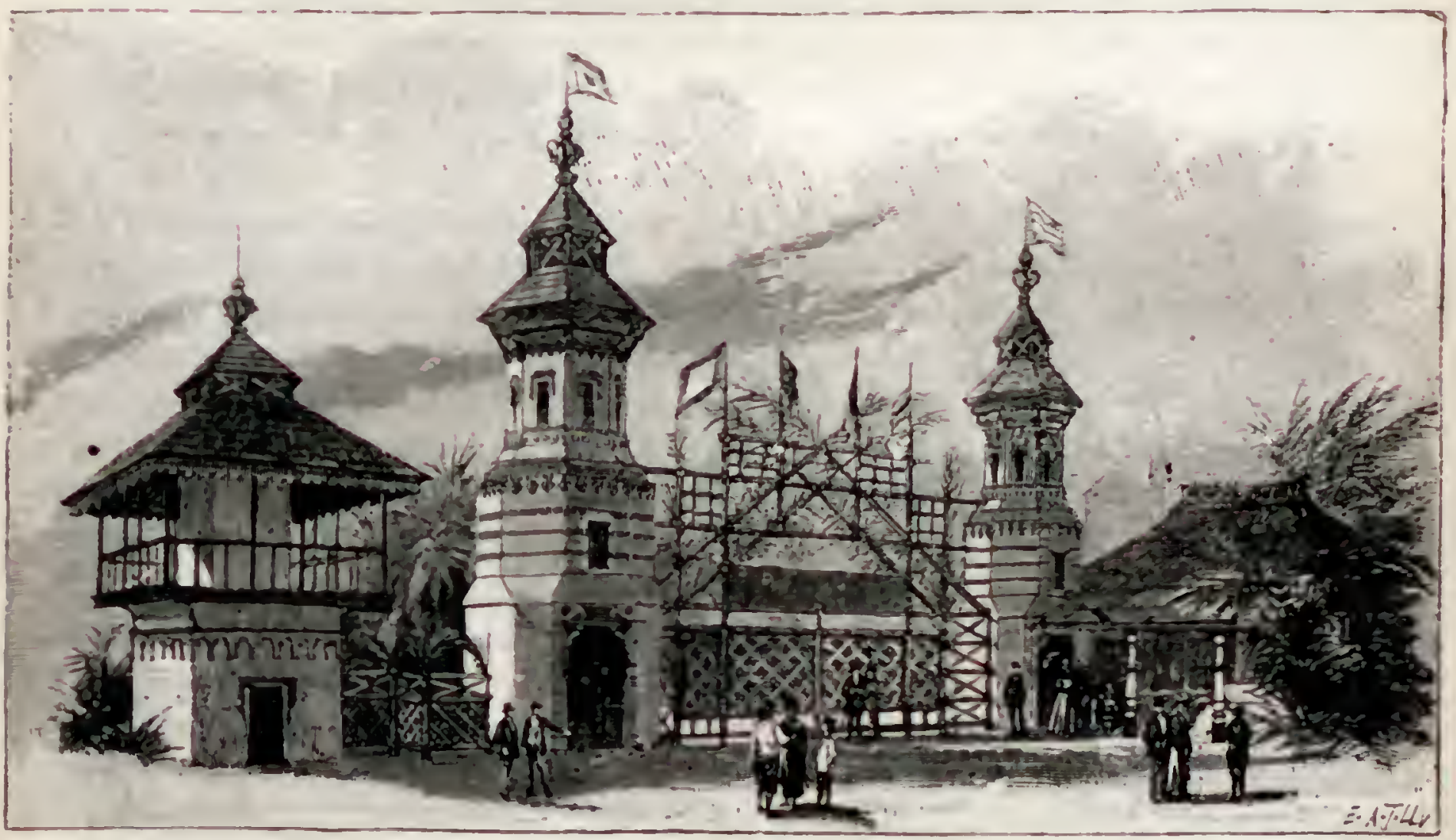

Entrée du Kampong javanais.
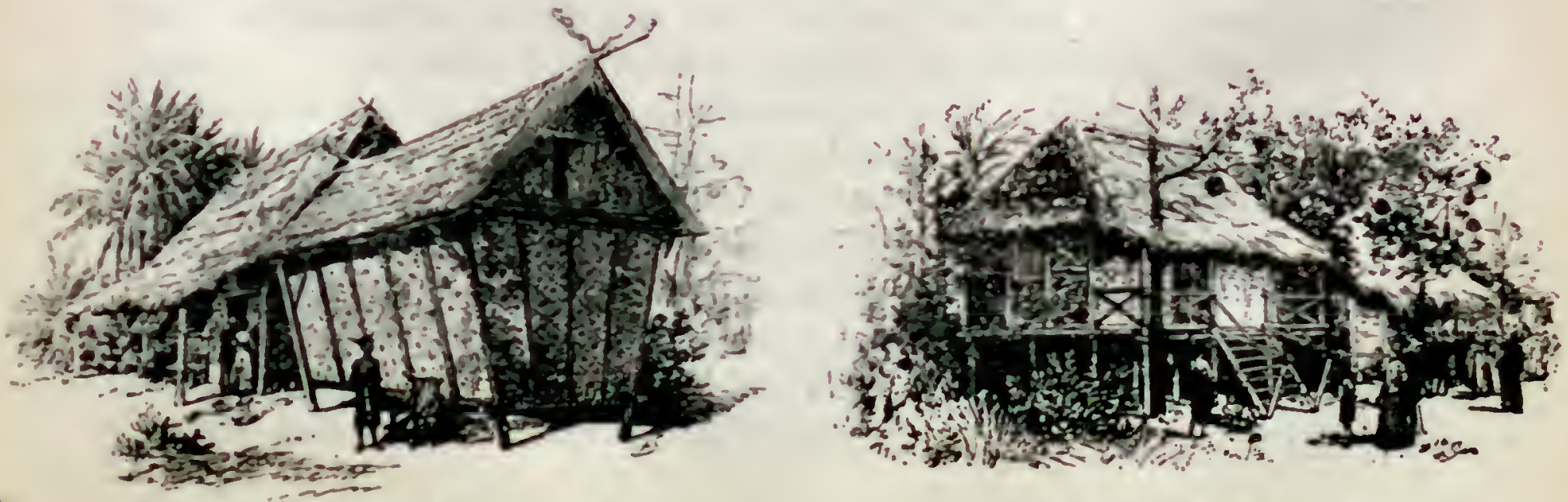

Magasin de ris.

LE KAMPOXg JaVANAIS.

Une maison sur pilotis.

Lir. 54.

Mataruss Exposinox. 
voyons un sac de riz non décortiqué, un coufin de caoutchouc brut, des gousscs de vanille, des amandes de cacao, du rafia en portières et en lanières, des chales en soie, des zagayes, des œufs d'épyornis, des nattes, des bonnets, des tabatières, des dessins, etc. Les principaux produits d'exportation sont les peaux de bouf séchécs et salées, le suif, le caoutchouc, le miel, la cire, la gomme copal, l'orseille, les écailles de tortue, les bois de construction et débénisterie. On y pourrait très hien développer par la culture le riz, le sésame, les arachides, le coton, la soie, le ricin, le café, la vanille, le tabac.

Les indigènes de Madagascar sont communément désignés sous le nom de Malgaches. M. Ilenri d'Escamps les a répartis en trois zones bien tranchées. Dans la zone orientale, il y place les Antankars, les Antavarts, les Betsimsaracs, les Bélanimènes. les Amlanivoules, les Bezouzous, les Antancayes, les Antarayes, les Antanosses. Dans la zone occidentale sont les Sakalives. Dans la zone centrale, les Ilovas, les Antscianacs, les Betsileos, les Bares. Ces peuples d'origine diverse, viennent de l'Afrique, et de la fusion des races ainsi juxtaposcees, il est résulté denx types essentiels: l'un, que M. d'liscanps décrit comme caractérisé, par un teint olivatre et des cheveux lisses, l'autre par un teint noir ou brun foncé et des cheveux crépus. "Les habitants de Madagascar, dit Grandidier, n'appartiennent pas plus à une seule et même race que l'ile entière n'appartient à un seul roi. Les races caucasique, cafre, mongrole se sont mélangées et croisées dans ce coin de terre avec les indigènes. Les autochtones sont facilement reconnaissables sur le côté est où le type s'est conservé plus pur; leur fice est ronde el aplatie, leur nez est écrasé à la racine et leur chevelure toufue ct globuleuse est en tête de vadrouille. Les peuples de la région occidentale qui, de temps inmémorial, sont en contact avec des nations étrangères, n'ont pas la laide physionomie des autres Malgaches; les navires de la Judée qui renaient jadis à Solala, les jonques chinoi=r; qui se rendaient à la côte sud-est d'Afrique, plus tard les boutres arabes aloordaient souvent la côte sud-ouest de Madagascar; aussi y trouve-t-on parmı les lıommes lilores beaucoup d'individus à type cauca-ique, à cheveux lisses ou ondulés, à teint assez clair: chez les esclaves, on constate les traces évidentes de croisements frúqummls avec les Cafres. Une troisième race bien distincte des deux aulres, qui appartient évidemment au grand tronc mongolique, a fait aussi irruption d Madagascar et s'e t longtemps conservée au centre de l'lle assez pure de tout mélinge; ce sont les lloviss. Des yeux allongés et bridés, des pommettes saillantes, des chereux lisses et raides, un teint jaune ou cuivré, ne permettent pas d'élever le moindre doute sur leur origine asiati(jue. "

Nous connaissons surtout en France les Hovas, dont le nom sest lu dans les journaux quotidiennement pendant l'expédition qui a abouti à l'établissenent de notre protectorat sur Madagascar; ils vivent dans les vallées du centre de l'lle, oil ils perpétuent la race malaise. Ils ont la taille petite, mais bien prise, le teint ulinitrr, les cheveux noirs droits ou bouclés. Ils sont agiles, intelligents, adrouts, mais lur caractère est haineux, vindicatif, bas et à la fuis orgueilleur à l'égard des faibles.

- On éprouve, dit le docteur Milhet Fontarabie, une émotion que l'on ne frut décrire en voyant ce pays, où la nature est si belle et l'homme si barba:c. La vie des campagnes vous entraine à la joie et au désir de dépenser la votre force volio jeunesse et votre intelligence, en y appelant tout le génie de l'industrie muderne; vous vous laissez bercer par de douces espérances et vous entrevoyez dans un arenir 
peu éloigné la prospérité de cẻ beau pays. Votre rêve serait achevé et ferait place à la réalité... Mais la vue de l'homme est lá pour arrêter les élans de votre imagination : cet homme, c'est le Howa. Il tient du Malais et de l'Arabe pour les traits, à part quelques variétés de types formés par le mélange de la race cafre : c'est vous dire ses instincts, ses vices, sa cruauté. Sa face fait évanouir votre rêve. Il semble vous dire : "Prenez garde à vous; quant à votre civilisation, nous n'en voulons pas : quant à votre religion, allez écouter les proclamations que l'on fait tous les quinze jours aux troupes. Et il ne faut pas longtemps pour voir, a la manière dont il traite les autres peuples conquis, que toute idée de civilisation, sous un pareil gouvernement, sera très lente à s'introduire et ne pourra se maintenir qu'autant qu'elle leur rendra

l'instant mème un service signalé pour ensuite disparaitre du moment que leur cupidité et leurs passions seront satisfaites. "

Les cases malgaches se composent d'une pièce où l'on mange et d'une autre pièce où l'on couche. Sur un vaste gril, on fait boucaner la viande, et plus ce gril est sale, plus le propriétaire est considéré, car on voit là une preuve de sa générosité à traiter ses amis. Parfois des nattes recouvrent les lattes de bambou qui, consolidées par du mortier, forment le plancher; pour meubles, un lit grossier, des tabourets de nattes rembourrées avec des feuilles sèches, des paniers, des pots en terre. Les Betsimsaracs mangent dans des feuilles de ravinala et se servent en guise de carafe d'un long bambou.

Le vètement le plus répandu est le siédik, pièce de toile large d'une demi-aune et longue d'une aune. "Ils l'attachent négligemment, dit M. d'Escamps, autour des reins, en ramenant les deux bouts entre leurs jambes et, après les avoir fixés dans les plis de la ceinture, les laissent pendre l'un en avant, l'autre en arrière, sans dépasser le genou; quelquefois, les deux extrémités du siédik sont réunies en avant comme un tablier. Les chefs s'en entourent ordinairement le corps, sans en relever les bouts entre les jambes. Le sim'bon ou simébon est la toge des Malgaches; c'est une pièce d'étofre d'environ quatre aunes de long sur trois de large. Ils s'en drapent à la manière des Grecs et des Romains ou le portent roulé en ceinture au-dessus du siédik, lorsqu'ils veulent avoir leurs mouvements libres. Tous les Malgaches des castes guerrières de l'nltérieur ont le rorps nuvert de cicatrices artificielles qui représentent diverses figures. Elles sont le résultat des tatouages qu'on leur fait dans leur enfance avec une sorte de bistouri. Les femmes portent le siédik, mais plus long que celui des hommes. Elles se drapent aussi du sim'bon; souvent aussi elles s'en enveloppent entièrement jusque sous les bras. C'est ainsi qu'on les voit sortir le matin. Vers une heure après nidi, elles se revètent de leur kantezon, espèce de corsage dont les manches descendent jusqu'au poignet et qui leur serre tellement la poitrine et les bras qu'il est très difficile de l'ôter sans le déchirer; elles le jettent lorsqu'il est sale, préférant en faire un neuf que de prendre la peine de le laver. Les satouks, coiffure commune aux deux sexes et assez semblable aux bonnets de nos avocats, sont des toques en jonc. Elles sont toujours plus larges que la tète et par conséquent fort incommodes; aussi ne s'en coilre-t-on que Dour se préserver du soleil. ,

Nous avons peu de chose à dire de Mayotte et de Nossi-Bé. Mayotte est une colonie française, tandis que les lles voisines de l'archipel des Comores sont simplement sous notre protectorat. La population indigène comprend des Indiens, des Malgaches, des Arabes, en tout 9,000 ames, auxquels il faut ajouter 200 Eurodéens. Le commerce 



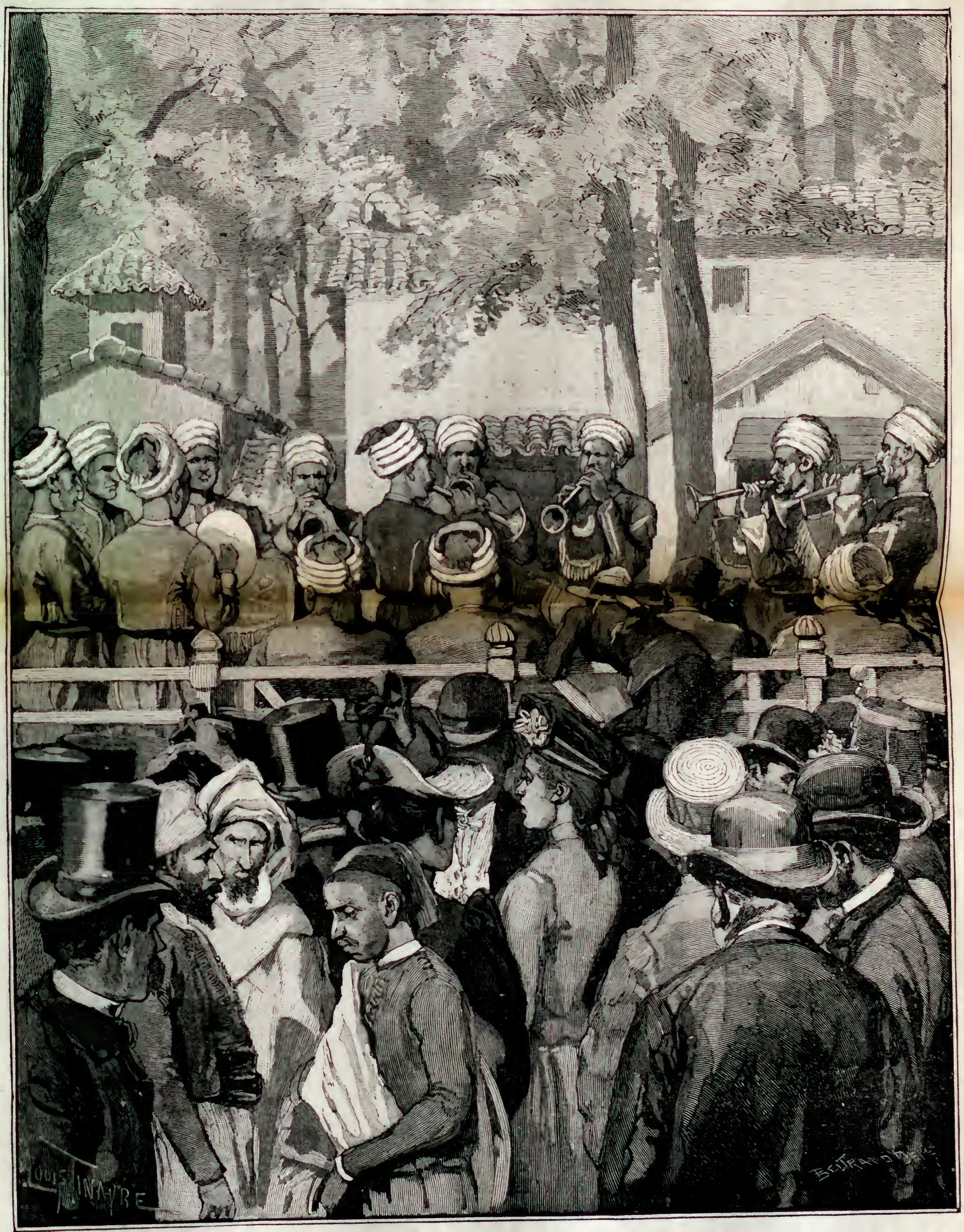


serait, relativement, assez prospère sans la crise sucrière, mais Mayotte, colonie agricole et industrielle, est trop isolée et trop peu étendue pour offrir au trafic européen un champ considérable. On y cultive la canne à sucre et la vanille; on y fabrique du rhum el l'huile de coco pourrait fournir une base sérieuse d'industrie.

Nossi-Bé, située près de la cóte occidentale de Madagascar, compte un peu plus de 9,000 habitants dont 200 blancs environ. Le mouvement commercial s'élève a

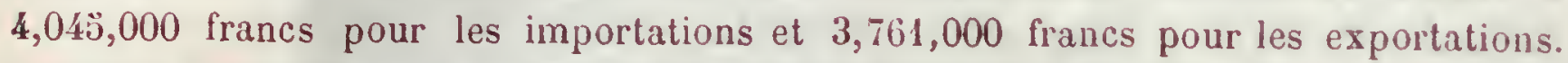
Dans ces dernières, nous relevons les articles suivants : écailles, cire, cuirs, bois d'ébénisterie, cristal de roche, orseille, gomme copal, caoutchouc, sésame, sucre, café, rhum, indigo, vanille, bois de mature et de construction, comestibles, palates, manioc, volailles, riz, rabanes (étoffes en faille de raphia), lambas (étoffes en soic), cotonnades, verroterie.

Sainte-Marie de Madagascar a un sol très fertile, sauf dans sa partie orientale qui est balayée par le vent de la mer; mais les indigènes ne tirent pas profit de celle fertilité. Ils cultivent un peu de riz, trop peu pour suffire d leur consommation, ils n'exportent guère d'autre denrée que la girofle. On donner'a volontiers un coup d'oil au racenal ou arbre du voyageur, plante qui vient tout naturellement dans les plaines de Sainte-Marie: le tronc et les feuilles de cette plante servent à construire des cascs relativement confortables. Pas d'animaux malfaisants, sauf peut-être des serpents, mais pas de crocodiles commeà Madagascar. Par contre, les requins abondent sur les cóles.

A quatre cents milles anglais à l'est de Madagascar se trouve une autre possession française, la Réunion, d'une superficie de 2,3011 kilomètres carrés, et d'une population de 181,000 Ámes. La majeure partie des terres cultivées est consacrée à la canne à sucre, plantée en mortaises ou petites fosses rectangulaires, et dont le rendement est de כ̋ว,000 à 100,000 kilogrammes par hectare. Nous avons vu, en dehors du sucre, des échantillons de café, de manioc, de maïs, de haricots, de pommes de terre, de céréales diver'ses, de vanille, de girofle, de muscade, de tabac, de plantes à essence, de coton, de quinquina, de cacao.

\section{LTDE FRANCAISE}

Les établissements français dans l'Inde se composent de fractions de territoire isolées les unes des autres et dont la superficie totale est de 50,803 hectares. Ce sont : sur la côte de Coromandel, Pondichéry et son territoire, Karikal; sur les côtes d'Orixa, Yanaon et la loge de Mazulipatam; - sur les côtes de Malalá, Mahé et la loge de Calicut; - dans la Gadjirah, la factorerie de Surate; - au Bengale Chandernargor et les loges de Cassimbazar, Janğdia, Dacca, Balassare et Patna. Le seul marché commercial, c'est Pondichéry, chef-lieu de l'Inde française. L'exportation des arachides y a pris une certaine extension au détriment de l'indigo, mais on cultive aussi le riz en paille ou nelly, le bétel, le tabac, le coton, la canne d sucre. Pondichéry a dans ses environs une filature de cotonnades bleues (guinées), des teintureries, des taneries, des forrs a briques, des huileries. L'exposition de l'Inde française, on le conçoit, ne pouvait qu'occuper une place secondaire. 


\section{OCÉANIE FRANCGAISE}

Nous possédons en Océanie un certain nombre d'archipels, dont les plus importants sont la Nouvelle-Calédonie et les Taïti. Les indigènes de la Nouvelle-Calédonie, qui sont représentés sur l'Esplanade par un village entier, sont les Canaques. Ils ont la peau couleur chocolat, les pommettes saillantes, les yeux noirs, la conjonctive oculaire rougeitre, les dents blanches et proéminentes. "Les femmes, qu'on appelle popinées, sont très laides en général, dit M. Ch. Lemire. Leur chevelure courte et crépue comme la chenille d'un casque de carabinier, leurs oreilles déchiquetées, leur's traits déformés, présentent un aspect peu séduisant. Souvent elles blanchissent leur chevelure avec de la cliaux. Elles sont flétries de bonne heure, tant par suites des privations qu'elles endırent que des rudes travaux auxquels elles sont soumises. "Vètu d'un pagne, quelquefois aussi d'un pantalon, mais plus souvent complètement nu, orné de jarretières qui ne retiennent aucune ombre de bas, couvert de verroterie et de menus bijoux, le Canaque n'est pas beau à voir. M. Lemire rapporte que, dans l'intérieur, on rencontre des indigènes portant un gilet et un chapeau de haute forme, mais pas de pintalon, ce qui évidenıment doit ètre d'un effet bizarre. Les femmes ont des colliers, des bracelets, et, pour vètements une ceinture, sauf à Nouméa, où elles se sont habituées à porter un long peignoir. Elles fument avec persistance.

La nourriture des Canaques se compose d'ignames, de toros, de patates, de cannes, de poissons, de coquillages; ils sont cannibales, mais l'extension de la colonisation met fin peu à peu à cette honteuse coutume. Les cases, en forme de niches, sont en écorce de niaouli, avec toit d'herbe; elles sont mal éclairées par une ouverture unique et étroite; on y trouve des poteries, des haches, des sagaies, des casse-tète en bois, des frondes. Les habitants des plaines font travailler leurs femmes à la culture de la terre et vivent daus l'oisiveté la plus complète. Les indigènes établis sur les côtes construisent des pirogues doubles qui résistent très bien aux flots, et sur lesquelles ils voyagent avec leurs femmes. Ils s'occupent très activement de la peche, et les femmes font fumer les poissons qu'ils échangent contre les légumes et les fruits de l'intérieur. Les Canaques qui confectionnent les pirogues sont tatoués, c'est-à-dire sacrés; ils ne s'occupent que de leur art, et tous les membres de la tribu contribuent à leur bien-être. Le chef de la tribu exerce un pouvoir absolu et prend toutes les décisions importantes; il surveille les chefs des petits villages qui dépendent de lui directement. Le Canaque n'a pas de religion proprement dile; il croit aux esprits et a toujours soin de mettre à la portée des tombeaux des personnes nouvellement décédées les aliments quil croit nécessaires aux besoins du mort. Les inhumations se font la nuit, à la lueur de torches résineusis.

l.ar Souvelle Calédonie est l'une des tles les plus considérables de l'Océanie. Son climat est l'un des plus sains que l'on connaisse, gråce aux vents alizés qui chaque jour balavent l'ile dans le sens de sa longueur. Les cultures sont celles du maïs, des haricots, du cafe, du ri\%, du manioc, du tabac, de la canne à sucre, des ananas, des cocotiers, des lizumes, elc. 11 y a des mines d'or, de cuivre, d'antimoine, de plomb, de nickel, de chrume, de cobalt, de houille. L'industrie est en voie de formation. Les travailleurs indigìnes ne sont malheureusement pas d'un grand secours. Ils travaillent par boutides, 
quand le genre de travail leur plaît. Le Canaque est naturellement indolent, réfractaire à toute occupation de longue durée, et, comme il n'a pas de désirs à satisfaire, il n'est pas aiguillonné par la nécessité.

Taïti n'est pas moins renommée pour la salubrité de son climat, et la culture y est la même qu'en Nouvelle-Calédonie. Les orangers y viennent mème naturellement. La pècherie des perles est l'industrie la plus florissante, on peut mème dire qu'elle est la seule qui soit vraiment prospère. Sur les indigènes taïtiens, voici ce que dit M. Aylic Marin, un de nos compatriotes qui les a visités : "Les Océaniens sont les privilégiés du ciel; ils se laissent vivre. Leur existence est toute de bonheur et de plaisirs faciles. Ils ont la physionomie riante et bonne parce qu'ils ne connaissent pas le souci, le front élevé et fier parce qu'ils se sentent libres. Le jour, ils se couchent à l'ombre et s'endorment; le soir, ils chantent de vieux hyménées, chansons de guerre ou damour, dansent la oupa-oupa ou composent des poèmes rythmés. Souvent, quand la nuit est venue, ils discutent la Bible ou écoutent les récits du conteur de la veillée. C'est une race dindolents et gais troubadours, entretenus par la nature. Rien de plus simple que leur cuisine ordinaire; elle est encore à peu près la mẻme qu'au temps de Cook et de Bougainville. Pour s'en convaincre, il suffit d'entrer dans la première case venue. Le sol, dans la maison, est jonché d'herbe épaisse; des nattes, parfois un lit grossier. et des malles fermant à clef, composent le mobilier. Une remarquable propreté distingue ces habitations. Les Taïliens mangent dehors, à l'ombre des cocotiers et des mailorés; ils cuisinent en plein air. La viande de porc, la seule qui soit mangeable dans le pays, est cuite à l'étouffée; un trou est creusé en terre et garni de cailloux rougis au feu; la chair, enveloppée de feuilles de bananier, y est placée el recouverte d'une autre couche de pierres brulantes; une couche de plantes aromatiques et quelques pelletées de terre ferment ce four improvisé. Quand le soleil marque l'heure du repas, la famille sassied en rond et le père dit la prière. Les mets sont apportés par des jeunes filles au front couronné de fleurs; des feuilles servent de plats et d'assiettes. On se couche alors pour manger à la manière antique. A côté de la viande et du feï bouilli est placé, devant chaque convive, une calebasse pleine d'eau oủ il trempe ses doigls à chaque instant. D’autres récipients contiennent soit le miti-miti, sauce aigrrelette dont on assaisonne le poisson mangé cru, soit le lait de coco, boisson habituelle. Quant au dessert, il suflit d'étendre la main au-dessus de sa tète; les oranges, les mangues, les bananes, mûrissent aux arhres pour tout le monde; les ananas sortent de terre d̀ vos pieds. . Les Taïtiens ont une grande force musculaire dont ils ne font guère usage, puisqu'ils n'ont pas besoin de travailler pour vivre agréablement, la nature prodigue leur fournissant amplement toutes les choses nécessaires à l'existence.

Aux îles Gambier, on se livre presque exclusivement à la péche des hultres perlières. Aux Tubuaï, on confectionne des gateaux de l'arrowroot. Aux Marquises, il y a beallcoup de bois de construction, des bœufs, des porcs, des moutons et de nombreux objets d'exportation. Quant aux Touamotou, elles n'ont pas, pour le moinent, d'importance économique, mais ses indigènes peuvent nous intéresser, l'Exposition coloniale ayant fait une large place à l'ethnographie. M. Bouchon-Brandely cliargé, en 1884, par le ministre dela Marine et des Colonies d'une mission d'étude aux Touamotou, en a rapporté de précieux renseignements. D'après lui la population des Touamolou se compose d'individus robustes, bien proportionnés. Les femmes sont gracieuses et grandes; elles ont une abondante chevelure lisse, noire et épaisse dont elles prennent grand soin. 


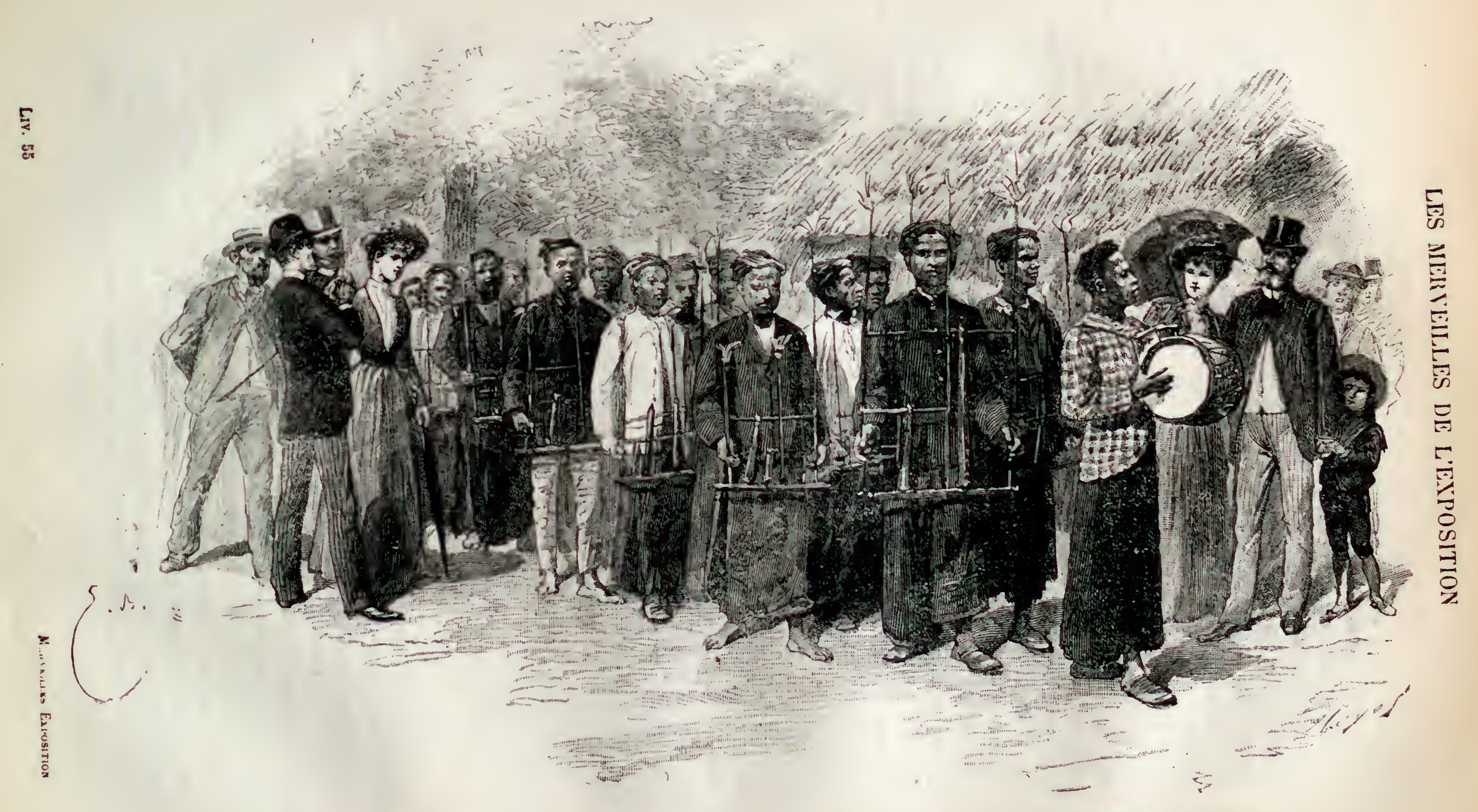

A KA 
Elles sont l'une propreté remarquable. Chez le l'uimotu, le nc\% est lo flus solurent épaté vers le bout; les narines, dilatées, se dessinent nettencnt sur deu lères charnues. Les yeux saillants et ombragés de longs cils unt choz les foumes une pxprosion à la fois douce et saurage. Les hommes compent leurs cheveux a jü jurb a la mode européenne el conservent rarement leur bajlue qui est peu fumbie. Jes mirtis, et surtout les demi-blanches, sont d’une beauté remarquable. La durée de la vio des indigines est a peu pris la mème qu'en Europe, mais l’age des vieillards est diffirile a appricier sur l'aspect de leur physionomie; les cheveux deviennent raremrut haurs et les ril s sont peu profondes et peu visibles. La sénilité est rare chez les vieillarls: peu derien. nent infirmes et tombent dans une désrépitude complete. - Noins lien partrage yue ceux-ei, relatirement à la conservation des agréments physiques, Ins frmmcs sont considérées comme rieillies dès l’age de trente à trente-deux ans. Du moins, à dater de ce moment, faut-il que la fenme abdique toute prétention al la jeuneses et a la siduction. Résignée d'avance a son sort, elle occupe sa cunlition nouvelle saus amertume et sans étonnement, dédaiguant de recourir aux artifices de la co juellerir puur dérul... a la vie frivole qui s'enfuit un jour encore, n’attendaut point non plus qun le dédnin urs hommes la vienne avertir que la place est dorénavant a de plus jeuns Les deuses fơles, les chants entrainants ne l'intéressent plus aussi vivement. Lille mélera sa viux a un clicur upaupa. Elle ne prendia plus part a la danse passionnee de la himene, inais vit désormais davantage en son intérieur, se confine de plus en plus dans sa cnęo à mesure quelle vieillit, se livre a quelques travaux sêdentaires, donne ses soins tux enfants. Cette déchéance prématurée, cet ostracisme lui paraissent la cliose la filus naturelle du monde; elle ne cherche ni à protester ni à s'y soustraire. F Fon relatious commerciales avec les Européens et sous l'influence de l'administratun frangagam, le Touamotu mesure le temps comme nous; mais, en ce qui le concerne et surtisut a cause des lacunes de l'état-civil, il n’a guère conscience de sa durée II est rarr qưu homme de cinquante ou soixante ans sache exactement son Age. Si un le lui demaidr. il répondra : "Sous tel commandant j'étas jeune homme. Sous Pourab II je une surs marié. , C’est en gẻnéral de cette façon qưils apprécient le tomps écuulé.

\section{CONGO FRANCAIS ET (I.IBUYY}

On désigne sous le nom d'Uuest "fricuin ou Cosljo frasenis uns colonie de 500,000 kilomètres carrés, qui ne nous a coulé presigue rien, grace an to lonement de Savorgnan de Brazza. Son climat cliaud et humide g dévoloppe une vígitatiun uncr. veilleuse, et si nous sarons en organiser l'exploitation, "'est d liru remultre a dus naturels sous notre direction le soin de mettre en villeur une terresur la ju•lle l'liurvpéen ne peut virre, nous en tirerons grand profit: bois de construction et de fonture. café, coton, canne à sucre, mais, banane, igname, patate dourp. cunere, tami. citrouilles, manioc, ananas, graines oléagineuses, chanbre indien, tuhac, ris, raran. poivre, gingembre, muscade, ranilie, arbre a suif, arbre d rimene, mbre a lmurm. palmier, bananier, gomme copal, etc. Le pays est peuplí d'éfiploul-, de lhopards, de gorilles, d'antilopes. L'hippopotame y' est iris comm. ain-i fue plu-mors espéces do 
singes. Dans l'iutérêt de l'unité de direction, le Galıon a été rattaché administratıvement au Congo français.

Les organisateurs de l'Exposition coloniale ont eu l'idée très heureuse de réserver un emplacement pour lí construction d'un village indigène. Les naturels de cette partie de l'Afrique ont été classés de la manière suivante par M. Hamy, qui les subdivise en trois grands groupes. Le premier de ces groupes, rattaché étroitement aux négrilles ou pygmées de l'Afrique équatoriale, dont les Akkas de Miani et de Schweinfurth sont la tribu la plus considérable, comprend les Okoas de l'estuaire de l'Ogooué, les Baboukos, et les Bungos, disséminés en petits groupes chez les Bo:llous, les Javis, les Adoumas, etc., du littoral de l'Ogooué. Les négrilles de l'Ouest africain, très peu nombreux d'ailleur's, ont la tẻte relativement très grosse et les łiamètres anté-postérieurs racculrcis, la face munie de machoires puissantes. Dans le second groupe viennent se placer les vrais nègres du pays, qui se rattaclıent a lit grande famille Bantou. L'ensemble de ces races juxtaposées, sous ce nom commun de Bantous, compte dans lesterritoires de notre Ouest africain plusieurs subdivisions assez marquées. La plus septentrionale, qui duit son nom de Bengo au peuple de l'ile de Corisco, comprend dans un ineme groupe les Okolas, les Yalimbongos, les Apingis, les Okandas, les Osyebis, les Adoumas et les Shébés, tribus qui sont échelonnées sur les rives de la grande corrbe de l'Ogooué. Une deuxidme subdivision, celle des Pongoués de l'estuaire du Gabon, renferme les Oroungons du cap Lopez, les Camas de l'estuaire du Fernand-Vaz et du littoral silué au sud de cet estuaire, jusque vers la rivière Sette, les Tontrou. joulis. les Adjuumbas, les Galoas, les Smengas et les règres du Bas-Ogooué et ri. lacs qui s’y déversent. Les Bengos et les Pongoués sont de véritables nègres et ils t.e diffèrent entre eux que par la beauté relative des Pongués qui a acquis en particulier aux Gábonais une réputation générale sur le littoral. Qunand on arrive au troisième groupe des Bantous de l'onest, les caractères généraux se modifient à tel point que l'on pourrait les clasier avec les Congos proprement dits, qui s'éloignent beaucoup des traits de la race nègre. Ce groupe se remarque à partir du point de la cote situé au sud de la rivière Setté, et continue avec les Mayoumbas, les Dibeias ou Sveias, et les Svilis. Les renseignements sur la population de l'intéricur manquent, pour que l'on puisse douner une limite orientale à ce groupe. La description physique des noirs des sources de l'Ogoou i et des bords du Congo n'a pas encore été donnée; on sait seulement qu'iu point de vue de la langue ils se rattachent aux Bantous.

Le troisière grand groupe qui se détache nettement dans l'Ouest africain est celui qui est formé par toutes les tribus d'immigration récente, descendues du nord-est et qui sont arrivées, sous le nom de Pahouins, jusqu'd l'estuaire du Gabon. Dans le bassin de l'Ggomué, on en trouve deux subdivisions, les Bakalais, précédemment arrivés et (pıi se sont installés jusquaux sources de la Setté, et les Osyebas, venus beaucuup fllus tard, qui, après avoir expulsé à peu près tous les nègres étalılis au nord de l'u zuoué. ont élé arrétés sur le burd du fleuve. Après ces Osyebas, d'autres conquérauts relièrent ces postes avancés, à travers le continent, aux Mombouttous, qui funt visblement partie du mime groupe ethnique.

Celu po-e, occupons-nous plus spécialement des Fan ou Pahouins, puisque nous a vons, à l'lixpusition, une colonie de ces indigènes. Les hommes, grands chasseurs, sont maigras et élancés. Leur front est bombé, leur regird fier, leur déurarche assurée. Les femmes au contraire, qui suppostent tout le poids des charges domesti- 

LES MERVEULLE DE L'EXPOSITION

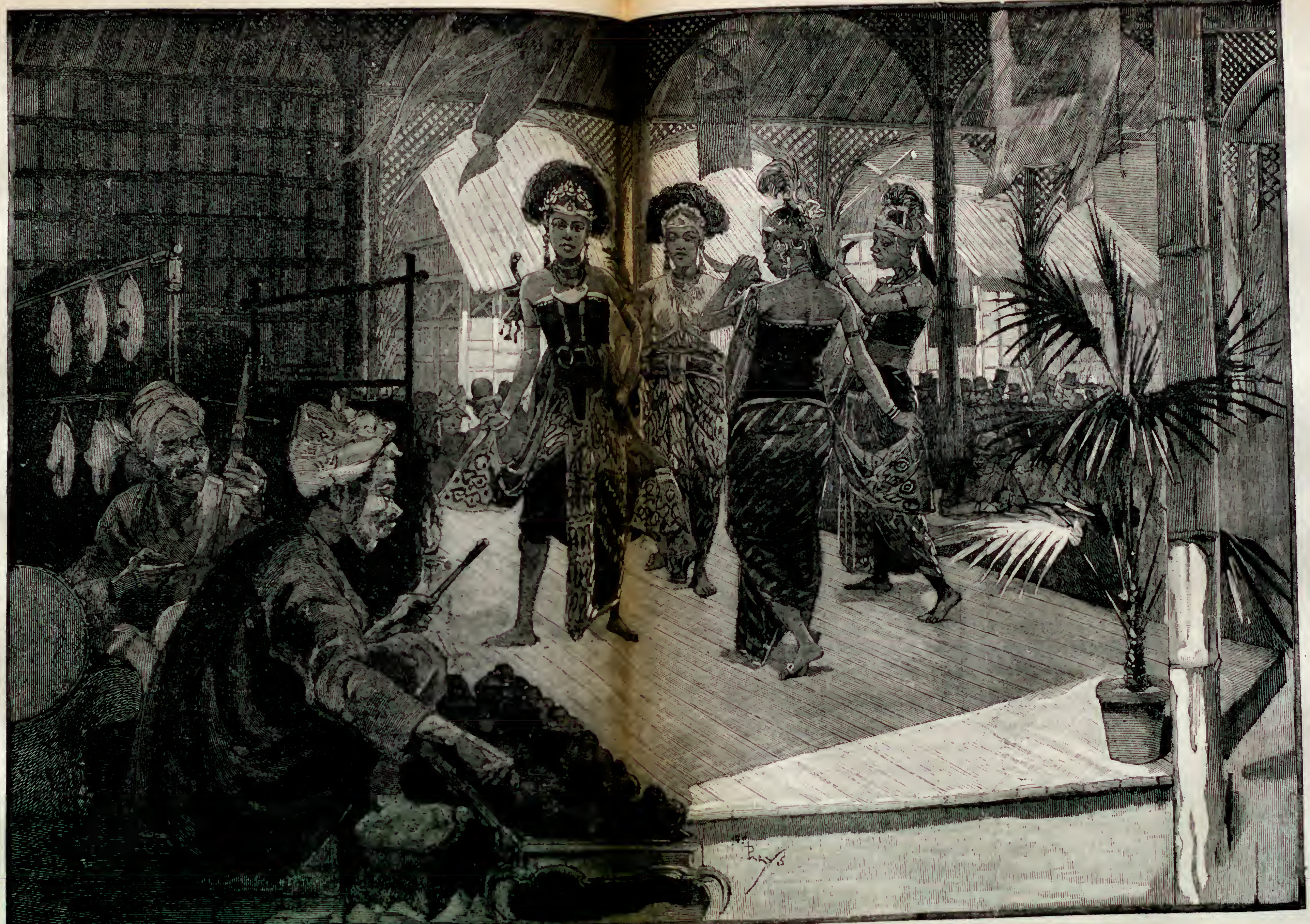


ques, sont lourdes, sans grdce. Ils aiment à se couvrir d'ornemeuts : pertes, phumes, herbes, verroteries, etc. Ilsétaient autrefois anthropoplatges, mais ils perdent peu à peu leurs habitudes sanguinaires à notre contact. Les Pahouins sont les plus industrieux des Gabonais. - Ce sont, dit E. Reclus, des forgerons liabiles, des armuriers ingénicux, ayant découvert l'art de fabriquer des arbalites d'ébène. dont its se servent pour la chasse aux singes et aux antilopes, que la ditonation des fusils effuruuche; its en trempent les flèches dans un poison tr's subtil, qu'ils appetlent omai. Comme poliers ils sont également renommés, et, dans le voisinage des Europrens, ce sout les uneilleurs jurdiniers: ils sont l'espoir de la colonie. Seuls entre luus les indigènes de la contrée ils connais-aient l'usage de la monnaie; pour eux le signe représentalif des valeurs était un petit disque de fer, qu'ils attachaient en ligatures comme tes Chinois. I.es Pahouins du liomo, encore dans l'état de transition entre la vie du chasseur uomade et celle de l'agriculteur sédentaire, entre l'ancienne condition de guerrier's libres et celle de fournisseurs des Frangais de Libreville, prentent soin d'avoir toujours deux habitations éloignées l'une de l'autre. Ils ont le village riverain, lien placé pour le commerce, mais exposé aux altaques des chaloupes de guerre. et le villago furestier, où ils se réfugient à temps, avertis par le tamtam ou par la trumpe d’ivoire yu und un danger les menace: quon brule leur village du bord de la riviser, peu leur imyrurte, c'est dans la demeure de la forèt qu’ils conservent leurs objets précieux; ell qu lijues jours les cases incendiées sont rebaties. Tuus les villages sout disposés de manìre a ne pouvoir être surpris brusquenent et des gardiens veillent toujours aux d ux extı'bmités de la rue. Au centre s’élève la case aux palabres, où vienucint ronférer lés guer. riers : quiconque d la force de porte: les armes a le droit de faire culudre sun conseil. ,

Par le nombre, les Bou-Banghi ou Alfourous du Congo français durvent etre placés à côté des Pahouius. Ils ont de grandes aptitudes pour le commeree, et, dans un autre ordre d'idées, ils donnent le ton aux élégants de la région, taut ils tısent avec habıleté leur chevelure et se tatouent le corps avec grace. Les femmes se mollent aux jambes et au cou de lourds bijoux de cuivre massif, qui rendent leur dénurche cmbanrussée.

\section{LES COLONIES HOLLANDAISES. - KAMIUX゚ J.A I.MIS.}

Nous aurions beaucoup ì apprendre des llollandais en ce qui concerne l'organisa. tion de nos colonies, car ils ont depuis trons siècles fail d'utiles expériences daus tos lles de la Sonde, et si leur domaine d'outre-iner n'est plus aussi cunsidérable qua autrafois, si en .Imérique ils n’ont plus que Surinam et Curaģau, its unt encore dans les Indes orientales un einpire colonial immense. Les lles de Java et de Madura unt 132,230 kilumetres carrés, une population de plus de 20 miltions d'indigènes, et c'est à 1,5206,000 kilomètres carrés (avec $8,400,000$ indigèues) qu'il faut évaluer ha superficie de Sumatra, de Burıén (partie néerlandaise, des Batka, de Billiton, le Riuuw, de Célibes, des Moluques, des pelites iles de la Sonde, de Timor (partie névelan láse, ol de la iuu. relle-Guinée partie néerlandaise). A la population indigl'u:, il faut joindre 46.837 Luropcens, 364,000 Chinois, 16,000 Arabes el 800 llinduu-.

" La domination néerlandaise est très inégalement établtr sur ces dillirentes possessions. A Java elte est complete, quoi quion y ail laissé subsistur tes deux princi- 
pautés de Sourakarta et de Djokjokarta. A la pointe nord-ouest de l'île de Sumatra, elle s'est heurtée à la résistance des Atchinois qu'elle n'a pas réussi et qu'elle a même pour le moment renoncé à dompter. Ailleurs elle s'est bornée à imposer sa suzeraineté. Dans la Nouvelle-Guinée elle est à peu près nulle.

- Le gouverneur général est un véritable vice-roi. Cette omnipotence était indispensable jadis, quand il s'agissait de régir à de pareilles distances un empire aussi vaste Elle est aujourd'hui restreinte en fait par la possibilité de correspondre télégraphiquement avec le ministere et en droit par les prérogatives conférées aux États-Généraux On a cru néanmoins devoir la laisser subsister.

- La règle est toujours qu'en cas de périls ou d'urgence, le gouverneur peut adopter toutes les résolutions qu'il jugge nécessaires. C'est, bien entendu, sols sa responsabilité qu'il a cette latitude; il est obligé de rendre compte au roi de l'usage qu'il en fait; en cas d'abus les sanctions de la responsabilité ministérielle lui seraient applicables. A la force qui résulte de l'étendue des pouvoirs s'ajoute celle qui vient de la durée: l'usaze est de laisser chaque gouverneur en fonctions pour un espace de cinq années.

- Tout en croyant utile d'établir une autorité aussi considérable, on a tenu à placer auprès d'elle un corps consultatif destiné à la conseiller, à l'avertir et à la prémunir ainsi contre l'irréflexion et l'entraînement. Je veux parler du Conseil des Indes dont l'avis est tantôt facultatif, tantôt obligatoire. Cet avis est obligatoire pour toutes les résolutions d'une natıre grave et pour les nominations importantes.

* Pour l'exercice de son autorité, le vice-roi a sous ses ordres un secrétaire général et cinq directeurs qui sont de véritables ministres. Les cinq départements entre lesquels !'administration a été repartie sont les suivants : $1^{\circ}$ la Justice; $2^{\circ}$ l'Intérieur; ¿' l'Instruction publique, les Cultes et l'Industrie; $4^{\circ}$ les Travaux publics; $3^{\circ}$ les Finances. Chacun des directeurs a $\$ 0,400$ francs de traitement.

- Le commandant de l'armée et celui de la marine font fonctions de directeurs pour les services militaires de terre et de mer qui forment deux autres départements.

- A moins de motifs de santé ou tout à fait exceptionnels, ce n'est qu'après 15 ans de séjour que les fonctionnaires peuvent obtenir une autorisation d'absence en gardant une partie de leur traitement.

- Pour les indigènes, la règle est de leur appliquer leurs lois et leurs coutumes en tant qu'elles ne sont pas contraires aux principes généraux de l'équité ; et celte application est confiée à des tribunaux composés en totalité ou en majorité d'indigènes. On a mème laissé subsister en certaines matières spéciales des juges ecclésiastiques. Mais toutes ces juridictions locales sont instituées par l'autorité néerlandaise. Les principales d'entre elles, les landraden, sont mème présidées par le résident ou par un magistrat assisté d'un greffler européen.

- Parmi les populations que comprennent les Indes Néerlandaises, les unes ont gardé leur's souverains les autres sont administrées directement par le gouvernement colonial. La liste est longue des princes et des chefs qui, n'ayant été maintenus que moyennant l'acceptation d'un lien de vassalité plus ou moins étroit, ont réussi à garder sinon toute leur autorité, du moins une partie des profits et des honneurs qui y étaient attachés. Les deux plus considérables sont les sultans Sourakarata et de Djokjokarta. En dehors de ces deux princes qui sont les plus connus, il y en a un très grand nombre d'antres plus ou moins importants à Sumatra, à Bornéo, dans les Moluques, d̀ Celebes et dans l'archipel de Timor. La situation de chacun de ces vassaux est diffé- 
rente et dépend des conventions qui sont intervenues entre lui et la Néerlande. Mais le gouverneur général est leur supérieur à tous et leur subordination est complète; ils ne sont respectés qu'à la condition d'obéir aux directions qui leur sont données. Le total des listes civiles ou traitements qui leur sont payés s'élève à la somme de $5,860,000$ francs.

- Les portions de territoire occupées directement sont administrées par des régents indigènes qui ont au-dessous d'eux des chefs de districts pris parmi les habitants et des chefs de villages élus par la population. Les régents sont choisis dans l'aristocratie locale el autant que possible dans les mèmes familles, mais sans autre chance d'ètre conservés que de se conformer à toutes les indications du pouvoir.

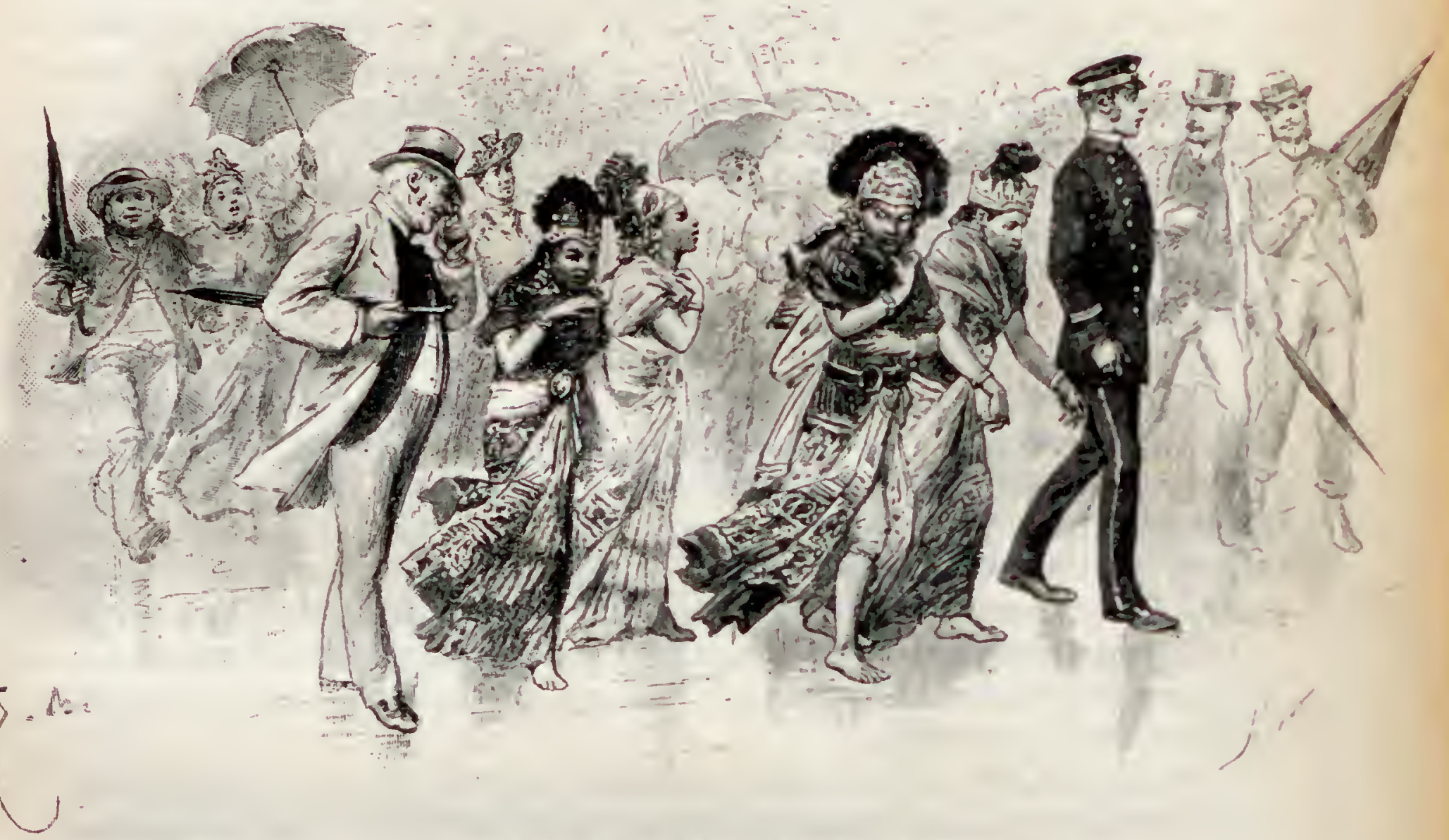

APRÈS LA REPRÉSENTATION

- Les étrangers, Orientaux, Chinois, Maures ou Arabes ont également des chef: spéciaux qui sont leurs compatriotes. C'est, du reste, pour l'autorité néerlandaise une règle traditionnelle d'éviter autant que possible de se faire sentir immédiatement aux populations assujetties; elle s'attache à n'exercersa domination sur elles que par l'intermédiaire de leurs propres chefs. Mais elle a soin de nommer elle-méme ces derniers ou de garder tout au moins le droit d'approuver leur nomination de facon à étre certaine de leur entière docilité.

Tous ces renseignements nous sont fournis par une brochure de M. Louis Legrand, ministre de France à la llaye, mais nous craignons que le visiteur ne prenne moins d'intérêt à celle grosse question d'administration qu'au plaisant spectacle que lui offrent les danseuses du Kampong ou village jaranais. Dans ce village, des Malaises vendent du cacao, des Malais tressent des chapeaux de paille, des Sundanaises au teint cuivré peignent à la cire des dessins rariés sur cette toile spéciale el barriolée (batili) 


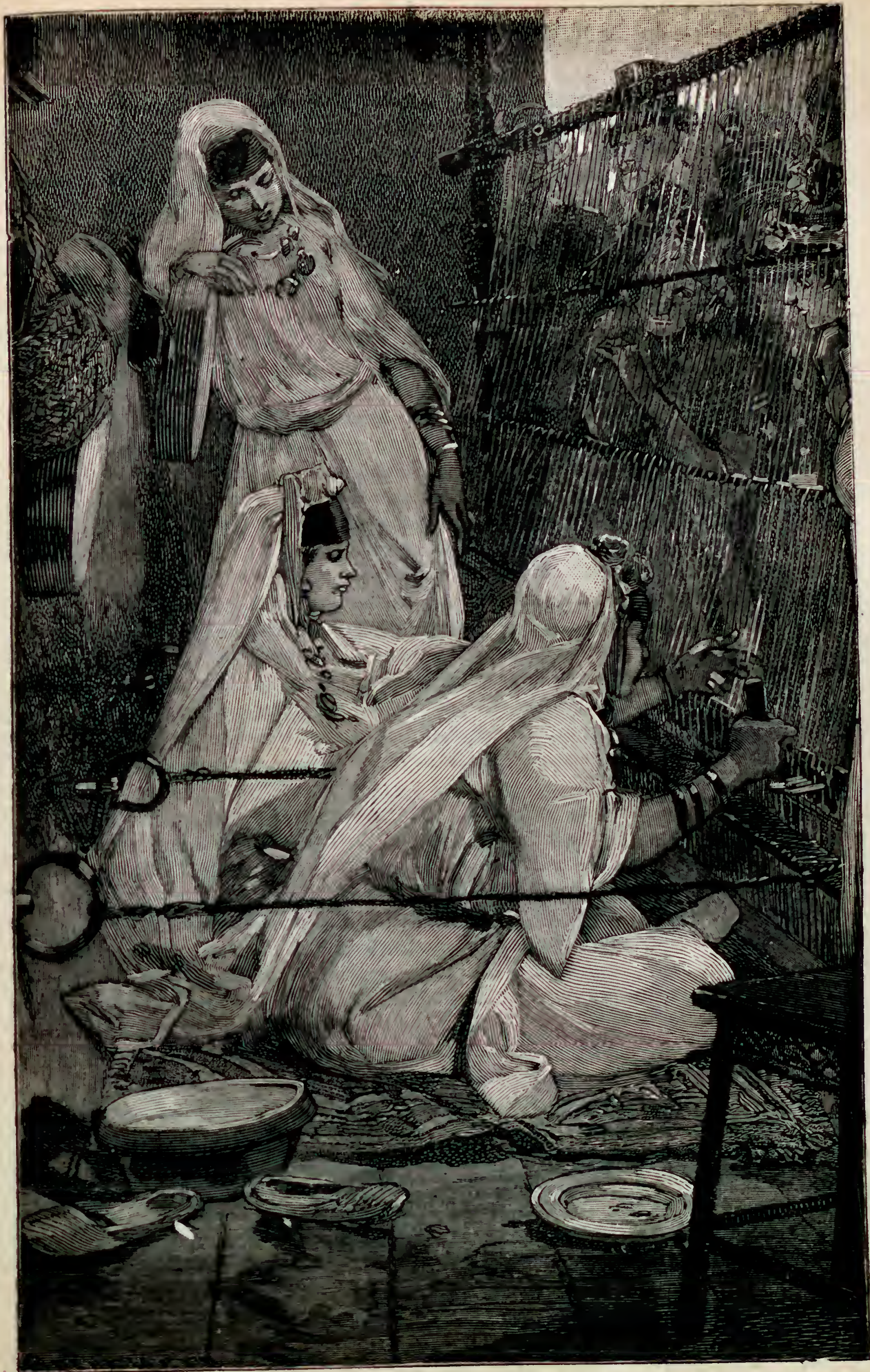

LES TISSEUSES KABYLES A L'LiSPLANADE DES INVALIDES. 
dont on fait des pantalons et des ceintures. Un bruit monotone vous assourdit dès l'entrée: c'est celui du gamelang, au son duquel les danseuses du prince Manka Negoro exécutent leur répertoire. Ces aimables personnes, assises sur une estradc, sont au nombre de quatre; elles s'appellent Wakiem, Damina, Seliem et Sakia. Notre confrère le Journal des Débats en donne une description toute charmante. Jugez-en : a Leur visage, leurs épaules, leurs bras et leurs jambes sont teints de safran. leur chevclure est noire et lustrée. Wakiem et Seliem portent sur la tète une sorte de tiare surmontée de plumes noires en éventail. Les deux autres sont casquées d'or. Les cils et les sourcils sont un peu noircis. Les lèvres épaisses sont accusées par des lignes d'ambre; les dents et les gencives rougies semblent sanglantes. Lin bustes graciles wais fermes sunt emprisonnés dans des corselets violet sombre ou vert émeraude. Aux bras, an cou, sur la poitrine, des bijoux et des amulettes miroitantes. Une sorle de jupc courle et étroite descend jusqu'au-dessus des genoux. A la taille une double ceinture, dont les pans larges et longs tombent deux par devant el deux par derriere, ces derniers relevés cu coques bouffantes, exagérées, à la façon de lin tournure des Parisienues. Çà et là, au corsage et parmi les plis capricieusement drapés de la jupe, passent de courtes écharpes multicolores. Lorsqu'elles sont assises, on les prendrait. par instants, pour des figurines peintes; mais un soufle d'air un peu frais les a fait grelotter sous les tricots dont elles s'affublent; un mot dit à mi-voix par l'une d'elles les a fait gentiment sourire, el elles s'animent soudain arec des gamineries de petites filles coquetles.

- Elles retombent en des postures hiératiques, aux premiers accords du gramelnug: c'est l'orchestre rangé derrière elles. Un violon à une seule corde doune le chant, mélodie triste et monotone, dont le rythme ira s'accélérant jusqu'd la fin de la danse. Des tambours, des harmonicas en lattes de bois, des gongs, des jeux de cloches, formis par une série de vases de bronze renversés, font l'accompagnement. Des Sundanais tapent sur tous ces instruments, les uns au visage séricux, les aułres dejà à demiironiques.

"Les quatre danscuses se lèvent et commencent leurs pas. C'est une longue suile de poses noblement rythmées. Les pieds glissent et les jambes se meuvent doucement sans jamais fléchir. Le buste suit en de brèves oscillations le mouveınent de la mélodie. La tête est légèrement renversée, le visage imp ssible. Toul est dans le lent inouvement des bras, tantòt déployés, tantòt relevés. Les poignets se touruent et se retournent avec une grâce inimitable. Les mains, sans cesse étendues, expriment tout le sens de la danse, elles s'allongent, se raidissent et jouent avec les pans de la ceinture. liest là, assure-t-on, unc danse guerrière... Peut-čtre; mais, comme par une pudeur sacrée, toutes les attitudes en sont si mesurées et si graves, qu'aux panvres blancs non initiés tout échappe du mystérieux symbolisme, et ils ne peuvent qu'adınirer cetle lente évolution de petites idoles jaunes, s'approchant et s'éloignant pour les causes incon nues, avec des gestes inintelligibles, mais d'une souveraine harmonie. Brusquement, la musique s'arrête; Damina, Wakiem, Seliem et Sakia saluent le public; méne mouvement, mème sourire qu'à l’Opéra.

- Un Javanais et une Javanaise, qui ne sont pas des danseurs de profession, unment ensuite une scène d'amour. Le dimseur et la danseuse se ponrsuivent, - lentement, - toujours sans s'atteindre. C'est encore la mème gravité dans la plastique, les mêmes torsions des bras et des mains. Ici pourtantle sens de la pantomine est un peu plus clair, - bicn qu'encore voilé par le rile traditionnel, qui riggle les attitudes el les 
pas. En certaines poses, à peine esquissées, on peut croire surprendre de vagues et lointains symboles de volupté. Ėncore ici la musique et la danse cessent brusquement, sans finir.

"Les danses terminées, tous les musiciens quittent l'estrade et parcourent à la file le Krompong: les uns frappent de la main leurs longs tambours: les autres agitent des instruments de bois dont les deux notes font un perpétuel glou-glou. La foule est doucement ahurie. Les Sundanais, tout en menant consciencieusement leur tapage, adressent aux spectateurs de bons sourires résignés. Ce spectacle mérite d'être vu. On éprouve un sentiment bizarre a la vue de cette danse lente, de ces mouvements reptiliens, de cette flexibilité ondoyante des bras, des jambes et du torse. Wakiem et ses compagnes ont une agilité indéniable, mais ce n'est pas une agilité comme la nôtre, et l'on est comme dérouté.

Après cela, vous pourrez vous promener sans regretter votre peine dans le village avec ses maisons construites en bambou et transportées pièce à pièce, et ses marrangs ou restaurant indigènes. Cinquante-quatre Asiatiques habitent le Kampong, -t sur ces cinquante étrangers, qui représentent toutes les professions, on comple dix femmes. L'exhibition de cette petite colonie est due d l'initiative de M. Freiwal, un délégué du comité nćerlandais. Dans le restaurant, on vend du riz accommodé de plusicurs façons.

Ces indigènes au teint safrané qui mangent, dorment, s'habillent et travaillent sous les yeux du promeneur, appartiennent d la race malaise. Ils sont doux, intelligents, et pas du tout vindicatifs, comme l'ont affirmé beaucoup d'écrivains. " Les Javanais, dit ĺlisée Reclus, sont les plus doux des hommes, quoiqu'il ne manque pas d'auteurs qui les accusent d'être fanatiques, perfides, rancuniers : mais il est facile de se laisser entratner a médire des faibles. , Ilabitants d'un sol fécond, ils sont bons agriculteurs. lls vivent de riz, de poisson, de viande de buffle. Ils sont, en somme, §ssez. gracieux et élancés, quoique de petite taille. Le nez n'est pas absolument épaté, les yeux larges et bien ouverts, les lères fortes, la figure ronde, la physionomie douce. L'industrie moderne, qui a naturellement pénétré dans leur pays, n'a pas entamé les procédés traditionnels de fabrication des objets ordinaires. a Les femmes tissent les étoffes et les ornent de couleur's très solides en les trempant dans un bain de teinture, après avoir recouvert de cire les parties qui doivent rester en blanc; les hommes travaillent les métaux et savent en faire des armes élégantes, notamment des kriss ou poignards de formes ondulées. Dans les terres princières de Djokjokarta s'est maintenue en toute propriété l'industrie des fabricants de gongs et d'instruments de musique pour les orchestres ou ganielang, rangées de cloches, cymbales, tambours, clochettes et languettes en cuivre et en bambou, que l'artiste frappe avec un marteau pour accompagner les représentations thédtrales ou les danses des roengeng ou bayadères. Les plus habiles artisans de Java sont les Chinois : c'est à eux que s'adressent surtout les Européens pour les travaux qui demandent de l'adresse et du goût. „ On s'assurera de la vérité de ce tableau en passant deux heures au Kampong de l'Esplanade, en examinant les indigenes dans leurs maisonnettes recouvertes d'ataps ou feuilles d'areng. 



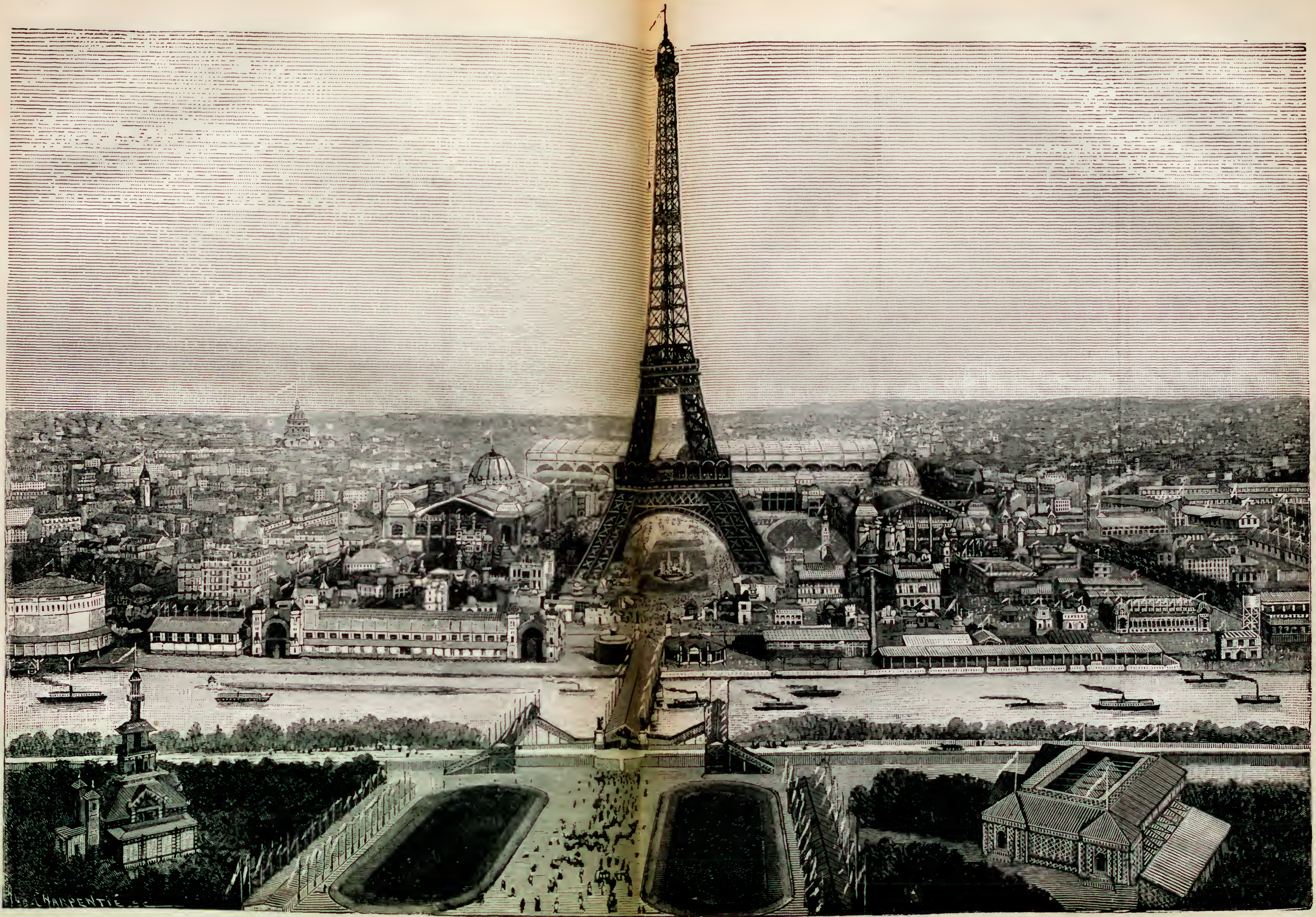




\section{RÉPUBLIQUE SUD-AFRIGAINE}

Bien que la République sud-africaine soit un Ếat indépendant (la suzerainetó anglaise n'est que nominale), nous en parlerons dans ce chapitre, parce que le pavillon de cet État se trouve à l'extrémité de l'Esplanade. près de l'Algérie el de la 'Tunisie. Le Transral (car on la désigne aussi sous ce nom), participe officiellement a l'Exposition universelle, et il a consacré une subvention de 80,000 francs à assurer sa représentation. Le pavillon reproduit le type des habitations européennes de Prétoria, capitale de la République. Il est rectangulaire, occupe une superficie de 200 mètres carrés, est peint en blanc avec filets bleus, et muni d'une véranda sur trois côtés.

La population duTransvaal est d'origine néerlandaise, et les Boer's actuels descendent directement des Hollandais qui, au xvıte siècle, s'établirent dans l'A frique australe; elle s'élève à environ 60,000 àmes, auxquels il faut joindre les Européens proprement dits et les indigènes, ce qui donne un chiffre total de 300,000 environ. Le pays est fertile; il donne déjà de beaux résultats, et il en donnera de bien plus beaux encore dans l'avenir. Faites un tour dans le pavillon : vous y verrez des céréales, du labac, de la laine, des cuirs et des peanx, des plurnes d'autruche, des cornes de buffes et d'antilopes, des minerais d'or, d'argent, de cuivre, de fer, de charbon. Michesse agricole, richesse minière, tel est le biban de la République sud-africaine. La vente des terres, des domaines, la taxe sur les cabanes des indigènes, les droits miniers alimentent le budget de l'État, lequel est gouverné par un président et par une Clıamlire (Volksraad) de trente-six membres.

Les Boers, selon le capitaine Lucas, vivent d'une façon toute particulière au milieu de leurs troupeaux. On ne les voit que rarement dans les centres d'habilation, où ils viennent seulement pour renouveler leurs approvisionnements ou vendre leurs produits. Ils sont en général d'une taille élevée; ils ont le teint jaune. les traits durs, et sont d'un carackère indolent et flegmatique. Ils vivent très simplement; leur nourriture se compose surtout de viande de chevreau ei de lait; ils absorbent en tout temps une grande quantité de café. Ils sont excellents tireurs, et c'est un jeu pour eux d'abattre à 300 yards un gnou ou une antilope. Leurs habitations sont des fermes entourées de terrains cultivés; l'intérieur n'en est point très propre. On nous a sıgnalé un trait curieux des mours boers. Le jeune homme qui veut se marier dresse une liste des jeunes filles des districts voisins, réfléchit, puis un beau jour monte à cheval et entre dans la maison qu'il a choisie. Là, sans mot dire, il sort de sa poclie une bolte de prunes confites pour la mère, et une chandelle de cire pour la jeune fille. Si celle-ci acceple le nouveau venu pour mari, la chandelle est allumée, et la mère se retire après avoir fiché une épingle à une distance quelconque de la flamme pour indiquer aux jeunes gens le temps pendant lequel ils peuvent s'entretenir de leurs fiançailles. Bible.

Le Boer est très religieux. Le soir, aux veillies, il n’a d'autre lecture que celle de la

\section{LA FETE COLONIALE}

Le 21 juin, à deux heures, le comité de l'Exposition coloniale a offert au Président de la République, sur l'Esplanade des Invalides, une fete exclusivement coloniale d'un caractère fort pittoresque. 
Dès une heure un quart, lous les délachements des troupes coloniales étaient massés devint le Palais central et formaient la haie dins l'avenue des Lions, sous le commandement de leurs officiers; les petits tirailleurs annamites aux uniformes sombres, qui:, pour la plupart, portent la médaille du Tonkin, formaient un contraste étrange avec les costumes éclatants des cipayes, des tirailleurs el des spahis sénégalais, presque tous des hommes superbes. Un piquet d'honneur, composé d'Annamites, de Sénégralais et de Salialaves était placé, en outre, à l'entrée des pavillons de la Cochinchine, du Tonkin et de Madagascar.

Le Président de la Répuhlique arriva à deux heures par la porte du quaid'Orsay.

Sa voiture se dirigea a travers la liaie des soldats indigènes jusqu'au Palais Central. A l'entrie du petil pont, M. Carnot fut reçu par II. Étienne, sous-secrétaire d'État, M. Henrique, commissaire général, MM. Revoil et Destournelles, comınissaires spéciaux, et par les sénateurs et députés des colonies.

Les indigènes des différentes colonies étaient groupés à droite el à gauche de l'entrée du palais; rien de plus curieux et de plus bizarre que ce mélange anthropologique réunissant des types de tous les coins de l'univers, depuis les belles et nobles figures des Tahitiens, au type presque indo-européen, jusqu’a la figure jaune et grimaçante des Annamites, en passant par les larges fices d'ébène des noirs du Sénégal.

II. Carnot visita dans tous ses détails le Palais Central, puis il se rendil successirement aux expositions particulieres qu'il visita dans l'ordre suivant: palais de la Cochinchine, paliais du Cambodge, village annamite, village canaque, palais de la Guadeloupe, fitclorerie du Gabon, village palıouin, village sénégalais. Dans chacune les expositions on offrit au Présillent de la République des petites notices statistiques et descriptives (qui seront dorénarant distribuées au public à chaque fète nouvelle; au Palais Central on lui remit un très bel album renfermant des vues de toutes nos colonies et un grand ourrage d'ensemble publić par l'Administration des Colonies.

11. Carnot se rendit alors au thédre annamite, où il s'arrêta pendant quelques minutes pour recevoir le laï des acteurs annamites, suite de saluts profonds qui ressemblent fort à des prosternations

Quelyues instants plus tard, II. Carnot pénétrait dans le palais du Tonkin et de l'Annam ouvert pour la première fois et dont l'installation venait d'ètre achevéc. Le palais est construit sur une place carrée, avec une cour centrale en partie occupée par un riche baldaquin abritant un magnifique génie. Cette statue est la montagne d. grand Bouddlıa de IIanoï. Disposćes sur les deux façades et reliées entre elles par deux galeries longeant la cour centrale, viennent ensuite deux salles dexpositions mesurant chacune $21^{\mathrm{m}}, 300$ sur 8 mètres de largeur. De très belles collections y ont été réunies. Celles-ci montrent surtout des armes, des panneaux sculptés ct laqués, des modèles de maisons, de jonques, d'instruments aratoires, d'argenterie, d’orférerie, de porcelaine, de bronzes, de boltes à chiłues de bétel, de marbres, d’instrumrnts de musique, etc. Les produits du sol sont égilement représentés dius le palais, notamment par la ramie, l'essence de citronnelle et le bé-moc. Un lunch ful alors offert a M. Carnot et à sa suite sur la terrasse de gauche; ce lunch, fort élégamment servi, avait lui-mène un peu le caractère colonial, ce qui n'a pas, loin de lì, empéclıé sun succès. Dans le menu figuraient des tartines annanites, des gateaux des colonies, des fruits exoliques, des liqueurs des lles, etc. Enfin, les comités coloniaux firent assister le l'résident de la liépublique à des répétitions curieuses des 
différentes cérémonies ou des pratiques civiles et religieuses en usage chez tous les échantillons de la race humaine rassemblés à l'Esplanade.

C'est ainsi que M. Carnot assista successivenent au pilou-pilou des Canaques, a l'hyménée de Tahiti, qui est fort gracieux et élégant, et à la procession tonkinoise dı Dragon. Rien de plus curieux et de plus piltoresque que celle-ci : les indigènes sont revètus de sortes de chasubles rouges brodées de vert. Ils portent sur la tète des coiffures compliquées, casques, couronnes barbelées, etc. Des bouffons, le visage couvert de grands masques grotesques, dansent au milieu du cortège, tout hérissé de drapeaux et de piques. Vient ensuite un immense dragon vert en carton et en étoffes peintes, de plus de 6 mètres de long, à la tête effroyable, porté par douze indigènes sur des perches qui s'agitent pour figurer les ondulations du serpent, tandis qu'un Annamite agite devant sa gueule une amulette dorée, figurant un système du monde, afin de l'empècher de dévorer les humains. Derrière marchent gravement des personnages religieux, qu'on nous a dit avoir rang d'archeveques et qui fument pacifiquement leur cigarette. Pour musique, une quantité de tambours, de timbales, de grosses caisses, de gongs, de tamtams, et des cris assourdissants.

M. Carnot termina sa visite à l'Esplanade des Invalides par une excursion au Kampong javanais, qui, en l'honneur du Président, a été orné de fleurs et de tapis. Le petit thédtre des danseuses javanaises est garni de chaises dorées, et ceux qui ont réussi à traverser la foule s'y installent. Après la danse, ces artistes descendent de la scène, et M. Georges Berger les présente à M. Carnot, à II. Tirard et aux dames. Le Président de la République fit le tour du rillage javanais avant de quitter l'Esplanade des Invalides. Il s'intéressà à l'industrie du c batick, et l'artiste lui donna un morceau de celte étoffe indigène décorée à la cire, sur laquelle elle avait peintlinscription suivante :

\section{- Victoire de Wattignies, 16 octobre 1793.,}

On avait songé a lui faire mettre : Vive Carnot! ", mais on a préféré ce sourenir du fait d'ar mes de Lazare Carnot, auquel son petit-fils fut très sensible. La visite s'acheva à cinq heures au milieu des applaudissements et des ovations accoutumés du public qui resta toute l'après-midi, par une chaleur étouffante, sur l'Ésplanade des Invalides, pour voir de loin le Président de la République assister à la féte donnée ea son honneur.

\section{XIV}

\section{a travers LB CHAHP DB yaRS}

Lo lecteur connait maintenant dans ses détails les partics essentielles de l'Exposition. Nous avons bien encore à décrire spécialement quelques parties du Champ de Mars, comme la Galerie du Travail, et, sur l'Esplanade, le Palais du Ministere de la Guerre, mais le moment nous semble venu de parcourir d'un bout à l'autre l'Exposition universelle, rappelant d'un mot ce que le lecteur connait déjả, insistant sur les points dont nous n'avons pas eu à nous occuper encore. 
Le Trocadéro. - Entrons par le Trocadéro et plaçons-nous au-dessus de la Cascade. La vue qui se déroule devant nous est véritablement d'une originalité grandiose. Les divers palais, leurs dômes éclatants, en avant desquels se dresse la Tour Eiffel, offrent un spectacle auquel les yeux n'étaient pas encore accoutumés : l'architecture du fer, la combinaison du métal et de la céramique. Nous avons décrit le Palais des BeauxArts, le Palitis des Arts libéraux et le Palais des Industries diverses. On en connait la

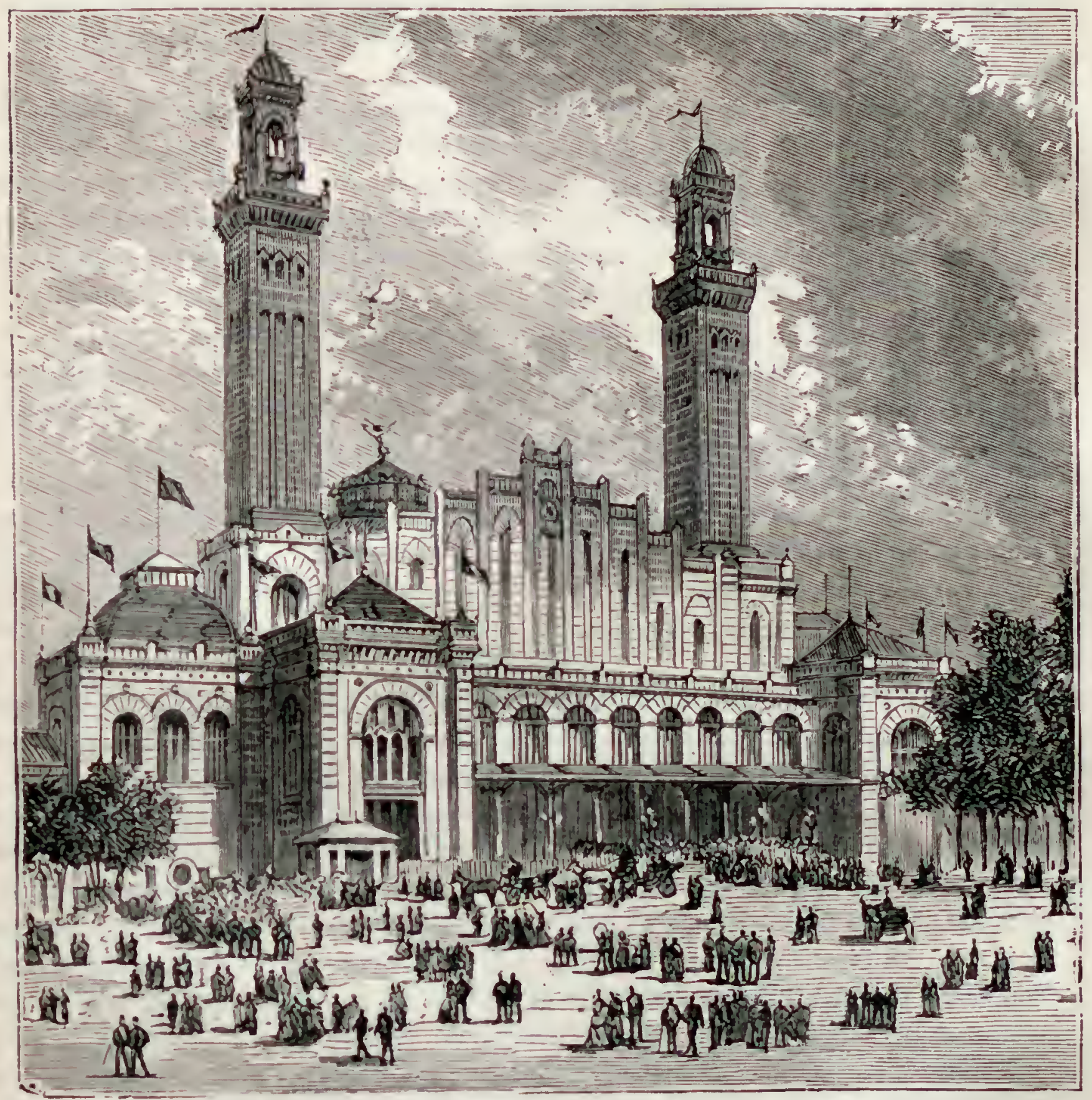

VCE DU TROCADÉRO, PRISE DE LA PLACE DU TROCADÉTO.

forme. On connalt aussi le Dôme central et l'étonnante Galerie des Machines : nous n'avons donc pas à y revenir.

Dans le Trocadéro mème, on a installé diverses expositions : le musée ethnographique, les trésors d'Église, les antiquités cambodgiennes. Tout cela mérite un examen serieux, approfondi; nous n’en saurions trop recommander la visite.

Tracaux publics. - A notre gauche, dans le parc mème du Trocadéro, nous apercerons un gracicux chalet : c'est celui du Ministère des Travaux publics, dont l'expo-

Liv. 37. 
sition la plus curieuse est celle des phares. L'éclairage des côtes, si indispensable aux navigateurs, est devenu l'objet de la sollicitude de tous les gouvernements. Il y avait donc un intérèt de premier ordre à nous montrer les progrès le plus récemment réalisés dans cet ordre d'idées. Le pavillon est du a $\mathbf{M}$. de Dartein. Le fer et la terre cuite s'y marient habilement, et il est d'un fort bel aspect. Il n'est pas trop heau pour contenir les nombreuses et utiles inventions de nos ingénieurs. - Tout près, se trouve l'aquarium, construction souterraine où s'ébattent des poissons de tout genre et de toute écaille.

Forêts. - A notre droite, le Pavillon des Forèts l'emporte comme originalité sur son pendant le Pavillon des Travaux publics. Les forèts de l'État occupent, à l'Lxposition universelle, un emplacement de quatre mille mètres environ, sur lequel l'administration forestière a fait construire le beau pavillon que représente notre gravure. C'est la que sont exposés, avec une entente remarquable, les modèles d'ouvrages, les bois de toute sorte, les outils, les plans d'exploitations forestières, deux belles vues panoramicgues, en un mot, tout ce qui cunstitue l'industrie et l'art de la sylviculture.

Le succès de l'Exposition forestière en 1878 avait été tel qu'on se demandait s'il serait possible de mieux faire cette année. C'est pourtant ce qua pu réaliser M. de Gayffier, conservateur des forèts.

Au lieu de construire un pavillon en bois ouvrés, soigneusement découpés, labotés, polis et vernissés, on s'est uniquement servi de bois non écorcés, dilférents de formes et de couleurs, en employant toutes les essences d'arbres que renferment nos forits de France. Ln juxtaposant des rondins de bouleau, de pin, de chene, de hêtre, de tremble, de peuplier, d'érable, etc., on est arrivé à constituer des panneanx d'un caractère rustique très original.

Cinquante ouvriers ont été occupés pendant plusicurs mois à débiter les bois et à préparer les matériaux qui ont servi à édifier ce pavillon dans la forèt de fontainebleıu, d'où il a été transporté par pièces pour ètre remonté au Trocadéro.

Un autre parillon a été construit au moyen des mèmes procédés et avec non inoins d'art et de goût que celui de l'administration forestière. Il s'agit de l'élégrant . Rendezvous de chasse exposé dans la partie est du Trocadéro, par M. Albert Prunières, entrepreneur de constructions rustiques à Sannois (Seine-et-Oise). M. I'runieres a démontré que l'industrie privée sait faire aussi bien, sinon mieux, que l'administrátion. Son pavillon, construit avec des bois non écorcés, est d'une élégance prarfaite et d'un travail irréprochable.

Un peu plus bas que le coquet "Rendez-vous de chasse, de M. Irunières, se trouve l'original jardin japonais de Kashawara, horticulteur d̀ Tokio (Japon). On y voit des arbres nains, vieux d'un siècle. Clòture, portails, kiosques en bambous, terrasses et bassins, tout est bien japonais, et surtout les plantes que les visiteurs verront lleurir très prochainement. Nais cel exotisme ne doit pas empecher de voil aussi les galeries d'horticulture destinées aux expositions d'orchidées, de rhododendrons, de rosiers, etc., qui se suceèdent sans interruption au Troeadéro. Kien de plus délicieux ıjue ces anoncellements de fleurs disposées avec art, au nilieu des massifs de verdure uả le visileur se réfugie volontiers quand il a parcouru pendant plusieurs heures les vastes galeries du Champ de Mars.

Mais terminons d'abord notre visite au Pavillon des Forets, dont la décuration, nons le répétons, est exclusivement faite de panneaux de bois non écorcés. 
La construction, non compris les annexes, occupe une superficie de 43 mètres sur 37; son élévation est de 20 mètres, et le coùt en a été de 110,000 francs. Entreprise par M. Lecour, architecte, sous la direction de M. de Gayffier, conservateur des forèts à Velun, qui a cléjà été chargé de l'organisation de l'Exposition forestière en 1867 et 1878. Il a été employé pour ce travail environ 1,800 mètres cubes de bois entièrement pris dans la forè de Fontainebleau où s'est faite la construction complète; une fois terminées, les diverses parties furent expédiées à Paris, au Champ de Maı,s, pour y ètre assemblées et montćes.

Lil grande galerie dı has, autour de laquelle est ménagé un promenoir, formée d'arbres et de panneaux très divers sur peaux, est entièrement polychrome, grace aux teintes diverses qui se mettent l'ume l'autre en valeur. De loin les colonnes, avec leur's chapiteaux, formées de chènes, de hêtres et d'érables entiers non écorcés, jouent le marbre. Par l'appareillage le choix des proportions et des motifs d'ornementation, M. Souc, lintelligent constructeur, arrive certainement à un effet très curieux et inconnu. A certains endroits, l’un ì còté de l'autre, pour mieux faire ressortir les différences, on place des panneaux de bois sains et d'autres attaqués par los insectes parasites; impossible rle pousser plus loin la passion du naturel.

L'exposition des collections forestières, particulièrement intéressantes en France, un des rares prys possédant des essences si diverses de bois, est de tous points réussie. Installés dans ce local original, produit de notre industrie nationale, les spécimens et ouvrages exposés attirent doublement l'attention des visiteurs. Ajoutons que. c'est l'Etat qui a fait les frais de cette exposition forestière.

IInrlimllure. - Pour l'horticulture, nous empruntons à II. Jules Richard l'agréable description qu'il en a faite, et $\mathbf{M}$. de Varigny nous fournira les détails les płıs curieux sul l'lixposition particulière du Japon.

- Ciest la première fois que l'exposition d'horticulture a conquis son autonomie. Jadis disséminée un peu partout, dans les jardins, le long des bâtiments, elle servait à l'ornementation générale; les plantes, les arbres et les fleurs n'avaient pas une place fixe sur le territoire du Champ de Mars. Si l'on voit encore dans notre grande Exposition, de-ci cle-la, quelques splendides parterres, de magnifiques massifs de rhododendrons et autres plantes décoratives, ils ne sont que des accessoires.

" L'Hllticulture, c'est le jardin du Trocadéro. On craignait au début qu'elle y füt noyćc dans l'espace: or l'espace a fait défaut au dernier moment: la Balgique avait demandé 2,000 mètres, elle a dú se contenter de 100 mètres. Son envoi est très intéressant, moins cependant que celui de sa voisine la llollande, dont les conifères sont hors ligne.

"Quant a l'Lxposition française, elle est splendide et nous ne saurions trop la recommander à l'altention du visileur. La France possède le climat le plus favorable à la culture des fleurs el des arbustes. Elle en exploite des quantités considérables. Nos rociéristes expédient leurs quenouilles jusque dans l'Amérique du Sud. Nos types de roses se comptent par plusieurs milliers, et, tous les ans, on en crée de nouveaux. En bouquets et pour la décoration des appartements, nous consommons annuellement pour une cinquantaine de millions de plantes et fleurs diverses. Dans Paris, les boutiques de fleuristes sont presque aussi nombreuses que les cafés et les marchands de liquide; c'est une rage, un délire. La mode, est aux fleurs, et nous nous en félicitons. 


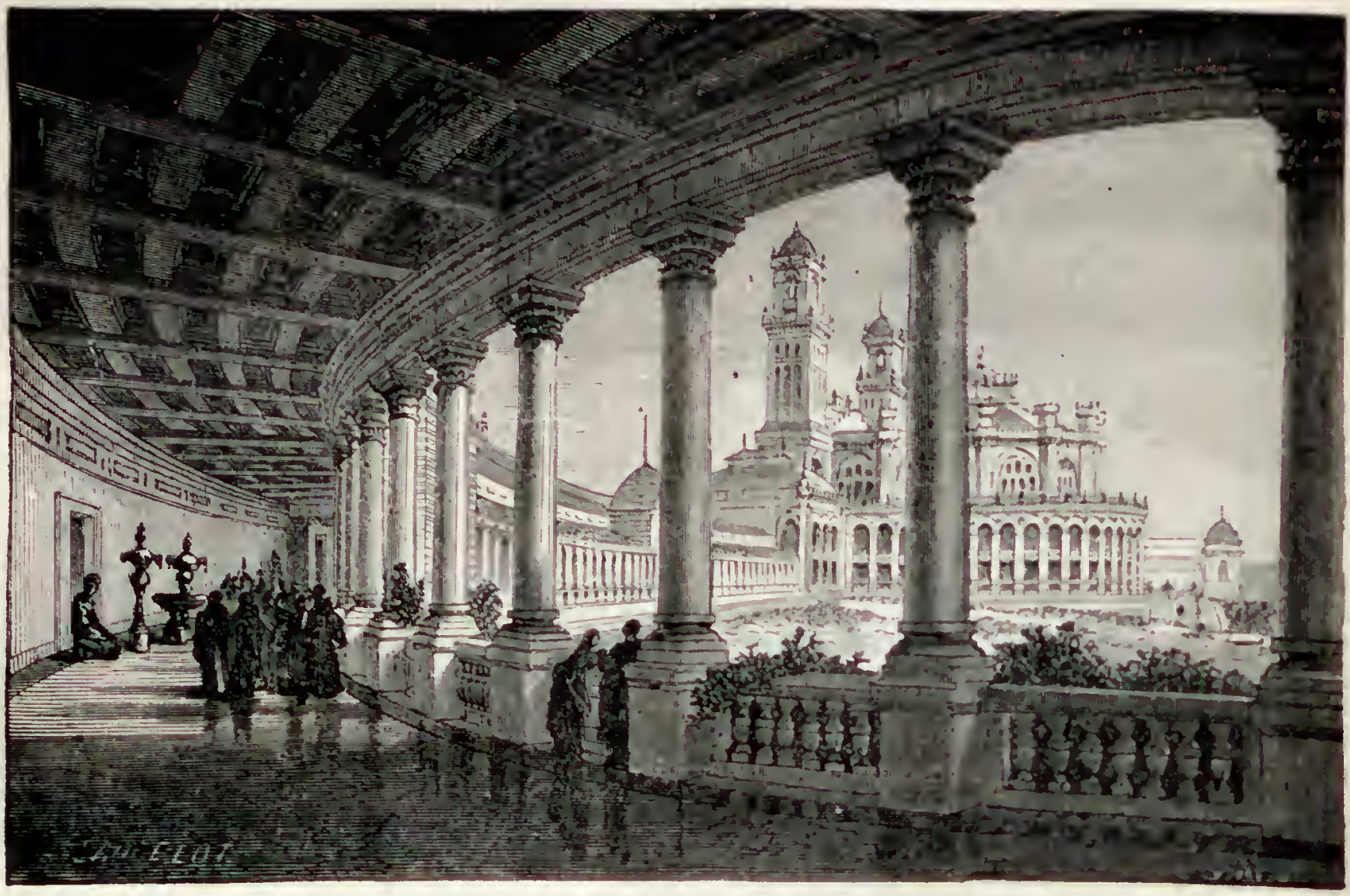

VeE de La Salle des Fetes, Prise d'un des porliques des siles.

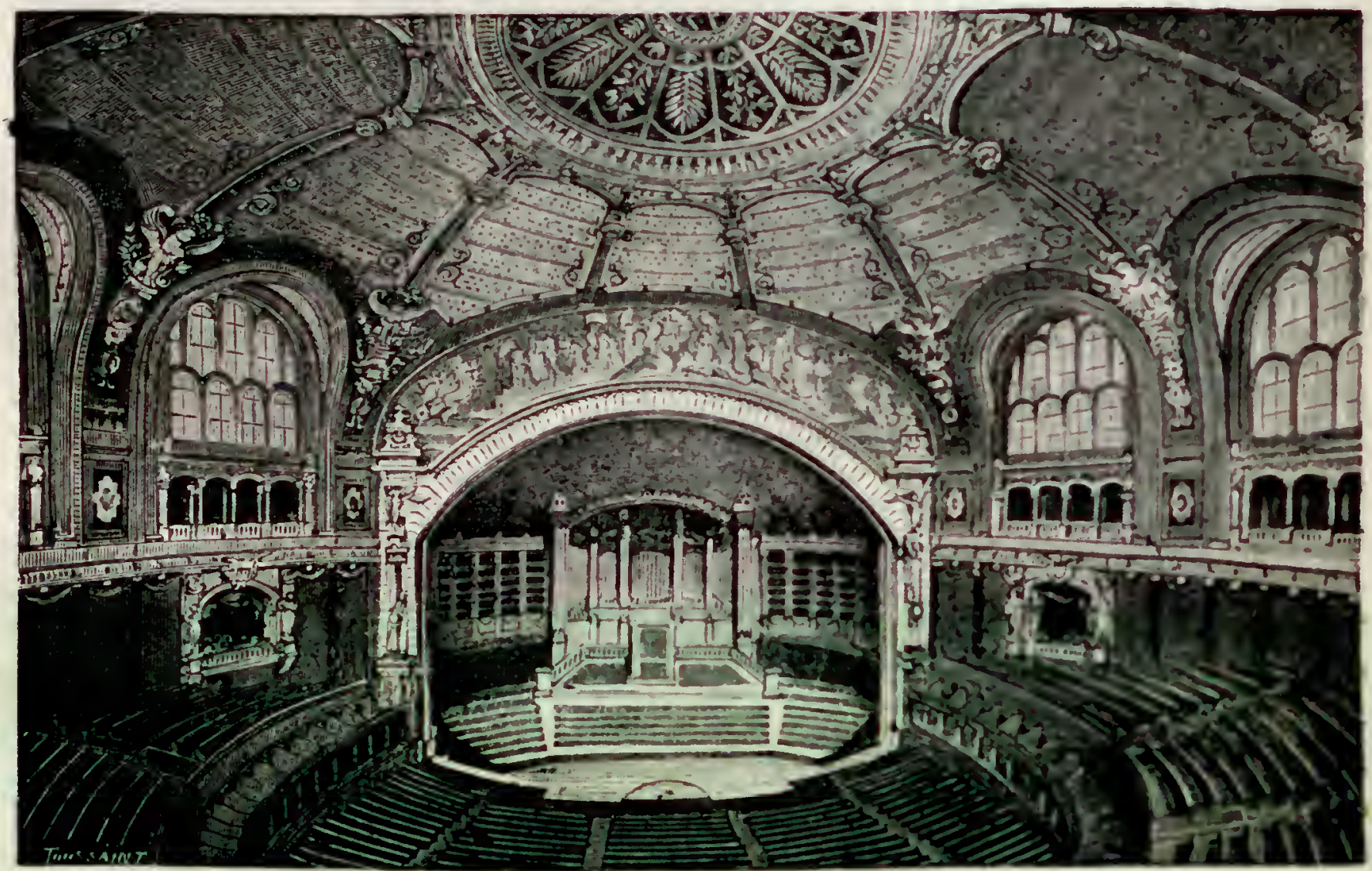

YUE DE LA SALLE DES Fit.TES, Prise d'une des tribunes. 


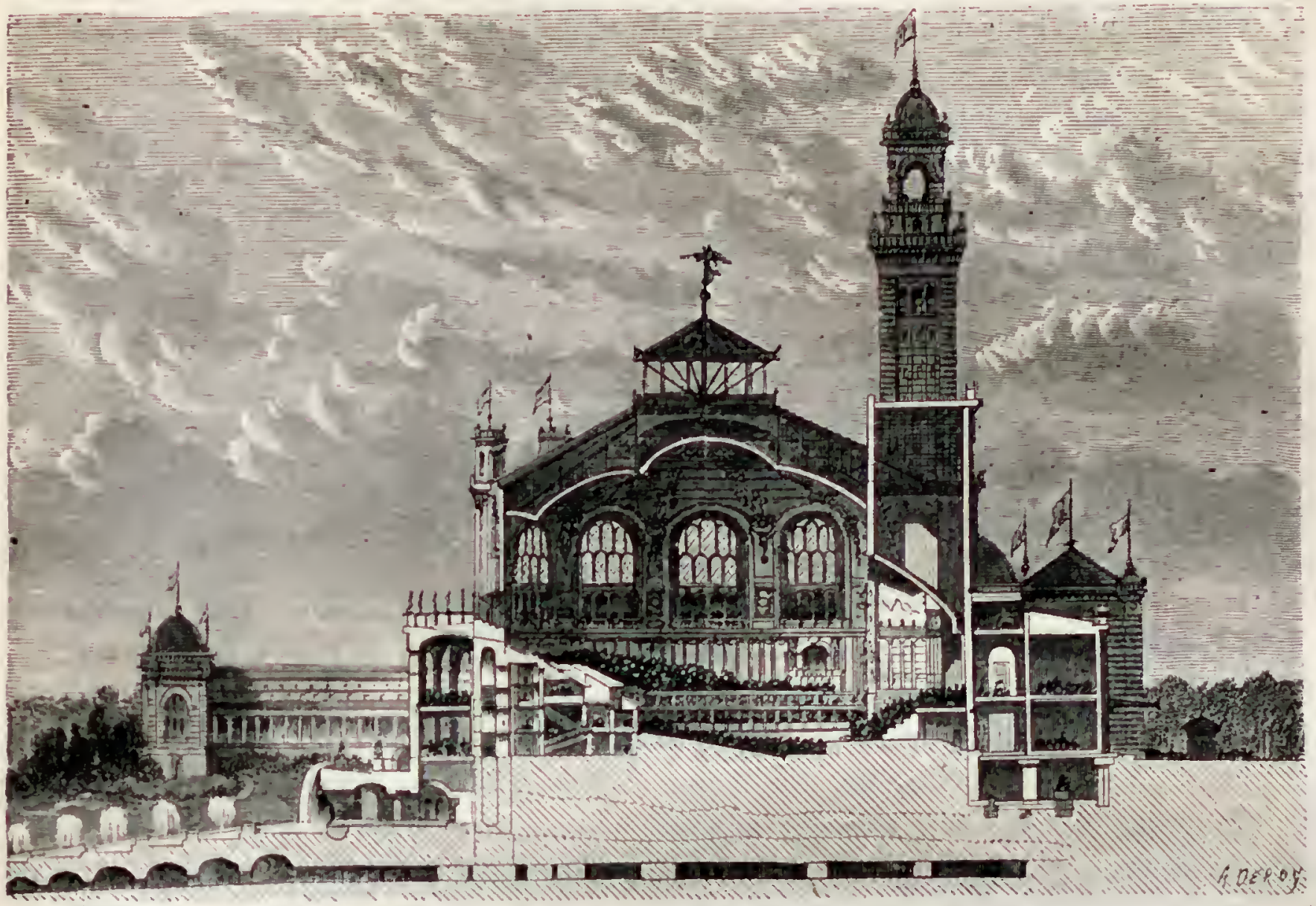

HELLAEO

Coupe slir le grayd axe De la Salde des fètes

Et de ses annexes.

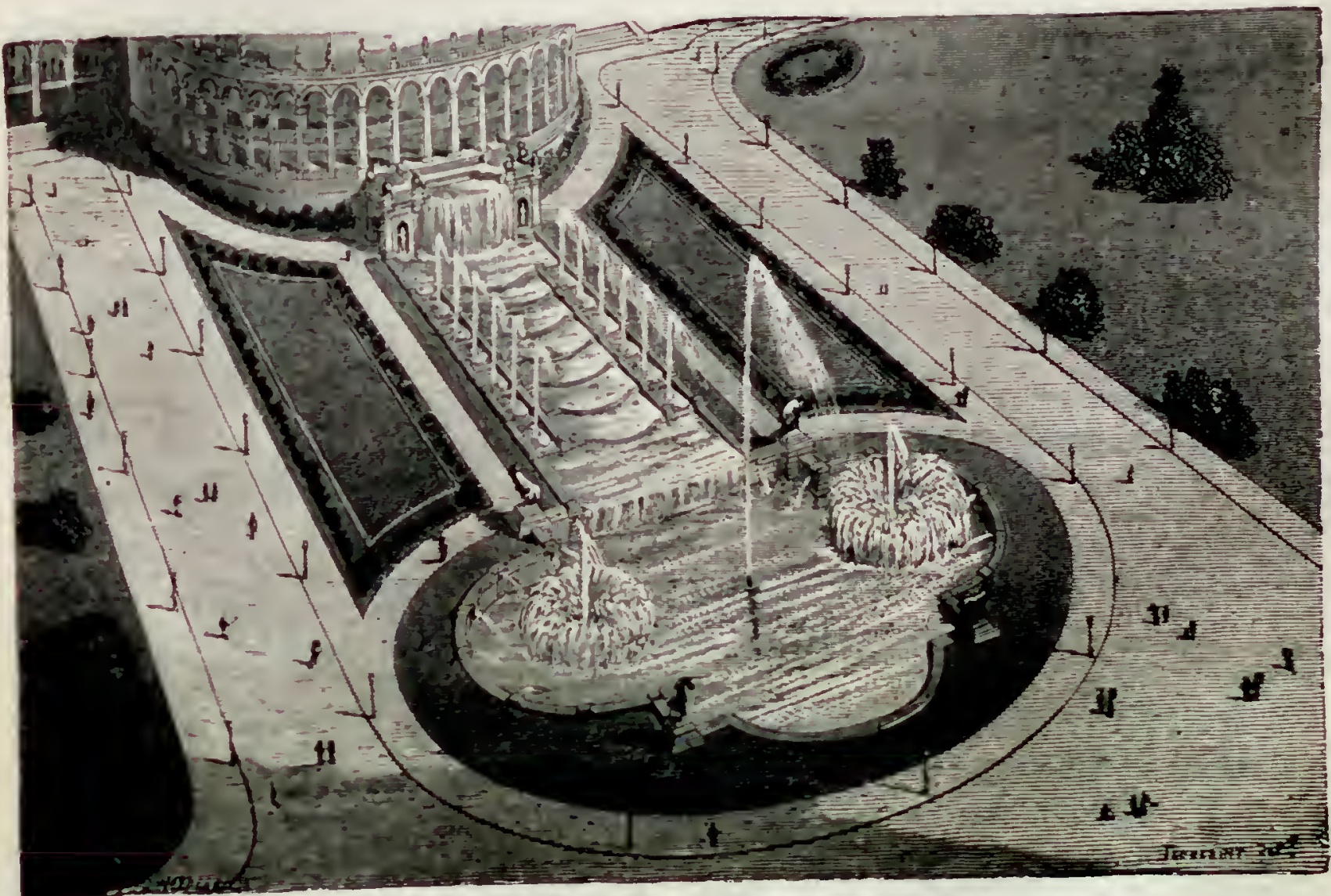

VEE DE LA CASCAUE.

Prise du las du jardin. 
- Vist-ce à ce hesoin nomrean, très encouragr par fes fommes. upue l'horlicullure doit sa grande concurie d’une expnsition spiciale el séparée: Nous le croyons et neus en remereions la plus belle moitiédu genre humain. C'est it M. Hardy, le chibhre directeur

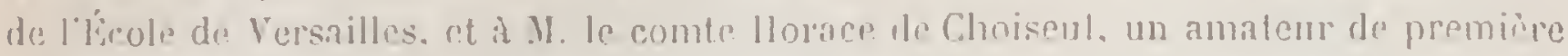
force. pine revient la gloire d'avoir su tirer aussi lion parli de untre glande imbustrie Ilorale et horticole. Plusieurs rxposants, horticulteurs distingure. Min. Deflesur et

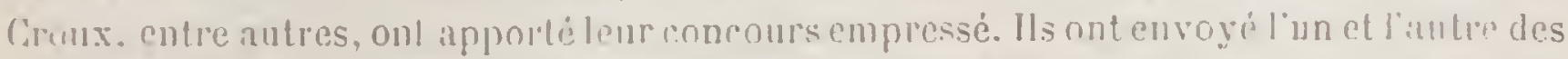

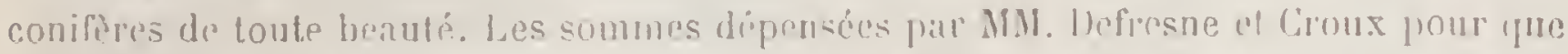

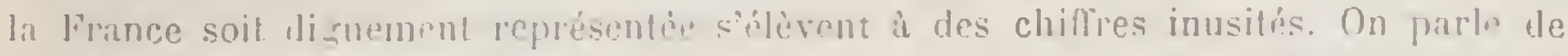

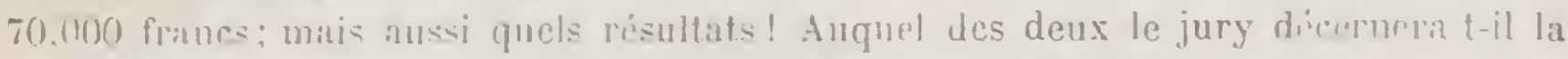
poume? Vous ne porrous le préroir. Si nous avious voix au chapilur, nous bus placezrions er argun con liste de lous les horticultenrs du monte.

- l'Exposition des fleurs presente cette particulariti que le vi-iteur jourra se promener sans cesse dins le Trocadrun arec lit certilude d'y rencontrer tonjours à voir.

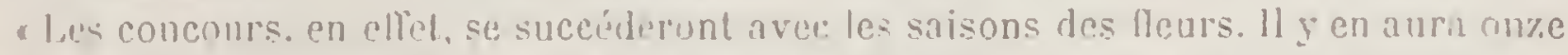

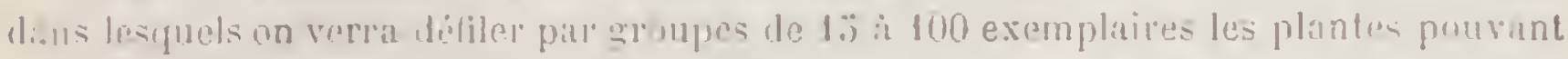
servir it l'ornmentation des jardins en plein air sous le climat de laris : des agaves,

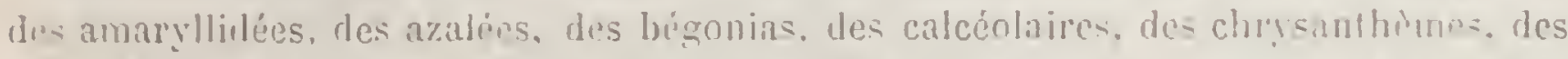
climatıles, des lahlias, des fougères, des fuchsias, des grenadiers, des hólinfonpes. des iris, der limmias, des liliacées. des marnolias, des mahonias. des myrtes. des isil-

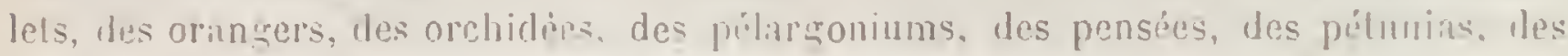
piroines. des ru-iers, des tulipes, des verveines, dres yuccas, des zimnias. Nums pur passone, car il y a 87 especes indiquées sur le programme, sans compter les arhere firuitires. les pliutes de serre, etc . Mte.

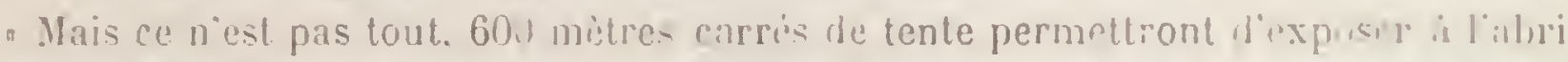

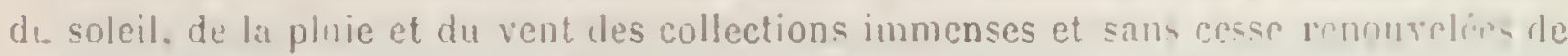

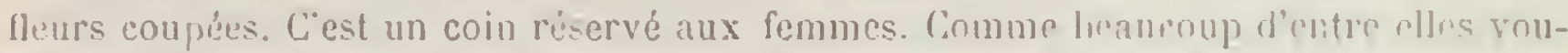
dront empnrler yueleque gracieux survenir de l'Exposition. elles trouveront. - c'est une idée qui appartient à. Il. Llorace de Choiseul, - elles troureront, avant de quillp le Trucatéro, an pied du pont d'léna, un vaste salon en plein air, où l'un pourra acheter des fleur's coupces. Ce salon contient, en cutre, un riste plan mural du pare ot sont indiqués et numérotés les emplacrments de chaque exprosint et le ritail de son exposition.

* Thut le monde ne sait pas distinguer à premiere vue les plantes puli compousnt la place de Paris et de ses environs, et chacun sera bien aise de se renscimncr exictement sur le nom et les propristaires de celles remarquées quelques instants aujaravant.

- En somme, c'est un spectacle qui n'est jamais le mème puisqu'il chinge fous les quinze jours.

Erposition japonaise. - Cette exposition a été or⿳彑口冖nisée par M. Lishawna, hurticulteur à Tokio; elle se trouve aupres du Pavillon des Travaux publics, dans un petit jardin en pente, clos d'une barriere en bambous, et on y accède parquelques marches, failes au moyen de trones d'arbres sciés et juxtaposẻs. Les plantes sont installies sous deux petit; pavillons et dans des massifs, au milieu de vases en faïences. Le rewird est immédiatrment altiré par des arbres nains, des arbres raccourcis, haut de 40 a 


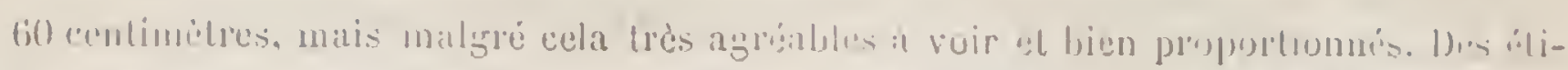

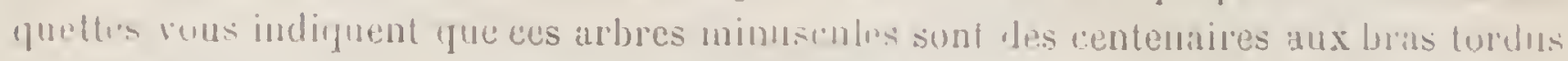
et enllewisisis.

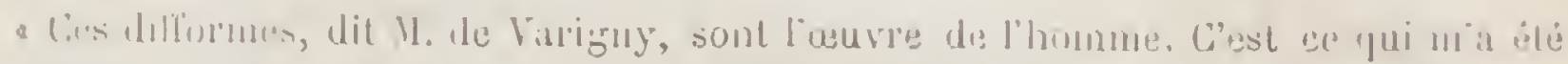

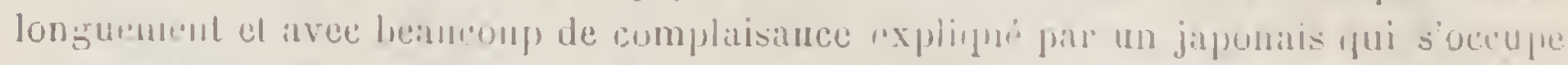

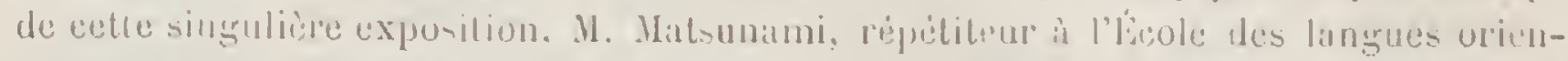

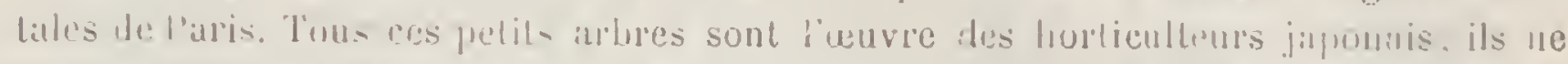

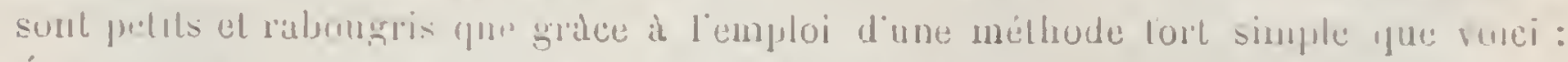

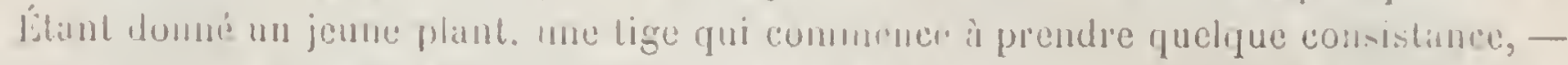

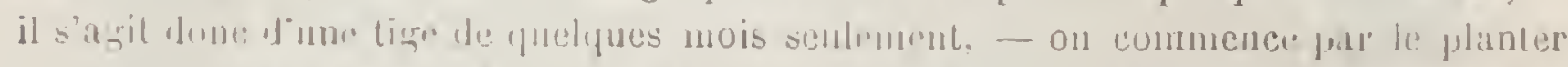

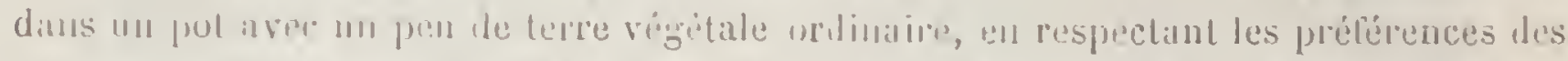

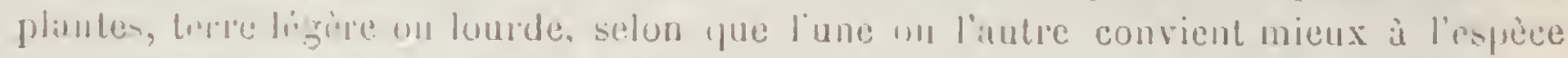
chuisie, mais terre matnelle, sans ancune smbstaner qui soit de nature à relarder la

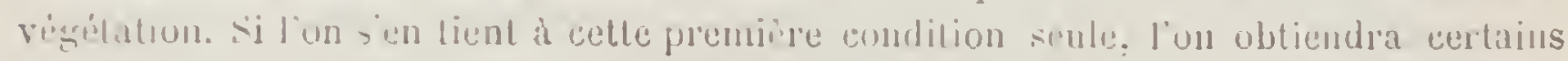

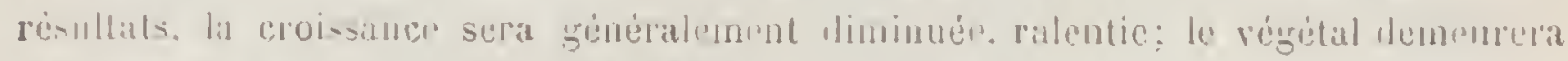
pelit, conme en rnfant mal nonrri demeure clıétit.

"Ponr uhtrenir cos albes si petits, el en mene temps si parfaits dans leurs propor-

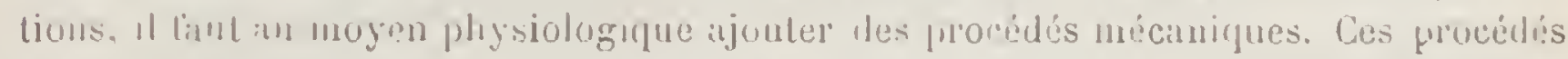

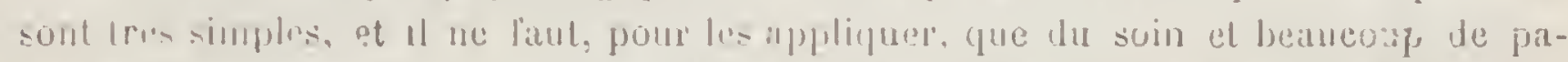

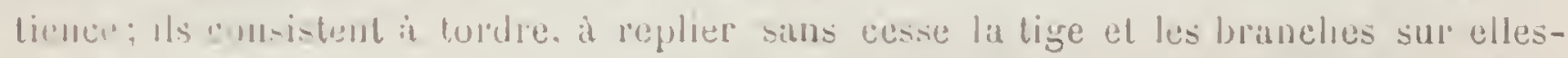
mome. an lur ol it mesure de leur eroissance, el a les fixer, duns leur torsion ou leur.

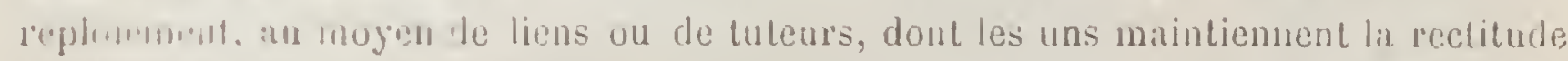

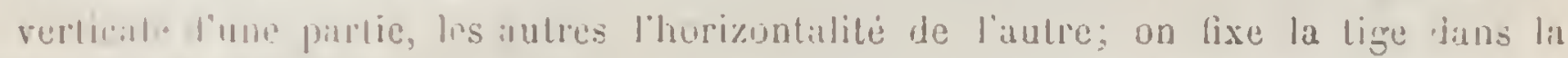

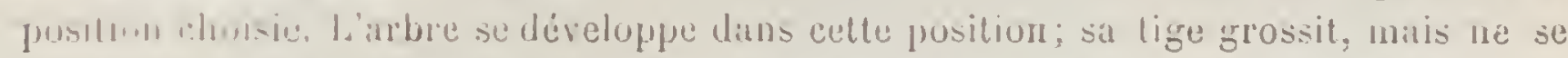
relibr punt: alle demenre conbée. Au cours de la croissance. l'extrémité supérieure de la 11 . ialloncre, et. par sal partic libre, tend à redevenir vertieale. Dès quelle a

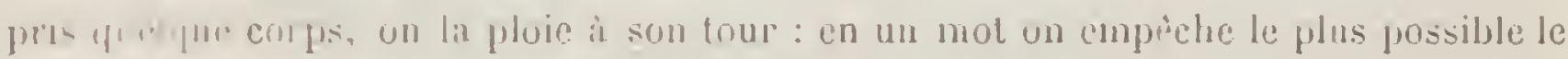

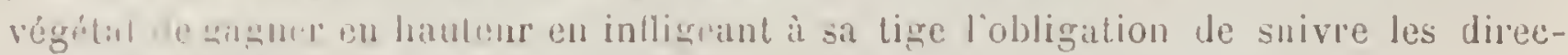
tions la fulus variées: un la fait aller horizontalement, puis en spirale raccourcie,

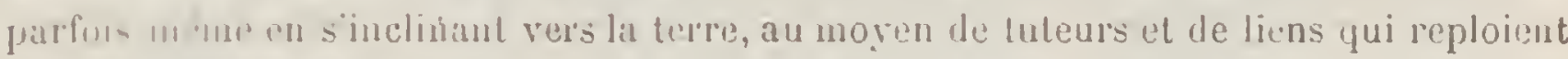

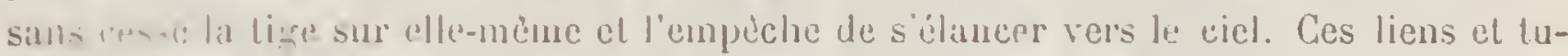
trur smit nees

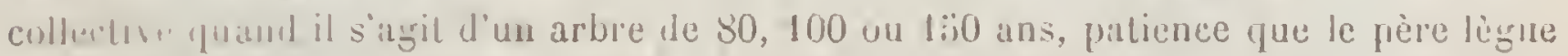

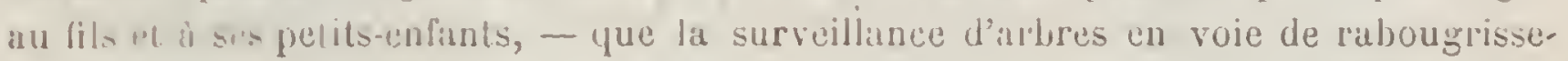
minll.

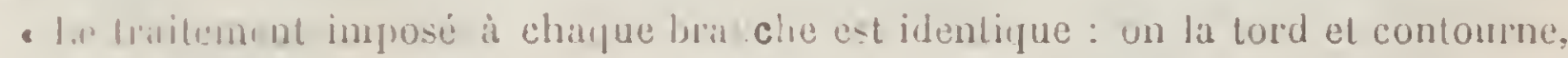

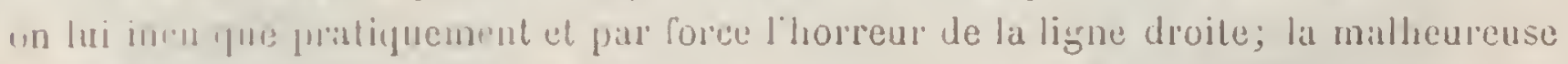

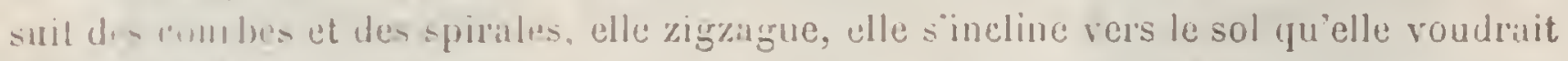

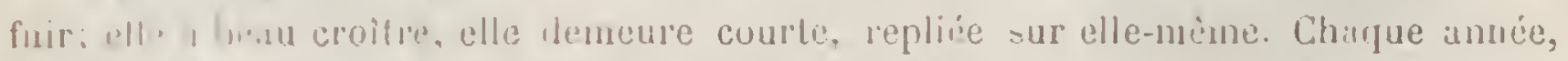

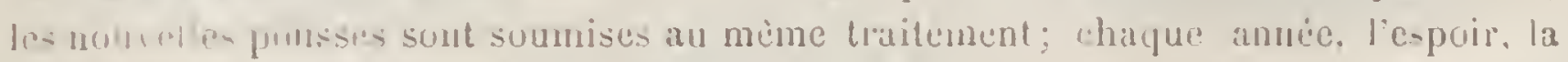

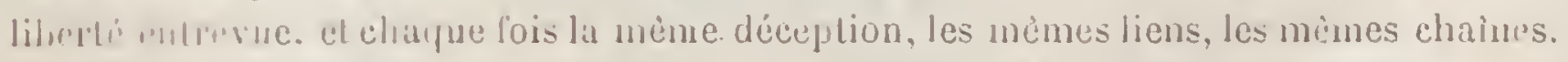

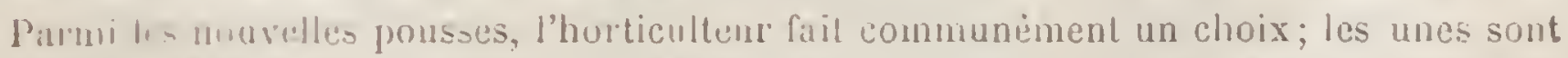
torturir. a la firoun du reste du végétil; pour les autres, on les détruil. Cette destruetion airle a donner aux branches une forme plus sinueuse, plus capricieuse, si ellı p" . "

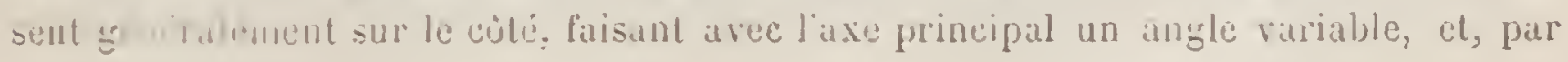


cela même, tendent moins que les bourgeons terminaux à augnienter la longueur de la branche dans le sens horizontal.

- La torture de l'arbre soumis au raccourcissement n'a point de fin, ou peu s'en faut;

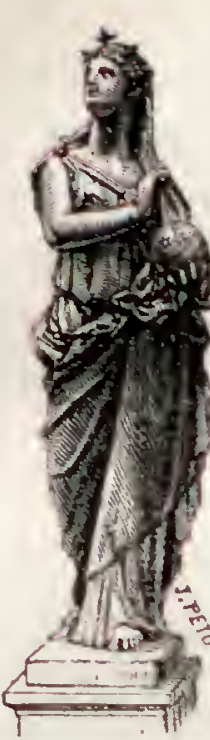

LAstronomie.

Statue elle cesse avec la vie même du malheureux. Sans doute, il vient un moment où les parties inférieures de la tige et des branches se passent de liens et de tuteurs; elles ont pris la courbure voulue, se sont épaissies et ont crú; elles se sont fixées dans leurs formes et ne se redresseront plus; il est trop tard pour cela; on peut les délivrer de leurs entraves. Mais les jeunes pousses veulent, - c'est ici un euphémisme d'une ironie dépla. cée, - être surveillées tant que la croissance de l'arbre n'est point complètement achevée; il les faut lier et ployer, sinon le développement en sera normal. C'est ce que montre fort bien un petit pin, agé d'une centaine. d'années, que l'on a pendant longtemps travaillé et torturé pour le laisser ensuite croitre normalement. Le de M. Hasse. tronc en est tordu ct contourné. L'unique branche qu'il

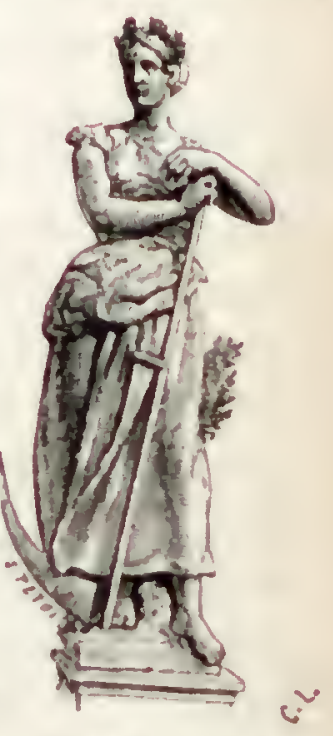

L'A Gaicultine. Slatue de M. Aubé. porte et qui s'est librement développée ne différe en rien de celle du pin normal, et fait avec le tronc qu'elle surmonte le contraste le plus instructif, puisque le méme arbre présente à la fois l'état naturel et l'état artificiel.

- Sous le petit pavillon de droite, on remarque trois relinosporas agés de 50 a 60 ans et hauts de $20 \mathrm{~d} 40$ centimètres; un érable de 80 ans ( 30 centimètres); un érable de 10 ans (כ0 centimètres). D'autres retinosporas, installés dans un tronc d'arbre, ont 80 ans et 20 à 50 centimètres; d'autres encore ont 150 ans. Il faut citer aussi les pins nains de 80 à 1500 ans dont les plus âgés ont 60 centimètres, des thuyas, des podocarpus macrophyllum, etc. La plupart des espèces exposées sont des coniferes, plus propres à supporter les fatigues d'une longue traversée.

- Le visiteur remarquera que différents thuyas, retinosporas et pinus sont fixés au

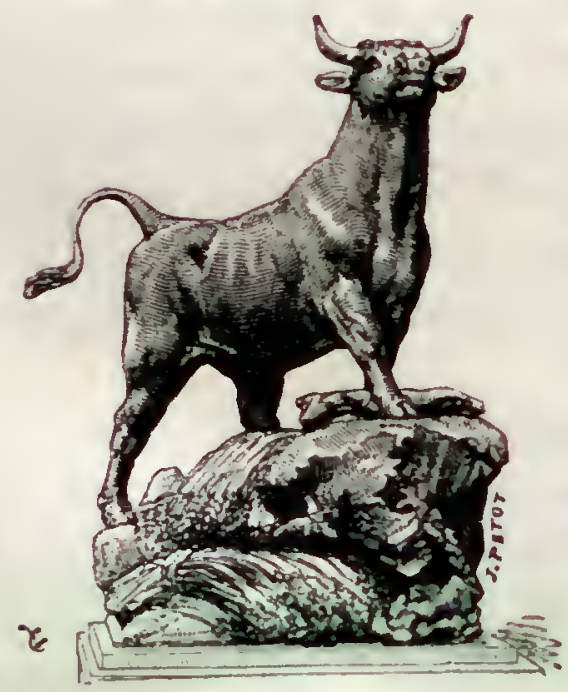

LE B OEV F.

Modèle de M. Cain. sol par des racines assez fortes, longues de 10 ou lij centimètres, qui font saillie verticalement hors de terre et soulèvent le tronc d'autant. C'est un effet de la croissance des racines. Celles-ci, ne trouvant point a traverser les parois du vase, l'effort, très considérable d'ailleurs et atleignant un nombre élevé de kilo. grammes, - quielles

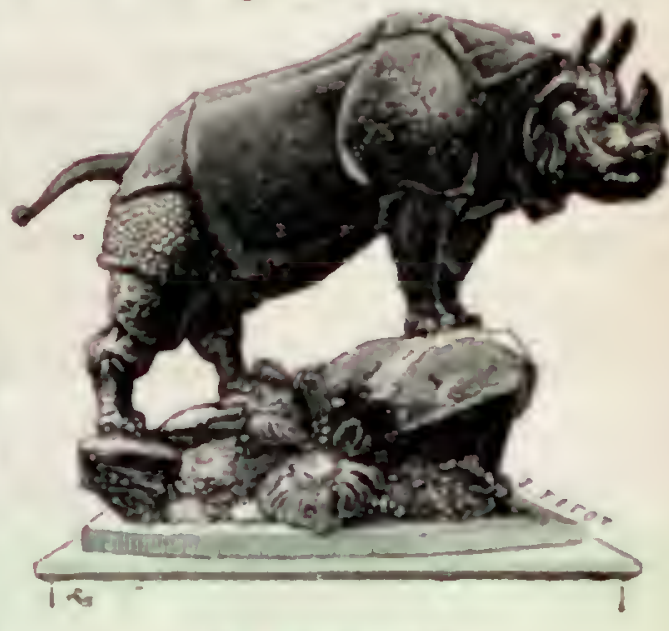

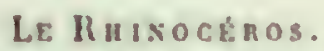
Modele de M. Sacquemarl.

exercent a pour résultat de repousser les racines principales hors de terre. Tel thuya de 100 ans a 40 centimètres de hautenr de tige; les racines hors de terre en ont 15 ou 18. Il est mème un retinospora dont la racine hors de terre a 130 contimetres de longueur, 
alors que la hauteur de la tige ne dépasse pas 10 centimètres. Il paraft avoir 26 centimètres et n'en a que 10 en réalité. Les arbres nains représentent évidemment la partie la plus curieuse, la plus nouvelle de l'Exposition horticole japonaise, mais non la plus jolie au sens de l'amateur européen. A ce dernier, nous pouvons cependant offrir une consolation. Il trouvera, avec de nombreux échantillons, des acer palmatum et

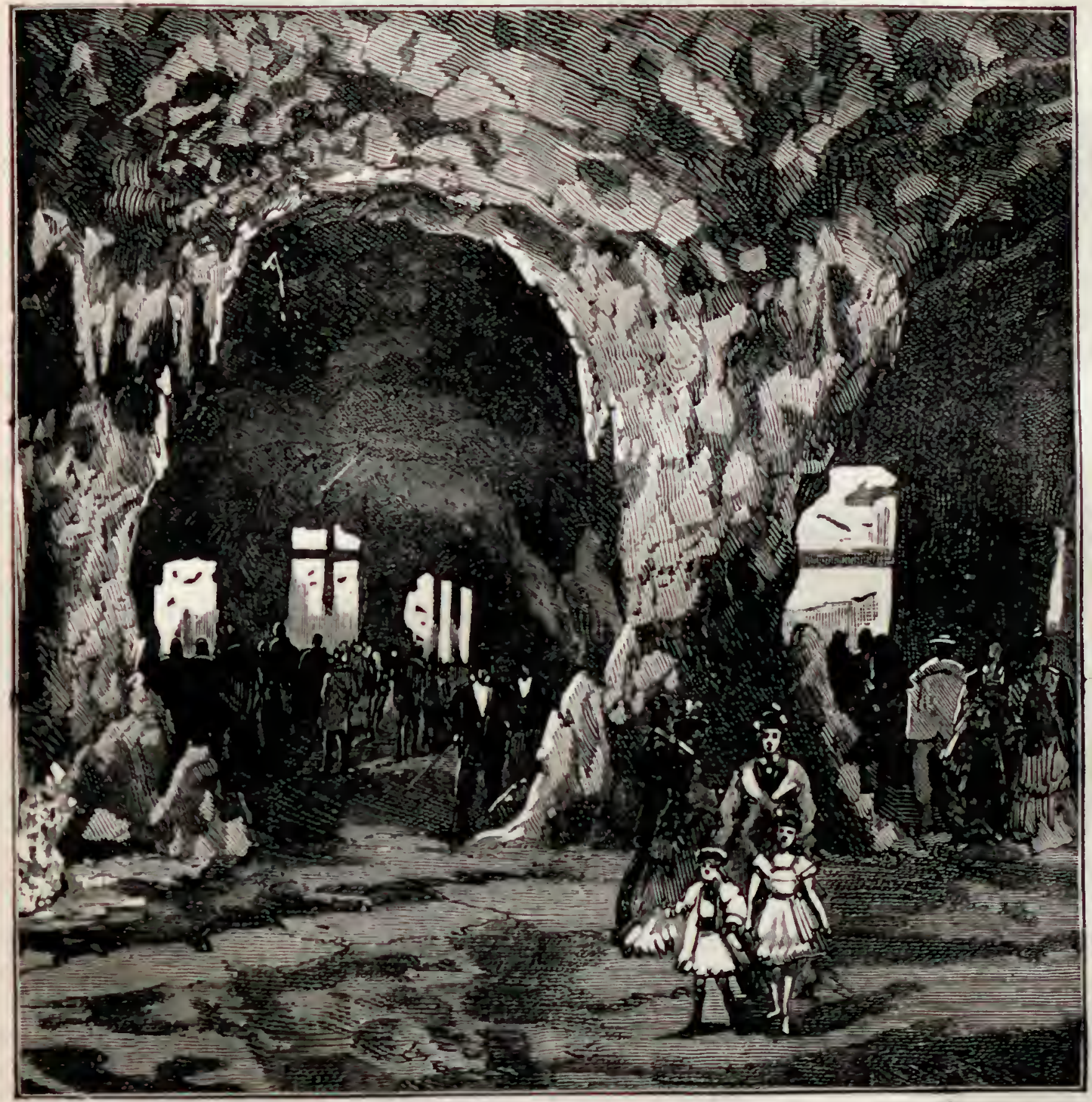

L'AQUARIUM DU TROCADÉRO.

japonicum, une belle exposition de quelque 600 Cycas, et plus tard il assistera \& la noraison de superbes plates-bandes de chrysanthèmes. ,

Le Gaz et le Pétrole. - Traversons maintenant le pont d'léna et arrivons le long du quai, à droite. Nous y trouvons les installations mécaniques, annexes de la classe 52 , les machines èlévatoires, l'exposition des applications du pétrole. Puisque nous avons a parler du pétrole, on nous permettra bien de parler en méme temps du gaz, bien que le Pavillon du Gaz sp trouve au Champ de Mars méme, à gauche de la Tour Eiffel. 
La lutte engagée entre les divers éclairages, et notamment, en ces derniers temps, entre la lumière électrique et le gaz, donne un intérét de plus à l’ítude des progrìs réalisés, sous l'impulsion de la concurrence, par cetle dernière industrie.

On ne peut s'empécher de reconnaitre qu'elle a dignement souteun la lutte et qu'il y a loin des premiers becs a flamme fuligincuse, installés il $y$ a cinquaute ans, à léclairage splendide que présentent depuis quelques jours la rue de la Paix et l'avenue de l'Opéra.

L'Exposition de 1889 a abandonné ses galeries el ses jardins it l'éclairage ślectrique; mais elle a réservé au gaz l'embrasement du Trocarléro, de la Tour Eiffel et du Dôme central. En outre, un pavillon, très bien aménagé et très inléressant, était construit par les sociétées de gaz réunies, pour montrer toutes les applications domes. tiques et industrielles auxquelles se prête ce merreilleux produit.

Avant d'entrer dans le détail, il est intéressant de donner une classification générale des malières employées dans l'éclairage, qui peuvent itre et qui sont de trois sortes : solides, liquides el gazeuses.

Les malières solides sont les branches de bois résineux. encore en usage dans quelques contrées peu civilisées: les chandelles, fabriquées avec le suif du bruf du mouton ou du bouc, et enfin les hougies proprement diles fabriqués avec la cire d'abeilles, le blanc de baleine et les acides margarique et stéarique. Les malières liquides sont les huiles grasses. En pratique, les plus usities sont celles d'olive. de coiza, de navette, d'œillette et de pavot. De nos jours cependant, les huiles erises sont de plus en plus délaissées et remplacées par les huiles de scluiste et fo pítrole dont l'emploi a pris en quelques années une extension considerahle, ot sur lespluplles nous reviendrons plus loin. La troisième catigorie enfin comprent le ginz, qualle que soit la matière dont il est extrait: résines, houilles, acides gras de loules natures, en un mot, matidres organiques, donnant par la distillation des carloues d'ludrugene, principe essentiel du gaz d'éclairage.

Le gaz fut découvert en 1799 , par Lebon, et une des premielres applicatuns fut l'eclairage de l'hópital Saint-Louis, en 1813. En 1820, divers quartiers le f'aris commnncèrent à s'éclairer, et en $1950 \mathrm{a}$, six compagnies gazières se partačtaimut l'eclairage de Paris. C'est a cette époque que fut créée la Compagnie parisienne du gaz par la fusion des six sociétés concurrentes. Sous sun impulsion, la consomnaliun se dérploppe avec une rapidité surprenante : tandis qu'elle n'était encore que de 20 millions de mètres cubes en 1853 , elle atteignait 60 millions en 1860 , et aujourd hui dépasce 200 millions.

Le gaz provient, comme nous venons de le dire, de la distillation de la louille et des huiles. Qurique le pouvoir éclairant du gazd'huile soit plus considérable que celui du gaz de houille, la houille est généralement adoptée en raison de son has prix. les houilles employées sont grasses à longues llanumes.

Lorsque, puur une fete publique, on est ohligé de produire rapidement une gramle quantité de gaz pour répondre à une exagération momentanée de consomuntion. on emploie des houilles spéciales anglaises, appelées cannel-coal, très riches en gaz eld'un prix plusélevé. On doità M. Audouin un appareil trìs ingénieux qui permet, en ume heure, de se rendre compte du rendement d'une houille en gaz. et en coke, ainsi que du pouroir éclairant et de la facilité d'épuration du gaz produit. I.es visiteurs en verront a l'lixpoposition un très beau spécimen. 
La première opération de la fabrication est la distillation.

Autrefois les cornues employées pour la distillation étaient en fonte, aujourd'hui on se sert de cornues en terre réfractaire qui se refroidissent beaucoup plus lentement. Les cornues sont placées au nombre de huit, en général, dans des fosses à récupération du système Siemens-Ponsard ou Lencauchez, dans lesquels les gaz de la combustion, après avoir parcouru une série de conduits en briques, disposées en chicane, et leurs avoir emprunté toute leur chaleur, viennent se brûler sous la sole où sont diposées les cornues et s'échappent dans une série de conduits semblables aux premiers, et dans lesquels ils se dépouillent de toute la chaleur inutilisée dans l'opération. L’arrivée et l'échappement des gaz sont alternativement inversés de telle sorte que dans chaque fournée on recueille la chaleur cédée pendant l'opération précédente au générateur par les gaz à leur sortie.

Au début du travail, les cornues sont chauffées lentement et portées progressivement au rouge cerise ( 8 à 900 degrés), température que l'on conserve constante ensuite pendant toute la distillation. La charge de chaque cornue n'est que de 120 a $150 \mathrm{ki}-$ logrammes de houille, bien que ce poids ne corresponde qu'à la moitié environ de ce que pourrait contenir la cornue, car la houille augmente à la distillation quelquefois de 2/5 de son volume. La distillation commence dès que l'air a élé chassé de la cornue, et dure 4 heures euviron. Le produit obtenu est très complexe et encore impropre d l'usage: c'est, en effet, un mélange de gaz, de vapeurs ammoniacales et sulfurées, et de goudron. 100 kilogrammes de houille donnent environ 28 à 29 mètres cubes de gaz, 72 kilogrammes de coke, 7 kilogrammes deaux ammoniacales et 6 kilogrammes de goudron.

A la sortie de la distillation, les produits dégagés passent dans un condenseur où ils se refroidissent et où se séparent les eaur ammoniacales et les goudrons. Ces condenseurs sont composés d'une série de tubes verticaux disposés en jeux d'orgue et dans lesquels circulent les gaz pour se refroidir et se débarrasser des vapeurs entraínées, tandis que le charbon de cornue ou coke, résidu de la distillation, se retire directement des cornues refroidies.

Du condenseur, le gaz passe à l'épurateur. Ces épurateurs sont des cuves en fonte hermétiquement fermées pendant la marche, et portant à l'intérieur des claies en fer ou en osier recouvertes de sciure de bois, de paille et d'une couche de chaux éteinte pulvérulente de 6 centimètres d'épaisseur. Le gaz traverse ces claies de bas en haut, et se débarrasse de l'acide carbonique et d'une partie de l'acide sulfhydrique qu'il contient; il faut 2 kilos de chaux pour 100 kilos de houille.

Le gaz passe ensuite à travers un mélange de sulfate de fer et de chaux, où il finit de se débarrasser de l'ammoniaque et de l'acide sulfhydrique restant, et, ainsi épuré, arrive enfin a un compteur de fabrication, et de là au gazomètre. Ce dernier appareil est réglé au moyen de contrepoids, pour contenir la quantité de gaz qui doit se consommer en un temps déterminé, et donner au gaz la pression voulue. Nous avons dit plus haut que le gaz pouvait se tirer d'autres matières que la houille. Ces procédés ne diffèrent en tout cas qu'insensiblement de celui que nous venons de décrire, c'est toujours la distillation qui est la base de l'opération.

Le gaz d'huiles lourdes sert principalement d l'éclairage des wagons, en raison de son pouvoir éclairant plus considérable que celui de la houille.

Le gaz transportable est tiré des schistes bitumeux par une distillation lente au 



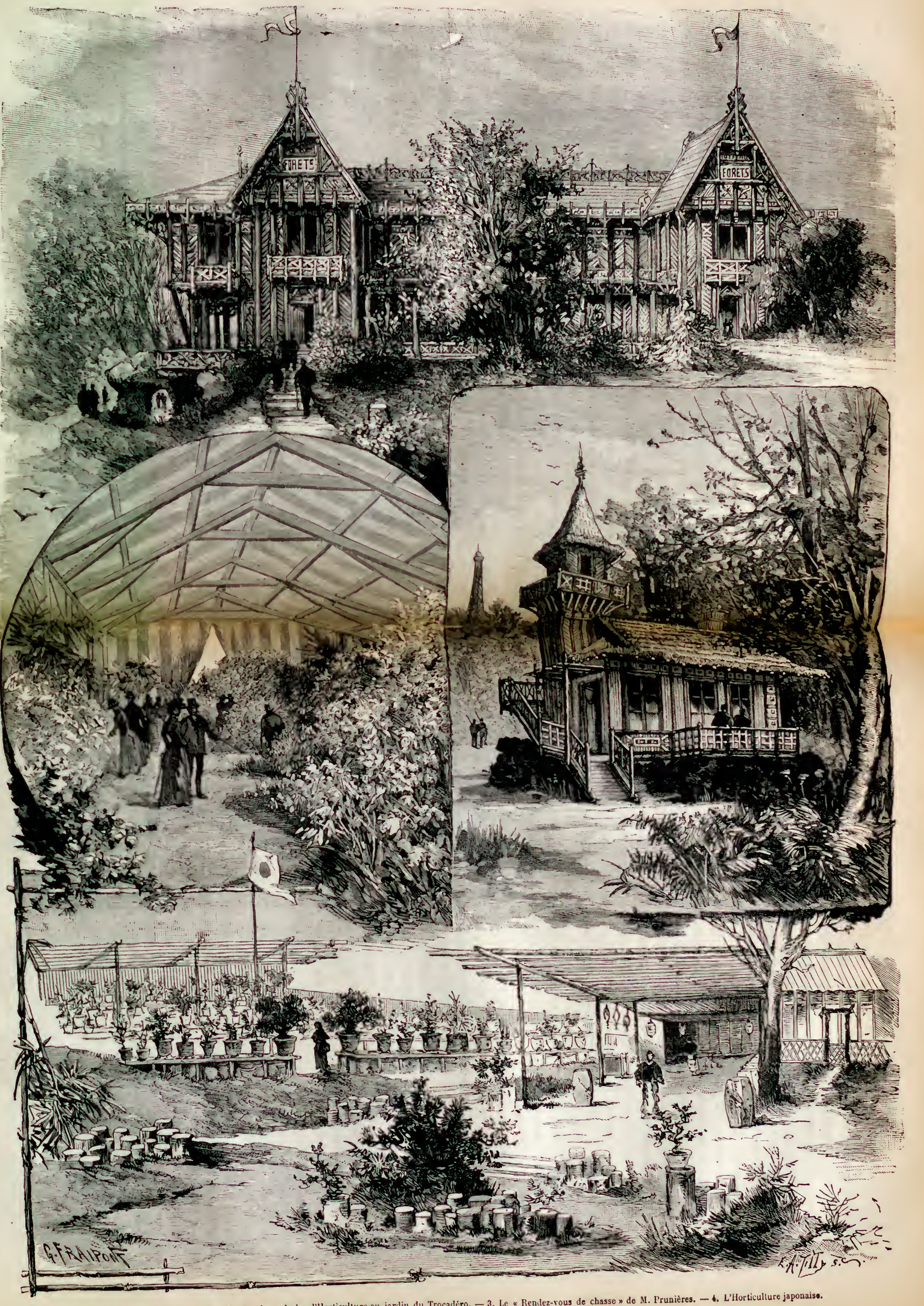


sortir de laquelle il est envoyé sous pression dans des gazometres, et de là, dans des caisses en tồe. Ce gaz est environ quatre fois plus éclairant que le gaz de houilie.

Il faut nous borner à renvoyer le visiteur au charmant pavillon où les compagnies du gaz ont rappelé tous ses emplois : éclairage, chauffage et force motrice; et, après avoir donné un aperçu des anciens appareils, ont réuni tous les ustensiles et machines les plus perfectionnés. Citons parmi les nouveautés une disposition heureuse de bec i flamme renversée, dans les appartements, une magnnifique cuisine où le gaz règne en maitre absolu, aussi bien pour l'éclairage que pour la cuisson des aliments; au soussol, une installation très soignée de moteurs a gaz dont l'emploi s'est répandu dans ces dernières années par suite de leur grande facilité d'installation el leur simplicité.

Malgré nous, notre pensée se reporte au xü siècle, alor's que vivait à Paris dans une des étroites rues du quartier du Fouarre, un juif nommé Ézéchiel, "grand liseur de grimoires, familier du diable, expert en toule sorcellerie "; les gens du quartier se signaient quand il passait, et, le soir venu, se montraient avec terreur la fenêtre du sorcier, vivement éclairée par la lueur d'une lampe qui, disait-on, brùlait sans mèclie et sans huile.

Cette lampe illumine aujourd'hui nos boulevards, nos maisons, nos chambres; elle a triomphé l'autre jour au Champ de Mars, lors de la fête d'inauguration du Pavillon du Gaz.

Les représentants les plus autorisés de l'industrie du gaz, frappés de l'ignorance dans laquelle se trouve encore une grande partie du public qui ne sait utiliser rationnellement le gaz, ni lui demander toutes les ressources si variées qüil procure tant pour l'éclairage que pour le chauffage, la force motrice et la ventilation, ont donc agi très sagement en présentant, installés et foncîionnant dans les conditions pratiques de la vie domestique, les appareils les plus variés et les plus parfaits.

Et notez que c'est là une exposition collective à laquelle ont participé presque toutes les usines à gaz de France. Chacune a donné suivant ses moyens : la Compagnie Parisienne a donné 80,000 francs, le Groupe lyonnais 10,000, la Société du gaz de Vire 50, et celle de Marmande 250 .

Mais ce n'est point seulement par l'électricité que l'éclairage au gaz est battu en brèche. Depuis quelque trente ans, un nouveau produit, le pétrole, a pris un développement considérable dans l'éclairage domestique

L'origine du pétrole est inconnue; on suppose qu'il résulte de la décomposition des plantes marines et des animaux vivants sur le rivage des mers primitives; on le trouve en nappes liquides à une certaine profondeur dans le sol, et son exploitation a donné naissance à une industrie de première importance. Le lecteur s'en rendra compte par la seule visite du charmant panorama dans lequel IIM. Deutsch, les grands raffineurs de pétrole, ont donné un aperçu des deux principaux centres de production : les collines verdoyantes et boisées de la Pensylvanie, d'un côté; la terre grise et inculte du Caucase, de l'autre. La représentation très fidele des puits de sondage, des derricks et de ces usines volantes qui les entourent, présente le plus haut intérét.

L'exploitation des sources de pétrole n'a guère connnencé qu'en 185ั, en Amérique. La première source mise à jour fut celle d'Oil-Creek; on trouva une nappe de pétrole à 21 mètres de profondeur. Le puits donna au début 1,817 litres. Ce fut donc à Oil-City, à 960 kilomètres de New-York, que l'exploitation se concentra eı premier lieu. C'était dans une vallée très pittoresque, où les habitants, pour ainsi dire nomades, 
dès qu'un puits ne donnait plus rien, l'abandonnaient de suite pour se transporter près des nouveaux sondages qui avaient révélé la présence de la nappe.

Les habitations se construisaient en $\mathbf{1 4}$ jours avec des troncs d'arbres. On travaillait jour et nuit, sans arrèt, dans une atmosphère que les vapeurs du pétrole rendaient épouvantable. Riches et pauvres étaient obligés de garder toujours les mêmes vêtements imprégnés de vapeurs de pétrole, et ne les quittaient que lorsque ceux-ci devenaient trop lourds it porter.

Dès qu'on avait rencontré un long sondage, il suffisait d'installer les pompes ot l'extraction commençait. Les hénéfices retirés de l'exploitation étaient de suite considérables; certaines sources ont donné jusqu'à 10 millions de francs pour une dépense

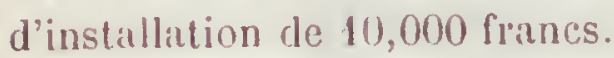

L'extraction, tout en devenant de plus en plus considérable, n'a guère changé de caractère. Les procédés et les inœurs sont restés identiques, bien que le pays soit profondémeut modifié.

En Pensylvanie, en 1862, la produclion était de 3,600,000 hectolitres; en 18\%0, de 7 millions; en 1873 , de 10 millions, et de nos jours, elle dépasse 13 millions d'hectolitres.

Les sources sont souvent à une grande profondeur, mais certaines ont une pression intérieure suffisante pour qu'on puisse employer à leur extraction le système du puits artésien. Ce sont les sources jaillissantes, et les constructions faite à l'entour s'appellent des ' derricks .

Dans le Caucase, la majeure partie des sources sont jaillissantes, et l'extraction, par cela seul, réduite à la plus grande simplicité.

Le pétrole, avant d'étre livré à la consommation, est distillé et épuré. A la distillation, on obtient des produits divers : de 400 à 70 degrés, l'éther de pétrole: de 70 à 120 degrés, l'essence minérale; de 120 a 180 degrés, l'huile de pétrole pour éclairage; et au-dessus, jusqu' i 400 degrés, les huiles lourdes, servant à fabriquer des graisses pour les machines, et entre autres, la parafine, d'un usage si fréquent et dont on tire également des bougies. Le résidu de la distillation donne un coke qui peut ètre employé pour le chauffage.

L'huile de pétrole se transporte dans des réservoirs en tôle montés sur wagons, ou sur des navires aménagés spécialement pour leur transport qui les reçoivent au sortir mème de la source et les amènent en Europe où se fait le raffinage.

Suez-Panama, - Quand nous aurons suffisamment vu l'Exposition du pétrole, nous remonterons au coin du pont d'Iéna, et laissant à notre droite l'Histoire de l'habitation de M. Garnier (que nous avons longuement décrite), nous arriverons à la Tour Eiffel.

Un batiment de style égyptien, avec de jolies peintures murales, frappe tout d'abord nos regards. C'est l'Exposition de Suez-Panama. Pour le canal de Suez, vous verrez les plaques indicatrices des distances, les modèles des gares entre Suez et PortSaîd, le plan des jetées immenses qui ferment l'avant-port de Port-Saïd, une drague de 30 mètres de long et de 9 mètres de large, des bateaux porteurs, des phares et balises. La question de l'éclairage mérite une mention spéciale. En 1885 , il fut reconnu que le canal de Suez ne répondait plus aux exigences de la navigation. On résolut alors d'augmenter la largeur du canal, et pour permettre aux navires de faire leur traversée la nuit, la Compagnie mità l'étude le projet d'éclairage que l'on est en train, 
aujourd'hui, de mettre à exécution: éclairage fixe, destiné à guider les navires, et situé sur les bords du canal; éclairage mobile porté par les navires eux-mémes. Après

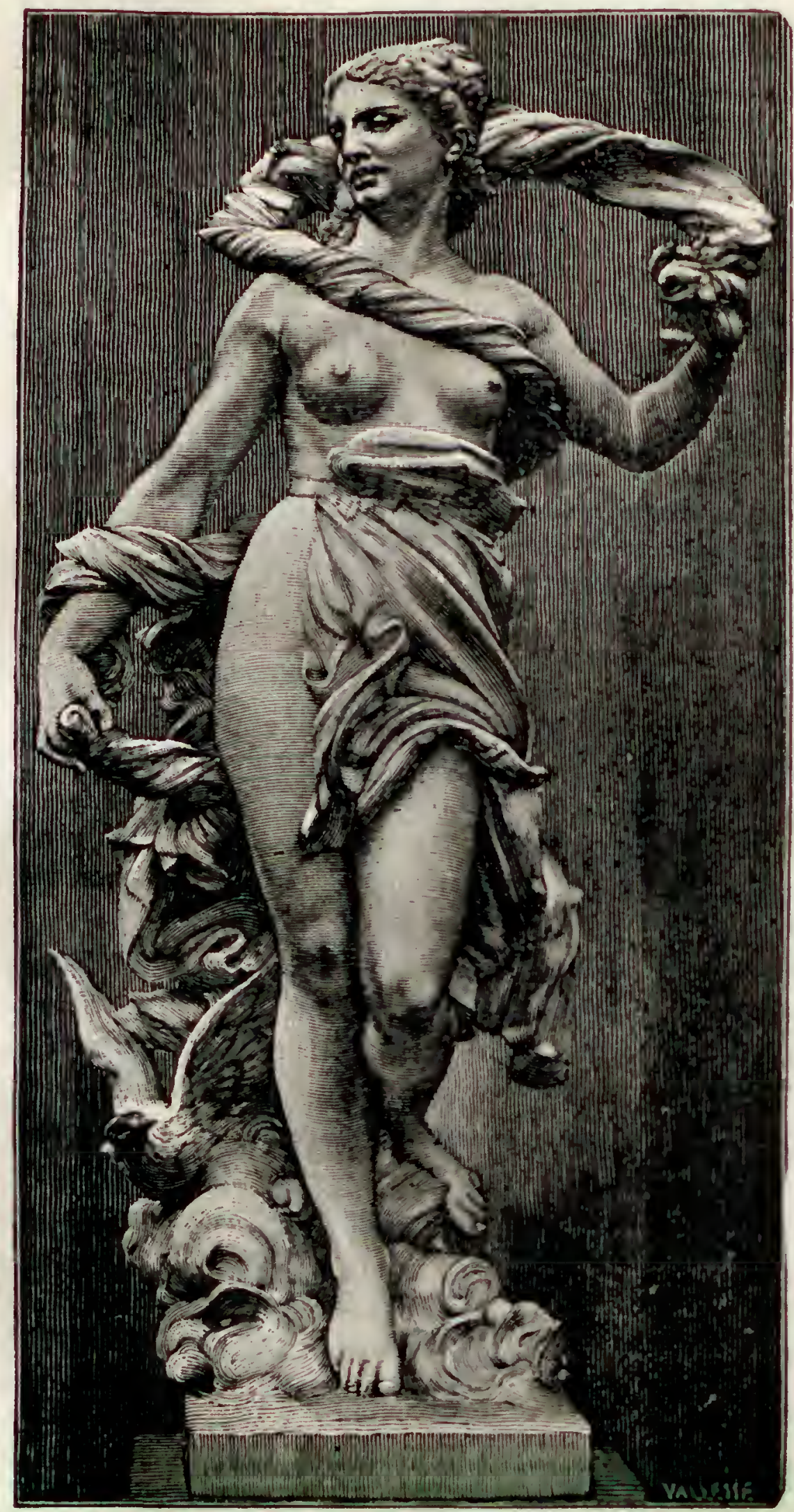

L'Ain.

Statue de M. Thomas, oraant Ia cascede du Trocadtro.

plusieurs essais sur les différents modes d'éclairage, on s'arrêta au gaz d'huile comprimé pour constituer les feux fixes, portés par des bouées nottantes et des fanaux.

On divisa les feux en deux classes et on leur donna trois coulcurs diférentes.

Une classe de feux est placée de façon à permettre aux navires de se diriger exac- 
tement au centre du chenal dans les parties étroites du canal. Ce sont les feux directeurs et leur pouvoir éclairant s'étend de 6 à 8 milles natutiques. Les feux de la deuxième classe sont destinés à permettre aux navires de rester dans des eaux suffisamment profondes dans les parties courbes du canal et dans les lacs. Ces feux. laissant libre une voie d'environ 20 mètres de largeur, sont placés alternativement sur les deux bords du chenal, à égale distance du centre. Ce sont les feux du canal. Pour les distinguer des feux directeurs qui sont tous blancs, les feux du canal sont verts du cóté de l'Asie et rouges du côté de l'Afrique.

Ces feux directeurs sont placés aux angles des deux parties droites du canal et les feux du canal dans les parties courbes et dans la traversée des lacs. Les pilotes peuvent toujours voir deux feux à la fois, ce qui leur permet mieux de prendre leur orientation. Ces feux sont fixés soit à des bouées, soit à des mats.

Pour l'éclairage mobile, c'est-à-dire l'éclairage des navires eux-mèmes, ce fut la lumière électrique qui l'emporta. Pour les navires qui ne sont pas spécialement outillés pour produire eux-mèmes des feux électriques on a imaginé des installations volantes que l'on peut monter très rapidement. Toutes les précautions' ont ćté prises pour éviter les collisions ou atterrissements et les navires sont soumis à des règles spéciales. En arrivant à Port-Saïd ou à Port-Tewfik, il faut qu'ils montrent aux agents de la Compagnie, s'ils veulent voyager de nuit, qu'ils ont des appareils ćlectriques convenables. On exige d'eux un feu pouvant projeter une nappe lumineuse d 1, 200 mètres et une lampe de mât pouvant éclairer un champ de 200 mètres. Quand les batiments se rencontrent de nuit, ils sont tenus de ralentir leur marche et de faire certains signaux.

Le cunal de Panama offre un intérèt plus actuel encore, si l'on paut dire, en raison mème des difficultés que présente son entière exécution.

Jamais on n'a remué un volume de terre équivalant aux immenses terrassements (qui se font à travers l'isthme qui relie les deux Amériques.

Le tracé du canal rencontre plusieurs des sommets qui abondent dans l'orograploie de cette région. Les sommets rencontrés sont la Culebra (190) inetres), le Nilio (138 mètres), la Luisa (170 mètres) et le Paraiso (152 mètres). De plus se présentent des cours d'eau et des torrents, notamment le Chagres, impétueux en certaines saisons au point de tout inonder. Il a fallu des travaux de défense tout spéciaux, fort couteux et imprévus dans les devis. De nouvelles diflicultés proviennent encore du climaı. (on sait qu'il existe déjà depuis un certain nombre d'années une lignne de chemin de fer allant de Colon à Panama.

C'est en 1789 qu'un congrès international d'ingénicurs réunis a Paris adopta, parmı les divers projets présentés, le tracé en exécution dù à MI. Wyse el lieclus, officiers de la marine française et concessionnaires du gouvernement colombien. Ce tracé arail 73 kilomètres de long et comprenait un canal de niveau, c'est-à-dire sans écluses et à ciel ouvert. La largeur au plafond était de 22 mètres et de 40 au plan d'eau. La pro. fondeur d'eau était de 9 mètres.

Une société présidée par M. de Lesseps fut fondée au capilal de cinq cents millions et dès 1881 les travaux commençaient. Mais l'attaquedu sol fit voir d'élıormes difficultés imprévues. Le terrain était d'une grande dureté, difficilement attaquable; et surtont enfin le calcul des terrassements à effectuer avait été déplorablement fait. Au lien de $100,000,000$ de mètres cubes de déblais, on arriva à 140,000,000 de mètres cubes, chiffre qui demeure encore très en dessous de l'exactitude. 
Des contrats furent faits avec les. plus grands entrepreneurs qui s'engageaient au prix de 1 fr. 5̃0 le inètre cube, et en 1883 les chantiers en pleine activité compı́aieut un effectif de onze mille ouvriers. Mais la difficulté capitale, c'est la traversée de la Culebra par une tranchée de près de 15 kilomètres de long et alteignant en certains points la hauteur clfrayante de 150 mètres.

A la longue on fut effrayé de l'immensité des travaux, et, en 1889, on abandonna le projet du canal de niveau pour un canal à écluses, ce qui augmente les difficultés d'exploitation, mais diminue les terrassements ì faire.

Le canal provisoire à écluses a pour principe l'établissement, dans le massif central, d'un bief supérieur (jui permettra de continuer les travaux du canal ì niveau. Le tracé du canal à bief diffère très peu du ilacé antéricur. Le canal ayant son origine dans la

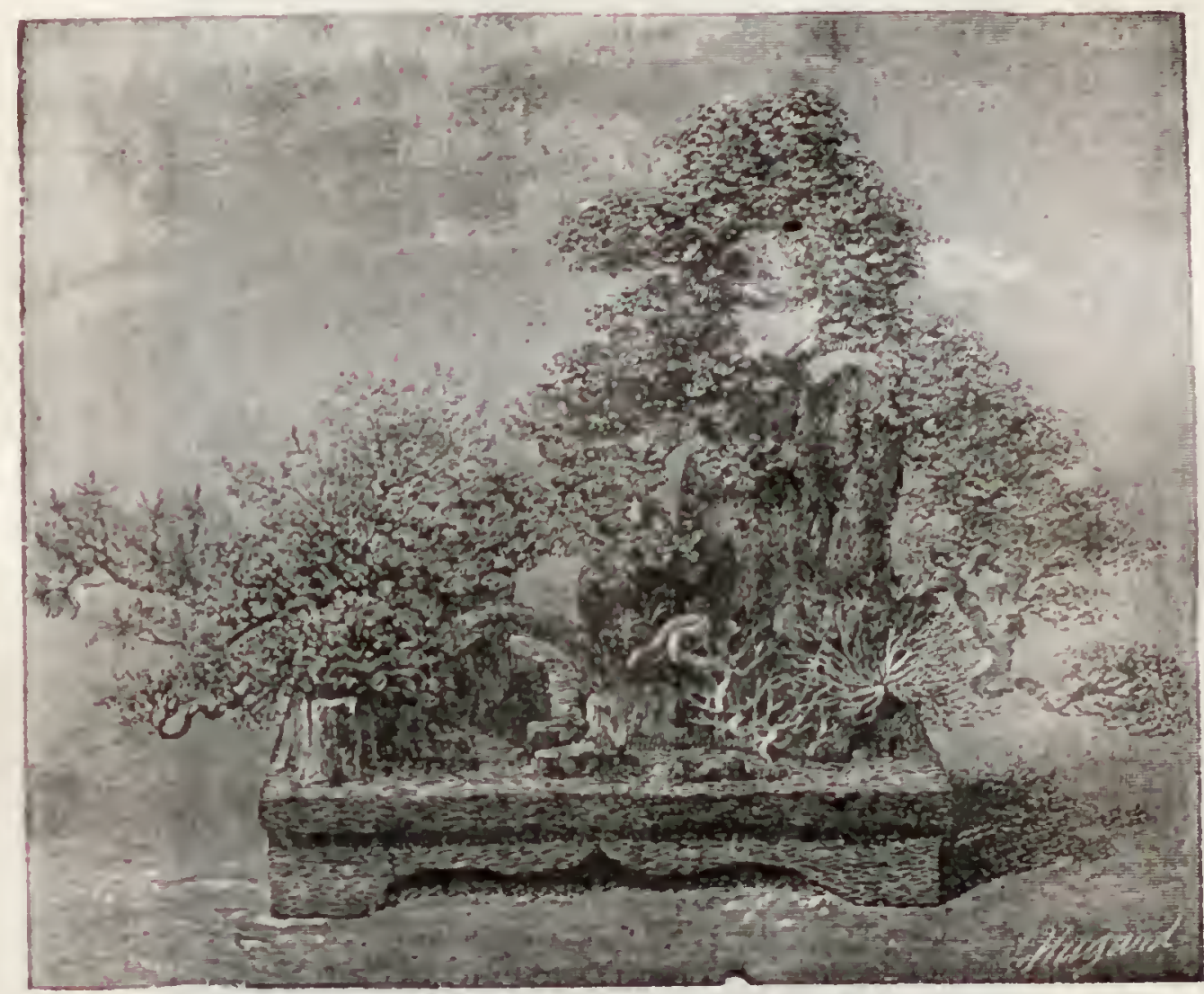

Paysage formé de l'ins, Thuyas, etc., plantẻs sur des trones de fougeres.

baie de Limon, sur le versant de l'Atlantique, reste au nireau mojen de la mer i Colon jusqu'an kilomètre 22,7 , où l'on se propose d’établir une première ëcluse du système de 8 inètres de chute. Une deuxième écluse, également de 8 mètres de chute, sera construite au kilomètre 37,2 . Puis successivement deux écluses de 11 mètres de chute aux kilometres 43,8 et 46,3. 11 y aura donc en totalité dans l'escalier de géants ainsi établi sur le versant de l'Atlantique 4 écluses rachetant la pente naturelle du sol jusqu'au bief de partage dont le plan d'eau est à l'altitude +38 mètres.

Du côté du Pacilígue le canal redescend par trois écluses de 11 mètres de chute a établir aux kilomètres 52,2,57,8 et 61,8 et une écluse de 8 mètres de chute au kilomètre 59,1 . On racliètera ainsi la différence du niveau de 41 mètres existant entre l'altitude +38 du bief supérieur et la cote -3 des basses mers de vives eaux à Punama.

Peut-être, en cas de circonstances difficiles, rencontrées au cours de l'exécution 
des travaux, la compagnie soulèvera-t-elle de 11 metres le bief supérieur en portant temporairement le plan d'eau de ce bief a l'altitude +49 . Cela entrafnerait la construction d'une cinquième écluse sur chacun des versants aux kilomètres 49,5 et 56,7 .

Dans chaque bief d’écluse, le profil normal adopté pour le canal à niveau est maintenu. La largeur des portes sera de 18 mètres. La longueur utile des écluses do 180 mètres. A l'entrée, côté Colon, le plafond du canal aura 180 mètres de largeur sur 3 kilomètres, et à la sortie, côté de Panama, 50 mètres de largeur sur 6 kilomètres. De la Bocca, versant du Pacifique jusqu'à Naos, le chenal en mer aura 50 mètres do largeur.

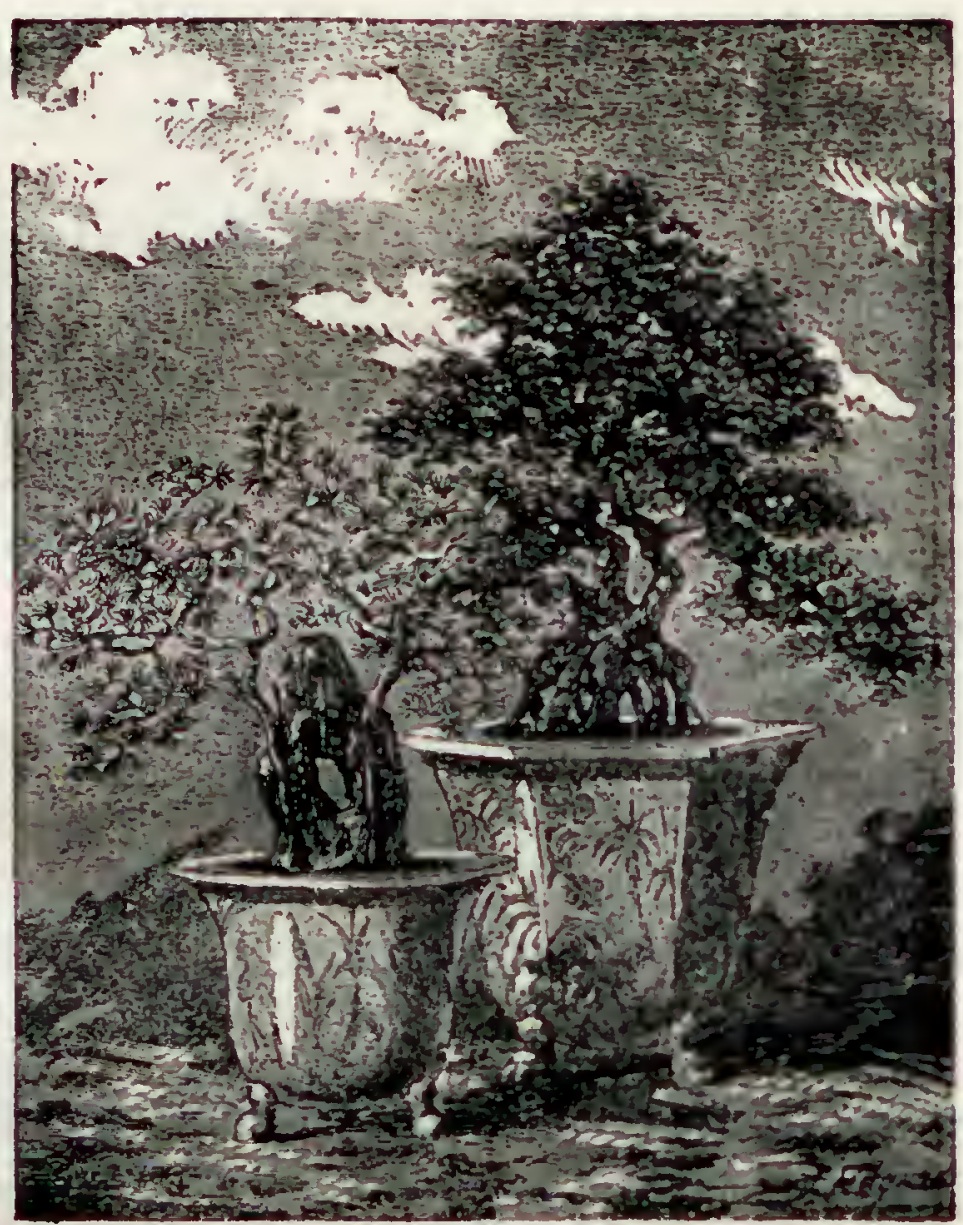

Thuya ágé de 30 ans et Relinospora ágé de 160 ans.

La construction d'écluses aussı vastes avec des chutes de $\mathbf{1 1}$ mètres a présenté de grandes difficultés, car l'on ne pouvait songer à employer - tant au point de vue de la résistance qu'à celui de la manœuvre d'ouverture - système de portes busquées analogues à celui que nous voyons fonctionner sur des canaux où la chute n'est que de 2 à 4 mètres. La difficulté a été résolue par $\mathbf{M}$. Eiffel, le constructeur parisien, qui a imaginé des portes roulantes formées de caisses métalliques à fortes nervures et portées par des galets de suspension par une sorte de petit pont tournant jeté au-dessus de la porte. Cette porte, ou ce caisson, roule normalement a l'axe du canal et vient se garer dans un logement taillé dans le mur perpendiculairement à l'axe du sas. La porte une fois dans son logement, le pont tournant qui a servi à supporter le mouvement de la porte s'efface à son tour par rotation et la voie est ouverte.

La construction des grandes parties roulantes a été répartie entre les usioes de 
M. Eiffel à Levallois-Perret et les chantiers de la Loire a Nantes. Trois écluses d'amont sont déjà terminées, dont deux démontées et prêtes à être expédiées. Cinq autres seront exécutées dans le délai de cinq mois.

Une porte d'écluse d'amont pèse 230 tonnes, se démonte en 110 morceaux et occupe un volume de 750 mètres cubes. Sa hauteur est de 10 mètres, sa longueur est de 24 mètres et son épaisseur de 3 mìtres. Les portes d'écluses d'aval, plus grandes, ont 21 mètres de haut, 24 mètres de long et 4 mètres de large. Le système de portes rou lantes en forme de caissons rectangulaires est celui qui semble devoir s'appliquer le mieux à de grandes chutes.

Pour ce qui concerne l'organisation de l'exploitation du canal de Panama, nous trouvons des renseignements très précis dans une étude de M. l'ingénieur Cossoux

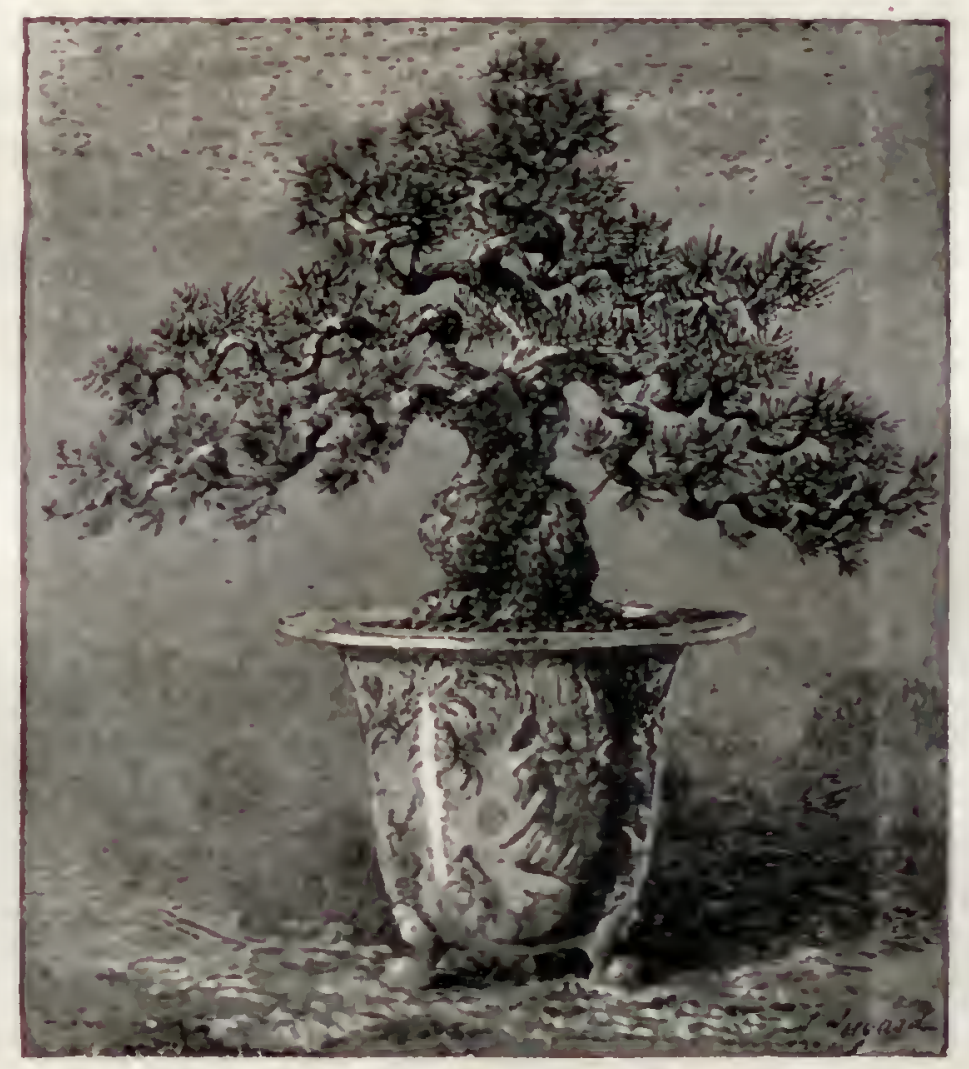

I'in naln japonais, ágé de 150 ans.

publié par le Journal des installations maritimes. Les disposilions adoptées pour le canal de Panama sont celles qui comportent le minimum des dépenses. Les navires passeront en convois. Dans les grands biefs et dans les parties maritimes, ils auront une vitesse de 10 kilomètres à l'heure; dans les biefs courts, c'est-d-dire dans ceux qui auront moins de 2,400 mètres de longueur, la vitesse sera de 3 kilom. 600 à l'heure, correspondant à une vitesse de 1 mètre par seconde. La durée d'occupation d'un sas d'écluse, y compris le temps nécessaire pour l'entrée et la sortie, sera de soirante minutes par narire isolé ou par deux navires passant simultanément. Les navires pourront donc se succéder dans les écluses à un intervalle d'une heure. Un navire marchant isolément nuit et jour mettra pour passer d'un océan à l'autre dix-sept beures.

Les convois seront les uns réguliers et journaliers pour le trafic habituel, les autres exceptionnels, pour les jours d'encombrement. Les convois réguliers auront deux 
croisements. Le nombre maximum des navires pouvant constituer le convoi journalier devra être tel que la durée d'occupation par le convoi de la partie éclusée du canal soit égale à 24 heures.

La durée moyenne du parcours, pour les navires transitant en convois, sera dixneuf heures d'un océan à l'autre.

Les convois exceptionnels, quand ils seront nécessaires, seront intercalés dans les convois réguliers et stationneront dens le bief no 3 pour laisser passer les convois régu'iers. Les convois réguliers occuperont les écluses pendant vingt heures sur quarante heures; celles-ci seront donc disponibles pour les convois exceptionnels pendant vingt-huit heures, soit pendant quatorze heures pour le convoi montant et quatorze heures pour le convoi descendant. Le tonnage moyen par éclusée peut ćtre estimé à

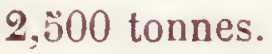

Les convois réguliers, s’ils étaient complets, donneraient un trafic journalier de

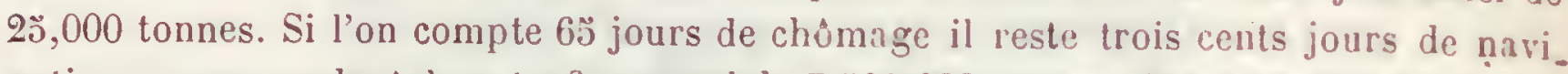
gation, correspondant à un trafic annuel de $\bar{\imath}, 300,000$ tonnes. Si les navires ne se présentent a l'entrée du canal avec assez de régularité pour que les convois réguliers suffisent a tous les besoins du trafic, les convois exceptionnels obvieront aux encom. brements qui pourront se produire et assureront la réalisation du trafic annuel annoncé.

Républuqe Argentune. - Nous voici devant le Pavillon de la République Argentine.

On sait que tous les pays d'Amérique prenrent part à l'Exposition; dès le début, tous s'étaient montrés favorables à une participation officielle, et, depuis lors, ce mouvement de sympathie n'a fait que s'accentuer.

En 1878, l’Amérique méridionale et l'Amérique centrale occupaient une surface de 2,000 mètres carrés. Pour 1889, il a fallu trouver des surfaces considérables. La place manquait dans les grands édifices du Clamp de Mars pour satisfaire a toutes les demandes; il a fallu prendre sur les jardins et, en quelque sorte, imposer a chaquo pays la construction d'un pavillon spécial. Loin de s'en plaindre, les républiques de l'Améque du Sud et du Centre-Amérique, le Mexique et le Brésil, ont vu là une occa-ion de se distinguer les unes des autres et de faire mieux ressortir leurs expositions si intiressantes et si variées.

C'est ainsi que près de la Tour Eiffel, en aval du pont d'léna, s'est élevée toute une ville. Il y a là des palais, des maisons d'babitation, les pavillons, des kiosques, des jardins et des serres remplis de plantes exotiques. Chaque gouvernement a fait des sacrifices considérables pour être représenté dignement; il y a eu un entralnement général et une heureuse rivalité; c'est à qui fera mieux et plus grand et plus beau que le voisin. Tout cela représente des millions, el c'est notre pays, nos architectes, nos décorateurs, nos constructeurs qui en ont profité. Merci donc au Nouveau-Mondel

Quelques pays ont eu l'heureuse idée d'élever des constructions rnppelant leur architecture nationale; tels sont : le Vénézuéla, le Mexique, l'Équateur et le Nicaragua. D'autres, sans adopter un style national, ont voulu néanmoins donner à leur pavillon un caractère spécial et ont recherché un genre de décoration suffisamment exolique. Enfin plusieurs États, comme la République Argentine, le Brésil, l'Uruguay, le Chili, la Bolivie, ont surtout voulu faire grand.

Chacun peut donc, en quelques jours, faire un voyage au Nouveau-Mlonde sans craindre la fièvre jaune, sans redouter les naufrages. 
Il y a ld les collections les plus étonnantes de toui ce que produit l'A mérique latine sous les climats les plus variés, depuis le Mexique jusqu'a la Terre de Feu, en passant par les zones équatoriales. On se rend compte des richesses inépuisables de ces pạys, car c'est un amoncellement de minerais chargés d'or et d'argent, de bois aux teintes superles, de tissus inconnus en Europe, de céréales de grosseur et de poids fantastiques, de produits alimentaires les plus divers et les plus tentants.

Grace à des plans en relief, à des cartes, à des vues photographiques, d̀ des tableaux, on royage sur des fleuves immenses, sous des forèts vierges et dans la Pampa sans fin. Pour nous faire connaftre les mœurs des indigènes, on nous montre leurs types, leurs habitations et mille objets encore employés par eux; on nous montre aussi des civilisations qui ont entièrement disparu; et à côté des restes des anciennes races, afin que nous soyons frappés des progrès qui ont été faits par les civilisateurs actuels du continent américain, on place sous nos yeux des renseignements, des livres, des albums qui contiennent des statistiques surprenantes.

Le public verra qu'il y a dans l'Imérique latine des villes qui égalent, par leur splendeur, leurs améliorations constantes, leurs universités et leurs établissements philanthropiques, nos plus helles cités de la vieille Europe; il comprendra qu'avec un amour aussi prononcé pour tout progrès non seulement dans l'agriculture, le commerce et l'industrie, mais aussi dans les sciences, les arts et les lettres, ces jeunes pays sont appelés a tenir une grande place dans l'univers.

La République .Irgentine, qui a eu des millions à sadisposition pour organiser son exposition, a construit un palais en fer et en briques destiné à ètre transporté à BuenosAyres. Mais ce fer et ces briques sont couverts, jusqu'à la profusion, d'une ornementation l'un éclat et d'une multiplicité de tons peut-être un peu criards. L'ensemble soullre de celte trop grande variété et de cette abondance de motifs décoratifs; toutefois il y a des détails intéressants qui gagneront à être vus avec plus de recul, lorsque l'édilice ne sera plus entouré des constructions qui encombrent les allées avoisinantes.

Certes, rien n'y manque : soubassements en terre cuite, briques vernissées, grès émaillés, mosaĩques, revétements de terre, panneaux de porcelaine, encadrements métalliques, un peu partout de l'or, de l'argent et du bronze. C'est étourdissart!

Le palais, construit par M. Ballu, est rectangulaire; la partie centrale se compose de cinq coupoles, dont les cein tures sout semées de caloochons de verres multicolores; le soir ces cabochons sont éclairés à la lumière électrique et produisent le plus curieux elfet.

I la hauteur du premier étage, il y a une série de loggias à trois arcades soutenues par d'élégantes colonnettes de bronze doré et reliées entre elles par des balcons en fer forgé d'une grande finesse.

A l'intérieur comme a l'extérieur la commission argentine a placé de véritables nuvres d'art. commandées aux peintres et aux artistes français les plus en renom. E. Barrias, Hugues, Dupuis ont fait les statues ou les groupes qui décorent les quatre pylones d'angle et la porte d'entrée.

Roll, T. Robert Fleury, Besnard, Gervex, Leroux, Duez, Merson, Cormon, Mantenard et d'autres encore ont fait des panneaux décoratifs qui donnent à l'intérieur du palais une réelle valeur artistique.

Le pavillon occupe une superficie de 1,600 mètres carrés au rez-de-chaussée et de 1,400 au premier étage. 
La République Argentine a certainement une exposition des plus intéressantes par la variété, l'abondance et la richesse de ses produits. L'avenir de ce pays est incalculable; pays d'agriculture, pays d'industrie, il a tout pour lui : au nord, près des tropiques,

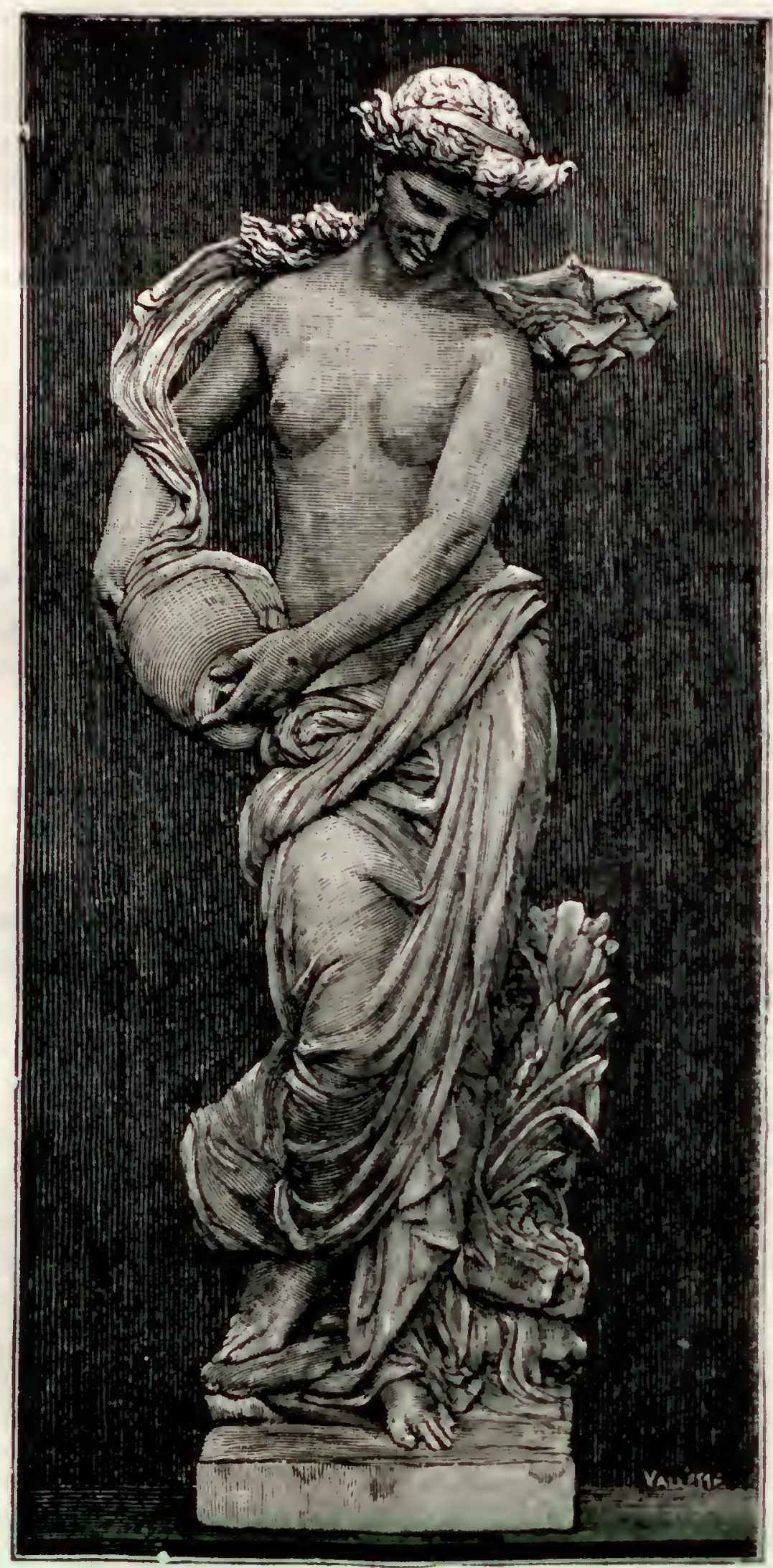

L'É $\mathbf{A}$.

Statue de M. Carelib, oroant la cascade du Trocadéro.

la canne à sucre; au centre les céréales, la vigne; au sud, dans la Patagonie, les forèts d'essences merveilleuses; pour l'élevage du cheval, du mouton et du bœuf, des prairies sans fin; et toutes les parties de ce vaste territoire sont reliées par des voies ferrées, qui assurent le transport des produits et facilitent les transaclions. 


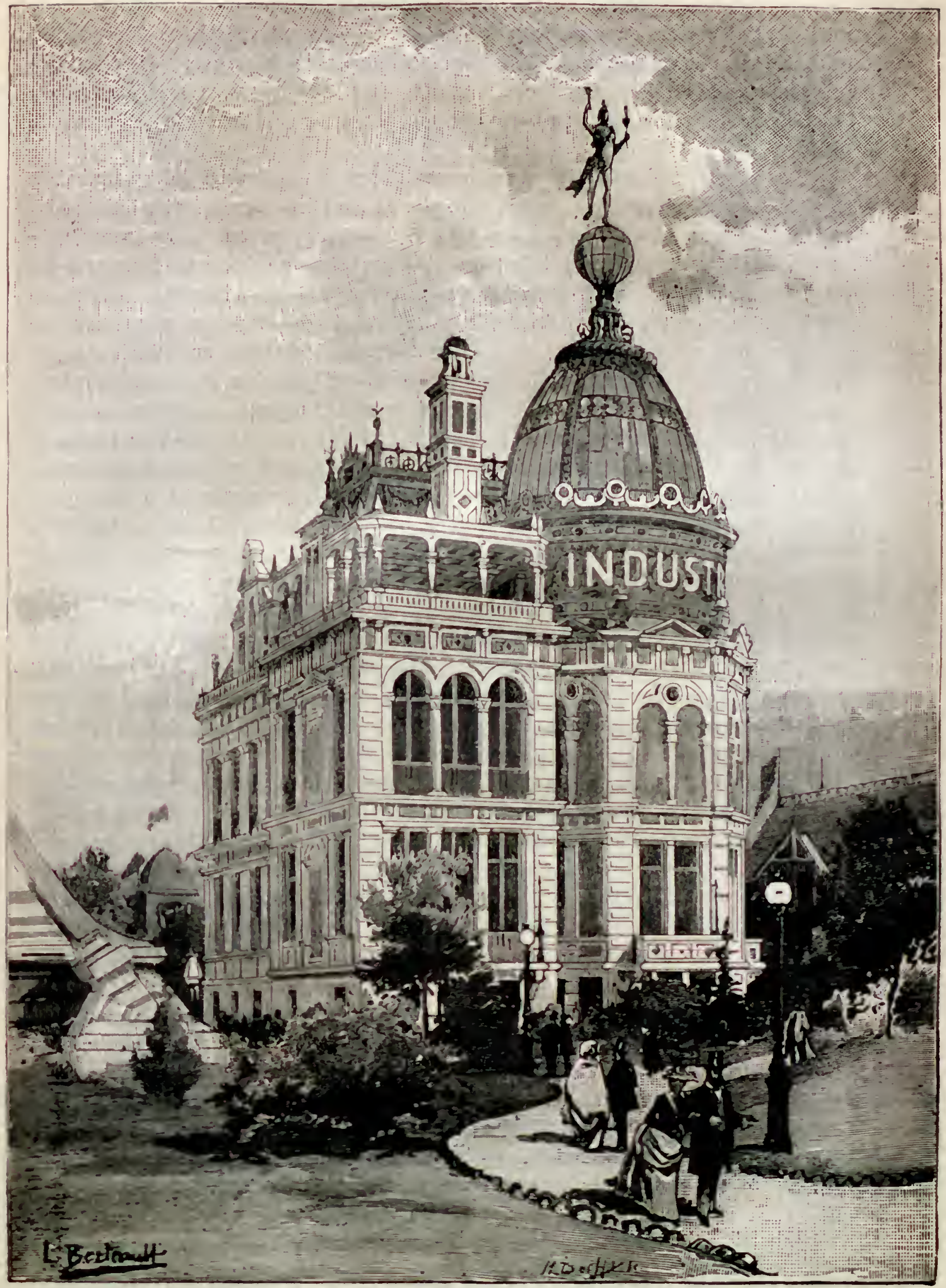

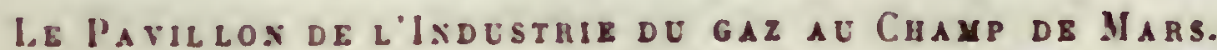


La Rẻpublique Argentine possède trente millions de betes a cornes; elle pourrait, dit $\mathbf{3}$. de Fontpertuis, en nourrir dix fois autant. La valeur d'exportation de ce produit des saladeros seélève, par an, à 250 millions. A Buenos-Ayres, on gaspille la viande; le prix antorise du reste ce gaspillage : le mouton vaut 3 ou 4 francs, le boul כo ou 6 francs les $2: 3$ livres. Encore la viande a-t-elle subi une hausse de prix depuis la sécheresse de 1874 !

- Dès à présent, c’est la Pampa qui approvisionne Rio-de-Janeiro de luétail surpied, et si la science parvient un jour à résondıe le problème de conserver les viandes abattues, de manière qu'elles puissent supporter de longs transports. les marchés dı monde entier deviendront les tributaires de l'Amérique méridionale. Mais tous les efforts tentés pour découvrir un moyen de conserver la viande à l'état frais ont échoué jusqu'ici. Un concours s'ouvrit a cet effet en 1886, a Buenos-Ayres, el soixante-douze systèmes, dont vingt-sept arec échantillons, y figurèrent; mais pas un ne fut jug digne du prix; pas un ne satisfit l'oxil, l'odorat el le gout tout ensemble. Pour combaltre l'air atmosphérique, qui est l'agent de putréfaction le plus énergique, on a essaýé de toutes les substances: de l'huile comme les Romains, du miel comme les Scythe-, de la graisse, du vinaigre, de l'alcool. On a mème recouru au procédé A ppert. qui con-iste à enfermer dans des boites hermétiquement closes la substance a conserver ct ensuife à la plonger dans un bain-marie. Mais ce procédé, outre qu'il ne laissait pas à la viande son aspect naturel, était d'une application trop couleuse, tandis que les autres, fort bien appropriẻs aux besoins limilès d'une famille. ne suffisaient pas pour la conservation de millions de bœufs et la consomınation de nations entières. En dernier lieu, on s'est arrèté à ia conservation par le froid, sans emploi direct d’aucun rénctif. on a tenté de disposer a bord des navires construits tout exprès de grandes glacieves et de transporter des bœufs entiers, pour les livrer aux boucheries européennes, tels qu’ils sortaient des abattoirs américains, et l'heureux voynge du Frigorifoque (en 1878) semble bien incluguer que la question est entrée dans la roie de sa solution définitive.

Liensemble des colonies agricoles de la République Argentine, principalement situées dans les provinces de Santa-Fé, de l'Entre-Rios et de Buenos-1yres, forment une superficie de 160 lieues carrées. Elles sont peuplées par 3, 900 familles environ, comprenant 16,678 individus. Ceux-ci se répartissent entre dix-sept nationalités: 5,8:7 Suisses, 4,1:7 Italiens, 2,364 Aigentins, 1,889 Français, 1,483 Altemands, 486 . Anglais, 213 Espagnols, 82 Nord-Américains, 54 Belges, 42 Damois, 15 Brúciliens, 11 Chiliens, 10 Suédois, 6 Polonais, 5 Paraguayens, 2 Orientaux. Ces colons cultivent le ble et le mais.

M. le lieutenant de vaisseau Peyrouton de Ladébat donneles renseiguements suivants sur le caractìre des colons d'après leur nationalité :

- La Suisse et l'ltalie sont jusqu'a présent les seules nations qui fournissent une émigration un peu nombreuse; el pourtant on sait que les sujets de ces deux nations professent pour le sol natal un attachement prononcé. Les familles qui s'expatrient ne le font qu'apres avoir perdu tout espoir d'un avenir favorable dans leur pays; a la suite de renseignements qu'elles obtiennent, elles émigrent pour les riviteres de is Plala.

- L'immigration suisse se dirige presque en tolalité vers les colonies; mais elle fournit une plus grande proportion de maurais colons que la France et l'ltalie. Cela tient à ce qu'elle se compose, en grande partie, de gens appartenant à la derniére 
classe de la snciété, n'ayant aucune notion d'agriculture. Les bonnes familles ellesmèmes, ayant quelque éducation et une certaine intelligence, une fois acclimatées, s'attachent à leur concession, et ne tardent pas a y construire de bonnes maisons de pierre, les entourant de toutesles commodités pourles jouissances de la vie domestique.

- L’immigration italienne est presque exclusivement composée de Lombards et de Piémontais, infatigables au travail, ayant de bonnes mœurs et une sobriété reconnuc. Nul mieux qu'eux ne sait tirer parti de la terre, mais ils se préoccupent peu d'embellir leur propriété. Arrivés à la fortune, ils n'en habitent pas moins le rancho primitif, et mènent la mème vie que lorquils gagnaient à peine leur subsistance. C'est là la règle générale qui souffre pourtant de nombreuses et remarquables exceptions.

- L’immigration française promet d'être un élément puissant pour l'agriculture. Elle fournit beaucoup de gens intelligents et le colon français a la louable ambition de s'entourer d'une certaine élégance si ü un bien-ètre qui va même jusqu'au confortable; il s'adonne particulièrement a la culture des arbres fruitiers.

- Limmigration basque ne sort guẻre de Buenos-Ayres et rayonne tout au plus dans les villages peu éloignés de celte capilale. On rencontre très peu de Basques dans les colonies. Ces immigrants arrivent toujours avec un but arrèté à l'avance, attirés par leurs relations de parenté ou d'amitié, et ils y trouvent immédiatement un emploi dans certains métiers spéciaux qu'ils exploitent comme un monopole. Les Basques recherchent les travaux qui exigent le plus de force et d'assiduité; ils accaparent les emplois dans les saladerus, les lriqueteries, conduisent les attelages de chars à bœufs, etc... C'est la nationalité qui adopte le plus facilement les inceurs du pays et qui est le plus sympattrique aux habitants.

- L'immiration allemande, qui a tant fait progresser la colonisation aux ÉtatsLinis, u'est représentée dans la Plata que par quelques colons de Würtemberg, de la Hesse, du grand-duché de Bade, du Hanovre et du Mecklembourg. Comme les Suisses, ils s'habituent diflicilement au pays, dont ils apprennent la langue avec peine; mais une fois acclimatés, il n'y a pas de meilleurs colons, ni d'agriculteurs plus intelli. gents.

Mexique. - Le Mexique a cmprunté à son ancienne civilisation les motifs du pavillon, ou plutol du palais qu'il a fait construire. On y voit, naturellement, les produits les plus divers du pays, mais aussi une galerie de tableaux, fort intéressante, une collection pédagogique très remarquable, et les costumes mexicains des diverses époques.

Nous tenons à nous arrèter sur le fait de l'indiscutable sympathie que les Mexicains ont, de tout temps, hautement manifestée pour nous. En effet, parmi les personnalités les plus marquantes, parmi les physionomies bien boulevardières, dans la foule des hôtes du grand monde cosmopolite, on compte de nombreux citoyens de la vieille terre des Montézumas.

Tout Paris connait, entre autres, les Y'turbe, dont l'hótel scigneurial, arenue du Bois-de-Boulogne, est situé presque en face de l'ancienne demeure du duc de Nemour's. Les Yturbe sont, inconstestablement, les Rothschild du Mexique. La légende les fait descendre des anciens rois du Pérou. Et, vraiment, leur fortune est deux fois péruvienne.

On sait encore que les réceptions du ministre du Mexique en France, M. Ramon 



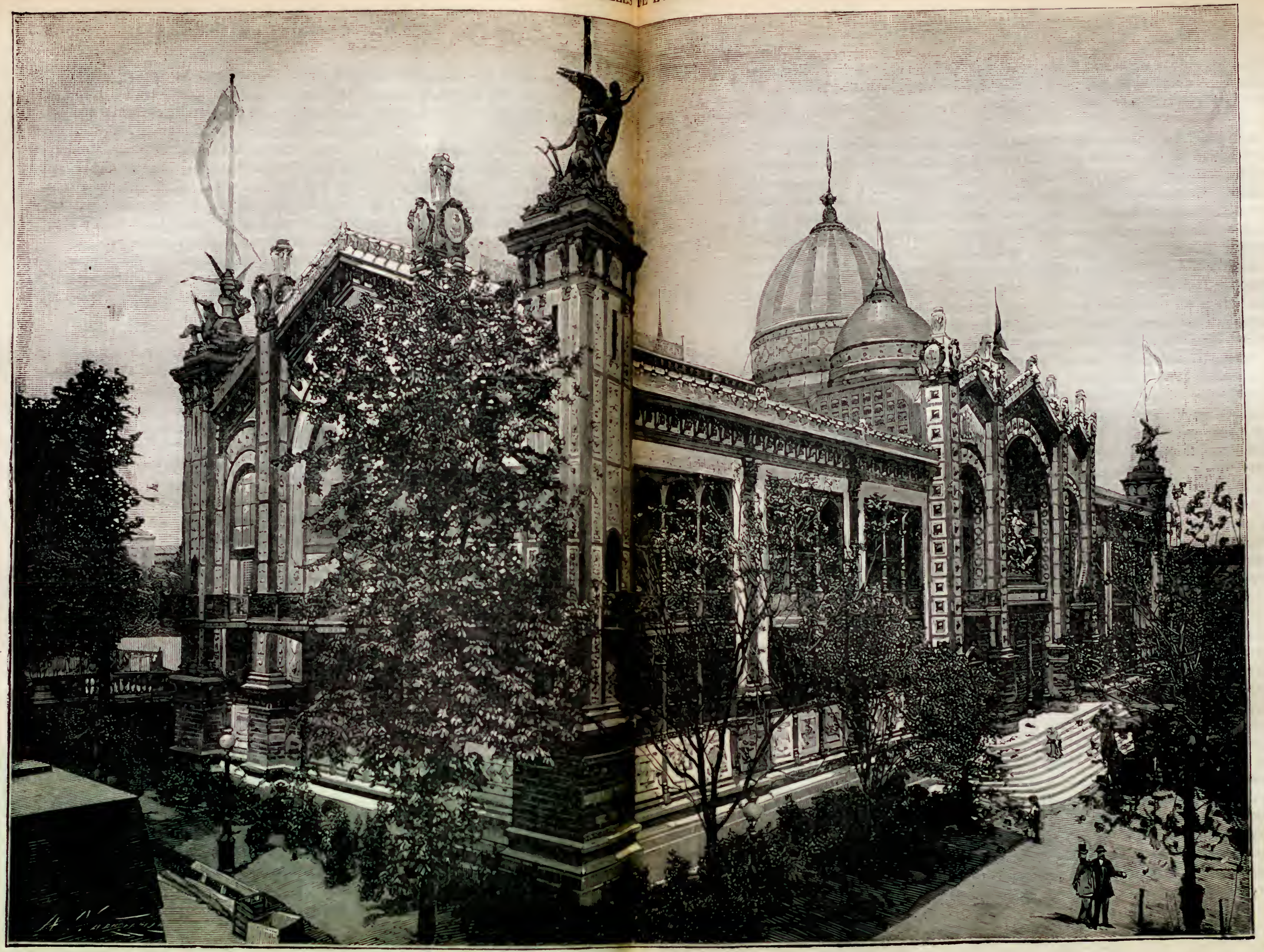

Le lavillox orla République argestise. 
Fernandez, un homme du monde et un savant, ont toujours été des plus recherchées et des plus suivies. Rappelons que 1I. Fernandez, qui se trouvait au delit des mers depuis quelques mois, a eu l'exquise délicatesse de rentrer à Paris pour les fétes du 6 mai.

La commission mexicaine à l'Exposition de Paris fonctionne sous la présidence de M. Diaz Mimiaga, commissaire général, assisté de M. Garcia Conde, consul général du Mexique au Havre, et de M. Manuel Payna, consul général du Mexique à Santander. M. Diaz Covarrubias, qui assistait également le président dans ses hautes fonctions, est aujourd'hui décédé. La perte de ce dernier a laissé bien des regrets, carr M. Covarubias, ancien sous-secrétaire d'Etat aux travaux pulslics, el, quand il est mort, consul général du llexique à Paris, était un homme de science d'une grande valeur.

M. Diaz Mimiaga a été pendant longlemps premier secrétairc de la légalion du Mexique à Paris; de Paris il fut envoyé, en qualité de ministre plínipotuntiaire, dans l'Amérique centrale; élu ensuile député au Pálement, il ne tarda pas à étre investi des fonctions de sous-secrétaire d'État au Ministère des Affaires étrangères. II. Paynat, ancien ministre des Finances, est un écrivain de talent.

Les membres délégués de la commission mexicaine récemment arrivis à Patis sunt: MM. Manuel Florès, Gaspar Salas, José Ramirez, Rodrigo Valdez, Augustin Chavez, Joaquin Beltran, Manuel Rivera, Manuel et Javier Garcia Torres. Huilulzo de Izua, José C. Segura Fernando Velasquez, Ricardo de M. Campos, linrique Ward. Lecunardo Apostela, İorenzo Caraza, Armando Ramirez, Francisco Cerro, Adrian Cihende, Angel Hernandez, Luis Léon, Antonio Espindola, Miguel Perez, Ignacio Lima, Alherlo llerry et José Perez, et on annonce en outre la prochaine arrivée de nouveaux délígutes: IIM. Alfred Bablot et Eduardo Zarate.

On peut voir par ce qui précède qu'en disant, au commencement de cet arlicle. le Mexique a voulu donner une signification politique toute particulière à sa participation à l'Exposition, nous étions parfaitement dans le vrai. Il est à propos de ramener l'attention sur la conduite suivie par le gouvernement mexicain lorspue la france convia les nations à l'Exposition universelle de 1859. Le général Porlirio Diaz, président de la République du Mexique, fit mettre immédialement à l’étude, sous la direction de M. le général Pacheco, ministre du Commerce, le projet d'organisation de sa participation. On conroqua à Mexico les exposants, établissant ainsi une sarte de concunrs restreint et préparatoire à celui de Paris. Le 20 janvier 1889, le président de la llípllblique, le général Diaz, se rendait à l'École des llines pour y visiter cette lixposition tout parliculièrement remarquable par les produits naturels et matières premières: bois précieux, plantes textiles et médicinales, et par les collections de minerais les plus variées el d'une richesse incomparable. On y voyait aussi des ouvrages en bois, des objets et instruments en fer fondu et forgé, des machines agricoles, des selles de chevaux (on sait que tout Mexicain est bon cavalier), des tissus des Etats de Puehla, de Durango, Coabnila, des costumes caractéristiques du pays, des ouvrages en copuillages, etc.; enfin une serviette destinée au président de la liépublique frangaise et sur laquelle est brodé, en soie noire, l'hynne national mexicain.

Tel est, en quelques mots, et dans ses grandes lignes, le résumé du cuncours mexicain à Paris. On pourrait y ajouter encore que le gouvernement de l'litat de Yucatan a fait dresser un plan de la péninsule; que, sur la commande du Minislre des Travaux publics, un éminent géographe, M. Antonio Garcia Cubas, a rédigé un tableau 
géographique, statistique et historique du Mexique, et qu'un patient collectionneur a réuni dans un album les spécimens les plus divers et très curieux du papier timbré en usage au Mexique depuis le règne de Philippe IV, en 1640, jusqu'd nos jours, en l'an 1889. Sans contredit, la pensée du collectionneur est très originale.

Avant d'entrer dans le palais où sont exposés les échantillons les plus variés de tout ce que produit le Mexique, faisons-en le tour.

Voici des alò̀s énormes (agane Mexicano), mais fatigués par le voyage et le soleil. - Regardez-les bien cependant, dit M. Paul Bourde, vous avez sous les yeux la vigne et le chanvre du Mexique. Pour le chanvre, c'est un peu une façon de parler; pour la vigne, rien n'est plus sùr, comme vous pouvez vous en assurer. Si on vous laisse franchir les fils de fer et si vous souleve\% les feuilles rabattues sur le cœur de ces plintes, vous découvrirez que ce cœur a élé évidé. Le creux, arrondi et grand comme un fond de soupière, se remplit sans cesse d'un liquide clair assez fortement sucré, qui est la sève de l'agave. Matin et soir un homme vient recueillir ce liquide (une plante en donne jusqu'à quinze litres en un jour), et le jette dans un tonneau où il fermente. Tant qu'il est doux, c'est l'eau de miel; quand il est fermenté, c est le pulque, la boisson nationale des Mexicains, une boisson qui rappelle pour le goût plutôt le cidre que le vin et qui grise aussi vite que ce dernier. "Passant ensuite au pulque, dont l'usage est jusqu'd̀ ce jour resté cantonné dans le Mexique : 'C'est peut-čtre la première fois, dit il. Bourde, qu'on fabrique du pulpe dans le vieux monde. Le transport de ces gros a ravrus a été un coûteux embarras, et les Ilexicains ont eu d'autant plus de mérite à l'arironter qu'ils n'avaient aucune compensation à attendre. Le pulque devant étre consommé frais, ils n'en sauraient expédier en Europe pour le vendre comme nous expródions nos vins par delì les mers. C'est donc dans le but tout à fait désintéressé de nous faire connaitre la boisson ordinaire de dix millions d'étres humains qu'ils se sont imposé cette dépense. Ils nous ont mème envoyé un hachiquero de profession, c'est-à-dire $11 n$ homme sachant fabriquer le pulque. Le Français qui voudrait essayer de doter son pays de cette culture nouvelle trouvera ainsi à l'Exposition tous les renseignements qu'il peut souhaiter. Une petite réduction en carton montre à l'Exposition l'intérieur du cellier à pulque."

A voir, aussi, le maguey des hautes terres du Mexique, qui ne fleurit et ne donne sa récolte qu'au bout de 10 ans. Aussi les Mexicains ont divisé en dix parts les exploitations de maguey de manière que chaque année ils aient quelque chose à récolter.

L édifice mexicain, à l'Exposition universelle de 1889, est construit d'après le style aztèque le plus pur. L'édifice se compose d'une partie centrale qui symbolise dans ses principaux attributs la religion aztèque, et de deux pavillons latéraux, représentation inythologique appropriée au but de l'lixposition.

l'édifice mesure 70 mètres de longueur, sur 30 de largeur; sa hauteur est de $14^{m}, 5^{\circ 0}$ jusqu’aux créneaux.

Le salon central mesure 40 mètres de longueur et $\mathbf{2 4}$ mètres de largeur; les pavillons latéraux ont $23^{\infty}, 80$ sur $12^{*}, 40$ de latitude.

L'édifice se compose de deux corps. Entre les pavillons latéraux et la partie centrale. on a placé six grandes figures pour personnifier, dans ses événements fondamentaur l'histoire mexicaine, le commencement et la fin de la nationalité et de l'autonomı des tribus aztèques, le commencement de son existence et la fin de sa période historique avec la conquète de Cortès. 
La forme générale de l'édifice a été empruntée aux rares débris qui restent des constructions d'une origine véritablement régionale des tribus mexicaines, tels que : un mur d'un ancien palais de Huexotla, parfaitement conservé, qui porte le nom de Texolocalco, et le magnifique monument de Xochicalco, qui se trouve dans l'ítat de Morelos.

La partie centrale de l'édifice est un portique auquel on monte par un escalier élevé et fortement incliné, comme ceux des anciens Tescalis. Aux côtés de cet escalier se trouvent deux grands pilastres ornés du signe du feu et couronnés des brasiers de IIuehueteotl, symbolisé par un vieillard assis, la tête chargée du bưcher sacré, où l'on

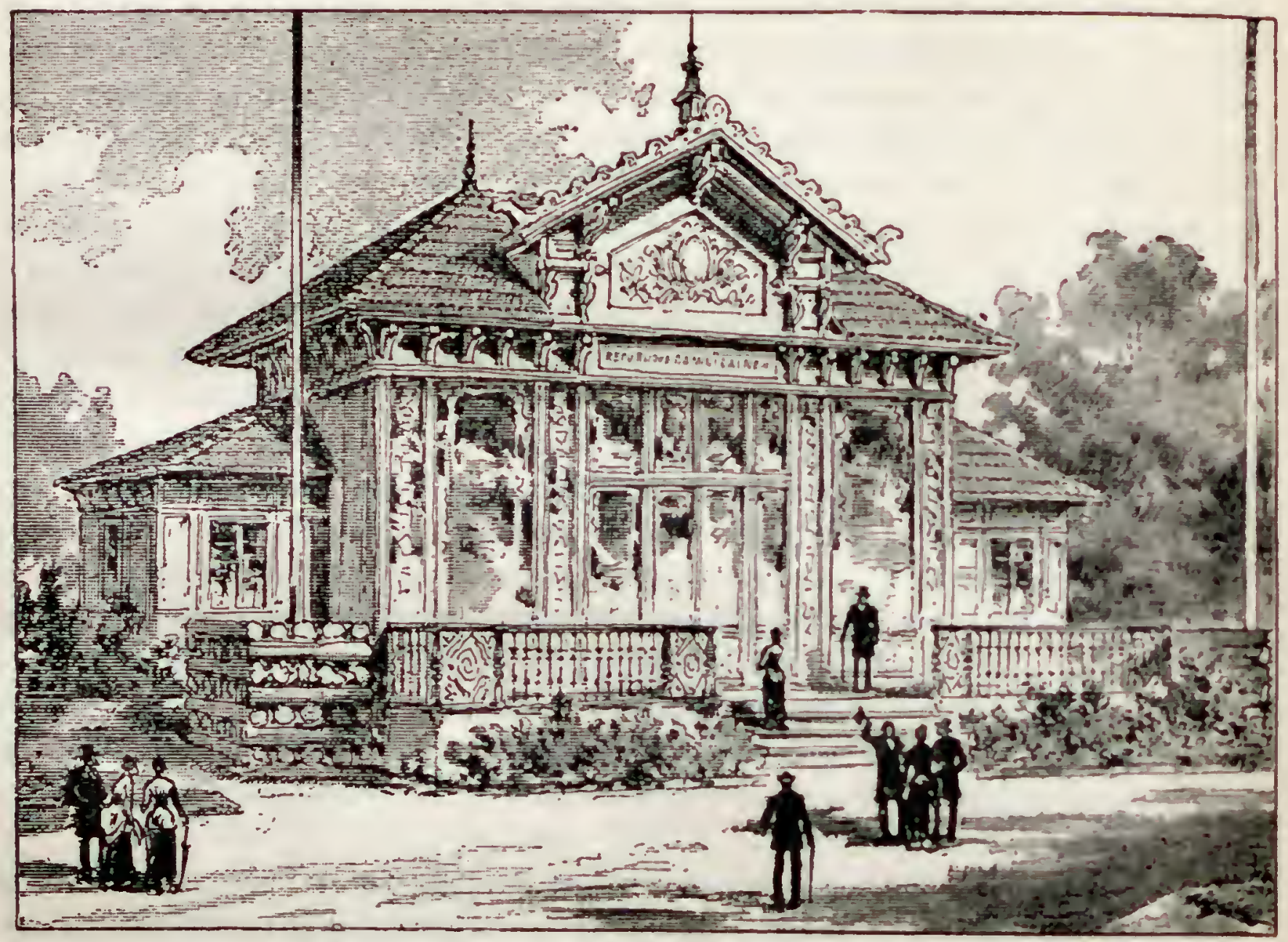

Le Pavillon de la Réptbliqub Domisicaise.

allumait périodiquement le feu nouveau, le feu séculaire, grand événement religieux chez les peuples d'Anahuac. La frise du frontispice est supportée par deux cariatides: c'est là le premier pilastre ou support complet découvert jusqu'à ce jour et dont on ait pu profiter dans une construction de style national: il représente une figure humaine, un homme avec un casque formé de la tête d'un serpent et ayant pour crinière le corps même du serpent; il est orné d'autres accessoires curieux, le maxtli ou pagne, partie de vêtement qui caractérise les hommes, et un bouclier sur la poitrine, cueacochimalli, dont se servaient seulement les hauts personnages.

La frise est décorée des dessins et des grecques qui donnent un caractère particulier à cette ornementation originale.

La corniche a été trouvée dans les ruines de Xochicalco, ruines tlalhuicas appartenant à la principale tribu de ces contrées, comme le prouvent les signes indubitables 
LES MERVEILLES DE L'EXPOSITION

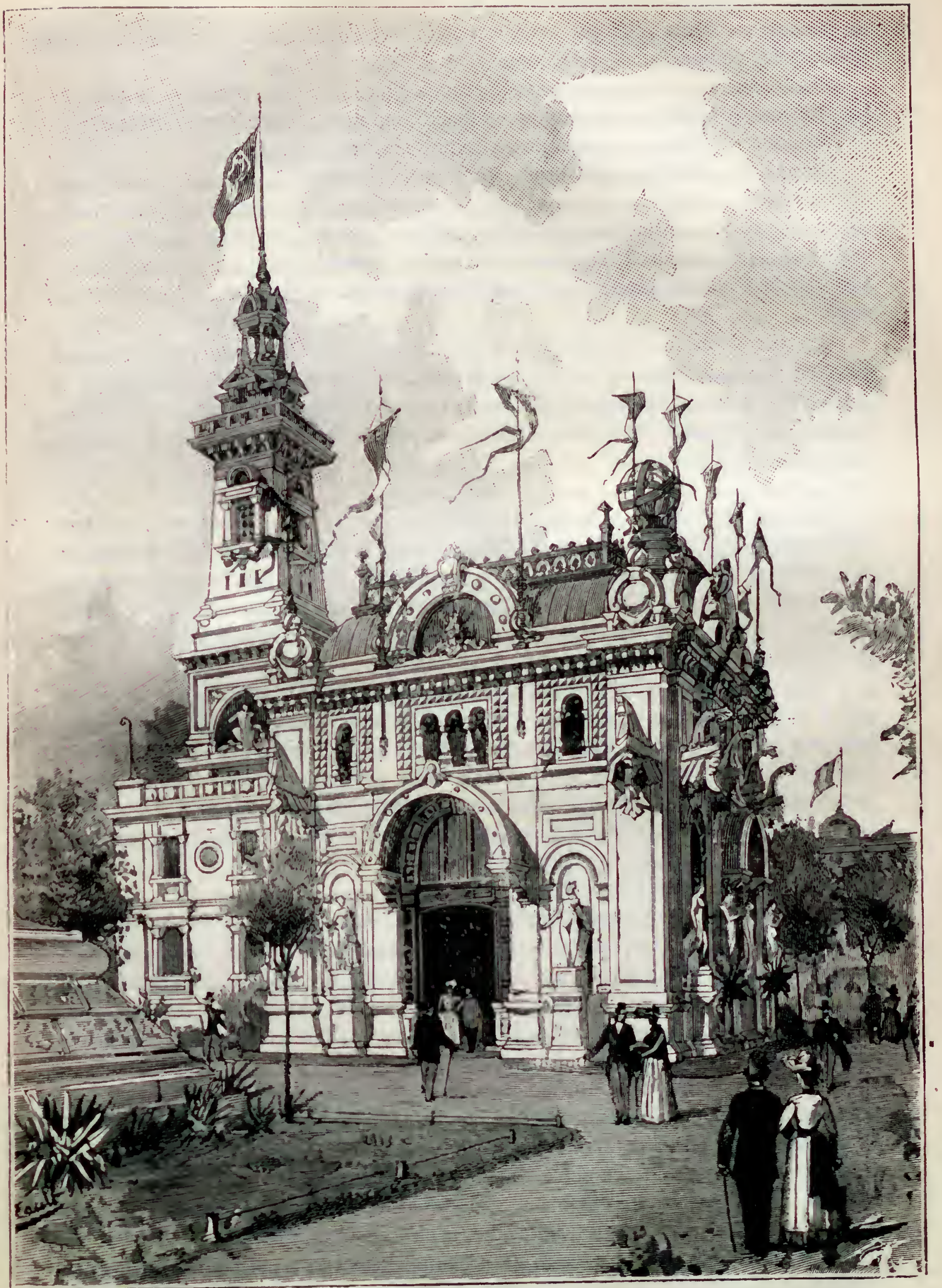

Le Pavillon du Brésil a Champ de Nars.

Liv. 61.

Menvelless Exposition. 
du calendrier en usage chez les Aztèques; cette partie de la construction est aussi une nouvelle acquisition pour l'archéologie.

Le portique a pour couronnement la grande figure du Soleil, Tonutiuh, enlouré de ses attributs, présidant à la création de Cipactli, qui représente la force fertilisante de lit Terre, force qui donne la vie et la nourriture au genre humain.

Les pavillons latéraux sont ornés d'une porte couronnée d'une date symbolique, leux roseaux ome acatl, année où eut lieu le renouvellement du feu, la grande fète sé. culaire et presque continentale des tribus nahoas. Le groupe mythologique placé audessus de la porte de droite contient les divinités: Centeoll, ayant à sa droite Tluloc at à sa gauche Chalchiuhtlicue; dans le pavillon opposé, Gumarlli, Xochiquetsul et lacatecuhtli.

La partie historique représentée entre les deux pavillons latéraux el le portique se

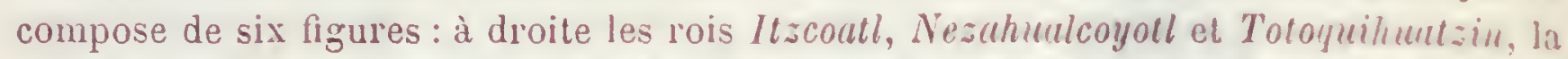
triple alliance des monarchies de Mexico, Texoco el Tlacopan. A gauche du partipue, Cacama, Cuitlahuac el Cuauhtemoc, les personnages de la chute tragique de l'empire mexicain.

Brésil et Véxézuéla. - La section brésilienne occupe une superficie de près de 1,200 mètres carrés, dont le tiers environ est occupé par un pavillon à baics cintrées, arec une tour carrée. Une serre magnifique est jointe au pavillon, qui est surmonté d'un campanile qui n'a pas moins de 4 ă mètres, et entouré d'imposintes stutués représentant les grands fleuves qui sillonnent le territoire de l'empire : le rio l'arana, le rio Amazonas, le rio San-Francisco, le rio Tiété.

Cette construction est joliment située près du lac qui se trouve au pied de la pile sud de la Tour Eiffel; elle est entourée de bosquets et de plantes exuliques; une petite galerie conduit à la serre dans laquelle sont exposées les plus merveilleusés collections d'orchidées. On a profité du voisinage du lac pour créer une pièce d'eau dont la température sera entretenue à 30 degrés pour permettre à la . Victoria kegra , d'y épanouir ses fleurs, sorte de nénuphars qui ne mesurent pas moins de deux nètres de diamètre.

L'intérieur du palais a trois étages pour pouvoir contenir les produits si multiples de ce vaste territoire, et principalement les cafẻs, les caoulchoucs, les bois de coustruction, les bois de teinture, la gutta-percha, le " maté ,, les fruits cunservés et lés céréales. La commission brésilienne a su donner à son exposition un caraclire à la fois attrayant et instructif, grâce à l'agréable aménageınent de ses galeries et à la répartition bien comprise de cartes et de tableaux qui fonl ressortir les ressources prodigieuses de ces régions inépuisables.

Peu de pays d'ailleurs ont affirmé d'une façon aussi complete leurs sympathies pour la France. L'empereur dom Pedro II s'est hautement prononcé, dès le principe, puur la participation officielle. Les Chambres ont vuté un crédit d'environ 800,000 francs. Dès provinces et des villes ont, en outre, voté des subveutions cousidérables. Pour que son beau pays fut dignement représenté au grrand tuurnoi international qui se préparait, l'empereur dom Pedro a ouvert à ltio de Janeiro une exposition particuliere el un comité a éliminé un certain nombre de produits. Ceux que nous pouvons examiner sont très variés, très intéressants. Citons particulièrement les échantillons le hois pour marqueterie, des poteries, des urnes en céramique, des motifs d'ảrchitecture et de 
constructions navales. Mais ce qui plaît surtout au visiteur, c'est la magnifique exposition de plantes et arbustes. La serre est reliée au bâtiment par une véranda légère et bragée de plantes grimpantes. Dans un étang voisin, chauffẻ artificiellement, s'étale. ou s'étalera dans quelques jours, car elle est encore bien modeste - la a Victoria gia s, cette plante aquatique géante qui, pour la seconde fois, va fleurir en Europe, Belgique ayant été la première à posséder ce phénomène; un minaret, contourné et racieux, domine cette petite colonie brésilienne qui forme un des décors les plus gais et les plus élégants de toute l'Exposition.

MM. Alfredo Michel, Eduardo da Silva Prado, Teixeira et Leisao, membres du comité organisateur, ont groupé à l'intérieur de ce palais en miniature les plus curieux produits du grand empire d'Amérique, et cette installation, dirigée avec un goût exquis et un sens artistique très sùr, échappe à l'aridité ordinairement inhérente à ces exhibitions techniques.

Il y a la la plus belle collection de bois - quarante mille essences! - que puisse rêver une ébéniste; il y a des monceaux de caoutchouc brut, des cotons, des éponges, des amoncellements de minerais d'or, d'argent et de diamant, des produits pharmaceutiques de quoi guérir toutes les maladies, et, pour rendre plus attrayante la visite de ces collections, on y a ajouté des meubles de style ancien, des tableaux et aquarelles représentant les sites les plus pittoresques du Brésil, des collections de méduilles où se voient les premières monnaies frappées en Amérique par les Hollandais en 1645 : cette curieuse série appartient à $\mathbf{M}$. le comte Cavalcanti; $\mathbf{M}^{\text {me }}$ Cavalcanti \& prèté elle-mème son richissime écrin qui contient pour quatre ou cinq millions de diamants et de pierres précieuses. N'oublions pas, sinon la plus précieuse, du moins la plus rare de toutes les pierres que l'on puisse voir, c'est-à-dire le fameux météorite de Bendago, tombé du ciel en 1784 : c'est une sorte de bloc de minerai de fer et de nickel, affectant la forme d'une énorme tortue sans tète : il pèse soixante-dix mille kilos, ce qui est un joli poids pour une pierre tombée de la lune... on d'ailleur's.

11. Ladislas Netto, le savant directeur du muséum de Rio-de-Janeiro, a complété de la plus heureuse façon l'exposition brésilienne en installant dans la maison des Aztèques, qui fait partie de l'Histoire de l'habitation, un petit musée rétrospectif.

Rien d'exotique dans la silhouette extérieure du Palais Brésilien. . Les concurrents seront libres, disait le programme du concours, de donner à leur composition le caractère architectural qu'ils croiront devoir convenir à un édifice destiné à l'exposition des produits naturels d'un empire latin et américain, particulièrement riche en matières premières d'origine minérale et végétale. 'Singulier problème, que M. Dauvergne a résolu à son grand honneur en élevant un pavillon fort élégant inspiré de l'architecture espagnole, contourné comme un Trianon de style Louis XV, où se reconnait l'emphase architecturale des pays du soleil.

Lors de la visite qu'il a faite le $\mathbf{1 4}$ juin à l'exposition brésilienne, M. Carnot s'est longuement arrété devant la reproduction du fameux "météorite de Bendago "qui se trouve au musée du roi. Ce météorite, comme nous l'avons dit, a la forme d'une gigantesque tortue.

Le Pavillon du Brésil contient une riche collection de meubles, des bois variés, des peaux d'animaux sauvages, ainsi que de grandes variétés de racines médicinales, de libres textiles, etc., etc. Il renferme également des cotons, des cuirs et des pierres pré- 


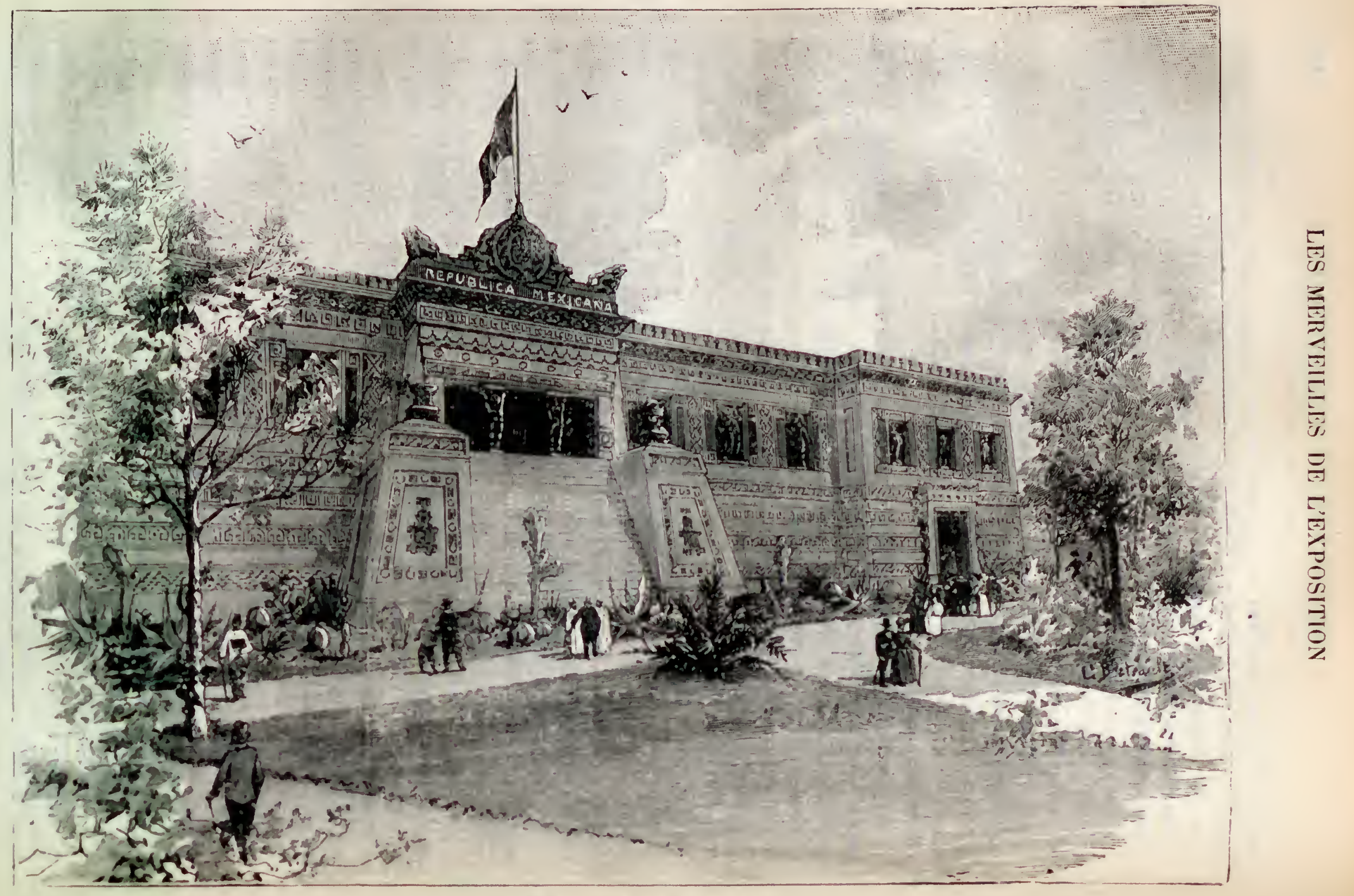

I.K PAVIR,ON DU MEXIUUE. 


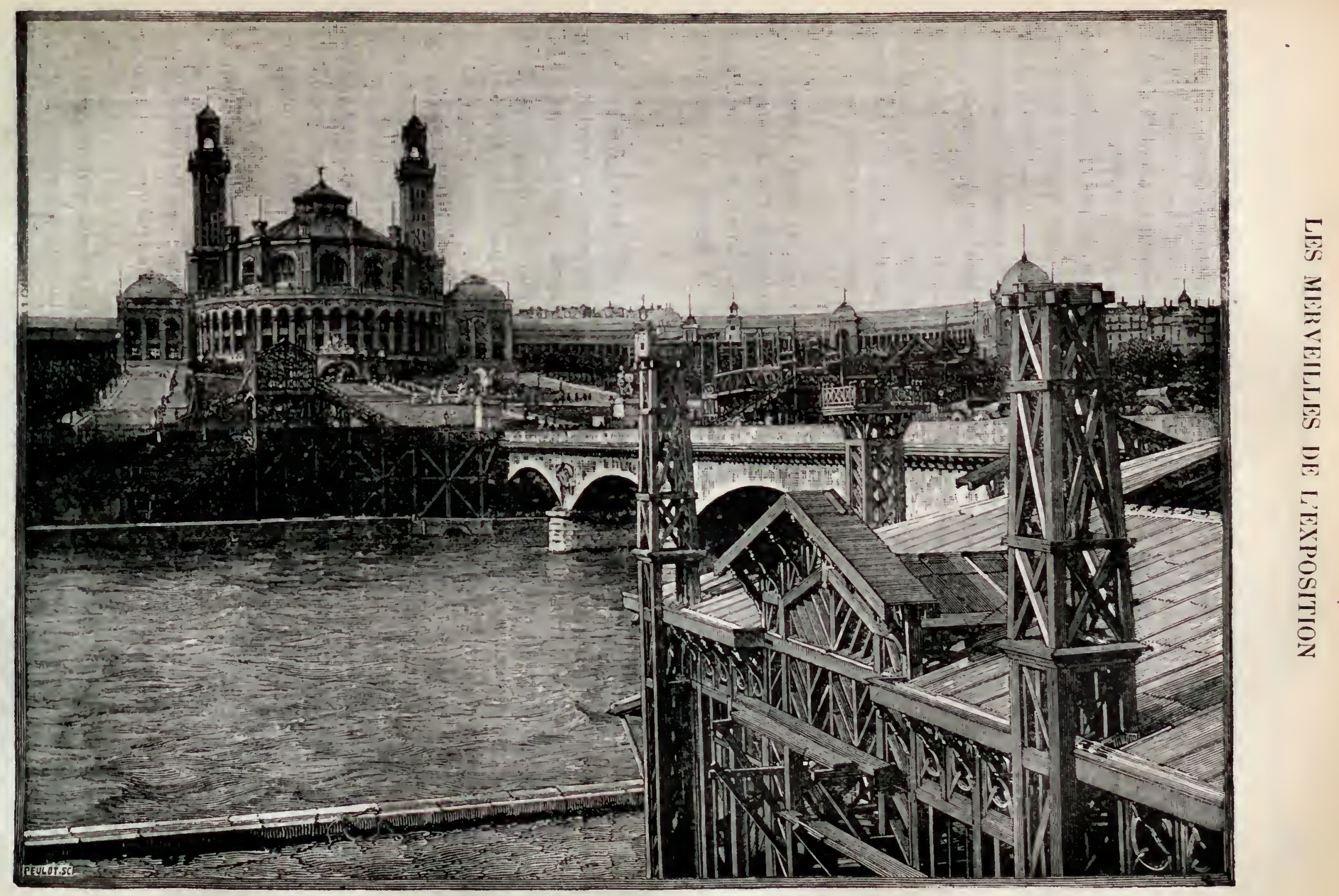

LES I ASSERELLES DU PONT D'I RNA (HIVE DROITE)

Servant de communication entre le Trocadéro et le Champ de Mars. 
cieuses en très grande quantité. Notons en passant la collection de pierreries exposées par Mme la vicomtesse de Cavalcanti qui vaut à elle seule toute une fortune.

Au pied de la rampe qui conduit au Palais des Arts libéraux se trouve le Pajas du Vénézuéla. Cette construction ost charmante et fait grand honneur au talent de l'architecte et au gout de la commission qui a su arrèter son choix sur ce prujet.

L'édifice est de ce style Louis XV dont les Espagnols et les Jésuites ont laissé tant de spécimens dans l'Amérique du Sud, àu Pérou, en Colombie, au Vénézuéla. C'est un gracieux palais de dispositions irrégulières, mais amusantes, avec un pavillon d'ansle qui se termine en forme originale, des ouvertures gaies entourées d'ornements pompeux, des balcons et des balustrades hien ajourées, des moulures formant de jolies saillies et une belle porte rappelant l'entrée de la cathédrale de Caracas; tout cela forme un ensemble des plus agréables. Le palais est bordé de verdure, d’arbustes rares, de plantes et de gazon. Pour l'intérieur, on a adopté le patio des constructions espagnoles, si gai et si frais. Cette disposition se prète parfaitement à l'installation d'une exposition.

Les plus importants produits exposés sont le café, le cacao, la canne à sucre. le coton, le tabac, la fève de Tonka, le bois de teinture, d'ćbénisterie et de construction, le caoutchouc, le quinquina et toutes sortes de racines alimentaires; les échantillons provenant des mines d'or, de cuivre, d'argent, de plomb et d'étaill, de houille, de soufre, de pétrole, de feldspath et d'asphalte.

ChILl. - Le gouvernement chilien, que des événements politiques avaient empéché de prendre part à l'Exposition de 1878, a voulu montrer, à notre solennité internationale de 1889 , les progrès surprenants qu'a pu faire le Chili sous une sage administration.

Ce pays qui, dans sa récente lutte contre le Pérou et la Bolivie, a fait preuve d'une grande énergie et d'une véritable sagesse, s'est montré dans la paix digne de la furlune qui a favorisé ses armes. Le peuple qui, au lendemain de victoires aussi éclatantes. ne se laisse pas griser par ses succès et pense avant tout à se soustraire à la dictature militaire, est appelé à jouer un rôle prépondérant parmi les républiques de l'Aınérique du Sud.

Le Chili, en pays sérieux et pratique, n'a pas cherché frapper le public par une construction étincelante d'or, de couleurs et de portiques lunineux. Il a mis son amourpropre à présenter aux visıteurs intelligents une exposition de tout ce que produit le territoire de la République, comptant uniquement sur l'intérèt que ne peuvent inanquer d'offrir ces collections présentées avec méthode.

Le Palais Chilien est une construction toute en fer, qui est destinée à être démontie et transportée à Santiago, au a Parc Cousino, ou à la "Quinta Norwal •. Il est situé non loin de la Tour Eiffel, sur la rampe qui conduit à la terrasse des Arts libéraux; il se compose d'un bâtiment central, à toiture en dôme régulier, flanqué de quatre pylónes rectangulaires surmontés de petits domes sphériques.

L'entrée, formée par un portique en saillie tenant toute la lauteur de la construc. tion, donne à celle-ci un caractère réellement monumental; un perion, de toute lit largeur du portique, conduit au péristyle, sur lequel s'ouvrent les baies donnant acci: dans l'intérieur de l'édifice.

La face opposée à l'entrée présente une saillie figurant une sorte de jardin d'liver coupé à mi-hauteur par un balcon en communication avec la galerie du preinier étage.

En dehors du fer, dont l'emploi élait impusé el que les constacteurs ont su utiliser 
non sculement comme ossature, mais encore comme motifs décoratifs, les terres cuites, lis staffs et quelques faiences ont été employés avec beaucoup de goùt. La note générale do l'édifice est discrète, et corrige néanmoins le caractère un peu sévère de l'ensemble irchitectural.

L'intérieur comprend un rez-de-chaussée et un premier étage; toutefois, le plancher In cel étage ne couvre pas complètenent le rez-de-chaussée : un espace vide a été riservé au centre, de façon à permettre aux visiteurs de voir d'un balcon circulaire les jroduits disposés à l'étage inférieur.

Au rez-de-chaussée sont réunis les produits alimentaires. D'abord les bois de Valdivia, de l'Araucanie et des contreforts boisés de la Cordillère; puis les saumons de cuivre de Lota, de Copiapo et de Coquimbo, des íchantillons de mercure, de plomb et de minerai de fer; des lingots d'or et d'argent, des salpètres du désert d'Acalama et des chatrons de Coronel.

Voila la riche collection des céréales, les blés qui s'exportent à la République Argentine, dans l'Uruguay el au Brésil. les farinesqui alimentent toutela côte du Pacifique jus(pu'a l'anama, les maïs et les haricots si renommés. Voilà toute la collection des vins : vins rouges, vins blancs, vins doux, vins sucrés et muscats, les vins de Limaché el Subercaseaux, les carbenets Urmeneta. Heureux pays qui n’a point de phylloxéra! Vuici encore des conserves, des confiseries, des sucres de canne raffinés à Vina del llar et des sucies de betteraves.

La fanille Cousiño a réuni tous les produits qui proviennent de ses usines : échantillons de charbon et de cuirre, bouteilles sorties de ses verreries, ouvrages en grès, poteres, luriques, produits de sa ferme-école et de ses vignobles.

Au premier étage sont exposés des produits manufacturés: draps, rètements, chinussures, chapeaux, papiers, toiles, meubles, qui montrent un pays chez lequel toutes les industries se créent el s'améliorent avec succès.

Ce grouvernement est très justement fier des statistiques qui prouvent le développement dlu pays; aussi la commission a-t-elle eu soin de placer sur les murs du palais des tableaux, des cartes, des renseignements des plus instructifs.

Le Chili n'est certes pas le pays le mieux partagé dans l'Amérique méridionale; mais le peuple chilien est essentiellement travailleur; il a un caractère, un tempérament et des qualités de premier ordre qui lui assurent un avenir de grande prospérité.

Bolıvie. - La Bolivie a voulu faire grand. Placée au premier rang, à l'entrée du jardin central, elle a certainement cherché à attirer l'attention par les proportions de son palais : domeinmense, tours terminées en proues de navire pour faire oublier que la Bolivie ne possède aucun port de mer, colonnades, portique à arcades surmontées de dòmes à reflets métalliques, beaucoup de sculptures et beaucoup de couleurs, des façades rayées de rouge brique. tout cela n'est pas ordinaire.

A l'intéricur, dans le grand hall sous le dủme, nous voyons des tentures, des oriflammes, des drapeaux vert, jaune et rouge, les couleurs nationales, et quelques vitrines destinćes aux produits. A la suite de la grande salle se trouve une plus petite salle bordée à droite el à gauche d'une volière, contenant une grande variété d'oiseaux du pays et d'une serre avec les différents spécimens de la fiore bolivienne. On débouche de cette salle dans deux autres séparées par une sorte de couloir, dans lequel est installée la reproduction d'une galerie de la mine de Huanchaca, une mine de plomb argentifère 
qui a déjà produit des centaines de millions et continue à faire la fortune de plusieurs familles du pays.

La Bolivie renferme des mines de cuivre, d'élain, d'argent, d'or ; celles d'argent surtout sont très abondantes, celles de Potosi ont, dit-on, produit 30 milliards. Le pays se divise en trois régions : $1^{\circ} \mathrm{Au}$ sud-ouest, le désert d'Atacama, commun au Chili,

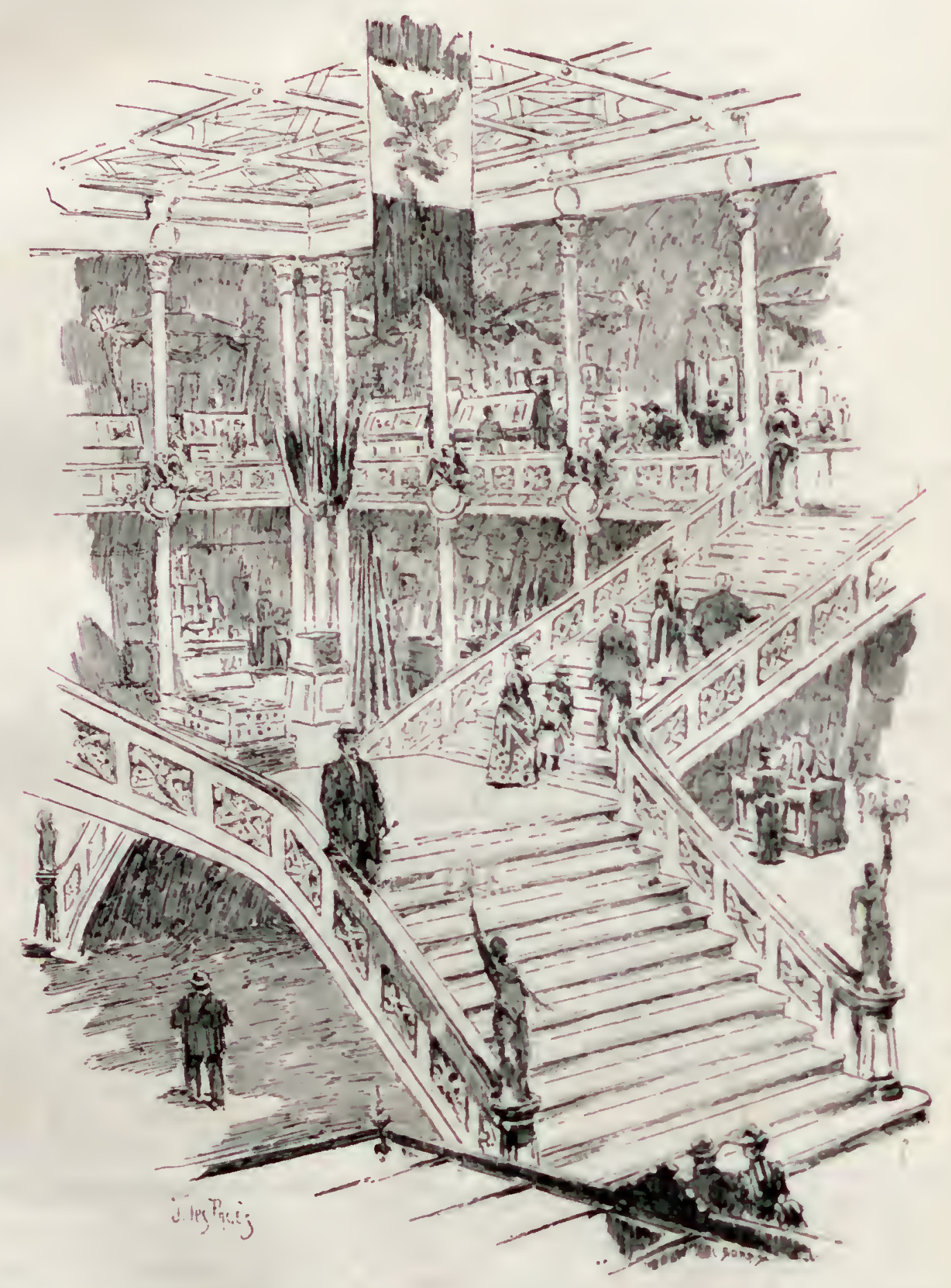

IXTEHIEUR DU PAVILLON UU IEXIQUR.

au Pérou et à la Bolivie, contrée desséchée, semée de rochers, d'argiles dénudées, riche en salpêtre et en guano; $2^{\circ}$ au centre, sur le plateau, la région des Punas, ou terres froides, où abondent les Cerros; $3^{\circ}$ au nord et à l'est, les plaines basses, boisées et fécondes, produisant les céréales, le sucre, le café, le tabac, le cacao, de magnifiques forèts (quinquina, vanille, caoutchouc, copah, rocou, etc.), de gras paturages qui nourrissent des bestiaux, des alpagas, lamas, vigognes. 


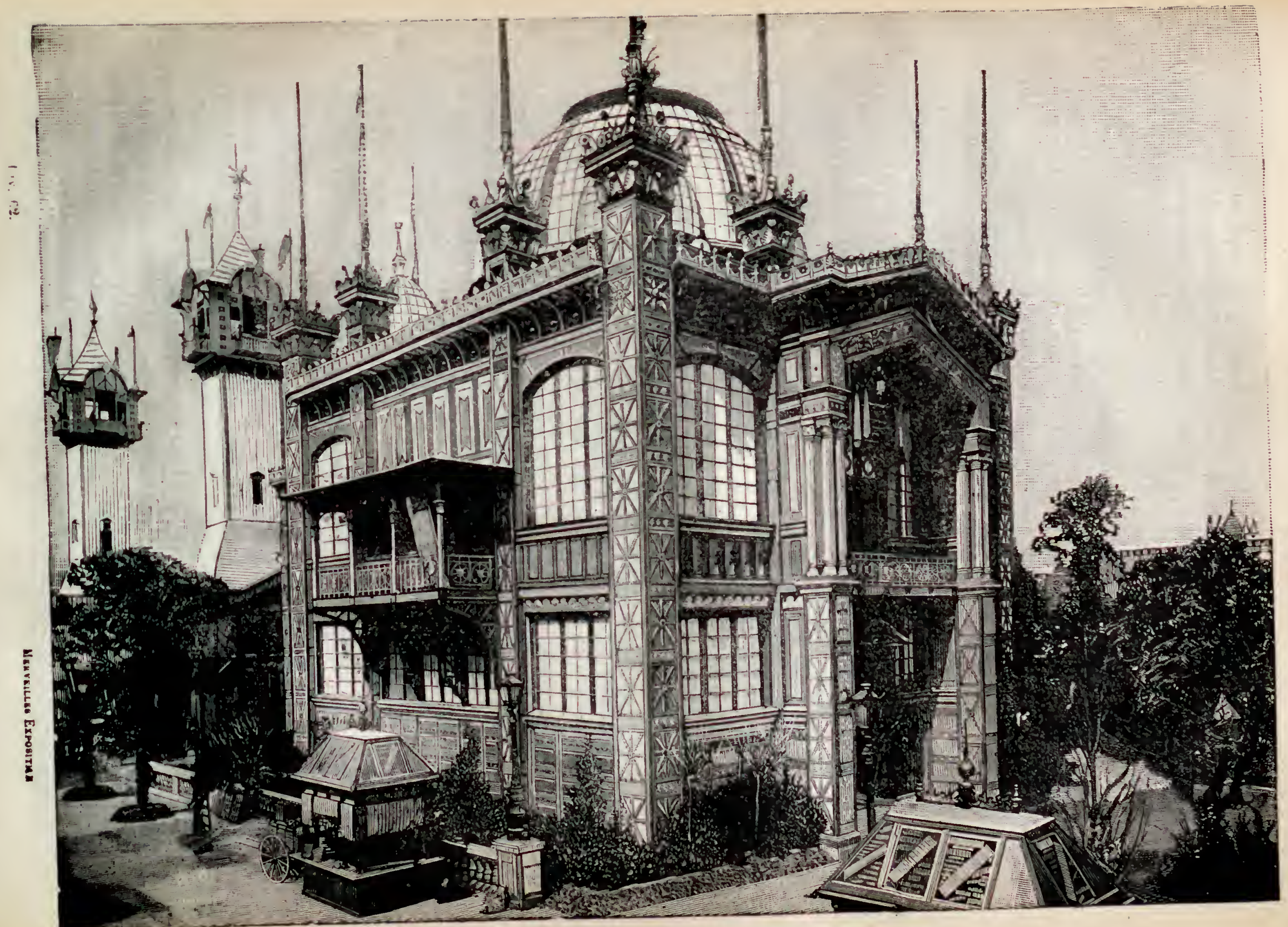

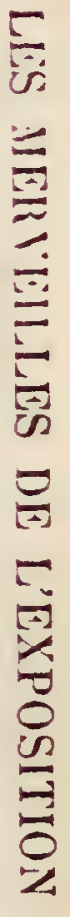


Equateur. - Le pavillon de la République de l'Équateur est situé au pied de la Tour Eiffel, tout minuscule à côté du géant. Il est de forme carrée, ainsi que l'étaient les temples incas, et a été composé d'après les documents authentiques du musće ethnographique du Trocadéro. Les crètes en point d'interrogation, les oiseaux bizarres de la frise, les masques humains qui entourent les portes, et les quatre grenouilles qui gardent l'entrée, sont la reproduction des moulages rapportés par des explorateurs.

Les produits du pays sont exposés dans de riches vitrines fort bien comprises, et la commission équatorienne a préféré placer sous les yeux du public des échautillons intelligemment choisis, sans chercher a faire des amoncellements de produits. On y peut voir, non sans quelque admiration, de charmants objets en paille tressée, des tissus, des hamacs, des paniers, des chapeaux surtout, dont la finesse et la légèreté surprennent, car c'est bien dans l'intérieur de la République de l'Équateur, à Guayaquil, que sont falıriqués les chapeaux dits de Panama et non dans l'isthme. Il y a aussi des broderies charmantes, des étoffes, des tapis faits à la main, puis du cacao, du café, du tabac, de l'ivoire végétal, des bois, de la bière mème, des vins, des liqueurs. En somme, cetle exposition, bien classée, arrangée avec goût dans un curieux palais, est des plus intéressantes.

Les productions naturelles sont très variées grace aux climats très différents suivant les hauteurs. On trouve de l'or, de l'argent, du mercure, du platine, de la houille, des salines, des émeraudes dans le Pichincha et dans le Cuença; la situation de ces mines dans des monts escarpés en empèche l'exploitation. Les végétaux sont abondants: on y trouve au premier rang le cacro, le coton, le tabac, le sucre, la vanille, l'orseille pour teinture, le riz, le coco, les ananas, l'orange, les bambous et autres bois, le café, le quinquina, le caoutchouc, les gommes, les résines et les céréales.

Palats des Enfants. - Dans cette partie du Chainp de Mars, à cóté el comme au milieu des pavillons de l'Amérique du Sud, se trouve l'altraction dont nous venons d'écrire le nom.

Le Palais des Enfants est un vaste théatre situé derrière le Pavillon du Chili. Toute journée, représentation de guignol, acrobates, tours de force, etc. Le soir, le Palais des Enfants devient le Palais des grandes personnes, qui y entendent le répertoire moderne le plus sérieux et en mème temps des opérettes empruntées au siècle qui vient de sécouler. A côté de l'histoire centennale de la peinture on a donc l'histoire centennale de l'opéra-comique.

Le programme comporte huit pièces jouées pendant la période révolutionnaire, sauf la première, le Barbier de Sérille, avec la musique, non pas de Rossini, comme vous pourriez le croire, mais de Paisiello. Il représentera l'année 1788. L'année 1789 fournit Raoul de Créqui, paroles de Monvel, musique de Dalayrac; la Soirce orageuse, paroles de Radet, musique de Dalayrac, une pièce politique qui célèbre le dernier rapprochement du peuple et de Louis XVI. Pour représenter l'opéra-coinique en 1791 , nous avons Nicodème dans la lune, par le Cousin Jacques, piece politique, satirique el un peu réactionnaire qui fut jouée quatre cents fois de suite; les Visilanlines, paroles de Picard, musique de Devienne (1792), se jouaient encore à Toulouse et a Lyon il y a une vingtaine d'années; la Partie carrée (1793), paroles de Hennequin, musique de Gaveaux, nous reporte en pleine Terreur et ne contient pas un seul role de femme. Pour 1794 nous avons les Vrais Sans-Culottes ou l'Hospitulité républicaine, paroles de Resicourt, musique de Lemoine, et, pour 1795, Madlme Angot, par Maillot. II est 
question de donner ce répertoire, non plus au Palais des Enfants, mais à l'OpéraComique, où les conditions d'exécution sont infiniment plus favorables.

L'idée de nous montrer la Révolution sous cette face particulière ne manque pas d'originalité.

Le Grobe tennestre. - Après l'agréable, l'utile. Entronś au Pavillon du Globe terrestre. Ce globe, dô à MM. Th. Villard et Ch. Cotard, est à l'échelle du millionième; sa circonférence est donc de 40 mètres, correspondant aux 40,000 kilomètres que mesure le méridien terrestre. A la surface de ce globe, chaque millimètre représente donc exactement un kilomètre; un mètre représente 1,000 kilomètres, etc. Le diamètre du globe est de 12,732 kilomètres.

L'aplatissement des pôles, qui est d'environ 21 kilomètres, ne serait, à l'échelle du globe, que de 21 millimètres, c'est-d̀-dire tout à fait insensible. La surface du globe a été obtenue au moyen de 586 panneaux découpés de dix en dix grades, suivant les méridiens et les parallèles, tous cintrés uniformément et munis, à l'intérieur, de cadres en bois. Ces cartons, dessinés et peints séparément, ont ensuite été fixés sur les méridiens de l'ossature métallique. Ils pourront ainsi se démonter ultérieurement aussi bien que l'ossature. Le poids du globe est, pour l'ossature métallique, de dix tonnes, pour les cartons de trois tonnes. Le globe est suspendu sur un pivot et peut être mis en mouvement au moyen d'un engrenage placé à sa partie inférieure. Il a été peint à l'huile. Le relief du sol n'a pas été indiqué en saillie, car les plus hautes montagnes, de 1,000 mètres d'altitude, n'auraient été représentées que par des hauteurs de 8 millimètres, à peine appréciables sur la surface du globe. La profondeur des mers a été aussi indiquée au moyen de la peinture. La teinte la plus claire, qui borde les continents et les lles, indique les profondeurs jusqu'à 2,000 mètres; la seconde teinte, les profondeurs de 2,000 à 4,000 mètres; la troisième teinte, celles de 4,000 à 6,000 mètres; la quatrième teinte, celles de 6,000 à 8,000 mètres; la cinquième teinte, qui est la plus foncée, indique les profondeurs dépassant 8,000 mètres.

Les noms des pays n'ont pas été indiqués; on a considéré qu'ils étaient suffisamment désignés par le nom de leur capitale et de leurs principales villes. Les frontières sont figurées par des lignes de croix noires. Les fleuves sont tracés en bleu. Les volcans sont indiqués par des points rouges. Les principales lignes de chemin de fer sont tracées en lignes rouges. Les télégraphes sont en traits dorés. Les grands services maritimes sont en traits de différentes couleurs: anglais, bleu; français, rouge; allemands, noir ; italiens, vert; américains, violet; autrichiens, orange; russes, blanc; espagnols et portugais, jaune et rouge; belges et hollandais, noir et rouge; suédois, norvégiens et danois, blanc et vert. Les principaux voyages sont indiqués par des traits ondulés avec flèches et des couleurs correspondantes, pour chaque nationalité, aux couleurs ci-dessus. Les gisements miniers sont figurés : la houille, par des points noirs; le cuivre, par des points bleus; le fer, par des points rouges; l'argent, par des points en métal blanc; l'or, par des points dorés; le diamant, par des pointes d'acier; le pétrole, par des points blancs. Aux deux pôles, les glaces flottantes sont repré sentées, dans leur étendue moyenne, par un moutonné blanc.

La surface des continents et des lles est d'environ 136 millions de kilomètres carrés et mesure une superficie de 136 mètres carrés sur le globe, dont la superficie totale est d'environ 510 mètres carrés. En faisant tourner le globe à la vitesse de rotation de la 



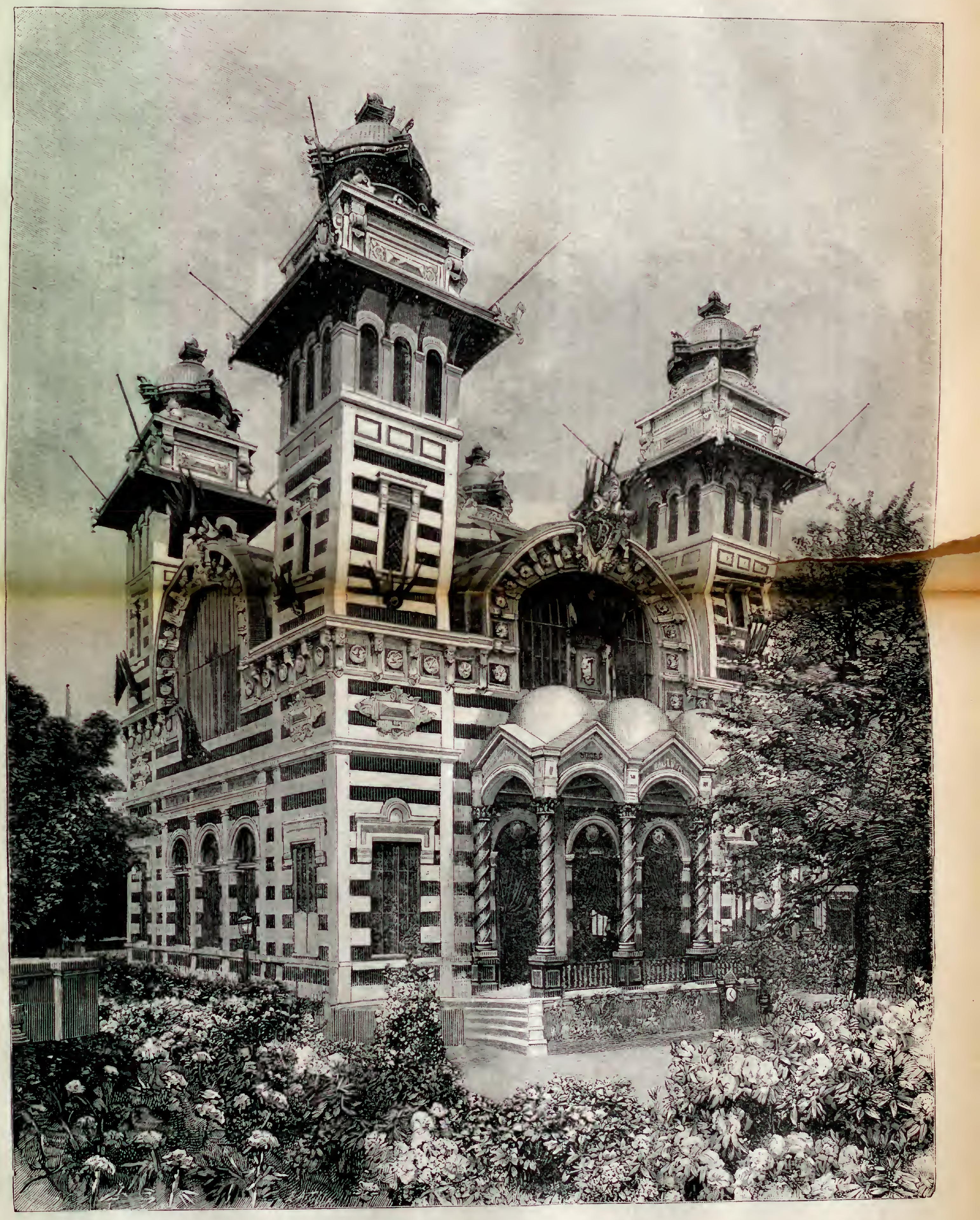


terre, un point de son équateur marcherait à une vitesse, d peine visible, d'environ un demi-millimètre par seconde, correspondant au demi-kilometre par seconde qup parcourt en réalité un point de la terre à l'équateur. Sur un dessin exposé dans lı: bâtiment est figurée, a la mème échelle que le globe, une coupe représentant l'éprisseur probable de la croute terrestre, la hauteur proportionnelle des montagnes, la profondeur des mers et la hauteur approximative de l'atmosphère. D'autres tableaux fournissent des données statistiques sur la population et les principales productions des divers pays. Tout cet ensemble est curieux; il faut le voir.

UNe ville japosaise. - Tel est le nom d'un intéressant musće, établi au milié des pavillons de l'Amérique du Sud aux frais de l'industrie privée. C'est une série de scènes qui nous fait pénétrer dans le vif de la vie et des mœurs au Japon.

Un ouvrier perfore une boite pour y placer des chevilles, tandis qu'à còté de lui un camarade enduit de laque, décore au pinceau et polit un couvercle, de sorte qu'il nous semble assister à la fabrication de ces mille objels qui ont acquis chez nous droit de cité. Plus loin, un tonnelier, dans sa maisonnette, achève un seau qu'il vient de fabriquer avec des outils primitifs, et un groupe d'ouvriers et d'artistes sont occupés a la confection des émaux cloisonnés. Voici le marchand de jouets, puis la tisseuse, qui active au moyen de pédales en bambou un métier de construction rudimentaire. Des charpentiers en tenue de travail élèent un échafaudage, tandis qu'un marcliand d'étoffes, tout affairé, fait des comptes, assisté de deux employés comptables armés d'une soroban ou table des quatre règles à grains de buis.

La hutte japonaise est représentée dans la galerie par un intérieur de cultivateurs qui viennent d’achever leur travail : au fond, un paysage des environs de lianagoura, et, dans le lointain, le Fousy-Yama, superbe volcan éteint qui domine la plaine de Kioto. Tout près, nous avons la chapelle sacrée du líioto; les idoles placées a l'entrée exhortent le fidèle à la convenance, au respect du bien; l'autel de Bouddlıa est chargé de flambeaux, de vases, de fleurs, de bronzes dont les ciselures rappellent des légendes traditionnelles; cinq bonzes musiciens cẻlèlırent. l'office du soir, coiffés d'un bonnt t rappelant le vieux casque national, et jouent de la flute traversière, de la flute de Pan. de la conque marine, des timbales, du kak-daïlio, etc.

Un kouli traine une voiture, 'un djiurikisha. Un gouverneur de province, escortí de ses gens, visite son' territoire, et ses administrés se prosternent sur son chemin, o ù un porteur de dépéches (coureur impérial) s'acquitte avec zèle de son office. Nous arrivons à la porte d'un temple, où des bonzes mendiants tendent la main en psalmodiant: un enfant porte son offrande, tandis que résonne sur le sol le baton d'appel, sorte de crosse ornée au sommet d'anneaux en métal.

On avait d'abord installé une scène de décapitation, une exécution de criminel. Vêtu de rouge, lepatient tendait le cou, à genoux, les bras liés derrière le dos, et le bourreau, son sabre en main, s'apprêtait à accomplir sa besogne sanglante, en présence du juge impassible appuyé sur son éventail. On a renoncé à conserver cette scène, autant parce qu'elle est hideuse que parce que la décollation est aujourd'hui remplacée an Japon par la guillotine. On a de méme supprimé, pour des raisons de convenances. une scène mortuaire et une scène de suicide, de kara-kiri, nom sous lequel on désigne la mort par ouverture du ventre, qui d'ailleurs est prohibée depuis vingt-cinq ans dans les États du Milkado. En revanche, le brigandage y est florissant, si nous en crojons ce 
brigand qui traîne sa victime sous une grotte pour la voler et lui jette une corde au cou en la menaçant de son sabre.

Tout ccla se trouve au rez-de-chausséc. Au premier étage, nous avons aussi des groupes intéressants. C'est d'abord un paysan et une dame en costume d'hiver; une installation de blanchisseuses dont l'une, comme gage de fidélité conjugale, s'est teint les dents en noir et arraché les sourcils. Un chiffonnier, portant une corbcille ct une paire de longs batonnets, parcourt les rucs et les places pour faire des prises. Dans une maison de thé, une guecha festoie avec ses amies autour d'un plateau rempli de riz, de poissons frits et de tasses. Plus loin, deux joueurs d'échecs sont aux prises dans une attitude songeuse, n'ayant pas l'air d'apercevoir un enfant qui les regarde en riant. Admirez aussi cette vieille femme qui bourre sa pipe de tabac, en racontant une histoire, ce groupe d'officiers et de soldats, cette école où des enfants accroupis apprennent le rudiment, ces dames en visite, ce jongleur, cette boutigue de brodeurs, ce salon de coiffure, ce gros personnage en habit de cour et enfin ce mariage symbolique qui nous montre tout un coin de la vie intime du Japon.

La ville japonaise mérite une visite; on ne s'y ennuie pas.

Salyador tit Nigalagua. - Ce qui frappe quand on arrive devant le coquet et arlistique pavillon du Salvador, c'est son architecture bizarre, à la fois arabe et espagnole. M. le consul général Pector, en le faisant construire, a, d'après les plans de M. Lequeux, voulu rappeler les constructions de ce petit pays de l'Amérique Centrale, très habité et très industrieux. La façade du pavillon est embellie de faïences sur lesquelles on retrouve une collection de symboles empruntés à l'ancienne civilisation nahua. Sur la façade principale des hiéroghyphes figurent les dix-huit mois de l'année mexicaine et les vingt jours de chaque mois, et dans la frise du premier étage le chiffre 1889 se lit écrit en nahua. Sur la façade postérieure, les anciens rois du Mexique et les noms de ses villes principales. Le signe placé devant la figure des rois indique qu'ils avaient sculs le droit de parler dans les conseils.

Dans l'intérieur sont deux grands panneaux où se trouvent représentés un temple et des cérémonies religieuses, l'entrée du port de la Libertad et le fameux lac Nilopango, avec son volcan, qui surgit au milieu des eaux.

Les objets exposés rentrent dans les rubriques suivantes : matériaux de construction, ébénisterie, plantes médicinales, plantes textiles, plantes tinctoriales, huiles, cires, produits de la pêche, produits miniers, produits alimentaires, conserves, légumes secs et graines, condiments, confitures, vins et alcools, produits chimiques et pharmaceutiques. Une place considérable est accordée à l'éducation et à l'enseignement, à la photographie, aux instruments de musique, à la céramique, aux meubles, à la joaillerie. loici des cigares d'un blond qui fait rèver. Nous mentionnerons spécialement lexposition de peinture, où les siles du pays et divers événements politiques sont retracés sur la toile par MM. Gonzalez, Ansola, Villanova, Cisneros, Villacorta, etc... La classe consacrée d̀ l'architecture contient une vue de la Casa Blanca, résidence du I'résident de la République.

Un peu plus loin, le visiteur voit une serre-orangerie qui sert d'annexe et où se trouve une collection de produits agricoles et forestiers, entre autres de nombreuses plantes médicinales.

Le pavillon du Nicaragua est une construction en bois, avec de jolies marqueteries; 


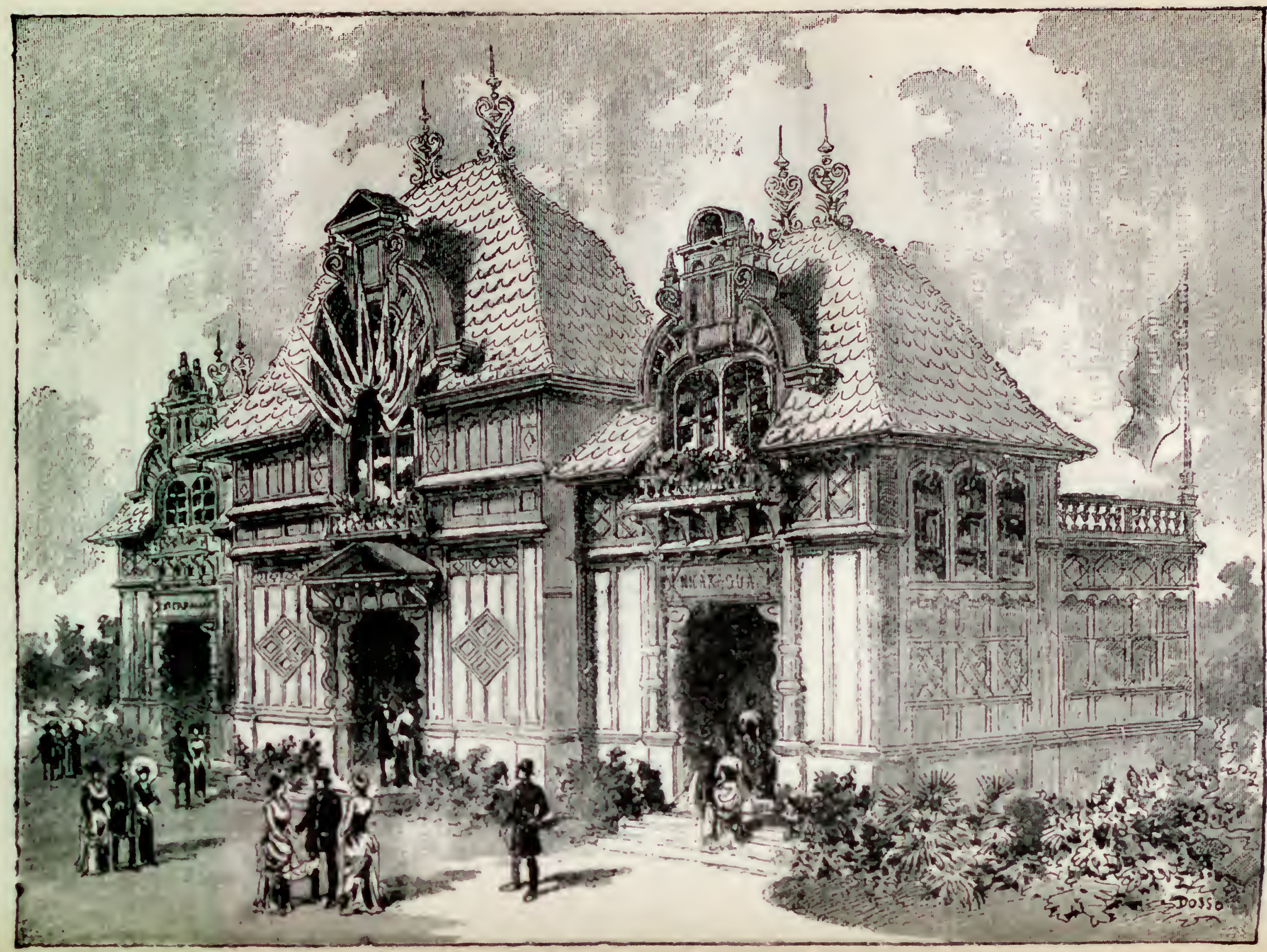

㝵 


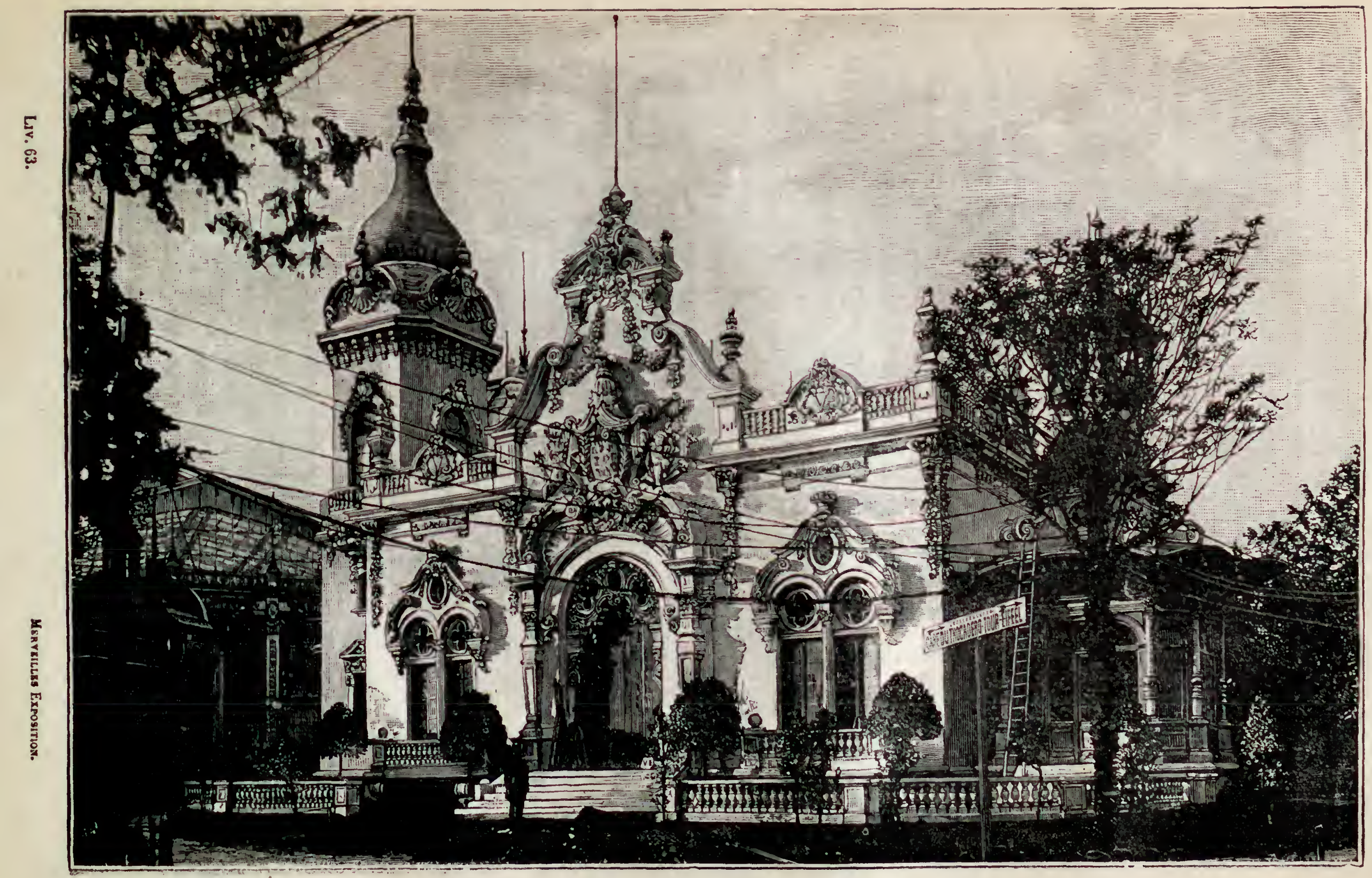

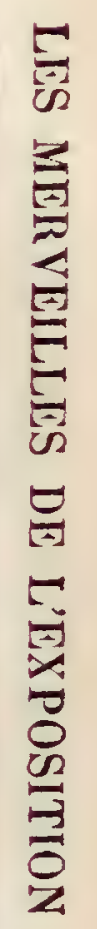

Le Pavillon du Vécézuéla. 
a toiture est de forme originale recouverte de tuiles-écailles couleur terre-cuite et couronnée d'épis en faïence. Le tout est d'un ton chaud et d'un dessin gracieux.

Uruguat, République Domixicaine, Paraguat, Guatémaba, Hawaï. - Les pavillons du Nicaragua et du Salvador sont en face de la porte du Palais des Arts libéraux, mais le long du Palais, au bord de l'avenue de Suffren, entre le Globe terrestre et le Pavillon Indien, s'échelonnent encore cinq pavillons intéressants: ceux de l'Urugruay, de la République Dominicaine, du Paraguay, du Guatémala et de Hawaï. Dans le pavillon de l'Uruguay, vous verrez exposés des échantillons de cuirs bruts, de cornes, de viande salée, etc. Les paturages du pays sont si fertiles qu'ils nourrissent 330,000 chevaux, 6,500 mulets, $6,500,000$ bètes à cornes, $13,000,000$ de brebis, 50,000 clievres, 70,000 porcs. II II est donc pas étonnant que l'industrie s'exerce surtout sur les bestiaux.

La Commission Dominicaine a très heureusement installé son Lixposition, qui comprend surtout des sucres, des cafés, des cacaos, du tahac, du coton, dez minerais et des bois rares, dans un petit pavillon élégant, construit du cóté lle l'avenue de Sufren, en face du Palais des Arts libéraux. Cette construction lég̣ire, due ì l'architecte 0. Cuurtois-Suffit, répond de la façon la plus complète aux exigences de sa destination ct fait bien ressortir les collections qui y sont exposées. La République Duminicaine a élé une des premières à répondre à l'appel du Gouvernement français, voulanf expriner à sa sœur aînée ses sentiments de concorde et de fraternité. Son ministre plénipotentiaire, le baron Emmanuel de Almeda, s'est donc occupé de réunir les productions nombreuses d'un pays qui occupe sous le soleil des tropiques une place importante. Les échantillons de son tabac sont magnifiques; sa feuille excrde celle de tous les tabacs de l'Amerique. L'exploitation des forèts est également représentée au Pavillon Dominicain frar une variẹté infinie de spécimens des divers hois durs et précieux, employés dans l'industrie du meuble, par les campèches et bois jaunes qui fournissent des matières colorantes, par des bois de construction superbes. Les produits de la pecclie figurent sous forme d'écailles de tortues, de peaux de caïmans et de requins liruts et travaillés. Les usines de premier traitement y sont représentées par des sucres clarifiés à un degrí diojà furt remarquable, par des rhums, des miels, des cires. L'industrie ininiere tient une place respectable avec les blocs de sel gemme, des sables auriferes, des pyrites, minerais de fer et autres. Enfin, on verra de nombreux produits industriels qu'on est habitué a considérer comme l'apanage exclusif de l'ancien continent, comme la broderie, la cordonnerie, la sellerie. La République Domnicaine a enfin prouvé qu'elle est loin d'être indifférente aux manifestations artistiques; elle a tenu ì rendre hommage au talent d'un sculpteur français en plaçant au centre de son exposition la matuefle de la statue de Christophe Colomb, exécutée pour elle et érigée sur la place principale de la ville de Saint-Domingue, sa capitale.

L'édifice du Paraguay se compose de deux parillons contigus et d'une tourell. carrée. Les deux pavillons reproduisent dans leurs colonnes légères et d’un aspect un peu imprévu, mi-palmiers, mi-torses, dans les ogives capricicuses des portes, flans les toitures avancées et découpées, soit des détails empruntés aux églises de Villa-lica e! d'Ita, soit à d'autres monuments de la domination espagnole. Quant il la tourelle, dont les principaux délails sont traités comme de la menuiserie d'art, c'est une élégante copie du mirador qui surmonte au Paraguay toutes les maisons isolées en rase cunpranne. Ces bâtiments seront démontés et expédiés à Asuncion, capilale du Paraguay, purr y 
ctre remontés et servir à une Exposition de produits français. Le gouvernement paraguayen a exposé des vues pholographiques, cartes, plans, timbres-poste et cartes postales, poteries diverses, jarres, sucriers, figurines, de nombreux produits textiles parmi lesquels des hamacs, des échantillons de minerais de diverses espèces de bois, des peaux de tigres, de cerfs, de tapirs, de fourmiliers, de renards, des cornes, des oiseaux sauvages empaillés, de l'indigo, du cachou, des semences, des plantes médicinales, des cigares, du tabac, des arcs avec flèches travaillés par les Indiens.

La République de Guatémala, la plus importante de l'Amérique Centrale, a été l'une des premières, elle aussi, à accepter l'invitation du gouvernement français. Le présiḍent Barillas a nommé a Guatémala une commission d'hommes importants, qui a travaillé activement pour réunir de très intéressantes collections de tous les produits du pays. A Paris, M. Crisanto Médina, ministre de Guatémala, a fait construire un -pavillon d'un aspect fort élégant, qui se compose d'un rez-de-chaussée et d'un premier étage, a doubles terrasses et vérandas nationales. Cette construction est en bois verni, avec de jolis tons jaunes et rouges; des faïences s'encadrent admirablement dans ces bois et viennent donner la note franche et gaie d tout l'ensemble. Ajoutons pour les gourmets que la commission a fait installer un comptoir de dégustation où l'on pourra savourer les cafés et les cacaos de Guatémala.

Dans le pavillon de Hawaî, le visiteur trouvera des produits analogues, car l'île d'Hawal est trds fertile: des bois, des fruits de toute sorte; des frangipaniers, des pins, des vignes, des orangers sauvages. Que de ressources à exploiter!

Palais Indian. - C'est un édifice rectangulaire entouré de vérandas et dont la coupole décagone reproduit le type de la tour célèbre de Delhi. Au centre, M. Joubert a élevé une jolie fontaine de marbre. Les murs extérieurs sont peints en rouge brun et couverts de fines dentelles blanches. Cette couleur rouge a été obtenue à l'aide d'un enduit dont le principal élément est le sang de bœuf.

Parmi les vingt exposants indous qui sont venus ou qui ont fait exhiber leurs produits dans le Palais se trouve le maharajah de Mysore. Nous trouvons là des vases et plats en cuivre, des cadres en mosaïque, des coffrets en bois de sandal, des tissus aux couleurs éclatantes, des jouets bizarres.

Nous nous asseyons devant de petites tables, autour de la fontaine, et des garçons vètus et coiffés de blanc avec une ceinture tricolore, - de vrais Indous, - nous apportent un thé exquis et un c prix-courant, où se lisent ces vers non moins exquis :

Lo the chinois vraiment ne vaut rien,

Nous voulons seul le bon the indien.

Le Palais mesure 60 mètres de longueur sur 15 de profondeur. A droite et à gauche du dome, douze coupoles dominent ce palais, et la porte centrale est surmontée de deux minarets. Nous retrouvons la l'art arabe, mais singulièrement modifié par le milieu où l'invasion musulmane l'a transplanté.

- L'imagination de la vieille Inde monstrueuse influe et sur les proportions qui s'accroissent et sur les lignes qui se tourmentent. , Les motifs sont empruntés aux collections du Musée indou de South-Kensington, de Londres.

L'architecte, M. C. Pardon Clarke, membre de l'Institut royal des architectes, a fait de lonģs séjours aux Indes; il connait à fond l'art indou, et mieux que personne il était 

LES MERVEIISS DE L'EXPOSITION

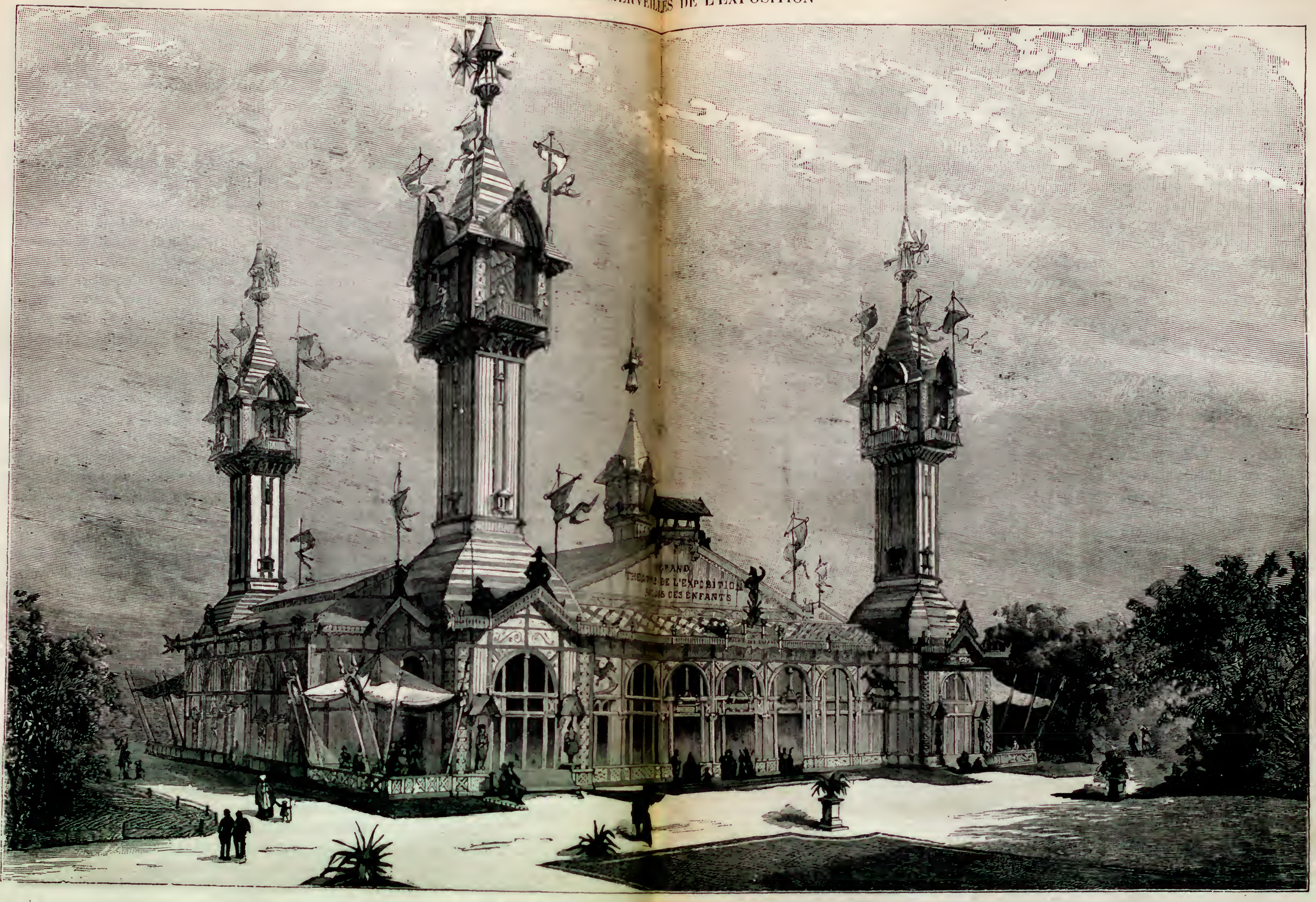

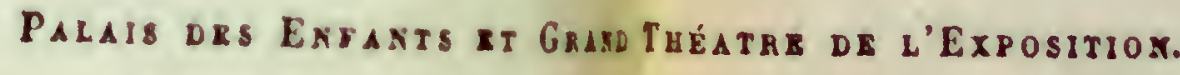


à même de faire, pour la Commission britannique, une reconstitution artistique d'un grand caractère. Il s'est inspiré de l'architecture indoue du xve siècle, et a copié les différentes parties de son palais sur des monuments qui datent de celte époque. Il a pris la véranda, ses colonnes et ses chapiteaux dans le Mahal de Tatlipur Sekri; les minarets de la porte sont ceux de la mosquée d'Ahmedabad; les colonnes de l'intérieur rappellent celles de la mosquée de Kíatub à Delhi.

L’intérieur a été disposé de façon à permettre l'installation d'une vaste Exposition. C'est une longue galerie sur laquelle s'ouvrent des boutiques séparées par de hautes colonnes et éclairées à la fois par des coupoles et par de petiles fenetres de forme originale. Au centre de la galerie, une rotonde ì deux étages, avec d'élégants balcons, correspond au grand dome; au milieu, une fontaine de marbre verse ses eaux dans un bassin de faïence multicolore.

Le bazar comprend trente boutiques; des fabricants de Calcutta, de Bombay, de Delhi, y ont exposé toutes les merveilles de l'Inde. Ces boutiques sont toutes étincelantes d'étoffes, de bijoux, de faïences, de tapis

Regardez cetétalage d'étoffes charmantes : des foulards léger's et soyeux, de toules nuances, pour robes, pour tentures ou rideaux; puis des cotonnades imprimées i la main, provenant d'Agra, grossières avec des dessins primitifs, mais très curieuses de tons et de composition; des tissus brodés de Madras, et des étoffes de Delhi avec des applications de verroteries.

Retournons-nous, et admirons les cuivres ciselés de Bénarés, et les cuivres avec incrustations de Moradabad, les filigranes et l'argenterie de Bombay, les bijoux de. Pondichéry. Là, c'est une boutique de mille objets divers : coffrets, plateaux, lonis sculptés, etc... Plus loin, c'est un comptoir de poteries : les plats immenses de Sindlı, et les faiences bleues de Bombay. Un peu partout des ivoires sculptés de Moorshivabad, des éventails, des écrans et les kus-kus parfumés.

Le Cachemir a une exposition importante. M. Bigen, un Français établi a sirinagar, expose d'admirables tapis fabriqués dans ses ateliers par des milliers d'indigénes; ce sont les dessins et les coloris des challes, aujourd"hui paesris de morle; nnus tronvons exposés des immenses tapis qui ne mesurent pas inoins de 90 à 110 mètres carrés. M. Bigen a complété cette exposition par des spécimens de tout ce que l'on fabrique dans le Cachemir; nous trouvons là aussi, des spécialités bien curieuses: d'abord les meubles, tables et tabourets laqués, si riches de dessin et de couleur; puis l'orfevreria cloisonnée el ciselée, de magnifiques aiguières de cuivre et d'argent martelés ou repoussés. M. Bigen, en Français de goùt, a su iustalier son exposition avec beaucoup d'art, beaucoup de soin et de couleur locale.

Sortons de cette longue et admirable galerie, et jetons un coup d'ceil dans la rotonde centrale. Autour de la fontaine et sous la véranda, la Compañie des thés de l'Inde fait déguster, comme nous le disons plus haut, ses produits qui commencent ì créer une véritable concurrence aux thés de Chine; clle a su domner à son intallation un côté vraiment pittoresque, en faisant faire le service par des indiginnes au teint brun, vêtus de longues chemises blanches et coiffés de turbans.

Cette Exposition des Indes anglaises, différente des bazal's orientaux du Maroc, de l'Égypte et de la Perse, a ún caractère particulier : mouvementée, pittoresque et variẻe d'aspects, elle attire tous les jours une foule de visiteurs, bien que située dans une partie un peu délaissée du Champ de Mars. 
Du Palais Inden a la rue du Game. - Dans l'allée qui conduit du Palais Indien à la rue du Caire s'éièvent, sur la droite, un certain nombre de pavillons. Sur la gauche sont les expositions de quelques sections étrangères: Saint-Marin, Grèce, Serbie, Japon, Siam, Perse.

La petite république de Saint-Marin a une façade monumentale, dont on admirera la porle Renaissance encadrée de fäiences, llanquée de verrières magnifiques. L'intérieur est tout à fait réjouissant pour l'œil; c'est, on l'a déjà remarqué, un salon plutôt qu'une Exposition : tapisseries, meubles Renaissance, services de table, trophées d'armes, cheminée sculptée, sièges d'un goût exquis, rien ne manque à cette charmante installation, rien, pas mème la carte en relief de la République.

L'Exposition de la Grice est plus considérable, naturellement, et non moins intéressante. Les objets qui s'y voient proviennent de l'Exposition qui a eu lieu en Grèce tout récemment, el en sont comme la quintessence.

Le Gouvernement grec donna 200,000 francs, le Comité de l'Exposition olympique 100,000 francs pour l'installation de la section, à Paris, section qui ne couvre pas moins de 600 mètres carrés. De chaque côté de la porle d'entrée, l'architecte, 11. Sauffroy, a fait représenter l'Acropole et les mines du Laurium. A l'intérieur, quelques types en cire, de grandeur naturelle, nous montrent les costumes particuliers aux principales régions de la péninsule Hellénique. Dans les vitrines, des tissus de soie, des tapis, les articles de lingerie et de confection; puis, de magnifiques échantillons de marbre et de minerais, des fruits secs (surtout des raisins), et des vins dont la réputation est universelle. Liarchéologie a aussi sa place dans la section. Les statues peintes tout dernièrement découvertes à l'Acropole et antérieures au temps de Périclès sont photographices pour la première fois.

Lia Serbie est un royaume encore neuf aux prises avec les pires difficultés intéricures. Cela ne l’a pas empèchée, dès le début, d'accepter de prendre part à notre Exposition universelle. La section serbe, ou nous voyons un portrait du jeune roi Alexandre, couvre une superficie de près de 600 mètres carrés. Sa façade monumentale, de style serlı-byzantin, avec mosaĩques émaillées et plaquées de marbre blanc, est due à II. Lafanège. Les tapis qui recouvrent les murs intérieurs font envie à plus d'une visiteuse, ainsi que les tissus aux riches couleurs, et les draps brodés, et les vestes et jupons aux ornements soutachés, et les ceintures et les gazes transparentes. Voici encore des objets d'église, qu'il sera intéressant le comparer à ceux qu'on voit au Trocadéro, qui révèlent l'inlluence de la Turquie; des oljjets en filigrane, des minerais, des produits de toute sorte, et comme couronnement, l'exposition de l'arsenal de Kragujevats.

De la Perse et du Maroc, nous avons peu de chose à dire: Le pavillon Marocain intéressera plus par son architecture, arabe comme on sait, que par les produits qui s'y rencontrent, car l'Orient triomphe à un tel point, au Champ de Mars et à l'Esplanade, qu'il faudrait à chaque pas recommencer les descriptions. Ce sont loujours les mèmes tissus, les mèmes yatagans, les mìmes meubles, les mèmes tapis. Qui a vu l'un de ces pavillons en a vu dix. Dans la section perse, un grand tableau d'un naïf artiste indigène représente le shah Naser-ed-Din, celui-là mème qui a profité de l'année de l'Exposition pour venir en Europe.

lieposons-nous un instant au Restaurant roumain. Tout Paris connait maintenant les Lautars, ces musiciens roumains qui ont gardé le costume national, et qui font 


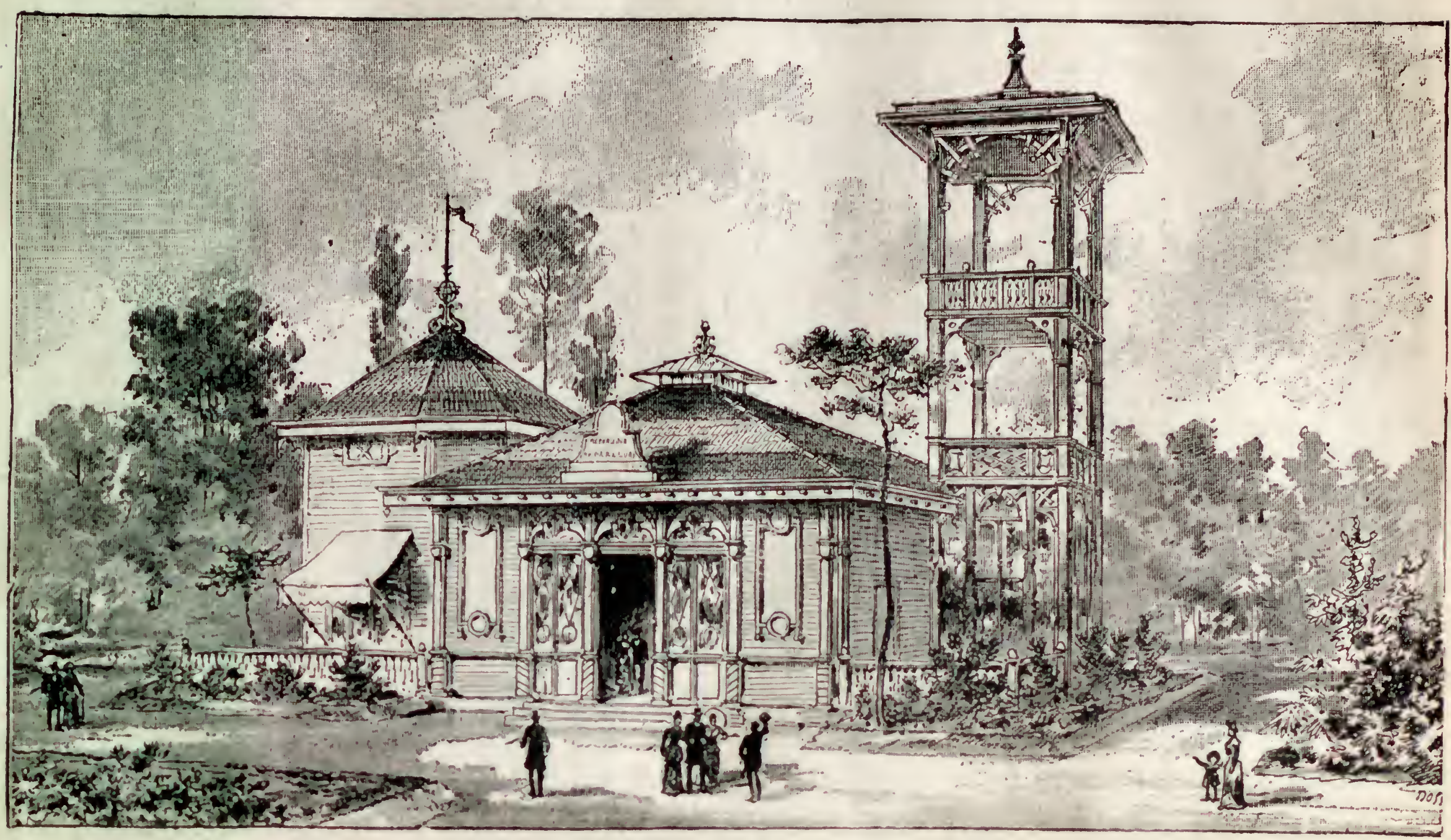

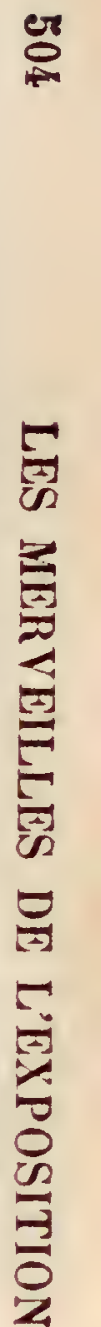

Le Pavillon du raraguar. 


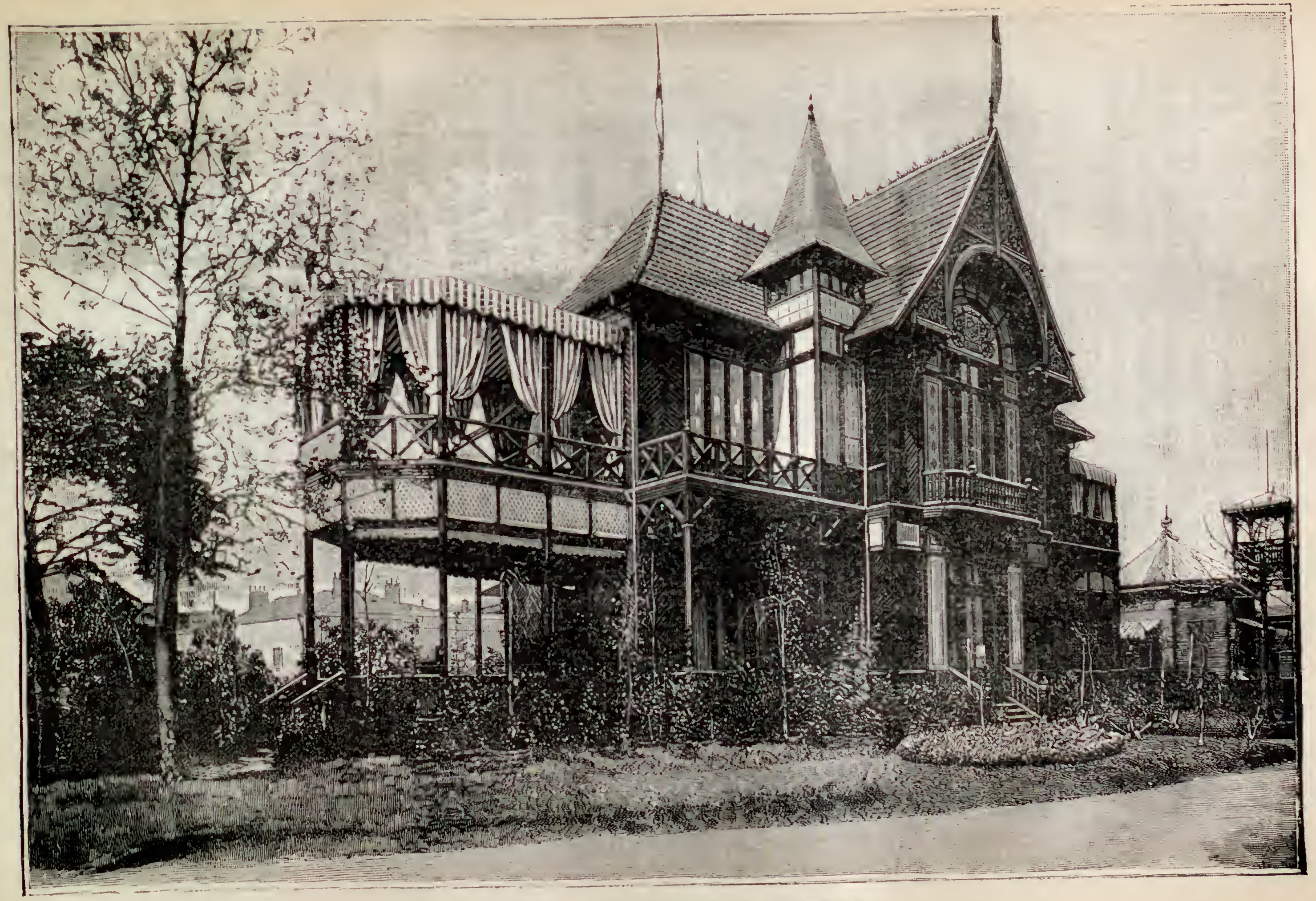


entendre les mélodies composées sur les rives du Danube, sous ce ciel qui annonce déjà l'Orient.

Les Lintars sont installés dans un chalet-restaurant qui, avec ses pignons, sa four et son toit saillant, reproduit facilement une maison de campagne des environs de Bucarest. Cette charmante construction a été élevée par M. Oscar Andrésur les plans de II. Mıncù Des garçons et des servantes en costume bariolé servent aux consomma. teurs le tatoux (lait de buffle caillé), le tronica (eau-de-vie de prunes), le tauvaioas (eau-de-vie du pays).

Par sa situation géographique la Roumanie, dit M. Camille Debans, parlicipe comme mours autint que comme cuisine, de la Turquie dont elle élait il $\mathrm{y}$ a trente. cing ans la rassale, et de la Russie qui a exercé et exerce encore une grande influence sur sa destinée. Prendre un repas au restaurant roumain. c'est donc manger a lit russe et à la turque en même temps. Le caviar joue un grand rôle dans l'anaire. l. sterlet du Volga y prédomine, l'esturgeon salé ne lui cède en rien, et les petits porsono qui poussent à boire s'y étalent en rangrs pressés. Voilł pour la Russie. In Turque ofre un pilaw un peu abatardi à la vérilé. mais encore très recommandable et surtout. ah! surtout la fameuse confiture de roses qui constitue pour les Roumains une friandise cles plus délicates et des plus exquises de l'univers. Nous verrons si les antres peuples seront de leur avis. En tous cas, comme on y mange aux sons entrilnants d'un orchestre oriental, les oreilles eeront charmées en méme tempis que l'pstumac

Pavillox Cinxols. - Nous n'insisterons pas sur le pavillon Chinois. Nous avons, on faisant la description de l'Histoire de l'habitation humaine, donne les caracteres carentiels de l'architecture du Céleste Empire et nous n’avons pas à y revenir. la Cune, d'ailleurs, re participe pas officiellement à l'lixposition. Ce sont des nf́rociants do Canton qui ont exposé leurs produits à titre purement privé.

A rrai dire, nous ne trouvons la qu'une édition agrandie des magasina de clanni. series que nous avons à Paris. Qu'y royons-nous? des soieries aux teintes vives rt solides, des vases, des boltes, des meubles vernis et laques, du the et ces mulle nbjots d'étagère aux formes bizarres. Il serait impossible d'énumérer tout cela : il faust fo volr.

- Pour terminer les sections orientales, écrivait récemment un de nos confrèren. nous aurions voulu parler de la Chine. Mais le mieux est de nen rien dire, et la (hiom elle-mème nous en saura gré.

- Le gouveruement de Pékin, qui a craint sans doute de se compromettre, en par. licipant à une solennité qui avait lieu a l'occasion du Centenaire de la Mévolution française, s'est abstenu; la vérité pourrait bien etre que l'administration dos douanes chinoises, toute-puissante, puisqu'elle tient les cordons de la bourse, et exclusivement composée d'un haut personnel anglais, s'est refusée à donner les fonds nécessaires pour organiser une section chinoise. Nous constatons sans apprócier.

- Toujours est-il qu'ur certain numbre de nigociants de Canton ont voulu, ã leurs frais, venir exposer des produils du Céleste Empire.

- Le bazar qu'ils ont installé est médiocre; des onvriers catalans sont venus monter une construction aussi ridicule que peu chinoise.

- Les exposants ont déballé sous cet abri bariolé une quantilé de prouluils posés comme au hasard, sur des comptoirs mal tenus, et au milim de caisons qui altendent encore leur ouverture. Il se peut qu'il y ait dar ce funillis quelıu oljets de raleur, 
mais il est impossible de les distinguer. Ce n'est point une section c'est à peine un bazar peu digne de l'Exposition.

Japos - Dès les premiers joul's qui ont suivi l'ouverture de l'Exposition, nous avons entendu critiquer la section japonaise : on comparait cette exposition de l'industrie et de l'art japonais à celle de 1878 , et naturellement tout à l'avantage de ce que nous avons vu, il y a onze ans. Ce sont des jugements bien sévères ou tout au moins exagérés.

- La vérité est qu'en 1878, l'Exposition japonaise comprenait une quantité d'oljets anciens, de tous styles et de toutes les époques, qui faisaient de cette Exposition une Exposition pour ainsi dire rétrospective.

- Aujourd'hui la section japonaise ne contient que des objets modernes; il est certain que la consommation considérable d'objets japonais dans le monde entier a nécessité une fabrication souvent moins soignée et une production beaucoup plus rapide. Mais à côté de ces produits ordinaires, on trouve des vitrines remplies de merveilles et qui prouvent que les anciennes traditions n'ont pas disparu. ,

Quoi qu'il en soit, on commence à revenir sul l'impression première, et nous engageons ceux qui se sont trop hatés de porter un jugement, à aller voir en détail cétte Exposition si riche encore en véritables objets d'art.

Parlons d'ahord du cadre: - La section japonaise occupe une surface de plus de 1,500 mètres carrés. A l'extérieur, elle comporte une façade qui, par son style, ses ornements, est la plus artistique de cette série de façades nationales.

- Au centre de la façade une porte monumentale donne accès au vestibule qui divise la section en deux compartiments. Cette porte se coinpose de montants en bois de cèdre rose très finement sculptés. Les sculptures ont été faites au Japon par deux artistes de Tokio, Miliouaki Ishikawa et Kódun-Takamura. Ce travail est très remarquable. De cliaque colé du portique, des façades qui n'ont pas moins de quatre-vingts mètres de développeinent, se prolongent avec des soubassements de faïences vertes et jaunes. Des balcons à charpente apparente, viennent rompre la monotonie de ces façades.

- A la hauteur des balcons, de petites fenetres donnent du jour dins la section.

- Une toiture recourbée à ses extrinités, et faite en tuiles d'uu grı is ardoise avec de discrels points d'or, termine la fiçade d'une façon fort pittoresque.

- Le portique est abrité par un auvent qui forme saillie el couvre un long tableau de laque noire, à coins de cuivre ciselés, sur lequel est inscrit , Japon , en caractères japonais. Tout cet ensemble n'a rien de choquant ni de disgracieux. M. Jules Gauthier, architecte de la Commission impériale, a su tirer parti, avec beaucoup de talent et de gout, des données qui lui étaient imposées.

- Lintérieur se compose d'un grand vestibule qui se trouve au centre de deux galeries dont l'une est destince aux objets manufacturés, aux objets d'art; l'autre renferme les produits alimentaires et les diverses expositions des Ministères.

- Le vestibule a grand air; au centre nous remarquons une pagode de bronze entouré de plantes et d'arbustes; aux angles, des expositions de faïence gigantesques et deux fontaines qui sont de vrais chefs-d'œuvre. Sous la coupole deux grandes peintures représentent de curieux paysages japonais.

- Dans les galeries nous trouvons des vitrines fort curieuses. Les murs sont tendus 



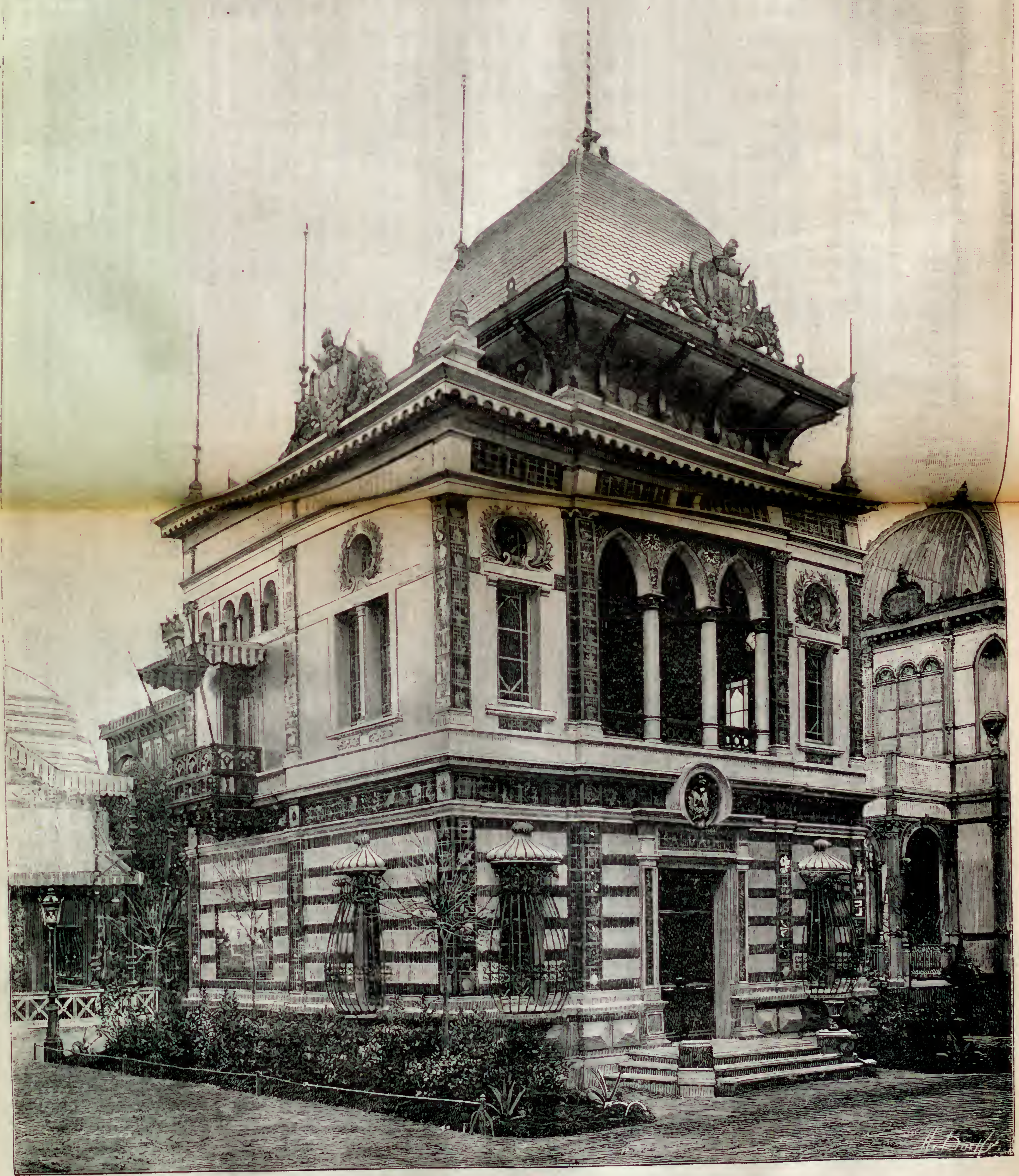


de papier japonais à personnages et à fleurs. Çà et là des étoffes, des portières, etc.... La section japonaise a ainsi une couleur locale qu'elle n'avait pas en 1878.

- En entrant dans le compartiment qui se trouve a droite du vestibule, on trouve tout d'abord les faïences et les porcelaines. Voici les satsuma modernes, d'énormes vases, les porcelaines de Kanha genre Kutani, plus loin les terres fines de Kioto. Kooransha expose les produits de ses fabriques d'Arita, plats, vases, etc...

- Histiyen, de Tokio, qui est un décorateur plutót qu'un fabricant de porcelaines, a réuni une collection de menus objets d'une grande finesse de décoration.

- Avouons que la céramique ne nous semble pas en progrès au Japon. On sent la préoccupation trop souvent dominante de suffire aux demandes du commerce d'exportation; l'ouvrier, l'artiste paraissent avoir perdu de leur personnalité.

- La mème crilique pourrait être adressée aux bronzes. Mais où nous pouvons admirer sans réserve, c'est dans le compartiment des laques, des cloisonnés, des marqueteries et des tissus. Signalons aussi, parmi les produits nouveaux, des tapis de toutes dimensions, qui non seulement sont d'une qualité excellente, mais sont ravissants de composition et de coloris. Les laques, les ivoires, sont vraiment de toute beauté. Ici tout est vendu, le moindre objet a trouvé un acquéreur.

- Si la production japonaise n'est que stationnaire pour beaucoup de branches, il en est dans laquelle elle a fait d'immenses progrès depuis l'Exposition de 1878; ce sont les cloisonnés. Les exposants japonais en sont très fiers et à juste titre. Les spécimens exposés dans les deux vitrines situées près dela section de Siam sont en tous points des chefs-d'œuvre. Très désireux de faire oublier qu'il y avait naguère des mœurs et des coutımes japonaises, très fier de montrer les résultats obtenus par l'adoption de méthodes et d'usages empruntés à l'Europe, le gouvernement de Tokio a fait une exposition aussi officielle que possible. Il a altaché une grande importance au succès que pourrait remporter auprès du public le compartiment où ont été réunis lous les documents de nature a faire comprendre que le Japon a bien définitivement adopté la civilisation européenne.

- Les différents ministères ont envoyé tous les tableaux, toutes les statistiques et les brochures publiés par leur département. Le ministère du Commerce a ses talleaux dı commerce extérieur. Le ministère des Postes expose d'intéressantes publicalions sur les caisses d'épargne pustales. Le département de l'Agriculture a groupé des collections. des produits divers obtenus dans les fermes-écoles, puis des spécimens de la flore el de la faune. Le ministère de l'Instruction publique a l'exposition la plus intportante. Le gouvernement impérial a mis une certaine gloire à montrer ce qui a été fait en quelques années pour le développement de l'instruction à tous les degrés.

- C'est d'abord la Faculté des lettres, des sciences; puis l'École supérieure de cornmerce, l'École normale supérieure, l'École normale ordinaire, les lycées supérieurs de Tokio, de Kumanoto, de Sendaï, l'École des aveugles el des sourds-muets ont aussi leur exposition. Les écoles primaires nous montrent leur malériel scolaire, leurs méthodes, des képis et des tuniques pour les élèves. Les salles d'asile exposent des reproductions de leurs installations, de petits livres d'images el des jouets pour occuper les enfants, C'est également dans cette partie de la section japonaise que se trouvent exprusés les produits alimentaires, les produits naturels du sol el certains produits maufacturiers. Au centre du compartiment, nous trouvons les céréales, les fruments, les riz, elc..., les this enfermés dans de jolies boites; des bonbons, des patisseries, des confitures, des 
conserves de chez Matsumoto, les kahi en pátes et les yokan en gelée, des vins de riz, des liqueurs, etc...

Regardez dans les vitrines à l'abri de la poussière, voici les scies en écheveaux, les fils d'or pour broder; puis toute la collection des papiers admirables, en feuilles, en rames, en louleaux, etc., minces, légers ou épais; c'est une merveilleuse exposition. Voyez sur les murs, tous ces papiers peints avec des reliefs bronze et or! Et si vous nllez plus loin, n'oubliez pas de jeter un coup d'œil sur les cotons, les lins, les chanvres et toute la série des fibres végétales; les bois en blocs luisants ou en feuilles minces comme des papiers; les bambous de toutes grosseurs; les tabacs, les cires et les huiles de toutes couleurs.

- En somme, l'Exposition japonaise est digne de celles que nous avons vues en 1867 et 1878 ; elle est pittoresque, elle offre un intérêt réel et son caractère artistique est encore merveilleux. ,

Section siamorse. - Le gouvernement de Banglkok participe officiellement d l'Exposition de 1889. Sa Majesté le roi de Siam a accepté l'invitation du gouvernement français ct a tenu d ce que l'Exposition siamoise fut plus brillante encore que celle de 1878. Depuis bientôt deux ans des collections ont été réunies pour figurer au Champ de Mars.

- Toutes ces curiosités arrivées depuis peu en France sont exposées dans la galerie des pays du soleil, du côté de l'avenue de Suffen. M. Grehan, consul général de Siam a Paris, a dirigé l'iustallation de cette exposition arec beaucoup de soin.

- L'entrée de la section est accusée par une façade composée de trois portes d'un rouge de laque de Chine avec des applications de ferrures et de clous rehaussés d'or; des piliers vert et bronze forment encadrement, et un large auvent, surmonté de pyramides en pointes bizarres, abrite l'ensemble de cetle façade.

- L'intérieur de l'édifice est tendu d'un rouge vif, qui fail ressortir l'or dont sont couverts les moindres objets; car, à vrai dire, aucune section n'est plus éblouissaute, l'or étincelle partout, et cependant ce n'est ni trop criard ni trop choquant.

- L'Exposition comprend surtout des mobiliers complets qui ont été envoyés par le roi. Nous pouvons y voir 4 lits qui ontété placés aux quatre angles de la section; mais voyons un peu en délail les ameublements que nous y trouvons. Voici d’abord une chambre à coucher, avec son lit à colonnes et à baldaquin, tout sculpté et doré, ses divans recouverts de riches coussins de soie, sa toilette à niroir, son armoire à panneaux laqués.

- Voila un salon avec ses sièges, ses bahuts, ses long6 canapés, ses guéridons et ses fines étagères. Tout cela est en bois doré, avec des incrustations de glaces miroitantes.

- Ln autre salon en laque, d'un bleu turquoise, est plus sombre de tons; sur les boiseries sunt peintes des fleurs assez fines. En somme, ce sont des meubles peu confortables, et qui malgré leurs ornements n'ont pas un aspect plus gracieux. Nous n'en dirons pas autant des paravents, qui sont plus légers et mieux peints. Au centre de la bection une immense vitrine contient l’orfevrerie, des services à thé, des plats, etc... il y a aussi de nombreux objets en cuivre repoussé, puis des aiguières, des cofres d'ivoire et de bois odorant, et une jolie collection d'éventails, rtc... quelques bijoux en or avec pierreries et surtout des émer'audes, des bracelets, des bagues, des colliers. 


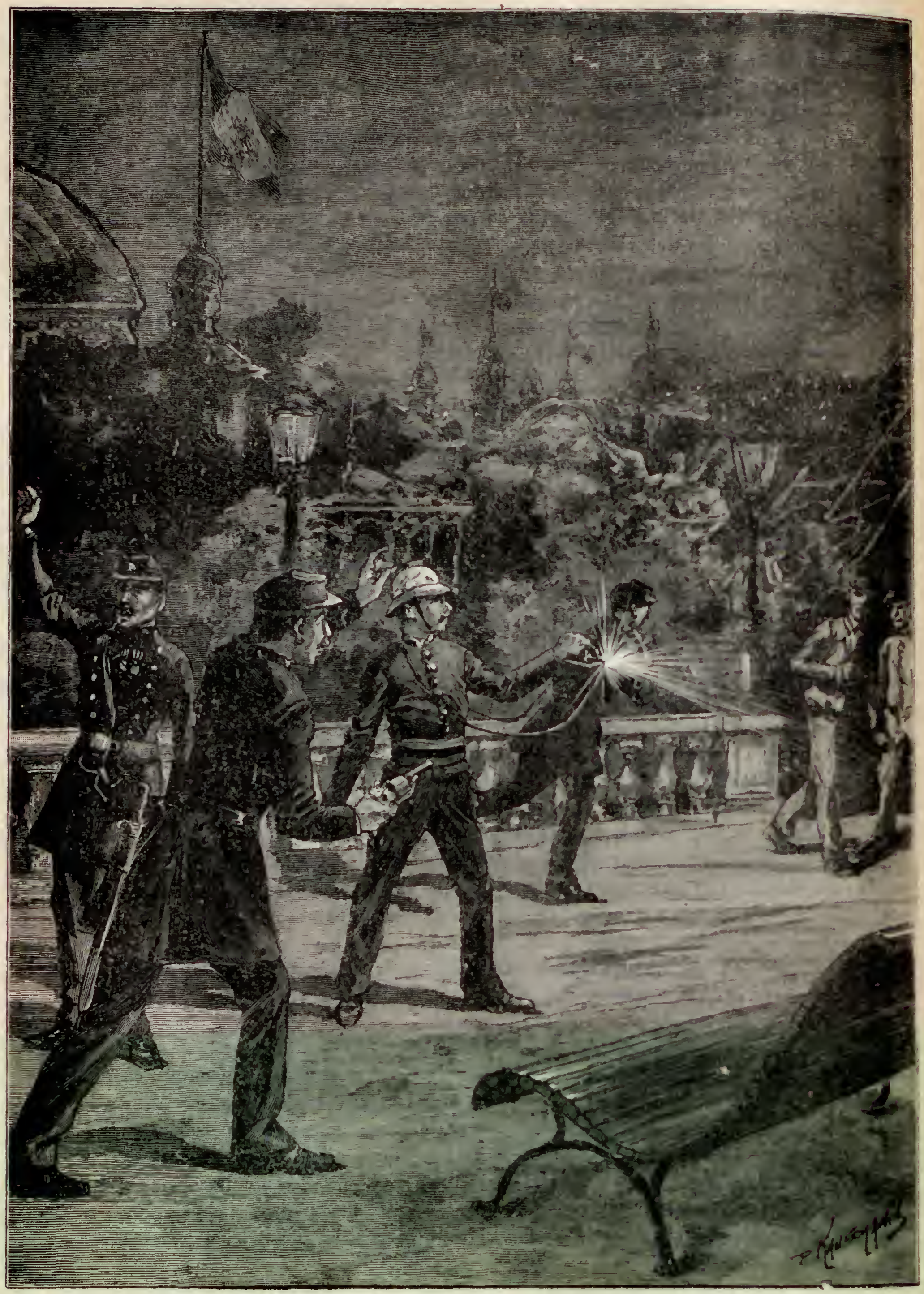


LES MERVEILLES DE L'EXPOSITION

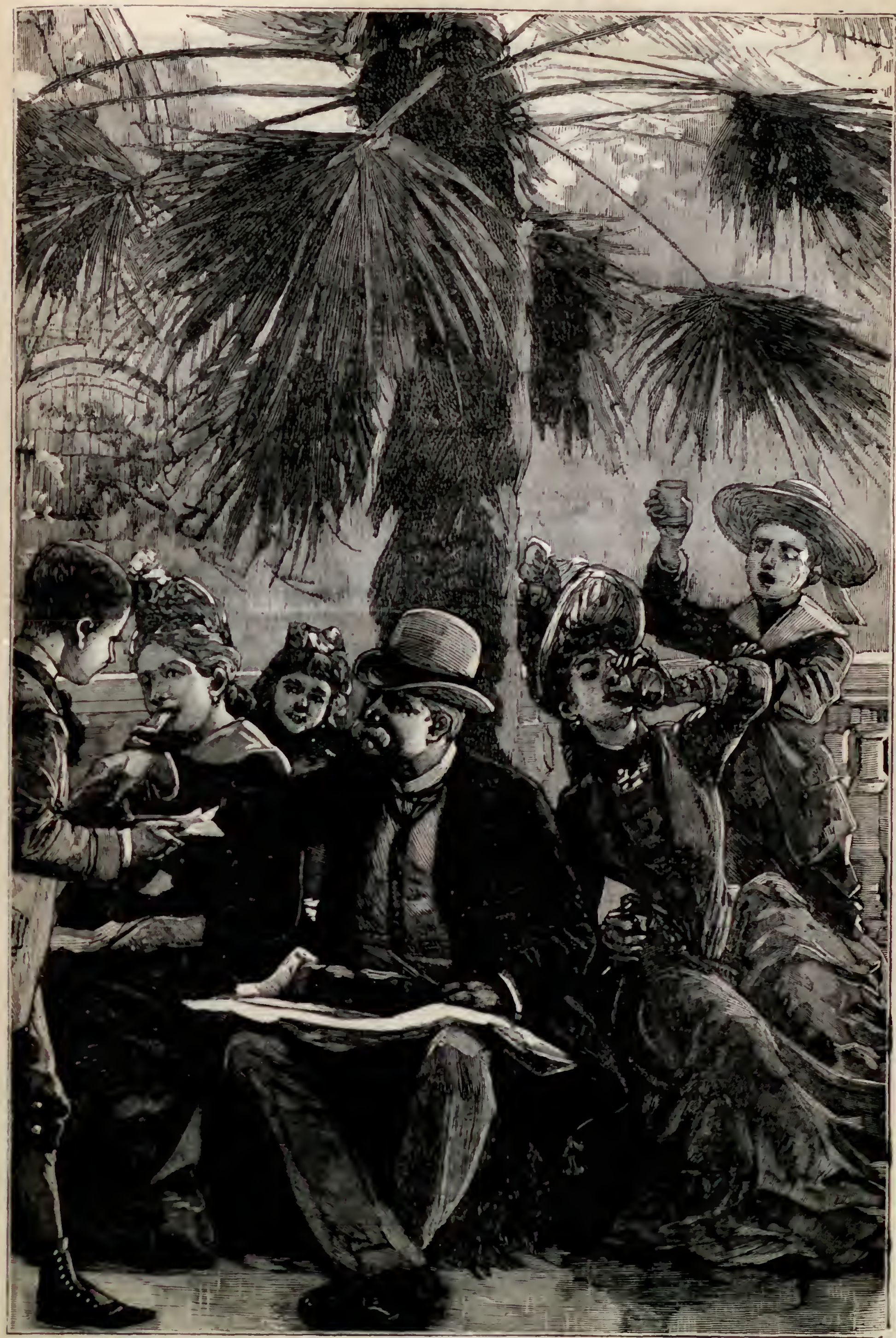

L'HEURE DU DISER AU Cha UP DE MARS.

Liv. 63. 
Le public est ensuite fort intrigué par une suite de petits personnages en bois sculpté, formant des groupes très virants; il $\mathrm{y}$ a la évidemment une histoire complète dont il est difficile de saisir le sens. "Le gouvernement siamois a tenu a nous montrer également un spécimen de ces kiosques si curieux d'architecture et de décoration, qui ornent les jardins royaux. Il a expédié à Paris un parillon qui a été construit à Bangkok tout spécialement pour figurer à l'Exposition.

- Cette étonnante contruction est formée de colonnettes qui reposent sur un plancher surélevé au-dessus du sol, et supportent une toilure de pagode au profil original toute hérissée de bois découpé en forme de flamme et recouverle d'écailles de bois jaunes et vertes. Lior ne manque pas dans cette construction; les colonnes sont recouvertes de petits miroirs et de paillettes chatoyantes, et le plafond est d'un ton rose Chine arec des mosaïques de verre.

- On arrive au pavillon par quatre escaliers dont les rampes sont chargées de sculptures. C'est un mélange de fieur's et de personnages dorés, qui se délachent sur un fond bleu foncé. Puis au pied de chaque escalier, nous voyons se dresser deux guerriers dans une attitude menaçante et guerrière, brandiseant des lances, des sabres ou des poignards.

- C'est d'un effet très étrange, et pourtant c'est bien dans la note générale de cette Exposition siamoise si caractérisque, si merveilleuse de couleur el d'éclat. ,

LA RCE dU GAira. - Voulez-vous connattre l'Egypte, non celle des Pharaona, mais celle des musulmans? Allez a l'Exposition et promenez-vous quelques instants dans cette rue du Caire, si habilement restituce pour le plaisir des yeux et pour la joie de l'esprit. Lá. pas de symétrie, pas de règlements de police pour inposer les monotones régularités de l'alignement. Chacune de ces maisons s'oriente à sa guise, avec ses fenètres en saillie, ses moucharabiés, qui protègent le passant contre les ardeurs d'un soleil de plomb. Ici se dresse la mosquée, avec son minaret, d'oủ le muezzin appelle les fidèles à la prière; là, dans le bazar, grouille un peuple de inarchands en costume indigène, tandis que les musiciens arabes font retentir l'air du bruit de leurs instruments. Et dans cette infinie rariété de coulcurs qui s'étalent sous les moucha rabiés et sur les façades, les Anes blancs, de vrais Anes venus d'tigypte, jettent une note claire, imprévue, qui fixe le regard. On ne peut visiter la section egyptienne sans se croire transporté dans quelque coin perdu de l'Orient, loin de notre cıvilisa. tion industrielle, et c'est un bien étrange contraste que cette restitution du vieux Caire à l'ombre de la Tour Eiffel.

Elle est déjà fameuse dans Paris, cette rue du Caire, écrivait hier un chroniqueur de l'Exposition. "Quand rous sortez du Palais des Industries diverses, un peu ahuri et endolori d'une décoration tapageuse, vos yeux s'y débarbouillent, et 8 'y défaliguent instantanément. Aucun art n'a poussé, au inéme degré de perfection que l'art arabe, l'élégance et la grace des lignes; il semble que liidéal de la vie heureuse a consisté pour lui ả paresser dans un endroit frais avec des formes exquises el legères autour de soi; il vous pénètre de je ne sais quelle douce lnngueur. Il est sans riral encore dans ce qu'on a appelé de son nom l'arabesque, dans les subtile combinaisons géométriques; c'est proprement le don de cette race, au gínie abstrait, qui n'a jaunis connu nos cultes de la nature. Ur. cette rue du Caire est la réunion charınante de quelquues parties de mosquées et de vingl-cinq maisons de cette ville prises parmi les plus carac- 
téristiques depuis l'époque lointaine de Tauloun jusqu'au siècle dernier. Le principe n'en a guuère changé à travers les temps; c'est toujours un rez-de-chaussée à porte basse, un étage en encorbellement, dont les fenêtres sont masquées par des moucharabiés et une terrasse avec des crètes se découpant sur le ciel. Tantôt la saillie de l'étage repose tout bonnement sur les poutres dépassant le mur du rez-de-chaussée, tantôt ces bouts de poutre grossiers sont transformés en corbeaux plus ou moins historiés.

- Le mérite de cette reproduction revient tout entier à M. le baron Delort, premier député de la nation française au Caire. Il n'a voulu d'aide que dans la conduite des travaux, pour laquelle il s'est associé un jeune architecte, M. Gillet. C'est lui d'abord qui, aidé de quelques amis, a constitué les fonds de l'Exposition égyptienne, laquelle est toute privée. C'est lui ensuite qui a collectionné les moucharabiés et choisi avec un goùt si pur les types à reproduire. Les moucharabiés sont d'ingénieux grillages en bois s'avançant en balcons sur la rue, qui ne laissent pénétrer dans les appartements qu'un demi-jour et qui permettent aux femmes de voir sans être vues. Ceux que vous trouverez là n'ont pas été faits pour la circonstance; ils proviennent de maisons démolies. De même, il n'est pas un des ornements employés qui n'ait été moulé sur quelque monument. Le minaret est la copie, moins un étage, du minaret de Kaïd-Bey, un chef-d'œuvre du $x^{\circ}$ siècle renommé pour la richesse de ses détails. Les faïences qui forment inscription au-dessus de l'une des portes ont été arrachées par des mains impies du cylindre d'une coupole; elles ne figurent là que parce que l'indolence orientale s'est refusée à les remettre en place.

- Le Caire est une ville étrange, moitié arabe, moitié européenne; la ville arabe, la ville orientale si admirablement décrite par Gérard de Nerval, se démolit, hélas! tous les jours. L'Exposition nous en offre un échantillon superbe.

- Là-bas, dans la cité, les anes célebres du Caire et les aniers, des chameaux couchés ou debout obstruent la voie dans laquelle se promènent lentement les fellahs avec leurs robes bleues et leurs turbans blancs dont les tons doux varient à l'infini, rehaussés seulement par les vestes de couleurs crues qui jettent au soleil leurs notes gaies.

- Jadis, tout le Caire, grace à ses rues étroites, était ombragé d'une maison à l'autre par des toiles, des planchers, des morceaux de bois jetés sur des poutrelles; on marchait ainsi à l'ombre sans avoir besoin d'ombrelles. Mais depuis que le Caire se modernise, depuis surtout que des maisons à plusieurs étages viennent remplacer la pittoresque demeure des Arabes, on étouffe dans les voies nouvelles et la circulation y est très pénible de onze heures à quatre heures. Il n'en est pas de même à l'Exposition, qui nous donne dans ce coin l'illusion de l'Orient. '

En arrivant dans la rue du Caire un bruit de musique frappe notre oreille et nous nous dirigeons comme malgrré nous vers le café Égyptien. Nous entrons et nous nous trouvons en présence de la musulmane Aioucha, la danseuse almée qui interprète ce qu'on appelle en France la danse du ventre, mais c avec les restrictions commandées par la décence . On nous assure qu'Aïoucha a sa réputation déjà faite en Égypte où clle est classée première danseuse. . Elle est l'étoile de la ville du Caire. Elle apporte ì sa dảnse une virtuosité surprenante. Ses pas répondent à la musique avec une cadence parfaite. Revètue de riches costumes, elle danse avec des castagnettes en cuivre jaune qui suivent le temps de la musique. Le sentiment musical seul la guide, 



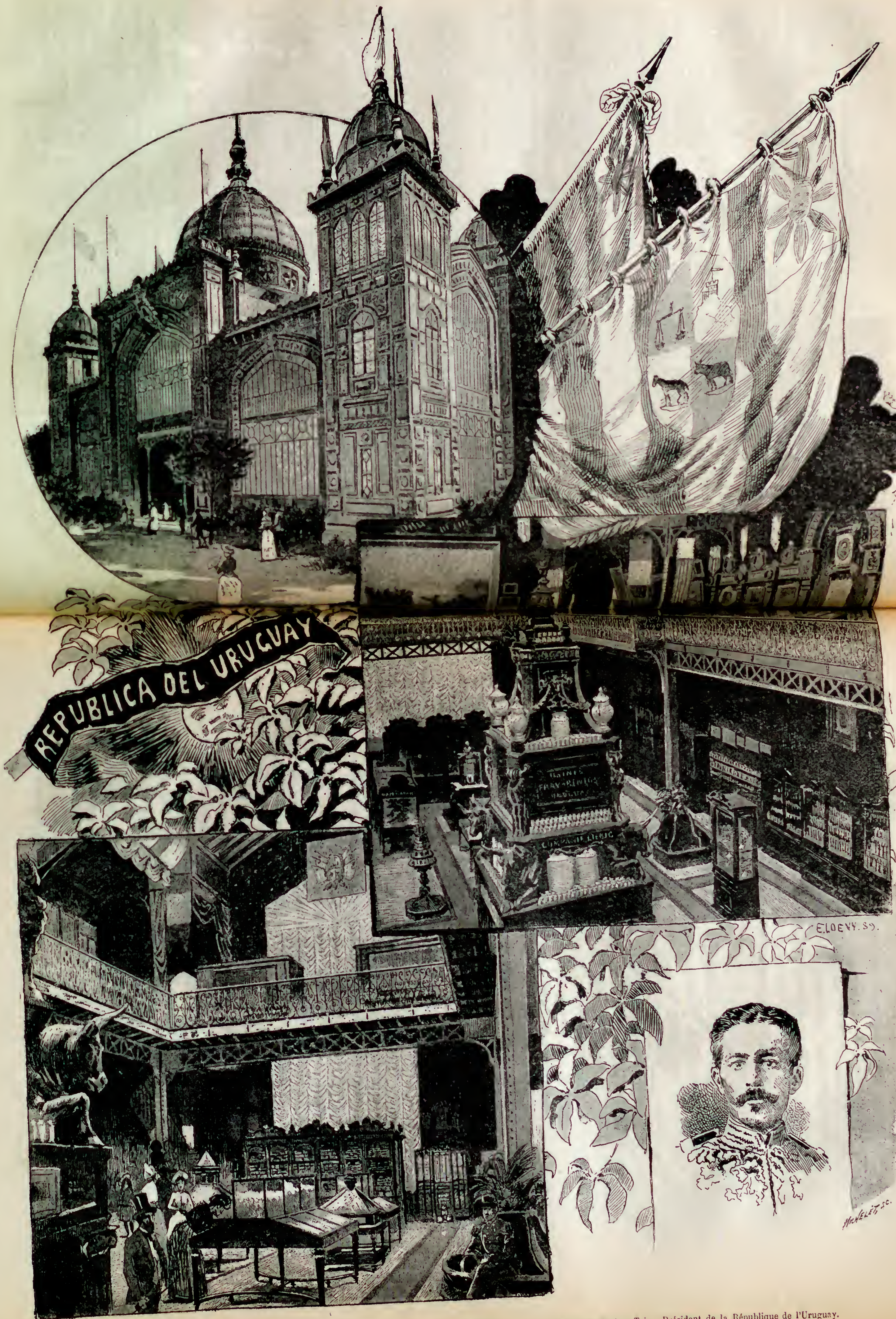


mais avec un perfectionnement surprenant. Sa danse, très originale, est variée. Aïouclıa attire déjà vers elle tout Paris.

Cet éloge est emprunté à un prospectus, que l'on nous remet à la porte du café Égyptien, où nous apprenons en outre que la deuxicme danseuse appartient au genre grave. Elle danse le pas syrien, "danse fort décente et admise dans les familles, et aussi avec une cruche pleine d'eau sur la tète ou une bouteille à laquelle est adaptée une bougic allumée.s. Ce prospectus est un pur chef-d'œuvredans son gerire; continuons dlonc à le lire.

" Entre les deux danses si différentes d'Aïoucha et de Zénab, a lieu la représentation du derviche tourneur, Ab-del-Fattah, qui appartient à la célèbre secte des Nallaouï. Il tourne sur ses pieds duranl 20 minutes, en accélérant son mouvement. Il est vêtu d'une sorte de jupe à plis qui s'entrouvre au moment de la danse et forme un cercle autour de lui. , Suit une digression sur le café, qui, paralt-il, est fait avec des grains Yéméni-moka; il est servi à l'arabe par des farraches (cafédjis) égyptiens * très habiles, polis, richement vètus et de différents types $\$$.

Les musiciens sont en mème temps chanteurs. C'est un chanteur a grand mérite, très appréciẻ en Égypte, du nom de Cheïk-Hassan ", qui entonne le couplet; le chour ¿ui réplique. Les chants sont des poésies arabes populaires. Et l'orchestre?

- L'orchestre du café Égyptien est un des plus complets de l'Orient. , On y entend l'ond, sorte de guitare; le canoun, sorte de piano sans touches; le daf, ou rech, sorte de cymbale; le darabouké, petit tambour en terre cuite, érasé et ouvert par le bas; le zamr, la flute en roseau du berger égyptien; le macrazane, deux petits tambours jumeaux, très bas, en cuirre; le tare, large tambour plat, sur lequel on frappe de la main droite.

"L'intérieur est recouvert d'une tente immense d'une grande beauté, qui est une broderie générale. Des lampes anciennes et des jardinières arabes y sont suspendues. La façade est faite entièrement de moucharabiés. La corniche de la façade contient le vers suivant en lettres persanes: Azza siouanon fi daroukom, fadkhonlouhou bislamain oua serour. En voici la traduction, toujours d'apres le prospectus: ANotre tente s'honore de se trouver dans vos pays. - Entrez-y en paix et bouheur.,

Nous entrons, en effet, car il est impossible de ne pas visiter au moins un de ces nombreux cafés orientaux qui, tant à l'Esplanade des Invalides qu'd la rue du Caire, nous offrent comme principale attraction des danses d'almées. Nous avons le choix entre le café Marocain, la tente Marocaine, le café Tunisien, elc., mais nous sommes dans la rue du Caire et nous franchissons les portiòres du Concert qui se trouve au débouclsé de la galerie des Machines. Rangées en demi-cercle sur une estrade basse dont l'orchestre occupe le fond, les almées juives et musulmanes, vêtues d'un pantalon bouffant et d'une petite veste à la turque atlendent d'un air de profond ennui que leur lour soil venu de danser. Sur un signe du chef des musiciens, l'une d'elles se léve el commence à parcourir lentement la scène, a vec des gestes nonchalants des bras, les yeux fixésen l'air. La nouba presse un peu le mouvement, l'alınée s'anime, tourne avec plus d'entrais, puis se livre à un déhanchement plus étrange que joli, connu sous le $110 n$ de dause du ventre. Après avoir fait sautiller pendant quelques instants sa poitrine, sun abdomen ou ses reins, l'almée salue et cède la place d̀ne autre qui va se livrer aux mènes exercices. Que l'almée se nomme Mouny, Farila, Zaïna ou Fatima, qu'elle soit de Tanger, de Tunis, d'Alger ou du Caire, les pas qu'elles dansent ne s'en ressentent guère; c'est 
toujours kif-kif, pour rester arabe. C'est à croire qu'elles sont toutes sorties d'une mème école, qu'elles suivent toutes sévèrement une même tradition.,

Au concert Marocain, en dehors de la danse du ventre, nous avons la danse du sabre. Une almée, qui répond au nom de Zohra et qui, parait-il, vient tout droit de Tanger, tourne avec une rapidité vertigineuse, en tenant deux yatagans qu'elle prend télicatement entre ses dents, dont elle appuie les pointes sur sa gorge ou sur sa poitrine, a vec lesquels elle fait le moulinet. Au concert Égyptien nous avons bien un exercice dont les yatagans font tous les frais, mais cette fois ce sont des Druses du Liban quise battent en combat singulier. On a bien dit que toutes les danseuses ne sortaient pas sans exception de l'Orient authentique et que les Batignolles ont fourni déjà un contingent au bataillon édénique des almées, mais il est bien certain que la contrefaçon n'est pas générale. Il nous a paru que certaines de ces dames avaient, sous leurs habits à pailletles, le plus pur aspect parisien, mais la plupart ne sont point dans ce cas, cela n'est pas dlouteux. Donc, trève de critique.

$\Lambda$ peine sorti du café Égyptien, nous sommes arrétés par un marchand de Pain Suint-Jean du Désert, qui nous dit que c cette douceur est très délicieuse » (sic), digestive, stomachique, nutritive et pectorale, et qu'elle est fabriquée à Jérusalem même, avec le fruit du caroubier, appelé arbre du pain de Saint-Jean, parce que le saint de de ce nom passe pour s'en être nourri dans le désert. Pẻndant que le marchand nous vante les qualités de ce pain spécial, des cris assourdissants sortent d'un édifice sur les murs duquel nous lisons ces mots: Ecurie des dnes d'Égypte. Il y a, en effet; des ânes égyptiens très authentiques avec des aniers habillés de longues robes bleues, et ce sont les àniers qui, assis en rond, font en chantant tout ce vacarme. L'écurie est bien garnie de bètes et de gens. Les premières se contentent de braire, les gens préfèrent tendre la main et vous soutirer quelques sous. Somme toute, il vaut infiniment mieux voir les anes dans la rue que dans leurs écuries. Le spectacle est plus ágréable à l'œil, plus pittoresque.

Dans une des maisons voisines, la compagnie Cook a installé une reconstitution très exacte du temple d'Edfou. Parmi les divers styles architecturaux de l'antiquité, le plus curieux est certainement le style égyptien. On peut diviser l'architecture de l'ancienne Égypte en trois ordres ou périodes. La première période, où furent érigés les temples, les Pyramides et les tombeaux, va de la $11^{\mathrm{e}}$ à la $12^{\circ}$ dynastie. La $2^{\mathrm{e}}$ période embrasse tont le moyen Empire, finissant à la conquête du monde civilisé par Alexandre. La $3^{e}$ période comprend le cycle Ptolémaïque qui dura jusqu'au $1 v^{0}$ siècle de notre ère, époque où disparurent les derniers vestiges de l'ancien paganisme. Le temple a Ptolémaĭque , d'Edfou, dont la reproduction présente est l'exacte copie, fait donc partie de la $3^{e}$ période architecturale d'Égypte, et c'est certainement un des meilleurs spécimens de celte époque. Tout, hormis cependant quelques colonnes et chapiteaux qui ont eu à souffrir d'un incendie, y est dans un parfait état de conservation. A l'intérieur, comıne à l'extérieur, ce temple est dans le même état et aussi solide que, lorsqu'il y a 2,000 ans, les longues théories des habitants de la grande cité d'A pollon défilaient sous les adınirables portiques, parmi les Stèles, allant sacrifier à Vénus Égyptienne, ‘ la Reine du genre humain '. Ainsi que les autres édifices de ce genre, le temple d'Edfou servait au royaume de citadelle, en mème temps que de temple aux prètres. La hauteur et la massive épaisseur des inurs d'enceinte, où cinq ou six portes seulement et très aigue̋s furent ménagées, en faisaient un lieu inexpugnable. Parni les temples de la mẻme 
époque, beaucoup - le temple de Dendérah, par exemple - sont absolument parfaits d'archilecture el ressemblent fort à celui d'Edfou comme ensemble; mais aucun ne peut rivaliser avec celui-ci pour le superbe effel de ses " pylúnes * formant une énorme façade et pour le caractère grandiose de ses murs d'enceinte. Comparé à l'architecture de la $2^{\mathrm{e}}$ période, le temple d'Elfou offre une étonnante précocilé architecturale pour l'ornementation des chapiteaux qui rappellent - avec justesse - l'ordre corinthien. Une véritable profusion d'hiéroglyphes en orne les corniches et les frises. Il fut érigé par Plolémée Philopator qui en fit construire le sanctuaire et les salles qui l'entourent. Les nefs centrales et toutes leur's décorations sont dues ì Ptolémée Philomète; tandis que la masse du portail fut édifiée sous le règne de Ptolémée Plilonète et d'Évergète II. Évergète II commençait à élever les murs d'enceinte qu'achevait après

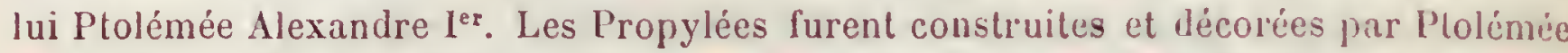
Dionysique. Maintes fois interrompue par les guerres, l'édification du temple

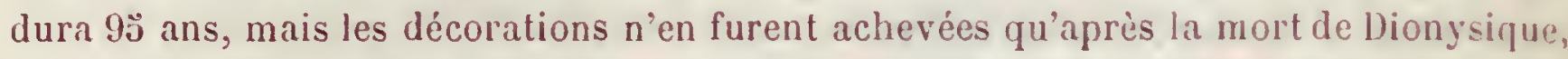
c'est-à-dire 70 ans plus tard. La longueur du temple, en y comprenant la masse des propylées, est d'environ 143 mètres. La façade de $36^{m}, 70$ de hautcuŕ, et de près de 80 mètres de largeur, était décorée d'énormes mats de pavillon fixés diıns la muraille extérieure. Enfin, encerclant le tout, un mur massif de 7 mètres de haut. Des pylônes ou (propylées) décorés richement de batailles symboliques - imitations des sculptures des premiers temples du cycle Pharaonique - nous passons dans la première nef, entourée sur trois củtés d'un péristyle de trente-deux colonnes; c’est là le plus vénéré de tous les lieux de pèlerinage égyptiens, et peut-être du inonde.

Dans l'épaisseur des murs formant le cỏté sud de cette immense salle. deux portes - ouvrant chacune sur un escalier de 1430 marches - donnent accès dans les pylùnes au sommet desquels on jouit d'une vue admirable sur le fleuve et le pays environnant. Les escaliers, éclairés par des embrasures, sont divisés en 14 étages, et à chaque pilier se trouve une chambre spacieuse pouvant servir de magasin. Passant ensuite dans la 2o salle, on admire une double rangée de stèles (colonnes) finement sculptées: en outre, des deux côtés de l'entrée, un vaste écran de pierre fait fleurir trois autres stèles, ce qui porte à dix-huit le nombre de celles qui décorent celte nef.

La troisième supportée par 12 piliers contient plusieurs chambres minuscules, ciui. ayant deux issues, permettent de passer de la nef dans le couloir extérieur. Vieni ensuite une petite salle communiquant des deux côtés sur un escalier, celui de droite menant directement à la toiture, landis que celui de gauche aboutit à un dédale de cellules et de couloirs. La salle qui suit sert d'entrée - de chaque cùté - à une chambre et donne accès, par un vestibule, au sanctuaire. Dans un coin de ce vaisseau, se dresse un superbe monolithe de granit gris, ayant appartenu a un temple plus ancien encore et servi de nid à l'Épervier sacré, - symbule du dieu flur-llat, - la principale divinité qu'on adorait dans le vieux Temple. Autour du sanctuaire rigne une série de chambres, assez petites d'ailleurs; pal' les inscriptions qui les recourrent on voit qu'elles devaient servir de lieux de dépúts ou magasius pour les offrandes des fidèles, les vases sacrés, les objets du culte, etc... Un magnilique mur, couvert l'inscriptions, court depuis le vaisseau tout autour du Temple. Les rites impusints du culte égyptien, offrandes aux idoles, sacrifices, thẻories sacrées, se déroulant antumb des autels; l'histoire aux précieux enseignements et la géographic, telle que la connaissaient alors ces races disparues; tout cela vit, se mẻle, se déruule parmi 


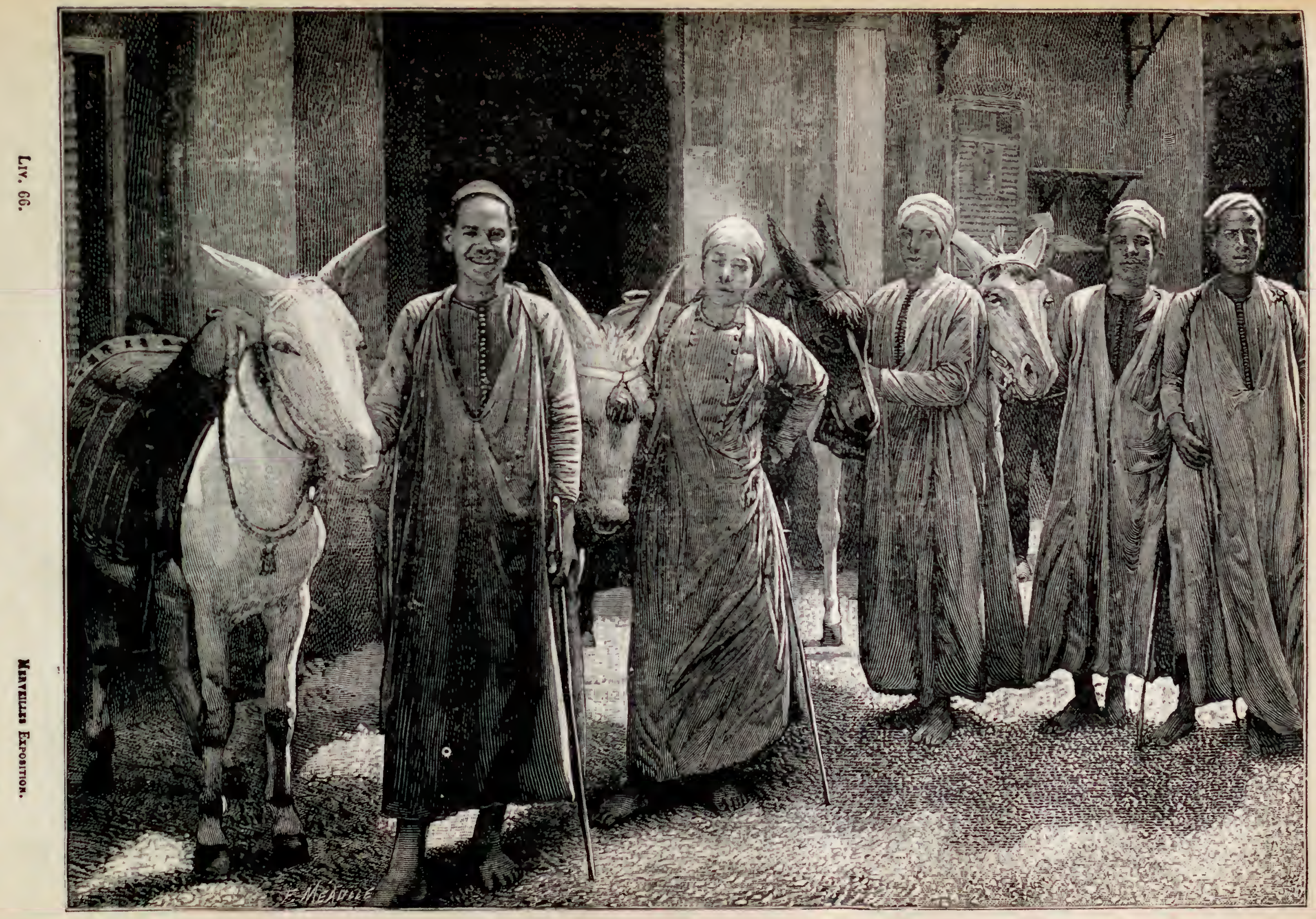

密 
les sculptures et les hiéroglyphes dont chaque pierre du temple est revelue. Celte reproduction - propriété personnelle de $\mathbf{M}$. John M. Cook, le directeur actuel le l'agence universelle Th. Cook et fils - a du couter des sommes très considérables et un incroyable travail d'art. Deux artistes se sont rendus a Edfou tneme et y prenant les mesures minutieusement, copiant avec la plus scrupuleuse exactilude les colonnes, les chapiteaux, les hiéroglyphes, etc..., ont reconstitué cette merveilleuse réduction à laquelle travaillaient d'autres artistes encore. Cette œuvre n'exigrea pas moins de deur années. C'est, en ce genre, la plus parfaite réduction qui ait jamais été offerte à la curiosité publique et on fera bien de l'examiner de près.

Ainsi, à côté de l'Égypte contemporaine, nous avons un charmant spécimen de l'Égypte ancienne, de celle des grands Pharaons. La rue du Caire, nous le répétons, n'est point sortie tout entière de l'imagination de l'architecte. Elle reproduit à s'y méprendre une rue de la vieille ville, une ruelle plutôt, avec ses moucharabiés et ses arabesques, ses boutiques de brodeurs, d'orfèvres, de fabricants de vitraux, de tisseurs de tapis, de tourneurs, de fripiers, de marchands de ineubles et de poteries. Et remarquez que tous les détails architecturaux sont absolument authentiques, que beaucoup de sculptures et de panneaux viennen! du Caire méme. On ne saurait donc trop remercier M. Delort de Gléon, commissaire de la section égyptienne, et l'architecte, M. Gillet, Les moucharabiés, qui intriguent fort les promeneurs, viennent en ligne droite de la vallée du Nil.

L'un des hommes qui ont le mieux connu l'Egypte, Ebers, a liaconté ses impressions de voyage. En lisant sa description du Caire, on se demanderait presque sil veut parler de la rue du Champ de Mars, tant la reproduction de $\mathrm{M}$. Gillet est frappante.

"Il $\mathrm{y}$ a, dans un conte des Mille el une Nuits, un homme de Mossoul qui loue Bagdad comme étant la Ville de la joie et la mère du monde; aussitot le plus vieur des assistants répond: “Qui n'a vu le Caire, n'a vu le monde. La terre y est de l'or, les - femmes y sont un enchantement perpétuel, et le Nil y est une merveille. , La nuit d'après, Shéhérazade vante les charmes de la cité des pyramides en paroles enthousiastes: " Qu'est-ce que le bonheur de contempler une maftresse face à face, au prix - de l'aspect du Caire? Qui l'a vu comprend qu'il n'y a pas pour les seux de trop - hautes jouissances; et si l'on pense à la nuit pendant laquelle le vil atteint la - hauteur désirable, on rend la coupe encore pleine de vin à la main qui la tend, - et on ne songe plus à rien d'autre qu'd l'eau. Si tu voyais l'lle de Rúda arec ses - arbres ombreux, tu serais jeté dans des transports de joie, et si tu étais au Caire, - auprès du Nil, vers le moment où le soleil couchant l'enveloppe d'un iranteau de - lumière, tu te sentirais tout à fait revivre au souffle de la douce brise qui passe sur - les rives ombreuses.

- Ce sont là des paroles sonores que l'imagination ardente du poete revét de couleurs aussi éclatantes que le soleil couchant fait le ciel d'tigyple. lit puturtant, si jamais du haut de la citadelle, rous avez contemplé la foret des minarets, le Nil, ut, bien loin, à l'horizon d'occident, les pyl'amides; si rous avez parcouru les rues et les ruelles, les bazars et les mosquées, les places et les jardins; si vous rons éles mêlé d la vie bariolée, changeante, exubérante, à la presse et au tunulte des habilants, quand le destin aura refusé à rotre âme le don précieux de l'imagination el a rutre cœur toute émotion poétique, vous songerez toujours au temps de volre séjour au 
Caire comme à une époque où il vous aura été donné de vivre au pays des fables et des merveilles.

" Ici, se promener au hasard est rencontrer quelque chose de nouveau; ici, regarder seul est un plaisir; ici observer et s'instruire ne sont qu'un. Personne n'a quitté le Caire sans profit et sans chagrin; car, si chaque voyageur emporte d'ici des impressions multiples et des souvenirs qui illumineront longtemps sa mémoire, toujours se glisse au fond de son cœur une sorte de regret mélancolique, et il se sent rappelé aux bords du Nil comme par un ami dont les mains lui feraienl signe de revenir. "Qui a bu l'eau a dlu fleuve, dit l'Arabe, la regrette toujours, et on ne s'égare pas impunément sous les "jalmiers.

" Comment expliquer la fascination que cette ville étrange n'a jamais manqué d'exerccr? Mème dans ses parties les plus attachantes, elle n'est nullement ce que nous entendons par une belle ville. La montagne à laquelle elle s'appuie est entièrement dénuée de végétation, et elle-mème est une des plus jeunes parmi les grandes villes de l'Orient. Par un côté seulement elle bat toutes les villes que je connais: elle est si féconde en changements que, dans l'espace d'une courte promenade, elle nous conduit à travers plus d'éléments divers de la civilisation, plus de manifestations opposées de l'art, plus de contrastes naturels, que nul endroit au monde.

- Nous n'avons pas encore secoué la poussière que le vent nous apportait parmi les restes grandioses de la cité des Pharaons, et déjà nous voici sur le trottoir soigneusement arrosé d'une rue dont les deux côtés sont bordés de maisons élégantes bâties à l'européenne. Quelques pas plus loin, nous nous enfonçons entre les deux hauts murs de pierre d'une ruelle sombre. Aucune fenêtre aux vitres éclatantes ne met gaiement la vie en rapport avec le va-et-vient de la rue : des balcons scrupuleusement grillés de treillages en bois font saillie devant nous, derrière nous, par-dessus nous, à droite et à gauche, et dérobent tout ce qui loge et s'agite au delà, aux regards des passants ou des voisins. A travers lesfentes et les ouvertures l'œil de plus d'une femme arabe s'abaisse sur nous, car le moucharabié, - c'est ainsi qu'on appelle ces cages, formées de lattes disposées sur un riche modèle et artistement tordues, - donne de l'air aux appartements dss femmes et permet aux belles de voir sans ètre vues. Le nom de ces saillies qui sont parmi les particularités qu'on n'oublie pas du vieux Caire, vient de l'arabe shardle, boire : c'est la, en effet, dans des cavités rondes ménagées au plancher, qu'on met les goullèhs, vases en terre poreuse qui servent à rafrał́chir l'eau. Ces ruelles vraiment orientales, si étroites que deux cavaliers ont peine à y passer de front, sont toujours remplies d'ombre et de fraicheur! le Cairote a bien raison de les préférer aux larges rues de quartiers nouveaux.

- Nous nous frayons un chemin à travers l'une des grandes artères de la ville, et flitssons devant la haute porte d'une mosquée. De pieux musulmans sortent et se irirangent poliment, pour faire place à des moines franciscains, qui semblent sérieusement se consulter auprès de la maison d'Allah. Ici, nous tournons dans une rue plus spacieuse, hommes, betes, voitures s'y pressent; tandis que les premiers causent ou s'appellent, on entend çà et là le bralment d'un ane ou le grognement d'un chameau, mais nulle part l'oreille n'est blessée par le tintamarre étourdissant des cités européennes, car les roues roulent sans bruit sur la chaussée molle et non pavée. Nous arons à peine réussi à nous ouvrir un passage d travers la presse, et déjà nous sommes arrivés sur une place déserte environnée de maisons en ruines : des vautours planent 



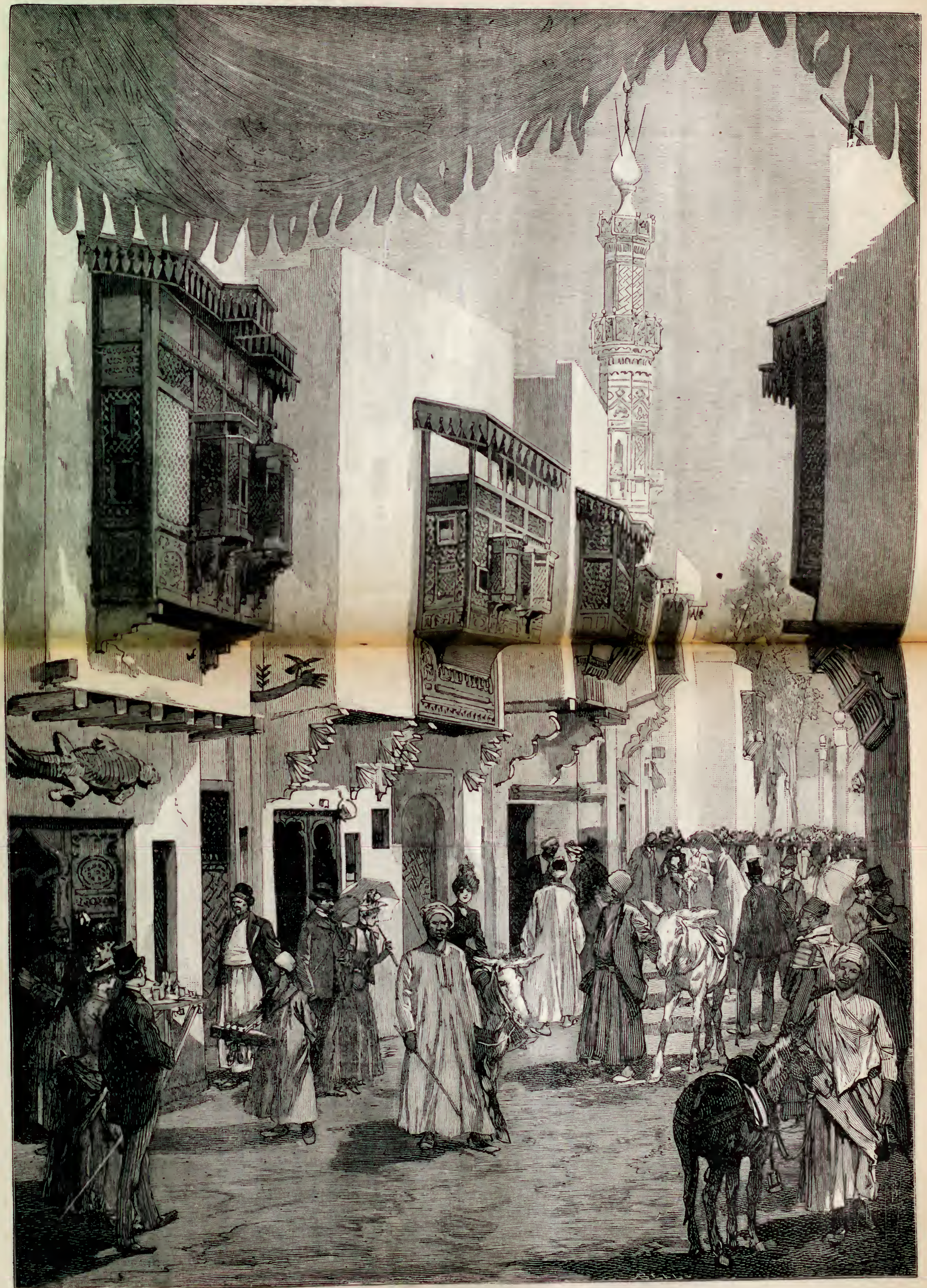


eirculairement, et, dans la boue, des chiens errants cherchent des os. Une ordure sèche et poudreuse, dans laquelle même les mauvaiscs herbes n'ont garde de prendre racine, s'entasse ici en monceaux épais, tandis que là-bas, derrière ee mur, dans les jardins bien arrosés d'un riehe, les plantes de toutes les zones se trouvent rassemblées, se gonflent de sue, et grandissent avee une rapidité merveilleuse. Devant la porte du pare un eunuque monte sur un cheval arabe richement caparaçonné, et jette un coup d'œil sombre sur les belles Européennes qui, riant et le visage déconvert, passent a grand bruit devant lui dans leur voiture viennoise. Un coureur préeède les ehevaux laneés, et leur fraye un chemin à travers la foule, jusqu'au moment où ils s'arrêteront devant un magasin brillant, dont l'étalage met en vente tout ce que les eapitales de l'Europe ont inventé de plus réeent pour la parure des femmes. Juste en face, un Arabe offre, sur un char à bras misérable, sa pitoyable camelote à laquelle il est difficile de donner un nom spéeial. Une longue file de chameaux nous force à nous ranger. Comme des navires que traîne un remorqueur, chacun d'eux est attaché au précédent, ct a sur le dos une balle de marehandises. Dans les superbes jardins de l'Ezbékiyèh, la noire gardienne d'un marmot arabe s'assied à côté d'une bonne française et de l'enfant blond qu'elle surveille, tandis qu'un petit-mattre italien allume sa cigarette à celle d'un trafiquant nubien. Des fenêtres ouvertes d'un salon orné de tables de marbre et de glaees à eadres dorés, s'éehappent les derniers airs europiens chantés devant une réunion de dames.

- Vous écoutez machinalement, et vous etes brusquement tiré de votre rêverie par le son clair de l'or que des joueurs échauffés lancent sur la roulette, dans une pièce roisine de la salle de concert. Vous tombez de là dans une ruelle latérale, bordée de balcons et de fenètres de harem finement tournées. Devant un café, assis sur la terre nue, des personnages basanés et noirs écoutent avee beaucoup d'agrément le récitatif nasal d'un chanteur populaire; mais eette musique simple ne dit rien à votre oreille blasée et vous vous dégagez de la foule. Cette fois, c'est une belle allée, et vous marchez à l'ombre de grands lebbakhs, pour vous retrouver bientùt entre les parois d'une ruelle étroite, bariolée, vivante. Le large Nil vous apparalt et seintille au loin, une forêt de mâts se dresse devant vous: e'est la porte de Boulaq. Côte à côte avec un steamer richement équipé aborde un lourd ehaland nubien aux voiles latines en lambeaux, identique pour la forme aux bateaux que nous voyons, sur les tableaux du temps des Pharaons, apporter les tributs du Soudan à l'Egypte. Non loin du port s'élève un superbe musée, dans lequel les monuments de l'antiquité sont elassés selon les données les plus rigoureuses de la scienee oeeidentale, et, parmi tous les Egyptiens qui passent devant cet établissement, vous en trouverez à peine un entre cent qui soit capable de vous apprendre son age ou de vous dire si Pharaon, - c'est le nom dans lequel il résume toute l'histoire de son pays avant Jésus-Christ, - a vécu il y a trois cents ans ou il y a trois mille ans. Pourtant, mème chez ces ignorants, le désir de science habite parfois. Dans ce grand batinent de Boulaq, de finés mains égyptiennes tirent des presses européennes les feuilles imprimées soigneusement d'ourrages d'érudition arabes. Si nous tournons le dos à l'lunprimerie nationale et au port, et que nous rentrions dans le Caire proprement dit, nous rencontrerons dans les eours de la mosquée El Azhar, qui lient lieu d'université, plus d'étluiants peut-être que daus n'inporte quelle école publique d'Oceident. Apprenez seulement à connaltre les savants, qui, avee une fruggalité sans pareille, n’aspirent ici qu’à se rassasier du pain de l'esprit, 
et demandez-vous ensuite si vous avez jamais vu quelque part un chercheur aussi absorbé dans son étude que le vieux musulman qui là-bas s'efforce de bien comprendre le sens d'un passage difficile du Coran. »

La rue du Caire fait partie de l'Exposition égyptienne, qui occupe une superficie de 3,000 mètres carrés. L'Égypte est un beau pays, on conçoit que les Anglais s'y zoient établis ì demeure; l'on conçoit moins que nous n'y soyons pas avec eux. Lille renfer'me des carrières d'albâtre, de granit, de porphy rae rouge, de syénite et de marbre. Ses salines sont d'un bon rapport, et, pour la terre, on sait ce que le Nil lui donne de fécondité. Quant aux soieries, lainages, bijoux et mêmes objets, le visiteur trouvera au Champ de Mars les échantillons les plus variés.

Matériel des chemins de FEr. - En sortant de la rue du Caire, nous rencontrons l'Exposition du matériel des chemins de fer. Tout d'abord, les pièces détachées: ressorts, tampons, freins, etc.; puis, le matériel fixe : rails, coussinets, éclisses, changements de voie, aiguilles, plaques tournantes, tampons de choc, grues d'alimentation et réservoirs, signaux optiques et acoustiques, appareils de sécurité et de bloquage des trains; le matériel fixe et roulant pour tramways; le matériel roulant : wagons à voyageurs, ì terrassement, à marchandises et à bestiaux, locomotives et tenders; les voitures automobiles et les locomotives routières; les machines spéciales et l'outillage des ateliers d'entretien, de réparation et de construction du matériel, les machines pour plans inclinés et plans automoteurs, enfin les modèles, plans et dessins de gares, stations, remises et dépendances de l'exploitation des chemins de fer.

Les types et spécimens de l'industrie des chemins de fer occupent donc une place considérable à l'Exposition. Tous les progrès réalisés depuis dix ans dans la construction l'exploitation des voies ferrées s'y trouvent représentés. Les nouvelles voitures oyageurs, - les freins instantanćs à vide et à air comprimé, - les signaux électriques et purement mécaniques, assurant la sécurité de la voie, par la mise en pratique du Block-system, - les manceuvres automatiques de l'aiguillage central et les cabines Saxby-Farmer, ete., figurent dans les envois des six grandes compagnies françaises et dans le: sections étrangères.

La question qui, actuellement, domine toutes les autres, en fait de chemins de fer, c'est, dit M. Louis Figuier, l'accroissement de la vitesse des trains. En France, la vitesse moyenne des trains n'est pas inférieure, quoi qu'on en dise, à celle qui est réalisée en Angleterre et en Amérique. Nos principales lignes marchent avec toute la vitesse compatible avec la sécurité publique. Cependant, on voudrait dépasser la limite actuelle sans, d'ailleurs, compromettre la stabilité des convois ou des machines, et en écartant toute chance d'accident.

Or, ce qui promet, dans un intervalle prochain, l'augmentation de vitesse, c'est l'application aux locomotives des machines à vapeur du système compound. Le système compound a révolutionné les machines à vapeur fixes, et permis à la navigation par la vapeur d'obtenir des vitesses et une économie de combustible absolument inespérées. On voudrait faire profiter les locomolives des arantages économiques de ce système.

Ilais le lecteur nous demandera d'abord ce que c'est que le système compound. Ce mot rébarbatif déconcerte quelque peu le public étranger aux choses de la science; il importe donc de le bien fixer à l'égard de cette dénomination.

Compound n'est pas le nom d'un inventeur ou d'un constructeur, et celui qui dirait 
"la machine à vapeur de M. Compound ", comme on dit a la machine à vapeur de II. Corliss s, prendrait, comme le singe de la fable, le nom d'un port pour le nom d'un homme. Compound vient du mot anglais composed, qui signifie composé. Le système

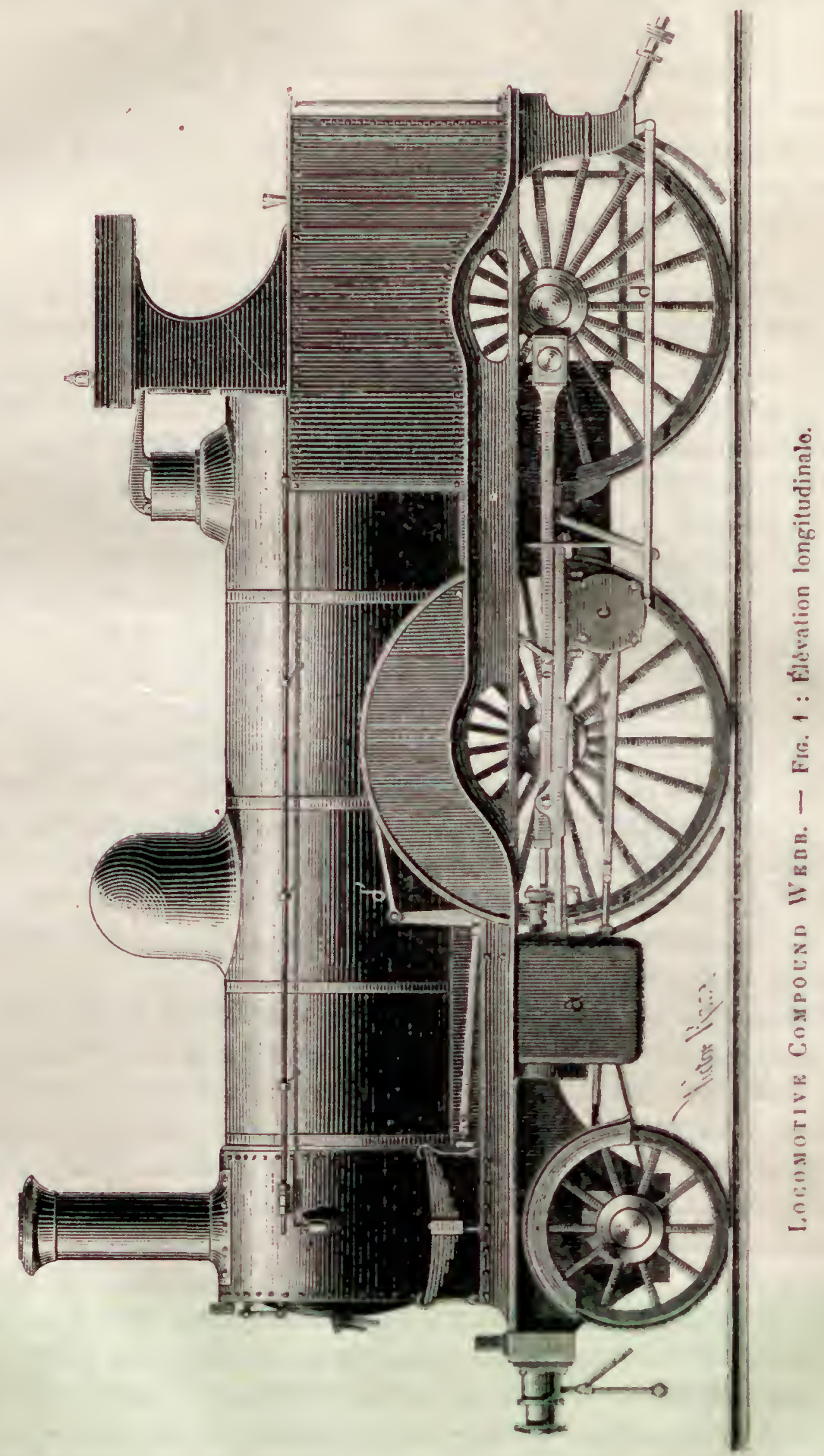

dont il s'agit est, en effet, composé de la réunion de divers perfectionnements des organes de la machine à vapeur, et particulièrement de l'emploi de deux ou trois cylindres successifs, au lieu d'un seul, pour faire agir la force élastique de la vapeur.

Et pourquoi deux ou trois cylindres au lieu d'un seul? 


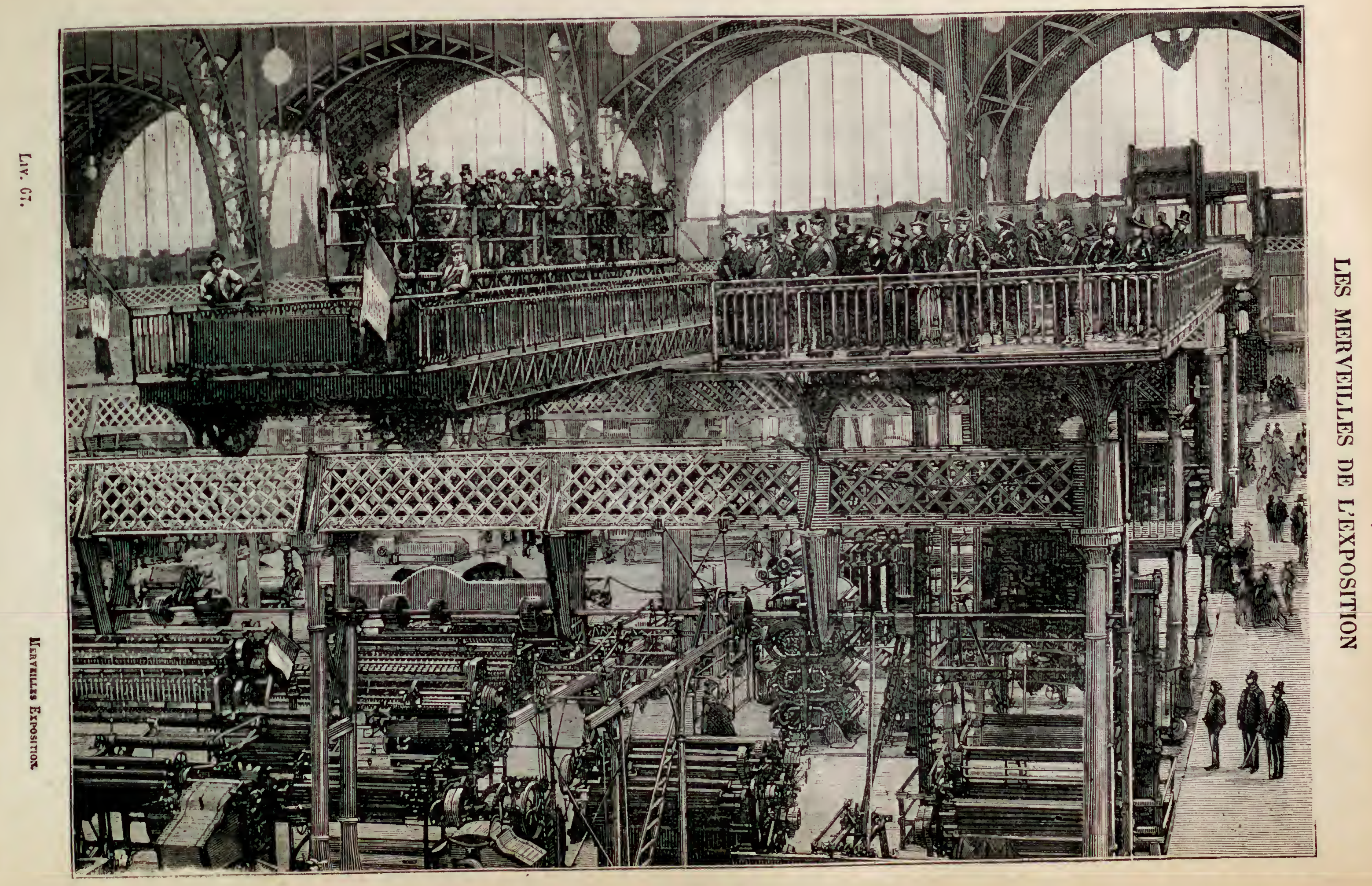

GaleRIE DES MaghiNes: Les PUNTS HOULANIS. 
Vous n'êtes pas, cher lecteur, sans avoir remarqué le courant conlinu de vapeur qui s'échappe, comme un nuageux panache, du fuyau qui s'élève au haut du toit des usines, et qui provient du cylindre de la machine it vapeur. Et en voyant ledit panache, vous vous êtes certainement demandé, avec l'esprit judicicux qui vous est propre, pourquoi on laissait perdre ainsi, inutilement, une énorme quantité de vapeur, dont il serait possible peut-être de tirer un parti utile.

C'est précisément pour mettre ì profit cette vapeur sortant des cylindres, et qui ćtait perdue jusqu'ici, qu'ont été imaginées, en Angleterre et en Amérique, les machines à vapeur dites compound, ainsi qu'on le faisaił déjà, du reste, dans l'ancienne machine de Wvalf, dune fagun rudimentaire. On a recucilli celte vapeur finale, et, au lieu de la

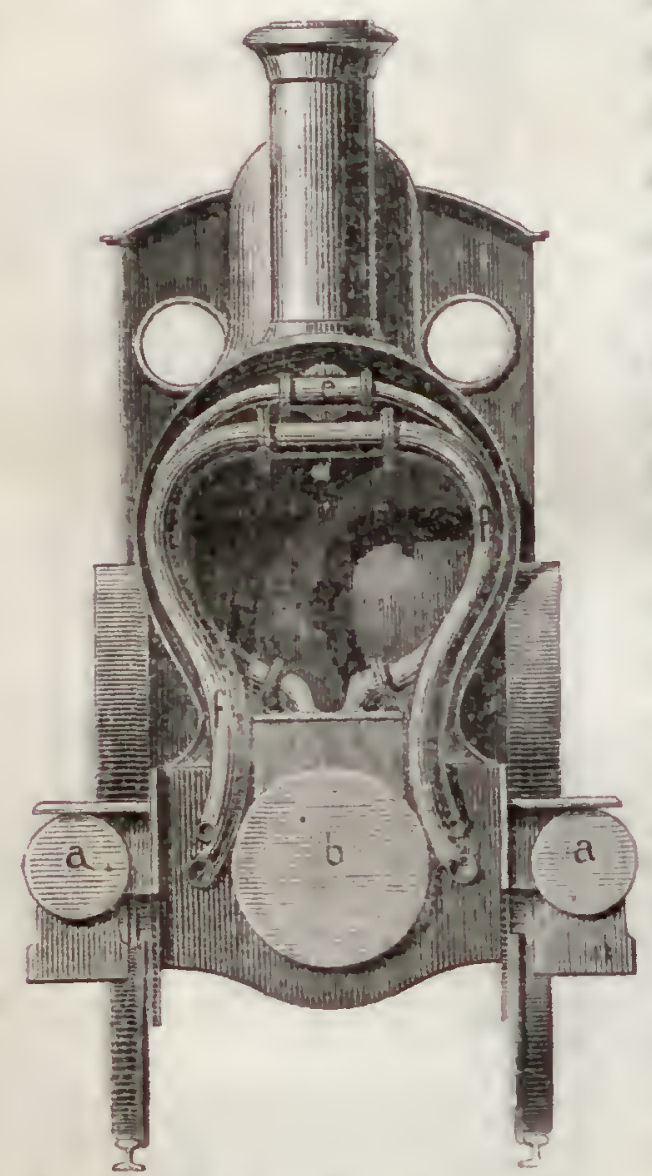

Loconotive Compoexd Webr.

Fig. 2: Coupe transversale. laisser perdre dans l'air, on l'a dirigée dans un second cylindre, plus grand que le premier, et pourvu d'un piston; et on a obtenu là un nouvel effort mécanique. Et comme la vapeur, après aroir été recue, après avoir été détendue, comme on le dit en termes techniques, n’avait pas épuisé son énergic thermique et mécanique, on l'a reçue dans un troisiène cylindre, également pourvu d'un piston moteur, et l'on a réalisé là un troisième et dernier effort d'impulsion motrice. Après ces trois délentes successives, la vapeur est entièrement utilisée; on lui a fait rendre tout l'effort qu'elle pouvait fournir.

Ajoutez à ces deux on trois cylindres din detente des dispositions particulières pour faire agir le piston sur l'arbre moteur, ct vous aurez les machines compound, qui, appliquées aux machines fixes des usines, ont donné ce résultat de n'exiger que 730 grammes de charbon pour produire, pendant une heure, la force d'un cheval-vapeur, alors que les anciennes machines dépensaient 3 kilogrammes de charbon pour développer le méme effort, daus le même temps.

Il était naturel de chercher à appliquer aux locomotives le principe qui avait donné de si beaux résultats dans les maclines à rapeur fixes et les machines marines. Et, de fait, il $y$ a longtemps que l'on a cherché a réaliser ce perfectionnement. On pourrait signaler, dès l'année 1850, des tentalives de ce genre faites en Angleterre, par M. John Nicholson, sur le chemin de fer du GreatEastern, et en France, en 1886, par M. de la Morandière, sur le chemin de fer de l'Ouest.

Ilais les difficultés pour installer quatre cylindres à vapeur sur une locomolive étaient énormes. Dans les usines et sur les navires, la place ne manque pas pour recevoir une machine à vapeur; mais sur une locomotive, où l'espace est si exigu, et llijd occupé par tant d'apparcils volumincux, tous essentiels, comment placer quatre cylindres avec leurs pistons et leurs bielles? Il n'est déjà pas facile d'y installer une paire de cylindres, puisque vous les voyez placés de tant de manières différentes : on les établit tantôt à l'intérieur, tantôt à l'extéricur, tantùt latéralement, tantôt sous la 
chaudière, etc. Il a fallu bien des études nour arriver à trouver l'emplacement de l'appareil à double ou triple détente.

C'est à un savant ingénieur du chemin de fer du Midi, M. Mallet, qu'appartient le mérite d'avoir résolu le problème, non approximativement, mais d'une manière irréprochable et tout à fait pratique, puisque les locomotives compound de M. Mallet sont en service depuis 1878 sur les lignes de Bayonne à Biarritz, et qu'elles n'ont jamais été abandonnées depuis cette époque.

C'est en $\mathbf{1 8 7 5}$ que M. Mallet fit construire, au Creusot, douze locomotives compound, dont l'une figura à l'Exposition universelle de Paris en 1878. Il n'y a que deux paires de cylindres à vapeur dans les locomotives de M. Mallet, et la distribution de vapeur employée a cela de remarquable que la vapeur peut agir à volonté dans le système compound et dans le système ordinaire, c'est-à-dire qu'il est possible, selon les circonstances, de faire arriver la vapeur dans le petit cylindre pour le faire fonctionner en compound ou de la rejeter dans la cheminée pour la faire agir dans le procédé ordinaire.

En 1830, un ingénieur allemand, M. Van Borries, employa trois petits cylindres à détente au lieu de deux, comme l'avait fait M. Mallet. Deux locomotives compound, qu'il installa sur la ligne de Hanovre, réalisaient une économie de 18 0/0 sur les anciennes machines.

C'est en s'inspirant des idées de M. Mallet et de M. Yan Borries, qu'en Angleterre, M. Webb, ingénieur de la ligne London and North Western liniluay, créa une locomotive, l'Experiment, qui marqua l'accession du nouveau système dans lexploitation des chemins de fer anglais.

Les figures 1 et 2 donnent l'élévation et la coupe de la locomotive Webb, dont on peut voir les plans a la section anglaise de l'Exposition. Elle comporte deux petits cylindres $a, a(f i g .2)$ et un troisieme $b$, dans lequel la vapeur agit à basse pression. Les cylindres à haute pression $a, b$

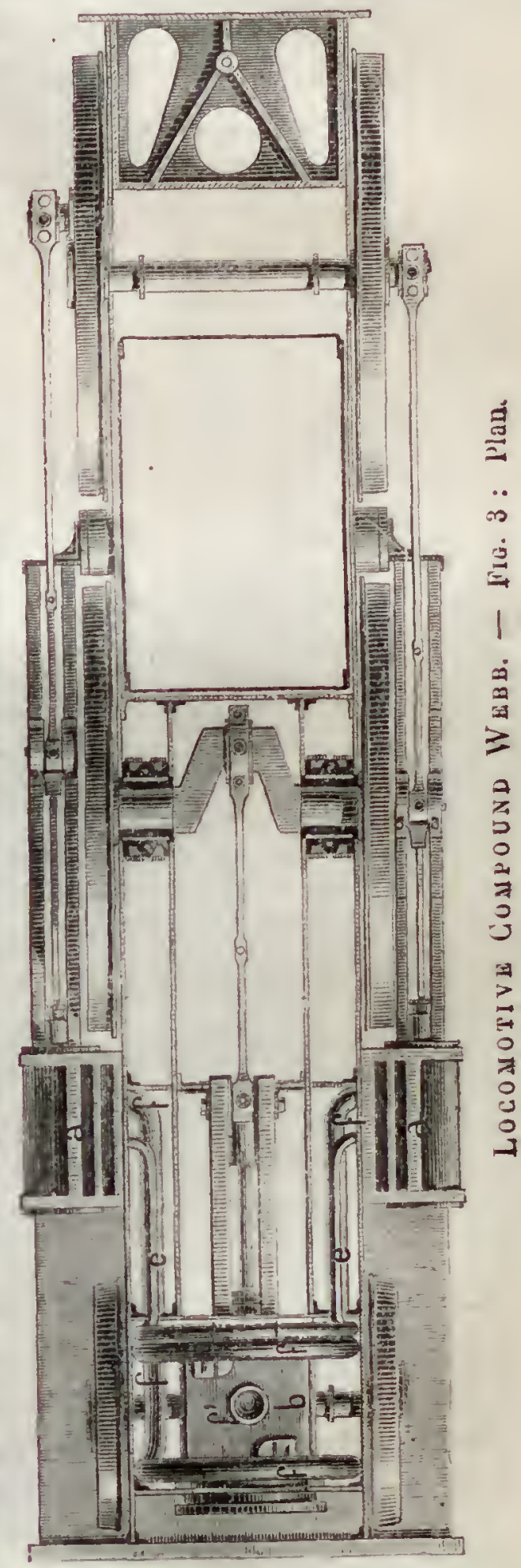
sont placés à l'intérieur du chassis et reçoivent la vapeur sortant de la chaudière. Le grand cylindre $b$, situé sur la bolte fermée ( $f g .3)$, achève de détendre la vapeur sortant des cylindres à haute pression. Ce système d'orģanes actionne l'essieu d'avant; l'essieu d'arrière est actionné par les pistons des pelits cylindres. C'est ce qui est reconnaissable sur le plan ( $f g .3)$. La vapeur sortant des cylindres de haute pression passe dans les tuyaux $f, f$, placés dans la boite a fumée (fig. 2), dans laquelle elle se sèche avant d'entrer dans les cylindres a basse pression. 



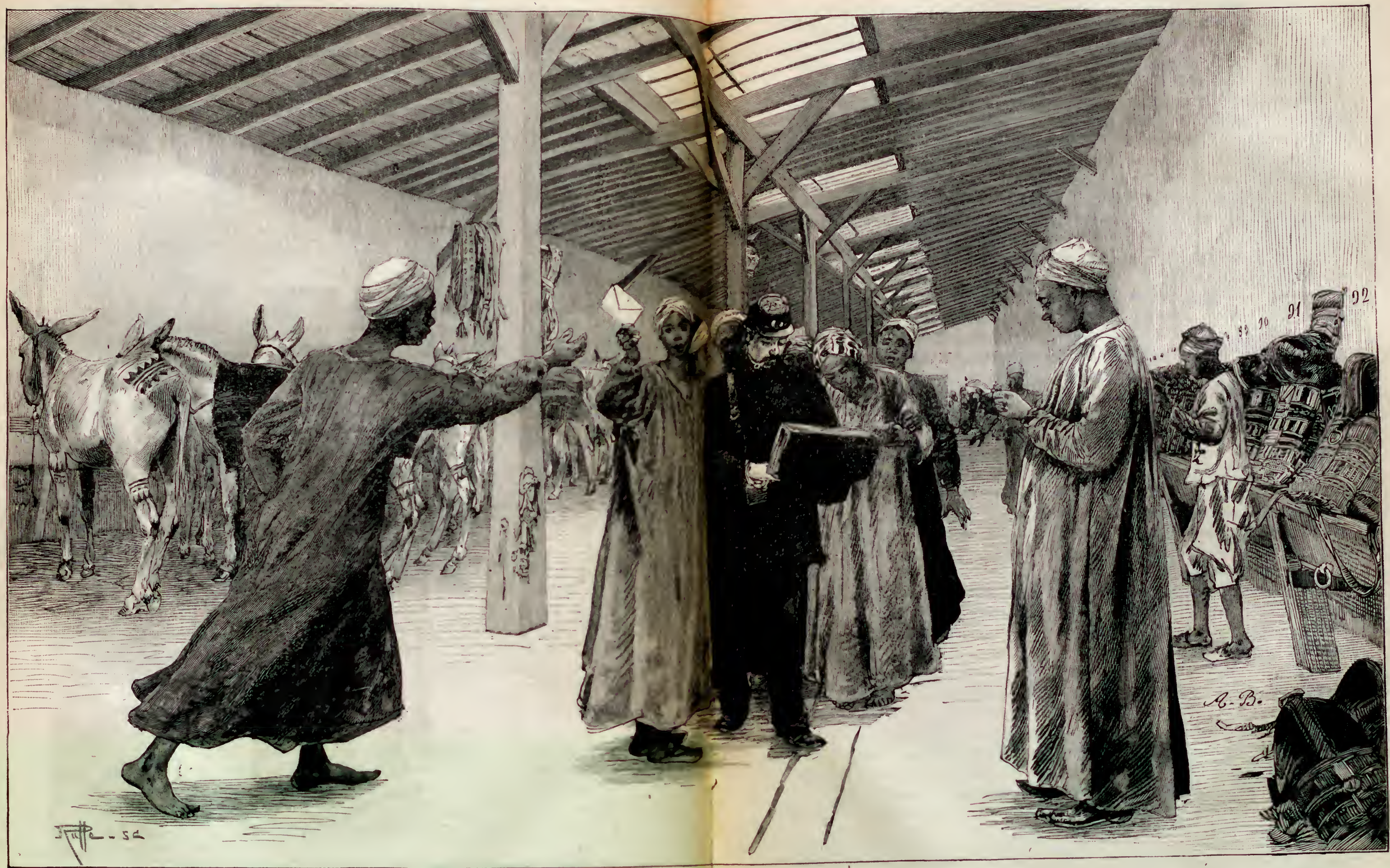


La figure 4, qui donne le détail du tiroir, fera comprendre comment la vapeur peut agir à volonté en marche simple avec admission directe de la vapeur dans les trois cylindres, ou en compound, ainsi d'ailleurs qu'on le voit sur la locomotive de M. Mallet. Le cylindre à basse pression $b$ porte deux tiroirs, $t^{\prime}$ et $t^{\prime \prime}$. Dans la position indiquée pour $t^{\prime}$, la vapeur d'échappement des cylindres de haute pression arrive par $a^{\prime}$ au tiroir $b^{\prime}$, et par $a^{\prime \prime}$ au cylindre $b$; on marche alors en compound. Si l'on deplace par sa tige $t^{\prime \prime}$ le tiroir $b^{\prime}$, de manière à l'amener dans la position indiquée par la figure 3 , la vapeur arrive directement par $b^{\prime} a^{\prime \prime}$ au cylindre $b$ et la vapeur d'échappement des cylindres de haute pression se joint, par $a^{\prime} b^{\prime \prime} c$, à celle du gros cylindre.

Un caractère particulier de la machine anglaise, c'est sa chaudière. Daus l'espace réservé à l'eau entourant la boîte à feu, s'étend, au-dessus de la grille, le cendrier. qui se compose ainsi de l'espace compris entre les barreaux de la grille et la colonne d'eau inférieure.

Il parait certain que l'Experiment a réalisé une notable économie de combustible, qui dépasserait, dit-on, 20 0/0, comparativement avec les machines express. On a dit aussi que la locomotive anglaise avait, sur la locomotive Mallet, l'arantage de

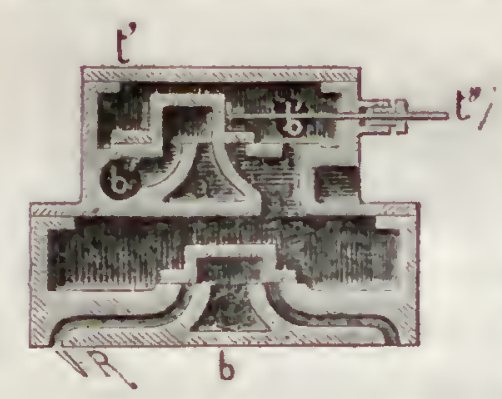

Locomotrve Conpoeñ Webr. - FIg. 4: Distribution de vapeur (détail du tiroir). plus de stabilité, malgré le non-accouplement des roues.

Nous ne devons pas manquer de mentionner ici que, sur les chemins de fer russes, un savant ingénieur du pays, M. Borodine, a mis à l'essai des locomotires compound construites sur le type de celles de M. Mallet, et munies d'un réservoir intermédiaire de vapeur, placé dans la boîte à fumée. M. Borodine aurait ainsi réalisé une économie de 15 a 20 0/0 sur la consommation de charbon des locomotives des trains express.

Mais c'est la Compagnie du chemin de for du Nord qu s'est distinguée, dans ces dernières années, par ses patientes études du système crom. pound. Transportons-nous à la galerie de l'Exposition consacréc au matériel de la Compagnie du chemin de fer du Ford, nous y trouverons trois types différents de ce nouveau genre de locomotive.

Le premier est une locomotive à grande vitesse, à quatre roues couplées, dont lez figures 6 et 7 représentent l'élévation et la coupe transversale.

Cette machine differe de la locomotive compound Vebb par plusieurs dispositions nouvelles, qui peuvent se résumer ainsi :

Le mécanisme intérieur, composé des deux cylindres $A^{\prime} B^{\prime}$ actionnant l'essieu, agit à haute pression. L'accouplement est supprimé et deux cylindres à basse pression IBB' (fig. 5) sont placés à l'intérieur des longerons au milieu de l'intervalle entre l'essieu d'avant et le premier essieu moteur, actionnant l'essieu d'arrière. I.eurs liroirs sont placés en dessous. Les deux cylindres de détente sont placés sur la chaudière.

Comme dans les locomotives Mallet et W'ebl), la distribution de vapeur est telle que l'on peut marcher à volonté en compound ou dans le système ordinaire.

Deux tuyaux CC', placés dans la bolte i fumée (fig. : ö), sont destinés à réchaulfer la vapeur qui passe des pelits aux grands cylindres.

Il résulte des nombreuses expériences faites a la Compaguie du chemin de fer du Nord par M. Pulin, ingénieur chargé de cette étude, que cette locomotive, qui a fait un service prolongé sur les lignes du Nord, a pu réaliser une éconounie de 18 0/0 
sur les machines du même type à grande vitesse non compound. L'un des tiroirs à basse pression de cette locomotive figure à l'Exposition, après avoir accompli un parcours total de 146,000 kilomètres.

La seconde machine compound que l'on voit à l'Exposition ( $n^{\circ} 4733$ ) est une locomotive à huit roues couplée, et qui marche a 18 kilogrammes de pression de vapeur.

Il résulte d'expériences récentes que les machines de ce type ont traîné $68 \%$ tonnes sur des rampes de 11 millimètres à la vitesse de 15 kilomètres à l'heure, en réalisant une économie très importante par rapport aux machines ordinaires qui, dans ces conditions, doivent etre employées en double traction.

La Compagnie du Nord a commandé vingt locomotives de ce nouveau type d l'usine de Fives-Lille, en portant la pression a 12 kilogrammes au lieu de $\mathbf{1 0 .}$

La troisième locomotive compound qui se voit dans la mème galerie est à six roues couplées et à trois cylindres. Elle est timbrée à 14 kilomètres et porte, sur le cylindre de haute pression placé au milieu, une distribution à deux tiroirs, qui permet de limiter la pression.

On peut diriger la vapeur, si l'on ne veut pas marcher en compound, dans les grands cylindres, qui sont extérieurs.

Celte machine est très puissante et, par le diamètre de ses roues, qui est de $\mathbf{1}^{\mathrm{m}}, 630$, elle est apte d marcher vite. Après avoir fait le service des voyageurs, elle a été essayéc pour le service des marchandises, et elle a pu remorquer la charge maxima des locomotives à huit roues couplées, à la même vitesse. D'autre part, elle a amené un train de cliarbon pesant 550 tonnes sur un trajet de 210 kilomètres en six heures et demic, sans exagération de la vitesse sur les pentes. Les expériences ont été interrompues par l'envoi de la machine d̀ l'Exposition.

La Compagnie de Fives-Lille expose, à côté des locomotives compound du chemin de fer du Nord, une machine à marchandises qui résulte de la transformation d'une locomotive à huit roues couplées en machine de Wolf à deux cylindres ( $n^{\circ} 370 \%$ ). Cette locomotive compound a été commandée par la Compagnie du chemin de fer du Nord.

Nous ne devons pas manquer d'ajouter que la Compagnie de Paris-Lyon-Méditerranée présente, comme celle du clıemin de fer du Nord, des locomotives compound. La première est destinée aux trains express ou aux fortes rampes ( $n^{\circ} 4301$ ). Elle a été construite aux ateliers d'Oullins.

La seconde, destinée égalenent aux trains express, est à quatre cylindres, comme celle du Nord. Les deux cylindres d'admission de vapeur sont placés à l'intérieur des longerons, et les deux cylindres de détente sont à l'extérieur.

Les locomotives compound ne se voient pas seulement aux expositions du chem in de fer du Nord et de Paris-Lyon-Méditerranée. Les sections étrangères ont présenté des plans de locomotives du mème tỹpe. Il se manifeste, en effet, un mouvement général en faveur de l’application du principe compound aux chaudières et cylindres à vapeur des locomolives. On espère que, sous le rapport de l'économie du combustible, le passage de la vapeur dans deux ou trois cylindres successifs pourra présenter un jour autant d'avantages sur les locomotives que dans les machines fixes et les machines marines. Les tentatives faites en différents pays pour l'application de ce système prouvent son importance. Les locoinotives compound commencent a entrer dans la pratique. C'esl ce que prouve l'emploi fait en ce moment, en Angleterre, des machines de M. Wondell sur le North Eastern Railuay, où l'on a réalisé, lors du concours de trains 
qui a eu lieu en 18S8, entre Londres et Edimbourg, des vitesses inconnues en France.

Cette question est donc tout ì fait a l'ordre du jour, et une visite aux expositions de la Compagnie du chemin de fer du Nord et de Paris-Lyon-Mẻditerranée renseignera parfaitement sur son étal actuel les hommes spéciaux.

GÉxérateurs. - Parallèlement à l'École militaire sont les gémérateurs à vapeur. Les générateurs doivent évaporer 49,600 litres d'eau par minute au minimun ef

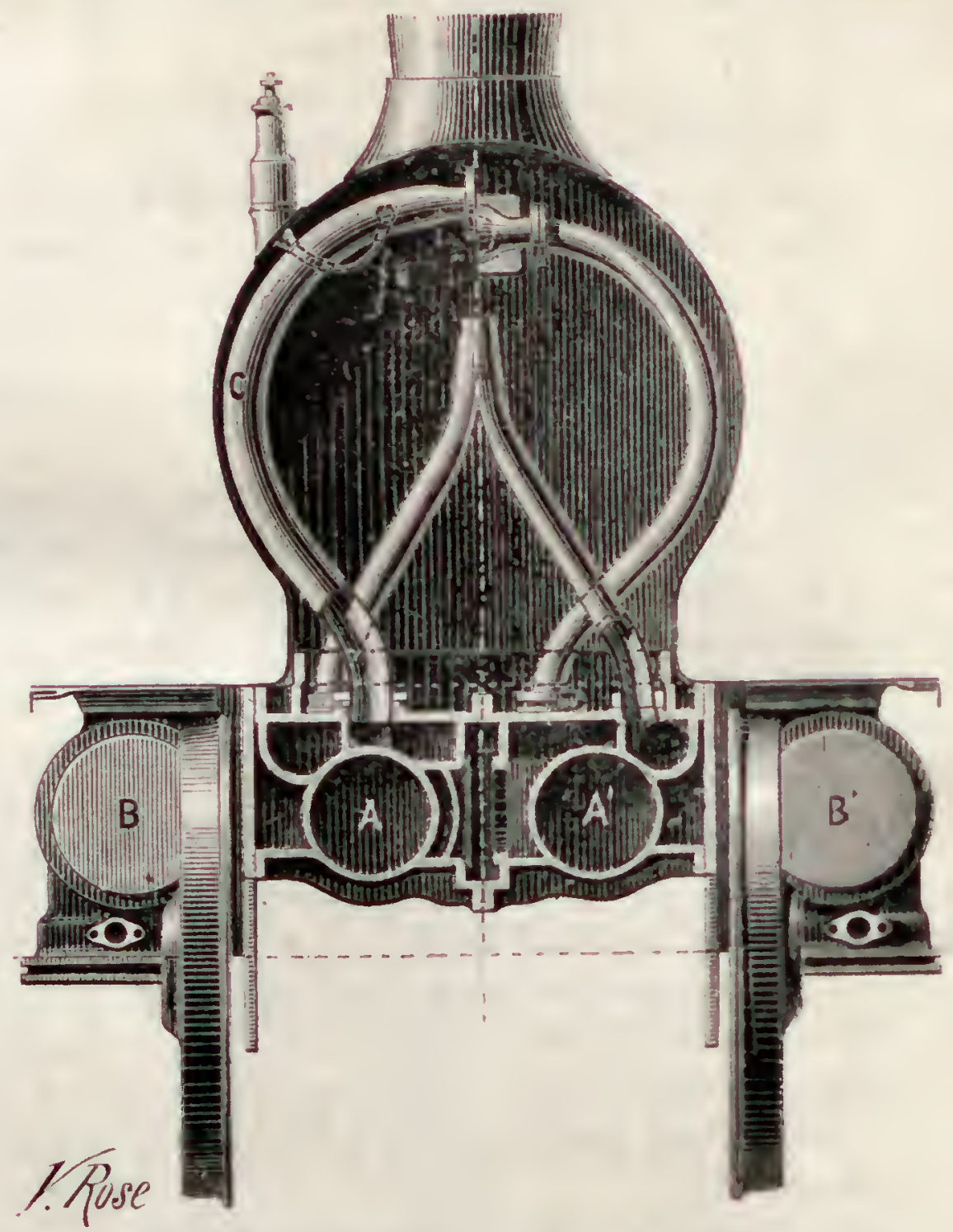

Loconotra Conpound - Fsa. 3 : Coupe transversule d'une locomolive du Chenin de fer du Nord.

fournir 5,500 chevaux-vapeur. Veut-on des chiffres qui permeltent de se faire une idée de ce simple renseignement? en voici :

A l'Exposition de $18 \% \%$, la première où il fut donné de voir des machines en inouvement, la force motrice était de 330 chevaux; a l'Exposition de 1867, elle était do $62 כ$ chevaux; à l'Exposition de 1878, de $2,300$.

Les machines motrices sont au nombre de trente-deux, fournies par trente et un exposants. La vapeur est fournie gratuitement aux proprićtaires de ces machines. Is traité passé avec l'administration porte que les inachines pourront domer une force égale à 2,300 chevaux-vapeur; 233 chevaux environ sont fournis en plus sous conditions, ce qui porte à près de 2,600 chevaux la force motrice disponille sur les arbres de couche du Palais des Machines. 


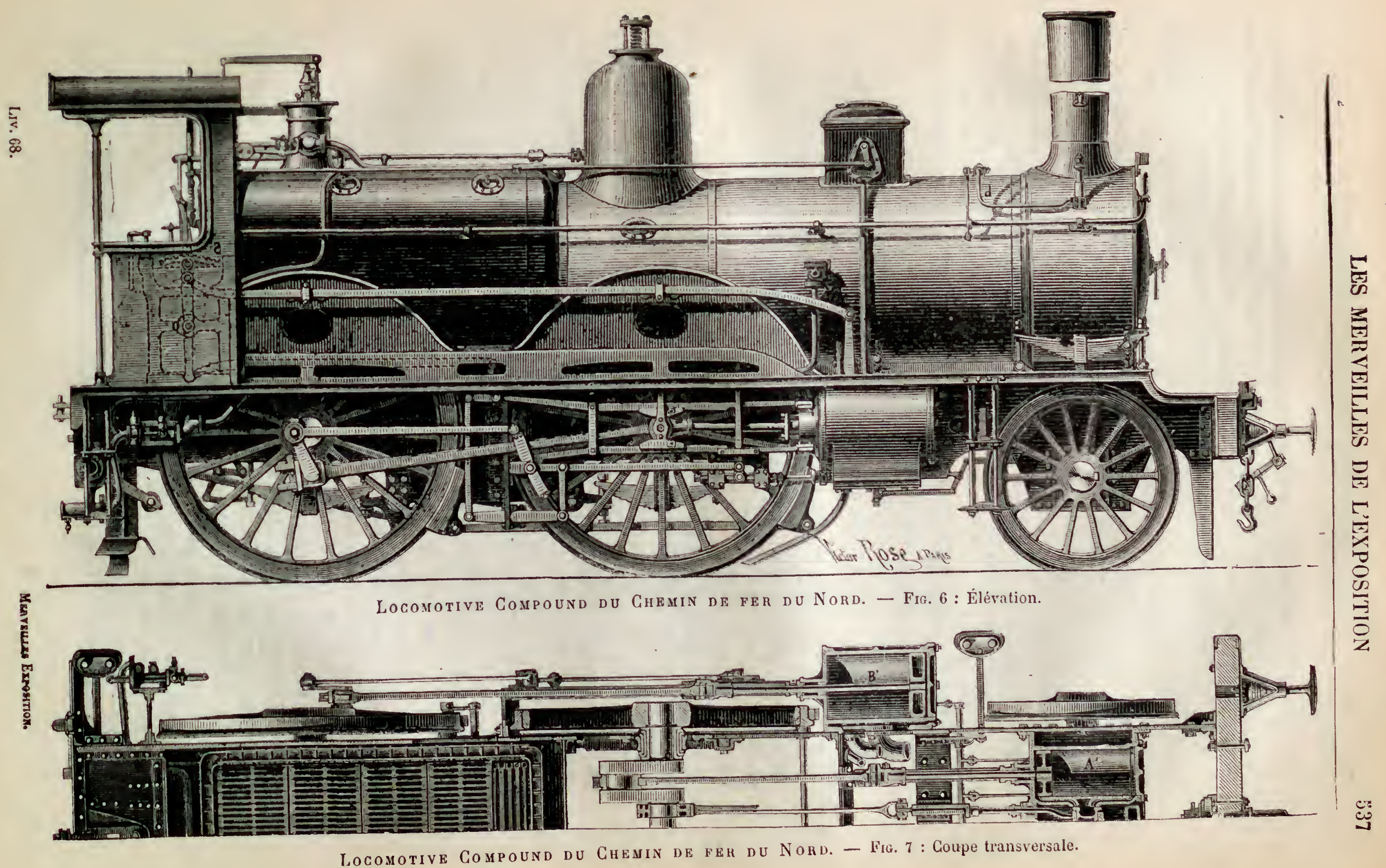


La puissance maxima que les trente-deux maclines seraient susceptibles de développer est donc supéricure à celle pour laquelle il a été traité, puisque, comme nous

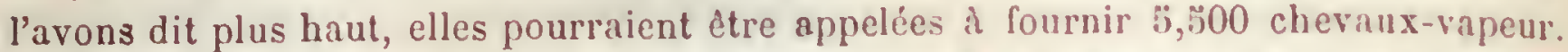

Dans la répartition de la force motrice entre divers exposants, l'Administration s'est laissé guider par le désir de donner satisfaction à tous ceux qui lni ont manifesté l'intention de voir produire un travail utile a leurs machines.

La transmission principale du mouvement comprend quatre lignes d'arlores allant d'un bout à l'autre du Palais des Machines et ayant une longueur totale de 1,359", Outre cette transmission principale, on a installé dans diffirentes classes de la galerie des transmissions de moindre importance. Enfin en dehors du Palais des Miachines, les galeries de l'Agriculture sont desservies par une transmission de $206^{\mathrm{m}}, 66$ de longueur.

Toutes ces transmissions donnent une longueur tolale d'arbres de couche de 1,67 mètres.

En 1S85̄, la transmission qui donnait le mouvement aux machines exposées élait formée d'un arbre unique long de 420 metres.

En 1867, l'arbre de transmission avait une longueur totale de 731 metres.

En 1878, on avait élabli une double ligne d'arbres de couche dont la longueur lotale était de 2,176 mètres.

Les canalisations destinées au service des machines motrices et des générateurs ont nécessité, par leur pose, la construction de deux importantes galeries sonterraines placées dans le sens longitudinal du Palais et ayant l'une 350 métres et l'nutre 179 mètres de longueur.

Ces deux galeries à plein cintre ont des sections différentes : la premiére a une hauteur de $1^{m}, 90$ et une largeur de $2^{m}, 40$; la seconde, $1^{m}, 70$ et 2 metres. Elles conticnnent chacune trois tuyaux, pour l'eau froide, pour la vapeur et pour la condensation.

Des galeries secondaires transversales, également souterraines, allant des galeries principales aux différents groupes de générateurs, amènent d'une part l'eau froide aux chaudières, d’autre part la vapeur de la chaudière à un tuyau de vapeur fui est divisé en sections isolées les unes des autres et alimentées chacune par un groupe.

D'autres galeries transversales en maçonnerie et des caniveaux boisés relient les galeries principales aux trente-deux machines motrices.

L'alimentation en eau froide el l'évacuation des eaux chaudes de condensation sont assurées par deux conduits en fonte de $0^{m}, 69$ placés le long de l'avenue Sufren cl aboutissant, l'un au réservoir d'eau placé sur le quai d'Orsay, l'autre d la Seine.

La longueur des galeries souterraines est de 700 métres. La longueur totale, des égouts est de 3,000 mètres; celle de la canalisalion de gaz de 3,000 métres el celle des conduits d'eau de près de 15 kilomètres.

Veut-on encore des chiffres comparatifs?

En 1867, ta surface totale mise da la disposition des exposants des machines était de 42,380 mètres, en 1878 elle élait de 85,5 ti 4 mètres.

A lui seul le Palais des Machines, avec ses galeries annexes, a 420 mètres de lungueur et 145 de largeur, soit une superfcie de 60,900 inètres, et il faut ajouter à ce chiffre ceux que donne la surface des galeries extérieures, ol un grand nombre de machines-outils sont installées.

Ponts roduasts. - Nous sommes si près de la falerie des Machines que mous nous y arrêtons, bien que nous la connaissions déja, mais celte fois nous monterons a la galene 
du 1 er étage, et, pour épargner nos pas (car nous avons encore beaucoup à voir), nous avons recours aux ponts roulants.

Les nombreux visiteurs de la Galerie des Machines à l'Exposition sont visiblement intrigués lorsque les ponts roulants installés au-dessus des machines transportent d'un bout a l'autre de l'immense galerie leur chargement de voyageurs. Point de moteur visible. Ils accomplissent leur trajet à la façon des convois électriques, sans que rien trahisse au dehors la force qui les anime. Chacun d'eux roule sur deux grandes lignes de poutrelles parallèles d'une longueur de 300 mètres environ. Des générateurs d'électricité établis dans la cour produisent la force motrice, que des fils conducteurs amenent et distribuent au sommet des lignes de poutrelles ou ils se trouvent en contact avec le mécanisme électrique du pont. Chacun des ponts est mú par un système différent: l'un, de MM. Mégy, Écheverria et Bazan, est à engrenage; l'autre, de MM. Bon et Lustrement, est à godets s'actionnant par le frottement. Tous deux sont d'une portée de 18 mètres sur $4^{m}, 25$ environ delargeur et peuvent transporter de 160 à 200 voyageurs.

On sait qque ces ponts roulants ont une autre raison d'ètre. Pendant l'aménagement, du Palais, ils ont assuré le service de la manutention. C'est avec leur aide qu'on a mis en place les énormes machines maintenant en marche dans la nef. C'est avec leur concours encore qu'on déménagera le Palais.

Actuellement, moyennant la somme de 50 centimes, ils prennent les voyageurs et font quotidiennement des recettes de quatre cents francs en moyenne. Ils sont dirigés par un mécanicien et des aides.

Les industries Mécaniques et l'électricité. - Legroupe 6 du Catalogue général est un des plus importants de l'Exposition. Il comprend d'abord le matériel et les procédés de l'exploitation des mines et de la métallurgie : matériel des sondages pour recherches, pour puits artésiens et pour puits à grandes sections; modèles, plans et vues de travaux d'exploitation des mines et carrières; travaıx de captage des eaux minérales; machines et appareils destinés à l'extraction, à la descente et à la remonte des ouvriers dans la mine, machines d'épuisement et pompes; appareils d'aérage et ventilateurs; lampes de sùreté ; appareils de sauvetage, parachutes et signaux; appareils de préparations mécaniques des minerais et des combustibles minéraux; appareils à agglomérer les combustibles et à les carboniser; foyers et fourneaux métallurgiques ; matériel spécial des forges et fonderies; matériel des ateliers d'élaboration des métaux sous toutes les formes.

Vıennent ensuite les machines et appareils de la mécanique générale. Jamais on n'a vu pareille profusion de supports, de galets, de glissières, d'excentriques, d'engrenages, de billes, de parallélogrammes, de joints, de poulies, de courroies, de systèmes funiculaires, de régulateurs, de modérateurs et d'appareils de graissage. A côté, les compteurs, les dynamomètres, les appareils de dosages, les machines à élever les fardeaux, toute la série des hydrauliques, pompes, tympans, béliers, turbines, presses, et le défilé des machines motrices fixes, demi-fixes et locomobiles, des chaudières et générateurs, des moulins à vent et des pananémones.

Les machines-outils pullulent. Il y en a de toute catégorie et de toute dimension : à mortaiser, à percer, à découper, à fraiser, à décolleter, à poinçonner, à tarauder, à fileter, ì river, à ébarber, à affuter, à polir, à broyer, à presser, à malaxer, à estamper et à emboutir. En voici d'autres pour filer les matières textiles, pour produire des fils 



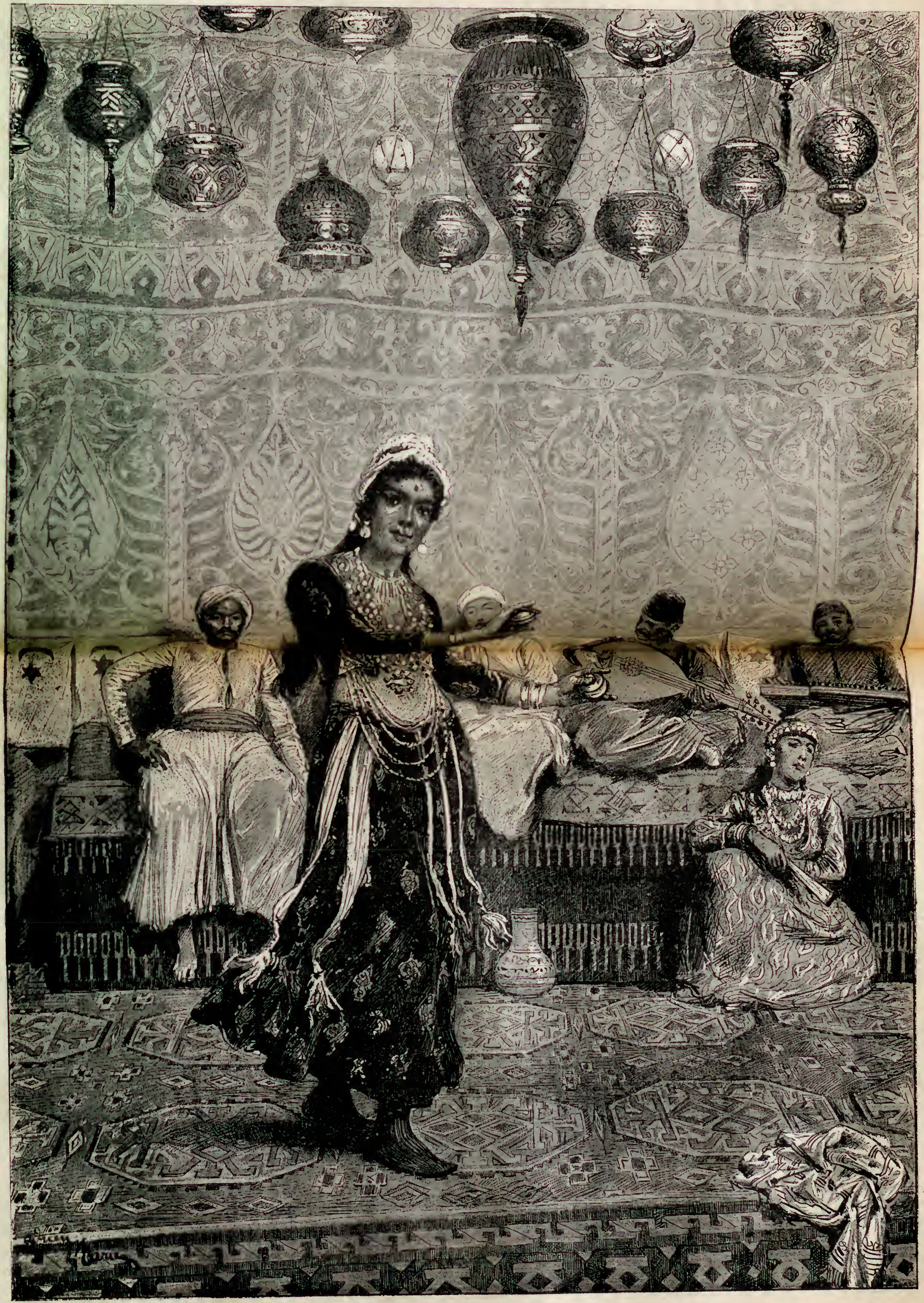


ténus comíme un cheveu ou des cables gros comme le bras, pour ourdir et bobiner, pour fabriquer les tapis et les tapisseries; puis, des métiers à maille pour la fabrication de la bonneterie, des tulles, des métiers de haute lisse, des scies à découper les étofles, des machines pour l'appropriation du caoutchouc.

Tout ce qui sert à la confection du mobilier et de la maison a été groupé dans la classe 56 , et tout ce qui sert au matériel et à la fabrication de la papeterie, des teintures et des impressions dans la classe 58. Le groupe 6 comprend enfin le matériel de production des épingles, des plumes, de la reliure, de la carrosserie, de la sellerie, des chemins de fer et de l'électricité.

M. Henri de Parville a dit excellemment : c On peut bien dire qu'il existe en réalité deux Expositions en 1889, l'Exposition du jour et l'Exposition du soir. Celui qui n'aurait vu que l'une des deux n'emporterait certainement pas un souvenir exact des splendeurs accumulées au Champ de Mars et aux Invalides. Le coup d'œil pendant la soirée est indescriptible. Le regard reste tout surpris devant cette illumination magique. C'est une orgie de lumière à laquelle on n'a vait encore jamais assisté. Tout brille, scintille, flamboie. C'est une fête perpétuelle pour les yeux. On dirait qu'un artiste habile s'est servi d'une palette étincelante pour couvrir de lumière l'Exposition, pour poudrer d'or les grands dômes, pour piquer de traits de feu les pelouses et les pavillons. De loin on voit comme une mosaique aux couleurs miroitantes, puis des taches rutilantes dans les masses sombres, des éclairs à travers les vitraux, des flammes dans les massifs. Nous sommes au milieu de jardins enchantés. Le Trocadéro est magnifiquement éclairé, c'est presque un brasier; l'eau de la cascade tombe de degré en degré en nappe enflammée comme de la fonte en fusion. Le grand arc, le premier étage et le haut de la Tour Eiffel sont garnis de perles lumineuses. Au sommet scintille le phare électrique arec ses feux rouge, vert et blanc éblouissants; on dirait d'une grosse étoile délicatement posée sur la grande tour. Le projecteur promène dans l'espace son immense rayon de comete qui fait jaillir des étincelles de la crête des arbres; quand le rayon blanc emeure les statues du parc, il semblerait qu'il les anime; il les couvre d'efnuves brillants et les enloure d'une auréole d'argent bleuatre comme dans une apothéose. Lumière d'nurore! ,

L'éclairage électrique de l'Exposition est fait par un syndicat international qui a reçu une idemnité fixe de $1,800,000$ francs. Il y a six stations d'électricité au Champ de Mars : la station de la Société Gramme, la station Edison, la station de la transmission électrique de la force, la station de la Société l'Éclairage électrique, la station Ducommun et la station spéciale du Syndicat international. La station de la transmission de la force comprend une machine Corliss à cylindres accouplés de 500 chevaux chacun. La station Edison courre 400 metres carrés; ses moteurs (800 chevaux) activent 2 dynamos en dérivation Edison de 120 volts et de 1000 ampères, 6 dynamos en dérivation Edison de 120 rolts et 550 ampères. En somme, le syndicat fispose d'une force de 4,000 chevaux. La Galerie des Machines est si brillamment éclairée qu'on y croit être en plein jour, mais ce n'est pas la seule partic de l'Exposition où rayonne cette lumière merveilleuse : la classe des chemins de fer, le vestibule d'entrée du Palais des Machines, la rue centrale du Dôme, la pelouse centrale, divers établissements privés, la porte Rapp, certains pavillons, etc., resplendissent tous les soirs. L'intensité tolale est åun million et demi de bougies, et la combustion est de plus de 10,000 kilogrammes de houille par heure. 
On comprend que nous ne puissions décrire en détail une à une les Expositions qui rentient dans le groupe des Industries mécaniques. La Galerie des Machines est déjà par elle-même un pur chef-d'œuvre, qu'on ne se lasse ni de regarder ni d'admirer, surtout lorsqu'elle est en mouvement. Les poutres de transmission de mouvernent supportent des chaises en métal à travers lesquelles passent les arbres à poulies où les machines, par le moyen de courroies, viennent prendre la force motrice. Les machines motrices sont au nombre de trente-deux. La France est représentée dans ce hall immense par de nombreuses installations, notamment les presses Marinoni et la papeterie Darblay, mais nous devons aussi mentionner l'Exposition mécanique de la Suisse, celle de l'Angleterre, celle des États-Unis.

L'Exposition américaine d'Edison couvre à elle seule 675 mètres carrés, donnés par un foyer de 20,000 lampes à incandescence. C'est à elle que se rattachent les auditions téléphoniques, qui ont lieu toutefois, non dans la Galerie des Machines, mais dans le Pavillon des Téléphones. On peut, grace à ces auditions, se rendre compte des importants perfectionuements apportés au phonographe et qu'un ami d'Edison, M. Gouraud, a décrits dans les termes suivants : e Le phonographe perfectionné d'aujourd'hui enregistre et répète tout, non seulement avec la plus grande précision, mais sans jamais faire d'erreurs, et apparemment jusqu'à l'infini. Le phonographe resta dans son imperfection pendant une dizaine d'années; M. Edison était occupé à perfectionner d'autres inventions, telles que le téléphone. Le premier instrument auquel M. Edison donna bien a propos le nom de phonographe, démontra tout de suite que la parole pouvait s'enregistrer et se reproduire avec la plus grande précision par des moyens mécaniques. Mais ce n'était encore qu'un instrument de curiosité, ne répétant qu'un petit nombre de fois, les répétitions devenant d'ailleurs plus faibles et moins exactes à chaque reproduction. Pendant ces dix années, à ses moments de loisir, il aimait à retourner son travail, mais il ne le reprit sérieusement qu'il y a deux ans. Le bruit se répandit bientôt qu'il était parvenu à reproduire fidèlement les sons de la voix humaine et de la musique, et, lorsque pour la première fois, il $y$ a quelques mois, j'entendis en Angleterre, par l'intermédiaire du phonographe, la voix de M. Edison avec toutes ses inflexions, vous pouvez vous imaginer le plaisir que j’éprouvai.

- Comme dernière explication, et une des plus intéressantes, je vais vous dire ce qui a été obtenu dernièrement en faisant travailler le phonographe concurremment avec le téléphone.

a New-York, on parla et on fit de la musique, et les paroles et la musique furent cntendues dans une salle a Philadelphie par un auditoire nombreux, la distance étant de 140 kilomètres.

- Voici comment se fit l'expérience :

- On parla à New-York dans le phonographe, celui-ci répéta son enregistrement daus le téléphone, qui, au moyen de son transınetteur de charbon, le transmit a un motographe récepteur qui répéta à haute roix sur un autre phonographe à Philadelphie. Ce dernier répéta dans un second transmetteur de charbon sur un second motographe récepteur qui, enfin, reproduisit à haute voix tout ce qui avait été enregistré, devant un grand nombre de personnes, à Philadelphie, à l'Institut Franklin, dont la réputation est conıue du monde entier.

- Dans cette expérience merveilleuse; on se servit de trois des plus remarquables inventions de M. Edison : son téléplione à transmetteur de charbon, son téléphone 
LES MERVEILLES DE L'EXPOSITION

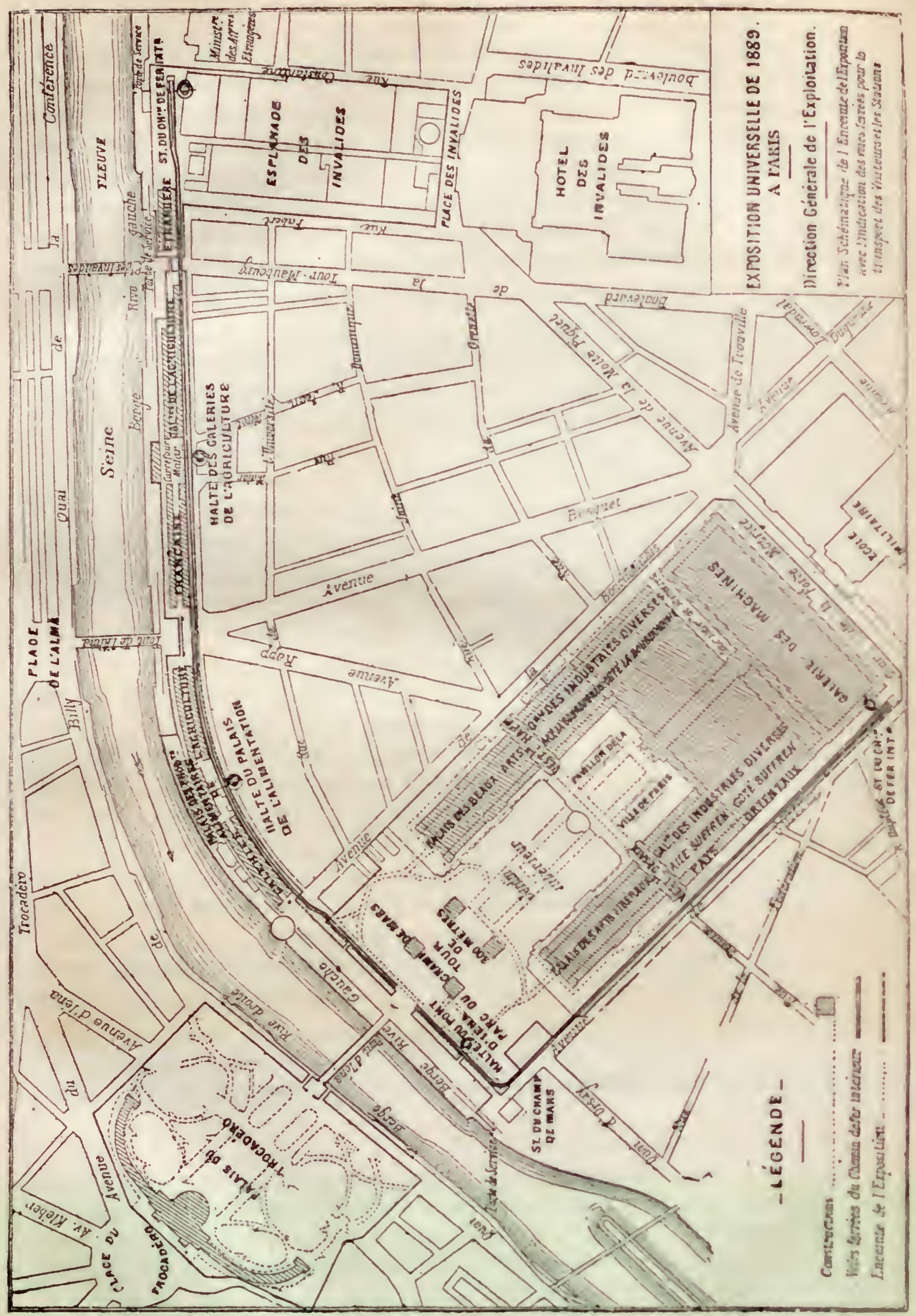


motographe et son phonographe. Le son qui avait été produit à New-York et qui avait été entendu à Philadelphie passa successivement à travers cinq couches d'air différentes, par conséquent s'entendit cinq fois pendant le trajet. De plus, le son, ou cette onde sonore, anima, ou dans un sens passa au travers de dix corps différents, sans parler du courant électrique du verre, du fer, du mica, de la craie, de la cire, du charbon, de l'acier et du cuivre.

- Cette expérience avait été faite par un des ingénieurs les plus habiles du laboratoire de M. Edison, M. IIammer, qui dirige à l'Exposition l'installation des nombreuses inventions de M. Edison.

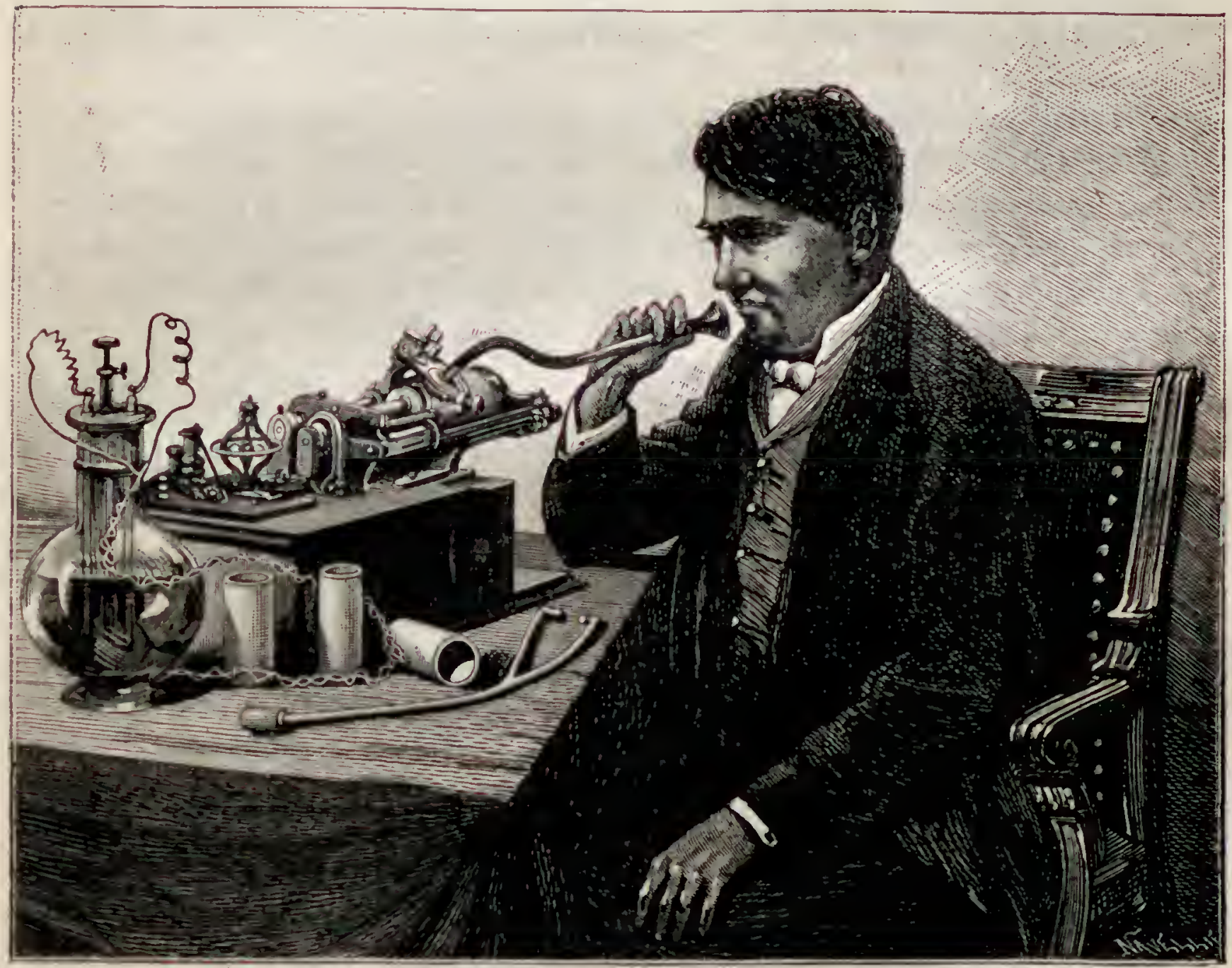

EDISON PARLANT DANS SON PHONOGRAPHE.

- Dans cette première lettre parlante, on entendit l'inventeur comme s'il était assis devant nous, parlant, toussant, riant et finissant sa lettre en exprimant le plaisir qu'il aurait à entendre ma voix, au lieu de se fatiguer à lire ma mauvaise écriture. Par la mème poste, on entendit aussi des morceaux de musique qui avaient été joués en Amérique, le son des bruits de son laboratoire, tels que le bruit du marteau frappant sur l'enclume, celui de la lime sur le fer, et finissant par les hourras poussés par les ouvriers en l'honneur du départ de la première voix qui se mettait en route. Tous ces sons étaient si clairs et sidistincls que l'on aurait pu aisément se passer de la voix de M. Edison annonçant chaque fois leur origine. ,

- Voici maintenant un aperçu de l'emploi que l'on peut faire du phonographe: 
" $1^{\circ}$ On peut dicter la correspondance et la faire transcrire à loisir par un employé ne sachant qu'écrire et épeler correctement; on peut la faire transcrire par le typo.

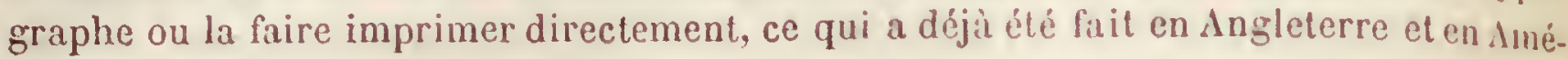
rique.

" 20 On peut transmettre sa voix par la poste au moyen du phonogramme. La voix de celui qui parle s'entend avec ses propres inflexions.

\& $3^{\circ}$ Les hommes d'État, les avocats, les prédicateur's et l'oratcur peuvent étudier leurs discours, ayant l'avantage inappréciable d'enregistrer leurs idées au fur et d inesure qu'elles se présentent, avec une rapidité que l'articulation seule peut égaler; ils peuvent surtout s'entendre parler comme les autres les entendent. Les acteurs, les chan. teurs peuvent répéter leurs roles et sont en mesure de corriger enx-mèmesleur diction; on peut entendre les derniers adieux d'un mourant on les paroles d'un parent que l'on aime.

- Pour vous donner une idée réelle de son utilité, je n’ai qu' ì vous dire que, depuis que je suis arrivé à Paris, je reçois tous les matins une lettre parlante, me donnant tous les détails de ce qui se passe chez moi en mon absence. J'ai pu entendre la dernière que j'ai reçue à une distance de trois mitres, sans en perdre un seul mot.

- Déjàla France a suivil'exemple de l'Angleterre, car votre ancien président, II. Jans. sen, a été le premier qui ait fait entendre la langue française dans le laboratoire de M. Edison au moyen du phonographe.

" Quelle meilleure idée puis-je vous donner de son utilité qu'en vous disant que je m'en sers tous les jours comme d'un sténographe dictant ma réponse à mes lettres. lorsque je les lis, et la repassant à mon employé qui, à son lnisir, transcrit ce qu'il entend? Il n'a besoin que de savoir écrire et épeler convenablement.

- Ce que je fais tous les jours, tout le monde peut le faire facilement, quelle que solr sa nationalité.

- On peut donc affirmer, sans crainte d'ètre contredit, que, quoique jeune et susceptible d'ètre encore perfectionné par le génie de son inventeur, le phonographe daujourd'hui est un instrument pratique et capable de rendre de grands services a tout le monde.

- M. Edison a déjà établi un grand atelier spécial pour la fabrication des phonographes. Il peut en fabriquer deux cents par jour; des centaines d'ouvriers sunt dija au travail, et on peut espérer que, sous peu, il sera à même de livrer au commerce des milliers d'instruments.

* Vous avez aujourd'hui l'appareil avec ses améliorations les plus récentes; quelques-unes mèmes ont été faites en vue de cette séance et me sont parvenues à Paris, il y a deux jours. C'est donc la première apparition qu'elles font en Europe. ,

Le public s'arrête volontiers devant l'exposition des usines belges de Willebroeck, qui comprend notamment une fabrique de pattes chimiques à papier, une papeterie ayant sept machines it papier et des ateliers de fonderie. La production moyenne de pate, par jour, est de 400,000 kilogrammes, celle de papier de 33 a 40,000 , et les usines exigent une dépense de force de 5,000 chevaux produite par 31 chaudières de Naejer. La Compagnie de Willebroeck a exposé dans la Galerie des Machines une fabriq̨ue de papior au grand complet, avec calandre, coupeuse, machines it lignes, ctc., et nous rojons s'effectuer sous nos yeux une production de 300 kilos a l'heure. Au bout de celte fabrique se trouve une pyramide composé de 62 espèces végétales, des 62 lypos de pates 
fabriquées avec ces matières et des 62 sortes de papier fabriquées avec ces pàtes. Des mêmes usines sortent les chaudières multitubulaires en fer laminé du type de celles qui fournissent 2,200 chevaux-vapeur à la Galeric des Machines.

Au coin de l'avenue de La Bourdonnais et de la Galerie des Machines commence la tris remarquable exposition des grandes compagnies industrielles. C'est la rue des Grandes-Usines, comme on l'a déja baptisée : pavillon des $\Lambda$ sphaltes, pavillon de Montchanin (briquelerie), pavillon des Émaux céramiques, Forges de Saint-Denis, anciens Établissements Cail, Fonderies et Forges de l'Horme, etc.

Les petits pavillons de la briqueterie sont construits avec beaucoup de goût. On apprend, en s'y promenant, les applications de la brique à la construction des murs courbes, au coffrage des puits, aux voutes, aux cheminées d'usines, aux hauts fourneaux, aux four's a chaux el à ciment, el mème à la construction des hangars.

La Compagnie des Fonderies et Forges de l'IIorme comprend deux groupes d'établissements industriels : 10 les usines métallurgiques de l'Horme, près Saint-Chamond (Loire), et les Chantiers de la Buire, à Lyon.

L'exposition des Chantiers de la Buire n'est pas la moins intéressante de cette partic du Champ de Mars. Nous y avons vu une foule de choses, et cette variété même est une altraction de plus. Dans l'ordre de l'éclairage électrique, voici un chandelier automatiqne à dérivation pour bougies Jablochkoff, dont l'invention est due à M.oL. Bobenrieth, ingénieur électricien aux Chantiers de la Buire, qui se propose de détrôner les régulateurs; puis l'interrupleur automatique du mème ingénieur, destiné à couper le courant des accumulateurs, lorsque le moteur se ralentit et s'arrête, et à empêcher ce courant de se renverser dans la dynamo.

Le métier à tisser des Chantier's de la Buire diffère des autres métiers mécaniques par les organes suivants: le remisse, la mécanique d'armure, le battant, le régulateur, la bascule et la chasse. Les directeurs des chantiers estiment qu'il augmente la production quotidienne dans la proportion de $20 / 0$. Sa marche normale varie de 90 à 200 coups ì la minute, suivant les tissus, car il s'applique aussi bien aux belles sortes qu'aux soies inférieures et très chargées. - Le métier à velours construit par les mèmes cliantiers a ceci de particulier que l'arbre-manivelle, au lieu d'ètre derrière le remisse, est placé sous des barres du rabol ou rasoir, disposition qui rend le remisse abordable de tous côtés. L'ouvrière peut donc passer ou rhabiller ses fils sans ètre gènée autour du remisse par aucune des parties du mécanisme. - Le métier à deux et a trois lats suivis, dit Pique-Pique, est d'une grande simplicité, et son garage aussi facile que celui d'un métier ordinaire à une navette. Sa production est d'ailleurs la mène. - Le nouveau métier \ 4 navettes n'est qu'une forme complémentaire du métier ordinaire; il peut s'adjoindre à tout métier simple sortant des Chantiers de la Buire, en sorte qu'arec le méme instrument, on peut, suivant les exigences de la mode, tisser tous les genres d'étoffes en uni el en façonné. Cet appareil consiste en une mécanique de changement de narettes, à combinaison d'excentriques et montée sur un petit báti spécial qui se place sur le côté du métier.

Mentionnons enfin la machine pour la teinture en flottes, la machine à teindre en pieces, et la secoucuse, dresseuse double, qui évite à l'ouvrier teinturier le secouage à la main ou au chevillon.

Le visiteur qui entre dans l'exposition des Chantiers de la Buire est absolument étourdi par le va-et-vient de tous ces métiers en mouvement. Ces métiers sont au nombre 



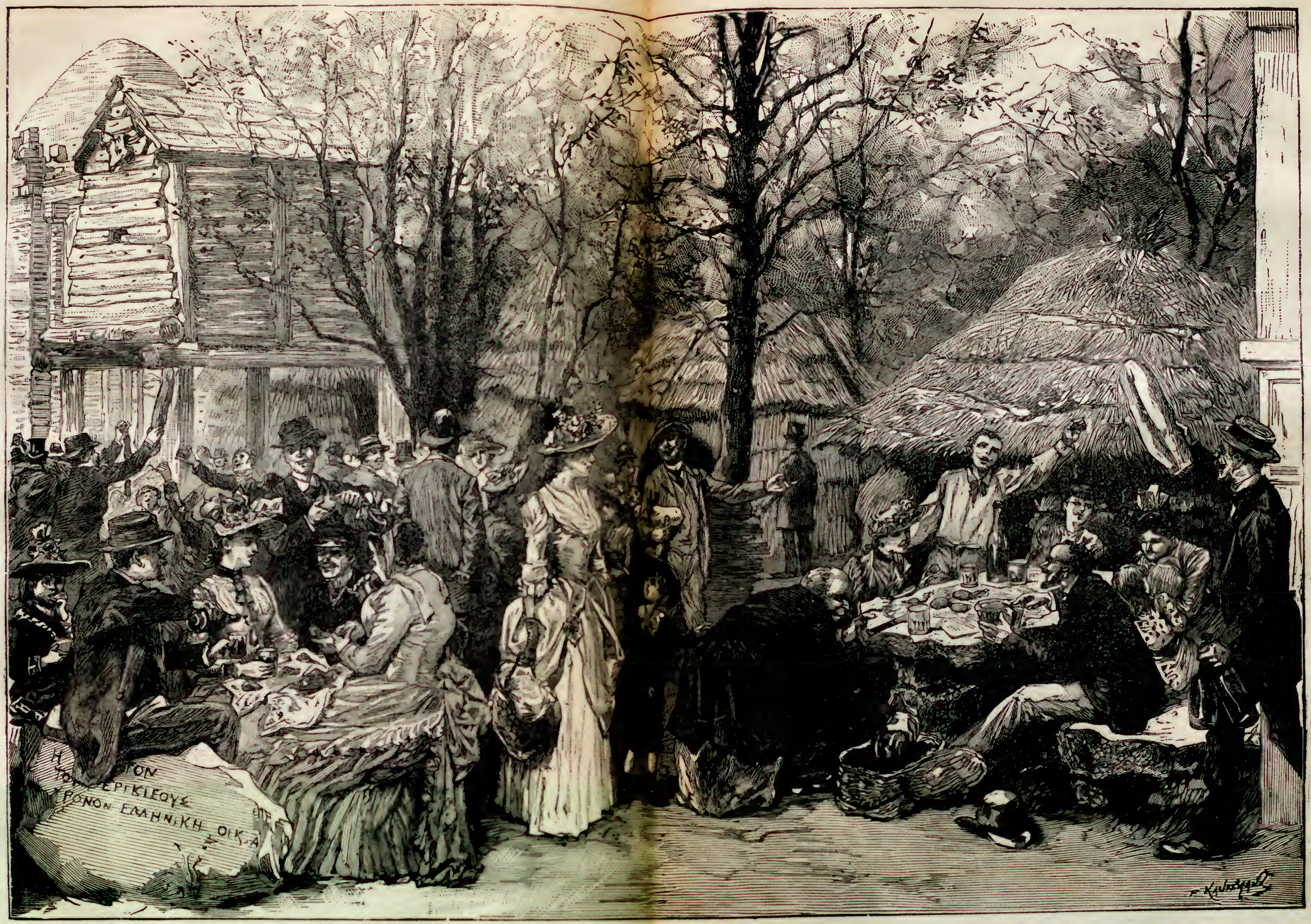


de neuf. On remarquera dans le métier pique-pique: 10 le fonctionnement des deux naveltes qui partent l'une après l'autre deux fois d'un côté, deux fois de l'autre; 20 la connexion existant entre le mécanisme du changement de nuances de trames, el celui de la mécanique Jacquard. Dans le métier qui porte le no $̋$, on remarquera le pnigne renversé à inclinaison variable, avec arrèt au passage de la navetle, dont le mouvement assure la régularité des intervalles de trames, et dans le métier $n^{\circ} 6$, la position de l'arbre coudé par rapport au battant (d'où résulte la possibilité d'employer un nombre indéfini de lisses), l'arrèt du donneur de poils et du régulateur au moment du passage du couteau; enfin, la possibilité pour l'ouvrière de donner au métier une marche en arrière et de réparer le cas échéant une faute de tissage. Citons aussi l'appareil de mise au point du métier $n^{\circ} 8$ el le tempia à pinces du métier n $n^{\circ} 9$. Ce delnier appareil maintient en largeur une étoffe (China tissé en soie mouillée) ayant au lissage un retrait de $10 \%$.

On nous avait recommandé de ne pas oublier deux appareils inventes par .I. Líon Camel pour le filage des cocons: le jette-bout et les asples de filature. II. Líon Camel a bien voulu nous donner les renseignements qui suivent:

" De toutes les opérations du'filage, la plus délicate est sans contredit la jetie du bout. Aucun filateur n'ignore quelle habileté et quel tour de main l'ouvrière doit açuérir pour jeter le bout dans de bonnes conditions, c'est-ì-dire sans tâtonnement, sans perte de temps, de telle sorte que ce bout reste toujours court et que les durets de juctée soient évités; il sait aussi quelle dextérité il faut à l'ourrière pour conserver sa régularité. Si la fileuse à la main n'est pas habile, elle laisse tomber son bout; le fil devenu trop fin ne tarde pas à se rompre, et le produit obtenu est de qualité inférieure, le déchet considérable.

a La difficulté augmente encore lorsque la vitesse du filage est modérée; lout lilateur sait combien il est malaisé de bien jeter le bout avec une marche lente, el cependant il sait aussi combien cette marche est avantageuse au rendement, surtout lorsun il s'agit de cocons de qualité inférieure. '

Le jette-bout Camel remplace la jetée à la main par un entraínement mécinique. II permet donc à l'ouvrière la moins expérimentée de filer au bout de quelques jours et, de plus, il jette le bout toujours court, quelle que soit la vitesse du tournage, et par conséquent sans duvet. Au microscope, la jetée à la main donne une série de nœuds et de bouclettes autour du fil, tandis que, dans le cas de la jetée faite par l'appareil, le brin forme autour du fil c une espèce de nœud de cravate , toujours le misme, el rien de plus. - La nouvelle disposition des asples a pour objet de permettre à l'ourrière de conduire deux, quatre, six bouts ou mème davantage, et par suite de produire une plus grande quantité de soie qu'avec les anciennes dispositions. Chaque flotle est cnvidéc sur uñ asple indépendant, en sorte que, sans sortir la flotte de son guruindre, on peut opérer à peu de frais le dévidage a la déroulée. L'économie de temps, on le devine, est considérable.

Nous arrivons à la Compagnie des Fonderies et Forges de l'Horme. Nous y remarquons un moteur à gaz à compression et à 4 temps, avec inflammation du mélange explosif par une étincelle électrique continue; des presses à agglomérés ovoîdes; des cadres métálliques pour galeries de mines; des générateurs à vaporisation instantance; une roue de chemin de fer à moyeu renforcé en fer et en bois; des machines à denx cylindres compound, à condensation, avec détente à vapeur variable par le régulateur 
et fermeture rapide au petit cylindre; des machines simples à un seul cylindre, à détente cinématique avec ou sans condensation.

Dans le Pavillon de la Compagnie des Asphaltes de France, propriétaire des mines de Seyssel, nous apprenons les applications de l'asphalte en nature et en mastic, et dans celui de la Vieille-Montagne les applications du zinc. Le Pavillon des Mines et Fonderies de la Vieille-Montagne, où sont exposés divers systèmes de couvertures, est lui-même un spécimen des diverses applications du zinc laminé et de la peinture au silicate à base de zinc. Sa décoration extérieure représente une construction en pierres blanches où toutes les parties architecturales et le revètement sont en zinc peint à l'oxyde pierreux; sa décoration extérieure se compose également d'applications diverses du zinc sous différentes formes: les lambris comportent, entre la plinthe et l'appui, des plaques de zinc à doubles nervures peintes en imitation de bois; les plafonds sont aussi formés de ces plaques, en partie peintes en imitation de bois ou décorées de différents dessins. Les parois sont garnies de panneaux peints en imitation de marbre sur zinc laminé, de tableaux peints au silicate à hase de zinc sur toile, le tout entouré de bordures en zinc peintes en imitation de porcelaine. Ces parois sont divisées en plusieurs compartiments, de même que le plafond, et séparées par des pilastres en zinc peints en imitation de bois. Dins Ie compartiment du milieu se trouve une balustrade en zinc peinte à l'oxyde pierreux, et une lucarne peinte également en imitation de pierre blanche; celle-ci sert de motif pour l'application du zinc à la couverture d'un brisis avec œils-de-bœuf. D'un côté de la lucarne, ce brisis est couvert en écailles de poisson et de l'autre en ardoises hexagonales à nervures plombaginées. C'est le triomphe du zinc!

L'exposition de la Société générale des Forges et Ateliers de Saint-Denis a eu l'idée de donner une vue panoramique de ses chanticrs de construction. Cette Société a exposé dans les classes 61 (matériel de chemin de fer), 62 (électricité), 6 (matériel de navigation), 66 (matériel militaire), mais son exposition principale est celle de la classe 61 où elle a installé, dans un pavillon sis à l'entrée du Palais des Machines, un type de wagon de terrassement et une grande voiture à boggies. Les deux véhicules représentent les deux extrêmes de ce que la Société de Saint-Denis peut exécuter comme matériel roulant.

La grande voiture de première classe exécutée pour les chemins de fer de l'État, en mème temps que les trois voitures de première, dẹxième et troisième classes exposées directement dans le Palais des Machines, sont remarquables par ceci que les ingénieurs ont adopté un seul et même type pour toutes les classes de voitures, y compris même celles de luxe.

L'exposition des anciens Établissements Cail est un exemple hors pair d'un établissement de construction qui a appliqué ses ressources aux branches les plus diverses de l'industrie. Elle couvre un terrain de plus de 700 mètres carrés. On sait que la Société des anciens Établissements Cail a son siège à Paris et deux succursales, l'une ả Douai, l'autre à Denain: elle a construit à la foïs des appareils pour l'industrie, des chemins de fer, des locomotives, des ponts et charpentes nétalliques à grande portée, des canons, des torpilleurs, des avisos. Son pavillon est en fer et maçonnerie, avec treillis, colonnades, plaques en marbre vert où sont gravés les noms des spécialités de l'activité industrielle de la Société. Y sont exposés les produits suivants, dont nous empruntons la description à M. Gentilini, ingénieur des ponts et chaussées : 
Un moteur à gaz, système Otto, commandant une presse monétaire; uns locomolive Crampton de 1830 , ayant déjà fait un parcours de 1,10\%,000 kilomètres, c'est-à-dire équivalant à 28 fois le tour de la terre; une locomolive-tender à deux essieux couplés, de 1889; ane locomotive a voie de $0^{\mathrm{m}}, 80$; un pompe de retour d'eau condensée pour appareil à cuire de sucrerie; un compresseur d'air, système Burckhardt; un extracteur de gaz, système Beale; un purificateur d'eau Anderson; un filtre à sacs système Kasalowski pour jus sucrés, un canot avec moteur à pétrole, système Quillfeldt; des dessins de tubes lance-torpilles; un appareil d'évaporation à basse température et ì triple effet pour sucreries; une chaudière close pour cuire en grains dans le vide; un appareil a

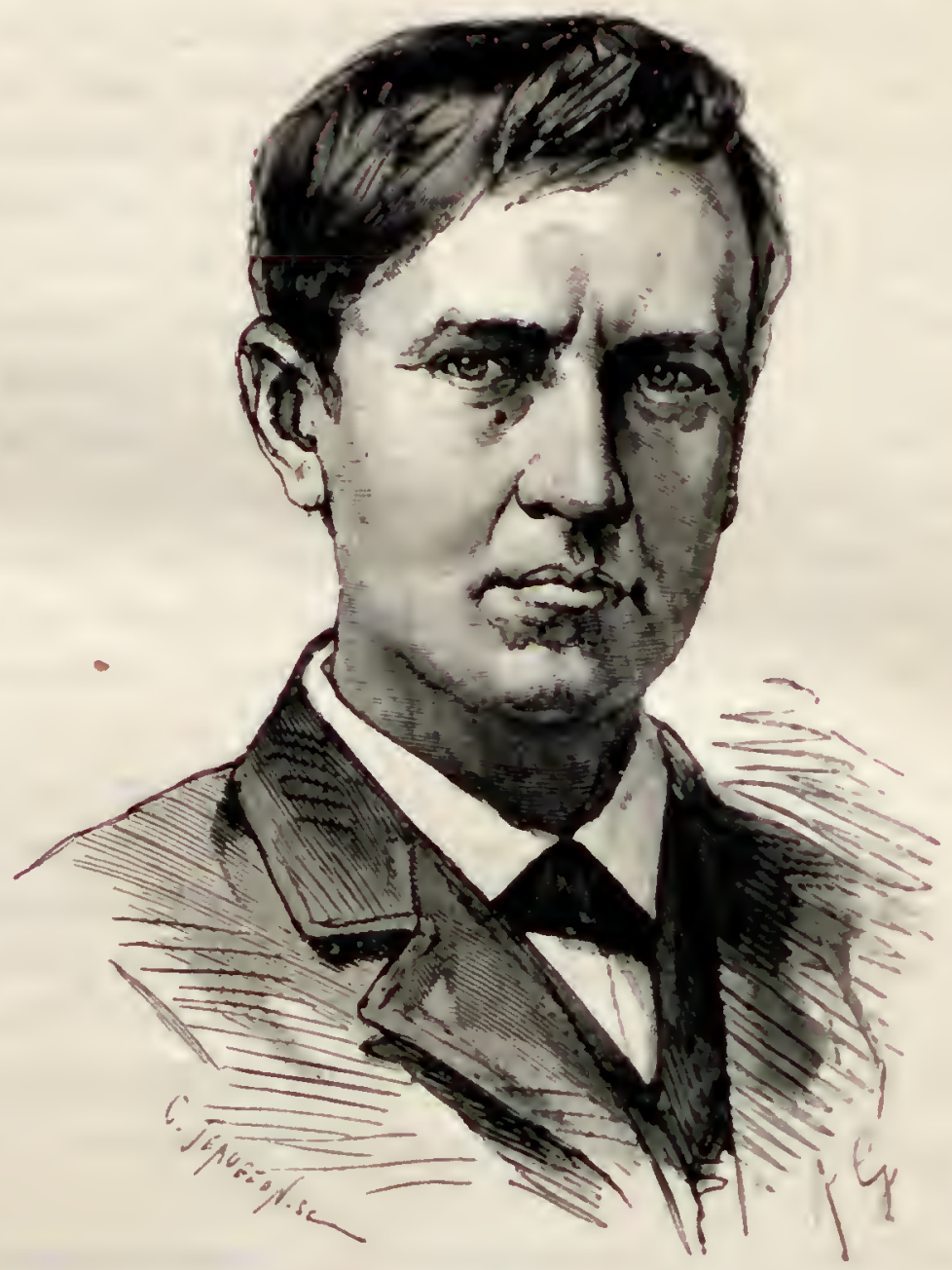

Tн. ALVA EDISOX.

distiller continu pour traiter les liquides alcooliques et principalement les mélasses; un condenseur chauffe-vin, un coupe-racines pour transformer la betterave en rubans, une demi-batterie de diffusion, un filtre-presse pour sucreries; une pompe a vapeur d jus trouble, un groupe de trois turbines pour le raflinage du sucre.

- Une des parties les plus intéressantes de l'exposition Cail est celle qui comprend le matériel d'artillerie exposé sur un terre-plein qui fait suite au pavillon. Ce maléricl se compose essentiellement de pièces de montagre, de campagne, de sidge et de plnce, de marines et de côtes, qui sont toutes du système de Bange, et de canons à tir rapide du système Engstrom.

- La bouche à feu exposée est du calibre de 80 millimètres, elle est semblable au canon réglementaire dans l'artillerie française. L'affut diffère de l'afrut réglementaire en France en ce qu'il ne comporte pas de rallonge de flèche et qu'il est muni d'enrayures 
LES MERYEILLES DE L'EXPOSITION

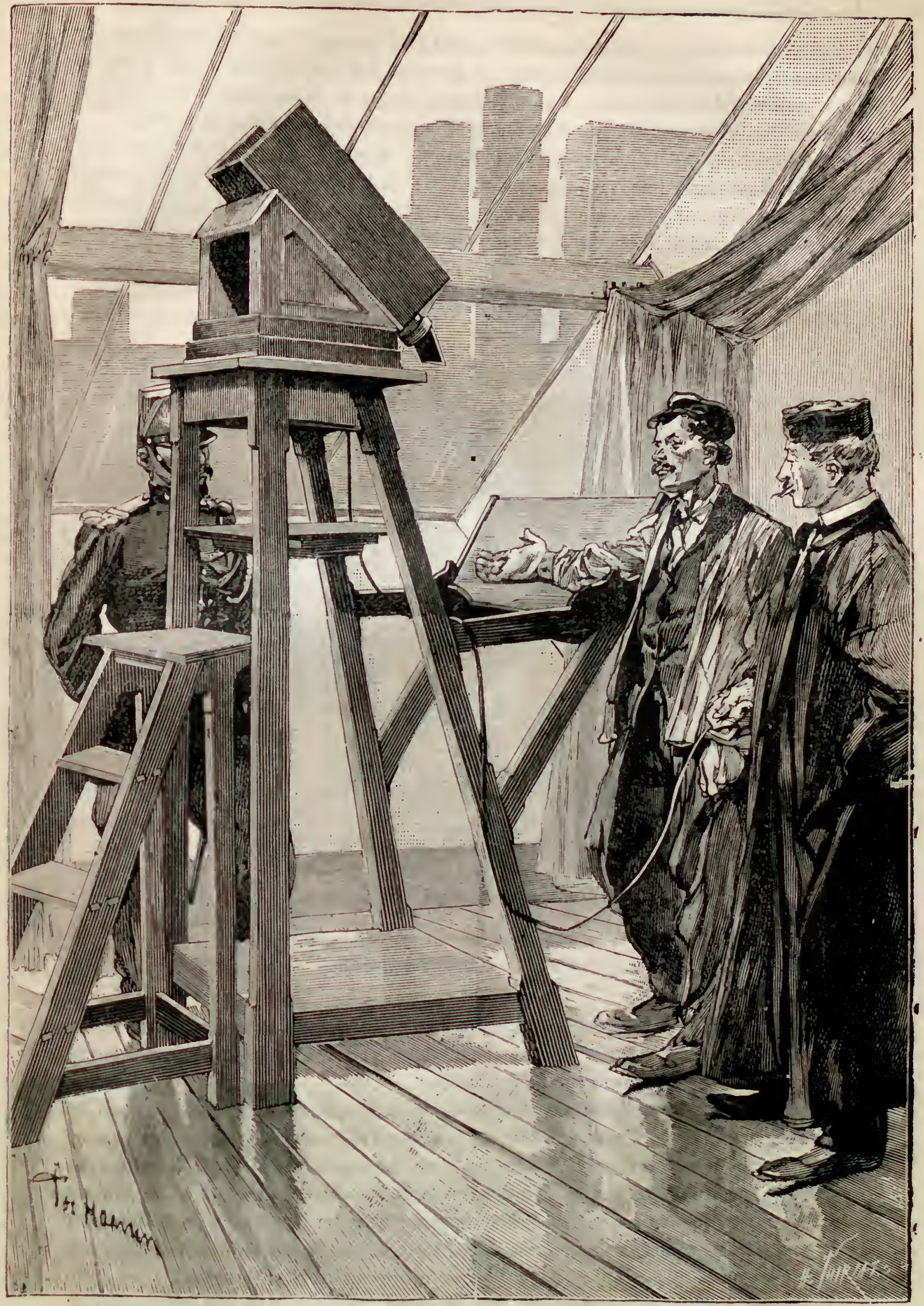

Lir. 70.

Service didextification de la Vilit de Paris. 
à ressorts pour limiter le recul. Le matériel peut être transporté à dos de mulct ou sur roues au moyen d'une limonière; dans le premier cas, un premier mulet porte le canon, un second mulet l'affut, un troisième les roues et la limousine; les caisses a munitions sont portécs deux par deux par un mulet, chacune contient sept coups.

- Les bouches à feu exposées sont également du calibre 80 ; l'une est un canon léger destiné aux pays montagneux, l'autre est le canon réglementaire dans l'armée française. Pour le canon léger, l'affut est en tôle d'acier et muni de sabots d'enrayage, l'avant. train est complètement métallique, lc coffre à munitions contient 18 projectiles dans

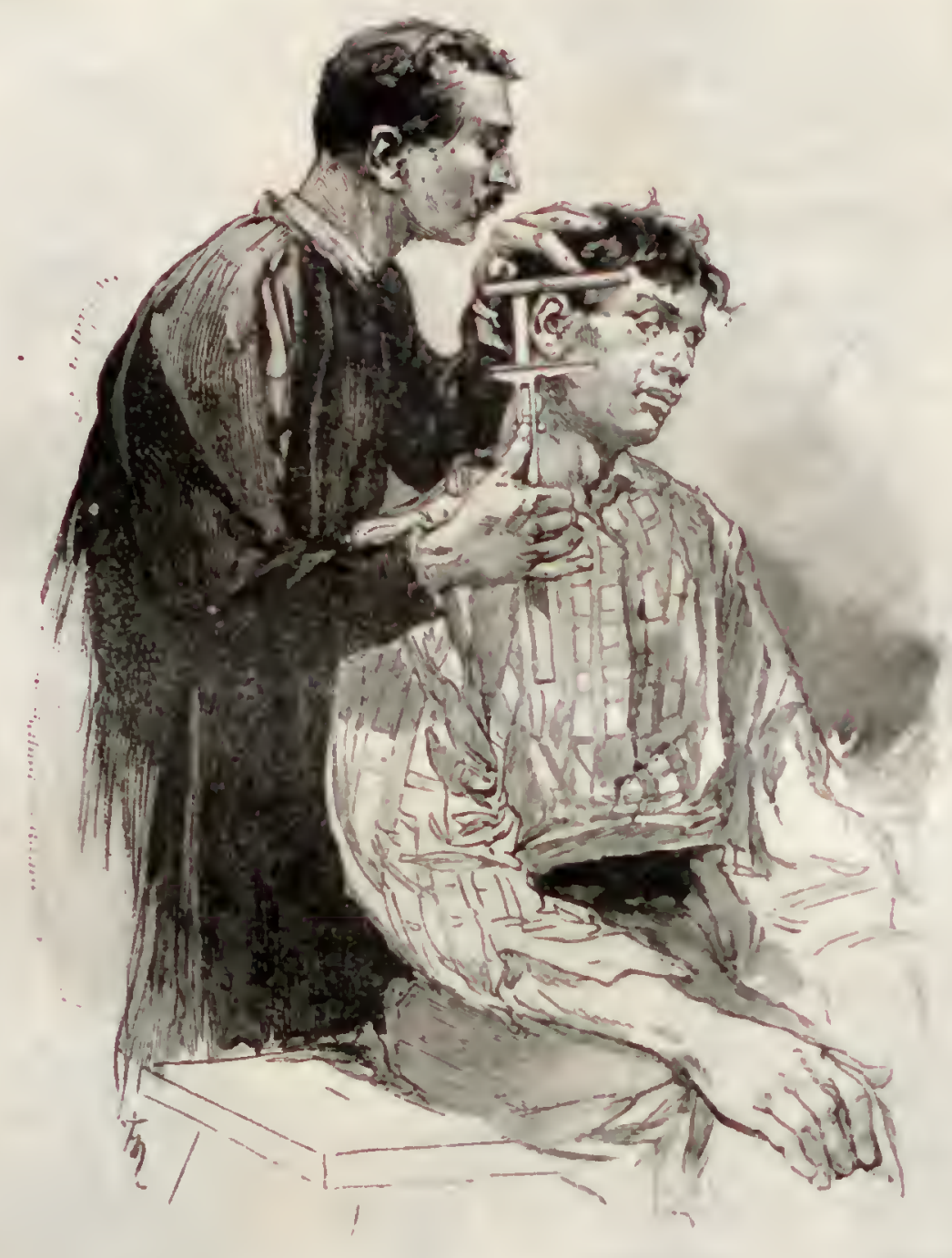

SERVIGE AXTHIOPOMETALUUE DE LA VILLE DE PARIs. - Mesure de loreille.

6 porte-obus et 20 gargousses dans 5 porte-charge en cuir. Larrière-train ne differe de l'avant-train que par le remplacement du timon par une flèche munic d'un porte. roue pour le transport d'une rouc de rechange.

- Un canon de 120 millimètres et un obusier de 155 millimetres. Le canon est du modèle réglementaire en France. Liaffut est égalenent de modèle réglementaire el muni du frein hydraulique; il est entièrement en acier. Lobusier de 155 est la bouche a feu qui est réglementaire en France, sous le nom de canon de 1005 court. L'afrat, tout en acier, ne diffère que légèrement de l'affut réglementaire par la position de l'essieu, par la disposition des roulettes de rentrée en balterie et par la suppression de la fausse flèche : c'est un affut glissant qui ne reçoit de roues que pour le transport.

Un canon de 155 millimètres, sur affut de bord, un mortier de 970 millimètres et 
un canon de 320 millimètres, sur affüt de côtes. Le canon de 15̆̈, destiné à tirer $\grave{a}$ de grandes vitesses, a 35 calibres de longueur. La mise à feu pour les tirs de mer devant ètre effectuée par le pointeur lui-mème, placé derrière la pièce, il est nécessaire d'avoir une étoupille obturatrice; celle employée est du système de Bange, elle est à friction: et l'on agit sur le rugueux au moyen d'un verrou de mise de feu qui sert également d'appareil de sûreté, car il ne peut fonctionner que lorsque la fermeture est complète. L'affùt en acier coulé est à pivot central et à frein hydraulique. Un appareil spécial assure la rentrée en batterie et fixe le corps d'affút dans cette position d'une façon

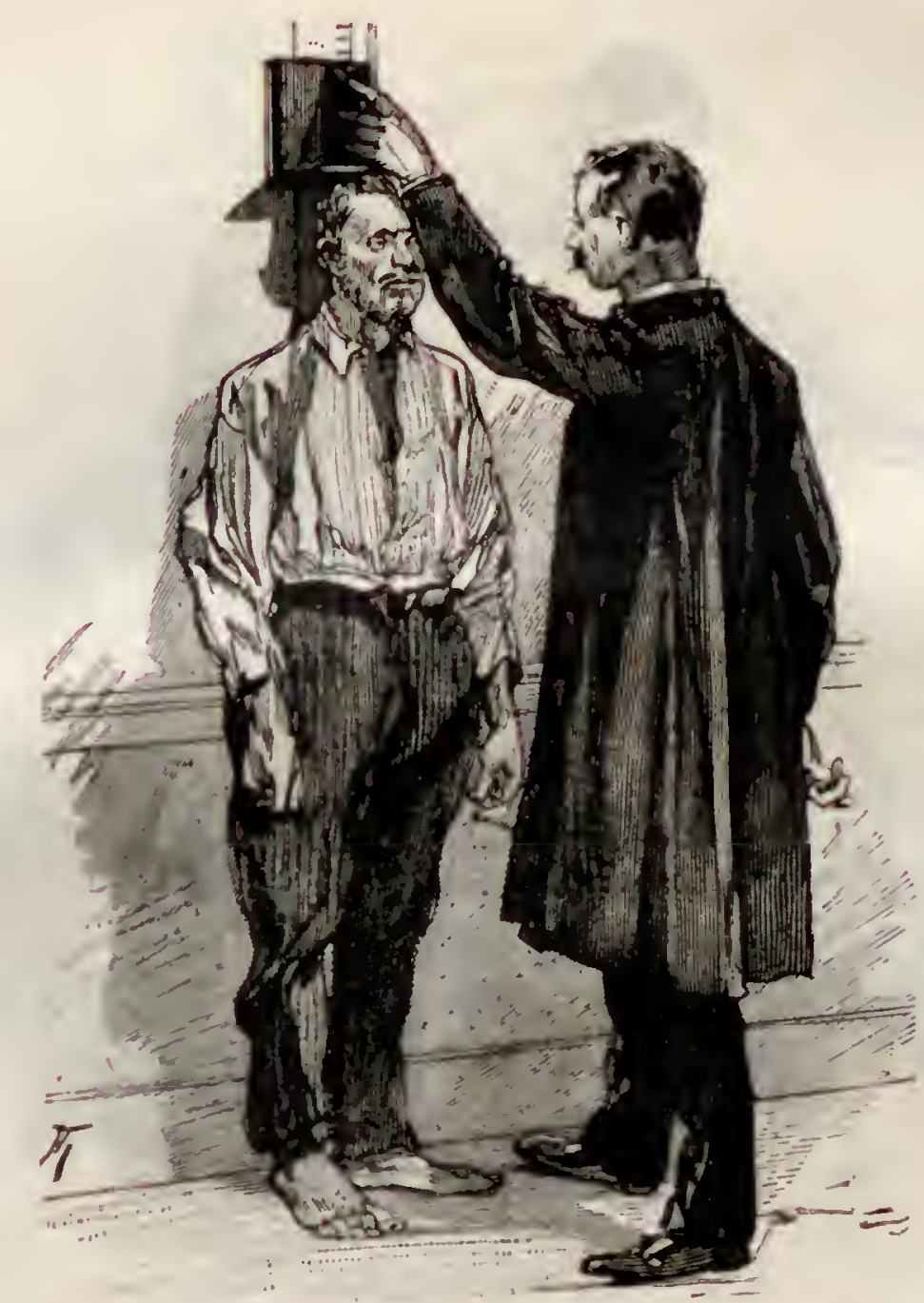

SERVICE ANTHROPOAÉTRIQUE DE LA VILLE DE PARIS. - La toise.

suffisante pour le soustraire à l'influence du roulis. Un masque en tôle d'acier chromé fixé au chassis garantit les servants contre le tir de la mousqueierie et des canonsrevolvers. Le mortier de 270 millimètres est semblable à celui adopté en France pour le service des côtes. L'affat, en acier, est un affut glissant qui ne reçoit de roues que pour les transports. Le canon de 320 millimètres est un canon à grande puissance monté sur un affut de côtes, mais qui pourrait ètre mis à bord d'un narire, en le plaçant sur un affüt différent. Ce canon très léger pour sa grande puissance, est renforcé au moyen du frettage bi-conique du colonel de Bange qui a pour but de faire concourir les frettes à la résistance longitudinale du canon. La mise de feu s'obtient de la mème façon que dans le canon de 15 š. L'affut, tout en acier, est disposé de façon à permettre le tir sous des limites d'angles très étendues et à rendre le pointage, la 
direction très facile : tout le poids de i'équipage étant reporté sur la selletle-pivot, au moment du recul seulement l'arrière du chAssis vient porter sur ses circulaires; les freins hydrauliques s'opposent à la fois au recul et au soulèvement de l'affut.

- Les deux canons exposés sont du mème calibre (57 millimètres); le plus léger est spécialement destiné à servir pour le flanquement des fossés ou à être employé comme canon de campage; le plus lourd tirant à grande vitesse est destiné au lir contre les torpilleurs. La fermeture est du système de M. Engstrom, capitaine de vaisseau de la marine suédoise; la manœuvre en est très facile et nullement fatigante.

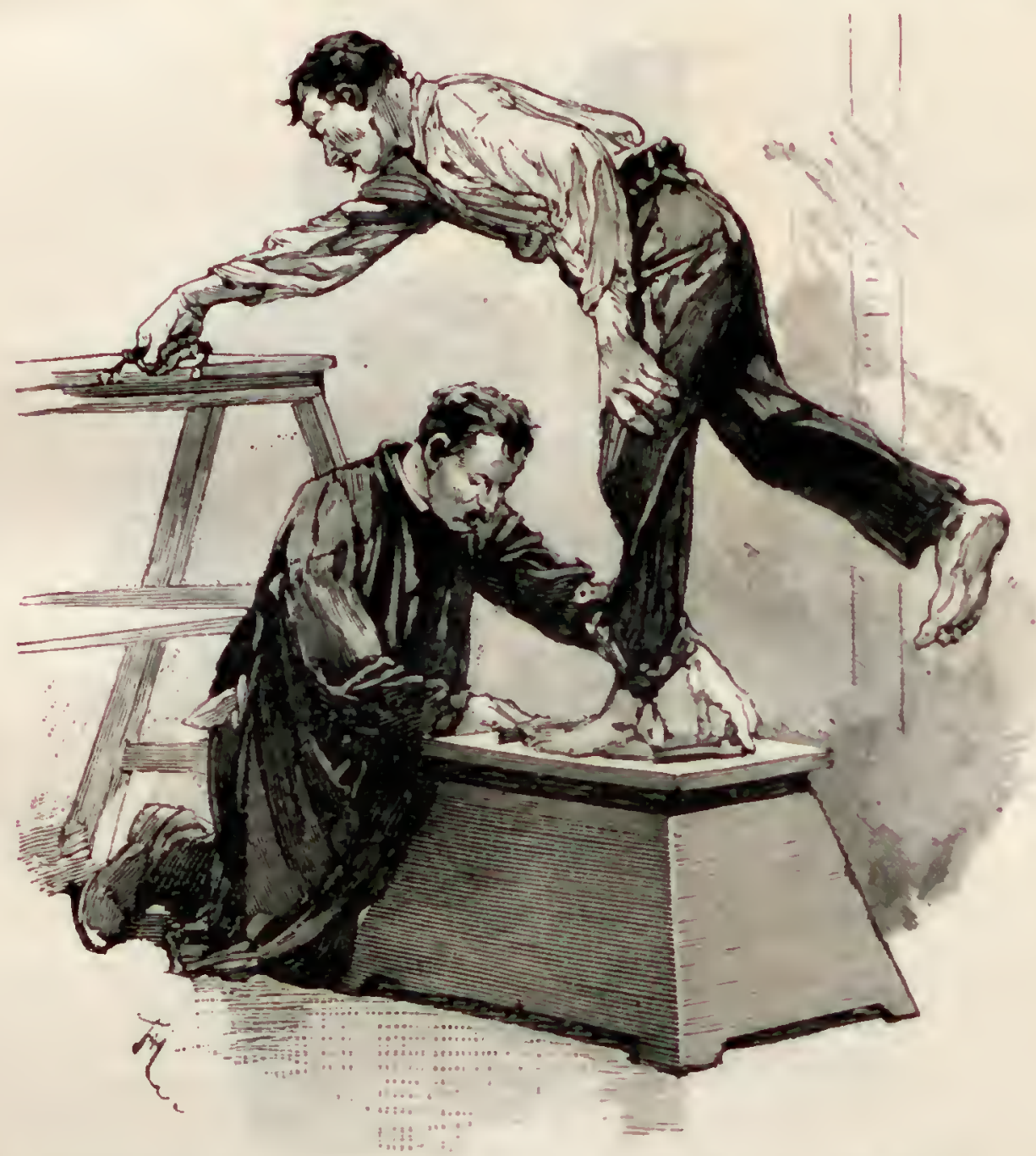

Serife anthroponetrigue de la Ville de Paris.

Mesure du pied.

L'affùt du canon léger est un affut élastique dans lequel des rondelles Belleville absorbent la force vive du recul, qui est très faible; il ne porte pas d'appareil de pointage, le canon étant muni d'une crosse qui sert à tirer à lépaule. L'affìt da canon lourd est à frein hydraulique et à pivot central; le recul est également très faible, ot le pointage s'obtient au moyen d'une crosse fixée à l'affùt.

- Les projectiles (calibre de 57) des canons à tir rapide sont : pour le canon léger l'obus ordinaire et l'obus à balles, pour le canon lourd l'obus ordinaire et l'obus de perforation. L'obus ordinaire est en fonte, il est armé d'une fusée percutante; il en est de même de l'obus à balles. L'obus de perforation, en fonte dure, est armé d'une fusée de culot. Pour le calibre de 80 , les projectiles sont l'obus à balles, en fonte, armé d'une fusée percutante; le shrapnel à enveloppe en tỏle d'acier embouti à balles en ploinb 
durci, séparées par des galettes segmentées en fonte, qui a sa charge dans une grenade en fonte, placée dans l'ogive, et est armé d'une fusée à double effet d'une durée de 13 secondes correspondant à une portée de 4,000 mètres; la boîte à mitraille en tôle de zinc, qui contient des balles en plomb durci, maintenues par du soufre fondu. Pour le calibre de 120, il y a un obus ordinaire et un shrapnel; pour le calibre de 10̃̄, il y a un obus ordinaire en fonte, armé d'une fusée percutante et un projectile d'essai spécial au canon de 35 calibres; pour le calibre de 320 , il n'y a qu'un seul projectile d'essai spiral en fonte pesant 400 kilogrammes. ,

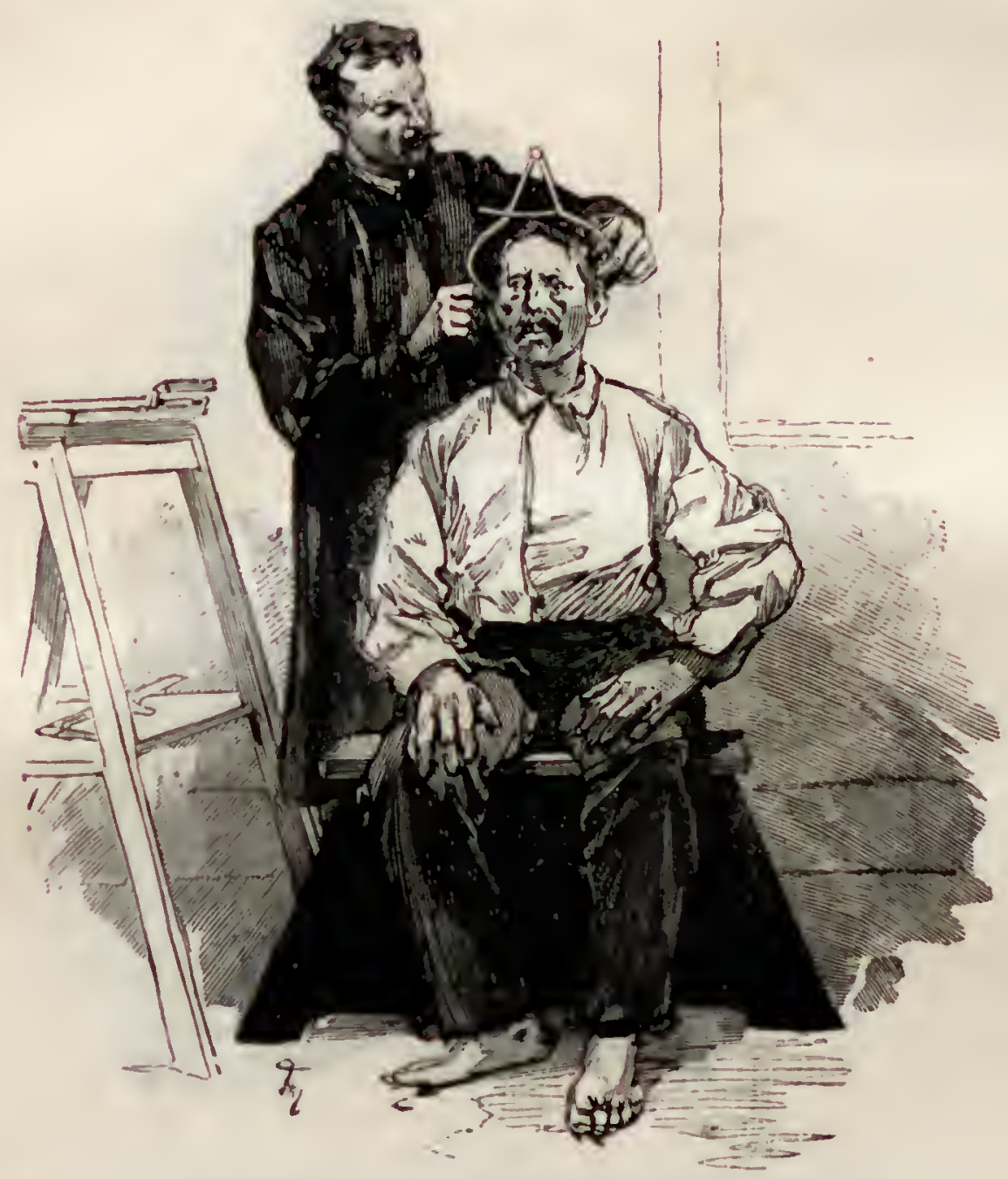

Service axthropométrique de la Ville de Paris. Mesure de la largeur de la téte.

Il faut mentionner aussi une locomotive, système de Bange, dont les roues sont mobiles sur leur fusée, ce qui leur permet de passer dans des courbes de très faible rayon, et l'ascenseur des Fontinettes, le plus grand travail hydraulique construit dans notre pays. Cet appareil, établi près de Saint-Ouen, sur le canal de Neuffossé, fait franchir d un tronçon de canal, avec les bateaux qu'il contient, une chute de plus de 13 inètres. Le canal de Neuffossé relie les ports de Calais, de Gravelines et de Dunkerque au réseau des canaux du Nord, et tous les bateaux venant de nos grands ports du Pas de Calais doivent passer par ce tronçon commun pour se rendre à Lille ou à Paris. C'est précisément sur ce tronçon si chargé que se trouve, au lieu dit cles Fontinettes ", un chapelet de cinq écluses devant lequel les bateaux doivent souvent attendre leur tour de passage pendant cinq ou six jours. L'attention de l'administration 
fut appelée sur un ascenseur pour bateaux qui venait d'etre construit en Angleterre sur le canal de Trent et Mersey à Anderton, et, a la suite d'un rapport de M. l'ingénieur Berton, elle adopta l'ascenseur d'Anderton pour remplacer le second chapelet d'écluses tout d'abord projeté. La Société des anciens lítablissements Caid dressa ellemême les dessins détaillés de tous les oưrages. Si l'on compare les dimensions de l'ascenseur d'Anderton destiné à des |bateaux de 80 tonneaux à celles de l'ascenseur des Fortinettes, qui élève des bateaux de 300 tonneaux, on se rendra compte des immenses difficultés que rencontra la Société des anciens lítablissements Cail.

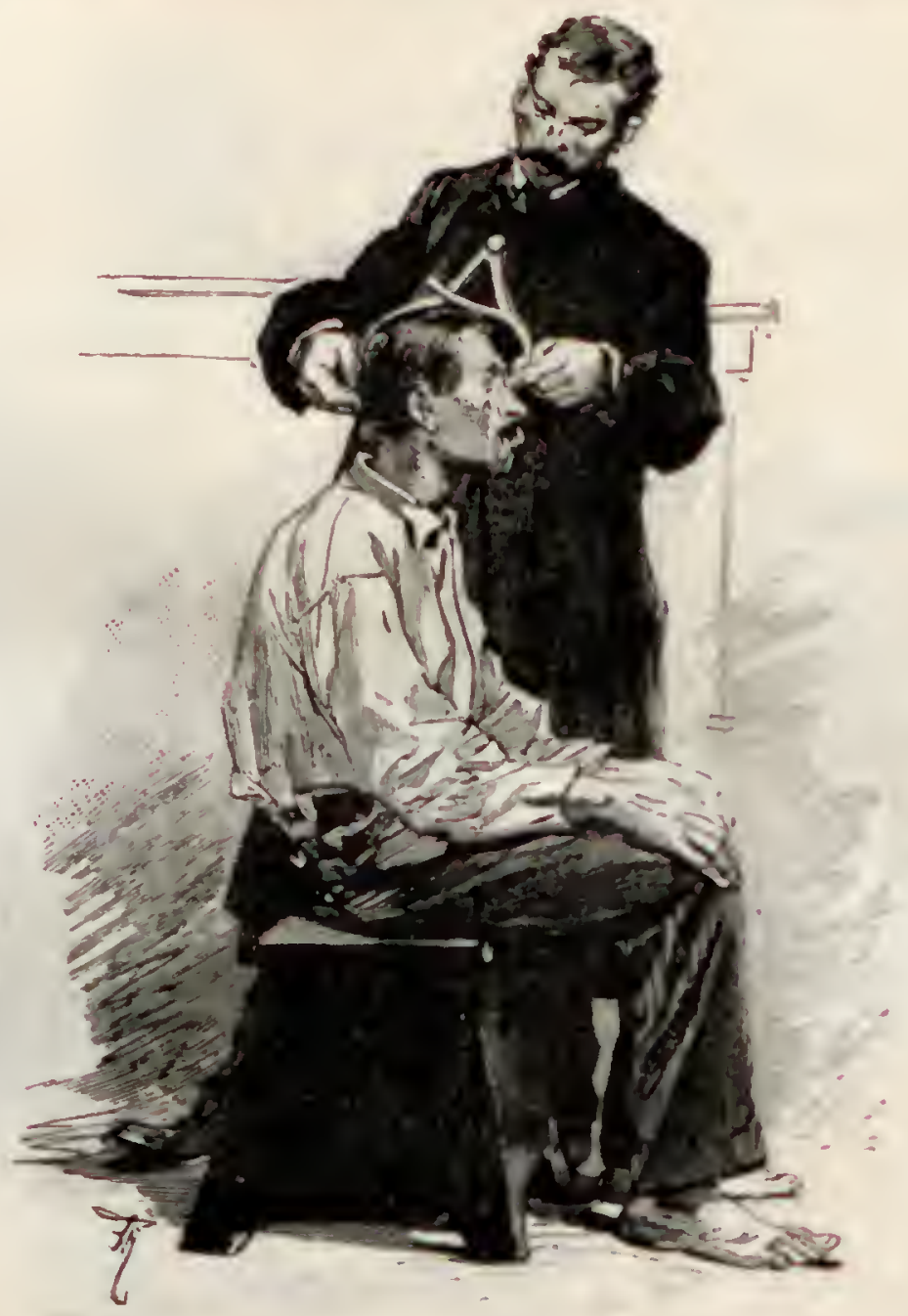

SER VICE ANTHROPOMETIUCF, UE LA VIILE DE PARIS. - Mesure de la longueur de la têle.

L'appareil est essentiellement formé de deux portions de canal en tôle, appelées sas; chacun de ces sas repose en son centre sur la téte d'un piston qui plonge dans un cylindre de presse hydraulique installé au centre d'un puits. Les deux presses comnuniquent par un tuyau muni d'un robinet-vanne permeltant de les isoler ou de les réunir. Le robinet-vanne ouvert, on a une véritable balance hydrostatique. Si l'un des deux sas est plus chargé que l'autre, il descend en forsant le plus léger à monter. Tel est l'appareil dans son ensemble.

La course des presses est égale à la différence de niveau entre les canaux, soit $13^{\mathrm{m}}, 13$. Les sas sont de dimensions suffisantes pour recevoir les plus gros bateaux circulant sur les canaux du Nord; leur longueur est de $\mathbf{4 0}$ metres, leur largeur de $\mathrm{5}^{\mathrm{m}}, 80$ et leur tirant de $2^{\mathrm{m}}, 10$. Le poid d'un sas plein d'eau est de 800 tonnes. C'est donc une masse de 1,600 tonnes qui est en mouvement a chaque manœurre. 
Obsarvez maintenant le fonctionnement de l'appareil. Quand le piston de l'une des presses est en haut, le piston de l'autre au bas de sa course et la vanne du tuyau de communication fermée, le sas placé a l'extrémité du piston sorti de sa presse se trouve au niveau du canal supérieur, et le sas placé à l'extrémité du piston complètement enfoncé dans sa presse se trouve au niveau du canal inférieur. Si l'on introduit un bateau dans chacun des sas qui prolongent en ce moment chacun des canaux et sil'on ferme les portes des sas et des canaux de manière à isoler complètement les sas, rien ne sera troublé dans l'équilibre du système qui restera immobile. Si l'on ouvre alors

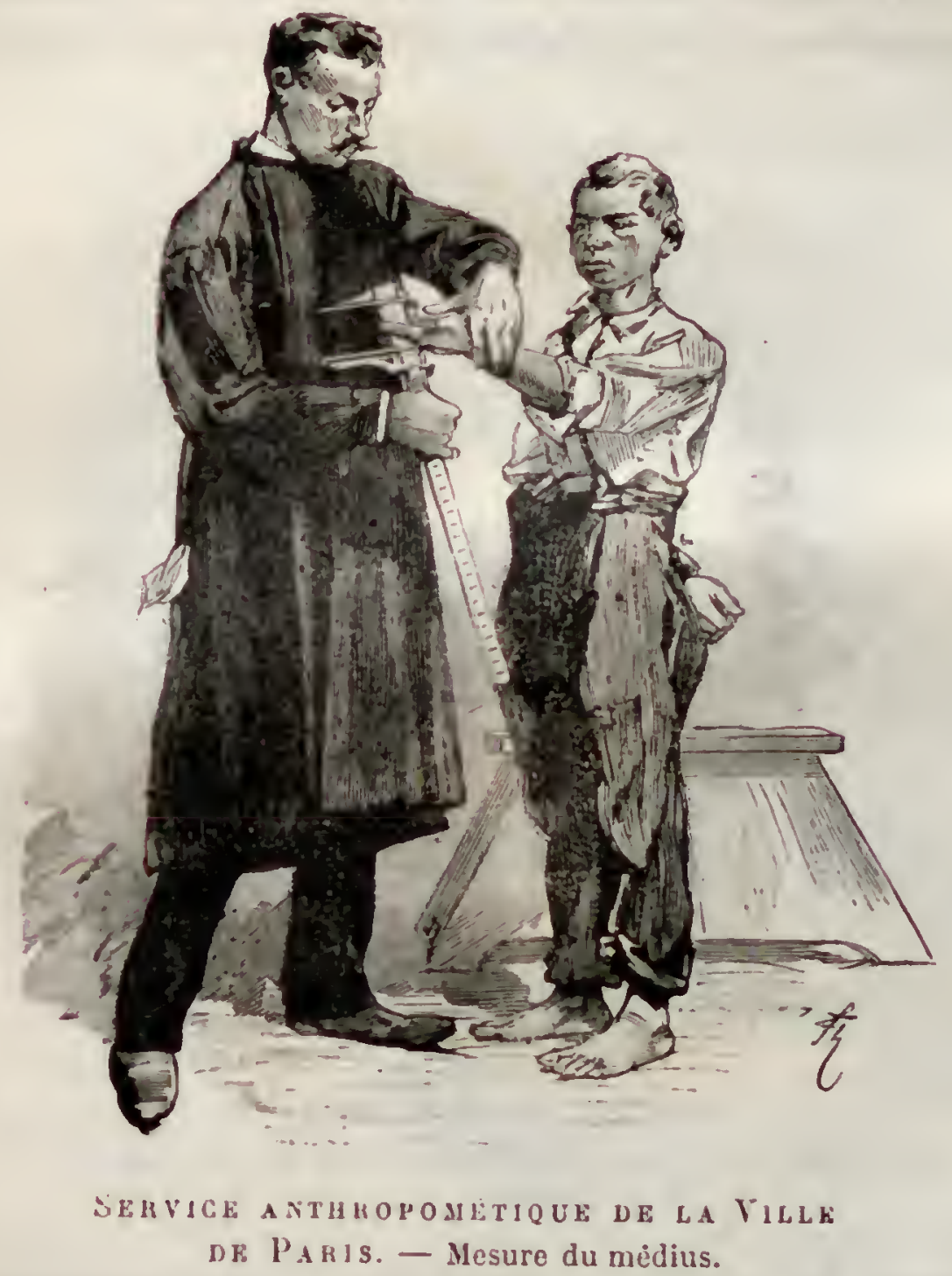

la vanne de communication des deux presses, le sas supérieur descendra tandis que le sas inférieur montera et ce mouvement se produira jusqu'à ce que les deux sas soient au mème niveau. A cet instant les deux sas seront au milieu de leur course et en équilibre sur leurs presses, qui contiennent la mème hauteur d'eau. Pour forcer le sas qui était au niveau du bief supérieur à descendre, au lieu de lui donner la même quantité d'eau qu'au sas inférieur, on l'a surchargé au début d'un poids d'eau égal à celui que. contient une presse. Au lieu de s'arrêter au milieu de sa course, il poursuit donc son mouvement jusqu'd̀ ce qu'il ait atteint le niveau du canal inférieur. Les presses dépassent de plus du double comıne đämension les plus grandes presses existantes: ělles ont 17 mètres de hauteur, $2^{\varpi}, 06$ de diamètre et résistent à une pression intérieure de 27 atmosphères. 
Les exploitations houillères de Mariemont et de Bascoup, en Belgique, ont un pavillon spécial situé près du commissariat général de ce pays. Les concessions contiguës des charbonnières de Mariemont et de Bascoup occupent la partie orientale du bassin du Centre dans le Hainaut et comportent une étendue totale de 4,073 hectares dont 1,663 pour la première et 2,410 pour la seconde.

L'objet de leur exploitation est la belle série des couches du Comble du Nord, reposant sur la base du terrain houiller formée par les phtanites, limitée au nord par les affleurements de ces terrains et au Midi par un grand dérangement qui interrompt brusquement l'allure régulière des couches. La puissance de ces couches varie entre $0^{\mathrm{m}}, 35$ et $\mathbf{1}^{\mathrm{m}}, 70$. Le charbon qu'elles produisent, propre aux divers usages de l'industrie,

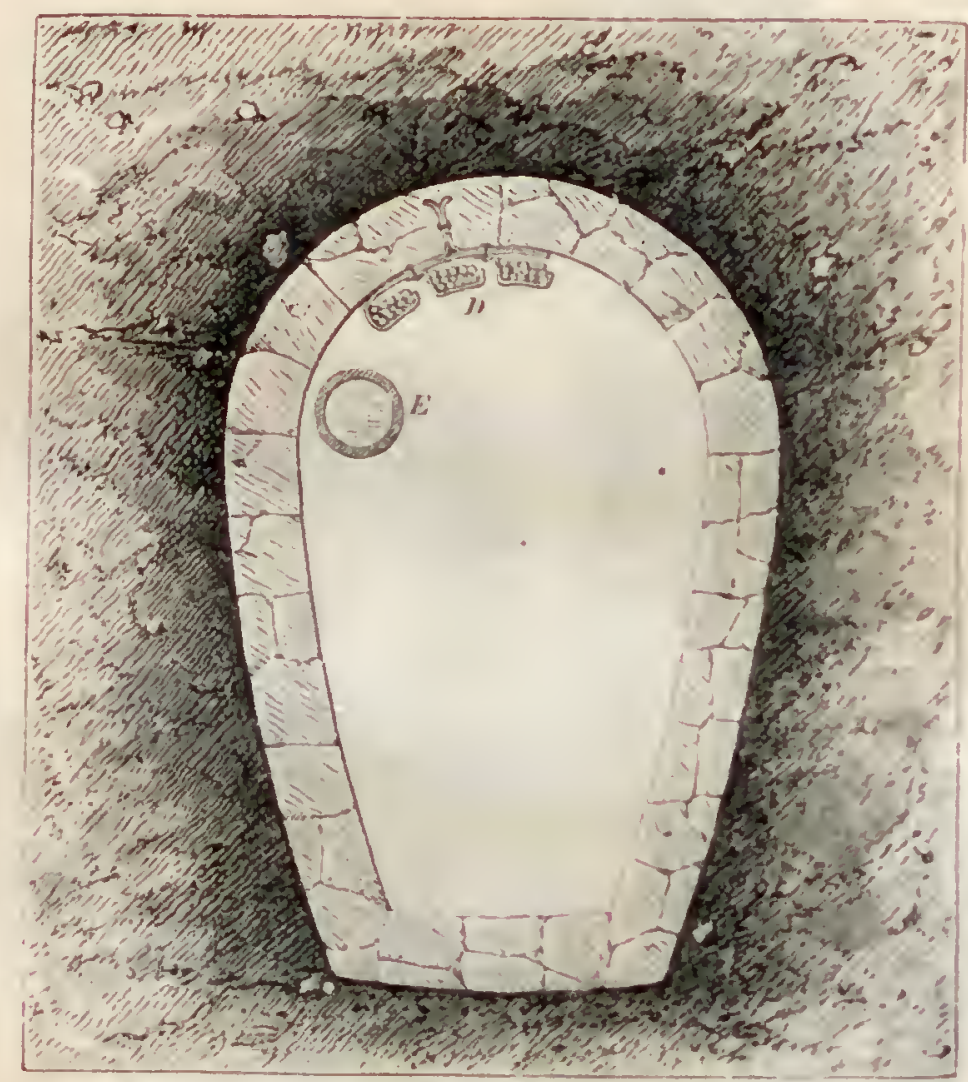

UN ÉGOUT DE PARIS.

$A$, fond de l'egout; D, cábles téléphoniques; E, conduit des eaux de la ville

a acquis une réputation toute spéciale comme combustible de foyers domestiques et de générateurs à vapeur. L'extraction annuelle dépasse un million de tonnes. Elle s'eflectue au moyen de onze puits, dont sept pour Mariemont et quatre pour Bascoup.

Les deux Sociétés ne sont restées étrangères à aucun progrès technique, et elles ont accordé un soin tout spécial aux institutions ouvrières de prévoyance. Nous reviendrons sur ce dernier point quand nous nous occuperons de l'Exposilion d'hygiène et d'assistance (sur l'Esplanade des Invalides).

Pavillons de la Ville de Paris. - Ils s'élèvent entre les deux ailes du Palais des Industries diverses. Les murs extérieurs sont recouverts d'appliques en bois découpé et d'un treillage tout à fait de circonstance, puisque des jardins règnent tout à l'entour en compagnie de statues nombreuses. Au milieu, des platanes superbes.

Voirie et service des égouts, assistance publique, enscignement, orphelinats, 


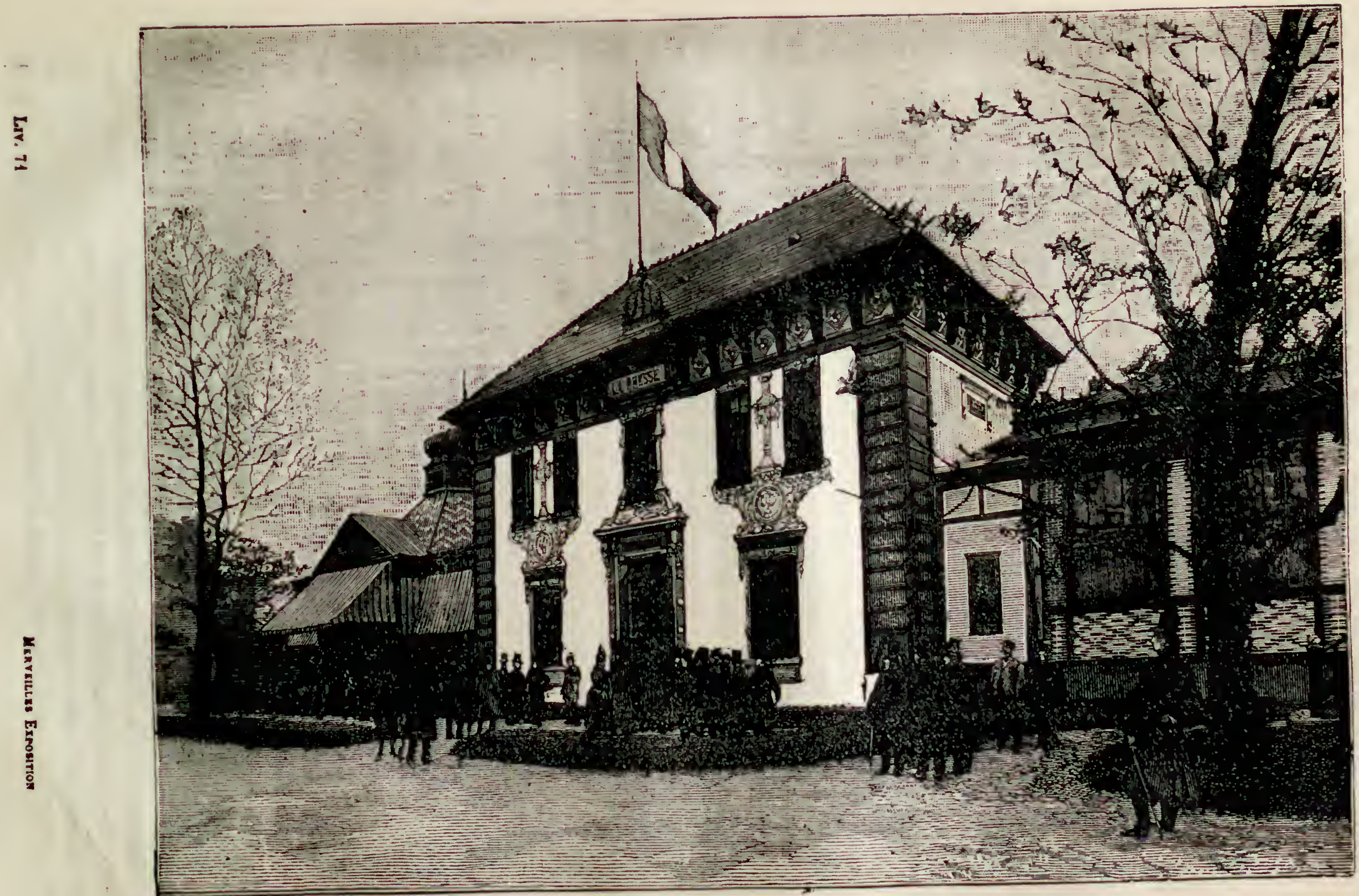

黛

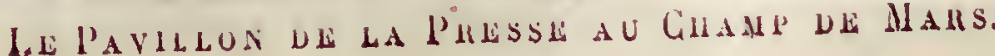


sapeurs-pompiers, tout ce qui de pres ou de loin tonche aux services municipaux a été réuni dans une section spéciale. Dans une autre, a on a réuni d'abord en allas les anciens plans de Paris, au nombre de plus de trente: plan de la cité gauloise, plan de Lutèce, plan sous le règne de Philippe-Auguste, plan sous le règne de Philippe le liel, plan au commencement du règne de Charles $\mathrm{V}$, plan archéologique aux xu et $\mathrm{xv}^{\circ}{ }^{\circ}$ siecles; plan de Munster, plan de G. Braun, plan dit de Tapisseric, plan de Gaignières, plan dit de Bale, plan dit de Saint-Victor, plan de Belleforest, plan de François Cuesnel, plan de Vassalien, plan de Mathieu Brériot, plan de Melchior T'avernier, plan des Colonnelles, plan de G. Boisseau, plan de Goneboust, plan de Bullet-Blondel, plan de Jouvin de Rochefort, plan de Nicolas de Fer, plan de B. Jaillot, plan de Lacaille, plan de l'abbé de la Grive, plan Roussel, plan de Turgot, plan de Vaugondy, plan de Deharme, plan de Jaillot et plan de Verniquet. Dans ces divers plans, le vieux Paris se montre à travers les áges avec ses agrandissements successifs. Cel atlas est un véritable monument historique. M. Ie géomètre en chef a fait ensuite reproduire le plan de Paris en 1789 à l'échelle de 1/3000 et le plan de Paris en 1889) a la mème échelle; ce dernier comprenant les bois de Boulogne et de Vincennes et indipuant les divisions administratives. Un autre plan de Paris, toujonrs à l'échelle de 1/\%000e, indique les percements effectués depuis $\mathbf{1 8 7 1}$ (avenue de l'Opéra, boulevard Saint-Germain, rues du Louvre, Monge, Caulaincourt, avenues de la République, Ledru-Rollin, Parmentier, Niel et Mac-Mahon, etc.), ainsi que les édifices publics élevés depuis cette époçue. II y a aussi un atlas comprenant les plans de Paris par arrondissements, avec les numéros des maisons aux angles des voies. Un plan spécial indique les preements projetés, ainsi que les divisions administratives. Sur un plan à l'échelle de 1/1000 sont indiqués les squares et parcs municipaux, les mairies, les établissements scolaires et universitaires, les édifices des divers cultes, les édifices départementaux, les halles et marchés, les abattoirs, les entrepôts, les thédtres et les fontaines monumentales. Les bois de Boulogne et de Vincennes ont leurs plans spćciaux. Enfin, pour terminer cette partie de l'Exposition de la Ville, mentionnons un allas de la triangulalicin de la capitale.

Nous passons brièvement devant les modeles de reconstruction de la sorljonne, devant des plans de casernes, d'écoles, de cimetieres, en un mot devant ces mille dessins ou moulages qui représentent l'architecture de la ville. jous jetons un coup d'œil sur les peintures de Lansyer et les aquarelles de M. Bourgeois, consacrées à nous conserver le souvenir des vieux quartiers devenus la proic du démolisseur, ct nons arrivons devant la section des Beaux-Arts pour la sculpture, les Premières funerailles de Barrias, l'Avenir de Mathurin Moreau, le Paradis perdu de Gautherin, Une jeune femme de Charpentier, les Blanchisseuses et l'Abreuvoir, de M. P.-A. Baudoin destinés à la mairie d'Arcueil-Cachan; le Mariage, de Glaize, destiné à la mairie du XXje arrondissement; les Saisons, de Séon, pour la mairie de Courbevoie et le Comerre, pour celle du $\mathrm{IV}_{\mathrm{e}}$ arrondissement, la Défense de Pantin en 1814, de Schommer.

Il n'y a pas, à moins d'être instituteurou médecin, un puissant intérèt à contempler les tables basses, casiers, etc., qui constituent le mobilier scolaire des enfants et des adultes; ni à lire les devoirs des élèves, ni a contempler leurs essais en dessin. II y en a, au contraire, un très grand à voir les appareils en usage pour les secours ḋ lonner aux noyés, aux asphyxiés et aux blessés, mais surtont les chimistes qui nous montrent les expériences en usage au laboratoire municipal. L'Inspection de la Boucherie ne 
manque pas d'imprévu ni d'utilité, puisqu’on y apprend à distinguer les os de lapin des os de chat, mais ce qui nous intéresse c'est l'étude des difformités spéciales à certaines professions. - Par exemple, dit Olivier Merson, la main de la buraliste se reconnait aux callosités que produisent le frottement répété des doigts contre le bord du pot à tabac, et le rendement fréquent de la monnaie; la casserole marque d'un durillon inévitable, paralt-il, la première phalange droite du cuisinier, et les mains du chaudronnier, du coupeur en métaux, du bijoutier, du passementier, du ciseleur, de tous ceux, en un mot, qui tiennent un outil et peinent à la besogne, se distinguent par des déformations caractéristiques. C'est le travail qui imprime lui-mènıe son cachet professionnel.

- Au reste, l'inertie n'est pas non plus sans inettre parfois sa signáture sur les mains oisives. N'avons-nous pas tous rencontré des petites maltresses dont les doigls se rebiffent en arrière connme s'ils allaient friser? A glaner et à battre le grain, à rincer la lessire, tantùt rôtis par le soleil, tantot gercés par le froid ou gonflés par la pluie, ces doigts-là se fussent déformés autrement, c'est sủr, mais sans aboutir à un miracle plus extravagant de laideur. ,

La Préfecture de police a exposé un de ses services les plus curieux, celui de l'anthroponétrie, qui a été organisé par M. Bertillon, et qui a pour objet la notation des longueurs osseuses relevées sur un individu : taille, longueur de la main, du pied, longueur et largeur de la tète. Il y a à la Préfecture de police 60,000 photographies de criminels a mine patibulaire. Le fonctionnement du service, le voici tel que l'expose II. Jean Sigaux.

- Nous sommes en présence de 60,000 photographies. La première division qui se présente à l'esprit est celle basée sur la taille, mais la taille peut se inodifier avec les années, elle prète à la tricherie, elle se mesure mal; de plus elle ne varie couramment d'un individu à un autre que de 30 centimètres, d'où il résulte que si nous admettons qu'on ne puisse la mesurer qu'd 3 centimètres près, nous ne pourrions établir que dix groupes différents de tailles : avec la tẻte, au contraire, qui se mesure à 1 millimètre près et qui varie de 30 inillimètres, nous pourrons établir 30 catégories. De plus, le critne, passé vingt ans d'âge, ne se développe plus que trẻs légèrement. Pour ces raisons, c'est la longueur de la tète, de la concavité, de la racine du nez au point le plus saillant de la base occipitale, qui a prévalu comme division primordiale. Nous partagerons donc les 60,000 individus en trois divisions suivant la longueur, pelite, moyenne ou grande, de la tête, et nous n'aurons déjà plus qu'à opérer sur 20,000 photographies-fiches. Mais l'expérience prouve que la largeur de la tète varie indépendamment de sa longueur, et celte différence nous permettra de diviser les 20,000 sujets d'une des séries ci-dessus en trois autres catégories, suivant la largeur, petite, moyenne ou grande, de leur tete, soit un peu plus de 6,000 photographies. La longueur du doigt médius donnera une troisième indication encore plus précise qui divisera à nouveau chacun des paquets de photographies précédents en trois et le réduira à des séries de 2,000 divisées elles-mèmes, d'après la longueur du pied gauche, en trois autres de 600. Ces 600 partagées en trois, suivant la lengueur de la coudée, il ne nous reste plus que 200 pliotographies, réduites a 70 avec la longueur de l'auriculaire, à 25 avec la taille, et à 9 ou 10 avec l'envergure des bras. C'est' ainsi qu'au moyen des coefficients anthropométriques, la collection des 100,000 photographiesfiches peut-etre divisée en groupes d'une dizaine seulement qu'il eșt facile dès lors de 


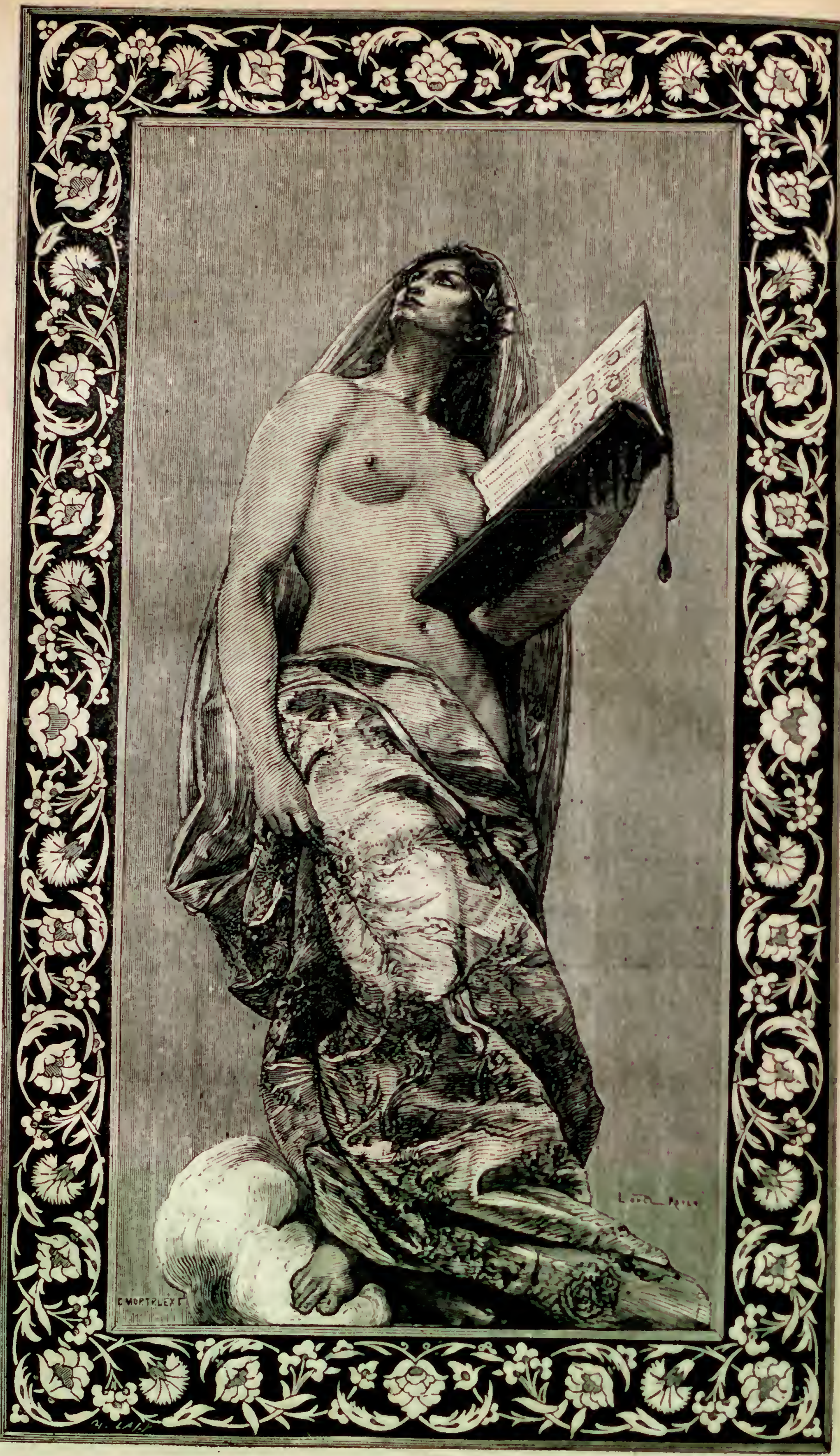

La Pexsér. - Panneau en füence décorant le porche du Pavillon de la Presse. 


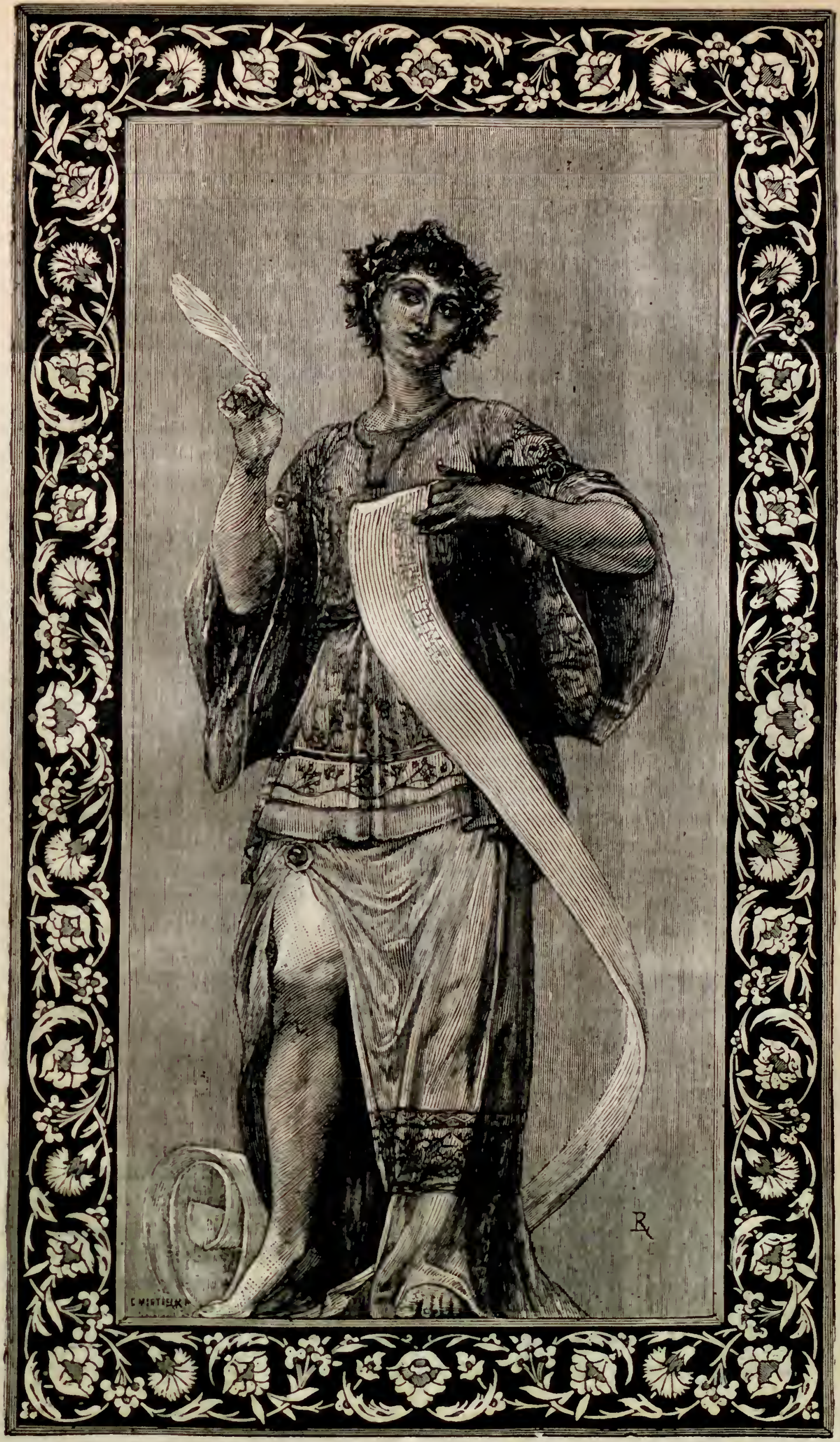

L 1 Caitique. - Panneau en faience décorant le porche du Pavillon de la Presse. 
parcourir rapidement. Supposons donc qu'on arrète un malfaiteur qui cache son nom et que l'on veuille savoir s'il a déjì été mesuré ou pholographié : on prendra la long'ueur de sa tète, et l’on saura déjà dans quelle série de cartons on trouvera son portrait. La largeur de sa tête désignera plus spécialement un de ces cartons. La longueur du doigt médius, du pied, de la taille, l'envergure de ses bras, permettrunt d'arriver à l'endroit précis où doit être rangée cette photographie. "

Le service d'identification, anthropométrie et photographie, fonctionne au dernier étage d'un des pavillons du Palais de Justice. Arrivé dans la salle des gardes, le prévenu, revètu de son pantalon et de sa chemise, est conduit dans la salle d'anthropométrie, où il est mesuré sur toutes les coutures, après quoi, dans une autre salle, où l’on prend sa photographie.

A l'une des extrémités de l'un des pavillons, on a édifié deux maisons se faisant face: la maison salubre et la maison insalubre. Pas d'explication écrite, mais un enseignement par les yeux qui montre bien que la les lois de l'hygiène n'ont pas été suivies; tandis qu'i còté on en a tenu tout le compte possible.

Les modèles en relief des réservoirs de Montmartre, de la prise d’eau d'lvry-surSeine, des Drains de Flacy, du Bassin de captation des sources d'Armenticres, de l'écluse de Saint-Denis, de l'appareil à faucher l'herbe qui pousse au fond du canal de l'Ourcq, etc., nous amènent à l'Exposition du service des caux, lequel assure à la grande ville l'alimentation de la ruc, des maisons, des besoins industriels ou domestiques, au moyen de cinq dérivations (le canal de l’Oureq, l'aqueduc de la Dlınis, l'aqueduc de la Vanne, etc.), des deux puits artésiens de Grenelle et de Passy, de 20 usines élévatoires avec 41 machines et 2? moteurs hydrauliques d'une force de 4,000 chevaux. Les dix-huit réservoirs de distribution, en maçonnerie, ont une capracité de 600,000 mètres cubes, la canalisation unc longueur de 2,000 kilomdtres; les appareils de distribution sont au nombre de 17,000 et on compte 66.000 prises d'eau. L'eau quotidiennement distribuée est en mojenne de 42,000 mètres cubes.

Depuis le passage de M. Belgrand a la direction générale des travaux de la ville de Paris, l'Administration a adopté un double système de canalisation, l'un ponr la vole publique et l'industrie, l'autre pour les habitations privées : les caux de source pour celui-ci, les eaux de la Marne et de l'Ourcq pour le premier. Tous les travanx le la distribution, l'entretien, la surveillance, l'exploitation, rentrent, dit II. P'aul Joamé, dans les attributions du service municipal. La Compagnie générale des kaux, régisseur intéressé de la Ville, n'est autre chose qu'un intermédiaire commercial, cliargé de provoquer les abonnements et d'en encaisser les produits. Cette situation, qui doit durer jusqu'en 1910, est le résultat d'une transaction intervenue en 1860, lors du déplacement de l'enceinte parisienne, entre la Ville qui faisait sa distribution en régie et la compagnie concessionnaire des services d'eau de l'ancienne bantieue. Le service dre l'arrosage des rues s'affectue au moyen de tuyaux nexibles el de lances que l'un raccorde sur les bouches spéciales établies au niveau el derrière les loordures des troltoirs. Dautres bouches, dont l'orifice est dans la borlure mbe, servent au laviz" régulier des caniveaux, qui s'effectue deux fois par jour. Des chasses d'eau sunt fuites dans les dgouts par 800 appareils automatiques. Les promenades sont largement alimentées et de véritables rivières artificielles coulent au bois de Bouloğne et au bois de Vincennes. Les nombreuses fontaines monumentales desservies en eaux d'Ourcq jouent tous les jours; celles qui reçoivent l'eau de Seine tous les dimanches et jours de fète., 
Deux mille cinf cents bouches sont mises à la disposition du service d'incendie, et les particuliers achìtent l'eau à débit mesuré, au moyen du compteur d'eau ou au mojen de la jaugre. La Viile retire plus de six millions, produit net, de la vente de i’indispensable liquide.

L'Exposition des égouts vient ensuite. Le grand égout collecteur est celui d'Asnières (4,600 mètres de longueur), qui va du pont d'Asnières ì la place de la Concorde et reçoit: sur la l'ive droite, le collecteur des coteaux, le collerteur du Centre, le collecteur de la rue de Rivoli, le collecteur des quais de la rive droite, tous les quatre reliés entre eux par l'égout du boulevard Sébastopol; - sur la rive gauche, le grand collecteur de la rive gauche qui part des fortifications pour rejoindre le collecteur général au delà de Levallois-Perret. Le collecteur dit du Nord est celui auquel aboutissent les eaux de Charonne, Ménilmontant, Belleville el Montmartre. Les documents réunis dans le pavillon de la Ville donneront certainement au visiteur l'idée de faire une viaie promenade dans les égouts. La préfecture de la Seine dílivre les autorisations, et on s'installe, au Chatelot, dans de julis wagonnets poussés par les égoutiers. On traverse ainsi le centre de Paris, puis sous la place de la Cuncorde, on s'embarque sur des espèces de radeaux qui vous conduisent jusqu'au-dessous de la Madeleine. C'est une des visites les plus curieuses que l'on puisse faire. Les galeries d'égout renferment les condıites d'eau de la double canalisation, les fils télégraphiques el téléphoniques, les tubes pneumatiques du service des télégraphes, les conduites d'ail comprimé. Des plaques indiquent les rues au-dessous desquelles on passe. On n'est pas peu surpris, durant ce trajet souterrain, de n'ètre nullement incommodé; mais quoi d'étonnant en somme, puisque plus de 800 ouvriers procèdent au curage des collecteurs avec des bateaux, wagonnots et broucttes.

Les eaux journellement charriées par les égouts de Paris sont estimécs ì 300,000 mètres cubes; elles charrient 4,500,000 kilogramınes de matières azotécs. Comme l'action de ces matiches n'est ainsi d'aucun sccours a l'agriculture et que d'autre part le système du - tout à l'égurt, pourrait bien à la longue infecter la Seine, il est question de se débarrasser des matières des eaux d'égouts en les utilisant, après les avoir retirées, soit par la précipitation chimique, soit par la précipitation mécanique, soit par filtration. Un premier essai de fertilisation par les eaux d'égout a été fait dans la plaine de Gennevilliers, oủ les eaux sont amenées par les collecteurs d'Asnières et de Saint-Ouen et débouchent dans des conduites à ciel ouvert. Le succès obtenu avait encouragé la ville à appliquer le mème système dans une partie de la forèt de Saint-Germain, mais les coinmunes intéressées ont fait à ce projet une résistance qui ne se lasse pas.

Ceux qu'intéressent ces grosses questions d'édilité auront dans les Pavillons de la Ville loutes les pièces du procès.

Pavillos de la Presse. - Continuods maintenant notre promenade le long de l'avenue de La Bourdonnais. Nous longeons les batiments de la direction des travaux, nous passons devant la porte Rapp, et nous voici derant l'Exposition collective des Forges du Nord, voisine de la station d'électricité d'Edison. Quelques pas encore, et, touchant un bureau de poste, nous nous trourons au Pavillon de la Presse, face à l'aile gauche du Palais des Beaux-Arts. Construit a pans de bois par M. Vaudoyer, ce pavillon comprend, au rez-de chaussée, une salle de réception, une salle de comité, une salle de lecture et de correspondance, une salle de téléphones et des pièces de service. Au pre- 
mier étage, desservi par un large escalicr, deux salles privées, la bibliothèqque et de nouvelles pièces de service. Deux pavillons attenant au corps de batiment principal en sont le complément obligatoire : le Pavillon des Postes et Télégraphes, communiquant avec celui de la Presse par ses guichets particulicrs, et le restaurant, une grande salle de 17 mètres de long sur $8 \mathrm{~m}, 20$ de large, qui, par des cloisons mobiles, pourra s'agrandir les jours de fète, et à laquelle donne accès une salle des Pas-Perdus établie à niveau, au rez-de-chaussée du pavillon central. La décoration extérieure du Pavillon de la Presse est d'un très bel aspect.

Le porche est décoré de panneaux en faïence, exécutés par la maison G. Mortreux d'après les peintures de M. Lionel Royer.

Aquarellistes et Pastellistes. - La société des Aquarellistes français, dont l'Exposition se trouve un peu plus bas que le Pavillon de la Presse, expose les œuvres de

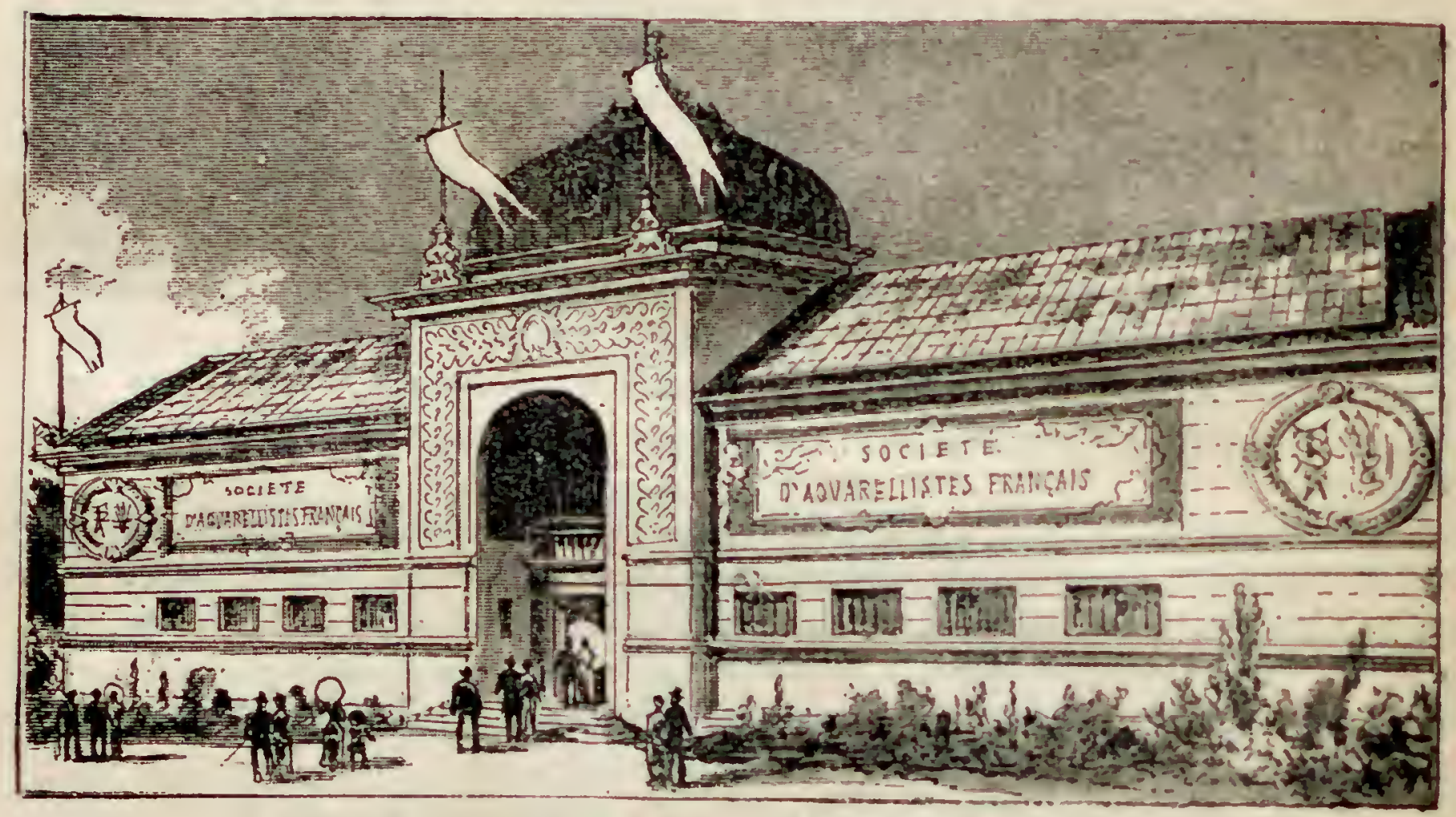

Le Patilion des aquargleistes fraxigais.

MM. Louis-Émile Adam, Jean Béraud, Albert Besnard, Gaston Béthune, Émile Boilvin, John-Lewis Brown, Charles Cazin, Claude Max, Georges Claude, Maurice Courant, Robert de Cuvillon, Charles Delort, Édouard Detaille, Guillaume Dubufe, Ernest Duez, Nicolas Escalier, François-Louis Français, Émile Friant, Victor Gilbert, Lucien Gros, Henri Harpignies, Ferdinand Heilbuth, Georges Janniot, Roger Jourdain, Eugène Lambert, Eugène Lami, Julien Le Blant, Maurice Leloir, Léon Lhermitte, Auguste Loustaunau, Albert Maignan, Adrien Marie, Charles Meissonier, Boutet de Monvel, Eugène Morand, Adrien Moreau, Olivier de Penne, Paul Pujol, Georges Vibert, Jules Worms, Edmond Yon et Ilenri Zubert, $M^{m}$ Madeleine Lemaire et la baronne Nathaniel de Rothschild.

L'aquarelle est en pleine renaissance depuis quelques années, et ce genre a produit des ouvres gracieuses, exquises, très capables de soutenir la comparaison avec les œuvres belges ou anglaises. La socićté des Aquarellistes français a été fondée en 1879 
par.M. Vibert; elle est tout à fait indépendante de l'État, s'alimente par les cotisations de ses membres, et, comme on vient de'le voir par l'énumération des exposants, se recrute à la fois parmi les spécialistes et parmi les peintres. Vous admirerez au Champ de Mars les paysages de $M^{\text {me }}$ la baronne de Rotschhild, les Espagnols de M. Vibert, les fleurs de Mme Lemaire, les petits chats au nez.rose d'Eugène Lami.

La construction est d un étage. Son escalier monumental est orné de peintures de $M^{110}$ Lemaire et divise le pavillon en deux ailes, subdivisées en petits salons. Quatre cent soixante-trois œuvres sont exposcees.

Quel que soil l'intérèt de l'Exposition des aquarellistes, il nous paraft que l'Exposition des pastellistes a quelque chose de plus neuf, mais non de plus cliarmant. Ia société des Pastellistes français, fondée en 1885 sous la présidence de M. Roger Ballı, a réuni dans un coquet pavillon les œuvres de M. Louis-Émile Adam, Jean Bérand, Paul-Albert Besnard, Jacques-Rmile Blanche, John-Lewis Brown, Mwe Marie Cazin. Chàrles-Jean Cazin, Dagnan-Bouveret, Guillaume Dubufe, Ernest Duez, François Flameng, Ulenri Gervex, Paul IJelleu, Ferdinand Heilbuth, Jules-Joseph Lefelvvre, Madeleine Lemaire, Émile Lévy, Léon Lhermitte, Jules-Louis Machard, Albert Mai nan, Frédéric Montenard, Adrien Moreau, Alexandre Nozal, Puvis de Chavannes, Ch.-A. Roll, François Thévenot, James Tissot, Edmond-Charles Yon.

Principauté de monaco. - L'Exposition monégasque ne pouvait qu'ètre réussie, car les produits de ce joyeux coin de l'Europe sont par eux-mèmes intéressants ou beaux d voir. C'est le pays des fleurs et des plantes, des citronniers, des oliviers, des orangers, des eucalyptus, des caroubiers. En effet, sous l'influence d'un climat égal et doux, la flore monégasque prend un développement extraordinairc. Lorsque l'on vient de quitter les rocher's brûlés et arides de la petite Afrique auprès d'lize, I ceil, en se rap. prochant de Monaco, est réjoui par une verdure aussi opulente que variée, qui part du rivage pour s'élever aux deux tiers des montagnes.

Près du rivage, le feuillage du citronnier se marie à celui de l'oranger avivés tous deux par les fleurs et les fruits qui se succèdent presque toute l'année. Puis, ce sont les figuiers tourmentés et les caroubiers. Un peu plus haut.sur les premiersescarpements, parait le feuillage argenté de l'olivier dontle tronc acquiert des dimensions colossales; plus haut encore, le pin, après lequel on, ne voit plus sur la teinte grise de la roche que le vert tendre des touffes d'euphorbe ou la glauque verdure des plantes alpestres. Les rochers qui protègent ou soutiennent Monaco sont tapissés de plantes grasses, qui poussent dans les anfractuosités: Aloès, agaves, et surtout les rejets épincux et charnus du Cactus opuntia, vulgairement appelé raquette ou figuier de Barbarie. Quel grand coloriste que la nature, et comme toutes les couleurs s'harmonisent avec les teintes varićes de la roche et avec l'azur perpétuel du ciel et celui de la mer !

En dehors de l'Exposition très brillante de la flore monégasque, nous trunvons quelques jolies peintures à l'huile, une statue de la Vierge destinée à la cathédrale de Monaco (style roman du $x^{e}{ }^{e}$ siècle). Une partie qui ne manquera pas d'altirer les savants, c'est celle où le prince Albert a groupé les appareils destinés aux recherches zoologiques sous-marines : chaluts, dragues, barres a fauberts, nasses pour grandes profondeurs, filets pélagiques pour la surface, collections d'animaux marins, lacustres et terrestres, résultats des campagnes scientifiques de l'Hiromlelle. Les organisateurs ont réuni une magnifique collection de moulages sigillog! aphiqueș, principalement des 


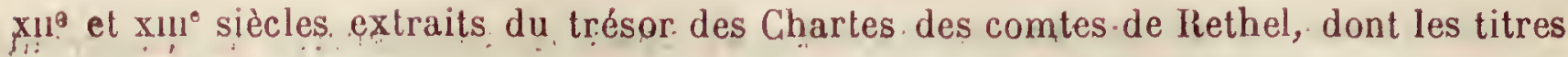
sont conservés aux archives du palais de Monaco. Les dames s'arrêteront de préférence, nous le croyons du moins, devant ces cache-pots et jardinières artistiques, devant les grandes vasques en terre cuite et devant ces multiples eaux de toilette aux qualités surprenantes depuis le dermophilia aux mille fleurs jusqu'aux essences de rose nostrale.

Les pavillóns des pays de Nord; Nonvège et SuĖde. - Nous avons vu le long de l'avenue de Suffren les Pavillons de l'Amérique latine, de l'Orient et de l'extrêmeOrient. Du côté opposé, le long de l'avenue de Suffren sont les pavillons des pays du Nord, au milieu d'arbres et d'arbustes magnifiques, des essences des pays froids : pins, buis, épicéas, ifs, tilleuls et bouleaux.

La Norvège, la Suede, la Finlande et la Russie ont chacune leur chalet dans cet océan de verdure; et ces chalets ont été construits dans les pays mêmes; on les a remontés à Paris morceau par morceau.

Les deux maisonnettes norvégienne et suédoise sont exposées par des sociétés de construction qui exportent des pavillons démontables et transportables. Point n'est besoin à l'acheteur d'architecte ni de maçon. Il suffit de faire venir de Scandinavie une habitation analogue a celle du Champ de Mars, et une équipe débarque avec elle pour la monter. Notez que ces constructions de pin rouge, à deux étages, avec fenêtres, balcons, véranda, perrons, n'ont point l'air de baraquements élevés à la hâte, mais de maisons dont la légèreté est très compatible avec la solidité et le confortable. Les objets exposés sont des fourrures d'ours, de martre zibeline, de loutre, de castor, de renard, etc.; des lames de couteau; des meubles en bois; des liqueurs. Des bijoutiers suédois en costume national forgent et cisèlent sous les yeux du public des bijoux d'or et d'argent, qui sont vendus par des Suédoises, coiffées du petit bonnet en pointe. Les murs de l'atelier de bijouterie sont tendus de vieilles toiles peintes, ornés de broderies, d'appliques, de vieux cuivres et de faiences.

Le vestibule et l'escalier de la inaison suédoise sont agrémentés de peintures murales reproduisant des sites du pays.

Le modèle de ferme ou plutôt de bergerie norvégienne attire beaucoup de curieux. Une seule ouverture sert de fenêtre et de porte, et on y accède par un escalier sommaire. On y a déposé des conserves de lait pur non écrémé, 'qui ont dix-huit mois de date. Du lait de dix-huit mois, c'est beaucoup pour qu'il soit bon. Nous n'avons pas la curiosité d'y gouter.

Deux modèles de petits chalets, de dimension réduite, sont exposés à l'intérieur du Pavillon Norvégien. Ce sont de jolis petits jouets, qui feraient les délices des jeunes visiteurs. La façade est remarquable : au centre, un porche surmonté d'un clocheton à colonnettes et à petites fenètres, et aux deux extrémités, deux clochetons plus petits reliés au centre par des arcades. La corniche et la toiture sont faites d'écailles de bois; l'extérieur est peint en vieux brun.

Rappelons que la Suède est un des quatre pays qui n'ont pas jugé à propos de prendre part àl'Exposition, sans doute parce que le roi de Suède est d'origine française.

L'IZBa RUSSE. - Il n'est personne qui, ayant été à Moscou, n'ait visité le couvent dé Troïtz ou Sughivo-Lavra, situé à 60 verstes de Moscou; deux routes parallèles le: relient à l'ancienne capitale; grand nombre de pèlerins font ce trajet à pied. 
Le chemin de fer de Jaroslaw y mene en moins de trois heures, en traversant une série de stations où se rattachent bien des souvenirs historiques. On franchit d'abord la forêt de Marie(Marino-Rotcha), anciennement le cimetière des étrangers. C'est à que fut inhumé le célèbre explorateur français Tavernier. On s'arrête ensuite a Hotkoff, qui possède un couvent et une des plus anciennes églises de Russie. Sous le règne de Pierre Ier des ouvrières hollandaises apprirent aux sœurs à faire de la den-

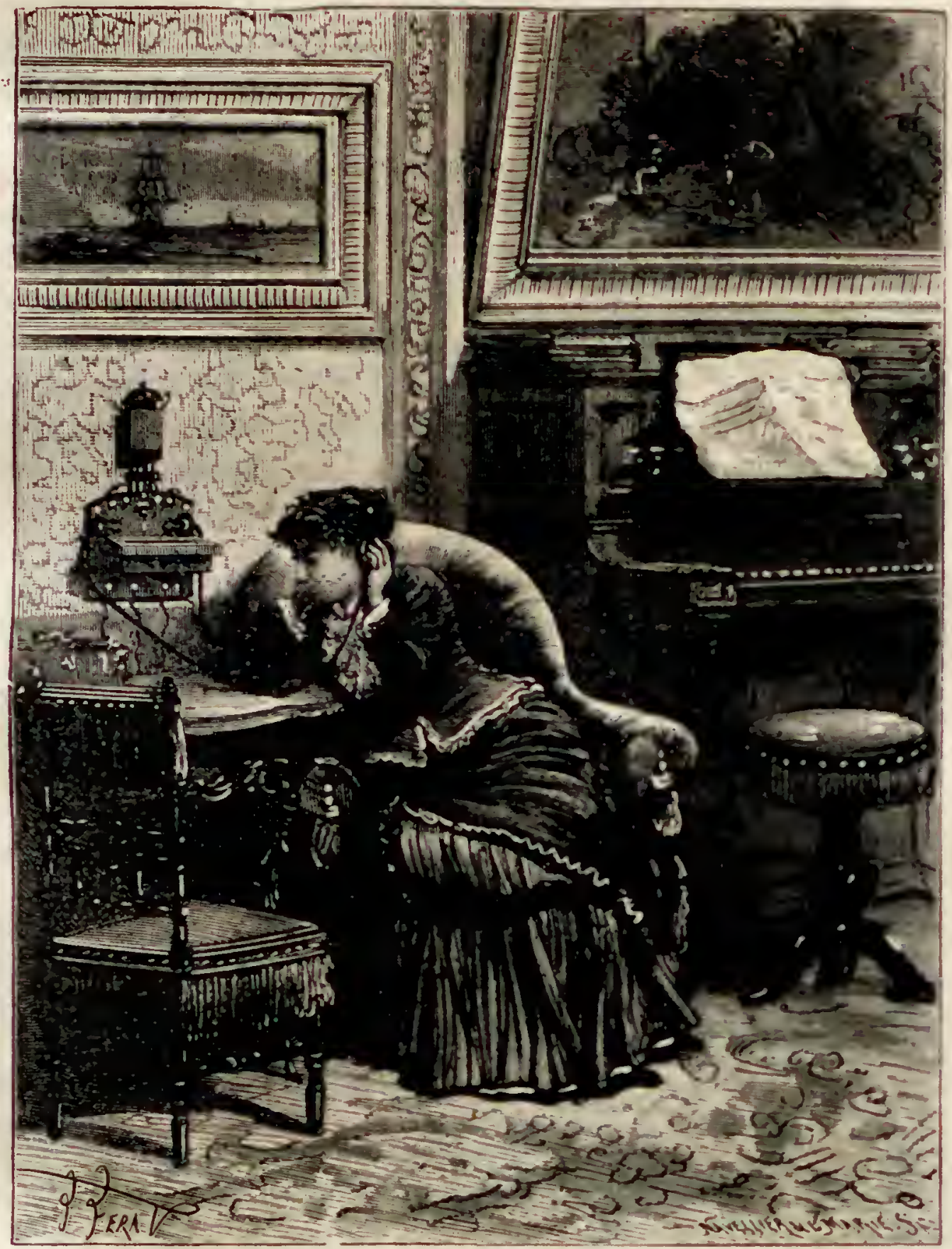

L'OPÉRA A DOMICILE. - Chez soi.

telle; depuis lors, l'ouvrage des religieuses forme le fond principal de ce couvent. C'est là également qu'ont étẻ déposés les restes des parents de saint Serge Radonège, où se passa son enfance, il est situé aux environs.

De l'avis unanime des voyageurs, la vue de Troïtz est magique, non par la somptuosité de ses batisses, mais bien par l'originalité de son aspect; la ville par elle-mème est peu importante, aucune industrie ne s'y est établie; c'est la, pourtant, que des moujiks, artistes sculpteurs sur bois, exécutent arec tant de perfection ces images saintes, ces 
cuillères, ces triptyques dont le fini étonne et que tous les étrangers ne manquent pas de se procurer; car c'est le produit typique de l'endroit qui les attire.

Le couvent, qui domine la ville, est entouré d'un mur coupé par des tourelles, dont les clochetons aux couleurs variées se détachent gracieusement; l'enceinte contient onze églises, dont la Sainte-Trinité est la principale. Elle est fort riche en fresques exécutées par les deux peintreś célèbres, les moines Daniel Tiklon et André Roubleff.

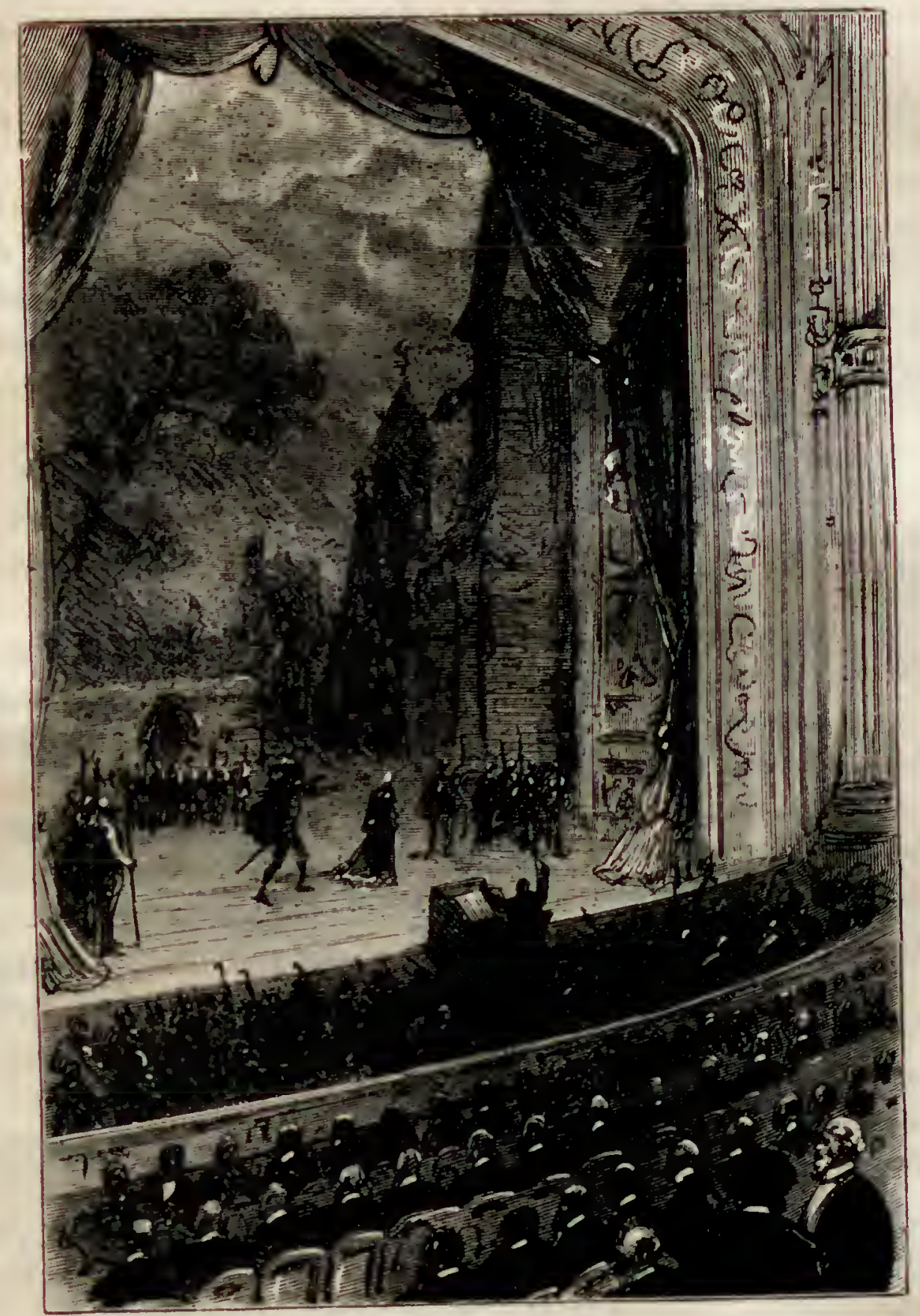

L'OPÉRA A DOMICILE. - Au théảtro.

ce sont eux qui crérent l'école iconographique novgorodiennne. L'École de peinture occupe l'aile des battiments où se trouve l'asile des incurables. Les élèves y sont au nombre de trente; ils sont sous la surveillance d'un moine. La cathédrale de l'Assomption, avec ses cinq grandes coupoles, se trouve au milieu de l'enceinte; elle fut érigée en 1585. Il y a également l'église de Saint-Serge, dont la voûte est d'une architecture spéciale; c'est dans la nef de cette église que les moines prennent leurs repas. Un réfectoire spécial offre gratuitement la nourriture aux pèlerins. Il est curieux de voir aux 
heures des repas, s'abattre une nuée de pigeons qui viennent becqueter le pain dẹ moines.

Il serait trop long d'énumérer ici les richesses que contient le trésor de Troïtz, elles sont incalculables : des croix d'or, des vases sacrés dont se servait saint Sergę; ses habits sacerdotaux sont en grossière étoffe. Le calice dont il se servait était en bois peint en rouge; mais, à côté de ces objets, on rencontre des panagies enrichies de pierres précicuses, dont le rubis du milieu est évalué a plus de vingt mille roubles; une riche collection de mitres entourées de diamants; des plats d'or' et de vermeil, des documents dont la valeur historique est inappréciable. Toutes ces richesses sont des dons faits par tous les empereurs de Russie, car chacun d'eux a voulu prouver que la foi et la religion constituaient une des forces de la Russie.

C'est dans la petite ville de Troïtz que plusieurs familles de moujiks fabríguent ces menus objets en bois, bien connus des étrangers qui font le pèlerinage du couvent de Saint-Serge. Ces moujiks sont de véritables artistes; ils sculptent avec une facilité surprenante des images saintes, des triptyques, des groupes, des cuillères, des couteaux qui sont des petits chefs-d'œuvre d'une perfection et d'une naïveté charmantes. D'autres exécutent des peintures sur bois et sur nacre.

Un Français de Moscou, M. Lutun, a eu l'excellente idée de faire une cxposition de ces menus objets au Champ de Mars. Il a apporté un peu de bien-être dans ces quelques familles qui ont travaillé tout l'hiver et sont très fières d'avoir envoyé leurs produits à Paris.

Cette petite mais intéressante exposition est installée dans une véritable izba russe, toute simple dans sa rusticité, et bien authentique; elle est faite de troncs de sapin superposés, et recouverte de roseaux; une porte avec quelques peintures primitives, quatre petites fenétres dont les volets sont passés à la peinture, deux bancs sur le seuil de la porte, et c'est tout. La chaumière est joliment située dans un des massifs, près de la Tour Eiffel, enfouie sous les bouleaux, les tilleuls et les saules pleureurs.

A l'intérieur, la disposition est toute simple, mais bien pittoresque. Sur les inurs des broderies accrochées, des images saintes et des étagères rustiques chargées de bibelots anciens. Un moujik en costume national travaille et sculpte, avec un simple canif, des petits bas-reliefs d'une extrême finesse. Au fond, sur unle grande table, sont étalées les sculptures, les peintures et mille objets des plus variés. Deux jeunes filles russes font les honneurs de l'izba. Nous trouvons aussi, installée à l'intérieur de la construction, l'exposition collective des paysans de Troitz.

Tout cet ensemble forme un véritahle petit tableau; c'est un des julis coins de l'Exposition.

Pavillon de la Finlande. - Voilà un des pavillons les moins connus et pourtant l'un des plus curieux, l'un des plus instructifs du Champ de Mars. Les industriels finlandais se sont syndiqués pour assurer l'exposition de leur produits. L'agriculture est l'industrie-mère de la Finlande; elle occupe 80 0/0 de la population, et plus de la moitié des terres est aux mains des paysans. Le seigle de Finlande, séché à l'étuve, est de très bonne qualitê, et l'avoine est exportée en Angleterre. L'élève des bestiaux y est florissante, gràce à la richesse du pajs en prairies naturelles et en paturages; les produits de la vacherie forment une ressource considérable. Nais ce sont les bois qui occupent le premier rang dans le commerce de la Finlande. La notice officielle nous apprend. 
que $640 / 0$ de la superficie totale du pays sont couverts de forêts; les produits forestiers qui entrent pour la plus grande part dans l'exportation sont les bois sciés, la poix et le goudron. L'emploi de "la pate de bois pour la fabrication du papier a beaucoup contribué à développer l'industrie de la papeterie, a laquelle de nombreux rapides fournissent à bon marché une énorme force motrice. Nous citerons encore comme importantes les industries des tissus, des cuirs, du fer, de la pierre, du verre, de la distillerie et de la brasserie.

La Société des touristes finlandais, qui se propose de faire mieux connaltre la - Finlande et de faciliter des voyages dans ce pays, a organisé une Exposition dont un document officiel nous expose le détail avec beaucoup de méthode.

Les oljets exposés pirr la Société couvrent une paroi du fond el les partics adjacentes des parois des galeries du Pavillon Finlandais. Le centre de la première est occupé par une carte du grand duché de Finlande; au-dessus est l'écusson finlandais, flanqué de têtes d'ours el de bois d'éläns. Celte carte mérite un instant d'altention.

Les sites les plus intéressants sont facilement accessibles. Sur la carte, des traits rouges marquent les principales lignes du bateau à vapeur. Par ce moyen facile de communication, le voyageur pénétrera au cœur mème du pays. Parti de Stockholn, par exemple, il traversera le labyrinthe de l'archipel du sud et du sud-ouest el arrivera à llelsingfors, capitale du pays, jolie ville, jeune encore, mais en plein et rapide développement; continuant ensuite à l'est jusqu'd Viborg, de ld il se dirigera au nord par le canal de Saîma et arrivera au vaste bassin du Saïma. Il aura le choix entre deux routes : un parcours de $\mathbf{4 . 4 0}$ kilometres à travers de nombreux lacs le conduira à Joensun et à Nurmis, sur la côte nord du lac de Pielis, ou mieux encore il gagnera Kuopio et Idensalmi après une navigation de 380 kilomètres, au cours de laquelle il verra se dérouler à ses yeux la nature idyllique de l'intérieur du pays. Il pourra même parcourir de la mème façon des centaines de kilomètres sur les autres systèmes de lacs, celui du Paijanne; dans le centre celui des environs de Tammerfors el de Tavastehus; dans l'ouest et dans le nord, le lac d'Uléas et ses nombreux embranchements, pour ne pas parler du Ladoga au sud-est, cette mer intérieure dont la côte septentrionale.est bordée d'un archipel d'une romantique beauté.

Les peintures décoratives de la paroi du fond représentent, celle de droite, un paysage de l'archipel cotier, celle de gauche un paysage de l'intérieur du pays.

l.es objets exposés entre ces peintures et la carte centrale, représentent à droite la peche, à gauche la chasse.

$\|$ y a d'abord parmi les premiers, des échantillons de poissons, les plus communs dans les eaux finlandaises, entre autres le saumon et la truite si appréciés de l'amateur de peclie et qui se trouvent en grand nombre dans les rivières et les rapides, l'ombre ou thymalle, commun dans les cours d'eau du centre el du nord, le brochet, le sandre, la lote et la perche abondants partout. On voit aussi là les engins de péche les plus usités dans le pays et qui y sont fabriqués. De l'autre côté, le gibier est représenté par un lièvre en pelage d'hiver et en pelage d'été, des tétras, des lagopèdes, des gílinottes, des oiseaux aquatiques; les uns et les autres abondent et font l'objet d'une exportation assez considérable. Des fusils pour la chasse du phoque et de l'ours donnent une idée des armes dont se servent les paysans finlandais.

Les deux colonnes qui flanquent la carte sont revètues de faisceaux de raqueties avec leurs batons et reliés par des guirlandes de patins. Les raquettes ne sont pas 
seulement un article de sport, c'est un moyen de locomotion souvent indispensable en hiver pour parcourir les campagnes couvertes d'une profonde couche de neige. $A u$ moyen des raqueltes on glisse légèrement à la surface, sans enfoncer. Avec de l'exercice on peut faire ainsi 10 d 14 kilomètres à l'heure; des courses en raquelles de 100 kilomètres en 10 heures ne sont pas rares. Dans les forêts épaisses ou quand la neige est très molle, on se sert avec avantage d'une autre espece de raquettes, plus courtes et plus larges, ressemblant à des raquettes à jouer, et dont on peut voir quelques

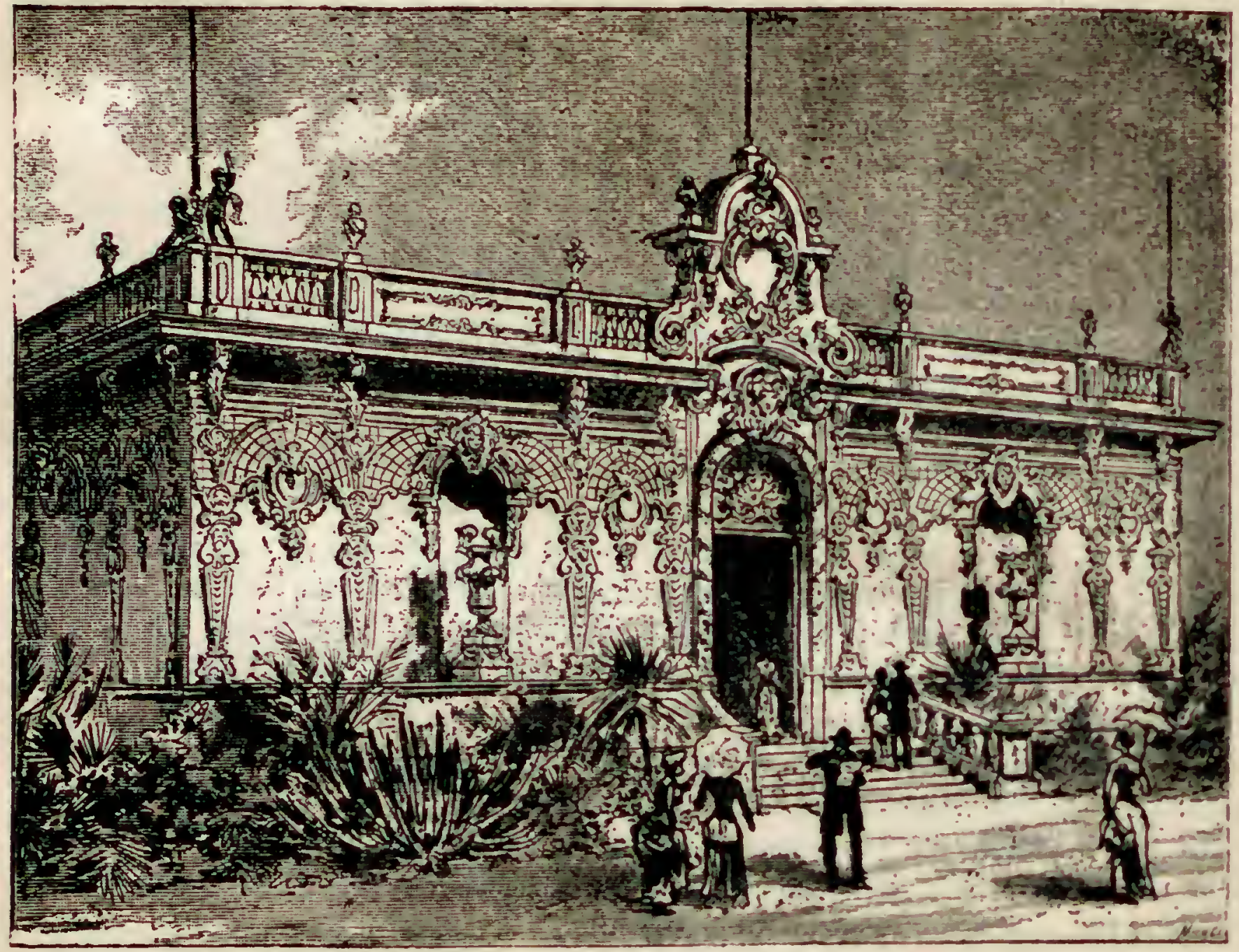

Le Paylllon des Pastellistes francais.

exemplaires exposés au-dessus des engins de peche et de chasse. Les photographies qu'on voit près des colonnes de raquelles représentent des hommes équipés de l'une et de l'autre sorte.

L'Exposition comprend encore d'autres animaux qui font l'objet de la chasse en Finlande. Contre la paroi du fond, tout à gauche on voit outre un renard ordinaire et un glouton, un renard blanc, variété inconnue dans le Midi. Un ours avec ses deux oursons, deux loups, un phoque, un chien lapon, un exemplaire du ires rare renard noir, un renne sauvage en pelage d'été et plusieurs espèces d'oiseaux finlandais, son: dispersés çà et là. A droite de lạ paroi principale et en quelques autres endroits, on a exposé des ouvrages en écorce de bouleau, pour donner quelques échantillons de la manière dont la population des campagnes tire parti de celte matière si commune partout et qui joint la solidité à la légèreté. On trouvera entre autres, un havre-sac err écorce de bouleau. 


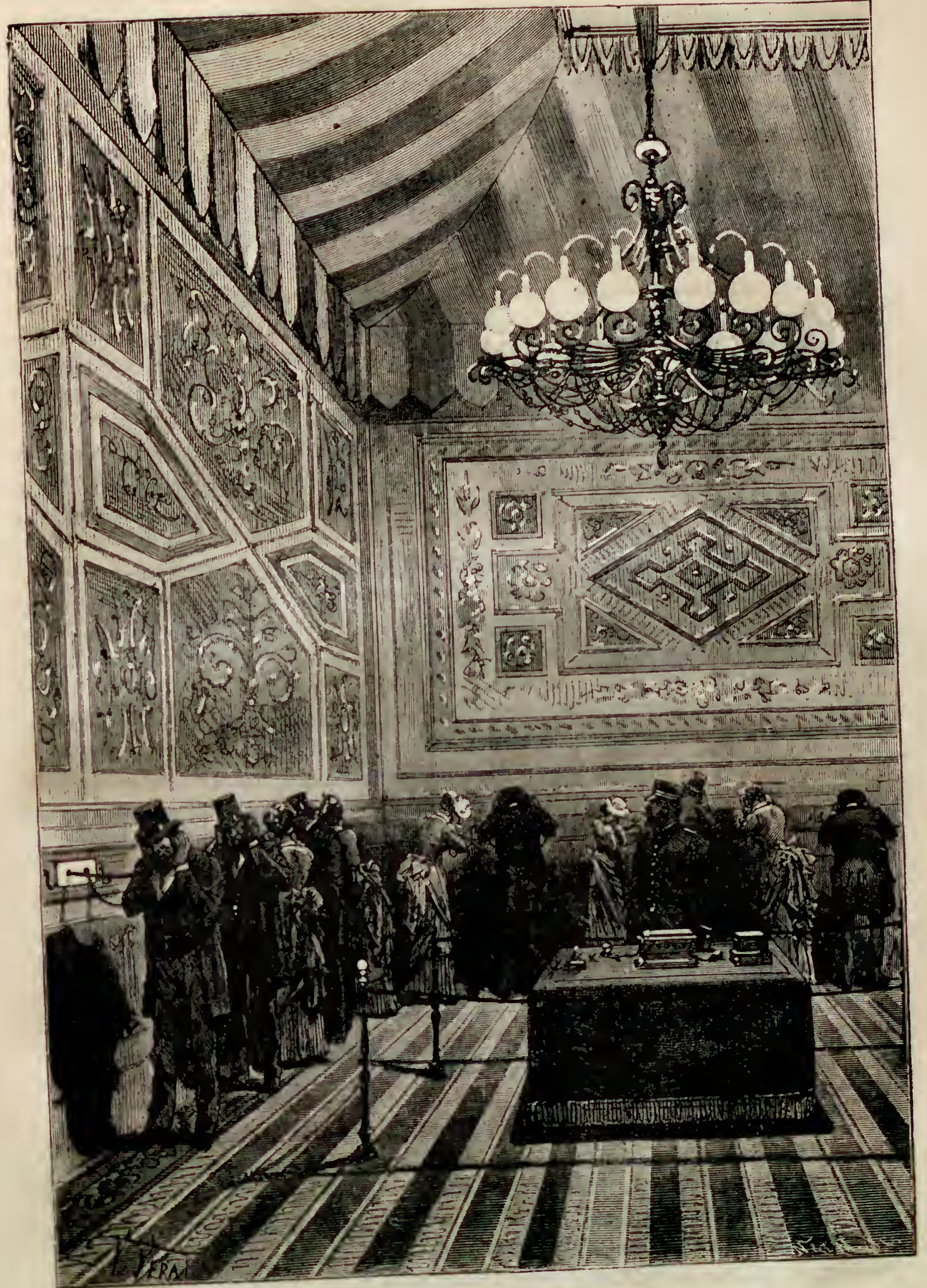

UNB SALL D'AUDITIONS TELEPHONIQUES. 
Les vitrines qui courent le long de la paroi du fond contiennent des photegraphies de tableaux de paysagistes finlandais; celle du milieu, sous la carte, des vues de la capitale Helsingfors : c'est au centre, le port, les principaux édifices publics, le palais du Sénat siège du gouvernement, l'Université, le palais de la Diete, la maison de la No. blesse, etc. Dans une vitrine au milieu de cette collection sont exposés des échantillons de la monnaie courante du grand-duché; on trouvera li une brochure rendant compte de la monnaie finlandaise, des établissements de crédit et de leur situation financière.

Sur la paroi de droite, on aura sur les moyens de communication certains renseignements qui ne sont pas indiqués sur la gl'ande carte centrale. C'est d'ahord une carte d'Europe, avec la Finlande coloriée et les principales voies qui y aboutis. sent, les lignes de chemins de fer, y compris celles de l'intérieur du pays mèmes y sont marquées en noir. Les traits rouges marquent les lignes finlandaises de bateaux d vapeur faisant le service entre la Finlande et les pays étrangers. Des photographies et des plans donnent une idée de l'aménagement de ces bateaux.

A droite de la carte d'Europe est une carte des communications postales. On peut y constater que la poste finlandaise dessert les endroits les plus reculés, jusque sous le 70 e degré de latitude. Le texte qui accompagne celte carte fournit des renseignements sur la poste aux chevaux.

A gauche est une carte des lignes de télégraphes et de téléphones. Un tableau statistique des communications téléphoniques, joint a cette carte, montre combien l'emploi de ce moyen de correspondance est répandu relativement au chiffre de la population, et cela non seulement dans les villes, grandes et petites, mais aussi en quelques endroits dans les campagnes.

Des modèles de voitures et de charrettes donnent une idée des véhicules en usage dans le pays; on trouvera entre autres un de ces tralneaux (grandeur naturelle) auxquels les Lapons attellent leurs rennes. Les embarcations dont se servent les populations riveraines sont représentées par deux modèles de bateaux, l'un de l'archipel de la côte sud, l'autre de l'archipel Ostrobothnien. Il y a aussi un modéle de ces carols au moyen desquels on descend les rapides.

Sur la paroi de gauche on voit, au milieu, une carte orographique de la Finlande, qui fait bien ressortir la nature très accidentée du terrain. A gauche de celle-ci, une carte des productions du sol montre la grande étendue couverte de forêts, les parties colorées en jaune indiquent les champs et les prairies: on voit par lit comment la culture du sol s'est propagée le long des cours d'eau; la carte de droite montre la densite de la population dans les campagnes, celle des villes est indiquée sur la carte générale, par des chiffres pour les plus grandes, et pour les petites, par la grandeur relative du cercle marquant la ville.

Les photographies exposées sur les parois latérales et dans les deux montres tournantes, donnent une idée des paysages finlandais, des types, des costumes et des habitations de la population, et de quelques branches de sport.

On a réuni dans l'une de ces montres des vues de l'extreme nord, de la rone glaciale, des environs de Kajana et d'Uléaborg, de la Finlande occidentale, de Tammerfors, du pittoresque archipel du sud-ouest, enfin de la capitale et de ses er rirons Parmi les photographies de l'extrême nord, on remarque des vues de la rivière d'Ivalo, avec ses lavages d'or, d'où provient l'or d'une partie des pieces de 20 et de $10^{*}$ marcs du grand-duché. D'autres photographies reproduisent différentes scènes 
caractérisant la Laponie et qui ne se retrouvent nulle part dans le reste de la Finlande. C'est en effet une erreur commune a l'étranger que de confondre deux nations parfaitement distinctes, Laponie et Finlande, bien que celle-là fasse parlie de celle-ci. Les vue des environs de Kajana et d'Uléaborg ne peuvent donner au touriste qu'une faible idée des inpressions et des émotions qu'ils trouveraient dans un voyage de l'une à l'autre de ces villes par la voie des rapides.

Les types ethnographiques marquent la différence entre les populations d'origines scandinave el finnoise. On pourra aussi se faire une idée des pittoresques costumes nationaux, bigarrés et originaux, qui se portent encore dans quelques endroits, mais deviennent de plus en plus rares.

Ici encore on voit reproduits les genres de sport les plus goútés en Finlande : par cxcmple, les bateaux du Yacht-Club, du Neyland, le ring et les montagnes russes du club des l'atineurs, à Helsingfors, et des vues représentant des coureurs sur raquettes; ce moyen commode et rapide de locomotion dans un pays couvert de neige pendant une grancle partie de l'année a été mis à profit pour les besoins militaires.

La collection exposée dans la seconde des montres tournantes contient des rues de j̧uelques villes, puis des paysages de la Finlande orientale : Viborg avec son chateau du xü ${ }^{\circ}$ siècle, le canal de Saïma, les rapides d'Imatra, les belles contrées du Saïma et du Ladoga et les non moins pittoresques environs de Nyslott avec le Pinkakaryus, et de Kuapio.

L'Exposition renferme enfin des publications illustrées et des ouvrages se rapportant à la Finlande. On y trouvera entre autres des guides en français et en anglais et une intéressante publication de l'Association des touristes, faite en rue de l'Exposition universelle, sous le titre de . la Finlande et les Finlandais ,. La grande épopée finnoise, le Kalevala, célèbre bien au dela des frontières du pays, est là dans l'original finnois, ainsi que des traductions suédoise, anglaise, russe, allemande, hongroise et une traduction française en prose. - Des publications illustrées fournissent des renseignements sur l'archéologie, l'ethnographie finlandaises. On trouve aussi des reproductions lithographiques de poissons, d'oiseaux, d'œufs d'espèces indigènes en Finlande; puis les feuilles parues jusqu'ici de l'atlas géologique; enfin des cartes marines d'une partie de l'Archipel et une collection des cartes météorologiques.

Une collection de publications rendent compte des conditions politiques, de l'administration et de la situation économique du grand-duché. On y trouve le précis du droit public du grand-duché de Finlande par L. Mechelin, en français et en anglais; un annuaire statistique, des publications du bureau central de statistique, des rapports des administrations centrales, etc.

Les tentures et draperies qui décorent l'Exposition de la Société des touristes sont des produits de l'industrie indigène d'après des dessins finnois. On rencontre de ces dessins un peu partout, en Finlande, et ils different selon les endroits. Ces tissus servent de tentures, de couvertures, de tapis, etc. Il y a plusieurs écoles de tissage, dont quelques-unes sont subventionnées par le gouvernement. Il s'est formé à Helsingfors, une société finlandaise des Amis du travail manuel qui a pour objet de recueillir ces dessins et de les appliquer aux besoins de l'industrie. Les tissus exposés ont été fournis jar cette société et par une école particulière de tissage établie à Gerknäes.

Dernièrement nous avons assisté a l'inauguration du Pavillon Finlandais. Elle a eu lieu à l'cccasion de la visite que venait y faire le Président de la République, M. Carnot, 


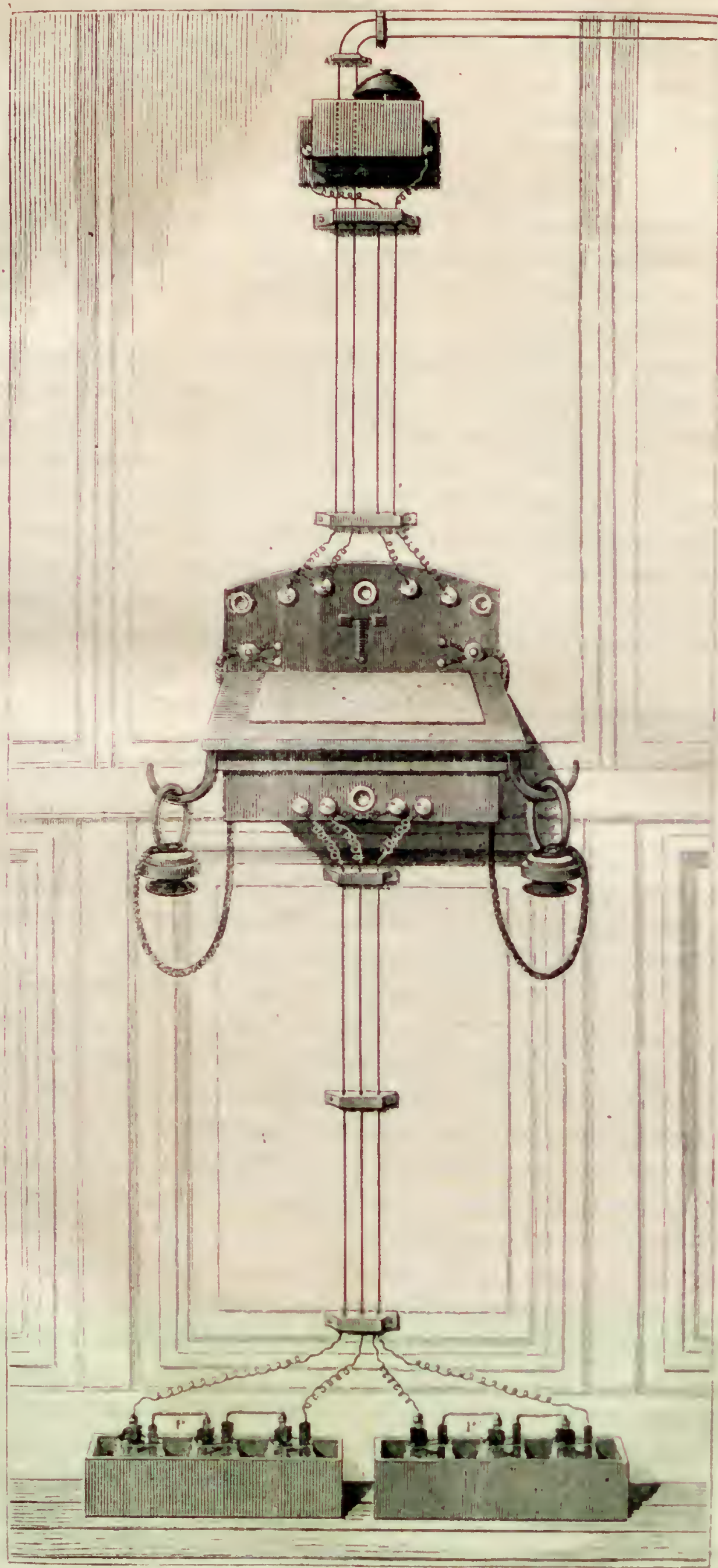

CNSEMBL DU TÉLF́PLONB ADBR-BELL, BN USAGB EX FBANCE. 


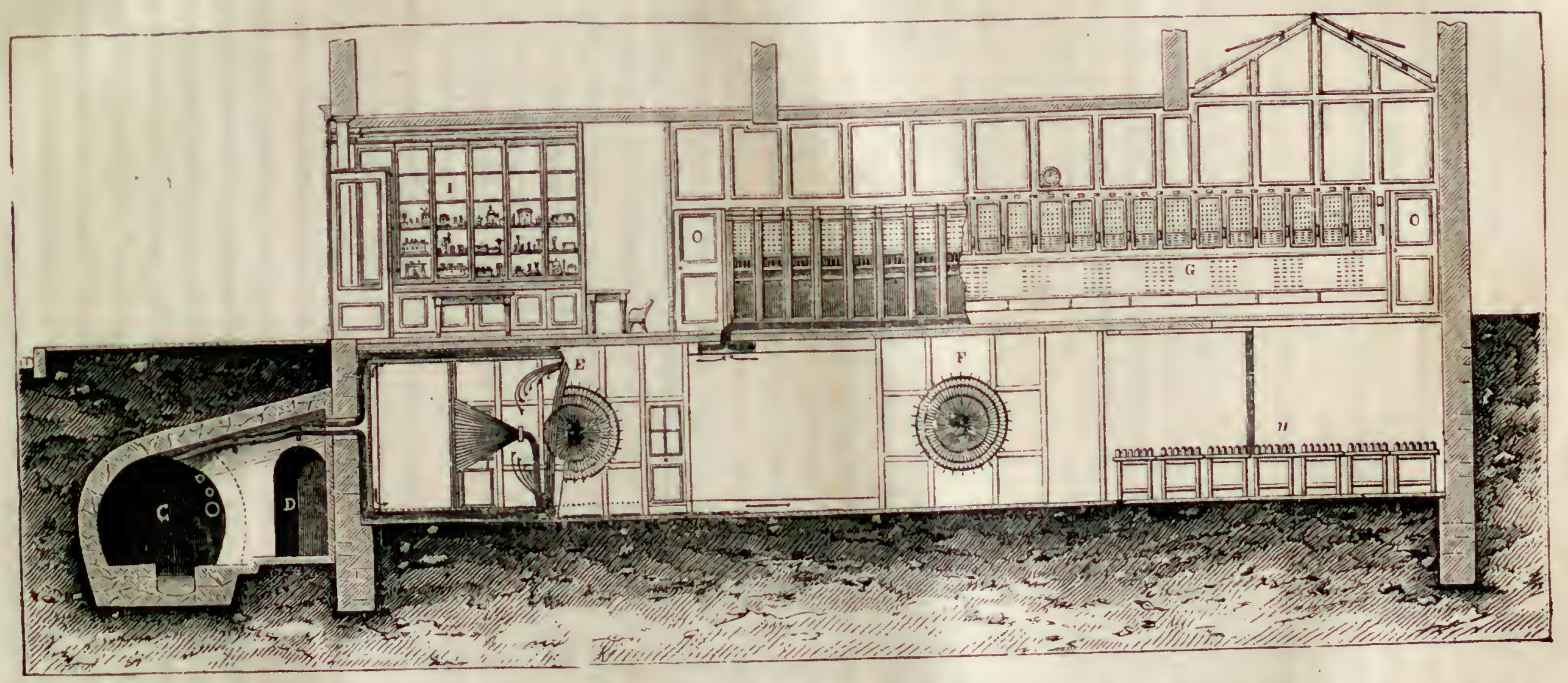



Installation générale du bureau central téléphonique de l'a venue de l'0péra

INSTALLATION GÉNÉRALE DU BUREAU CENTRAL TELEPHONQUE DE LiA C, ègout de l'avenue de l'opéra. - D, branchement d'égout de la maison. - A, entrée de la cave de la maison. - E, rosace de fils à la sortie de la guérite. - ee, ils seéparés et dépouillés de leur enveloppe de plomb, pour pénétrer dans le bureau central. - M, percée du sol au rez-de-chaussée du bureau central, donnant access aux du téseau. - G, salle du bureau. - P, rosace faisant partie do la seconde guérite. - H, salle contenant les tables quí supportent les

bureau, avec les tableaux annonciateurs et les commulateurs. - I, salle de vente. - PP', avenue de l'Opéra. 
grâce à la présence des étudiants finlandais, a été agréablement surpris de la réception toute particulière qui lui a été faite.

Ces étudiants, qui appartiennent à l'Université d'Helsingfors, sont constitués en société chorale, et sont connus en Russie sous le nom de : Chœur des M. M., ce qui signifie le chœur des Muntere Musikanten, ou, en français, des joyeux musiciens. Ils ont donné dernièrement deux concerts dans la grande salle du Trocadéro, et ont tenu leur auditoire sous le charme pendant plusieurs heures. Tour à four tristes, joyeux, ils ont toutes les notes; leur répertoire est des plus variés. D'abord les chants naliotionaux et les marches: " Le chant de Suomi. ,

Puis la fière marche du bataillon de Vasa, le chant populaire finnois, le chant Savalaksien, le chant dalécarlien, la marche de Bjorncborg.

Après, les chants guerriers, les douces romances : Ma bien-aimée est lom, les Etoiles, etc... Un baryton s'est fait entendre à plusieurs reprises, chantant arec un accompagnement du chœur, qui remplaçait l'orchestre, une Sérénade an bord de la mer.

Les Finlandais et leur chef, le docteur G. Pohlstrom, ont du quilter la France sulis. faits de l'accueil qui leur a été fait.

Les talllerues de diamant. - Le diamant l'Impérial, exposé dans la seclion française de joaillerie, est un très gros diamant taillé; mais on a découvert il y aura bientôt un an, dans les mines du Cap, un diamant plus gros encore et qui est exposé au Champ de Mars. Il pèse 228 caiats et demi, et il est jaune, tandis que l'Impérial est hlanc. I.e visiteur qui voudra le voir n'aura qu'à se rendre dans le pavillon du Con p, où sont des machines à laver les graviers diamantifères et où l'on extrait sous les yeux du public le précieux caillou. L'exploitation des diamants a commencé au Cap en $186 \bar{t}$ et elle a déjà à cette époque produit plus de deux millions. Les mines les plus importantes sont celles de Kimberley, du Toit's Pan, de Bultfontcin, cette dernière surtout dont le plan en relief existe au Champ de Mars. Les compagnies de diamants engagent des nègres pour un temps limité, pendant lequel ils sont parqués en un enclos qui communique avec la mine directement, car on se défie des voleurs. Notre confrère, M. Paul Bourde, décrit de la manière suivante les diverses opérations aurquelles on assiste dans le Pavillon du Cap : "Voici, dit-il, la mine évasée comme un entonnoir. Voici la terre bleue qu'on en extrait; dans les morceaux exposés, des diamants bruts scmblables à des lames de verre grossier sont à demi enfouis. Voici les wagonnels sur lesquels la terre se charge. Voici les machines qui les montent au niveau du sol. Voici les Roors sur lesquels cette terre s'étend, car elle est trop dure pour qu'on puisse y trier le diamant sans préparation. On l'étend donc, on l'arrose fréquemment et, sous la double action du soleil et de l'évaporation, elle se délite. Voici la machine où on la lave ensuite.

- Cette machine est une vraie machine qui sera envoyéc au Cap aprd́s l'Lxposition. On a emporté à Paris cent mille kilos de cette terre bleue diamantifère, et chaque jour on en lave un sac sous les yeux du public. Des rateaux circulaires tournent dans une grande cuve en ne laissant tomber au fond que le gravier. Ce gravier est mis sur une table et trié à la main. Quand l'un des trieurs trouve un diamant, il le montre trionphalement aux curieux sur sa planchette de bois. On aura une idée de la fréquence de ces trouvailles par ce fait que le cube des diamants produit par la mine est, en mojenne, If huit-millionième du cube de la terre bleue extraite.

- Ce diamant. réellement découvert devant vous, une taillerie élablie dans le pavillon 
même s'en empare. Les ouvriers qui travaillent, separés des indiscrets par une barrière de vitres, le laveront, le tailleront et le poliront. Et il ira rejoindre, dans la solide cage de fer qui se dresse au milieu du pavillon, le gros diamant jaune qui y brille au milieu d'une grande quantité d'autres de toutes grandeurs.

"L'amas unique de pierres précieuses enfermé sous cette cage semble être considéré par la foule avec plus d'étonnement que de véritable intérêt. On est surpris de se sentir aussi froid devant un trésor d'une pareille valeur. Pour mon compte, les diamants me plaisent dans une belle chevelure ou sur un cou blanc. Je les admire encore, quoique déjà moins, aux vitrines des joailliers dans un objet où ils ont servi à l'expression du sentiment d'un artiste; mais là, en tas, nus et réduits à leurs effets intrinsèques, ils ne m’émeuvent d'aucune façon. Et cependant, quand on lit les contes arabes ou les récits d'un connaisseur comme M. Tavernier, on voit qu'une pierre a ses beautés propres et qu'elle peut échauffer jusqu'à l'enthousiasme l'homme qui la manie. Si la foule passe presque indifférente, c'est sans doute que nous ne savons rien d'instinct; tout sentiment esthétique est le produit d'une culture.

Le Pavillon des diamants du Cap couvre dans l'allée des grandes usines une surface de 400 metres, et une circulation bien entendue permet au visiteur de ne rien perdre de ces travaux successifs. Les petits grenats qui se trouvent en abondance dans les terres lavées sont distribués gratuitement au public. Si donc, lors des précédentes expositions, les ateliers où l'on procédait à la préparation du diamant étaient abondamment visités, il en sera de même, à plus forte raison, cette année, car parmi les divers pavillons disséminés dans les jardins, deux sont occupés par des tailleries de diamants. En effet, à côté du Pavillon du Cap, nous avons à ganche de la Tour Eiffel, près du thédtre des Folies-Parisiennes, une charmante maison hollandaise du $\mathrm{xvI}^{\mathrm{e}}$ siècle, très pure de style, avec une jolie façade en briques, des balcons ajourés, des fenêtres entourées de véritables faïences de Delft. Là est installée la taillerie de diamants hollandaise.

Les dames considereront d'un œil d'envie des eaux merveilleuses, des feux éblouissants; elles ne quitteront qu'à regret les vitrines des frères Boas, d'Amsterdam. L'intérieur du pavillon représente exactement un des ateliers de MM. Boas. Le rez-dechaussée est occupé par les ouvriers, le premier étage sert de salle des séances à la commission néerlandaise.

C'est au rez-de-chaussée que l'on voit dans des vitrines des échantillons de diamants bruts et taillés de toute grosseur et de toute couleur. Tout autour, des photographies représentent l'histoire de l'extraction du diamant, le type de la machine qui fait mouvoir les meules, etc. Une douzaine d'ouvriers nous initient, comme dans le Pavillon du Cap, aux mystères de la taille du diamant. Le bruteur examine le diamant brut; le cliveur le coupe s'il $\mathrm{y}$ a lieu; sur les meules, les lapidaires se livrent à la taille et au polissage.

Pavillon de la Société Elfferl. - Le Pavillon de la Société Eiffel montre au visiteur ce que l'ingénieur de la Tour, aujourd'hui fameuse, a fait avant d'entreprendre le gigantesque travail du Champ de Mars. M. Eiffel a construit surtout des ponts et des viaducs, et dans le monde des ingénieurs sa réputation a été particulièrement établie par le pont du Douro et le viaduc de Garabit dont nous avons des modèles_dans le pavillon.

Le pont Maria-Pia, exécuté pour le passage au-dessus du Douro de la ligne des 
chemins de fer portugais, a une travée centrale de 160 mètres d'ouverture et sa hauteur au-dessus des basses mers est de $61^{\mathrm{m}}, 28$, ce qui a permis d'éviter l'établissement très difficile d'une pile en rivière. Cette travée unique de 160 mètres était la plus grande de toutes celles qui existaient alors, sans en excepter le pont Britannia (140 mètres), le pont hollandais de Kuilembourg ( 150 metres), le grand pont de Saint-Louis sur le Mississipi $\left(158^{m}, 50\right)$. Le pont du Douro a été surpassé depuis, mais il l'a été par M. Eiffel, ingénieur du viaduc de Garabit, construit pour faire franchir la ligne de Marvejols à Neussargues la vallée de la Truyère, à une hauteur maxima de 12:i mètres au-dessus du lit du torrent. La distance horizontale est de 350 mètres. c Le problène,

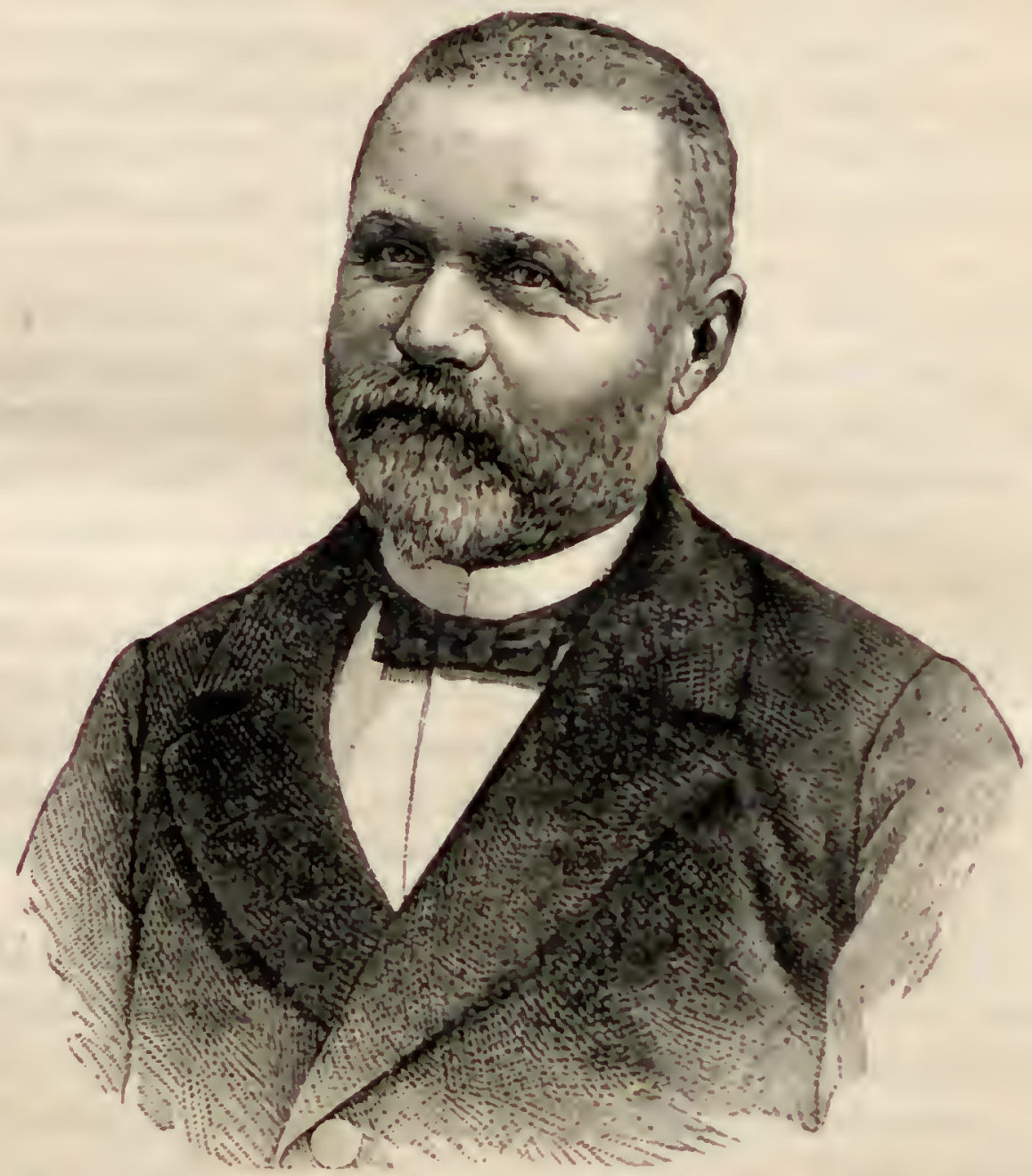

M. Compagros. - Conducteur des travaux de la Tour Fiffel.

dit M. G. Dumont, a été résolu de la façon suivante : la partie la plus profonde de la vallée a été franchie par un arc métallique de 163 mètres de portée et de 52 mètres de flèche, analogue à celui employé au pont du Douro, et l'accès au sommet de cet arc a lieu par des travées métalliques de 52 à 55 mètres de portée, qui reposent sur des piles en métal avec soubassement en maçonnerie. Les piles sont au nombre de 5, dont 4 du côté de Marvejols et une du côté de Neussargues; les soubassenents des piles 4 et 5 supportent les retombées du grand arc. A chacune de ces extrémités le tablier repose sur un petit viaduc en maçonnerie qui y donne accès. Enfin, on a disposé comme points d'appui, outre le sommet de l'arc, deux piles montées sur ce dernier. Ces grandes piles sont à six étages, et leur partie métallique a $61^{m}, 16$ de hauteur. La largeur des grands côtés est de 15 mètres à la base et de 5 mètres au sommet; les petits cotés mesurent 7 mètres à la base et $\mathbf{2}^{\mathrm{m}}, 33$ au sommet. Quant au tablier, c'est une partie droite d 
LES MERVEILLES DE L'EXPOSITION

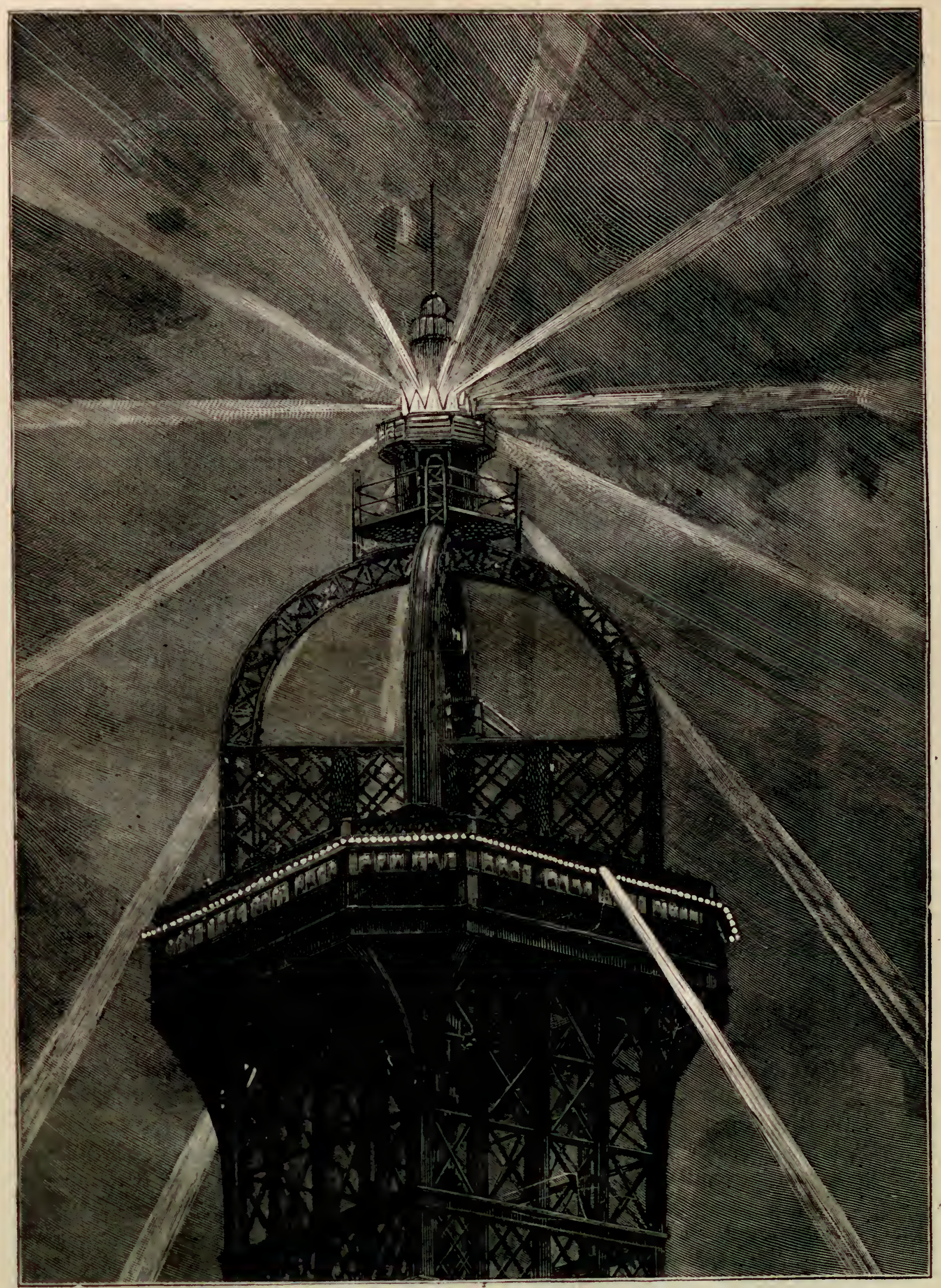

Le Phare électrioue de La Tour Eiffet. 
treillis de $3^{\mathrm{m}}, 16$ de hauteur. Le poids du métal employé est de 3,200,000 kilogrammes.

Pour le lançage, M. Eiffel a imaginé des piles métalliques d'une hauteur de 80 md̀res, élevées par de simples chèvres qu'on remontait au fur et à mesure de l'avancement de la construction. La partie du tablier correspondant à chaque rive a été montée sur des plates-formes de lançage préparées à cet effet, et, à l'aide de chassis à double paroi reposant en leur milieu sur un arc, on a fait glisser le tablier de manière à lui faire parcourir 8 à 10 mètres par lieure.

Pavillox des Téléphoxes. - Depuis une dizaine d'années, les installations téléphoniques se sont développées d'une manière extraordinaire. En Europe, il n'est pas de ville de quelque importance qui aujourd'hui ne soit munie d'un réseau téléphonique, et en France des bureaux ont été installés à Lille, Lyon, Marseille, Nantes, le Ifarre, Bordeaux, Rouen. Peu à peu ce moyen de communication prendra de plus en plus de grands développements, aussi bien entre les villes que dans les villes mèmes, entre simples particuliers. Pour ne citer qu'un exemple, chacun sait que Paris est relié à Bruxelles par une ligne téléphonique. Dans les villes, les abonnés vienneut de plus en plus nombreux, et dans quelques années les propriétaires des maisons nouvellement construites offriront à leurs localaires le téléphone à tous les étages comme l'eau ct le gaz. Dans les villes, outre les postes placés dans les maisons des abonnés, il y a aussi des cabines publiques. Là, moyennant une légère rétribution, chacun peut causer avec un abonné, et règle ses affaires beaucoup plus rapidement, beaucoup plus facilement que par lettres. Ces cabines sont établies a Paris dans tous les bureaux de poste de quelque importance et rendent de très grands services.

Les systèmes employés par les compagnies diffèrent un peu critre eux. Nous allons sommairement indiquer l'installation du réseau téléphonique de Paris, telle que l'a décrite M. Figuier :

S'il ne s'agissail que de mettre en rapports deux personnes dans une ville. le muyen serait tout simple: il suffirait de placer deux téléphones, l'un transmetteur et l'autre receveur, chez l'une et l'autre personne, et de relier les deux locaux par un fil cunvenablement isolé. Mais pour qu'un particulier puisse communiquer avec différentes personnes dans une ville, il faudrait poser des fils allant de chez lui à ses divers correspondants. Poser autant de fils qu'il y a de correspondants, serait ruineux. La criation du bureau central téléphonique est venue résoudre cette immense difficulté. On étalslit un poste général, que l'on nomme bureau central, et auquel aboulissent tous les fils allant chez chaque abonné. L'abonné commence par parler au bureau central et par lui demander de le mettre en rapport avec tel autre abonné, qu'il designe par son nom et par son adresse. Alors un employé du bureau rattache les deux correspondants par un fil de jonction, et de cette manière ceux-ci peuvent se parler tout à leur aise. Quand l'entretien est terminé, l'abonné en prévient le bureau central, qui rétablit les choses en l'état.

Dans une ville d'une population moyenne un bureau central suffit, mais a Paris un seul bureau ne peut suffire, en raison de la longueur de certaines lignes, qui rendraient leur exécution infiniment trop chère. Paris a doncété divisé en quartiers têléplıoniques, ayant chacun son bureau central. Ces quartiers sont : l'Opéra, le Parc Monceau, la Villette, le Chateau-d'Eau, la rue de Lyon, l'avenue des Gobelins, la rue du Bac, la rue Lafayette et la rue Étienne-Marcel. Ces onze bureaux sont reliés entre eux par des ligncs 
qu'on appelle auxiliaires, dont le nombre est réglé sur la fréquence des communications échangées entre eux.

Toutes les lignes auxilaires convergent vers le Bureau central. Les lignes qui font communiquer les bureaux téléphoniques avec les abonnés sont aériennes ou souterraines. A Paris, les fils aériens sont en infime minorité; il n'y a guère plus de 100 kilomètres de fils aériens sur 1,900 kilomètres de réseau et leur disposition diffère peu de celle des fils télégraphiques ordinaires.

Les fils souterrains, dit M. Berthon, sont réunis dans des câbles recouverts de plomb, suspendus à la voûte des égouts. Chaque cable contient quatorze conducteurs, isolés les uns des antres, constituant sept lignes doubles d'abonnés.

Chez les abonnés, l'entrée du poste est très simple. Il n'arrive chez chacun qu'un petit cable sous plomb, contenant deux conducteurs. Il va de l'égout à la maison de l'abonné, par une tranchée souterraine. 11 monte ensuite le long de la façade, ou mieux dans l'intérieur de la cour, si possible, et dans les escaliers de service.

Pour mettre en communication les employés les uns avec les autres, gràce à un Bureau central, on a imaginé des tableaux annonciateurs munis de commutateurs, empruntés à la téléphonie américaine. Lorsque la personne qui veut avertir le Bureau central a appelé, au moyen de sa sonnerie, le courant de la pile étant laissé dans la ligne, l'armature de l'électro-aimant de chacun des numéros du tableau annonciateur est attirée et déclanche le disque. Au-dessus du disque et en communication avec la sonnerie, est une bande de cuivre, bouclée, sur laquelle tombe ce disque. Le contact métallique étant ainsi établi, le numéro apparaît, et la sonnerie retentit, jusqu'au moment où l'employé peut remettre le disque dans sa position primitive.

Au-dessous du tableau annonciateur'se trouvent les commutateurs.

Quel que soit le système de commutateurs que l'on emploie, il se réduit toujours à deux chevilles de bois, attachées à un cordon mobile, qui sert à mettre en communication les deux points de chaque tableau auxquels viennent aboutir les lignes des abonnés.

Supposons que l'abonné no 1 ait demandé la communication avec l'abonné no 1 \%̆. L'employé muni d'un téléphone transmetteur et d'un récepteur, enfonce dans les $n^{\text {os }} 1$ et 13 du tableau les deux branches de deux cordons flexibles communiquant avec les lignes de chacun des deux abonnés. Il en résulte que les lignes des deux abonnés n'en forment plus qu'une seule, et qu'ils peuvent entrer en communication.

Quand l'entrelien est terminé, l'un des abonnés en donne avis au Bureau central, et le mène employé replace les chevilles des cordons à leur place dans le tableau.

Le service est fait, au Bureau central de l'avenue de l'Opéra, par trente-trois jeunes filles, distribuées dans deux bureaux contigus, le nombre correspondant aux besoins du service de chaque bureau, l'un étant, en général, plus occupé que l'autre, à certaines heures, comme au moment de la Bourse.

Un ordre parfait règne dans les bureaux. Les consignes sont même très sévères, en ce qui concerne l'accès du public. On ne peut pénétrer dans le bureau qu'avec une autorisation spéciale, et une fois admis dans ce gynécée du travail et de l'ordre, on est reçu par la directrice, dans une petite salle, complètement séparée du bureau.

II n'existe pas dans nos grandes villes de France de réseau d'égouts, offrant comme à Paris des facilités toutes particulières pour l'établissement des fils conducteurs des courants téléphoniques. La téléphonie, dans les villes de province, fait donc 


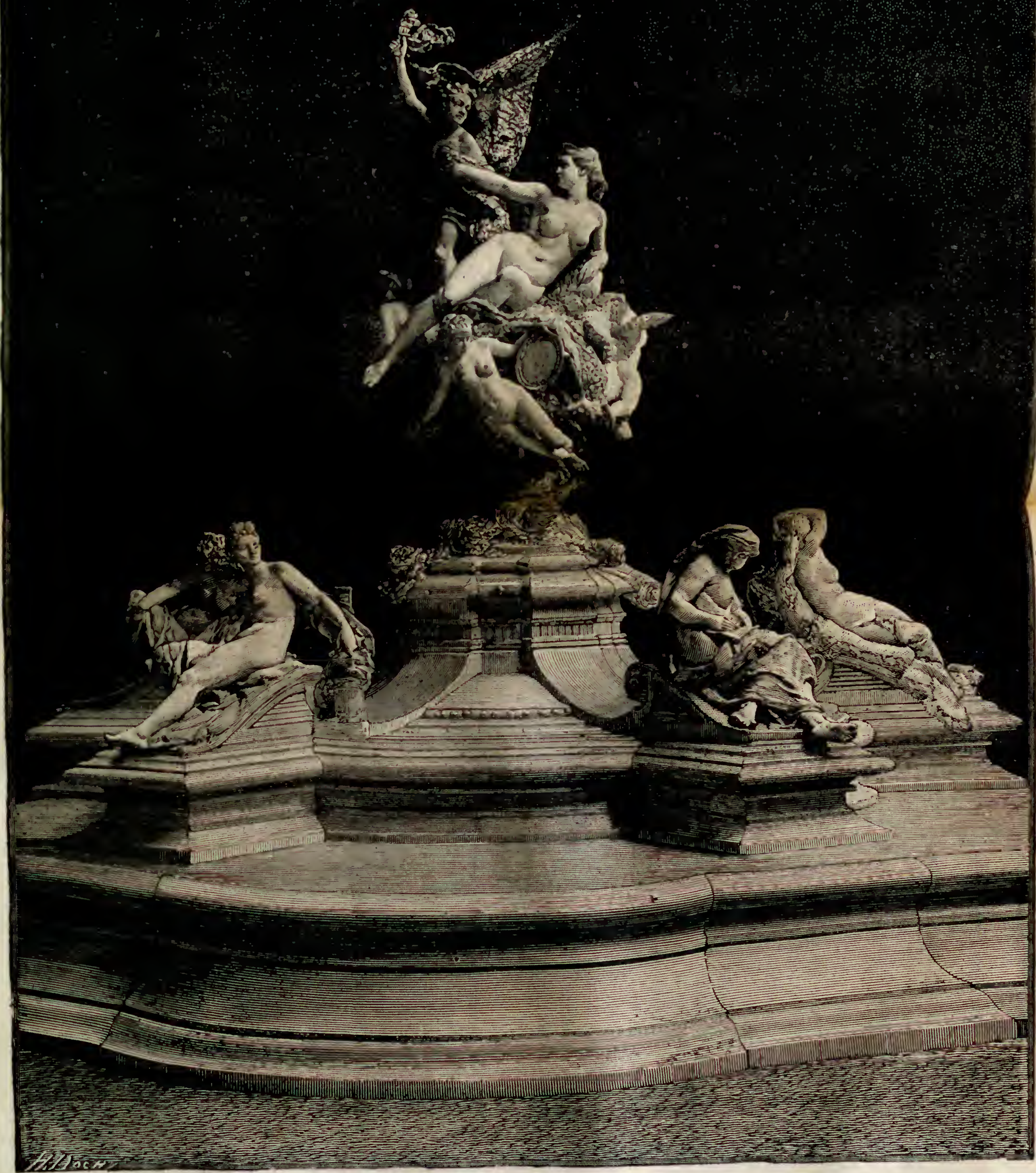

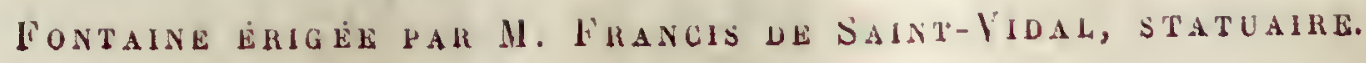


usage des lignes aériennes. Ce n'est que dans des cas tris rares que l'on crée des lignes souterraines.

Les fils réunis en faisceaux passent par-dessus les toits ou dans les rues. On les fait supporter par des colonnes.

Les faisceaux sont attachés à des isolateurs en porcelaine, semblables à ceux des fils télégraphiques. Quelquefois, les isolateurs sont en caoutchouc. On les fixe sur des chevalets de bois ou sur des cornières de fer. attachées au moyen de montants, également en fer.

En Angleterre, en Belgique, on a adopté une excellente disposition. On se sert de véritables câbles conducteurs. On donne ce nom à la réunion diun grand nombre de fils formant un cordon unique de fils très fins, enveloppés chacun de matière isolnnte. telle que la gutta-percha, le caoutchouc, le coton ou la soie. On suspend les cibles en l'air ou bien on les attache le long des murs. On les fait ensuite passer au-dessus des toits, en les supportant par un fil de fer attaché à des supports.

A l'étranger aucun systime n'est employé à l'exclusion des autres, comme on le fait à Paris où le téléphone Ader-Bell est le seul en usaģe. En Angleterre, le systène Groseeley est surtout employé, ainsi que dans plusicurs réscaux créés en ltalie. Lin A mérique on fait généralement usage du système Blake, qui consiste en une ingénieuse disposition du microphone Hughes. En Belgique, la forme de ce dernier appareil a été modifiée par M. Bède. Mais est-ce bien l’organisation du téléplıone qui attire surtout le visiteur? Ne sont-ce pas plutôt les auditions de l'Opéra, de l'Opéra-Comique, de l'Eden-Théàtre, et surtout le phonographe Edison? Que chacun s'interroge et s'avoue ses preférences.

Maxufactures de l'État. - Les manufactures de tabac de l'État français nous vendent des cigares particulièrement bien soignés et nous font assister aux phases diverses de la fabrication des cigares et cigarettes, à la confection des paquets, au pesage du tabac, etc. Un rapport de M. Iamile nous servira à expliquer ces dernières opérations.

Tout d'abord, le tabac est transporté en feuilles dans les magasins spriciaux dits magasins de culture, où elles subissent diverses préparations destinćes à leur faire perdre l'excédent d'eau qu'elles contiennent encore et développer leur arome; après quoi, elles sont expédiées dans les manufactures. A leur arrivée en manufacture, les tahacs sont emmagasinés par espèces et qualités dans des locaux disposés de faron à contenir les quantités qui sont nécessaires à une fabrication de plusieurs mois. C'est de ces magasins que sortentles balles de tabac indigène et les boucauts exotiques pour se rendre à la $1^{\text {re }}$ section, où sont concentrées toutes les opérations dont l'ensemble conslitue ce que l’on appelle la préparatiop générale des matières. Dans ces ateliers, on ourre les colis, puis on pèse les matières qu'ils contiennent, on procède ensuite a l'écalıochage ou au coupage des tabacs exotiques et des tabacs indigines qui n'auraient pas reçu cette main-d'œuvre en magasin. Eusuite, viennent l'époulardage, destiné ì séparer les feuilles d'une même marque les unes des autres, et a les étaler; les mouillatles préparatoires qui ont pour but d'assouplir les tabacs, de façon a éviter la production des débris; le trillage des feuilles suivant la falırication à laquelle elle sont destillées; enfin, la composition, c'est-d-dire la séparation des différentes espèces et qualités cntre les divers genres de produits, conformément aux prescriptions de l'administration centrale. 
La plupart de ces opérations se font à la main; elles sont facilitées par l'agencement rationnel des locaux, qui permet d'éviter les transpórts inutiles et de conduire les matières du magasin d'entréc aux ateliers où elles subiront la série des tranformations par lesquelles elles arrivent à l'état de produits fabriqués. Cette partie si importante de la fabrication, puisque, du soin avec 'equel sont faits les divers triages, dépendent, dans une large mesure, le bon emploi des matières et la qualité des produits, n'a que peu participé au bénéfice de l'introduction des machines. L'attention de l'ouvrier et la connaissance qu'il peut avoir des tabacs sont en effet plus importants ici que la force ou la vitesse.

Une fois nouillés, les tabacs sont mis en masse jusqu'au moment où ils sontlivrés. au capsage; on appelle ainsil'opération qui pour le scaferlati ordinaire, a été substituée a l'ancien écotage conservé seuiement pour le scaferlati supérieur. Au capsage, les feuilles alignées à la main, de façon que tous les côtés soient bien parallèles et réunis en ballotin, sont en cet état portées au hachage. Cette opération s'effectue maintenant mécaniquement, à l'aide de machines qui, depuis quinze ans, ont subi de nombreux perfectionnements. L'ouvrier place les baliots de feuilles dans son hachoir, de manière que la lame du couteau vienne trancher tranversalément tous les côtés; il parvient à éviter ainsi, sans recourir à l'écotage, la production de ces aiguilles ligneuses si désagréables aux fumeurs.

Du hachage, le scaferlati passe immédiatement à la torréfaction. Cette opération, jallis aussi nuisible au goût du tabac qu'à la santé des ouvriers, s'effectue maintenant dans un appareil dont le fonctionnement laisse peu de chose à désirer. Le scaferlati est introduit automatiquement dans un cylindre creux, qui tourne lentement dans une enveloppe en tôle. De l'air, chauffé dans un double foyer, circule dans l'enveloppe et dans le cylindre, où il traverse le tabac, en lui enlevant son humidité. Un ingénieux mécanisme règle l'introduction de l'air sous les foyers de manière à maintenir la température constante dans l'enveloppe. De la sorte, on n'a plus à craindre que le tabac ne soit ou grillé ou trop humide, et la torréfaction se fait rapidement et sans danger pour personne, les vapeurs étant entrainées dans une cheminée d'appel.

De là, le tabac passe au cylindre sécheur, où il se débarrasse des poussières, et après un sćjour d'un mois environ en masses de maturation, il est livré au paquetage. Le paquetage s'effectue inaintenant à l'aide d'une machine à colonne d'eau, imaginée en 1863 à la manufacture de Lille. Gràce à cette machine, qui se prête également à la confection de tous les modèles de paquets, nous n'arons plus sous les yeux le spectacle pénible des ouvriers qui étaient autıefois obligés de peser de tout leur poids sur un levier pour comprimer le tabac dans les moules.

Nous ferons remarquer qu'à l'Exposition de 1889, comme à celle de 1878, les visiteurs pourront acheter des tabacs, des cigares et des cigarettes de provenances étrangères.

L'administration française avait d'abord décidé que l'exposition seule serait autorisée et que la vente et la dégustation seraient absolument interdites. Elle redoutait les fraudes et elle craignait surtout, qu'à la suite de ces dégustations, le consommateur ne s'habituât à rechercher d'autres tabacs que ceux préparés par les manufactures de l'État. Mais en présence des réclamations venues de tous les pays qui récoltent des tabacs et fabriquent des cigares et des cigarettes, l'administration, un peu à contrecœur, a dû céder. 
La vente est donc permise, entourée naturellement de toutes les précautions qui sauvegardent les intérèts du Trésor : acquitlement des droits à l'entrée des produits étrangers, appositions des vignettes de l'Étal, vente dans l'intérieur de l'Exposition sous la surveillance constante de l'administration.

Bien que ces nouvelles décisions aient été tardivement connues, les producteurs et les fabricants de tous les pays ont préparé une exposition des plus complètes, et lc nombre des comptoirs de vente est considérable.

- La Ilavane, tout d'abord, est très brillamment représentée; plus de trente inaisonc, et des meilleures marques, ont envoyé leurs produits. Divers pays de l'Amérique du

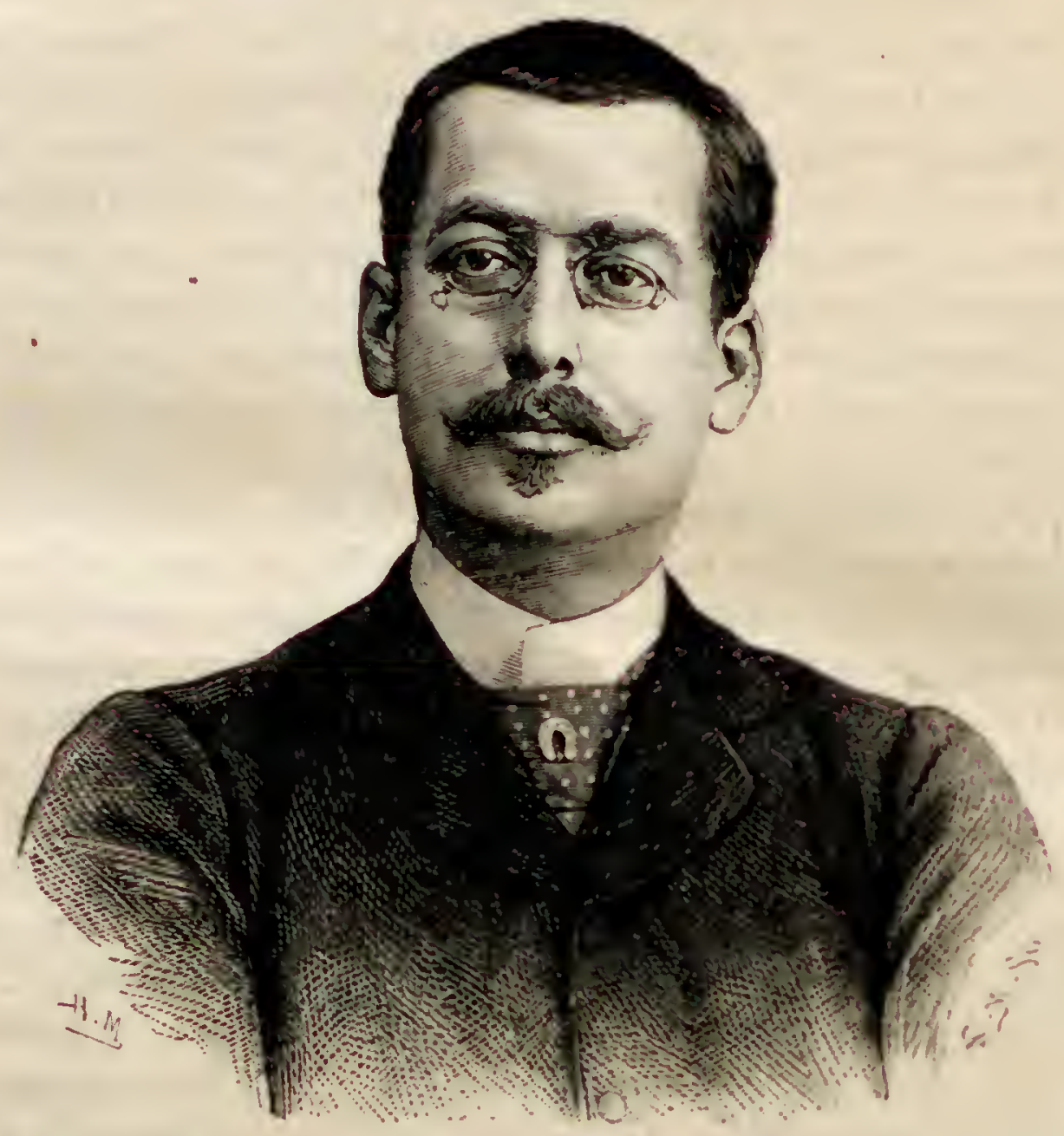

11. SAlles. - Ingénieur de la Tour Eilfel.

Sud, entre autres l'Équateur, le Chili, le Salvador, veulent profiter de cetle occasion pour faire connaitre d'excellents tabacs. Le Mexique comple beaucoup sur la dégusta. tion de ses cigares. Les États-Unis vendent surtout leurs cigarelles de tabac quelque peu sucré, enveloppées dans d'amusantes vigneltes.

En Europe, l'Espagne, la Belgique, la Russie, l'Autriche el méme la Suisse, s'attendent aux plus hautes récompenses.

L'Orient fait des expositions pittoresques. La régie impériale ottomane s'est installée dans un charmant kiosque copié sur les meilleurs modèles de Constantinople et du Bosphore, une véritable dentelle de stuc. Dans la rue du Caire, le fournisseur habituel du khédive a aménagé une boutique de beaucoup de caractère. Les Indes anglaises et néerlandaises vendent leurs tabacs dans le séraï indien au Champ de Mars ou dans le kampong de Batavia, sur l'Esplanade des Invalides. 
Les visiteurs peuvent donc se livrer aux dégustations les plus variées.

Au pied de la Tour Eiffel. - Nous voici revenus au pied de la Tour Eiffel. Profitonsen pour nous reposer et jeter un coup d'œil sur la nuée de visiteurs qui circule dans le parc du Champ de Mars. Les Parisiens avaient fait une réputiation méritée au magnifique parc qui occupait la partie du Champ de Mars voisine de la Scine. Les plantes les plus belles et lesplus rares y étaient en plein épanouissement, et, en nul autre endroit de Paris, l'on ne pouvait voir d'aussi beaux massifs de rhododendrons. Deux lacs, peuplés de cygnes et de canards, étalaient leurs miroirs d'argent au pied des rochers couverts de plantes alpines d'où tombaient des cascades. Mais il a bien fallu, le cœur saignant, mettre la pioche des terrassiers dans ces pelouses ravissantes, dans ces merveilleux massifs, et déloger les grands arbres acclimatés au sol du parc.

La Tour de 300 mètres allait mettre ses pieds inonstrueux là où étaient les plantes rares et les fleurs délicates. Un éléphant piétinant une toile d'araignée.

Mais M. Laforcade n'est pas seulement un arliste hors de pair ; c'est aussi un père pour ses plantes. Et il n'a eu garde de laisser celles du pare du Champ de Mars livrées aux brutalités de la . Terrasse ,. Les arbustes furent soigneusement enlevés et mis en subsistance en lieu sûr. Les grands arbres, une centaine de marronniers entre autres, eurent l'honneur de changer de place en équipage. Ils ont été transporlés en chariot. La terre végétale elle-même fut mise de côté, soigneusement. Puis la balu-trade de la terrasse fut démolie et le sol livré à la bousculade la plus pliénoménale, a partir du 15 décembre 1886. De leur coté, les travanx de mise en réserve des plantes déloǵ̣cs furent terminés en janvier 1887. Dès le moment oủ l'lixposition de 1889 fut cliose résolue, M. Laforcade songea à c préparer , les jardins : ce qui veut dire qu'il s’occupa de créer les plantes nécessaires pour peupler les innombrables massifs du Champ de Mars, du Trocadéro et de l'Esplanade. Il s'occupa aussi d'avoir du gazon tout prét pour l'ouverture de l'Exposition; ce qui est assez difficile pour le mois de mai, si l'on a recours à la semence. Il y a pourvu en créant une gazonnière immense, an fond du parc des Princes, capable de fournir aux pelouses et aux bordures plis de $2.5,000$ carrés de gazon, tout venu, que je pourrai appeler a gazon d'improvisation '. Au commencement de 1888 , on avait mis à leur place définitive, - et dans d'excellentes conditions, - plus de 400 gros arbres d'essences variées. D'autre part, la municipalité de Paris avait, au bois de Boulogne, des spécimens uniques, qu’elle voulut bien perinellre de transporter au Champ de Mars, où ils font l'admiration des connaisseurs. Il y a, parmi ces sujets rares, des érables, des bouleaux. des calalpas, des gainiers, des cytises, des plaqueminiers, des féviers, des noyers, des mûriers, des peupliers, des robiniers, des micocouliers, des sorbiers, des ormes, des tilleuls, des virgiliers de tonte beauté, qui ont été amenés par $\mathbf{M}$. Laforcade avec des soins minutieux. On voit dans les jardins du Champ de Mars, plus de 400 variétés d'arbres d'ornement ou forestiers, et plus de 600 variétés d'arbustes de toutes fanilles, it feuilles persistantes ou d feuilles caduques. On a rarement vu une collection aussi complete; jamais, peut-eire, une collection composée d'aussi beaux sujets. Le jardin compris entre les lenx Palais des Arts mesure environ cinq hectares. Il est en contre-bas, un peu en cuvette, entouré de terrasses à balustrades. Au pied de ces balustrades seront des plates-bandes de rliododendrons de toute beauté avec des magnoliers de dislance en distance. Les terrasses qui entourent le jardin seront une des attractions de l'kxposition On $\mathrm{y}$ voit soixante 
palmiers (Chamerops excelsa), hauts de 4 à 5 mètres. Ils sont exposés par MM. Beson frères, de Nice. Le jardin est superbe, avec ses doux vallonnements, ses arbres rares et ses massifs, de fleurs sans cesse renouvelés jusqu'd la clôture de l'Exposition. Audessus de ce jardin est celui des Expositions diverses mesurant 3 hectares.

Au centre, un tapis vert, avec des fleurs, entre les pavillons de la. Ville de Paris, décorés de plantes grrimpantes et entourés d'arbustes. Des rangées de platanes, plantés il y a plus d'un an, et bien repris, se trouvent entre les galeries des restaurants et les pavillons de la Ville de Paris et forment promenades.

Ilais c'est dans la rue de l'llistoire de l'habitation humaine que M. Laforcade a trouvé à montrer ses talents. Il s'agit d'entourer chaque habitation de la végétation et de la flore correspondant à l'àge qu'elle rappelle, et de donner au jardinet qui l'entoure la disposition de son temps, depuis la végétation inculte des temps primitifs, jusqu’aux jardins raffinés de notre époque. Des ronces, des aloès, des yuccas, des euphorbes sont les mélancoliques témoins de l'époque du renne et de la pierre éclatée. Autour de la cité lacustre, on voit des touffes de roseaux, les iris fétides, les renoncules de marais et l'oseille sauvage sur les bords et, dans le lac, des nénuphars, des nymphéas, des cypérus, des joncs, des épilobium et toute la perruque des plantes natantes. Les cèdres du Liban et les arbres de Judée sont groupés autour des constructions égyptienne, nssyrienne, hébraïque et phẻnicienne. Les virgiliers et les tamarins sont réservés pour les.hahitations des Pélasges et des Étrusques. La construction persane aura les lilas, les paranes, les héracléums et d'autres belles plantes. Les lauriers d'Apollon font une couroune à l'habitation grecque. Les inyrtes odorants, les oranger's, les citronniers et les mimosas sont pour l'habitation des Romains, te pin et le sapin aux sombres frondaisons pour celles des Scandinaves; les clématites et les capucines, fleurs de chatelaines, égayent la précieuse construction de la Renaissance. Des allées torturées, bordées de chamerops et de bambou, les thés et les azalées sont pour la maison chinoise, et pour la maison japonaise, les hortensias, les fusains, les accubas, les cydonias et cent plantes aux couleurs éblouissantes? Que sais-je encore? Toujours est-il que l'on voit cette restitution de la flore du temps autour de l'habitation de chaque age; grìce à la science et a la conscience de M. Laforcade.

Le nombre des entrées à l'Exposition de 1889 a pris des proportions phénoménales, et depuis le jour de l'ouvertıre, on a pu suivre une progression constante, qui n'a cer tainement pas atteint son maximum.

D'après les statistiques la plus forte recette de $18 \mathbf{z}^{8} \mathrm{a}$ été enregistrée le lundi de la P'entecóte, avec 160,000 entrées; en en 1889 on a complé ce mème jour de fète, 3333,000 entrées; plus du double! En présence de tels résultats, qui dépassent toutes les prévisions possibles, l'administration s'est trouvée momentanément prise au dépourvu, à bien des points de vue, guichets insuffisants, chemins trop petits, passerelles et ponts trop étroits. Elle s'efforce de remédier à ces gros inconvénients, et déjà beaucoup d'excellentes mesures ont été prises. Mais la question de l'alimentation s'est surtout présentée plus urgente et plus difficile à résoudre que les autres; là, toutes les combinaisons de l'administration ont été déjouées par l'afluence considérable des visiteurs. On avait biell adjugé un grand nombre de restaurants, de brasseries, de cafés, de buffets, de bars, en tout près de š0 établissements de ce genre, à bon marché ou de luxe, a prix fixe ou à la carte. Que peuvent tous ces établissements pour une population de 200,000 habitants? Oủ trouver à manger et à boire pour tout ce monde? Duval 



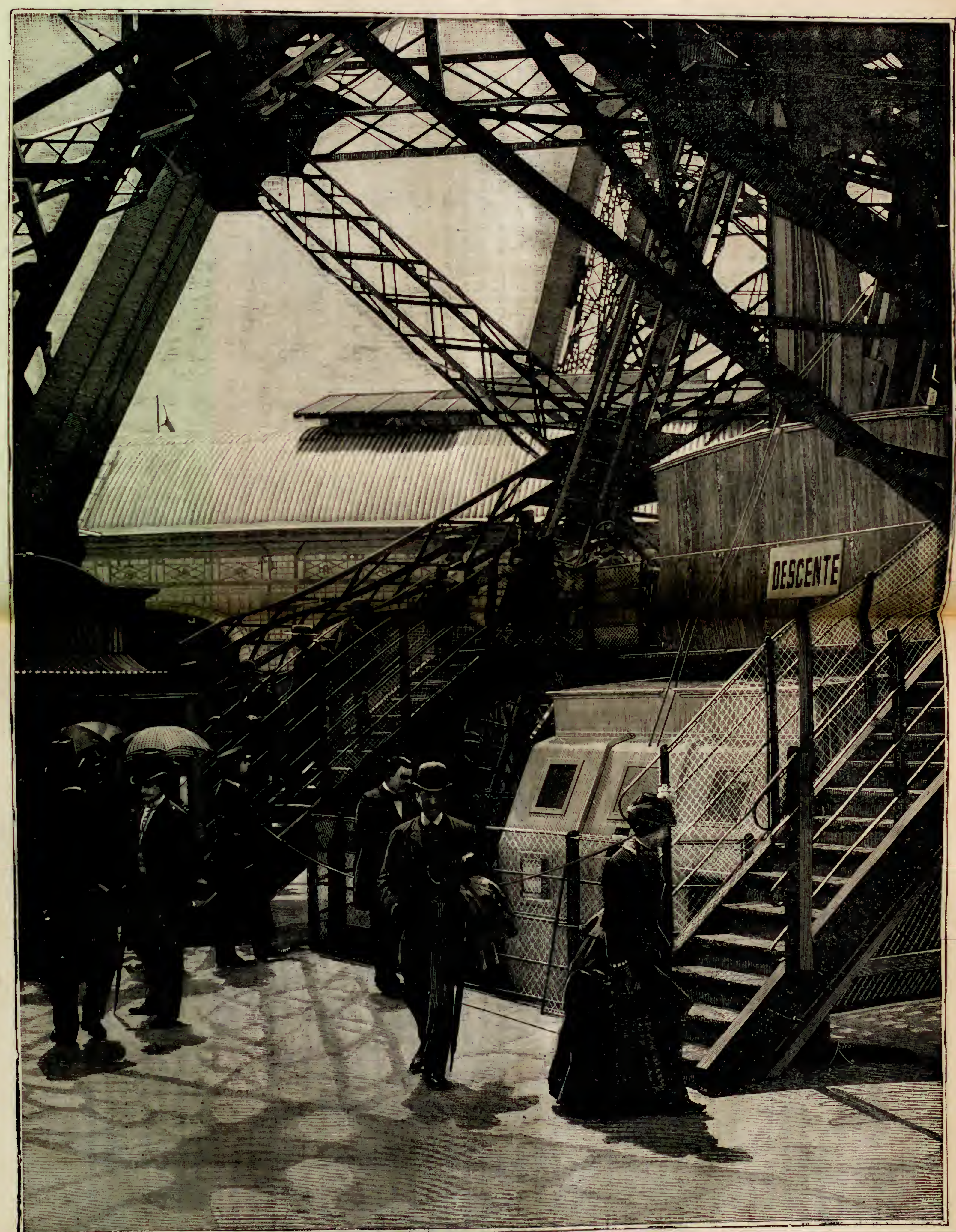


croyait faire grandement les choses en demandant trois établissements de proportions colossales; une bagatelle! On fait queue pendant trois quarts d'heure a la porle de ces - bouillons „, attendant que les tables se dégarnissent pour les prendre d'assaut. L'administration a aussitòt autorisé la vente de tous les aliments possibles, dans les nombreux kiosques des jardins, destinés tout d'abord aux journaux, aux menus souvenirs de l'Exposition et à quelques rafraichissements. Deux fois parjour, ces kiosques s'emplissent de gateaux, de pain, de viande, de vin, de bière, et deux fois par jour tout disparait dans le gouffre.

Ce n'était pas encore assez pour approvisionner la foule. Aussi le public a-t-il pris le parti d'apporter son repas et de dîner sans façon sur les pelouses.

Le bruit des ascenseurs de la Tour nous fait lever la tète; ils ne désemplissent pas. Voici les détails intéressants que nous trouvons à ce sujet dans le Bulletin Officiel de l'Exposition :

- Daprès le cahier des charges de l'entreprise de la Tour, le concessionnaire s'est obligé statutairement à élever 2,356 personnes par heure à la première plate-forme et 7 כ0 personnes par heure au sommet. Le tarif des ascensions est fixé a 2 francs pour le premier étage, à 3 francs pour le deuxième et à 5 francs pour le sommet. Contrairement à ce qui se passe ordinairement, les prix sont abaissés pour les dimanches : c'est 1 franc jusqu'à la première plate-forme, 1 fr. 50 jusqu'à la seconde, 2 francs jusqu'au sommet, mais ce tarif n'est applicable que de onze heures du matin à six heures du soir. Comment se fait le contrôle? ou, pour être plus précis, comment paye-t-on son droit d'ascension? L'administration a ouvert a cet effet 16 guichets : 10 au rez-dechaussée, 4 à la première plate-forme et à 2 à la deuxième. On y délivre des tickets : rouges pour la première plate-forme, blancs pour la seconde et bleus pour le sommet. La personne à destination de la première plate-forme remet son ticket rouge à l'arrivée. N'en ayant plus, elle ne peut monter plus haut que si elle achète un second tickel, - le blanc, - qui sert entre le premier et la seconde plate-forme. - Enfin, pour monter au sommet, il faut un ticket bleu. Total : 5 francs. Et les piétons? Ceux que les ascenseurs effrayent ou impressionnent ont à leur disposition deux escaliers confortables pour le service de la premiere plate-forme : celui du pied numéro 4 pour monter et celui du pied numéro 2 pour descendre. Ils en ont quatre à leur disposition entre la première et la seconde plate-forme, deux pour l'ascension et deux pour la descente. Que l'on monte à pied ou en ascenseur, c'est le méme prix, et les tickets sont pareils. Si bien que les tickets une fois pris, pour le sommet par exemple, on peut varier ses plaisirs en faisant une moilié du trajet d'une façon et l'autre d'une autre façon. Quelques personnes ont critiqué l'égalité du prix adoplé pour les deux modes d'ascension, en disant que la personne à pied aurait dú payer moins cher que celle qui se sert des ascenseurs. Mais on a voulu simplifier pour éviter des complications de vente et de contròle. La Tour, lorsqu'elle reçoit son maxinum de visiteurs, peut en contenir, savoir :

Chacun des restaurants du premier étage 400, soit pour les $4 .$.

1,000 environ peuvent se mouvoir sur chacune des 4 galeries exté-

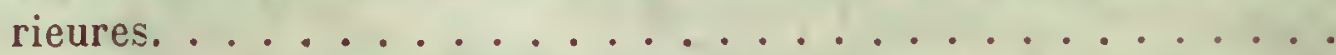

Entre les restaurants, il y a des galeries intéricures pouvant en

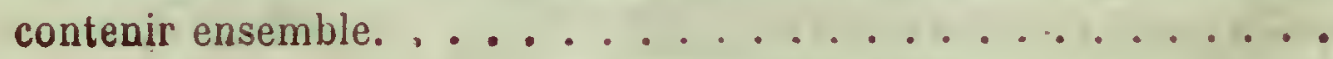


Report.....

On peut être 1,500 au second étage et 500 au sommet, ensemble

Les personnes en voie d'ascension, plus les gens de service, peuvent

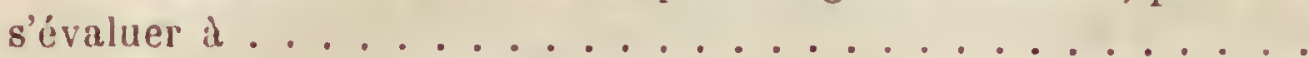

Et vous avez, lorsque la Tour est saturée de visiteurs, un total d'en-

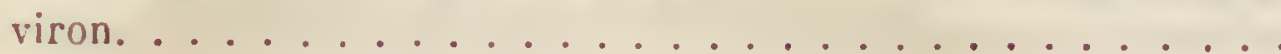

- Dix inille personnes dans cette résille en fer! quel bourdonnement! quelle vie! Et les jours de cohue, le dimanche, par exemple, cela peut durer de 10 heures du matin i 11 heures du soir. Il y a, au premier étage, quatre restaurants amplement pourvus de cuisines et le caves, qui sont logées dans le treillage de la charpente de fer, à cinquante-cing mètres au-dessus du niveau du Champ de Mars. Il y a, dans les angles, douze houtiques dont sept réservées à l'Administration. Les cinq autres sont affectées à des ventes diverses, la vente du tahac, du Guide officiel de la Tour, etc. C'est bien la tour de Babel, renouvelée avec succès, des premiers temps du monde! Et quand il tonne lit-dessus, quel vacarme! Et quel beau paratonnerre que cette pyramide de fer remplie d'ètres humains que l'électricité caresse sans les toucher! ,

Vous êtes-vous jamais demandé de quelle couleur est la Tour Eiffel? Ses tons changeants défient la sagacité de plus d'un curieux. Ėlle paraît rouge à ceux-ci, bronzée à ceux-là. D'aucuns la voient comme nick elée par endroits. Cela tienta la composition spéciale des enduits adoptés par le constructeur et au jeu de la lumière. M. Eiffel s'est longtemps préoccupé de la tonalité qu'il donnerait à son chef-d'œuvre. Il voulait du nouveau, de l'original, du solide aussi. Après deux ans d'essais multipliés, les produits de la Société des liommes nouvelles ( $t$ Vernis fixèrent son choix. Ces peintures ont le poli du stuc, de la faîence; elles jouent l’émail à s’y méprendre, deviennent très dures, craignent peu la poussic̀re, et se lavent mème à l'eau chaude sans altération. Le Léviathan de fer du Champ de Mars va populariser ces charmantes imitations céramiques. Au pied de la première plate-forme, on lui a donné le ton bronzé Barbedienne tirant un peu sur le rouge. De cette première plate-forme a la seconde, mème teinte mais plus claire. De la au sommet trois autres teintes gradućes de moins en moins foncées (la coupole est presque jaune d'or), complètent un ensemble harmonieux el qui fera beaucoup pour la vogue des peintures vernissées qui sont du reste déjả adoptées par les ministères el les principaux chemins de fer.

La fontaine monumentale de M. de Saint-Vidal est depuis longtemps complètement achevée; elle orne aujourd'hui le jardin que domine la Tour Eiffel.

Cette fontaine a été commandée à II. Francis de Saint-Vidal sur la proposition de M. Mphand, directeur général des travaux de l'Exposition universelle de 1889, par M. Dautresme, ministre du Commerce et de l'Industrie, pour ètre placée au centre du jardin situé sous la Tour Eiffel.

Le bassin au milieu duquel s élève cette fontaine mesure environ vingt-quatre mètres de dianetre Elle-nème a douze mètres de diamètre au niveau de l'eau de ce bassin et neuf mètres de hauteur au-dessus de ce ınème niveau.

Elle se compose de onze figures d'une fois et demie grandeur nature. Six de ces figures forment le groupe central et cinq sont placées autour, en contre-bas, dans une circonférence de neuf mètres de diamètre. 
Ces cinq dernières figures représentent les cinq parties du monde; mais bien plus par leur caractère et leur action que par leurs attributs.

L'Europe, représentée par une figure de femme de quarante ans, appuyée sur les grands agents de la pensée, la presse à imprimer et le livre, semble comme abìmée dans de pro?ondes et soucieuses méditations.

Dans l'Amérique, c'est uil ordre d'idées tout différent, c'est la jeunessé, l'énergie, la virginité; la Diane de la civilisation, Diane un peu riolente et toute pleine des audaces qui caractérisent le peuple américain.

L'Asie, berceau du genre humain, représente bien la volupté et le sensualisme : sa pose, son corps tordu sur lui-même, l'expression de son visage, rendent toul à la fois l'énergie et l'abandon de la passion chez les peuples orientaux.

L'Afrique, représentée par une figure de femme dans une attitude craintive, est bien le symbole des peuples sauvages asservis par la civilisation jusqgu'au jour où ils so-vent s'y associer.

Dansl'Australie, l'état sau. vage reste intact. Cetie femme arc-boutée sur ellemème rend bien l'animal non encore apprivoisé, confiant uans sa force primitive et prèt ì se jeter sur sa proie sans attendre d'être attaqué.

Dans la composition cen-

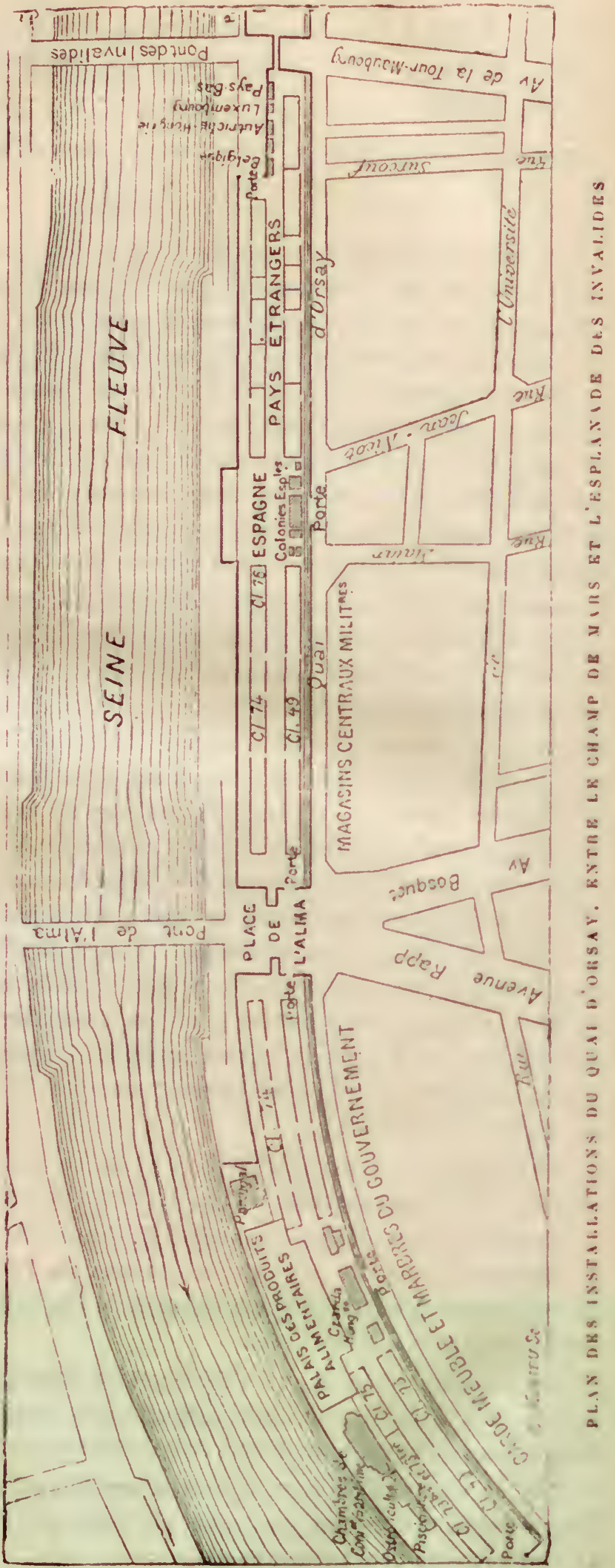


trale, six fignres sont groupées autour d'une sphère portée par des nuagras. A la partie supériére dn groupe s’élance, ailes déployées, une torche dans la main droite, le génie de la lumière qui déggage de ses voiles l'humanité. Celle-ci est représentée par une figure de femme assise sur la sphère.

Au-dessus de l'Australie, Mercure descend des nuages tenant dams ume main le caducée et dans l'autre un sac d’argent, ces deux emblèmes de l'éloquence et de la persuasion.

Au-dessus de l'Asic et l'Afrique, l'Amour et le Sommeil dans l'ombre d'une draperie volante comme dans un berceau. Enfin. entre l'Europe et l'Amérique, une jeune fille symbolise l'Histoire. Dans l'écusson qu'elle soutient de la main gauche sont inscrites les deux dates 1789-1859.

Lieau très ahondante tombe en nappes des draperies qui relient ensemble les figures du groupe central et s'échappe en pluie et en poussière très fine des groupes de nuages ménagés a cet effel, au milieu desquels la splière el les six figures centrales sont comme suspendues.

Ilais pendant que nous regardons toutes ces belles choses, l'heure arance, et la nuit est venue. La féerie va commencer, nul ne saurait la décrire. Dans la pénonulire au sein de laquelle on distingue encore les silhouettes d’édifices, les dúmes, les ccupoles, les façades des palais, les galeries se profilant, des gerbes de flammo ont jailli sourlain. Puis, dans cel embrasement général, nall unc symélric lumineuse qui envalil les espaces. se poursuit dans les lointains. Aux grandes lignes succede un enguirlandement général. Les dỏmes apparaissent recouverts d'une dentelle de feu; en intma teinp̧s des projections électriquess’étendent sur Paris, jouent dans l'espace, font passér loules les couleurs re l'arc-en-ciel sur les fontrines jaillissantes, sur la multitude qui s'amasse longnement et fait une houle noire dans le clair intense où elle se meut. Iamais on ne vit le réel enveloppé d'une telle fantasmagorie. Toute les perspectives sont changiec, prodigieusement élargies; les étres eux-mèmes sont comme tran-fizurḱs, les groupes des fontaines ressemblent à des tableaux virants, du còt du Palais des Benux-olrtз, les statues qui se dressent à l'extérieur semblent participer au u uvement ginéral. Charlotte Corday médite de nouvelles représailles, Inditl cherche un autre llolr filierne, le berger Jupille étrangrle un second loup, et le musici n liongrois a la luwjp ismule de bronze joue plus furieusement que jamais la * Marche de Rakuc.y. Ju-yue dans les profondeurs des salles de la sculpture, rayécs par les torses les matlires et des platres, il semble qu'il ait pénétré quelque chose de celle vie surchantrée êt de ce soulfle qui sévit en tempète au dehors. A la longre seulement la rumpur tombe el la

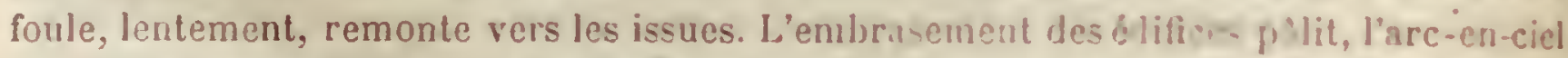
de couleurs s'efface, les girandoles de lumières s'éteignent. La fantasma g, rie cerse ot la nuit, longtemps refoulée, déploie enfin ses ombres sur celle synthise los cinq jurties du monde. Encore quelques instants el l'univers enti r formira dons la mime nuit: l'univers où il fait jour d'un côté quand il fait nuit, de l’autre!

Les galerios de l'Agriculture sont fermées le suir, romme tontes les autrea; ausi, pour gagner l'Esplanade des Invalides, prendrons-nüs le clremn de fer 1), cauraln.

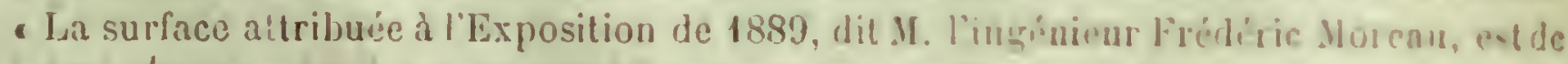
beaucrúp supérieure à celle qui fut occupée par les lixpusitions pricéduntess. Oulre le Trocadéro, elle englobe le Champ de Mars et l'Fisplinnade des luralider. avec le facile intermédiaire du quai d'Orsay sur nne longueur de 1,500 mèlres environ, sont, an tutal, 
une superficie de 90 hectares. Le visiteur qui, entrant par la porte située près du Ministère des Affaires étrangères, voudrait contourner l'Esplanade des Invalides, en longeant la palissade, puis suivre le quai, faire égalementle tour du Champ de Nars, pour traverser enfin la Seine sur le pont d'Iéna et sortir sur la place du Trocadéro, aurait environ 7 kilometres à parcourir, soit une heure un quart de marche au pas accéléré. Avec un semblable développement il était absolument nécessaire de mettre à la dispositon du public un moyen de locomotion pratique, rapide et peu dispendieux. Il fut donc décidé que l'intérieur de l'Exposition serait desservi par un chemin de fer La ligne dont le parcour's a été alopté a son point de départ vis-à-vis de l'angle du Ministère des Affaires étrangères près de la Seine; elle traverse l'Esplanade dans sa largeur et suit le quai intérieurement à la clòture de l'Exposition, entre les deux rangées d'arbres les plus éloignées de la berge. Elle traverse ainsi l'avenue de Latour-Mauboug, le passage à niveau, passe le tunnel sous le carrefour de l'avenue Rapp et l'avenue Bosquet, croise l'avenue de la Bourdonnais, s'engage dans la tranchéc qui limite le Chimp de Mars en avant de la Tour de 300 mètres, et tourne ensuite à angle droil pour longer l'avenue de Suffren presque près de l'École militaire, où se trouve la station terminus. La longueur totale de ce tracé est de plus de 3 kilomètres. La surveillance de l'exécution des travaux a été confiée à M. J. Charton, ingénieur en chef adjoint du contrôle des constructions métalliques, qui s'est particulièrement occupé de l'installation des voies ferrées au Champ de Mars. Entre les deux gares extrêmes, trois stations intermédiaires ont été prévues aux points suivants, sur lequaid'Orsay : la première au carrefour Malar, la seconde en face du Palais des Produits alimentaires, la troisıème a l'angle lll quai et de l'avenue de Suffren. Le matériel fixe, comme d'ailleurs aussile matériel roulant, est fourni par la Société Decauville. La vois est double, avec une entre-voie de 2 mètres. Le mode de traction adopté en principe est la vapeur. Les locomotives sont de plusieur's modèles. L'une des plus intéressantes est celle du capitaine Péchot. Cette machine, dite locomotive Duplex, a été combinée spécialement pour les usages des armées, et en particulier pour le transport du matériel de siège et de place.

- On emploie également les locomotives du type Mallet, bien connu et justement apprécié, appelées à servir dans les mêmes conditions que les précédentes.

- L'usage des lignes a écartement réduit, ayant pris depuis quelques années un développement considérable, tant pour les usages industriels et les services militaires que pour le transport des voyageurs et l'établissement des voies de pénétration aux colonies, tout ce qui concerne des installations semblables est à l'ordre du jour. Aussi le chemin de fer-tramway de II. Decauville, outre les services qu'il rend aux nombreux visiteurs de l'Lxposition, présente-t-il, au point de vue technique, un réel intérèt, tant par ta voie que par le matériel employé. Le cahier des charges réglemente l'exploitation de cette ligne par le concessionnaire. Quvique sur presque loute sa longueur la voie soit complitement défendue contre la circulation du public, on a jugé prudent d'imposer un faible maximum de vitesse qui est de 10 kilomètres à l'heure. Cetle vitesse doit méme dtre réduite à 4 kilomètres en certains points du parcours, et en particulier aux passages ì niveau. La longueur des trains ne doit pas excéder 50 mètres, et chacun d'eux est muni d'un frein à arrèt instantané. Le prix du transport est fixé uniformément à 20 centimes par per'sonne, et à 0 centimes pour les wagons de première classe, quelle que soit la longueur du trajet. Si le chemin de fer-tramway doit être un 

moyen de transport commode pour circuler à l'intérieur de l'Exposition, il présente aussi un autre avantage : la station du départ est située à $2: 30$ mètres à peine du pout de la Concorde. On voit combien il est commode, au lieu de gagner le frocadéro ou la porte Rapp, d'aller simplement monter en wagon à quelques pas du Palais-Bourloon et de pouvoir se rendre ainsi jusqu'à la Galerie des Machines, au fond du cliamp de Mars. La sécurité est complètement assurée; dans chaque gare, il y a un disque manœurrant à distance, et, dans les deux passages à niveau le disque ne peut s'ouvrir que lorsque la barrière est fermée. Tous les trains sont annoncés par un système de cloches électriques aboutissant aux passages à niveau et à la station suivante."

-Exposition panoramigue du pétrole. - Nous avons vu en venant du Trocadéro, a droite du pont d'Léna, un pavillon consacré aux applications du pétrole. Du cúté opposé, également sur la berge, se trouve un panorama dont nous conseillons la visite.

MM. Deutsch, qui ont les premiers recherché les procédés pour le rafinage et les applications dece produit, ont dû, pour rendre leur Exposition accessible au plus grand public, la présenter sous une forme à la fois attrayante et instructive; dans ce but, ils ont entrepris de faire passer successivement sous les yeux du visiteur les différentes phases de l'exploitation minière, industrielle et commerciale du pétrole depuis son extraction jusqu'ì sa complète élaboration. Indépendamment des documents techniques, cartes, dessins, modèles, photographies, qui permettent au public de suivre progressivement les diverses opérations de cette industric, deux vues panoraniques, qui sont la reproduction fidèle d'une portion de deux gisements pétrolifères les plus intéressants du globe, transportent le visiteur au milieu de ces pays lointains que la nature a lichement dotés du précicux liquide.

Voici ce que nous apprend sur cette Exposition une brochure destinée à la décrire:

L'Exposition panoramique est renfermée dans un vaste réservoir en fer dont l'assemblage des tỏles est fait au moyen de rivets en plomb qui en rendent le montage et le démontage rapide. Ce réservoir, d'une contenance de plus de vingt mille hectolitres, est destiné à ètre édifié, après la cloture de l'Exposition, dius l'usine de lá lauciline, à Rouen-Quévilly.

L'aménagement intérieur de ce réservoir se compose d'un rez-de-chaussée et d'un premier étage. Au rez-de-chaussée, dans une galerie circulaire, sont disposées une série de vitrines renfermant les appareils, les outils, etc., servant à l'extraction du pétrole et du naphte; ainsi que des plans modèles, photographies, relatives au rafli. nage et au transport des divers produits bruts ou raffinés.

En face de ces vitrines, et sur le pourtour dans lequel se trouvent les escalicrs conduisant à la plate-forme du premier étage, figurent des vues perspectives, aquarelles, photographies, représentant les divers établissements de France, Espagne, Amérique, Autriche-IIongrie et Russie, que M.M. Deutsch ont crécs ou auxquels ils prètent un concours actif.

De cette galerie deux escaliers conduisent à la plate-forme du premier étage d'où se déroulent aux yeux des spectateurs les deux vues panorimiques peintes par M. Poilpot. Cette partie de l'Exposition offrant un intérêt exceptionnel, M.M. Weutsch croient devoir donner quelques explications détaillees pouvant servil de guide dans l'examen et l'étude des tableaux qui y sont présentés. 
Le spectateur est placé sur la toiture d'un réservoir à pétrole. L'une des rues panoramiques représente une des exploitations d'Amérique (district de IVashington, Élats-Unis).

L'autre est l'exploitation du naphte sur le plateau de Balachané, près Bakou (Caucase). En Amérique, le pétrole brut est extrait des profondeurs de la terre à l'aide de puits artésiens. Ces puils forés à la corde ou à la tigge en bois, jusqu'à des profondeurs variant entre 900 et 1,800 pieds, sont, ou flowing wells (puits jaillissants) ou pumping wells (puits exploités par la pompe).

De grands échafaudages en bois nommés derricks, dressés sur l'emplacement, servent à la manceuvre de la corde et des outils de forage actionnés par des machines à vapeur.

Le liquide extrait, soit par la pompe, soit par la pression naturelle des gaz, est envoyé ensuite dans ces réservoirs en fer servant à l'emmagrasiner. Quelques-uns do ces réservoirs ont parfois des dimensions prodigieuses. De ces réservoirs, le pétrole est dirigé sur les ports du littoral: New-York, Philadelphie, Baltimore, pour l'alimentation des diverses raffineries des États-Unis ou d'Europe.

Ce transport s'effectue soit par des wagons-citernes, soit par des pompes et des lignes de tuyaux. Ces lignes de tuyaux (pipes-lines), qui traversent les rivières, serpentent dans les vallées, passent sur les collines, et ont un développement de 12,002 kilomitres.

Les réservoirs servant à l'emmagasinage dans les stations intermédiaires des pipeslines ont une contenance de plus de soixante inillions de barils.

Des rlocks 'l'embarquement installés à New-York ou Philadelphie permettent d'y accumuler les stocks l'huile destinés à l'exportation, et de l'expédier soit en barils, soit en caisses, soit en navires-citernes (tacksteamers), dans les différents ports du monde. L'étendue des districts pétrolifères d'Amérique, reconnus jusqu'ì ce jour, est considérable, et le nombre des puits forés est d'environ $9 \ddot{3}, 000$.

La première vue panoramique mise sous les yeux du spectateur est celle du nouveau district de Washington (Pensylvanie).

Là, au milieu de collines verdoyantes, se dressent des derriclis pour le forage et l'extraction de l'huile, des réservoirs, des stations de pompes pour le refoulement dans les pipe-lines et des trains de wagons-citernes parcourant le pays.

La seconde vue panoranique est celle de Balachané, près Bakou, dans la presqu'lle d'I pcheron, sur les bords de la mer Caspienne (Caucase). C'est sur ce plateau, dans un espace de 20 lílomètres de côté, que se trouvent actuellement concentrées toutes les exploilations de naphte.

L'extraction s'y fait comme en $\Lambda$ mérique, à l'aide des puits artésiens ; mais la nature des terrains traversés oblige à employer des tubes de grand diamètre, et le forage se fait à l'aide de tiges en fer et de trépans d'un poids considérable. Bien que restreint dans un petit espace, le district pétrolifère de Bakou offre des richesses abondantes. Les puits sont extrènement rapprochés, et, contrairement à la production des puits d'Amérique, ils donnent des quantités considérables de naphte. Le naphte est un liquide bitumineux plus doux que le pétrole. La proportion d'huile éclairante qu'il renferme est de deux tiers mons riche que l'huile brute de Pensylvanie.

Le liquide jaillit parfois à des hauteurs considérables. La vue panoramique présente une de ces fontaines jaillissantes qui, souvent, sont des fortunes pour leur propriétaire, 
mais aussi occasionnent fréquemment de véritables désastres. La vue d'une de ceg fontaines est un spectacle terrifiant : le naphte projeté par la pression des gaz souter rains entraîne avec lui le sable et les roches, brisant tout sur son passage, allant retomber tout autour, entrainé par le vent. ensevelissant sous des monticules de sable et débris de rochers, les exploitations voisines avec leurs pompes, machines, etc. Le naphte s'écoule ainsi pendant des semaines, formant des ruisseaux qui se créent un lit à travers les sables pour aller former de véritables lacs dans les bas-fonds. Avec des calpats, on arrive souvent à se rendre maître des fontaines et à les capter pour en tirer ensuite le liquide nécessaire aux besoins. Quand, pendant le forage d'un puits, ces fontaines jaillissant à l'improviste s'enflamment au contact des chaudières à vapeur voisines qu'on n'arrive pas éleindre à temps, le feu constamment alimenté par de nouvelles quantités de naphte brule parfois durant des mois. Le naphte extrait est recueilli dans un réservoir voisin, et de li pompé dans des réservoirs plus grands, d'où il est dirigé sur Bakou et la Russic.

Navigation et sauvetage. - Le pavillon de la Navigation et du Sauvetage sélève sur la berge de la Seine entre la panorama du pétrole et le panorama de la Compagnie transatlantique. C'est une assez gracieuse construction, avec tourelles, mats croisés de vergues, haubans et pavillons.

I a classe $6 \ddot{3}$, matériel de la navigation et du sauvetage, comprend des dessins el modèles de cales, bassins de radoub, docks flottants, bâtiments en tout genre usités pour la navigation fluviale et maritime, les types et modeles des systèmes de construction adoptés dans les marines marchande et militaire, les torpilleurs, les canots et embarcations, le matériel du gréement des navires, grues, cabestans, etc., la timonerie, l'armement, les pavillons et signaux, les appareils destinés à prérenir les cullisions en mer, les bouées et les balises, le matériel de natation, de plongeage et de sauveloge, les cloches à plongeurs, nautilus et scaphandres, les bateaux sous·marins, le matériel de sauvetage maritime, les porte-amarres, les bateaux dits life-boats, le matériel de sauvetage pour les incendies et autres accidents, enfin la navigation de plaisance. C'est un programme assez vaste, mais qui a été fort bien rempli.

Nous entrons par le côté du pont d'léna et nous nous trourons en face de l'irros, magnifique yacht qui porte le guidon du Yacht-Club et qui est de construction anglaise. Plusieurs modèles exposés montreront les progrès d'un sport dont on ne saurait (rop) encourager le développement.

Dans la section du sauvetage, on a réuni les engins de la Socièté centrale des nau. fragés, des pormpes, des échelles, des seaux, etc., en un mot tout ce qui est destiné à préserver la vie humaine dans toutes les circonstances où elle se trouve en danger. Les bouées et les gaffes coudoient les ceintures de tout système, el nous remarifuons notamment une bouée-gaffe qui se plie et se replie au point de tenir dans la poche, bien qu'elle ait quinze mètres de lignes.

C'est probablement aux catastrophes de l'Opéra-Comique et aux autres analogues que l'on doit l'attention accordée dans ces derniers temps aux inventions préservalrices de la vie humaine en cas d'incendie: échelles de sauvetage, systemes d'inondations rapides, procédés d'ininflammabilité, telles sont les principales rubriques sous lesquelles on a rangé les appareils exposés.

Lavoisier et Gay-Lussac avaient dit: 


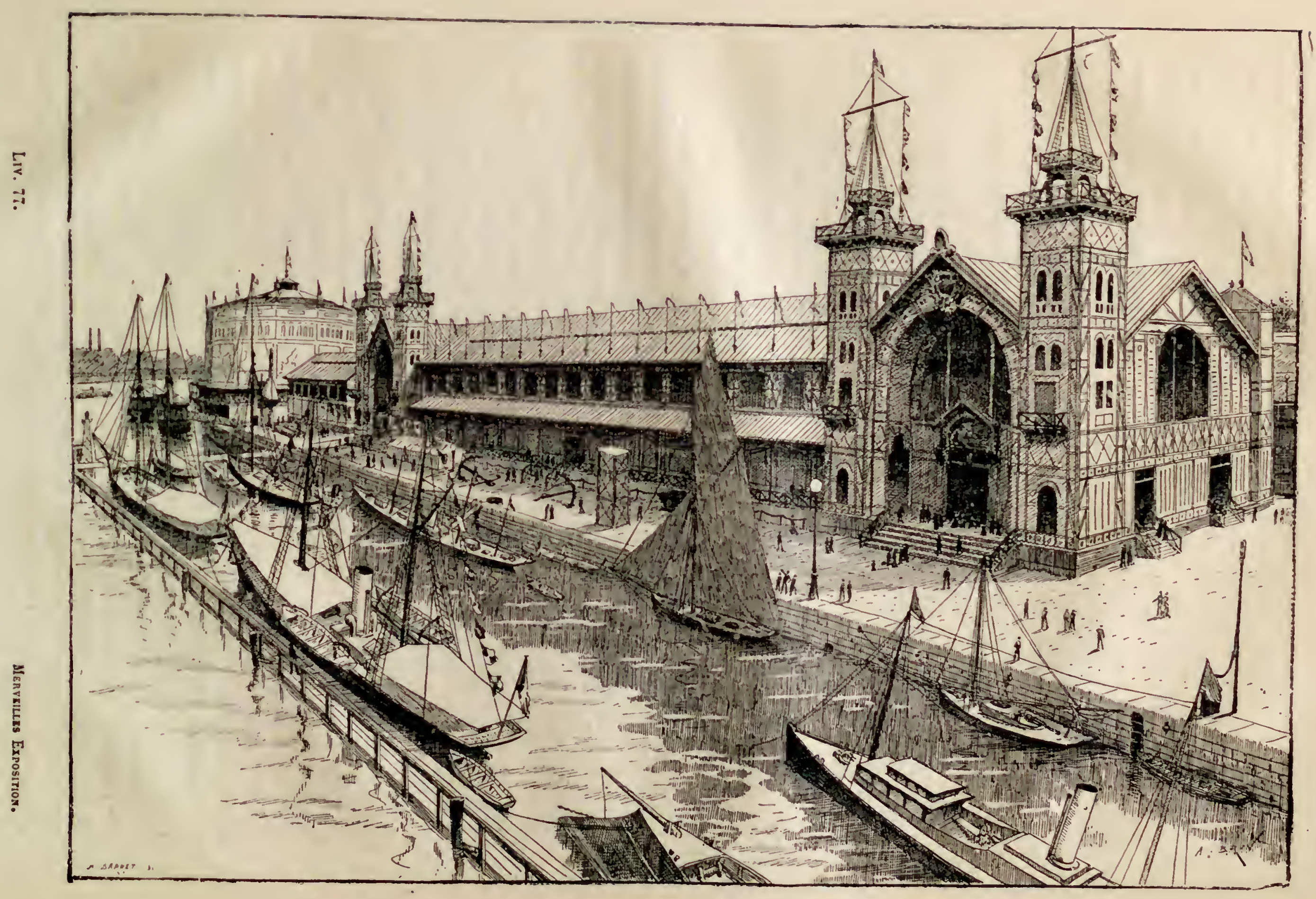

密

Exposition aratiane: Le Pavilion de la Marine et le Bassin a flot. 
- Une matière combustible s'enflamme dès qu'elle est soumise a l'influence d'une élévation de température suffișante pour dégager des gaz qui, en présence de l'oxygèae de l'air, brùlent et propagent la combustion. Pour empécher cette propagationde la flamme, il fant imprégner la matière susceptible d'ètre exposée au fen d'une ou plusieurs substances nouvelles qui devront avoir pour effet de se décomposer d'une part en produits volatils éminemment propres à empecher chimiquement la formation de la flamme et, d'autre part, en produits vitreux, pourant sopposer physiquement au contact de l'oxỹgène de l'air.

11 a suff d’appliquer ce principe aux décors et bois de thédtres, aux charpentes, aux tentures, aux archives et bibliothèques, pour obtenir des résultats déja tris appréciables. Hais cela n'a pas empèché, pour facilitel l'évacuation des locaux en feu, de songer aux échelles fixes et mobiles, aux échelles-ascenseurs montées sur un chariot el dressées au mojen d'un treuil.

L'Exposition proprement maritime est bien organisée ef facile à voir tout entierre, grace à l’heureuse disposition qu'on lui a donnée. Elle coinprend des modèles le paquebots, des cargo-boats et des navires de guerre, le salon des dames du paquebot l'Australien, grandeur naturelle, des pholographies, des coupes en relief, des chaines, des boussoles, des matéviols d'ordre, et tout cela a pour complément les canons de marine exposés dans le Palais de la Guerre des malelots en cire, des blindages, des engins ne servant qu'd la marine militaire. Cet éparpillement de choses qui devraient ètre réunies en un seul groupe, parce qu'elles se complètent et seéclairent mutuellemeri, a été critiqué par les écrivains spéciaur, tels que M. E. Wey!. le rédacteur maritime du Tomps. En réalité, dit M. Weyl, la marine nexpose que des modèles de navires les beaux spécimens d'artillerie qu'on voit surtout al l'lisplanade des Invalides sont des produits de l'industrie privée; il y a bien sur la berge deux grosses ancres en fer, forgées par son usine de la Chaussade, dans l'intérieur du pavillon quelques appareils le transmission dordre, et une vieille torpille en vraie grandeur; mais la partio imnortante de l'Exposition consiste en réductions de navires certainement très intéressantes, bien qu'elles nz puissen! donner une idée sincère de ce que sont les originaux. Il dépend, en effet, de l'échelle de réduction qu'un torpilleur de 100 tonneaux paraisse plus imposant qu'un cuirassé de 10,000 tonneaux.

- D'ailleurs, la preuve est là sous les yeux, les Chantiers et les Ateliers de la Loire montrent un modẻle d'un éclaireur-torpilleur de 1:50 tonnes, modile plus grand que celui du croiseur le Surcouf, de 1,950 tonnes. De tous les navires dont on voit des ré. ductions, ciest le cuirassé le Trident qui frappe le plus les regards par ses dimensions, et certes il en vaut la peine avec ses canons en batterie, sa mature élevée el sos filets Bullivan en place. Il parait ainsi bien plus puissant que son voisin le Formidable, et c'est le contraire dans la réalité. Le Formudable est en acier, déplace 11,380 tonneaux et file 16 næuds; le Trident est en bois, déplace 8,946 tonneaux et ne fileque 14 nouds. C'est d'ailleurs le seul spécimen de navire de combat tout en bois qui figure dans la classe 63 . Le fer et l'acier règnent en maltres dansles autres navires.

- Ceux-ci sont nombreux, chacun de nos arşenaux ayaut envoyé quelques uns de ses produits. Voilà les cuirassés le Trident, le Formidable - ce dernier vient lientrer en ligne après dix ans de travail et porte le pavillon du chef de l'escadre de la Méditerranée, - le Hoche qu'on arme à Lorient, le Magenta, qui est sur cale à 'Toulon depuis plus de six ans. Voilà des croiseurs de toute espèce, les uns en construction, les 
autres armés. Le plus remarquable est le Dupuy-de-Lóme avec ses trois hélices et ses murailles entièrement cuirassées. C'est un retour vers le passé. Les navires blindés étaient d'abord protégés par des blindages recouvrant toute la surface visible de leur carène; puis on a limité la protection à la flottaison et aux réduits de l'artillerie; plus lar'd on l'a encore diminuée; aujourd'hui, on combine les gros blindages destinés à résister aux gros projectiles avec des blindages de 8 a $12 \mathrm{c} / \mathrm{m}$, contre lesquels on espère que les obus chargés d'explosifs puissants éclateront prématurément. Je me contente de donner les noms des croiscurs exposés: Duquesne, en station dans l'Océan Pacifique; Dupuy-de-Lome, Davout, Surcouf, Jean-Bart, en construction; Condor, Sfax, armés pour les manouvres navales.

* La marine a fait établir des coupes en relief de la plupart de ses nouveaux navires; elles sont instructives, car elles montrent fort bien le systèrne de construction adopté pour chaque type et comment le fer et l'acier se plient à tous les besoins de la navigation. '

A côté des batiments de l'ítat, les l'orges et Chantiers de la Méditerranée exposent le modèle du cuirassé espagnol le Pelryo, le croiseur le Cécille, l'aviso-torpilleur la Bombe, un cuirassé grec, un cuirassé japonais, etc. Les Chantiers et les Ateliers de la Loire exposent, de leur côté, le morlèle de l'Amiral Korniloff, croiseur russe sur lequel le tsal' Alexandre III doit se rendre à Copenhague, un modèle de torpilleur, des batiments de guerre et de commerce, l'intérieur du steamer le Paraguay. C'est en sornme un petit musce de marine.

Tout près, au bas du parc du Trocadéro, se trouve une des curiosités de l'Exposition, dont il y a licu de parler à la suite de l'Exposition de marine, il s'agit de la Siręn

- C'est une après-midi qu'elle a fait entendre pour la première fois son cacophonique mugissement. L'effet produit a été immense. Les promeneurs de l'Exposition se sont arrètés pétrifiés, toutes les conversalions ont cessé. Il y a eu une anxiété générale au point que les Triganes ont cessé un moment de jouer Estudiantina, ce qui, chez eux, est un fait rare, indice de graves perturbations.

Inquiet, chacun cherchait de quel orage lointain venait ce terrible éclat de tonnerre, quel tremblement de terre avait fait çémir les entrailles du sol; on se demandait si les menbrures de la Tour de fer n’avaient pas craqué longuement et n'allaient pas s'effondrer sur la foule.

lit le bruit était si intense, réperenté sur les bords de la Seine, répélé par les échos des palais, qu'il semblait venir de partout ensemble, et qu’on ne pouvait discerner s'il descendait du ciel ou montait du Champ de Mars...

Il venait du Trocadéro, tout en has du jardin; d'un petit chalet grand comme ça, caché sous les arbres. Construction plus que modeste, tenant de l'usine par la simplicité de son aspect, de la maison de garde par l'exiguïté de ses proportions.

Assez banalc en somme, sans le parillon de cuivre d'une immense trompette, visible du premier coup d'œil, qui traverse son toit.

C'est de la que vient tout le bruit. Un bruit effroyable, intense comme le rugisscmest d'une arnée de lions, harmonieux comne le reniflement de cent mille nez formiclablement enrhumés. Un bruit de trompettes, mais de ces trompettes de Josué dont le son renversa les murailles de Jéricho ou plutôt celles que les archanges emboucheront pour réveiller les morts.

Scientifiquement parlant, ce n'est pas une trompette, mais une sirène, ce qui est 



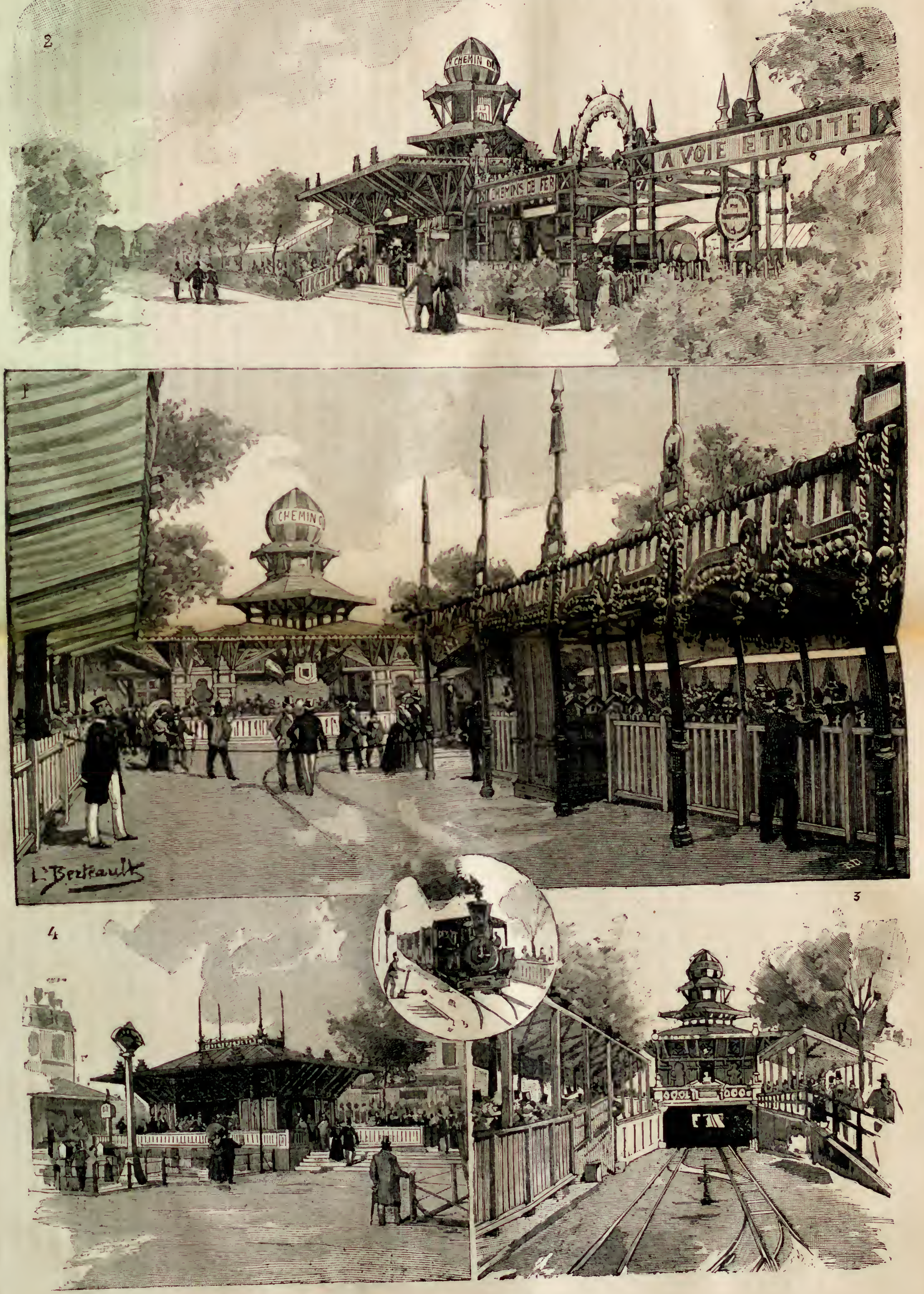


bien différent, comme jene tâcherai pas de vous l'expliquer, crainte de détails oiseux ou obscurs.

Cet appareil a été fabriqué et exposé par MII. Sauter et Lemonnier.

La sirène est un appareil dont les dimensions sont très variables. Il y en a de petites dans les laboratoires de physique et qui sont presque musicales. Il y en a d'énormes sur nos côtes, qui avertissent les navires au large des récifs dont ils approchent à travers le brouillard. Elles font un vacarme tonitruant qu'on entend, quand le vent est favorable, jusqu'à treize et quinze kilomètres, comme celle du Trocadéro.

Le principe de la sirène est des plus simples, et très connu de quiconque a ouvert une physique élénıentaire.

La sirène se compose essentiellement d'un tambour cylindrique et, au-dessus de ce cylindre, d'un disque qui peut tourner sur lui-mème comme une roue.

La surface supérieure du cylindre et le disque sont percés de trous displosés circulairement.

Ces trous sont inclinés de telle façon que l'air amené d'une soufferie dans le rylindre, par un tuyau adducteur, produit une impulsion sur les parois des ouvertures du disque.

Celui-ci se met en mouvement. Et ce mọurement, plus ou moins rapide. proiluit un son plus ou moins aigu...

Voilà tout.

Ce dispositif reproduit dans d'énormes proportions est tout le secret de la sirène du Trocadéro.

Celle-ci est actionnée par l'air comprimé, comme les petites sirènes dr pliysurue.

Mais, ici, l'air comprimé n’est plus obtenu par une soufflerie à pédales, il eit foirni par un moteur à air chaud d'une assez grande puissance.

La machine absorbe, en effet, une quantité considérable de travail; et l'on calcule que, si elle marchait d'une façon continue, elle einploierait une force d'environ soixinte chevaux.

Aussi ne lui fait-on émettre que des sons intermittents, de telle sorte que l'air comprimé, emmagasiné dans les réservoirs, ne se dépense qu’à petites doses.

Sa quantité est toujours suffisante pour assurer le fonctionnement de la sirène pendant la mise en marche du moteur à air chaud.

Faute de ces précautions, la sirène ne peut fonctionner d temps cl n'est plus d'aucun secours. Le paquebot la Victoria en a fait l'an dernier, près de Calais, je crois, ia triste expérience.

Les transatlantiques ont à leur bord des sirènes de dimensions moindres. afin de s'avertir et de se signaler les uns aux autres.

Nous avons dit que la sirène du Trocadéro peut ètre entendue jusipuat 13 hilomètres: à contre-vent, elle n'est entendue qu à 3,000 inetres environ.

Son mugissement serait, en général, perçu de tout ''aris, si notre ville, par le relief de son terrain et par le dispositif de ses maisons, qui forment écrans pour le sun, n'avait une acoustique particulièrement défectueıse.

L'administration de l'Exposition avait pensé à utiliser le cri de la sirène pour indiquer les heures d'ouverture et de fermeture de l'Exposition; mais finalement on a préféré le canon de la Tour, qui est plus prestigieux. 
L'apparei! du 'Trocadéro, que les badauds maudissent aujourd'hui, est destiné au phare de la pointe de Barfleur.

Peut-ètre gardera-t-il les vaisseaux de nombreux naufrages, peut-être évitera-t-il bien des deuils, des chagrins, des misères...

Que lesvisiteurs de l'Exposition y songent, et qu'ils aient un peu plus de considérition pour cet utile instrument - quelque douloureux qu'il soit pour leurs oreilles.

Panorama de la Compane transatrantique. - Ce panorama est une merveille dans son genre. Il est situé à l'extrémité de l'avenue de la Bourdonnais, et on y accède par un escalier, au haut duquel se déroule devant les yeux toute la flotte de la Compagnie transatlantique, en rade du Havre. L'illusion est complète, quand de la passerelle de la Touraine le visiteur voit l'entrée du port, l'embouchure de la Seine, Sainte-Adresse, les falaises normandes. Savez-vous que cette flotte compte 70 navires, tous plus beaux les uns que les autres!

Mais ce n'est pas tout, et les organisateurs de cette "attraclion ont tenu à nous montrer autre chose que cette vue d'ensemble. Au panorama est joint un diorama.

Nous voici devant le fumoir de $1^{\text {re }}$ classe de la Touraine. On y est très bien, dans ce fumoir, à en juger par les figures réjonies de ces passagers qui, un londrès à la bouche, citusent sur des sièges moelleux ou font leur partie d'écliecs alsolument comme au ccrcle. La salle à manger de $1^{\text {re }}$ classe de la Champagne est aussi agréable à voir; on a l'air d'y avoir bon appétit, et cela se concoit, car les tables sont bien servies. Le salon de conversation de la Bretagne présente un tableau fort animé. Que de luxe, mais quel contraste avec ce carré de $3^{e}$ classe de la Griscogré! O incomparable puissance des bituknotes l

Plus loin, nous assistons à l'embarquement des passagers à bord de la Normandie, au Havre. C'est l'inévitable scène des adieux, la bousculade ordinaire, les voyageurs qui se garent des colis. Beaucoup de vérité dans le rendu.

On'a eu l'heureuse inspiration de nous faire voil' un atelier d'ajustage et de montage du cliantier de Penhoët, el une vue générale de ce chantier. C'est une leçón de choses.

Voici une chaufferie de la Champagne. Il doit y faire chaud, et l'on ne peut s'empècher de plaindre ces malheureux chauffeurs qui, le torse nu, excitent l'ardent foyer et le gavent de combustible. C'est grace à eux, pourtant, que toute cette flotle navigue, que la Bourgogne entre dans le port de New-York, que l'Eugène-Pereire entre dans le port de Marseille el que la Ville-de-Rome sort du port d'Alger.

Nous le répétons, cette exposition de la Compagnie transatlantique mérite une longue visite, parce qu'elle fait comprendre à ceux qui n'ont jamais vu, nous ne disons pas la mer, mais un grand port marchand, ce que sont ces immenses batiments qui vont porter aux quatre coins du monde nos négociants et leurs produits. Les paquebots sont de véritables maisons flottantes. Le confort et le luxe s'y trouvent réunis à un tel degré que c'est vraiment plaisir d'y prendre place et d'y passer quelques jours de traversée.

L'Aguculture. - La classe 49 du groupe 6, dénommée Matériel et procédés des exploilations rurales et forestieres, embrasse tout ce qui concerne les plans de culture, assolements et aménagements agricoles; le matériel et les travaux du génie agricole (desséchements, drainages, irrigations); les plans et modèles de batiments ruraux; 
les outils, instruments, machines et appareils servant au labourage et autres laçons données à la terre, à l'ensemencement et aux plantations, à la récolte, à la pré. paration et à la conservation des produits de la culture; les machines agricoles mues par la vapeur ou par des attelages, le matériel des chariols et des transports ruraux; les machines locomobiles spéciales et les manèges; les matières fertilisantes d'origine organique ou minérale; les appareils pour l'étude physique el chimique des sols; les plans de systèmes de reboisement, d'aménagement, de culture des forêts; le matériel des exploitations et des industries forestières.

A côté du matériel des procédés des exploitations rurales et forestières, la classe 50 nous offre l'Exposition du matériel et des procédés des usines agricoles el des industries alimentaires. C'est là que vous vous instruirez sur les fabriques d'engrais artificiels et de tuyaux de drainage; sur les minoleries, féculeries, amidonneries, huileries, brasseries, distilleries, sucreries, raffineries; sur les pétrisseurs et fours mécaniques; sur les ustensiles de pâtisserie et de confiserie; sur la fabrication des pâtes, du biscuit de mer et du chocolat; sur la torréfaction du café; sur la confection des glaces el des sorbets.

Dans la classe de statistique agricole et d’agronomie, on a rangé les études relatives au sol, aux eaux, au climat, aux populations rurales, aux stations agronomiques et laboratoires agricoles, aux syndicats, sociétés et comices, aux institutions de crédil pour l'agriculture, à l'administration agricole. On s'arrètera avec profit devant les cartes agrunomiques, agrologiques, hydrographiques et climatériques, devant les plans de fermes-écoles, d'exploitations rurales, d'usines agricoles. Il y’ a la des écuries, des bergeries, des étables, des chenils, des poulaillers, des pigeonniers, des faisanderies en miniature, à côté de machines agricoles des types les plus variós.

Les couveuses artificielles sont très entourées. Imaginez. une bolte a la phartie supirieure de laquelle est une caisse de zinc reposant sur une toile métalliqune galvanisée ct contenant une certaine quantité d'eau. Dans un retrait ménagé sous celle caisse, une lampe sert à élever au degré voulu la température de l'eau, et au-dessous de la toile métallique un tiroir contient les œufs disposés sur une couche de paille ou de foin. Au bout de quelques jours, l'incubation est parfaite, mais on laisse les retits poulets encore vingt-quatre heures dansle tiroir, après quoi on les trunsporte dans une sorle de cage. au bout de laquelle est un bassin de zinc pour recevoir de leau chaude. On adapte au-dessous du bassin une peau destinée à abriter les petits qui, après huit jours de réclusion, sont assez forts pour être exposés au grand air. C'est simple, comme on voit, mais nous ne prétendons décrire ici qu'un type entre cent, et il est possible qu'il y ait dans les galeries de l'agriculture des appareils plus perfectionnés que celui que nous avons vu fonctionner.

Un industriel anglais a installé un moulin complet a cylindre qui, paralt-il, moud cent quintaux métriques par vingt-quatre heures. Le matéricl comprend un moteur a vapeur avec sa chaudière, un neltoyage complet, des broyeurs el des convertisscurs, des tamis extracteurs, des sasseurs, des aspirateurs, elc. Il fonctionne, près de l'Esplanade, en face d'une boulangerie hollandaise, a cóté d'une coquette laiterie anglaise.

La viticulture est représentée par des types de batiments d'exploitation, par le matériel de la culture de la vigne, par des réductions de chais et des caves, par une belle collection de cépages et par la réunion de tout ce qui sert a combaltre les mala- 


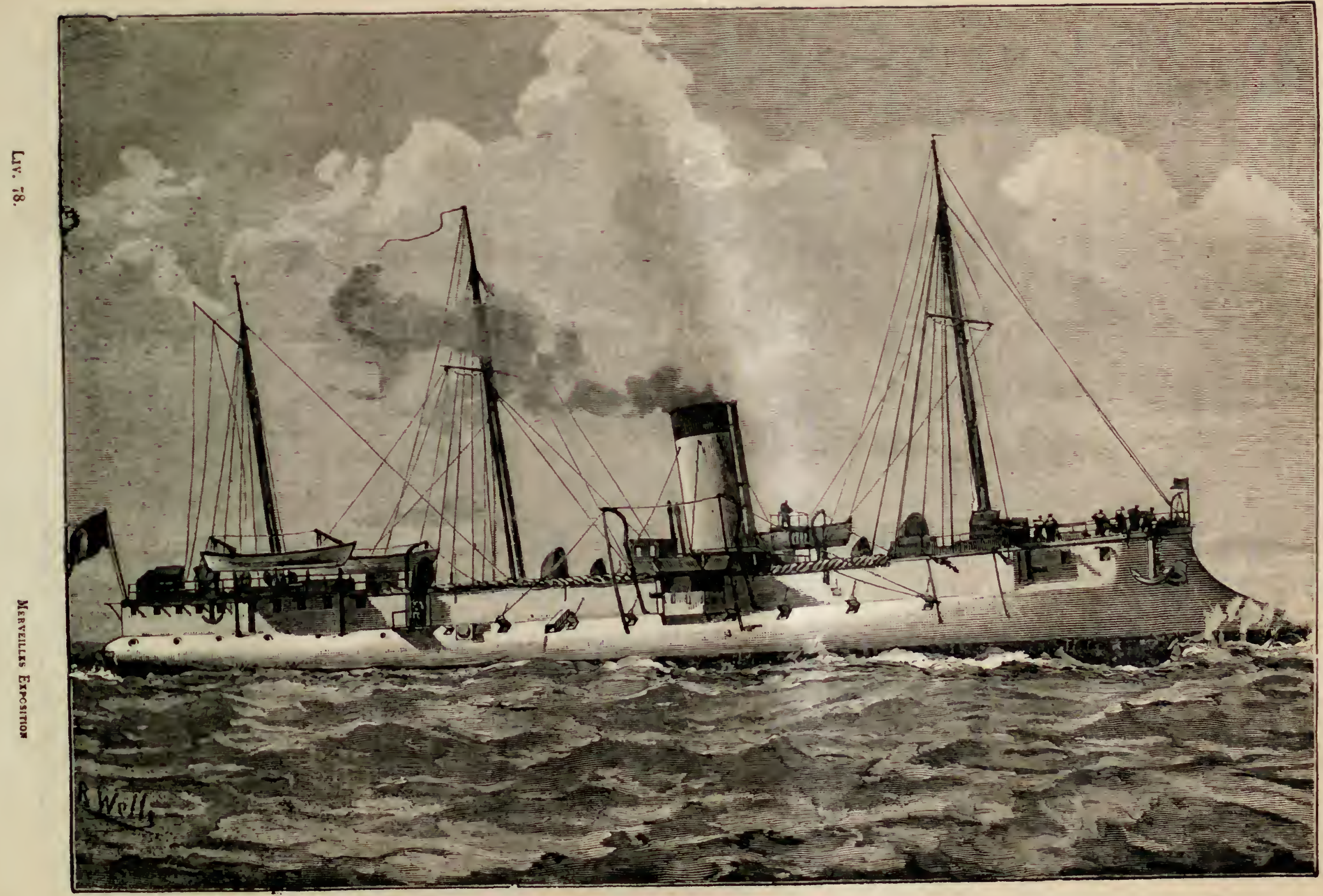

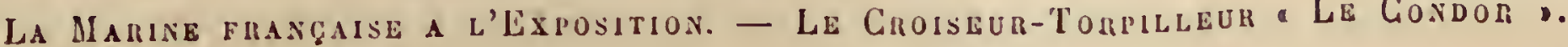


dies de la vigne. C'est dans cette classe que se trouve la Porte de la Cité de Carcassonne toute en bouteilles et en tonneaux, et surtout le tonneau monstre.

On sait par quelles péripéties a passées le tomneau monstre que M.M. Mlereier el Cie, d'Épernay, ont expédié à Paris, pour figurer a l'lixposition : chemins défoncés et obstrués, chariot embourbé, ponts et portes trop étroits, rien n’a été épargoné à ce lourd voyageur que traînaient dix paires de boufs en plaine et plusicurs chevaux de renfort aux montées. Enfin, il a fait son entrẻe daus la houne ville de Paris un dimanche matin, par un beau soleil, qui avait permis a la foule d'aller lui souhaiter la bienvenue.

Là, M. Mercier, qui accompagnait son tonneau, se croyait au buut de ses peines, Hélas! il fallail pénétrer dans le Champ de Mars, et que d’obstacles encore!

La demeure de ce foudre se trouvait au Palais des P'roduits alimentiires, sur le quai d'Orsay. Pour lui faire gagner son gite, on a dủ supprimer loute une paliscade déjà couverte d'affiches Crespin, et dénolir une partie de la csarda hongroise, dont les propriétaires se demandaient, ellrayés, si le Tisza n'arait pas dit vrai, l’année dernière, lorsqu'il piédisait à ses compatriotes qu'ils ne seraient en sécurité à Paris, ni eux ni leurs biens.

Ce n'est pas tout: plusicurs bancs gênaient, on a dû les enlever; puis deux arbres se trouvaient trop rapprochés. M. Alphand a autorisé qu'on les déplaçâl momentanément. Enfin, on a pu rouler le tonneau sur un lit de maçonuerie préparé à son intertion, de crainte que son poids n'enfonçàt le plancher.

Donc aujourd'hui il repose sur de solides supports en fer, majestueux, tranquille, et montrant aux visiteurs ses cercles immenses, ses sculptures, ses ornencntations de métal et surtout sa capacité surprenante, soit deux cent mille boutcilles.

M. Mercier n'est pas prèt à recommencer cette odysscee. Que de peines, que d'ennuis et que de paniers de champagne distribués à droite el a gauche, d litre de dommagesintérèts, pour calmer les justes colères I

La partie des galeries consacrée à la lutte contre le phylloxera, le mildew et autres insectes de même acabit est très réussie. Il faut voir surtout les Lxpositions spéciales de la Société centrale d'agriculture de l'Hérault, des Sociétés du Gard, de l'Aude, des Pyrénées orientales, de la Gironde, de Chalon-sur-Saône, de Lyon. Les chais modèles, avec leurs pastaurisateurs, méritent une visite spéciale.

Vans la section d'apiculture, nous remarquons les ruches a cadres mohiles, et dans la section de sériciculture les moyens préventifs contre la maladie dis ver's a soie.

On a pu se rendre compte, au concours de Koisiel qui a cu lieu du 19 a 22 juillet, des progrès réalisés dans l'outillage agricole. Plus de 20 faucheuses prirent part au concours. Les moissonneuses étaient de deux sortes: moissunneuses ordinaires et moissonneuses-licuses. Le directcur de la station agronomique de l'Est, II. L Grandeau, expose ainsi les résultats du concours, dont il a suivi toutes les expériences. - D'ulsord, dit-il, les moissonneuses-lieuses semblent aroir cumpuis définitivernent leur place dins la mécanique agricole; les grandes exploitations, où la rareté et le prix de la mund'œuvre entrent en ligne de compte d'une façon dominante, peuvent les emploger ar c succès; il y aurait cependant, de l'avis des hommes les plus compétents, intérét a modifier la dimension de quelques-unes de leurs pieces afin de les meltre en accord avec la taille de nos céréales, beaucoup plus élevée que celle des récoltes arnéricames. En ce qui concerne les moissonueuses simples el les faucheuses, des progrds riels se font chaque jour, mais il n'en est pas qui ail un caractere exceptionnel; ces deur 
excellents outils se propagent de plus en plus dans nos exploitations rurales. Non senlement leur emploi diminue le prix de revient de la moisson ou de la fenaison dans la plupart des régions agricoles, mais il a l'énorme avantage de permettre la récolte rapide, ce qui, avec les variations de climat, les pluics fréquentes et les autres accidents atmosphériques, est loin d'ètre sans importance.

- Un autre résultat du concours de Noisie!, très agréable pour nous à enregistrer, c'est le progrès notable que la construction française a faite depuis dix ans. Sans doute, les machines américaines conservent les qualités qui ont fait leur succès, et la fabrication des États-Unis demeurc tout à fait remarquable: mais il n'est que juste, c'est, je crois, l'opinion du jury, si compétent, qui a suivi les essais de Noisiel, - de constater que la France a conquis définitivement une place excellente dans la construction des faucheuses et des moissonneuses.

- La dernière conclusion qui se dégage de ce que nous avons vu avec tant d'intérêt à Noisiel mérite, je crois, quelque attention.

- Pour se faire une idćc exacte de la valeur d'une machine agricole, il faut l'expérimenter dans des conditions différentes de celles que permet un concours public, si bien conçu et dirigé qu ill soit, ce qui était le cas de Noisicl. Aussi la création récente de la Station d'essais de machines agricoles de l'Institut agronomique nous paraît-elle appelée à combler de la façon la plus heureuse ce desideratum. Dans cet établissement dont la direction a élé confiée à un jeune professeur distingué de Grignon, M. Ringelminn, se trouvent réunis les instruments de précision et les moyens d'essai à l'aide de prucédés scientifiques dont l'emploi peut seul permettre de déterminer d'une façon alssolue la valeur réelle d'une machine.

Nous cédons maintenant la parole a M. Jules Richard. a'Exposition de l'agriculture tient tout entière sur le quai d'Orsay. Curvilignes entre le Champ de Mars et le pont de l'Alma, puis rectilignes jusqu'au pont des Invalides, les batiments qui lui sont consacrés s'étendent en delıx séries de pavillons séparés par une voie assez large.

"Ici, les splendeurs architecturales et le luxe du décor ont été sacrifiés à de commodes installations où s'ćtalent, classées méthodiquement, toutes les richesses agricoles que l'homme, par son industrie, a su tirer de la terre. Il faut être un peu spécialiste pour visiter avec fruit ces longues galeries. Et cependant, elles sont dignes d'un haut intérêt. Si la table est mise tous les jours pour le déjeuner et le diner de l'univers eutier, c’est grace à l'agriculture, la mère nourrice du genre humain.

- Sans nous appesantir longuement sur les belles choses que l'on nous présente. à chaque pas, nous allons indiquel les principales divisions dans lesquelles elles sont classées : cela gruidera mieux chacun dans ses recherches privilégiées.

- Et d'ahord rappelons tout de suite que depuis trente années notre industrie agricole marche à pas de géant. L'impulsion fut vigoureusement imprimée sous l'Empire et elle se continue toujours sans s'arrêter.

- Bien que les cultivateurs se plaignent très haut de quelques-unes des dernières récoltes et des conditions économiques au milieu desquelles ils vivent, ils ne ralentissent pas leurs efforts généreux. Ils se disent que si la récolte n'a pas été bonne cette année, elle sera meilleure l'an prochain. La culture est l'industrie du lendemain plein d'espoir et de promesses. L'homme isolé et silencieux ne se laisse jamais aller au découragement, il croit dans l'avenir. 

LES MERVEILLES DE L'EXPOSITION

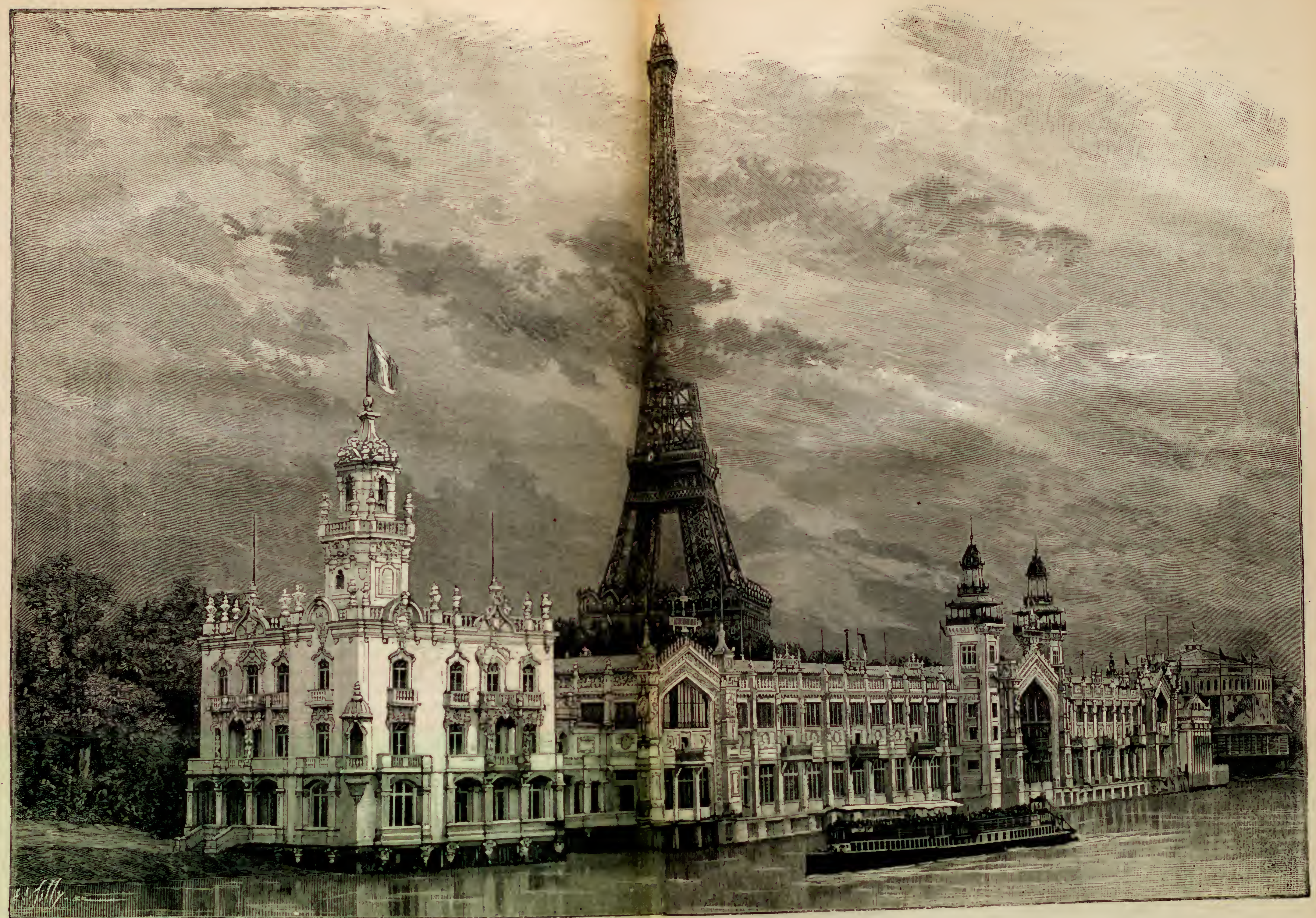

LE PALAIS dES PrOdUITS ALI DENTAIREs. 
- En agriculture, nous ne sommes tributaires de l'étranger que pour le llé, et encore dans une proportion infime: un vingt-deuxième au plus sur une moyenne de dix ans. Nous exportons du vin, des eaux-de-vie, des machines agricoles pour des sommes considérables. Le commerce des graines de serrence produit les résultats suivants : quinze millions d'exportation, ciny d'imporlation. Celui des fleurs se traduit par un mouvement de cinquante à soixante millions à l'extéricur.

r Les États-Unis d'Amérique, le Mexique, la République Argentine sadressent presque uniquement à nous pour les graines.

" On le comprend, nous entrons dans une partie de l'Exposition dont les halbilants sont habitués à faire des miracles; ils fabriquent de l'or avec une graine et un peu de fumier. Nous sommes dans le temple de la vraie pierre philosophale.

La première partie sur le bord de l'eau en quittant le Champ de Mars nous montre les produits des collectirités régionales. Chaque région de la France y est représentée par l'ensemble de ses produits; tel pays produit des tertiles, tel autre des huiles; celui-ci des vins, celui-là du blé. C'est une sorte de géographie agricole sùrement éliquetée et cataloguée avec preuves à lappui. En cinquante minutes, on peut apprendre la statistique complète de la production végétale en France.

Sauf les bestiaur el les animaux de basse-cour, qui auront leur exposition à part, tout ce qui constitue la vie rurale est représenté au quai d'Orsay.

Nous avons constaté, en traversant le Trocadéro, que le climat de la France était particulièrement favorable à la culture des fleurs. Nous pourons affirmer qu il l'est au moins autant pour la grande culture et l'éleruge des troupeaux; cette heureuse disposition du climat a développé chez nous, plus que chez toutes les autres nations d'Europe, le gout de l'acclimatation des plantes exotiques de toutes les espices, aussi le besoin d'inventer tous les jours des instruments plus perfectionnés et le consljuire une quantité considérable d'engins nouveaux.

La partie curviligne du quai d'Orsay est sectionnce en deux parties égales séparécs par un vaste palais qui a reçu le nom de Pulais des Produits alimentaires. Sa destination est suffisamment indiquée. Il contient lous les échantillons des classes : cla-ic 67, céréales, produits farineux avec leurs dérivés; classe 68, produits de la boulangerie et de la pâtisserie; classe 72, condiments, stimulants, sucres et produits de la confiserie. Ici on peut consommer, - naturellement en payant, - tout ce que l'oil caresse.

En outre, sur la face extérieure regardant le fleuve, des bars et restaurants offrent les moyens de transformer une dégustation sommaire en repas plus solide. L'essai des vins et liqueurs n'y perdra rien, car le règlement dit que toutes les matières comestibles exposées devront être mises, dans le Pulais des Produits alinentaires et ses annexes, à la disposition des consommateurs.

La classe 73 bis et la classe 73 ter: Agronomic, statistique agricole, organisation, méthodes et matériel de l'enseignement agricole, sont placées entre le Palais dlimentaire et le Champ de Mars.

Nous les avons vues un peu en courant, car il fiudrait passer plusicurs jours pour les examiner en détail, et encore si l'on s'y connaissait. Après le Pallais. ccla devient bien plus intéressant pour le rulgum pecus.

On n'a pas besoin d'être un initié pour admirer les curieux spécimens d'exploilations rurales et d'usines agricoles exposés dans la classe 74. Tous les types de construclions sont reproduits en petits modèles: distilleries, sucreries, raffineries, brasseries, mino- 
teries, féculeries, amidonneries, magnaneries, fromageries et laiteries s'offrent aux yeux, permettent tout le mouvement industriel issu de la production agricole.

La galerie parallèle à celle que nous venons de décrire et qui suit le quai, contre le petit chemin de fer Decauville, - une des curiosités de l'Exposition, - est consacrée au matéricl agricole et viticole. Cette portion, fort intéressante sans doute, mais un peu spéciale, est séparée au milieu de la face du palais alimentaire par un orchestre de Triganes, jouant furieusement des air's hongrois endiablés. Les organisateurs de l'Exposition ont voulu certainement compenser par des flots d'harmonie tumultueux le silence relatif qui règne dans cette portion où l'on passe assez rapidement.

Avant de quitter ces pavillons, n'oublions pas de visiter avec attention et avec respect toute l'Exposition de la viticulture, l'une des gloires et l'une des richesses de la France.

Les procédés de culture, la fabricalion, - mon Dieu! oui, la fabrication, - car le vin qui sort du pressoir n'est pas buvable, ni surtout conservable et transportable, enfin le vin elı fut et en bouteille méritent notre admilation, nous dirons plus: notre vénération.

La lutte contre le phylloxcra est aussi décrite en entier avec ses différentes méthodes plus ou moins efficaces. Un ministre de l'agriculture consciencieux, - trop consciencieux mème, - avait imaginé d'ordonner que des spécimens de vignes contaminées fussent amenés au quai d'Or'say pour' y représenter les diver's états de la maladie. Outre qu'elles auraient pu infecter les plantes voisines, il y avait un danger grave à donner une place oflicielle au p!'ylloxera sur le calalogue de l'Exposition. C'était offrir une raison aux ennemis de la France de refuser ses produits.

Ne voyons-nous pas les Anglais, sous prétexte que la peste bovine a sévi sous l'Empire, il y a vingt-cinq ans, par'mi les habitants de nos paturages, repousser nos bœufs à l'importation, landis qu'ils achètent de toute confiance la viande abattue de mème provenalice.

Le mème raisonnement serait à craindre pour la viticulture. Évidemment l'étranger se fera toujuurs une fẻte de boire nos vins exquis, - les rois de toutes les tables, - le vin I'est pas phylloxéré et ne phylloxere pas. Mais la vigne, dont nous avons fait jadis un grand commerce, - commerce que nous reprenons déjà, - la vigne, c'esi bien diflerent.

Pendant vingt ans, les étrangers nous auraient dit : Vous avez encore le phylloxera; vous l'aviez encore en 1889, puisque vous aviez exposé des vignes phylloxérées. C'est officiel. Regardez plutut les circulaires d'un de vos ministres. "Heureusement en France les ministires changent, et avec eux les instructions ministérielles.

Après le remplacement du ministre phylloxérant, les viticulteurs français ont respiré.

Culte première partie absolument terminée, il nous faut gravir un escalier, traverser un pont volant, redescendre un autre escalier, afin de gagner la $2^{\circ}$ partie.

Ces escaliers à inonter et à descendre sont les seuls inconvénients de l'Exposition; mais il était impossible de les éviter, puisqu'on ne pouvait trouver à Paris le terrain énorme, alssolument de plain-pied, nécessaire pour loger près de quarante mille exposants.

Mais ici la fatigue est heureusement compensée par la vue d'une porte monumentale sous liquelle passent aussi les personnes qui circulenten dehors. Le pont franchi, nous 
retombons en pleine exposition agricole, et il nous faut examiner pas à pas ou franchir rapidement l'espace. Il n'y a pas de milieu.

Les expositions agricoles étrangères succèdent à nos produits nationaux.

Les connaisseurs admirent pour leur importance et leur curiosité celles des États-Unis d'Amérique, du royaume de IIollande, de l'Angleterre et de l'Espagne; nous donnons la palme pour le progrès aux États-Unis et à l'Angleterre.

Il ne faut pas croire que les Expositions étrangères sont la répétition en petit de notre Exposition agricole. I.es procédés et les instruments difèrent beaucoup plus en agriculture que dans l'industrie. La nature du sol, la différence du climat et surtout celle des produits engendrent des outils et des méthodes très diverses. Pour les connaisseurs en agriculture, l'Angleterre, où l'on recherche en mème temps l'économie dans la dépense et la perfection dans le produit, et les lítats-Unis, où l'on s"inspire surtout du besoin de procéder rapidement, sont utiles à étudier de près.

Si les organisateurs du quai d'Orsay ne s’étaient pas inspirés du désir de faire du pittoresque en dehors de la portion absolument sérieuse de l'Exposition agricole la promenade serait un peu fastidieuse. Mais en outre, les objets agréables ì voir, ou que l'on utilise chaque jour à la campagne, distraient agréablement. Aujourd'hui que la villégiature remplit la moitié de la vie des citadins, que tout le monde possède une maison des champs vaste ou petite, l'Exposition agricole attirera beaucoup de visiteurs. Nous recommandons spécialement aux personnes qui veulent explorer avec soin l'Lxposition d'agriculture de ne pas craindre de retourner sur leurs pas. Cette Exposition, en effet, est divisée d'abord en deux galeries parallèles, puis, chaque galerie elle-mème est subdivisée dans sa longueur en deux ou trois rues qu'il ne faut pas omettre de visiter successivement, sous peine de perdre tout le fruit de son travail.

Quelques détails sur l'Exposition des produits alimentaires ne seront pas déplacés. Nous remarquons dans la classe 67 , les céréales et les produits farineux avec leurs dérivés. Le froment, le seigle, l'orge, le riz, le mais, le millet y coudoient les gruaux, les grains mondés, les fécules, les pates el les diverses préparations propres, comme les nouilles et les bouillies à remplacer le pain. Les patisseries de toutes les nations ont rivalisé de zèle poar confectionner les gateaux les plus alléchants, et le visiteur qui veut se réconforter a le choix entre ces pièces de patisseries et le pain sous toutes formes: avec ou sans levain, pain comprimé pour voyage, pain façonné, pain de fantaisie.

Le pain ne suffit pas, car sans ètre gourmel on aime à lui enlever sa sécheresse par une habile annexion de poisson ou de viande. Passez donc dans la classe 70 , et choisissez, si vous pouvez, dans ces multiples étalages: viande salée et conservée, extrait de viande, jambons, volailles, gibier, poissons, crustacés et coquillages, etc. L'appétit ne vous vient-il pas devant toutes ces bonnes choses? Arancez jusqu â la classe 72, où vous trouverez du poivre, de lacannelle, des piments, de la moutarde, des karis, des sauces toutes faites. Pour votre dessert, cette meme classe 72 vous donnera tous les produits de la confiserie et la classe 70 les plus beaux fruits. Vous vous arréterez malgré vous devant un bloc gigantesque de chocolat Menier, qui représente la fabrication d'un jour : 50,000 kilos $=200,000$ francs.

Les appareils automatiques à écrémer le lait ont fait d'immenses progrès. L'usage de ces appareils, originaire de Suède et de Danemark, a aujourd'hui droit de cité dans 


\section{LES MERVEILLES DE L'EXPOSITION}

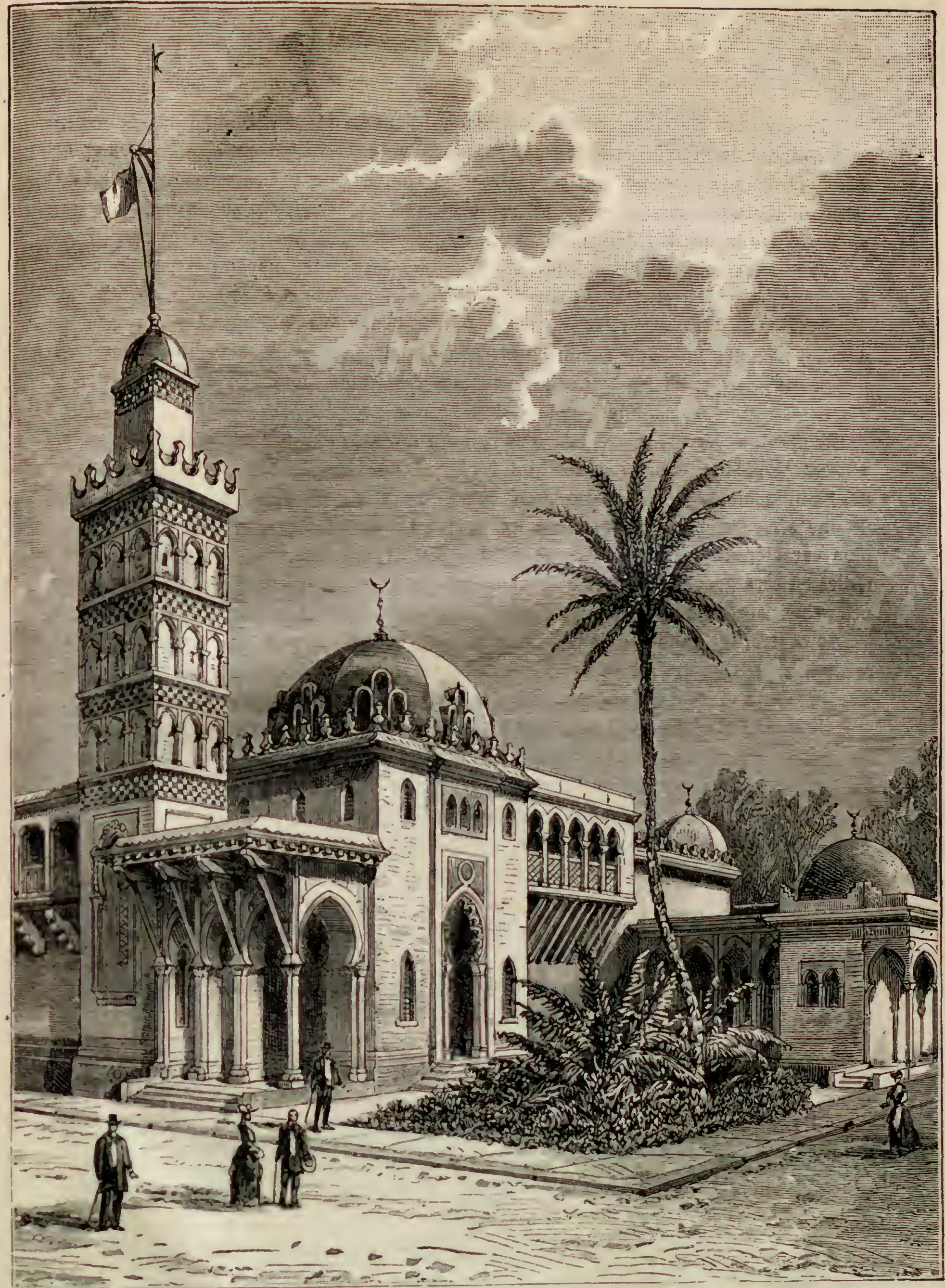

Le Palais de L'Algérie.

Liv. 79.

Meaveilles Exrositios 
la mécanique agricole. Ce sont des turbines d'où s'écoulent d'un côté la crème, de l'autre le lait écrémé.

Ux tour sur l'esplaiade des miraldes. - Nous avons encore bien des choses à apprendre, bien des choses à voir sur l'Esplanade des Invalides, car l'Exposition coloniale n'a été terminée que fort tard. On y voit même encore des ouvriers occupés à

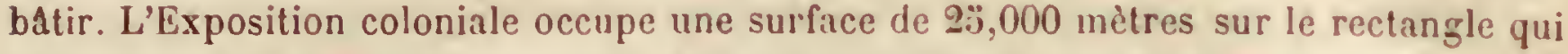
s'étend entre la rue de l'Université, la rue de Grenelle el la rue de Constantine.

L'autre rectangle de l'Esplanade des Invalides est occupé par les Expositions du Ministère de la Guerre, du Ministère de la Marine, d'hygiène et d'économie sociale.

Réaliser une figuration rationnelle et attrayante à la fois de l'industrie, des mæurs, de l'aspect extérieur de chacun de nos groupes de possessions dans les différentes parties du monde, tel est le programme que s'est tracé, pour l'Lxposition de 1899. l'Administration des colonies. On sait si elle a réussi.

Le plan qui répond a l'exécution de ce programme comprend : $1^{\circ}$ un palais central où sont réunies les collections de l'État, les Expositions des Travaux publics, les envois des établissements pénitentiaires, ainsi que les travaux géographiques et statistiques; 2o une série de pavillons spéciaux qui seront la reproduction des constructions les plus caractéristiques des différents pays et constitueront autant d'expositions partielles où sera groupé tout ce qui peut donner la physionomie vraie et pittoresque de nos principales colonies. Nous en arons donué une description détiillée.

Au centre, le grand Palais des Colonies arec ses tourelles et pavillons en saillies, ses toitures ślégantes et sa large véranda circulaire; des revêtements de briqques émaillées aux vives couleurs compléteront l'originalité el l'éclat de ce monument.

Sur la droite se dresse la pagode d Angkor (Lxposition du Cambodae), reproduction fidèle d'un des édifices de cette étonnante cité d'Angkor, la merveille de l'architecture khmer qui peut rivaliser avec les chefs-d'œuvre de l'architecture hindoue.

Le palais placé sur la gauche du Palais des Colonies et qui sert à l'lixposition de la Cochinchine, offre le contraste d'un art tout différent. Les plans en ont été dressés à Saïgon. C'est l'image très fidèle de ces riches et curieuses habitations qui nous ont b́té si souvent décrites depuis quelques années par les nombreux visiteurs de l'extrème Orient. Au premier plan, en avant du Palais colonial, à droite et à gauche, s'ếèrent la Pagode de Chandernagor (Inde française) et la Pagode tonkinoise.

Une maison créole dans laquelle est établi un restaurant colonial complète l'en. semble des constructions les plus importantes.

Puis vient la série des habitations indigènes; le village pahouin (Gabon), le village apfourou (Congo), le village tahitien, le village canaque, avec sa grande case de chel d'une forme et d'une décoration si pittoresques; le village sínégalais, enfin, lanqué de la tour de Saldé, un des plus beaux modèles des noınbreux blockhaus que le général Faidherbe a construits pour la défense du pays. Dans ces villages des indigines exercent sur place leur industrie et constituent un des attraits de l'Txposition culoniale de 1889. Tous aujourd hui sont en activité.

Voici encore une case de colon concessionnaire, un grand bazar ngricole, des pavillons de dégustation.

Enfin une grande scrre étale dans toute sa richesse, la flore coloniale depuis scs plus beaux arbustes jusqu'à ses fleurs les plus étranges el les plus délicates. 
Ce programme est on le voit très complet. Il a été élaboré sous l'administration successive de MM. de la Porte, Étienne et Félix Faure, sous-secrétaires d'état des colonics qui ont eu pour collaborateurs, dans cette œuvre patriotique, une commission exécutive représentant la commission d'organisation et présidée par M. Jacques Hé Irard, sénateur de l'Inde française; M. Isaac, sénateur de la Guadeloupe, remplit les fonctions de rapporteur. L'Administration est représentée par M. L. Henrique, commissiire, MM. des Tournelles et Paul Révoil, commissaires-adjoints. Les plans officiels approuvés par l'Administration et la Commission sont dus à M. des Tournelles et à M. Sauvestre. Ce dernier, architecte de la Tour Eiffel.

Sans doute, le public fait de lui-même des classifications dans l'Exposition et chacun va, d'instinct, où le poussent son tempérament et ses goúts.

Un des coins les plus curieux de l'Exposition universelle est la partie de l'Esplanade des Invalides réservée aux colonies. Cette agglomération de constructions originales offre un aliment aussi bien à la simple curiosité du simple badaud qu'à l'observation du penseur et à l'étude de l'artiste. Dans ces sortes d'exhibitions, on avait généralement reproduit pour ainsi dire en décors les habitations dont on voulait montrer un spécimen, et, dans ces baraques en toiles peintes, on avait installé des aborigènes de Montmartre ou de Belleville accoutrés de costumes plus ou moins exacts empruntés à la friperie d'un théatre quelconque. Cette fois, ce n'est pas une reproduction, c'est la maison elle-mème que l'on voit, et les ètres qui vivent la sont débarqués hier des contrées lointaines dont on veut révéler l'existence.

Rien ne peut donner une impression plus saisissante des mœurs arabes que l'intérieur kabyle, reproduit par notre gravure. Dans un gourbi grossier construit en torchis et dont le sol est fait de terre battue, réduit sombre et triste où le jour et l'air pénètrent à peine, des femmes accroupies sur les talons travaillent à tisser de la toile sur un métier primitif. Ces fellahs exécutent leur besogne avec régularité et sans lever les yeux sur les visages curieux de la foule qui les entoure, sans se préoccuper du milieu grouillant et si nouveau dans lequel elles ont été brusquement emportées. Elles ont des attitudes pleines de gràce hiératique et simple qui rappellent certaines peintures égyptiennes du temps de Sésostris; leurs mains agiles vont et viennent sans relâche, ne s'arrètant qu'à l'heure d'un maigre repas composé de riz, de galette de maïs et d'eau. Aucune pose, aucun effet voulu, aucun cabotinage; on a la vision d'une scène biblique.

L'étonnement des visiteurs de l'Exposition n'a pas été mince en apercevant dans la section des colonies plusieurs rangées d'élégants petits cabriolets, légèrement construits et pourvus de brancards très courts, cet étonnement s'est accru lorsqu'on a vu ces nignons véhicules trainés par des Annamites et faisant aux fauteuils roulants, en usage depuis l'inauguration, une sérieuse concurrence.

Ces voitures ont un nom, on les appelle des pousse-pousse; vous en dire l'origine me serait véritablement impossible, bien que je l'aie patiemment cherchée et demandée à tous les échos de l'extrême-Orient. En apparence cette appellation semble avoir une origine française, et cependant rien n'est moins probable car le pousse-pousse est peu en usage dans nos possessions des mers de Chine.

ه

On n'en trélve notamment pas un seul à Saïgon et pas davantage à Pnom-Penh; ils ont fait leur apparition à IIanoï et à Haïphong depuis un an environ.

C'est que, si l'on y réfléchit, ce mode de locomotion n'est pas en rapport avec nos 

LES MERVEILLES DE L'EXPOSITION

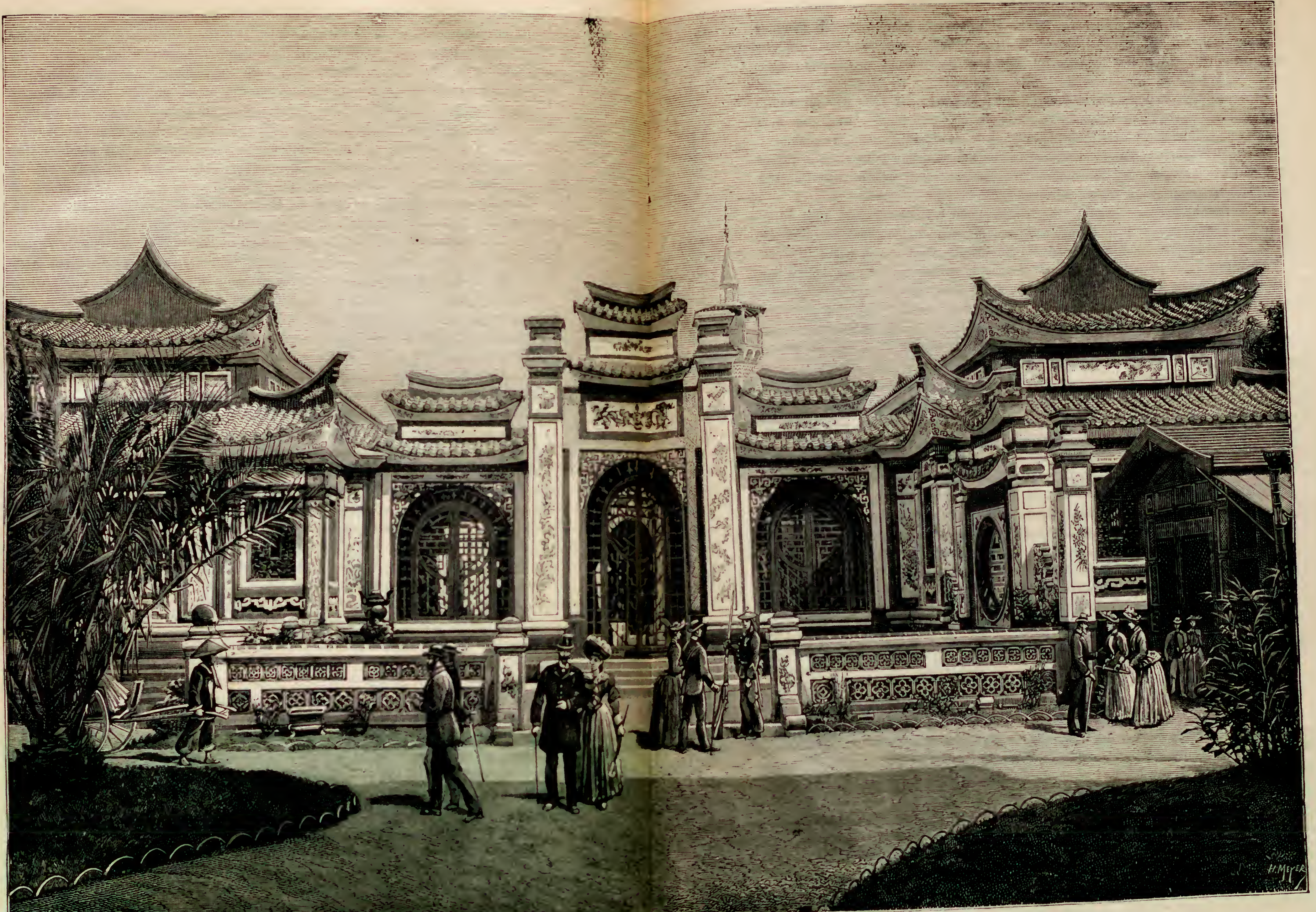

LE PALAIS DE LAMRAY-TOKEIN A L'ESPLANADR DES INYLIDES. 
mœurs et notre caractère. Nous nous faisons difficilement à cette idée que le rôle d'un homme; quel qu'il soit, est d'en trainer un autre, et nous nous faisons difficilement a cette idée, par contre, bien anglaise, que rien n'est plus naturel et plus logique que ce simple fait.

Après ça, vous m'objecterez sans doute que le fauteuil roulant présente les mènes inconvénients et se prète aux mêmes critiques. Je n'y contredis pas, mais, pour mon humble part, il ne m'est arrivé qu'une seule fois de me servir des pousse-pousse.

C'était à Singapore, où le port est assez éloigné du centre de la ville. Le pilquebot qui me porlait, moi et ma fortune, allait lever l'ancre; il était près de minuit et déjà le sifflet avertisseur s'était fait entendre une fois.

Il me restait donc tout au plus vingt minutes pour rejoindre le bord, et il fallait. bien s'en contenter, car, selon l'usage antique et fort peu agréable, mais parfaitement justifié, le commandant eùt donné, malgré mon absence, l'ordre du départ.

Un Anglais que je consultais sur les moyens de locomotion les plus rapides, ine conseilla vivement de ne prendre ni fiacre, ni tramway et de héler un " poussepousse.

N'ayant pas le loisir d'objecter fuor que ce soit et de discuter, je me rendis a ces raisons el je n'eus qu'à m'en féliciter. car, grace à cette petite voiture j’arrivai sur le quai d'embarquement bien avant le départ du paquebot.

Mais, dans les Indes comme en Chine et au Japon, les a pousse-pousse , sunt. presque invariablement trainés par des Chinois et des Japonais qui, à cet exercice, acquièrent des biceps qu'envieraient nos plus célẻbres lutteurs de foire. De quoi ils ne se portent pas mieux d'ailleurs. Car a plusicurs reprises une campagne fut faite par les Européens et les Chinois contre ce métier que l'on peut à juste titre appeler un métier de cheval et qui vaut à ceux qui s'y livrent un épuisement rapide. En effet malgré leurs apparences robustes, tous les traineurs de "pousse-puusse vneurent jeunes. Mais cette campagne n'obtint jamais aucun succès. Les Anglais pour qui le bien-ètre, qu'il gène ou ne goène pas le prochain, est la première des nécessités de la vie, la combattirent vivement et obtinrent gain de cause chaque fois.

Ainsi qu'on a pu le voir, les Annamites affectés au service des a pousse-pousse od l'Exposition n'ont rien qui les désigne spécialement pour cette dure besoğne. Chélifs et malingres comme presque tous leurs compatriotes, on a eu l'idée bizarre de leur faire faire ici, sous un climal qui ne leur est pas familier, un travail qu'ils ne font pas. chez eux. C'est pour le moins imprudent. Aussi leur a succès, est-il plus que douteux; ils ne a chargent pas '. Le public quelque envie qu'il en ait, n'ose monter dans les petits cabriolets, et nous avons entendu des visiteurs protester a ce propos sur l'exploitation de l'enfance!... Franchement, s'est même écrié hier un confrère, impossible, quand on est gros et quand on a un peu de pudeur, de monter lì dedans!

Mais on se trompe étrangement en prenant ces Annamites pour des eufants. Il en est peu, au contraire, qui aient moins de trente ans. Jusqu'd près de quarante ans l'Annamite conserve, en effet, une physionomie enfantine.

Postes et télégraphes. - En arrivant sur l'Esplanade, nous rencontrons à main droite, en face du Palais de l' $\Lambda$ lgérie, le pavillon très remarquable de l'administration des Postes et des Télégraphes. Des employés font fonctionner sous nos yeux des appareils de toute sorte, particulièrement l'appareil Baudot, télégraphe-imprimeur a trans- 
mission multiple, dont voici d'après le savant M. Vernier, la composition et le mécanisme.

- Imaginez un simple petit clavier composé de cinq touches; à cỏté est un enregistreur avec son petit rouleau de papier bleu sur lequel s'impriment les lettres. Ne nous occupons point des communications de mouvement et ne regardons que les résultats. Quand l'employé presse une touche, l'appareil imprimeur imprime la lettre A, par exemple; en appuyant sur une autre touche, sur deux touches à la fois, sur trois, on imprime les autres lettres de l'alphabet. On conçoit aisément qu'avec cinq touches touchées, ou isolément, ou par groupes, on puisse obtenir un certain nombre de combinaisons égal ì celui des lettres de l'alphabet. On obtient ainsi l'impression d'une dépèche sur le ruban de papier, sans fatigue, comme on joue du piano, sans faire entendre le bruit sec et insupportable des anciens appareils.

- Pour la démonstration, on a placé le récepteur et le manipulateur l'un à côté de l'autre; dans la pratique, ils sont aux deux extrémités du courant : au point de départ et au point d'arrivée. Quand on appuie sur les touches, des courants sont automatiquement transmis sur la ligne, et le sens de ces courants, leur durée, leur nombre, dépendent du jeu du manipulateur. Au point d'arrivée, les courants actionnent les petits organes délicats qui règlent l'impression. Il faut remarquer que la traduction de ces signaux et leur impression se font à l'aide d'organes indépendants de ceux qui servent à la réception proprement dite; ainsi les opérations en quelque sorte locales de l'impression n'entravent pas le travail de la ligne qui peut ètre, pendant le même temps, utilisée pour la transmission d'autres signaux.

- On voit à l'Exposition des appareils où deux employés transmettent deux dépêches en mime temps, avec deux claviers différents, sur le même fil. Les deux courants, qui ne se contrarient en rien, peuvent être de mème sens ou de sens inverse. On peut, dans la pratique, envoyer, par exemple, deux dépèches en mème temps de Paris à Rome ou une autre de Rome à Paris. Sur des distances moindres, par exemple, de Paris aus grandes villes de France, on arrive, a l'aide de ces appareils, à faire marcher quatre dépêches sur un seul fil; on est mème allé jusqu'à six. On conçoit qu'avec de tels appareils, avec les Baudot duplex, quadruplex, sextuplex, on arrive à des rendements tout it fait extraordinaires. On m'a parlé de 9,000 mots envoyés à l'heure; le duplez donne couramment 3,000 mots à l'heure.

- Ce qui caractérise ce systìme, c'est que la transmission des signaux et leur traduction sont choses tout a fait indépendantes; il en résulte que les organes par lesquels passent les signaux sont indépendants et peuvent etre utilisés aussitôt qu'ils deviennent libres. Le plus important de ces organes est le fil mème de la ligne; il peut transmettre un signal, mème quand celui qu'il a déjà reçu se traduit dans les organes qui l'emmagasinent, en quelque sorte, et l'impriment. Que faut-il pour cela? Un second manipulateur qui travaille à coté du premier, avec un second groupe de relais et un second traducteur de signaux. C'est ainsi que se réalise le problème des transmissions multiples au moyen d'un seul fil. Le principe général exposé, on comprendra que nous ne puissions entrer ici dans aucun détail sur les très ingénieux et très délicats mécanismes qui servent à l'appliquer; ceux qui ont un peu de familiarité avec la télégraphie et ses procédés auront plaisir à les admirer dans le pavillon de la Télégraphie. ,

a. M. Baudot a fait breveter son appareil en juin 18 1 '4 et l'a mis al'essai en 1870̆ sur un fil partant de Paris, passant par le Havre et Lisieux, revenant à Paris et touchant 
à Versailles. C'était une longueur de 5500 kilometres. En 18ī, on mit cinq appareils en service sur la ligne de Paris a Bordeaux. Ces appareils ont figuré à l'Exposition de 1878. En 1879, on mit en service sur la même ligne deux nouveau: appareils à transmission quadruple; on appliqua ensuite le système sur la ligne de Paris à Lyon, avec les meilleurs résultats. "

On ne peut constater sans un vif plaisir le développement de notre service de com. munications. Savez-vous bien que la circulation télégraphique dépasse 31,000 télégrammes? Et le développement du réseau télégraphique?

Lignes aériennes ........ $\begin{aligned} & 86, \text { כ00 kilomètres de ligne. } \\ & 264,980 \text { kilomètres de fil. }\end{aligned}$

Lignes souterraines ordinaires $\ldots .\left\{\begin{array}{l}1,719 \text { kilomètres de ligne. } \\ 15,168 \text { kilomètres de fil. }\end{array}\right.$

Lignes souterraines à grande distance. $\left\{\begin{array}{l}\mathbf{4 , 5 2 4} \text { kilomètres de ligne. } \\ 30,237 \text { kilomètres de fil. }\end{array}\right.$

Lignes sous-marines.

(6,004 kilomètres de ligne.

(3,293 kilomètres de ligne.

Lignes d'intérèt privé ...... 6,51 2 kilomètres de fil.

12,388 kilomètres de ligne.

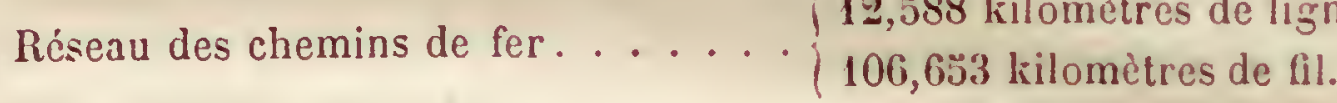

Pour les appareils en service, nous avons 12,759 Morse, 993 Hughes, 25 Wheatstone, כ̊8 Baudot, 1 Meyer, elc., en tout 15,932 appareils, et plus de 8,800 bureaux Isont ouverts au service télégraphique. Le plus important de ces bureaux, c'est le poste central de Paris, et comme le visiteur peut s'intéresser à son fonctionnement, voici des renseignements qui l'aideront à comprendre les explications de l'emplojé; ils sont de M. Alexis Belloc, inspecteur du contrỏle à la direction générale des postes et télégraphes.

a C'est au poste central des télégraphes de Paris que viennent aboutir toutes les dépêches télégraphiques échangées entre Paris et les départements ou l'étranger, ainsi qu'un grand nombre de celles qu'échangent entre elles les différentes villes.

- Le poste central est exclusivement un bureau de transmissions; aucune dépêche n'y est déposée directement et il n'en distribue directement aucune. Le service, assuré par des hommes et par des dames, est permanent de jour et de nuit.

- Le personnel comprend actuellement un chef de service, assisté de chefs el de sous-chefs de section, et de 62 commis principaux ayant sous leurs ordres 466 télégraphistes hommes, 404 dames télégraphistes, 16 mécaniciens et 99 facteurs.

- On conçoit qu'un personnel aussi nombreux ne puisse ètre installé que dans de vastes locaux spécialement aménagés. Deux nouvelles sailes viennent d'ètre construites tout récemment et livrées à l'exploitation. Leur installation ne laisse rien à désirer, la lumière y pénètre par des baics largement ouvertes, la nuil, elles sont éclairées à la lumière électrique. L'une de ces salles est occupée par des télégraphistes hommes, la seconde par les dames télégraphistes.

- Les 362 appareils de diverse nature en service au poste central sont groupés dans chacune de ces salles, suivant un ordre méthodique basé sur la classification régionale. 


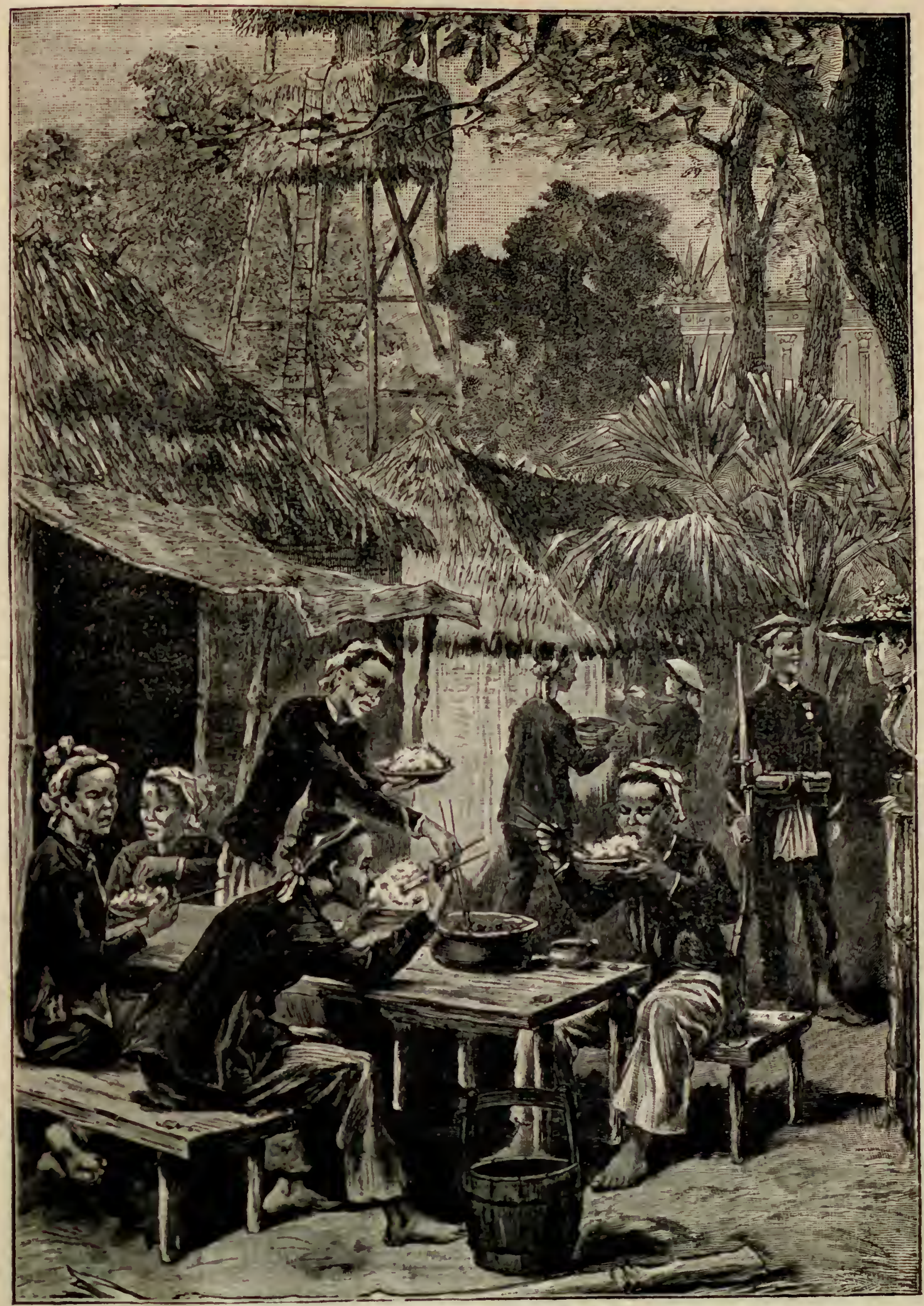

LI REPAS DES TONEINOIS.

Lv. 80. 
- On sait que les appareils du syslème Baudol sont les plus rapides usités en télégraphie; ils desservent les villes de Marseille, le Havre, Lille, Bordeaux, Toulouse, Lyon, Brest, Caen, Clermont-Ferrand, Nantes. Ils permeltent ì plusicurs employés de travailler à deux, à quatre et mème ì six sur un mème fil, gritce à l'ingínieuse application de la division du temps réalisće par II. Baudot, ingénieur de l'administratiun.

" Un autre agent de l'administration, aujourd'hui en retraite, M. E-lienne, a imaginé un appareil a double style imprimant dans le sens vertical les signaux de l'appareil Norse.

- Le nombre de fils aboutissant au poste central se décompose ainsi qu’il suit: 36 fils intęrnalionaux, 216 intérieurs, 108 urbains, 00 sonterrains, 23 fils de presse, 7 fils d'intérèt privé.

- Tous les chefs-lieux de département sont reliés directement avec Piris, al l'exception des quinze villes suivantes: Digne, Gap, Privas. Foix, Careassonne, Tulle, Ajaccio, Quimper, Mont-de-Marsan, Cahors, Mende, Draguignan, MIger, Oran et Constantine.

- Le sous-sol est assurément l'une des parties les plus intéressantee du poste central : là nous trouvons des salles voutées, affectées aux 9,000 élérnents de piles en service, d'autres où l'on voit des machines a vapeur, des machines dyıano-électriques, des pompes refoulantes. Ce n'est certes pas un des colés les moins piltoresques que de voir des machines à vapeur devenir les auxiliaires de la télégraphie.

a Ces machines actionnent, d'une part, les pompes refoulantes de-tinées à faire fonctionner les appareils IIughes et les machines dynamo-électriques nécessaires à la production de l'éclairage électrique. Elles actionnent également un appareil lynamoélectrique auto-régulateur qu'un agent du poste central, M. Pierre Picard, a eu l'idée ingénieuse d'imaginer pour remplacer les piles. '

Nous recommandons une carle en relief du réseau de Paris ct un talsleau contenant des spécimens des dépèches de pigeons en 1870-71.

A côté du télégraphe, nous avons le réscau pneumatique, qui a aujourd hui une longueur de 178 kilomètres et se compose d'un réseau principal auquel alumli--ent d'autres réseaux secondaires avec divers embranchements, plus une doulle voie direct entre le bureau central et le bureau de la Bourse. Ce service a été inauguré a l'aris en 1867, mais il n'a pris son plein développement que dans ces derniéres années.

Nous appelons enfin l'attention sur le wagon-poste exposé à l'extreimité du pavillon. Cette voiture-bureau, avec ses multiples casiers, n'est pas accessible au public en temps ordinaire : profitons de l'Exposition pour en visiter une.

L'exposttion de La guerize. - Voulez-vous avoir une idlée précise de notre organisation militaire, de son passé, de son présent et jusqu'ì un certain point de son avenir? Entrez dans le Palais du Ministère de la Guerre, rempli d’armes, de plans, de vues, de portraits, d'uniformes, et vous trouverez. la de quoi vous éclairer sur les applications de la science à l'art de la guerre (utilisation des cours d'eau, des chemins de fer, de la photogr'aphie); sur l'emploi des télégraplıes, des applareils électriquues et d'éclairage, des ventilateurs; sur notre histoire militaire au point de vue des engins; sur les progrès des diverses arınes de guerre; sur l'histoire des cartes de troupe; sur la bibliographie et la cartographie militaires; sur l'équipement, les uniformes, les insignes, les drapeaux. Les organisateurs ont réussi a nous instruire sans riéu révéler des secrets de notre outillage. 
s Le Pavillon de la Guerre comporte trois parties bien distinctes : le pavillon proprement dit, vaste latiment d'une architeclure sobre et correcle, d'une superficie de cent cinquat te inèlres de longueur sur vingt-deux mètres de largeur; il comprend un rez-de-chausséc très élevé et un élage éclairé par le haut el auquel on accède par ull escalier inonumental à double révolution. Devant le palais, un porche d'entrée, style moyen ige, rappelant les batiments d'avant-garde, avec ses tours en poivrières, ses ponts-levis, ses douves, ses milchicoulis, ses créneaux et ses archères. Entre le palais et le porche d'entrée, une cour très vaste dans laquelle sont rangées les bouches à feu de campagne, de place et de sière, les mitrailleuses et les canons-revolvers.

Les annexes du batiment principal comprennent les hangars abritant le matériel roulaut, les wagons destinés à transporter les hommes et les chevaux, les trains sanitaires, les appareils spéciaux employés par les chirurgiens et par les intendants. Ces annexes comprennent aussi le pavillon des poudres et salpêtres, où vous trouverez tous les spécinens d'explosifs employés depuis Jean Bruno jusqu'aux inventeurs de la dynamite et de la mélinite.

Dans les salles de droite du rez-de-chausséc du Palais vous admirerez des modèles de canons en bronze, en fonte, en acier, avec leurs caissons et leurs attelages; vous trouverez aussi une collection complète d'obus, de boulets, d'ancres, de plans en relief des ouvrages avancés de nos fortifications, etc., etc.

Jetez les yeux, dans cetle salle, sur les appareils récents construits par nos ingénicur's-électriciens. Ne passez pas, sans les examiner avec attention, les appareils qui permettent aux défenseurs d'une place forte d'éviter les surprises de l'ennemi en éclairant subitement, grace aux procédés mis en action par la lumière électrique, les troupes de l'adversaire qui, tranquilles, protégées par l'ombre de la nuit, comptent arriver jusque sur les remparts.

Et votre visite terminée, en revenant sur vos pas, contemplez, sur les murailles de la salle, les panoplies et les attributs de nos guerriers, les portraits de nos généraux et de nos maréchaux qui se sont illustrés dans maints combats.

Dans la salle de gauche vous passerez en revue tous les progrès faits depuis deux siccles par l'artillerie et le génie. Il y a là tous les ponts en usage à la guerre, depuis les ponts de bateaux, jusquaux ponts de cordages et de fils de fer.

Dans une grande galerie parallele aux deux salles que nous venons de visiter, vous trouverez tous les appareils de précision, télescopes, sextants, chronomètres, etc., en usage sur nos naviles de guerre.

A noter aussi l'exposition de la télégraphie militaire, qui nous donne une idée nette de tous les procédés employés pour meltre nos avant-postes en communication avec le gros de l'arméc.

Le luxe des détails sur les anciens armements et les vieux procédés tient précisément à ce qu'on a tenu a nous faire juger des progrès accomplis par comparaison, et non pas sur les récentes manifestations scientifiques. Le coup d'œil rétrospectif qu'on doit ainsi jeter forcément est des plus instructifs, puisquil nous montre les machines de guerre du temps de Vitruve, l'artillerie de Charles le Téméraire, les chariots du temps de Henri II, les canons de Louis .IIV et l'artillerie de Gribeauval.

La comparaison des projectiles et des blindages n'est pas la partie ı́ moins curicuse. Cetle grande lutte du canon et de la cuirasse est comme matérialisée par l'exposition du blindage du Formidable. 



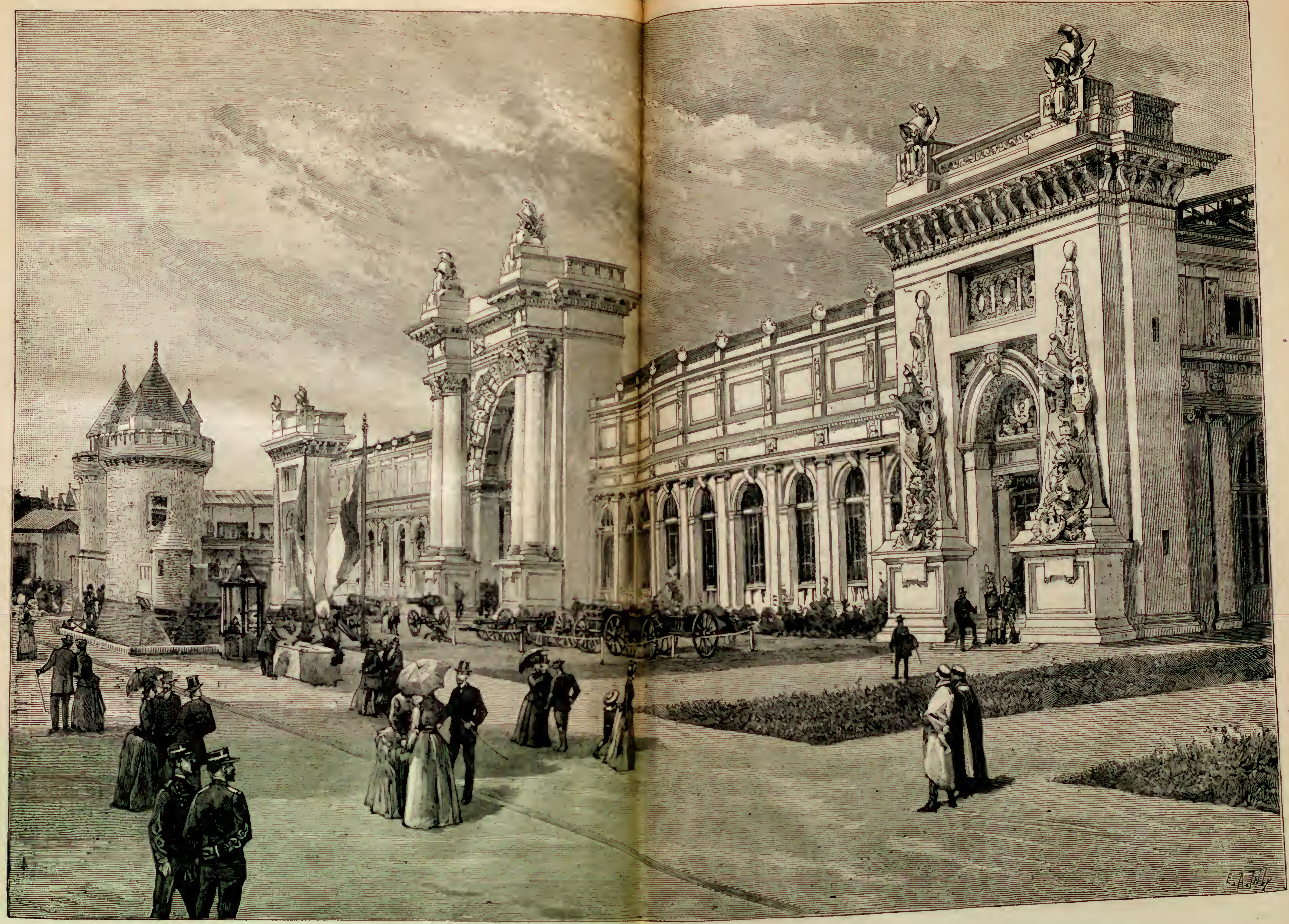

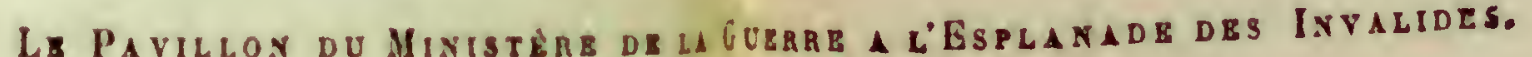


L'Exposition du génic offre un intérêt de mème nature : même reconstitution rétrospective. Défenses, villes, ponts, chemins de fer, ces figurations captivent singulièrement lattention. Il suffit de voir pour apprendre, pour avoir le sentiment de quelques réalités utiles à connaitre. La représentation des divers syștèmes de ponts improvisés, les plans en relief de Cirenoble, de Laon, des forts de Joux et du Larniont. le front de Garnot, la représentation de faits de guerre supposćs, tuut cela constitue autant de spectacles intéressants qui rendent agréable au public une partie qui aurait été forcément stérile, si l'on se füt strictement placé au point de vue technique.

Le service géographique de l'armée est très brillamment représenté. Quels précicux documents a fournis le Ministère sur cette utile institution! Que de cartes! Que d'instruments de précision!

Au premier élage, on trouve à droite de nombreux tableaux, portraits, scènes de bataille, représentations d'uniformes, etc.; à gauche, des chevaux tout harnachés et surtout un camp, avec des soldats de toutes armes, grandeur naturelle. C'est l'armic française au grand complet, en tenue, dans les attitudes particulic̀res qui conviennent au rùle que remplissent officiers et soldats. On a pris, dans tous nos corps de troupes, un modèle qu'on a fidèlement rendu au point de vue de la taille, de l'expression, de l'habillement.

On croit à première vue, tant la resscmblance est frappante et l'illusion coinplète, que les soldats vont parler et traduire ce qu'ils pensent... des visiteurs. Nos fintassins, nos petits a pioupious ", nos zouaves, nos pompiers, nos artilleurs, nos gendarmes, nos cuirassiers ont le sac au dos, le fusil à la main.

Les élèves de l'École de Saint-Cyr et de l'École polytechnique, les enfants de troupe, les chasseurs d'Afrique, les fusiliers marins sont aussi représentés, grandeur naturclle.

Au centre de ce camp d'un genre tout particulier, un général de division lisant un ordre et, à ses còtés, un officier d'ordonnance, dans l'attitude militaire, attendant un commandement de son supéricur.

On croirait qu'il y a là, en chair et en os, les représentants de tous nos corps de troupe.

Notons, dans les salłes voisines, l'Exposition des chaussures militaires, des instruments de musique, des tambours, trompettes, etc.

Noublions pas de mentionner aussi, et tout particulièrement, la salle de l'escrime où vous aurez le plaisir de voir le fleuret de Jean-Louis, les rapières du $\times$ vin $^{\mathbf{e}}$ siécle, les fleurets modernes, les dessins, les autographes, les portraits de nos grands maltres d'armes.

Enfin, contentons-nous d'attirer l'altention sur les cartes de géographie de la guerre.

Ces cartes marquent un progrès considérable. Nous n'insisterons pas sur ce point. On ne dira plus que nos officiers ne savent pas la topographie de leur pays.

Ambllasces et secours aux blessés. - Tous ccux qui anront visilé celle partie de l'Exposition ne sauraient se défendre d'un sentiment de reconnaissance pour ceux rt celles qui, durant la paix, emploient leurs efrorts à assurer le soulagement futur dis victimes de la guerre. La Société française de secours aux blessés militaires, qui a son siège central à Paris, a unc exposition importante.

La convention que signaient à Genève, en 1864, neuf gouvernements dont l'exemple a été suivi depuis cette époque par vingt-trois autres États, proclamait la nentralité des ambulances. La protection qu'elle étendait ainsi sur le personnel et le matériel 
hospitaliers provoqua dans toute l'Europe la création de sociétés spéciales, chargées de centraliser, at profit des victimes de la guerre, les ressources de la charité privée. Lil Société francrise de secours aux blessés militaires est née de ce mouvement.

Reconnue dès 1866 comme établissement d'utilité publique, elle recut la mission formulée par l'arlicle $t^{\text {or }}$ de ses staluts, a de concourir, par tous les moyens en son pouvoir, au soulagement des blessís et des malades, sur les champs de bataille; dans les ambulances et dans les hôpitaux .. Un décret, en date du 3 juillet 1884, confirmant plusicurs décrets antérieurs et portant règlement pour le fonctionnement de la Société en campaģne, l'a constituce l'auxiliaire permanente du service de santé des armées, dispensatrice, ì l'égard des blessés, des ressources de l'assistance volontaire.

La Société se compose indistinctement d'hommes el de femmes, elle est administrée par un conseil composé de 50 membres, élus par les fondateurs et choisis parmi eux. Elle institue dans les chefs-licux de département et d'arrondissement des comités dhommes et des comités de dames. Pour les chefs-licux de canton, elle s'attache des membres correspondants. Considérée dans ses rapports avec l'État, la société est représentée : $1^{\circ}$ à l'intérieur, auprès de .I. le ministre de la Guerre et de II. le ministre de la Marine et des Colonies, par le Président de la Société; dans chaque région de corps d’armée, par un délégué régional, officiellement accrédité auprès du général commandant le corps d'armée, ainsi qu'auprès de M. le vice-amiral commandant en chef, pour clacun dos arrondissements maritimes; $2^{\circ}$ aux armées pendant la guerre, dans chaque al'méc ou corps d'armée opérant isolément, par un délégué d'arméc.

En 1877, sept ans après les dures leçons que la guerre franco-allemande nous avaient dlonnées, aucune société de dames ne s'était encore organisée en France, pendant qu'en sllemagne plus de 60,000 femmes avaient répondu à l'appel de l'impératrice Augusla et s'étaient fortement organisées en vue des secours à donner aux soldats en cas de guerre. Les quelques comités qui s'étaient improvisés en France comme auxiliaires de la Société de secours anx blessés en 1870 s'étaient dissous après la guerre; ils n'avaient jamais admis la nécessité de préparer les femmes par un enseignement spécial et donne d'une manière permanente en temps de paix; de les organiser en temps de paix en comilís distincls de la sociélé d'hommes.

Les meinlıres les plus autorisés de la Société de secours aux blessés, pressentis sur l'utilité qu'il y aurait d'imiter sur ce point l'organisation des dames allemandes, ne crurent pas d la possibilité de réussir. Et pourtant la statistique nous disait qu'il faudra 200,000 personnes pour soigner nos malades et nos blessés dans la prochaine guerre! C'est alors que le doctcur Duchaussoy, professeur agrégé à la faculté de Paris, fonda avec le concours de la Société de médecine pratique, la première école d'ambulancières et de gardes-malades en France, et qu'encouragé par les excellents résultats de cet enseignement, il fonda deux ans plus tard en 1879, l'Association des dames françaises. Cette Association fut autorisée en 1881, reconnue d'utilité publique en 1883, rattachée aux ministeres de la Guerre et de la Marine en 1886.

Ainsi fut comblée la grave lacune laissée en France par les organisations précédentes; ainsi fut créée l'armée secourable des femmes instruites dès le temps de paix en vuc du temps de guerre et distribuant des secours soit aux militaires malades ou blessés, soit aux victimes des calamités pulliques. C'est ainsi qu'une forme pratique et efficace fut donnée à l'idée du devoir que les femmes, comme les hommes, ont à remplir en temps de guerre. 
Pendant toute la durée des guerres de la Tunisie, du Tonkin, de l'Annam, de la Chine, de Madagascar et du Sénégal, l'Association a envuyé aux armées pour les malades, les blessés et les convalescents tout ce que la sollicitude des mères éclairées peut imaginer de plus utile. Médicaments, lingerie de pansement et d'hôpital, vins réconfortants, lait concentré, ceintures et chemises de flanelle, jeux de toutes espèces, bibliothèques, etc. IIygiène physique, hygiène morale, elle a pensé à tout.

Pour améliorer la traversée des convalescents rapatriés elle a envoyé de l'argent; à peine débarqués en France, le comité de Marseille les a aidés; à Nice et à Cannes, on a fait de même; à Porquerolles ses envois ont beaucoup contribué au bien-être des convalescents; à Paris, plus de trois mille rapatriés ont reçu de l'ar'gent, des vêtements, à beaucoup elle a procuré du travail.

Aux viclimes des calamités publiques, aux inondés d'Alsace-Lorraine, du Midi, de Perregaux, etc; aux victimes des tremblements de terre, à Nice, il Menton, à DianoMarina; aux victimes des naufrages, à Boulogne, à Dieppe, au Crotay, a Paimpol, au Tréport; aux victimes du torpilleur 110; aux incendiés, à Aiguilles, Selonnet, le Villard, elc; aux victimes du grisou à Saint-Étienne; à celles du choléra, a Toulon, à Marseille, à Paris, Audierne, Yport et à celles de la peste jaune, au Sénégal, et du bombardement d'Alexandrie, l'Association a distribué des sommes considérables ou envoyé des secours en nature.

En ce moment Mssociation s'attache à l'organisation en personnel et en matériel des hôpitaux auxiliaires dont elle serait chargée en cas de guerre.

Depuis sa fondation elle distribue largement l'enscignement de l'hygriene et des soins à donner aux blessés; plus de 1,500 personnes ont suivi ses cours, plus de $1: 00$ ont obtenu le diplòme.

Et pour suffire à tous ces bienfaits qui dépassent 600,000 francs, les vaillantes dames de l'Association ont trouvé des ressources dans l'activité, le dérouement el l'in. telligence avec lesquels elles ont organisé chaque année des futes de charité.

Ce qu'elles ont donné, on peut dire avec justice qu'elles l'ont gagnẻ.

L'Association des dames françaises, en créant l'armée des femmes ambulancières, laisse à l'armée de la défense nationalc bien des milliers de bras valides; elle donne à des milliers de mères de famille des connaissances d'hygiène extrimement utiles; elle a mis en relief pour le bien de la France, des capacilés jusque-là ignorées, elle a révélé aux dames une des formes de leur puissance et leur a donné les moyens de l'exercer.

Nous trouvons enfin en troisième lieu, l'Union des femmes de France fondée en 1931 e! qui a pour but de grouper et d'organiser a Paris et dans tous les départements un personnel et un matériel qui puissent, le cas éclıéant, être mis à la disposition de l'autorité militaire, et de réunir sur tous les points du territoire ce qui est nécessaire pour une rapide organisation des secours sur place. Elle doit s'applizguer à donner a ses adhérentes une instruction théorique et pratique en rapport arec les fonctions diverses qu'elles pourront ètre appelées ì exercer. 


$8, y, x$,

$+4$

कet?

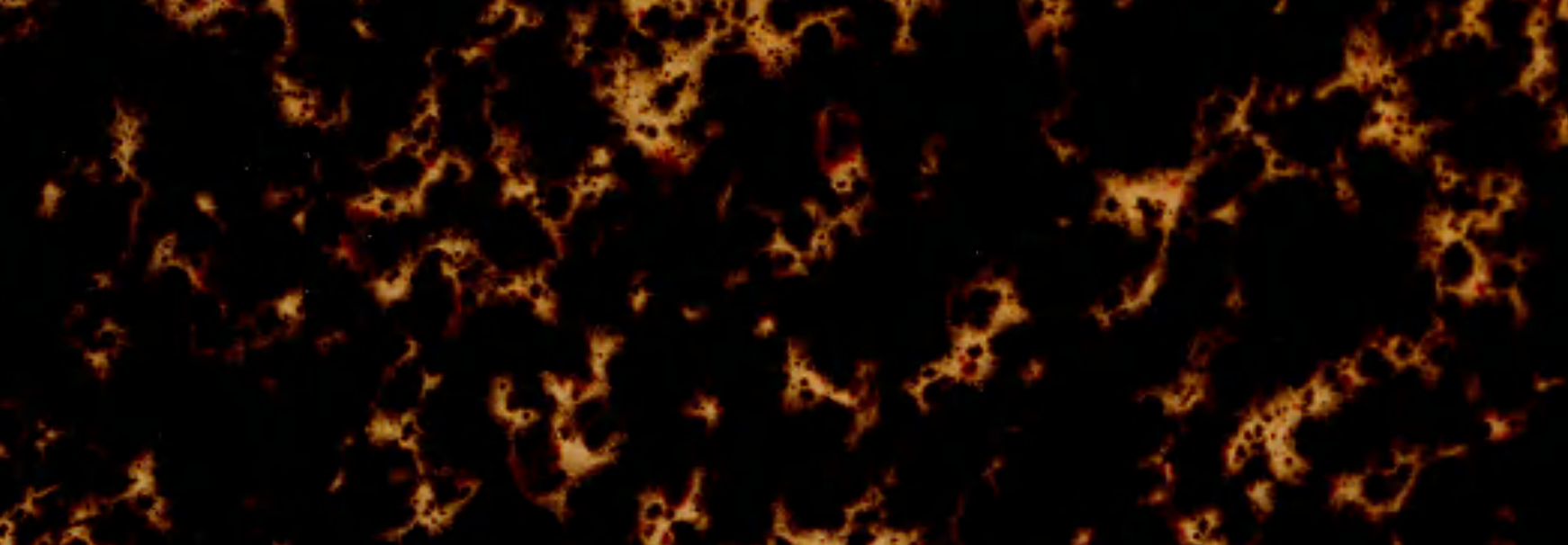

of

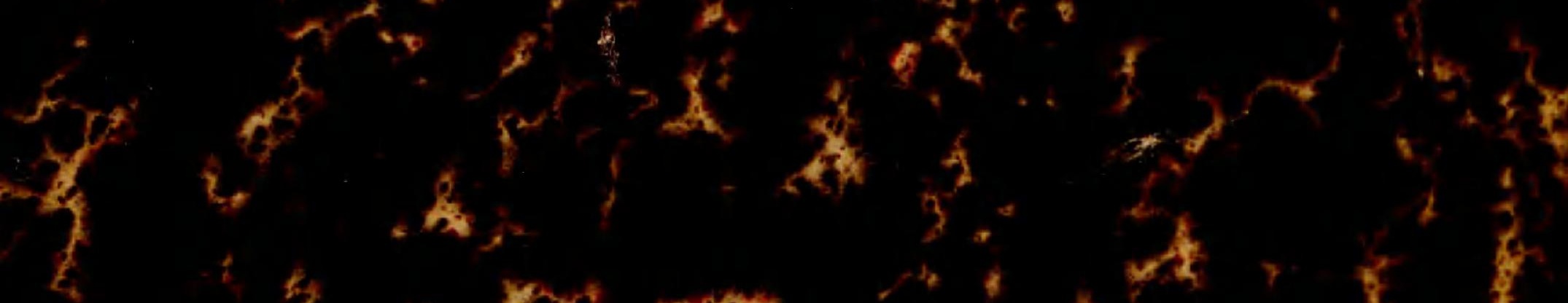

$4 y^{2}+x^{2}+7 x^{4}$

की

$6 t^{4}+2 x+4$

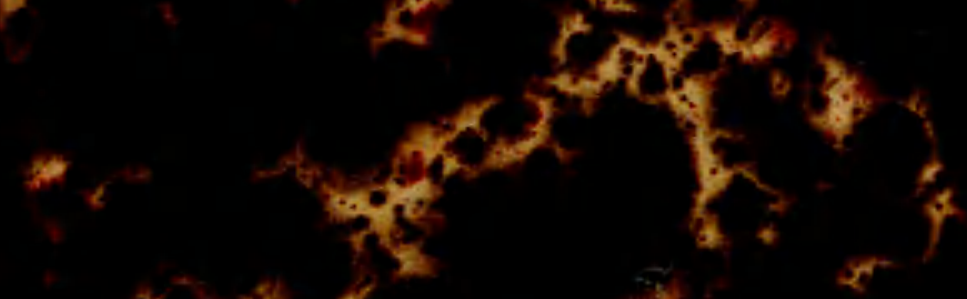

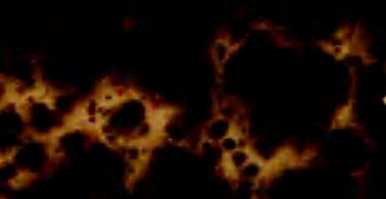

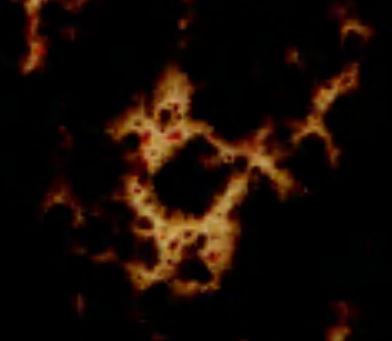

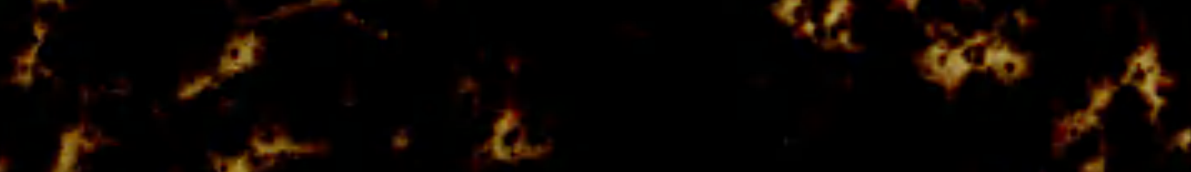

28.

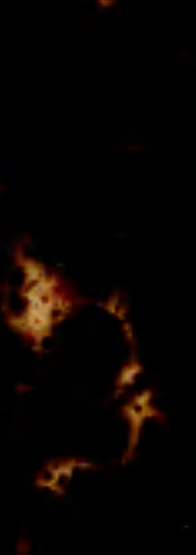

13

$y^{2}$

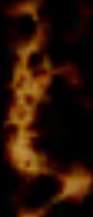

$\mathbf{r}$

s 